\title{
WestVirginiaUniversity
}

THE RESEARCH REPOSITORY @ WVU

Graduate Theses, Dissertations, and Problem Reports

2016

\section{Application of 1,2,3-Triazole in Gold Catalysis and Photoredox Catalysis}

Rong Cai

Follow this and additional works at: https://researchrepository.wvu.edu/etd

\section{Recommended Citation}

Cai, Rong, "Application of 1,2,3-Triazole in Gold Catalysis and Photoredox Catalysis" (2016). Graduate Theses, Dissertations, and Problem Reports. 5298.

https://researchrepository.wvu.edu/etd/5298

This Dissertation is protected by copyright and/or related rights. It has been brought to you by the The Research Repository @ WVU with permission from the rights-holder(s). You are free to use this Dissertation in any way that is permitted by the copyright and related rights legislation that applies to your use. For other uses you must obtain permission from the rights-holder(s) directly, unless additional rights are indicated by a Creative Commons license in the record and/ or on the work itself. This Dissertation has been accepted for inclusion in WVU Graduate Theses, Dissertations, and Problem Reports collection by an authorized administrator of The Research Repository @ WVU.

For more information, please contact researchrepository@mail.wvu.edu. 


\title{
Application of 1, 2, 3-Triazole in Gold Catalysis and Photoredox Catalysis
}

\author{
Rong Cai \\ Dissertation submitted to the Eberly College of Arts and Sciences \\ at West Virginia University \\ in partial fulfillment of the requirements \\ for the degree of \\ Doctor of Philosophy \\ in \\ Organic Chemistry \\ Approved by \\ Björn C.G. Söderberg, Ph.D., Chair \\ Xiaodong Shi, Ph.D., Advisor \\ Brian V. Popp, Ph.D. \\ Jessica M. Hoover, Ph.D. \\ Jeffrey L. Petersen, Ph.D. \\ Patrick S. Callery, Ph.D. \\ C. Eugene Bennett Department of Chemistry \\ Morgantown, West Virginia \\ 2016
}

Keywords: 1,2,3-triazole, triazapentalene, fluorescence probe, redox gold catalysis, arenediazonium salts, cross-coupling, porous polymer, heterogeneous gold catalyst, triazole-gold catalyst, photocatalyst

Copyright 2016 Rong Cai 


\section{Abstract \\ Application of 1, 2, 3-Triazole in Gold Catalysis and Photoredox Catalysis Rong Cai}

Homogeneous gold catalysis has envisioned a rapid development during the past decade due to the remarkable efficiency of $A u(I)$ in alkyne and allene activation. Air and thermally stable triazapentalene zwitterionic compounds (TAPZ) were prepared through $\mathrm{Au}(\mathrm{I})$-catalyzed triazole-alkyne 5-endo-dig cyclization. While effective gold catalyst turnover was achieved, the stability of these new 10-m-electron bicyclic structures was also significantly improved through the introduction of electron-withdrawing groups, which allowed the further application of these fluorescent dyes in cell imaging.

Silver salts are generally used for the activation of $\mathrm{LAuCl}$ through $\mathrm{Cl}^{-}$removal, and they are assumed to be innocent in $A u(I)$ catalysis. For the first time, experimental evidences from XPS and ${ }^{31} \mathrm{P}$ NMR were obtained to confirm that the combination of $\mathrm{Ag}^{+}$cation with [L-Au] $]^{+}$resulted in the formation of different complexes in solution. Cationic gold was proved to be inactive without the presence of silver salts and it could be re-activated by the addition of silver salts in several precedent reactions. This study revealed a long-overlooked "silver effect" and initiated a mechanistic reconsideration in gold catalysis.

Compared with $\mathrm{Au}(\mathrm{I})$ catalysis, redox gold catalysis is far less developed due to the relatively high oxidation potential of $\mathrm{Au}(\mathrm{I}) / \mathrm{Au}(\mathrm{III})$. With the assistance of bpy ligand, gold-catalyzed $s p-s p^{2}$ and $s p^{2}-s^{2}$ cross-coupling reactions are accomplished with aryldiazonium salts as the coupling partner. The gold(I) species were oxidized to gold(III) by diazonium without any external oxidants. Monitoring the reaction with NMR and ESI-MS provided strong evidence for the nitrogen extrusion as the key step followed by $\mathrm{Au}(\mathrm{III})$ reductive elimination. To further extend the scope of the gold redox chemistry with aryldiazonium salts, gold-catalyzed Sandmeyer reactions were investigated using different nucleophiles, forming $\mathrm{C}-\mathrm{Br}, \mathrm{C}-\mathrm{S}$ and $\mathrm{C}-\mathrm{P}$ bonds in high yields and selectivity.

Despite the high efficiency of gold catalysts, their application for large-scale synthesis is limited due to the high catalyst cost. A recyclable triazole-gold catalyst, which dramatically decreases the catalyst cost, is prepared using porous polymer as the support ligand. This unique catalyst is successfully applied into previously challenging transformations with good efficiency and recyclability.

Visible light photocatalysis is an efficient and green method that can convert the energy from visible light to chemical energy. One challenge to accomplish the catalytic cycle is the matching of redox potential between the substrate and the photocatalyst. With the easily tunable triazole ligands, N-2-Aryl chelated triazole-Ir(III) complexes with various substituents were prepared. These Ir(III) complexes were tested in photoredox catalysis with different reactivities related with their tunable photoredox potentials. 


\title{
Dedicated to
}

\author{
My Dear Parents \\ \& \\ Grandparents
}




\section{Acknowledgment}

I would like to express my deepest gratitude to my supervisor, Prof. Xiaodong Michael Shi, for his guidance during my PhD studies. He is the one who led me to the door of organic chemistry and guided me through the jungle of obstacles. His enthusiasm, diligence, persistence and broad knowledge in chemistry have always inspired me. Not only has he taught me how to become a better chemist, but also he has never hesitated to offer me advise and support whenever they are needed throughout my graduate life. Without him, I would have never got this far.

I am deeply thankful for Prof. Björn Söderberg, who has encouraged me a lot. $\mathrm{He}$ is very knowledgeable about natural products and his sense of humor always adds some fun to our seminars. Thanks him for being my co-advisor and for all the kind help.

Thanks for the valuable advice and suggestion from my committee members, Prof. Kung Wang, Prof. Brian Popp, Prof. Jessica Hoover, Prof. Jeffrey Petersen, and Prof. Patrick Callery. I would like to thank our NMR expert Dr. Novruz Akhmedov for his enthusiastic and instructive help to analyze complex structures. Thanks Prof. Petersen for his help on crystallography. I would also like to thank Prof. Harry Finklea for the help on electrochemistry, Dr. Huiyuan Li for her kind help in biochemistry studies, Prof. Xingbo Liu for his advice and support, and all other professors in the department of chemistry.

The collaboration with Prof. Hao Chen in Ohio University and Prof. Shengqian Ma in University of South Florida are highly appreciated.

I have always enjoyed the life being in the "Shi Family". I received numerous help during the past five years from the Shi group members: Dr. Dawei Wang, Dr. Wuming Yan, Dr. Lekh Nath Gautam, Dr. Qiaoyi Wang, Dr. Xiaohan Ye, Dr. Yijin Su, Dr. Haihui Peng, Dr. Shengtao Ding, Tao Liao, Yanwei Zhang, Sravan Kumar, Siddhita Aparaj, Stephen Motika, Yumeng Xi, Boliang Dong, Seyedmorteza Hosseyni, Ying He, Chiyu Wei and our new members. Thank you all for being here with me. Thanks for the excellent undergraduate students who 
worked with me, Matt Bologna, Natalie Geise, Ellen Aguilera and Edward McClain. I would also like to thank all my colleagues in WVU, for their kind help in my research, study, and daily life. Thanks to all my friends in Morgantown, they made my PhD life much more wonderful and colorful.

The last year of my PhD study in University of South Florida is fantastic. I have learned a lot about material science and biochemistry from Prof. Shengqian Ma, Prof. Jianfeng Cai and their group members. Thanks all of them for their generous help and advice. Especially thanks Wenyang Gao and Dr. Qi Sun for all the help and our great collaboration.

Finally, I would like to express my appreciation to my friends and family in China, for their love and support. Even though we are separated by distance, they are always there for me. Every moment that I spend with them makes me feel like I am the luckiest people in the world.

Financial support form the C. Eugene Bennett Department of Chemistry at West Virginia University (John R. Conard Fellowship, C. Eugene Bennett Fellowship, and travel support form Schuler family), the WV HEPC grant, and the National Science Foundation is greatly appreciated. 


\section{TABLE OF CONTENT}

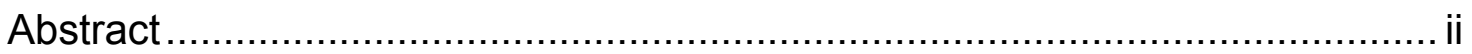

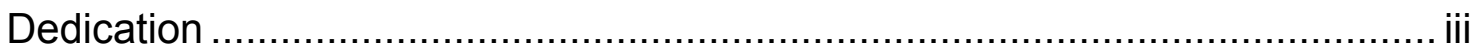

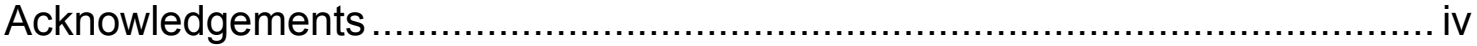

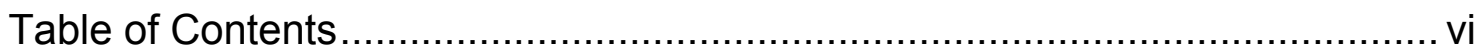

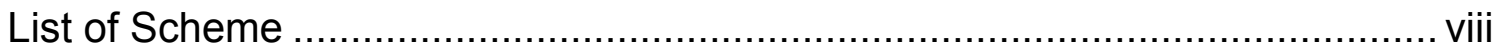

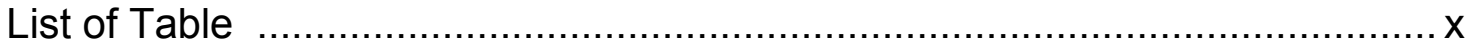

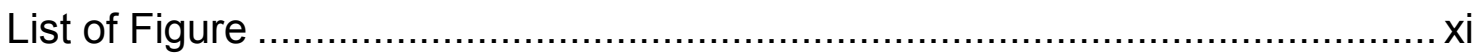

Chapter 1. Gold-Catalyzed Synthesis of Triazapentalene Zwitterions ......... 1

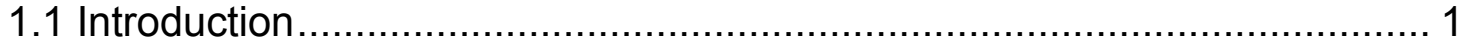

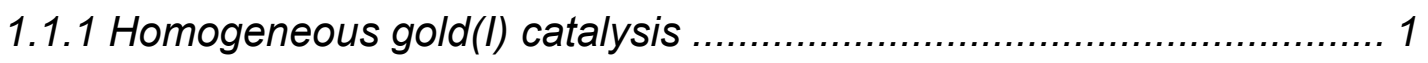

1.1.2 Triazole-gold(I) catalyst with improved stability ................................ 3

1.1.3 Acid-stable vinyl-gold complexes................................................. 4

1. 2 Catalytic cyclization of propargyl triazole ……................................... 5

1. 3 Triazapentalenes as biocompatible fluorophores .................................. 8

1.3.1 Triazapentalenes from cascade click chemistry ............................... 8

1.3.2 Triazapentalenes with improved stability ...................................... 9

1.3.3 Fluorescence investigation of selected triazapentalenes .................. 10

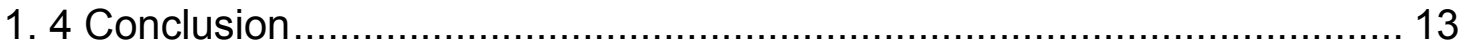

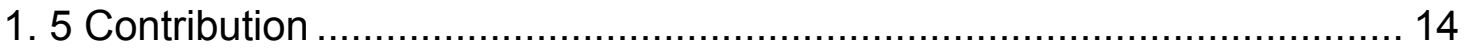

Chapter 2. "Silver Effect" in Gold(I) Catalysis .............................................. 17

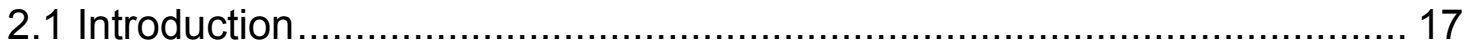

2. 2 Gold(I)-catalyzed propargyl ester hydration ........................................ 18

2. 3 "Silver effect" in alkyne hydration ...................................................... 20

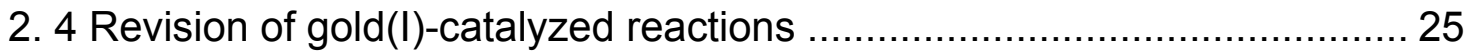

2.4.1 Different types of gold(I) catalysis............................................. 25

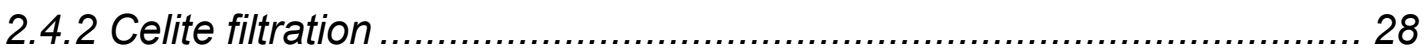

2.4.3 Other activation factors in gold(I) catalysis ................................... 29

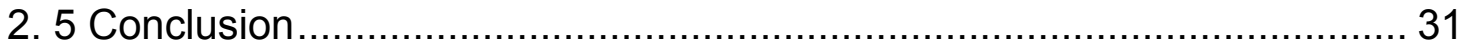




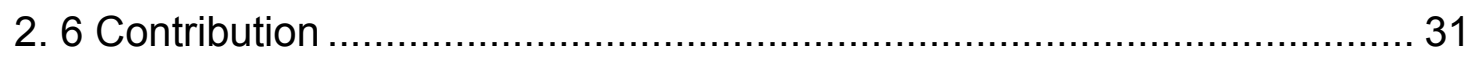

Chapter 3. Gold-Catalyzed Cross-Coupling with Aryldiazonium Salts........ 34

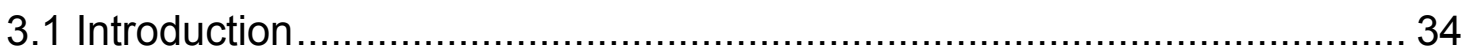

3. 2 Cross-coupling of alkyne and aryldiazonium ......................................... 38

3. 3 Reactions of diazonium salts with gold complexes .............................. 42

3. 4 Cross-coupling of aryl boronic acid and diazonium ............................. 46

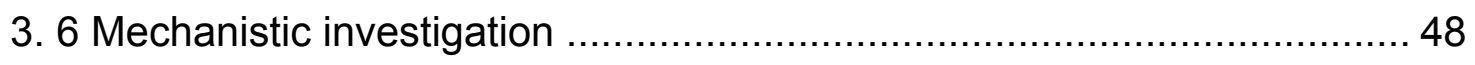

3. 7 Gold-catalyzed C-X formation with aryldiazonium ............................... 52

3.7.1 Catalytic Sandmeyer reaction .................................................... 52

3.7.2 Gold-catalyzed C-S and C-P bond formation ................................ 54

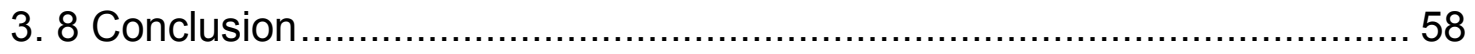

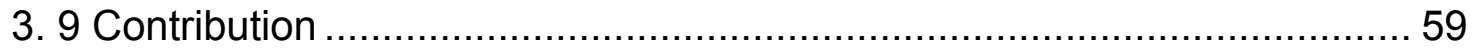

Chapter 4. Porous Polymer-Supported Heterogeneous Gold(I) Catalysis .. 64

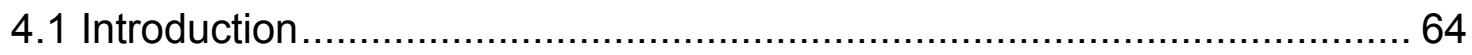

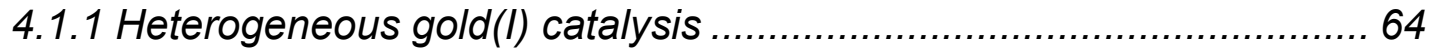

4.1.2 Porous polymer for transition-metal catalysts ................................. 66

4. 2 Porous polymer-supported triazole-gold catalyst ................................... 66

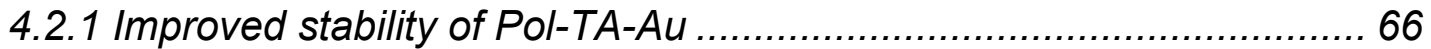

4.2.2 Combining Lewis acid with Pol-TA-Au ......................................... 70

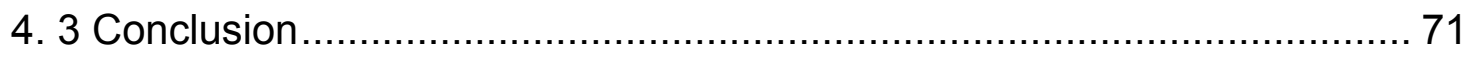

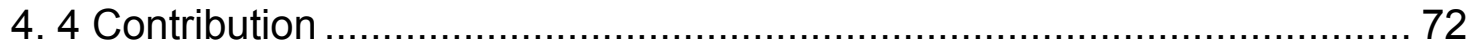

Chapter 5. N-2-Aryl-1,2,3-Triazole as Ligands for Iridium Photocatalysts .. 74

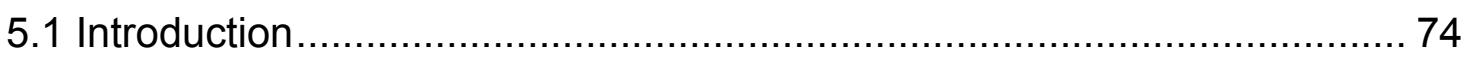

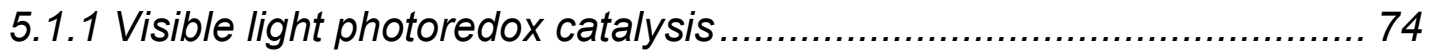

5.1.2 Iridium photocatalysts utilizing triazole ligands ................................ 77

5. 2 NAT-based iridium complexes as photocatalysts................................. 79

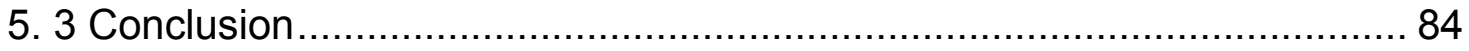

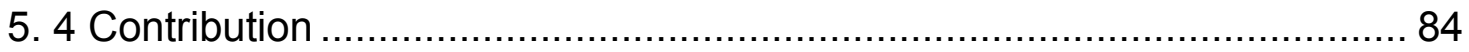

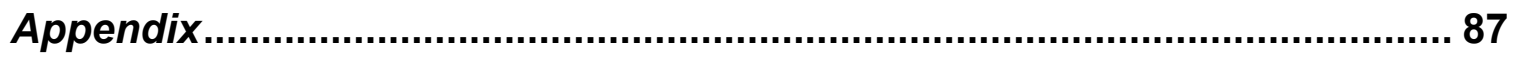

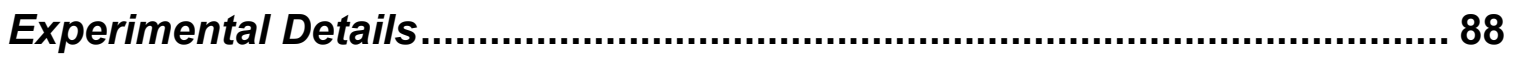




\section{List of Schemes}

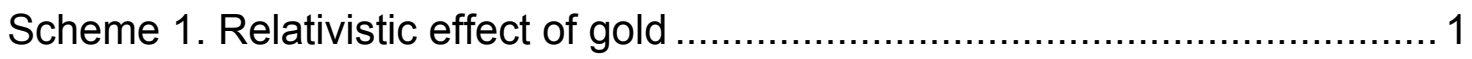

Scheme 2. Nucleophilic addition to gold-activated alkynes ........................... 2

Scheme 3. Examples for nucleophilic addition to gold-activated alkynes .......... 3

Scheme 4. Triazole-gold catalyst for intermolecular alkyne hydroamination ..... 4

Scheme 5. Formation of acid-stable vinyl-gold complexes ............................. 5

Scheme 6. Proposed strategy for gold turnover ....................................... 6

Scheme 7. Triazapentalene synthesis from click-cyclization-aromatization ...... 8

Scheme 8. Preparation of EWG-free TAPZ through decarboxylation............... 9

Scheme 9. Will silver influence gold catalysis? .......................................... 17

Scheme 10. Proposed asymmetric synthesis of a-hydroxyl methyl ketone ....... 18

Scheme 11. Refining gold catalysis based on the reactivity ........................... 25

Scheme 12. Purely Au-catalyzed reactions ............................................... 26

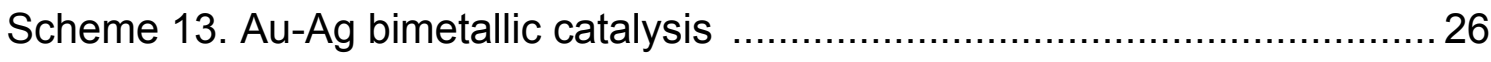

Scheme 14. Ag-assisted Au catalysis .................................................... 27

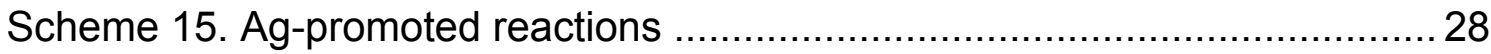

Scheme 16. Gold catalysis using $\mathrm{Tf}_{2} \mathrm{~N}^{-}$as the activation factor ...................... 30

Scheme 17. Representative examples of redox gold catalysis........................ 34

Scheme 18. Combining gold catalysis with photocatalysis ............................. 35

Scheme 19. Selected examples of gold(I) oxidative addition to $\mathrm{C}-\mathrm{X}$ bonds ...... 36

Scheme 20. Examples for reductive elimination from gold(III) ........................ 37

Scheme 21. Oxidative cross-coupling of terminal alkynes............................... 39

Scheme 22. Summary of reaction between diazonium and gold complexes..... 45

Scheme 23. Radical trapping experiment .................................................. 49

Scheme 24. Proposed mechanism of gold-catalyzed C-C cross-coupling ........ 51

Scheme 25. Literature precedence of solid-supported gold catalysts ................ 65

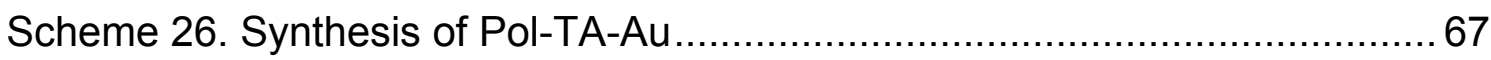

Scheme 27. Representative hydration reactions with Pol-TA-Au .....................69

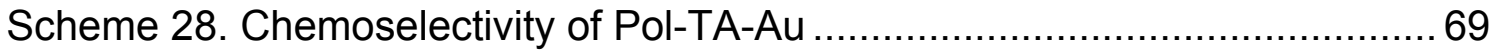


Scheme 29. Hydroamination of alkyne with Pol-TA-Au .................................. 70

Scheme 30. Examples for Pol-TA-Au catalyzed challenging reactions ............. 71

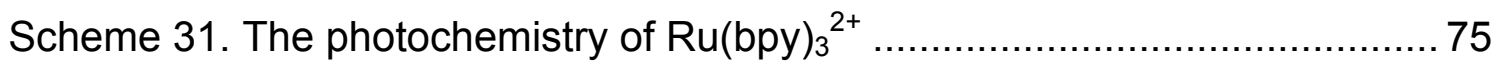

Scheme 32. Selected example of photoredox catalysis ................................. 76

Scheme 33. The ligand effect in photocatalysis.............................................. 77

Scheme 34. C-Aryl-Ir(III) complex with 1,2,3-triazole ligands .......................... 78

Scheme 35. Proposed new N-Aryl-Ir(III) complexes ....................................... 79

Scheme 36. Synthetic route for NAT-Ir(III) complexes ….............................. 79

Scheme 37. TA-Ir as effective photocatalysts ............................................. 83 


\section{List of Tables}

Table 1. Optimization of reaction conditions for TAPZ synthesis ..................... 6

Table 2. Reaction substrate scope for TAPZ synthesis .................................. 7

Table 3. Fluorescence properties of selected TAPZs ................................... 11

Table 4. Fluorescence properties of diester TAPZs ..................................... 12

Table 5. Optimization of conditions for propargyl ester hydration ..................... 19

Table 6. Substrate scope for propargyl ester hydration .................................... 20

Table 7. Silver effect in propargyl ester hydration........................................ 21

Table 8. Silver effect in IPr-Au catalyzed alkyne hydration .............................. 24

Table 9. Comparison of celite filtration and acid activation .............................. 29

Table 10. Gold-catalyzed C(sp)-C(sp $\left.{ }^{2}\right)$ coupling without external oxidants ....... 39

Table 11. Condition optimization for gold-catalyzed C(sp)-C(sp ${ }^{2}$ ) coupling ....... 40

Table 12. Substrate scope for gold-catalyzed $C(s p)-C\left(s^{2}\right)$ coupling ............... 42

Table 13. Condition optimization for gold-catalyzed $\mathrm{C}\left(\mathrm{sp}^{2}\right)-\mathrm{C}\left(\mathrm{sp}^{2}\right)$ coupling ..... 46

Table 14. Substrate scope for gold-catalyzed $\mathrm{C}\left(\mathrm{sp}^{2}\right)-\mathrm{C}\left(\mathrm{sp}^{2}\right)$ coupling .............. 47

Table 15. Gold-catalyzed C-Br bond formation............................................. 53

Table 16. Substrate scope for gold-catalyzed $\mathrm{C}-\mathrm{Br}$ bond formation .................. 54

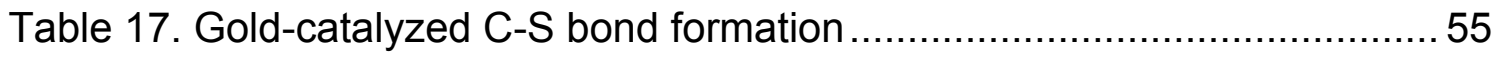

Table 18. Substrate scope for gold-catalyzed C-S bond formation .................. 56

Table 19. Gold-catalyzed C-P bond formation ............................................. 57

Table 20. Substrate scope for gold-catalyzed C-P bond formation .................. 58

Table 21. Redox potential of selected iridium complexes ................................ 81

Table 22. Redox potential of selected iridium complexes with tapy ligand ........83 


\section{List of Figures}

Figure 1. X-ray crystal structure of TAZ-Au-IPr........................................ 5

Figure 2. Stability comparison of different triazapentalenes ........................... 9

Figure 3. Emission spectra of TAPZs with different substitutes ...................... 10

Figure 4. X-ray crystal structures and emission spectra for selected TAPZs .... 11

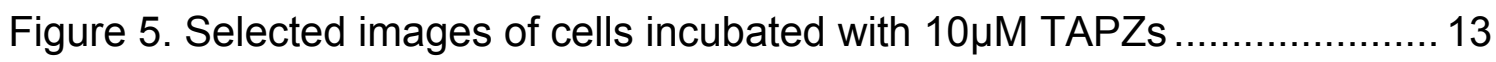

Figure 6. X-ray crystal structure of [IPr-Au-TA] ${ }^{+}$OTf complex ......................... 21

Figure 7. XPS spectra of the $\left(\mathrm{PPh}_{3}\right) \mathrm{AuCl} / \mathrm{AgSbF}_{6}$ mixture after filtration ........... 22

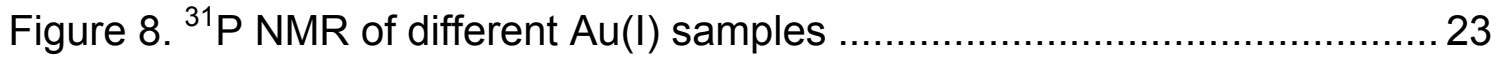

Figure 9. ${ }^{31} \mathrm{P}$ NMR comparison of different $\mathrm{Au}(\mathrm{I})$ catalysts ................................ 29

Figure 10. Reaction between diazonium and $\mathrm{Ph}_{3} \mathrm{PAuNTf}_{2} \ldots \ldots \ldots \ldots \ldots \ldots \ldots \ldots \ldots . . . . . . . . . . . . . . .43$

Figure 11. Reaction between diazonium and gold acetylide ........................... 44

Figure 12. Reaction between diazonium and aryl gold complex...................... 44

Figure 13. Monitoring the catalytic $\mathrm{C}(\mathrm{sp})-\mathrm{C}\left(\mathrm{sp}^{2}\right)$ coupling ............................... 48

Figure 14. ESI-MS spectra of reaction mixture between diazonium and alkyne 49

Figure 15. Explore the reaction intermediate with ESI-MS spectra .................. 48

Figure 16. Teles hydration reaction with Pol-TA-Au ................................... 68

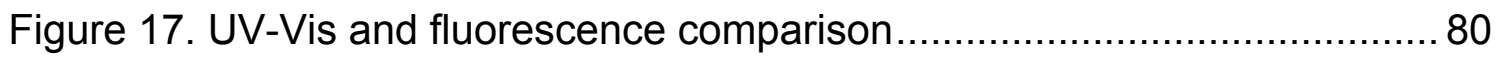

Figure 18. Fluorescence comparison of different substituent ......................... 81 


\section{Chapter 1. Gold-Catalyzed Synthesis of Triazapentalene Zwitterions}

\subsection{Introduction}

\subsubsection{Homogeneous gold(I) catalysis}

Homogeneous gold catalysis has been considered as one of the most important developments in organic synthesis during the last decade. ${ }^{1}$ One reason for the vast development is the unique reactivity of gold as a strong alkynophilic Lewis acid. ${ }^{2}$ In 2007, Toste reported "the relativistic effect in homogeneous gold catalysis", which provided some theoretical insights into the observed reactivity of gold catalysts (Scheme 1). ${ }^{3}$ Because of the relativistic contraction of $6 \mathrm{~s}$ orbital, the gold-ligand bond is strengthened. The contracted $6 \mathrm{~s}$ orbital also provides better shielding effect for the electrons in the $5 d$ orbital, leading to the expansion of $5 d$. Since the electrons in $5 d$ orbital are more dispersed, gold is a stronger Lewis acid compared with silver (non-relativistic). For the same reason, gold $(\mathrm{I})$ is retarded for oxidative addition, which allows ambient conditions for gold catalysis without the need for inert-gas protection.

\section{Scheme 1. Relativistic effect of gold}

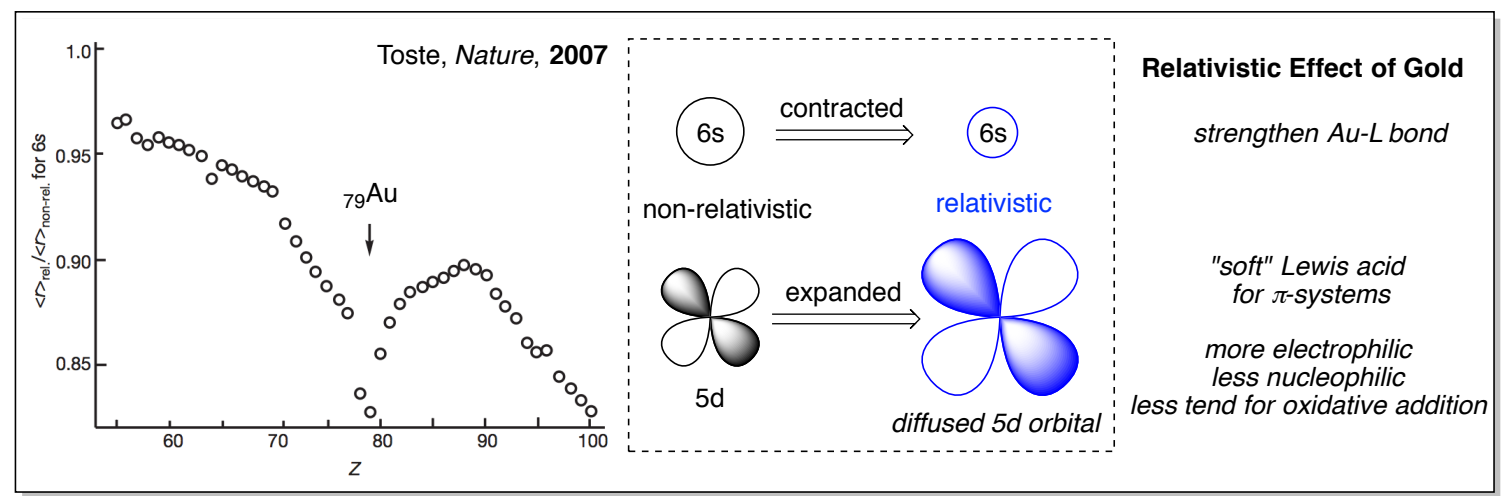


One typical reaction mode for $A u(l)$ is the activation of $\pi$-systems towards nucleophiles (Scheme 2). ${ }^{4}$ For most cases, the nucleophiles attack the goldactivated alkyne from the trans position to Au, forming a vinyl-gold intermediate. The product is then formed from proto-deauration of the vinyl-gold. ${ }^{5}$ As a highly reactive intermediate in $\mathrm{Au}(\mathrm{I})$ catalysis, the vinyl-gold species could also be trapped by other electrophiles, ${ }^{6}$ or following a carbenoid-like reaction route through backbonding from gold. ${ }^{7}$

\section{Scheme 2. Nucleophilic addition to gold-activated alkynes}

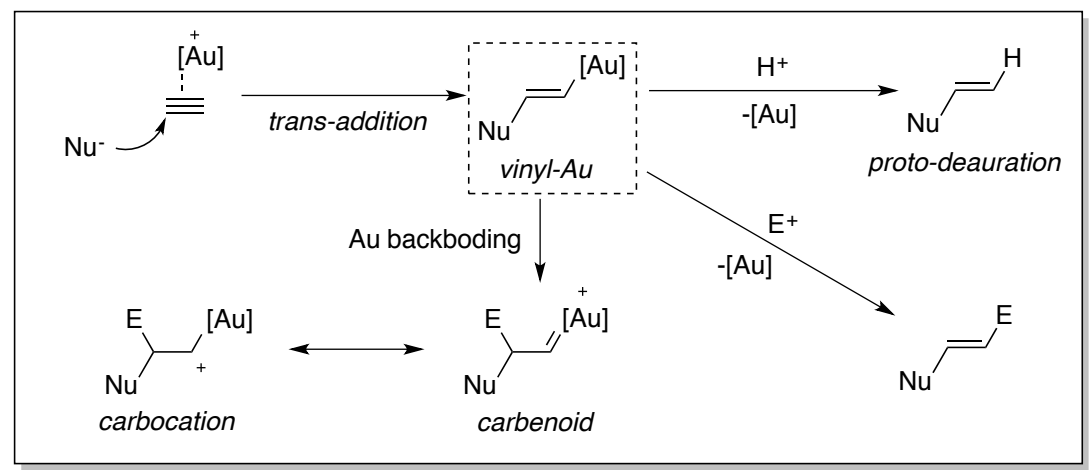

In 1998, Teles reported the addition of alcohols to alkynes using a cationic phosphine-Au(I) catalyst with very high reactivity (TOF up to $1500 \mathrm{~h}^{-1}$ ). ${ }^{8}$ He was also the first one who used acid to activate the homogeneous $\mathrm{Au}(\mathrm{I})$ catalyst. For the reaction of diphenylacetylene (Scheme 3A), an initial dominance of Z-isomer was observed $(Z: E=8: 1)$, suggesting the trans-addition of methanol to alkyne. The final Z:E selectivity decreased, possibly due to isomerization through the corresponding acetal. Hydroamination with terminal alkynes have also been achieved using gold catalyst with an acid promoter (Scheme 3B). ${ }^{9}$ Another example of gold-catalyzed nucleophilic addition to alkynes is the Conia-ene reaction (Scheme $\mathbf{3 C}$ ), which incorporated an enolate as the nucleophile for the intramolecular cycloaddition. ${ }^{10}$ Cationic gold(I) catalyst could promote this reaction with high efficiency at room temperature (Conia-ene reactions usually require high temperature for the thermal cyclization) $)^{11}$. 
Scheme 3. Selected examples for nucleophilic addition to gold-activated alkynes

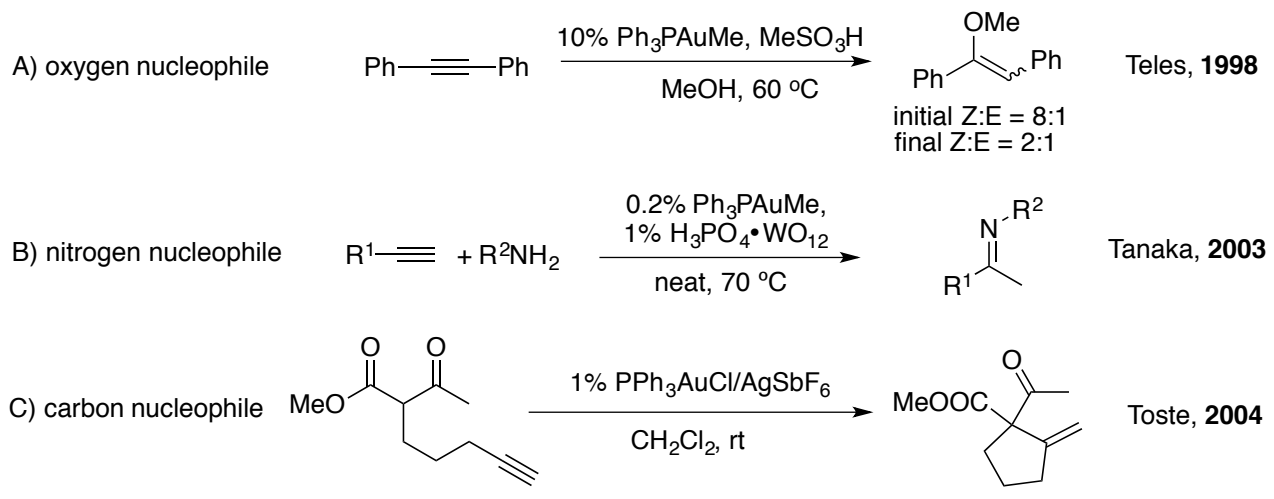

After the discovery of these early examples, homogeneous gold(I) catalysts have been rapidly developed for various transformations that involving activation of $\pi$-systems and applied into complex molecular synthesis. ${ }^{12}$

\subsubsection{Triazole-gold(I) catalyst with improved stability}

Despite the remarkable efficiency of homogeneous $\mathrm{Au}(\mathrm{I})$ catalysts, one big challenge is the poor stability of cationic gold $(\mathrm{I})$ complexes $\left(\mathrm{L}-\mathrm{Au} \mathrm{u}^{+}\right)$, especially at elevated temperatures. Among the reported ligands, $\mathrm{N}$-heterocyclic carbenes (NHCs) has been observed to give improved catalyst stability. ${ }^{13}$ Compared with other counteranions for $\mathrm{L}_{-} \mathrm{Au}^{+}$, such as $\mathrm{OTf}^{-}, \mathrm{SbF}_{6}^{-}$, and $\mathrm{BF}_{4}^{-}, \mathrm{NTf}_{2}^{-}$as the conteranion for $\mathrm{L}_{-} \mathrm{Au}^{+}$also helped increase catalyst stability through a dynamic Au-N coordination. ${ }^{14}$

Our group has focused on the investigation of 1,2,3-triazoles and their coordination with transition metals. ${ }^{15}$ The electron-deficient nature of triazoles has made them less attractive as ligands for transition metals. ${ }^{16}$ However, since the coordinating lone pair electrons on nitrogen are not conjugated with $\pi$ electrons, 1,2,3-triazole appears to be a good $\sigma$-donor. The three adjacent nitrogen atoms also increase the electron density on the nitrogen side, which could further increase the $\sigma$-donating ability. Meanwhile, the electronic deficiency makes triazole a potential $\pi$-acceptor for metal backbonding. Based on the unique properties of 1,2,3-triazole, it is a feasible consideration to employ 1,2,3-triazole as a ligand to enhance the stability of $\mathrm{Au}(\mathrm{I})$ catalysts. 
In 2009, our group successfully developed triazole-gold complexes (TA-Au) as an effective catalyst for alkyne hydroamination with improved thermal stability (Scheme 4). ${ }^{17}$ Compared with triazole-gold catalyst, other gold(I) catalysts decomposed before reaction completion. By the in situ activation of TA-Au by an acid promoter, the desired imine was formed in high yields, which highlighted the good balance between reactivity and stability of TA-Au complexes.

Scheme 4. Triazole-gold catalyst for intermolecular alkyne hydroamination
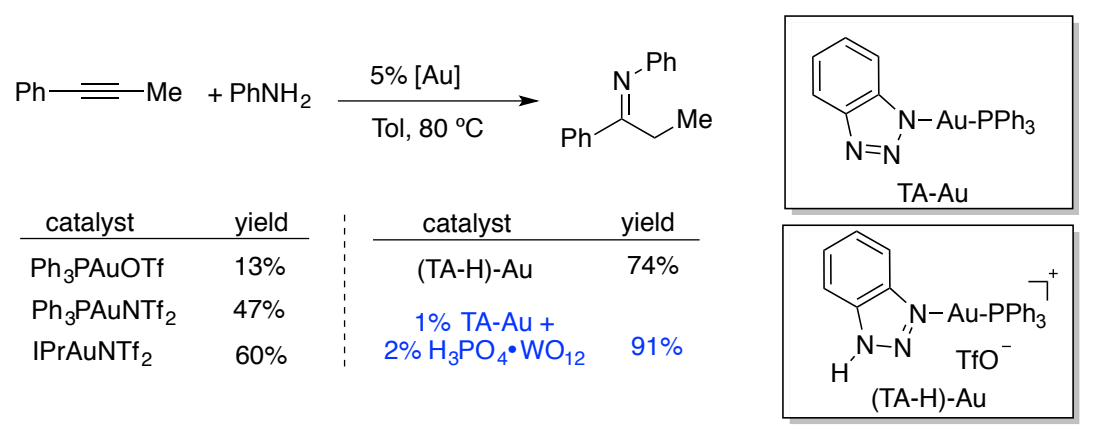

\subsubsection{Acid-stable vinyl-gold complexes}

As mentioned in section 1.1.1 (Scheme 2), the vinyl-gold species is a critical intermediate in gold-catalyzed alkyne activation. However, the study of vinyl-gold complexes is often more difficult due to the high reactivity of vinyl-Au complexes, such as easy proto-deauration. ${ }^{18}$ To trap this intermediate, we postulate that with 1,2,3-triazole as a stabilizing ligand for gold catalyst, isolation of the desired vinyl-gold complex may be feasible.

Our group discovered the gold-catalyzed nucleophilic addition of triazole to alkynes, forming the corresponding vinyl triazoles in good yields. ${ }^{19}$ However, an intramolecular addition of triazole to alkyne did not give the desired product. Instead, a vinyl-Au complex was formed when propargyl triazole was treated with a stoichiometric amount of cationic gold catalyst (Scheme 5). This complex was successfully isolated in high yield. Unlike other reported organo-Au complexes, this vinyl-Au complex is stable toward air, moisture, and even survives upon treatment with HOTf for more than $12 \mathrm{~h}^{20}$ 
Scheme 5. Formation of acid-stable vinyl-gold complexes

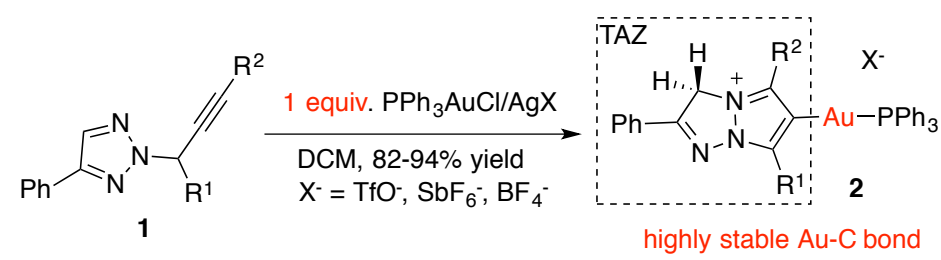

Considering that triazolium (TAZ) is a neutral ligand with a C-binding site, it is similar to the well-known N-heterocyclic carbene (NHC) ligands. To understand the reactivity of TAZ-Au complex 3, we prepared the corresponding NHC-gold complex. The crystal structure is shown in Figure 1.

Figure 1. X-ray crystal structure of TAZ-Au-IPr

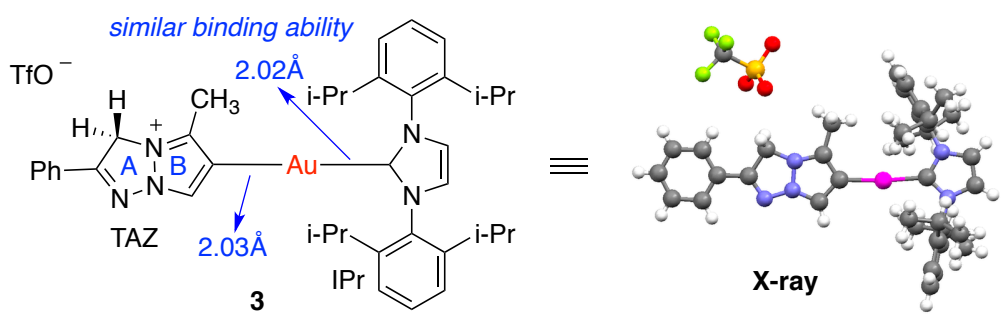

As shown in the crystal structure, the TAZ ligand bound to $A u$ in a similar fashion as IPr ligand, ${ }^{21}$ giving almost identical C-Au bond lengths. This result suggests the possibility for applying this TAZ as a ligand to stabilize gold catalysts similar to the well-explored IPr ligand.

\section{2 Catalytic cyclization of propargyl triazole}

One challenge for efficient synthesis of TAZ ligand is the poor gold catalyst turnover due to the formation of a stable $\mathrm{C}-\mathrm{Au}$ bond in complex 3 . Considering that protonation in TAZ complexes occurred on ring $A$ instead of the C-Au bond, we postulated that the introduction of an electron-withdrawing group (EWG) on ring A may reduce the basicity of the corresponding carbanion, which will "redirect" the protonation to the C-Au bond, leading to gold catalyst turnover 
through protodeauration. As the result, the proposed triazapentalene zwitterions (TAPZ) synthesis could be achieved with catalytic amount of gold (Scheme 6).

\section{Scheme 6. Proposed strategy for gold turnover}

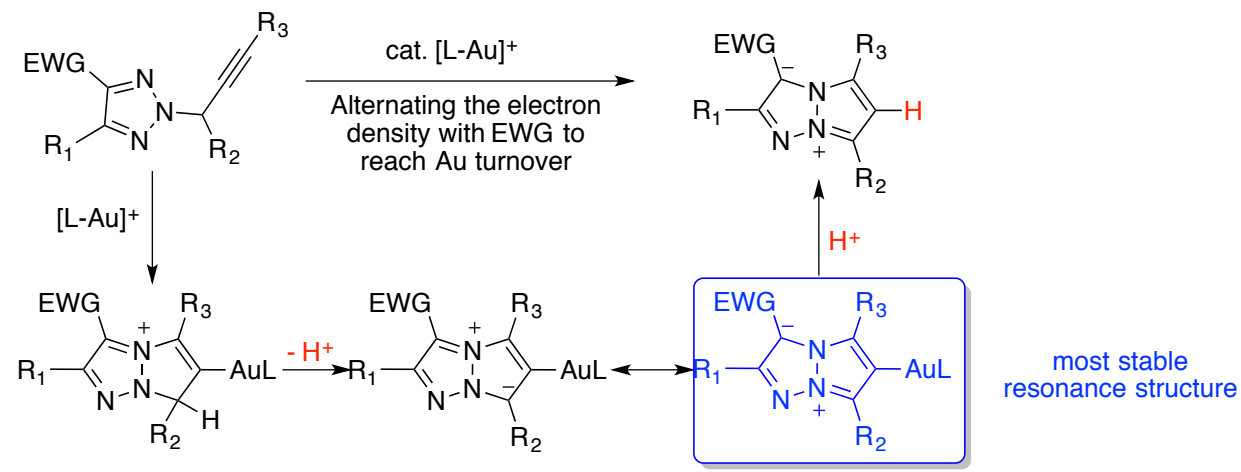

To verify our hypothesis, triazole-alkyne 4a was prepared and charged with [Au] catalyst (1\% $\left.\mathrm{PPh}_{3} \mathrm{AuCl} / \mathrm{AgOTf}\right)$. As expected, TAPZ 5a was successfully prepared in good yield (91\%) and its structure was confirmed by X-ray crystallography. Further screening (Table 1) revealed elevated temperature (60 ${ }^{\circ} \mathrm{C}$ ) in DCE as the optimal conditions, giving 5a in excellent isolated yield (96\%) with only $0.5 \%$ catalyst loading.

Table 1. Optimization of reaction conditions for TAPZ synthesis ${ }^{a}$
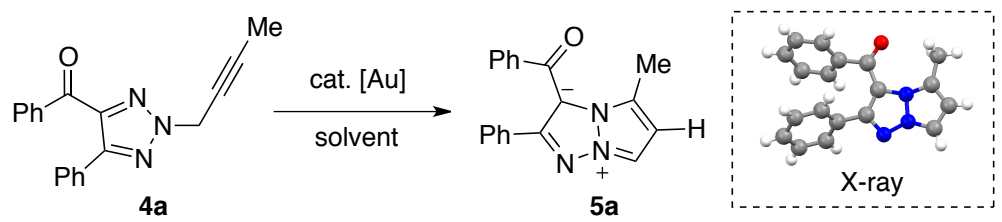

\begin{tabular}{cccccccc}
\hline Entry & Catalyst & $\begin{array}{c}\text { Loading } \\
(\%)\end{array}$ & Solvn $^{[\mathrm{b}]}$ & $\begin{array}{c}\text { Temp } \\
\left({ }^{\circ} \mathrm{C}\right)\end{array}$ & $\begin{array}{c}\text { Time } \\
(\mathrm{h})\end{array}$ & $\begin{array}{c}\text { Convn } \\
(\%)\end{array}$ & $\begin{array}{c}\text { Yield } \\
(\%)^{[\mathrm{c}]}\end{array}$ \\
\hline 1 & $\mathrm{AuPPh}_{3} \mathrm{Cl} / \mathrm{AgOTf}$ & 1.0 & $\mathrm{DCM}$ & $\mathrm{rt}$ & 48 & 96 & 91 \\
2 & $\mathrm{AuPPh}_{3} \mathrm{Cl} / \mathrm{AgBF}_{4}$ & 1.0 & $\mathrm{DCM}$ & $\mathrm{rt}$ & 48 & 76 & 72 \\
3 & $\mathrm{AuPPh}_{3} \mathrm{Cl} / \mathrm{AgSbF}_{6}$ & 1.0 & $\mathrm{DCM}$ & $\mathrm{rt}$ & 48 & $>98$ & 94 \\
4 & ${\text { [PPh3Au}(\mathrm{TA})]^{+} \mathrm{TfO}^{-[\mathrm{e}]}}$ & 1.0 & $\mathrm{DCM}$ & $\mathrm{rt}$ & 48 & 69 & 64 \\
5 & $\mathrm{AuPPh}_{3} \mathrm{Cl} / \mathrm{AgSbF}_{6}$ & 1.0 & $\mathrm{DCE}$ & $\mathrm{rt}$ & 48 & $>98$ & 92 \\
6 & $\mathrm{AuPPh}_{3} \mathrm{Cl}_{\mathrm{AgSbF}}$ & 1.0 & $\mathrm{THF}$ & $\mathrm{rt}$ & 48 & 75 & 69 \\
7 & $\mathrm{AuPPh}_{3} \mathrm{Cl}_{6} / \mathrm{AgSbF}_{6}$ & 1.0 & $\mathrm{MeCN}$ & $\mathrm{rt}$ & 48 & $<5$ & -
\end{tabular}




\begin{tabular}{|c|c|c|c|c|c|c|c|}
\hline 8 & $\mathrm{AuPPh}_{3} \mathrm{Cl} / \mathrm{AgSbF}_{6}$ & 1.0 & $\mathrm{MeNO}_{2}$ & $\mathrm{rt}$ & 48 & 7 & - \\
\hline 9 & $\mathrm{AuPPh}_{3} \mathrm{Cl} / \mathrm{AgSbF}_{6}$ & 1.0 & DCE & 60 & 3 & $>98$ & $>98$ \\
\hline 10 & $\mathrm{AuPPh}_{3} \mathrm{Cl} / \mathrm{AgSbF}_{6}$ & 0.5 & DCE & 60 & 4 & $>98$ & $96^{[\mathrm{d}]}$ \\
\hline 11 & AuPPh3Cl/AgSbF6 & 0.2 & DCE & 60 & 48 & 79 & $77^{[\mathrm{d}]}$ \\
\hline
\end{tabular}

${ }^{a}$ General reaction conditions: $4 a(0.5 \mathrm{mmol})$, catalyst $(0.2-1.0 \mathrm{~mol} \%)$ in $5 \mathrm{~mL}$ solvent, the reactions were monitored by TLC, rt- $60{ }^{\circ} \mathrm{C} ;{ }^{b} \mathrm{DCE}: 1,2$-dichloroethane; ${ }^{c} \mathrm{NMR}$ yields of $\mathbf{5 a}$ with 1,3,5-trimethoxybenzene as internal standard; ${ }^{d}$ Isolated yield; ${ }^{e} \mathrm{TA}=\mathrm{N}$-methyl-benzotriazole.

With the optimal conditions in hand, various $\mathrm{N}$-2-alkynyl-triazoles were prepared to explore the reaction substrate scope. Some representative substrates are summarized in Table 2.

Table 2. Reaction substrate scope for TAPZ synthesis ${ }^{a}$

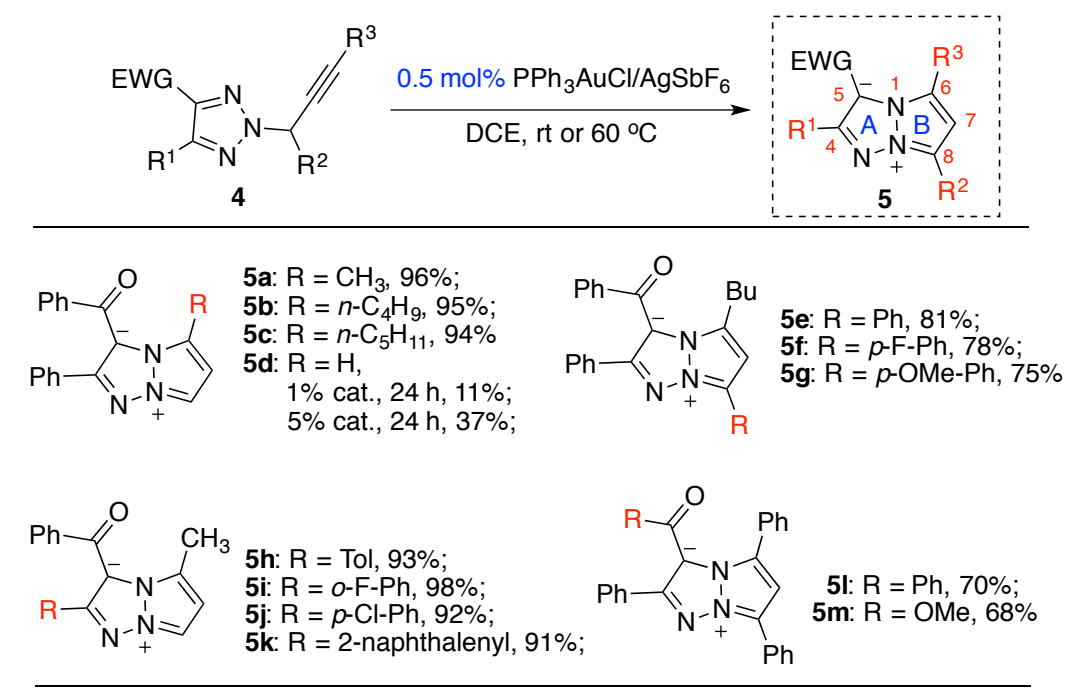

${ }^{a}$ Standard reaction condition: $4(0.5 \mathrm{mmol}), \mathrm{AuPPh}_{3} \mathrm{Cl} / \mathrm{AgSbF}_{6}(0.5 \mathrm{~mol} \%)$ in DCE $(5 \mathrm{~mL})$, the reactions were monitored by TLC $(3-24 \mathrm{~h}), 60{ }^{\circ} \mathrm{C}$; ${ }^{b}$ Isolated yield.

As shown in Table 2, this reaction tolerates a large group of substrates. Both alkyl (5a-5c) and aryl (5I) groups are suitable for the alkyne terminal, giving the corresponding TAPZ in excellent yields. The terminal alkyne $(\mathbf{5 d})$ is problematic due to the slow reaction rate and eventual gold catalyst decomposition (after long reaction time). This is likely caused by the unfavored anti-Markovnikov addition to the alkyne. In addition, an ester can also be used as the EWG $(\mathbf{5 m})$ to 
promote the gold turnover (though with lower yields), which further extended the scope of TAPZ with this method.

\section{3 Triazapentalenes as biocompatible fluorophores}

Fluorescent probes have been recognized as powerful tools for chemistry and biology research. ${ }^{22}$ Various systems of small organic fluorophores have been widely utilized in cell labeling and recognition. ${ }^{23}$ Despite the rapid development in this field, many of the reported systems involve large conjugated structures, which are often associated with some limitations, including difficult synthesis, small Stokes shift and/or poor water solubility. ${ }^{24}$ Thus, the development of new organic fluorophores with tunable emission wavelengths is of great interest for chemical, medicinal and biological research.

\subsubsection{Triazapentalenes from cascade click chemistry}

In 2011, Namba and Tanino prepared similar TAPZ via cascade clickcyclization-aromatization (Scheme 7). ${ }^{25}$ One interesting observation from their work was the strong fluorescence emission in the visible light region with $\lambda_{\max }$ between $380 \mathrm{~nm}$ to $560 \mathrm{~nm}$. However, these TAPZs also indicated modest to poor stability especially under acidic conditions, which made them less practical as fluorescent dyes in biological systems. Meanwhile, the reported synthetic route is only suitable for terminal alkynes (necessary for click chemistry) and involves a highly reactive di-triflate moiety, which significantly limits the substrate scope and makes these novel fluorophores less attractive.

Scheme 7. Triazapentalene synthesis from click-cyclization-aromatization

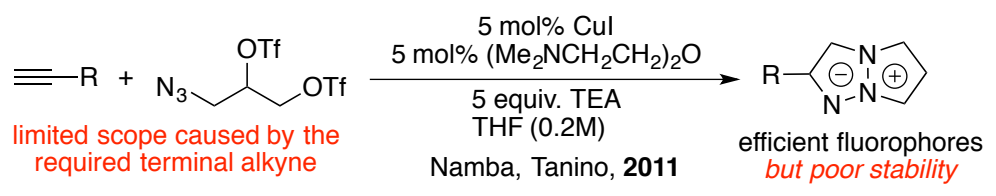




\subsubsection{Triazapentalenes with improved stability}

Compared with the synthesis using click chemistry, our gold-catalyzed approach allows effective syntheses of TAPZ derivatives with various substituents at C-4, C-5, C-6 and C-8 positions, which provides a good opportunity to construct a TAPZ library for the fluorescence evaluation. Notably, the EWG-free TAPZ (reported by Namba and Tanino), ${ }^{25}$ although much less stable, can also be prepared using this method through a simple decarboxylation as shown in Scheme 8.

Scheme 8. Preparation of EWG-free TAPZ through decarboxylation

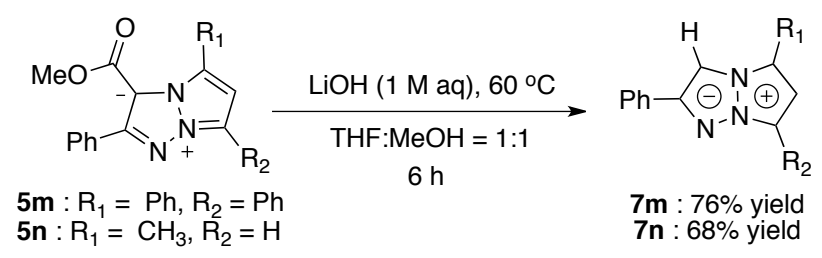

As discussed in the previous section, another concern for the monosubstituted TAPZs is their poor stability. For example, dissolving 7 in untreated $\mathrm{CDCl}_{3}$ caused an immediate color change from light yellow to green, probably due to the protonation by trace amount of acid in $\mathrm{CDCl}_{3}$.

Figure 2. Stability comparison of different triazapentalenes

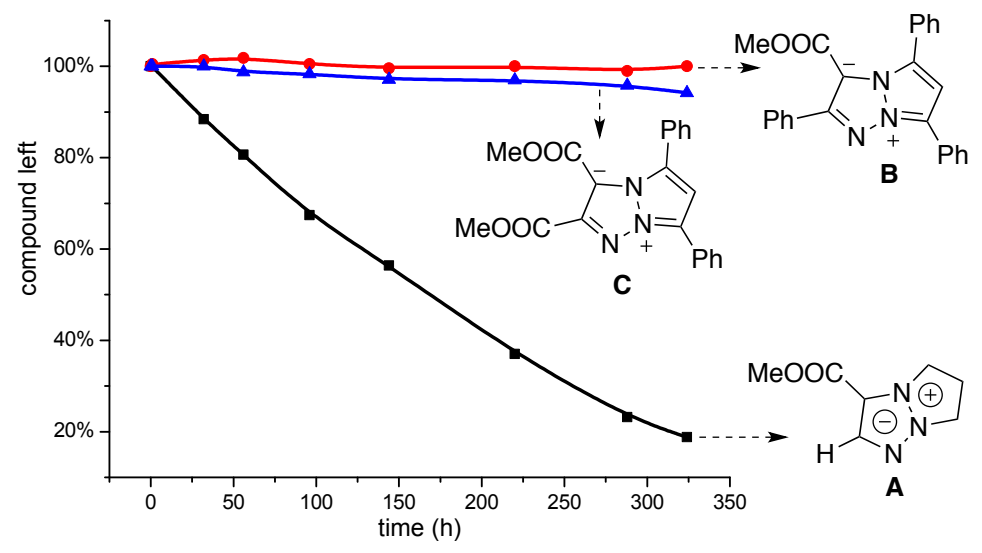


To quantize the decomposition, we monitored the TAPZ solution with ${ }^{1} \mathrm{H}$ NMR over time. The C-4, C-5 di-substituted TAPZs prepared using our method indicated significantly improved stability, giving almost no decomposition under the identical conditions over two weeks (Figure 2). The significantly improved stability of the di-substituted TAPZs makes further investigation and application feasible.

\subsubsection{Fluorescence investigation of selected triazapentalenes}

With the ability to prepare various new TAPZ derivatives, we turned our attention toward evaluating TAPZ fluorescence activities. As shown in Figure 3A and $\mathbf{3 B}$, the fluorescence emission of ketone and ester TAPZs can be easily tuned by substituent on ring B. Interestingly, with p-nitrophenyl group on C-8 position, a red shift was observed (emission $\lambda_{\max }: 5 p=594 \mathrm{~nm}, 5 \mathrm{~s}=587 \mathrm{~nm}$ ) and the fluorescence intensity was also increased. Compared with nitro group, cyano group ( $\mathbf{5 q}$ and $\mathbf{5 t})$ showed a different trend in fluorescence.

Figure 3. Emission spectra of TAPZs with different substitutes
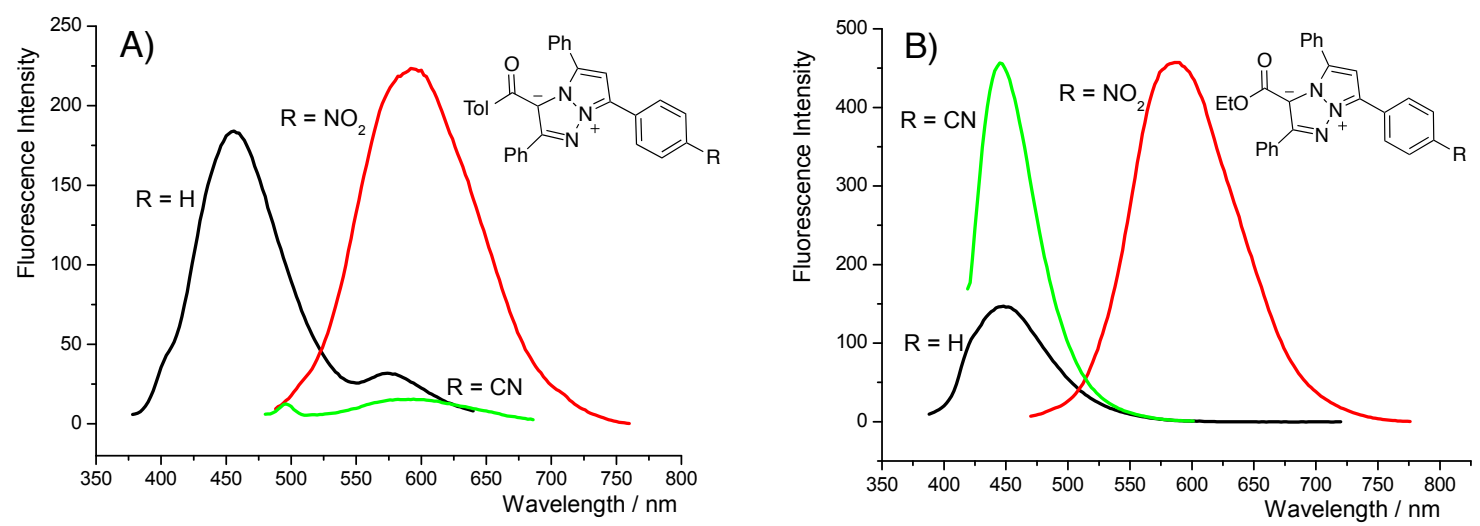

However, the fluorescence intensities of these newly developed TAPZs are quite low with quantum yields less than $1 \%$ (Table 3). Compared with ketone (5o-q) and mono-ester (5r-m), the diester derivative (6a) exhibited a much stronger emission. Furthermore, the yield and stability of these TAPZs is also improved. 
Table 3. Fluorescence properties of selected TAPZs ${ }^{a}$

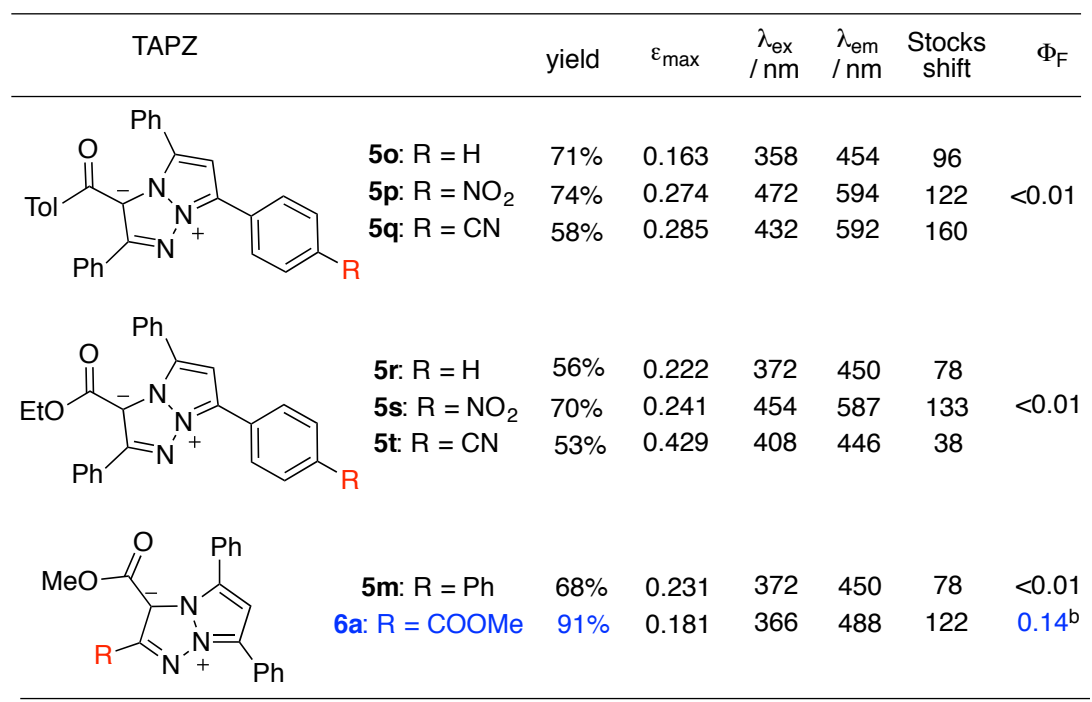

${ }^{a}$ All data obtained at room temperature, $10^{-5} \mathrm{M}$ solution in $\mathrm{DCM} ;{ }^{b}$ measured in $10^{-6} \mathrm{M} \mathrm{DCM}$ solution; ${ }^{c}$ extinction coefficient in $10^{5} \mathrm{M}^{-1} \mathrm{~cm}^{-1} ;{ }^{d}$ quantum yields were measured with quinine sulfate as reference $\left(\Phi=0.60\right.$ in $\left.0.1 \mathrm{~N} \mathrm{H}_{2} \mathrm{SO}_{4}\right) ;{ }^{e}$ isolated yields.

To understand the substituent effect on fluorescence properties, crystal structures of several representative TAPZs were determined (Figure 4).

Figure 4. X-ray crystal structures and emission spectra for selected TAPZs
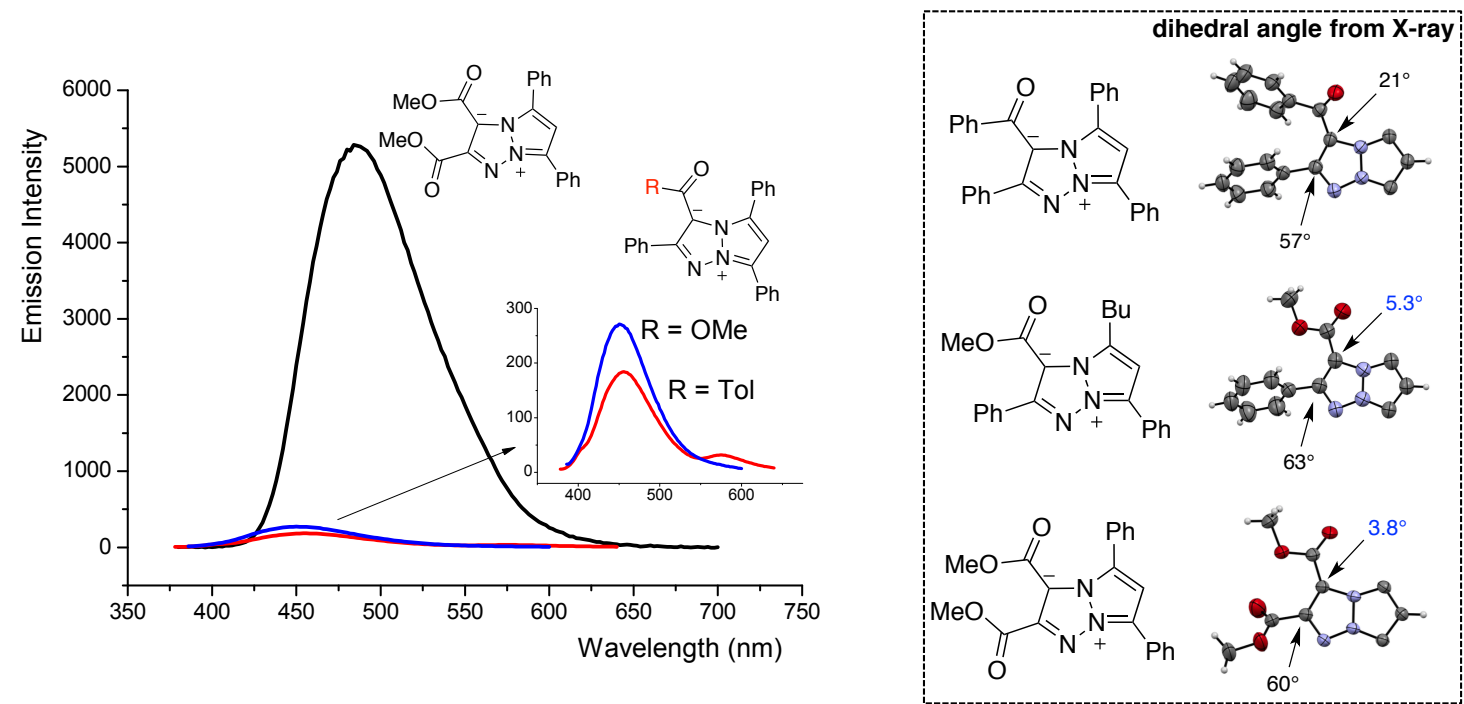

As revealed by the X-ray structural analyses, switching ketone to an ester group led to better conjugation between carbonyl and TAPZ ring A, which is likely 
caused by the reduced steric repulsion of the smaller ester group. Since ring $A$ is electron rich (negative charged), a second EWG in the diester TAPZ will help improve the stability and likely enhance fluorescence emission.

Considering that the diester TAPZ gave the strongest emission, a small library of diester derivatives were prepared to further evaluate this new class of fluorophores. Their fluorescence properties are summarized in Table 4.

Table 4. Fluorescence properties of diester TAPZs ${ }^{a}$

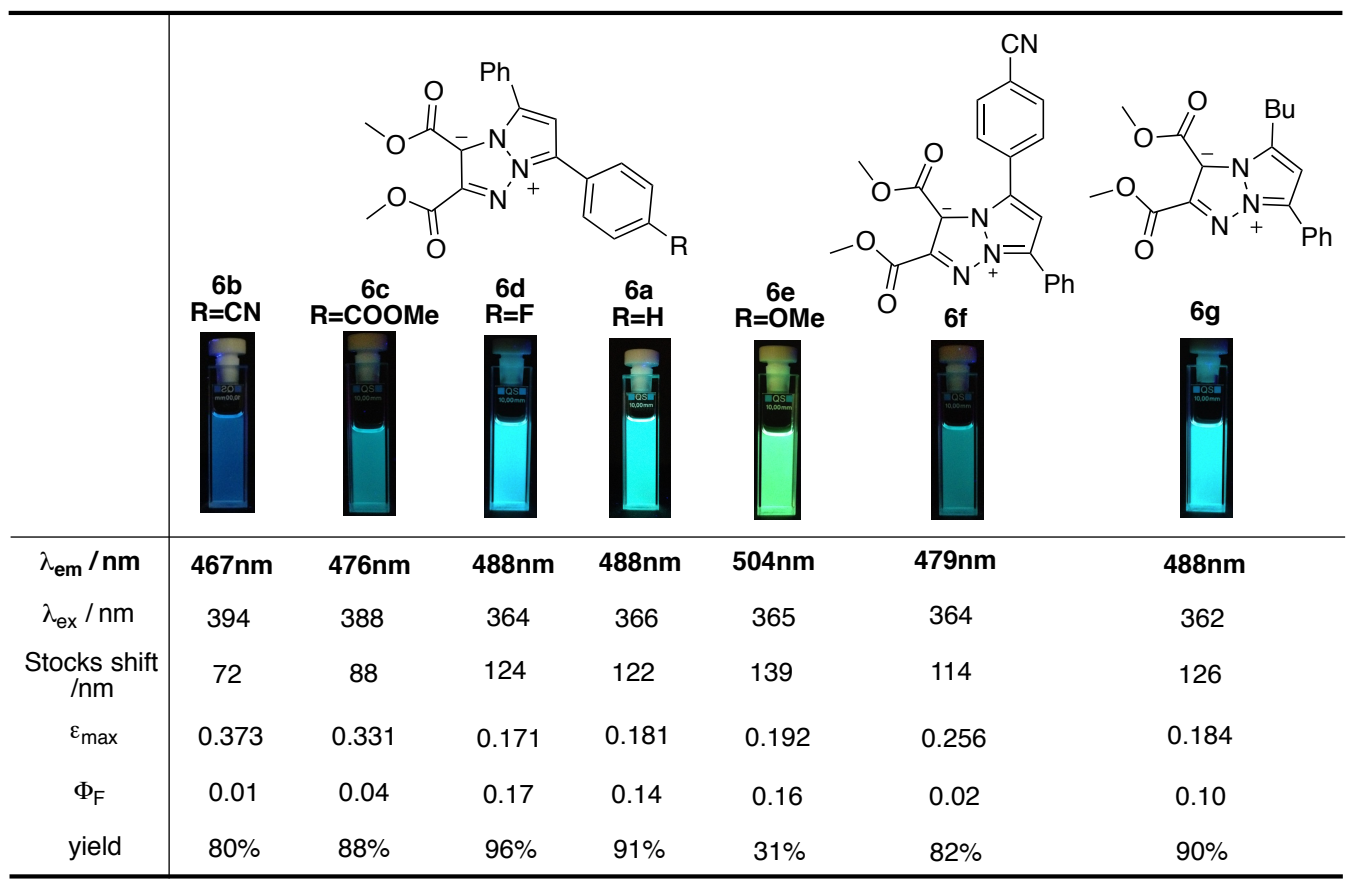

${ }^{a}$ All data obtained at room temperature, $10^{-6} \mathrm{M} \mathrm{DCM}$ solution; ${ }^{b}$ extinction coefficient in $10^{5} \mathrm{M}^{-1} \mathrm{~cm}^{-}$ ${ }^{1} ;{ }^{c}$ quantum yields were measured with quinine sulfate as reference $\left(\Phi=0.60\right.$ in $\left.0.1 \mathrm{~N} \mathrm{H}_{2} \mathrm{SO}_{4}\right){ }^{d}$ isolated yields.

As shown in Table 3 and 4, these new 4,5-disubstituted TAPZ fluorescent dyes gave tunable emission with $\lambda_{\max }$ between $450 \mathrm{~nm}$ to $590 \mathrm{~nm}$. The Stokes shifts ranged from $38 \mathrm{~nm}$ to $160 \mathrm{~nm}$. For the diester TAPZs, electron-withdrawing groups such as $\mathrm{CN}(\mathbf{6 b}, \mathbf{6 g})$ and COOMe (6c) caused lower quantum yield, whereas the TAPZ with p-fluorophenyl on C-8 gave a stronger emission. Red shift was observed by incorporating strong electron-donating groups (EDGs) on the positively charged B-ring $\left(R=C N, \lambda_{\max }=467 \mathrm{~nm} ; \mathrm{R}=\mathrm{OMe}, \lambda_{\max }=504 \mathrm{~nm}\right)$. 
Introducing a strong electron-withdrawing nitro $\left(\mathrm{NO}_{2}\right)$ group led to less than $10 \%$ yield of TAPZ with low fluorescence activity. This is totally opposite to the ketone (5p) and mono-ester (5s) for which higher yield and stronger emission were observed. Clearly, the overall TAPZ emission relies on substituents on both rings.

Although these di-substituted TAPZs are much more stable than the monosubstituted TAPZs, their overall stability followed the general trend as diester $>$ mono-ester > ketone. These dyes also tolerate various environments, from $\mathrm{CH}_{2} \mathrm{Cl}_{2}$ to more polar solvents like DMSO and water, which enables us to test the feasibility of using TAPZs in cell imaging. After incubating the cells with selected TAPZ solutions for 10 minutes, the illumination of the cells was observed under a fluorescence microscope (Figure 5). This result suggested promising future applications of these TAPZs as new biocompatible fluoroscence probes.

Figure 5. Selected images of cells incubated with $10 \mu \mathrm{M}$ TAPZs

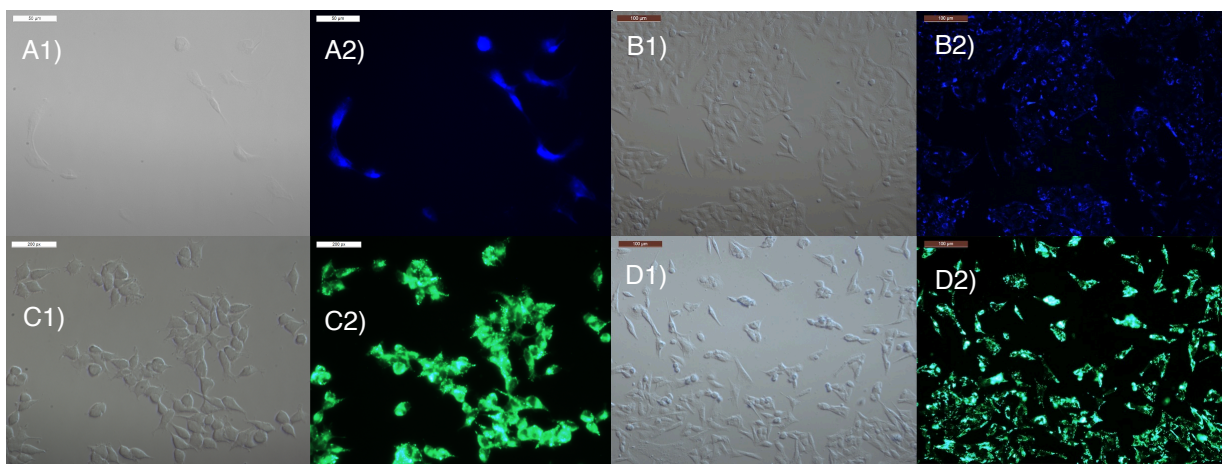

A1) and C1): bright-field view of HEK-293t cells incubated with $10 \mu \mathrm{M} \mathbf{6 a}$ or $\mathbf{5 s}$ in $1 \%$ DMSO/media solution, scale bar $=50 \mu \mathrm{m} ; \mathrm{A} 2$ ) and C2): fluorescence images of the same cells; B1) and D1): bright-field view of A549 cells incubated with $10 \mu \mathrm{M}$ 6a or 5 s in $1 \% \mathrm{DMSO} /$ media solution, scale bar $=100 \mu \mathrm{m} ; \mathrm{B} 2)$ and D2): fluorescence images of the same cells.

\section{4 Conclusion}

In summary, we report the investigation of gold catalyzed triazole-alkyne 5endo-dig cyclization for the synthesis of stable triazapentalene zwitterions (TAPZs). Through the introduction of electron-withdrawing groups, the electron 
density distribution on the triazapentalene was altered, which resulted in effective gold catalyst turnover. Good to excellent yields of desired TAPZs were achieved in most of the cases. In addition, the resulting ester modified TAPZs gave excellent fluorescence, with tuneable optical properties. The cell imaging highlighted great potential of this new class of TAPZs as new biocompatible probes and the unique advantage of the gold catalyzed cyclization.

\section{5 Contribution}

Dr. Dawei Wang was the first investigator of this gold-catalyzed cyclization. He developed the optimal conditions and synthesized part of the substrates. Rong Cai developed TAPZs with esters as EWG and investigated fluorescence properties as well as cell imaging. Dr. Yunfeng Chen developed the acid-stable vinyl-gold complexes. Dr. Wuming Yan provided help on the iron-catalyzed propargylation of triazole for the substrate synthesis. Natalie Geise and Sripadh

Sharma helped with substrate preparation. Dr. Huiyuan Li provided help on the bio-related experiments. Dr. Jeffrey Petersen performed the X-ray crystallographic analyses.

Part of this project is published on Chem. Commun., 2014, 50, 7303-7305.

\section{References:}

1 For selected recent reviews on homogeneous gold catalysis, see: a) Furstner, A.; Davies, P. W. Angew. Chem. Int. Ed. 2007, 46, 3410; b) Arcadi, A. Chem. Rev. 2008, 108, 3266; c) Gorin, D. J.; Sherry, B. D.; Toste, F. D. Chem. Rev. 2008, 108, 3351; d) Widenhoefer, R. A. Chem. Eur. J. 2008, 14, 5382; e) Hashmi, A. S. K. Angew. Chem. Int. Ed. 2010, 49, 5232; f) Nolan, S. P. Acc. Chem. Res. 2011, 44, 91;

g) Rudolph, M.; Hashmi, A. S. K. Chem. Comun., 2011, 47, 6536.

2 Furstner, A. Acc. Chem. Res. 2014, 47, 925.

3 Gorin, D. J.; Toste, F. D. Nature 2007, 446, 395.

4 Selected examples, see: a) Fukuda, Y.; Utimoto, K. J. Org. Chem. 1991, 56, 3729; b) Reetz, M.; Sommer, K. Eur. J. Org. Chem. 2003, 18, 3485; c) Staben, S.; Kennedy- 
Smith, J.; Huang, D.; Corkey, B.; LaLonde, R.; Toste, F. D. Angew. Chem. Int. Ed. 2006, 45, 5991.

5 Wang, Z. J.; Benitez, D.; Tkatchouk, E.; Goddard lii, W. A.; Toste, F. D. J. Am. Chem. Soc. 2010, 132, 13064.

6 Yu, M.; Zhang, G.; Zhang, L. Org. Lett. 2007, 9, 2147. For reviews for cycloisomerization, see: a) Jimenez-Nunez, E.; Echavarren, A. M. Chem. Rev. 2008, 108, 3326; b) Obradors, C.; Echavarren, A. M. Acc. Chem. Res. 2014, 47, 902.

7 a) Fürstner, A.; Morency, L. Angew. Chem., Int. Ed. 2008, 47, 5030; b) Zhang, L. Acc. Chem. Res. 2014, 47, 877; b) Yeom, H.-S.; Shin, S. Acc. Chem. Res. 2014, 47, 966.

8 Teles, J.; Brode, S.; Chabanas, M. Angew. Chem. Int. Ed. 1998, 37, 1415.

9 Mizushima, E.; Hayashi, T.; Tanaka, M. Org. Lett. 2003, 5, 3349.

10 a) Kennedy-Smith, J.; Staben, S.; Toste, F. D. J. Am. Chem. Soc. 2004, 126, 4526;

b) Corkey, B.; Toste, F. D. J. Am. Chem. Soc. 2005, 127, 17168.

11 Conia, J. M.; Perchec, P. L. Synthesis, 1975, 1, 1.

12 a) Alcaide, B.; Almendros, P. Acc. Chem. Res. 2014, 47, 939; b) Fensterbank, L.; Malacria, M. Acc. Chem. Res. 2014, 47, 953.

13 a) Marion, N.; Nolan, S. P. Chem. Soc. Rev. 2008, 37, 1776; b) Díez-González, S.; Marion, N.; Nolan, S. P. Chem. Rev. 2009, 109, 3612; c) Nolan, S. P. Acc. Chem. Res. 2011, 44, 91.

14 Mézailles, N.; Ricard, L.; Gagosz, F. Org. Lett. 2005, 7, 4133.

15 a) Duan, H.; Sengupta, S.; Petersen, J. L.; Shi, X. Organometallics 2009, 28, 2352;

b) Liao, W.; Chen, Y.; Duan, H.; Liu, Y.; Petersen, J. L.; Shi, X. Chem. Commun. 2009, 6436; c) Yan, W.; Wang, Q.; Chen, Y.; Petersen, J. L.; Shi, X. Org. Lett.2010, 12, 3308; d) Yan, W.; Ye, X.; Akhmedov, N. G.; Petersen, J. L.; Shi, X. Org. Lett. 2012, 14, 2358.

16 Suijkerbuijk, B. M. J. M.; Aerts, B. N. H.; Dijkstra, H. P.; Lutz, M.; Spek, A. L.; van Koten, G.; Klein Gebbink, R. J. M. Dalton Trans. 2007, 1273.

17 Duan, H.; Sengupta, S.; Petersen, J. L.; Akhmedov, N. G.; Shi, X. J. Am. Chem. Soc. 2009, 131, 12100.

18 Wang, Z. J.; Benitez, D.; Tkatchouk, E.; Goddard lii, W. A.; Toste, F. D. J. Am. Chem. Soc. 2010, 132, 13064

19 Duan, H.; Yan, W.; Sengupta, S.; Shi, X. Bioorg. Med. Chem. Lett. 2009, 19, 3899. 
20 Chen, Y.; Wang, D.; Petersen, J. L.; Akhmedov, N. G.; Shi, X. Chem. Commun. 2010, 46, 6147.

21 P. de Frémont, N. M. Scott, E. D. Stevens, S. P. Nolan, Organometallics 2005, 24, 2411.

22 a) B. N. G. Giepmans, S. R. Adams, M. H. Ellisman, R. Y. Tsien, Science 2006, 312, 217. b) D. W. Domaille, E. L. Que, C. J. Chang, Nat. Chem. Biol. 2008, 4, 168-175. c) J. Chan, S. C. Dodani, C. J. Chang, Nat. Chem. 2012, 4, 973-984. d) Y. Yang, Q. Zhao, W. Feng, F. Li, Chem. Rev. 2012, 113, 192-270. e) M. Vendrell, D. Zhai, J. C. Er, Y.-T. Chang, Chem. Rev. 2012, 112, 4391-4420.

23 a) M. S. T. Gonçalves, Chem. Rev. 2008, 109, 190-212. b) H. Kobayashi, M. Ogawa, R. Alford, P. L. Choyke, Y. Urano, Chem. Rev. 2009, 110, 2620-2640. c) R. W. Sinkeldam, N. J. Greco, Y. Tor, Chem. Rev. 2010, 110, 2579-2619.

24 J. Fan, M. Hu, P. Zhan, X. Peng, Chem. Soc. Rev. 2013, 42, 29-43.

25 K. Namba, A. Osawa, S. Ishizaka, N. Kitamura, K. Tanino, J. Am. Chem. Soc. 2011, 133, 11466-11469. 


\section{Chapter 2. "Silver Effect" in Gold(I) Catalysis}

\subsection{Introduction}

It has been generally accepted that the $[\mathrm{L}-\mathrm{Au}]^{+}$was the actual catalyst toward alkyne and alkene activation in homogeneous $\mathrm{Au}(\mathrm{I})$ promoted reactions. Currently, the dominant approach for the $[\mathrm{L}-\mathrm{Au}]^{+}$preparation was through the treatment of $\mathrm{L}-\mathrm{Au}-\mathrm{Cl}$ with corresponding silver salts to abstract chloride. Since $\mathrm{AgCl}$ was not involved in the reaction, it has been assumed that removing or keeping the $\mathrm{AgCl}$ salts in the reaction mixtures should not make a difference, giving "identical" results. Although it has been reported in a few cases that the presence of silver would help the reactivity of gold catalysts, ${ }^{26}$ it is still widely accepted that all these reactions were catalyzed by gold cation as long as silver salt itself could not catalyze the reaction.

Scheme 9. Will silver influence gold catalysis?

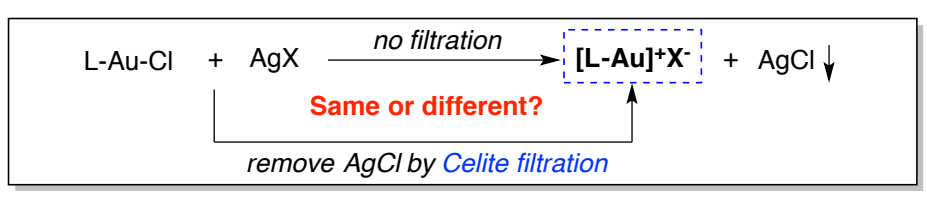

However, based on our experimental evidences, gold catalysis was not simply activated by the $[\mathrm{L}-\mathrm{Au}]^{+}$as previously assumed. In some reactions, the Ag-free $[\mathrm{L}-\mathrm{Au}]^{+}$catalysts showed absolutely no reactivity. With the clear experimental support described in this work, this long overlooked "silver effect" should lead to serious reconsideration for the reported and yet to be reported results. More importantly, these results raise a more significant question regarding the true nature of the catalytically active gold species. 


\section{2 Gold(I)-catalyzed propargyl ester hydration}

The "silver effect" was discovered during the exploration of triazole-gold (TA$\mathrm{Au}$ ) catalyzed reactions. Considering the importance of the a-hydroxyl methyl ketone in medicinal chemistry ${ }^{27}$ and the readily availability of enantiomeric pure propargyl alcohols, our initial attempt was to investigate the possibility of direct alkyne hydration to form ketone with retention of stereochemistry at the hydroxy position (Scheme 10A). However, after screening a series of $\mathrm{Au}(\mathrm{l})$ complexes, no catalysts, including TA-Au, promoted this reaction effectively even at $80^{\circ} \mathrm{C}$. It is well known that terminal propargyl ester could undergo 1,2-migration with gold catalyst, forming the oxonium cation (Scheme 10B). ${ }^{28}$ Therefore, it is possible to reach the desired a-hydroxy methyl ketone through water trapping of the oxonium cation. To explore this, propargyl ester 1a was prepared to react with different gold catalysts under various conditions.

Scheme 10. Proposed asymmetric synthesis of $\alpha$-hydroxyl methyl ketone

(A)

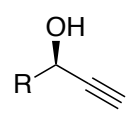

Highly effectient approach, but does not work with various gold catalysts, including TA-Au.

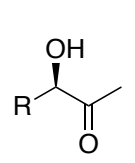

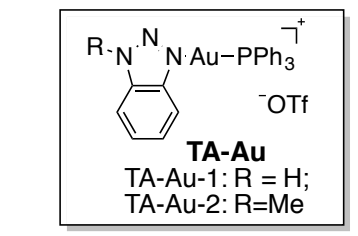

(B)

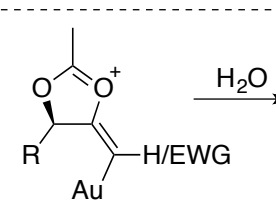

Concerns:

- Catalyst activity

- Chirality retention

As shown in Table 5, both TA-Au-1 and TA-Au-2 could effectively promote this reaction. Screening of the conditions revealed acetone as the optimal solvent, giving the desired $\alpha$-acetate-ketone in nearly quantitive yield (1\% loading). It should be noted that the $\left[\mathrm{PPh}_{3}-\mathrm{Au}\right]^{+}$and $[\mathrm{IPr}-\mathrm{Au}]^{+}$complexes did NOT promote this reaction at all (Table 5, entries 1-3) and most of the starting material 1a was recovered. This result highlighted the advantage of the triazole-gold catalyst: simple modification resulted in high efficiency and new reactivity. 
Table 5. Optimization of conditions for propargyl ester hydration ${ }^{a}$

\begin{tabular}{|c|c|c|c|c|}
\hline & $\overbrace{8 a}^{O A C}$ & $\overbrace{9 a}^{O A C}$ & 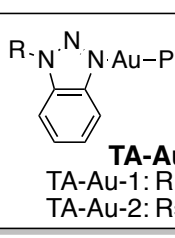 & \\
\hline Entry & Catalyst $^{\mathrm{b}}$ & Solvent & Time $(\mathrm{h})$ & Yield $(\%)^{c}$ \\
\hline 1 & {$\left[\left(\mathrm{PPh}_{3}\right) \mathrm{Au}\right]^{+} \mathrm{TfO}^{-}$} & dioxane & 12 & 0 \\
\hline 2 & {$\left[\left(\mathrm{PPh}_{3}\right) \mathrm{Au}\right]^{+} \mathrm{SbF}_{6}^{-}$} & dioxane & 12 & 0 \\
\hline 3 & {$[(\mathrm{IPr}) \mathrm{Au}]^{+} \mathrm{SbF}_{6}^{-}$} & dioxane & 12 & 0 \\
\hline 4 & TA-Au-1 & dioxane & 12 & 87 \\
\hline 5 & TA-Au-2 & dioxane & 12 & 85 \\
\hline 6 & TA-Au-1 & $\mathrm{DCM}$ & 12 & 32 \\
\hline 7 & TA-Au-1 & THF & 12 & $<5$ \\
\hline 8 & TA-Au-1 & $\mathrm{MeOH}$ & 12 & 24 \\
\hline 9 & TA-Au-1 & DMF & 12 & $<5$ \\
\hline 10 & TA-Au-1 & $\mathrm{CH}_{3} \mathrm{NO}_{2}$ & 12 & 11 \\
\hline 11 & TA-Au-1 & $\mathrm{CH}_{3} \mathrm{CN}$ & 4 & 89 \\
\hline 12 & TA-Au-1 & acetone & 4 & $99(96)^{d}$ \\
\hline
\end{tabular}

${ }^{a}$ General reaction conditions: 8 a $(0.5 \mathrm{mmol})$, catalyst $(0.2-1.0 \mathrm{~mol} \%)$ in $5 \mathrm{~mL}$ solvent, the reactions were monitored by TLC, rt- $60^{\circ} \mathrm{C} ;{ }^{b} \mathrm{DCE}: 1,2$-dichloroethane; ${ }^{c} \mathrm{NMR}$ yields of $9 \mathrm{a}$ with 1,3,5-trimethoxybenzene as internal standard; ${ }^{d}$ Isolated yield; ${ }^{e} \mathrm{TA}=\mathrm{N}$-methyl-benzotriazole.

With the optimal conditions in hand, the reaction substrate scope was explored (Table 6). While we were excited about this result that TA-Au offered new reactivity over $[\mathrm{L}-\mathrm{Au}]^{+}$, Sahoo and co-workers reported the same transformation using the $\mathrm{PPh}_{3} \mathrm{AuCl} / \mathrm{AgSbF}_{6}$ mixtures. ${ }^{29}$ This result was shocking because we have observed that the $[\mathrm{L}-\mathrm{Au}]^{+}$could not promote this reaction (Table $\mathbf{5}$, entries 1-3). These conflicting results were significant and need to be further investigated. 
Table 6. Substrate scope for propargyl ester hydration ${ }^{a, b}$

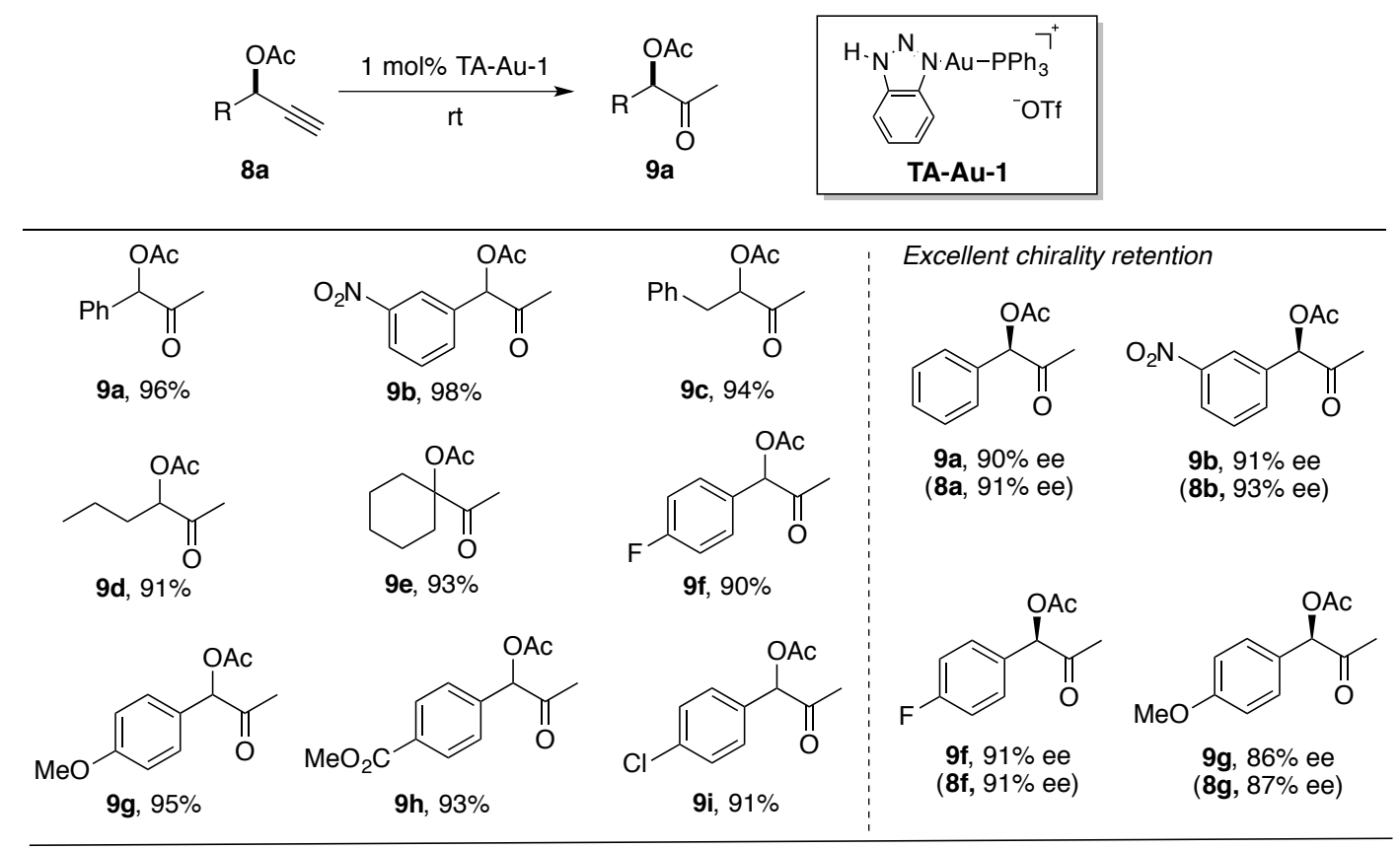

${ }^{a}$ General reaction condition: 8 ( $0.25 \mathrm{mmol}, 1.0$ equiv.) and TA-Au-1 (1.0 mol\%) in acetone (2.5 $\mathrm{mL}$ ), $\mathrm{H}_{2} \mathrm{O}$ (3.0 equi.) Reactions were monitored by TLC (4-10 h), rt. ${ }^{b}$ Isolated yields.

\section{3 "Silver effect" in alkyne hydration}

To understand the different reactivity that we observed for propargyl ester hydration using the same catalytic system $\left(\mathrm{PPh}_{3} \mathrm{AuCl} / \mathrm{AgSbF}_{6}\right)$, the direct comparison of the gold catalyst with or without $\mathrm{AgCl}$ presence was then carried out. As shown in Table 6, under the optimal conditions reported by Sahoo (entry 2 ), none of the tested silver salts could catalyze the reaction, with mostly $\mathbf{8 a}$ recovered. The $\left[\left(\mathrm{PPh}_{3}\right) \mathrm{Au}\right]^{+} \mathrm{A}^{-}$, which was prepared from celite filtration of the $\mathrm{PPh}_{3} \mathrm{AuCl} / \mathrm{Ag}^{+} \mathrm{A}^{-}$mixtures, also did not promote this reaction (entry 3 ). However, when the mixtures of $\mathrm{PPh}_{3} \mathrm{AuCl}$ and $\mathrm{Ag}^{+} \mathrm{A}^{-}$were used directly without filtration to remove $\mathrm{AgCl}$, the reaction worked as reported, but with complete racemization (entries 4, 5). Careful degassing and $N_{2}$ protection helped to avoid the racemization (entry 6). Interestingly, the mixture of $\left[\left(\mathrm{PPh}_{3}\right) \mathrm{Au}\right]^{+} \mathrm{TfO}^{-}$(inactive complex obtained from the filtration through celite) and $\mathrm{AgSbF}_{6}$ could promote 
this reaction effectively (entry 7 ), which suggested that the combination of these gold and silver complexes was necessary for the catalytic reactivity.

Table 7. Silver effect in propargyl ester hydration ${ }^{a}$
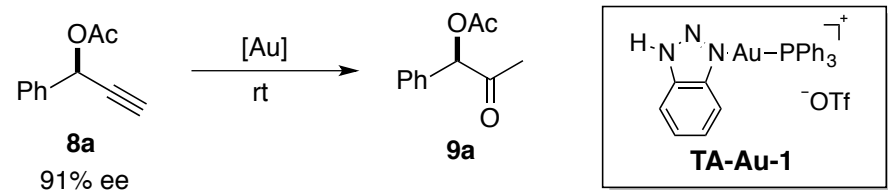

\begin{tabular}{|c|c|c|c|c|}
\hline Entry & Catalyst $^{\mathrm{b}}$ & Time $(h)$ & Yield $(\%)^{b}$ & ee $(\%)$ \\
\hline 1 & $1 \%$ TA-Au-1 & 5 & 87 & 90 \\
\hline 2 & $10 \%$ AgOTf, $\mathrm{AgSbF}_{6}$ or $\mathrm{AgBF}_{4}$ & 12 & 0 & - \\
\hline 3 & $2 \%\left[\left(\mathrm{PPh}_{3}\right) \mathrm{Au}\right]^{+} \mathrm{A}^{-}\left(\mathrm{A}^{-}=\mathrm{TfO}^{-}, \mathrm{SbF}_{6}^{-}, \mathrm{BF}_{4}^{-}\right)$ & 12 & 0 & - \\
\hline 4 & $2 \%\left(\mathrm{PPh}_{3}\right) \mathrm{AuCl} / \mathrm{AgOTf}$ & 12 & 90 & 0 \\
\hline 5 & $2 \%\left(\mathrm{PPh}_{3}\right) \mathrm{AuCl} / \mathrm{AgSbF}_{6}$ & 8 & 97 & 0 \\
\hline 6 & $2 \%\left(\mathrm{PPh}_{3}\right) \mathrm{AuCl} / \mathrm{AgOTf}$ (with $\mathrm{N}_{2}$ protection) & 5 & 92 & 90 \\
\hline 7 & $2 \%\left[\left(\mathrm{PPh}_{3}\right) \mathrm{Au}\right]^{+} \mathrm{SbF}_{6}^{-}+2 \% \mathrm{AgSbF}_{6}$ & 12 & 91 & - \\
\hline
\end{tabular}

${ }^{a}$ General reaction condition: 1 a (1.0 equiv.) and cat. in $2.5 \mathrm{~mL}$ dioxane/water $\left(\mathrm{H}_{2} \mathrm{O}, 3.0\right.$ equiv.), rt. reactions were monitored by TLC. ${ }^{b}$ NMR yields.

Notably, filtration through celite is a practical procedure used in our group during the preparation of the TA-Au complexes. In general, silver salts could decompose to silver nanoparticle or $\mathrm{Ag}_{2} \mathrm{O}$ precipitate over time, and this process is accelerated in the presence of $\mathrm{AgX}$, forming a dark purple solution over time. Filtration through celite allows the majority of $[L-A u]^{+} A^{-}$to go through and removes most of the silver salts that can pass through regular filter paper.

Figure 6. X-ray crystal structure of [IPr-Au-TA] $]^{+} \mathrm{OTf}$ complex
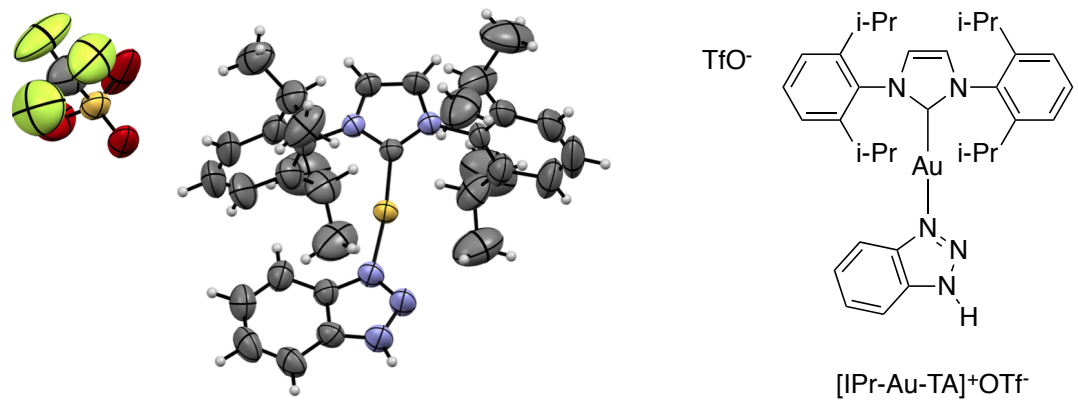

$[\mathrm{IPr}-\mathrm{Au}-\mathrm{TA}]^{+} \mathrm{OTf}-$ 
This procedure has no influence on the counteranion and worked for various ligands. For example, Figure 6 shows the crystal structure of [(IPr)Autriazole $]^{+} \mathrm{TfO}^{-}$, which was prepared from the celite filtration of triazole and (IPr)AuCl/AgOTf mixture, giving the desired [IPr-Au-TA] ${ }^{+}$OTf complex in $92 \%$ yield.

To verify the difference between celite filtration and paper filtration, X-ray photoelectron spectroscopy (XPS) was applied (Figure 7).

Figure 7. XPS spectra of the $\left(\mathrm{PPh}_{3}\right) \mathrm{AuCl} / \mathrm{AgSbF}_{6}$ mixture after filtration ${ }^{\mathrm{a}}$

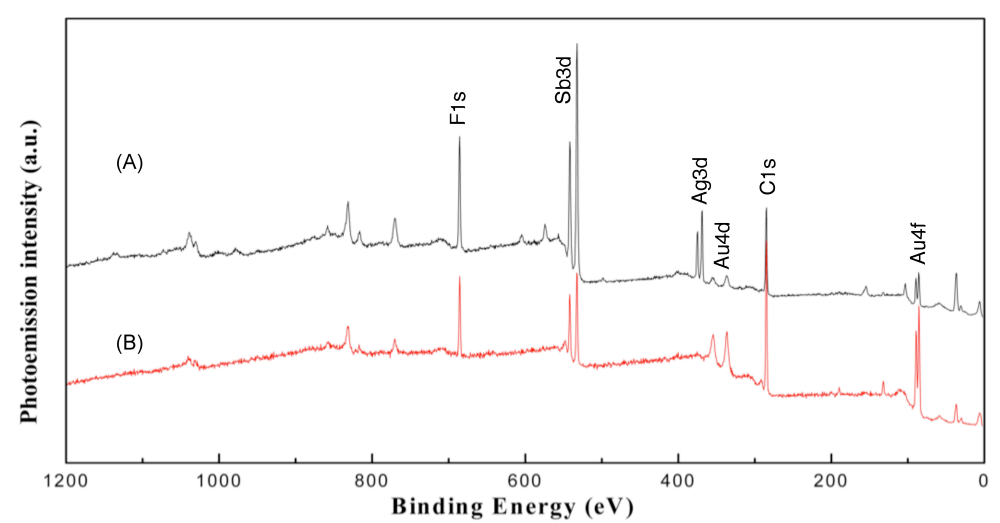

${ }^{a}\left(\mathrm{PPh}_{3}\right) \mathrm{AuCl}: \mathrm{AgSbF}_{6}=1: 1.5$, (A) filtration through regular filter paper; (B) filtration through celite.

As shown in the XPS spectra, gold was observed in both filtrates. The binding energies ( $A u 4 f_{7 / 2}, 85.5 \mathrm{ev}$; $A u 4 f_{5 / 2} 89.2 \mathrm{ev}$ ) suggested the presence of $A u(I)$ cation after celite filtration. The silver signal was observed in the filtrate when the mixture of $\left(\mathrm{PPh}_{3}\right) \mathrm{AuCl}$ and $\mathrm{AgSbF}_{6}$ is filtered through regular filter paper (Figure 7A: Ag 3d $d_{5 / 2}, 368.7 \mathrm{ev;} \mathrm{Ag} \mathrm{3} d_{3 / 2}, 374.7 \mathrm{ev}$ ). Interestingly, the filtrate obtained after celite filtration did not contain any silver (Figure 7B), even when excess amounts of silver salt was added ( $\mathrm{Au}: \mathrm{Ag}=1: 1.5)$. These results indicated that the filtrate from celite contained only $\left[\left(\mathrm{PPh}_{3}\right) \mathrm{Au}\right]^{+}$and no detectable amount of $\mathrm{Ag}^{+}$. Similar results were observed with the (IPr)AuCl/AgSbF 6 system. These XPS results supported the observation that the presence of $\mathrm{Ag}^{+}$influenced the gold cation reactivity. 
Meanwhile, for $\mathrm{PR}_{3}-\mathrm{Au}-\mathrm{X}$ complexes, ${ }^{31} \mathrm{P}$ NMR could help to evaluate the electronic nature of the gold cation in solution. In general, more cationic gold complexes would give the up-field shift ${ }^{31} \mathrm{P}$ signals (Figure 8A). The chemical shift of $\left[\mathrm{PPh}_{3} \mathrm{Au}\right]^{+} \mathrm{TfO}^{-}$(after celite filtration) is $27.1 \mathrm{ppm}$ whereas it is $33.8 \mathrm{ppm}$ for $\mathrm{PPh}_{3} \mathrm{AuCl}$, suggesting the formation of cationic $\left[\mathrm{PPh}_{3} \mathrm{Au}\right]^{+}$species. However, the $\left(\mathrm{PPh}_{3}\right) \mathrm{AuCl} / \mathrm{AgOTf}$ (with no filtration) give a different chemical shift at $28.1 \mathrm{ppm}$ (Figure $8 \mathrm{~A}, \mathrm{~b}$ ). Although this ${ }^{31} \mathrm{P}$ NMR data supports the formation of a new complex, the true structure of this species has not been determined at this time.

\section{Figure 8. ${ }^{31} \mathrm{P}$ NMR of different $\mathrm{Au}(\mathrm{I})$ samples}

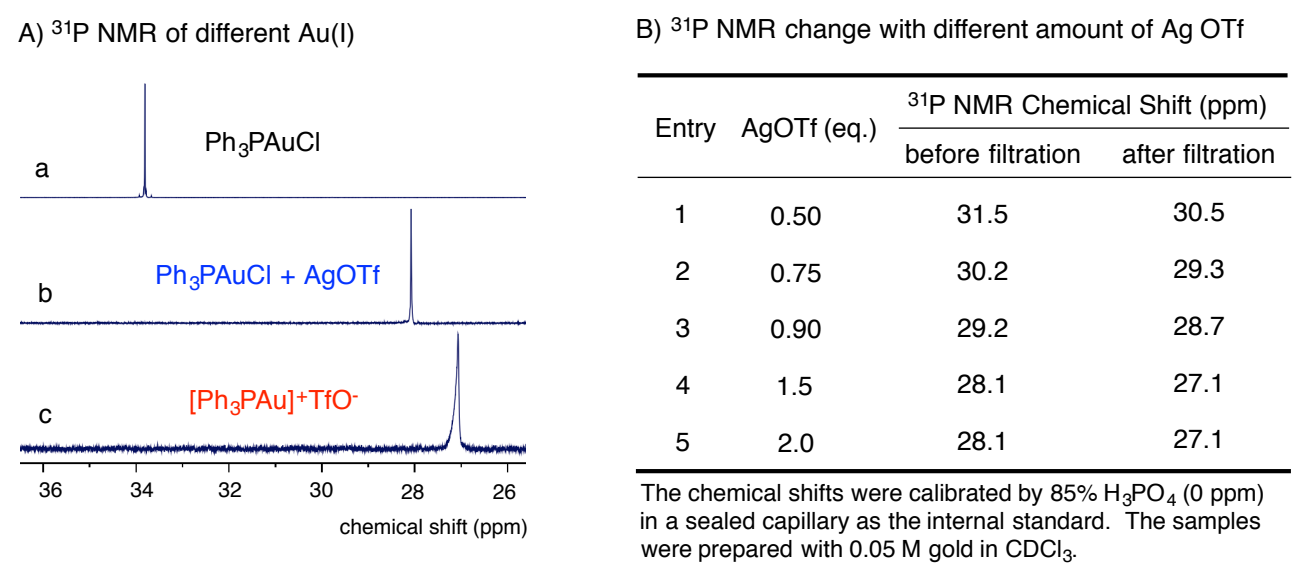

Since the purpose of AgOTf is to remove the chloride anion from $\mathrm{PPh}_{3} \mathrm{AuCl}$, it is anticipated that more AgOTf should lead to an upfielded chemical shift of the ${ }^{31} \mathrm{P}$ signal due to the formation of more cationic gold (Figure 8B, entry 1 to 4 ). After a stoichiometric amount of AgOTf is added, no further chemical shift change is observed even with the addition of excess AgOTf (Figure 8B, entry 4 and 5). Notably, different chemical shifts are observed after filtering the sample through celite to remove the silver. Addition of AgOTf to the solution of $\left[\left(\mathrm{PPh}_{3}\right) \mathrm{Au}\right]^{+} \mathrm{OTf}$ gave a slow conversion back to the species corresponding to the ${ }^{31} \mathrm{P}$ signal at $28.1 \mathrm{ppm}$ (the gold species prior to filtration). The gold species generated is independent of the amount of AgOTf added: both 0.5 eq and $1.0 \mathrm{eq}$ of AgOTf shifted the ${ }^{31} \mathrm{P}$ signal from $27.1 \mathrm{ppm}$ to $28.1 \mathrm{ppm}$. No change in the chemical shift is observed while $\mathrm{AgCl}$ is added to the silver-free [ $\left.\left(\mathrm{PPh}_{3}\right) \mathrm{Au}\right]^{+} \mathrm{TfO}^{-}$ solution, which suggests that the influence is from the $\mathrm{Ag}^{+}$instead of $\mathrm{AgCl}$. This 
discovery is critical since it will lead to a revision of the current assumed mechanism of homogenous gold $(\mathrm{I})$ catalysis, because the actual catalyst may not be simply a cationic gold species.

The reaction of the gold-catalyzed propargyl ester hydration shown above is a good example that highlighted the importance of the silver effect (i.e., $\left[\left(\mathrm{PPh}_{3}\right) \mathrm{Au}\right]^{+} \mathrm{TfO}^{-}$alone does not promote the reaction unless silver salt was added). One concern is that the presence of silver may help the hydration of the oxzonium cation intermediate, which plays an important role in promoting the overall reaction. However, the reaction with TA-Au, which did not contain silver, led to effective transformation with a faster reaction rate, suggesting that hydration of the oxzonium cation is fast and silver is not required in this step.

To ensure that this "silver effect" did not only occur in propargyl ester hydration, we extended the investigation to more general alkyne hydration reactions. It has been reported by Nolan and coworkers that (IPr)AuCl/AgSbF 6 was the optimal catalyst to promote challenging internal alkyne hydration. ${ }^{30}$

Table 8. Silver effect in IPr-Au catalyzed alkyne hydration

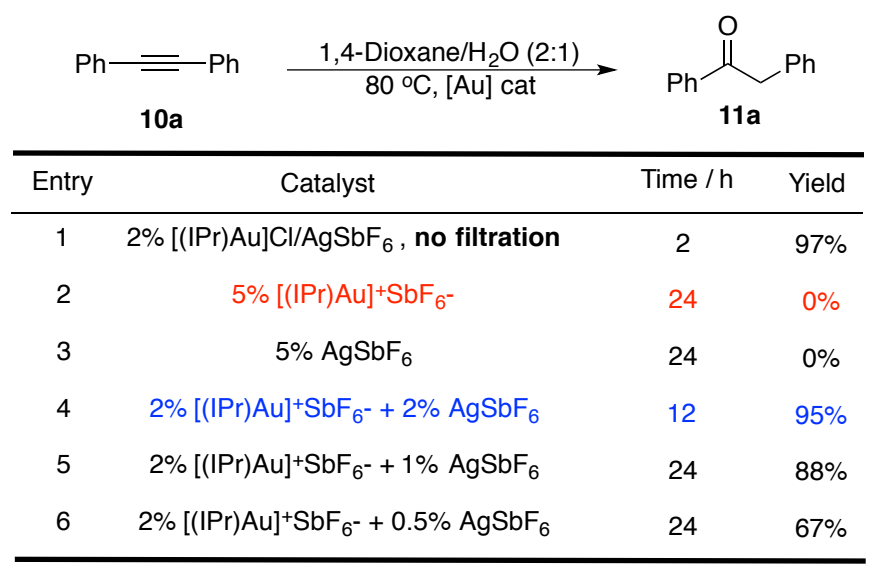

As shown in Table 8, excellent yield of the ketone 11a was obtained when (IPr)AuCl/AgSbF 6 mixtures was used without filtration. When 10a was charged with $[\mathrm{IPr}-\mathrm{Au}]^{+}$(the same catalyst mixture after celite filtration), no reaction occurred even with increased catalyst loading ( $5 \mathrm{~mol} \%$ ) and prolonged reaction time (entry 2). In contrast, the addition of $2 \% \mathrm{AgSbF}_{6}$ reactivated the catalyst, giving ketone 11a in excellent yield though with longer reaction time (entry 4). 
Notably, silver salts alone could not promote this reaction (entry 3). Reducing the amounts of silver salts caused the slower reaction rate. When a 0.25 equivalent of silver (relative to gold) was used (entry 6), the reaction could not reach complete conversion (around 25\% starting materials recovered under identical conditions). These results demonstrate again that the combination of $[\mathrm{L}-\mathrm{Au}]^{+}$and $\mathrm{Ag}^{+}$was the actual active catalysts for these transformations, which revised the previous assumption regarding homogeneous gold(I) catalysis.

\section{4 Revision of gold(I)-catalyzed reactions}

The discovery of "silver effect" led to a revision of previously reported goldcatalyzed reactions. Based on the different reactivity of gold, we divided gold catalysis into three categories (Scheme 11).

\section{Scheme 11. Refining gold catalysis based on the reactivity}

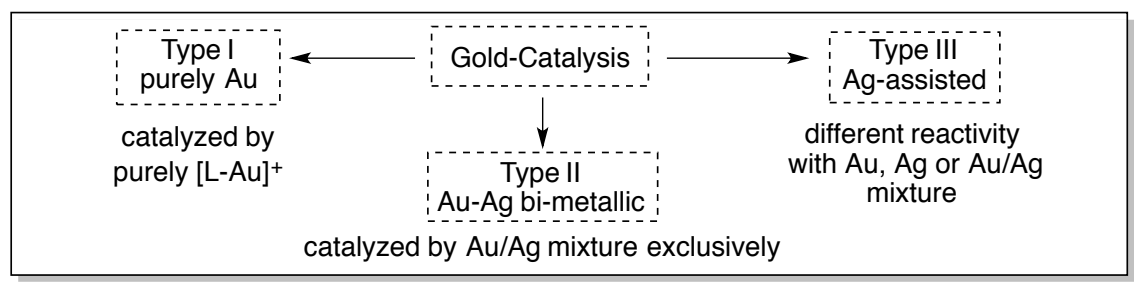

\subsubsection{Different types of gold(I) catalysis}

Type I. Purely Au catalysis

Purely $\mathrm{Au}$ catalysis refers to the type of reactions promoted by $[\mathrm{L}-\mathrm{Au}]^{+}$with competitive or even better reactivity than the $[\mathrm{L}-\mathrm{Au}]^{+} / \mathrm{Ag}^{+}$mixtures. Among the 14 reported reactions we screened, only two examples belong to this category that are promoted by $\mathrm{Ag}$-free $[\mathrm{L}-\mathrm{Au}]^{+}$without losing reactivity (compared with $\mathrm{Au} / \mathrm{Ag}$ mixture).

The first example was the Hashmi phenol synthesis, where gold promoted furan-yne rearrangement to phenol through the formation of gold carbene intermediates (Scheme 12A). ${ }^{31}$ Our investigation revealed similar reactivity of the Ag-free Au catalyst (filtration through celite) compared with the mixture of $\mathrm{Au}$ 
and Ag. Similar results were obtained in the gold catalyzed oxidative coupling reaction between vinyl gold and boronic acid shown in Scheme 12B, which was originally reported by Zhang and co-workers. ${ }^{32}$

\section{Scheme 12. Purely Au-catalyzed reactions}

only Au
only Ag

\section{Type II. Au-Ag bimetallic catalysis}

Au-Ag bi-metallic catalysis includes reactions that are promoted exclusively by the mixture of $\mathrm{Au}$ and $\mathrm{Ag}$. Neither $\mathrm{Au}$ nor $\mathrm{Ag}$ could catalyze these reactions alone. Besides the alkyne hydration shown in Table 7 and Table 8, four more transformations were identified with the same catalytic pattern (Scheme 13). ${ }^{33}$

\section{Scheme 13. Au-Ag bimetallic catalysis}

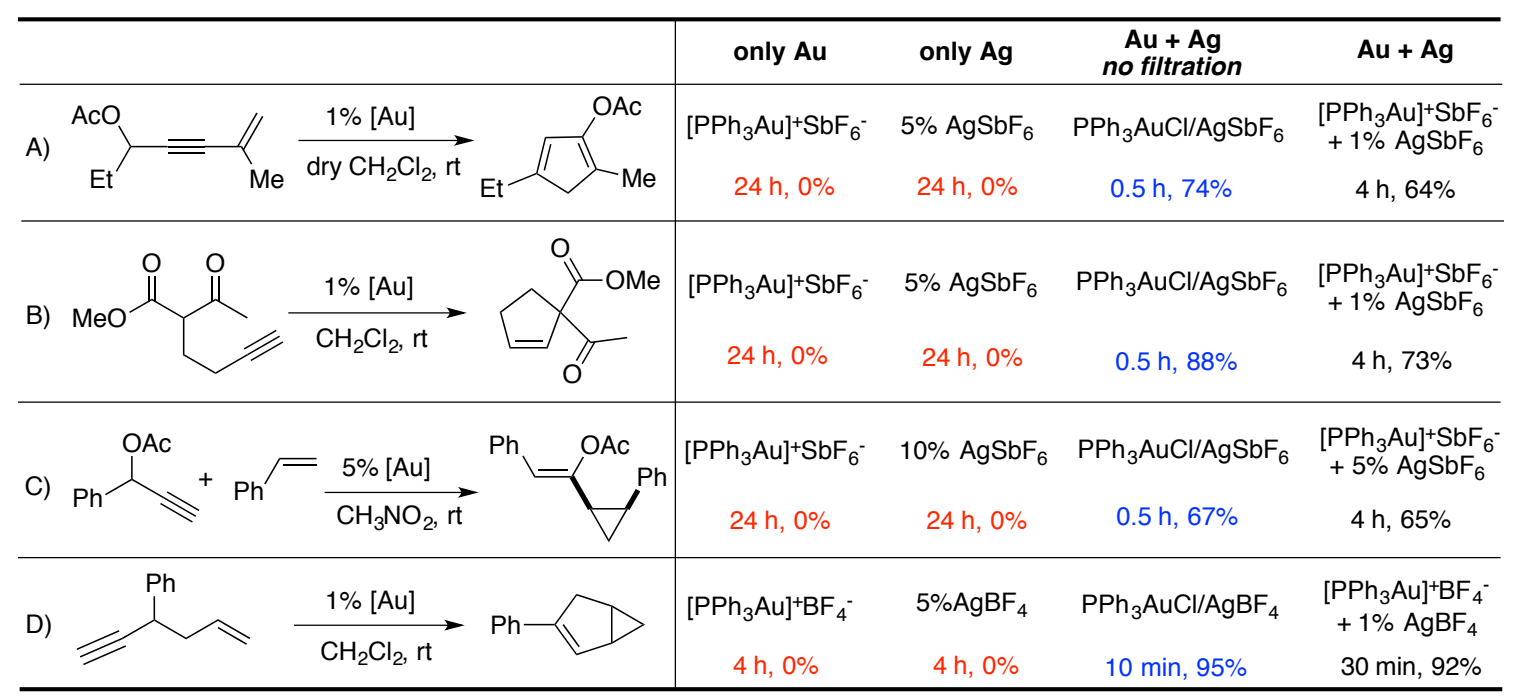


Again, these transformations were all previously assumed as gold catalysis since silver salts could not promote these reactions at all. However, based on our investigation, purely cationic gold catalysts could not promote these reactions. Addition of the silver salts ( $\mathrm{AgCl}$ could not activate the gold) resulted in reactivation of the gold catalysts, though longer reaction times were needed.

Type III. Ag-assisted Au catalysis

The type III gold catalysis, on the other hand, combines the transformations that promoted by either gold or silver or the combination of both metals.

\section{Scheme 14. Ag-assisted Au catalysis}

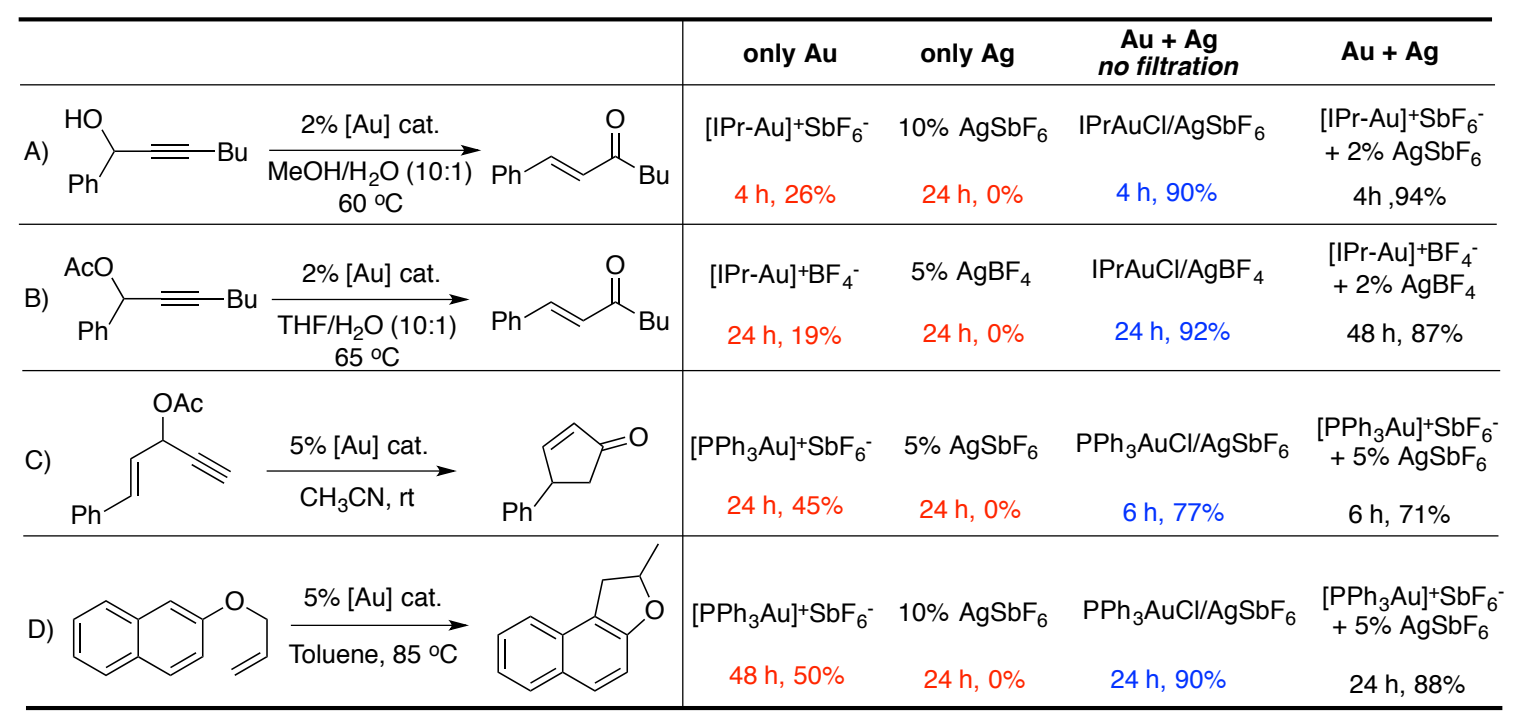

As shown in Scheme 14, ${ }^{34}$ although pure gold could promote these reactions, the combination of gold and silver gave better results. In addition, these reactions could not be promoted by silver.

Notably, two other reactions were also identified that could be promoted by both gold and silver. However, gold/silver mixture or even gold alone gave better performance than simply silver (Scheme 15). ${ }^{35}$ Furthermore, in the a-bromoenone synthesis, the $E / Z$ selectivity was altered when the combination of gold and silver catalysts was used. 
Scheme 15. Ag-promoted reactions

B)

\subsubsection{Celite filtration}

The results shown above clearly suggest that silver salts have a great influence in gold catalysis. In 2009, Gagné and co-workers reported Au-Ag dinuclear resting states in the catalytic cycle in their mechanistic investigation of gold-catalyzed allene hydroarylation, which was consistent with this "silvereffect" ${ }^{36}$

As described in section 2.3, celite filtration allows $[L-A u]^{+} A^{-}$to pass through and removes most of the silver salts without altering the counteranion $\left(\mathrm{NTf}_{2}{ }^{-}, \mathrm{TfO}^{-}\right.$, $\mathrm{SbF}_{6}^{-}$or $\left.\mathrm{BF}_{4}^{-}\right)$. One concern about celite filtration is whether it can deactivate the gold catalysts. Although sequential addition of silver salts to the celite filtrates resulted in reactivation of the catalyst, the influence from celite filtration was still unclear.

Another general strategy for the preparation of [L-Au $]^{+}$is the acid activation of $\mathrm{L}-\mathrm{Au}-\mathrm{Me}$ or L-Au-Ph (formation of methane or benzene). This process was extremely sensitive to solvents, which made the silver salt activation of L-Au-Cl a better practical choice. For example, addition of $\mathrm{TfOH}$ to $\mathrm{PPh}_{3}-\mathrm{Au}-\mathrm{Me}$ in $\mathrm{CH}_{2} \mathrm{Cl}_{2}$, $\mathrm{CH}_{3} \mathrm{NO}_{2}$ or $\mathrm{CH}_{3} \mathrm{CN}$ caused immediate catalyst decomposition, forming gold nano particles or a gold mirror. Therefore, it is very difficult to directly compare the reactivity difference of $[\mathrm{L}-\mathrm{Au}]^{+}$formed from $\mathrm{PPh}_{3}-\mathrm{Au}-\mathrm{Me} / \mathrm{TfOH}$ or from celite filtration of $\mathrm{PPh}_{3}-\mathrm{AuCl} / \mathrm{AgOTf}$. Fortunately, through screening, dioxane was identified as one optimal solvent with much slower catalyst decomposition using the acid activation approach, which allowed the parallel comparison of the propargyl acetate hydration for the claimed "silver effect". 
Table 9. Comparison of celite filtration and acid activation

\begin{tabular}{|c|c|c|c|}
\hline & $\frac{[\mathrm{Au}]}{\text { dioxane } / \mathrm{H}_{2} \mathrm{O}, \mathrm{rt}}$ & $\overbrace{9 a}^{O A c}$ & \\
\hline Entry & {$[\mathrm{Au}]$ catalyst } & Time / h & Yield \\
\hline 1 & $\begin{array}{l}5 \%\left[\mathrm{PPh}_{3} \mathrm{Au}\right]^{+} \mathrm{TfO}^{-} \\
\text {(celite filtration) }\end{array}$ & 12 & $\begin{array}{c}0 \% \\
91 \% \mathbf{8 a} \text { recovered }\end{array}$ \\
\hline 2 & $\begin{array}{l}5 \%\left[\mathrm{PPh}_{3} \mathrm{Au}\right]^{+} \mathrm{TfO}^{-} \\
\text {(celite filtration) }\end{array}+5 \% \mathrm{AgOTf}$ & 2 & $90 \%$ \\
\hline 3 & $5 \% \mathrm{PPh}_{3} \mathrm{AuMe}+20 \% \mathrm{TfOH}$ & 12 & $\begin{array}{c}0 \% \\
90 \% 8 \text { a recovered }\end{array}$ \\
\hline 4 & $5 \% \mathrm{PPh}_{3} \mathrm{AuMe}+20 \% \mathrm{TfOH}+5 \%$ AgOTf & 12 & $97 \%$ \\
\hline
\end{tabular}

As shown in Table 9, the $\left[\mathrm{PPh}_{3} \mathrm{Au}\right]^{+} \mathrm{TfO}^{-}$obtained from $\mathrm{PPh}_{3} \mathrm{AuMe} / \mathrm{TfOH}$ gave the exactly same results as observed with celite filtration. Without the addition of AgOTf, $\left[\mathrm{PPh}_{3} \mathrm{Au}\right]^{+} \mathrm{TfO}^{-}$indicated no reactivity, which provided an unambiguous evidence for the observed "silver effect" in gold catalysis.

\subsubsection{Other activation factors in gold(I) catalysis}

While the silver influence on gold catalysis was unexpected and influential, the reactivity offered by triazole-gold (TA-Au) catalyst suggested that silver salts were not the only "activation factor" for gold. Interestingly, the two purely goldcatalyzed reactions shown in Scheme 13 both contained a coordinating $\mathrm{Tf}_{2} \mathrm{~N}^{-}$ anion. In general, The L-Au-NTf 2 complexes were different than the gold catalysts $[\mathrm{L}-\mathrm{Au}]^{+} \mathrm{X}^{-}$formed with non-coordinated counter anions, such as $\mathrm{TfO}^{-}$.

Figure $9 .{ }^{31} \mathrm{P}$ NMR comparison of different $\mathrm{Au}(\mathrm{I})$ catalysts

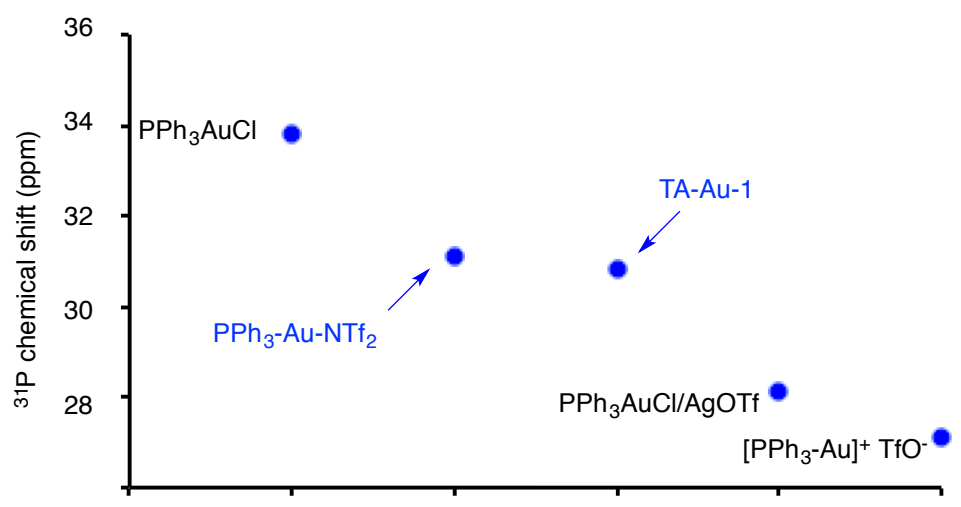


As indicated by ${ }^{31} \mathrm{P}$ NMR (Figure 9), the ${ }^{31} \mathrm{P}$ chemical shift of $\mathrm{PPh}_{3}-\mathrm{Au}-\mathrm{NTf}_{2}(\delta$ $31.1 \mathrm{ppm})$ is between $\left[\mathrm{PPh}_{3} \mathrm{Au}\right]^{+} \mathrm{TfO}^{-}(\delta 27.1 \mathrm{ppm})$ and $\mathrm{PPh}_{3} \mathrm{AuCl}(\delta 33.8 \mathrm{ppm})$. The $\mathrm{PPh}_{3}-\mathrm{Au}-\mathrm{NTf}_{2}$ complex has a similar chemical shift as TA-Au ( $\left.\delta 30.8 \mathrm{ppm}\right)$, suggesting the coordination of $\mathrm{Tf}_{2} \mathrm{~N}^{-}$anion with $\left[\mathrm{PPh}_{3}-\mathrm{Au}\right]^{+}$, which is also supported by crystal structure. ${ }^{37}$

The silver-free TA-Au effectively promoted the hydration of $\mathbf{8}$, suggesting that other coordination ligands, such as 1,2,3-triazoles, could serve as potential "activation factors" for gold catalysts.

Scheme 16. Gold catalysis using $\mathrm{Tf}_{2} \mathrm{~N}^{-}$as the activation factor

(B)

To investigate the influence from $\mathrm{Tf}_{2} \mathrm{~N}^{-}$, silver-free $\mathrm{PPh}_{3}-\mathrm{AuNTf}_{2}$ and IPr-Au$\mathrm{NTf}_{2}$ were prepared with celite filtration (confirmed by XPS). Using these silverfree catalysts, several Au-Ag bi-metallic catalysed reactions were re-evaluated (Scheme 16). Indeed, the silver-free L-Au-NTf ${ }_{2}$ indicated good reactivity toward these transformations that were not promoted by [L-Au] ${ }^{+} \mathrm{TfO}^{-}$. This is interesting due to the fact that a coordinating anionic ligand enhanced the reactivity despite reducing the cationic nature of the gold catalyst. Notably, for the intermolecular cyclopropanation reaction (Scheme 16E), the combination of $\left[\mathrm{Ph}_{3} \mathrm{P}-\mathrm{Au}\right]^{+} \mathrm{TfO}^{-}$and 
$\mathrm{AgNTf}_{2}$ showed improved reactivity compared with $\mathrm{Ph}_{3} \mathrm{P}-\mathrm{Au}-\mathrm{NTf}_{2}$, which once again demonstrated the enhanced reactivity of the gold catalytic system in the presence of silver salt.

Overall, the revision of previously reported gold-catalyzed reactions confirmed the unexpected observations that gold catalysis was greatly influenced by the presence of silver salts.

\section{5 Conclusion}

Considering the tremendous efforts that have been put into homogeneous gold catalysis, better understanding of the reaction mechanism is crucial to further advance this research field. With the non-coordination anions $\left(\mathrm{TfO}^{-}, \mathrm{SbF}_{6}{ }^{-}\right.$ and $\mathrm{BF}_{4}{ }^{-}$), purely cationic gold complexes [L-Au] ${ }^{+}$was less active or even inactive in most of the tested reactions without the presence of silver salts. Addition of $\mathrm{AgCl}$ salts did not activate gold catalysts in all tested cases, which ruled out the formation of $[\mathrm{Ag}-\mathrm{Cl}-\mathrm{Au}]^{+}$as the actual catalyst. The relatively broad scope of the reactions tested in this work confirmed the widely overlooked influence of silver ion in contemporary gold catalytic systems. Although the exact complexes formed from cationic gold and silver salts are not certain at this moment, this discovery initiated a revision of gold catalysis.

\section{6 Contribution}

Dr. Dawei Wang investigated the proparyl ester hydration, discovered the "silver effect" in gold catalysis and evaluated various gold-catalyzed reactions. Rong Cai further evaluated the influence from celite filtration and the activation factors in gold catalysis. Sripadh Sharma, James Jirak, and Sravan K. Thummanapelli helped with substrates preparation. Dr. Novruz G. Akhmedov provided help with NMR studies. Dr. Hui Zhang and Dr. Xingbo Liu did the XPS analysis of the gold complexes. Dr. Jeffrey Petersen performed the X-ray crystallographic analyses. 
This project is published on J. Am. Chem. Soc. 2012, 134, 9012-9019.

\section{References:}

26 Patrick, S. R.; Boogaerts, I. I. F.; Gaillard, S.; Slawin, A. M. Z.; Nolan, S. P. Beilstein J. Org. Chem. 2011, 7, 892.

27 a) Liu, R.; Lin, Z.; Zhu, T.; Fang, Y.; Gu, Q.; Zhu, W. J. J. Nat. Prod. 2008, 71, 1127;

b) Wang, S.-K.; Huang, M.-J.; Duh. C.-Y. J. Nat. Prod. 2006, 69, 1411; c) Chen, F.C.; Peng, C.-F.; Tasi, I.-L.; Chen, I.-S. J. Nat. Prod. 2005, 68, 1318; d) Chen, F.-C. Peng, C.-F. Tasi, I.-L. Chen, I.-S. J. Nat. Prod. 2005, 68, 1318; e) Liu, Y.-B.; Su, E.N.; Li, J.-L.; Yu, S.-S.; Liu, J.; Li, Y. J. Nat. Prod. 2009, 72, 229.

28 Shi, X.; Gorin, D.; J. Toste, F. D. J. Am. Chem. Soc. 2005, 127, 5802-5803. Selected examples for gold-catalyzed 1,2-shifts, see: a) Wang, S.; Zhang, L. J. Am. Chem. Soc. 2006, 128, 14274; b) Hashmi, A. S. K.; Hutchings, G. J. Angew. Chem. Int. Ed. 2006, 45, 7896; c) Barluenga, J.; Riesgo, L.; Vicente, R.; Lopez, L.; Tomas, M. J. Am. Chem. Soc. 2007, 129, 7772. Selected examples for 1,3-shifts, see: d) Zhang, L. J. Am. Chem. Soc. 2005, 127, 16804; e) Buzas, A.; Gagosz, F. J. Am. Chem. Soc. 2006, 128, 12614; f) Marion, N.; Nolan, S. P. Angew. Chem. Int. Ed. 2007, 46, 2750.

29 Ghosh, N.; Nayak, S.; Sahoo. A. J. Org. Chem. 2011, 76, 500.

30 Marion, N.; Ramon R. S.; Nolan, S. P. J. Am. Chem. Soc. 2009, 131, 448.

31 Hashmi, A. S. K.; Weyrauch, J. P.; Rudolph, M.; Kurpejovic, E. Angew. Chem. Int. Ed. 2004, 43, 6545.

32 Zhang, G.; Peng, Y.; Cui, L.; Zhang, L. Angew. Chem. Int. Ed. 2009, 48, 3112.

33 a) Zhang, L.; Wang, S. J. Am. Chem. Soc. 2006, 128, 1442; b) Staben, S. T.; Kennedy-Smith, J. J.; Toste, F. D. Angew. Chem. Int. Ed. 2004, 43, 5350; c) Johansson, M. J.; Gorin, D. J.; Staben, S. T.; Toste, F. D. J. Am. Chem. Soc. 2005, 127, 18002; d) Luzung, M. R.; Markham, J. P.; Toste, F. D. J. Am. Chem. Soc. 2004, 126, 10858.

34 a) Ramon, R. S.; Marion, N.; Nolan, S. P. Tetrahedron, 2009, 65, 1767; b) Marion, N.; Carlqvist, P.; Gealageas, R.; de Frémont, P.; Maseras, F.; Nolan, S. P. Chem. Eur. J. 2007, 13, 6437; c) Shi, X.; Gorin, D. J.; Toste, F. D. J. Am. Chem. Soc. 2005, 127, 5802; d) Reich, N. W.; Yang, C. G.; Shi, Z.; He, C. Synlett. 2006, 8, 1278. 
35 a) Marion, N.; Diez-Gonzalez, S.; Fremont, P.; Nolan, S. P. Angew. Chem. 2006, 118, 3729; b) Yu, M.; Zhang, G.; Zhang, L. Org. Lett. 2009, 11, 3646.

36 a) Weber, D.; Gagné, M. R. Org. Lett. 2009, 11, 4962; b) Weber, D.; Tarselli, M. A.; Gagné, M. R. Angew. Chem. Int. Ed. 2009, 48, 5733.

37 Mézailles, N.; Ricard, L.; Gagosz, F. Org. Lett. 2005, 7, 4133. 


\section{Chapter 3. Gold-Catalyzed Cross-Coupling with Aryldiazonium Salts}

\subsection{Introduction}

Homogeneous gold catalysis has grown rapidly during the past decade. Within this enduring field, the m-activation mode has gained far more attention than redox gold catalysis. ${ }^{38}$ This reluctance is likely due to concerns regarding the high redox potential between $\mathrm{Au}(\mathrm{I})$ and $\mathrm{Au}(\mathrm{III}){ }^{39}$ The "seal of hesitation" was clearly broken in the past few years with some breakthrough examples. ${ }^{40}$

For example, Zhang reported the propargyl ester rearrangement and sequential coupling with boronic acid using Selectfluor as the oxidant. ${ }^{41}$ Russell also developed the arene cross-coupling with $\mathrm{Phl}(\mathrm{OAc})_{2}$ (PIDA) as the oxidant (Scheme 17). ${ }^{42}$ In these representative cases, strong oxidants were required to operate the $\mathrm{Au}(\mathrm{I}) / \mathrm{Au}(\mathrm{III})$ catalytic cycle.

Scheme 17. Representative examples of redox gold catalysis

A)

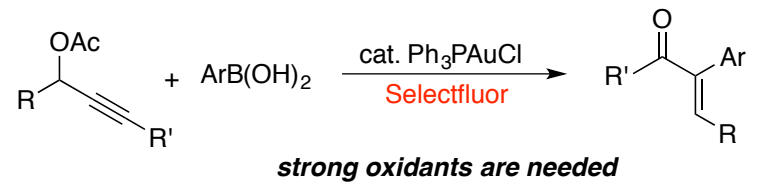

B)
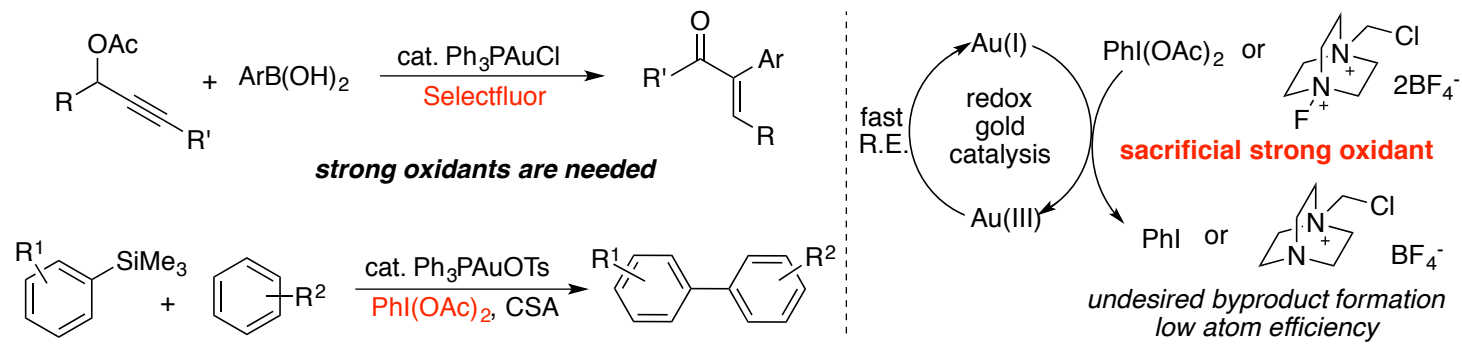

More recently, Glorius and Toste groups demonstrated that the $\mathrm{Au}(\mathrm{I}) / \mathrm{Au}(\mathrm{III})$ catalytic cycle could be alternatively accessed through the combination of a photocatalyst and a radical precursor, such as aryldiazonium salts (Scheme 18) ${ }^{43}$ As proposed by the authors, the oxidation of gold catalyst was achieved through initial combination of aryl radical to gold (I) species and sequential single electron transfer from the resulting gold(II) intermediate to the photocatalyst. 
Scheme 18. Combining gold catalysis with photocatalysis

A)

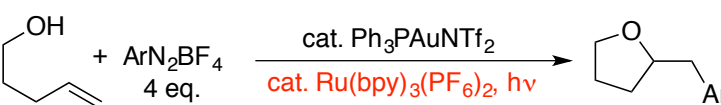

B)

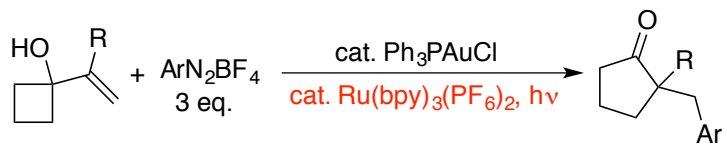

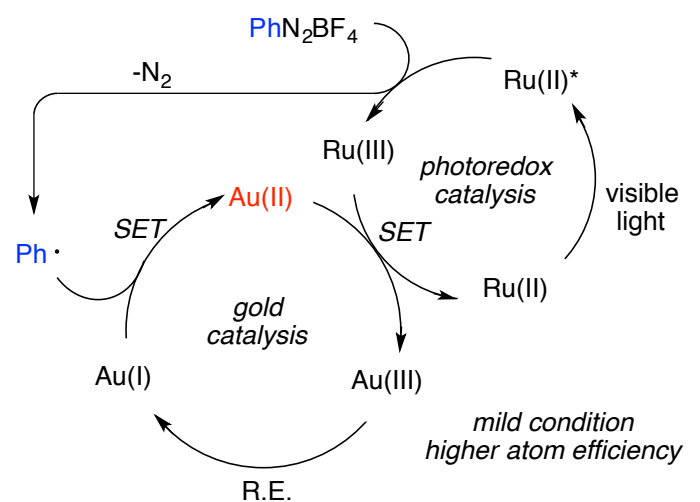

As mentioned in Section 1.1.1, because of the relativistic effect, $A u(I)$ possesses more dispersed $5 d$ electrons, which retards the rate of oxidative addition. $^{3}$ Compared with the isoelectronic $\operatorname{Pd}(0)$ complexes, which undergo oxidative addition with aryl halide easily, $A u(I)$ shows far less reactivity for this classic type of organometallic reactions. Only limited examples of $A u(I)$ oxidative addition has been reported (Scheme 19). ${ }^{44}$

In the 1970s, Kochi, Schmidbaur, and Puddephatt discovered that phosphine gold(I) methyl complex could react with methyl iodide slowly under room temperature, generating phosphine gold(I) iodide and ethane (Scheme 19A) ${ }^{45}$ The gold(III) intermediate likely formed through a $S_{N} 2$-type addition of gold(I) to methyl iodide, which is common among late transition metals. More recently, Toste reported a photo-initiated oxidative addition of $\mathrm{CF}_{3} \mathrm{l}$ to aryl gold(I) complexes (Scheme 19B) ${ }^{46}$ Detailed mechanistic studies suggested a radical chain reaction starting from the photoinitiated excitation of $\mathrm{CF}_{3} \mathrm{l}$. The resulting gold(III) complex is stable towards air, water, and even column purification.

In 2014, Amgoune and Bourissou reported a strategy using phosphinechelated aryl halide to direct the gold(I) center close to the $\mathrm{C}-\mathrm{X}$ bond through phosphine coordination, which led to a facile intramolecular oxidative addition of $\mathrm{C}-\mathrm{I}$ or $\mathrm{C}-\mathrm{Br}$ bonds (Scheme 19C). ${ }^{47}$ This is the first example for the $\mathrm{C}\left(\mathrm{sp}^{2}\right)-\mathrm{X}$ oxidative addition to a single gold center. The activation barrier determined by NMR (confirmed by DFT calculations) is $10-15 \mathrm{kcal} / \mathrm{mol}$ lower than the predicted activation barrier of a similar intermolecular oxidative addition. 


\section{Scheme 19. Selected examples of gold(I) oxidative addition to C-X bonds}

A) $S_{N}$ 2-type oxidative addition

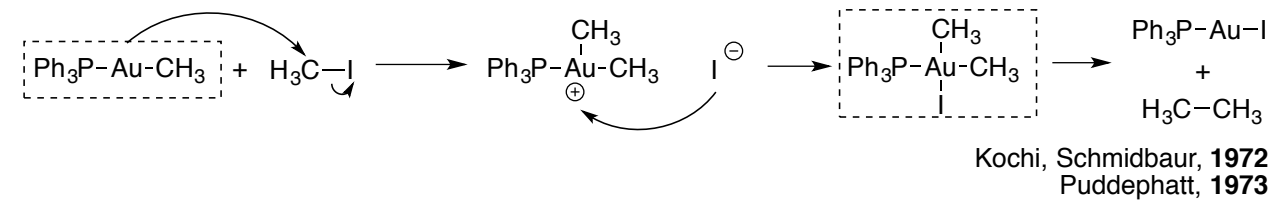

B) Radical chain mechanism

$\mathrm{Cy} \mathrm{y}_{3} \mathrm{P}-\mathrm{Au}-\mathrm{Ar}$

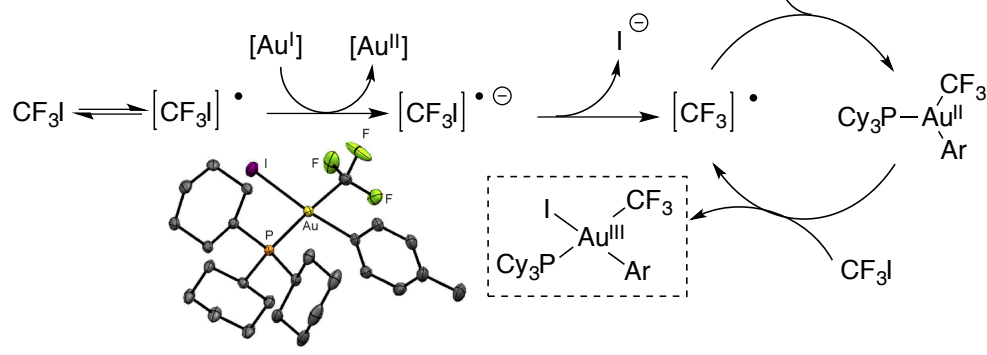

Toste, 2014

C) Phosphine-directed oxidative addition

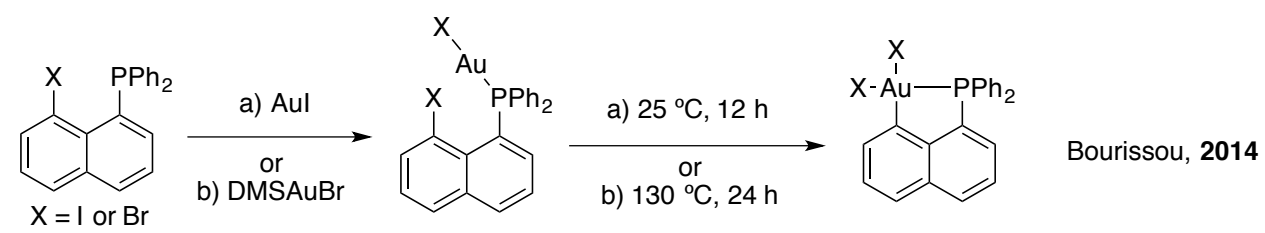

\section{D) Bending turns on reactivity}
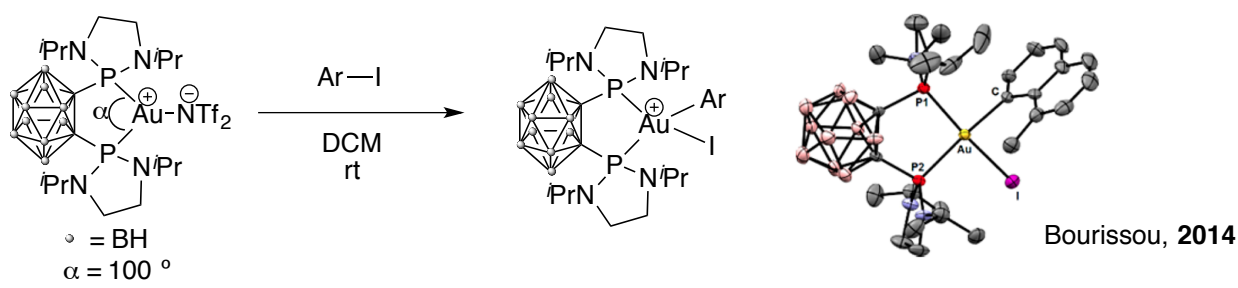

Later, the same group reported another example using a specially designed carborane diphosphine (DPCb) ligand to trigger the oxidative addition to gold(I). ${ }^{48}$ This DPCb ligand is one rare example that could chelate gold $(I)$ with a small bite angles $\left(100^{\circ}\right.$, usually $180^{\circ}$ for two-coordinated gold(I) complexes), which facilitates gold $(I)$ to undergo oxidative addition of aryl iodides under mild conditions with broad substrate scope.

Although the studies of gold(III) reductive elimination is limited compared with oxidative addition, there is clear evidence that gold(III) undergoes efficient reductive elimination. Not until the recent development of well-characterized 
gold(III) complexes through oxidative addition, that significant progress in mechanistic understanding of gold(III) reductive elimination has been achieved.

Early kinetic studies suggested that dissociation of phosphine ligand form four-coordinate gold complexes to generate a Y-shape (or T-shape) intermediate is the rate-determining step for reductive elimination of $\mathrm{C}\left(\mathrm{sp}^{3}\right)-\mathrm{C}\left(\mathrm{sp}^{3}\right)$ and $\mathrm{C}\left(\mathrm{sp}^{3}\right)$ $\mathrm{C}\left(\mathrm{sp}^{2}\right) .{ }^{49}$ In accordance with the dissociative mechanism, less coordinating phosphine ligands enhance the reductive elimination reaction rate. ${ }^{50}$ Recently, the Toste group reported more detailed mechanistic studies on gold(III) reductive elimination (Scheme 20).

Scheme 20. Examples for reductive elimination from gold(III)

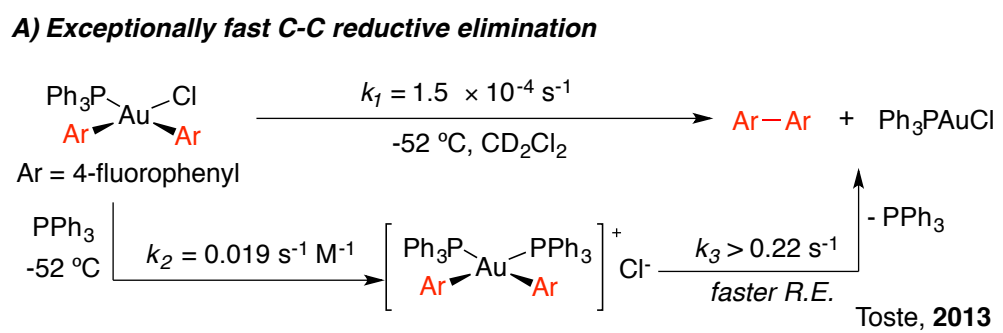

B) $C-X$ and $C-C F_{3}$ reductive elimination

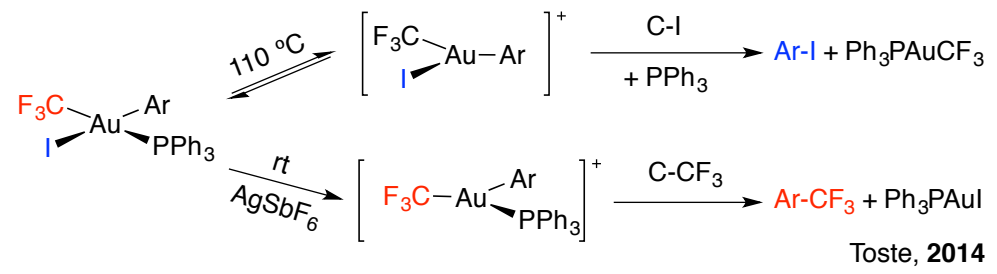

C) C-P reductive elimination

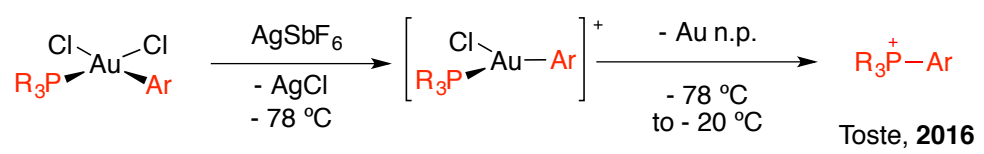

The $C\left(\mathrm{sp}^{2}\right)-\mathrm{C}\left(\mathrm{sp}^{2}\right)$ bond reductive elimination is among the fastest $\mathrm{C}-\mathrm{C}$ coupling reactions catalyzed by transition metals (Scheme 20A). ${ }^{51}$ Interestingly, the reaction is accelerated by addition of excess $\mathrm{PPh}_{3}$ ligand, which is opposite to that observed for $\mathrm{C}\left(\mathrm{sp}^{3}\right)-\mathrm{C}\left(\mathrm{sp}^{3}\right)$. The gold(III) complex possibly undergoes associative ligand exchange with excess $\mathrm{PPh}_{3}$, generating a cationic bis- $\mathrm{PPh}_{3}$-biaryl gold complex, which rapidly eliminates the biaryl product. Without excess 
$\mathrm{PPh}_{3}$, the square-planar gold(III) complex could generate biaryl directly through reductive elimination.

The other three examples all follow dissociative mechanism (Scheme 20B, 20C). ${ }^{52}$ The four-coordinated Au(III) complexes, in these cases, are very stable and do not decompose under room temperature. At elevated temperature, the phosphine ligand dissociates to generate the reactive $\mathrm{Y}$-shaped intermediate, which will reductively eliminate to form carbon-halide bonds, with a reaction rate $\mathrm{I}>\mathrm{Br}>\mathrm{Cl}(\mathrm{C}-\mathrm{F}$ bond formation is not observed). By extract the halides out from the initial gold(III) complex using a silver salt, a different $Y$-shaped intermediate is formed and undergoes rapid reductive elimination within seconds, forming $\mathrm{C}_{-} \mathrm{CF}_{3}$ or C-P bonds.

Although the scope for redox gold catalysis is still limited, the unique properties of $A u(I)$, such as efficient $\pi$-activation and non-parallel reactivity with other group 10 metals, makes redox gold chemistry very attractive. Based on the different reaction pathways of $\mathrm{Au}(\mathrm{I})$ and $\mathrm{Pd}(0)$ toward oxidative addition, redox

gold chemistry will not become an alternative of palladium chemistry but rather a irreplaceable supplement. Recent progress in this field has certainly enriched gold catalysis regarding elementary organometallic reactions, while further mechanistic investigation and new transformation discovery remain challenging.

\section{2 Cross-coupling of alkyne and aryldiazonium}

Our group recently disclosed a gold-catalyzed cross-coupling between aromatic and aliphatic terminal alkynes, which was achieved through the selective formation of gold acetylide intermediates. ${ }^{53}$ With the aid of a strong oxidant (PIDA) and phenanthroline ligand, rapid reductive elimination of $\mathrm{Au}(\mathrm{III})$ intermediate led to facile and selective diyne formation (Scheme 21). Encouraged by this success and inspired by previous works from Glorius and Toste (Scheme 18), we were intrigued by the possibility of $\mathrm{sp}-\mathrm{sp}^{2}$ cross-coupling using aryldiazonium salts as the coupling partner under mild photocatalytic conditions. $^{54}$ 
Scheme 21. Oxidative cross-coupling of terminal alkynes

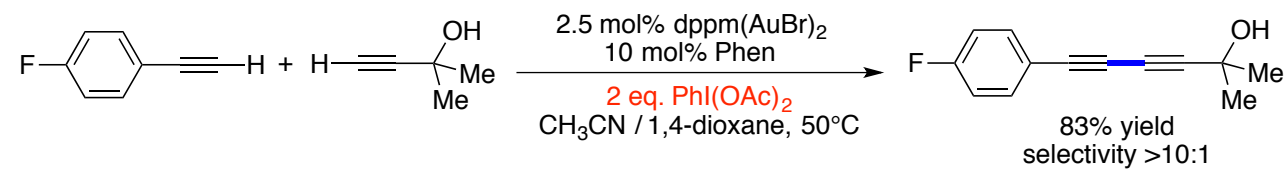

To test this hypothesis, alkyne $1 \mathrm{a}$ and diazonium salt $2 \mathbf{a}$ were selected as the model substrates and charged into the "dual" photoredox and gold catalysis conditions.

Table 10. Gold-catalyzed C(sp)-C(sp $\left.{ }^{2}\right)$ coupling without external oxidants ${ }^{a, b}$

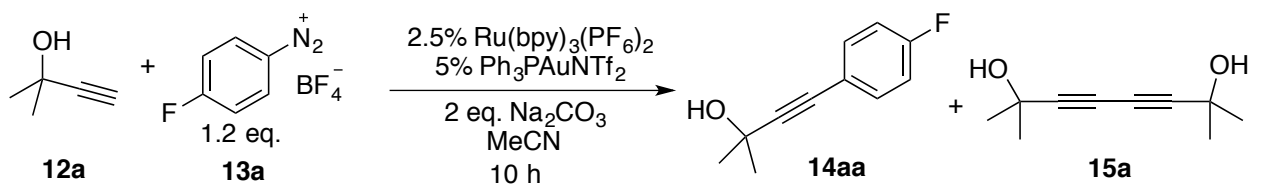

\begin{tabular}{|c|c|c|c|c|c|}
\hline \multirow{2}{*}{ Entry } & \multirow{2}{*}{ Variations from above conditions } & \multirow{2}{*}{$\begin{array}{c}\text { Conc. } \\
\text { (M) }\end{array}$} & \multirow{2}{*}{$\begin{array}{c}\text { Convn } \\
(\%)\end{array}$} & \multicolumn{2}{|c|}{ Yield (\%) } \\
\hline & & & & $14 a^{d}$ & $15 a^{c}$ \\
\hline 1 & No Change & 0.2 & 46 & 41 & 0 \\
\hline 2 & No $\mathrm{Na}_{2} \mathrm{CO}_{3}$ & 0.2 & 9 & 0 & 0 \\
\hline 3 & No $\mathrm{Ph}_{3} \mathrm{PAuNTf}_{2}$ & 0.2 & 0 & 0 & 0 \\
\hline 4 & $\mathrm{No} \mathrm{Ru}(\mathrm{bpy})_{3}\left(\mathrm{PF}_{6}\right)_{2}$ & 0.2 & 44 & 41 & 0 \\
\hline 5 & No light & 0.2 & 40 & 36 & 0 \\
\hline 6 & $\mathrm{PdCl}_{2}(5 \%)$ as the catalyst & 0.5 & 0 & 0 & 0 \\
\hline 7 & $\mathrm{PdCl}_{2}(5 \%)$ and $\mathrm{Ph}_{3} \mathrm{PAuNTf}_{2}(5 \%)$ as the catalyst & 0.5 & 86 & 56 & 13 \\
\hline 8 & $\mathrm{Pd}(\mathrm{OAc})_{2}(5 \%)$ as the catalyst & 0.5 & 83 & 13 & 8 \\
\hline 9 & $\mathrm{Pd}(\mathrm{OAc})_{2}(5 \%)$ and $\mathrm{Ph}_{3} \mathrm{PAuNTf}_{2}(5 \%)$ as the catalyst & 0.5 & 100 & 62 & 6 \\
\hline
\end{tabular}

${ }^{a}$ Reaction conditions: 12a $(0.1 \mathrm{mmol}), 13 \mathbf{a}(0.12 \mathrm{mmol})$, catalysts and additives in acetonitrile (ACN), rt, $10 \mathrm{~h} ;{ }^{b}$ Less than $1 \%$ of $13 \mathrm{a}$ homo-coupling product 4,4 '-difluorobiphenyl (16a) was detected; ${ }^{c}$ Determined by ${ }^{1} \mathrm{H}$-NMR using p-xylene as the internal standard; ${ }^{d}$ Determined by ${ }^{19} \mathrm{~F}$ NMR using benzotrifluoride as the internal standard.

As shown in Table 10 (entry 2), reaction of 12a and 13a in the presence of both photocatalyst and gold catalyst gave no desired coupling products (low conversion of 12a). Considering that the formation of gold acetylide could be critical, a base $\left(\mathrm{Na}_{2} \mathrm{CO}_{3}\right)$ was added to assist the alkyne deprotonation. As expected, the cross-coupling product 14aa was formed, though in modest yield 
(entry 1). In the control experiments (entries 3-5), almost identical kinetics and yields were observed under standard or dark conditions in the absence of photocatalyst, which negated the involvement of a photocatalytic process. This result was exciting since it implied that the diazonium salt alone, in this reaction, might be fully capable of oxidizing the active gold(I) species to gold(III).

It has been reported that trace amount of $\mathrm{Pd}(\mathrm{II})$ in gold salts might contribute to Sonogashira-type coupling. ${ }^{55}$ To rule out this possibility, $\mathrm{PdCl}_{2}$ was tested as the catalyst either by itself or combined with gold. The negative results obtained from the studies (Table 10, entries 6-9) confirmed this reaction as a goldcatalyzed process. ${ }^{56}$

Table 11. Condition optimization for gold-catalyzed $\mathbf{C}(\mathbf{s p})-\mathbf{C}\left(\mathbf{s p ^ { 2 }}\right)$ coupling $^{a, b}$

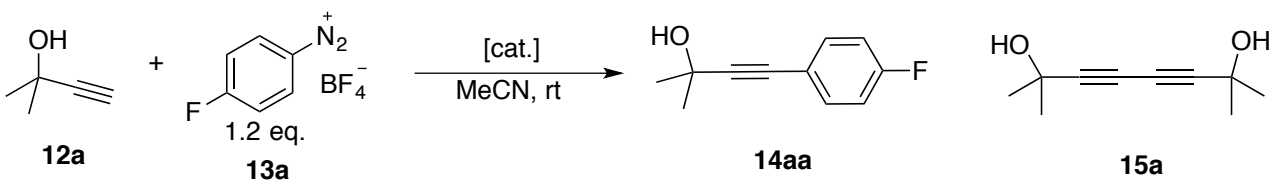

\begin{tabular}{|c|c|c|c|c|c|c|c|}
\hline \multirow{2}{*}{ Entry } & \multirow{2}{*}{ Catalyst (\%) } & \multirow{2}{*}{ Additive (equiv) } & \multirow{2}{*}{$\begin{array}{c}\text { Time } \\
(\mathrm{h})\end{array}$} & \multirow{2}{*}{$\begin{array}{c}\text { Conc. } \\
\text { (M) }\end{array}$} & \multirow{2}{*}{$\begin{array}{c}\text { Convn } \\
(\%)\end{array}$} & \multicolumn{2}{|c|}{ Yield (\%) } \\
\hline & & & & & & $14 \mathbf{a a}^{d}$ & $15 a^{c}$ \\
\hline 1 & $\mathrm{Ph}_{3} \mathrm{PAuNTf}_{2}(5)$ & - & 20 & 0.2 & 9 & 0 & 0 \\
\hline 2 & $\mathrm{Ph}_{3} \mathrm{PAuNTf}_{2}(5)$ & $\mathrm{Na}_{2} \mathrm{CO}_{3}(2)$ & 20 & 0.2 & 44 & 41 & 0 \\
\hline 3 & $\mathrm{Ph}_{3} \mathrm{PAuNTf}_{2}(5)$ & bpy (2) & 20 & 0.2 & 73 & 60 & 5 \\
\hline 4 & $\mathrm{Ph}_{3} \mathrm{PAuNTf}_{2}(5)$ & bpy (2) & 8 & 0.5 & 100 & 83 & 8 \\
\hline 5 & $\mathrm{Ph}_{3} \mathrm{PAuNTf}_{2}(5)$ & $\mathrm{Na}_{2} \mathrm{CO}_{3}(2)$, bpy (0.2) & 6 & 0.5 & 100 & 94 & 2 \\
\hline 6 & $\mathrm{Ph}_{3} \mathrm{PAuNTf}_{2}(2)$ & $\mathrm{Na}_{2} \mathrm{CO}_{3}(2)$, bpy $(0.2)$ & 10 & 0.5 & 53 & 40 & 2 \\
\hline 7 & $\mathrm{Ph}_{3} \mathrm{PAuNTf}_{2}(5)$ & $\mathrm{Li}_{2} \mathrm{CO}_{3}(2)$, bpy $(0.2)$ & 6 & 0.5 & 50 & 39 & 2 \\
\hline 8 & $\mathrm{Ph}_{3} \mathrm{PAuNTf}_{2}(5)$ & $\mathrm{K}_{2} \mathrm{CO}_{3}(2)$, bpy $(0.2)$ & 6 & 0.5 & 64 & 62 & 2 \\
\hline 9 & $\mathrm{Ph}_{3} \mathrm{PAuOAc}(5)$ & $\mathrm{Na}_{2} \mathrm{CO}_{3}(2)$, bpy (0.2) & 6 & 0.5 & 100 & 88 & 2 \\
\hline 10 & $\mathrm{Ph}_{3} \mathrm{PAu}(\mathrm{TA}) \mathrm{OTf}(5)^{e}$ & $\mathrm{Na}_{2} \mathrm{CO}_{3}(2)$, bpy (0.2) & 6 & 0.5 & 100 & 88 & 2 \\
\hline 11 & $\mathrm{Ph}_{3} \mathrm{PAuCl}(5)$ & $\mathrm{Na}_{2} \mathrm{CO}_{3}(2)$, bpy (0.2) & 12 & 0.5 & 30 & 27 & 12 \\
\hline 12 & $\mathrm{Et}_{3} \mathrm{PAuNTf}_{2}(5)$ & $\mathrm{Na}_{2} \mathrm{CO}_{3}(2)$, bpy (0.2) & 12 & 0.5 & 59 & 44 & 5 \\
\hline 13 & $(\operatorname{ArO})_{3} \mathrm{PAuNTf}_{2}(5)^{f}$ & $\mathrm{Na}_{2} \mathrm{CO}_{3}(2)$, bpy $(0.2)$ & 12 & 0.5 & 42 & 40 & 5 \\
\hline
\end{tabular}

${ }^{a}$ Reaction conditions: 12a $(0.1 \mathrm{mmol}), 13 \mathrm{a}(0.12 \mathrm{mmol})$, catalysts and additives in acetonitrile (ACN), rt; ${ }^{b}$ Less than $1 \%$ of $\mathbf{1 3 a}$ homo-coupling product $4,4^{\prime}$-difluorobiphenyl (16a) was detected; ${ }^{c}$ Determined by ${ }^{1} \mathrm{H}$-NMR using $\mathrm{p}$-xylene as the internal standard; ${ }^{d}$ Determined by ${ }^{19} \mathrm{~F}-\mathrm{NMR}$ using benzotrifluoride as the internal standard. 
To optimize the reaction conditions, various additives and catalysts were tested (Table 11). An organic base 2, 2'-bipyridine (bpy) gave better yield (60\%) among all tested organic and inorganic bases (entry 3 ). We reasoned that the bpy additive served both as a base and an ancillary ligand. ${ }^{57}$ Complete consumption of $12 \mathrm{a}$ (14aa in $83 \%$ yield, entry 4 ) was achieved by simply increasing the reaction concentration. The combination of $\mathrm{Na}_{2} \mathrm{CO}_{3}$ as the base and bpy as the ligand gave the best result with 14aa obtained in $94 \%$ yield (entry 5). Reducing the catalyst loading led to lower conversion likely due to gold decomposition (entry 6). Other inorganic bases proved to be less effective compared with $\mathrm{Na}_{2} \mathrm{CO}_{3}$. Screening of the gold catalysts revealed that cationic $\left[\mathrm{Ph}_{3} \mathrm{PAu}\right]^{+} \mathrm{X}^{-}$gave optimal yields regardless of the counteranion (entry 9,10 ). The more electron-rich $\mathrm{PEt}_{3}$ ligand (entry 12 ) and electron-poor phosphite ligand (entry 13) are both less efficient in this reaction. A neutral gold $(I)$ complex $\mathrm{Ph}_{3} \mathrm{PAuCl}$ could catalyze this cross coupling but with a much lower conversion and yield, which is probably due to its difficulty in forming a gold acetylide intermediate compared to the cationic gold catalysts.

With the optimized conditions in hand, we explored the reaction scope (Table 12). Electron-deficient diazonium 14aa $(4 \mathrm{~h})$ reacted faster than 14ab $(6 \mathrm{~h})$. On the contrary, electron-rich diazonium 14ac reacted slower $(8 \mathrm{~h})$. Orthosubstituted phenyldiazonium salts gave lower conversion and yield $(<30 \%)$, which hinted at the steric sensitivity of this reaction. Various terminal alkynes (both aliphatic and aromatic) with different functional groups such as hydroxyl (14a), ester (14e), heterocycles $(\mathbf{1 4 g}, \mathbf{1 4 h})$ and estrone derivative (140) were well tolerated under this mild and efficient condition. The high reactivity of $p$ methoxyphenyl acetylene (14I) resulted in a messy reaction with the desired product isolated in only $36 \%$ yield (16\% alkyne homo-coupling product detected with NMR). In general, aliphatic alkynes reacted faster than aromatic alkynes, suggesting that the gold oxidation likely occurred after the formation of gold acetylide since aliphatic gold acetylides are more electron-rich. 
Table 12. Substrate scope for gold-catalyzed C(sp)-C(sp $\left.{ }^{2}\right)$ coupling $^{a}$

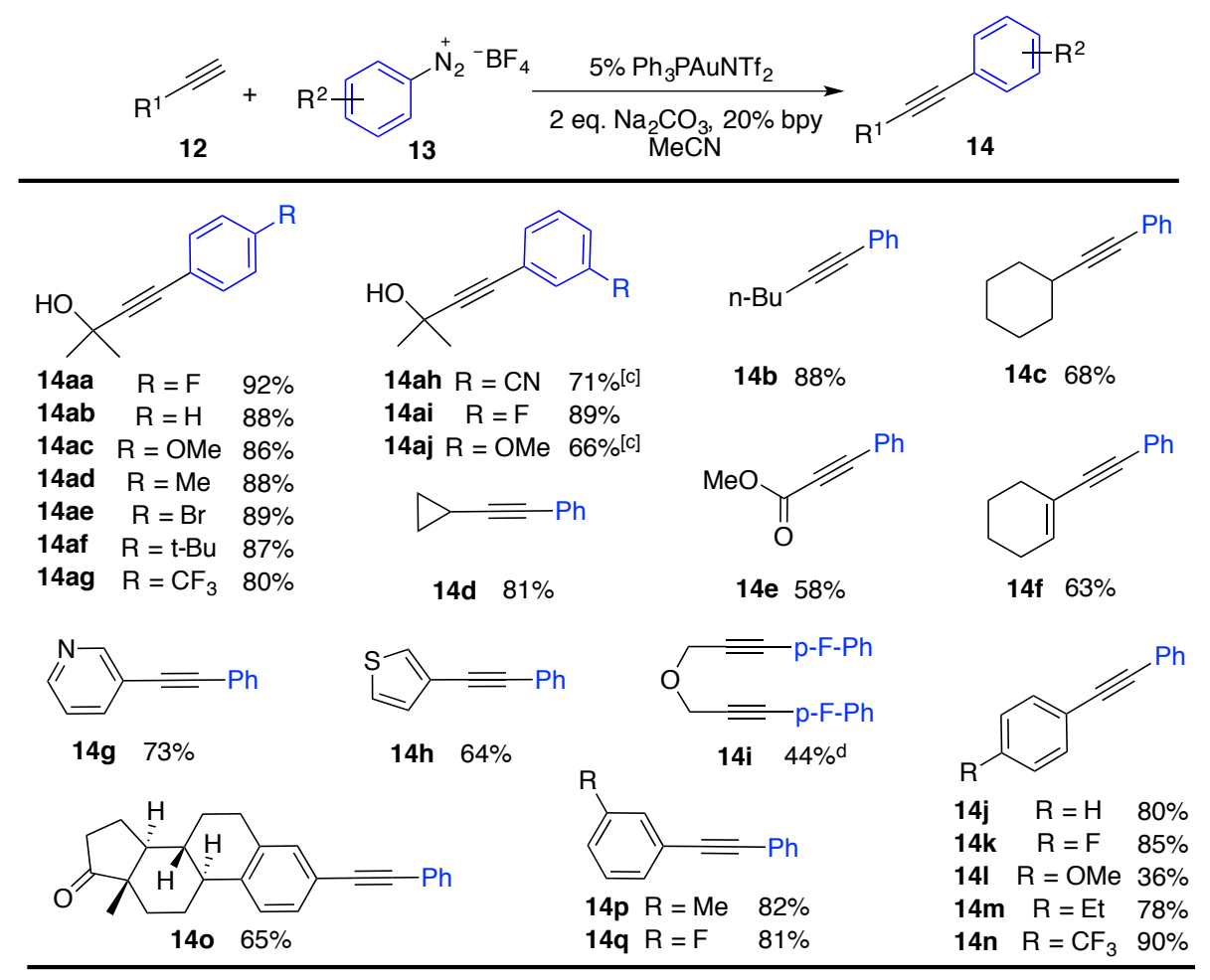

${ }^{a}$ Reaction condition: 12 (0.4mmol), 13 (0.48mmol), $\mathrm{Ph}_{3} \mathrm{PAuNTf}_{2}(0.02 \mathrm{mmol})$, bpy $(0.08 \mathrm{mmol})$ and $\mathrm{Na}_{2} \mathrm{CO}_{3}(0.8 \mathrm{mmol})$ in $0.8 \mathrm{~mL} \mathrm{ACN}, \mathrm{rt}^{b}{ }^{b}$ Isolated yields; ${ }^{c} 10 \%$ of $\mathrm{Ph}_{3} \mathrm{PAuNTf} \mathrm{P}_{2}$ was used; ${ }^{d} 3$ eq. of 13a was used.

\section{3 Reactions of diazonium salts with gold complexes}

To study the reaction mechanism, different types of gold complexes were prepared and treated with diazonium salts. The cationic gold catalyst $\mathrm{Ph}_{3} \mathrm{PAuNTf}_{2}$ did not react with diazonium salts without bpy. No decomposition of both diazonium 13a and gold catalyst was observed even after 18 hours (Figure 10: $a-b)$. With the addition of bpy in a parallel NMR tube, the $\left[\mathrm{Ph}_{3} \mathrm{PAu}(\mathrm{bpy})\right]^{+}$ complex ( $\left({ }^{31} \mathrm{P}\right.$ NMR: $\left.\delta 31.6 \mathrm{ppm}\right)$ was formed instantly (Figure 10: c). Interestingly, this gold complex decomposed during the reaction with $\mathrm{ArN}_{2}{ }^{+}$, forming phosphonium $\mathbf{M}$ overtime through reductive elimination of the corresponding $\mathrm{Au}(\mathrm{III})$ complex (Figure 10: d-e). After complete conversion of $\left[\mathrm{Ph}_{3} \mathrm{PAu}(\mathrm{bpy})\right]^{+}$, 
diazonium 13a was no longer being consumed, which refuted the possibility of $\mathbf{M}$ to be an active species.

Figure 10. Reaction between diazonium and $\mathrm{Ph}_{3} \mathrm{PAuNTf}_{2}$
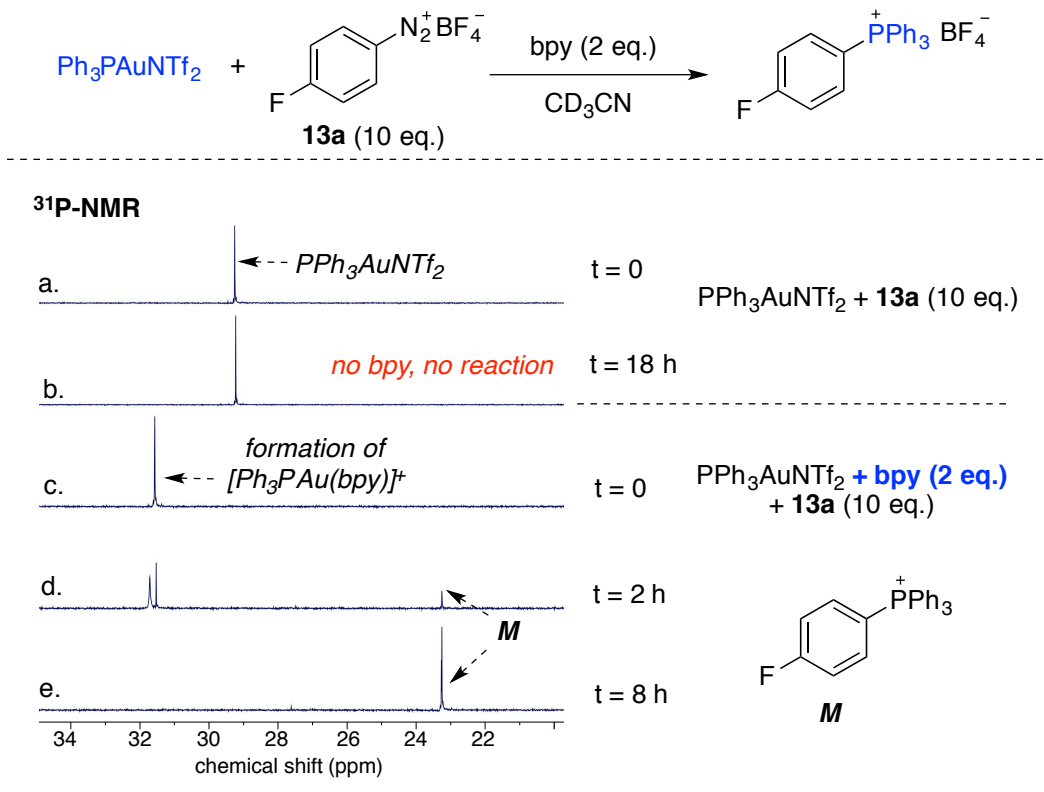

It is known that cationic $\mathrm{Au}(\mathrm{I})$ complexes can react rapidly with terminal alkynes to form gold acetylides, especially under basic conditions. ${ }^{58}$ To prove that the gold acetylide was the reaction intermediate, complex 17a was prepared and treated with diazonium $\mathbf{1 3 b}$ (1.1 eq.).

As shown in Figure 11A, without bpy, gold acetylide 17a decomposed overtime with only $22 \%$ of the cross-coupling product $15 \mathrm{r}$ formed (no further conversion after $4 \mathrm{~h})$. The formation of gold mirror and $\left.\left[\left(\mathrm{Ph}_{3} \mathrm{P}\right)_{2} \mathrm{Au}\right]\right]^{+}\left({ }^{31} \mathrm{P}\right.$ NMR: $\delta$ $44.9 \mathrm{ppm}$ ) was observed within $1 \mathrm{~h}$. Impressively, with the addition of bpy, 15r was formed instantly and the reaction was completed in a nearly quantitative yield (Figure 11B). After reaction was complete, the $\left[\mathrm{Ph}_{3} \mathrm{PAu}(\mathrm{bpy})\right]^{+}$complex was confirmed as the final gold species (small amount of $\left[\mathrm{Ph}_{3} \mathrm{P}-\mathrm{Ar}\right]^{+} \mathbf{M}$ was formed after reaction completion from the reaction between excess $13 \mathrm{~b}$ and $\left.\left[\mathrm{Ph}_{3} \mathrm{PAu}(\mathrm{bpy})\right]^{+}\right)$. 
Figure 11. Reaction between diazonium and gold acetylide
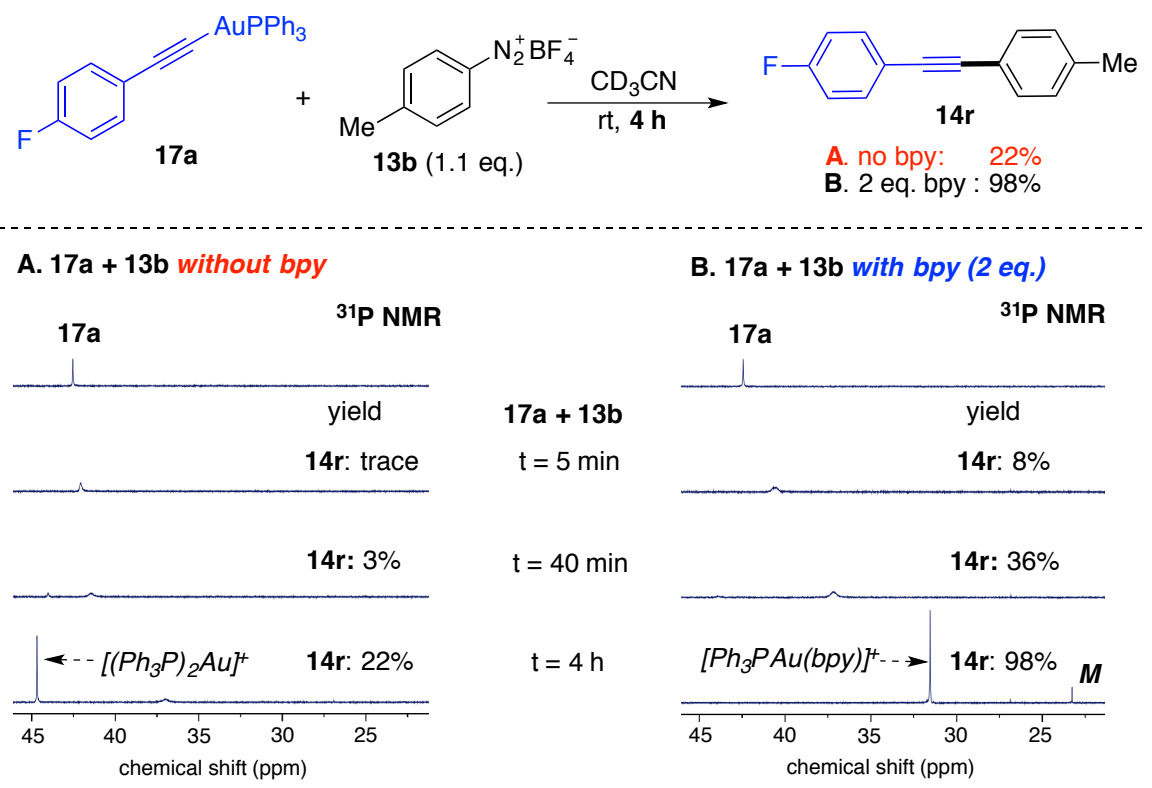

Compared to the $C(s p)-C\left(s p^{2}\right)$ coupling (Figure 11), the $C\left(s p^{2}\right)-C\left(s p^{2}\right)$ coupling with aryl gold complex is much faster (Figure 12). Rapid gas evolution was observed almost simultaneously with the addition of diazonium salt to the mixture of $17 \mathbf{b}$ and bpy in $\mathrm{CD}_{3} \mathrm{CN}$.

Figure 12. Reaction between diazonium and aryl gold complex

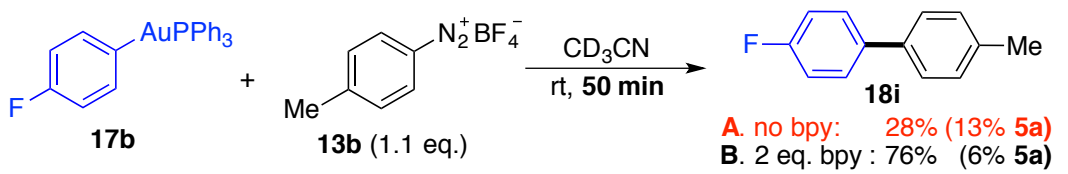

A. $17 b+13 b$ without bpy

${ }^{31}$ P NMR
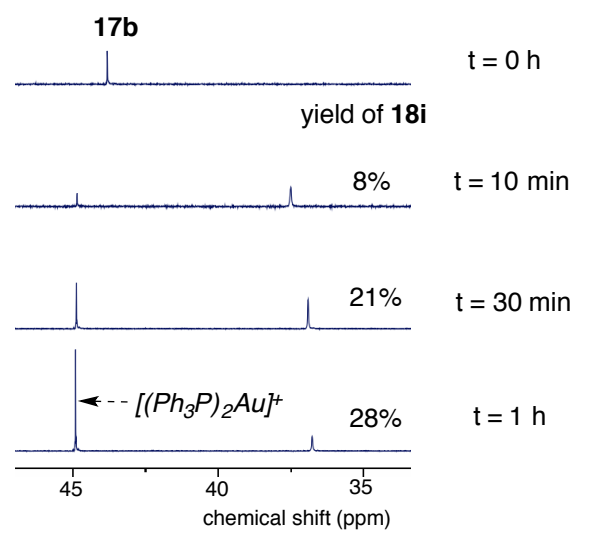

$\mathrm{t}=30 \mathrm{~min}$

$t=1 h$
B. $17 b+13 b$ with bpy (2 eq.)
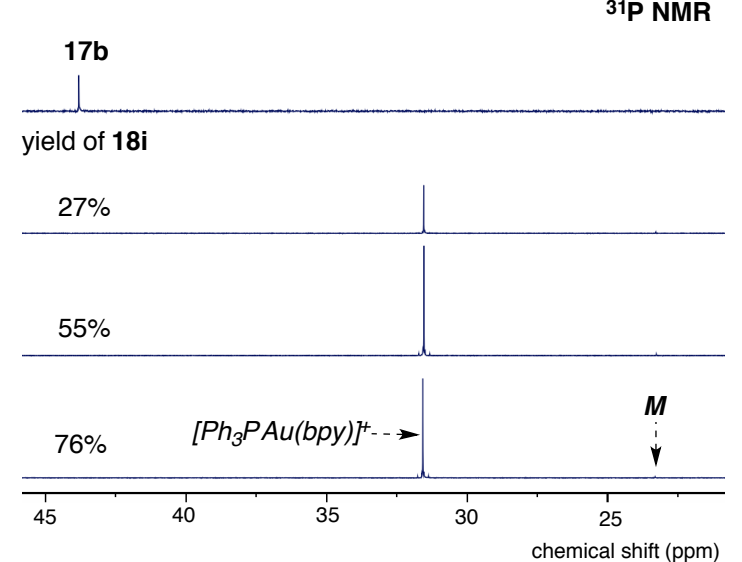
Similar to the $\mathrm{C}(\mathrm{sp})-\mathrm{C}\left(\mathrm{sp}^{2}\right)$ coupling, addition of bpy was critical for the reaction outcome. In the absence of bpy, a gold mirror was observed within 10 min. When bpy was present (Figure 12B), the $\left[\mathrm{Ph}_{3} \mathrm{PAu}(\mathrm{bpy})\right]^{+}(\delta 31.6 \mathrm{ppm})$ was the major species in the ${ }^{31} \mathrm{P} N M R$ from the beginning of the reaction, suggesting that the reductive elimination of the biaryl product from the $\mathrm{Au}(\mathrm{III})$ intermediate is very rapid, which is in accordance with previous report from Toste. Phosphonium $\mathbf{M}\left[\mathrm{Ph}_{3} \mathrm{P}-\mathrm{Ar}\right]^{+}$was also generated, though in a trace amount. One issue for the $C(s p)-C\left(s p^{2}\right)$ coupling is the formation of $C\left(s p^{2}\right)-C\left(s p^{2}\right)$ homocoupling product, possibly formed from transmetallation of aryl gold(I) 17b with the corresponding gold(III)-aryl intermediate (generated from reaction of gold(I) with diazonium) and sequential reductive elimination. The presence of bpy helped to suppress homo-coupling pathway, which facilitated the formation of cross-coupling product. At this point, the role of bpy in the overall reaction is unclear.

The reaction with $\mathrm{Ph}_{3} \mathrm{PAuMe}$ was quite sluggish both with and without bpy. In the absence of bpy, the gold complex $\mathrm{Ph}_{3} \mathrm{PAuMe}$ (terrible solubility in $\mathrm{CD}_{3} \mathrm{CN}$ ) slowly decomposed to yield gold mirror with the formation of small amount of unidentified mixture. Although no gold mirror was observed in the presence of bpy, the reaction was also slow and yielded a messy mixture. The desired product ( $p$-xylene) was not detected by ${ }^{1} \mathrm{H}$ NMR.

\section{Scheme 22. Summary of reaction between diazonium and gold complexes}

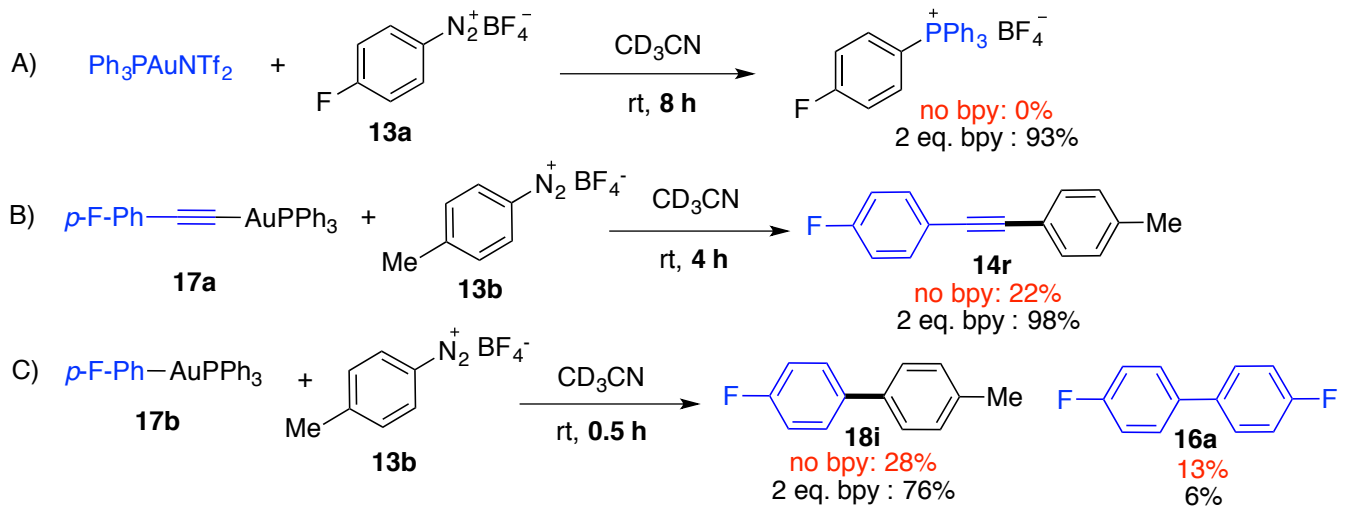


These NMR experiments provided important mechanistic insights. First, the $\mathrm{Ph}_{3} \mathrm{PAuNTf}_{2}$ catalyst alone could not promote diazonium decomposition (Scheme 22A). The addition of bpy is crucial in assisting the nitrogen extrusion. However, the gold acetylide species reacted with diazonium without bpy, generating the cross-coupling products, though in low yield. In the presence of bpy, a significantly faster reaction rate was observed (Scheme 22B). Considering the fact that $\mathbf{M}\left(\left[\mathrm{Ph}_{3} \mathrm{P}-\mathrm{Ar}\right]^{+}\right)$was only formed after reaction completion, it is clear that the oxidation of $A u(I)$ preferred to occur on gold acetylide rather than $\left[\mathrm{Ph}_{3} \mathrm{PAu}(\mathrm{bpy})\right]^{+}$. This discovery was rather exciting since it suggested that $\left[\mathrm{Ph}_{3} \mathrm{P}-\mathrm{Au}-\mathrm{R}\right]$ complexes were more feasible than cationic gold in diazonium promoted gold oxidation. By forming the $\left[\mathrm{Ph}_{3} \mathrm{P}-\mathrm{Au}-\mathrm{R}\right]$ intermediate in situ, similar cross-coupling reactions with different $\mathrm{R}$ group could be achieved under proper conditions.

\section{4 Cross-coupling of aryl boronic acid and diazonium}

According to literature, aryl boronic acids can react with $A u(I)$ under basic conditions to form the corresponding aryl gold complexes. ${ }^{59}$ Thus, it is reasonable to envision a catalytic $\mathrm{sp}^{2}-\mathrm{sp}^{2}$ cross-coupling between aryl boronic acid and diazonium salts.

Table 13. Condition optimization for gold-catalyzed $C\left(s p^{2}\right)-C\left(s p^{2}\right)$ coupling $^{a}$

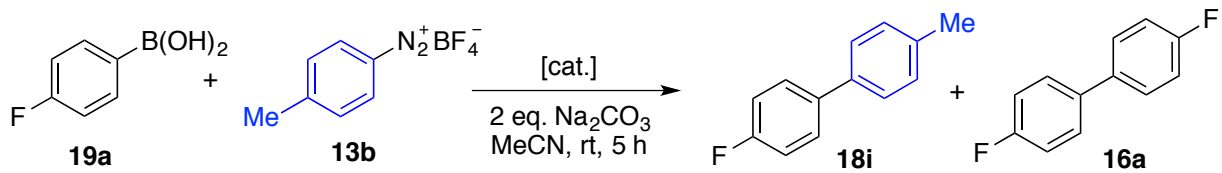

\begin{tabular}{|c|c|c|c|c|c|}
\hline \multirow{2}{*}{ Entry } & \multirow{2}{*}{ Catalyst (\%) } & \multirow{2}{*}{$\begin{array}{c}\text { Ligand } \\
(20 \%)\end{array}$} & \multirow{2}{*}{ Convn (\%) } & \multicolumn{2}{|c|}{ Yield (\%) } \\
\hline & & & & $18 i^{D}$ & $16 a^{c}$ \\
\hline 1 & $\mathrm{Ph}_{3} \mathrm{PAuNTf}_{2}(5)$ & bpy & 90 & 38 & 6 \\
\hline 2 & $\mathrm{Ph}_{3} \mathrm{PAu}(\mathrm{TA}) \mathrm{OTf}(5)^{d}$ & bpy & 86 & 64 & 7 \\
\hline 3 & $\mathrm{Ph}_{3} \mathrm{PAu}(\mathrm{TAa})(5)^{e}$ & bpy & 76 & 47 & 9 \\
\hline 4 & $(\mathrm{ArO})_{3} \mathrm{PAu}(\mathrm{TA}) \mathrm{OTf}(5)^{f}$ & bpy & 80 & 33 & 11 \\
\hline 5 & $\mathrm{Et}_{3} \mathrm{PAu}(\mathrm{TA}) \mathrm{OTf}(5)$ & bpy & 68 & 10 & 10 \\
\hline
\end{tabular}




\begin{tabular}{cccccc}
6 & $(4-\mathrm{OMe}-\mathrm{Ph})_{3} \mathrm{PAu}(\mathrm{TA}) \mathrm{OTf}(5)$ & bpy & 69 & 29 & 11 \\
7 & $\mathrm{Ph}_{3} \mathrm{PAu}(\mathrm{TA}) \mathrm{OTf}(10)$ & bpy & 100 & 86 & $\mathbf{8}$ \\
8 & $\mathrm{Ph}_{3} \mathrm{PAu}(\mathrm{TA}) \mathrm{OTf}(10)$ & dtbbpy & 88 & 75 & 6 \\
9 & $\mathrm{Ph}_{3} \mathrm{PAu}(\mathrm{TA}) \mathrm{OTf}(10)$ & bisquinoline & 74 & 37 & 10 \\
\hline
\end{tabular}

${ }^{a}$ Reaction conditions: $19 \mathrm{a}(0.1 \mathrm{mmol}), 13 \mathrm{~b}(0.12 \mathrm{mmol})$, catalysts and additives in acetonitrile (ACN), rt; ${ }^{b}$ Determined by ${ }^{1} \mathrm{H}$-NMR using p-xylene as the internal standard; ${ }^{c}$ Determined by ${ }^{19} \mathrm{~F}$ NMR using benzotrifluoride as the internal standard; ${ }^{d} \mathrm{TA}=1$-methylbenzotriazole; ${ }^{e} \mathrm{TAa}=$ benzotriazole anion; ${ }^{f} \mathrm{Ar}=2,4$-di-tert-butyl-phenyl.

Under previously optimized conditions (Table 13, entry 1 ), the desired crosscoupling product 18 was successfully obtained. However, the yield is much lower (around $40 \%$ ), presumably due to fast catalyst decomposition. Applying the more stable triazole-gold complex $\mathrm{Ph}_{3} \mathrm{PAu}(\mathrm{TA}) \mathrm{OTf}$ developed by our group, ${ }^{60}$ higher yields approaching $65 \%$ were observed (entry 2). Changing the phosphine ligand did not help improve the reaction performance (entry 4-6). The full conversion of starting material was obtained by an increase in the catalyst loading to $10 \%$ (entry 7 ). The bpy ligand is still the optimal choice among all tested chelating ligands (entry 8,9 ).

Under this new condition, various substituted aryl boronic acids and diazonium salts were tested. Overall, good to excellent yields were obtained for most of the tested substrates (Table 14). Considering the importance of C-C bond formation in organic synthesis, this new approach in redox gold catalysis is of great interest since it offers an alternative strategy for cross-coupling. ${ }^{61}$

\section{Table 14. Substrate scope for gold-catalyzed $C\left(s^{2}\right)-C\left(s^{2}\right)$ coupling $^{a, b}$}

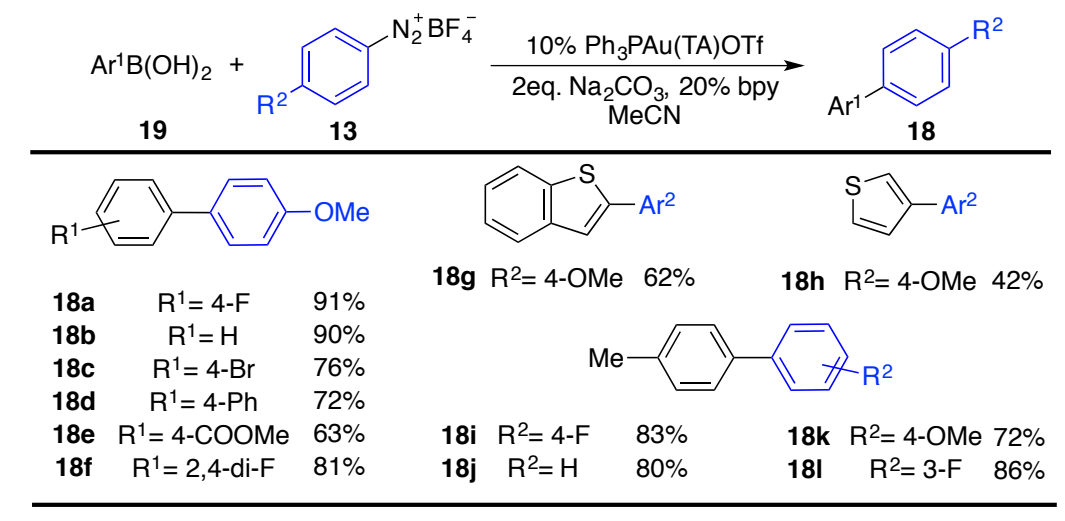


a Reaction condition: 19 (0.4mmol), 13 (0.48mmol), $\mathrm{Ph}_{3} \mathrm{PAu}(\mathrm{TA}) \mathrm{OTf}(0.04 \mathrm{mmol})$, bpy (0.08 $\mathrm{mmol})$ and $\mathrm{Na}_{2} \mathrm{CO}_{3}(0.8 \mathrm{mmol})$ in $0.8 \mathrm{~mL} \mathrm{ACN}, \mathrm{rt} ;{ }^{b} \mathrm{NMR}$ yields.

\section{6 Mechanistic investigation}

After study of the stoichiometric reactions using NMR, the catalytic reaction between alkyne and diazonium was investigated as well. Based on ${ }^{31} \mathrm{P} N M R$ data, the $\left[\mathrm{Ph}_{3} \mathrm{PAu}(\mathrm{bpy})\right]^{+}$complex ( $\delta 31.6 \mathrm{ppm}$ ) was the major gold species detected during the reaction. As the reaction proceeded toward completion, this $\left[\mathrm{Ph}_{3} \mathrm{PAu}(\mathrm{bpy})\right]^{+}$complex started to accumulate. After the reaction was complete $(7 \mathrm{~h})$, phosphonium $\mathbf{M}\left(\left[\mathrm{Ph}_{3} \mathrm{P}-\mathrm{Ar}\right]^{+}\right)$started to form. No induction period was observed for this reaction, suggesting that the formation of catalytically active intermediate was very rapid.

Figure 13. Monitoring the catalytic $\mathrm{C}(\mathrm{sp})-\mathrm{C}\left(\mathrm{sp}^{2}\right)$ coupling

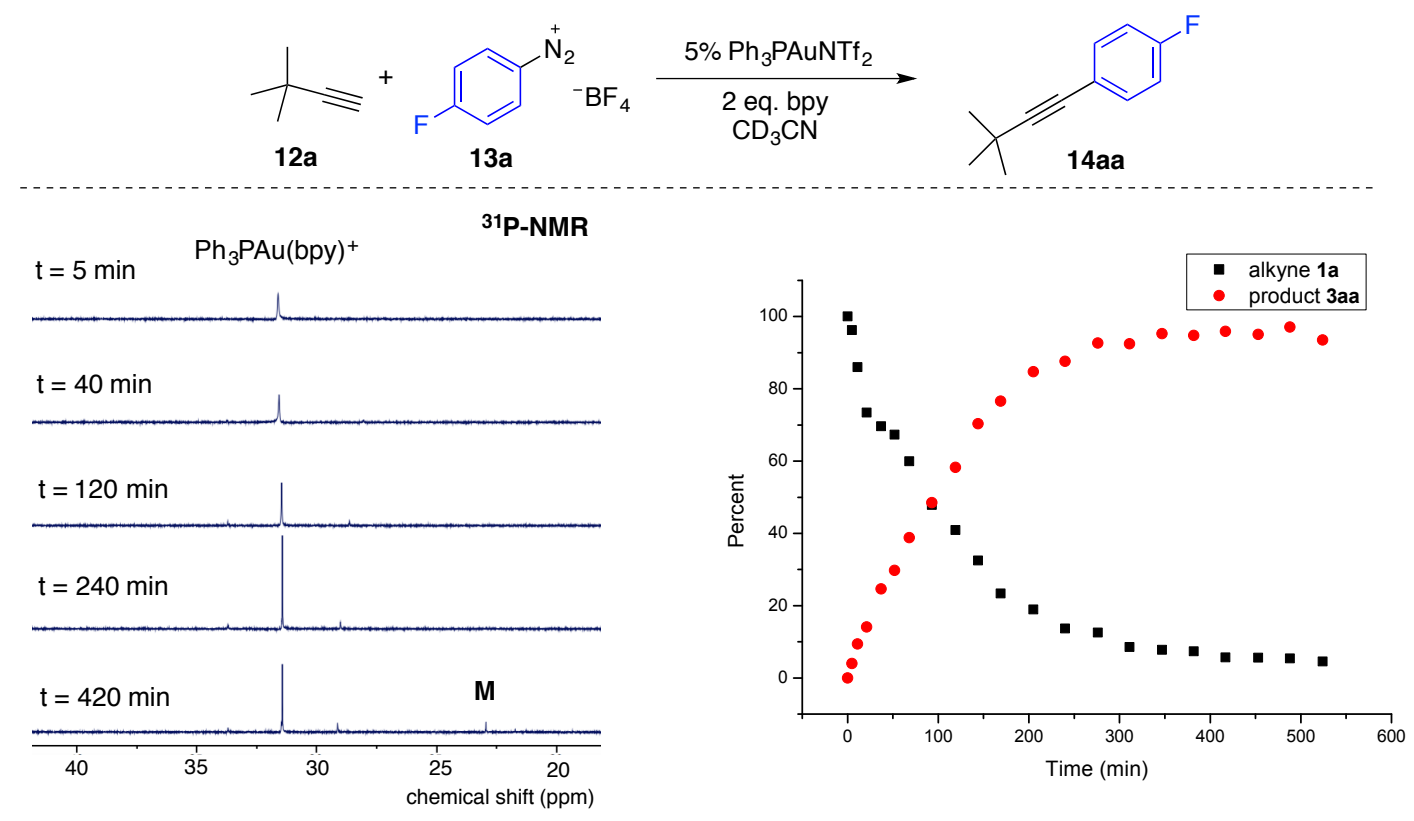

To verify whether the reaction proceeded through a radical mechanism, diazonium salt 13c was prepared and charged into the optimal conditions. As shown in Scheme 23, the reaction of $13 c$ with $12 a$ was quite sluggish with only $25 \%$ of the desired coupling product 20 a formed. The radical trapping product $3-$ methyl-dihydrobenzofuran was not detected, but a cyclized byproduct 20b, 
generated from two molecule diazonium salt $13 \mathrm{c}$, was isolated and characterized by NMR and HR-MS. The mechanism of $20 \mathrm{~b}$ formation is still unclear to this point. It is highly likely that the aryl radical formation is not a key step in this cross-coupling reaction but it cannot be ruled out from possible reaction pathways.

\section{Scheme 23. Radical trapping experiment}

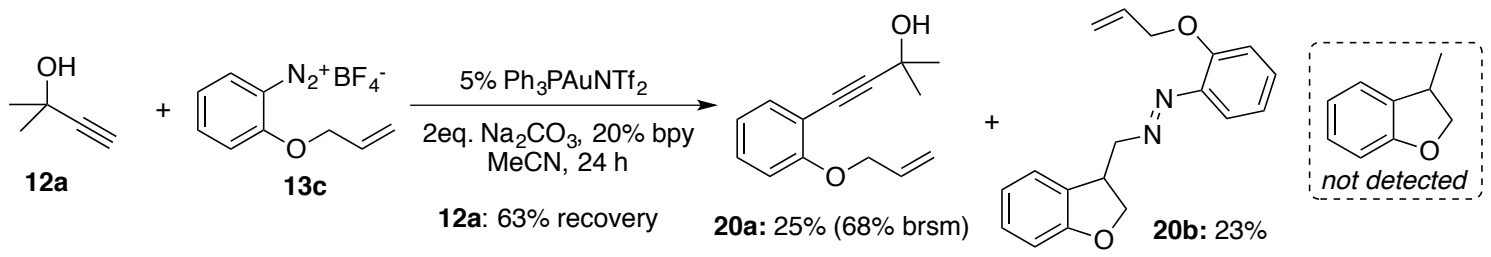

Figure 14. ESI-MS spectra of reaction mixture between diazonium and alkyne
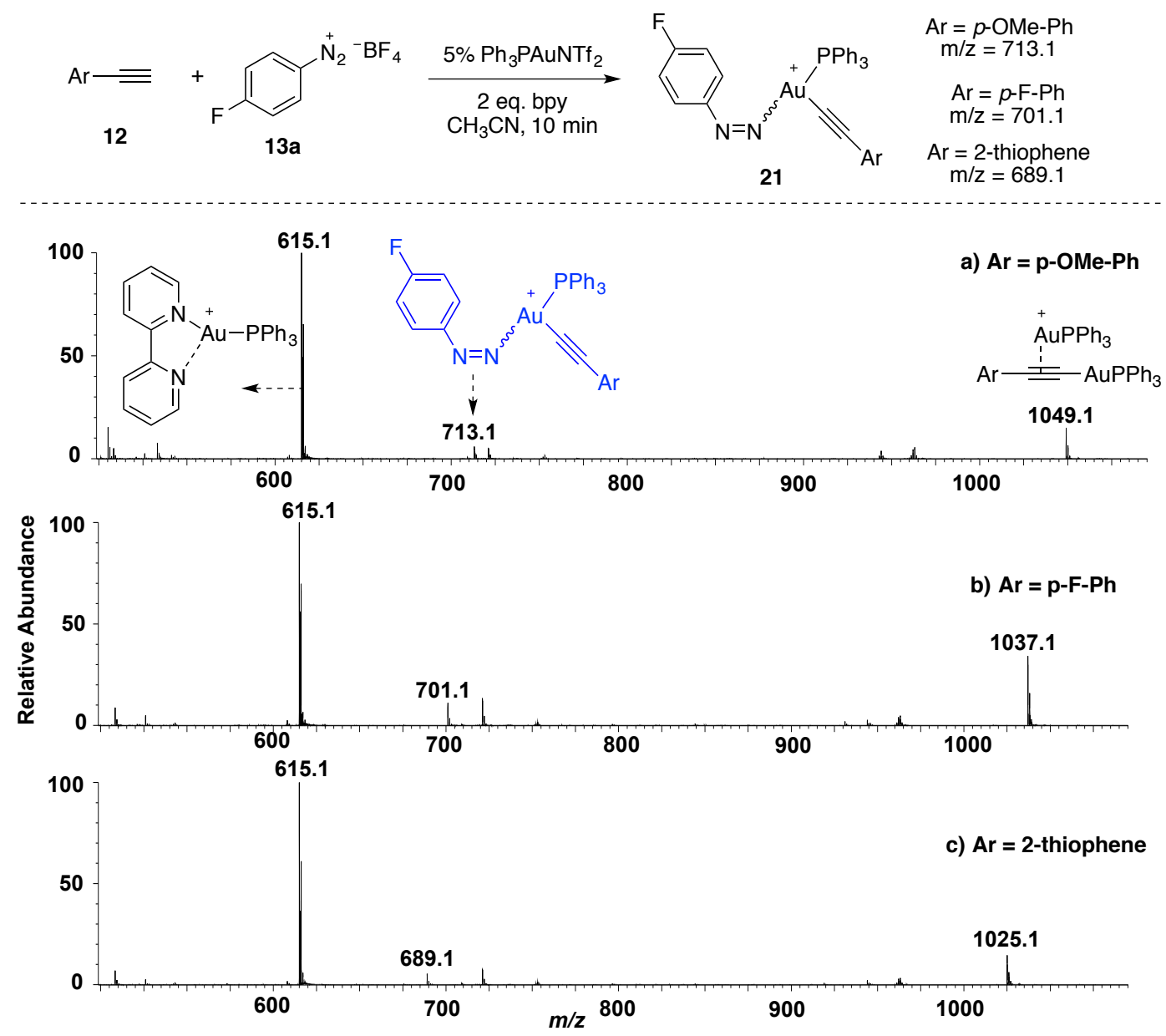
To further shed light on the reaction mechanism, we utilized the electrospray ionization mass spectrometry (ESI-MS) studies to detect possible intermediates. ${ }^{62}$ As shown in Figure 14, aryldiazenido gold complexes 21 were observed at $m / z 713,701$ and 689 respectively for the three different alkynes. ${ }^{63}$ The intensities of $\mathbf{2 1}$ were quite low compared with other gold complexes $\left(\left[\mathrm{Ph}_{3} \mathrm{PAu}(\mathrm{bpy})\right]^{+}\right.$and $\sigma, \pi$-acetylide gold complex) in the reaction mixture. In fact, the intensity of $\mathbf{2 1}$ decreased as the reaction proceeded (almost not detectable after $2 \mathrm{~h}$ ), which suggested $\mathbf{2 1}$ as an active reaction intermediate. The MS/MS fragment analysis confirmed the composition of 21 (see details in the experimental section).

Figure 15. Explore the reaction intermediate with ESI-MS spectra
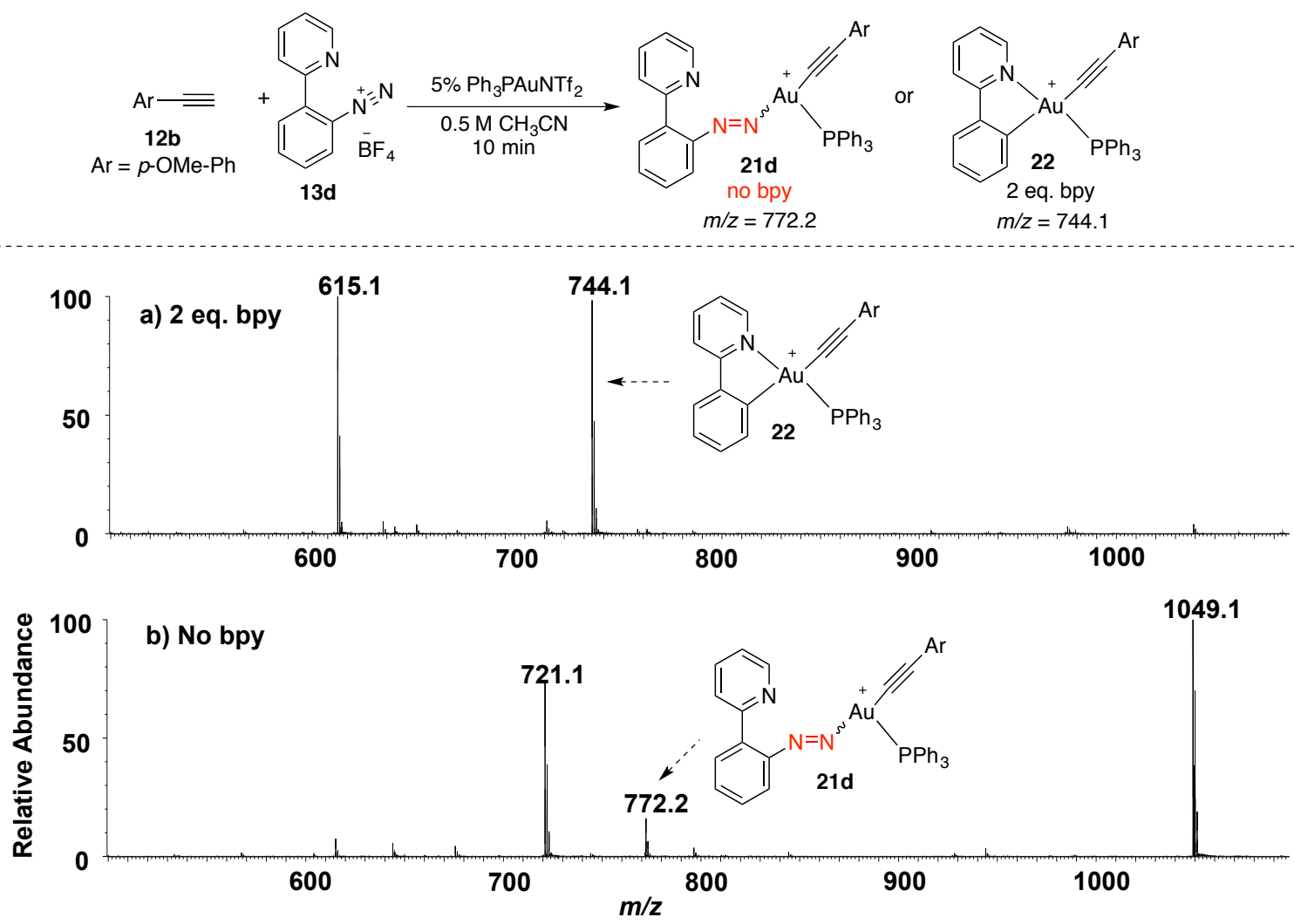

In order to trap plausible intermediates, compound 13d was prepared. Under the standard conditions, very low intensity of the coupling product 20c was detected with crude NMR and ESI-MS. Analyzing the reaction mixture with ESIMS after 10 min revealed the formation of a major ion with $\mathrm{m} / \mathrm{z} 744.1$. With the 
help from MS/MS fragment analysis, structure 22 was proposed as the gold(III) intermediate.

It was highly likely that the potential coordination from pyridyl group with gold restricted the reductive elimination of 22. However, without the presence of bpy, a dominant gold cation was detected with $\mathrm{m} / \mathrm{z}$ 772.2, which is tentatively assigned as the aryldiazenido gold complex 21d based on the MS/MS analysis. Although the exact reason is uncertain at this moment, the presence of bpy clearly assisted the nitrogen extrusion, which was a crucial step for the overall transformation.

Based on the above-discussed experimental results, a simplified mechanism was proposed as shown in Scheme 2. Both ${ }^{31} \mathrm{P}-\mathrm{NMR}$ and ESI-MS confirmed the formation of the more stable gold complex $\left[\mathrm{Ph}_{3} \mathrm{PAu}(\mathrm{bpy})\right]^{+}$by the addition of bpy. Based on current evidence, the diazonium oxidation occurred preferentially on either aryl gold or gold acetylide, forming intermediate A. The bpy-assisted nitrogen extrusion followed by rapid $\mathrm{Au}(\mathrm{III})$ reductive elimination gave the desired coupling product and regenerated the $\mathrm{Au}(\mathrm{I})$ catalyst. Certainly, it is interesting to uncover how L-Au-R reacts with the diazonium to form $\mathbf{A}$ and understand the exact function of bpy.

Scheme 24. Proposed mechanism of gold-catalyzed C-C cross-coupling

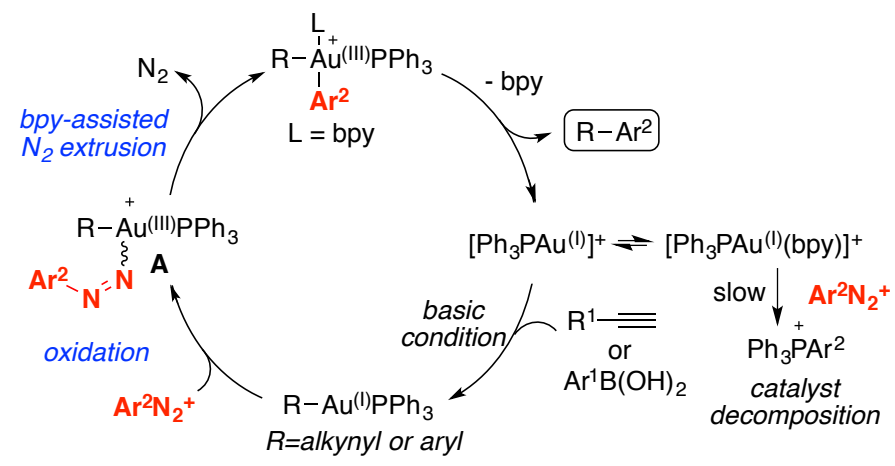




\section{7 Gold-catalyzed C-X formation with aryldiazonium}

Although redox gold catalysis has attracted much attention during recent years, most of the reported systems are focused on $\mathrm{C}-\mathrm{C}$ bond formation. There

are very few successful examples regarding $\mathrm{C}$-heteroatom $(\mathrm{C}-\mathrm{X})$ coupling ${ }^{64}$ One problem in gold-catalyzed $\mathrm{C}-\mathrm{X}$ bond formation is the fast $\mathrm{C}-\mathrm{C}$ homo-coupling (via transmetallation and reductive elimination) ${ }^{65}$ Thus, to achieve this challenging $\mathrm{C}-\mathrm{X}$ coupling, lowering the activation energy is crucial to avoid undesired homocoupling. To develop an effective system for $\mathrm{C}-\mathrm{X}$ formation under mild conditions, we investigated the diazonium-promoted gold oxidation conditions and applied that chemistry in catalytic Sandmeyer reactions toward C-Br, C-S and C-P bond syntheses.

\subsubsection{Catalytic Sandmeyer reaction}

Conversion of $\mathrm{ArN}_{2}{ }^{+}$to $\mathrm{ArBr}$ or $\mathrm{ArCl}$ is usually achieved using stoichiometric amount of $\mathrm{CuBr}$ or $\mathrm{CuCl}$ under standard Sandmeyer conditions. ${ }^{66}$ Successful examples of catalytic Sandmeyer reaction are rare. Initiated by our previous investigation on the reaction between gold and diazonium salts, $\mathrm{Ph}_{3} \mathrm{PAuNTf}_{2}$ and bpy were charged into the mixture of diazonium and $\mathrm{NaBr}$. To our delight, aryl bromide product was successfully obtained in $63 \%$ yield. Different from previous $\mathrm{C}-\mathrm{C}$ cross-coupling reactions, the bpy ligand did not help with the reaction performance in this case (Table 15, entry 6,7).

Through screening, the less reactive $\mathrm{Ph}_{3} \mathrm{PAuCl}$ catalyst is revealed to give the optimal result (entry 1 ). Without the gold catalyst, the only product observed is fluorobenzene formed from diazonium decomposition (Table 15, entry 2). Only trace amount of aryl chloride was detected by GC-MS when using $\mathrm{LiCl}$ as the nucleophile source (entry 3). This is consistence with the recent study reported by Toste and coworkers, in which the reductive elimination rate is suggested as I > $\mathrm{Br}>\mathrm{Cl}$ through the evaluation of different $\mathrm{Au}(\mathrm{III})-\mathrm{X}$ bond dissociation energies. ${ }^{67}$ Changing the solvent to acetone led to $100 \%$ conversion but with majorly homocoupling product, possibly generated from radical process (entry 4). Lowering gold loading to $3 \mathrm{~mol} \%$ gave a similar result $(80 \%)$. A further decrease of 
catalyst loading to $1 \mathrm{~mol} \%$ led to poor yield. To the best of our knowledge, this is the first example of catalytic Sandmeyer reaction using only the gold catalyst.

Table 15. Gold-catalyzed C-Br formation ${ }^{a, b}$

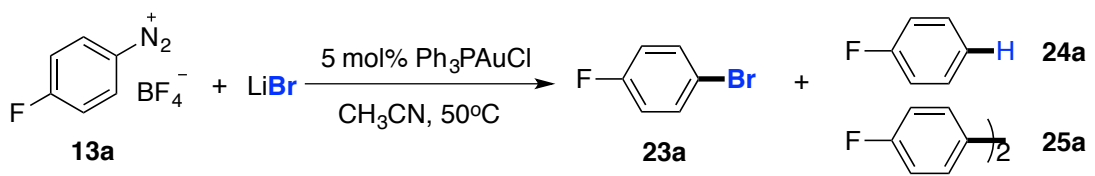

\begin{tabular}{|c|c|c|c|c|c|c|}
\hline \multirow{2}{*}{ Entry } & \multirow{2}{*}{ Variations from above conditions } & \multirow{2}{*}{ Time $(\mathrm{h})$} & \multirow{2}{*}{ Convn (\%) } & \multicolumn{3}{|c|}{ Yield (\%) } \\
\hline & & & & $23 a$ & $24 a$ & $25 a$ \\
\hline 1 & none & 5 & 100 & 81 & 7 & $<5$ \\
\hline 2 & without $\mathrm{Ph}_{3} \mathrm{PAuCl}$ & 12 & 50 & $<10$ & trace & 33 \\
\hline 3 & $\mathrm{LiCl}$ instead of $\mathrm{LiBr}$ & 12 & 70 & $<5$ & trace & 38 \\
\hline 4 & acetone instead of $\mathrm{ACN}$ & 12 & 100 & 11 & 37 & $<5$ \\
\hline 5 & $\mathrm{Ph}_{3} \mathrm{PAuNTf} f_{2}$ instead of $\mathrm{Ph}_{3} \mathrm{PAuCl}$ & 12 & 100 & 68 & 10 & 7 \\
\hline 6 & $\mathrm{Ph}_{3} \mathrm{PAuNTf} \mathrm{N}_{2}$ with $20 \mathrm{~mol} \%$ bpy & 5 & 100 & 63 & 8 & 15 \\
\hline 7 & with $3 \mathrm{~mol} \% \mathrm{Ph}_{3} \mathrm{PAuCl}$ & 12 & 100 & 80 & 7 & $<5$ \\
\hline
\end{tabular}

${ }^{a}$ Reaction conditions: $13 \mathrm{a}(0.1 \mathrm{mmol}), \mathrm{LiBr}(0.3 \mathrm{mmol})$, cat. $\mathrm{Au}(5 \mathrm{~mol} \%)$ in acetonitrile (ACN), 50 ${ }^{\circ} \mathrm{C} ;{ }^{b}{ }^{19} \mathrm{~F}$ NMR yield with benzotrifluoride as the internal standard.

With the optimal conditions in hand, the reaction substrate scope was explored. As shown in Table 16, excellent substrate compatibility was found with the gold-catalyzed conditions. Diazonium with EWGs and EDGs all furnished the products in good yields (23a-23g). Notably, aryl iodide is also compatible in this catalytic system (23e), highlighting the orthogonal reactivity of Au catalyst over $\mathrm{Pd}, \mathrm{Cu}$, and $\mathrm{Ni}$, for which oxidative addition could occur with aryl iodide. Carbonyl groups (23h, 23i, 23j), benzodioxo (23k), azobenzene (23q) are all well tolerated in this reaction. Hetero-aromatic diazonium salts, such as pyridines $(23 m, 23 n)$ and indole (23p) also worked well in this reaction. Moreover, this reaction proceeded with high efficiency and selectivity with $\alpha, \beta$-unsaturated ester (23s) and $p$-acetylide aryl diazonium (23r) to give the corresponding products. To further evaluate the synthetic utility and generality of this reaction, coumarin derivative (23I) and estrone derivative (23t) were tested under the reaction 
conditions. The desired products were achieved with good yields, highlighting the potential application of this catalytic system for complex molecular synthesis.

Table 16. Substrate scope for gold-catalyzed C-Br bond formation ${ }^{a}$

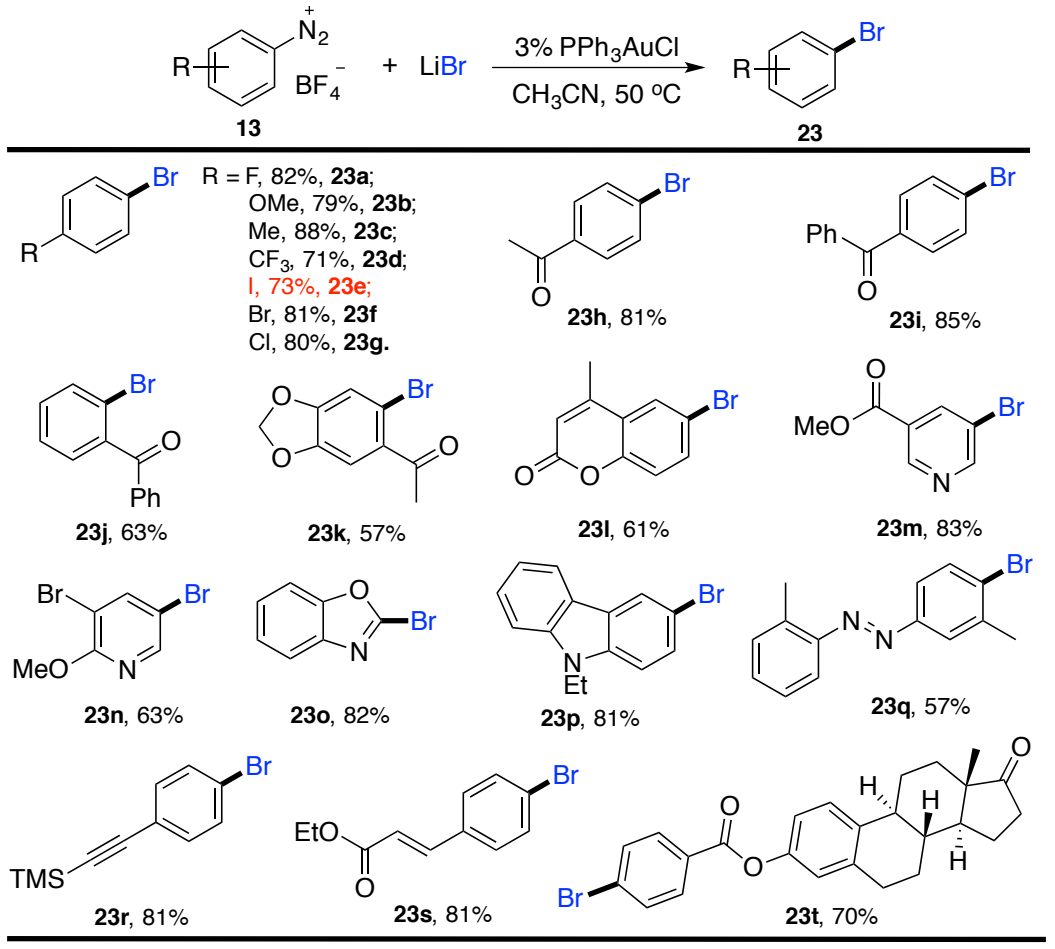

${ }^{a}$ Reaction conditions: 13 (0.2 mmol), $\mathrm{LiBr}(0.6 \mathrm{mmol}), \mathrm{PPh}_{3} \mathrm{AuCl}(3 \mathrm{~mol} \%)$ in acetonitrile (ACN), $50{ }^{\circ} \mathrm{C}, 5 \mathrm{~h} ;{ }^{b}$ Isolated yield; ${ }^{c}$ determined by ${ }^{19} \mathrm{~F}-\mathrm{NMR}$ with benzotrifluoride as the internal standard; ${ }^{d}$ determined by GC-Mass using decane as the internal standard.

\subsubsection{Gold-catalyzed C-S and C-P bond formation}

Encouraged by the success of gold-catalyzed $\mathrm{C}-\mathrm{Br}$ bond formation, we turned our attention to the synthesis of $\mathrm{C}-\mathrm{S}$ and $\mathrm{C}-\mathrm{P}$ bonds. Unlike $\mathrm{C}-\mathrm{Br}$ bond, which can be alternatively prepared using stoichiometric amount of $\mathrm{CuBr}$, thiols and phosphonates are not valid nucleophiles under Sandmeyer conditions due to the coordination of sulfur or phosphine with $\mathrm{Cu}$ cation, which could potentially quench catalyst reactivity.

Thiols are good nucleophiles and can react with arenediazonium through $\mathrm{S}_{N} \mathrm{Ar}$ mechanism with the assistance of a base, especially for acidic thiophenols. ${ }^{68}$ However, one side reaction of diazonium decomposition is the 
formation of $\mathrm{Ar}-\mathrm{H}$. This side reaction turned to be even more severe when using proton-containing nucleophiles $(\mathrm{NuH})$. Therefore, reaction of cysteine derivative 26a with diazonium 13a gave only Ar-H 24a (23\%) as the product (Table 17, entry 1). Addition of base could produce thioether 27 a in $37 \%$ yield, along with $55 \%$ of $24 \mathrm{a}$ (entry 2 ). Using stoichiometric $\mathrm{Cu}(\mathrm{OAc})_{2}$ did not improve the reaction performance $(31 \%$, entry 3$)$.

Interestingly, with $\mathrm{PPh}_{3} \mathrm{AuCl}$ as the catalyst, the desired thiolether $27 \mathrm{a}$ was obtained even without base ( $49 \%$ yield). These results suggested that with the help of thiol nucleophile, $\mathrm{PPh}_{3} \mathrm{AuCl}$ could be an effective catalyst for diazonium decomposition. With the aid from base, this challenging C-S coupling was achieved in $86 \%$ yield with only $3 \mathrm{~mol} \%$ gold catalyst loading. Based on the reaction kinetics, the C-S bond formation was dramatically improved with gold catalyst. Without catalyst, C-S coupling prodcut 7 a has nearly same kinetics with byproduct $4 a$; with the gold catalyst, the formation of $7 \mathbf{a}$ is accelerated while less than $10 \%$ a was formed.

Table 17. Gold-catalyzed C-S bond formation ${ }^{a, b}$

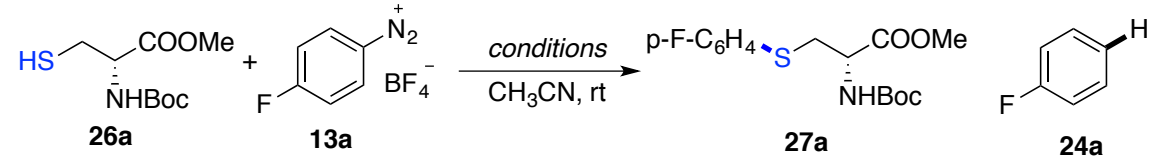

\begin{tabular}{ccccccc}
\hline \multirow{2}{*}{ Entry } & Catalyst (mol\%) & Base (eq.) & Time $(\mathrm{h})$ & Conv. $(\%)$ & \multicolumn{2}{c}{ Yield (\%) } \\
\hline 1 & $\mathrm{None}$ & $\mathrm{None}$ & 24 & 30 & $\mathbf{2 4 a}$ \\
\hline 2 & $\mathrm{None}$ & $\mathrm{Na}_{2} \mathrm{CO}_{3}(2)$ & 10 & 100 & 37 & 55 \\
3 & $\mathrm{Cu}(\mathrm{OAc})_{2}(100)$ & $\mathrm{Na}_{2} \mathrm{CO}_{3}(2)$ & 10 & 100 & 31 & 65 \\
4 & $\mathrm{PPh}_{3} \mathrm{AuCl}(5)$ & $\mathrm{None}$ & 10 & 55 & 49 & 38 \\
5 & $\mathrm{PPh}_{3} \mathrm{AuCl}(5)$ & $\mathrm{Na}_{2} \mathrm{CO}_{3}(2)$ & 3 & 100 & 87 & 8 \\
6 & $\mathrm{PPh}_{3} \mathrm{AuCl}(3)$ & $\mathrm{Na}_{2} \mathrm{CO}_{3}(2)$ & $\mathbf{3}$ & 100 & $\mathbf{8 6}$ & $\mathbf{7}$ \\
7 & $\mathrm{PPh}_{3} \mathrm{AuCl}(1)$ & $\mathrm{Na}_{2} \mathrm{CO}_{3}(2)$ & 7 & 100 & 53 & 30 \\
\hline
\end{tabular}

${ }^{a}$ Reaction conditions: $13 \mathrm{a}(0.2 \mathrm{mmol}), 26 \mathrm{a}(0.1 \mathrm{mmol})$, cat. $\mathrm{Au}(5 \mathrm{~mol} \%)$ and $\mathrm{Na}_{2} \mathrm{CO}_{3}(0.2 \mathrm{mmol})$ in acetonitrile (ACN), $50{ }^{\circ} \mathrm{C} ;{ }^{b 19} \mathrm{~F}$ NMR yield with benzotrifluoride as internal standard. 
With the optimal conditions, various cysteine derivatives were successfully prepared in good yields (Table 18). Both electron-rich and electron-deficient diazonium salts were suitable for this transformation with excellent yields. Diazonium with iodide substituent is also tolerated in this reaction (27e), which could be a potential synthetic handle for further functionalization. Heterocycles, including various substituted pyridines (27j-27I) and benzothiazole $(27 \mathrm{~m})$, gave the desired products efficiently with this catalytic system. Acetylide (27n) and $\alpha$, $\beta$-unsaturated ester (270) also reacted with good yields. Notably, sulfur containing molecules, as an important class of compounds for both chemical and biological research, are challenging to construct through traditional crosscoupling strategies because of the potential coordination between sulfur and transition metal catalysts. ${ }^{69}$ Our catalytic system thus provided an efficient and easy way to achieve these bioactive amino acids.

Table 18. Substrate scope for gold-catalyzed C-S bond formation ${ }^{a}$

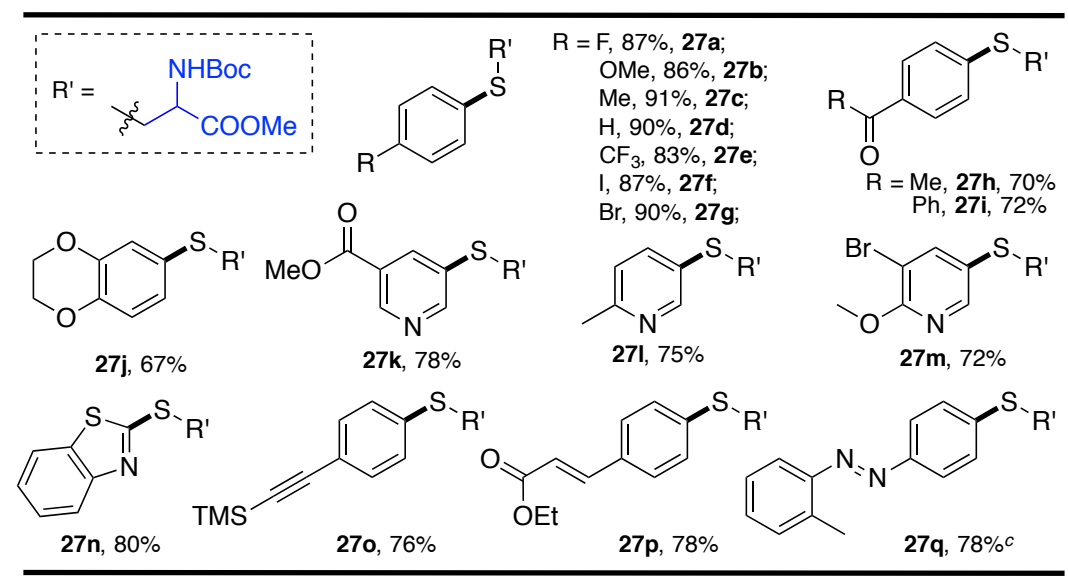

${ }^{a}$ Reaction conditions, C-S formation: $13(0.4 \mathrm{mmol}), 26(0.2 \mathrm{mmol}), \mathrm{PPh}_{3} \mathrm{AuCl}(3 \mathrm{~mol} \%)$ and $\mathrm{Na}_{2} \mathrm{CO}_{3}(0.4 \mathrm{mmol})$ in acetonitrile (ACN), rt, $3 \mathrm{~h} ;{ }^{b}$ isolated yield; ${ }^{c}$ determined by ${ }^{1} \mathrm{H}-\mathrm{NMR}$ using 1,3,5-trimethoxybenzene as the internal standard with $E / Z$ selectivity $1: 1$.

Another application using this methodology is the preparation of arylphosphonate. Compared with sulfur, this C-P bond formation is more

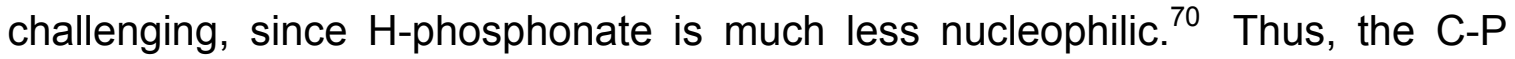
bond formation with diazonium cannot be achieved through either $\mathrm{S}_{\mathrm{N}} \mathrm{Ar}$ or $\mathrm{Cu}$ - 
promoted Sandmeyer reactions. Recently, Toste reported the application of photocatalyst in gold-catalyzed oxidative coupling to achieve this C-P bond formation. ${ }^{71}$ Based on the results discussed above, we were wondering whether this challenging C-P bond formation could be achieve with our newly discovered nucleophile-promoted gold redox catalysis under mild conditions.

As shown in Table 19, no arylphosphonate (28a) was obtained with copper acetate or without a catalyst (entry 1-3). In contrast, the product 28a could be achieved with $5 \% \mathrm{PPh}_{3} \mathrm{AuCl}$ (entry 4), although with low yield (25\%) due to the poor nucleophilicity of phosphonate. Addition of $\mathrm{Na}_{2} \mathrm{CO}_{3}$ did not improve the yield of the coupling but promoted the $\mathrm{Ar}-\mathrm{H}$ formation. The combination of $\mathrm{PPh}_{3} \mathrm{AuNTf}_{2}$ and bpy in the presence of $\mathrm{Na}_{2} \mathrm{CO}_{3}$ (previously reported $\mathrm{C}-\mathrm{C}$ bond cross-coupling conditions) also failed to increase the yield. Considering that nucleophilic ligand is crucial in this gold redox catalysis, we focused our attention of additives to other pyridine derivatives. Through screening, 3-Cl-pyridine was identified to give the optimal result. With the addition of 2 eq. 3-Cl-pyridine, $\mathrm{PPh}_{3} \mathrm{AuCl}$ could effectively catalyze this C-P bond coupling, giving the desired product 28a with $83 \%$ isolated yield in $5 \mathrm{~h}$. In contrast, with $\mathrm{PPh}_{3} \mathrm{AuNTf}_{2}$, the major product was the diaza compound $29 a{ }^{72}$

Table 19. Gold-catalyzed C-P bond formation ${ }^{a, b}$

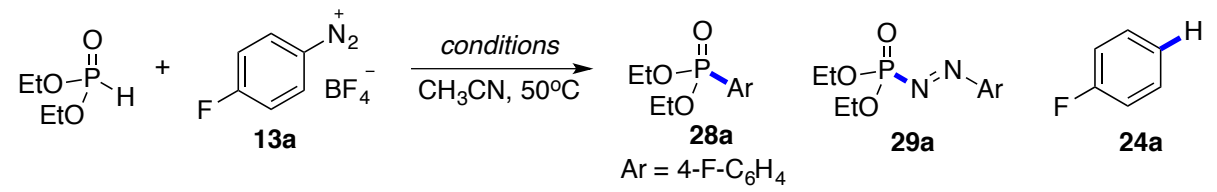

\begin{tabular}{|c|c|c|c|c|c|c|c|}
\hline \multirow{2}{*}{ Entry } & \multirow{2}{*}{ Catalyst (mol\%) } & \multirow{2}{*}{ Additives (eq.) } & \multirow{2}{*}{ Time $(h)$} & \multirow{2}{*}{ Conv. (\%) } & \multicolumn{3}{|c|}{ Yield (\%) } \\
\hline & & & & & $28 a$ & $29 a$ & $24 a$ \\
\hline 1 & None & None & 10 & 50 & 0 & 0 & 31 \\
\hline 2 & None & $\mathrm{Na}_{2} \mathrm{CO}_{3}(2)$ & 10 & 100 & 0 & 0 & 70 \\
\hline 3 & $\mathrm{Cu}(\mathrm{OAc})_{2}(100)$ & $\mathrm{Na}_{2} \mathrm{CO}_{3}(2)$ & 10 & 100 & 0 & 0 & 75 \\
\hline 4 & $\mathrm{PPh}_{3} \mathrm{AuCl}(5)$ & None & 10 & 50 & 25 & 0 & 13 \\
\hline 5 & $\mathrm{PPh}_{3} \mathrm{AuCl}(5)$ & $\mathrm{Na}_{2} \mathrm{CO}_{3}(2)$ & 10 & 100 & 11 & 0 & 38 \\
\hline 6 & $\mathrm{PPh}_{3} \mathrm{AuNTf}_{2}(5)$ & bpy (0.2), $\mathrm{Na}_{2} \mathrm{CO}_{3}(2)$ & 10 & 100 & $<5$ & 11 & 53 \\
\hline 7 & $\mathrm{PPh}_{3} \mathrm{AuCl}(5)^{c}$ & 3-Cl-py (2) & 5 & 100 & 83 & 0 & 7 \\
\hline
\end{tabular}




\begin{tabular}{llllllll}
8 & $\mathrm{PPh}_{3} \mathrm{AuNTf}_{2}(5)$ & $3-\mathrm{Cl}-\mathrm{py}(2)$ & 5 & 100 & 0 & 71 & 22 \\
\hline
\end{tabular}

${ }^{a}$ Reaction conditions: 13a $(0.2 \mathrm{mmol}), \mathrm{HP}(\mathrm{O})(\mathrm{OEt})_{2}(0.1 \mathrm{mmol})$, cat. $[\mathrm{Au}](5 \mathrm{~mol} \%)$ and base $(0.2$ $\mathrm{mmol}$ ) in acetonitrile (ACN), $50{ }^{\circ} \mathrm{C} ;{ }^{b}{ }^{19} \mathrm{~F}-\mathrm{NMR}$ yield with benzotrifluoride as the internal standard; ${ }^{c} \mathrm{ACN}: \mathrm{EtOH}=6: 1$ as the solvent.

Similar to the $\mathrm{C}-\mathrm{Br}$ and $\mathrm{C}-\mathrm{S}$ bond coupling, broad substrate scope is obtained in the C-P bond formation reactions (Table 20). Aryl phosphonates with electron-rich (28b, 28c) and electron-deficient (28a, 28d-28h) substituents could be generated with good yields. Halogen-substituted groups (28a, 28e, 28f) were all tolerated. Alkyne (28i), $\alpha, \beta$-unsaturated ester (28j) and azobenzene (28k) also gave good results, suggesting potential synthetic application of this methodology.

Table 20. Substrate scope for gold-catalyzed C-P bond formation ${ }^{a}$

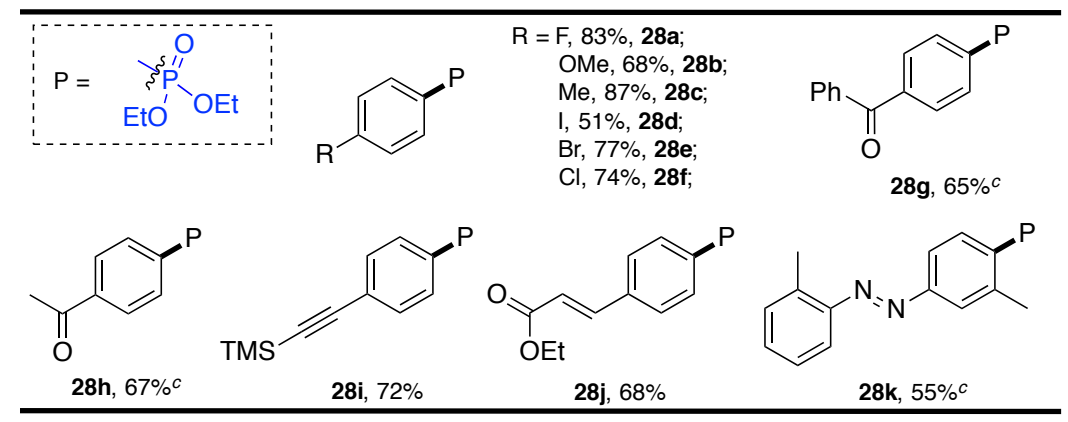

${ }^{a}$ Reaction conditions: 1 (0.4mmol), $\mathrm{HP}(\mathrm{O})(\mathrm{OEt})_{2}(0.2 \mathrm{mmol}), \mathrm{PPh}_{3} \mathrm{AuCl}(5 \%)$ and 3-Cl-Py $(0.4$ $\mathrm{mmol}$ ) in acetonitrile (ACN), $50{ }^{\circ} \mathrm{C}, 5 \mathrm{~h} ;{ }^{b}$ isolated yield; ${ }^{c}$ determined by ${ }^{1} \mathrm{H}-\mathrm{NMR}$ using $1,3,5-$ trimethoxybenzene as the internal standard.

\section{8 Conclusion}

In summary, we discovered a novel gold-catalyzed cross-coupling strategy using aryldiazonium salts as the oxidant. By forming an alkynyl or aryl gold complex in situ, oxidation of $A u(I)$ to $A u(I I I)$ was achieved without strong oxidants or photocatalysts. Preliminary studies revealed the importance of the bpy ligand in assisting nitrogen extrusion, which appeared to be a key step in this 
transformation. This strategy offers a new effective cross-coupling approach together with insight about gold redox catalysis.

The reaction between gold and diazonium is further applied to C-Br, C-S, and C-P bond formation reactions through gold redox catalysis. Other than the previously reported bpy ligand, nucleophiles played a crucial role in the goldpromoted diazonium decomposition. Various C-X coupling could be achieved with excellent yields and broad substrate scope simply using $\mathrm{Ph}_{3} \mathrm{PAuCl}$ as the catalyst (no need for external oxidant).

\section{9 Contribution}

For the C-C cross-coupling reaction (sections 3.1 to 3.6), Rong Cai discovered and investigated this redox gold catalysis. Mei Lu and Prof. Hao Chen helped with the ESI-MS studies. Ellen Y. Aguilera helped with substrate preparation. Yumeng Xi helped with manuscript preparation. Dr. Novruz G. Akhmedov provided help with 2D-NMR studies. Dr. Jeffrey L. Petersen carried out the X-ray crystallographic analyses.

For the C-X coupling (section 3.7), Dr. Haihui Peng discovered the developed these reactions. Rong Cai helped with substrate preparation and mechanistic investigations.

The C-C cross-coupling is published on Angew. Chem. Int. Ed. 2015, 54, 8772-8776. The manuscript for C-X coupling is in preparation.

\section{References:}

38 For reviews of $\mathrm{Au}(\mathrm{I})$ catalysis, see: a) Hashmi, A. S. K.; Schwarz, L.; Choi, J. H.; Frost, T. M. Angew. Chem. Int. Ed. 2000, 39, 2285; b) Hashmi, A. S. K. Chem. Rev. 2007, 107, 3180; c) Fürstner, A.; Davies, P.W. Angew. Chem. Int. Ed. 2007, 46, 3410; d) Arcadi, A. Chem. Rev. 2008, 108, 3266; e) Li, A.; Brouwer, C.; He, C. Chem. Rev. 2008, 108, 3239; g) Gorin, D. J.; Sherry, B. D.; Toste, F. D. Chem. Rev. 2008, 108, 3351.; h) Widenhoefer, R. A. Chem. Eur. J. 2008, 14, 5382; i) Sengupta, S.; Shi, 
X. Chemcatchem 2010, 2, 609; j) Nolan, S. P. Acc. Chem. Res. 2011, 44, 91; k) Wang, Y.-M.; Lackner, A. D.; Toste, F. D. Acc. Chem. Res. 2014, 47, 889; I) Zhang, L. Acc. Chem. Res. 2014, 47, 877; m) Dorel, R.; Echavarren, A. M. Chem. Rev. 2015, 115, 9028.

$39 \mathrm{E}^{0}\left(\mathrm{Au}^{\prime} / \mathrm{Au}^{\prime \prime \prime}\right)=+1.40$ V. See: D. R. Lide, ed., CRC Handbook of Chemistry and Physics, Internet Version 2005, CRC Press: Boca Raton, FL, 2005, pp. 8-24.

40 For reviews of redox gold catalysis, see: a) Garcia, P.; Malacria, M.; Aubert, C.; Gandon, V.; Fensterbank, L. Chemcatchem 2010, 2, 493; b) Wegner, H. A.; Auzias, M. Angew. Chem. Int. Ed. 2011, 50, 8236. For selected examples, see: c) Zhang, G.; Cui, L.; Wang, Y.; Zhang, L. J. Am. Chem. Soc. 2010, 132, 1474; d) Melhado, A. D.; Brenzovich, W. E.; Lackner, A. D.; Toste, F. D. J. Am. Chem. Soc. 2010, 132, 8885; e) Haro, T. d.; Haro, T. d.; Nevado, C.; Nevado, C. J. Am. Chem. Soc. 2010, 132, 1512; f) Zhang, G.; Luo, Y.; Wang, Y.; Zhang, L. Angew. Chem. Int. Ed. 2011, 50, 4450; g) Qian, D.; Zhang, J. Beilstein J. Org. Chem. 2011, 7, 808; h) LeyvaPérez, A.; Doménech, A.; Al-Resayes, S. I.; Corma, A. ACS Catalysis 2012, 2, 121; i) Levin, M. D.; Toste, F. D. Angew. Chem. Int. Ed. 2014, 53, 6211; j) Wu, Q.; Du, C.; Huang, Y.; Liu, X.; Long, Z.; Song, F.; You, J. Chem. Sci. 2015, 6, 288; m) Wu, C.Y.; Horibe, T.; Jacobsen, C. B.; Toste, F. D. Nature 2015, 517, 449; n) Joost, M.; Estévez, L.; Miqueu, K.; Amgoune, A.; Bourissou, D. Angew. Chem. Int. Ed. 2015, 54, 5236.

41 Zhang, G.; Peng, Y.; Cui, L.; Zhang, L. Angew. Chem. Int. Ed. 2009, 48, 3112.

42 a) Ball, L. T.; Lloyd-Jones, G. C.; Russell, C. A. Science 2012, 337, 1644; b) Ball, L. T.; Lloyd-Jones, G. C.; Russell, C. A. J. Am. Chem. Soc. 2014, 136, 254.

43 a) Sahoo, B.; Hopkinson, M. N.; Glorius, F. J. Am. Chem. Soc. 2013, 135, 5505; b) Shu, X.-Z.; Zhang, M.; He, Y.; Frei, H.; Toste, F. D. J. Am. Chem. Soc. 2014, 136, 5844.

44 Joost, M.; Amgoune, A.; Bourissou, D. Angew. Chem. Int. Ed. 2015, 54, 15022.

45 a) Tamaki, A.; Kochi, J. K. J. Organomet. Chem. 1972, 40, C81; b) Shiotani, A.; Schmidba.H J. Organomet. Chem. 1972, 37, C24; c) Johnson, A.; Puddephatt, R. J. J. Organomet. Chem. 1975, 85, 115.

46 Winston, M. S.; Wolf, W. J.; Toste, F. D. J. Am. Chem. Soc. 2014, 136, 7777.

47 Guenther, J.; Mallet-Ladeira, S.; Estevez, L.; Miqueu, K.; Amgoune, A.; Bourissou, D. J. Am. Chem. Soc. 2014, 136, 1778. 
48 Joost, M.; Zeineddine, A.; Estevez, L.; Mallet-Ladeira, S.; Miqueu, K.; Amgoune, A.; Bourissou, D. J. Am. Chem. Soc. 2014, 136, 14654.

49 a) Tamaki, A.; Magennis, S. A.; Kochi, J. K. J. Am. Chem. Soc. 1974, 96, 6140; b) Komiya, S.; Albright, T. A.; Hoffmann, R.; Kochi, J. K. J. Am. Chem. Soc. 1976, 98, 7255; c) Komiya, S.; Kochi, J. K. J. Am. Chem. Soc. 1976, 98, 7599.

50 Komiya, S.; Shibue, A. Organometallics 1985, 4, 684.

51 Wolf, W. J.; Winston, M. S.; Toste, F. D. Nature 2013, 6, 159.

52 a) Winston, M. S.; Wolf, W. J.; Toste, F. D. J. Am. Chem. Soc. 2015, 137, 7921; b) Kawai, H.; Wolf, W. J.; DiPasquale, A. G.; Winston, M. S.; Toste, F. D. J. Am. Chem. Soc. 2016, 138, 587.

53 Peng, H.; Xi, Y.; Ronaghi, N.; Dong, B.; Akhmedov, N. G.; Shi, X. J. Am. Chem. Soc. 2014, 136, 13174.

54 For reviews on diazonium salts in cross coupling, see: a) Roglans, A.; Pla-Quintana, A.; Moreno-Mañas, M. Chem. Rev. 2006, 106, 4622; b) Mo, F.; Dong, G.; Zhang, Y.; Wang, J. Org. Biomol. Chem. 2013, 11, 1582.

55 a) Lauterbach, T.; Livendahl, M.; Rosellón, A.; Espinet, P.; Echavarren, A. M. Org. Lett. 2010, 12, 3006; b) Corma, A.; Juárez, R.; Boronat, M.; Sánchez, F.; Iglesias, M.; García, H. Chem. Commun. 2011, 47, 1446.

56 There are two precedent examples regarding the cross-coupling of aryldiazonium salts and alkyne: a) Fabrizi, G.; Goggiamani, A.; Sferrazza, A.; Cacchi, S. Angew. Chem. Int. Ed. 2010, 49, 4067; b) Panda, B.; Sarkar, T. K. Chem. Commun. 2010, 46,3131 . In both cases, the reductive elimination occurred on the Pd center. To the best of our knowledge, there is no literature precedence regarding the diazonium salt cross-coupling purely catalyzed by gold.

57 The crystal structure of $\left[\mathrm{Ph}_{3} \mathrm{PAu}(\mathrm{bpy})\right]^{+}$has been reported previously: Clegg, W. Acta Crystallographica Section B 1976, 32, 2712. The bpy ligand possesses a pseudothree-coordination with gold. For the coordination of bpy with $\mathrm{Au}(\mathrm{III})$, see: Shaw, A. P.; Ghosh, M. K.; Törnroos, K. W.; Wragg, D. S.; Tilset, M.; Swang, O.; Heyn, R. H.; Jakobsen, S. Organometallics 2012, 31, 7093.

58 a) Brown, T. J.; Widenhoefer, R. A. Organometallics 2011, 30, 6003; b) Liu, L.-P.; Hammond, G. B. Chem. Soc. Rev. 2012, 41, 3129. 
59 a) Partyka, D. V.; Zeller, M.; Hunter, A. D.; Gray, T. G. Angew. Chem. Int. Ed. 2006, 45, 8188; b) Hashmi, A. S. K.; Ramamurthi, T. D.; Rominger, F. J. Organomet. Chem. 2009, 694, 592.

60 Duan, H.; Sengupta, S.; Petersen, J. L.; Akhmedov, N. G.; Shi, X. J. Am. Chem. Soc. 2009, 131, 12100.

61 Much lower yield was observed using $p$-iodide diazonium salts. This is likely caused by the potential oxidative addition of aryl iodide by gold(I): Guenther, J.; MalletLadeira, S.; Estevez, L.; Miqueu, K.; Amgoune, A.; Bourissou, D. J. Am. Chem. Soc. 2014, 136, 1778.

62 For reviews of ESI-MS in mechanistic studies, see: a) Santos, L. S. J. Braz. Chem. Soc. 2011, 22, 1827; b) Schröder, D. Acc. Chem. Res. 2012, 45, 1521; c) Ma, X.; Zhang, S.; Zhang, X. TrAC, Trends Anal. Chem. 2012, 35, 50.

63 Cationic aryldiazenido palladium complexes have been previously reported: Yamashita, R.; Kikukawa, K.; Wada, F.; Matsuda, T. J. Organomet. Chem. 1980, 201, 463.

64 For selected examples, see: a) Peng, Y.; Cui, L.; Zhang, G.; Zhang, L. J. Am. Chem. Soc. 2009, 131, 5062; b) Marchetti, L.; Kantak, A.; Davis, R.; DeBoef, B. Org. Lett. 2015, 17, 358.

65 The monitored quantitative rate constant for $s p^{2} \mathrm{C}-\mathrm{C}$ coupling is $(1.5 \pm 0.1) \times 10^{-4} \mathrm{~S}^{-1}$ $\left(\mathrm{k}_{\mathrm{obs}},-52{ }^{\circ} \mathrm{C}\right)$, see reference 51 ; the homo-coupling product was generated from transmetallation between $A u(I I)$ and $A u(I)$ intermediate followed by reductive elimination, see reference $40 \mathrm{f}$.

66 For reviews on diazonium salts in cross-couplings, see: a) Roglans, A.; Pla-Quintana, A.; Moreno-Mañas, M. Chem. Rev. 2006, 106, 4622; b) Mo, F.; Dong, G.; Zhang, Y.; Wang, J. Org. Biomol. Chem. 2013, 11, 1582. For recent selected examples using diazonium, see: a) Beletskaya, I. P.; Sigeev, A. S.; Peregudov, A. S.; Petrovskii, P. V. Synthesis, 2007, 16, 2534; b) Danoun, G.; Bayarmagnai, B.; Grünberg, M. F.; Gooßen, L. J. Angew. Chem. Int. Ed. 2013, 52, 7922; c) Dai, J.-J.; Fang, C.; Xiao, B.; Yi, J.; Xu, J.; Liu, Z.-J.; Lu, X.; Liu, L.; Fu, Y. J. Am. Chem. Soc. 2013, 135, 8436; d) Wang, X.; Xu, Y.; Mo, F.; Ji, G.; Qiu, D.; Feng, J.; Ye, Y.; Zhang, S.; Zhang, Y.; Wang, J. J. Am. Chem. Soc. 2013, 135, 10330; e) Matheis, C.; Wagner, V.; Goossen, L. J. Chem. Eur. J. 2016, 22, 79.

67 Winston, M. S.; Wolf, W. J.; Toste, F. D. J. Am. Chem. Soc. 2015, 137, 7921. 
68 Page, P. C. B.; Wilkes, R. D.; Reynolds, D. in Comprehensive Organic Functional Group Transformations, ed. A. R. Katritzky, O. Meth-Cohn and C. W. Rees, Elsevier, Oxford, 1995, vol. 2, ch. 2.03, p. 113; For selected recent examples, see: a) Barbero, M.; Degani, I.; Diulgheroff, N.; Dughera, S.; Fochi, R.; Migliaccio, M. J. Org. Chem. 2000, 65, 5600; b) Majek, M.; von Wangelin, A. J. Chem. Commun. 2013, 49, 5507.

69 Selected recent examples: (a) Johannesson, P.; Lindeberg, G.; Johansson, A.; Nikiforovich, G. V.; Gogoll, A.; Synnergren, B.; Le Grèves, M.; Nyberg, F.; Karlén, A.; Hallberg, A. J. Med. Chem. 2002, 45, 1767; (b) Llauger, L.; He, H.; Kim, J.; Aguirre, J.; Rosen, N.; Peters, U.; Davies, P.; Chiosis, G. J. Med. Chem. 2005, 48, 2892; (c) Gangjee, A.; Zeng, Y.; Talreja, T.; McGuire, J. J.; Kisliuk, R. L.; Queener, S. F. J. Med. Chem. 2007, 50, 3046.

70 For recent examples on C-P bond formation, see: (a) Deal, E. L.; Petit, C.; Montchamp, J.-L. Org. Lett. 2011, 13, 3270; b) Shen, C.; Yang, G.; Zhang, W. Org. Biomol. Chem. 2012, 10, 3500; c) Rummelt, S. M.; Ranocchiari, M.; van Bokhoven, J. A. Org. Lett. 2012, 14, 2188; d) Bloomfield, A. J.; Herzon, S. B. Org. Lett. 2012, 14, 4370; e) Xu, K.; Hu, H.; Yang, F.; Wu, Y. Eur. J. Org. Chem. 2013, 2013, 319; f) Berger, O.; Petit, C.; Deal, E. L.; Montchamp, J.-L. Adv. Synth. Catal. 2013, 355, 1361; g) Gao, Y.; Huang, Z.; Zhuang, R.; Xu, J.; Zhang, P.; Tang, G.; Zhao, Y. Org. Lett. 2013, 15, 4214; h) Xuan, J.; Zeng, T.-T.; Chen, J.-R.; Lu, L.-Q.; Xiao, W.-J. Chem. Eur. J. 2015, 21, 4962.

71 He, Y.; Wu, H.; Toste, F. D. Chem. Sci. 2015, 6, 1194.

72 In Palladium catalyzed C-P coupling with diazonium in the presence of Cul, 9a was also isolated as the major byproduct. See: Berrino, R.; Cacchi, S.; Fabrizi, G.; Goggiamani, A.; Stabile, P. Org. Biomol. Chem. 2010, 8, 4518. Under basic condition in aqueous solutions, 9 a could be isolated in $75 \%-80 \%$ crude yields. Lewis, E. S.; Nieh, E. C. The Journal of Organic Chemistry 1973, 38, 4402. 


\section{Chapter 4. Porous Polymer-Supported Heterogeneous Gold(I) Catalysis}

\subsection{Introduction}

As we discussed in the previous sections, homogeneous gold catalysis has experienced a big leap during the past decade. As a carbophilic Lewis acid, cationic gold $(\mathrm{I})$ catalyst facilitated various $\mathrm{C}-\mathrm{C}$ and $\mathrm{C}$-heteroatom bond formation through the activation of alkynes, allenes and alkenes under mild conditions. While being highly efficient, cationic gold $(\mathrm{I})$ complexes usually suffer from poor stability, especially at elevated temperatures or in the presence of the substrate. ${ }^{73}$ The high cost of gold catalysts also prevented their application in large-scale syntheses and industrial processes.

\subsubsection{Heterogeneous gold(I) catalysis}

The development of solid-phase chemistry has led to great advancements in the field of heterogeneous catalysis. ${ }^{74}$ Compared with expensive homogeneous transition-metal catalysts, solid-supported heterogeneous catalysts are much more economically appealing due to easy separation of product from support and effective catalyst recycling protocols (catalyst dependent). ${ }^{75}$ The easy separation and good recyclability could significantly reduce the cost of the overall process, as well as simplify the handling and purification. Despite decades of advancements in the field of solid-phase catalysis, immobilization of the transition metal catalysts to a solid-supported ligand can cause problems, such as: 1) low reactivity due to limited access to the active catalytic site; 2 ) undesired interaction between the solid support and the metal complex or the reaction substrate; 3 ) leaching of metal catalyst due to weak linkage between the metal and the solid support; 4) substrate induced catalyst deactivation. Considering these limitations, the key to designing heterogeneous transition-metal catalysts relies on the 
development and synthesis of suitable solid supports for transition metals and transition metal complexes.

Although solid-supported gold nanoparticles has been extensively investigated, there are only limited examples regarding heterogeneous gold(I) catalysis. $^{76}$ In 2011, a polystyrene-supported gold(I) catalyst was reported by $\mathrm{Yu}$ and co-workers using triazole-functionalized polystyrene resin as the ligand for $\mathrm{PPh}_{3} \mathrm{Au}^{+}{ }^{77}$ Although this catalyst showed good reactivity towards enyne cyclization, it suffered from gold leaching each cycle, possibly because of the dynamic coordination between $\mathrm{Au}$ and triazole ligand (Scheme 25A). Later, the same group developed another gold catalyst using a polystyrene-supported phosphine ligand (Scheme 25B). ${ }^{78}$ Compared with triazole, phosphine ligands coordinate stronger with gold. However, the activation of this gold catalyst required stoichiometric amount of silver salt as simple $\mathrm{R}_{3} \mathrm{PAuCl}$ is usually not active for alkyne activation. The $\mathrm{AgCl}$ generated in this process cannot be removed from the polymer gold catalyst and may influence the catalyst reactivity.

\section{Scheme 25. Literature precedence of solid-supported gold catalysts}
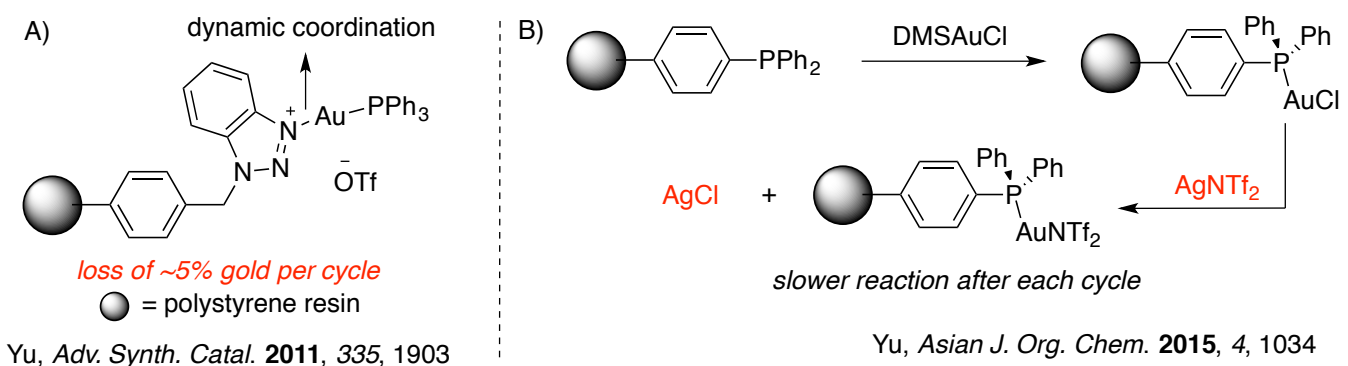

In 2015, the Toste group reported the synthesis of a heterogeneous gold catalyst by absorbing cationic gold onto mesoporous silica via hydrogen bonding. ${ }^{79}$ Because of the surface acidity of silica, the protodeauration of this catalyst is greatly accelerated. Using a chiral bisphosphine ligand, the regio- and enantioselectivity for lactonization of allenoic acid are significantly improved for the heterogeneous catalyst ( $81 \%$ ee) compared with the homogeneous analogue $(0 \%$ ee). At the same time, the mesoporous structure of the silica support also helped to enhance the enantioselectivity ( $50 \%$ ee for nonmesoporous silica). 


\subsubsection{Porous polymer for transition-metal catalysts}

Mesoporous supported materials are usually applied in heterogeneous catalysts because of their high surface area and easily accessible pores, which could help to enhance both the reactivity and selectivity of the catalysts. Among different mesoporous polymer ligands, porous organic polymers (POPs) exhibited excellent performance as the ligand supports for transition metal catalysts. ${ }^{80}$ Because of the stable covalent bond linkage, these POPs are very robust toward acidic/basic conditions and high temperature (normally higher than $300{ }^{\circ} \mathrm{C}$ ), which make them more feasible as ligands for heterogeneous catalysis compared to metal-organic frameworks (MOFs) or covalent-organic frameworks (COFs) (reversible linkage, sensitive to acid/base). ${ }^{81}$ Moreover, POP ligands possess hierarchical porosity that could enhance the catalytic reactivity and substrate diffusion, as well as lead to different reactivity compared with homogeneous catalysts. ${ }^{82}$ At the same time, the high surface area and good solvent swellability also benefit the overall performance of transition-metal catalysts using POP ligands. ${ }^{83}$

In 2014, a porous organic polymer ligand of $\mathrm{PPh}_{3}\left(\mathrm{POL}-\mathrm{PPh}_{3}\right)$ has been reported to facilitate hydroformylation of olefins using the corresponding $\mathrm{Rh}$ catalyst. $^{84}$ Excellent activity and selectivity are achieved with this heterogeneous catalyst and are further improved using POL-dppe ligand. ${ }^{85}$

Based on the broad application of phosphine ligands in gold catalysts, the $\mathrm{POL}-\mathrm{PPh}_{3}$ ligand could be a good starting point to investigate heterogeneous gold(I) catalysts.

\section{2 Porous polymer-supported triazole-gold catalyst}

\subsubsection{Improved stability of Pol-TA-Au}

As we mentioned in Scheme 25B, silver salt is usually involved in the activation of $\mathrm{R}_{3} \mathrm{PAuCl}$. During this activation protocol, a celite filtration is used to remove any insoluble Ag-salts leading to differential Au-catalyst reactivity. When considering the development of a polymer-supported Au-catalyst (presumably 
using a polymer based phosphine to bind to $\mathrm{L}-\mathrm{Au}-\mathrm{Cl}$ precursor), removing silver salts via celite filtration (following $\mathrm{R}_{3} \mathrm{PAuCl}$ activation) would be challenging due to the insolubility of many solid support catalysts in organic solvents and water. With that being said, we had set our eyes on developing a new heterogeneous catalyst synthesis that avoids the use of Ag-salts for chloride abstraction. This could be performed using a ligand exchange method whereby the generation of a more strongly binding X-type ligand could displace the chloride. Luckily, our group has developed syntheses toward the introduction of anionic triazole ligands to $\mathrm{Au}(\mathrm{I})$-complexes, followed by acidification to the corresponding L-type triazole ligand. This would also be especially efficacious due to our previous discovery of triazole-gold (TA-Au) complex as a thermally more stable and chemoselective cationic gold catalyst, which selectively activate alkynes over allenes. ${ }^{86}$ Intrigued by the unique reactivity and easy synthesis of TA-Au, we put our effort into the development an efficient synthesis of a heterogeneous triazolegold catalyst.

\section{Scheme 26. Synthesis of Pol-TA-Au}

A) Synthesis of POL-PPh

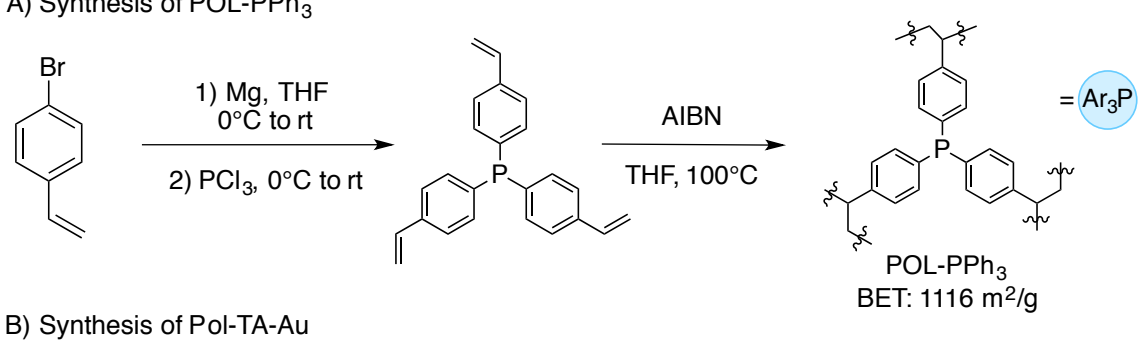

B) Synthesis of Pol-TA-Au

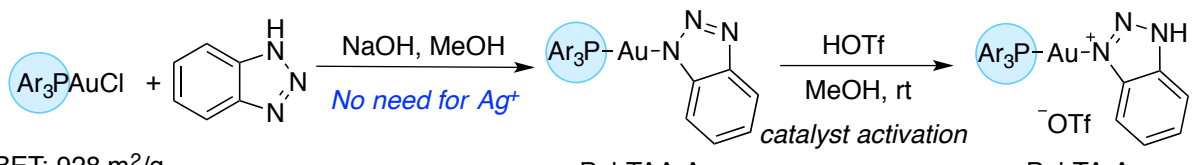

BET: $928 \mathrm{~m}^{2} / \mathrm{g}$

Pol-TAA-Au

Pol-TA-Au

As shown in Scheme 26, Pol-TA-Au was successfully prepared with high yields. The $\mathrm{POL}-\mathrm{PPh}_{3}$ could be easily synthesized from solvothermal polymerization of vinyl-functionalized $\mathrm{PPh}_{3}$. The corresponding $\mathrm{Ar}_{3} \mathrm{PAuCl}$ was obtained by reacting $\mathrm{POL}-\mathrm{PPh}_{3}$ with DMSAuCl. Using anionic triazole to exchange out the chloride ligand, a neutral gold complex Pol-TAA-Au could be generated. This complex is catalytically inactive due to the difficult ligand 
exchange required between the substrate and X-type triazole ligand. With the addition of an acid, this Pol-TAA-Au complex could be easily activated to the cationic Pol-TA-Au.

With this heterogeneous catalyst in hand, we explored the reactivity of it using Teles hydration as a model reaction. Under the same conditions, homogeneous TA-Au decomposed after $2 \mathrm{~h}$, generating the hydration product in $78 \%$ yield (Figure 16A). Although the reaction with Pol-TA-Au is initially slower than TA-Au, it could give a $95 \%$ yield because of the much better stability of the gold catalyst. By increasing the concentration of the starting material, the reaction is greatly accelerated and completed within $1 \mathrm{~h}$. The Pol-TAA-Au without acid activation is not able to catalyze this reaction. Treating the Pol-TAA-Au with a weaker acid (such as TFA) prior to the reaction could activate the catalyst but with a much slower reaction rate.

Figure 16. Teles hydration reaction with Pol-TA-Au

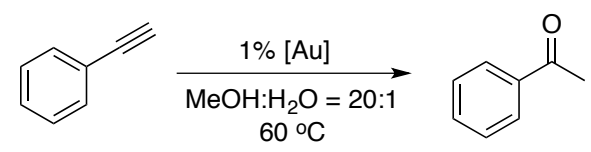

A) comparison between homo and heterogeneous catalyst

B) Recyclability test of the Pol-TA-Au catalyst
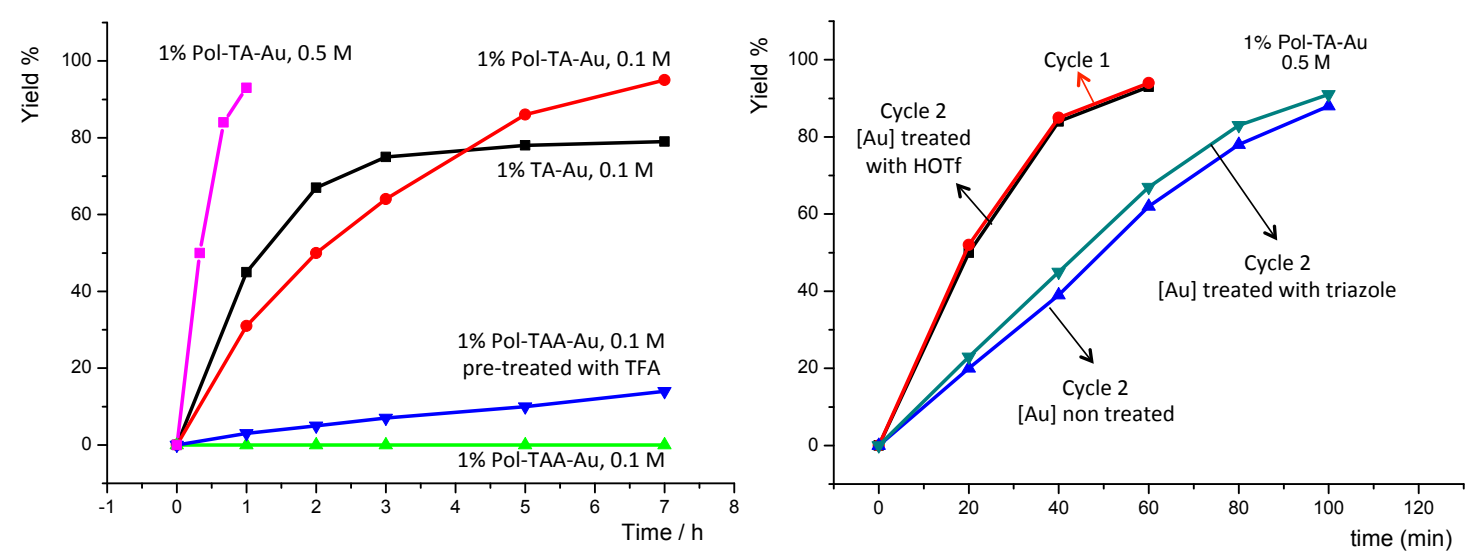

After separating the heterogeneous catalyst Pol-TA-Au from the reaction mixture by centrifuge and charging it into another portion of starting material, a slower reaction was observed (Figure 16B). We reasoned the decreased reactivity from either catalyst decomposition due to the loss of triazole ligand, or 
the difficulty in triazole ligand dissociation due to the loss of HOTf. With this hypothesis, we treated the catalyst with either triazole or triflic acid after first cycle of the hydration reaction. To our delight, the catalyst was re-activated by triflic acid, promoting the reaction in a same efficiency as the first cycle. The catalyst treated with triazole ligand did not show any improvement on the reactivity, suggesting that the triazole ligand had not leached from polymer catalyst. This Pol-TA-Au catalyst has been recovered and recycled for more than 5 times without any loss of reactivity by using triflic acid to reactivate the catalyst between each cycle.

\section{Scheme 27. Representative hydration reactions with Pol-TA-Au}
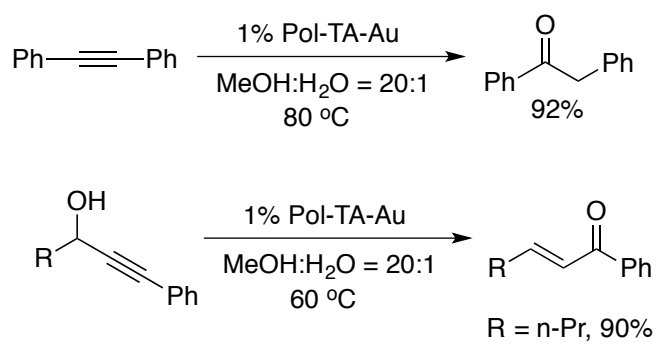
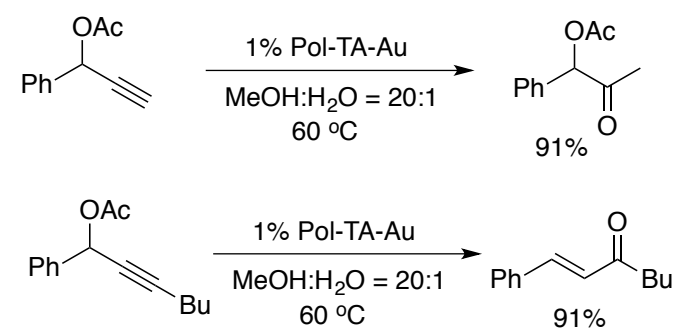

Hydration reactions of other alkynes were also tested with Pol-TA-Au catalyst. With the less reactive internal alkyne, excellent yield was achieved at a higher temperature (Scheme 27A). Monitoring the reaction revealed that methanol was a non-innocent solvent in this reaction, which formed the vinyl ether intermediate through nucleophilic addition to the alkyne and help to accelerate the hydration. ${ }^{87}$ Propargyl acetates also gave good yields (Scheme 27B). For the internal propargyl alcohol (Scheme 27C) and acetate (Scheme 27D), the corresponding enones were produced with excellent yields.

Scheme 28. Chemoselectivity of Pol-TA-Au
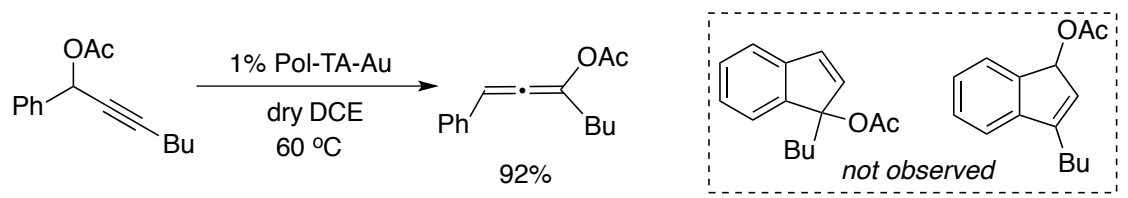
Other than increased thermal stability, this Pol-TA-Au catalyst also presented good chemoselectivity in the 3,3-rearrangment of propargyl esters (Scheme 28). ${ }^{88}$ Similar to the homogeneous TA-Au catalyst, only allene was observed as the product with the Pol-TA-Au catalyst in a dry solvent.

Despite the excellent reactivity for hydration reactions, this Pol-TA-Au catalyst showed much lower reactivity for other gold-catalyzed nucleophilic addition to alkyne with weaker nucleophiles such as sulfinic acid, and 1,3-diketone. It is worth noting that the homogeneous TA-Au analogue gave lower yields or even no desired product for these reactions.

\subsubsection{Combining Lewis acid with Pol-TA-Au}

Our group reported that the addition of a Lewis acid could increase the reactivity of TA-Au catalysts. By coordination with the Lewis acid, triazole ligand became easier to dissociate from cationic gold, making the gold catalyst more reactive for alkyne activation through the associative ligand exchange. With this strategy, several challenging reactions were achieved with different TA-Aucatalysts. To test whether the Lewis acid strategy is effective for Pol-TA-Au catalyst, hydroamination reaction of alkynes was investigated.

Scheme 29. Hydroamination of alkyne with Pol-TA-Au

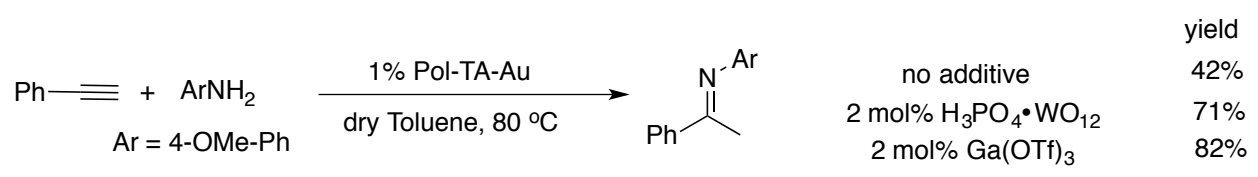

As shown in Scheme 29, the addition of either a Brønsted acid or a Lewis acid enhanced the catalyst's performance. With $2 \mathrm{~mol} \%$ Lewis acid $\mathrm{Ga}(\mathrm{OTf})_{3}$, the desired imine product was observed in $82 \%$ yield with only $1 \mathrm{~mol} \%$ gold catalyst loading. Other Lewis acids could also help to increase the reactivity of gold catalyst but gave lower yields.

Combining Lewis acids with gold catalysis, Nakamura reaction ${ }^{89}$ and vinyl sulfone formation ${ }^{90}$ have been developed by our group using either XPhosAu(TA)OTf or BrettPhosAu(TA)OTf as the catalyst precursor(Scheme 30). 
The steric hindered XPhos or BrettPhos ligands could help increase the stability of the catalytically active gold catalyst enabling the execution of several challenging reactions.

Scheme 30. Examples for Pol-TA-Au catalyzed challenging reactions

A)

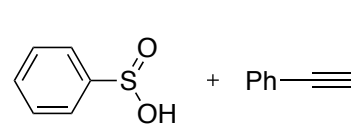

homogeneous gold

BrettPhosAu(TA)OTf

$\mathrm{Ph}_{3} \mathrm{PAu}(\mathrm{TA}) \mathrm{OTf}$

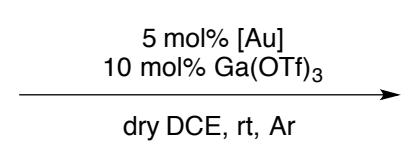

yield
$91 \%$
$0 \%$ dry DCE, rt, Ar

$$
\begin{array}{cc}
\text { heterogeneous gold } & \text { yield } \\
\text { Pol-Au(TA)OTf } & 72 \% \\
\text { PS-Ph } 2 \text { P-Au(TA)OTf } & 0 \% \\
\text { (PS = polystyrene resin) } &
\end{array}
$$
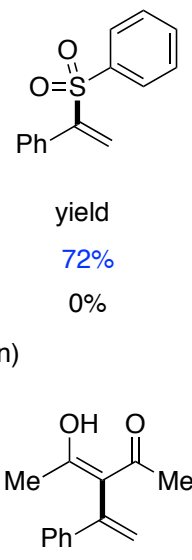

homogeneous gold

XPhosAu(TA)OTf $\mathrm{Ph}_{3} \mathrm{PAu}(\mathrm{TA}) \mathrm{OTf}$

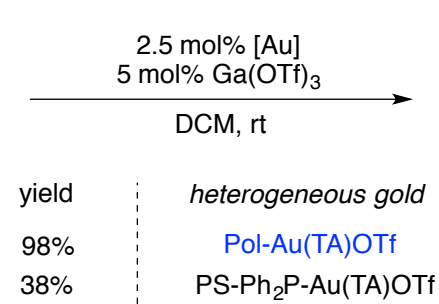

yield $92 \%$ $0 \%$
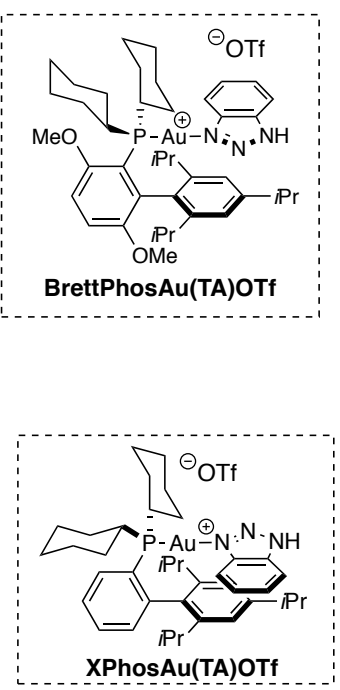

Additionally, the reactions outlined above (Scheme 30) were also successfully achieved with the heterogeneous Pol-TA-Au catalyst. As a comparison, the homogeneous $\mathrm{Ph}_{3} \mathrm{PAu}(\mathrm{TA}) \mathrm{OTf}$ does not catalyze the $\mathrm{C}-\mathrm{S}$ bond formation and gives a much lower yield for Nakamura reaction. Another heterogeneous catalyst prepared from polystyrene resin supported $\mathrm{PPh}_{3}$ failed to give the desired products.

Compared with expensive XPhos or BrettPhos ligands, the POL-PPh 3 ligand is much cheaper and easily accessible. Meanwhile, Pol-TA-Au could be efficiently recycled by centrifuge and applied to the next cycle without any loss of reactivity.

\section{3 Conclusion}

In summary, we synthesized and developed a heterogeneous triazole-gold catalyst using a porous polymer as the support. This Pol-TA-Au catalyst showed increased thermal stability and good chemoselectivity compared with the 
homogeneous TA-Au catalyst. More importantly, this heterogeneous catalyst was successfully applied to challenging transformations that were previously achieved with expensive phosphine ligands, which further highlighted the potential application of Pol-TA-Au in large-scale synthesis and flow reactions. At this time, further studies need to be performed to answer several important structural and functional aspects of this newly designed system.

\section{4 Contribution}

Rong Cai developed this heterogeneous gold catalyst and investigated its reactivity. Dr. Qi Sun helped with polymer preparation and preformed characterization of the polymers. Ying He helped with substrate preparation.

The manuscript of this project is in preparation.

\section{References:}

73 Kumar, M.; Jasinski, J.; Hammond, G. B.; Xu, B. Chem. Eur. J. 2014, 20, 3113.

74 Ma, Z.; Zaera, F. In Encyclopedia of Inorganic Chemistry; John Wiley \& Sons, Ltd: 2006.

75 Heitbaum, M.; Glorius, F.; Escher, I. Angew. Chem. Int. Ed. 2006, 45, 4732.

76 For recent review of supported gold catalysis, see: Liu, X.; He, L.; Liu, Y.-M.; Cao, Y. Acc. Chem. Res. 2014, 47, 793. Selected examples, see: a) Abad, A.; Corma, A.; García, H. Chem. Eur. J. 2007, 14, 212; b) Zhu, F.-X.; Wang, W.; Li, H.-X. J. Am. Chem. Soc. 2011, 133, 11632; c) Ren, D.; He, L.; Yu, L.; Ding, R.-S.; Liu, Y.-M.; Cao, Y.; He, H.-Y.; Fan, K.-N. J. Am. Chem. Soc. 2012, 134, 17592; d) Lee, L.-C.; Zhao, Y. ACS Catalysis 2014, 4, 688; e) Liang, S.; Jasinski, J.; Hammond, G. B.; Xu, B. Org. Lett. 2015, 17, 162.

77 Cao, W.; Yu, B. Adv. Synth. Catal. 2011, 353, 1903.

78 Zhu, Y.; Laval, S.; Tang, Y.; Lian, G.; Yu, B. Asian J. Org. Chem. 2015, 4, 1034.

79 Shu, X.-Z.; Nguyen, S. C.; He, Y.; Oba, F.; Zhang, Q.; Canlas, C.; Somorjai, G. A.;Alivisatos, A. P.; Toste, F. D. J. Am. Chem. Soc. 2015, 137, 7083.

80 Sun, Q.; Dai, Z.; Meng, X.; Xiao, F.-S. Chem. Soc. Rev. 2015, 44, 6018. 
81 a) Gao, W.-Y.; Chrzanowskik, M.; and Ma, S. Chem. Soc. Rev., 2014, 43, 5841; b) El-Kaderi, H. M.; Hunt, J. R.; Mendoza-Cortés, J. L.; Côté, A. P.; Taylor, R. E.; O'Keeffe, M.; Yaghi, O. M. Science 2007, 316, 268.

82 Su, B.-L. In Hierarchically Structured Porous Materials; Wiley-VCH Verlag GmbH \& Co. KGaA: 2011, p 577.

83 Sun, Q.; Dai, Z.; Meng, X.; Wang, L.; Xiao, F.-S. ACS Catalysis 2015, 5, 4556.

84 Sun, Q.; Jiang, M.; Shen, Z.; Jin, Y.; Pan, S.; Wang, L.; Meng, X.; Chen, W.; Ding, Y.; Li, J.; Xiao, F.-S. Chem. Commun. 2014, 50, 11844.

85 Sun, Q.; Dai, Z.; Liu, X.; Sheng, N.; Deng, F.; Meng, X.; Xiao, F.-S. J. Am. Chem. Soc. 2015, 137, 5204 .

86 a) Duan, H.; Sengupta, S.; Petersen, J. L.; Akhmedov, N. G.; Shi, X. J. Am. Chem. Soc. 2009, 131, 12100; b) Wang, D.; Gautam, L. N. S.; Bollinger, C.; Harris, A.; Li, M.; Shi, X. Org. Lett. 2011, 13, 2618.

87 Marion, N.; Ramón, R. S.; Nolan, S. P. J. Am. Chem. Soc. 2009, 131, 448.

88 Wang, D.; Zhang, Y.; Harris, A.; Gautam, L. N. S.; Chen, Y.; Shi, X. Adv. Synth. Catal. 2011, 353, 2584.

89 Xi, Y.; Wang, D.; Ye, X.; Akhmedov, N. G.; Petersen, J. L.; Shi, X. Org. Lett. 2013, 16, 306.

90 Xi, Y.; Dong, B.; McClain, E. J.; Wang, Q.; Gregg, T. L.; Akhmedov, N. G.; Petersen, J. L.; Shi, X. Angew. Chem. Int. Ed. 2014, 53, 4657. 


\section{Chapter 5. N-2-Aryl-1,2,3-Triazole as Ligands for Iridium Photocatalysts}

\subsection{Introduction}

\subsubsection{Visible light photoredox catalysis}

As early as the $19^{\text {th }}$ century, Dr. Ciamician proposed a pioneer idea about photochemistry. ${ }^{91}$ He envisioned the future of artificial photosynthesis as a green and renewable process in chemical industry, by which the solar energy could be converted to chemical energy. One challenge for the application of sunlight in photochemical reactions in organic synthesis is that most of the organic molecules have poor absorption of visible light. Usually, the high-energy ultraviolet light, which is not abundant in solar light, is required for organic synthesis using photochemistry. ${ }^{92}$ Although visible-light photochemistry is limited for organic molecules, many organometallic compounds have strong absorption in the visible light region, such as $\operatorname{Ru}(\mathrm{bpy})_{3}{ }^{2+}$ and $\left[\operatorname{Ir}(\mathrm{ppy})_{2}(\mathrm{bpy})\right]^{+}$. While being stable in the ground state, these complexes could be easily activated by visible light to the photoexcited state, which could provide electrochemical potential to facilitate redox reactions. ${ }^{93}$

Using $\mathrm{Ru}(\mathrm{bpy})_{3}{ }^{2+}$ as an example, upon irradiation with visible light, one electron from a metal $t_{2 g}$ orbital is excited to the $\pi^{*}$ orbital of the ligand through a metal to ligand charge transfer (MLCT) and rapid intersystem crossing (Scheme 31). ${ }^{94}$ The resulted triplet excited state has a relatively long lifetime because that the decay to the singlet ground state is spin-forbidden. This photoexcited state is both a much better oxidant and better reductant compared with the ground state based on the reduction potentials. For example, the reduction potential of the excited state $E_{1 / 2}{ }^{\|1 / *\|}=-0.81 \mathrm{~V}$ vs SCE, which suggested that the excited-state ${ }^{*} \mathrm{Ru}(\mathrm{bpy})_{3}{ }^{2+}$ is easier to be oxidized (tend to donate electrons) compared with the ground-state $\mathrm{Ru}(\mathrm{bpy})_{3}{ }^{2+}\left(\mathrm{E}_{1 / 2}{ }^{111 / 1 / 1}=+1.29 \mathrm{~V}\right.$ vs SCE$)$. Similarly, the reduction 
potential $E_{1 / 2}{ }^{* 11 / 1}=+0.77 \mathrm{~V}$, which suggested that ${ }^{*} \mathrm{Ru}(\mathrm{bpy})_{3}{ }^{2+}$ is easier to be reduced than $\mathrm{Ru}(\mathrm{bpy})_{3}{ }^{2+}\left(\mathrm{E}_{1 / 2}{ }^{11 / 1}=-1.33 \mathrm{~V}\right.$ vs SCE$)$. This could also be rationalized from the molecular orbital diagram. In the triplet excited state, the high-energy electron in the $\pi^{*}$ orbital is much easier to lose, while the low-energy vacant in the $t_{2 g}$ orbital is much easier to accept an eletron.

\section{Scheme 31. The photochemistry of $R u(b p y)_{3}{ }^{2+}$}

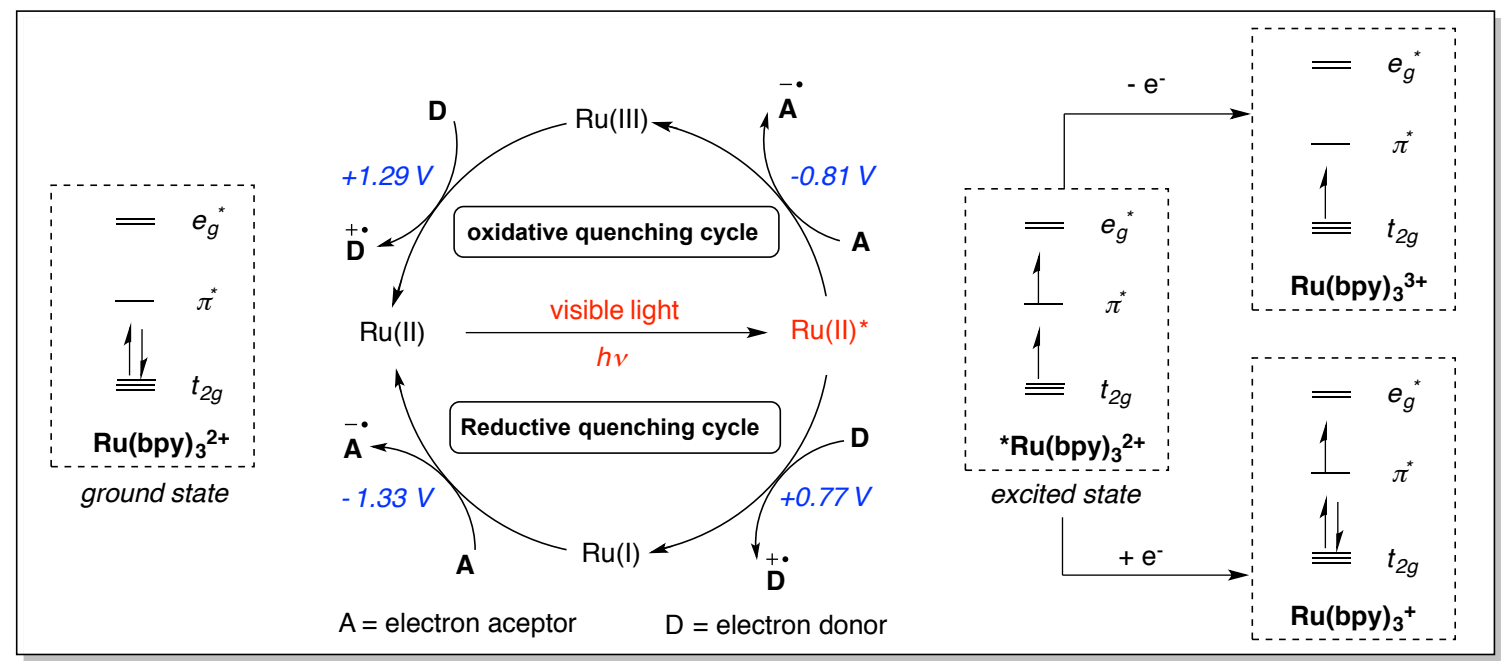

Based on the unique "dual" property of the photoexcited state, $\mathrm{Ru}(\mathrm{II})^{*}$ can undergo either an oxidative quenching by losing one electron to an electron acceptor, or an reductive quenching by accepting one eletron from an electron donor. The resulting $\mathrm{Ru}(\mathrm{III})$ from oxidative quenching serves as a strong oxidant $\left(E_{1 / 2}{ }^{I I / I I}=+1.29 \mathrm{~V}\right.$ vs SCE$)$, while $\mathrm{Ru}(\mathrm{II})$ from reductive quenching serves as a strong reductant $\left(E_{1 / 2}^{11 / 1}=-1.33 \vee\right.$ vs SCE).

The first application of photoredox catalysis in organic synthesis is a $\mathrm{Ru}(\mathrm{bpy})_{3} \mathrm{Cl}_{2}$ catalyzed Pschorr reaction reported in 1984 for the synthesis of phenanthrene from diazonium salt. ${ }^{95}$ Very few examples have been reported since then. It was not until the year 2008 that visible-light photoredox catalysis started to catch attention from chemists and be explosively explored.

In 2008, Yoon and coworkers reported a visible-light photocatalyzed [2+2] cycloaddition reaction using $\mathrm{Ru}(\mathrm{bpy})_{3} \mathrm{Cl}_{2}$ as the catalyst (Scheme $\left.32 \mathrm{~A}\right){ }^{96}$ This reaction proceeded through a reductive quenching mechanism by using DIPEA 
to reduce the photoexcited $\mathrm{Ru}(\mathrm{II})^{*}$. The resulting $\mathrm{Ru}(\mathrm{I})$ could reduce enone to a radical anion, which then induced the cyclization. The same group later developed an oxidative quenching condition for electron-rich substrates using methyl viologen as the oxidative quencher.

\section{Scheme 32. Selected example of photoredox catalysis}

A) [2+2] cycloaddition
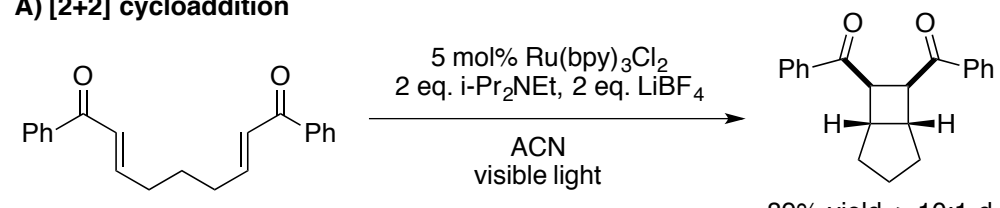

Yoon, 2008

$89 \%$ yield, > 10:1 d.r.

B) Enantioselective $\alpha$-alkylation of aldehydes
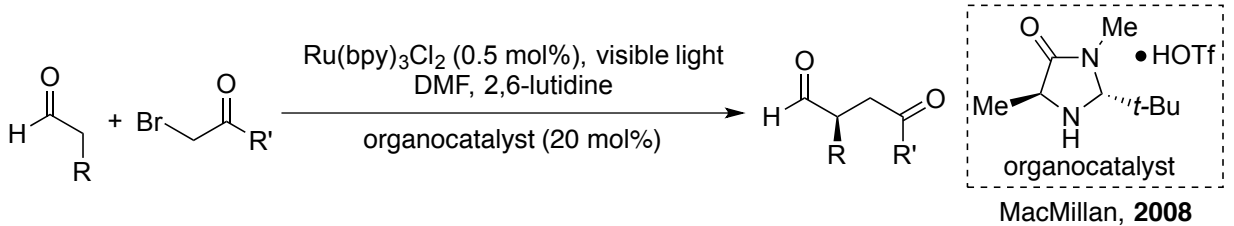

C) Aza-Henry reaction
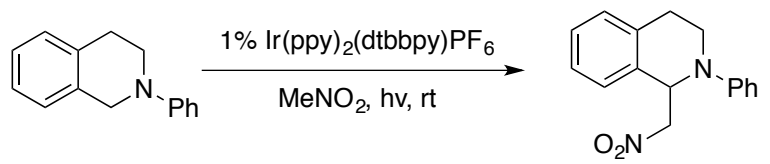

Stephenson, 2010

In the same year, MacMillan and his coworkers reported an enantioselective $\alpha$-alkylation reaction of aldehyde through the combination of photoredox catalysis and organocatalysis (Scheme 32B). ${ }^{97}$ In this case, the enamine intermediate could serve as a reductive quencher to initiate the photocatalytic cycle.

Another pioneer example in visible light photoredox catalysis is an oxidative aza-Henry reaction developed by Stephenson in 2010. ${ }^{98}$ An iminium cation was generated from tetrahydroisoquinoline by reductive quenching of the photocatalyst followed by single electron oxidation. A sequential nucleophilic addition to the iminium cation yielded the product. Later on, other groups extensively studied the aza-Henry reactions employing various nucleophiles such as vinyl ether ${ }^{99}$ phosphonate, ${ }^{100}$ acetone,${ }^{101}$ alkynes ${ }^{102}$ etc.

One big challenge in order to operate a photoredox catalytic cycle is to find a suitable photocatalyst, for which the redox potential could match with the substrates. As we know, the redox potential of transition metal photocatalysts is 
highly dependent on the ligands. Using a more electron-deficient ligand could effectively increase the reduction potential $E_{1 / 2}\left(M^{+} / M\right)$, making $M^{+}$a stronger oxidant, which could be applied into more challenging substrates that are more reluctant towards oxidation. At the same time, the reduction potential $E_{1 / 2}\left(M^{*} / M^{-}\right)$ could also be increased, making $\mathrm{M}^{*}$ a better oxidant as well. For instance, when 2,2'-bipyrazine (bpz) is used as the ligand for $\mathrm{Ru}(\mathrm{II})$ instead of bpy ligand, the $E_{1 / 2}\left(\mathrm{M}^{*} / \mathrm{M}^{+}\right)$is increased $\left(+1.45 \mathrm{~V}\right.$ compared with $+0.77 \mathrm{~V}$ for $\left.\mathrm{Ru}(\mathrm{bpy})_{3}\right)$, making $\mathrm{Ru}(\mathrm{II})^{*}$ a much better oxidant that is sufficient to oxidize the dienophile $(+1.1 \mathrm{~V})$ in this [4+2] cycloaddition reaction (Scheme 33). ${ }^{103}$

\section{Scheme 33. The ligand effect in photocatalysis}

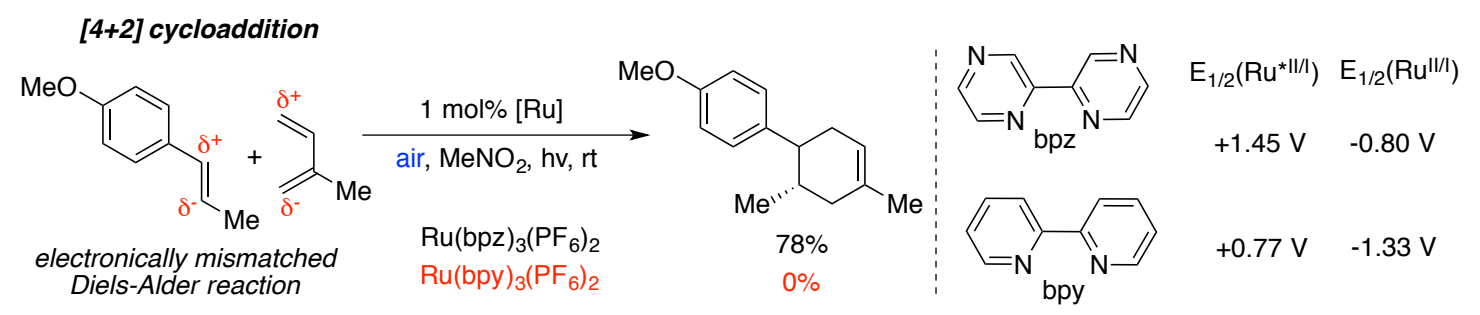

The rapid development of visible light photocatalysis led to a strong need for new catalysts with potentially new reactivity, especially with controllable photoredox potentials.

\subsubsection{Iridium photocatalysts utilizing triazole ligands}

Cationic Ir(III) polyimine complexes have been widely applied in various areas, ${ }^{104}$ including live cell imaging, ${ }^{105}$ electroluminescent materials, ${ }^{106}$ and water oxidation. ${ }^{107}$ Recently, $\left[\operatorname{lr}(\mathrm{ppy})_{2}(\mathrm{bpy})\right]^{+}$and $\left[\operatorname{Ir}(\mathrm{ppy})_{2}(\mathrm{dtbbpy})\right]^{+}$have gained tremendous attention as efficient photocatalysts in promoting organic transformations. ${ }^{108}$ Instead of the 2-pheynylpyridine (ppy) ligand, a more electron-deficient ligand $\mathrm{dF}\left(\mathrm{CF}_{3}\right)$ ppy (3,5-difluoro-2-[5-(trifluoromethyl)-2-pyridinyl] phenyl) is more widely applied because of the stronger redox potential of the excited state $\left(\mathrm{E}_{1 / 2}{ }^{111^{*} / l}=+1.21 \mathrm{~V}\right.$ for $\left.\left[\operatorname{Ir}\left(\mathrm{dF}\left(\mathrm{CF}_{3}\right) \mathrm{ppy}\right)_{2}(\mathrm{dtbbpy})\right]^{+}\right)\left(\mathrm{dtbbpy}=4,4^{\prime}-\right.$ bis(tert-butyl)-2,2'-bipyridine) compared with the ppy complex $\left[\operatorname{lr}(\mathrm{ppy})_{2}(\mathrm{dtbbpy})\right]^{+}$ $\left(E_{1 / 2}{ }^{I I * / I I}=+0.66 \mathrm{~V}\right)$. 
After the discovery of "click chemistry", 1,2,3-triazole (TA) became one of the most important hetereocycles in chemical research. ${ }^{109}$ During the past several years, our group has been working on developing new synthetic methods toward triazole functionalization while investigating the coordination ability of various triazole derivatives. Inspired by recent success on $\operatorname{Ir}(\mathrm{III})$-promoted photocatalysis, we became interested in studying triazole, a electron-deficient ligand, for the binding ability with $\operatorname{Ir}(\mathrm{III})$ and hope to develop a new class of photoactive complexes with the potential to further extend the reaction scope of photocatalysis.

In 2009, Schubert and co-workers reported the first triazole coordinated $\operatorname{Ir}(I I I)$ complexes using N1-substituted 1,2,3-triazole as the $\mathrm{C}^{\wedge} \mathrm{N}$ ligand (bis-chelating $\mathrm{C}$ $\mathrm{N}$ ligand). ${ }^{110}$ Later, De Cola and co-workers reported the electroluminescent properties of similar Ir(III) complexes (Scheme 34A). ${ }^{111}$ Although these and other pioneering work ${ }^{112}$ revealed good coordination ability of TA ligands with $\operatorname{Ir}(I I I)$, no photocatalytic reactivity has been reported. More importantly, as mentioned by Schubert, only C-aryl-TA chelated $\operatorname{Ir}(\mathrm{III})$ complexes could be produced. The attempts to form $\mathrm{N}$-aryl-TA chelating complexes were unsuccessful due to either poor complex stability or the formation of unidentified byproducts.

\section{Scheme 34. C-Aryl-Ir(III) complex with 1,2,3-triazole ligands}

(A) C-Aryl TA-Ir complexes reported by Schubert
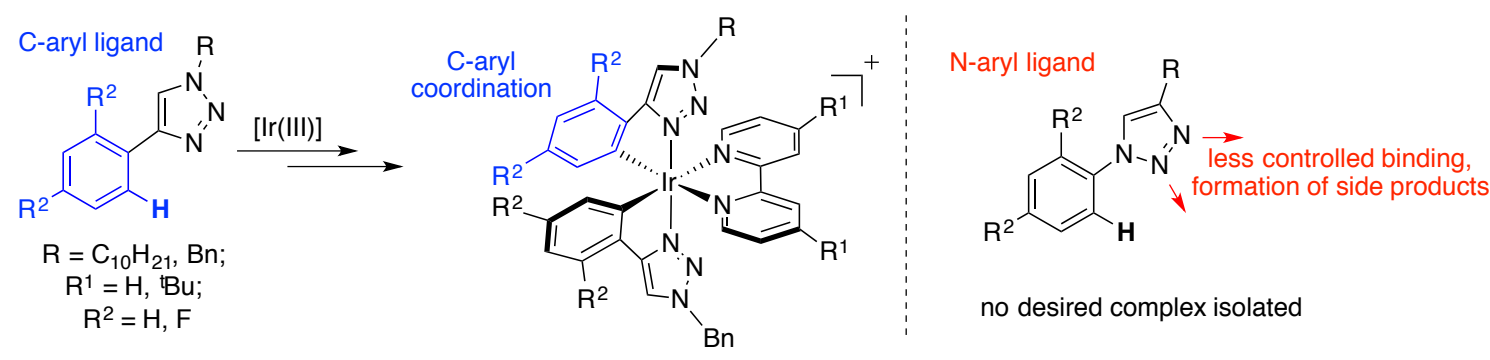

(B) Strong substituent influence at $\mathrm{N}$-aryl position revealed from fluorescence emission
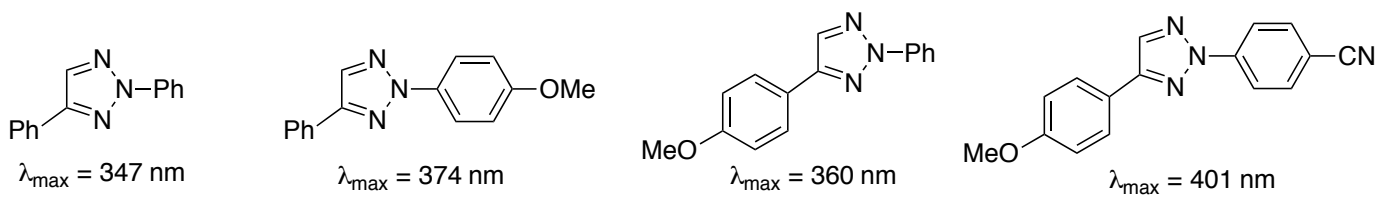
Among various triazole derivatives, one particularly interesting compound is the fluorescence active N-2-aryl triazoles (NATs). As revealed by the crystal structures, the N-2-aryl group holds a perfect co-planar conformation with the triazole ring, resulting in a strong fluorescence emission, whereas the $\mathrm{N}$-1-isomer exhibits no emission. ${ }^{113}$ Moreover, substitution on the $\mathrm{N}$-2-aryl group exhibited strong influence on fluorescence emission wavelengths (Scheme 34B).

Based on these results, we postulated that NAT may be used as the $\mathrm{C}^{\wedge} \mathrm{N}$ ligand to prepare novel $\mathrm{N}$-aryl-chelated $\operatorname{Ir}(\mathrm{III})$ complexes, by providing specific coordination sites as well as easily tunable functional groups (Scheme 35). ${ }^{114}$ At the same time, $\mathrm{N}$-pyridine-triazole (tapy) could serve as the $\mathrm{N}^{\wedge} \mathrm{N}$ ligand to further diversify the proposed $\operatorname{Ir}(\mathrm{III})$ complexes.

Scheme 35. Proposed new N-AryI-Ir(III) complexes
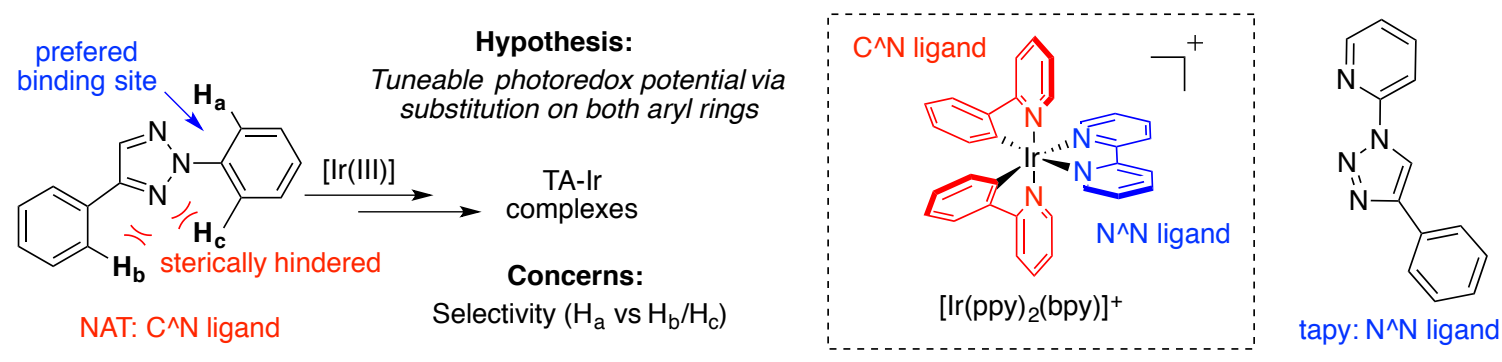

\section{2 NAT-based iridium complexes as photocatalysts}

To test our hypothesis, NATs were prepared and used for $\operatorname{Ir}(I I I)$ complex formation. The general synthetic route is summarized in Scheme $36 .{ }^{115}$

Scheme 36. Synthetic route for NAT-Ir(III) complexes

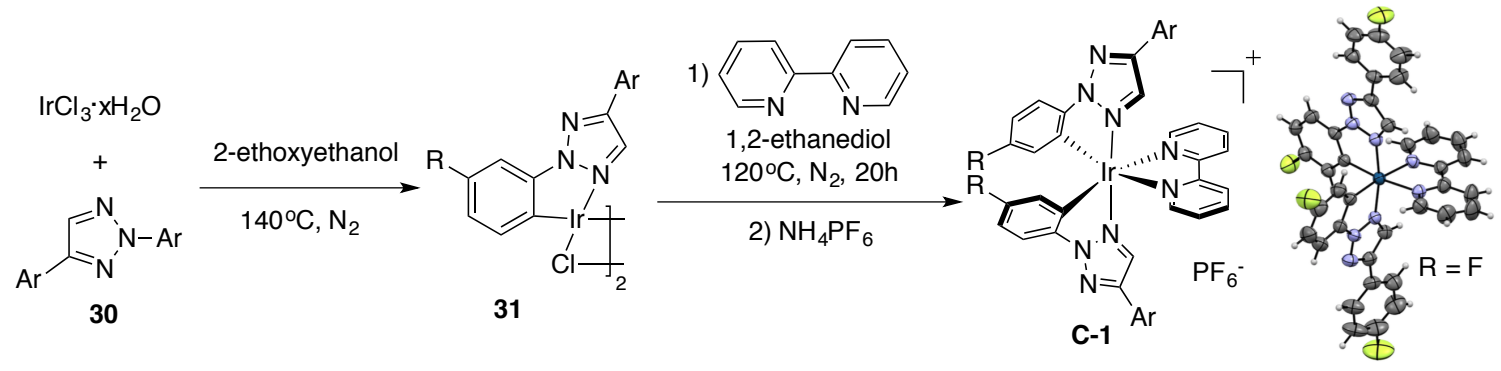


As expected, treating NAT 30 with $\operatorname{IrCl}_{3} \times \mathrm{xH}_{2} \mathrm{O}$ gave the corresponding chlorobridged iridium(III) dimer 31 in excellent yields (generally $>80 \%$ ). Subsequent reaction with bpy ligand gave the corresponding NAT-Ir(III) complex (C-1). Notably, unlike $\mathrm{N}$-1-aryl triazoles, the $\mathrm{N}$-2-aryl triazoles indicated strong coordination ability, forming stable Ir(III) complexes, which could be purified by column chromatography without decomposition. With this synthetic method, various TA-Ir complexes were prepared. Good to excellent yields were obtained in most cases, which warranted further applications of $\mathrm{N}$-2-aryl triazoles as the $\mathrm{C}^{\wedge} \mathrm{N}$ ligand for iridium photocatalysts.

Similar to $\mathrm{Ru}(\mathrm{bpy})_{3}{ }^{2+}$, the general mechanism of photocatalysis with iridium is initiated from the promotion of $\operatorname{Ir}(\mathrm{III})$ to excited-state $\operatorname{Ir}(\mathrm{III})^{*}$ by visible light, followed by oxidative or reductive quenching through single-electron transfer. The resulting $\operatorname{Ir}(\mathrm{IV})$ or $\operatorname{Ir}(\mathrm{II})$ will be reduced or oxidized to regenerate the ground state $\operatorname{Ir}(\mathrm{III})$. The redox potential for each step is crucial for an operative catalytic cycle. Compared to ppy ligand, N-phenyl-triazole (pta) is more electron-deficient. Thus, higher oxidation potentials of the corresponding iridium complexes are expected. To evaluate the photophysical properties of these new TA-Ir complexes, UV-Vis absorption and fluorescence emission were tested. Compared with $\operatorname{Ir}\left[(\mathrm{ppy})_{2}(\mathrm{bpy})\right] \mathrm{PF}_{6}$, the TA-Ir cationic complexes $\left[\operatorname{Ir}(\mathrm{pta})_{2}(\mathrm{bpy})\right] \mathrm{PF}_{6}$ indicated better absorption of blue light and stronger fluorescence emission in the visible light region (Figure 17).

Figure 17. UV-Vis and fluorescence comparison of TA-Ir
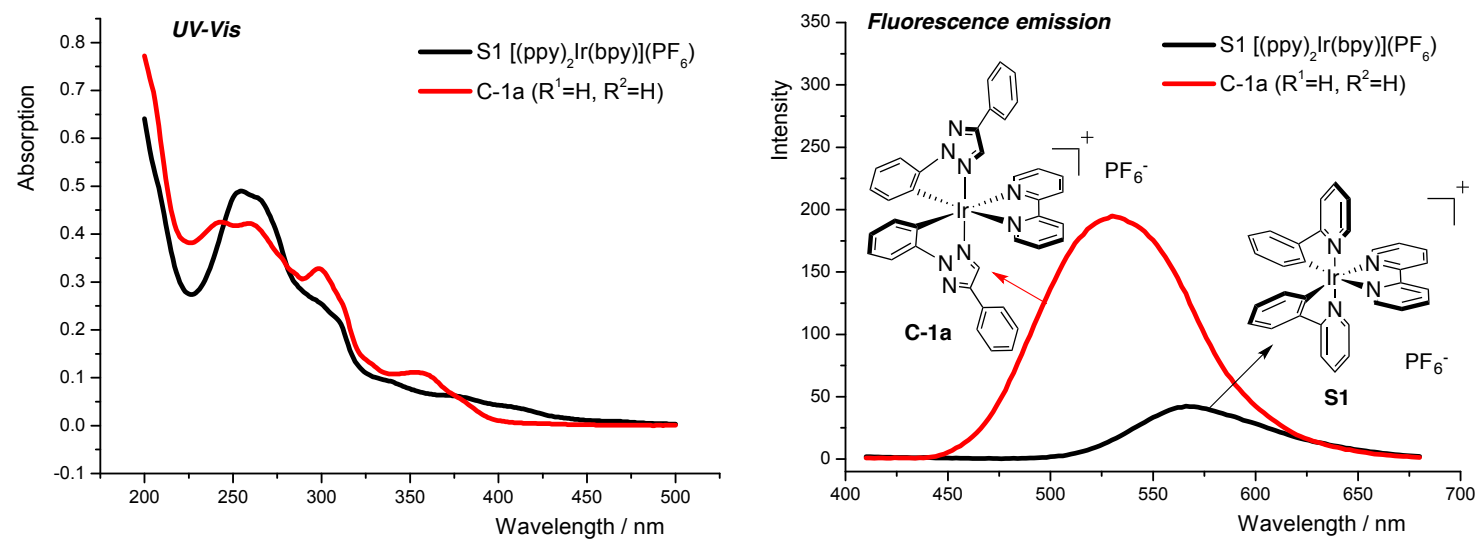
The fluorescence spectra of TA-Ir complexes with different substituents are compared (Figure 18). Introducing an EWG at the $\mathrm{R}^{1}$ position showed a blue shift while EDG showed a red shift. Variation at the $R^{2}$ position did not have much influence on the emission wavelength.

Figure 18. Fluorescence comparison of different substituented TA-Ir
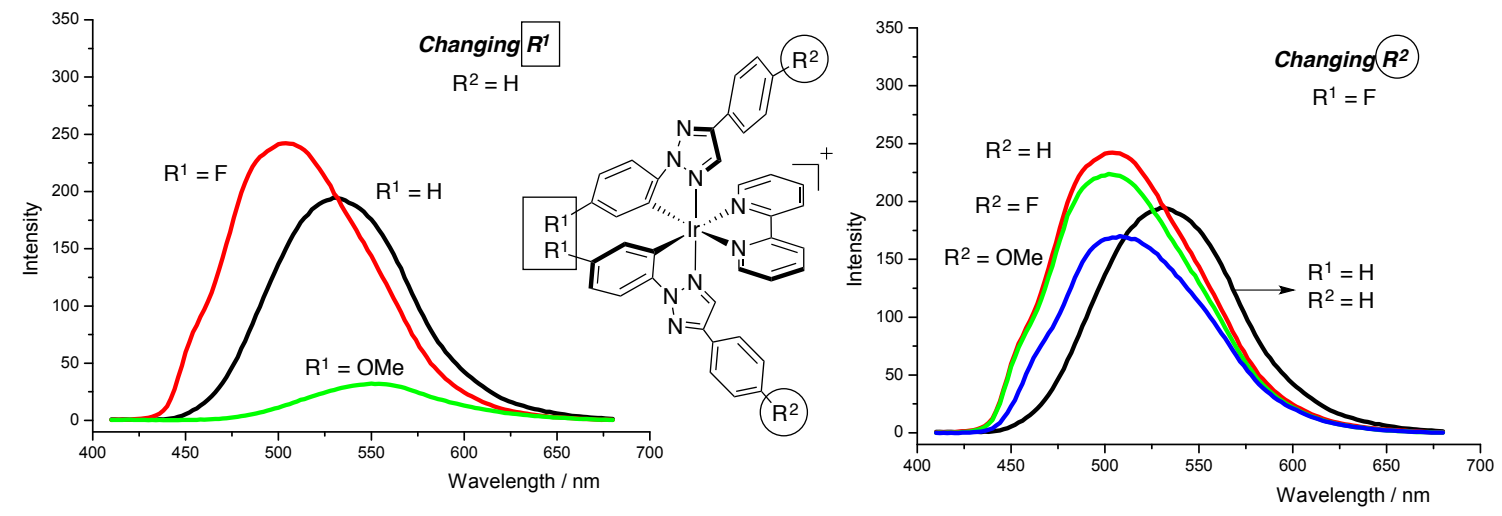

Other than photophysical properties, the redox potential of these iridium complexes are measured with cyclic voltammetry. The results are summarized in Table 21.

Table 21. Redox potential of selected iridium complexes ${ }^{a, b}$

\begin{tabular}{cccccccccc}
\hline & \multirow{2}{*}{$\mathrm{R}^{1}$} & $\mathrm{R}^{2}$ & $\lambda_{\mathrm{em}}(\mathrm{nm})$ & $\Phi^{\mathrm{c}}$ & $\mathrm{T}^{\mathrm{d}}(\mathrm{ns})$ & $\left(\mathrm{Ir}^{4+/ 3+}\right)$ & $\left(\mathrm{Ir}^{4+/ 3+}\right)$ & $\left(\mathrm{Ir}^{3+/ 2+}\right)$ & $\left(\mathrm{Ir}^{3+\star / 2+}\right)$ \\
\hline S1 & - & - & 566 & & & +1.28 & -0.91 & -1.38 & +0.81 \\
C-1a & $\mathrm{H}$ & $\mathrm{H}$ & 530 & 0.32 & 266 & +1.54 & -0.80 & -1.34 & +1.00 \\
$\mathbf{C}-1 \mathbf{b}$ & $\mathrm{F}$ & $\mathrm{H}$ & 503 & 0.39 & 358 & +1.67 & -0.80 & -1.33 & +1.14 \\
C-1c & $\mathrm{OMe}$ & $\mathrm{H}$ & 550 & 0.02 & 30 & +1.37 & -0.88 & -1.35 & +0.90 \\
C-1d & $\mathrm{F}$ & $\mathrm{F}$ & 501 & 0.29 & 270 & +1.66 & -0.82 & -1.33 & +1.15 \\
C-1e & $\mathrm{OMe}$ & $\mathrm{F}$ & 554 & 0.02 & 32 & +1.37 & -0.87 & -1.35 & +0.89 \\
C-1f & $\mathrm{F}$ & $\mathrm{OMe}$ & 508 & 0.21 & 172 & +1.61 & -0.83 & -1.32 & +1.12 \\
C-1g & $\mathrm{OMe}$ & $\mathrm{OMe}$ & 558 & 0.01 & 18 & +1.25 & -0.90 & -1.37 & +0.85 \\
\hline
\end{tabular}

${ }^{a} \mathbf{S 1}=\left[\operatorname{lr}\left[(\mathrm{ppy})_{2}(\mathrm{bpy})\right] \mathrm{PF}_{6} ;\right.$ All potentials are given vs saturated calomel electrode (SCE). Measurements were performed at room temperature in acetonitrile using an internal standard $\mathrm{Fc} / \mathrm{Fc}^{+}$redox couple $(0.40 \mathrm{~V}$ vs. $\mathrm{SCE}) ;{ }^{b} \mathrm{PF}_{6}{ }^{-}$is the counter anion; ${ }^{c}$ The quantum yields were calculated relative to $\mathrm{Ru}(\mathrm{bpy})_{3}\left(\mathrm{PF}_{6}\right)_{2}(\Phi=0.062$ in $\mathrm{ACN}) ;{ }^{d}$ Excited-state lifetime. 
The data in Table 21 revealed a clear substituent effect on the $\mathrm{Ir}^{4+/ 3+}$ reduction potential. First, with more electron-deficient pta ligand, C-1a gave higher reduction potential $\mathrm{E}_{1 / 2}\left(\mathrm{Ir}^{4+/ 3+}\right)=+1.54 \mathrm{~V}(\mathrm{vs} \mathrm{SCE})$ than $\left[\operatorname{Ir}(\mathrm{ppy})_{2}(\mathrm{bpy})\right] \mathrm{PF}_{6}$ $(\mathbf{S 1},+1.28 \mathrm{~V})$. The introduction of electron withdrawing groups (such as $\mathbf{F}, \mathbf{C}-\mathbf{1 b}$ ) at $\mathrm{R}^{1}$ position ( $\mathrm{N}-2$ aryl) further increased the $\mathrm{E}_{1 / 2}\left(\mathrm{Ir}^{4+/ 3+}\right)$ to $+1.67 \mathrm{~V}$. In contrast, complex C-1c (with electron-donating $\mathrm{OMe})$ gave lower $\mathrm{E}_{1 / 2}\left(\mathrm{Ir}^{4+/ 3+}\right)(+1.37 \mathrm{~V})$, which was still higher than ppy complex S1. A similar trend was also observed in the reduction potential $E_{1 / 2}\left(I^{3+\star / 2+}\right)$, though with a smaller variation. Substitution at $R^{2}$ position indicated little influence to the redox potential (eg. $\mathbf{C}-1 \mathbf{b},+1.67 \mathrm{~V}$ vs C-1d, $+1.66 \mathrm{~V}$ ), suggesting that the electronic effect influence from the ring that is directly touching the metal center is much more important. Similarly, introducing EWG at $R^{1}$ position $(\mathbf{C}-\mathbf{1 b})$ helped to increase the excited-state lifetime and quantum yield while introducing EDG (C-1c) impaired the excited-state lifetime and quantum yield.

The reduction potential $E_{1 / 2}\left(\mathrm{Ir}^{3+/ 2+}\right)$ of all tested C-1 TA-Ir complexes were almost the same even with different $C^{\wedge} N$ ligands. To fully elucidate the ligand effect on redox potential, we prepared triazole-pyridine (tapy) ${ }^{116}$ as a new type of $\mathrm{N}^{\wedge} \mathrm{N}$ ligands to coordinate with Ir cations. The reaction between the chlorobridged iridium dimer $2 \mathrm{a}$ and $\mathrm{N}$-2-tapy gave messy mixtures with no desired complex isolated. Interestingly, a much cleaner reaction was obtained with N-1tapy. Although growing a single crystal is unsuccessful at this moment, the TA-Ir complexes with $\mathrm{N}$-1-tapy as an $\mathrm{N}^{\wedge} \mathrm{N}$ ligand have been successfully prepared and characterized by ${ }^{1} \mathrm{H},{ }^{13} \mathrm{C},{ }^{19} \mathrm{~F}$ NMR and HRMS. The fluorescence emission and redox potentials of these complexes were then determined as shown in Table 22.

Interestingly, compared to complex $\mathbf{S 1}$ (with ppy $\mathrm{N}^{\wedge} \mathrm{N}$ ligand), complex $\mathbf{C}-\mathbf{2}$ (with tapy $\mathrm{N}^{\wedge} \mathrm{N}$ ligand) resulted in a clear change of $\mathrm{E}_{1 / 2}\left(\mathrm{Ir}^{3+/ 2+}\right)$ reduction potential, from $-1.38 \mathrm{~V}$ to $-1.48 \mathrm{~V}$, similar to complex $\mathbf{S} 2$ (with dtbbpy $\mathrm{N}^{\wedge} \mathrm{N}$ ligand). Notably, the $E_{1 / 2}\left(\mid r^{3+/ 2+}\right)$ reduction potential remained almost the same when changing the $\mathrm{C}^{\wedge} \mathrm{N}$ ligand to pta. These $\left[\operatorname{Ir}(\mathrm{pta})_{2}(\text { tapy })\right]^{+}$complexes are even stronger oxidants compared with $\left[\operatorname{Ir}(\mathrm{pta})_{2}(\mathrm{bpy})\right]^{+}$. These results highlighted the excellent viability of these new triazole based Ir photocatalysts: using pta as the $\mathrm{C}^{\wedge} \mathrm{N}$ ligand to adjust 
the $\mathrm{Ir}^{4+/ 3+}$ oxidation potential while using tapy as the $\mathrm{N}^{\wedge} \mathrm{N}$ ligand to tune the $\mathrm{Ir}^{3+/ 2+}$ reduction potential.

Table 22. Redox potential of selected iridium complexes with tapy ligand ${ }^{a, b}$
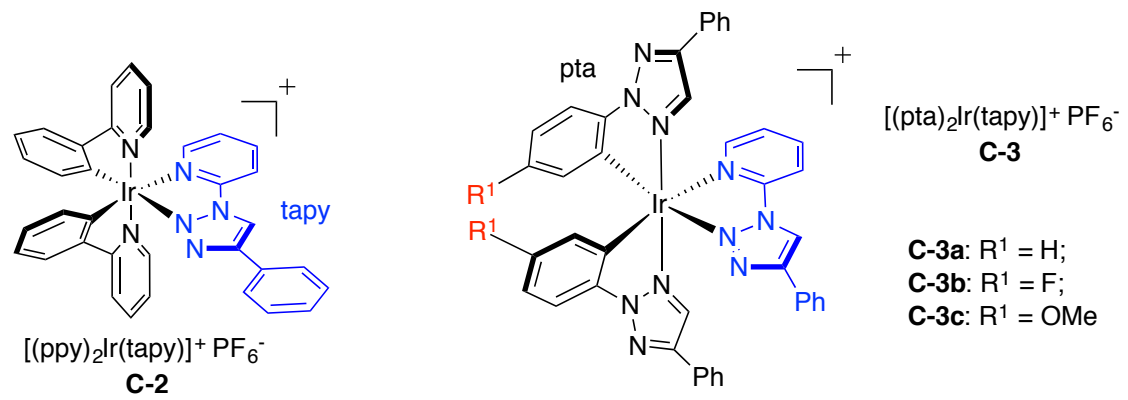

\begin{tabular}{ccccccccc}
\hline & \multirow{2}{*}{$\mathrm{R}^{1}$} & \multirow{2}{*}{$\lambda_{\mathrm{em}}(\mathrm{nm})$} & $\Phi^{\mathrm{c}}$ & \multirow{2}{*}{$\mathrm{T}^{\mathrm{d}}(\mathrm{ns})$} & $\left(\mathrm{Ir}^{4+/ 3+}\right)$ & $\left(\mathrm{Ir}^{4+/ 3+\star}\right)$ & $\left(\mathrm{Ir}^{3+/ 2+}\right)$ & $\left(\mathrm{Ir}^{3+\star / 2+}\right)$ \\
\hline S1 & - & 566 & & & +1.28 & -0.91 & -1.38 & 0.81 \\
S2 & - & 560 & 0.20 & 175 & +1.25 & -0.96 & -1.48 & 0.73 \\
$\mathbf{C - 2}$ & - & 546 & 0.12 & 110 & +1.37 & -0.90 & -1.48 & 0.79 \\
$\mathbf{C - 3 a}$ & $\mathrm{H}$ & 462,486 & 0.06 & 217 & +1.61 & -0.94 & -1.45 & 1.10 \\
$\mathbf{C - 3 b}$ & $\mathrm{F}$ & 458,482 & 0.07 & 375 & +1.75 & -0.82 & -1.41 & 1.16 \\
$\mathbf{C - 3 C}$ & $\mathrm{OMe}$ & 508 & 0.01 & 108 & +1.37 & -1.07 & -1.43 & 1.01 \\
\hline
\end{tabular}

${ }^{a} \mathbf{S} 1=\left[\operatorname{Ir}\left[(\mathrm{ppy})_{2}(\mathrm{bpy})\right] \mathrm{PF}_{6} ; \mathbf{S 2}=\left[\operatorname{Ir}(\mathrm{ppy})_{2}(\mathrm{dtbbpy})\right] \mathrm{PF}_{6} ;{ }^{b, c, d}\right.$ Same conditions as Table 21 applied.

Two typical photocatalytic reactions ${ }^{117}$ were performed to prove the feasibility of these new TA-Ir complexes. Although the reactions are slower, good yields were obtained as shown in Scheme 37.

Scheme 37. TA-Ir as effective photocatalysts

A)<smiles>CO[N+]([O-])([O-])c1ccccc1</smiles>

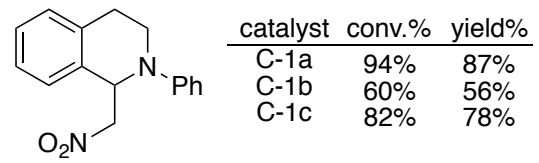

B)<smiles>COC(=O)c1ccc(I)cc1</smiles>
\begin{tabular}{llll} 
catalyst & conv.\% & yield $\%$ \\
\hline $\mathrm{C}-1 \mathrm{a}$ & $77 \%$ & $55 \%$ \\
$\mathrm{C}-1 \mathrm{~b}$ & $56 \%$ & $54 \%$ \\
$\mathrm{C}-1 \mathrm{c}$ & $70 \%$ & $68 \%$
\end{tabular} 


\section{3 Conclusion}

In summary, we synthesized and characterized N-2-aryl-1,2,3-triazole- $\operatorname{lr}(\mathrm{III})$ complexes (TA-Ir). A series of complexes with different substituents have been prepared and their photophysical properties were evaluated. With the electrondeficient triazole ligands, TA-Ir complexes are stronger oxidants compared with the commonly used $\left[\operatorname{Ir}(\mathrm{pta})_{2}(\mathrm{bpy})\right]^{+}$. Tunable redox potentials were achieved through varying substituents on either the pta $C^{\wedge} N$ ligand or the tapy $N^{\wedge} N$ ligand, which indicated promising future of these new photocatalysts. Other functional groups could be installed to further modify these types of complexes to improve their photophysical and photocatalytic properties.

\section{4 Contribution}

Rong Cai developed, characterized these cationic TA-Ir complexes and applied them in photocatalysis. Dr. Wuming Yan initiated this project and developed part of the synthetic methods. Matthew G. Bologna helped with ligand preparation. Kaushalya de Silva and Dr. Harry O. Finklea helped with cyclic voltammetry measurements. Zhao Ma helped with manuscript preparation. Dr. Jeffrey L. Petersen performed the X-ray structural analyses.

This project is published on Org. Chem. Front. 2015, 2, 141-144.

\section{References:}

91 Ciamician, G. Science 1912, 36, 385.

92 Hoffmann, N. Chem. Rev., 2008, 108, 1052.

93 Recent reviews on visible light photocatalysis: a) Zeitler, K. Angew. Chem. Int. Ed. 2009, 48, 9785; b) Narayanam, J. M. R.; Stephenson, C. R. J. Chem. Soc. Rev. 2010, 40, 102; c) Xuan, J.; Xiao, W.-J. Angew. Chem. Int. Ed., 2012, 51, 6828; d) Xi, Y.; Yi, H.; Lei, A. Org. Biomol. Chem. 2013, 11, 2387.

94 Prier, C. K.; Rankic, D. A.; MacMillan, D. W. C. Chem. Rev. 2013, 113, 5322.

95 Cano-Yelo, H.; Deronzier, A. J. Chem. Soc., Perkin Trans. 1984, 2, 1093. 
96 Ischay, M. A.; Anzovino, M. E.; Du, J.; Yoon, T. P. J. Am. Chem. Soc. 2008, 130, 12886.

97 Nicewicz, D. A.; MacMillan, D. W. C. Science 2008, 322, 77.

98 Condie, A. G.; González-Gómez, J. C.; Stephenson, C. R. J. J. Am. Chem. Soc. 2010, 132, 1464.

99 Zhao, G.; Yang, C.; Guo, L.; Sun, H.; Chen, C.; Xia, W. Chem. Commun. 2012, 48, 2337.

100 Rueping, M.; Zhu, S.; Koenigs, R. M. Chem. Commun. 2011, 47, 8679.

101 Rueping, M.; Vila, C.; Koenigs, R. M.; Poscharny, K.; Fabry, D. C. Chem. Commun. 2011, 47, 2360.

102 Rueping, M.; Koenigs, R. M.; Poscharny, K.; Fabry, D. C.; Leonori, D.; Vila, C. Chem.-Eur. J. 2012, 18, 5170.

103 Lin, S.; Ischay, M. A.; Fry, C. G.; Yoon, T. P. J. Am. Chem. Soc. 2011, 133, 19350.

104 Flamigni, L.; Barbieri, A.; Sabatini, C.; Ventura, B.; Barigelletti, F. Top. Curr. Chem. 2007, 281, 143.

105 a) Lo, K. K.-W.; Hui, W.-K.; Chung, C.-K.; Tsang, K. H.-K.; Lee, T. K.-M.; Li, C.-K.; Lau, J. S.-Y.; Ng, D. C.-M. Coord. Chem. Rev. 2006, 250, 1724; b) Zhang, K. Y.; Lo, K. K.-W. Inorg. Chem. 2009, 48, 6011; c) Zhao, Q.; Zhao, Q.; Yu, M.; Yu, M.; Shi, L.; Shi, L.; Liu, S.; Liu, S.; Li, C.; Li, C.; Shi, M.; Shi, M.; Zhou, Z.; Zhou, Z.; Huang, C.; Huang, C.; Li, F.; Li, F. Organometallics 2010, 29, 1085.

106 a) Grushin, V. V.; Herron, N.; LeCloux, D. D.; Marshall, W. J.; Petrov, V. A.; Wang, Y. Chem. Commun. 2001, 1494; b) Tamayo, A. B.; Alleyne, B. D.; Djurovich, P. I.; Lamansky, S.; Tsyba, I.; Ho, N. N.; Bau, R.; Thompson, M. E. J. Am. Chem. Soc. 2003, 125, 7377; c) Slinker, J. D.; Gorodetsky, A. A.; Lowry, M. S.; Wang, J.; Parker, S.; Rohl, R.; Bernhard, S.; Malliaras, G. G. J. Am. Chem. Soc. 2004, 126, 2763; d) Tamayo, A. B.; Garon, S.; Sajoto, T.; Djurovich, P. I.; Tsyba, I. M.; Bau, R.; Thompson, M. E. Inorg. Chem. 2005, 44, 8723.

107 a) Lowry, M. S.; Goldsmith, J. I.; Slinker, J. D.; Rohl, R.; Pascal, R. A.; Malliaras, G. G.; Bernhard, S. Chem. Mater. 2005, 17, 5712; b) McDaniel, N. D.; Coughlin, F. J.; Tinker, L. L.; Bernhard, S. J. Am. Chem. Soc. 2007, 130, 210; c) Whang, D. R.; Sakai, K.; Park, S. Y. Angew. Chem. Int. Ed. 2013, 52, 11612.

108 Other selected examples for visible-light photoredox catalysis: a) Neumann, M.; Fueldner, S.; Koenig, B.; Zeitler, K. Angew. Chem. Int. Ed. 2011, 50, 951; f) Maity, 
S.; Zheng, N. Angew. Chem. Int. Ed. 2012, 51, 9562; g) Wallentin, C.-J.; Nguyen, J. D.; Finkbeiner, P.; Stephenson, C. R. J. J. Am. Chem. Soc. 2012, 134, 8875; h) Yasu, Y.; Koike, T.; Akita, M. Angew. Chem. Int. Ed. 2012, 51, 9567; i) Mizuta, S.; Verhoog, S.; Engle, K. M.; Khotavivattana, T.; O'Duill, M.; Wheelhouse, K.; Rassias, G.; Médebielle, M.; Gouverneur, V. J. Am. Chem. Soc. 2013, 135, 2505; j) Zhu, S.; Das, A.; Bui, L.; Zhou, H.; Curran, D. P.; Rueping, M. J. Am. Chem. Soc. 2013, 135, 1823.

109 a) Crowley, J.; McMorran, D. in Click Triazoles, ed. Košmrlj, J. Springer Berlin Heidelberg, 2012, pp. 31-83; b) Schulze, B.; Schubert, U. S. Chem. Soc. Rev. 2014, 43, 2522.

110 Beyer, B.; Ulbricht, C.; Escudero, D.; Friebe, C.; Winter, A.; González, L.; Schubert, U. S. Organometallics 2009, 28, 5478.

111 Fernández-Hernández, J. s. M.; Yang, C.-H.; Beltrán, J. I.; Lemaur, V.; Polo, F.; Fröhlich, R.; Cornil, J. r. m.; De Cola, L. J. Am. Chem. Soc. 2011, 133, 10543.

112 a) Ladouceur, S.; Fortin, D.; Zysman-Colman, E. Inorg. Chem. 2011, 50, 11514; b) Swanick, K. N.; Ladouceur, S.; Zysman-Colman, E.; Ding, Z. Chem. Commun. 2012, 48, 3179.

113 Yan, W.; Wang, Q.; Lin, Q.; Li, M.; Petersen, J. L.; Shi, X. Chem. Eur. J. 2011, 17, 5011.

114 There is one reported example of $\mathrm{N}$-2-phenyl-1,2,3-triazole-Ir(III) complex, though with no studies on the substituent influence: Shavaleev, N. M.; Scopelliti, R.; Grätzel, M.; Nazeeruddin, M. K. Inorg. Chim. Acta 2012, 388, 84.

115 a) You, Y.; Park, S. Y. J. Am. Chem. Soc. 2005, 127, 12438; b) Ladouceur, S.; Fortin, D.; Zysman-Colman, E. Inorg. Chem. 2011, 50, 11514.

116 Previous reported tapy compounds: Stengel, I.; Mishra, A.; Pootrakulchote, N.; Moon, S.-J.; Zakeeruddin, S. M.; Gratzel, M.; Bauerle, P. J. Mater. Chem. 2011, 21, 3726.

117 Nguyen, J. D.; D'Amato, E. M.; Narayanam, J. M. R.; Stephenson, C. R. J. Nat. Chem. 2012, 4, 854. 


\section{Appendix}

Publications during Ph.D. research at West Virginia University:

(1) Cai, R.; Lu, M.; Aguilera, E. Y.; Xi, Y.; Akhmedov, N. G.; Petersen, J. L.; Chen, H.*; Shi, X.. "Ligand-Assisted Gold-Catalyzed Cross-Coupling with Aryldiazonium Salts: A Case of External Oxidant Free Redox Gold Catalysis" Angew. Chem. Int. Ed. 2015, 54, 8772-8776.

(2) Gao, W.; Cai, R.; Pham, T.; Forrest, K. A.; Hogan, A.; Nugen, P.; Williams, K.; Wojtas, L.; Luebke, R.; Weselinski, L. J.; Zaworotko, M. J.; Space, B.; Chen, Y.; Eddaoudi, M.; Shi, X.;* Ma, S.* "Remote Stabilization of Copper Paddlewheel Based Molecular Building Blocks in Metal Organic Frameworks" Chem. Mater. 2015, 27, 2144-2151.

(3) Cai, R.; Yan, W.; Bologna, M. G.; De Silva, K.; Finklea, H. O.; Petersen, J. L.; Shi, $X$. * "Synthesis and Characterization of N-2-Aryl-1,2,3-Triazole Based Iridium Complexes as Photocatalysts with Tuneable Photoredox Potential " Org. Chem. Front. 2015, 2, 141-144.

(4) Cai, R.; Wang, D.; Chen, Y.; Yan, W.; Geise, N. R.; Sharma, S.; Li, H.; Petersen, J. L.; Li, M.*; Shi, X.* "Facile synthesis of fluorescent active triazapentalenes through gold-catalyzed triazole-alkyne cyclization" Chem. Commun. 2014, 50, 7303-7305.

(5) Gao, W.; Cai, R.; Meng, L.; Wojtas, L.; Zhou, W.; Yildirim, T.; Shi, X.*; Ma, S.* "Quest for a highly connected robust porous metal-organic framework on the basis of a bifunctional linear linker and a rare heptanuclear zinc cluster" Chem. Commun. 2013, 49, 10516-10518.

(6) Wang, D.; Cai, R.; Sharma, S.; Jirak, J.; Thummanapelli, S. K.; Akhmedov, N. G.; Zhang, H.;Liu, X.; Petersen, J. L.; Shi, X.* "'Silver Effect' in Gold(I) Catalysis: An Overlooked Important Factor" J. Am. Chem. Soc. 2012, 21, 9012-9019.

(7) Gao, W.; Yan, W.; Cai, R.; Williams, K.; Salas A.; Wojtas, L.; Shi, X.*; Ma, S.* "A pillared metal-organic framework incorporated with 1,2,3-triazole moieties exhibiting remarkable enhancement of $\mathrm{CO}_{2}$ uptake" Chem. Commun. 2012, 48, 8898-8900.

(8) Gao, W.; Yan, W.; Cai, R.; Meng, L.; Salas, A.; Wang, X.; Wojtas, L.; Shi, X.*; $\mathrm{Ma}, \mathrm{S}^{*}$ "Porous Double-Walled Metal Triazolate Framework Based upon a Bifunctional Ligand and a Pentanuclear Zinc Cluster Exhibiting Selective $\mathrm{CO}_{2}$ Uptake" Inorg. Chem. 2012, 51, 4423-4425.

(9) Wang, D.; Zhang, Y.; Cai, R.; Shi, X.* "Triazole-Au(I) Complex as Chemoselective Catalyst in Promoting Propargyl Ester Rearrangements" Beilstein J. Org. Chem. 2011, 7, 1014-1020. 


\title{
Experimental Details
}

\section{Application of 1, 2, 3-Triazole in Gold Catalysis and Photoredox Catalysis}

\author{
Rong Cai
}




\section{TABLE OF CONTENT}

Chapter S1. Gold-Catalyzed Synthesis of Triazapentalene Zwitterions.............................S1

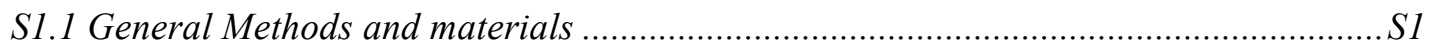

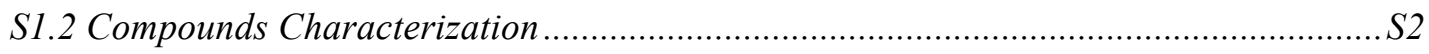

S1.3 ORTEP Drawing of the Crystal Structures.................................................................

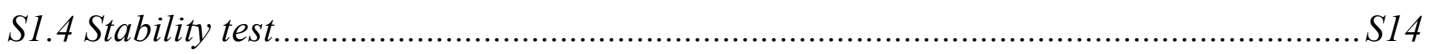

S1.5 UV-Vis Spectra and Fluorescence Spectra ........................................................... S16

Chapter S2. "Silver Effect" in Gold(I) Catalysis...................................................................S30

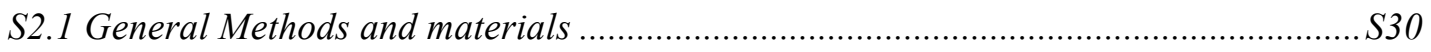

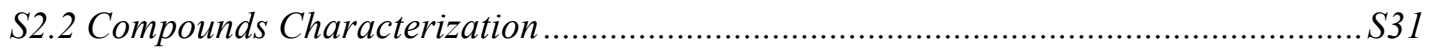

S2.3 ORTEP Drawing of the Crystal Structures for IPr-TA-Au .......................................S35

$S 2.4{ }^{31} P$ NMR comparison between different gold catalyst ...............................................S35

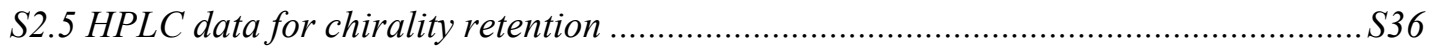

Chapter S3. Gold-Catalyzed Cross-Coupling with Aryldiazonium Salts ............................S39

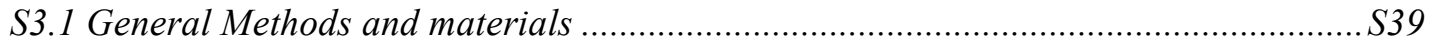

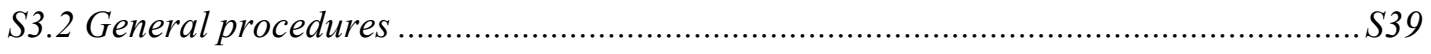

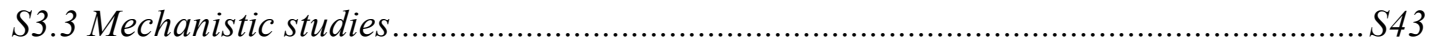

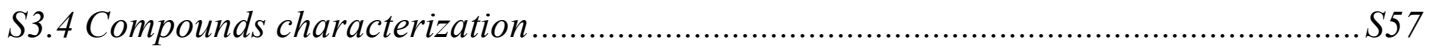

Chapter S4. Porous Polymer-Supported Heterogeneous Gold(I) Catalysis ......................S78

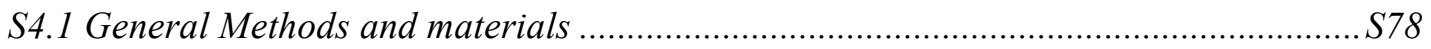

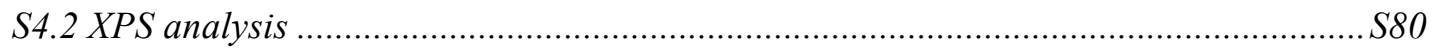

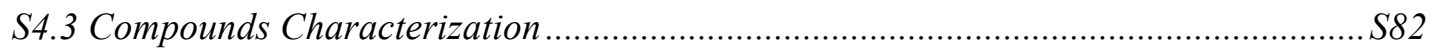

Chapter S5. N-2-Aryl-1,2,3-Triazole as ligand for Iridium Photocatalyst .........................S84

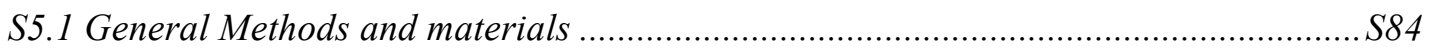

S5.2 Compounds characterization ................................................................................... 887

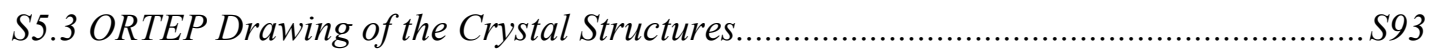

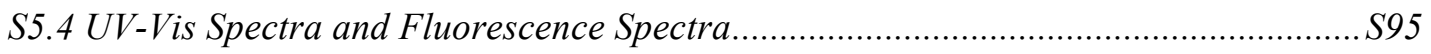

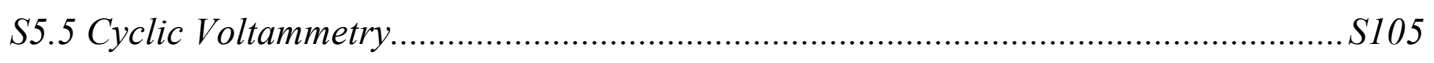

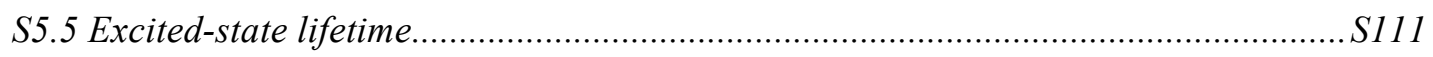

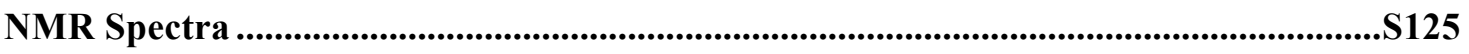




\section{Chapter S1. Gold-Catalyzed Synthesis of Triazapentalene Zwitterions}

\section{S1.1 General Methods and materials}

All of the reactions dealing with air and/or moisture-sensitive reactions were carried out under an atmosphere of nitrogen using oven/flame-dried glassware and standard syringe/septa techniques. Unless otherwise noted, all commercial reagents and solvents were obtained from the commercial provider and used without further purification. ${ }^{1} \mathrm{H}$ NMR and ${ }^{13} \mathrm{C}$ NMR spectra were recorded on Varian $600 \mathrm{MHz}$ or Agilent $400 \mathrm{MHz}$ spectrometer. Chemical shifts were reported relative to internal tetramethylsilane $(\delta 0.00$ ppm) or $\mathrm{CDCl}_{3}(\delta 7.26 \mathrm{ppm})$ for ${ }^{1} \mathrm{H} \mathrm{NMR}$ and $\mathrm{CDCl}_{3}(\delta 77.0 \mathrm{ppm})$ for ${ }^{13} \mathrm{C}$ NMR. Flash column chromatography was performed on 230-430 mesh silica gel. Analytical thin layer chromatography was performed with precoated glass baked plates $(250 \mu)$ and visualized by fluorescence and by charring after treatment with potassium permanganate stain. HRMS were recorded on LTQ-FTUHRA spectrometer.

The UV-Vis spectra were obtained with a Shimadzu UV-1800 UV spectrophotometer in $10 \mathrm{~mm}$ path length quartz cuvettes with $1 \times 10^{-5} \mathrm{M}$ TAPZ solutions in freshly distilled methylene chloride (DCM). The fluorescence spectra were obtained in $10 \mathrm{~mm}$ path length quartz cuvettes using Shimadzu RF-5301 PC spectrofluorophotometer with $1 \times 10^{-}$ ${ }^{5} \mathrm{M}$ (for $5 \mathbf{m}-\mathbf{5 t}$ ) or $1 \times 10^{-6} \mathrm{M}$ (for $\mathbf{6 a - 6 g}$ ) TAPZ solutions in DCM.

The fluorescence quantum yields of TAPZs $\left(\Phi_{\mathrm{x}}\right)$ were calculated based on equation (1) using quinine sulfate in $0.1 \mathrm{~N} \mathrm{H}_{2} \mathrm{SO}_{4}$ solution $(\Phi=0.55)^{[1]}$ as a standard. The absorption of TAPZs and standard was less than $0.05\left(1 \times 10^{-6} \mathrm{M}\right.$ solution).

$$
\Phi_{x}=\frac{n_{x}^{2}}{n_{s t d}^{2}} \cdot \frac{1-10^{-A b s_{s d d}}}{1-10^{-A b s_{x}}} \cdot \frac{I_{x}}{I_{s t d}} \cdot \Phi_{s t d}
$$

$\Phi$ is the quantum yield, I is integrated emission intensity, Abs is the absorption at the excitation wavelength, and $\mathbf{n}$ is the refractive index of pure solvents $\left(\mathrm{n}_{\mathrm{x}}=1.424\right.$, $\mathrm{n}_{\text {std }}=1.333$ ); 'std' stands for reference standard samples, ' $\mathrm{x}$ ' stands for samples.

All the cells were grown in BioNano Research Facility in West Virginia University. The HEK 293t cells were cultured in complete medium (Dulbecco's modified Eagle's Medium, supplemented with $10 \%$ fetal bovine serum (FBS), 1\% penicillin-streptomycin) at $37{ }^{\circ} \mathrm{C}$ in atmosphere containing $5 \% \mathrm{CO}_{2}$. The A549 cells were cultured in complete medium (Kaighn's Modification of Ham's F-12 Medium, supplemented with $10 \%$ fetal bovine serum (FBS), $1 \%$ penicillin-streptomycin) at $37{ }^{\circ} \mathrm{C}$ in atmosphere containing $5 \%$ $\mathrm{CO}_{2}$. The cell images were taken with a Leica DMI6000 B Inverted Fluorescent Microscope.

For microscopic observation, HEK-293t cells or A549 cells were seeded onto coverslips in 6-well plates at $1 \times 10^{5}$ cells $/$ well $(4 \mathrm{~mL}$ cell suspensions per well), and allowed to attach overnight at $37^{\circ} \mathrm{C}$ in atmosphere containing $5 \% \mathrm{CO}_{2}$. Cells were then treated with $10 \mu \mathrm{M}$ TAPZ in $1 \% \mathrm{DMSO} /$ media for $30 \mathrm{~min}$. After TAPZ solutions were aspirated, the cells were washed with PBS for three times. Then the cells were incubated with $1.5 \mathrm{~mL} /$ well

1 A. M. Brouwer, Pure Appl. Chem. 2011, 83, 2213-2228. 
$3.7 \%$ paraformaldehyde for another $10 \mathrm{~min}$. After washing the cells with PBS three times, the coverslips were placed on glass microscope slides with $20 \mu \mathrm{L}$ Prolong ${ }^{\circledR}$ Gold Antifade reagent. The slides were left in a $4^{\circ} \mathrm{C}$ refrigerator overnight and observed under a Leica DMI6000 B Inverted Fluorescent Microscope. Cells incubated with 5s were examined under fluorescent microscope at $365 \mathrm{~nm}$ excitation wavelength while cells incubated with $6 \mathbf{a}$ were excited at $470 \mathrm{~nm}$.

Substrates 4 were synthesized according to the literature as below:

1. Chen, Y.; Liu, Y.; Petersen, J. L.; Shi, X. Chem. Commun. 2008, 3254-3256.

2. Yan, W.; Wang, Q.; Chen, Y.; Petersen, J. L.; Shi, X. Org. Lett. 2010, 3308-3311.

\section{Representative procedure for the preparation of triazapentalene}
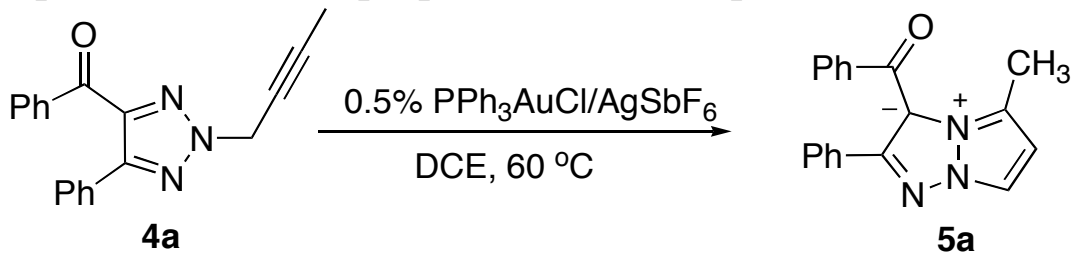

To a solution of $\mathrm{PPh}_{3} \mathrm{AuCl}(1.24 \mathrm{mg}, 0.0025 \mathrm{~mol})$ in DCE $(1 \mathrm{~mL}), \mathrm{AgSbF}_{6}(0.86 \mathrm{mg}$, $0.0025 \mathrm{mmol}$ ) was added at RT. The mixture was stirred for $2 \mathrm{~min}$ at RT and added 4a $(150 \mathrm{mg}, 0.50 \mathrm{mmol})$ dissolved in another $4 \mathrm{~mL}$ DCE. The reaction mixture was stirred at $60{ }^{\circ} \mathrm{C}$ and monitored by TLC. After the reaction was completed $(4 \mathrm{~h})$, the solvent was removed under reduced pressure and the residue was purified by flash chromatography on silica gel (ethyl acetate/hexane $=1: 5, \mathrm{~V} / \mathrm{V}$ ) to give $\mathbf{5 a}$ (96\% yield) as a yellow solid. The product was further purified by recrystallization from ethanol.

\section{Procedure for the preparation of triazapentalene 6 from 5m:}<smiles></smiles>

$5 \mathrm{~m}$

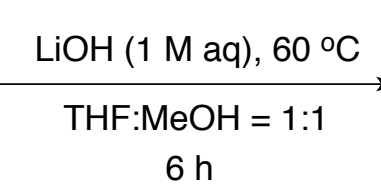

$6 \mathrm{~h}$<smiles></smiles>

$7 \mathrm{~m}$

To a solution of $\mathbf{5 m}(222 \mathrm{mg}, 0.87 \mathrm{mmol})$ in THF: $\mathrm{MeOH}(10 \mathrm{~mL}: 10 \mathrm{~mL}), 10 \mathrm{~mL} 1 \mathrm{M}$ $\mathrm{LiOH}$ (aq.) was added. The reaction mixture was stirred at $70{ }^{\circ} \mathrm{C}$ for $8 \mathrm{~h}$. After the reaction was completed, the solution was extracted with methylene chloride for four times. The combined organic layer was dried over anhydrous $\mathrm{MgSO}_{4}$, filtered, and concentrated under reduced pressure. The residue was purified by flash chromatography on silica gel (pre-washed with triethylamine, ethyl acetate/hexane $=1: 10, \mathrm{~V} / \mathrm{V}$ ) to give 6 ( $76 \%$ yield) as a yellow solid.

\section{S1.2 Compounds Characterization}<smiles>Cc1ccnn1C(C(=O)c1ccccc1)c1ccccc1</smiles> 
5a: ${ }^{1} \mathrm{H}$ NMR $\left(600 \mathrm{MHz}, \mathrm{CDCl}_{3}\right): \delta 7.62(\mathrm{~d}, J=2.4 \mathrm{~Hz}, 1 \mathrm{H}), 7.46-7.48(\mathrm{~m}, 2 \mathrm{H}), 7.11-7.19$ $(\mathrm{m}, 4 \mathrm{H}), 7.02-7.05(\mathrm{~m}, 4 \mathrm{H}), 6.47-6.48(\mathrm{~m}, 1 \mathrm{H}), 2.79(\mathrm{~s}, 3 \mathrm{H}) ;{ }^{13} \mathrm{C}$ NMR $(150 \mathrm{MHz}$, $\left.\mathrm{CDCl}_{3}\right): \delta 179.7,154.8,139.0,131.1,130.9,129.7,129.4,128.5,127.6,127.5,122.7$, 113.6, 109.6, 108.2, 14.1; HRMS Calculated for $\left[\mathrm{C}_{19} \mathrm{H}_{15} \mathrm{~N}_{3} \mathrm{O}+\mathrm{Na}\right]^{+}: 324.1113$, Found: 324.1121 .<smiles></smiles>

5b: ${ }^{1} \mathrm{H}$ NMR $\left(600 \mathrm{MHz}, \mathrm{CDCl}_{3}\right): \delta 7.64(\mathrm{~d}, J=2.1 \mathrm{~Hz}, 1 \mathrm{H}), 7.46-7.48(\mathrm{~m}, 2 \mathrm{H}), 7.10-7.19$ (m, 4H), 7.01-7.05 (m, 4H), $6.51(\mathrm{~d}, J=3.0 \mathrm{~Hz}, 1 \mathrm{H}), 3.29(\mathrm{t}, J=7.5 \mathrm{~Hz}, 2 \mathrm{H}), 1.66$ (quin, $J=7.7 \mathrm{~Hz}, 2 \mathrm{H}), 1.37$ (sex, $J=7.4 \mathrm{~Hz}, 2 \mathrm{H}), 0.91(\mathrm{t}, J=7.5 \mathrm{~Hz}, 3 \mathrm{H}) ;{ }^{13} \mathrm{C}$ NMR $(150 \mathrm{MHz}$, $\left.\mathrm{CDCl}_{3}\right): \delta 179.6,154.9,139.1,131.1,130.9,129.6,129.3,128.4,127.5,127.4,127.3$, 113.7, 108.4, 108.2, 30.5, 27.1, 22.0, 13.9; HRMS Calculated for $\left[\mathrm{C}_{22} \mathrm{H}_{21} \mathrm{~N}_{3} \mathrm{O}+\mathrm{H}\right]^{+}$: 344.1763, Found: 324.1764 .<smiles></smiles>

5c: ${ }^{1} \mathrm{H}$ NMR $\left(600 \mathrm{MHz}, \mathrm{CDCl}_{3}\right): \delta 7.64(\mathrm{~m}, 1 \mathrm{H}), 7.47(\mathrm{~d}, J=8.4 \mathrm{~Hz}, 2 \mathrm{H}), 7.15-7.19(\mathrm{~m}$, $3 \mathrm{H}), 7.10-7.13(\mathrm{t}, J=7.2 \mathrm{~Hz}, 1 \mathrm{H}), 7.01-7.04(\mathrm{t}, J=7.8 \mathrm{~Hz}, 4 \mathrm{H}), 6.51(\mathrm{~m}, 1 \mathrm{H}), 3.28(\mathrm{t}, J=$ $7.8 \mathrm{~Hz}, 2 \mathrm{H}), 1.62$ (quin, $J=7.5 \mathrm{~Hz}, 2 \mathrm{H}), 1.26-1.39(\mathrm{~m}, 4 \mathrm{H}), 0.85(\mathrm{t}, J=6.9 \mathrm{~Hz}, 3 \mathrm{H}) ;{ }^{13} \mathrm{C}$ NMR (150 MHz, $\left.\mathrm{CDCl}_{3}\right): \delta 179.6,154.8,139.1,131.0,130.8,129.6,129.3,128.4,127.5$, 127.4, 127.3, 113.7, 108.3, 108.2, 31.0, 28.0, 27.3, 22.4, 13.9; HRMS Calculated for $\left[\mathrm{C}_{23} \mathrm{H}_{23} \mathrm{~N}_{3} \mathrm{O}+\mathrm{H}\right]^{+}: 358.1919$, Found: 358.1912.<smiles></smiles>

5d: ${ }^{1} \mathrm{H}$ NMR $\left(600 \mathrm{MHz}, \mathrm{CDCl}_{3}\right): \delta 8.44(\mathrm{~d}, J=3.0 \mathrm{~Hz}, 1 \mathrm{H}), 7.70(\mathrm{~d}, J=3.0 \mathrm{~Hz}, 1 \mathrm{H})$, 7.32-7.34 (m, 2H), 7.19-7.23 (m, 4H), 7.09 (t, $J=7.2 \mathrm{~Hz}, 2 \mathrm{H}), 7.04(\mathrm{t}, J=7.2 \mathrm{~Hz}, 2 \mathrm{H})$, $6.81(\mathrm{~d}, J=3.0 \mathrm{~Hz}, 1 \mathrm{H}) ;{ }^{13} \mathrm{C}$ NMR $\left(150 \mathrm{MHz}, \mathrm{CDCl}_{3}\right): \delta 180.8,153.8,138.5,130.4$, $129.7,128.9,128.6,127.8,127.5,113.0,111.9,111.8,109.0,108.2,108.1$; HRMS Calculated for $\left[\mathrm{C}_{18} \mathrm{H}_{13} \mathrm{~N}_{3} \mathrm{O}+\mathrm{H}\right]^{+}: 288.1137$, Found: 288.1125 .<smiles></smiles> 
5e: ${ }^{1} \mathrm{H}$ NMR $\left(600 \mathrm{MHz}, \mathrm{CDCl}_{3}\right): \delta 8.18(\mathrm{~d}, J=8.4 \mathrm{~Hz}, 2 \mathrm{H}), 7.49(\mathrm{~d}, J=7.2 \mathrm{~Hz}, 2 \mathrm{H})$, $7.46(\mathrm{t}, J=7.2 \mathrm{~Hz}, 2 \mathrm{H}), 7.31(\mathrm{t}, J=7.5 \mathrm{~Hz}, 1 \mathrm{H}), 7.23(\mathrm{~d}, J=6.6 \mathrm{~Hz}, 2 \mathrm{H}), 7.18$ (t, $J=7.5$ $\mathrm{Hz}, 1 \mathrm{H}), 7.13$ (t, $J=7.5 \mathrm{~Hz}, 1 \mathrm{H}), 7.05$ (q, $J=8.4 \mathrm{~Hz}, 4 \mathrm{H}), 6.83$ (s, 1H), 3.30 (t, $J=7.8$ $\mathrm{Hz}, 2 \mathrm{H}$ ), 1.65 (quin, $J=7.6 \mathrm{~Hz}, 2 \mathrm{H}), 1.43$ (sex, $J=7.4 \mathrm{~Hz}, 2 \mathrm{H}), 0.93(\mathrm{t}, J=7.5 \mathrm{~Hz}, 3 \mathrm{H}$ ); ${ }^{13} \mathrm{C}$ NMR $\left(150 \mathrm{MHz}, \mathrm{CDCl}_{3}\right): \delta 179.7,154.5,139.2,131.2,130.9,129.9,129.4,128.8$, $128.5,127.7,127.6,127.5,127.47,127.46,125.2,121.6,113.5,105.7,30.3,27.1,22.0$, 13.9; HRMS Calculated for $\left[\mathrm{C}_{28} \mathrm{H}_{25} \mathrm{~N}_{3} \mathrm{O}+\mathrm{H}\right]^{+}: 420.2076$, Found: 420.2081 .

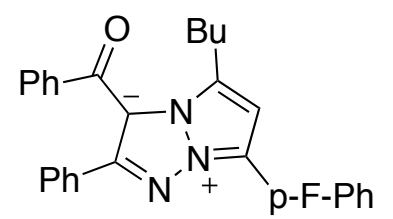

5f: ${ }^{1} \mathrm{H}$ NMR $\left(600 \mathrm{MHz}, \mathrm{CDCl}_{3}\right): \delta 8.16-8.19(\mathrm{~m}, 2 \mathrm{H}), 7.50(\mathrm{~d}, J=7.8 \mathrm{~Hz}, 2 \mathrm{H}), 7.13-7.23$ (m, 6H), 7.03-7.08 (m, 4H), $6.78(\mathrm{~s}, 1 \mathrm{H}), 3.30(\mathrm{t}, J=7.8 \mathrm{~Hz}, 2 \mathrm{H}), 1.64$ (quin, $J=7.6 \mathrm{~Hz}$, $2 \mathrm{H}), 1.44$ (sex, $J=7.6 \mathrm{~Hz}, 2 \mathrm{H}), 0.93(\mathrm{t}, J=7.5 \mathrm{~Hz}, 3 \mathrm{H}) ;{ }^{13} \mathrm{C} \mathrm{NMR}\left(150 \mathrm{MHz}, \mathrm{CDCl}_{3}\right): \delta$ $179.7,162.1(\mathrm{~d}, J=247.1 \mathrm{~Hz}), 154.6,139.1,131.1(\mathrm{~d}, J=24.6 \mathrm{~Hz}), 129.9,129.4,128.5$, 127.6, 127.5, 127.4, 127.1 (d, $J=7.7 \mathrm{~Hz}), 123.9,120.7,116.0,115.8,113.5,105.5,30.4$, 27.1, 22.1, 13.9; HRMS Calculated for $\left[\mathrm{C}_{28} \mathrm{H}_{24} \mathrm{FN}{ }_{3} \mathrm{O}+\mathrm{H}\right]^{+}: 438.1982$, Found: 438.1997.<smiles>COc1cc(C(=O)c2ccccc2)n2c1C(c1ccccc1)=C(c1ccccc1)N=[N+]2</smiles>

5g: ${ }^{1} \mathrm{H}$ NMR (600 MHz, $\left.\mathrm{CDCl}_{3}\right): \delta 8.12(\mathrm{~d}, J=9.0 \mathrm{~Hz}, 2 \mathrm{H}), 7.48(\mathrm{~d}, J=8.4 \mathrm{~Hz}, 2 \mathrm{H})$, $7.22(\mathrm{~d}, J=7.2 \mathrm{~Hz}, 2 \mathrm{H}), 7.17(\mathrm{t}, J=7.5 \mathrm{~Hz}, 1 \mathrm{H}), 7.13(\mathrm{~d}, J=7.5 \mathrm{~Hz}, 1 \mathrm{H}), 6.99-7.06(\mathrm{~m}$, $6 \mathrm{H}), 6.74(\mathrm{~s}, 1 \mathrm{H}), 3.84(\mathrm{~s}, 3 \mathrm{H}), 3.30(\mathrm{t}, J=7.5 \mathrm{~Hz}, 2 \mathrm{H}), 1.64$ (quin, $J=7.6 \mathrm{~Hz}, 2 \mathrm{H}), 1.43$ (sex, $J=7.6 \mathrm{~Hz}, 2 \mathrm{H}), 0.92$ (t, $J=7.5 \mathrm{~Hz}, 3 \mathrm{H}) ;{ }^{13} \mathrm{C}$ NMR $\left(150 \mathrm{MHz}, \mathrm{CDCl}_{3}\right): \delta 179.4$, 159.3, 154.7, 139.4, 131.4, 130.8, 129.9, 129.4, 128.4, 127.6, 127.5, 127.4, 126.9, 121.9, $120.4,114.3,113.5,105.0,55.3,30.4,27.1,22.1,13.9$; HRMS Calculated for $\left[\mathrm{C}_{29} \mathrm{H}_{27} \mathrm{~N}_{3} \mathrm{O}_{2}+\mathrm{H}\right]^{+}: 450.2182$, Found: 450.2173 .<smiles></smiles>

5h: ${ }^{1} \mathrm{H}$ NMR (600 MHz, $\left.\mathrm{CDCl}_{3}\right): \delta 7.59(\mathrm{~d}, J=3.0 \mathrm{~Hz}, 1 \mathrm{H}), 7.47(\mathrm{~d}, J=7.8 \mathrm{~Hz}, 2 \mathrm{H})$, $7.19(\mathrm{t}, J=7.5 \mathrm{~Hz}, 1 \mathrm{H}), 7.02-7.04(\mathrm{~m}, 4 \mathrm{H}), 6.83(\mathrm{~d}, J=7.8 \mathrm{~Hz}, 2 \mathrm{H}), 6.45(\mathrm{~d}, J=2.4 \mathrm{~Hz}$, $1 \mathrm{H}), 2.77(\mathrm{~s}, 3 \mathrm{H}), 2.21(\mathrm{~s}, 3 \mathrm{H}) ;{ }^{13} \mathrm{C}$ NMR $\left(150 \mathrm{MHz}, \mathrm{CDCl}_{3}\right): \delta 179.6,154.7,139.0$, 138.3, 130.7, 129.4, 129.3, 128.2, 128.0, 127.3, 122.5, 113.4, 109.4, 108.1, 21.1, 14.1; HRMS Calculated for $\left[\mathrm{C}_{20} \mathrm{H}_{17} \mathrm{~N}_{3} \mathrm{O}+\mathrm{Na}\right]^{+}: 338.1269$, Found: 338.1272 . 


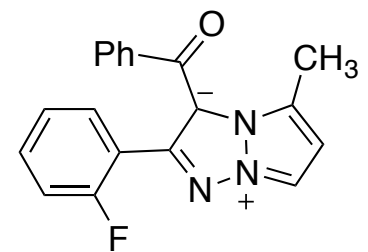

5i: ${ }^{1} \mathrm{H}$ NMR (600 MHz, $\left.\mathrm{CDCl}_{3}\right): \delta 7.61-7.62(\mathrm{~m}, 1 \mathrm{H}), 7.48(\mathrm{~d}, J=7.2 \mathrm{~Hz}, 2 \mathrm{H}), 7.20(\mathrm{t}, J$ $=7.2 \mathrm{~Hz}, 1 \mathrm{H}), 7.08-7.16(\mathrm{~m}, 2 \mathrm{H}), 7.02(\mathrm{t}, J=7.8 \mathrm{~Hz}, 2 \mathrm{H}), 6.91(\mathrm{t}, J=7.5 \mathrm{~Hz}, 1 \mathrm{H}), 6.66$ (t, $J=8.7 \mathrm{~Hz}, 1 \mathrm{H}), 6.46(\mathrm{~s}, 1 \mathrm{H}), 2.79(\mathrm{~s}, 3 \mathrm{H}) ;{ }^{13} \mathrm{C} \mathrm{NMR}\left(150 \mathrm{MHz}, \mathrm{CDCl}_{3}\right): \delta 179.6$, $158.5(\mathrm{~d}, J=247.7 \mathrm{~Hz}), 148.6,138.5,131.1,130.8(\mathrm{~d}, J=8.3 \mathrm{~Hz}), 130.6,128.8,126.9$, $123.3(\mathrm{~d}, J=3.2 \mathrm{~Hz}), 122.5,119.5(\mathrm{~d}, J=14.7 \mathrm{~Hz}), 114.9(\mathrm{~d}, J=21.3 \mathrm{~Hz}), 113.9,109.4$ $(\mathrm{d}, J=7.2 \mathrm{~Hz}), 108.4,13.8$; HRMS Calculated for $\left[\mathrm{C}_{19} \mathrm{H}_{14} \mathrm{FN}_{3} \mathrm{O}+\mathrm{H}\right]^{+}: 320.1199$, Found: 320.1206 .<smiles></smiles>

5j: ${ }^{1} \mathrm{H}$ NMR $\left(600 \mathrm{MHz}, \mathrm{CDCl}_{3}\right): \delta 7.61(\mathrm{~d}, J=3.0 \mathrm{~Hz}, 1 \mathrm{H}), 7.44-7.46(\mathrm{~m}, 2 \mathrm{H}), 7.24-7.26$ $(\mathrm{m}, 1 \mathrm{H}), 7.06-7.08(\mathrm{~m}, 4 \mathrm{H}), 7.00-7.02(\mathrm{~m}, 2 \mathrm{H}), 6.47-6.48(\mathrm{~m}, 1 \mathrm{H}), 2.78(\mathrm{~s}, 3 \mathrm{H}) ;{ }^{13} \mathrm{C}$ NMR (150 MHz, $\left.\mathrm{CDCl}_{3}\right): \delta 179.6,153.5,138.9,134.7,131.2,130.9,129.6,129.4,127.8$, 127.7, 122.9,113.5, 109.7, 108.4, 14.1; HRMS Calculated for $\left[\mathrm{C}_{19} \mathrm{H}_{14} \mathrm{ClN}_{3} \mathrm{O}+\mathrm{H}\right]^{+}$: 336.0904, Found: 336.0912.

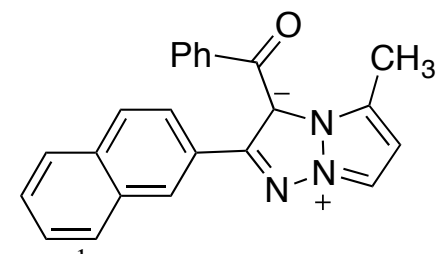

5k: ${ }^{1} \mathrm{H}$ NMR $\left(600 \mathrm{MHz}, \mathrm{CDCl}_{3}\right): \delta 7.85(\mathrm{~d}, J=7.8 \mathrm{~Hz}, 1 \mathrm{H}), 7.63-7.65(\mathrm{~m}, 2 \mathrm{H}), 7.57(\mathrm{~d}, J$ $=8.4 \mathrm{~Hz}, 1 \mathrm{H}), 7.35-7.40(\mathrm{~m}, 2 \mathrm{H}), 7.23(\mathrm{dd}, J=7.8 \mathrm{~Hz}, 1.2 \mathrm{~Hz}, 1 \mathrm{H}), 7.18(\mathrm{dd}, J=7.8 \mathrm{~Hz}$, $1.2 \mathrm{~Hz}, 2 \mathrm{H}), 7.13(\mathrm{t}, J=7.8 \mathrm{~Hz}, 1 \mathrm{H}), 6.85(\mathrm{t}, J=7.5 \mathrm{~Hz}, 1 \mathrm{H}), 6.61(\mathrm{t}, J=7.8 \mathrm{~Hz}, 2 \mathrm{H})$, 6.48-6.49 (m, 1H), $2.83(\mathrm{~s}, 3 \mathrm{H}) ;{ }^{13} \mathrm{C}$ NMR $\left(150 \mathrm{MHz}, \mathrm{CDCl}_{3}\right): \delta 180.1,153.2,138.6$, $132.8,131.9,130.3,129.1,128.8,128.4,128.1,127.7,126.4,126.3,125.6,125.1,124.2$, 122.8, 115.1, 109.4, 108.6, 14.0; HRMS Calculated for $\left[\mathrm{C}_{23} \mathrm{H}_{17} \mathrm{~N}_{3} \mathrm{O}+\mathrm{H}\right]^{+}: 352.1450$, Found: 352.1461.<smiles></smiles>

51: ${ }^{1} \mathrm{H}$ NMR (400 MHz, $\left.\mathrm{CDCl}_{3}\right): \delta 8.26(\mathrm{dd}, J=8.0 \mathrm{~Hz}, 1.2 \mathrm{~Hz}, 2 \mathrm{H}), 7.51(\mathrm{tt}, J=9.2 \mathrm{~Hz}$, 1.6Hz, 4H), 7.35-7.43 (m, 4H), 7.27-7.34 (m, 4H), 7.17-7.23 (m, 2H), 7.17 (s, 1H), 7.03$7.12(\mathrm{~m}, 4 \mathrm{H}) ;{ }^{13} \mathrm{C}$ NMR $\left(100 \mathrm{MHz}, \mathrm{CDCl}_{3}\right): \delta 178.9,153.8,138.8,131.2,131.0,130.0$, 129.4, 129.3, 128.9, 128.6, 128.2, 128.0, 127.6, 127.5, 127.4, 127.3, 125.4, 124.7, 122.3, 113.5, 107.1; HRMS Calculated for $\left[\mathrm{C}_{30} \mathrm{H}_{21} \mathrm{~N}_{3} \mathrm{O}\right]^{+}: 439.1685$, Found: 439.1680 . 
<smiles></smiles>

5m: ${ }^{1} \mathrm{H}$ NMR (600 MHz, $\left.\mathrm{CDCl}_{3}\right): \delta 8.22(\mathrm{~d}, J=8.4 \mathrm{~Hz}, 2 \mathrm{H}), 7.97-7.99(\mathrm{~m}, 2 \mathrm{H}), 7.48-$ $7.51(\mathrm{~m}, 7 \mathrm{H}), 7.46(\mathrm{t}, J=8.4 \mathrm{~Hz}, 2 \mathrm{H}), 7.40(\mathrm{t}, J=5.4 \mathrm{~Hz}, 1 \mathrm{H}), 7.34(\mathrm{t}, J=7.8 \mathrm{~Hz}, 1 \mathrm{H})$, $7.03(\mathrm{~s}, 1 \mathrm{H}), 3.29$ (s, 3H); ${ }^{13} \mathrm{C} \mathrm{NMR}\left(150 \mathrm{MHz}, \mathrm{CDCl}_{3}\right): \delta$ 158.5, 154.6, 130.8, 130.6, 130.3, 129.6, 128.9, 128.0, 127.8, 127.8, 127.7, 127.6, 127.2, 125.1, 123.9, 121.5, 106.9, 102.4, 50.4; HRMS Calculated for $\left[\mathrm{C}_{25} \mathrm{H}_{19} \mathrm{~N}_{3} \mathrm{O}_{2}\right]^{+}: 393.1477$, Found: 393.1475.<smiles></smiles>

5n: ${ }^{1} \mathrm{H}$ NMR $\left(600 \mathrm{MHz}, \mathrm{CDCl}_{3}\right): \delta 7.70(\mathrm{~m}, 2 \mathrm{H}), 7.54(\mathrm{~d}, J=3.0 \mathrm{~Hz}, 1 \mathrm{H}), 7.43(\mathrm{~m}, 3 \mathrm{H})$, $6.39(\mathrm{~d}, J=3.0 \mathrm{~Hz}, 1 \mathrm{H}), 3.68(\mathrm{~s}, 3 \mathrm{H}), 2.76(\mathrm{~s}, 3 \mathrm{H}) ;{ }^{13} \mathrm{C} \mathrm{NMR}\left(150 \mathrm{MHz}, \mathrm{CDCl}_{3}\right): \delta$ $159.5,154.6,131.2,129.9,129.2,127.7,121.1,109.3,107.2,102.2$, 50.6, 14.0; HRMS Calculated for $\left[\mathrm{C}_{14} \mathrm{H}_{13} \mathrm{~N}_{3} \mathrm{O}_{2}+\mathrm{H}\right]^{+}: 256.1086$, Found: 256.1092 .<smiles></smiles>

7m: ${ }^{1} \mathrm{H}$ NMR (600 MHz, $\left.\mathrm{CDCl}_{3}\right): \delta 8.27(\mathrm{~d}, J=7.2 \mathrm{~Hz}, 2 \mathrm{H}), 7.94(\mathrm{~d}, J=7.2 \mathrm{~Hz}, 2 \mathrm{H})$, $7.86(\mathrm{~s}, 1 \mathrm{H}), 7.65(\mathrm{~d}, J=7.2 \mathrm{~Hz}, 2 \mathrm{H}), 7.45-7.51(\mathrm{~m}, 6 \mathrm{H}), 7.38(\mathrm{t}, J=7.2 \mathrm{~Hz}, 1 \mathrm{H}), 7.28$ $(\mathrm{q}, J=7.8 \mathrm{~Hz}, 2 \mathrm{H}), 7.19(\mathrm{~s}, 1 \mathrm{H}) ;{ }^{13} \mathrm{C} \mathrm{NMR}\left(150 \mathrm{MHz}, \mathrm{CDCl}_{3}\right): \delta 148.1,131.3,129.8$, 129.2, 128.8, 128.7, 128.6, 126.4, 126.2, 126.1, 123.8, 123.8, 117.9, 116.0, 103.4, 94.2; HRMS Calculated for $\left[\mathrm{C}_{23} \mathrm{H}_{17} \mathrm{~N}_{3}+\mathrm{H}\right]^{+}: 336.1495$, Found: 336.1498 .<smiles></smiles>

7n: (known compound, See: Namba, K.; Osawa, A.; Ishizaka, S.; Kitamura, N.; Tanino K. J. Am. Chem. Soc. 2011, 133, 11466-11469.) ${ }^{1} \mathrm{H}$ NMR (600 MHz, $\left.\mathrm{CDCl}_{3}\right)$ : d 7.79 (d, $J$ $=7.8 \mathrm{~Hz}, 2 \mathrm{H}), 7.39-7.43(\mathrm{~m}, 3 \mathrm{H}), 7.34(\mathrm{t}, J=7.2 \mathrm{~Hz}, 1 \mathrm{H}), 7.16($ br s, $1 \mathrm{H}), 6.34(\mathrm{~d}, J=$ $2.4 \mathrm{~Hz}, 1 \mathrm{H}), 2.42(\mathrm{~s}, 3 \mathrm{H}) ;{ }^{13} \mathrm{C} \mathrm{NMR}\left(150 \mathrm{MHz}, \mathrm{CDCl}_{3}\right): \delta 147.7,131.8,128.7,128.2$, $125.8,109.8,107.3,102.2,90.3,11.2$.<smiles></smiles> 
5o: ${ }^{1} \mathrm{H}$ NMR (400 MHz, $\left.\mathrm{CDCl}_{3}\right): \delta 8.26(\mathrm{~d}, J=7.6 \mathrm{~Hz}, 2 \mathrm{H}), 7.50(\mathrm{t}, J=8.0 \mathrm{~Hz}, 2 \mathrm{H})$, 7.29-7.42 (m, 10H), $7.20(\mathrm{t}, J=7.6 \mathrm{~Hz}, 1 \mathrm{H}), 7.16(\mathrm{~s}, 1 \mathrm{H}), 7.11(\mathrm{t}, J=7.6 \mathrm{~Hz}, 2 \mathrm{H}), 6.85$ $(\mathrm{d}, J=8.4 \mathrm{~Hz}, 2 \mathrm{H}), 2.23(\mathrm{~s}, 3 \mathrm{H}) ;{ }^{13} \mathrm{C}$ NMR $\left(100 \mathrm{MHz}, \mathrm{CDCl}_{3}\right): \delta 179.0,153.5,141.8$, 136.1, 131.1, 130.0, 129.5, 129.3, 128.9, 128.5, 128.3, 128.1, 127.9, 127.6, 127.5, 127.4, 127.3, 125.3, 124.3, 122.0, 113.3, 107.0, 21.4; HRMS Calculated for $\left[\mathrm{C}_{31} \mathrm{H}_{23} \mathrm{~N}_{3} \mathrm{O}\right]^{+}$: 453.1841, Found: 453.1837.

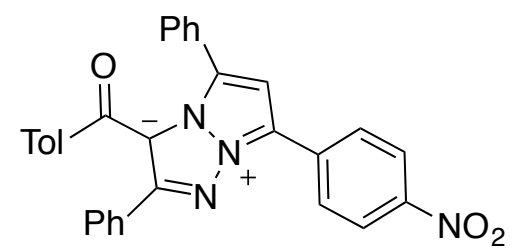

5p: ${ }^{1} \mathrm{H}$ NMR (400 MHz, $\mathrm{CDCl}_{3}$ ): $\delta 8.44(\mathrm{~d}, J=9.2 \mathrm{~Hz}, 2 \mathrm{H}), 8.35$ (d, $\left.J=8.8 \mathrm{~Hz}, 2 \mathrm{H}\right)$, $7.43(\mathrm{~d}, J=8.0 \mathrm{~Hz}, 2 \mathrm{H}), 7.38-7.40(\mathrm{~m}, 5 \mathrm{H}), 7.23-7.36(\mathrm{~m}, 3 \mathrm{H}), 7.27$ (s, $1 \mathrm{H}), 7.19$ (t, $J=$ $7.6 \mathrm{~Hz}, 2 \mathrm{H}), 6.89(\mathrm{~d}, J=8.0 \mathrm{~Hz}, 2 \mathrm{H}), 2.25(\mathrm{~s}, 3 \mathrm{H}) ;{ }^{13} \mathrm{C} \mathrm{NMR}\left(100 \mathrm{MHz}, \mathrm{CDCl}_{3}\right): \delta$ $179.8,153.1,146.1,142.6,135.5,133.6,130.5,129.9,129.6,128.9,128.8,128.6,128.5$, 127.9, 127.6, 127.3, 124.9, 124.5, 124.5, 119.1, 113.6, 108.2, 21.5; HRMS Calculated for $\left[\mathrm{C}_{31} \mathrm{H}_{22} \mathrm{~N}_{4} \mathrm{O}_{3}\right]^{+}: 498.1692$, Found: 498.1688 .<smiles></smiles>

5q: ${ }^{1} \mathrm{H}$ NMR (400 MHz, $\left.\mathrm{CDCl}_{3}\right): \delta 8.38(\mathrm{~d}, J=8.8 \mathrm{~Hz}, 2 \mathrm{H}), 7.77(\mathrm{~d}, J=8.4 \mathrm{~Hz}, 2 \mathrm{H})$, $7.43(\mathrm{~d}, J=8.0 \mathrm{~Hz}, 2 \mathrm{H}), 7.22-7.39(\mathrm{~m}, 8 \mathrm{H}), 7.22(\mathrm{~s}, 1 \mathrm{H}), 7.16(\mathrm{t}, J=7.6 \mathrm{~Hz}, 2 \mathrm{H}), 6.89$ $(\mathrm{d}, J=7.6 \mathrm{~Hz}, 2 \mathrm{H}), 2.25(\mathrm{~s}, 3 \mathrm{H}) ;{ }^{13} \mathrm{C}$ NMR $\left(100 \mathrm{MHz}, \mathrm{CDCl}_{3}\right): \delta 179.6,153.2,142.5$, 135.6, 132.7, 131.7, 130.6, 129.9, 129.6, 128.9, 128.8, 128.5, 128.4, 127.8, 127.6, 127.3, $125.0,124.4,119.4,118.9,113.5,110.3,107.8,21.5$; HRMS Calculated for $\left[\mathrm{C}_{32} \mathrm{H}_{22} \mathrm{~N}_{4} \mathrm{O}\right]^{+}:$478.1794, Found: 478.1790 .<smiles></smiles>

5r: ${ }^{1} \mathrm{H}$ NMR $\left(600 \mathrm{MHz}, \mathrm{CDCl}_{3}\right): \delta 8.23(\mathrm{dd}, J=8.4,1.2 \mathrm{~Hz}, 2 \mathrm{H}), 7.98(\mathrm{dd}, J=7.8,1.8$ $\mathrm{Hz}, 2 \mathrm{H}), 7.44-7.52(\mathrm{~m}, 9 \mathrm{H}), 7.27$ (s, $1 \mathrm{H}), 7.39$ (tt, $J=7.2,1.2 \mathrm{~Hz}, 1 \mathrm{H}), 7.35$ (tt, $J=7.2$, $1.2 \mathrm{~Hz}, 1 \mathrm{H}), 7.05(\mathrm{~s}, 3 \mathrm{H}), 3.86(\mathrm{q}, J=7.2 \mathrm{~Hz}, 2 \mathrm{H}), 0.73(\mathrm{~d}, J=7.2 \mathrm{~Hz}, 3 \mathrm{H}) ;{ }^{13} \mathrm{C}$ NMR $\left(150 \mathrm{MHz}, \mathrm{CDCl}_{3}\right): \delta 158.3,154.7,130.8,130.7,130.4,129.6,128.9,128.0,127.9$, $127.7,127.7,127.7,126.8,125.1,123.7,121.6,106.9,102.7,59.9,13.5$; HRMS Calculated for $\left[\mathrm{C}_{26} \mathrm{H}_{21} \mathrm{~N}_{3} \mathrm{O}_{2}\right]^{+}: 407.1634$, Found: 407.1630. 
<smiles></smiles>

5s: ${ }^{1} \mathrm{H}$ NMR (600 MHz, $\left.\mathrm{CDCl}_{3}\right): \delta 8.40(\mathrm{~d}, J=9.0 \mathrm{~Hz}, 2 \mathrm{H}), 8.35(\mathrm{~d}, J=8.4 \mathrm{~Hz}, 2 \mathrm{H})$, 7.97-7.98 (m, 2H), 7.43-7.52 (m, 8H), $7.17(\mathrm{~s}, 1 \mathrm{H}), 3.87$ (q, $J=7.2 \mathrm{~Hz}, 2 \mathrm{H}), 0.75(\mathrm{~d}, J=$ $7.2 \mathrm{~Hz}, 3 \mathrm{H}) ;{ }^{13} \mathrm{C}$ NMR $\left(150 \mathrm{MHz}, \mathrm{CDCl}_{3}\right): \delta 158.0,154.4,146.0,133.7,130.3,130.2$, $130.1,130.0,128.5,128.1,127.9,127.0,124.7,124.5,124.3,118.8,108.2,104.0,60.4$, 13.4; HRMS Calculated for $\left[\mathrm{C}_{26} \mathrm{H}_{20} \mathrm{~N}_{4} \mathrm{O}_{4}\right]^{+}: 452.1485$, Found: 452.1484 .<smiles>CCOC(=O)C1C(c2ccccc2)=N[n+]2c(-c3ccc(C#N)cc3)cc(-c3ccccc3)n21</smiles>

5t: ${ }^{1} \mathrm{H}$ NMR $\left(600 \mathrm{MHz}, \mathrm{CDCl}_{3}\right): \delta 8.35(\mathrm{~d}, J=8.4 \mathrm{~Hz}, 2 \mathrm{H}), 7.95-7.97(\mathrm{~m}, 2 \mathrm{H}), 7.76(\mathrm{~d}, J$ $=9.0 \mathrm{~Hz}, 2 \mathrm{H}), 7.42-7.51(\mathrm{~m}, 8 \mathrm{H}), 7.12(\mathrm{~s}, 1 \mathrm{H}), 3.86(\mathrm{q}, J=7.2 \mathrm{~Hz}, 2 \mathrm{H}), 0.74(\mathrm{~d}, J=7.2$ $\mathrm{Hz}, 3 \mathrm{H}) ;{ }^{13} \mathrm{C}$ NMR $\left(150 \mathrm{MHz}, \mathrm{CDCl}_{3}\right): \delta 158.1,154.4,132.7,131.8,130.4,130.3,130.2$, $129.8,128.4,128.0,127.9,126.9,124.8,124.1,119.1,119.0,110.1,107.8,103.7,60.3$, 13.4; HRMS Calculated for $\left[\mathrm{C}_{27} \mathrm{H}_{20} \mathrm{~N}_{4} \mathrm{O}_{2}\right]^{+}: 432.1586$, Found: 432.1585.<smiles></smiles>

6a: ${ }^{1} \mathrm{H}$ NMR (400 MHz, $\left.\mathrm{CDCl}_{3}\right): \delta 8.13(\mathrm{~d}, J=7.2 \mathrm{~Hz}, 2 \mathrm{H}), 7.49(\mathrm{t}, J=7.2 \mathrm{~Hz}, 2 \mathrm{H})$, 7.39-7.45 (m, 5H), $7.34(\mathrm{t}, J=7.2 \mathrm{~Hz}, 1 \mathrm{H}), 7.05(\mathrm{~s}, 1 \mathrm{H}), 4.03(\mathrm{~s}, 3 \mathrm{H}), 3.50(\mathrm{~s}, 3 \mathrm{H})$;

${ }^{13} \mathrm{C}$ NMR $\left(100 \mathrm{MHz}, \mathrm{CDCl}_{3}\right): \delta 161.7,157.4,144.6,129.5,128.9,128.5,128.1,127.8$, 127.6, 126.9, 125.1, 123.8, 122.0, 108.2, 103.8, 53.1, 51.3; HRMS Calculated for $\left[\mathrm{C}_{21} \mathrm{H}_{17} \mathrm{~N}_{3} \mathrm{O}_{4}\right]^{+}: 375.1219$, Found: 375.1218 .<smiles></smiles>

6b: ${ }^{1} \mathrm{H}$ NMR (400 MHz, $\left.\mathrm{CDCl}_{3}\right): \delta 8.28(\mathrm{~d}, J=8.4 \mathrm{~Hz}, 2 \mathrm{H}), 7.77(\mathrm{~d}, J=8.4 \mathrm{~Hz}, 2 \mathrm{H})$, 7.40-7.48 (m, 5H), $7.16(\mathrm{~s}, 1 \mathrm{H}), 4.05(\mathrm{~s}, 3 \mathrm{H}), 3.52(\mathrm{~s}, 3 \mathrm{H}) ;{ }^{13} \mathrm{C}$ NMR $\left(100 \mathrm{MHz}, \mathrm{CDCl}_{3}\right)$ : $\delta 161.3,157.2,144.2,132.7,131.1,129.1,128.9,127.9,127.9,125.0,124.1,119.5$, 118.8, 110.7, 109.1, 105.0, 53.3, 51.7; HRMS Calculated for $\left[\mathrm{C}_{22} \mathrm{H}_{16} \mathrm{~N}_{4} \mathrm{O}_{4}\right]^{+}: 400.1172$, Found: 400.1171 . 
<smiles></smiles>

6c: ${ }^{1} \mathrm{H}$ NMR $\left(600 \mathrm{MHz}, \mathrm{CDCl}_{3}\right): \delta 8.22(\mathrm{~d}, J=8.4 \mathrm{~Hz}, 2 \mathrm{H}), 8.14(\mathrm{~d}, J=8.4 \mathrm{~Hz}, 2 \mathrm{H})$, 7.41-7.46 (m, 5H), $7.14(\mathrm{~s}, 1 \mathrm{H}), 4.05(\mathrm{~s}, 3 \mathrm{H}), 3.94(\mathrm{~s}, 3 \mathrm{H}), 3.51(\mathrm{~s}, 3 \mathrm{H}) ;{ }^{13} \mathrm{C}$ NMR $(150$ $\left.\mathrm{MHz}_{\mathrm{CDCl}}\right): \delta 166.5,161.5,157.3,144.4,131.1,130.2,129.3,129.0,128.7,127.9$, 127.8, 124.6, 124.0, 120.6, 109.0, 104.5, 53.2, 52.2, 51.5; HRMS Calculated for $\left[\mathrm{C}_{23} \mathrm{H}_{19} \mathrm{~N}_{3} \mathrm{O}_{6}\right]^{+}: 433.1274$, Found: 433.1274 .<smiles>COC(=O)C1=[N+]n2c(-c3ccc(F)cc3)cc(-c3ccccc3)[n+]2N1</smiles>

6d: ${ }^{1} \mathrm{H}$ NMR (600 MHz, $\left.\mathrm{CDCl}_{3}\right): \delta 8.11-8.14(\mathrm{~m}, 2 \mathrm{H}), 7.40-7.45(\mathrm{~m}, 5 \mathrm{H}), 7.18(\mathrm{t}, J=8.4$ $\mathrm{Hz}, 2 \mathrm{H}), 7.00(\mathrm{~s}, 1 \mathrm{H}), 4.03(\mathrm{~s}, 3 \mathrm{H}), 3.51(\mathrm{~s}, 3 \mathrm{H}) ;{ }^{13} \mathrm{C} \mathrm{NMR}\left(150 \mathrm{MHz}, \mathrm{CDCl}_{3}\right): \delta 162.3$ $(\mathrm{d}, J=247.2 \mathrm{~Hz}), 161.7,157.4,144.6,129.5,128.6,127.8$ (d, $J=26.4 \mathrm{~Hz}), 127.1$ (d, $J=$ $7.9 \mathrm{~Hz}), 123.8,123.3,123.3,121.1,116.1,115.9,108.0,103.9$, 53.2, 51.3; HRMS Calculated for $\left[\mathrm{C}_{21} \mathrm{H}_{16} \mathrm{FN}_{3} \mathrm{O}_{4}\right]^{+}: 393.1125$, Found: 393.1124 .<smiles></smiles>

6e: ${ }^{1} \mathrm{H}$ NMR $\left(600 \mathrm{MHz}, \mathrm{CDCl}_{3}\right): \delta 8.07(\mathrm{~d}, J=9.0 \mathrm{~Hz}, 2 \mathrm{H}), 7.40-7.45(\mathrm{~m}, 5 \mathrm{H}), 7.02(\mathrm{~d}, J$ $=9.0 \mathrm{~Hz}, 2 \mathrm{H}), 6.96(\mathrm{~s}, 1 \mathrm{H}), 4.03(\mathrm{~s}, 3 \mathrm{H}), 3.86(\mathrm{~s}, 3 \mathrm{H}), 3.50(\mathrm{~s}, 3 \mathrm{H}) ;{ }^{13} \mathrm{C}$ NMR $(150 \mathrm{MHz}$, $\left.\mathrm{CDCl}_{3}\right): \delta 161.9,159.5,157.5,144.8,129.7,128.4,127.9,127.6,126.8,123.8,122.3$, 119.7, 114.4, 107.5, 103.5, 55.3, 53.1, 51.2; HRMS Calculated for $\left[\mathrm{C}_{22} \mathrm{H}_{19} \mathrm{~N}_{3} \mathrm{O}_{5}\right]^{+}$: 405.1325, Found: 405.1324.<smiles></smiles>

6f: ${ }^{1} \mathrm{H}$ NMR (600 MHz, $\left.\mathrm{CDCl}_{3}\right): \delta 8.07(\mathrm{~d}, J=7.8 \mathrm{~Hz}, 2 \mathrm{H}), 7.46(\mathrm{t}, J=7.8 \mathrm{~Hz}, 2 \mathrm{H}), 7.33$ $(\mathrm{t}, J=7.8 \mathrm{~Hz}, 1 \mathrm{H}), 6.77(\mathrm{~s}, 1 \mathrm{H}), 4.01(\mathrm{~s}, 3 \mathrm{H}), 3.85(\mathrm{~s}, 3 \mathrm{H}), 3.25(\mathrm{t}, J=7.8 \mathrm{~Hz}, 2 \mathrm{H}), 1.67$ (quin, $J=7.8 \mathrm{~Hz}, 2 \mathrm{H}), 1.43(\mathrm{sex}, J=7.8 \mathrm{~Hz}, 2 \mathrm{H}), 0.96(\mathrm{t}, J=7.8 \mathrm{~Hz}, 3 \mathrm{H}) ;{ }^{13} \mathrm{C} \mathrm{NMR}$ $\left(150 \mathrm{MHz}, \mathrm{CDCl}_{3}\right): \delta 162.3,158.2,145.2,128.8,127.9,127.2,126.1,125.1,121.4$, 106.6, 102.9, 53.1, 51.6, 30.9, 26.3, 22.1, 13.9; HRMS Calculated for $\left[\mathrm{C}_{19} \mathrm{H}_{21} \mathrm{~N}_{3} \mathrm{O}_{4}\right]^{+}$: 355.1532, Found: 355.1530 . 
<smiles>COC(=O)C1=Nn2nc(-c3ccccc3)cc2Oc2ccccc21</smiles>

6g: ${ }^{1} \mathrm{H}$ NMR $\left(600 \mathrm{MHz}, \mathrm{CDCl}_{3}\right): \delta 8.14(\mathrm{~d}, J=7.8 \mathrm{~Hz}, 2 \mathrm{H}), 7.53(\mathrm{~d}, J=8.4 \mathrm{~Hz}, 2 \mathrm{H})$, $7.50(\mathrm{~d}, J=8.4 \mathrm{~Hz}, 2 \mathrm{H}), 7.40(\mathrm{t}, J=7.5 \mathrm{~Hz}, 1 \mathrm{H}), 7.15(\mathrm{~s}, 1 \mathrm{H}), 4.05(\mathrm{~s}, 3 \mathrm{H}), 3.68(\mathrm{~s}, 3 \mathrm{H})$;

${ }^{13} \mathrm{C}$ NMR $\left(150 \mathrm{MHz}, \mathrm{CDCl}_{3}\right): \delta 161.5,157.4,144.9,133.6,131.4,129.1,128.7,128.1$, 126.5, 125.4, 123.0, 121.7, 118.6, 111.7, 108.7, 104.4, 53.3, 51.8; HRMS Calculated for $\left[\mathrm{C}_{22} \mathrm{H}_{16} \mathrm{~N}_{4} \mathrm{O}_{4}\right]^{+}: 400.1172$, Found: 400.1171 .

\section{S1.3 ORTEP Drawing of the Crystal Structures}

\section{ORTEP Drawing of the Crystal Structures for compound 3}

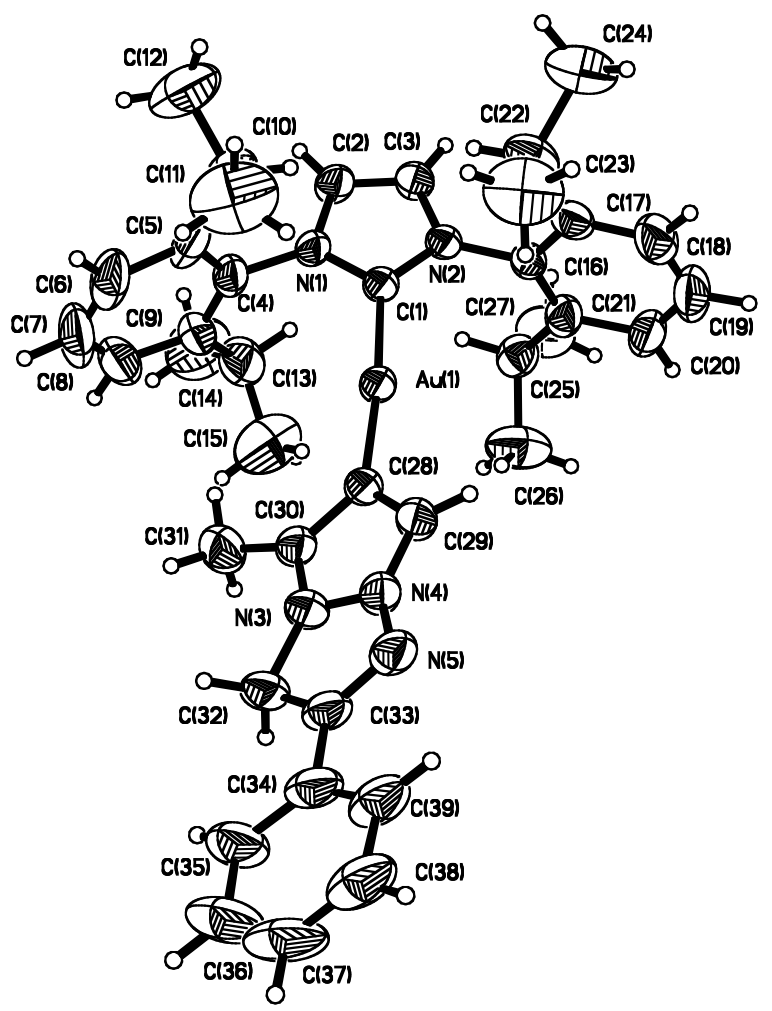

Perspective view of the molecular structure of $\mathrm{Au}\left(\mathrm{C}_{27} \mathrm{H}_{36} \mathrm{~N}_{2}\right)\left(\mathrm{C}_{12} \mathrm{H}_{11} \mathrm{~N}_{3}\right)^{+}$cation (molecule 1) with the atom labeling scheme. The thermal ellipsoids are scaled to $30 \%$ probability. CCDC number: 855874 


\section{ORTEP Drawing of the Crystal Structures for compound 5a}

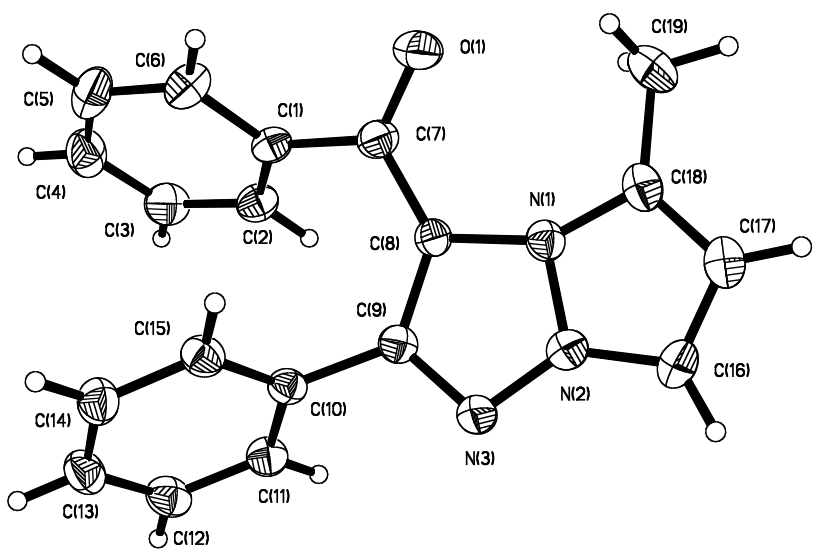

Perspective view of the molecular structure of $\mathrm{C}_{19} \mathrm{H}_{15} \mathrm{~N}_{3} \mathrm{O}$ with the atom labeling scheme. The thermal ellipsoids are scaled to enclose $30 \%$ probability. CCDC number: 855875

\section{ORTEP Drawing of the Crystal Structures for compound 51}

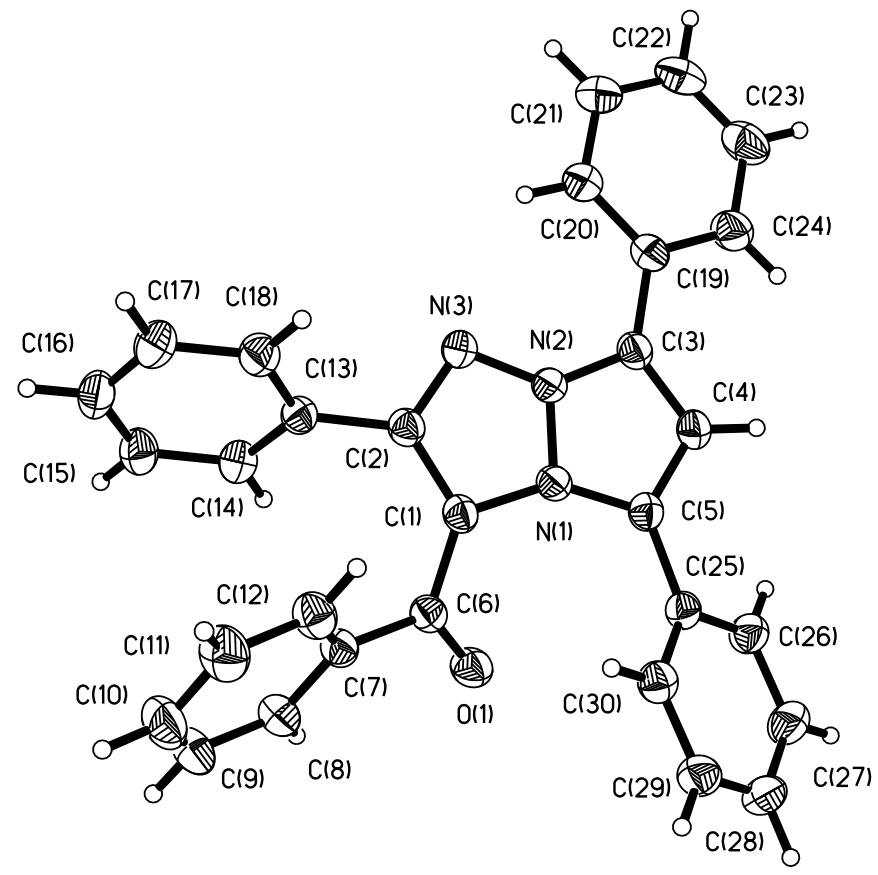

Perspective view of the molecular structure of $\mathrm{C}_{30} \mathrm{H}_{21} \mathrm{~N}_{3} \mathrm{O}$ with the atom labeling scheme provided for the non-hydrogen atoms. The thermal ellipsoids are scaled to enclose $30 \%$ probability. CCDC number: 987461 


\section{ORTEP Drawing of the Crystal Structures for compound $5 u$}

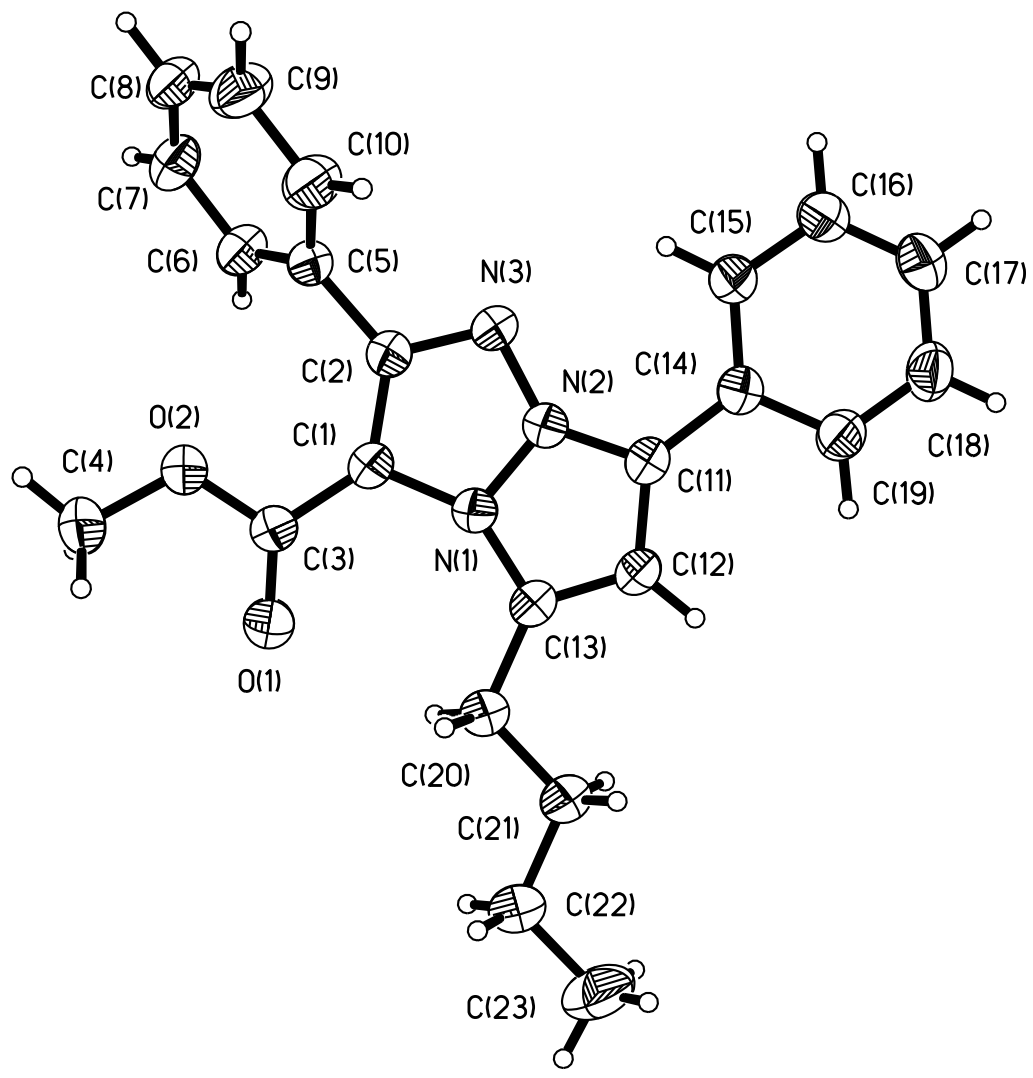

Perspective view of the molecular structure of $\mathrm{C}_{23} \mathrm{H}_{23} \mathrm{~N}_{3} \mathrm{O}_{2}$ with the atom labeling scheme provided for the non-hydrogen atoms. The thermal ellipsoids are scaled to enclose $30 \%$ probability. CCDC number: 987462 


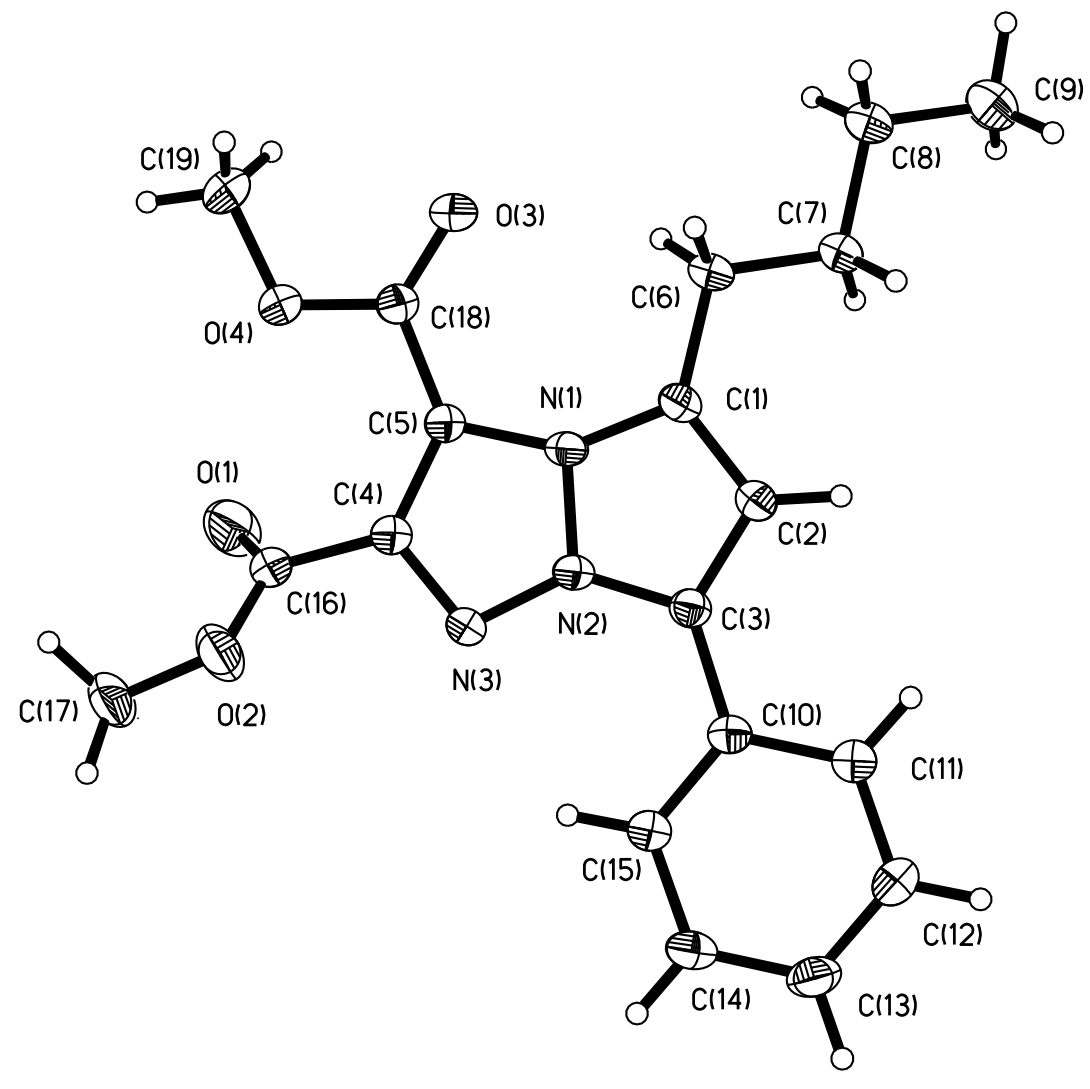

Perspective view of the molecular structure of $\mathrm{C}_{19} \mathrm{H}_{21} \mathrm{~N}_{3} \mathrm{O}_{4}$ with the atom labeling scheme provided for the non-hydrogen atoms. The thermal ellipsoids are scaled to enclose $30 \%$ probability. CCDC number: 987463 


\section{S1.4 Stability test}

The samples were prepared with $0.1 \mathrm{mmol}$ compounds dissolved in $0.5 \mathrm{~mL} \mathrm{CDCl}_{3}$ with ca. 0.3 equiv. 1,3,5-trimethoxybenzene as an internal standard. H-NMR spectra were monitored over two weeks.
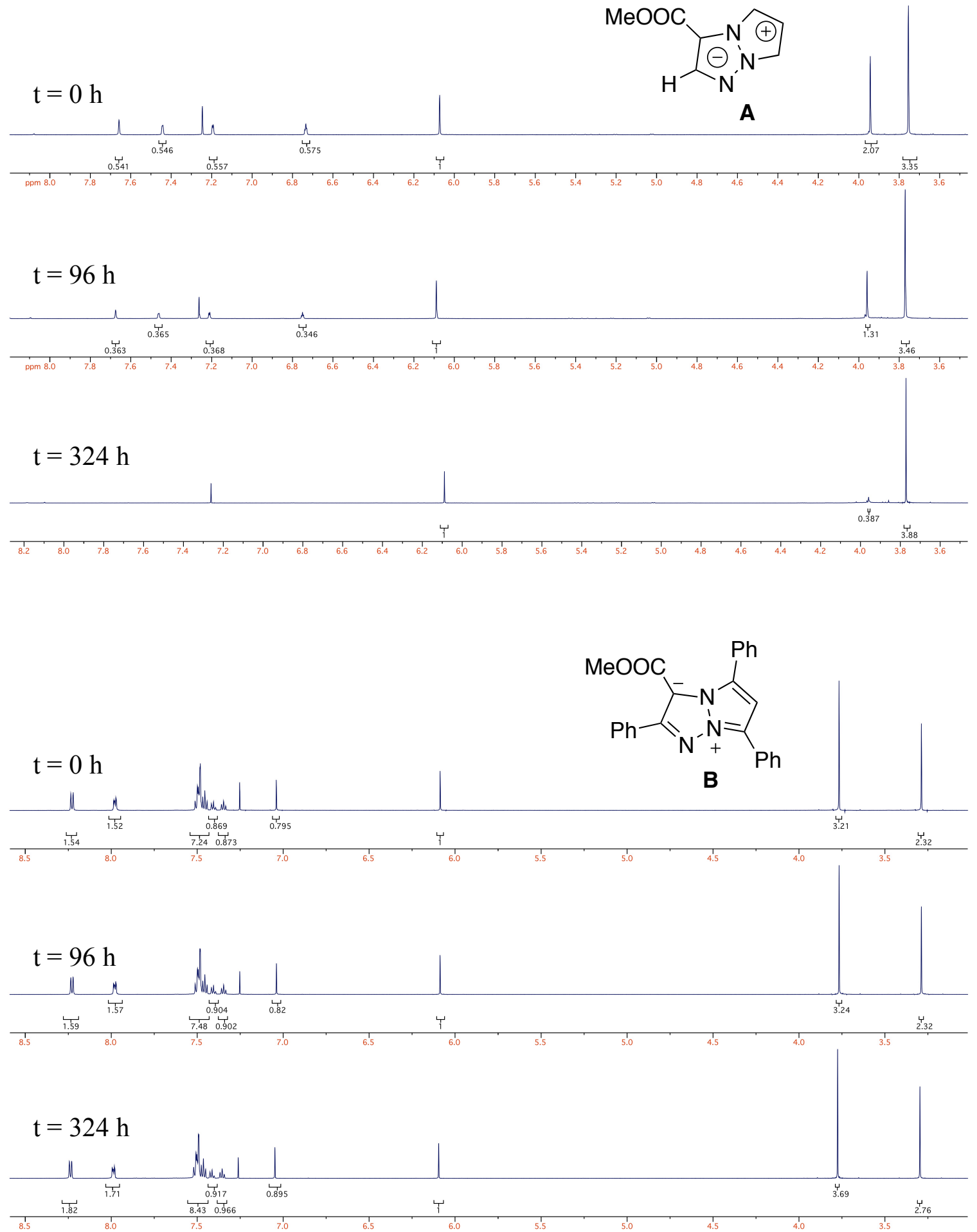

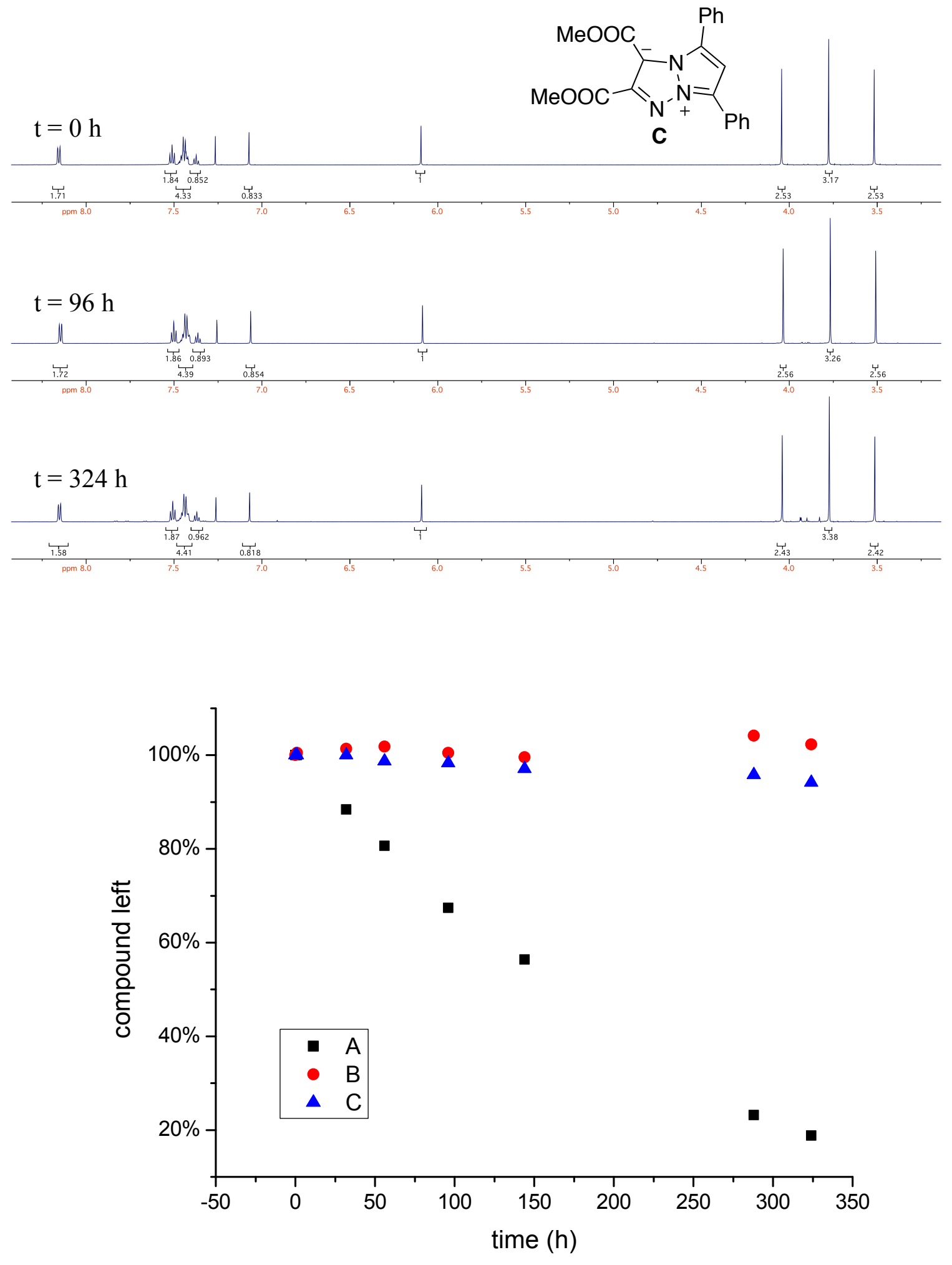


\section{S1.5 UV-Vis Spectra and Fluorescence Spectra}
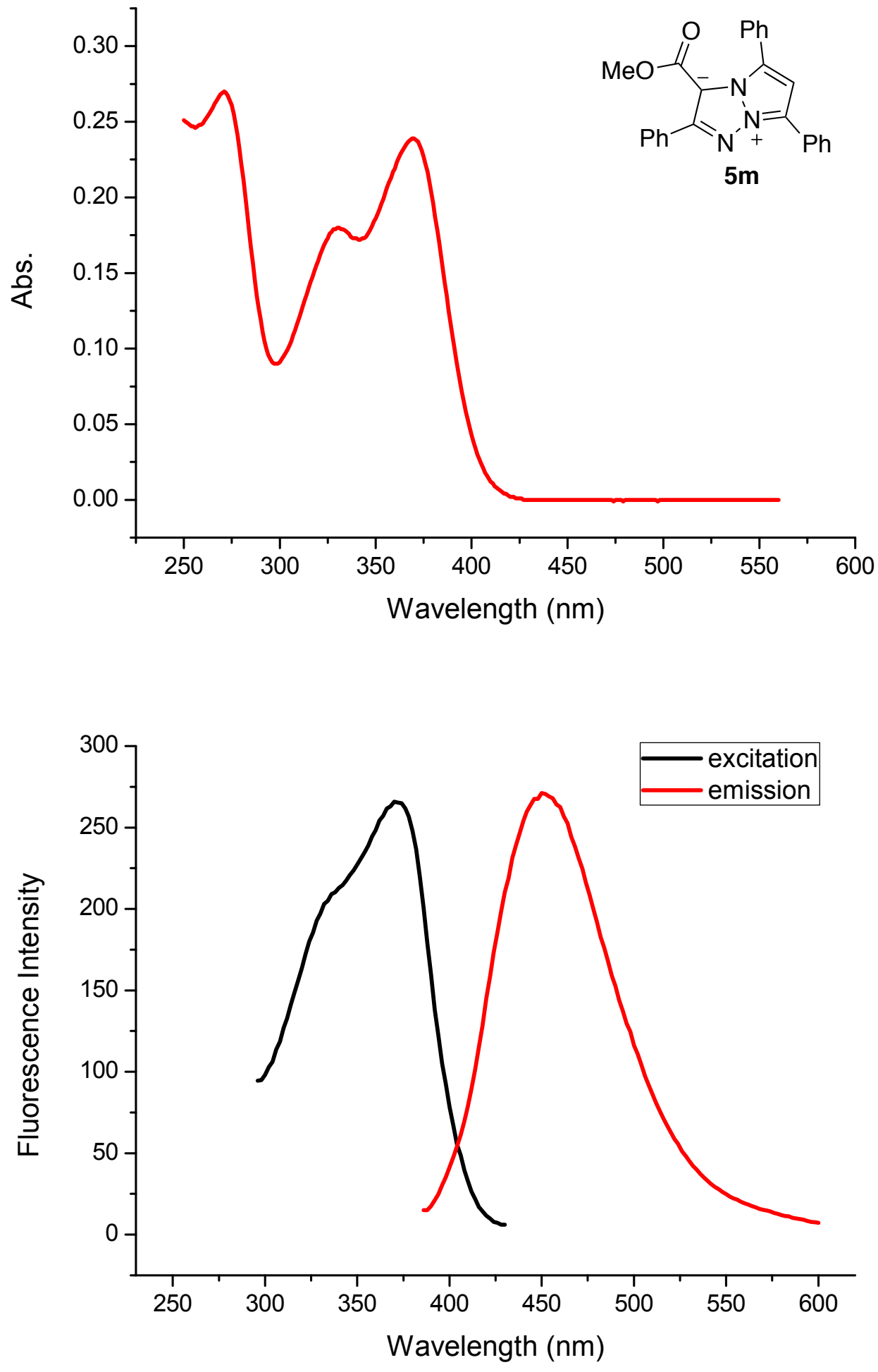

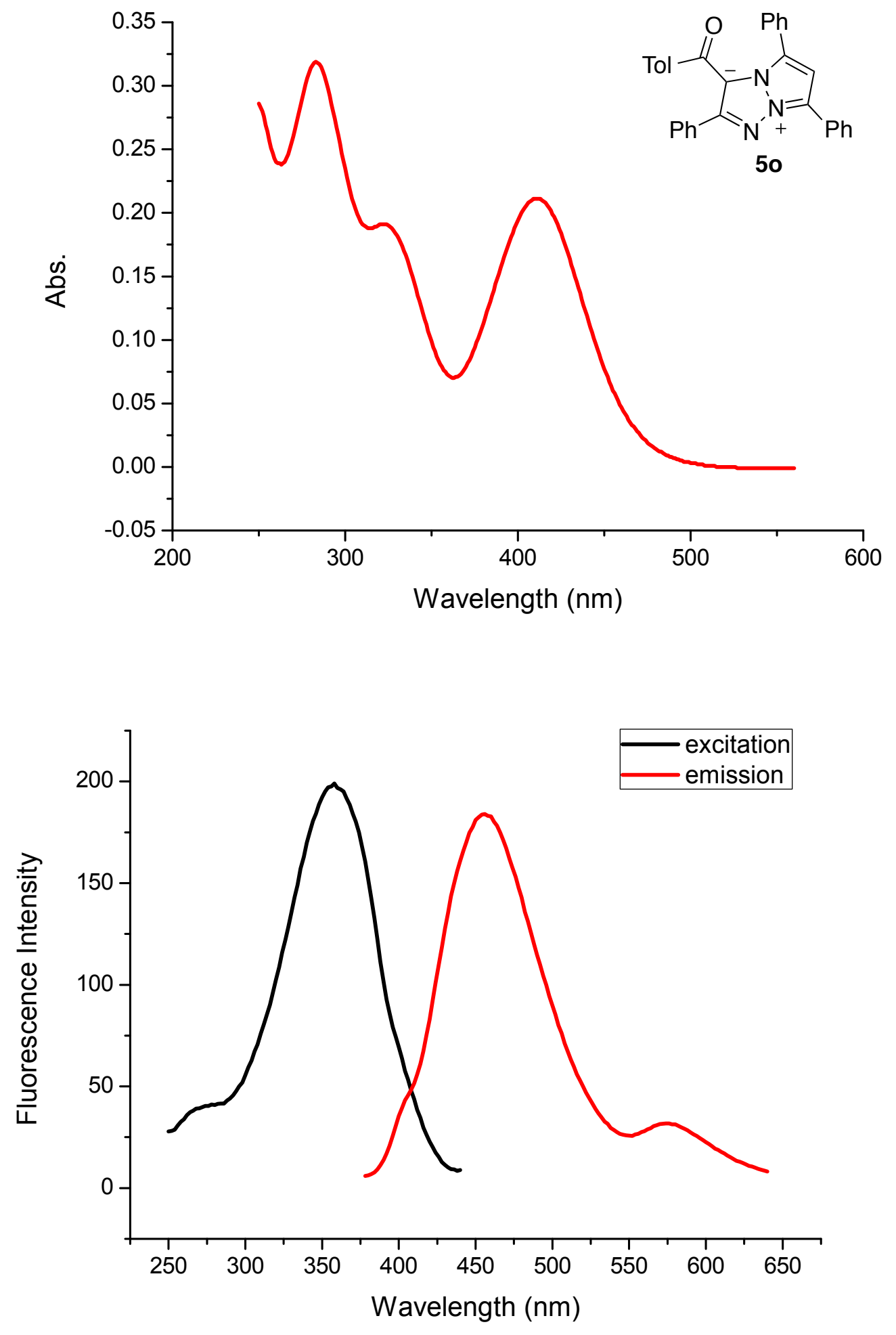

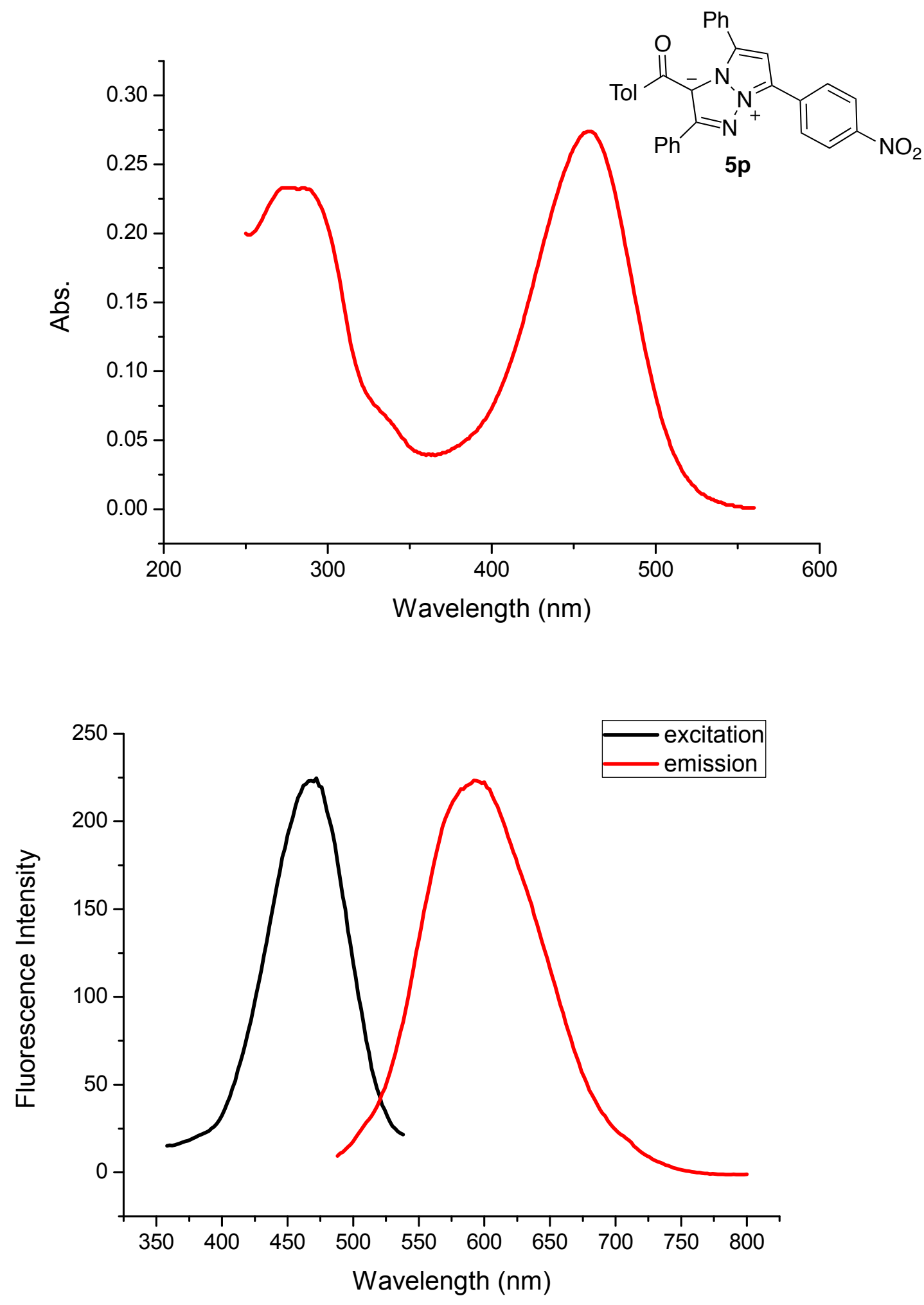

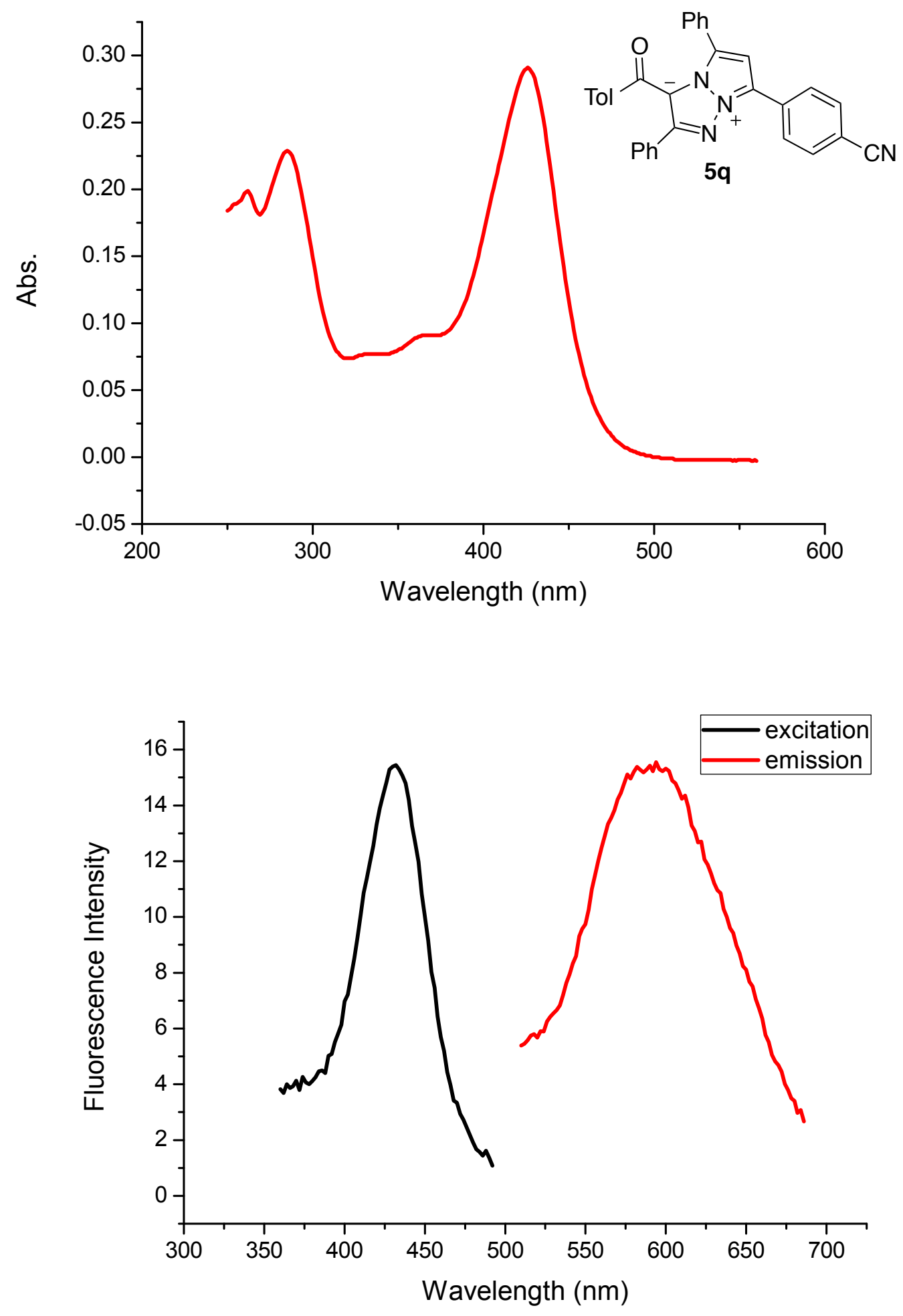

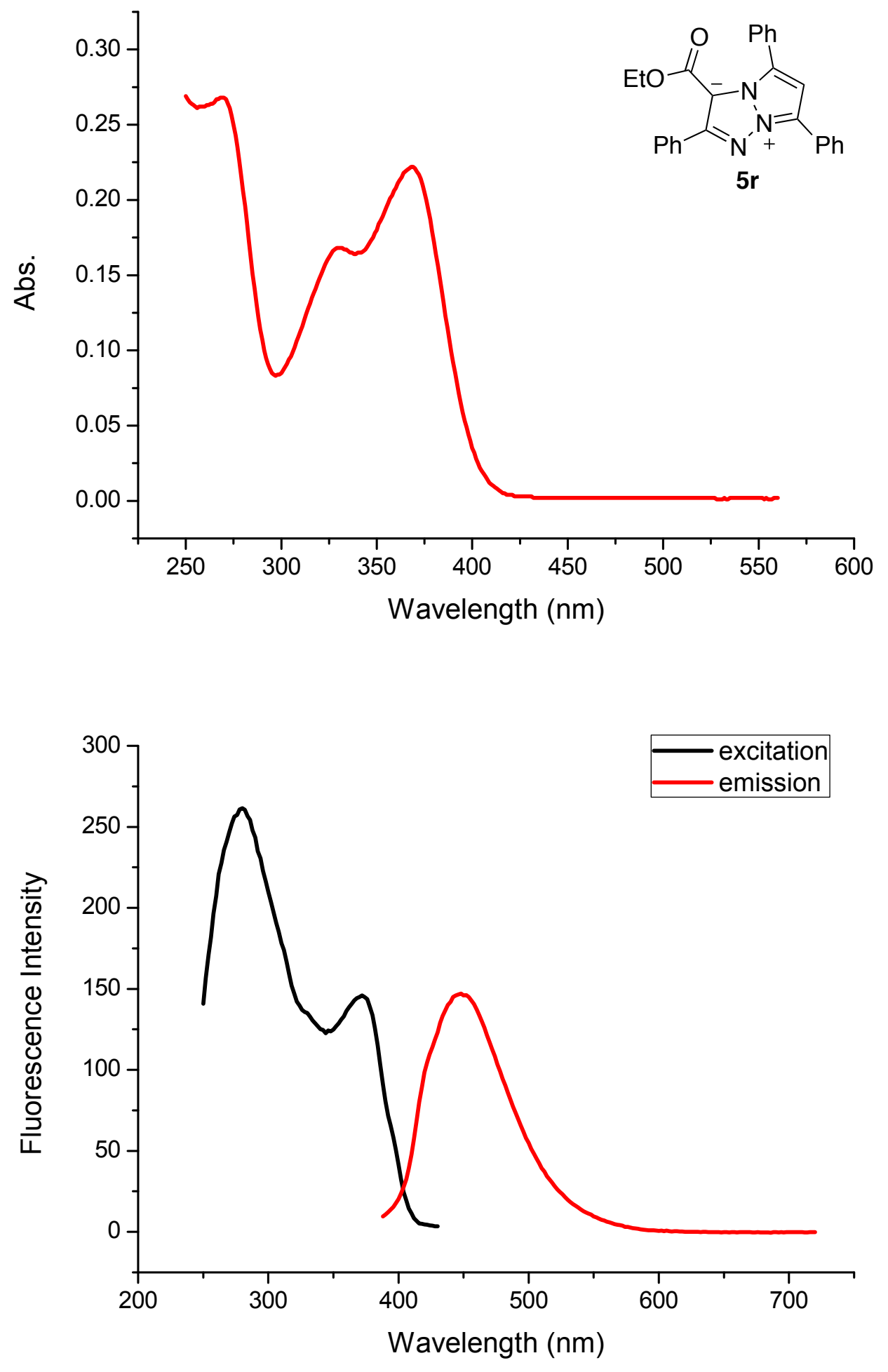

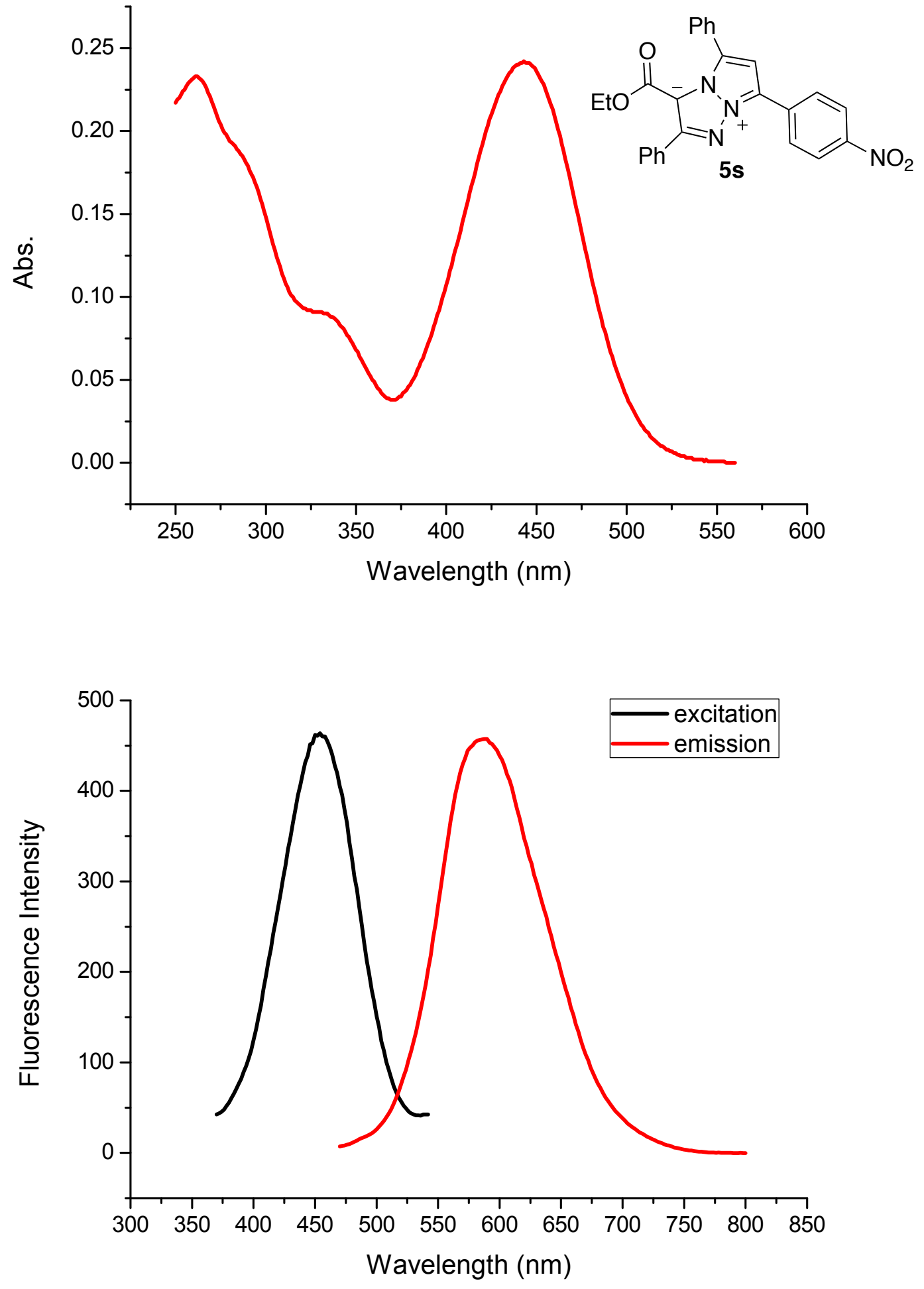

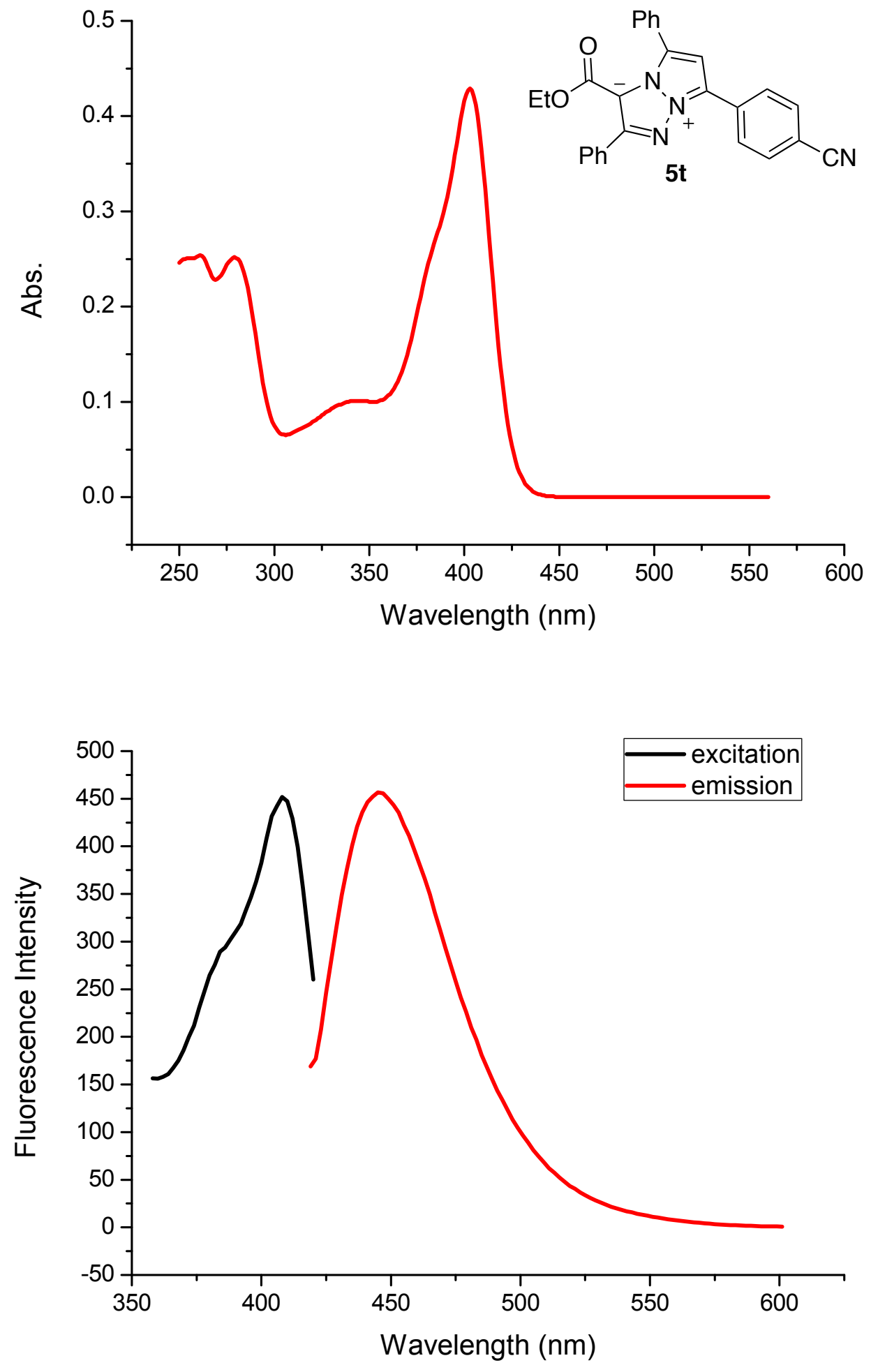

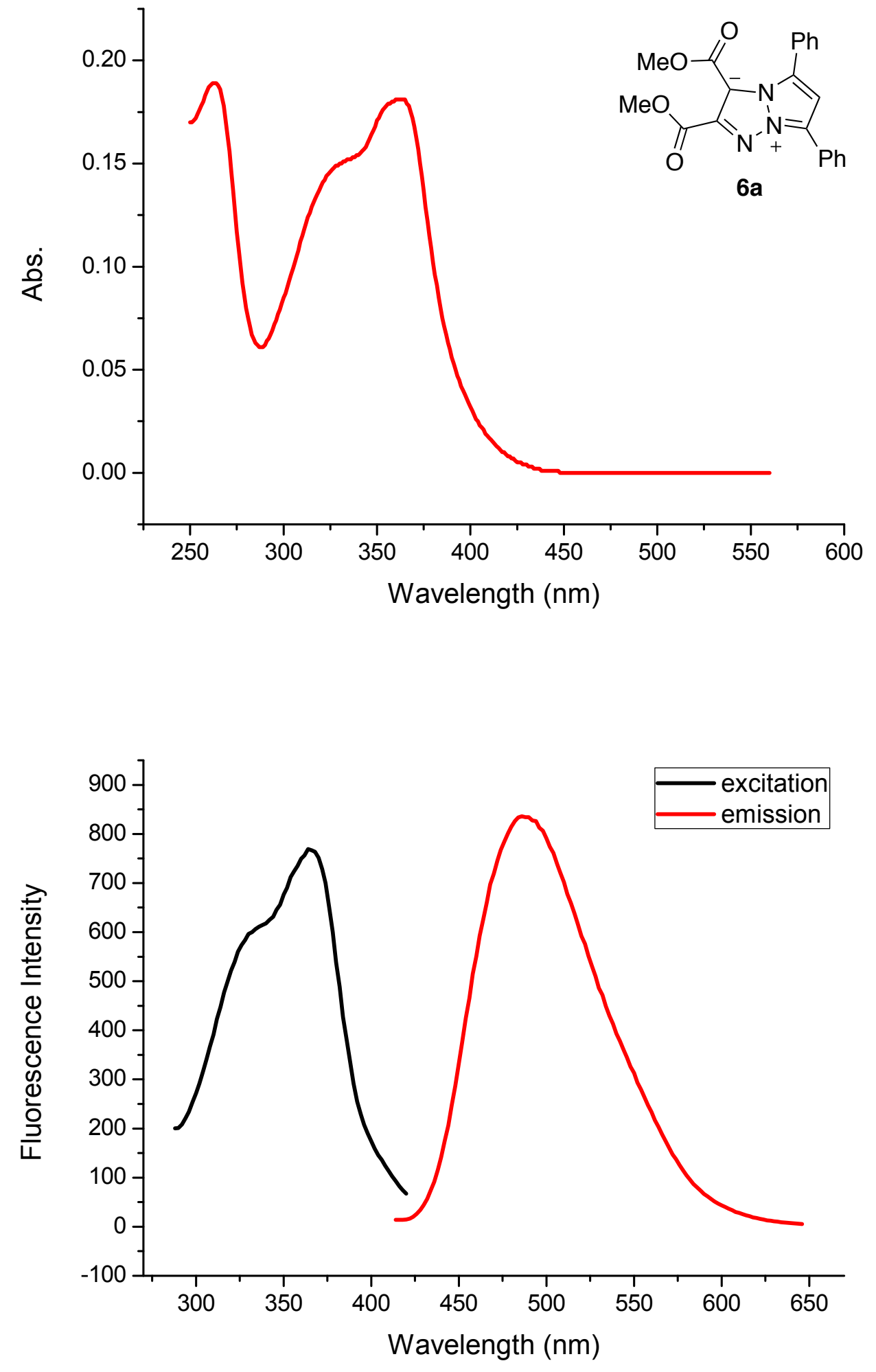

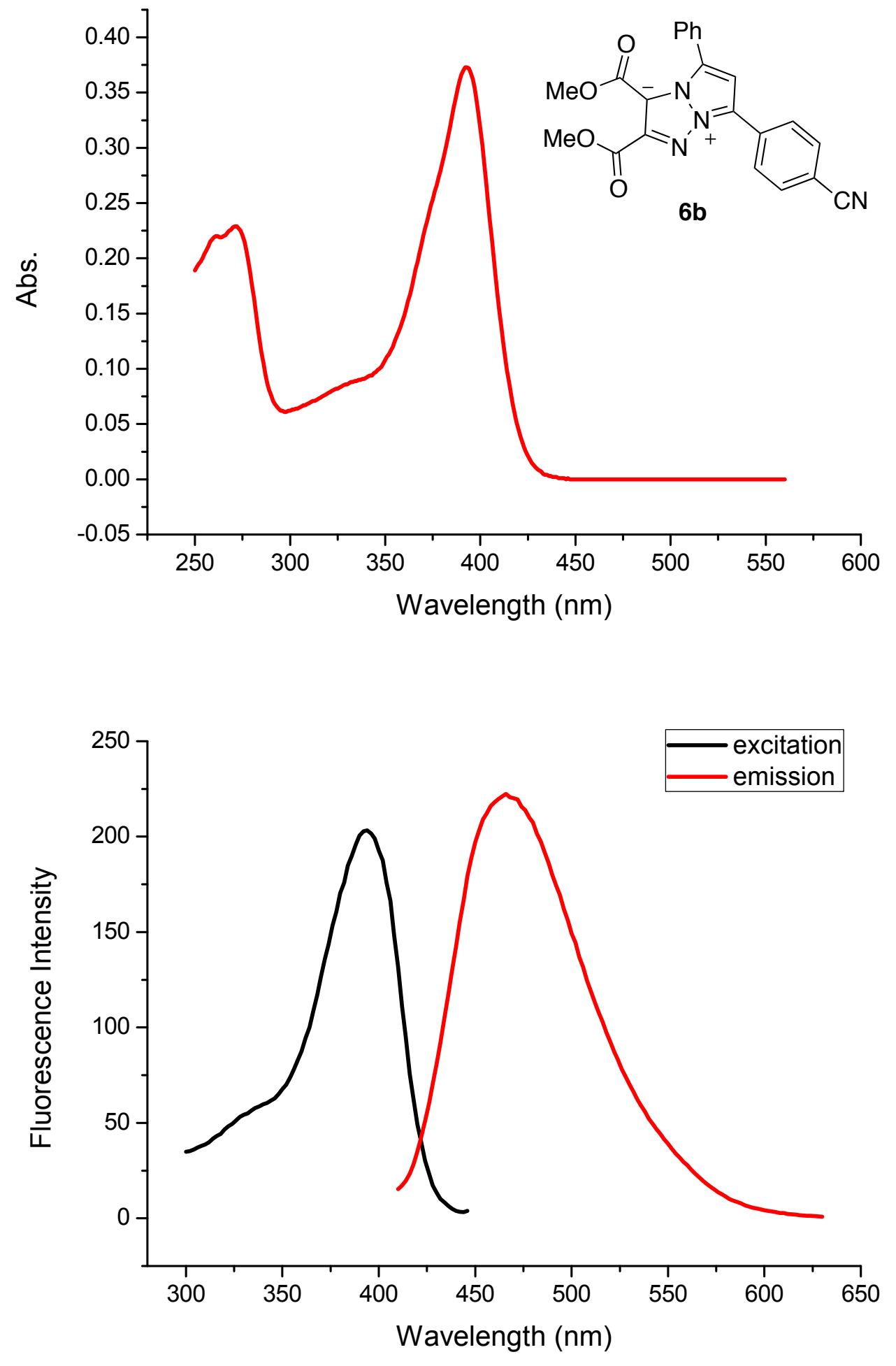

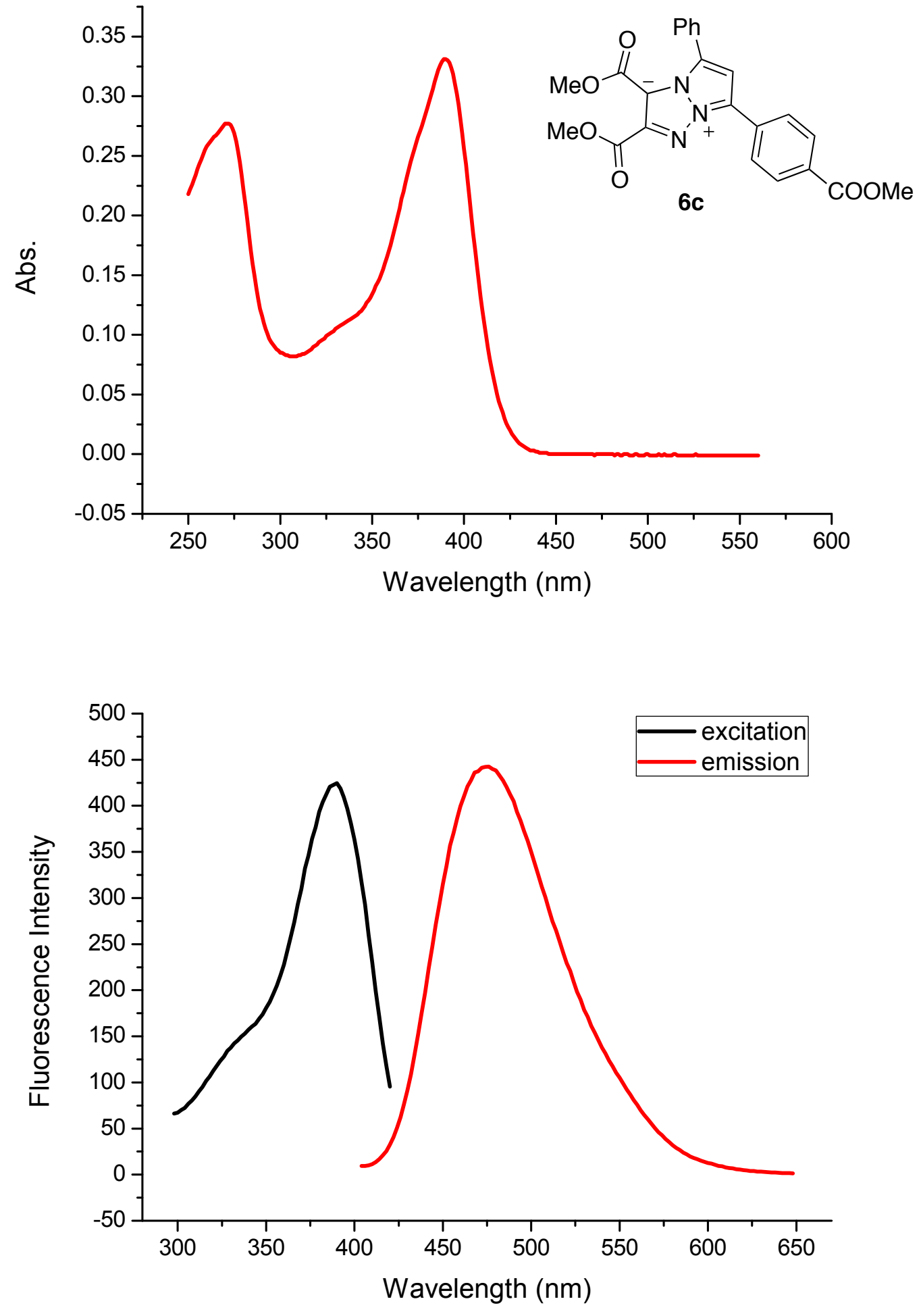

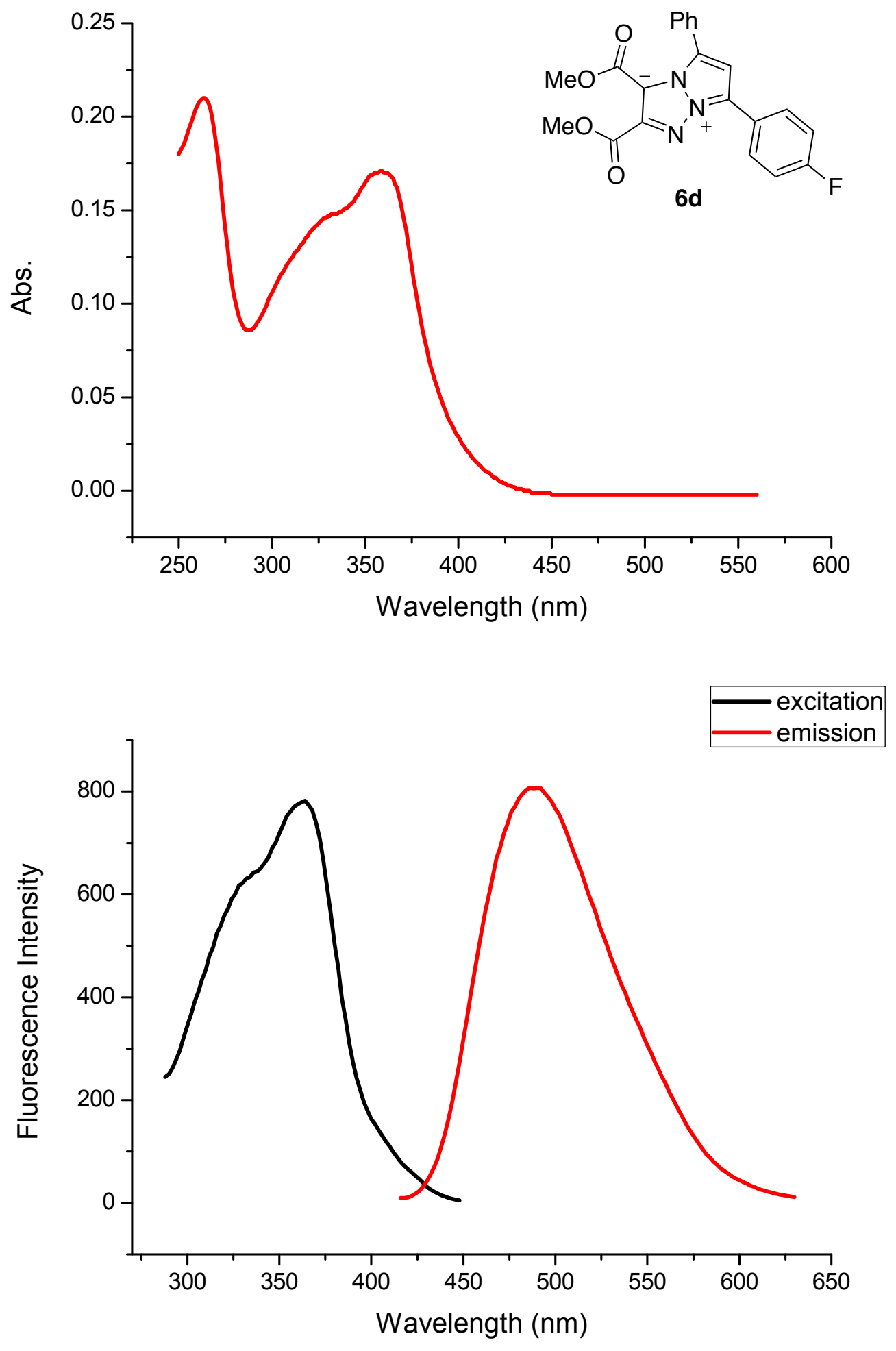

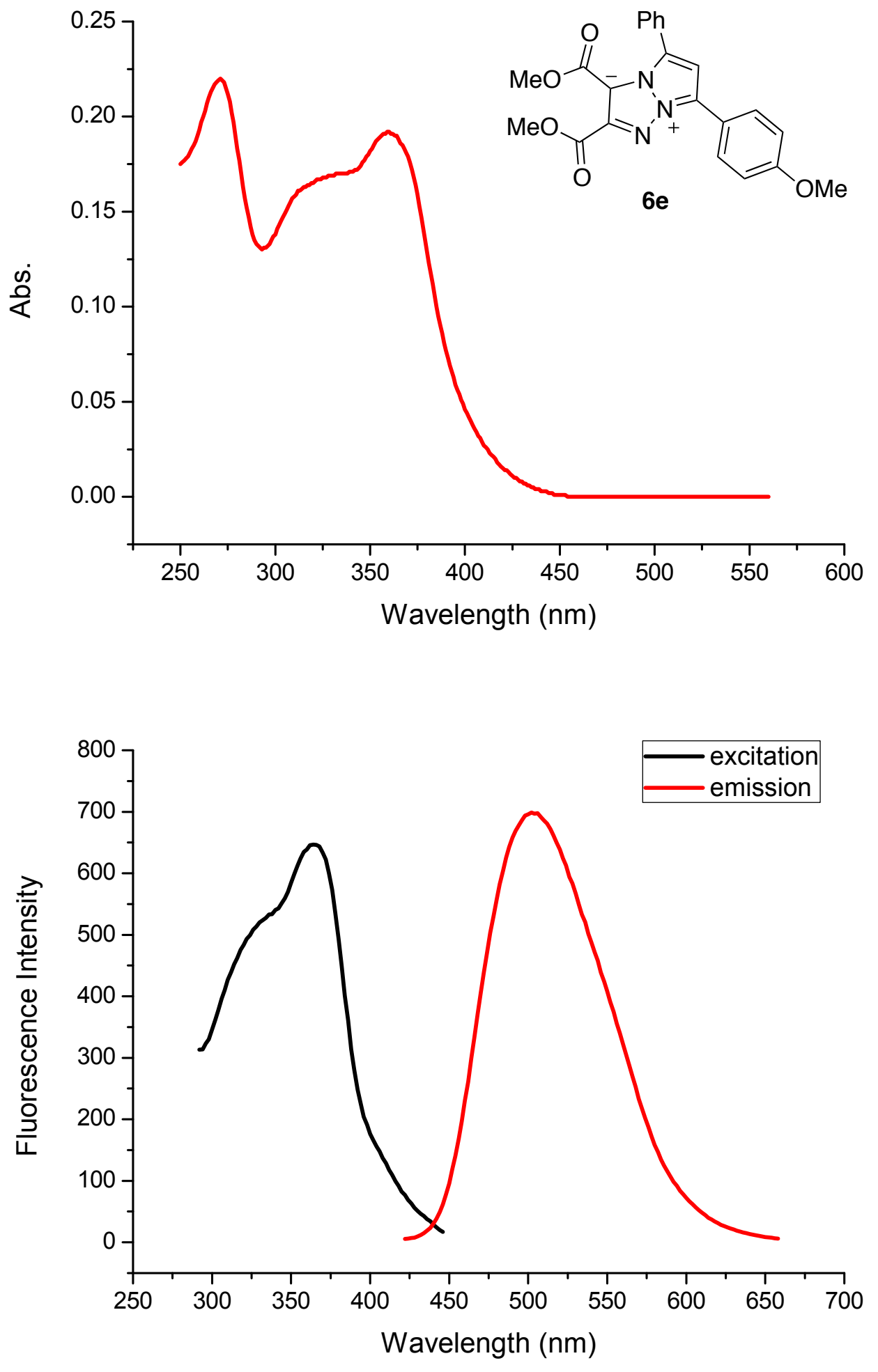

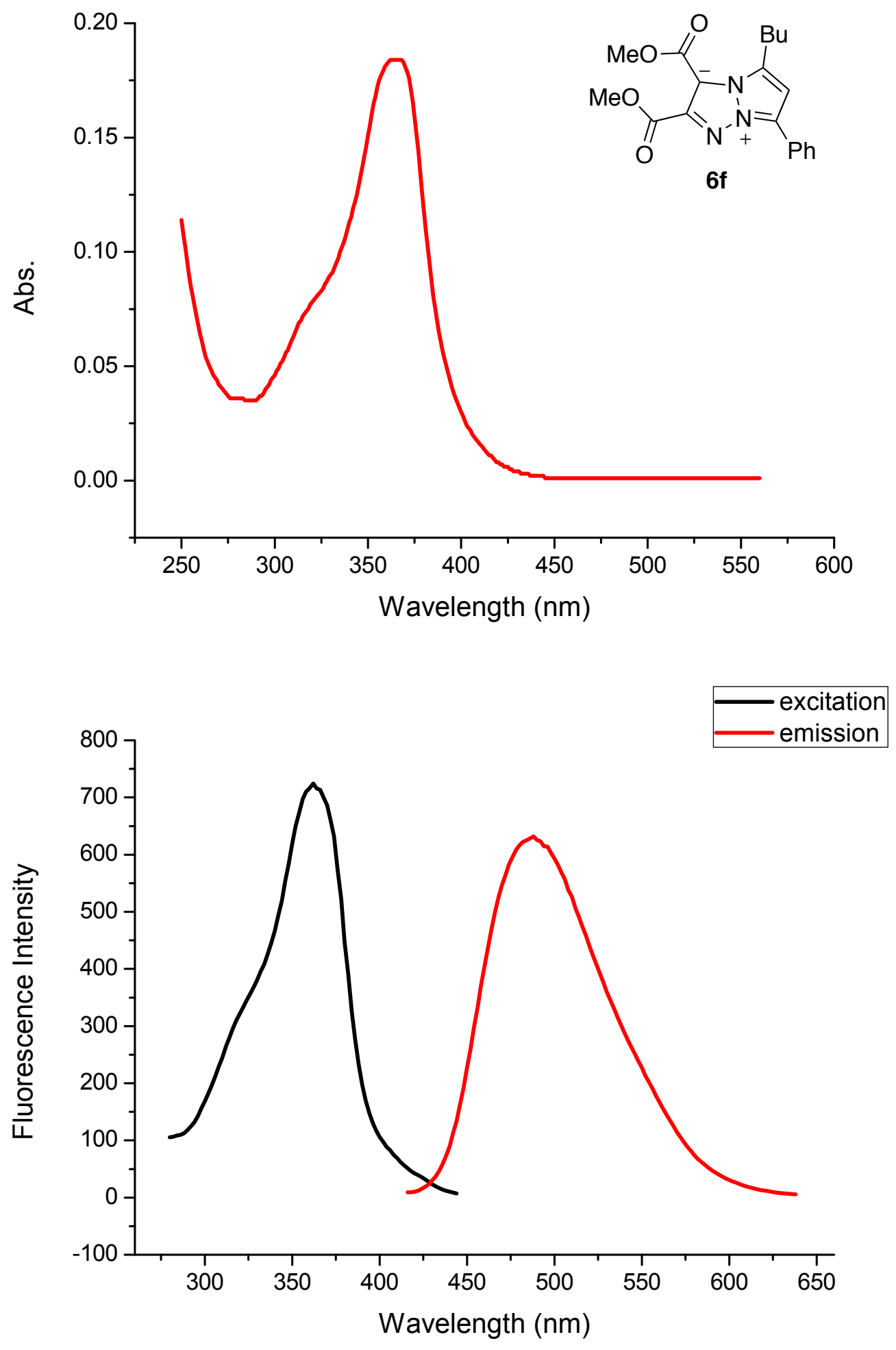

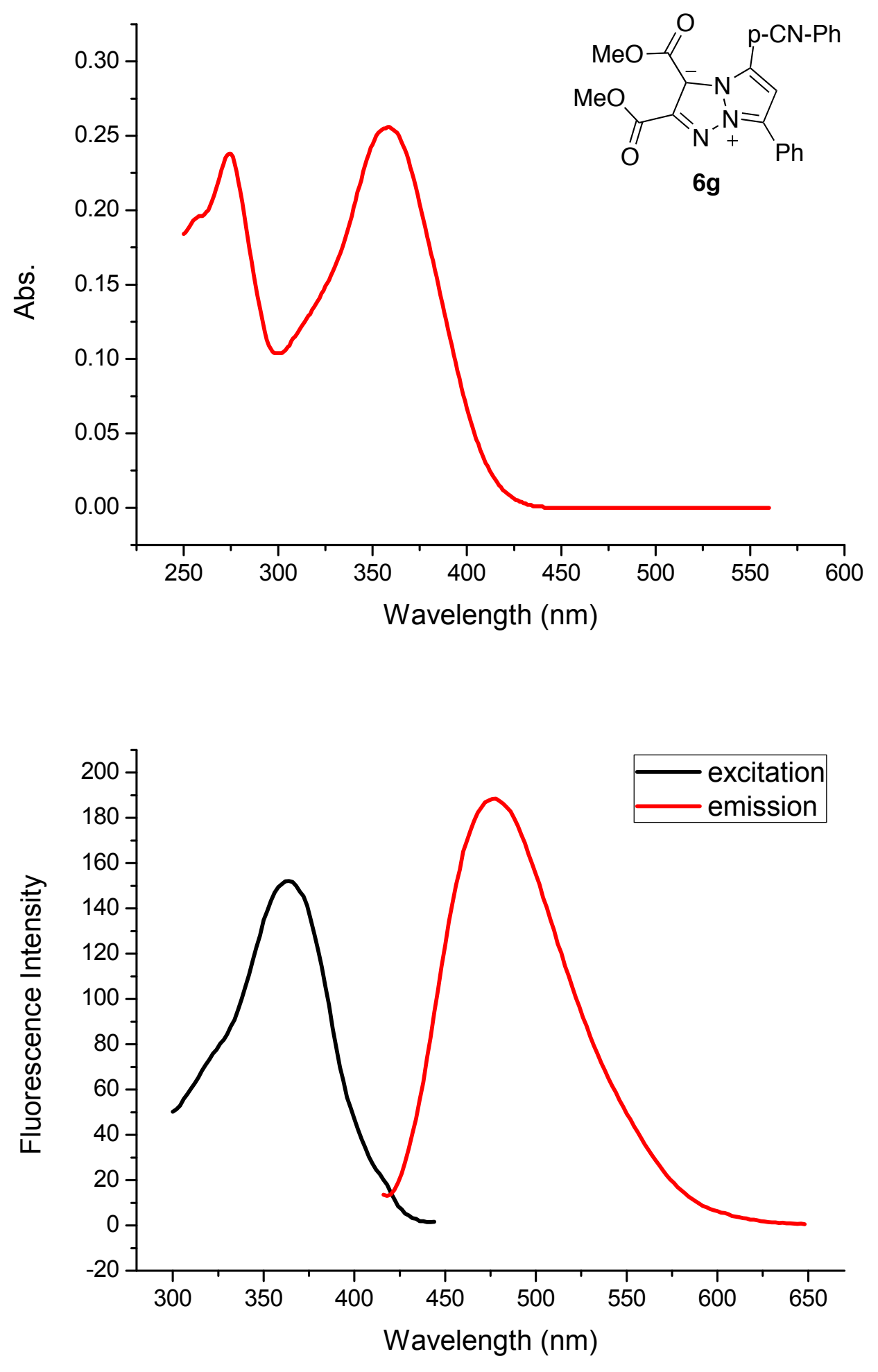


\section{Chapter S2. "Silver Effect" in Gold(I) Catalysis}

\section{S2.1 General Methods and materials}

All of the reactions dealing with air and/or moisture-sensitive reactions were carried out under an All of the reactions dealing with air and/or moisture-sensitive reactions were carried out under an atmosphere of nitrogen using oven/flame-dried glassware and standard syringe/septa techniques. Unless otherwise noted, all commercial reagents and solvents were obtained from the commercial provider and used without further purification. ${ }^{1} \mathrm{H}$ NMR and ${ }^{13} \mathrm{C}$ NMR spectra were recorded on Varian $600 \mathrm{MHz}$ spectrometers. Chemical shifts were reported relative to internal tetramethylsilane $(\delta 0.00$ ppm) or $\mathrm{CDCl} 3$ ( $\delta 7.26 \mathrm{ppm}$ ) for ${ }^{1} \mathrm{H} \mathrm{NMR}, \mathrm{CDCl}_{3}$ ( $\left.\delta 77.0 \mathrm{ppm}\right)$ for ${ }^{13} \mathrm{C} \mathrm{NMR}$ and $\mathrm{H}_{3} \mathrm{PO}_{4}$ $(85 \%)(\delta 0.00 \mathrm{ppm})$ for ${ }^{31} \mathrm{P}$ NMR. Flash column chromatography was performed on 230 430 mesh silica gel. Analytical thin layer chromatography was performed with precoated glass baked plates $(250 \mu)$ and visualized by fluorescence and by charring after treatment with potassium permanganate stain. The X-ray photoelectron spectroscopy (XPS, Physical Electronics VersaProbe 5000) measurements were conducted with Al Ka radiation $(1486.71 \mathrm{eV})$, the binding energy scale was calibrated by a C 1s peak at 284.8 $\mathrm{eV}$.

Substrates 8 were synthesized according to the literature as below:

1. Yu, M.; Zhang, G.; Zhang, L. Org. Lett. 2007, 9, 2147-2150.

2. Marion, N.; Carlqvist, P.; Gealageas, R.; Fremont, P.; Maseras, F.; Nolan, S. P. Chem. Eur. J. 2007, 13, 6437-6451.

\section{Representative procedure for the preparation of 9a}
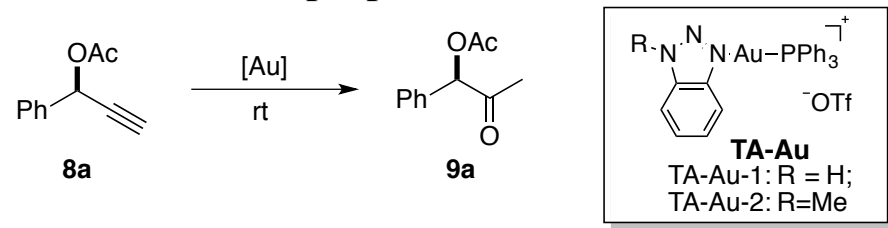

To a solution of $8 \mathbf{a}(44 \mathrm{mg}, 0.25 \mathrm{mmol})$ in acetone $(2.5 \mathrm{~mL}, 0.1 \mathrm{M})$, was added $\mathrm{Au}(\mathrm{I})$ catalyst (1.8 mg, $0.0025 \mathrm{~mol}, 1.0 \mathrm{~mol} \%)$ and $\mathrm{H}_{2} \mathrm{O}(0.75 \mathrm{mmol}, 3.0$ equiv.) at RT under nitrogen. The reaction mixture was stirred at RT and monitored by TLC. After the reaction was completed $(5 \mathrm{~h})$, the solvent was removed under reduced pressure and the residue was purified by flash chromatography on silica gel (ethyl acetate/hexane $=1: 20$, $\mathrm{V} / \mathrm{V})$ to give $9 \mathbf{a}(96 \%$ yield) as a colorless oil. 


\section{S2.2 Compounds Characterization}<smiles>CC(=O)OC(C(C)=O)c1ccccc1</smiles>

2-oxo-1-phenylpropyl acetate (9a): 96\% yield, ${ }^{1} \mathrm{H}$ NMR (600 $\left.\mathrm{MHz}, \mathrm{CDCl}_{3}\right): \delta$ 7.38$7.42(\mathrm{~m}, 5 \mathrm{H}), 5.98(\mathrm{~s}, 1 \mathrm{H}), 2.19(\mathrm{~s}, 3 \mathrm{H}), 2.11(\mathrm{~s}, 3 \mathrm{H}) ;{ }^{13} \mathrm{C} \mathrm{NMR}\left(150 \mathrm{MHz}, \mathrm{CDCl}_{3}\right): \delta$ 201.6, 170.2, 133.2, 129.3, 129.0, 128.0, 80.9, 26.1, 20.7.<smiles>CC(=O)OC(C(C)=O)c1cccc([N+](=O)[O-])c1</smiles>

1-(3-nitrophenyl)-2-oxopropyl acetate (9b): 98\% yield, ${ }^{1} \mathrm{H}$ NMR (600 $\left.\mathrm{MHz}, \mathrm{CDCl}_{3}\right)$ : $\delta 8.30-8.31(\mathrm{~m}, 1 \mathrm{H}), 8.25(\mathrm{dq}, J=8.4,1.2 \mathrm{~Hz}, 1 \mathrm{H}), 7.78(\mathrm{~d}, J=6.6 \mathrm{~Hz}, 1 \mathrm{H}), 7.62(\mathrm{~d}, J=$ $8.1 \mathrm{~Hz}, 1 \mathrm{H}), 6.08(\mathrm{~s}, 1 \mathrm{H}), 2.45(\mathrm{~s}, 3 \mathrm{H}), 2.20(\mathrm{~s}, 3 \mathrm{H}) .{ }^{13} \mathrm{C} \mathrm{NMR}\left(150 \mathrm{MHz}, \mathrm{CDCl}_{3}\right): \delta$ $201.1,169.8,148.5,135.5,133.6,130.0,124.1,122.6,79.5,26.1,20.5$.<smiles>CC(=O)OC(Cc1ccccc1)C(C)=O</smiles>

3-oxo-1-phenylbutan-2-yl acetate (9c): 94\% yield, ${ }^{1} \mathrm{H}$ NMR $\left(600 \mathrm{MHz}, \mathrm{CDCl}_{3}\right)$ : $\delta$ 7.20-7.32 (m 5H), 5.21 (q, $J=3.3 \mathrm{~Hz}, 1 \mathrm{H}), 3.10$ (dd, $J=13.8,4.8 \mathrm{~Hz}, 1 \mathrm{H}), 3.00$ (dd, $J=$ 13.8, 8.4 Hz, 1H), $2.08(\mathrm{~s}, 3 \mathrm{H}), 2.07(\mathrm{~s}, 3 \mathrm{H}) .{ }^{13} \mathrm{C} \mathrm{NMR}\left(150 \mathrm{MHz}, \mathrm{CDCl}_{3}\right): \delta 205.3$, $170.3,135.8,129.2,128.5,126.9,79.0,36.6,26.8,20.5$.<smiles>CCCC(OC(C)=O)C(C)=O</smiles>

2-oxohexan-3-yl acetate (9d): $91 \%$ yield, ${ }^{1} \mathrm{H}$ NMR (600 $\left.\mathrm{MHz}, \mathrm{CDCl}_{3}\right): 4.99$ (dd, $J=$ 8.4, $4.8 \mathrm{~Hz}, 1 \mathrm{H}), 2.16(\mathrm{~s}, 3 \mathrm{H}), 2.15(\mathrm{~s}, 3 \mathrm{H}), 1.68-1.76(\mathrm{~m}, 2 \mathrm{H}), 1.39-1.46(\mathrm{~m}, 2 \mathrm{H}), 0.95$ (t, $J=7.5 \mathrm{~Hz}, 3 \mathrm{H}) ;{ }^{13} \mathrm{C} \mathrm{NMR}\left(150 \mathrm{MHz}, \mathrm{CDCl}_{3}\right): \delta 205.4,170.6,78.5,32.2,26.0,20.6$, $18.5,13.6$.<smiles>CC(=O)OC1(C(C)=O)CCCCC1</smiles>

1-acetylcyclohexyl acetate (9e): 93\% yield, ${ }^{1} \mathrm{H} \mathrm{NMR}\left(600 \mathrm{MHz}, \mathrm{CDCl}_{3}\right): 2.13(\mathrm{~s}, 3 \mathrm{H})$, $2.09(\mathrm{~s}, 3 \mathrm{H}), 2.02-2.05(\mathrm{~m}, 2 \mathrm{H}), 1.62-1.69(\mathrm{~m}, 5 \mathrm{H}), 1.49-1.56(\mathrm{~m}, 2 \mathrm{H}), 1.24-1.29(\mathrm{~m}$, $1 \mathrm{H}) ;{ }^{13} \mathrm{C} \mathrm{NMR}\left(150 \mathrm{MHz}, \mathrm{CDCl}_{3}\right): \delta 207.2,170.2,85.2,30.8,24.9,23.6,21.2,21.0$. 
<smiles>CC(=O)OC(C(C)=O)c1ccc(F)cc1</smiles>

1-(4-fluorophenyl)-2-oxopropyl acetate (9f): 90\% yield, ${ }^{1} \mathrm{H}$ NMR (600 $\left.\mathrm{MHz}, \mathrm{CDCl}_{3}\right)$ : $\delta$ 7.38-7.42 (m, 2H), 7.08-7.12 (m 2H), $5.96(\mathrm{~s}, 1 \mathrm{H}), 2.19(\mathrm{~s}, 3 \mathrm{H}), 2.12(\mathrm{~s}, 3 \mathrm{H}) .{ }^{13} \mathrm{C}$ NMR (150 MHz, $\left.\mathrm{CDCl}_{3}\right): \delta 201.5,170.1,162.4$ (d, $\left.J=247.5 \mathrm{~Hz}\right), 129.9$ (d, $\left.J=8.1 \mathrm{~Hz}\right)$, $129.1(\mathrm{~d}, J=3.3 \mathrm{~Hz}), 116.1(\mathrm{~d}, J=21.3 \mathrm{~Hz}), 80.0,26.1,20.6$.<smiles>COc1ccc(C(OC(C)=O)C(C)=O)cc1</smiles>

1-(4-methoxyphenyl)-2-oxopropyl acetate (9g): 95\% yield, ${ }^{1} \mathrm{H}$ NMR $(600 \mathrm{MHz}$, $\left.\mathrm{CDCl}_{3}\right): \delta 7.32(\mathrm{dt}, J=8.4,2.4 \mathrm{~Hz}, 2 \mathrm{H}), 6.92(\mathrm{dt}, J=9.0,2.7 \mathrm{~Hz}, 2 \mathrm{H}), 5.93(\mathrm{~s}, 1 \mathrm{H}), 3.82$ $(\mathrm{s}, 3 \mathrm{H}), 2.17(\mathrm{~s}, 3 \mathrm{H}), 2.10(\mathrm{~s}, 3 \mathrm{H}) .{ }^{13} \mathrm{C} \mathrm{NMR}\left(150 \mathrm{MHz}, \mathrm{CDCl}_{3}\right): \delta 201.8,170.3,160.4$, $129.6,125.0,114.5,80.4,55.3,26.1,20.7$.<smiles>CC(=O)OC(C(C)=O)c1ccc(C(C)=O)cc1</smiles>

1-(methyl-4-benzoate)-2-oxopropyl acetate (9h): 93\% yield, ${ }^{1} \mathrm{H}$ NMR (600 MHz, $\left.\mathrm{CDCl}_{3}\right): \delta 8.07(\mathrm{~d}, J=8.4 \mathrm{~Hz}, 2 \mathrm{H}), 7.50(\mathrm{~d}, J=8.4 \mathrm{~Hz}, 2 \mathrm{H}), 6.02(\mathrm{~s}, 1 \mathrm{H}), 3.93(\mathrm{~s}, 3 \mathrm{H})$, $2.22(\mathrm{~s}, 3 \mathrm{H}), 2.13(\mathrm{~s}, 3 \mathrm{H}) .{ }^{13} \mathrm{C} \mathrm{NMR}\left(150 \mathrm{MHz}, \mathrm{CDCl}_{3}\right): \delta 201.2,170.0,166.4,137.9$, $131.0,130.2,127.8,80.4,52.3,26.0,20.6$.<smiles>CC(=O)OC(C(C)=O)c1ccc(Cl)cc1</smiles>

1-(4-chlorophenyl)-2-oxopropyl acetate (9i): 91\% yield, ${ }^{1} \mathrm{H} \mathrm{NMR}\left(600 \mathrm{MHz}, \mathrm{CDCl}_{3}\right)$ : $\delta$ 7.34-7.40 (m, 4H), $5.94(\mathrm{~s}, 1 \mathrm{H}), 2.19(\mathrm{~s}, 3 \mathrm{H}), 2.12(\mathrm{~s}, 3 \mathrm{H}) .{ }^{13} \mathrm{C}$ NMR $(150 \mathrm{MHz}$, $\left.\mathrm{CDCl}_{3}\right): \delta 201.3,170.1,135.4,131.7,129.3,129.2,80.7,26.1,20.6$.<smiles>CC(=O)OC(C=Cc1ccccc1)C(C)=O</smiles>

(E)-4-oxo-1-phenylpent-1-en-3-yl acetate (9j): 87\% yield, ${ }^{1} \mathrm{H}$ NMR (600 $\left.\mathrm{MHz}, \mathrm{CDCl}_{3}\right)$ : $\delta$ 7.39-7.40 (m, 2H), 7.28-7.36 (m, 3H), $6.81(\mathrm{~d}, J=16.2 \mathrm{~Hz}, 1 \mathrm{H}), 6.16(\mathrm{dd}, J=16.2$, $7.8 \mathrm{~Hz}, 1 \mathrm{H}), 5.94(\mathrm{dd}, J=7.8,1.2 \mathrm{~Hz}, 1 \mathrm{H}), 2.23(\mathrm{~s}, 3 \mathrm{H}), 2.20(\mathrm{~s}, 3 \mathrm{H}) .{ }^{13} \mathrm{C} \mathrm{NMR}(150$ $\left.\mathrm{MHz} \mathrm{CDCl}_{3}\right): \delta 202.3,170.1,136.3,135.5,128.7,126.8,120.5,79.8,26.1,20.7$. 
<smiles>O=C(Cc1ccccc1)c1ccccc1</smiles>

1,2-diphenylethanone (11a): ${ }^{1} \mathrm{H} \mathrm{NMR}\left(600 \mathrm{MHz}, \mathrm{CDCl}_{3}\right): \delta 8.00-8.02(\mathrm{~m}, 2 \mathrm{H}), 7.53$ $7.56(\mathrm{~m}, 1 \mathrm{H}), 7.45(\mathrm{~d}, J=7.8 \mathrm{~Hz}, 2 \mathrm{H}), 7.32(\mathrm{~d}, J=7.5 \mathrm{~Hz}, 2 \mathrm{H}), 7.24-7.27(\mathrm{~m}, 3 \mathrm{H}), 4.28$ (s, 2H). ${ }^{13} \mathrm{C}$ NMR $\left(150 \mathrm{MHz}, \mathrm{CDCl}_{3}\right): \delta 197.6,136.6,134.5,133.1,129.4,128.6,128.6$, $128.5,126.9,45.5$.<smiles>O=C(Br)/C(=C/c1ccccc1)c1ccccc1</smiles>

(E)-1,2-diphenylhept-1-en-3-one (Scheme 12B): (known compound, See: Zhang, G.;

Peng, Y.; Cui, L.; Zhang, L. Angew. Chem. Int. Ed. 2009, 48, 3112-3115.) ${ }^{1} \mathrm{H}$ NMR (600 $\left.\mathrm{MHz}_{\mathrm{CDCl}}\right): 7.62(\mathrm{~s}, 1 \mathrm{H}), 7.43-7.39(\mathrm{~m}, 3 \mathrm{H}), 7.22-7.12(\mathrm{~m}, 5 \mathrm{H}), 7.03(\mathrm{~d}, J=6.0 \mathrm{~Hz}$, $2 \mathrm{H}), 2.55(\mathrm{t}, J=7.8 \mathrm{~Hz}, 2 \mathrm{H}), 1.61-1.58(\mathrm{~m}, 2 \mathrm{H}), 1.33-1.26(\mathrm{~m}, 2 \mathrm{H}), 0.87(\mathrm{t}, J=7.2 \mathrm{~Hz}$, $3 \mathrm{H}) ;{ }^{13} \mathrm{C} \mathrm{NMR}\left(150 \mathrm{MHz}, \mathrm{CDCl}_{3}\right): \delta 201.8,140.8,137.7,137.1,134.7,130.8,129.6$, $129.0,128.2,127.8,39.6,26.5,22.3,13.9$.

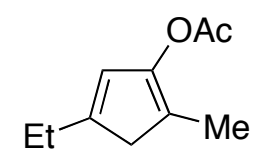

4-ethyl-2-methylcyclopenta-1,4-dienyl acetate (Scheme 13A): (See: Zhang, L.; Wang, S. J. Am. Chem. Soc. 2006, 128, 1442-1443.) ${ }^{1} \mathrm{H}$ NMR $\left(600 \mathrm{MHz}, \mathrm{CDCl}_{3}\right): \delta 5.95(\mathrm{~s}$, $1 \mathrm{H}), 2.81(\mathrm{~s}, 2 \mathrm{H}), 2.33(\mathrm{q}, J=7.2 \mathrm{~Hz}, 2 \mathrm{H}), 2.22(\mathrm{~s}, 3 \mathrm{H}), 1.82(\mathrm{~s}, 3 \mathrm{H}), 1.11(\mathrm{t}, J=7.2 \mathrm{~Hz}$, $3 \mathrm{H}) .{ }^{13} \mathrm{C}$ NMR $\left(150 \mathrm{MHz}, \mathrm{CDCl}_{3}\right): \delta 169.1,147.8,145.6,122.5,121.5,43.4,24.0,20.7$, 13.2, 11.3 .

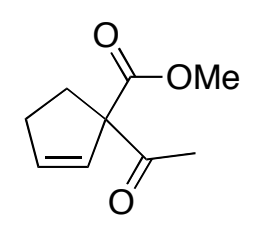

methyl 1-acetylcyclopent-2-enecarboxylate (Scheme 13B): (See: Staben, S.T.; Kennedy-Smith, J.J.; Toste, F.D. Angew. Chem. Int. Ed. 2004, 43, 5350-5352.) ${ }^{1} \mathrm{H}$ NMR $\left(600 \mathrm{MHz}, \mathrm{CDCl}_{3}\right): \delta 6.03(\mathrm{td}, J=5.4,2.4 \mathrm{~Hz}, 1 \mathrm{H}), 5.86(\mathrm{td}, J=5.4,1.8 \mathrm{~Hz}, 1 \mathrm{H}), 3.74$ $(\mathrm{s}, 3 \mathrm{H}), 2.35-2.51(\mathrm{~m}, 4 \mathrm{H}), 2.18(\mathrm{~s}, 3 \mathrm{H}) .{ }^{13} \mathrm{C} \mathrm{NMR}\left(150 \mathrm{MHz}, \mathrm{CDCl}_{3}\right): \delta 203.8,172.3$, $136.4,128.7,73.5,52.6,31.9,30.1,26.4$.

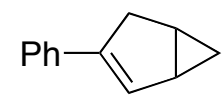

3-phenylbicyclo[3.1.0]hex-2-ene (Scheme 13D): (See: Luzung, M.R.; Markham, J.P.; Toste, F.D. J. Am. Chem. Soc. 2004, 126, 10858-10859.) ${ }^{1} \mathrm{H}$ NMR (600 MHz, $\left.\mathrm{CDCl}_{3}\right): \delta$ $7.38(\mathrm{~d}, J=7.8 \mathrm{~Hz}, 2 \mathrm{H}), 7.30(\mathrm{t}, J=7.8 \mathrm{~Hz}, 2 \mathrm{H}), 7.21(\mathrm{t}, J=7.8 \mathrm{~Hz}, 1 \mathrm{H}), 6.42(\mathrm{~d}, J=1.8$ $\mathrm{Hz}, 1 \mathrm{H}), 3.02(\mathrm{dd}, J=16.8,7.2 \mathrm{~Hz}, 1 \mathrm{H}), 2.75$ (d, $J=16.8 \mathrm{~Hz}, 1 \mathrm{H}), 1.98-1.94(\mathrm{~m}, 1 \mathrm{H})$, 1.76-1.72 (m, 1H), 0.97-0.93 (m, 1H), 0.11-0.09 (m, 1H). $\left.{ }^{13} \mathrm{C} \mathrm{NMR} \mathrm{(150} \mathrm{MHz,} \mathrm{CDCl}_{3}\right): \delta$ $139.7,136.6,129.6,128.2,126.7,125.1,36.3,24.1,17.6,15.4$. 
$\mathrm{N}_{\mathrm{Bu}}^{\mathrm{O}}$

(E)-1-phenylhept-1-en-3-one (Scheme 14A): (known compound, See: Wang, D.; Zhang, Y.; Harris, A.; Gautam, L. N. S.; Shi, X. Adv. Syn. Cat. 2011, 353, 2584-2588.) ${ }^{1}$ H NMR $\left(600 \mathrm{MHz}, \mathrm{CDCl}_{3}\right): \delta$ 7.53-7.56 (m, 3H), 7.38-7.40 (m, 3H), $6.73(\mathrm{t}, J=16.2 \mathrm{~Hz}, 1 \mathrm{H})$, 2.66 (t, $J=7.5 \mathrm{~Hz}, 2 \mathrm{H}$ ), 1.66 (quintet, $J=7.5 \mathrm{~Hz}, 2 \mathrm{H}$ ), 1.37 (sextet, $J=7.4 \mathrm{~Hz}, 2 \mathrm{H}$ ), 0.94 (t, $J=7.5 \mathrm{~Hz}, 3 \mathrm{H}) ;{ }^{13} \mathrm{C} \mathrm{NMR}\left(150 \mathrm{MHz}, \mathrm{CDCl}_{3}\right): \delta 200.8,142.5,134.8,130.6,129.1$, $128.4,126.5,40.9,26.7,22.7,14.1$.<smiles>CC1Cc2c(ccc3ccccc23)O1</smiles>

1,2-dihydro-2-methylnaphtho[2,1-b]furan (Scheme 14D): (known compound, See: Reich, N.W.; Yang, C.G.; Shi, Z.; He, C. Synlett. 2006, 8, 1278-1280.) ${ }^{1}$ H NMR (600 $\left.\mathrm{MHz}, \mathrm{CDCl}_{3}\right): \delta 7.77(\mathrm{~d}, J=8.4 \mathrm{~Hz}, 1 \mathrm{H}), 7.64(\mathrm{~d}, J=8.4 \mathrm{~Hz}, 1 \mathrm{H}), 7.53(\mathrm{~d}, J=8.4 \mathrm{~Hz}$, $1 \mathrm{H}), 7.43(\mathrm{t}, J=7.2 \mathrm{~Hz}, 1 \mathrm{H}), 7.27(\mathrm{t}, J=7.2 \mathrm{~Hz}, 1 \mathrm{H}), 7.07(\mathrm{~d}, J=9.0 \mathrm{~Hz}, 1 \mathrm{H}), 5.12-5.07$ (m, $1 \mathrm{H}), 3.56(\mathrm{dd}, J=15.6,9.6 \mathrm{~Hz}, 1 \mathrm{H}), 3.04(\mathrm{dd}, J=15.0,7.2 \mathrm{~Hz}, 1 \mathrm{H}), 1.52(\mathrm{~d}, J=6.6$ $\mathrm{Hz}, 3 \mathrm{H}) .{ }^{13} \mathrm{C}$ NMR $\left(150 \mathrm{MHz}, \mathrm{CDCl}_{3}\right): \delta 156.9,130.9,129.1,128.9,128.7,126.5,122.6$, $118.3,112.1,80.2,35.9,22.1$.<smiles>O=C(Br)/C(Br)=C/c1ccccc1</smiles>

(Z)-2-bromo-1-phenylhept-1-en-3-one (Scheme 15B-Z): (known compound, See: Wang, D.; Ye, X.; Shi, X. Org. Lett. 2010, 12, 2088-2091.) ${ }^{1} \mathrm{H}$ NMR (600 MHz, $\left.\mathrm{CDCl}_{3}\right)$ : $\delta 8.03(\mathrm{~s}, 1 \mathrm{H}), 7.84-7.86(\mathrm{~m}, 2 \mathrm{H}), 7.42-7.44(\mathrm{~m}, 2 \mathrm{H}), 2.93(\mathrm{t}, J=7.5 \mathrm{~Hz}, 2 \mathrm{H}), 1.69$ (quintet, $J=7.5 \mathrm{~Hz}, 2 \mathrm{H}), 1.40$ (sextet, $J=7.4 \mathrm{~Hz}, 2 \mathrm{H}), 0.96(\mathrm{t}, J=7.5 \mathrm{~Hz}, 3 \mathrm{H}) ;{ }^{13} \mathrm{C} \mathrm{NMR}$ $\left(150 \mathrm{MHz}, \mathrm{CDCl}_{3}\right): \delta 195.6,138.8,133.9,130.4,130.2,128.4,123.2,38.8,26.8,22.3$, 13.9.<smiles>O=C(Br)/C(Br)=C\c1ccccc1</smiles>

(E)-2-bromo-1-phenylhept-1-en-3-one (Scheme 15B-E): (known compound, See: Wang, D.; Ye, X.; Shi, X. Org. Lett. 2010, 12, 2088-2091.) ${ }^{1} \mathrm{H}$ NMR (600 MHz, $\left.\mathrm{CDCl}_{3}\right)$ : $\delta$ 7.32-7.33 (m, 3H), $7.25(\mathrm{~s}, 1 \mathrm{H}), 7.21-7.23(\mathrm{~m}, 2 \mathrm{H}), 2.53(\mathrm{t}, J=7.5 \mathrm{~Hz}, 2 \mathrm{H}), 1.55$ (quintet, $J=7.5 \mathrm{~Hz}, 2 \mathrm{H}$ ), 1.23 (sextet, $J=7.4 \mathrm{~Hz}, 2 \mathrm{H}), 0.83(\mathrm{t}, J=7.5 \mathrm{~Hz}, 3 \mathrm{H}) ;{ }^{13} \mathrm{C} \mathrm{NMR}$ $\left(150 \mathrm{MHz}, \mathrm{CDCl}_{3}\right): \delta 201.0,136.0,134.7,128.9,128.7,128.2,120.4,41.0,26.0,22.0$, 13.7. 


\section{S2.3 ORTEP Drawing of the Crystal Structures for IPr-TA-Au}

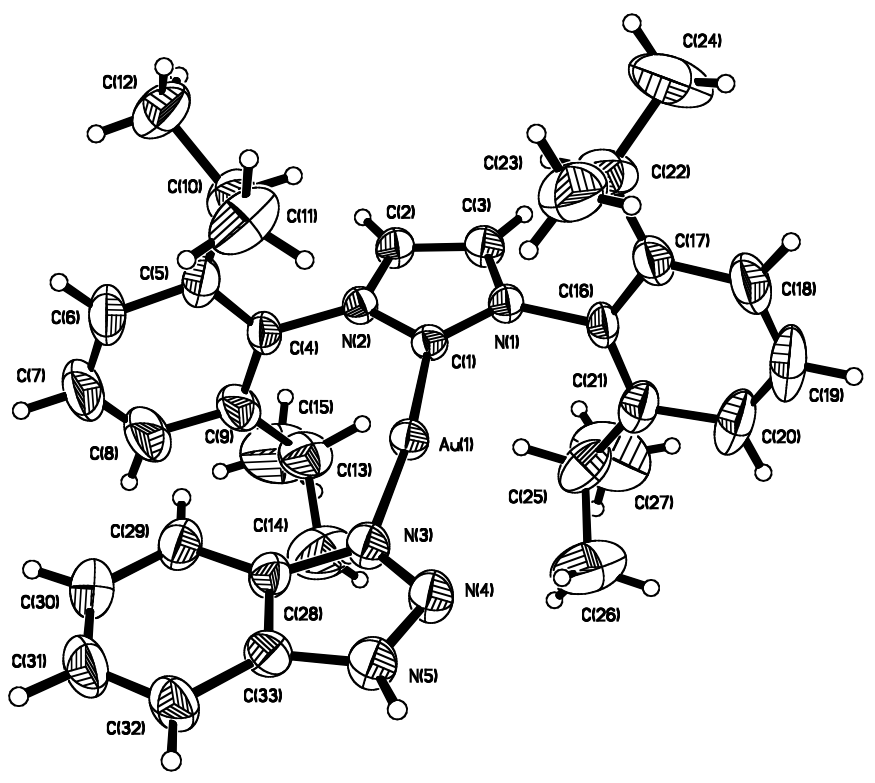

Perspective view of the molecular structure of the $\left[\mathrm{Au}\left(\mathrm{C}_{27} \mathrm{H}_{36} \mathrm{~N}_{2}\right)\left(\mathrm{C}_{6} \mathrm{H}_{5} \mathrm{~N}_{3}\right)\right]^{+}$cation with the atom labeling scheme. The thermal ellipsoids are scaled to enclose $30 \%$ probability. CCDC number: 855876

\section{S2.4 ${ }^{31} \mathrm{P}$ NMR comparison between different gold catalyst}

$\left[\left(\mathrm{PPh}_{3}\right) \mathrm{Au}\right]^{+} \mathrm{TfO}^{-}$

$\left(\mathrm{PPh}_{3}\right) \mathrm{AuCl} / \mathrm{AgOTf}$

$\left(\mathrm{PPh}_{3}\right) \mathrm{AuCl}$

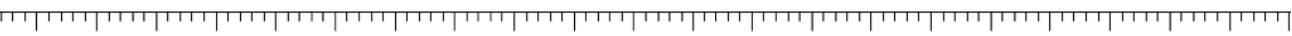

$\begin{array}{lllllllllllllllllllll}40.0 & 39.0 & 38.0 & 37.0 & 36.0 & 35.0 & 34.0 & 33.0 & 32.0 & 31.0 & 30.0 & 29.0 & 28.0 & 27.0 & 26.0 & 25.0 & 24.0 & 23.0 & 22.0 & 21.0 & 20.0\end{array}$ ppm (11) 


\section{S2.5 HPLC data for chirality retention}

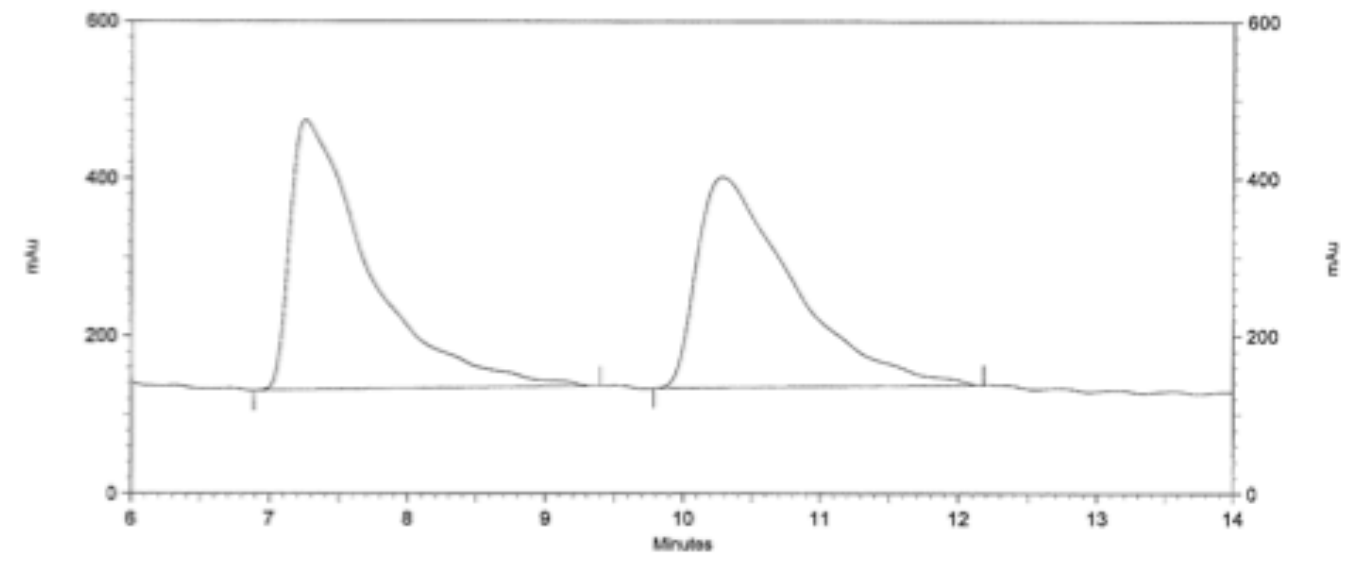

1: 254 nm, 4 nm Results

Retention Time

Area

Area \%

7.268

1767294

51.19

10.292

1685065

48.81

\begin{tabular}{|r|r|r|}
\hline Totals & 3452359 & 100.00 \\
\hline
\end{tabular}

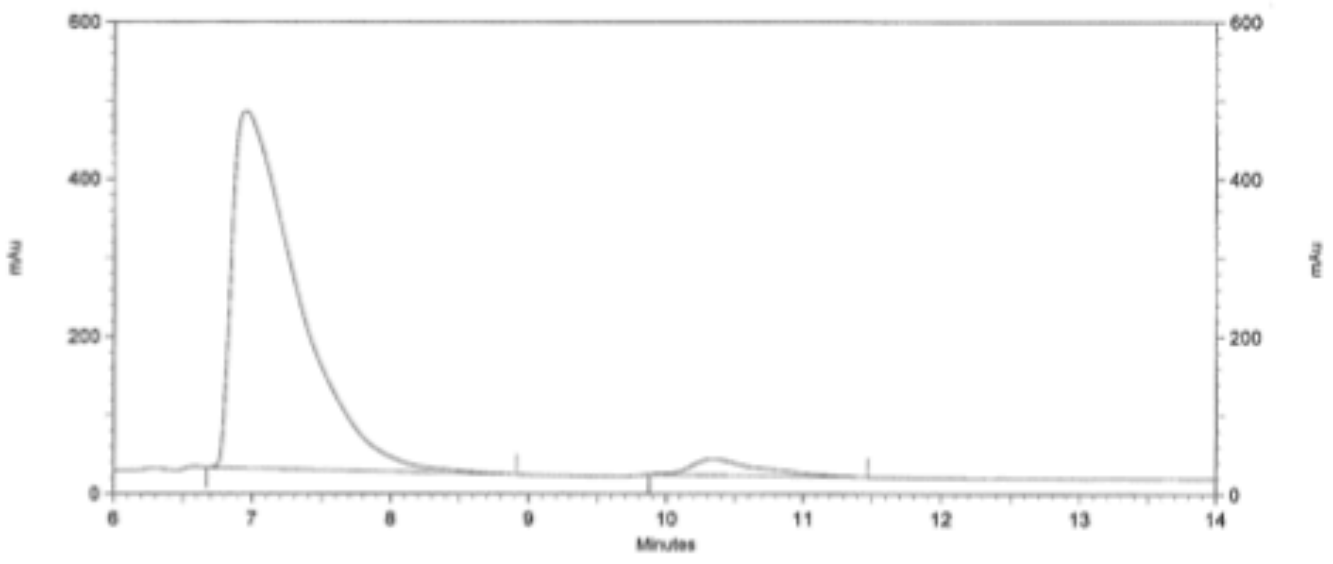

1: $254 \mathrm{~nm}, 4 \mathrm{~nm}$ Results

Retention Time

6.968

Area

Area \%

10.352

30921254

95.48

Totals<smiles>CC(=O)OC(C(C)=O)c1cccc([N+](=O)[O-])c1</smiles> 


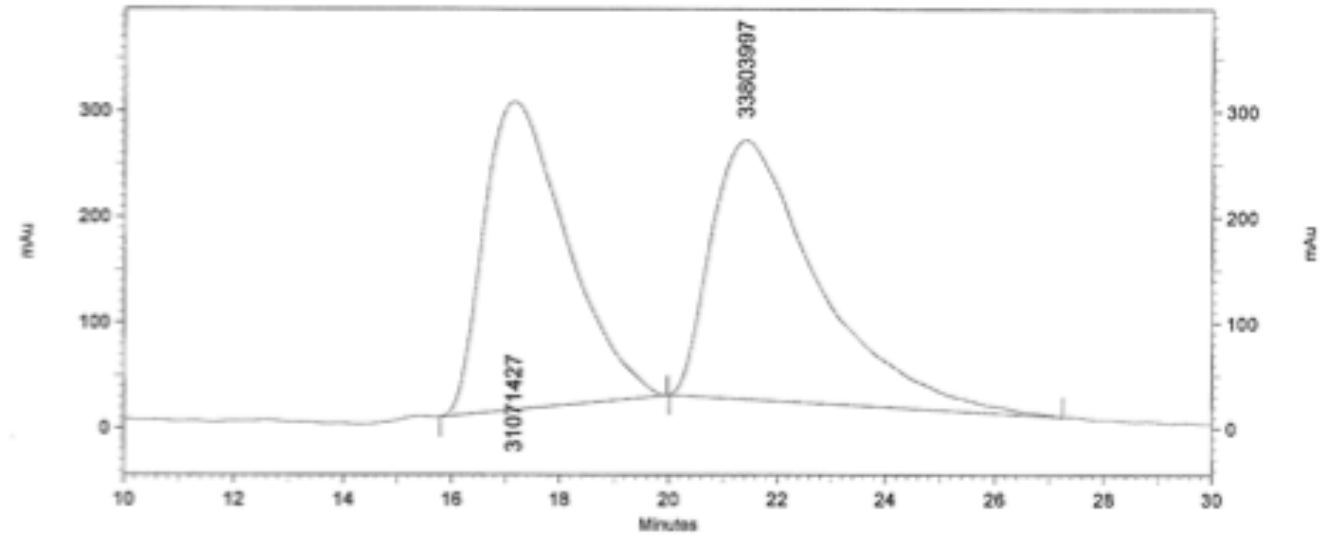

Spectrum Max Plot Results

Retention Time

\begin{tabular}{rrr|}
\multicolumn{1}{r|}{ Retention Time } & Area & Area $\%$ \\
\hline 17.14 & 31071442 & 48 \\
21.39 & 33803912 & 52 \\
\hline Totals & 64875424 & 100
\end{tabular}

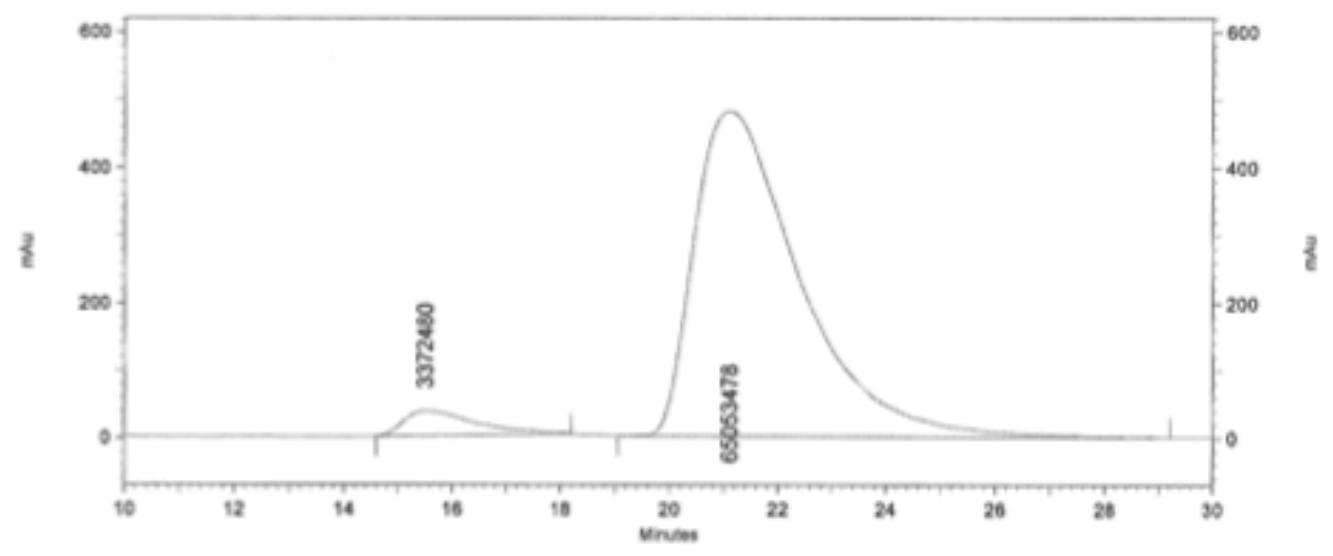

Spectrum Max Plot Results

Retention Time

15.50

21.10

Area

Area \%

Totals

3372480

4.9

65053478

95.1

68425958

100.0<smiles>CC(=O)OC(C(C)=O)c1ccc(F)cc1</smiles> 


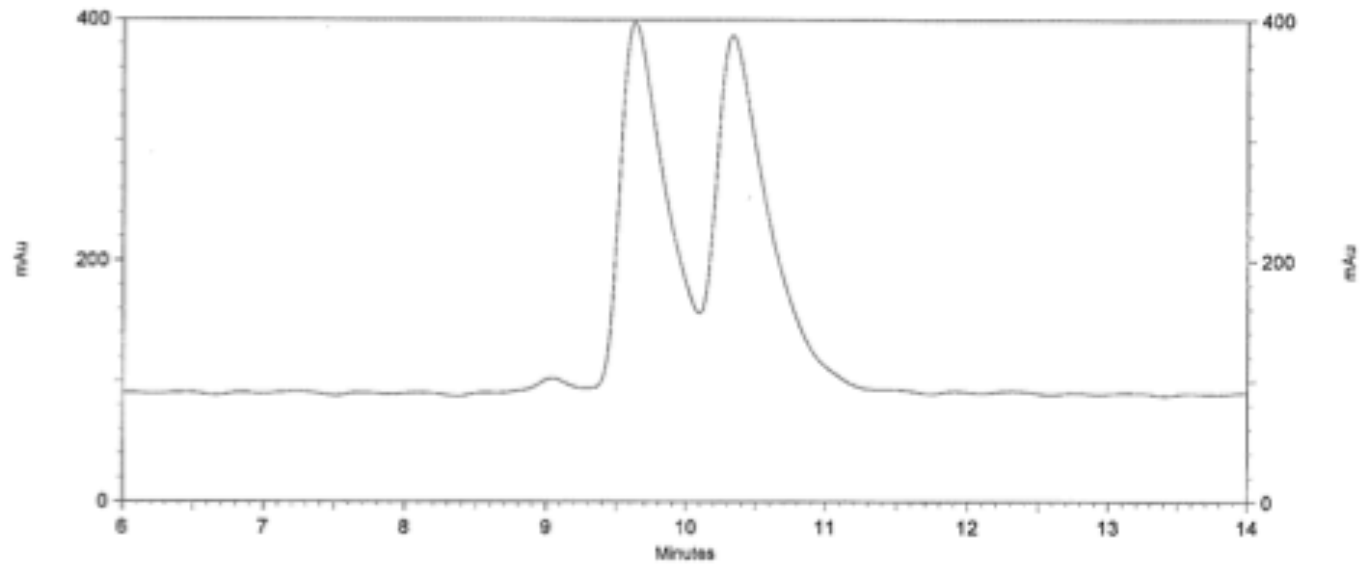

Printed: $\quad$ 9/11/2011 7:12:10 PM

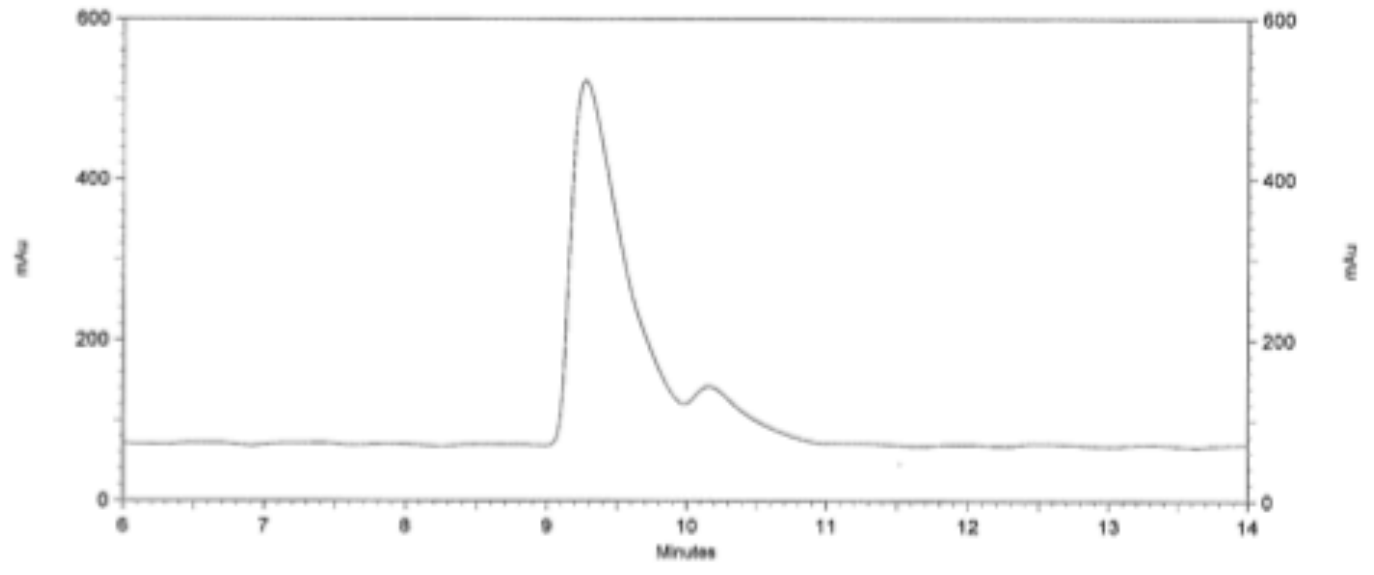<smiles>COc1ccc(C(C(C)=O)C(C)=O)cc1</smiles> 


\section{Chapter S3. Gold-Catalyzed Cross-Coupling with Aryldiazonium Salts}

\section{S3.1 General Methods and materials}

All of the reactions dealing with air and/or moisture-sensitive reactions were carried out under an atmosphere of nitrogen using oven/flame-dried glassware and standard syringe/septa techniques. Unless otherwise noted, all commercial reagents and solvents were obtained from the commercial provider and used without further purification. ${ }^{1} \mathrm{H}$ NMR and ${ }^{13} \mathrm{C}$ NMR spectra were recorded on Varian $600 \mathrm{MHz}$ or Agilent $400 \mathrm{MHz}$ spectrometer. Chemical shifts were reported relative to internal tetramethylsilane $(\delta 0.00$ ppm) for ${ }^{1} \mathrm{H}$ NMR and $\mathrm{CDCl} 3(\delta 77.0 \mathrm{ppm})$ for ${ }^{13} \mathrm{C}$ NMR. Flash column chromatography was performed on 230-430 mesh silica gel. Analytical thin layer chromatography was performed with precoated glass baked plates $(250 \mu)$ and visualized by UV lamp. ESI-MS spectra for products were recorded on Thermo Scientific Qexactive spectrometer in West Virginia University BioNano Research Facility. The Xray crystal structure was acquired with a Bruker AXS D8 Venture X-ray diffractometer.

ESI-MS spectra for monitoring reaction mixtures were collected in Ohio University using a Waters Xevo QTof mass spectrometer (Milford, MA, USA) in the positive ion mode. The samples were infused with a flow rate of $2 \mu \mathrm{L} / \mathrm{min}$ and spray voltage of $5 \mathrm{kV}$.

\section{S3.2 General procedures}

\section{A. Preparation of aryldiazonium salts:}

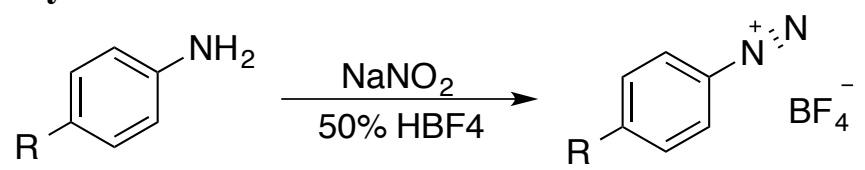

The preparation aryldiazonium salts is adapted from literature report. ${ }^{2}$ The aniline $\mathbf{1}$ (10 mmol) was added to a mixture of $50 \%$ fluoroboric acid $(3 \mathrm{~mL})$ and distilled water $(3 \mathrm{~mL})$ in ice bath. To this solution, an ice-cold solution of sodium nitrite (704 mg, $10.2 \mathrm{mmol}$ ) in distilled water $(3 \mathrm{~mL})$ was added. After stirring for 30 mins, the precipitate was collected on a hirch funnel and washed with small amount of ice-cold distilled water. The solid was dissolved in acetone and precipitated with slow addition of ethyl ether. White crystalline solids were obtained after repeat this trituration two to three times. Yields of the aryldiazonium salts 2 are ranged from $65 \%$ to $92 \%$.

\section{B. Condition optimization of sp-sp ${ }^{2}$ coupling:}

The gold catalyst and additives were added to $0.2 \mathrm{~mL}$ freshly distilled acetonitrile (or other solvents) in a 1-dram vial. To this solution was added the alkyne 12a $(0.1 \mathrm{mmol}$, $8.4 \mathrm{mg})$ and the diazonium salt 13a $(0.12 \mathrm{mmol}, 25.6 \mathrm{mg})$. The conversions of 12a and yields of 15a were determined by ${ }^{1} \mathrm{H}$-NMR using p-xylene as the standard. The yields of 14aa, 16a, and 16a' were determined by ${ }^{19} \mathrm{~F}-\mathrm{NMR}$ using trifluorotoluene as the standard.

\footnotetext{
${ }^{2}$ Broxton, T. J.; Bunnett, J. F.; Paik, C. H. J. Org. Chem. 1977, 42, 643.
} 


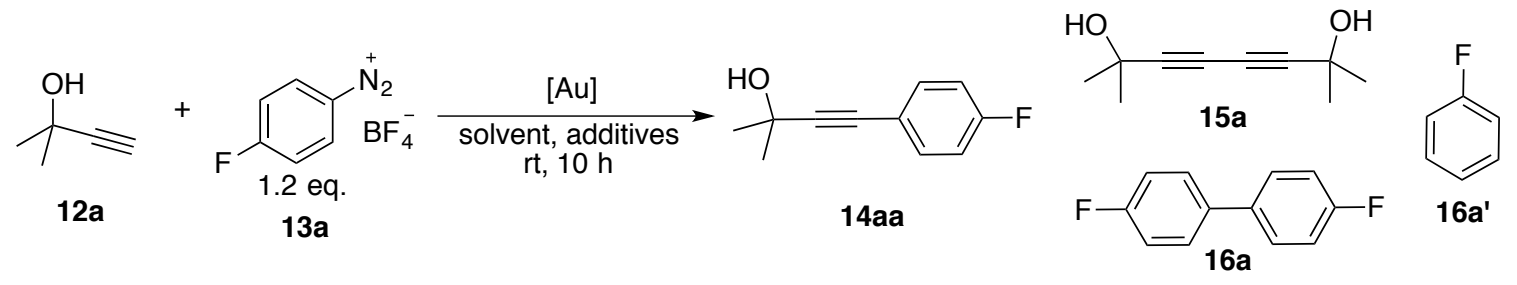

\section{a. Effects of different bases}

The gold catalyst and additives were added to freshly distilled acetonitrile (ACN) in a 1dram vial. To this solution was added the alkyne 12a $(0.1 \mathrm{mmol}, 8.4 \mathrm{mg})$ and the diazonium salt 13a $(0.12 \mathrm{mmol}, 25.6 \mathrm{mg})$.

\begin{tabular}{|c|c|c|c|c|c|c|c|c|c|}
\hline \multirow[t]{2}{*}{ Entry } & \multirow{2}{*}{$\begin{array}{c}\text { Catalyst } \\
(\%)\end{array}$} & \multirow{2}{*}{$\begin{array}{l}\text { Additive } \\
\text { (equiv.) }\end{array}$} & \multicolumn{3}{|c|}{ Time Conc. Conv } & \multicolumn{4}{|c|}{ Yield (\%) } \\
\hline & & & (h) & (M) & $(\%)$ & 14aa & $15 \mathbf{a}$ & $16 \mathbf{a}$ & $16 a^{\prime}$ \\
\hline 1 & $\mathrm{Ph}_{3} \mathrm{PAuNTf}_{2}(5)$ & - & 20 & 0.2 & 9 & 0 & 0 & 0 & 0 \\
\hline 2 & $\mathrm{Ph}_{3} \mathrm{PAuNTf}_{2}(5)$ & $\mathrm{Na}_{2} \mathrm{CO}_{3}(2)$ & 20 & 0.2 & 44 & 41 & 0 & $<1$ & 9 \\
\hline 3 & $\mathrm{Ph}_{3} \mathrm{PAuNTf}_{2}(5)$ & $\mathrm{Li}_{2} \mathrm{CO}_{3}(2)$ & 20 & 0.2 & 48 & 47 & 0 & $<1$ & 24 \\
\hline 4 & $\mathrm{Ph}_{3} \mathrm{PAuNTf}_{2}(5)$ & $\mathrm{K}_{2} \mathrm{CO}_{3}(2)$ & 20 & 0.2 & 40 & 38 & 0 & 0 & 24 \\
\hline 5 & $\mathrm{Ph}_{3} \mathrm{PAuNTf}_{2}(5)$ & $\mathrm{NaOAc}(2)$ & 20 & 0.2 & 37 & 31 & 0 & 0 & 16 \\
\hline 6 & $\mathrm{Ph}_{3} \mathrm{PAuNTf}_{2}(5)$ & DBMP (2) & 20 & 0.2 & 45 & 42 & 0 & 0 & 4 \\
\hline 7 & $\mathrm{Ph}_{3} \mathrm{PAuNTf}_{2}(5)$ & 2,6-lutidine (2) & 20 & 0.2 & 38 & 31 & 0 & $<1$ & 12 \\
\hline 8 & $\mathrm{Ph}_{3} \mathrm{PAuNTf}_{2}(5)$ & DIPEA (2) & 20 & 0.2 & 28 & 23 & 0 & 2 & 16 \\
\hline 9 & $\mathrm{Ph}_{3} \mathrm{PAuNTf}_{2}(5)$ & bpy (2) & 20 & 0.2 & 73 & 60 & 5 & 0 & 7 \\
\hline 10 & $\mathrm{Ph}_{3} \mathrm{PAuNTf}_{2}(5)$ & phen (2) & 20 & 0.2 & 40 & 23 & 7 & 2 & 8 \\
\hline 11 & $\mathrm{Ph}_{3} \mathrm{PAuNTf}_{2}(5)$ & $\mathrm{Na}_{2} \mathrm{CO}_{3}(2)$ & 20 & 0.5 & 74 & 62 & 0 & $<1$ & 8 \\
\hline 12 & $\mathrm{Ph}_{3} \mathrm{PAuNTf}_{2}(5)$ & bpy (2) & 8 & 0.5 & 100 & 83 & 8 & 0 & 3 \\
\hline 13 & - & $\mathrm{Na}_{2} \mathrm{CO}_{3}(2)$ & 12 & 0.5 & 74 & 0 & 0 & $<1$ & 8 \\
\hline 14 & - & bpy (2) & 12 & 0.5 & 100 & 0 & 0 & 0 & 0 \\
\hline 15 & $\mathrm{Ph}_{3}$ PAuNTf $_{2}$ (5) & $\mathrm{Na}_{2} \mathrm{CO}_{3}(2)$, bpy $(0.2)$ & 6 & 0.5 & 100 & 94 & 2 & $\mathbf{0}$ & 2 \\
\hline 16 & $\mathrm{Ph}_{3} \mathrm{PAuNTf}_{2}(5)$ & $\mathrm{Li}_{2} \mathrm{CO}_{3}(2)$, bpy $(0.2)$ & 6 & 0.5 & 50 & 39 & 2 & 0 & 0 \\
\hline 17 & $\mathrm{Ph}_{3} \mathrm{PAuNTf}_{2}(5)$ & $\mathrm{K}_{2} \mathrm{CO}_{3}(2)$, bpy $(0.2)$ & 6 & 0.5 & 64 & 62 & 2 & $<1$ & 6 \\
\hline 18 & $\mathrm{Ph}_{3} \mathrm{PAuNTf}_{2}(5)$ & $\mathrm{NaOAc}(2)$, bpy $(0.2)$ & 6 & 0.5 & 66 & 38 & 1 & 0 & 2 \\
\hline 19 & $\mathrm{Ph}_{3} \mathrm{PAuNTf}_{2}(5)$ & $\operatorname{DBMP}(2)$, bpy $(0.2)$ & 6 & 0.5 & 43 & 37 & 0 & 0 & 4 \\
\hline 20 & $\mathrm{Ph}_{3} \mathrm{PAuNTf}_{2}(5)$ & $\mathrm{Na}_{2} \mathrm{CO}_{3}(2)$, bpy $(0.1)$ & 12 & 0.5 & 86 & 74 & 2 & 0 & 3 \\
\hline 21 & $\mathrm{Ph}_{3} \mathrm{PAuNTf}_{2}(5)$ & $\mathrm{Na}_{2} \mathrm{CO}_{3}(2)$, bpy $(0.4)$ & 6 & 0.5 & 100 & 92 & 1 & 0 & 5 \\
\hline 22 & $\mathrm{Ph}_{3} \mathrm{PAuNTf}_{2}(5)$ & $\mathrm{Na}_{2} \mathrm{CO}_{3}(3)$, bpy $(0.2)$ & 6 & 0.5 & 100 & 87 & 2 & 0 & 5 \\
\hline 22 & $\mathrm{Ph}_{3} \mathrm{PAuNTf}_{2}(5)$ & $\mathrm{Na}_{2} \mathrm{CO}_{3}(2)$, phen $(0.2)$ & 12 & 0.5 & 86 & 73 & 3 & $<1$ & 5 \\
\hline
\end{tabular}

\section{b. Effects of different solvents}

The gold catalyst and additives were added to $0.5 \mathrm{~mL}$ solvent in a 1-dram vial. To this solution was added the alkyne 12a $(0.1 \mathrm{mmol}, 8.4 \mathrm{mg})$ and the diazonium salt 13a $(0.12$ $\mathrm{mmol}, 25.6 \mathrm{mg}$ ). The mixture was stirred under room temperature for $20 \mathrm{hrs}$. 


\begin{tabular}{cccccccccc}
\hline \multirow{2}{*}{ Entry } & Catalyst & Additive & \multirow{2}{*}{ Solvent } & \multicolumn{3}{c}{ Conc. Conv. } & \multicolumn{3}{c}{ Yield (\%) } \\
\cline { 6 - 11 } & $(5 \%)$ & $(2$ equiv. $)$ & & $(\mathrm{M})$ & $(\%)$ & 14aa & 15a & 16a & 16a' \\
\hline 1 & $\mathrm{Ph}_{3} \mathrm{PAuNTf}_{2}$ & bpy & $\mathrm{ACN}$ & 0.2 & 73 & 60 & 5 & 0 & 8 \\
2 & $\mathrm{Ph}_{3} \mathrm{PAuNTf}_{2}$ & bpy & $\mathrm{MeOH}$ & 0.2 & 71 & 62 & - & 0 & 23 \\
3 & $\mathrm{Ph}_{3} \mathrm{PAuNTf}_{2}$ & bpy & ACN/MeOH $(1: 1)$ & 0.2 & 69 & 57 & 6 & 0 & 8 \\
4 & $\mathrm{Ph}_{3} \mathrm{PAuNTf}_{2}$ & bpy & Acetone & 0.2 & 53 & 40 & 2 & 0 & 6 \\
\hline
\end{tabular}

\section{c. Effects of gold catalysts}

The gold catalyst ( $0.005 \mathrm{mmol}), \mathrm{Na}_{2} \mathrm{CO}_{3}(0.2 \mathrm{mmol}, 21.2 \mathrm{mg})$, and 2,2'-bipyridine (bpy, $0.02 \mathrm{mmol}, 3.1 \mathrm{mg}$ ) were added to $0.2 \mathrm{~mL}$ freshly distilled ACN in a 1-dram vial. To this solution was added the alkyne 12a $(0.1 \mathrm{mmol}, 8.4 \mathrm{mg})$ and the diazonium salt 13a $(0.12$ $\mathrm{mmol}, 25.6 \mathrm{mg}$ ). The mixture was stirred under room temperature for $12 \mathrm{hrs}$.

\begin{tabular}{|c|c|c|c|c|c|c|c|c|}
\hline \multirow[t]{2}{*}{ Entry } & \multirow{2}{*}{$\begin{array}{c}\text { Catalyst } \\
(\%)\end{array}$} & \multirow{2}{*}{$\begin{array}{l}\text { Time } \\
\text { (h) }\end{array}$} & \multirow{2}{*}{$\begin{array}{l}\text { Conc. } \\
\text { (M) }\end{array}$} & \multirow{2}{*}{$\begin{array}{c}\text { Convn } \\
(\%)\end{array}$} & \multicolumn{4}{|c|}{ Yield (\%) } \\
\hline & & & & & 14aa & 15a & $16 \mathbf{a}$ & $16 a^{\prime}$ \\
\hline 1 & $\mathrm{Ph}_{3}$ PAuNTf $_{2}(5)$ & 6 & 0.5 & 100 & 94 & 2 & $\mathbf{0}$ & 2 \\
\hline 2 & $\mathrm{Ph}_{3} \mathrm{PAuOAc}(5)$ & 6 & 0.5 & 100 & 88 & 2 & 0 & 2 \\
\hline 3 & $\mathrm{Ph}_{3} \mathrm{PAuCl}(5)$ & 12 & 0.5 & 30 & 27 & 12 & $<1$ & 19 \\
\hline 4 & $\mathrm{Ph}_{3} \mathrm{PAu}(\mathrm{TA}) \mathrm{OTf}(5)^{a}$ & 6 & 0.5 & 100 & 88 & 2 & 0 & 5 \\
\hline 5 & $\mathrm{Et}_{3} \mathrm{PAuNTf}_{2}(5)$ & 12 & 0.5 & 59 & 44 & 5 & 0 & 12 \\
\hline 6 & $(\mathrm{ArO})_{3} \mathrm{PAuNTf}_{2}(5)^{b}$ & 12 & 0.5 & 42 & 40 & 5 & 0 & 10 \\
\hline 7 & JohnPhosAuNTf $f_{2}(5)$ & 12 & 0.5 & 23 & 17 & 6 & 0 & 12 \\
\hline 8 & $\operatorname{IPrAuNTf}_{2}(5)$ & 12 & 0.5 & 17 & 8 & 14 & 0 & 27 \\
\hline 9 & $\mathrm{AuCl}(5)$ & 12 & 0.5 & 8 & 4 & 7 & 0 & 14 \\
\hline 10 & $\mathrm{Ph}_{3} \mathrm{PAuNTf}_{2}(2)$ & 12 & 0.5 & 53 & 40 & 2 & 0 & 13 \\
\hline
\end{tabular}

${ }^{a} \mathrm{TA}=1$-methylbenzotriazole; ${ }^{b} \mathrm{Ar}=2,4$-di-tert-butyl-phenyl.

\section{d. Effects of other metal catalysts}

The catalysts and additives were added to freshly distilled ACN in a 1-dram vial. To this solution was added the alkyne 12a $(0.1 \mathrm{mmol}, 8.4 \mathrm{mg})$ and the diazonium salt 13a $(0.12$ $\mathrm{mmol}, 25.6 \mathrm{mg}$ ). The mixture was stirred under room temperature for $10 \mathrm{hrs}$.

\begin{tabular}{|c|c|c|c|c|c|c|c|c|}
\hline Entry & Catalyst & Additive & Time & Conc & Convn & & 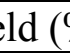 & \\
\hline & $(\%)$ & (equiv.) & (h) & $(\mathrm{M})$ & $(\%)$ & $\overline{14 \mathbf{a a}}$ & & 16a' \\
\hline 1 & $\mathrm{Ru}(\mathrm{bpy})_{3}\left(\mathrm{PF}_{6}\right)_{2}(2.5), \mathrm{Ph}_{3} \mathrm{PAuNTf}_{2}(5)$ & - & 10 & 0.2 & 9 & 0 & 0 & 0 \\
\hline 2 & $\mathrm{Ru}(\text { bpy })_{3}\left(\mathrm{PF}_{6}\right)_{2}(2.5), \mathrm{Ph}_{3} \mathrm{PAuNTf}_{2}(5)$ & $\mathrm{Na}_{2} \mathrm{CO}_{3}(2)$ & 10 & 0.2 & 46 & 41 & 0 & 5 \\
\hline 3 & $\mathrm{Ru}(\mathrm{bpy})_{3}\left(\mathrm{PF}_{6}\right)_{2}(2.5)$ & $\mathrm{Na}_{2} \mathrm{CO}_{3}(2)$ & 10 & 0.2 & 0 & 0 & 0 & 5 \\
\hline 4 & $\mathrm{Ph}_{3} \mathrm{PAuNTf}_{2}(5)$ & $\mathrm{Na}_{2} \mathrm{CO}_{3}(2)$ & 10 & 0.2 & 44 & 41 & 0 & 4 \\
\hline 5 & $\mathrm{Ph}_{3} \mathrm{PAuNTf}_{2}$ (5), (dark) & $\mathrm{Na}_{2} \mathrm{CO}_{3}(2)$ & 10 & 0.2 & 40 & 36 & 0 & 5 \\
\hline 6 & $\mathrm{PdCl}_{2}(5)$ & bpy (2) & 10 & 0.5 & 0 & 0 & 0 & 0 \\
\hline 7 & $\mathrm{PdCl}_{2}(5), \mathrm{Ph}_{3} \mathrm{PAuNTf}_{2}(5)$ & bpy (2) & 10 & 0.5 & 86 & 56 & 13 & $<2$ \\
\hline 8 & $\mathrm{Pd}(\mathrm{OAc})_{2}(5)$ & bpy (2) & 10 & 0.5 & 83 & 13 & 8 & 9 \\
\hline 9 & $\mathrm{Pd}(\mathrm{OAc})_{2}(5), \mathrm{Ph}_{3} \mathrm{PAuNTf}_{2}(5)$ & bpy (2) & 10 & 0.5 & 100 & 62 & 6 & 5 \\
\hline
\end{tabular}




\section{Gold-catalyzed cross coupling of alkynes and aryldiazonium salts:}

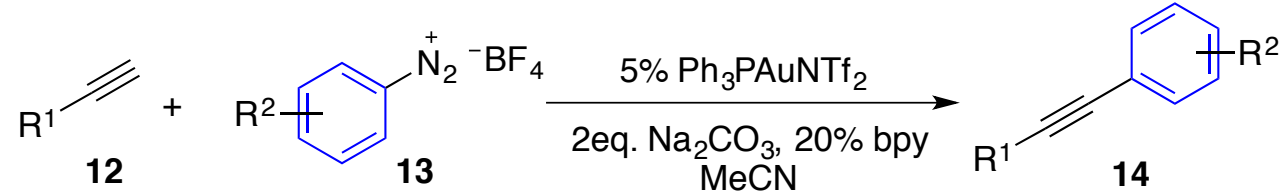

The gold catalyst $\mathrm{Ph}_{3} \mathrm{PAuNTf}_{2}(14.8 \mathrm{mg}, 0.02 \mathrm{mmol})$, bpy $(12.4 \mathrm{mg}, 0.08 \mathrm{mmol})$ and sodium carbonate $(84.8 \mathrm{mg}, 0.8 \mathrm{mmol})$ were added to $0.8 \mathrm{~mL}$ freshly distilled acetonitrile in a 1-dram vial. To this solution was added the alkyne $12(0.4 \mathrm{mmol})$ and the diazonium salt $13(0.48 \mathrm{mmol})$. The mixture was stirred under room temp for 4 to $15 \mathrm{hrs}$. Upon reaction completion, the solvent was removed under reduce pressure and the residue was purified by flash chromatography on silica gel using hexanes or hexanes/ethyl acetate.

\section{Condition optimization of $\mathrm{sp}^{2}$-sp $\mathrm{sp}^{2}$ coupling:}<smiles>[C-]#[N+]N(c1ccc(C)cc1)c1ccc(-c2ccc(F)cc2)cc1</smiles>

The gold catalyst, boronic acid $7 \mathbf{a}$ and additives were added to $0.2 \mathrm{~mL}$ freshly distilled acetonitrile in a 1-dram vial. To this solution was added the diazonium salt 2a $(0.2$ mmol, $42.0 \mathrm{mg}$ ). The conversions and yields were determined by ${ }^{19}$ F-NMR using trifluorotoluene as the standard.

\begin{tabular}{|c|c|c|c|c|c|c|c|}
\hline \multirow[t]{2}{*}{ Entry } & \multirow{2}{*}{$\begin{array}{c}\text { Catalyst } \\
(\%)\end{array}$} & \multirow{2}{*}{$\begin{array}{l}\text { Ligand } \\
(20 \%)\end{array}$} & \multirow{2}{*}{$\begin{array}{l}\text { Time } \\
(\mathrm{h})\end{array}$} & \multirow{2}{*}{$\begin{array}{l}\text { Convn } \\
(\%)\end{array}$} & \multicolumn{3}{|c|}{ Yield (\%) } \\
\hline & & & & & $18 \mathbf{i}$ & $16 a$ & 16a' \\
\hline 1 & $\mathrm{Ph}_{3} \mathrm{PAuNTf}_{2}(5)$ & bpy & 5 & 90 & 38 & 6 & 5 \\
\hline 2 & $\mathrm{Ph}_{3} \mathrm{PAu}(\mathrm{TA}) \mathrm{OTf}(5)^{a}$ & bpy & 5 & 86 & 64 & 7 & 0 \\
\hline 3 & $\mathrm{Ph}_{3} \mathrm{PAu}(\mathrm{TAa})(5)^{b}$ & bpy & 5 & 76 & 47 & 9 & 0 \\
\hline 4 & $(\mathrm{ArO})_{3} \mathrm{PAu}(\mathrm{TA}) \mathrm{OTf}(5)^{c}$ & bpy & 5 & 80 & 33 & 11 & 0 \\
\hline 5 & $\mathrm{Et}_{3} \mathrm{PAu}(\mathrm{TA}) \mathrm{OTf}(5)$ & bpy & 5 & 68 & 10 & 10 & 0 \\
\hline 6 & $(4-\mathrm{OMe}-\mathrm{Ph})_{3} \mathrm{PAu}(\mathrm{TA}) \mathrm{OTf}(5)$ & bpy & 5 & 69 & 29 & 11 & 0 \\
\hline 7 & $\mathrm{Ph}_{3}$ PAu(TA)OTf(10) & bpy & 5 & 100 & 86 & 8 & $\mathbf{0}$ \\
\hline 8 & $\mathrm{Ph}_{3} \mathrm{PAu}(\mathrm{TA}) \mathrm{OTf}(10)$ & dtbbpy & 5 & 88 & 75 & 6 & 0 \\
\hline 9 & $\mathrm{Ph}_{3} \mathrm{PAu}(\mathrm{TA}) \mathrm{OTf}(10)$ & bisquinoline & 5 & 74 & 37 & 10 & 0 \\
\hline
\end{tabular}

E. Gold-catalyzed cross coupling of boronic acids and aryldiazonium salts:

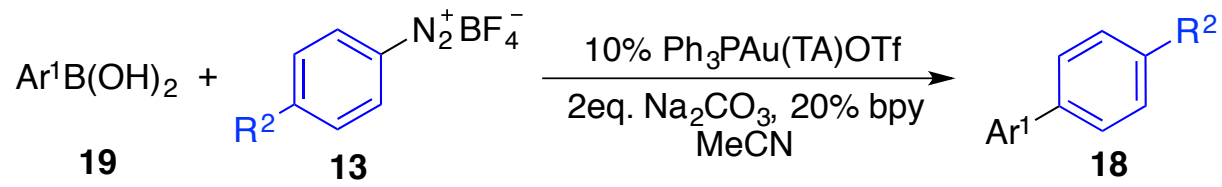

The gold catalyst $\mathrm{Ph}_{3} \mathrm{PAu}(\mathrm{TA}) \mathrm{OTf}(14.8 \mathrm{mg}, 0.04 \mathrm{mmol})$, bpy (12.4 mg, $\left.0.08 \mathrm{mmol}\right)$, sodium carbonate $(84.8 \mathrm{mg}, 0.8 \mathrm{mmol})$ and boronic acid $19(0.4 \mathrm{mmol})$ were added to 0.8 $\mathrm{mL}$ freshly distilled acetonitrile in a 1-dram vial. To this solution was added the 
diazonium salt $13(0.48 \mathrm{mmol})$. The mixture was stirred under room temp for 2 to $10 \mathrm{hrs}$. Upon reaction completion, the solvent was removed under reduce pressure and the residue was purified by flash chromatography on silica gel using hexanes.

\section{F. Gold-catalyzed C-Br bond formation:}

$$
\underset{13}{\left[\mathrm{ArN}_{2}\right]^{+}\left(\mathrm{BF}_{4}^{-}\right)}+\operatorname{LiBr} \underset{23}{\stackrel{3 \% \mathrm{PPh}_{3} \mathrm{AuCl}}{\mathrm{CH}_{3} \mathrm{CN}, 50^{\circ} \mathrm{C}}} \stackrel{\mathrm{Ar}-\mathrm{Br}}{2}
$$

In a dried glass tube, $13(0.2 \mathrm{mmol}), \mathrm{PPh}_{3} \mathrm{AuCl}(0.010 \mathrm{mmol}, 5 \mathrm{~mol} \%)$ and $\mathrm{LiBr}(0.6$ mmol, 3 equiv) were dissolved in $\mathrm{CH}_{3} \mathrm{CN}(0.5 \mathrm{~mL})$. The reaction mixture was stirred at $50{ }^{\circ} \mathrm{C}$ for $5 \mathrm{~h}$. After the reaction completed, the product was purified by column chromatography.

\section{G. Gold-catalyzed C-S bond formation:}

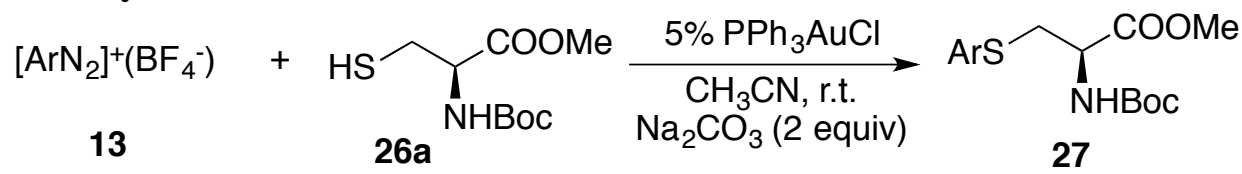

In a dried glass tube, 13 (0.4 mmol, 2 equiv), $\mathrm{PPh}_{3} \mathrm{AuCl}(0.010 \mathrm{mmol}, 5 \mathrm{~mol} \%), \mathrm{Na}_{2} \mathrm{CO}_{3}$ (2 equiv) and 26 ( $0.2 \mathrm{mmol}, 1$ equiv) were dissolved in $\mathrm{CH}_{3} \mathrm{CN}(0.5 \mathrm{~mL})$. The reaction mixture was stirred at room temperature for $3 \mathrm{~h}$. After the reaction completed, the product was purified by column chromatography.

\section{H. Gold-catalyzed C-P bond formation:}

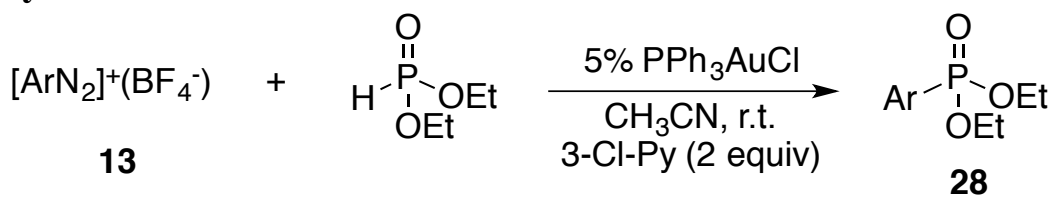

In a dried glass tube, 13 (0.4 mmol, 2 equiv), $\mathrm{PPh}_{3} \mathrm{AuCl}(0.010 \mathrm{mmol}, 5 \mathrm{~mol} \%)$, diethyl phophite ( 0.2 mmol, 1 equiv) and 3-Cl-Py $\left(0.4\right.$ mmol, 1 equiv) were dissolved in $\mathrm{CH}_{3} \mathrm{CN}$ $(0.5 \mathrm{~mL})$. The reaction mixture was stirred at $50{ }^{\circ} \mathrm{C}$ for $8 \mathrm{~h}$. After the reaction completed, the product was purified by column chromatography.

\section{S3.3 Mechanistic studies}

\section{A. The reaction of diazonium salts with gold complexes}

a. Reaction with $\mathrm{Ph}_{3} \mathrm{PAuNTf}_{2}$

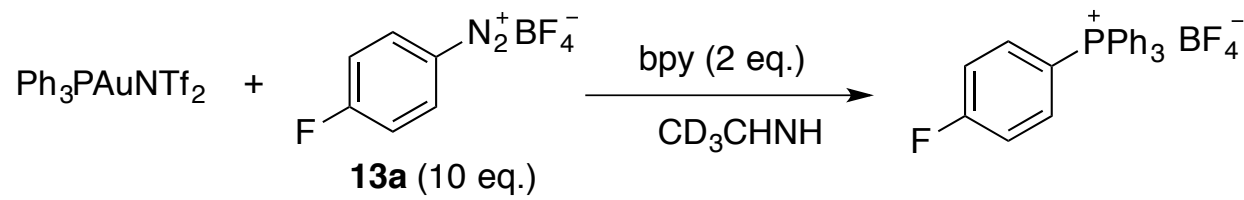

Three NMR tubes were labeled as $\mathbf{A}, \mathbf{B}$ and $\mathbf{C}$. The gold catalyst $\mathrm{Ph}_{3} \mathrm{PAuNTf}_{2}(7.4 \mathrm{mg}$, $0.01 \mathrm{mmol}$ ) was dissolved in $0.4 \mathrm{~mL} \mathrm{CD}{ }_{3} \mathrm{CN}$ in tube $\mathbf{A}$. The gold catalyst $\mathrm{Ph}_{3} \mathrm{PAuNTf}_{2}$ (7.4 $\mathrm{mg}, 0.01 \mathrm{mmol})$, and bpy $(3.1 \mathrm{mg}, 0.02 \mathrm{mmol})$ were added to $0.4 \mathrm{~mL} \mathrm{CD}{ }_{3} \mathrm{CN}$ in tube 
B. The gold catalyst $\mathrm{Ph}_{3} \mathrm{PAuCl}(4.9 \mathrm{mg}, 0.01 \mathrm{mmol})$ and $\mathrm{Ru}(\mathrm{bpy})_{3}\left(\mathrm{PF}_{6}\right)_{2}(0.6 \mathrm{mg}, 0.001$ mmol) were added to $0.4 \mathrm{~mL} \mathrm{CD}_{3} \mathrm{CN}$ in tube $\mathbf{C}(\mathbf{C}$ was used as reference regarding the formation of the phosphonium salt) ${ }^{3}$.

The diazonium salt 13a (10 eq.) was added to the three NMR tubes separately. Tube $\mathbf{C}$ was place under blue LED light. The reactions were monitored by ${ }^{1} \mathrm{H}-\mathrm{NMR}$ and ${ }^{31} \mathrm{P}$ NMR. The $\mathrm{D}_{2} \mathrm{O}$ solution of phosphoric acid in a seal tube was used as the standard for ${ }^{31} \mathrm{P}-\mathrm{NMR}$.

For tube $\mathbf{A}$ (without bpy present), no reaction was observed after addition of 13a for $18 \mathrm{~h}$. After $18 \mathrm{~h}, 10$ eq. of the alkyne 12a was added, still without any reaction.

For tube $\mathbf{B}$ (with 2 eq. bpy), the in-situ formed $\left[\mathrm{Ph}_{3} \mathrm{PAu}(\mathrm{bpy})\right]^{+}\left({ }^{31} \mathrm{P}\right.$ NMR: $\left.\delta 31.6 \mathrm{ppm}\right)$ reacted with the diazonium salt and generated a new species $\mathbf{M}$. The gold catalyst reached full conversion within $8 \mathrm{~h}$ to $\mathbf{M}$ with $10 \%$ consumption of the diaozonium salt 2a (10 eq. relevant to gold catalyst).

After comparison the NMR with tube $\mathbf{C}$, which is a method reported by the Toste group ${ }^{2}$ to generate phosphonium, we were able to conclude the formation of phosphonium $\mathbf{M}$ by simply reacting $\mathrm{Ph}_{3} \mathrm{PAuNTf}_{2}$ with diazonium salt with bpy present. However, adding 10 eq. of the alkyne 12a after $18 \mathrm{~h}$ did not form the cross-coupling product. This suggested that the phosphonium is not an active species in this transformation.
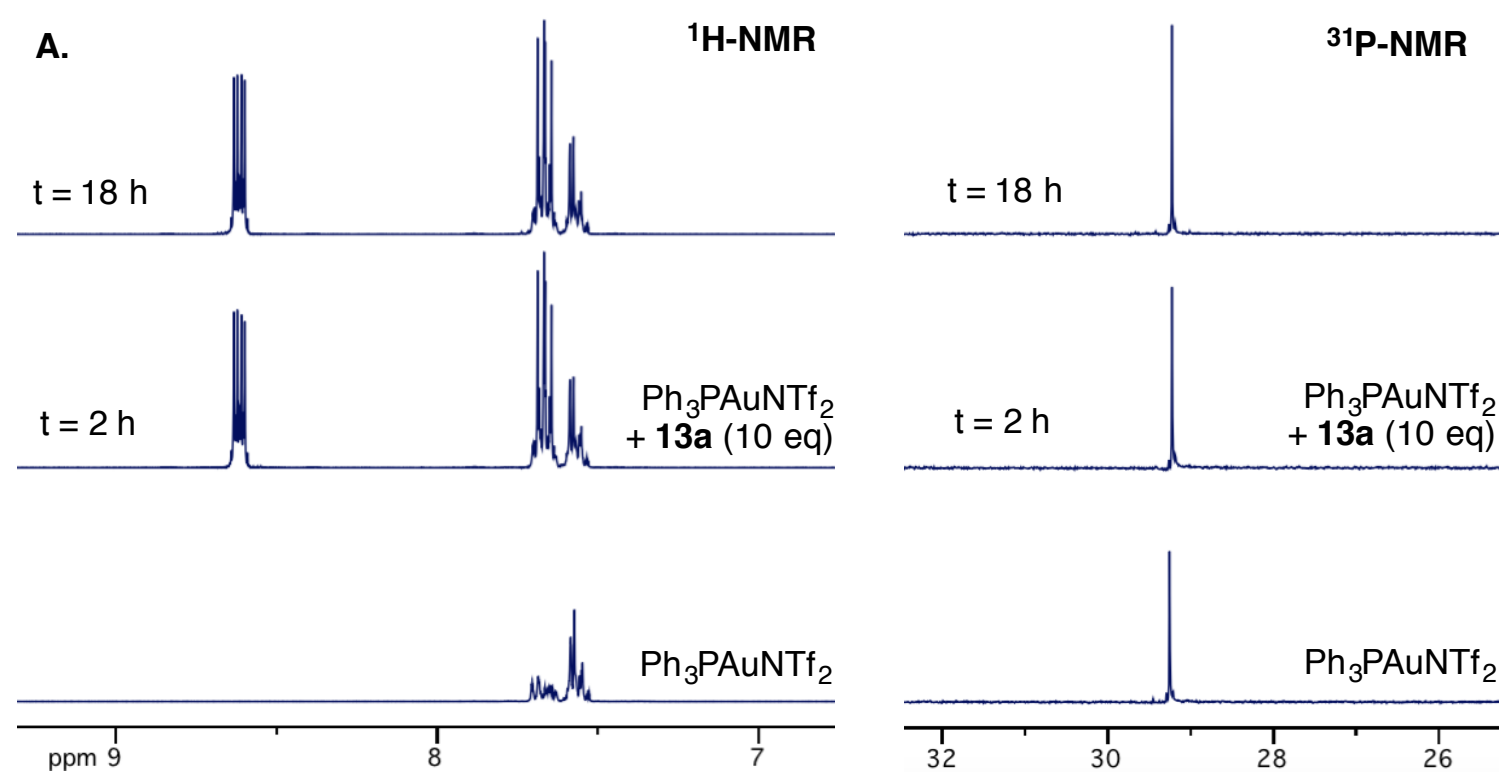

Figure S1. The NMR spectra for the reaction between $\mathrm{Ph}_{3} \mathrm{PAuNTf}_{2}$ and 13a (no bpy)

\footnotetext{
${ }^{3}$ Shu, X.-z.; Zhang, M.; He, Y.; Frei, H.; Toste, F. D. J. Am. Chem. Soc. 2014, 136, 5844.
} 

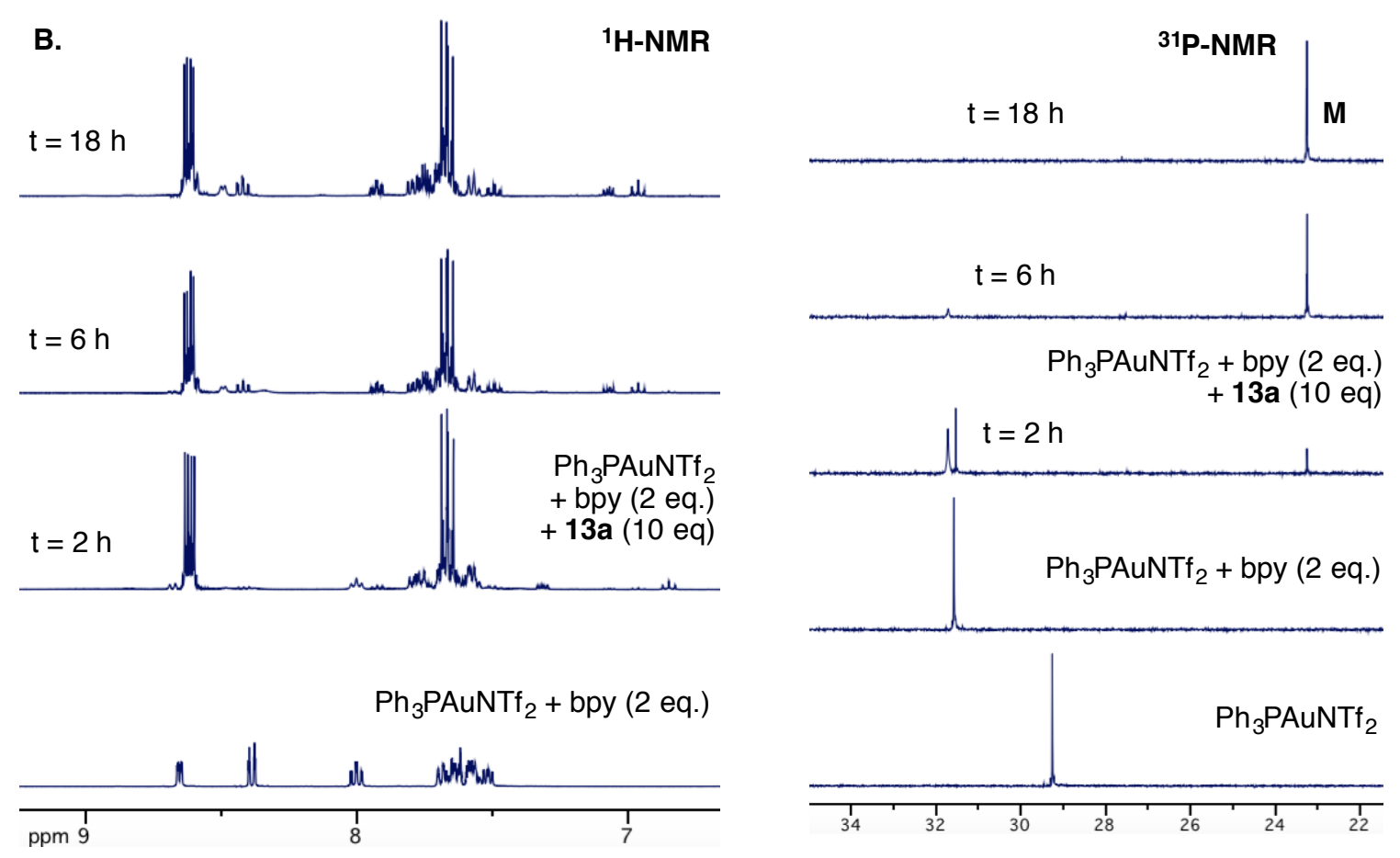

Figure S2. The NMR spectra for the reaction between $\mathrm{Ph}_{3} \mathrm{PAuNTf}_{2}$ and 13a (2 eq. bpy)
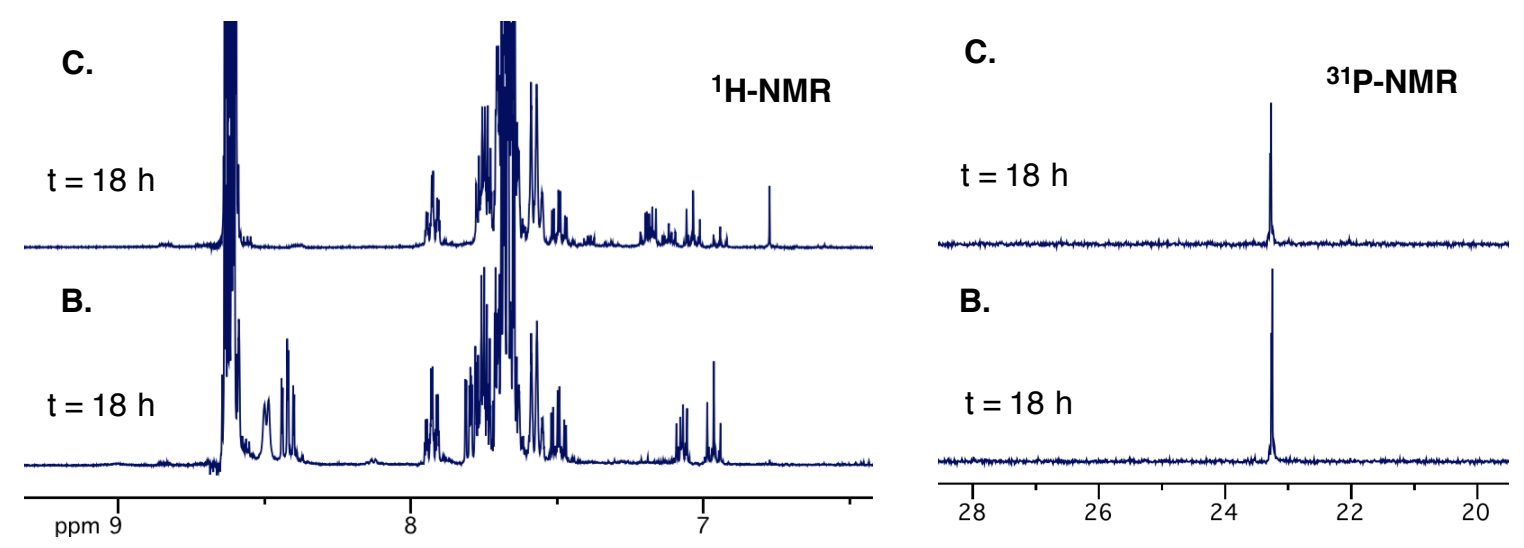

Figure S3. The NMR spectra for the phosphonium $\mathbf{M}$

\section{b. Reaction with gold acetylide}

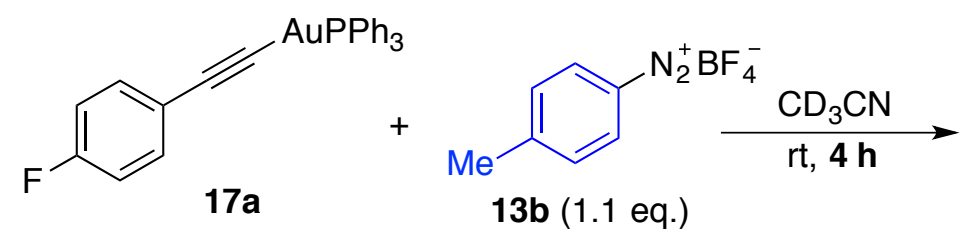<smiles>Cc1ccc(C#Cc2ccc(F)cc2)cc1</smiles>
A. no bpy: $22 \%$
B. 2 eq. bpy : $98 \%$ 
The synthesis of gold acetylide $\mathbf{1 7 a}$ was adapted from literature report. ${ }^{4}$

${ }^{1} \mathrm{H}$ NMR $\left(400 \mathrm{MHz}, \mathrm{CDCl}_{3}\right): \delta$ 7.58-7.43 (m, 17H), $6.94(\mathrm{t}, J=8.8 \mathrm{~Hz}, 2 \mathrm{H}) ;{ }^{31} \mathrm{P}$ NMR $\left(162 \mathrm{MHz}, \mathrm{CDCl}_{3}\right): \delta \quad 42.2 ;{ }^{19} \mathrm{~F}$ NMR (376 MHz, $\left.\mathrm{CDCl}_{3}\right): \delta \quad-114.3(\mathrm{~m}, 1 \mathrm{~F})$.

Two NMR tubes were labeled as A and $\mathbf{B}$. The gold acetylide 17a (17.4 $\mathrm{mg}, 0.03 \mathrm{mmol})$ was added to $0.4 \mathrm{~mL} \mathrm{CD}{ }_{3} \mathrm{CN}$ in tube $\mathbf{A}$. The gold acetylide $17 \mathbf{a}(17.4 \mathrm{mg}, 0.03 \mathrm{mmol})$ and bpy $(9.4 \mathrm{mg}, 0.06 \mathrm{mmol})$ were added to $0.4 \mathrm{~mL} \mathrm{CD}_{3} \mathrm{CN}$ in tube $\mathbf{B}$.

The diazonium salt $\mathbf{1 3 b}(6.8 \mathrm{mg}, 0.033 \mathrm{mmol})$ was added to the two NMR tubes separately. The reactions were monitored by ${ }^{1} \mathrm{H}-\mathrm{NMR},{ }^{19} \mathrm{~F}-\mathrm{NMR}$ and ${ }^{31} \mathrm{P}-\mathrm{NMR}$. A $\mathrm{D}_{2} \mathrm{O}$ solution of phosphoric acid in a seal tube was used as the standard for ${ }^{31} \mathrm{P}-\mathrm{NMR}$. Trifluorotoluene was used as the internal standard for ${ }^{19} \mathrm{~F}-\mathrm{NMR}$ and $\mathrm{p}$-xylene was used as the internal standard for ${ }^{1} \mathrm{H}-\mathrm{NMR}$. The yields of the product were calculated based on both the ${ }^{19} \mathrm{~F}$-NMR and the ${ }^{1} \mathrm{H}-\mathrm{NMR}$.

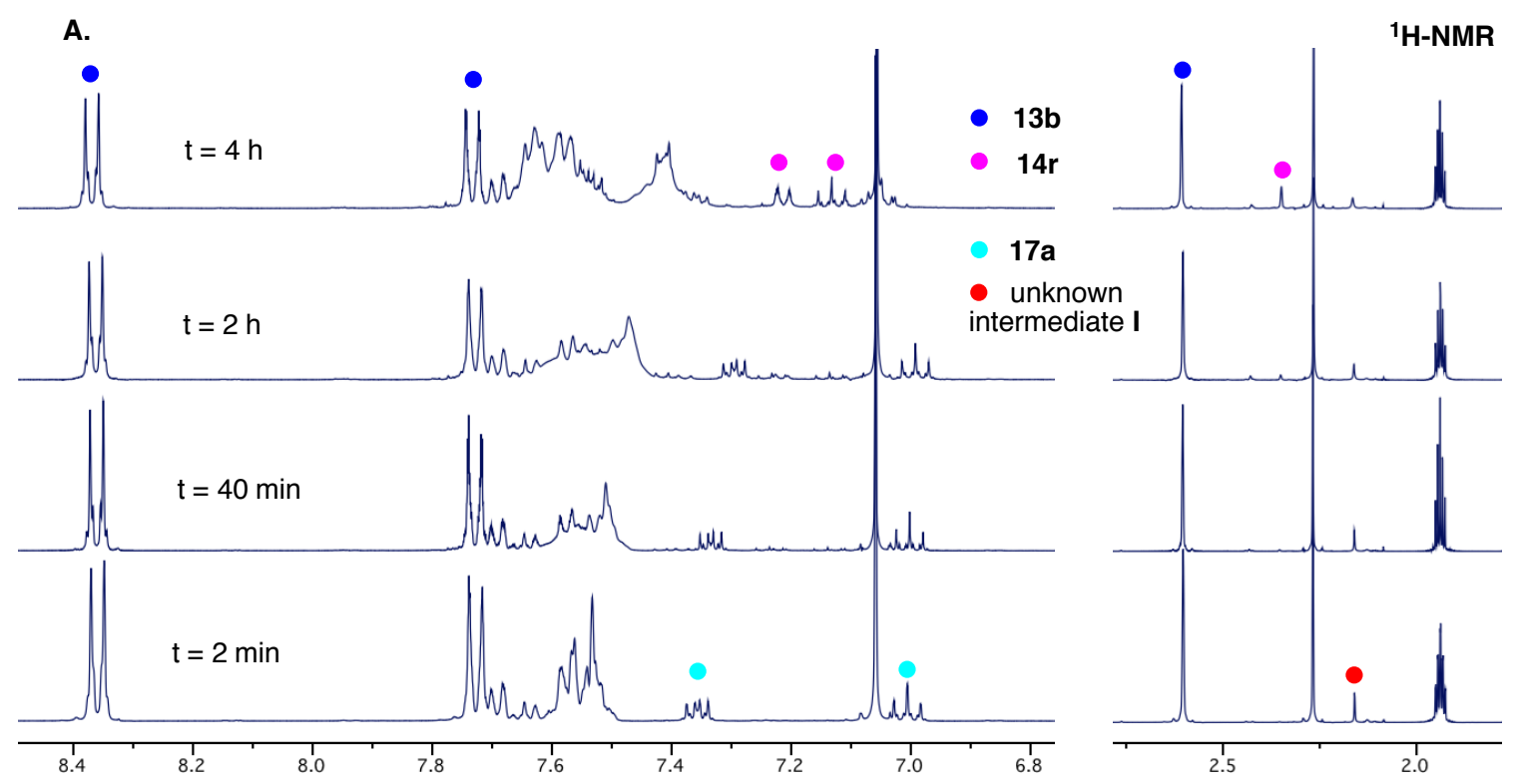

Figure S4. NMR spectra for the reaction between gold acetylide 17a and 13a (no bpy)

4 Kilpin, K. J.; Horvath, R.; Jameson, G. B.; Telfer, S. G.; Gordon, K. C.; Crowley, J. D. Organometallics 2010, 29 , 6186. 


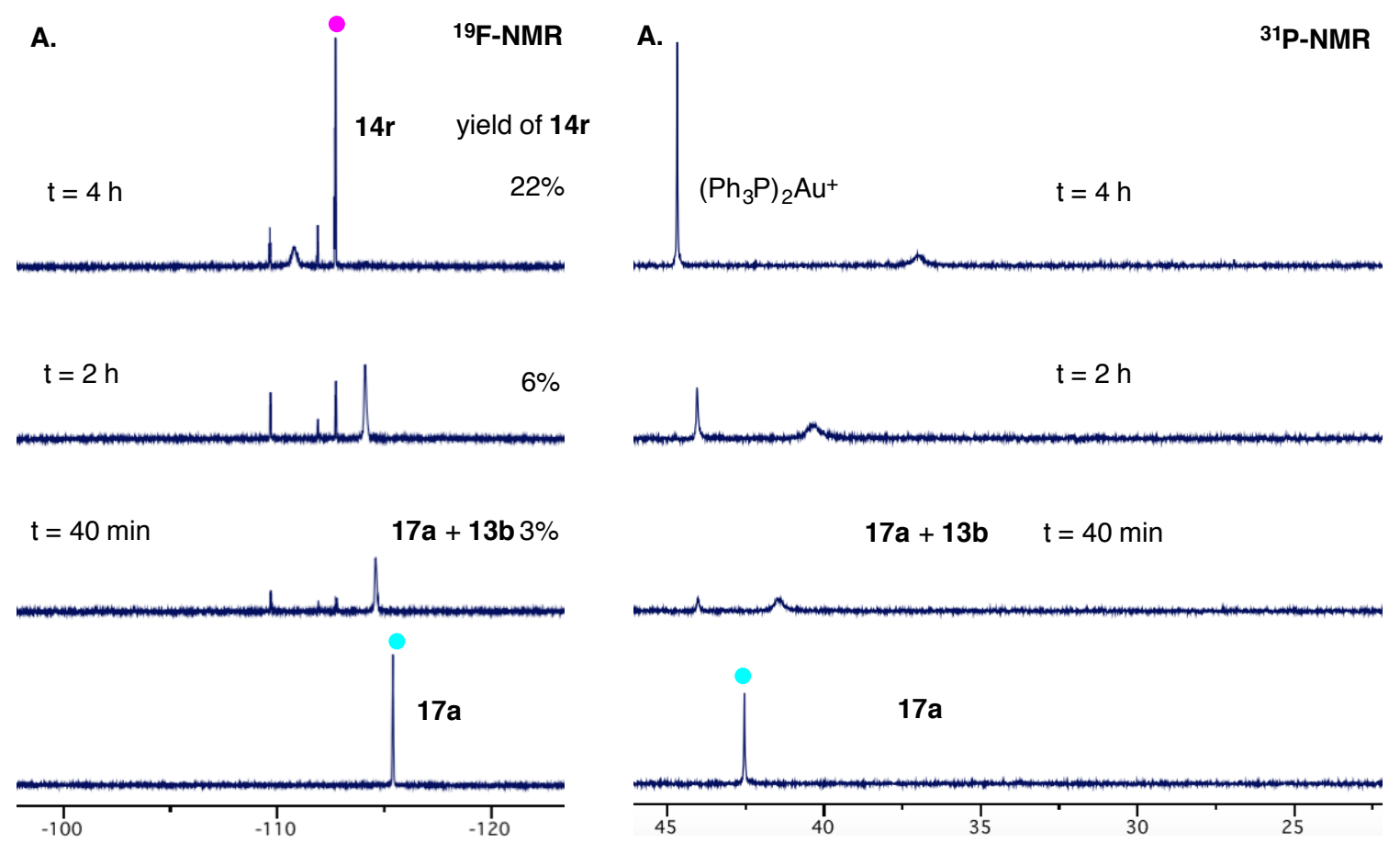

Figure S4. NMR spectra for the reaction between gold acetylide 17a and 13a (no bpy)

B.

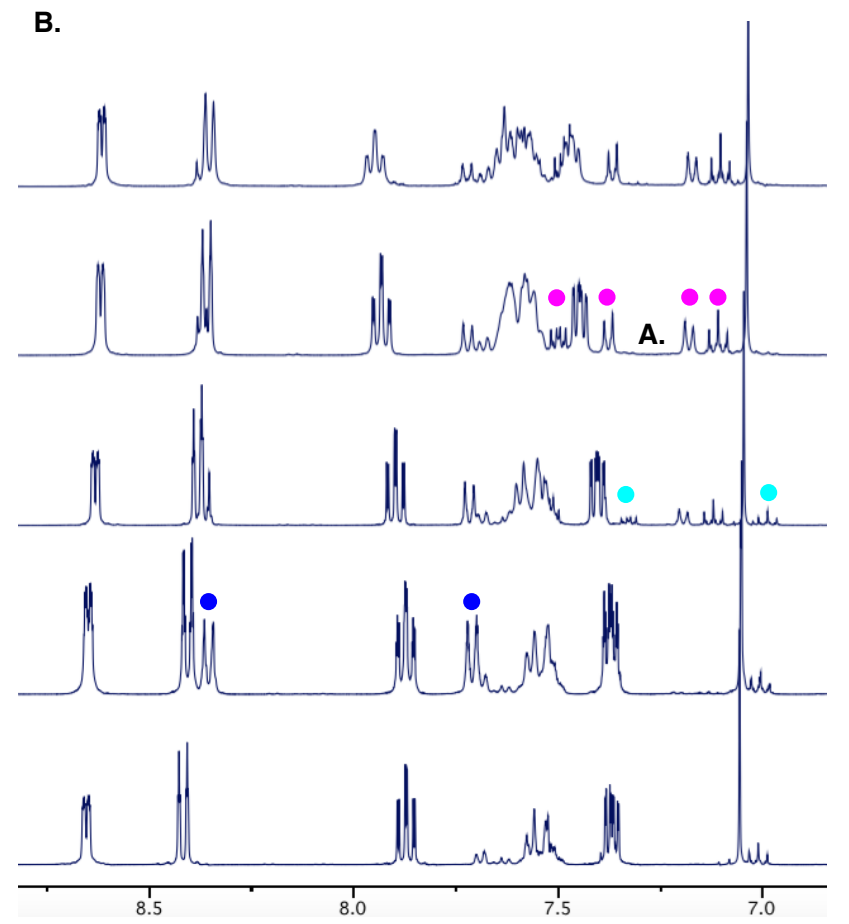

${ }^{1} \mathrm{H}-\mathrm{NMR}$

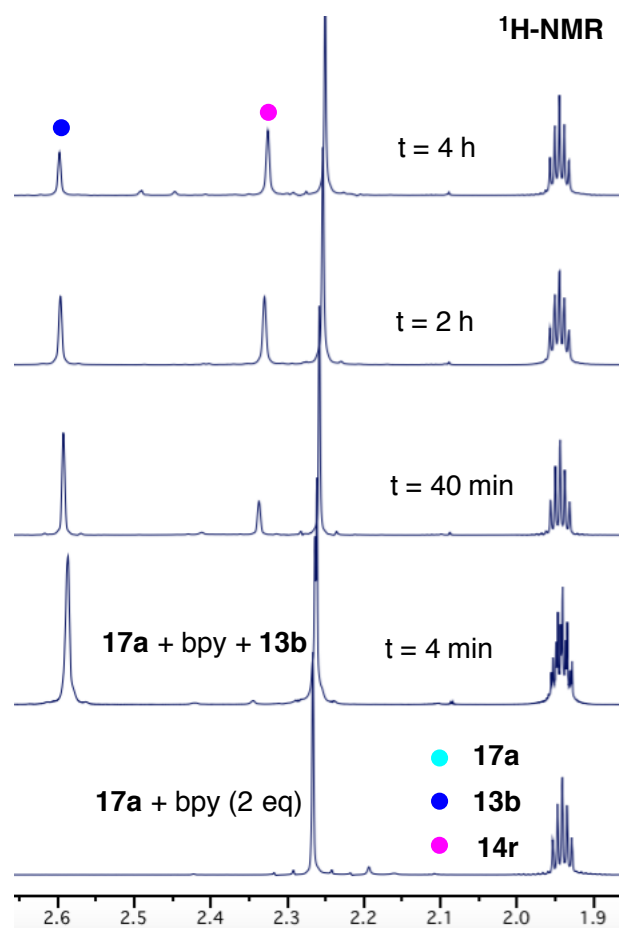

Figure S5. NMR spectra for the reaction between gold acetylide 6a and 2a (2 eq. bpy) 


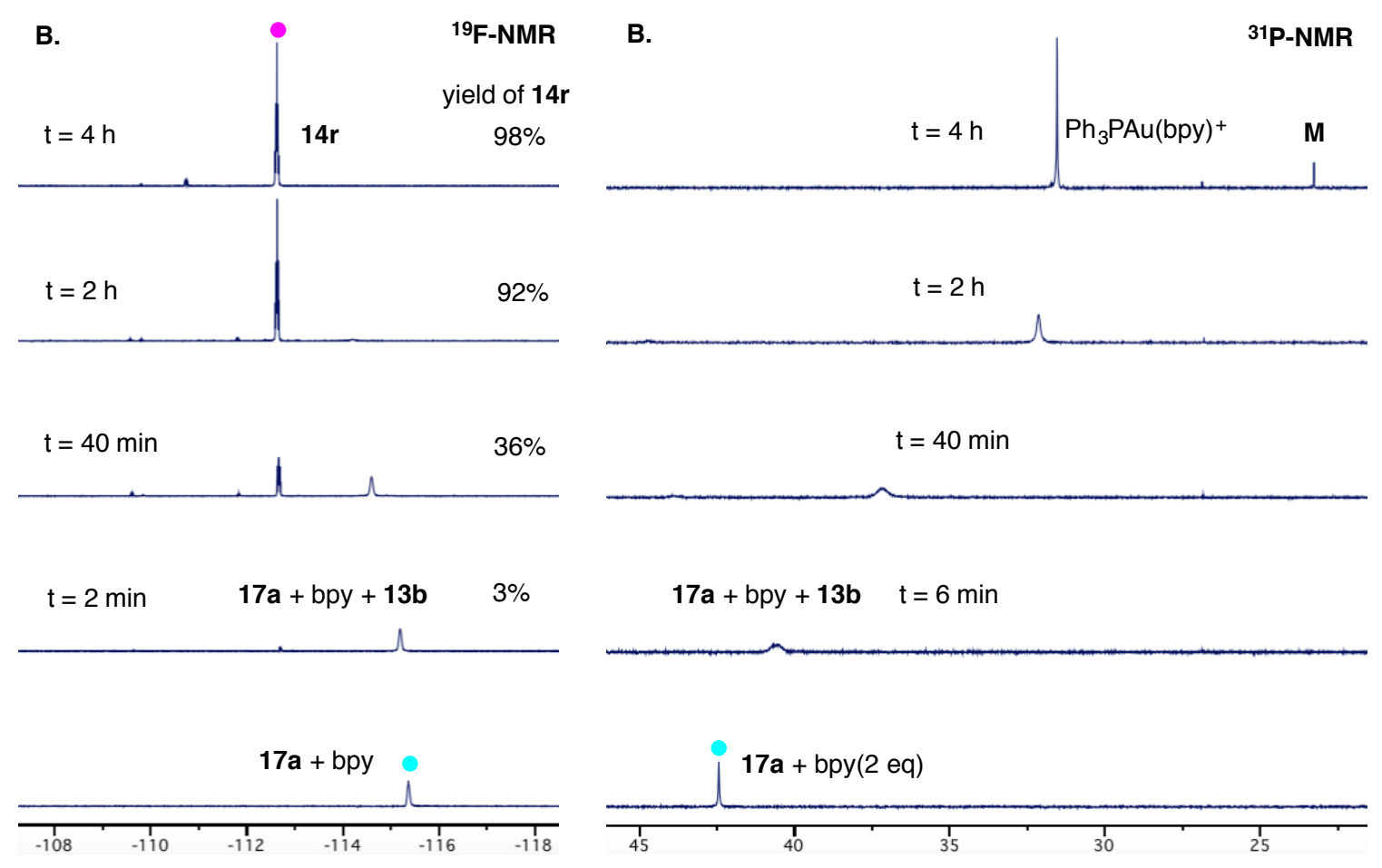

Figure S5. NMR spectra for the reaction between gold acetylide 6a and 2a (2 eq. bpy)

The gold acetylide 6a is poorly soluble in $\mathrm{CD}_{3} \mathrm{CN}$. However, it dissolved gradually as the reaction proceeded. Gold mirror formation was observed in tube $\mathbf{A}$ within $1 \mathrm{~h}$, whereas no decomposition of the gold complex was observed in tube $\mathbf{B}$ during the reaction. This is most likely due to the stabilization of cation gold complex and/or reaction intermediate by the bpy ligand. The bpy also contributed to the nitrogen extrusion based on the results in the previous section (III. A. 1), which might explain the much higher yield and reaction rate we observed in tube $\mathbf{B}$ compared to tube $\mathbf{A}$.

In tube $\mathbf{A}$, an unidentified intermediate $\mathbf{I}$ was observed from the beginning of the reaction. However, this intermediate is almost invisible in tube $\mathbf{B}$ (with 2 eq. bpy present, only trace amount was observed in the very beginning of the reaction). If our hypothesis is correct, this intermediate $\mathbf{I}$ should be the adduct between diazonium and gold acetylide, for which the nitrogen extrusion was a problem without the help from bpy.

In tube $\mathbf{B}$, the gold acetylide $\mathbf{6 a}$ was fully converted to $\left[\mathrm{Ph}_{3} \mathrm{PAu}(\mathrm{bpy})\right]^{+}$in $4 \mathrm{~h}$ with almost quantitative yield of the product $\mathbf{3 r}$. Upon reaction completion, phosphonium $\mathbf{M}$ was generated by the reaction between $\left[\mathrm{Ph}_{3} \mathrm{PAu}(\mathrm{bpy})\right]^{+}$with excess diazonium salt $\mathbf{2 b}$.

\section{c. Reaction with aryl gold}




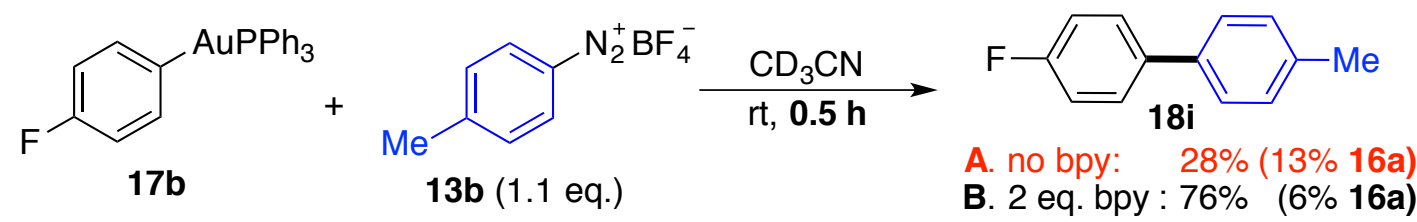

The aryl gold $\mathbf{6 b}$ was synthesized based on previous report. ${ }^{5}$

${ }^{1} \mathrm{H}$ NMR (400 MHz, $\left.\mathrm{CDCl}_{3}\right): \delta$ 7.62-7.43 (m, 17H), $7.01(\mathrm{ddd}, J=10.0,8.6,1.3 \mathrm{~Hz}, 2 \mathrm{H})$;

${ }^{31} \mathrm{P}$ NMR (162 MHz, $\left.\mathrm{CDCl}_{3}\right): \delta 43.5 ;{ }^{19} \mathrm{~F}$ NMR (376 MHz, $\left.\mathrm{CDCl}_{3}\right): \delta-117.3(\mathrm{~m}, 1 \mathrm{~F})$.

Two NMR tubes were labeled as $\mathbf{A}$ and $\mathbf{B}$. The aryl gold complex 17b $(16.6 \mathrm{mg}, 0.03$ mmol) was added to $0.4 \mathrm{~mL} \mathrm{CD}{ }_{3} \mathrm{CN}$ in tube $\mathbf{A}$. The aryl gold complex $\mathbf{1 7 b}(16.6 \mathrm{mg}$, $0.03 \mathrm{mmol})$ and bpy $(9.4 \mathrm{mg}, 0.06 \mathrm{mmol})$ were added to $0.4 \mathrm{~mL} \mathrm{CD}_{3} \mathrm{CN}$ in tube $\mathbf{B}$.

The diazonium salt $\mathbf{1 3 b}(6.8 \mathrm{mg}, 0.033 \mathrm{mmol})$ was added to the two NMR tubes separately. The reactions were monitored by ${ }^{1} \mathrm{H}-\mathrm{NMR},{ }^{19} \mathrm{~F}-\mathrm{NMR}$ and ${ }^{31} \mathrm{P}-\mathrm{NMR}$. The $\mathrm{D}_{2} \mathrm{O}$ solution of phosphoric acid in a seal tube was used as the standard for ${ }^{31} \mathrm{P}-\mathrm{NMR}$. Trifluorotoluene was used as the internal standard for ${ }^{19} \mathrm{~F}$-NMR and $\mathrm{p}$-xylene was used as the internal standard for ${ }^{1} \mathrm{H}-\mathrm{NMR}$. The yields of the product were calculated based on both the ${ }^{19} \mathrm{~F}-\mathrm{NMR}$ and the ${ }^{1} \mathrm{H}-\mathrm{NMR}$.

Similar to the gold acetylide, the aryl gold $\mathbf{1 7 b}$ is poorly soluble in $\mathrm{CD}_{3} \mathrm{CN}$. However, it dissolved gradually as the reaction proceeded. Gold mirror formation was observed in tube $\mathbf{A}$ within 10 min, whereas no decomposition of the gold complex was observed in tube $\mathbf{B}$ during the reaction. Much higher yield and reaction rate were observed in tube $\mathbf{B}$ compared to tube A.

Compared to the reaction with gold acetylide, the reaction of diazonium salt with aryl gold complex seemed to suffer from the homo-coupling especially without bpy present (tube A). When bpy presented (tube $\mathbf{B})$, the $\left[\mathrm{Ph}_{3} \mathrm{PAu}(\mathrm{bpy})\right]^{+}(\delta 31.6 \mathrm{ppm}$ ) was the major species in the ${ }^{31} \mathrm{P}$ NMR from the beginning of the reaction, suggesting the rapid reductive elimination from the $\mathrm{Au}(\mathrm{III})$ intermediate. Phosphonium $\mathbf{M}$ was also generated in the early stage of the reaction, which is consistent with the formation of $\left[\mathrm{Ph}_{3} \mathrm{PAu}(\mathrm{bpy})\right]^{+}$. Although the homo-coupling is suppressed with bpy present, it still was a problem that caused the lower yield of the cross-coupling product.

5 Peña-López, M.; Peña-López, M.; Ayán-Varela, M.; Ayán-Varela, M.; Sarandeses, L. A.; Sarandeses, L. A.; Sestelo, J. P.; Sestelo, J. P. Org. Biomol. Chem. 2012, 10, 1686. 
A.
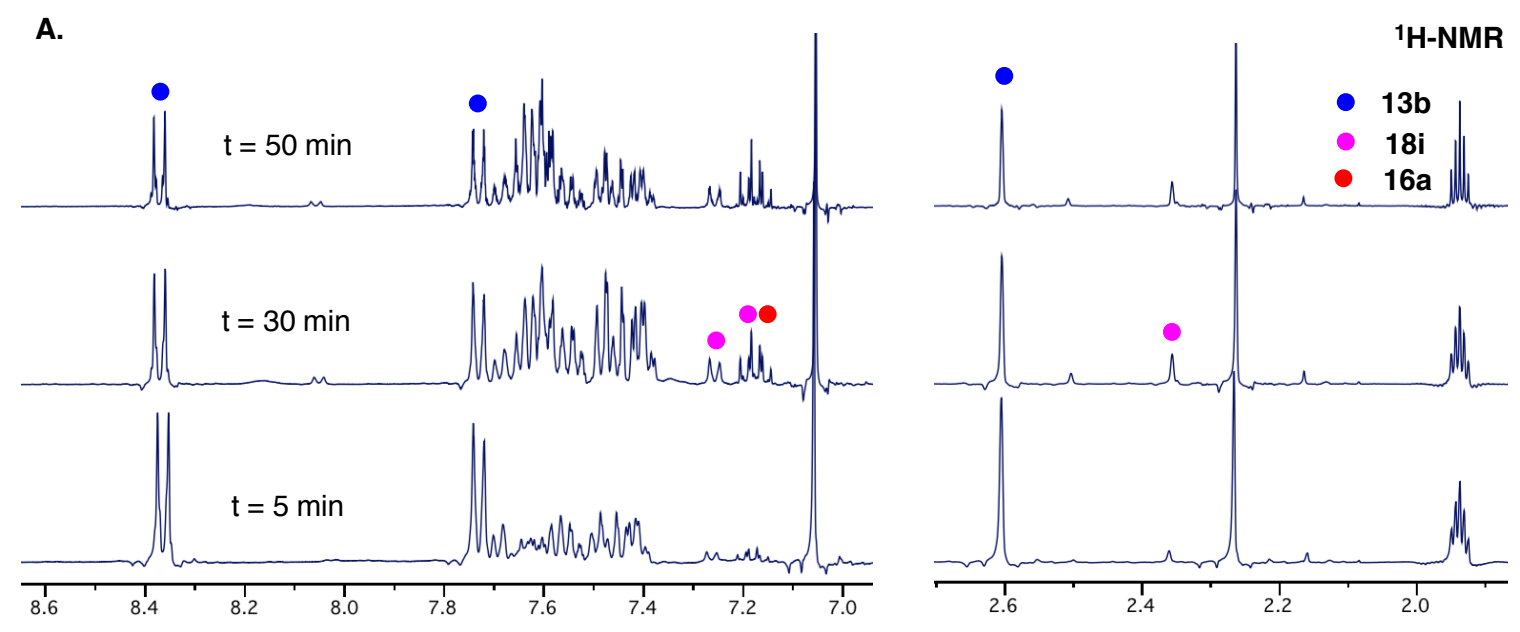

A.

${ }^{19}$ F-NMR
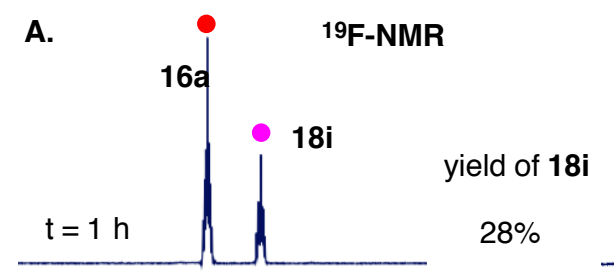

A.

31P-NMR

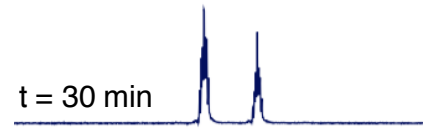

$21 \%$

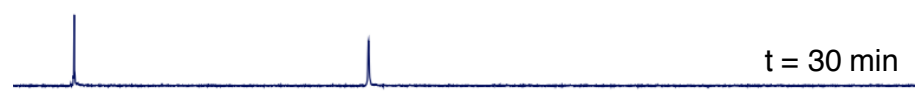

$t=10 \min \_\quad 17 b+13 b \quad 8 \%$

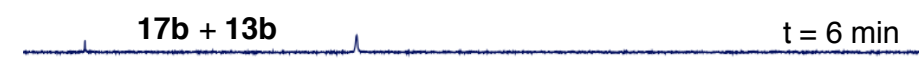

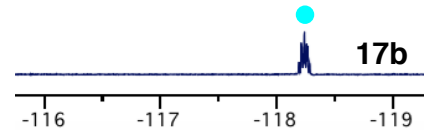
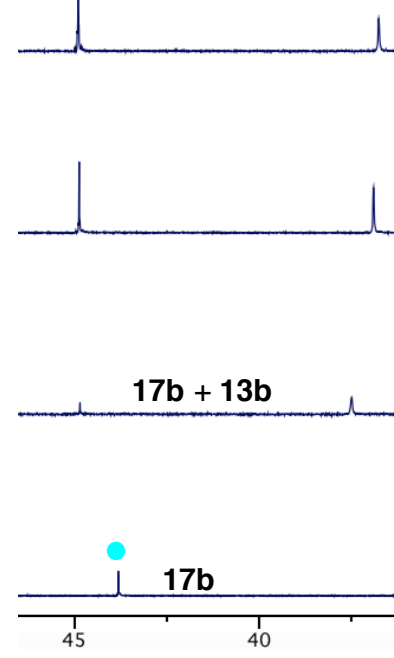

$t=1 h$

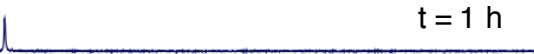

Figure S6. NMR spectra for the reaction between aryl gold 17b and 13a (no bpy) 

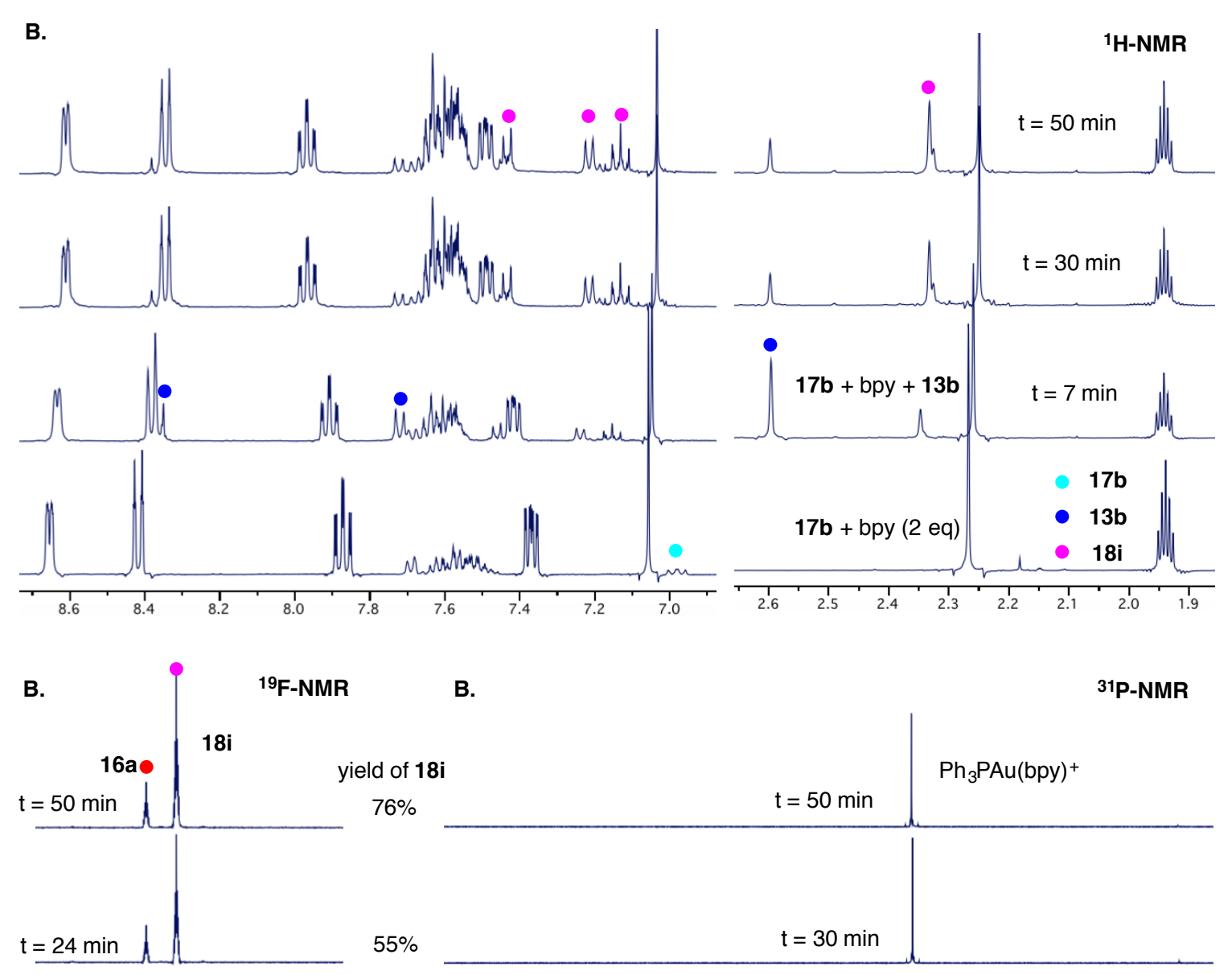

$t=3 \min a 17 b+b p y+13 b \quad 27 \% \quad 17 b+b p y+13 b \quad t=9 \min \mid \quad M$

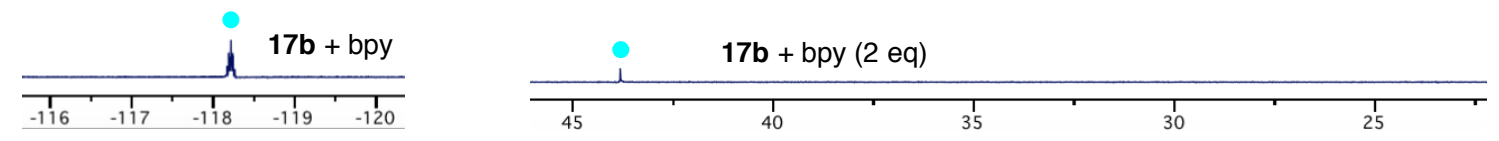

Figure S7. NMR spectra for the reaction between aryl gold $\mathbf{1 7 b}$ and 13a (2 eq. bpy)

\section{d. Reaction with alkyl gold $\mathrm{Ph}_{3} \mathrm{PAuMe}$}

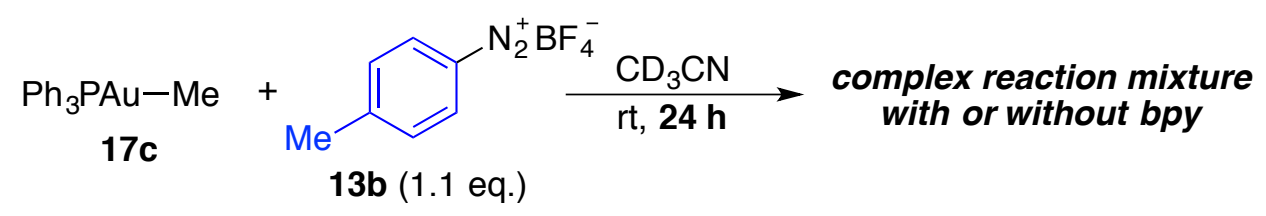

Two NMR tubes were labeled as A and B. The alkyl gold 17c $(14.2 \mathrm{mg}, 0.03 \mathrm{mmol})$ was added to $0.4 \mathrm{~mL} \mathrm{CD}_{3} \mathrm{CN}$ in tube $\mathbf{A}$. The gold acetylide $17 \mathbf{b}(14.2 \mathrm{mg}, 0.03 \mathrm{mmol})$ and bpy $(9.4 \mathrm{mg}, 0.06 \mathrm{mmol})$ were added to $0.4 \mathrm{~mL} \mathrm{CD}_{3} \mathrm{CN}$ in tube $\mathbf{B}$. The diazonium salt 13b $(6.8 \mathrm{mg}, 0.033 \mathrm{mmol})$ was added to the two NMR tubes separately. The reactions 
were monitored by ${ }^{1} \mathrm{H}-\mathrm{NMR}$ and ${ }^{31} \mathrm{P}-\mathrm{NMR}$. The $\mathrm{D}_{2} \mathrm{O}$ solution of phosphoric acid in a seal tube was used as the standard for ${ }^{31} \mathrm{P}-\mathrm{NMR}$. 1,3,5-tribromobenzene was used as the internal standard for ${ }^{1} \mathrm{H}-\mathrm{NMR}$.

The reaction with $\mathrm{Ph}_{3} \mathrm{PAuMe}$ was quite sluggish both with and without bpy. The alkyl gold $\mathrm{Ph}_{3} \mathrm{PAuMe}$ showed very terrible solubility in $\mathrm{CD}_{3} \mathrm{CN}$. In tube $\mathbf{A}$, the gold complex slowly decomposed to yield gold mirror with small amount of unidentified mixture formed. Although no gold mirror was observed in tube $\mathbf{B}$, the reaction was also slow and messy. The desired product ( $\mathrm{p}$-xylene) was not detected by ${ }^{1} \mathrm{H}-\mathrm{NMR}$.

\section{B. Monitoring the catalytic sp-sp ${ }^{2}$ coupling}

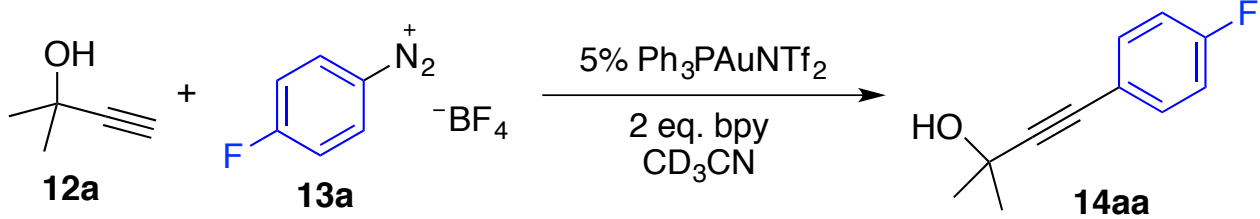

The alkyne 12a $(0.2 \mathrm{mmol}, 16.8 \mathrm{mg})$, bpy $(0.4 \mathrm{mmol}, 62.4 \mathrm{mg})$ and the diazonium salt 13a $\left(0.22 \mathrm{mmol}, 46.2 \mathrm{mg}\right.$ ) were dissolved in $0.4 \mathrm{~mL} \mathrm{CD}_{3} \mathrm{CN}$ in a NMR tube. To this solution was added the gold catalyst $\mathrm{Ph}_{3} \mathrm{PAuNTf}_{2}(7.4 \mathrm{mg}, 0.01 \mathrm{mmol})$. The reactions were monitored by ${ }^{1} \mathrm{H}-\mathrm{NMR}$ and ${ }^{31} \mathrm{P}-\mathrm{NMR}$. The $\mathrm{D}_{2} \mathrm{O}$ solution of phosphoric acid in a seal tube was used as the standard for ${ }^{31} \mathrm{P}-\mathrm{NMR}$. The conversions of 12a and yields of 14aa were determined by ${ }^{1} \mathrm{H}-\mathrm{NMR}$ using $\mathrm{p}$-xylene as the standard.

Based on the ${ }^{31} \mathrm{P}-\mathrm{NMR}$, the $\left[\mathrm{Ph}_{3} \mathrm{PAu}(\mathrm{bpy})\right]^{+}(\delta 31.6 \mathrm{ppm})$ was the major species detected during the reaction. As the reaction proceeded toward completion, the $\left[\mathrm{Ph}_{3} \mathrm{PAu}(\mathrm{bpy})\right]^{+}$ started to accumulate. After the reaction was completed $(7 \mathrm{~h})$, the phosphonium $\mathbf{M}$ formed. No induction period was observed for this reaction based on the ${ }^{1} \mathrm{H}-\mathrm{NMR}$.

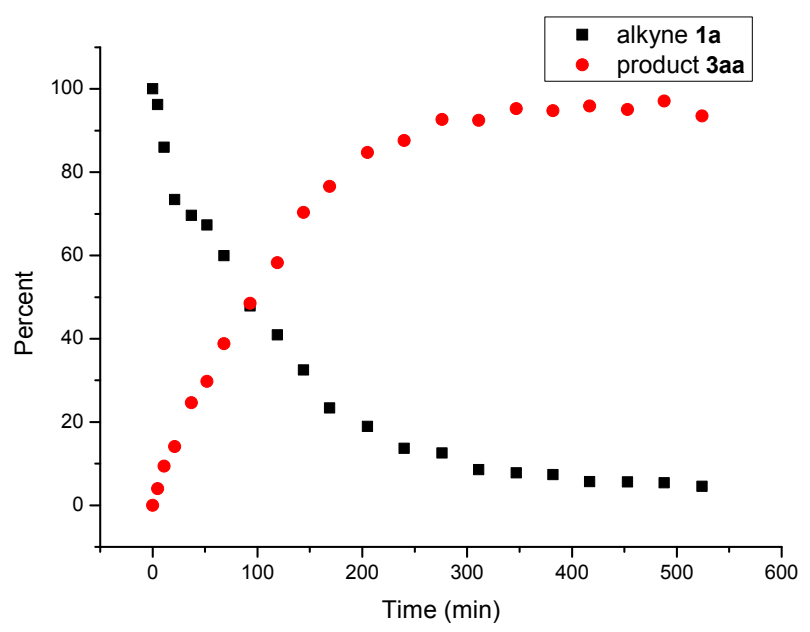

Figure S8. Reaction kinetics for the catalytic $s p-\mathrm{sp}^{2}$ cross-coupling 

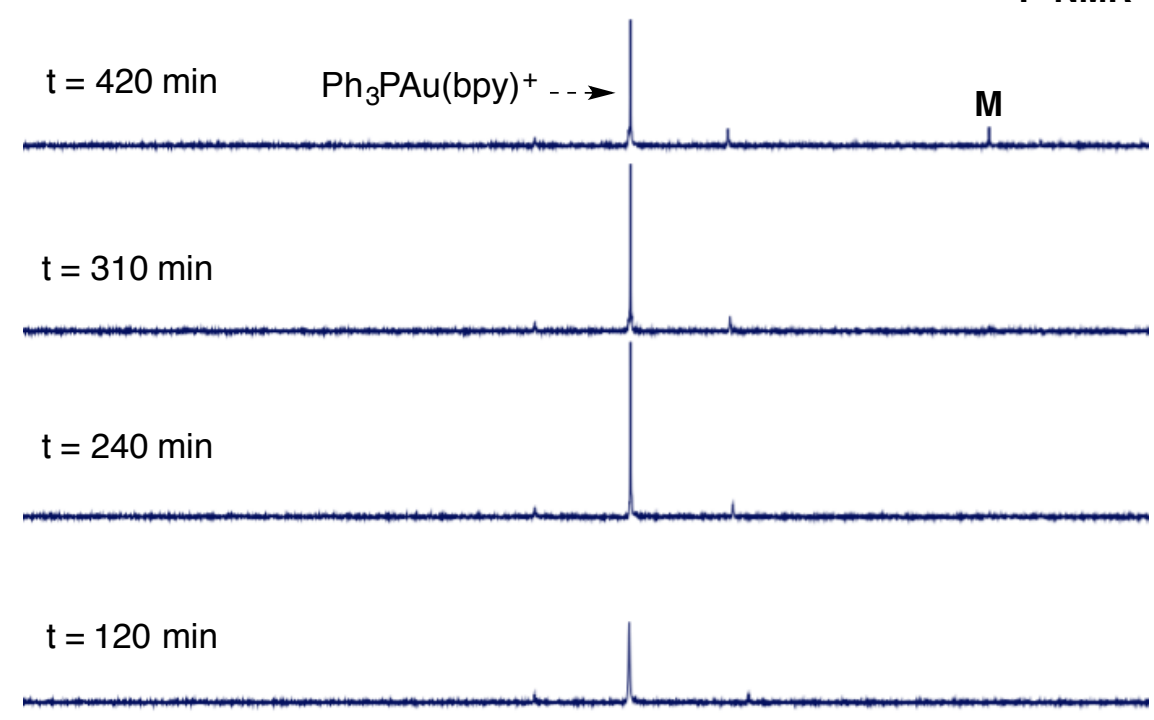

$t=40 \min$

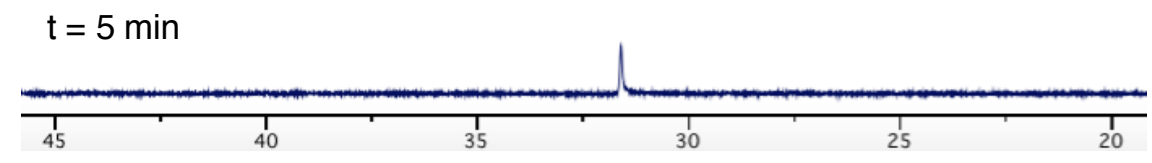

Figure S9. The ${ }^{31} \mathrm{P}-\mathrm{NMR}$ spectra for the catalytic $\mathrm{sp}-\mathrm{sp}^{2}$ cross-coupling

\section{Radical trapping experiment}

1) $\mathrm{Ac}_{2} \mathrm{O}$, EtOAc, r.t<smiles>Nc1ccccc1O</smiles>

2) Allyl bromide, $\mathrm{K}_{2} \mathrm{CO}_{3}$ Acetone, $60^{\circ} \mathrm{C}$

3) $6 \mathrm{M} \mathrm{HCl}, 100^{\circ} \mathrm{C}$<smiles>C=CCOc1ccccc1N</smiles><smiles>C=CCOc1ccc(C(F)(F)Br)cc1[N+](=O)[O-]</smiles>

To test whether this gold catalyzed cross-coupling was a radical process, diazonium salt 13c was synthesized from the corresponding aniline, which was synthesized according to literature report. ${ }^{6}$ The diazonium $13 \mathrm{c}$ was then was reacted with alkyne $12 \mathrm{a}$ under the optimized conditions.

The cross-coupling product $\mathbf{2 0 a}$ was successfully isolated in $25 \%$ yield with $37 \%$ of alkyne 12a consumed. This was consistent with the lower yield observed with orthosubstituted phenyldiazonium salts. The radical trapping product was not detected.

\footnotetext{
${ }^{6}$ Kumarasamy, E.; Raghunathan, R.; Jockusch, S.; Ugrinov, A.; Sivaguru, J. J. Am. Chem. Soc. 2014, 136, 8729.
} 
However, a cyclized byproduct $\mathbf{2 0 b}$, generated from two molecule diazonium salt $\mathbf{1 3 c}$, was isolated and characterized by NMR and HR-MS. The mechanism of the formation of 20b is still unclear to this point. But it is highly likely that the aryl radical formation is not a key step in this cross-coupling reaction.

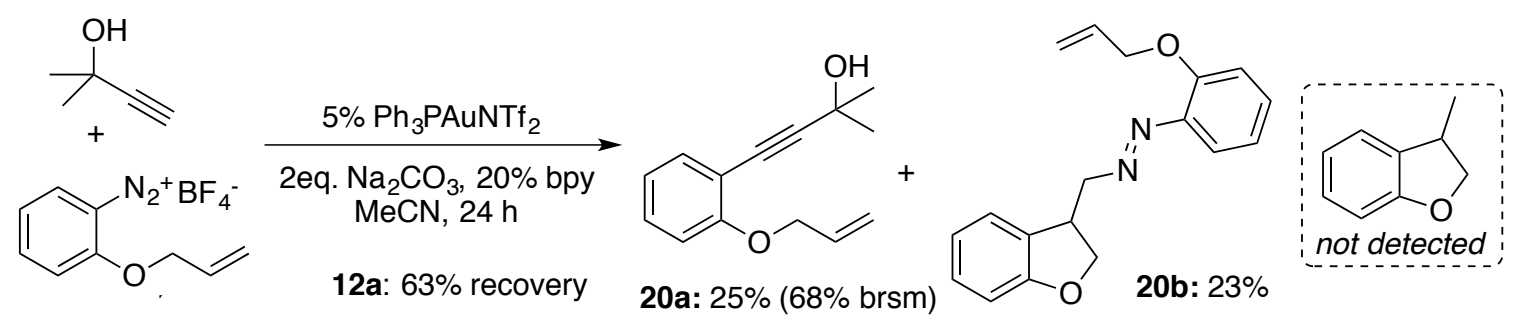

\section{Exploring the reaction intermediates with ESI-MS}

ESI-MS spectra were collected using a Waters Xevo QTof mass spectrometer (Milford, MA, USA) in the positive ion mode. The samples were infused with a flow rate of 2 $\mu \mathrm{L} / \mathrm{min}$ and sprayed at a high voltage of $5 \mathrm{kV}$.

The reactions were prepared using the same method as the in the general procedures. After 10 minutes, the reaction mixtures were tested with the ESI-MS.

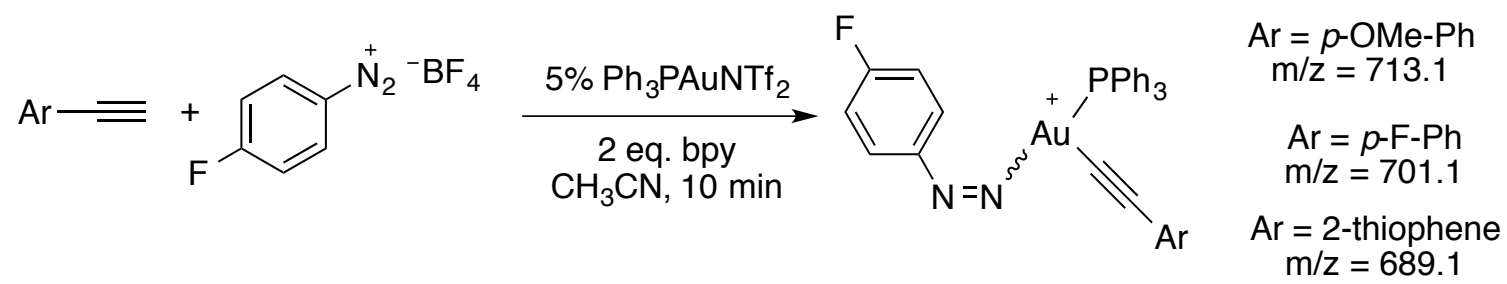

The adducts $\mathbf{2 1}$ from gold acetylides and the diazonium were successfully observed at $\mathrm{m} / \mathrm{z} 713,701$ and 689 respectively for the three different alkynes (Fig. 10). However, the intensities of $\mathbf{2 1}$ were quite low compared with other gold complexes in the reaction mixture. In fact, the intensity of $\mathbf{2 1}$ decreased as the reaction proceeded (almost not detectable after $2 \mathrm{~h}$ ). The MS/MS spectra confirmed the composition of 21 (Fig. 11). 


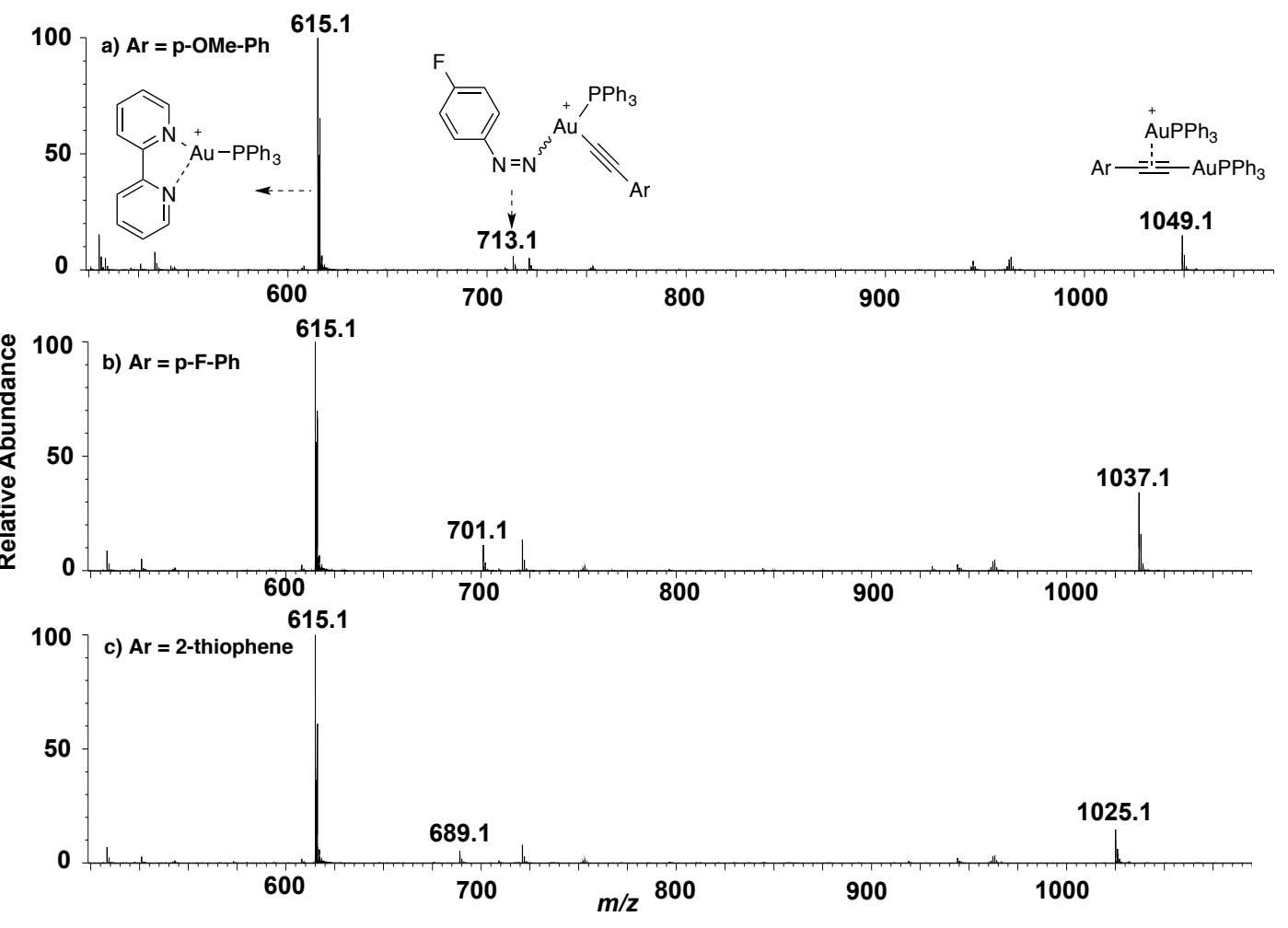

Figure S10. ESI-MS spectra of 10 min reaction mixture of 13a with different alkynes

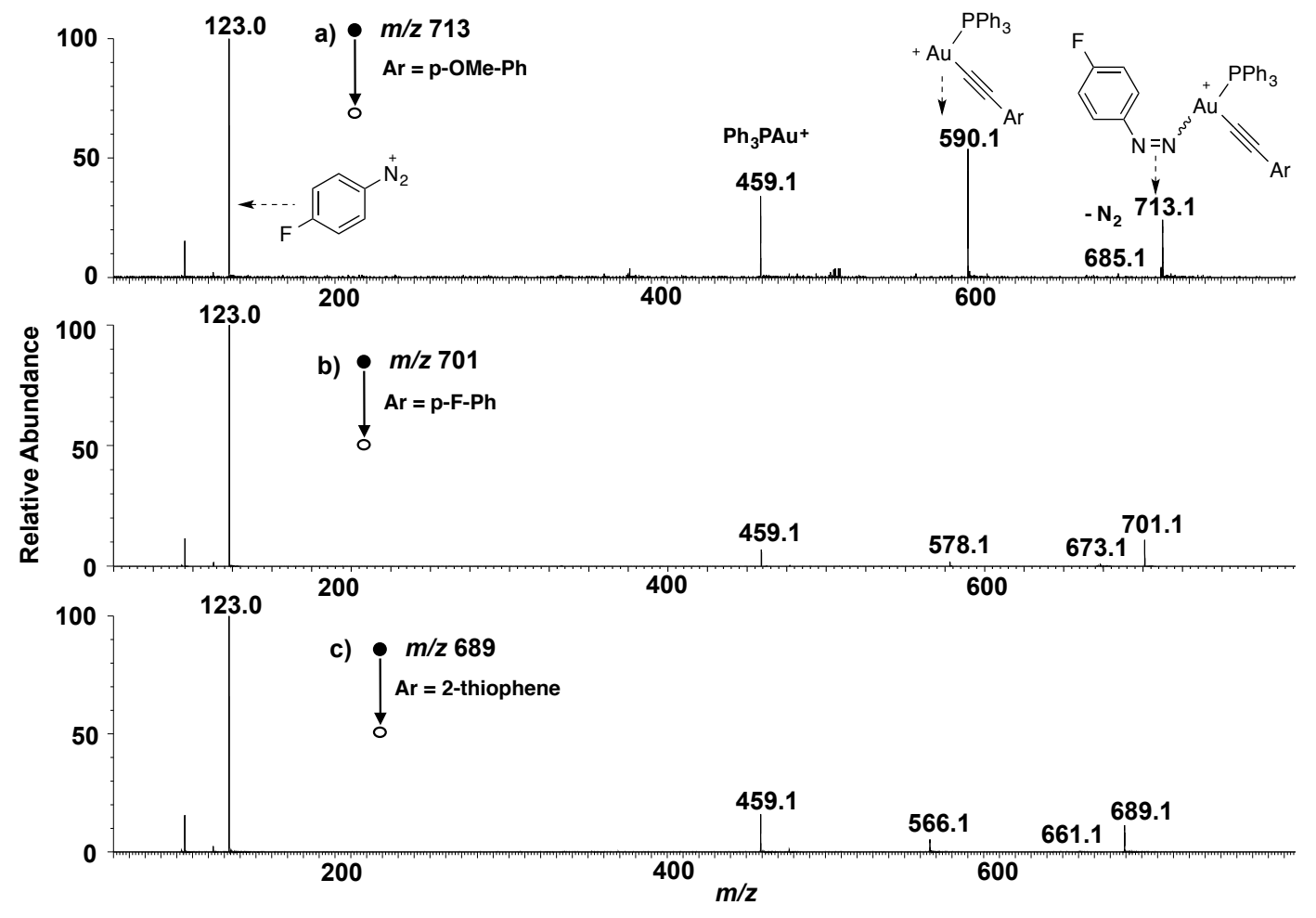

Figure S11. MS/MS spectra of mass-selected ions: a) $\mathrm{m} / \mathrm{z} 713$, b) $\mathrm{m} / \mathrm{z} 701$ and c) $\mathrm{m} / \mathrm{z} 689$ 
In order to trap the reaction intermediate, diazonium salt $13 \mathbf{d}$ was synthesized and tested under the same conditions. In the absence of bpy, a similar gold acetylide/diazonium adduct 21b was observed at $\mathrm{m} / \mathrm{z} 772$, though with a much higher intensity. However, with 2 eq. bpy added, high abundance of $\mathrm{Au}(\mathrm{III})$ intermediate ion (after nitrogen extrusion) was detected at $m / z$ 744., indicating that bpy helped to accelerate the nitrogen extrusion, which is consistent with the NMR data described in section III.A1. The MS/MS fragmentation of the intermediate ion $\mathrm{m} / \mathrm{z} 744$ (Fig. 13b) confirmed the composition of this $\mathrm{Au}(\mathrm{III})$ intermediate. The cross-coupling product was detected in low intensity with both the ESI-MS $(\mathrm{m} / \mathrm{z} 286)$ and crude NMR. It is possible that the coordination of pyridyl with $\mathrm{Au}(\mathrm{III})$ intermediate inhibited the reductive elimination.
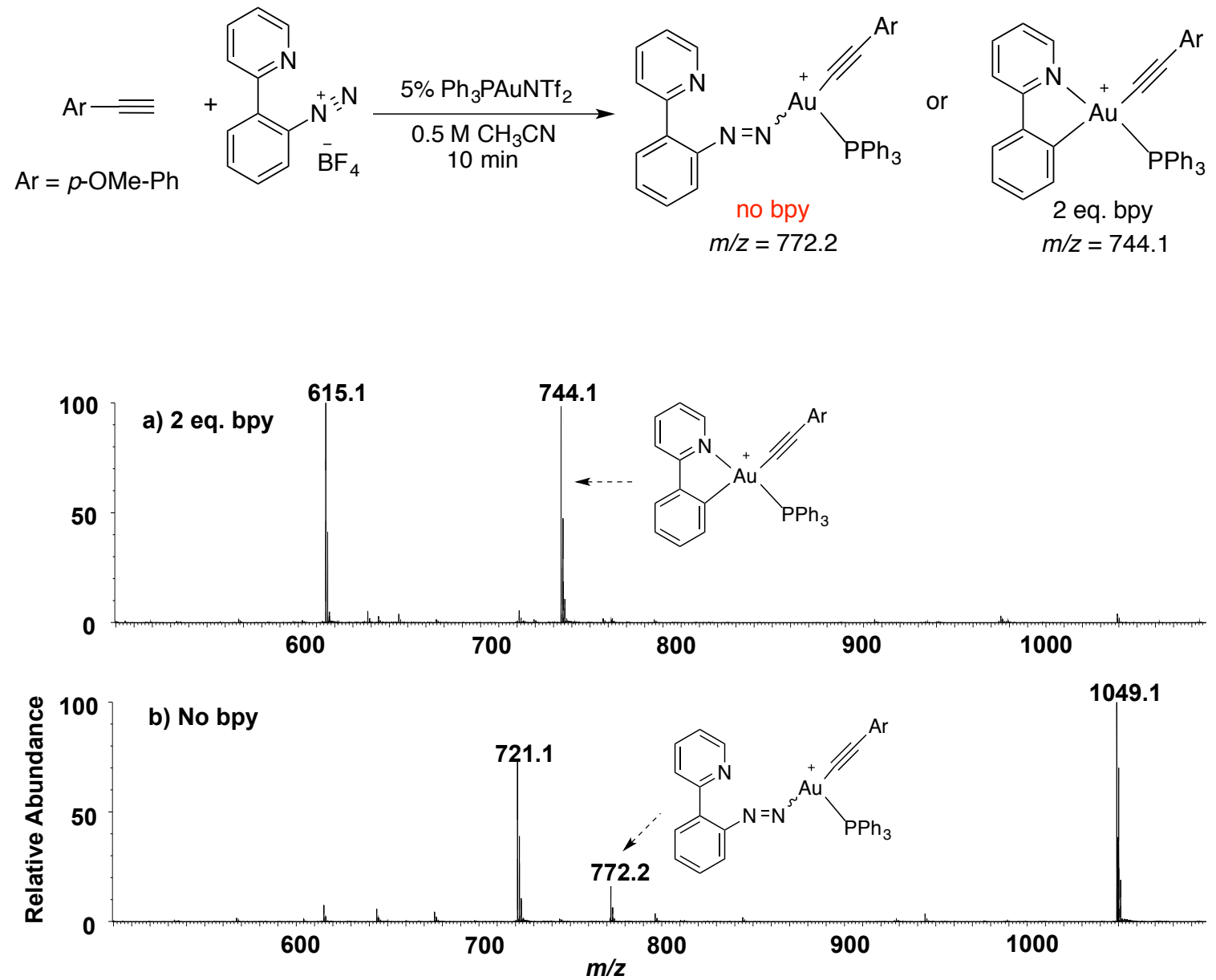

Figure S12. ESI-MS spectra of reaction mixture between diazonium 13d and alkyne 12b 


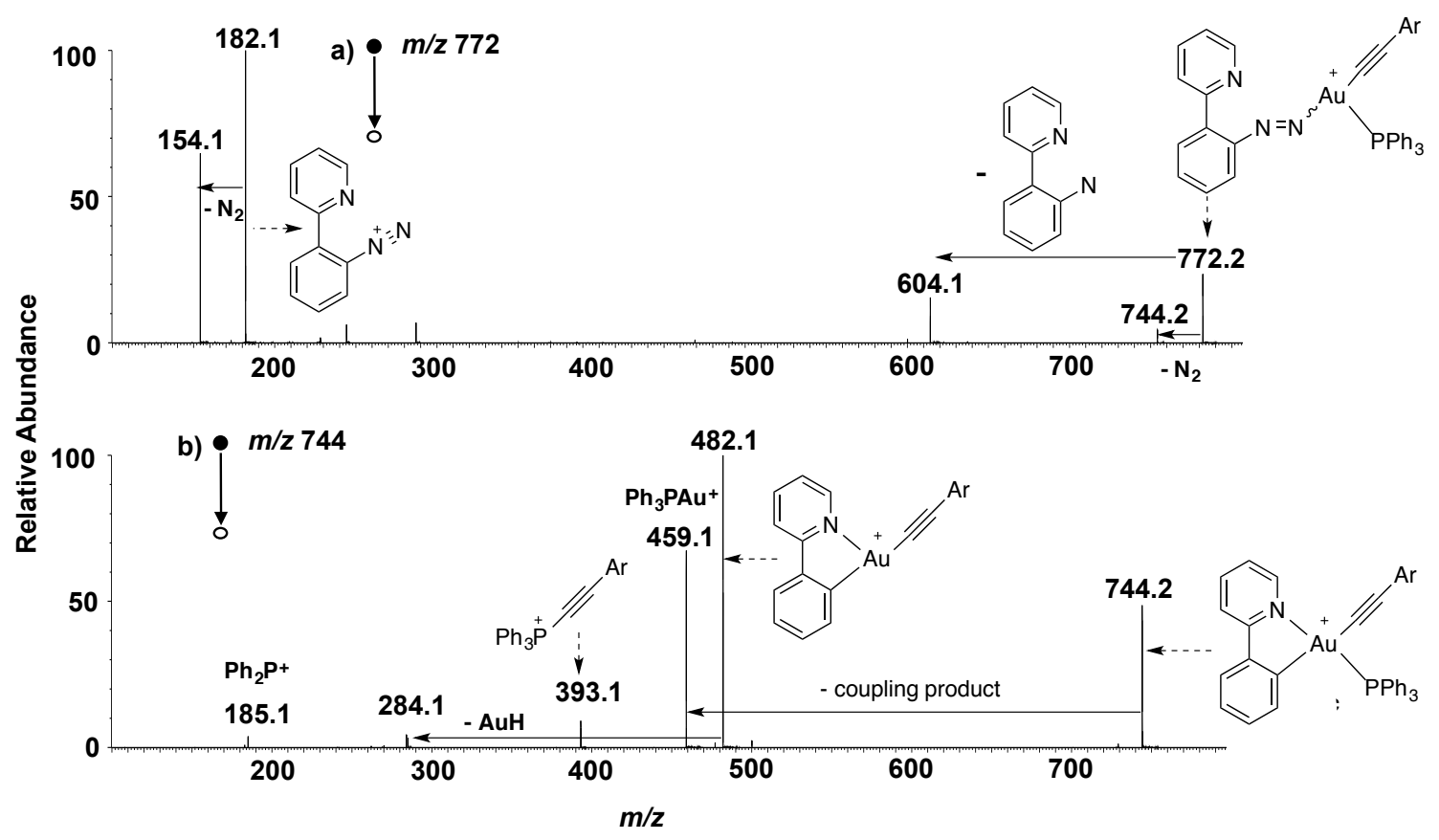

Figure S13. MS/MS spectra of mass-selected ions at a) $\mathrm{m} / \mathrm{z} 772.2$ and b) $\mathrm{m} / \mathrm{z} 744.2$

\section{S3.4 Compounds characterization}<smiles>CC(C)(O)C#Cc1ccc(F)cc1</smiles>

14aa: Yellow liquid (92\% yield).

${ }^{1} \mathrm{H}$ NMR $\left(400 \mathrm{MHz}, \mathrm{CDCl}_{3}\right): \delta$ 7.40-7.35 (dd, $\left.J=9.2,5.6 \mathrm{~Hz}, 2 \mathrm{H}\right), 7.00-6.95(\mathrm{t}, J=8.4$ $\mathrm{Hz}, 2 \mathrm{H}), 2.57$ (br. s, 1H), $1.61(\mathrm{~s}, 6 \mathrm{H})$;

${ }^{13} \mathrm{C} \mathrm{NMR}\left(100 \mathrm{MHz}, \mathrm{CDCl}_{3}\right): \delta 162.36(\mathrm{~d}, J=248.1 \mathrm{~Hz}), 133.43(\mathrm{~d}, J=7.8 \mathrm{~Hz}), 118.74$, $115.42(\mathrm{~d}, J=22.0 \mathrm{~Hz}), 93.46,81.01,65.51,31.36$;

${ }^{19} \mathrm{~F} \mathrm{NMR}\left(376 \mathrm{MHz}, \mathrm{CDCl}_{3}\right): \delta-112.1(\mathrm{~m}, 1 \mathrm{~F})$.

ESI-MS calculated for $\left[\mathrm{C}_{11} \mathrm{H}_{12} \mathrm{FO}\right]^{+}: 179.0867$, found: 179.0872 .

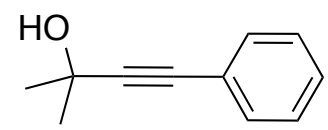

14ab: Yellow liquid ( $88 \%$ yield).

${ }^{1} \mathrm{H}$ NMR (400 MHz, $\left.\mathrm{CDCl}_{3}\right): \delta$ 7.43-7.40 (m, 2H), 7.31-7.28 (m, 3H), 2.10 (br s, $\left.1 \mathrm{H}\right)$, $1.62(\mathrm{~s}, 6 \mathrm{H})$;

${ }^{13} \mathrm{C} \mathrm{NMR}\left(100 \mathrm{MHz}, \mathrm{CDCl}_{3}\right): \delta$ 131.61, 128.21, 122.70, 93.75, 82.12, 65.61, 31.48.

ESI-MS calculated for $\left[\mathrm{C}_{11} \mathrm{H}_{13} \mathrm{O}\right]^{+}:$: 161.0961, found: 161.0968 . 


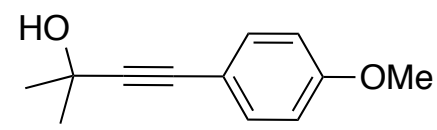

14ac: Yellow liquid ( $86 \%$ yield).

${ }^{1} \mathrm{H}$ NMR $\left(400 \mathrm{MHz}, \mathrm{CDCl}_{3}\right): \delta 7.34(\mathrm{~d}, J=8.9 \mathrm{~Hz}, 2 \mathrm{H}), 6.82(\mathrm{~d}, J=8.8 \mathrm{~Hz}, 2 \mathrm{H}), 3.80$ (s, 3H), 2.13 (br. s, 1H), $1.61(\mathrm{~s}, 6 \mathrm{H})$;

${ }^{13} \mathrm{C}$ NMR $\left(100 \mathrm{MHz}, \mathrm{CDCl}_{3}\right): \delta$ 159.50, 133.03, 114.80, 113.83, 92.38, 81.96, 65.61, $55.23,31.55$.

ESI-MS calculated for $\left[\mathrm{C}_{12} \mathrm{H}_{15} \mathrm{O}_{2}\right]^{+}: 191.1067$, found: 191.1075 .

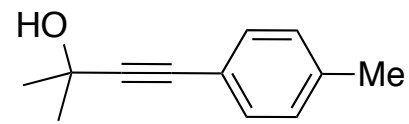

14ad: Yellow liquid ( $88 \%$ yield).

${ }^{1} \mathrm{H}$ NMR $\left(400 \mathrm{MHz}, \mathrm{CDCl}_{3}\right): \delta 7.30(\mathrm{~d}, J=8.1 \mathrm{~Hz}, 2 \mathrm{H}), 7.10(\mathrm{~d}, J=7.8 \mathrm{~Hz}, 2 \mathrm{H}), 2.33$ (s, 3H), 2.12 (br. s, 1H), $1.61(\mathrm{~s}, 6 \mathrm{H})$;

${ }^{13} \mathrm{C}$ NMR $\left(100 \mathrm{MHz}, \mathrm{CDCl}_{3}\right): \delta$ 159.49, 133.02, 114.79, 113.82, 92.36, 81.95, 65.60, $55.22,31.54$.

ESI-MS calculated for $\left[\mathrm{C}_{12} \mathrm{H}_{15} \mathrm{O}\right]^{+}: 175.1117$, found: 175.1125 .

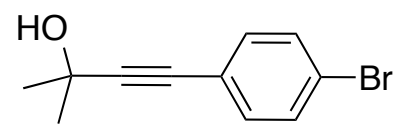

14ae: Yellow liquid ( $89 \%$ yield).

${ }^{1} \mathrm{H}$ NMR (400 MHz, $\mathrm{CDCl}_{3}$ ): $\delta 7.43(\mathrm{~d}, J=8.4 \mathrm{~Hz}, 2 \mathrm{H}), 7.27(\mathrm{~d}, J=8.4 \mathrm{~Hz}, 2 \mathrm{H}), 2.06$ (br. s, 1H), $1.61(\mathrm{~s}, 6 \mathrm{H})$;

${ }^{13} \mathrm{C}$ NMR $\left(100 \mathrm{MHz}, \mathrm{CDCl}_{3}\right): \delta$ 133.06, 131.49, 122.46, 121.68, 94.86, 81.11, 65.62, 31.39.

ESI-MS calculated for $\left[\mathrm{C}_{11} \mathrm{H}_{12} \mathrm{BrO}^{+}\right.$: 239.0066, found: 239.0074 .

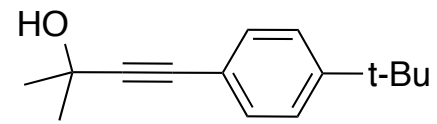

14af: Yellow liquid ( $87 \%$ yield).

${ }^{1} \mathrm{H}$ NMR $\left(400 \mathrm{MHz}, \mathrm{CDCl}_{3}\right): \delta 7.36(\mathrm{~d}, J=8.1 \mathrm{~Hz}, 2 \mathrm{H}), 7.32(\mathrm{~d}, J=8.4 \mathrm{~Hz}, 2 \mathrm{H}), 2.23$ (br. s, 1H), $1.62(\mathrm{~s}, 6 \mathrm{H}), 1.31(\mathrm{~s}, 9 \mathrm{H})$;

${ }^{13} \mathrm{C}$ NMR $\left(100 \mathrm{MHz}, \mathrm{CDCl}_{3}\right): \delta$ 151.41, 131.30, 125.18, 119.66, 93.12, 82.16, 65.59, $34.69,31.52,31.13$.

ESI-MS calculated for $\left[\mathrm{C}_{15} \mathrm{H}_{21} \mathrm{O}\right]^{+}: 217.1587$, found: 217.1595 .

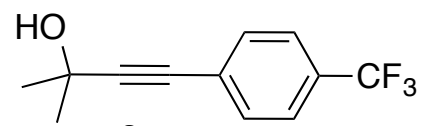

14ag: Yellow liquid ( $80 \%$ yield).

${ }^{1} \mathrm{H}$ NMR $\left(400 \mathrm{MHz}, \mathrm{CDCl}_{3}\right): \delta 7.53(\mathrm{~d}, J=8.5 \mathrm{~Hz}, 2 \mathrm{H}), 7.49(\mathrm{~d}, J=8.7 \mathrm{~Hz}, 2 \mathrm{H}), 2.51$ (br. s, 1H), 1.63 (s, 6H);

${ }^{13} \mathrm{C}$ NMR (100 MHz, $\left.\mathrm{CDCl}_{3}\right): \delta 131.79,129.94(\mathrm{q}, J=32.5 \mathrm{~Hz}), 126.55,125.09$ (q, $J=$ $3.8 \mathrm{~Hz}), 123.83$ (q, $J=270.8 \mathrm{~Hz}), 96.21,80.81,65.55,31.26$. 
${ }^{19} \mathrm{~F}$ NMR $\left(376 \mathrm{MHz}, \mathrm{CDCl}_{3}\right): \delta-62.9(\mathrm{~s}, 3 \mathrm{~F})$.

ESI-MS calculated for $\left[\mathrm{C}_{12} \mathrm{H}_{12} \mathrm{~F}_{3} \mathrm{O}\right]^{+}: 229.0835$, found: 229.0843 .<smiles>CC(C)(O)C#Cc1cccc(C#N)c1</smiles>

14ah: Yellow liquid (70\% yield).

${ }^{1} \mathrm{H}$ NMR $\left(400 \mathrm{MHz}, \mathrm{CDCl}_{3}\right): \delta 7.68(\mathrm{~s}, 1 \mathrm{H}), 7.62(\mathrm{~d}, J=7.8 \mathrm{~Hz}, 1 \mathrm{H}), 7.57(\mathrm{~d}, J=7.5$ $\mathrm{Hz}, 1 \mathrm{H}), 7.42$ (t, $J=7.8 \mathrm{~Hz}, 1 \mathrm{H}), 2.33$ (br. s, $1 \mathrm{H}), 1.62$ (s, 6H);

${ }^{13} \mathrm{C}$ NMR $\left(100 \mathrm{MHz}, \mathrm{CDCl}_{3}\right): \delta 135.66,134.90,131.38,129.13,124.36,117.94,112.66$, 96.28, 79.78, 65.47, 31.24.

ESI-MS calculated for $\left[\mathrm{C}_{12} \mathrm{H}_{12} \mathrm{NO}\right]^{+}: 186.0913$, found: 186.0920 .

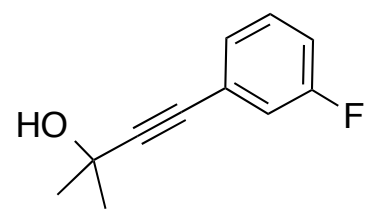

14ai: Yellow liquid (89\% yield).

${ }^{1} \mathrm{H}$ NMR $\left(400 \mathrm{MHz}, \mathrm{CDCl}_{3}\right): \delta 7.24(\mathrm{td}, J=7.9,5.8 \mathrm{~Hz}, 1 \mathrm{H}), 7.18(\mathrm{~d}, J=7.7 \mathrm{~Hz}, 1 \mathrm{H})$, $7.12-7.08(\mathrm{~m}, 1 \mathrm{H}), 7.02-6.97(\mathrm{~m}, 1 \mathrm{H}), 2.47$ (br. s, $1 \mathrm{H}), 1.61(\mathrm{~s}, 6 \mathrm{H})$;

${ }^{13} \mathrm{C}$ NMR $\left(100 \mathrm{MHz}, \mathrm{CDCl}_{3}\right): \delta 163.23(\mathrm{~d}, J=244.7 \mathrm{~Hz}), 129.74(\mathrm{~d}, J=8.4 \mathrm{~Hz}), 127.44$ $(\mathrm{d}, J=2.9 \mathrm{~Hz}), 124.51,118.37$ (d, $J=22.7 \mathrm{~Hz}), 115.50(\mathrm{~d}, J=20.9 \mathrm{~Hz}), 94.71,80.91$, 65.50, 31.31 .

${ }^{19} \mathrm{~F} \mathrm{NMR}\left(376 \mathrm{MHz}, \mathrm{CDCl}_{3}\right): \delta-113.1(\mathrm{~m}, 1 \mathrm{~F})$.

ESI-MS calculated for $\left[\mathrm{C}_{11} \mathrm{H}_{12} \mathrm{FO}\right]^{+}: 179.0867$, found: 179.0875 .

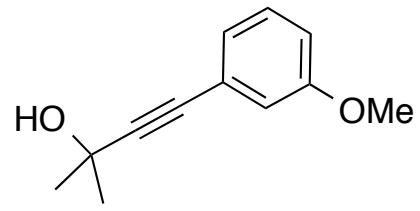

14aj: Yellow liquid (66\% yield).

${ }^{1} \mathrm{H}$ NMR (400 MHz, $\left.\mathrm{CDCl}_{3}\right): \delta 7.20(\mathrm{t}, J=8.0 \mathrm{~Hz}, 1 \mathrm{H}), 7.01(\mathrm{~d}, J=7.6 \mathrm{~Hz}, 1 \mathrm{H}), 6.94(\mathrm{t}$, $J=1.9 \mathrm{~Hz}, 1 \mathrm{H}), 6.86(\mathrm{dd}, J=8.3,2.6 \mathrm{~Hz}, 1 \mathrm{H}), 3.79(\mathrm{~s}, 3 \mathrm{H}), 2.07(\mathrm{~s}, 1 \mathrm{H}), 1.62(\mathrm{~s}, 6 \mathrm{H})$;

${ }^{13} \mathrm{C}$ NMR $\left(100 \mathrm{MHz}, \mathrm{CDCl}_{3}\right): \delta 159.24,129.29,124.15,123.70,116.39,114.91,93.54$, 82.04, 65.60, 55.22, 31.47 .

ESI-MS calculated for $\left[\mathrm{C}_{12} \mathrm{H}_{15} \mathrm{O}_{2}\right]^{+}: 191.1067$, found: 191.1074 .

$\mathrm{n}-\mathrm{Bu}=\mathrm{Ph}$

14b: Colorless liquid ( $88 \%$ yield).

${ }^{1} \mathrm{H}$ NMR $\left(400 \mathrm{MHz}, \mathrm{CDCl}_{3}\right): \delta$ 7.40-7.38 (m, 2H), 7.29-7.25 (m, 3H), $2.41(\mathrm{t}, J=7.0$ $\mathrm{Hz}, 2 \mathrm{H}), 1.63-1.56(\mathrm{~m}, 2 \mathrm{H}), 1.48(\mathrm{dq}, J=14.9,7.3 \mathrm{~Hz}, 2 \mathrm{H}), 0.95(\mathrm{t}, J=7.3 \mathrm{~Hz}, 3 \mathrm{H})$;

${ }^{13} \mathrm{C}$ NMR $\left(100 \mathrm{MHz}, \mathrm{CDCl}_{3}\right): \delta 131.51,128.14,127.41,124.09,90.38,80.53,30.85$, 22.01, 19.09, 13.63 .

ESI-MS calculated for $\left[\mathrm{C}_{12} \mathrm{H}_{15}\right]^{+}: 159.1168$, found: 159.1176 . 


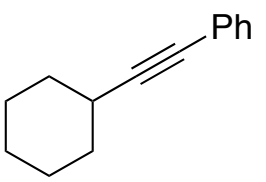

14c: Colorless liquid (68\% yield).

${ }^{1} \mathrm{H}$ NMR (400 MHz, $\left.\mathrm{CDCl}_{3}\right): \delta$ 7.40-7.37 (m, 2H), 7.29-7.24 (m, 3H), $2.58(\mathrm{tt}, J=8.8$, $4.2 \mathrm{~Hz}, 1 \mathrm{H}), 1.90-1.85$ (m, 2H), 1.79-1.72 (m, 2H), 1.58-1.49 (m, 3H), 1.40-1.30 (m, 3H); ${ }^{13} \mathrm{C}$ NMR $\left(100 \mathrm{MHz}, \mathrm{CDCl}_{3}\right): \delta 131.55,128.11,127.36,124.12,94.44,80.49,32.72$, 29.66, 25.93, 24.90.

ESI-MS calculated for $\left[\mathrm{C}_{14} \mathrm{H}_{17}\right]^{+}: 185.1325$, found: 185.1332 .

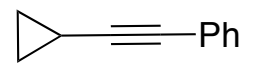

14d: Colorless liquid ( $81 \%$ yield).

${ }^{1} \mathrm{H}$ NMR $\left(400 \mathrm{MHz}, \mathrm{CDCl}_{3}\right): \delta$ 7.39-7.35 (m, 2H), 7.27-7.23 (m, 3H), 1.48-1.41 (m, $\left.1 \mathrm{H}\right)$, $0.88-0.83(\mathrm{~m}, 2 \mathrm{H}), 0.82-0.78(\mathrm{~m}, 2 \mathrm{H})$;

${ }^{13} \mathrm{C} \mathrm{NMR}\left(100 \mathrm{MHz}, \mathrm{CDCl}_{3}\right): \delta 131.58,128.13,127.41,123.90,93.38,75.74,8.58,0.15$. ESI-MS calculated for $\left[\mathrm{C}_{11} \mathrm{H}_{11}\right]^{+}: 143.0855$, found: 143.0862 .<smiles>COC(=O)C#Cc1ccccc1</smiles>

14e: Yellow liquid (58\% yield).

${ }^{1} \mathrm{H}$ NMR (400 MHz, $\left.\mathrm{CDCl}_{3}\right): \delta 7.58(\mathrm{~d}, J=8.3 \mathrm{~Hz}, 2 \mathrm{H}), 7.45(\mathrm{t}, J=7.5 \mathrm{~Hz}, 1 \mathrm{H}), 7.37$ (t, $J=7.9 \mathrm{~Hz}, 2 \mathrm{H}), 3.84(\mathrm{~s}, 3 \mathrm{H})$;

${ }^{13} \mathrm{C}$ NMR $\left(100 \mathrm{MHz}, \mathrm{CDCl}_{3}\right): \delta$ 154.44, 132.97, 130.65, 128.55, 119.50, 86.47, 80.33, 52.77.

ESI-MS calculated for $\left[\mathrm{C}_{10} \mathrm{H}_{9} \mathrm{O}_{2}\right]^{+}: 161.0597$, found: 161.0603 .

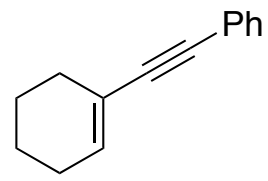

14f: Colorless liquid (63\% yield) .

${ }^{1} \mathrm{H}$ NMR (400 MHz, $\left.\mathrm{CDCl}_{3}\right): \delta$ 7.43-7.40 (m, 2H), 7.31-7.26 (m, 3H), $6.21(\mathrm{tt}, J=4.0$, $2.0 \mathrm{~Hz}, 1 \mathrm{H}), 2.25-2.20(\mathrm{~m}, 2 \mathrm{H}), 2.17-2.12(\mathrm{~m}, 2 \mathrm{H}), 1.71-1.59(\mathrm{~m}, 4 \mathrm{H})$;

${ }^{13} \mathrm{C} \mathrm{NMR}\left(100 \mathrm{MHz}, \mathrm{CDCl}_{3}\right): \delta 135.15,131.42,128.19,127.69,123.76,120.71,91.24$, 86.75, 29.24, 25.77, 22.35, 21.53 .

ESI-MS calculated for $\left[\mathrm{C}_{14} \mathrm{H}_{15}\right]^{+}: 183.1168$, found: 183.1176 .

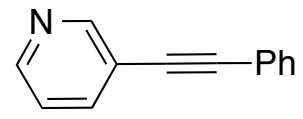

14g: Light brown solid (73\% yield).

${ }^{1} \mathrm{H}$ NMR $\left(400 \mathrm{MHz}, \mathrm{CDCl}_{3}\right): \delta 8.77(\mathrm{~s}, 1 \mathrm{H}), 8.54(\mathrm{~d}, J=4.8 \mathrm{~Hz}, 1 \mathrm{H}), 7.80(\mathrm{dd}, J=7.7$, 
$0.6 \mathrm{~Hz}, 1 \mathrm{H}), 7.56-7.53(\mathrm{~m}, 2 \mathrm{H}), 7.37-7.35(\mathrm{~m}, 3 \mathrm{H}), 7.26(\mathrm{dd}, J=7.8,4.9 \mathrm{~Hz}, 1 \mathrm{H})$;

${ }^{13} \mathrm{C}$ NMR $\left(100 \mathrm{MHz}, \mathrm{CDCl}_{3}\right): \delta 152.18,148.48,138.33,131.62,128.74,128.38,122.95$, $122.45,120.40,92.58,85.88$.

ESI-MS calculated for $\left[\mathrm{C}_{13} \mathrm{H}_{10} \mathrm{~N}\right]^{+}: 180.0808$, found: 180.0815 .

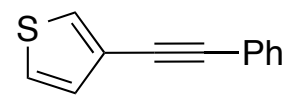

14h: Light yellow solid (64\% yield).

${ }^{1} \mathrm{H}$ NMR $\left(400 \mathrm{MHz}, \mathrm{CDCl}_{3}\right): \delta$ 7.53-7.50 (m, 3H), 7.36-7.32 (m, 3H), $7.30(\mathrm{dd}, J=5.0$, $3.0 \mathrm{~Hz}, 1 \mathrm{H}), 7.20(\mathrm{dd}, J=5.0,1.2 \mathrm{~Hz}, 1 \mathrm{H})$;

${ }^{13} \mathrm{C} \mathrm{NMR}\left(100 \mathrm{MHz}, \mathrm{CDCl}_{3}\right): \delta 131.50,129.85,128.56,128.31,128.18,125.33,123.18$, $122.28,88.85,84.48$.

ESI-MS calculated for $\left[\mathrm{C}_{12} \mathrm{H}_{9} \mathrm{~S}\right]^{+}: 185.0419$, found: 185.0425 .

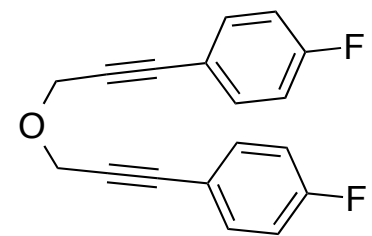

14i: Yellow liquid (44\% yield).

${ }^{1} \mathrm{H}$ NMR $\left(400 \mathrm{MHz}, \mathrm{CDCl}_{3}\right): \delta 7.44(\mathrm{dd}, J=8.9,5.4 \mathrm{~Hz}, 4 \mathrm{H}), 7.01(\mathrm{t}, J=8.8 \mathrm{~Hz}, 4 \mathrm{H})$, $4.52(\mathrm{~s}, 4 \mathrm{H})$;

${ }^{13} \mathrm{C}$ NMR (100 MHz, $\left.\mathrm{CDCl}_{3}\right): \delta 162.64(\mathrm{~d}, J=248.3 \mathrm{~Hz}), 133.73(\mathrm{~d}, J=8.3 \mathrm{~Hz}), 118.52$ (d, $J=3.6 \mathrm{~Hz}), 115.60(\mathrm{~d}, J=22.0 \mathrm{~Hz}), 85.76,84.03,57.43$.

${ }^{19} \mathrm{~F}$ NMR $\left(376 \mathrm{MHz}, \mathrm{CDCl}_{3}\right): \delta-110.5(\mathrm{~m}, 1 \mathrm{~F})$.

ESI-MS calculated for $\left[\mathrm{C}_{18} \mathrm{H}_{13} \mathrm{~F}_{2} \mathrm{O}\right]^{+}: 283.0929$, found: 283.0940 .

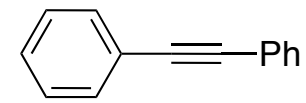

14j: White solid ( $80 \%$ yield).

${ }^{1} \mathrm{H} \mathrm{NMR}\left(400 \mathrm{MHz}, \mathrm{CDCl}_{3}\right): \delta$ 7.55-7.52 (m, 2H), 7.38-7.33 (m, 3H);

${ }^{13} \mathrm{C} \mathrm{NMR}\left(100 \mathrm{MHz}, \mathrm{CDCl}_{3}\right): \delta 131.58,128.32,128.23,123.26,89.36$.

ESI-MS calculated for $\left[\mathrm{C}_{14} \mathrm{H}_{11}\right]^{+}: 179.0855$, found: 179.0865 .

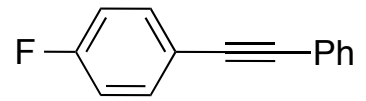

14k: White solid ( $85 \%$ yield).

${ }^{1} \mathrm{H}$ NMR (400 MHz, $\left.\mathrm{CDCl}_{3}\right): \delta$ 7.54-7.49 (m, 4H), 7.36-7.33 (m, 3H), $7.04(\mathrm{t}, J=8.8$ $\mathrm{Hz}, 2 \mathrm{H})$;

${ }^{13} \mathrm{C} \mathrm{NMR}\left(100 \mathrm{MHz}, \mathrm{CDCl}_{3}\right): \delta 162.48(\mathrm{~d}, J=248.2 \mathrm{~Hz}), 133.45(\mathrm{~d}, J=8.3 \mathrm{~Hz}), 131.53$, $128.35,128.31,123.08,119.36(\mathrm{~d}, J=3.5 \mathrm{~Hz}), 115.62(\mathrm{~d}, J=21.9 \mathrm{~Hz}), 89.02,88.27$.

${ }^{19} \mathrm{~F}$ NMR $\left(376 \mathrm{MHz}, \mathrm{CDCl}_{3}\right): \delta-111.0(\mathrm{~m}, 1 \mathrm{~F})$.

ESI-MS calculated for $\left[\mathrm{C}_{14} \mathrm{H}_{10} \mathrm{~F}\right]^{+}: 197.0761$, found: 197.0771 . 


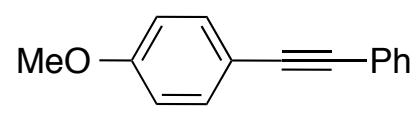

14l: Light yellow solid (36\% yield).

${ }^{1} \mathrm{H}$ NMR $\left(400 \mathrm{MHz}, \mathrm{CDCl}_{3}\right): \delta$ 7.52-7.50 (m, 2H), $7.47(\mathrm{~d}, J=8.8 \mathrm{~Hz}, 2 \mathrm{H}), 7.36-7.30$ $(\mathrm{m}, 3 \mathrm{H}), 6.88(\mathrm{~d}, J=8.8 \mathrm{~Hz}, 2 \mathrm{H}), 3.83(\mathrm{~s}, 3 \mathrm{H})$;

${ }^{13} \mathrm{C} \mathrm{NMR}\left(100 \mathrm{MHz}, \mathrm{CDCl}_{3}\right): \delta$ 159.60, 133.03, 131.43, 128.28, 127.91, 123.59, 115.37, $113.98,89.34,88.05,55.30$.

ESI-MS calculated for $\left[\mathrm{C}_{15} \mathrm{H}_{13} \mathrm{O}\right]^{+}:$209.0961, found: 209.0970 .<smiles>CCc1ccc(C#Cc2ccccc2)cc1</smiles>

14m: Colorless liquid (78\% yield).

${ }^{1} \mathrm{H}$ NMR (400 MHz, $\left.\mathrm{CDCl}_{3}\right): \delta$ 7.53-7.51 (m, 2H), $7.45(\mathrm{~d}, J=7.9 \mathrm{~Hz}, 2 \mathrm{H}), 7.36-7.31$ $(\mathrm{m}, 3 \mathrm{H}), 7.18(\mathrm{~d}, J=7.9 \mathrm{~Hz}, 2 \mathrm{H}), 2.66(\mathrm{q}, J=7.6 \mathrm{~Hz}, 2 \mathrm{H}), 1.24(\mathrm{t}, J=7.3 \mathrm{~Hz}, 3 \mathrm{H})$;

${ }^{13} \mathrm{C} \mathrm{NMR}\left(100 \mathrm{MHz}, \mathrm{CDCl}_{3}\right): \delta 144.66,131.57,131.53,128.28,128.04,127.89,123.49$, $120.41,89.57,88.69,28.83,15.34$.

ESI-MS calculated for $\left[\mathrm{C}_{16} \mathrm{H}_{15}\right]^{+}: 207.1168$, found: 207.1178 .

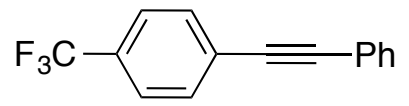

14n: White solid ( $90 \%$ yield).

${ }^{1} \mathrm{H}$ NMR (400 MHz, $\left.\mathrm{CDCl}_{3}\right): \delta$ 7.65-7.59 (m, 4H), 7.56-7.54 (m, 2H), $7.37(\mathrm{t}, J=3.2$ $\mathrm{Hz}, 3 \mathrm{H})$;

${ }^{13} \mathrm{C} \mathrm{NMR}\left(100 \mathrm{MHz}, \mathrm{CDCl}_{3}\right): \delta 131.78,131.73,129.88(\mathrm{q}, J=32.6 \mathrm{~Hz}), 128.81,128.43$, $127.12,125.25(\mathrm{q}, J=3.8 \mathrm{~Hz}), 123.44(\mathrm{q}, J=271.7 \mathrm{~Hz}), 122.56,91.75,87.96$.

${ }^{19} \mathrm{~F} \mathrm{NMR}\left(376 \mathrm{MHz}, \mathrm{CDCl}_{3}\right): \delta-62.8(\mathrm{~s}, 3 \mathrm{~F})$.

ESI-MS calculated for $\left[\mathrm{C}_{15} \mathrm{H}_{10} \mathrm{~F}_{3}\right]^{+}: 247.0729$, found: 247.0733 .

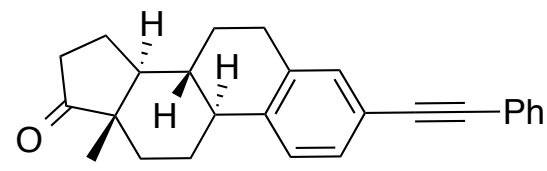

140: White solid (65\% yield).

${ }^{1} \mathrm{H}$ NMR $\left(400 \mathrm{MHz}, \mathrm{CDCl}_{3}\right): \delta$ 7.53-7.50 (m, 2H), 7.36-7.28 (m, 5H), $7.26(\mathrm{~s}, 1 \mathrm{H}), 2.91$ (dd, $J=8.8,4.0 \mathrm{~Hz}, 2 \mathrm{H}), 2.51$ (dd, $J=18.7,8.6 \mathrm{~Hz}, 1 \mathrm{H}), 2.45-2.40$ (m, 1H), 2.32 (td, $J=$ 10.6, 4.0 Hz, 1H), 2.20-1.96 (m, 4H), 1.69-1.41 (m, 6H), $0.92(\mathrm{~s}, 3 \mathrm{H})$;

${ }^{13} \mathrm{C} \mathrm{NMR}\left(100 \mathrm{MHz}, \mathrm{CDCl}_{3}\right): \delta 220.65,162.18,140.24,136.59,132.02,131.53,128.91$, $128.29,128.06,125.37,123.44,120.56,89.46,88.74,50.50,47.93,44.46,37.97,35.82$, $31.55,29.10,26.34,25.58,21.57,13.83$.

ESI-MS calculated for $\left[\mathrm{C}_{26} \mathrm{H}_{27} \mathrm{O}\right]^{+}: 355.2056$, found: 355.2072 .

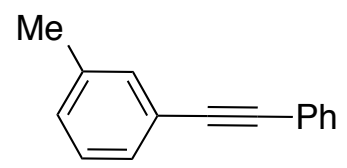

14p: Colorless liquid ( $82 \%$ yield). 
${ }^{1} \mathrm{H}$ NMR $\left(400 \mathrm{MHz}, \mathrm{CDCl}_{3}\right): \delta$ 7.54-7.51 (m, 2H), 7.37-7.32 (m, 5H), $7.23(\mathrm{~d}, J=7.6$ $\mathrm{Hz}, 1 \mathrm{H}), 7.15(\mathrm{~d}, J=7.7 \mathrm{~Hz}, 1 \mathrm{H}), 2.35(\mathrm{~s}, 3 \mathrm{H})$;

${ }^{13} \mathrm{C}$ NMR (100 MHz, $\left.\mathrm{CDCl}_{3}\right): \delta 137.96,132.15,131.56,129.13,128.65,128.29,128.20$, $128.13,123.35,123.04,89.55,89.02,21.20$.

ESI-MS calculated for $\left[\mathrm{C}_{15} \mathrm{H}_{13}\right]^{+}:$: 193.1012, found: 193.1021 .

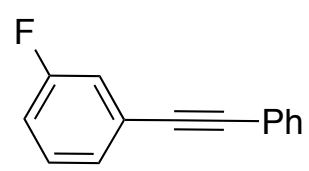

14q: Colorless liquid ( $81 \%$ yield).

${ }^{1} \mathrm{H}$ NMR (400 MHz, $\left.\mathrm{CDCl}_{3}\right): \delta$ 7.55-7.52 (m, 2H), 7.38-7.34 (m, 3H), 7.32-7.30 (m, 2H), 7.23 (dddd, $J=9.5,2.6,1.1,0.8 \mathrm{~Hz}, 1 \mathrm{H}), 7.07-7.01(\mathrm{~m}, 1 \mathrm{H})$;

${ }^{13} \mathrm{C} \mathrm{NMR}\left(100 \mathrm{MHz}, \mathrm{CDCl}_{3}\right): \delta 162.38(\mathrm{~d}, J=245.2 \mathrm{~Hz}), 131.65,129.87(\mathrm{~d}, J=8.8 \mathrm{~Hz})$, $128.56,128.37,127.46(\mathrm{~d}, J=3.1 \mathrm{~Hz}), 125.12(\mathrm{~d}, J=9.3 \mathrm{~Hz}), 122.77,118.33(\mathrm{~d}, J=$ $22.8 \mathrm{~Hz}), 115.54(\mathrm{~d}, J=21.2 \mathrm{~Hz}), 90.24,88.07$.

${ }^{19} \mathrm{~F} \mathrm{NMR}\left(376 \mathrm{MHz}, \mathrm{CDCl}_{3}\right): \delta-113.0(\mathrm{~m}, 1 \mathrm{~F})$.

ESI-MS calculated for $\left[\mathrm{C}_{14} \mathrm{H}_{10} \mathrm{~F}\right]^{+}: 197.0761$, found: 197.0771 .

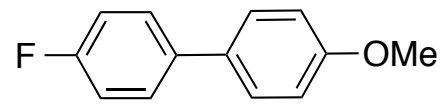

18a: White solid (91\% yield).

${ }^{1} \mathrm{H}$ NMR $\left(400 \mathrm{MHz}, \mathrm{CDCl}_{3}\right): \delta$ 7.52-7.45 (m, 1H), $7.10(\mathrm{t}, J=8.8 \mathrm{~Hz}, 1 \mathrm{H}), 6.97(\mathrm{~d}, J=$ $8.8 \mathrm{~Hz}, 1 \mathrm{H})$;

${ }^{13} \mathrm{C}$ NMR $\left(100 \mathrm{MHz}, \mathrm{CDCl}_{3}\right): \delta 162.08(\mathrm{~d}, J=244.4 \mathrm{~Hz}), 159.10,136.96(\mathrm{~d}, J=3.1 \mathrm{~Hz})$, $132.83,128.20$ (d, $J=8.2 \mathrm{~Hz}), 128.02,115.51(\mathrm{~d}, J=21.3 \mathrm{~Hz}), 114.24,55.35$.

${ }^{19} \mathrm{~F}$ NMR (376 MHz, $\left.\mathrm{CDCl}_{3}\right): \delta-116.8(\mathrm{~m}, 1 \mathrm{~F})$.

ESI-MS calculated for $\left[\mathrm{C}_{13} \mathrm{H}_{12} \mathrm{FO}\right]^{+}: 203.0867$, found: 203.0875 .

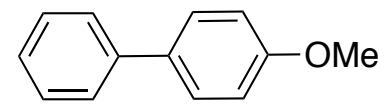

18b: White solid (90\% yield).

${ }^{1} \mathrm{H}$ NMR $\left(400 \mathrm{MHz}, \mathrm{CDCl}_{3}\right): \delta$ 7.56-7.52 (m, 4H), $7.41(\mathrm{t}, J=7.6 \mathrm{~Hz}, 2 \mathrm{H}), 7.32-7.28$ (m, $1 \mathrm{H}), 6.98(\mathrm{~d}, J=8.9 \mathrm{~Hz}, 2 \mathrm{H}), 3.85(\mathrm{~s}, 3 \mathrm{H})$;

${ }^{13} \mathrm{C}$ NMR (100 MHz, $\left.\mathrm{CDCl}_{3}\right): \delta 159.13,140.81,133.77,128.70,128.14,126.72,126.63$, $114.19,55.33$.

ESI-MS calculated for $\left[\mathrm{C}_{13} \mathrm{H}_{13} \mathrm{O}\right]^{+}: 185.0961$, found: 185.0969 .

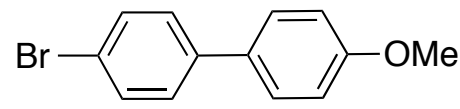

18c: White solid (76\% yield).

${ }^{1} \mathrm{H}$ NMR $\left(400 \mathrm{MHz}, \mathrm{CDCl}_{3}\right): \delta 7.53(\mathrm{~d}, J=8.7 \mathrm{~Hz}, 2 \mathrm{H}), 7.48(\mathrm{~d}, J=8.9 \mathrm{~Hz}, 2 \mathrm{H}), 7.41$ $(\mathrm{d}, J=8.7 \mathrm{~Hz}, 2 \mathrm{H}), 6.97(\mathrm{~d}, J=8.9 \mathrm{~Hz}, 2 \mathrm{H}), 3.85(\mathrm{~s}, 3 \mathrm{H})$;

${ }^{13} \mathrm{C}$ NMR $\left(100 \mathrm{MHz}, \mathrm{CDCl}_{3}\right): \delta 159.40,139.73,132.49,131.77,128.28,127.97,120.77$, 114.32, 55.36.

ESI-MS calculated for $\left[\mathrm{C}_{13} \mathrm{H}_{12} \mathrm{BrO}\right]^{+}: 263.0066$, found: 263.0076 . 


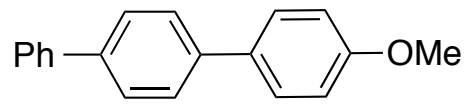

18d: White solid (72\% yield).

${ }^{1} \mathrm{H}$ NMR $\left(400 \mathrm{MHz}, \mathrm{CDCl}_{3}\right): \delta$ 7.67-7.62 (m, 6H), $7.58(\mathrm{~d}, J=8.9 \mathrm{~Hz}, 2 \mathrm{H}), 7.45(\mathrm{t}, J=$ $7.6 \mathrm{~Hz}, 2 \mathrm{H}), 7.35(\mathrm{tt}, J=7.4,1.6 \mathrm{~Hz}, 1 \mathrm{H}), 7.00(\mathrm{~d}, J=8.8 \mathrm{~Hz}, 2 \mathrm{H}), 3.86(\mathrm{~s}, 3 \mathrm{H})$;

${ }^{13} \mathrm{C} \mathrm{NMR}\left(100 \mathrm{MHz}, \mathrm{CDCl}_{3}\right): \delta 167.01,159.81,145.17,132.37,130.07,128.32,126.42$, 114.34, 55.34, 52.03.

ESI-MS calculated for $\left[\mathrm{C}_{19} \mathrm{H}_{17} \mathrm{O}\right]^{+}: 261.1274$, found: 261.1281 .

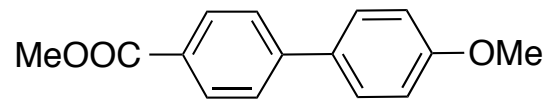

18e: White solid (63\% yield).

${ }^{1} \mathrm{H} \mathrm{NMR}\left(400 \mathrm{MHz}, \mathrm{CDCl}_{3}\right): \delta 8.07(\mathrm{~d}, J=8.6 \mathrm{~Hz}, 2 \mathrm{H}), 7.61(\mathrm{~d}, J=8.6 \mathrm{~Hz}, 2 \mathrm{H}), 7.57$ $(\mathrm{d}, J=8.9 \mathrm{~Hz}, 2 \mathrm{H}), 6.99(\mathrm{~d}, J=8.9 \mathrm{~Hz}, 2 \mathrm{H}), 3.93(\mathrm{~s}, 3 \mathrm{H}), 3.85(\mathrm{~s}, 3 \mathrm{H})$;

${ }^{13} \mathrm{C}$ NMR $\left(100 \mathrm{MHz}, \mathrm{CDCl}_{3}\right): \delta$ 167.01, 159.81, 145.17, 132.37, 130.07, 128.32, 126.42, 114.34, 55.34, 52.03.

ESI-MS calculated for $\left[\mathrm{C}_{15} \mathrm{H}_{15} \mathrm{O}_{3}\right]^{+}: 243.1016$, found: 243.1029 .

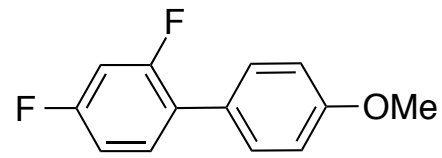

18f: White solid (81\% yield).

${ }^{1} \mathrm{H}$ NMR (400 MHz, $\left.\mathrm{CDCl}_{3}\right): \delta 7.43(\mathrm{dd}, J=8.7,1.7 \mathrm{~Hz}, 2 \mathrm{H}), 7.36(\mathrm{td}, J=8.7,6.5 \mathrm{~Hz}$, $1 \mathrm{H}), 6.98(\mathrm{~d}, J=8.8 \mathrm{~Hz}, 2 \mathrm{H}), 6.95-6.86(\mathrm{~m}, 2 \mathrm{H}), 3.85(\mathrm{~s}, 3 \mathrm{H})$;

${ }^{13} \mathrm{C}$ NMR $\left(100 \mathrm{MHz}, \mathrm{CDCl}_{3}\right): \delta 161.90(\mathrm{dd}, J=246.9,11.5 \mathrm{~Hz}), 159.64(\mathrm{dd}, J=248.6$, $11.6 \mathrm{~Hz}), 159.25,131.11(\mathrm{dd}, J=9.3,4.8 \mathrm{~Hz}), 130.00$ (d, $J=2.9 \mathrm{~Hz}), 127.34$ (d, $J=1.2$ $\mathrm{Hz}), 124.98$ (dd, $J=13.8,4.0 \mathrm{~Hz}), 113.99,111.42$ (dd, $J=21.2,3.8 \mathrm{~Hz}), 104.28$ (dd, $J=$ 25.2, $27.2 \mathrm{~Hz}), 55.32$.

${ }^{19} \mathrm{~F}$ NMR $\left(376 \mathrm{MHz}, \mathrm{CDCl}_{3}\right): \delta-112.4(\mathrm{dt}, J=15.4,7.8 \mathrm{~Hz}),-113.9(\mathrm{dd}, J=17.7,8.7$ $\mathrm{Hz}$ ).

ESI-MS calculated for $\left[\mathrm{C}_{13} \mathrm{H}_{11} \mathrm{~F}_{2} \mathrm{O}\right]^{+}: 221.0772$, found: 221.0783 .

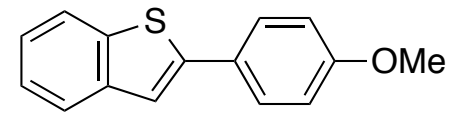

18g: White solid (62\% yield).

${ }^{1} \mathrm{H}$ NMR $\left(400 \mathrm{MHz}, \mathrm{CDCl}_{3}\right): \delta$ 7.82-7.79 (m, 1H), 7.75-7.73 (m, 1H), $7.64(\mathrm{~d}, J=8.9$ $\mathrm{Hz}, 2 \mathrm{H}), 7.42$ (d, $J=0.7 \mathrm{~Hz}, 1 \mathrm{H}), 7.35-7.26(\mathrm{~m}, 2 \mathrm{H}), 6.96(\mathrm{~d}, J=8.9 \mathrm{~Hz}, 2 \mathrm{H}), 3.86$ (s, $3 \mathrm{H})$;

${ }^{13} \mathrm{C}$ NMR $\left(100 \mathrm{MHz}, \mathrm{CDCl}_{3}\right): \delta 159.78,144.12,140.86,139.16,127.73,127.04,124.41$, 123.91, 123.22, 122.15, 118.18, 114.34, 55.38.

ESI-MS calculated for $\left[\mathrm{C}_{15} \mathrm{H}_{13} \mathrm{OS}\right]^{+}: 241.0682$, found: 241.0692 . 


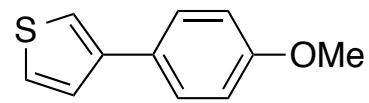

18h: White solid (42\% yield).

${ }^{1} \mathrm{H}$ NMR $\left(400 \mathrm{MHz}, \mathrm{CDCl}_{3}\right): \delta 7.53(\mathrm{~d}, J=8.9 \mathrm{~Hz}, 2 \mathrm{H}), 7.38-7.33(\mathrm{~m}, 3 \mathrm{H}), 6.94(\mathrm{~d}, J=$ $8.9 \mathrm{~Hz}, 2 \mathrm{H}), 3.84(\mathrm{~s}, 3 \mathrm{H})$;

${ }^{13} \mathrm{C} \mathrm{NMR}\left(100 \mathrm{MHz}, \mathrm{CDCl}_{3}\right): \delta$ 158.86, 142.00, 128.74, 127.54, 126.23, 126.03, 118.91, 114.17, 55.33.

ESI-MS calculated for $\left[\mathrm{C}_{11} \mathrm{H}_{11} \mathrm{OS}\right]^{+}: 191.0525$, found: 191.0534 .

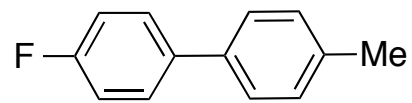

18i: White solid (83\% yield), previously reported (Döbele, M.; Vanderheiden, S.; Jung, N.; Bräse, S. Angew. Chem. Int. Ed. 2010, 49, 5986).

${ }^{1} \mathrm{H}$ NMR $\left(400 \mathrm{MHz}, \mathrm{CDCl}_{3}\right): \delta 7.52(\mathrm{dd}, J=8.9,5.4 \mathrm{~Hz}, 2 \mathrm{H}), 7.43(\mathrm{~d}, J=8.2 \mathrm{~Hz}, 2 \mathrm{H})$, $7.23(\mathrm{dd}, J=7.7,0.7 \mathrm{~Hz}, 2 \mathrm{H}), 7.10(\mathrm{t}, J=8.8 \mathrm{~Hz}, 2 \mathrm{H}), 2.39(\mathrm{~s}, 3 \mathrm{H})$;

${ }^{13} \mathrm{C}$ NMR $\left(100 \mathrm{MHz}, \mathrm{CDCl}_{3}\right): \delta 162.27(\mathrm{~d}, J=246.0 \mathrm{~Hz}), 137.36,137.24(\mathrm{~d}, J=3.1 \mathrm{~Hz})$, 137.00, 129.50, $128.43(\mathrm{~d}, J=8.2 \mathrm{~Hz}), 126.82,115.50(\mathrm{~d}, J=21.3 \mathrm{~Hz}), 21.04$.

${ }^{19} \mathrm{~F}$ NMR $\left(376 \mathrm{MHz}, \mathrm{CDCl}_{3}\right): \delta-116.4(\mathrm{~m}, 1 \mathrm{~F})$.

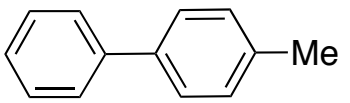

18j: White solid (80\% yield), previously reported (Bandari, R.; Höche, T.; Prager, A.; Dirnberger, K.; Buchmeiser, M. R. Chem. Eur. J. 2010, 16, 4650).

${ }^{1} \mathrm{H}$ NMR (400 MHz, $\left.\mathrm{CDCl}_{3}\right): \delta 7.57(\mathrm{~d}, J=7.5 \mathrm{~Hz}, 2 \mathrm{H}), 7.48(\mathrm{t}, J=7.9 \mathrm{~Hz}, 2 \mathrm{H}), 7.42$ (t, $J=7.7 \mathrm{~Hz}, 2 \mathrm{H}), 7.32(\mathrm{t}, J=7.3 \mathrm{~Hz}, 1 \mathrm{H}), 7.25(\mathrm{~d}, J=8.0 \mathrm{~Hz}, 2 \mathrm{H}), 2.39(\mathrm{~s}, 3 \mathrm{H})$;

${ }^{13} \mathrm{C} \mathrm{NMR}\left(100 \mathrm{MHz}, \mathrm{CDCl}_{3}\right): \delta 141.14,138.34,136.98,129.45,129.40,128.68,126.97$, $126.94,21.08$.

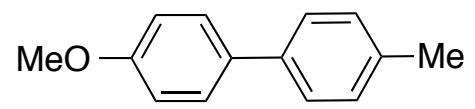

18k: White solid (72\% yield), previously reported (Lü, B.; Fu, C.; Ma, S. Tetrahedron Lett. 2010, 51, 1284).

${ }^{1} \mathrm{H}$ NMR $\left(400 \mathrm{MHz}, \mathrm{CDCl}_{3}\right): \delta 7.51(\mathrm{~d}, J=8.8 \mathrm{~Hz}, 2 \mathrm{H}), 7.44(\mathrm{~d}, J=8.2 \mathrm{~Hz}, 2 \mathrm{H}), 7.22$ $(\mathrm{d}, J=7.8 \mathrm{~Hz}, 2 \mathrm{H}), 6.96(\mathrm{~d}, J=8.8 \mathrm{~Hz}, 2 \mathrm{H}), 3.84(\mathrm{~s}, 3 \mathrm{H}), 2.38(\mathrm{~s}, 3 \mathrm{H})$;

${ }^{13} \mathrm{C} \mathrm{NMR}\left(100 \mathrm{MHz}, \mathrm{CDCl}_{3}\right): \delta 158.90,137.94,136.31,133.72,129.41,127.92,126.55$, 114.13, 55.31, 21.03.

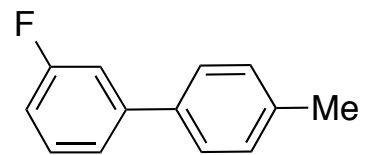

181: White solid (93\% yield), reported previously (Cheng, K.; Wang, C.; Ding, Y.; Song, Q.; Qi, C.; Zhang, X.-M. J. Org. Chem. 2011, 76, 9261).

${ }^{1} \mathrm{H}$ NMR (400 MHz, $\left.\mathrm{CDCl}_{3}\right): \delta \quad 7.47(\mathrm{~d}, J=8.2 \mathrm{~Hz}, 2 \mathrm{H}), 7.38-7.34(\mathrm{~m}, 2 \mathrm{H})$, 7.29-7.24 $(\mathrm{m}, 3 \mathrm{H}), 7.03-6.98(\mathrm{~m}, 1 \mathrm{H}), 2.40(\mathrm{~s}, 3 \mathrm{H})$;

${ }^{13} \mathrm{C} \mathrm{NMR}\left(100 \mathrm{MHz}, \mathrm{CDCl}_{3}\right): \delta 163.11(\mathrm{~d}, J=243.8 \mathrm{~Hz}), 143.42(\mathrm{~d}, J=7.6 \mathrm{~Hz}), 137.68$, 
137.03, $130.20(\mathrm{~d}, J=8.4 \mathrm{~Hz}), 129.57,126.89,122.50(\mathrm{~d}, J=2.9 \mathrm{~Hz}), 113.75(\mathrm{~d}, J=$ $21.5 \mathrm{~Hz}), 113.69$ (d, $J=21.0 \mathrm{~Hz}), 21.09$.

${ }^{19} \mathrm{~F} \mathrm{NMR}\left(376 \mathrm{MHz}, \mathrm{CDCl}_{3}\right): \delta-113.4(\mathrm{~m}, 1 \mathrm{~F})$.<smiles>C=CCOc1ccccc1C#CC(C)(C)O</smiles>

19a: Yellow liquid (68\% yield brsm).

${ }^{1} \mathrm{H}$ NMR $\left(400 \mathrm{MHz}, \mathrm{CDCl}_{3}\right): \delta 7.38(\mathrm{dd}, J=7.6,1.7 \mathrm{~Hz}, 1 \mathrm{H}), 7.27-7.22(\mathrm{~m}, 1 \mathrm{H}), 6.91-$ $6.84(\mathrm{~m}, 2 \mathrm{H}), 6.07$ (ddt, $J=17.2,10.6,4.8 \mathrm{~Hz}, 1 \mathrm{H}), 5.52(\mathrm{dq}, J=17.2,1.7 \mathrm{~Hz}, 1 \mathrm{H}), 5.29$ (dq, $J=10.6,1.6 \mathrm{~Hz}, 1 \mathrm{H}), 4.58$ (dt, $J=4.8,1.7 \mathrm{~Hz}, 2 \mathrm{H}), 2.17$ (br s, 1H), $1.63(\mathrm{~s}, 6 \mathrm{H})$;

${ }^{13} \mathrm{C} \mathrm{NMR}\left(100 \mathrm{MHz}, \mathrm{CDCl}_{3}\right): \delta$ 159.08, 133.43, 132.98, 132.96, 129.55, 120.65, 116.95, 112.53, 112.42, 97.99, 78.41, 69.11, 65.73, 31.50.

ESI-MS calculated for $\left[\mathrm{C}_{14} \mathrm{H}_{17} \mathrm{O}_{2}\right]^{+}: 217.1223$, found: 217.1231 .<smiles>C=CCOc1ccccc1N=NCC1COc2ccccc21</smiles>

19b: Yellow liquid (23\% yield).

${ }^{1} \mathrm{H}$ NMR $\left(400 \mathrm{MHz}, \mathrm{CDCl}_{3}\right): \delta 7.38(\mathrm{~d}, J=1.0 \mathrm{~Hz}, 1 \mathrm{H}), 7.33(\mathrm{dd}, J=8.0,1.7 \mathrm{~Hz}, 1 \mathrm{H})$, 7.28-7.26 (m, 1H), $7.17(\mathrm{~d}, J=0.6 \mathrm{~Hz}, 1 \mathrm{H}), 7.06(\mathrm{~d}, J=8.4 \mathrm{~Hz}, 1 \mathrm{H}), 6.98(\mathrm{t}, J=7.6 \mathrm{~Hz}$, $1 \mathrm{H}), 6.89$ (t, $J=7.4 \mathrm{~Hz}, 1 \mathrm{H}), 6.85$ (t, $J=6.8 \mathrm{~Hz}, 1 \mathrm{H}), 6.11$ (ddt, $J=17.3,10.5,5.2 \mathrm{~Hz}$, $1 \mathrm{H}), 5.45(\mathrm{dq}, J=17.3,1.6 \mathrm{~Hz}, 1 \mathrm{H}), 5.32(\mathrm{dq}, J=10.6,1.4 \mathrm{~Hz}, 1 \mathrm{H}), 4.79-4.74(\mathrm{~m}, 3 \mathrm{H})$, 4.53 (ddd, $J=17.6,11.4,6.1 \mathrm{~Hz}, 2 \mathrm{H}), 4.31(\mathrm{dd}, J=13.2,8.7 \mathrm{~Hz}, 1 \mathrm{H}), 4.17-4.10(\mathrm{~m}, 1 \mathrm{H})$; ${ }^{13} \mathrm{C} \mathrm{NMR}\left(100 \mathrm{MHz}, \mathrm{CDCl}_{3}\right): \delta 160.17,155.04,141.85,133.00,131.82,128.62,128.30$, 124.83, 120.92, 120.49, 117.85, 117.28, 114.36, 109.65, 75.29, 73.13, 69.99, 41.18.

ESI-MS calculated for $\left[\mathrm{C}_{18} \mathrm{H}_{19} \mathrm{~N}_{2} \mathrm{O}_{2}\right]^{+}:$295.1441, found: 295.1434 .

Compounds $\mathbf{2 3 a}$ to $\mathbf{2 3} \mathbf{g}$ are commercially available and volatile compounds. $\mathbf{2 3 \mathbf { h }},{ }^{[7]} \mathbf{2 3 \mathbf { i }},{ }^{[\mathbf{8}]}$ 23j $,^{[9]} 23 \mathbf{k},{ }^{[10]} 23 \mathbf{m},{ }^{[11]} 23 \mathbf{n},{ }^{[12]} 23 \mathbf{s o},{ }^{[13]} 23 \mathbf{p},{ }^{[14]} 23 \mathbf{r},{ }^{[15]} 23 \mathbf{s},{ }^{[16]} \mathbf{2 8 a}, 28 \mathbf{c},{ }^{[17]} \mathbf{2 8 d}, \mathbf{2 8 e},{ }^{[18]}$

7 Rühling, A.; Galla, H.-J.; Glorius, F. Chem. Eur. J. 2015, 21, 12291.

8 Gonzalez-de-Castro, A.; Xiao, J. J. Am. Chem. Soc., 2015, 137, 8206.

9 Skillinghaug, B.; Sköld, C.; Rydfjord, J.; Svensson, F.; Behrends, M.; Sävmarker, J.; Sjöberg, J. R.; Larhed, M. J. Org. Chem., 2014, 79, 12018.

10 Thomé, I.; Besson, C.; Kleine, T.; Bolm, C. Angew. Chem. Int. Ed. 2013, 52,7509.

11 Thompson, W. J.; Gaudino, J. J. Org. Chem., 1984, 49,5237.

12 Hibi, S.; Ueno, K.; Nagato, S.; Kawano, K.; Ito, K.; Norimine, Y.; Takenaka, O.; Hanada, T.; Yonaga, M. J. Med. Chem., 2012, 55, 10584.

13 Arora, A.; Teegardin, K.; Weaver, J. D. Org. Lett., 2015, 17, 3722.

14 Uemura, Y.; Mori, S.; Hara, K.; Koumura, N. Chem Lett. 2011, 40, 872

15 Uptmoor, A. C.; Freudenberg, J.; Schwäbel, S. T.; Paulus, F.; Rominger, F.; Hinkel, F.; Bunz, U. H. F. Angew. Chem. Int. Ed. 2015, 54,14673.

16 Tani, M.; Sakaguchi, S.; Ishii, Y. J. Org. Chem., 2004, 69, 1221.

17 He, Y.; Wu, H.; Toste, F. D. Chem. Sci., 2015, 6, 1194.

18 Ballester, J.; Gatignol, J.; Schmidt, G.; Alayrac, C.; Gaumont, A.-C.; Taillefer, M. ChemCatChem, 2014, 6, 1549. 
$\mathbf{2 8 g},{ }^{[19]}$ and $\mathbf{2 8 \mathbf { h } ^ { [ 2 0 ] }}$ were reported in literature.<smiles>Fc1ccc(Br)cc1</smiles>

23a: CAS: 460-00-4, GC-MS: 174.0, 95.1, 87.1, 75.1, 68.1, 50.1.<smiles>COc1ccc(Br)cc1</smiles>

23b: CAS: 104-92-7, GC-MS:187.8, 170.8, 142.9, 118.9, 92.0, 77.0, 63.0.<smiles>Cc1ccc(Br)cc1</smiles>

23c: CAS: 106-38-7, GC-MS: 169.9, 91.0, 65.0.<smiles>FC(F)(F)c1ccc(Br)cc1</smiles>

23d: CAS: 402-43-7, GC-MS: 223.8, 204.8, 173.8, 144.9, 125.0, 95.0, 75.0.<smiles>Brc1ccc(I)cc1</smiles>

23e: CAS: 589-87-7, GC-MS: 281.6, 154.8, 140.9, 126.8, 75.0.<smiles>Brc1ccc(Br)cc1</smiles>

23f: CAS: 106-37-6, GC-MS: 235.7, 154.8, 117.9, 75.0.<smiles>Brc1ccccc1</smiles>

23g: CAS: 108-86-1, GC-MS: 155.8, 77.0, 51.0.<smiles>CC(=O)c1ccc(Br)cc1</smiles>

23h: ${ }^{1} \mathrm{H}$ NMR (400 MHz, $\left.\mathrm{CDCl}_{3}\right): \delta 7.82(\mathrm{dt}, J=1.6,8.4 \mathrm{~Hz}, 2 \mathrm{H}), 7.61(\mathrm{dt}, J=1.6,8.8$ $\mathrm{Hz}, 2 \mathrm{H}), 2.61(\mathrm{~s}, 3 \mathrm{H})$.

${ }^{13} \mathrm{C}$ NMR $\left(100 \mathrm{MHz}, \mathrm{CDCl}_{3}\right): \delta 197.0,135.8,131.9,129.8,128.3,26.5$. 
<smiles>O=C(c1ccccc1)c1ccc(Br)cc1</smiles>

23i: ${ }^{1} \mathrm{H}$ NMR (400 MHz, $\left.\mathrm{CDCl}_{3}\right): \delta 7.77(\mathrm{~d}, J=7.2 \mathrm{~Hz}, 2 \mathrm{H}), 7.67$ (dt, $J=2.0,8.8 \mathrm{~Hz}$, $2 \mathrm{H}), 7.61(\mathrm{~m}, 3 \mathrm{H}), 7.49(\mathrm{t}, \mathrm{J}=7.6 \mathrm{~Hz}, 2 \mathrm{H})$.

${ }^{13} \mathrm{C}$ NMR $\left(100 \mathrm{MHz} \mathrm{CDCl}_{3}\right): \delta 195.6,137.1,136.3,132.6,131.6,131.5,129.9,128.4$, 127.5 .<smiles>O=C(c1ccccc1)c1ccccc1Br</smiles>

23j: ${ }^{1} \mathrm{H} \mathrm{NMR}\left(400 \mathrm{MHz}, \mathrm{CDCl}_{3}\right): \delta 7.81(\mathrm{dd}, J=1.2,8.4 \mathrm{~Hz}, 2 \mathrm{H}), 7.63(\mathrm{~m}, 2 \mathrm{H}), 7.45(\mathrm{~m}$, $3 \mathrm{H}), 7.35(\mathrm{~m}, 2 \mathrm{H})$.

${ }^{13} \mathrm{C}$ NMR $\left(100 \mathrm{MHz} \mathrm{CDCl}_{3}\right): \delta 195.9,140.7,136.1,133.8,133.2,131.2,130.3,129.0$, $128.7,127.2,119.5$.

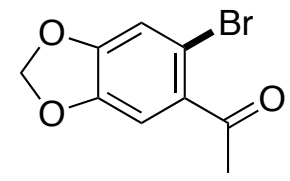

23k: ${ }^{1} \mathrm{H}$ NMR $\left(400 \mathrm{MHz}, \mathrm{CDCl}_{3}\right): \delta 7.04(\mathrm{~s}, 1 \mathrm{H}), 7.03(\mathrm{~s}, 1 \mathrm{H}), 6.04(\mathrm{~s}, 2 \mathrm{H}), 2.61(\mathrm{~s}, 3 \mathrm{H})$.

${ }^{13} \mathrm{C}$ NMR $\left(100 \mathrm{MHz}, \mathrm{CDCl}_{3}\right): \delta 199.4,150.3,147.3,134.2,113.8,109.8,102.4,33.8$, 30.2 .<smiles>Cc1cc(=O)oc2ccc(Br)cc12</smiles>

23I: ${ }^{1} \mathrm{H}$ NMR (400 MHz, $\left.\mathrm{CDCl}_{3}\right): \delta 7.45(\mathrm{~m}, 3 \mathrm{H}), 6.29(\mathrm{q}, J=1.6 \mathrm{~Hz}, 1 \mathrm{H}), 2.38(\mathrm{q}, J=$ $1.6 \mathrm{~Hz}, 3 \mathrm{H})$.

${ }^{13} \mathrm{C}$ NMR $\left(100 \mathrm{MHz} \mathrm{CDCl}_{3}\right): \delta 159.9,153.7,151.8,127.5,125.6,125.5,120.1,118.9$, $115.2,18.5$.

HRMS: m/z (ESI) Calculated for $[\mathrm{M}+\mathrm{H}]^{+}$238.9708, Found 238.9688.<smiles>COC(=O)c1cncc(Br)c1</smiles>

23m: ${ }^{1} \mathrm{H}$ NMR (400 MHz, $\left.\mathrm{CDCl}_{3}\right): \delta 9.13(\mathrm{~d}, J=2.0 \mathrm{~Hz}, 1 \mathrm{H}), 8.84(\mathrm{~d}, J=2.0 \mathrm{~Hz}, 1 \mathrm{H})$, $8.43(\mathrm{~d}, J=2.0 \mathrm{~Hz}, 1 \mathrm{H}), 3.97(\mathrm{~s}, 3 \mathrm{H})$.

${ }^{13} \mathrm{C} \mathrm{NMR}\left(100 \mathrm{MHz}, \mathrm{CDCl}_{3}\right): \delta 164.5,154.5,148.8,139.5,127.3,120.6,52.7$. 


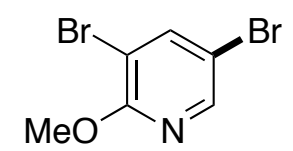

23n: ${ }^{1} \mathrm{H}$ NMR (400 MHz, DMSO-d 6 ): $\delta 8.30$ (d, $\left.J=2.4 \mathrm{~Hz}, 1 \mathrm{H}\right), 8.27$ (d, $\left.J=2.4 \mathrm{~Hz}, 1 \mathrm{H}\right)$, $3.88(\mathrm{~s}, 3 \mathrm{H})$.

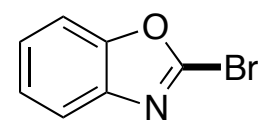

23o: ${ }^{1} \mathrm{H}$ NMR $\left(500 \mathrm{MHz}, \mathrm{CDCl}_{3}\right): \delta 7.99(\mathrm{~d}, J=7.0 \mathrm{~Hz}, 1 \mathrm{H}), 7.81(\mathrm{dd}, J=1.5,8.5 \mathrm{~Hz}$, $1 \mathrm{H}), 7.47(\mathrm{dt}, J=1.0,8.5 \mathrm{~Hz}, 1 \mathrm{H}), 7.42(\mathrm{dt}, J=1.5,8.0 \mathrm{~Hz}, 1 \mathrm{H})$.

${ }^{13} \mathrm{C}$ NMR $\left(125 \mathrm{MHz}, \mathrm{CDCl}_{3}\right): \delta 152.3,138.9,137.3,126.6,125.7,122.8,120.9$.<smiles>CCc1ccc(Br)cc1-c1ccccc1</smiles>

23p: ${ }^{1} \mathrm{H}$ NMR (500 MHz, $\left.\mathrm{CDCl}_{3}\right): \delta 8.20(\mathrm{~d}, J=2.0 \mathrm{~Hz}, 1 \mathrm{H}), 8.04(\mathrm{~d}, J=3.0 \mathrm{~Hz}, 1 \mathrm{H})$, $7.53(\mathrm{dd}, J=2.0,9.0 \mathrm{~Hz}, 1 \mathrm{H}), 7.47(\mathrm{ddd}, J=1.0,7.0 \mathrm{~Hz}, 1 \mathrm{H}), 7.40(\mathrm{~d}, J=8.0 \mathrm{~Hz}, 1 \mathrm{H})$, $7.26(\mathrm{~m}, 2 \mathrm{H}), 4.34$ (q, J = 7.5 Hz, 2H), $1.4(\mathrm{t}, \mathrm{J}=7.5 \mathrm{~Hz}, 3 \mathrm{H})$.

${ }^{13} \mathrm{C}$ NMR $\left(125 \mathrm{MHz}, \mathrm{CDCl}_{3}\right): \delta 140.2,138.5,128.2,126.3,124.7,123.1,121.9,120.6$, $119.2,111.5,109.9,108.7,37.7,13.7$.<smiles>Cc1cc(/N=N/c2ccccc2C)ccc1Br</smiles>

23q: ${ }^{1} \mathrm{H}$ NMR $\left(400 \mathrm{MHz}, \mathrm{CDCl}_{3}\right): \delta 7.55(\mathrm{~s}, 1 \mathrm{H}), 7.59(\mathrm{~m}, 3 \mathrm{H}), 7.31(\mathrm{~m}, 2 \mathrm{H}), 7.23(\mathrm{~m}$, $1 \mathrm{H}), 2.69(\mathrm{~s}, 3 \mathrm{H}), 2.46(\mathrm{~s}, 3 \mathrm{H})$.

${ }^{13} \mathrm{C}$ NMR $\left(100 \mathrm{MHz}, \mathrm{CDCl}_{3}\right): \delta 152.0,150.6,138.8,138.3,133.0,131.4,131.2,127.6$, 126.5, 125.3, 121.4, 115.4, 23.1, 17.6.

HRMS: m/z (ESI) Calculated for $[\mathrm{M}+\mathrm{NH}]^{+}$289.0340, Found 289.0335.

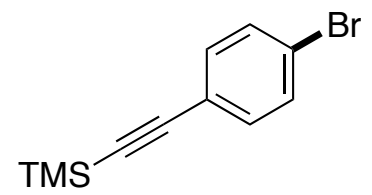

23r: ${ }^{1} \mathrm{H}$ NMR $\left(500 \mathrm{MHz}, \mathrm{CDCl}_{3}\right): \delta 7.52(\mathrm{~d}, J=8.0 \mathrm{~Hz}, 2 \mathrm{H}), 7.41(\mathrm{~d}, J=8.0 \mathrm{~Hz}, 2 \mathrm{H})$, $0.33(\mathrm{~s}, 9 \mathrm{H})$.

${ }^{13} \mathrm{C}$ NMR (125 MHz, $\left.\mathrm{CDCl}_{3}\right): \delta 133.4,131.5,122.7,122.1,103.8,95.6,29.7,-0.1$.<smiles>CCOC(=O)/C=C/c1ccc(Br)cc1</smiles>

23s: ${ }^{1} \mathrm{H}$ NMR $\left(500 \mathrm{MHz}, \mathrm{CDCl}_{3}\right): \delta 8.20(\mathrm{~d}, J=2.0 \mathrm{~Hz}, 1 \mathrm{H}), 8.04(\mathrm{~d}, J=3.0 \mathrm{~Hz}, 1 \mathrm{H})$, 
$7.61(\mathrm{~d}, J=16.0 \mathrm{~Hz}, 1 \mathrm{H}), 7.52(\mathrm{~d}, J=8.0 \mathrm{~Hz}, 2 \mathrm{H}), 7.38(\mathrm{~d}, J=8.0 \mathrm{~Hz}, 2 \mathrm{H}), 6.42(\mathrm{~d}, J=$ $16.0 \mathrm{~Hz}, 1 \mathrm{H}), 4.26$ (q, $J=7.5 \mathrm{~Hz}, 2 \mathrm{H}), 1.33(\mathrm{t}, J=7.5 \mathrm{~Hz}, 3 \mathrm{H})$.

${ }^{13} \mathrm{C}$ NMR $\left(125 \mathrm{MHz}, \mathrm{CDCl}_{3}\right): \delta 166.7,143.2,133.4,132.1,129.4,124.4,119.0,60.6$, 14.3 .

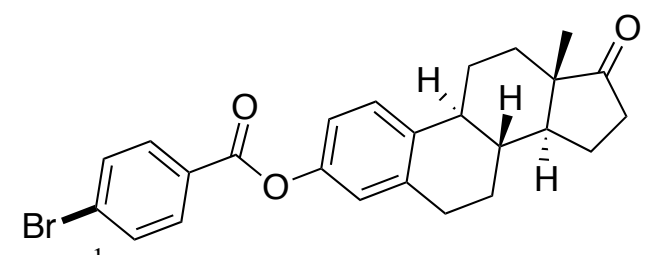

23t: ${ }^{1} \mathrm{H}$ NMR (400 MHz, $\left.\mathrm{CDCl}_{3}\right): \delta 7.94(\mathrm{dd}, J=2.0,6.4 \mathrm{~Hz}, 2 \mathrm{H}), 7.53(\mathrm{dd}, J=2.0,6.4$ $\mathrm{Hz}, 2 \mathrm{H}), 7.23(\mathrm{~d}, J=8.4 \mathrm{~Hz}, 1 \mathrm{H}), 6.88(\mathrm{dd}, J=2.8,8.4 \mathrm{~Hz}, 1 \mathrm{H}), 6.84(\mathrm{~d}, J=2.8 \mathrm{~Hz}, 1 \mathrm{H})$, $2.83(\mathrm{dd}, J=4.4 \mathrm{~Hz}, 2 \mathrm{H}), 2.42(\mathrm{~d}, J=8.4 \mathrm{~Hz}, 1 \mathrm{H}), 2.32(\mathrm{~m}, 2 \mathrm{H}), 2.20(\mathrm{~m}, 1 \mathrm{H}), 1.97(\mathrm{~m}$, $4 \mathrm{H}), 1.41(\mathrm{~m}, 6 \mathrm{H}), 0.83(\mathrm{~s}, 3 \mathrm{H})$.

${ }^{13} \mathrm{C}$ NMR $\left(100 \mathrm{MHz}, \mathrm{CDCl}_{3}\right): \delta 220.5,164.5,148.5,138.0,137.5,131.7,131.5,131.4$, 128.5, 126.4, 121.4, 118.6, 50.4, 47.9, 44.2, 38.0, 35.9, 31.5, 29.4, 26.3, 25.7, 21.6, 13.8 . HRMS: $\mathrm{m} / \mathrm{z}$ (ESI) Calculated for $[\mathrm{M}+\mathrm{H}]^{+} 453.1065$, Found 453.1061 .<smiles>COC(=O)CCSc1ccc(F)cc1</smiles>

27a: ${ }^{1} \mathrm{H}$ NMR (400 MHz, $\left.\mathrm{CDCl}_{3}\right): \delta 7.39(\mathrm{dd}, J=5.6,9.2 \mathrm{~Hz}, 2 \mathrm{H}), 6.96(\mathrm{t}, J=8.8 \mathrm{~Hz}$, $2 \mathrm{H}), 5.35(\mathrm{~d}, J=7.6 \mathrm{~Hz}, 1 \mathrm{H}), 4.50(\mathrm{~m}, 1 \mathrm{H}), 3.53(\mathrm{~s}, 3 \mathrm{H}), 3.27(\mathrm{~m}, 2 \mathrm{H}), 1.38(\mathrm{~s}, 9 \mathrm{H})$.

${ }^{13} \mathrm{C}$ NMR $\left(100 \mathrm{MHz}, \mathrm{CDCl}_{3}\right): \delta 170.9,162.1(\mathrm{~d}, J=246.0 \mathrm{~Hz}), 154.8,133.9(\mathrm{dd}, J=8.0$, $13.2 \mathrm{~Hz}$ ), 129.6, 116.0 (d, $J=21.7 \mathrm{~Hz}), 80.0,53.2,52.2$ (d, $J=12.2 \mathrm{~Hz}), 38.1,28.1$ (d, $J$ $=6.8 \mathrm{~Hz})$.

HRMS: $\mathrm{m} / \mathrm{z}$ (ESI) Calculated for $[\mathrm{M}+\mathrm{Na}]^{+}$352.0995, Found 352.0983 .

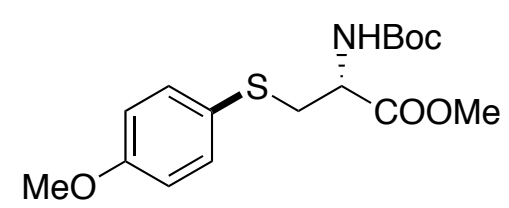

27b: ${ }^{1} \mathrm{H}$ NMR (400 MHz, $\mathrm{CDCl}_{3}$ ): $\delta 7.39$ (dt, $\left.J=2.0,7.2 \mathrm{~Hz}, 2 \mathrm{H}\right), 6.83(\mathrm{dt}, J=2.0,7.2$ $\mathrm{Hz}, 2 \mathrm{H}), 5.35(\mathrm{~d}, J=6.0 \mathrm{~Hz}, 1 \mathrm{H}), 4.50(\mathrm{~m}, 1 \mathrm{H}), 3.78(\mathrm{~s}, 3 \mathrm{H}), 3.54(\mathrm{~s}, 3 \mathrm{H}), 3.25(\mathrm{~d}, J=$ $4.0 \mathrm{~Hz}, 2 \mathrm{H}), 1.42(\mathrm{~s}, 9 \mathrm{H})$.

${ }^{13} \mathrm{C}$ NMR (125 MHz, $\left.\mathrm{CDCl}_{3}\right): \delta 171.1,159.4,154.9,134.4,124.7,114.6,79.9,55.2,53.1$, 52.2, 38.7, 28.2.

HRMS: $\mathrm{m} / \mathrm{z}$ (ESI) Calculated for $[\mathrm{M}+\mathrm{Na}]^{+}$364.1195, Found 364.1185.<smiles>CC(=O)OCCSc1ccc(C)cc1</smiles>

27c: ${ }^{1} \mathrm{H}$ NMR (500 MHz, $\left.\mathrm{CDCl}_{3}\right): \delta 7.31(\mathrm{~d}, J=8.0 \mathrm{~Hz}, 2 \mathrm{H}), 7.09(\mathrm{~d}, J=8.0, \mathrm{~Hz}, 2 \mathrm{H})$, $5.37(\mathrm{~d}, J=7.0 \mathrm{~Hz}, 1 \mathrm{H}), 4.53(\mathrm{~m}, 1 \mathrm{H}), 3.54(\mathrm{~s}, 3 \mathrm{H}), 3.31(\mathrm{~d}, J=5.0 \mathrm{~Hz}, 2 \mathrm{H}), 2.31(\mathrm{~s}, 3 \mathrm{H})$, 
$1.41(\mathrm{~s}, 9 \mathrm{H})$.

${ }^{13} \mathrm{C} \mathrm{NMR}\left(125 \mathrm{MHz}, \mathrm{CDCl}_{3}\right): \delta 171.0,154.9,137.1,131.6,130.8,129.7,79.9,53.2,52.2$, 37.7, 28.1, 20.9.

HRMS: m/z (ESI) Calculated for $[\mathrm{M}+\mathrm{Na}]^{+}$348.1245, Found 348.1258.<smiles>CC(=O)N[C@@H](CSc1ccccc1)C(=O)O</smiles>

27d: ${ }^{1} \mathrm{H}$ NMR (500 MHz, $\left.\mathrm{CDCl}_{3}\right): \delta 7.41(\mathrm{~d}, J=8.0 \mathrm{~Hz}, 2 \mathrm{H}), 7.28(\mathrm{t}, J=8.0 \mathrm{~Hz}, 2 \mathrm{H})$, $7.21(\mathrm{t}, J=7.5 \mathrm{~Hz}, 1 \mathrm{H}), 5.39(\mathrm{~d}, J=7.0 \mathrm{~Hz}, 1 \mathrm{H}), 4.56(\mathrm{~m}, 1 \mathrm{H}), 3.53(\mathrm{~s}, 3 \mathrm{H}), 3.37$ (m, $2 \mathrm{H}), 1.42(\mathrm{~s}, 9 \mathrm{H})$.

${ }^{13} \mathrm{C} \mathrm{NMR}\left(125 \mathrm{MHz}, \mathrm{CDCl}_{3}\right): \delta 171.0,155.0,134.7,131.0,129.0,127.0,80.1,53.2,52.3$, 37.2, 28.2 .

HRMS: m/z (ESI) Calculated for $[\mathrm{M}+\mathrm{Na}]^{+}$334.1089, Found 334.1097.<smiles>COC(=O)[C@H](CSc1ccc(C(F)(F)F)cc1)NC(C)(C)C</smiles>

27e: ${ }^{1} \mathrm{H}$ NMR (400 MHz, $\left.\mathrm{CDCl}_{3}\right): \delta 7.52(\mathrm{~d}, J=8.4 \mathrm{~Hz}, 2 \mathrm{H}), 7.46(\mathrm{~d}, J=8.4 \mathrm{~Hz}, 2 \mathrm{H})$, $5.34(\mathrm{~d}, J=6.4 \mathrm{~Hz}, 1 \mathrm{H}), 4.56(\mathrm{~m}, 1 \mathrm{H}), 3.59(\mathrm{~s}, 3 \mathrm{H}), 3.35(\mathrm{~m}, 2 \mathrm{H}), 1.41(\mathrm{~s}, 9 \mathrm{H})$.

${ }^{13} \mathrm{C}$ NMR (125 MHz, $\left.\mathrm{CDCl}_{3}\right): \delta 170.7,154.9,140.5,129.3,128.5(\mathrm{q}, J=26.2 \mathrm{~Hz}), 125.7$, $(\mathrm{d}, J=2.7 \mathrm{~Hz}), 124.0(\mathrm{q}, J=216.3 \mathrm{~Hz}), 80.3,53.3,52.5,36.0,28.2$.

HRMS: m/z (ESI) Calculated for $[\mathrm{M}+\mathrm{Na}]^{+}$402.0963, Found 402.0970.

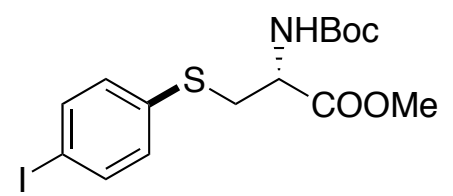

27f: ${ }^{1} \mathrm{H}$ NMR (400 MHz, $\left.\mathrm{CDCl}_{3}\right): \delta 7.60(\mathrm{dd}, J=2.0,6.8 \mathrm{~Hz}, 2 \mathrm{H}), 7.14(\mathrm{dt}, J=1.6,6.8$ $\mathrm{Hz}, 2 \mathrm{H}), 5.29(\mathrm{~d}, J=8.0 \mathrm{~Hz}, 1 \mathrm{H}), 4.57(\mathrm{~m}, 1 \mathrm{H}), 3.60$ (s, 3H), 3.37 (m, 2H), $1.42(\mathrm{~s}, 9 \mathrm{H})$.

${ }^{13} \mathrm{C}$ NMR $\left(125 \mathrm{MHz}, \mathrm{CDCl}_{3}\right): \delta 170.8,154.8,138.0,132.5,92.1,80.2,53.3,52.5,37.0$, 28.2.

HRMS: m/z (ESI) Calculated for $[\mathrm{M}+\mathrm{Na}]^{+}$460.0055, Found 460.0063.

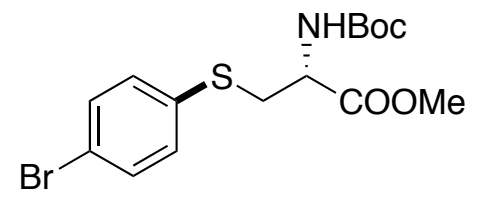

27g: ${ }^{1} \mathrm{H}$ NMR $\left(500 \mathrm{MHz}, \mathrm{CDCl}_{3}\right): \delta 7.40(\mathrm{dt}, J=2.5,9.0 \mathrm{~Hz}, 2 \mathrm{H}), 7.27(\mathrm{dt}, J=2.0,8.5$ $\mathrm{Hz}, 2 \mathrm{H}), 5.35(\mathrm{~d}, J=7.5 \mathrm{~Hz}, 1 \mathrm{H}), 4.56(\mathrm{~m}, 1 \mathrm{H}), 3.59(\mathrm{~s}, 3 \mathrm{H}), 3.35(\mathrm{~m}, 2 \mathrm{H}), 1.41(\mathrm{~s}, 9 \mathrm{H})$.

${ }^{13} \mathrm{C}$ NMR (125 MHz, $\left.\mathrm{CDCl}_{3}\right): \delta 170.8,154.8,134.0,132.4,132.0,120.9,80.1,53.2,52.4$, 37.1, 28.2 .

HRMS: m/z (ESI) Calculated for $[\mathrm{M}+\mathrm{Na}]^{+}$412.0194, Found 12.0189. 
<smiles>CC(=O)OCC(N)CSc1ccc(C(C)=O)cc1</smiles>

27h: ${ }^{1} \mathrm{H}$ NMR $\left(500 \mathrm{MHz}, \mathrm{CDCl}_{3}\right): \delta 7.87(\mathrm{~d}, J=8.5 \mathrm{~Hz}, 2 \mathrm{H}), 7.40(\mathrm{~d}, J=8.5 \mathrm{~Hz}, 2 \mathrm{H})$, $5.32(\mathrm{~d}, J=7.5 \mathrm{~Hz}, 1 \mathrm{H}), 4.57(\mathrm{~m}, 1 \mathrm{H}), 3.56(\mathrm{~s}, 3 \mathrm{H}), 3.37(\mathrm{~m}, 2 \mathrm{H}), 2.57(\mathrm{~s}, 3 \mathrm{H}), 1.41(\mathrm{~s}$, 9H).

${ }^{13} \mathrm{C}$ NMR $\left(125 \mathrm{MHz}, \mathrm{CDCl}_{3}\right): \delta 197.0,170.7,154.9,142.4,134.7,128.8,128.1,80.3$, 53.2, 52.6, 35.4, 28.2, 26.5 .

HRMS: m/z (ESI) Calculated for [M+Na] ${ }^{+}$376.1195, Found 376.1198.<smiles>COC(=O)[C@H](CSc1ccc(C(=O)c2ccccc2)cc1)NC(C)(C)C</smiles>

27i: ${ }^{1} \mathrm{H}$ NMR (400 MHz, $\left.\mathrm{CDCl}_{3}\right): \delta 7.76(\mathrm{~d}, J=7.6 \mathrm{~Hz}, 2 \mathrm{H}), 7.73(\mathrm{~d}, J=8.4 \mathrm{~Hz}, 2 \mathrm{H})$, 7.59 (t, $J=7.6 \mathrm{~Hz}, 1 \mathrm{H}), 7.49(\mathrm{~d}, J=7.6 \mathrm{~Hz}, 2 \mathrm{H}), 7.43(\mathrm{~d}, J=8.4 \mathrm{~Hz}, 2 \mathrm{H}), 5.41(\mathrm{~d}, J=$ $6.8 \mathrm{~Hz}, 1 \mathrm{H}), 4.65(\mathrm{~m}, 1 \mathrm{H}), 3.66(\mathrm{~s}, 3 \mathrm{H}), 3.47(\mathrm{~m}, 2 \mathrm{H}), 1.43(\mathrm{~s}, 9 \mathrm{H})$.

${ }^{13} \mathrm{C}$ NMR $\left(125 \mathrm{MHz}, \mathrm{CDCl}_{3}\right): \delta 195.6,170.8,154.9,141.6,137.5,135.0,132.4,130.6$, $129.8,128.3,127.9,80.3,53.2,52.5,35.4,28.2$.

HRMS: m/z (ESI) Calculated for $[\mathrm{M}+\mathrm{Na}]^{+} 438.1351$, Found 438.1350.

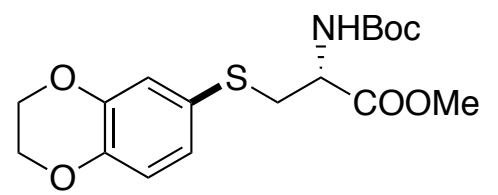

27j: ${ }^{1} \mathrm{H}$ NMR $\left(400 \mathrm{MHz}, \mathrm{CDCl}_{3}\right): \delta 6.97(\mathrm{~d}, J=2.0 \mathrm{~Hz}, 1 \mathrm{H}), 6.92(\mathrm{dd}, J=2.0,6.4 \mathrm{~Hz}$, $1 \mathrm{H}), 6.78(\mathrm{~d}, J=6.8 \mathrm{~Hz}, 1 \mathrm{H}), 5.34(\mathrm{~d}, J=5.6 \mathrm{~Hz}, 1 \mathrm{H}), 4.51(\mathrm{~m}, 1 \mathrm{H}), 4.23(\mathrm{~s}, 4 \mathrm{H}), 3.61$ (s, $3 \mathrm{H}), 3.26(\mathrm{~m}, 2 \mathrm{H}), 1.42(\mathrm{~s}, 9 \mathrm{H})$.

${ }^{13} \mathrm{C}$ NMR $\left(125 \mathrm{MHz}, \mathrm{CDCl}_{3}\right): \delta 171.1,154.9,143.6,143.4,125.8,121.4,117.8,79.9$, 64.3, 64.2, 53.2, 52.3, 38.4, 28.2.

HRMS: m/z (ESI) Calculated for $[\mathrm{M}+\mathrm{Na}]^{+}$392.1144, Found 392.1130.<smiles>COC(=O)c1cncc(SC[C@H](NC(C)=O)C(C)=O)c1</smiles>

27k: ${ }^{1} \mathrm{H}$ NMR $\left(500 \mathrm{MHz}, \mathrm{CDCl}_{3}\right): \delta 9.05(\mathrm{~s}, 1 \mathrm{H}), 8.76(\mathrm{~d}, J=1.5 \mathrm{~Hz}, 1 \mathrm{H}), 8.31(\mathrm{~s}, 1 \mathrm{H})$, $5.39(\mathrm{~d}, J=7.5 \mathrm{~Hz}, 1 \mathrm{H}), 4.60(\mathrm{~m}, 1 \mathrm{H}), 3.96(\mathrm{~s}, 3 \mathrm{H}), 3.64(\mathrm{~s}, 3 \mathrm{H}), 3.46(\mathrm{~m}, 2 \mathrm{H}), 1.41$ (s, 9H).

${ }^{13} \mathrm{C}$ NMR $\left(125 \mathrm{MHz}, \mathrm{CDCl}_{3}\right): \delta 170.6,165.1,154.6,148.7,138.6,132.7,126.1,80.4$, 53.2, 52.6, 36.9, 28.2.

HRMS: m/z (ESI) Calculated for $[\mathrm{M}+\mathrm{Na}]^{+}$393.1096, Found 393.1074. 
<smiles>COC(=O)[C@H](CSc1ccc(C)nc1)NC(C)(C)C</smiles>

27l: ${ }^{1} \mathrm{H}$ NMR $\left(400 \mathrm{MHz}, \mathrm{CDCl}_{3}\right): \delta 8.53(\mathrm{~s}, 1 \mathrm{H}), 7.65(\mathrm{dd}, J=1.6,7.6 \mathrm{~Hz}, 1 \mathrm{H}), 7.10(\mathrm{~d}, J$ $=8.4 \mathrm{~Hz}, 1 \mathrm{H}), 5.38(\mathrm{~d}, J=6.8 \mathrm{~Hz}, 1 \mathrm{H}), 4.53(\mathrm{~m}, 1 \mathrm{H}), 3.60(\mathrm{~s}, 3 \mathrm{H}), 3.33(\mathrm{~m}, 2 \mathrm{H}), 2.53(\mathrm{~s}$, $3 \mathrm{H}), 1.41$ (s, $9 \mathrm{H})$.

${ }^{13} \mathrm{C}$ NMR $\left(125 \mathrm{MHz}, \mathrm{CDCl}_{3}\right): \delta 170.6,157.4,154.8,151.8,139.8,128.2,123.4,80.1$, 53.2, 37.8, 28.2, 23.9 .

HRMS: $\mathrm{m} / \mathrm{z}$ (ESI) Calculated for $[\mathrm{M}+\mathrm{Na}]^{+} 349.1198$, Found 349.1187 .<smiles>COC(=O)N[C@@H](CSc1cnc(OC)c(Br)c1)C(=O)OC</smiles>

27m: ${ }^{1} \mathrm{H}$ NMR $\left(400 \mathrm{MHz}, \mathrm{CDCl}_{3}\right): \delta 8.17(\mathrm{dd}, J=1.6,7.6 \mathrm{~Hz}, 1 \mathrm{H}), 7.10(\mathrm{~d}, J=8.4 \mathrm{~Hz}$, $1 \mathrm{H}), 5.38(\mathrm{~d}, J=6.8 \mathrm{~Hz}, 1 \mathrm{H}), 4.53(\mathrm{~m}, 1 \mathrm{H}), 3.60(\mathrm{~s}, 3 \mathrm{H}), 3.33(\mathrm{~m}, 2 \mathrm{H}), 2.53(\mathrm{~s}, 3 \mathrm{H}), 1.41$ (s, 9H).

${ }^{13} \mathrm{C}$ NMR $\left(125 \mathrm{MHz}, \mathrm{CDCl}_{3}\right): \delta 170.8,159.8,154.8,149.6,145.9,123.9,106.9,80.3$, 54.7, 53.3, 52.5, 38.9, 28.2 .

HRMS: $\mathrm{m} / \mathrm{z}$ (ESI) Calculated for $[\mathrm{M}+\mathrm{Na}]^{+} 443.0252$, Found 443.0250.

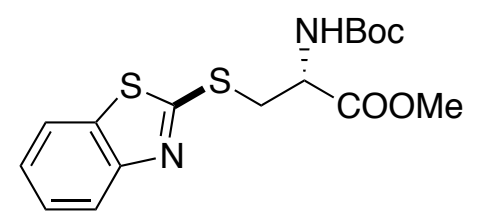

27n: ${ }^{1} \mathrm{H}$ NMR (500 MHz, $\left.\mathrm{CDCl}_{3}\right): \delta 7.87(\mathrm{~d}, J=8.0 \mathrm{~Hz}, 1 \mathrm{H}), 7.75(\mathrm{~d}, J=8.0 \mathrm{~Hz}, 1 \mathrm{H})$, $7.42(\mathrm{t}, J=7.5 \mathrm{~Hz}, 1 \mathrm{H}), 7.31(\mathrm{t}, J=7.5 \mathrm{~Hz}, 1 \mathrm{H}), 6.19$ (d, $J=7.5 \mathrm{~Hz}, 1 \mathrm{H}), 4.75$ (dd, $J=$ $5.5,12.0 \mathrm{~Hz}, 1 \mathrm{H}), 3.82(\mathrm{~d}, \mathrm{~J}=5.0 \mathrm{~Hz}, 2 \mathrm{H}), 3.73(\mathrm{~s}, 3 \mathrm{H}), 1.41(\mathrm{~s}, 9 \mathrm{H})$.

${ }^{13} \mathrm{C}$ NMR $\left(125 \mathrm{MHz}, \mathrm{CDCl}_{3}\right): \delta 170.9,152.7,135.5,127.1,126.2,124.6,121.6,121.0$, $111.8,80.0,53.9,52.7,35.4,28.2$.

HRMS: $\mathrm{m} / \mathrm{z}$ (ESI) Calculated for $[\mathrm{M}+\mathrm{Na}]^{+}$391.0762, Found 391.0743 .

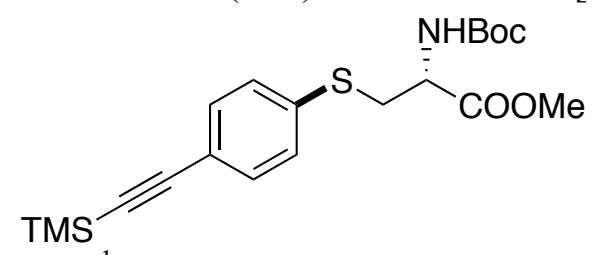

27o: ${ }^{1} \mathrm{H}$ NMR (500 MHz, $\left.\mathrm{CDCl}_{3}\right): \delta 7.35(\mathrm{~d}, J=8.5 \mathrm{~Hz}, 2 \mathrm{H}), 7.29(\mathrm{~d}, J=8.0 \mathrm{~Hz}, 2 \mathrm{H})$, $5.32(\mathrm{~d}, J=7.5 \mathrm{~Hz}, 1 \mathrm{H}), 4.57(\mathrm{~m}, 1 \mathrm{H}), 3.56(\mathrm{~s}, 3 \mathrm{H}), 3.37(\mathrm{~m}, 2 \mathrm{H}), 1.41(\mathrm{~s}, 9 \mathrm{H}), 0.23$ (s, 9H).

${ }^{13} \mathrm{C}$ NMR $\left(125 \mathrm{MHz}, \mathrm{CDCl}_{3}\right): \delta 170.8,154.9,135.8,132.3,129.8,121.5,104.4,95.1$, 80.2, 53.2, 52.4, 36.6, 28.2, -0.1 .

HRMS: $\mathrm{m} / \mathrm{z}$ (ESI) Calculated for $[\mathrm{M}+\mathrm{Na}]^{+} 430.1484$, Found 430.1481 . 
<smiles>CCOC(=O)/C=C/c1ccc(SC[C@H](NC(C)(C)C)C(=O)OC)cc1</smiles>

27p: ${ }^{1} \mathrm{H}$ NMR $\left(500 \mathrm{MHz}, \mathrm{CDCl}_{3}\right): \delta 7.68(\mathrm{~d}, J=16.5 \mathrm{~Hz}, 1 \mathrm{H}), 7.58(\mathrm{~s}, 4 \mathrm{H}), 6.47(\mathrm{~d}, J=$ $16.5 \mathrm{~Hz}, 1 \mathrm{H}), 5.53(\mathrm{~d}, J=7.5 \mathrm{~Hz}, 1 \mathrm{H}), 4.76(\mathrm{~m}, 1 \mathrm{H}), 4.27(\mathrm{q}, J=7.0 \mathrm{~Hz}, 2 \mathrm{H}), 3.96(\mathrm{~m}$, $2 \mathrm{H}), 3.73(\mathrm{~s}, 3 \mathrm{H}), 1.42(\mathrm{~s}, 9 \mathrm{H}), 1.34(\mathrm{t}, J=7.5 \mathrm{~Hz}, 3 \mathrm{H})$.

${ }^{13} \mathrm{C}$ NMR $\left(125 \mathrm{MHz}, \mathrm{CDCl}_{3}\right): \delta 170.9,166.6,154.9,152.1,143.2,135.8,128.8,122.0$, 119.4, 80.1, 60.6, 53.2, 52.6, 36.7, 28.2, 14.2 .

HRMS: m/z (ESI) Calculated for $[\mathrm{M}+\mathrm{Na}]^{+} 432.1457$, Found 432.1416.<smiles>CCOC(=O)/C=C\c1ccc(SC[C@H](NC(C)=O)C(=O)OC)cc1</smiles>

(Z)-27q: ${ }^{1} \mathrm{H}$ NMR $\left(500 \mathrm{MHz}, \mathrm{CDCl}_{3}\right): \delta 7.62(\mathrm{~d}, J=15.5 \mathrm{~Hz}, 1 \mathrm{H}), 7.43(\mathrm{~d}, J=8.5 \mathrm{~Hz}$, 2H), 7.37 (d, $J=8.0 \mathrm{~Hz}, 2 \mathrm{H}), 6.40(\mathrm{~d}, J=15.5 \mathrm{~Hz}, 1 \mathrm{H}), 5.38$ (d, $J=7.5 \mathrm{~Hz}, 1 \mathrm{H}), 4.60$ (m, $1 \mathrm{H}), 4.26(\mathrm{q}, J=7.0 \mathrm{~Hz}, 2 \mathrm{H}), 3.60(\mathrm{~s}, 3 \mathrm{H}), 3.41(\mathrm{~m}, 2 \mathrm{H}), 1.41(\mathrm{~s}, 9 \mathrm{H}), 1.34(\mathrm{t}, J=7.0 \mathrm{~Hz}$, $3 \mathrm{H})$.

${ }^{13} \mathrm{C}$ NMR $\left(125 \mathrm{MHz}, \mathrm{CDCl}_{3}\right): \delta 170.7,166.8,154.8,152.1,143.5,132.6,129.8,128.4$, $118.1,80.0,60.5,53.2,52.4,36.2,28.2,14.2$.

HRMS: m/z (ESI) Calculated for $[\mathrm{M}+\mathrm{Na}]^{+} 432.1457$, Found 432.1416.<smiles>CC(=O)OC(C)=O</smiles>

(E)-27q: ${ }^{1} \mathrm{H}$ NMR $\left(400 \mathrm{MHz}, \mathrm{CDCl}_{3}\right): \delta 7.73(\mathrm{~s}, 1 \mathrm{H}), 7.72(\mathrm{~d}, J=8.0 \mathrm{~Hz}, 1 \mathrm{H}), 7.60(\mathrm{~d}, J$ $=8.4 \mathrm{~Hz}, 1 \mathrm{H}), 7.46(\mathrm{~d}, J=8.0 \mathrm{~Hz}, 1 \mathrm{H}), 7.33(\mathrm{~m}, 2 \mathrm{H}), 7.24(\mathrm{~m}, 1 \mathrm{H}), 5.38(\mathrm{~d}, J=7.6 \mathrm{~Hz}$, $1 \mathrm{H}), 4.65(\mathrm{~m}, 1 \mathrm{H}), 3.63(\mathrm{~s}, 3 \mathrm{H}), 3.45(\mathrm{~m}, 2 \mathrm{H}), 2.71(\mathrm{~s}, 3 \mathrm{H}), 2.47(\mathrm{~s}, 3 \mathrm{H}), 1.43(\mathrm{~s}, 9 \mathrm{H})$.

${ }^{13} \mathrm{C}$ NMR $\left(100 \mathrm{MHz}, \mathrm{CDCl}_{3}\right): \delta 170.9,154.9,151.2,150.7,138.7,138.0,131.2,130.8$, 129.2, 129.1, 126.3, 124.4, 121.0, 115.3, 80.2, 53.2, 52.5, 35.8, 29.6, 28.2, 20.6, 17.4.

HRMS: m/z (ESI) Calculated for $[\mathrm{M}+\mathrm{Na}]^{+} 466.1776$, Found 446.1752.<smiles>CCOP(=O)(OCC)c1ccc(F)cc1</smiles>

28a: ${ }^{1} \mathrm{H}$ NMR (400 MHz, $\left.\mathrm{CDCl}_{3}\right): \delta 7.83(\mathrm{ddd}, J=5.6,8.4,13.6 \mathrm{~Hz}, 2 \mathrm{H}), 7.15$ (ddd, $J=$ $3.2,9.2 \mathrm{~Hz}, 2 \mathrm{H}), 4.12(\mathrm{~m}, 4 \mathrm{H}), 1.33(\mathrm{t}, J=7.2 \mathrm{~Hz}, 6 \mathrm{H})$.

${ }^{13} \mathrm{C}$ NMR (100 MHz, $\left.\mathrm{CDCl}_{3}\right): \delta 165.3(\mathrm{~d}, J=199.3 \mathrm{~Hz}), 134.3(\mathrm{t}, J=9.1 \mathrm{~Hz}), 124.4(\mathrm{~d}, J$ $=150.7 \mathrm{~Hz}), 115.8(\mathrm{dd}, J=12.9,16.6 \mathrm{~Hz}), 62.1(\mathrm{~d}, J=3.8 \mathrm{~Hz}), 16.2(\mathrm{~d}, J=4.9 \mathrm{~Hz})$. 
<smiles>CCOP(=O)(OCC)c1ccc(OC)cc1</smiles>

28b: ${ }^{1} \mathrm{H}$ NMR (400 MHz, $\left.\mathrm{CDCl}_{3}\right)$ : $\delta 7.75(\mathrm{dd}, J=8.8,12.4 \mathrm{~Hz}, 2 \mathrm{H}), 6.97(\mathrm{dd}, J=3.6,8.8$ $\mathrm{Hz}, 2 \mathrm{H}), 4.09$ (m, 4H), 3.85 (s, 3H), 1.31 (t, $J=6.8 \mathrm{~Hz}, 6 \mathrm{H})$.

${ }^{13} \mathrm{C}$ NMR $\left(125 \mathrm{MHz}, \mathrm{CDCl}_{3}\right): \delta 162.8,133.8(\mathrm{~d}, J=11.4 \mathrm{~Hz}), 119.5(\mathrm{~d}, J=193.6 \mathrm{~Hz})$, $114.0(\mathrm{~d}, J=15.6 \mathrm{~Hz}), 61.9(\mathrm{~d}, J=5.2 \mathrm{~Hz}), 53.3,16.3(\mathrm{~d}, J=6.6 \mathrm{~Hz})$.

HRMS: m/z (ESI) Calculated for $[\mathrm{M}+\mathrm{H}]^{+}$245.0943, Found 245.0931.<smiles>CCOP(=O)(OCC)c1ccc(C)cc1</smiles>

28c: ${ }^{1} \mathrm{H}$ NMR $\left(400 \mathrm{MHz}, \mathrm{CDCl}_{3}\right): \delta 7.70(\mathrm{dd}, J=8.0,13.0 \mathrm{~Hz}, 2 \mathrm{H}), 7.27(\mathrm{dd}, J=3.5,8.0$ $\mathrm{Hz}, 2 \mathrm{H}), 4.10(\mathrm{~m}, 4 \mathrm{H}), 2.40(\mathrm{~s}, 3 \mathrm{H}), 1.31(\mathrm{t}, J=7.0 \mathrm{~Hz}, 6 \mathrm{H})$.

${ }^{13} \mathrm{C}$ NMR $\left(100 \mathrm{MHz}, \mathrm{CDCl}_{3}\right): \delta 142.9(\mathrm{~d}, J=2.3 \mathrm{~Hz}), 131.8(\mathrm{t}, J=7.9 \mathrm{~Hz}), 129.2(\mathrm{~d}, J=$ $12.1 \mathrm{~Hz}), 124.9(\mathrm{~d}, J=155.0 \mathrm{~Hz}), 61.9(\mathrm{~d}, J=4.2 \mathrm{~Hz}), 21.6,16.3(\mathrm{~d}, J=5.3 \mathrm{~Hz})$.<smiles>CCOP(=O)(OCC)c1ccc(I)cc1</smiles>

28d: ${ }^{1} \mathrm{H}$ NMR (400 MHz, $\left.\mathrm{CDCl}_{3}\right): \delta 7.83(\mathrm{dd}, J=3.6,8.4 \mathrm{~Hz}, 2 \mathrm{H}), 7.52(\mathrm{dd}, J=8.0,12.8$ $\mathrm{Hz}, 2 \mathrm{H}), 4.11(\mathrm{~m}, 4 \mathrm{H}), 1.32(\mathrm{t}, J=7.2 \mathrm{~Hz}, 6 \mathrm{H})$.

${ }^{13} \mathrm{C} \mathrm{NMR}\left(125 \mathrm{MHz}, \mathrm{CDCl}_{3}\right): \delta 137.7(\mathrm{~d}, J=15.2 \mathrm{~Hz}), 133.1(\mathrm{~d}, J=10.4 \mathrm{~Hz}), 128.0(\mathrm{~d}, J$ $=188.8 \mathrm{~Hz}), 100.1(\mathrm{~d}, J=3.9 \mathrm{~Hz}), 62.3(\mathrm{~d}, J=5.3 \mathrm{~Hz}), 16.3(\mathrm{~d}, J=6.2 \mathrm{~Hz})$.<smiles>CCOP(=O)(OCC)c1ccc(Br)cc1</smiles>

28e: ${ }^{1} \mathrm{H}$ NMR (400 MHz, $\left.\mathrm{CDCl}_{3}\right)$ : $\delta 765(\mathrm{~m}, 4 \mathrm{H}), 4.12(\mathrm{~m}, 4 \mathrm{H}), 1.32(\mathrm{t}, J=7.2 \mathrm{~Hz}, 6 \mathrm{H})$.

${ }^{13} \mathrm{C}$ NMR $\left(100 \mathrm{MHz}, \mathrm{CDCl}_{3}\right): \delta 133.2(\mathrm{~d}, J=8.3 \mathrm{~Hz}), 131.7(\mathrm{~d}, J=12.1 \mathrm{~Hz}), 127.5(\mathrm{~d}, J$ $=3.1 \mathrm{~Hz}), 127.4(\mathrm{~d}, J=151.9 \mathrm{~Hz}), 62.2(\mathrm{~d}, J=4.2 \mathrm{~Hz}), 16.2(\mathrm{~d}, J=5.4 \mathrm{~Hz})$.<smiles>CCOP(=O)(OCC)c1ccc(Cl)cc1</smiles>

28f: ${ }^{1} \mathrm{H}$ NMR (400 MHz, $\left.\mathrm{CDCl}_{3}\right): \delta 7.75(\mathrm{dd}, J=8.4,13.2 \mathrm{~Hz}, 2 \mathrm{H}), 7.45(\mathrm{dd}, J=3.6,8.4$ $\mathrm{Hz}, 2 \mathrm{H}), 4.11(\mathrm{~m}, 4 \mathrm{H}), 1.32(\mathrm{t}, J=7.2 \mathrm{~Hz}, 6 \mathrm{H})$.

${ }^{13} \mathrm{C} \mathrm{NMR}\left(100 \mathrm{MHz}, \mathrm{CDCl}_{3}\right): \delta 138.9(\mathrm{~d}, J=3.0 \mathrm{~Hz}), 133.1(\mathrm{~d}, J=8.7 \mathrm{~Hz}), 128.8(\mathrm{~d}, J=$ $12.5 \mathrm{~Hz}), 126.9(\mathrm{~d}, J=151.8 \mathrm{~Hz}), 62.2(\mathrm{~d}, J=4.2 \mathrm{~Hz}), 16.2(\mathrm{~d}, J=5.4 \mathrm{~Hz})$.

HRMS: $\mathrm{m} / \mathrm{z}$ (ESI) Calculated for $[\mathrm{M}+\mathrm{H}]^{+}$249.0447, Found 249.0439. 
<smiles>CCOP(=O)(OCC)c1ccc(C(=O)c2ccccc2)cc1</smiles>

28g: ${ }^{1} \mathrm{H}$ NMR (500 MHz, $\left.\mathrm{CDCl}_{3}\right): \delta 7.94(\mathrm{dd}, J=8.0,12.8 \mathrm{~Hz}, 1 \mathrm{H}), 7.85(\mathrm{~m}, 1 \mathrm{H}), 7.81$ $(\mathrm{m}, 3 \mathrm{H}), 7.63(\mathrm{~m}, 2 \mathrm{H}), 7.51(\mathrm{~m}, 2 \mathrm{H}), 4.15(\mathrm{~m}, 4 \mathrm{H}), 1.36(\mathrm{t}, J=7.2 \mathrm{~Hz}, 6 \mathrm{H})$.<smiles>CCOP(=O)(OCC)c1ccc(C(C)=O)cc1</smiles>

28h: ${ }^{1} \mathrm{H}$ NMR (400 MHz, $\left.\mathrm{CDCl}_{3}\right): \delta 7.75(\mathrm{dd}, J=8.4,13.2 \mathrm{~Hz}, 2 \mathrm{H}), 7.45(\mathrm{dd}, J=3.6,8.4$ $\mathrm{Hz}, 2 \mathrm{H}), 4.11(\mathrm{~m}, 4 \mathrm{H}), 1.32(\mathrm{t}, J=7.2 \mathrm{~Hz}, 6 \mathrm{H})$.

${ }^{13} \mathrm{C}$ NMR (125 MHz, $\left.\mathrm{CDCl}_{3}\right): \delta 138.9(\mathrm{~d}, J=3.0 \mathrm{~Hz}), 133.1(\mathrm{~d}, J=8.7 \mathrm{~Hz}), 128.8(\mathrm{~d}, J=$ $12.5 \mathrm{~Hz}), 126.9$ (d, $J=151.8 \mathrm{~Hz}), 62.2(\mathrm{~d}, J=4.2 \mathrm{~Hz}), 16.2(\mathrm{~d}, J=5.4 \mathrm{~Hz})$.

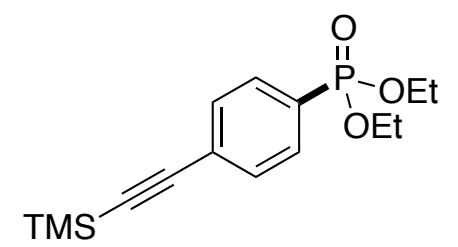

28i: ${ }^{1} \mathrm{H}$ NMR $\left(500 \mathrm{MHz}, \mathrm{CDCl}_{3}\right): \delta 7.74(\mathrm{dd}, J=8.5,13.5 \mathrm{~Hz}, 2 \mathrm{H}), 7.54(\mathrm{dd}, J=3.5,8.5$ $\mathrm{Hz}, 2 \mathrm{H}), 4.10(\mathrm{~m}, 4 \mathrm{H}), 1.32$ (t, $J=7.2 \mathrm{~Hz}, 6 \mathrm{H}), 0.25(\mathrm{~s}, 9 \mathrm{H})$.

${ }^{13} \mathrm{C}$ NMR $\left(125 \mathrm{MHz}, \mathrm{CDCl}_{3}\right): \delta 131.8(\mathrm{~d}, J=14.6 \mathrm{~Hz}), 131.5(\mathrm{~d}, J=9.9 \mathrm{~Hz}), 128.2(\mathrm{~d}, J$ $=188.3 \mathrm{~Hz}), 127.3(\mathrm{~d}, J=3.3 \mathrm{~Hz}), 103.8,97.4,62.2(\mathrm{~d}, J=5.3 \mathrm{~Hz}), 16.3(\mathrm{~d}, J=6.7 \mathrm{~Hz})$, -0.2 .

HRMS: m/z (ESI) Calculated for $[\mathrm{M}+\mathrm{H}]^{+}$311.1232, Found 311.1220.<smiles>CCOC(=O)/C=C/c1ccc(P(=O)(OCC)OCC)cc1</smiles>

28j: ${ }^{1} \mathrm{H}$ NMR (400 MHz, $\left.\mathrm{CDCl}_{3}\right): \delta 7.83(\mathrm{dd}, J=8.0,12.8 \mathrm{~Hz}, 2 \mathrm{H}), 7.78(\mathrm{~d}, J=16.0 \mathrm{~Hz}$, $1 \mathrm{H}), 7.60(\mathrm{dd}, J=3.6,8.0 \mathrm{~Hz}, 2 \mathrm{H}), 6.51(\mathrm{~d}, J=16.0 \mathrm{~Hz}, 1 \mathrm{H}), 4.28$ (q, $J=7.2 \mathrm{~Hz}, 2 \mathrm{H})$, $4.13(\mathrm{~m}, 4 \mathrm{H}), 1.35$ (t, $J=7.2 \mathrm{~Hz}, 3 \mathrm{H}), 1.33(\mathrm{t}, J=7.2 \mathrm{~Hz}, 6 \mathrm{H})$.

${ }^{13} \mathrm{C}$ NMR $\left(125 \mathrm{MHz}, \mathrm{CDCl}_{3}\right): \delta 166.5,143.1,138.2(\mathrm{~d}, J=3.3 \mathrm{~Hz}), 132.3(\mathrm{~d}, J=10.0$ $\mathrm{Hz}), 127.8$ (d, $J=15.2 \mathrm{~Hz}), 120.7,130.1$ (d, $J=187.9 \mathrm{~Hz}), 62.3$ (d, $J=5.6 \mathrm{~Hz}), 60.8$, $16.3(\mathrm{~d}, J=6.6 \mathrm{~Hz}), 14.3$.

HRMS: m/z (ESI) Calculated for $[\mathrm{M}+\mathrm{H}]^{+}$313.1205, Found 313.1200. 
<smiles>CCOP(=O)(OCC)c1ccc(/N=N/c2ccccc2C)cc1C</smiles>

(E)-28k: ${ }^{1} \mathrm{H}$ NMR $\left(500 \mathrm{MHz}, \mathrm{CDCl}_{3}\right): \delta 8.07(\mathrm{dd}, J=8.5,13.5 \mathrm{~Hz}, 1 \mathrm{H}), 7.76(\mathrm{~m}, 2 \mathrm{H})$, $7.76(\mathrm{~d}, J=8.0 \mathrm{~Hz}, 1 \mathrm{H}), 7.38(\mathrm{~m}, 2 \mathrm{H}), 7.27(\mathrm{dt}, J=2.0,8.0 \mathrm{~Hz}, 1 \mathrm{H}), 4.16(\mathrm{~m}, 4 \mathrm{H}), 2.74$ $(\mathrm{s}, 3 \mathrm{H}), 2.69(\mathrm{~s}, 3 \mathrm{H}), 1.36(\mathrm{t}, J=6.5 \mathrm{~Hz}, 6 \mathrm{H})$.

${ }^{13} \mathrm{C}$ NMR $\left(125 \mathrm{MHz}, \mathrm{CDCl}_{3}\right): \delta 155.0(\mathrm{~d}, J=4.3 \mathrm{~Hz}), 150.7,143.1,138.7,135.0(\mathrm{~d}, J=$ $13.6 \mathrm{~Hz}), 130.2$ (d, $J=188.6 \mathrm{~Hz}), 131.4,126.4,125.4(\mathrm{~d}, J=19.5 \mathrm{~Hz}), 119.4(\mathrm{~d}, J=19.0$ $\mathrm{Hz}), 115.4,62.0(\mathrm{~d}, J=6.6 \mathrm{~Hz}), 21.3(\mathrm{~d}, J=4.2 \mathrm{~Hz}), 17.6,16.3(\mathrm{~d}, J=7.8 \mathrm{~Hz})$.

HRMS: $\mathrm{m} / \mathrm{z}$ (ESI) Calculated for $[\mathrm{M}+\mathrm{H}]^{+} 347.1525$, Found 347.1510.<smiles>CCOP(=O)(OCC)c1ccc(/N=N\c2ccccc2C)cc1C</smiles>

(Z)- 28k: ${ }^{1} \mathrm{H}$ NMR $\left(500 \mathrm{MHz}, \mathrm{CDCl}_{3}\right): \delta 7.72(\mathrm{dd}, J=8.0,13.5 \mathrm{~Hz}, 1 \mathrm{H}), 7.18(\mathrm{~d}, J=8.0$ $\mathrm{Hz}, 1 \mathrm{H}), 7.06(\mathrm{t}, J=7.5 \mathrm{~Hz}, 1 \mathrm{H}), 6.91(\mathrm{t}, J=8.0 \mathrm{~Hz}, 1 \mathrm{H}), 6.83(\mathrm{dd}, J=1.5,5.0 \mathrm{~Hz}, 1 \mathrm{H})$, $6.54(\mathrm{dt}, J=2.5,7.5 \mathrm{~Hz}, 1 \mathrm{H}), 6.19(\mathrm{~d}, J=8.0 \mathrm{~Hz}, 1 \mathrm{H}), 4.09(\mathrm{~m}, 4 \mathrm{H}), 2.49$ (s, 3H), 2.33 (s, $3 \mathrm{H}), 1.30(\mathrm{t}, J=6.5 \mathrm{~Hz}, 6 \mathrm{H})$.

${ }^{13} \mathrm{C}$ NMR $\left(125 \mathrm{MHz}, \mathrm{CDCl}_{3}\right): \delta 156.5(\mathrm{~d}, J=4.3 \mathrm{~Hz}), 152.8,143.2,141.4,134.3(\mathrm{~d}, J=$ $13.6 \mathrm{~Hz}), 131.1(\mathrm{~d}, J=188.6 \mathrm{~Hz}), 128.2,127.7,125.9,123.1(\mathrm{~d}, J=19.0 \mathrm{~Hz}), 117.1$, $115.8(\mathrm{~d}, J=19.5 \mathrm{~Hz}), 62.0(\mathrm{~d}, J=6.6 \mathrm{~Hz}), 21.2(\mathrm{~d}, J=4.2 \mathrm{~Hz}), 17.5,16.2(\mathrm{~d}, J=7.8 \mathrm{~Hz})$. HRMS: $\mathrm{m} / \mathrm{z}$ (ESI) Calculated for $[\mathrm{M}+\mathrm{H}]^{+} 347.1525$, Found 347.1510. 


\section{Chapter S4. Porous Polymer-Supported Heterogeneous Gold(I) Catalysis}

\section{S4.1 General Methods and materials}

All of the reactions dealing with air and/or moisture-sensitive reactions were carried out under an atmosphere of nitrogen using oven/flame-dried glassware and standard syringe/septa techniques. Unless otherwise noted, all commercial reagents and solvents were obtained from the commercial provider and used without further purification. ${ }^{1} \mathrm{H}$ NMR and ${ }^{13} \mathrm{C}$ NMR spectra were recorded on Varian $600 \mathrm{MHz}$ or Agilent $400 \mathrm{MHz}$ spectrometer. Chemical shifts were reported relative to internal tetramethylsilane $(\delta 0.00$ ppm) or $\mathrm{CDCl}_{3}(\delta 7.26 \mathrm{ppm})$ for ${ }^{1} \mathrm{H} \mathrm{NMR}, \mathrm{CDCl}_{3}(\delta 77.0 \mathrm{ppm})$ for ${ }^{13} \mathrm{C} \mathrm{NMR}$. Flash column chromatography was performed on 230-430 mesh silica gel. Analytical thin layer chromatography was performed with precoated glass baked plates $(250 \mu)$ and visualized by UV lamp. The X-ray photoelectron spectroscopy (XPS, Physical Electronics VersaProbe 5000) measurements were conducted with Al Ka radiation $(1486.71 \mathrm{eV})$, the binding energy scale was calibrated by a C 1s peak at $284.8 \mathrm{eV}$.

The yields of hydration reactions and hydroamination reactions were obtained by Gas Chromatography (Agilent 7890B GC) using bromobenzene as the internal standard. The yields of other reactions were calculated from NMR data using p-xylene as the internal standard.

\section{Procedure for the preparation of the solid support ligand Pol-PPh}

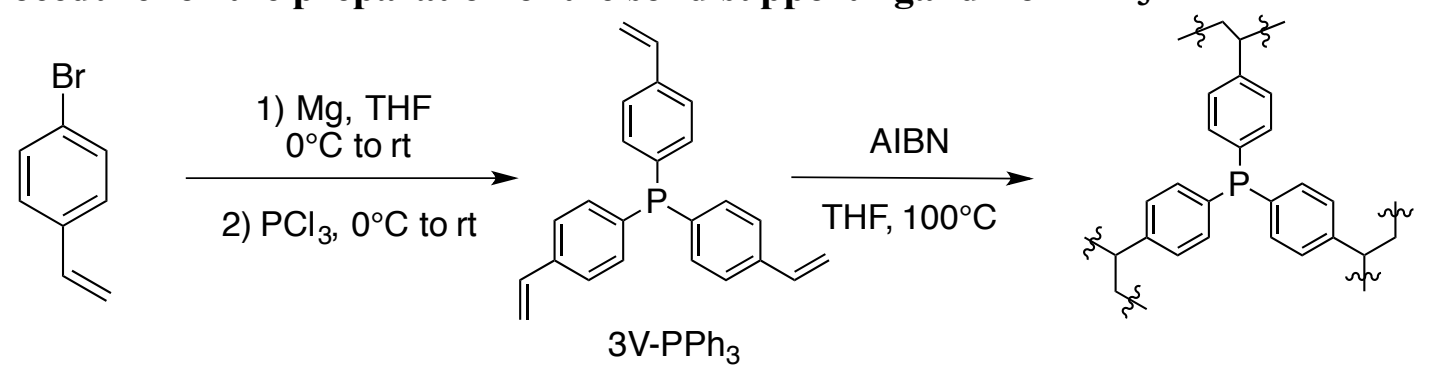

Prior to reaction, 4-bromo-vinylbenzene was purified by vacuum distillation to give a colorless liquid. In a flame-dried $500 \mathrm{~mL}$ round-bottom flask, $3 \mathrm{~g} \mathrm{Mg}$ was dried under vacuum with a heat gun. After the addition of $200 \mathrm{~mL}$ anhydrous THF, $0.5 \mathrm{~mL} \mathrm{1,2-}$ dibromoethane was added to initiate the Grignard reaction. After the solution is cooled down, $18.31 \mathrm{~g}$ 4-bromo-vinylbenzene was added slowly at $0{ }^{\circ} \mathrm{C}$ and stirred for $3 \mathrm{~h}$ at room temperature. This solution was cooled in an ice bath and a solution of $3.66 \mathrm{~g} \mathrm{PCl}_{3}$ in $20 \mathrm{~mL}$ THF was added over $2 \mathrm{~h}$ via a syringe pump. After stirring for another $2 \mathrm{~h}$ at $\mathrm{rt}$, $50 \mathrm{~mL}$ of saturated $\mathrm{NH}_{4} \mathrm{Cl}$ aqueous solution was added to quench the reaction. The organic layer was separated and the aqueous layer was extracted with hexanes. The combined organic layer was dried with $\mathrm{MgSO}_{4}$ and filtered through a short silica column. The solvent was removed under reduced pressure. After recrystallization from $\mathrm{MeOH}$, $7.93 \mathrm{~g}$ trivinyl-functionalized $\mathrm{PPh}_{3}\left(3 \mathrm{~V}-\mathrm{PPh}_{3}\right)$ was obtained as a white solid (88\% yield).

Pol- $\mathrm{PPh}_{3}$ was synthesized from polymerization of $3 \mathrm{~V}-\mathrm{PPh}_{3}$ under solvothermal conditions. Generally, $1.0 \mathrm{~g}$ of $3 \mathrm{~V}-\mathrm{PPh}_{3}$ was dissolved in $10 \mathrm{~mL}$ of THF, followed by the addition of $20 \mathrm{mg}$ of azobisisobutyronitrile (AIBN). This clear solution was transferred 
into an autoclave at $100{ }^{\circ} \mathrm{C}$ for $12 \mathrm{~h}$. After evaporation of THF under vacuum, the white solid was DCM and acetone and dried under vacuum at $80^{\circ} \mathrm{C}$ over night.

\section{Procedure for the preparation of the heterogeneous gold catalyst Pol-TA-Au}

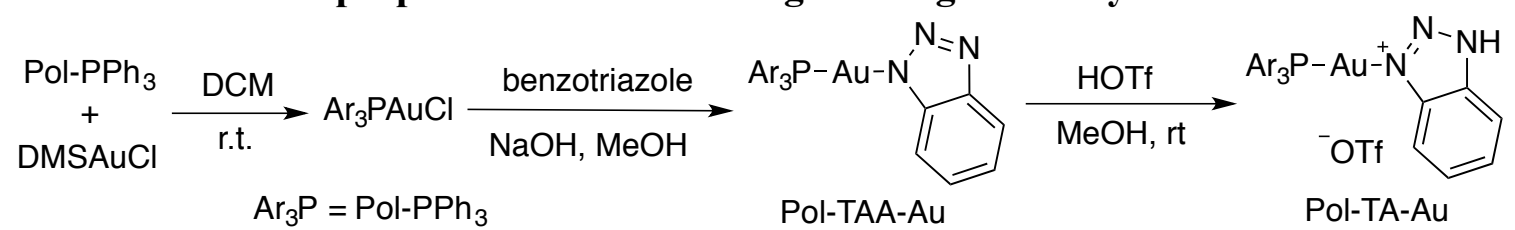

Dimethyl sulfide gold chloride (DMSAuCl, $173 \mathrm{mg}$ ) was dissolved in $50 \mathrm{~mL}$ methylene chloride (DCM). To this solution, $1 \mathrm{~g} \mathrm{Pol}-\mathrm{PPh}_{3}$ (mol ratio of $\mathrm{P}: \mathrm{Au}=5: 1$ ) was added and stirred for $10 \mathrm{~h}$. The solid was isolated by vacuum filtration and washed with DCM. After drying under vacuum, the solid was dispersed in $50 \mathrm{~mL}$ methanol. To this mixture was added a solution of $140 \mathrm{mg}$ benzotriazole (2 eq. based on the mol of $\mathrm{Au}$ ) and $47 \mathrm{mg}$ $\mathrm{NaOH}$ ( 2 eq. based on the mol of $\mathrm{Au}$ ). After stirring for $12 \mathrm{~h}$, Pol-TAA-Au was isolated by vacuum filtration and washed with methanol, water and acetone. To a suspension of Pol-TAA-Au in $50 \mathrm{~mL} \mathrm{MeOH}$, a $0.5 \mathrm{M}$ HOTf in methanol solution (2.3 mL, 2 eq. based on the mol of $\mathrm{Au}$ ) was added. After stirring for $12 \mathrm{~h}$, the Pol-TA-Au catalyst was isolated by vacuum filtration, washed with methanol and dried under vacuum.

\section{Procedure for Pol-TA-Au catalyzed hydration reactions}
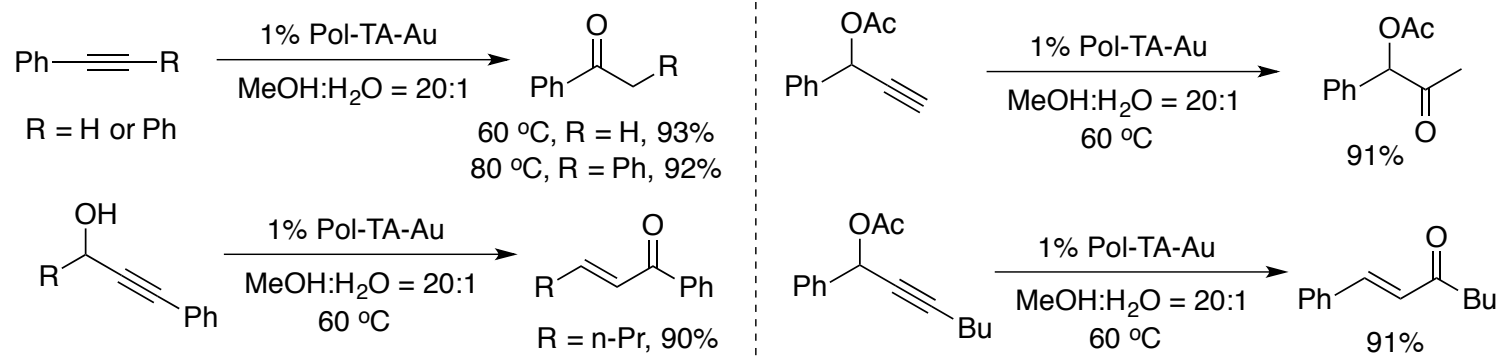

The starting alkynes $(0.2 \mathrm{mmol})$ are dissolved in $0.4 \mathrm{~mL}$ methanol (with $5 \%$ water) in a 2-mL centrifuge tube. To this solution, $8 \mathrm{mg}$ of the Pol-TA-Au catalyst was added (1 mol\%). The mixture was stirred at $60{ }^{\circ} \mathrm{C}\left(80^{\circ} \mathrm{C}\right.$ for internal alkynes $)$ and checked with $\mathrm{GC}$ for completion. After reaction was completed, the products were isolated by centrifuge. The heterogeneous catalyst (precipitated in the bottom of the vial) was treated with 2 eq. of $0.1 \mathrm{M} \mathrm{HOTf} / \mathrm{MeOH}$ solution for 10 mins and washed with $\mathrm{MeOH}$ three times. The same catalyst could be reused for the next batch of starting material without loss of reactivity.

\section{Procedure for Pol-TA-Au catalyzed hydroamination reaction}

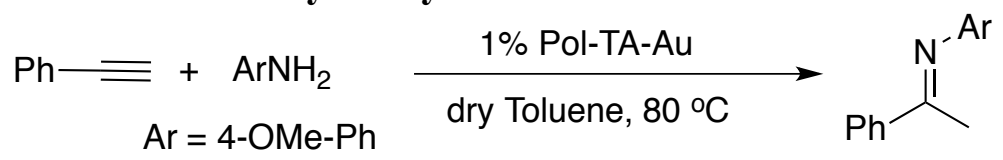

The aniline $(0.2 \mathrm{mmol})$ was dissolved in $0.4 \mathrm{~mL}$ dry Toluene in a $2-\mathrm{mL}$ centrifuge tube. To this solution was added $0.4 \mathrm{mmol}$ alkyne, $8 \mathrm{mg}$ Pol-TA-Au ( $1 \mathrm{~mol} \%)$, and $1.5 \mathrm{mg}$ 
$\mathrm{Zn}(\mathrm{OTf})_{2}(2 \mathrm{~mol} \%)$. This mixture was heated at $80{ }^{\circ} \mathrm{C}$ and checked with $\mathrm{GC}$ for completion. After reaction was completed, the products were isolated by centrifuge. The heterogeneous catalyst (precipitated in the bottom of the vial) was washed with toluene three times. The same catalyst could be reused for the next batch of starting material.

The other reactions were performed using previously reported methods:

1. Allene synthesis: Wang, D.; Zhang, Y.; Harris, A.; Gautam, L. N. S.; Chen, Y.; Shi, X. Adv. Synth. Catal. 2011, 353, 2584.

2. Nakamura reaction: Xi, Y.; Wang, D.; Ye, X.; Akhmedov, N. G.; Petersen, J. L.; Shi, X. Org. Lett. 2013, 16, 306.

3. Vinyl sulfone synthesis: Xi, Y.; Dong, B.; McClain, E. J.; Wang, Q.; Gregg, T. L.; Akhmedov, N. G.; Petersen, J. L.; Shi, X. Angew. Chem. Int. Ed. 2014, 53, 4657.

\section{S4.2 XPS analysis}

\section{$\mathrm{Pol}_{-\mathrm{PPh}}$}
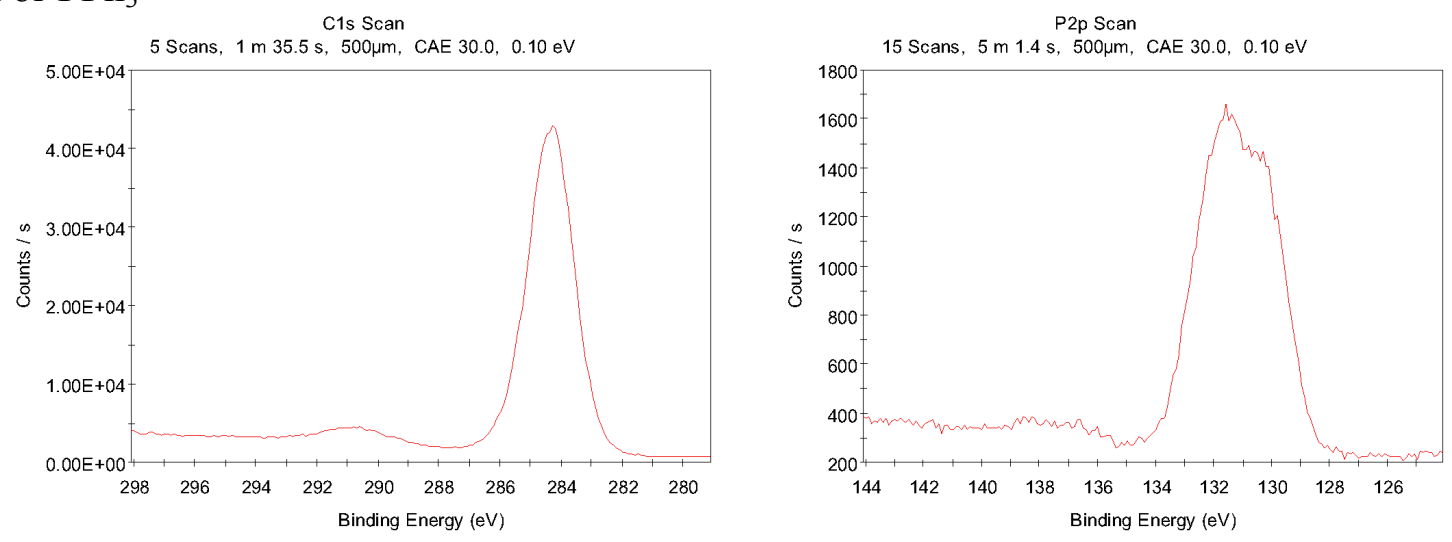

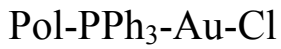
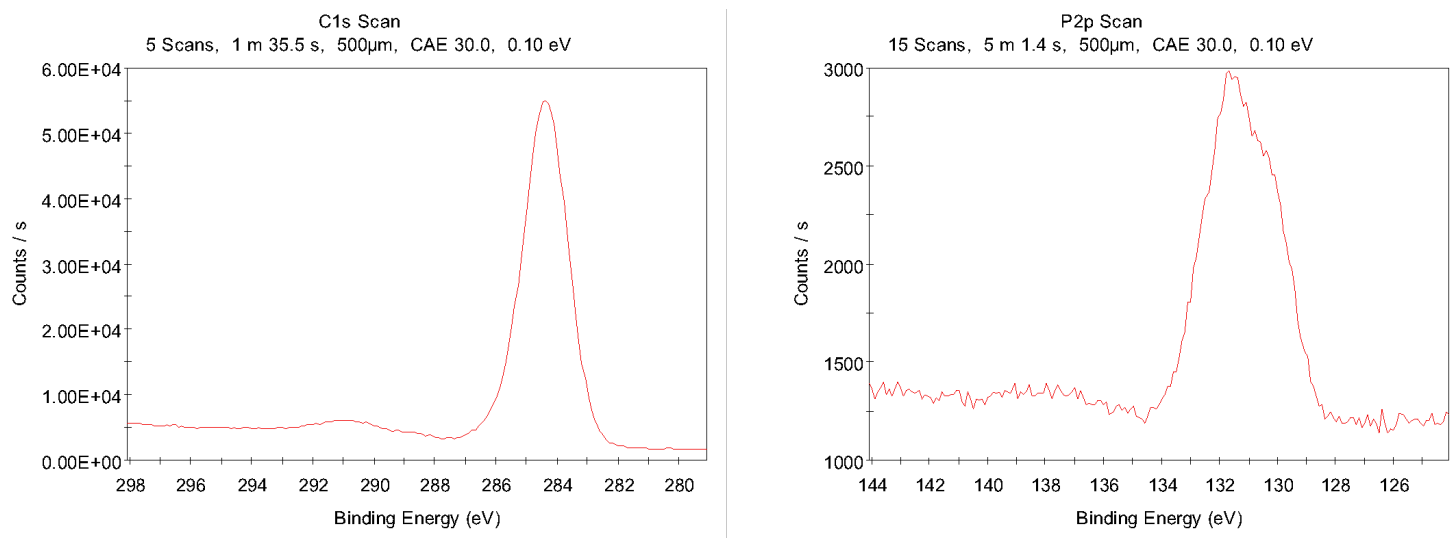

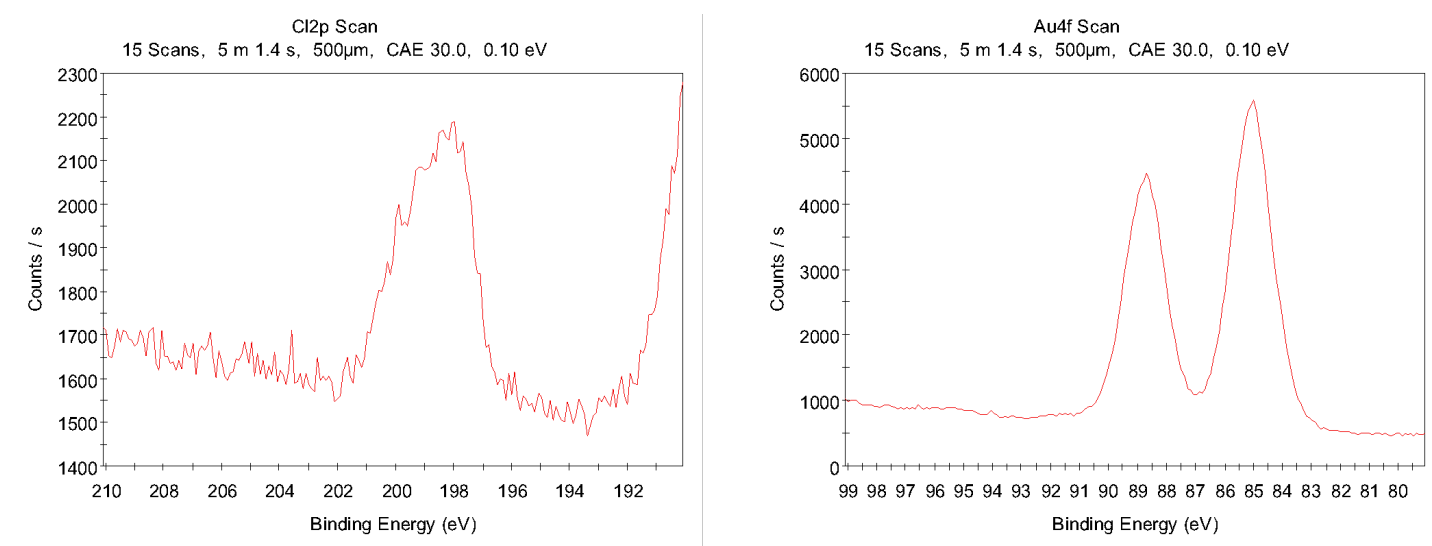

\section{$\mathrm{Pol}^{-\mathrm{PPh}_{3}-\mathrm{Au}-\mathrm{TA}}$}
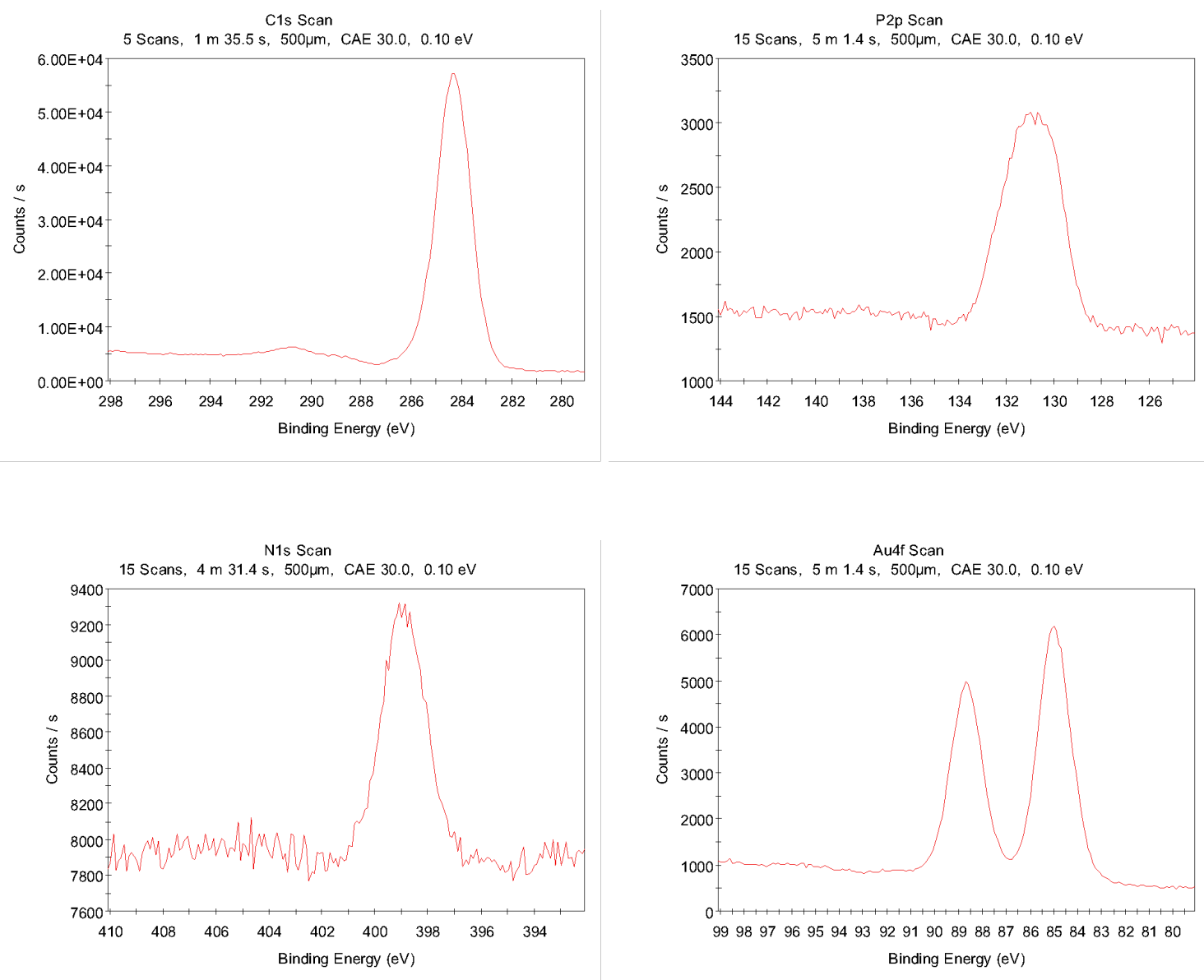


\section{Pol-PPh 3 -Au-(TA-H)OTf}
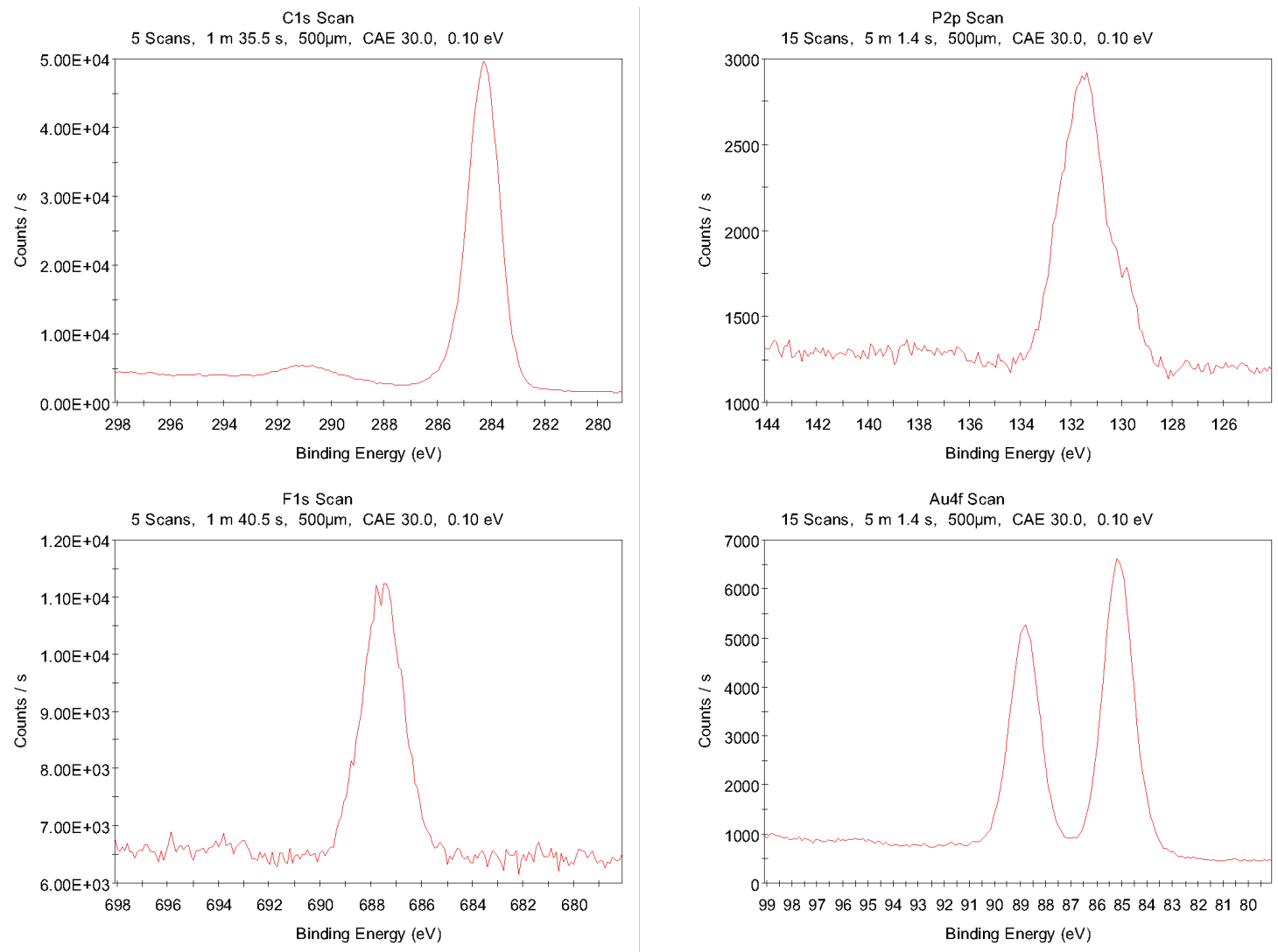

\section{S4.3 Compounds Characterization}

The following substrates are same as some substrates in S2.2. Other substrates have been reported previously.<smiles>CC(=O)OC(C(C)=O)c1ccccc1</smiles>

2-oxo-1-phenylpropyl acetate (9a): 96\% yield, ${ }^{1} \mathrm{H}$ NMR $\left(600 \mathrm{MHz}, \mathrm{CDCl}_{3}\right): \delta$ 7.38$7.42(\mathrm{~m}, 5 \mathrm{H}), 5.98(\mathrm{~s}, 1 \mathrm{H}), 2.19(\mathrm{~s}, 3 \mathrm{H}), 2.11(\mathrm{~s}, 3 \mathrm{H}) ;{ }^{13} \mathrm{C} \mathrm{NMR}\left(150 \mathrm{MHz}, \mathrm{CDCl}_{3}\right): \delta$ 201.6, 170.2, 133.2, 129.3, 129.0, 128.0, 80.9, 26.1, 20.7.<smiles>O=C(Cc1ccccc1)c1ccccc1</smiles>

1,2-diphenylethanone (11a): ${ }^{1} \mathrm{H}$ NMR $\left(600 \mathrm{MHz}, \mathrm{CDCl}_{3}\right): \delta 8.00-8.02(\mathrm{~m}, 2 \mathrm{H}), 7.53-$ $7.56(\mathrm{~m}, 1 \mathrm{H}), 7.45(\mathrm{~d}, J=7.8 \mathrm{~Hz}, 2 \mathrm{H}), 7.32(\mathrm{~d}, J=7.5 \mathrm{~Hz}, 2 \mathrm{H}), 7.24-7.27(\mathrm{~m}, 3 \mathrm{H}), 4.28$ (s, 2H). ${ }^{13} \mathrm{C}$ NMR $\left(150 \mathrm{MHz}, \mathrm{CDCl}_{3}\right): \delta 197.6,136.6,134.5,133.1,129.4,128.6,128.6$, $128.5,126.9,45.5$. 
<smiles>C1=C(c2ccccc2)CC2CC12</smiles>

3-phenylbicyclo[3.1.0]hex-2-ene (Scheme 13D): (See: Luzung, M.R.; Markham, J.P.; Toste, F.D. J. Am. Chem. Soc. 2004, 126, 10858-10859.) ${ }^{1} \mathrm{H}$ NMR $\left(600 \mathrm{MHz}, \mathrm{CDCl}_{3}\right): \delta$ $7.38(\mathrm{~d}, J=7.8 \mathrm{~Hz}, 2 \mathrm{H}), 7.30(\mathrm{t}, J=7.8 \mathrm{~Hz}, 2 \mathrm{H}), 7.21(\mathrm{t}, J=7.8 \mathrm{~Hz}, 1 \mathrm{H}), 6.42$ (d, $J=1.8$ $\mathrm{Hz}, 1 \mathrm{H}), 3.02$ (dd, $J=16.8,7.2 \mathrm{~Hz}, 1 \mathrm{H}), 2.75$ (d, $J=16.8 \mathrm{~Hz}, 1 \mathrm{H}), 1.98-1.94(\mathrm{~m}, 1 \mathrm{H})$, 1.76-1.72 (m, 1H), 0.97-0.93 (m, 1H), 0.11-0.09 (m, 1H). $\left.{ }^{13} \mathrm{C} \mathrm{NMR} \mathrm{(150} \mathrm{MHz,} \mathrm{CDCl}_{3}\right): \delta$ $139.7,136.6,129.6,128.2,126.7,125.1,36.3,24.1,17.6,15.4$.<smiles>O=C(Br)C=Cc1ccccc1</smiles>

(E)-1-phenylhept-1-en-3-one (Scheme 14A): (known compound, See: Wang, D.; Zhang, Y.; Harris, A.; Gautam, L. N. S.; Shi, X. Adv. Syn. Cat. 2011, 353, 2584-2588.) ${ }^{1} \mathrm{H}$ NMR $\left(600 \mathrm{MHz}, \mathrm{CDCl}_{3}\right): \delta 7.53-7.56(\mathrm{~m}, 3 \mathrm{H}), 7.38-7.40(\mathrm{~m}, 3 \mathrm{H}), 6.73(\mathrm{t}, J=16.2 \mathrm{~Hz}, 1 \mathrm{H})$, $2.66(\mathrm{t}, J=7.5 \mathrm{~Hz}, 2 \mathrm{H}$ ), 1.66 (quintet, $J=7.5 \mathrm{~Hz}, 2 \mathrm{H}$ ), 1.37 (sextet, $J=7.4 \mathrm{~Hz}, 2 \mathrm{H}$ ), 0.94 $(\mathrm{t}, J=7.5 \mathrm{~Hz}, 3 \mathrm{H}) ;{ }^{13} \mathrm{C} \mathrm{NMR}\left(150 \mathrm{MHz}, \mathrm{CDCl}_{3}\right): \delta 200.8,142.5,134.8,130.6,129.1$, 128.4, 126.5, 40.9, 26.7, 22.7, 14.1. 


\section{Chapter S5. N-2-Aryl-1,2,3-Triazole as ligand for Iridium Photocatalyst}

\section{S5.1 General Methods and materials}

All of the reactions dealing with air and/or moisture-sensitive reactions were carried out under an atmosphere of nitrogen using oven/flame-dried glassware and standard syringe/septa techniques. Unless otherwise noted, all commercial reagents and solvents were obtained from the commercial provider and used without further purification. ${ }^{1} \mathrm{H}$ NMR and ${ }^{13} \mathrm{C}$ NMR spectra were recorded on Varian $600 \mathrm{MHz}$ or Agilent $400 \mathrm{MHz}$ spectrometer. Chemical shifts were reported relative to internal tetramethylsilane $(\delta 0.00$ ppm) or $\mathrm{CD}_{3} \mathrm{CN}$ ( $\left.\delta 1.94 \mathrm{ppm}\right)$ for ${ }^{1} \mathrm{H}$ NMR and $\mathrm{CD}_{3} \mathrm{CN}(\delta 1.39 \mathrm{ppm})$ for ${ }^{13} \mathrm{C} \mathrm{NMR}$. Flash column chromatography was performed on 230-430 mesh silica gel. Analytical thin layer chromatography was performed with precoated glass baked plates $(250 \mu)$ and visualized by UV lamp. ESI-MS were recorded on Thermo Scientific Q-exactive spectrometer.

The UV-Vis spectra were obtained with a Shimadzu UV-1800 UV spectrophotometer in $10 \mathrm{~mm}$ path length quartz cuvettes with $1 \times 10^{-5} \mathrm{M}$ Iridium complex solutions in freshly distilled acetonitrile $(\mathrm{ACN})$. The fluorescence spectra were obtained in $10 \mathrm{~mm}$ path length quartz cuvettes using Shimadzu RF-5301 PC spectrofluorophotometer with $1 \times 10^{-}$ ${ }^{5} \mathrm{M}$ Iridium complex solutions in $\mathrm{ACN}$.

The fluorescence quantum yields of iridium complexes $\left(\Phi_{\mathrm{x}}\right)$ were calculated based on equation (1) using $\mathrm{Ru}(\mathrm{bpy})_{3}\left(\mathrm{PF}_{6}\right)_{2}$ in $\mathrm{ACN}(\Phi=0.094)^{21}$ as a standard. All the samples were tested with $1 \times 10^{-5} \mathrm{M}$ ACN solutions under argon protection.

$$
\Phi_{x}=\frac{n_{x}^{2}}{n_{s t d}^{2}} \cdot \frac{1-10^{-A b s_{s d d}}}{1-10^{-A b s_{x}}} \cdot \frac{I_{x}}{I_{s t d}} \cdot \Phi_{s t d}
$$

$\mathbf{\Phi}$ is the quantum yield, $\mathbf{I}$ is integrated emission intensity, $\mathbf{A b s}$ is the absorption at the excitation wavelength $(370 \mathrm{~nm})$, and $\mathbf{n}$ is the refractive index of pure solvents $\left(\mathrm{n}_{\mathrm{x}}=\mathrm{n}_{\text {std }}\right.$ in this case); 'std' stands for reference standard samples, ' $x$ ' stands for samples.

The excited-state lifetime were measured on a Horiba Fluorolog-3 spectrofluorometer with a NanoLED-370nm as the light source. The samples were prepared in ACN $\left(1 \times 10^{-}\right.$ ${ }^{5} \mathrm{M}$ solutions) and tested in $10 \mathrm{~mm}$ path length quartz cuvettes. A highly diluted colloidal silica solution ( $0.01 \%$ dilution of LUDOX AS- 40 colloidal silica using deionized water) was used to get the prompt spectra. All samples were tested under same conditions.

The cyclic voltammetry measurements were conducted on a WaveNow USB potentiostat in a three-compartment cell at $0.1 \mathrm{~V} / \mathrm{s}$ scan rate using $1 \mathrm{mM}$ Iridium complex solutions in freshly distilled acetonitrile with $0.1 \mathrm{M}$ tetrabutylammonium hexafluorophosphate as the

\footnotetext{
${ }^{21}$ J. M. Calvert, J. V. Caspar, R. A. Binstead, T. D. Westmoreland and T. J. Meyer, J. Am. Chem. Soc., 1982, 104, 6620-6627.
} 
supporting electrolyte. ${ }^{22}$ A platinum wire was used as the working electrode and a folded platinum plate was used as the counter electrode. A silver wire was used as the quasireference electrode. Potentials were calibrated using $\mathrm{Fc}^{+} / \mathrm{Fc}$ redox couple $(0.40 \mathrm{~V}$ in ACN) after each experiment and reported vs. SCE.

The N-2-aryl triazoles were synthesized according to the literature reported previously ${ }^{23}$. The photocatalytic reactions were performed under same conditions as previous literature reports. $^{24}$

\section{General procedure for the preparation of $\left[(p \operatorname{ta})_{2} \operatorname{Ir}(\mu-C l)\right]_{2}$ :}

$$
\mathrm{IrCl}_{3} \cdot \mathrm{xH}_{2} \mathrm{O}+\mathrm{Ar}_{140^{\circ} \mathrm{C}, \mathrm{N}_{2}}^{\text {2-ethoxyethanol }}
$$

The preparation $\left[(\text { pta })_{2} \operatorname{Ir}(\mu-\mathrm{Cl})\right]_{2}$ is adapted from literature report. ${ }^{25}$ The pta ligand 30 (2.5 mmol), $\mathrm{IrCl}_{3} \cdot \mathrm{xH}_{2} \mathrm{O}(353 \mathrm{mg}, 1 \mathrm{mmol})$ in $32 \mathrm{~mL}$ 2-ethoxyethanol/water (3:1) was refluxed at $140{ }^{\circ} \mathrm{C}$ under nitrogen or argon atmosphere for $24 \mathrm{~h}$. After cooled to room temperature, the yellow precipitate was isolated by filtration and washed with water and ethanol and allowed to air dry. The yellow solid was used for the next step without further purification. Yields of the $\mu$-dichloro-bridged iridium(III) dimer 31 are ranged from $53 \%$ to $95 \%$ (31a: $63 \%$, 31b: $92 \%$, 31c: $53 \%$, 31d: $78 \%$, 31e: $87 \%$, 31f: $89 \%$, 31g: $95 \%)$.

\section{Procedure for the preparation of $\mathrm{N}-1 \mathrm{~b}$ :}<smiles>CI(C)(C)(C)[n+]1cc(-c2ccccc2)nn1-c1ccc(F)cc1Cl</smiles><smiles>NC(=O)c1ccccn1</smiles>

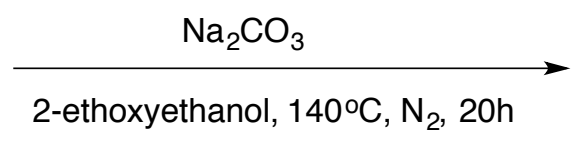

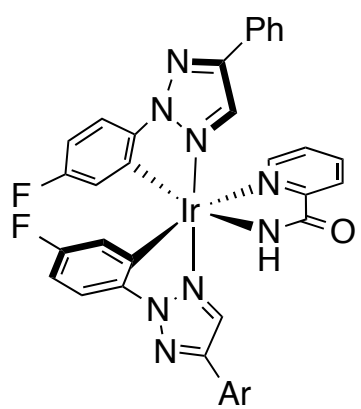

The procedure is adapted from literature report ${ }^{26}$. The $\mu$-dichloro-bridged iridium(III) dimer $31 \mathrm{~b}$ (424 mg, $0.3 \mathrm{mmol}$ ), sodium carbonate $\left(350 \mathrm{mg}, 3.3 \mathrm{mmol}\right.$ ) and the $\mathrm{N}^{\wedge} \mathrm{N}$

\footnotetext{
${ }^{22}$ K. N. Swanick, S. Ladouceur, E. Zysman-Colman and Z. Ding, Chem. Commun., 2012, 48, 3179.

23 a) Liu, Y.; Yan, W.; Chen, Y.; Petersen, J. L. ; Shi, X. Org. Lett. 2008, 10, 5389-5392. b) Yan, W.; Wang, Q.; Lin, Q.; Li, M.; Petersen, J. L. ; Shi, X. Chem. Eur. J. 2011, 17, 5011-5018.

${ }^{24}$ a) A. G. Condie, J. C. González-Gómez and C. R. J. Stephenson, J. Am. Chem. Soc., 2010, 132, 14641465; b) J. D. Nguyen, E. M. D’Amato, J. M. R. Narayanam and C. R. J. Stephenson, Nat. Chem., 2012, 4, 854-859.

${ }^{25}$ Fernández-Hernández, J. M.; Yang, C. H.; Beltrán, J. I.; Lemaur, V.; Polo, F.; Fröhlich, R.; et al and De Cola, L. J. Am. Chem. Soc. 2011, 133, 10543-10558.

${ }^{26}$ You, Y. ; Park, S. Y. J. Am. Chem. Soc. 2005, 127, 12438-12439.
} 
ligand 2-picolinamide (96 mg, $0.78 \mathrm{mmol}$ ) was suspended in $22 \mathrm{~mL}$ 2-ethoxyethanol. The reaction mixture was stirred at $140{ }^{\circ} \mathrm{C}$ for $20 \mathrm{~h}$ under nitrogen atmosphere. After the reaction was cooled to room temperature, $150 \mathrm{~mL}$ ethyl acetate was added. The solution was extracted with water three times. The organic layer was dried over $\mathrm{Na}_{2} \mathrm{SO}_{4}$ and concentrated under reduced pressure. The solid was then purified by flash chromatography on silica gel using ethyl acetate and recrystallized from ether / hexane to yield $\mathbf{N}-\mathbf{1 b}$ in $75 \%$ yield.

\section{General procedure for the preparation of $\left[(p t a)_{2} \operatorname{Ir}\left(p_{p y}\right)\right] \mathrm{PF}_{6}{ }^{27}$ :}<smiles></smiles><smiles>c1ccc(-c2ccccn2)nc1</smiles>

1) 1,2-ethanediol, $120^{\circ} \mathrm{C}, \mathrm{N}_{2}, 20 \mathrm{~h}$ 2) $\mathrm{NH}_{4} \mathrm{PF}_{6}$

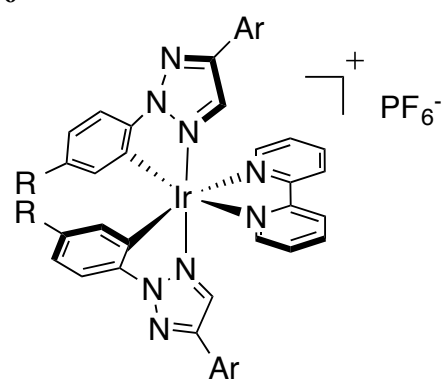

The $\mu$-dichloro-bridged iridium(III) dimer $31(0.15 \mathrm{mmol})$ and the $\mathrm{N}^{\wedge} \mathrm{N}$ ligand 2,2'bispyridine ( $58 \mathrm{mg}, 0.375 \mathrm{mmol}$ ) was suspended in $10 \mathrm{~mL} \mathrm{1,2-ethanediol.} \mathrm{The} \mathrm{reaction}$ mixture was stirred at $120{ }^{\circ} \mathrm{C}$ for $20 \mathrm{~h}$ under nitrogen or argon atmosphere. After the reaction was cooled to room temperature, $150 \mathrm{~mL}$ distilled water was added. The solution was extracted with ethyl ether three times to remove the excess bpy. Ammonium hexafluorophosphate solution $(1 \mathrm{~g}$ in $10 \mathrm{~mL}$ water $)$ was added to the aqueous layer to yield a yellow precipitate. The solution was then heated at $70{ }^{\circ} \mathrm{C}$ for $10 \mathrm{~min}$. After cooled to room temperature, the yellow precipitate was filtrated and further purified by flash chromatography on silica gel using 10\% DCM / acetone eluent. After the column, the solid was re-dissolved in minimum amount of methanol and precipitated again using $\mathrm{NH}_{4} \mathrm{PF}_{6}(1 \mathrm{~g}$ in $10 \mathrm{~mL}$ water). The yellow precipitate was filtered and washed with water and then recrystallized from minimum amount of hot acetonitrile for further experiments.

\section{General procedure for the preparation of $\left[(p \operatorname{ta})_{2} \operatorname{Ir}(\operatorname{tapy})\right] \mathrm{PF}_{6}$ :}
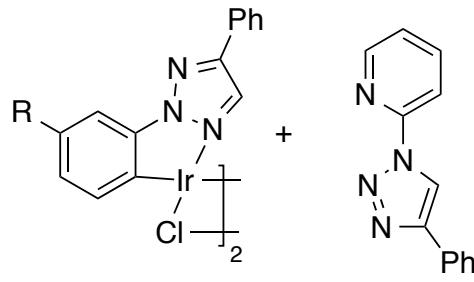

1) 1,2-ethanediol, $120^{\circ} \mathrm{C}, \mathrm{N}_{2}, 20 \mathrm{~h}$

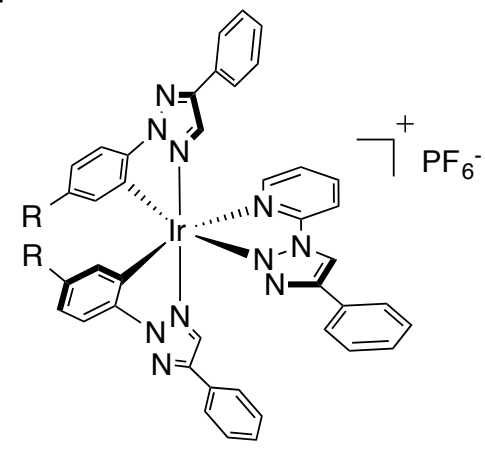

The $\mu$-dichloro-bridged iridium(III) dimer $31(0.15 \mathrm{mmol})$ and the $\mathrm{N}^{\wedge} \mathrm{N}$ ligand tapy (83

${ }^{27}$ Ladouceur, S.; Fortin, D. ; Zysman-Colman, E. Inorg. Chem. 2011, 50, 11514-11526. 
$\mathrm{mg}, 0.375 \mathrm{mmol}$ ) was suspended in $10 \mathrm{~mL} \mathrm{1,2-ethanediol.} \mathrm{The} \mathrm{reaction} \mathrm{mixture} \mathrm{was}$ stirred at $120{ }^{\circ} \mathrm{C}$ for $20 \mathrm{~h}$ under nitrogen or argon atmosphere. After the reaction was cooled to room temperature, $150 \mathrm{~mL}$ distilled water was added, followed by ammonium hexafluorophosphate solution ( $1 \mathrm{~g}$ in $10 \mathrm{~mL}$ water) to yield a yellow precipitate. The precipitate was filtered and further purified by flash chromatography on silica gel using $10 \%$ acetone/DCM eluent. After the column, the solid was re-dissolved in minimum amount of methanol and precipitated again using $\mathrm{NH}_{4} \mathrm{PF}_{6}(1 \mathrm{~g}$ in $10 \mathrm{~mL}$ water $)$. The precipitate was filtered and washed with water and then recrystallized from minimum amount of hot acetonitrile for further experiments.

\section{S5.2 Compounds characterization}

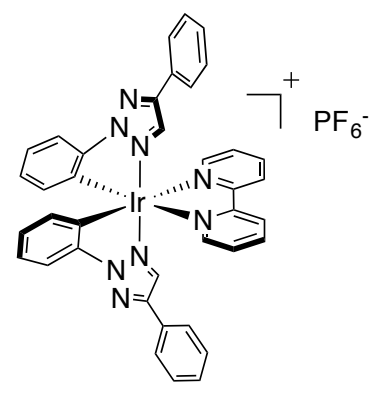

C-1a: Yellow Solid (79\% yield). ${ }^{1} \mathrm{H}$ NMR (400 MHz, $\left.\mathrm{CD}_{3} \mathrm{CN}\right): \delta 8.58(\mathrm{~d}, J=8.2 \mathrm{~Hz}$, $2 \mathrm{H}), 8.22-8.16(\mathrm{~m}, 4 \mathrm{H}), 7.88(\mathrm{dd}, J=8.1,1.5 \mathrm{~Hz}, 4 \mathrm{H}), 7.84(\mathrm{~s}, 2 \mathrm{H}), 7.80(\mathrm{dd}, J=8.0,1.2$ $\mathrm{Hz}, 2 \mathrm{H}), 7.57$ (ddd, $J=7.6,5.5,1.1 \mathrm{~Hz}, 2 \mathrm{H}), 7.51-7.45(\mathrm{~m}, 6 \mathrm{H}), 7.19(\mathrm{td}, J=7.7,1.1 \mathrm{~Hz}$, $2 \mathrm{H}), 7.00(\mathrm{td}, J=7.5,1.3 \mathrm{~Hz}, 2 \mathrm{H}), 6.52(\mathrm{dd}, J=7.5,1.2 \mathrm{~Hz}, 2 \mathrm{H}) ;{ }^{13} \mathrm{C}$ NMR $(100 \mathrm{MHz}$, $\left.\mathrm{CD}_{3} \mathrm{CN}\right): \delta 157.57,152.88,150.26,142.34,141.07,133.72,132.51,130.81,130.64$, $130.26,129.65,129.57,129.44,127.01,125.64,125.24,115.46$. ESI-MS calculated for $\left[\mathrm{C}_{38} \mathrm{H}_{28} \mathrm{IrN}_{8}\right]^{+}:$789.2066, found: 789.2047.

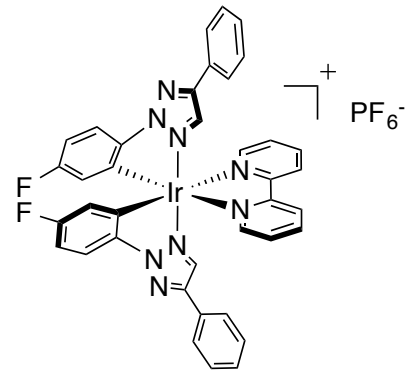

C-1b: Yellow Solid (85\% yield). ${ }^{1} \mathrm{H}$ NMR (400 MHz, $\left.\mathrm{CD}_{3} \mathrm{CN}\right): \delta 8.57(\mathrm{~d}, J=8.2 \mathrm{~Hz}$, $2 \mathrm{H}), 8.24-8.18(\mathrm{~m}, 4 \mathrm{H}), 7.88-7.83(\mathrm{~m}, 6 \mathrm{H}), 7.80(\mathrm{~s}, 2 \mathrm{H}), 7.59$ (ddd, $J=7.6,5.5,1.3 \mathrm{~Hz}$, 2H), 7.51-7.43 (m, 6H), $6.98(\mathrm{td}, J=8.8,2.6 \mathrm{~Hz}, 2 \mathrm{H}), 6.22(\mathrm{dd}, J=8.8,2.6 \mathrm{~Hz}, 2 \mathrm{H}) ;{ }^{13} \mathrm{C}$ NMR (100 MHz, $\left.\mathrm{CD}_{3} \mathrm{CN}\right): \delta 163.01(\mathrm{~d}, J=248.1 \mathrm{~Hz}), 157.48,153.12,150.33,141.32$, $138.90,133.39$ (d, $J=6.0 \mathrm{~Hz}), 132.66,130.86,130.25,129.55,129.48,127.05,125.71$, $120.13(\mathrm{~d}, J=20.4 \mathrm{~Hz}), 117.23(\mathrm{~d}, J=9.2 \mathrm{~Hz}), 112.05(\mathrm{~d}, J=14.6 \mathrm{~Hz}) ;{ }^{19} \mathrm{~F}$ NMR $(376$ $\left.\mathrm{MHz}, \mathrm{CD}_{3} \mathrm{CN}\right): \delta-73.84(\mathrm{~d}, J=706.8 \mathrm{~Hz}, 6 \mathrm{~F}),-114.80(\mathrm{~m}, 2 \mathrm{~F})$. ESI-MS calculated for $\left[\mathrm{C}_{38} \mathrm{H}_{26} \mathrm{~F}_{2} \mathrm{IrN}_{8}\right]^{+}:$825.1878, found: 825.1861. 


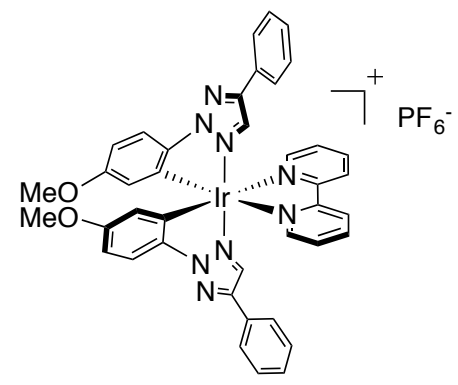

C-1c: Yellow Solid (68\% yield). ${ }^{1} \mathrm{H}$ NMR $\left(400 \mathrm{MHz}, \mathrm{CD}_{3} \mathrm{CN}\right): \delta 8.55(\mathrm{~d}, J=8.2 \mathrm{~Hz}$, $2 \mathrm{H}), 8.23-8.18(\mathrm{~m}, 4 \mathrm{H}), 7.85(\mathrm{dd}, J=8.1,1.6 \mathrm{~Hz}, 4 \mathrm{H}), 7.75(\mathrm{~d}, J=9.1 \mathrm{~Hz}, 2 \mathrm{H}), 7.74(\mathrm{~s}$, $2 \mathrm{H}), 7.58(\mathrm{ddd}, J=7.7,5.5,1.2 \mathrm{~Hz}, 2 \mathrm{H}), 7.50-7.41(\mathrm{~m}, 6 \mathrm{H}), 6.77(\mathrm{dd}, J=8.8,2.6 \mathrm{~Hz}$, $2 \mathrm{H}), 5.91(\mathrm{~d}, J=2.6 \mathrm{~Hz}, 2 \mathrm{H}), 3.63(\mathrm{~s}, 6 \mathrm{H}) ;{ }^{13} \mathrm{C} \mathrm{NMR}\left(100 \mathrm{MHz}, \mathrm{CD}_{3} \mathrm{CN}\right): \delta 160.70$, 157.54, 153.00, 149.67, 141.05, 136.24, 132.81, 131.68, 130.66, 130.24, 129.67, 129.42, 126.91, 125.56, 118.95, 116.72, 109.51, 55.96. ESI-MS calculated for $\left[\mathrm{C}_{40} \mathrm{H}_{32} \mathrm{IrN}_{8} \mathrm{O}_{2}\right]^{+}$: 849.2277, found: 849.2262.

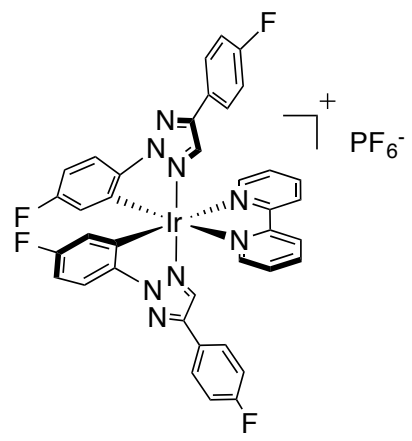

C-1d: Synthesized from one-Pot sequential reactions without isolating the $\mu$-dichlorobridged iridium(III) dimer. Yellow Solid (62\% yield over two steps). ${ }^{1} \mathrm{H}$ NMR (400 $\left.\mathrm{MHz}, \mathrm{CD}_{3} \mathrm{CN}\right): \delta 8.56(\mathrm{~d}, J=8.1 \mathrm{~Hz}, 2 \mathrm{H}), 8.24-8.17(\mathrm{~m}, 4 \mathrm{H}), 7.91-7.86(\mathrm{~m}, 4 \mathrm{H}), 7.84$ (dd, $J=8.8,4.8 \mathrm{~Hz}, 2 \mathrm{H}), 7.76(\mathrm{~s}, 2 \mathrm{H}), 7.59(\mathrm{ddd}, J=7.7,5.5,1.2 \mathrm{~Hz}, 2 \mathrm{H}), 7.26-7.20(\mathrm{~m}$, $4 \mathrm{H}), 6.98(\mathrm{td}, J=8.8,2.7 \mathrm{~Hz}, 2 \mathrm{H}), 6.21(\mathrm{dd}, J=8.8,2.6 \mathrm{~Hz}, 2 \mathrm{H}) ;{ }^{13} \mathrm{C}$ NMR $(100 \mathrm{MHz}$, $\left.\mathrm{CD}_{3} \mathrm{CN}\right): \delta 164.49(\mathrm{~d}, J=246.0 \mathrm{~Hz}), 163.03(\mathrm{~d}, J=248.1 \mathrm{~Hz}), 157.47,153.13,149.44$, $141.34,138.83,133.35$ (d, $J=6.0 \mathrm{~Hz}), 132.53,129.55,129.29$ (d, $J=8.5 \mathrm{~Hz}), 126.00$ (d, $J=2.9 \mathrm{~Hz}), 125.70,120.13(\mathrm{~d}, J=20.5 \mathrm{~Hz}), 117.20(\mathrm{~d}, J=22.1 \mathrm{~Hz}), 117.24(\mathrm{~d}, J=9.2$ $\mathrm{Hz}), 112.02(\mathrm{~d}, J=24.7 \mathrm{~Hz}) ;{ }^{19} \mathrm{~F}$ NMR $\left(376 \mathrm{MHz}, \mathrm{CD}_{3} \mathrm{CN}\right):-73.92(\mathrm{~d}, J=706.0 \mathrm{~Hz}, 6 \mathrm{~F})$, $-113.59(\mathrm{~m}, 2 \mathrm{~F}),-114.77(\mathrm{~m}, 2 \mathrm{~F})$. ESI-MS calculated for $\left[\mathrm{C}_{38} \mathrm{H}_{24} \mathrm{~F}_{4} \mathrm{IrN}_{8}\right]^{+}: 861.1689$, found: 861.1670 . 


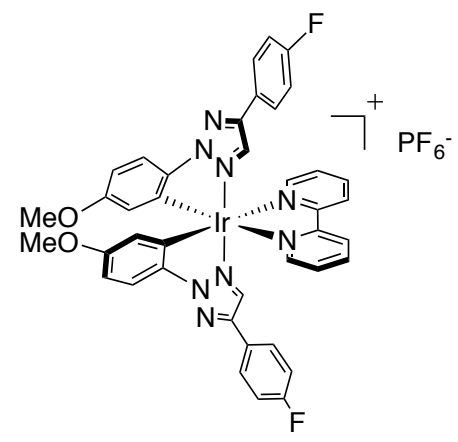

C-1e: Yellow Solid (55\% yield). ${ }^{1} \mathrm{H}$ NMR $\left(400 \mathrm{MHz}, \mathrm{CD}_{3} \mathrm{CN}\right): \delta 8.56(\mathrm{~d}, J=8.1 \mathrm{~Hz}$, $2 \mathrm{H}), 8.23-8.18(\mathrm{~m}, 4 \mathrm{H}), 7.89-7.84(\mathrm{~m}, 4 \mathrm{H}), 7.74(\mathrm{~d}, J=8.7 \mathrm{~Hz}, 2 \mathrm{H}), 7.71(\mathrm{~s}, 2 \mathrm{H}), 7.58$ (ddd, $J=7.7,5.5,1.2 \mathrm{~Hz}, 2 \mathrm{H}), 7.25-7.19(\mathrm{~m}, 4 \mathrm{H}), 6.76(\mathrm{dd}, J=8.8,2.6 \mathrm{~Hz}, 2 \mathrm{H}), 5.90(\mathrm{~d}$, $J=2.6 \mathrm{~Hz}, 2 \mathrm{H}), 3.63(\mathrm{~s}, 6 \mathrm{H}) ;{ }^{13} \mathrm{C} \mathrm{NMR}\left(100 \mathrm{MHz}, \mathrm{CD}_{3} \mathrm{CN}\right): \delta 164.36(\mathrm{~d}, J=246.0 \mathrm{~Hz})$, $160.72,157.53,152.98,148.78,141.08,136.19,132.77,131.55,129.42,129.12$ (d, $J=$ $8.4 \mathrm{~Hz}), 126.19(\mathrm{~d}, J=3.0 \mathrm{~Hz}), 125.57,118.99,117.16(\mathrm{~d}, J=22.0 \mathrm{~Hz}), 116.72,109.47$, 55.96; ${ }^{19} \mathrm{~F}$ NMR (376 MHz, $\left.\mathrm{CD}_{3} \mathrm{CN}\right):-73.84(\mathrm{~d}, J=706.2 \mathrm{~Hz}, 6 \mathrm{~F}),-113.93(\mathrm{~m}, 2 \mathrm{~F})$. ESIMS calculated for $\left[\mathrm{C}_{40} \mathrm{H}_{30} \mathrm{~F}_{2} \mathrm{IrN}_{8} \mathrm{O}_{2}\right]^{+}:$: 885.2089, found: 885.2078.

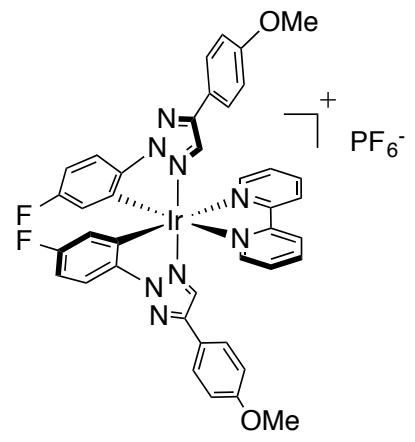

C-1f: Yellow Solid (56\% yield). ${ }^{1} \mathrm{H}$ NMR $\left(400 \mathrm{MHz}, \mathrm{CD}_{3} \mathrm{CN}\right): \delta 8.56$ (d, $J=8.1 \mathrm{~Hz}$, $2 \mathrm{H}), 8.23-8.17(\mathrm{~m}, 4 \mathrm{H}), 7.83-7.77(\mathrm{~m}, 6 \mathrm{H}), 7.69(\mathrm{~s}, 2 \mathrm{H}), 7.58$ (ddd, $J=7.7,5.5,1.2 \mathrm{~Hz}$, 2H), 7.04-7.00 (m, 4H), $6.97(\mathrm{td}, J=8.8,2.7 \mathrm{~Hz}, 2 \mathrm{H}), 6.19(\mathrm{dd}, J=8.8,2.6 \mathrm{~Hz}, 2 \mathrm{H}), 3.82$ $(\mathrm{s}, 6 \mathrm{H}) ;{ }^{13} \mathrm{C}$ NMR $\left(100 \mathrm{MHz}, \mathrm{CD}_{3} \mathrm{CN}\right): \delta 162.89$ (d, $\left.J=247.6 \mathrm{~Hz}\right), 162.00,157.47$, $153.09,150.30,141.28,138.98,133.29(\mathrm{~d}, J=6.0 \mathrm{~Hz}), 131.96,129.53,128.57,125.68$, $121.90,120.06(\mathrm{~d}, J=20.4 \mathrm{~Hz}), 117.02(\mathrm{~d}, J=9.1 \mathrm{~Hz}), 115.62,111.91(\mathrm{~d}, J=24.5 \mathrm{~Hz})$, 56.21; ${ }^{19} \mathrm{~F}$ NMR (376 MHz, $\mathrm{CD}_{3} \mathrm{CN}$ ): $-73.87(\mathrm{~d}, J=705.7 \mathrm{~Hz}, 6 \mathrm{~F}),-115.13(\mathrm{~m}, 2 \mathrm{~F})$. ESIMS calculated for $\left[\mathrm{C}_{40} \mathrm{H}_{30} \mathrm{~F}_{2} \mathrm{IrN}_{8} \mathrm{O}_{2}\right]^{+}:$: 885.2089, found: 885.2076. 


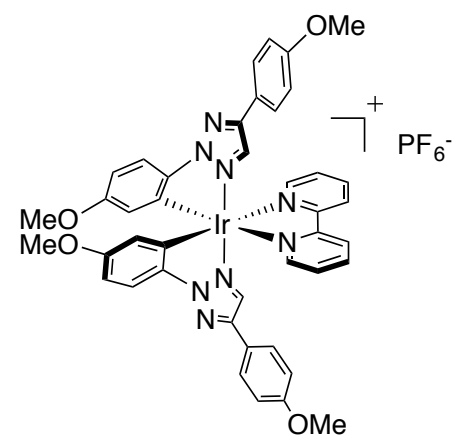

C-1g: Yellow Solid (38\% yield). ${ }^{1} \mathrm{H}$ NMR $\left(400 \mathrm{MHz}, \mathrm{CD}_{3} \mathrm{CN}\right): \delta 8.55(\mathrm{~d}, J=8.1 \mathrm{~Hz}$, $2 \mathrm{H}), 8.22-8.17(\mathrm{~m}, 4 \mathrm{H}), 7.79-7.75(\mathrm{~m}, 4 \mathrm{H}), 7.72(\mathrm{~d}, J=8.7 \mathrm{~Hz}, 2 \mathrm{H}), 7.64(\mathrm{~s}, 2 \mathrm{H}), 7.59-$ $7.56(\mathrm{~m}, 2 \mathrm{H}), 7.03-6.99(\mathrm{~m}, 4 \mathrm{H}), 6.76(\mathrm{dd}, J=8.8,2.6 \mathrm{~Hz}, 2 \mathrm{H}), 5.89(\mathrm{~d}, J=2.6 \mathrm{~Hz}, 2 \mathrm{H})$, $3.82(\mathrm{~s}, 6 \mathrm{H}), 3.62(\mathrm{~s}, 6 \mathrm{H}) ;{ }^{13} \mathrm{C}$ NMR $\left(100 \mathrm{MHz}, \mathrm{CD}_{3} \mathrm{CN}\right): \delta 161.84,160.55,157.53$, 152.96, 149.65, 141.00, 136.34, 132.70, 130.96, 129.39, 128.41, 125.54, 122.11, 118.96, 116.51, 115.59, 109.37, 56.19, 55.94. ESI-MS calculated for $\left[\mathrm{C}_{42} \mathrm{H}_{36} \mathrm{IrN}_{8} \mathrm{O}_{2}\right]^{+}: 909.2489$, found: 909.2478 .

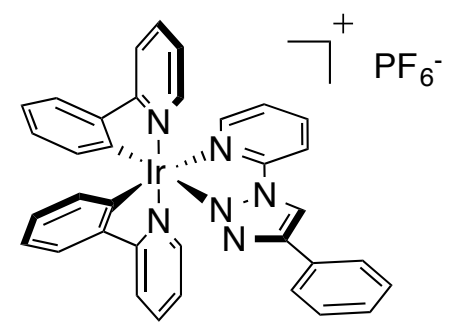

C-2: Yellow Solid (40\% yield). ${ }^{1} \mathrm{H}$ NMR $\left(600 \mathrm{MHz}, \mathrm{CD}_{3} \mathrm{CN}\right): \delta 8.42(\mathrm{~d}, J=8.4 \mathrm{~Hz}$, $1 \mathrm{H}), 8.26(\mathrm{td}, J=8.0,1.6 \mathrm{~Hz}, 1 \mathrm{H}), 8.09-8.07(\mathrm{~m}, 2 \mathrm{H}), 8.05(\mathrm{~s}, 1 \mathrm{H}), 7.95$ (ddd, $J=4.6$, $3.2,1.6 \mathrm{~Hz}, 2 \mathrm{H}), 7.90-7.88(\mathrm{~m}, 3 \mathrm{H}), 7.82-7.80(\mathrm{~m}, 3 \mathrm{H}), 7.73(\mathrm{dd}, J=5.8,0.7 \mathrm{~Hz}, 1 \mathrm{H})$, 7.54-7.49 (m, 4H), 7.10-7.04 (m, 4H), 6.93 (dtd, $J=14.5,7.3,1.3 \mathrm{~Hz}, 2 \mathrm{H}), 6.28$ (dd, $J=$ 21.6, 7.7 Hz, 2H); ${ }^{13} \mathrm{C}$ NMR (150 MHz, $\left.\mathrm{CD}_{3} \mathrm{CN}\right): \delta 168.48,167.95,153.69,150.90$, $150.83,150.18,149.39,148.19,145.52,145.21,145.19,143.13,140.05,139.98,136.93$, $132.94,132.38,131.81,131.47,131.03,130.42,128.56,127.76,127.61,126.00,125.74$, $124.78,124.67,124.12,123.92,121.01,120.97,115.87$. ESI-MS calculated for $\left[\mathrm{C}_{35} \mathrm{H}_{26} \mathrm{IrN}_{6}\right]^{+}: 723.1843$, found: 723.1858 .

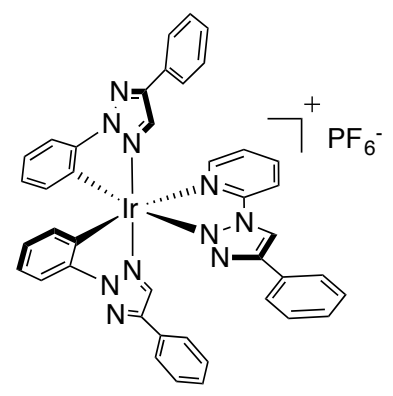


C-3a: Light yellow Solid ( $85 \%$ yield). ${ }^{1} \mathrm{H}$ NMR $\left(400 \mathrm{MHz}, \mathrm{CD}_{3} \mathrm{CN}\right): \delta 8.46(\mathrm{~d}, J=8.4$ $\mathrm{Hz}, 1 \mathrm{H}), 8.33$ (ddd, $J=8.4,7.6,1.6 \mathrm{~Hz}, 1 \mathrm{H}), 8.25(\mathrm{~s}, 1 \mathrm{H}), 8.13$ (s, 1H), 8.01-7.97 (m, $4 \mathrm{H}), 7.92-7.90(\mathrm{~m}, 4 \mathrm{H}), 7.82(\mathrm{~d}, J=7.9 \mathrm{~Hz}, 2 \mathrm{H}), 7.58-7.44(\mathrm{~m}, 10 \mathrm{H}), 7.26-7.19(\mathrm{~m}, 2 \mathrm{H})$, 7.02 (dtd, $J=10.6,7.5,1.3 \mathrm{~Hz}, 2 \mathrm{H}), 6.52(\mathrm{dd}, J=7.6,5.1 \mathrm{~Hz}, 2 \mathrm{H}) ;{ }^{13} \mathrm{C} \mathrm{NMR}(100 \mathrm{MHz}$, $\left.\mathrm{CD}_{3} \mathrm{CN}\right): \delta 153.49,151.48,150.37,150.20,149.76,143.74,142.50,142.24,138.52$, $134.05,133.56,133.35,133.33,131.88,130.91,130.88,130.51,130.35,130.33,129.64$, $129.59,129.56,129.26,128.57,127.72,127.69,127.47,127.02,126.98,125.79,125.56$, $124.70,115.77,115.59,115.37$. ESI-MS calculated for $\left[\mathrm{C}_{41} \mathrm{H}_{30} \mathrm{IrN}_{10}\right]^{+}: 855.2284$, found: 855.2269 .

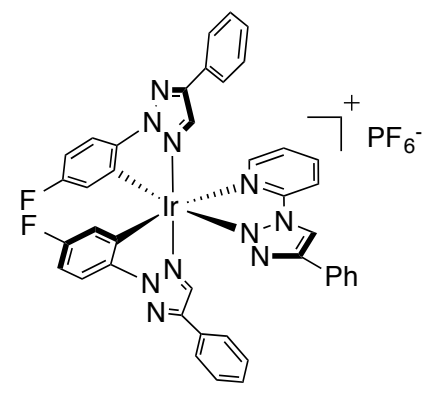

C-3b: Light yellow Solid (71\% yield). ${ }^{1} \mathrm{H}$ NMR $\left(400 \mathrm{MHz}, \mathrm{CD}_{3} \mathrm{CN}\right): \delta 8.46$ (ddd, $J=$ 8.4, 1.2, $0.8 \mathrm{~Hz}, 1 \mathrm{H}), 8.34$ (ddd, $J=8.4,7.6,1.6 \mathrm{~Hz}, 1 \mathrm{H}), 8.32(\mathrm{~s}, 1 \mathrm{H}), 8.10(\mathrm{~s}, 1 \mathrm{H}), 8.03-$ $7.99(\mathrm{~m}, 3 \mathrm{H}), 7.95(\mathrm{~s}, 1 \mathrm{H}), 7.91-7.88(\mathrm{~m}, 4 \mathrm{H}), 7.86(\mathrm{dd}, J=8.8,4.9 \mathrm{~Hz}, 2 \mathrm{H}), 7.59-7.44$ (m, 10H), 7.02 (tdd, $J=8.8,6.0,2.7 \mathrm{~Hz}, 2 \mathrm{H}), 6.23$ (ddd, $J=8.8,4.3,2.6 \mathrm{~Hz}, 2 \mathrm{H}) ;{ }^{13} \mathrm{C}$ NMR (100 MHz, CD $\left.{ }_{3} \mathrm{CN}\right): \delta 162.80(\mathrm{~d}, J=248.1 \mathrm{~Hz}), 162.64(\mathrm{~d}, J=247.9 \mathrm{~Hz}), 153.59$, $151.71,150.44,150.27,149.61,144.02,139.10,139.08,138.80,133.45$ (d, $J=3.6 \mathrm{~Hz})$, $131.95,130.94(\mathrm{~d}, J=2.1 \mathrm{~Hz}), 130.55,130.33,130.31,130.26,130.19,129.48,129.45$, $128.49,127.71,127.54,127.34,127.28,127.06,127.02,120.56(\mathrm{~d}, J=21.0 \mathrm{~Hz}), 120.12$ $(\mathrm{d}, J=21.1 \mathrm{~Hz}), 117.36(\mathrm{~d}, J=9.3 \mathrm{~Hz}), 117.05(\mathrm{~d}, J=9.3 \mathrm{~Hz}), 115.84,112.57(\mathrm{~d}, J=$ $19.4 \mathrm{~Hz}), 112.32(\mathrm{~d}, J=19.4 \mathrm{~Hz}) ;{ }^{19} \mathrm{~F}$ NMR $\left(376 \mathrm{MHz}, \mathrm{CD}_{3} \mathrm{CN}\right):-73.92(\mathrm{~d}, J=705.9$ $\mathrm{Hz}, 6 \mathrm{~F}),-114.50(\mathrm{~m}, 1 \mathrm{~F}),-115.05(\mathrm{~m}, 1 \mathrm{~F})$. ESI-MS calculated for $\left[\mathrm{C}_{41} \mathrm{H}_{28} \mathrm{~F}_{2} \mathrm{IrN}_{10}\right]^{+}$: 891.2096, found: 891.2083.

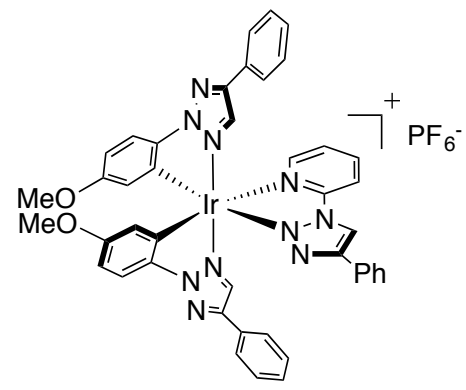

C-3c: Light yellow Solid (44\% yield). ${ }^{1} \mathrm{H}$ NMR ( $400 \mathrm{MHz}, \mathrm{CD}_{3} \mathrm{CN}$ ): $\delta 8.45$ (dd, $J=8.3$, $0.6 \mathrm{~Hz}, 1 \mathrm{H}), 8.33(\mathrm{td}, J=8.0,1.5 \mathrm{~Hz}, 1 \mathrm{H}), 8.29(\mathrm{~s}, 1 \mathrm{H}), 8.06-8.00(\mathrm{~m}, 3 \mathrm{H}), 8.05(\mathrm{~s}, 1 \mathrm{H})$, $7.90(\mathrm{~s}, 1 \mathrm{H}), 7.90-7.87(\mathrm{~m}, 4 \mathrm{H}), 7.76(\mathrm{~d}, J=8.7 \mathrm{~Hz}, 2 \mathrm{H}), 7.59-7.42(\mathrm{~m}, 10 \mathrm{H}), 6.80$ (ddd, 
$J=8.7,6.2,2.6 \mathrm{~Hz}, 2 \mathrm{H}), 5.91(\mathrm{dd}, J=2.2 \mathrm{~Hz}, 2 \mathrm{H}), 3.64(2 \mathrm{~s}, 6 \mathrm{H}) . ;{ }^{13} \mathrm{C} \mathrm{NMR}(100 \mathrm{MHz}$, $\left.\mathrm{CD}_{3} \mathrm{CN}\right): \delta 160.58,160.30,153.47,151.58,149.76,149.71,149.60,143.76,138.54$, $136.40,136.08,132.50,132.46,131.90,130.74,130.72,130.52,130.31,130.29,129.78$, 129.66, 129.63, 128.57, 127.72, 127.43, 126.92, 126.88, 126.83, 119.37, 118.81, 116.86, 116.56, 115.74, 110.01, 109.82, 56.02, 55.97. ESI-MS calculated for $\left[\mathrm{C}_{43} \mathrm{H}_{34} \mathrm{IrN}_{10} \mathrm{O}_{2}\right]^{+}$: 915.2495, found: 915.2481 . 


\section{S5.3 ORTEP Drawing of the Crystal Structures}

ORTEP Drawing of the Crystal Structures for complex N-1

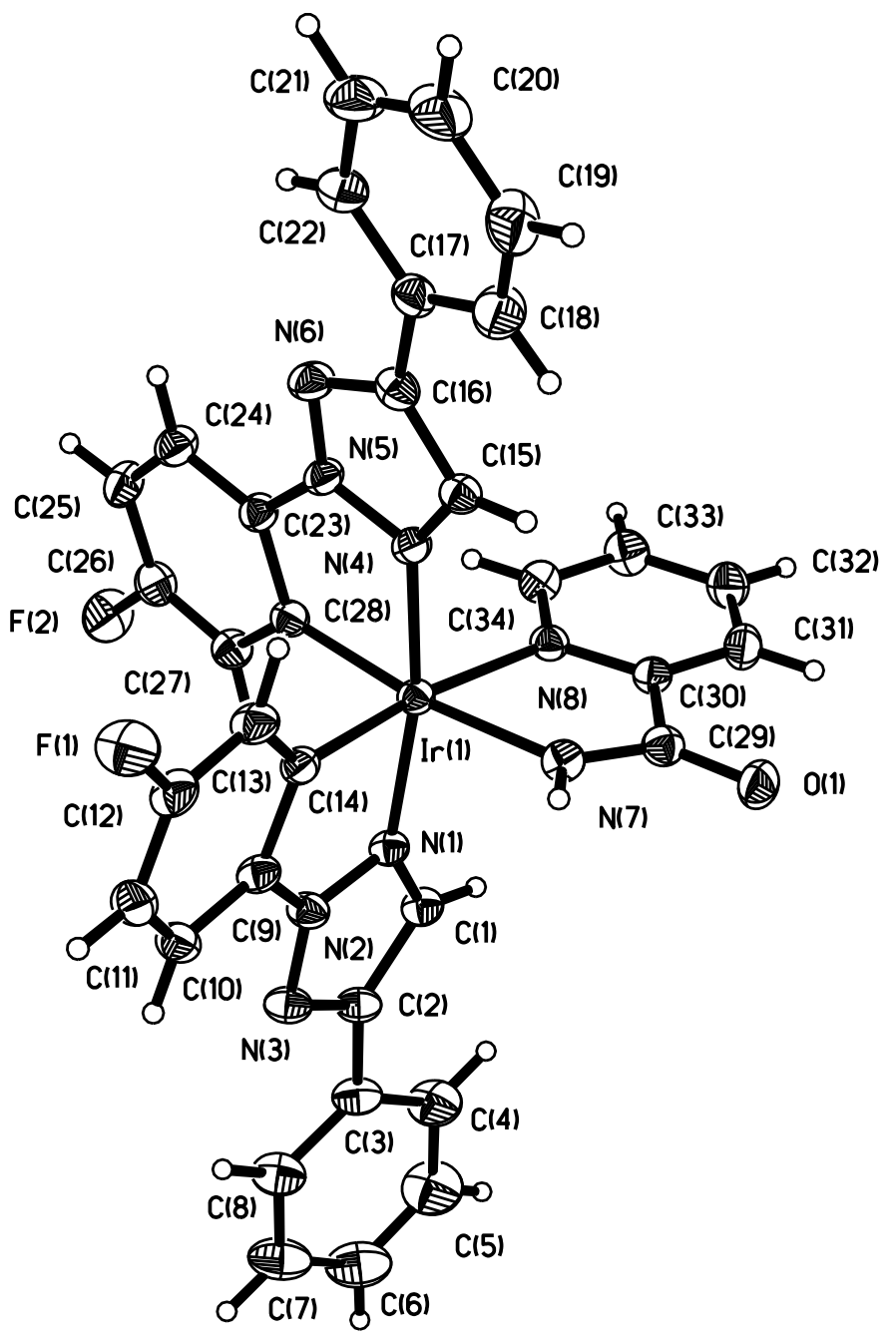

Perspective view of the molecular structure of $\operatorname{Ir}\left(\mathrm{N}_{3} \mathrm{C}_{14} \mathrm{H}_{9} \mathrm{~F}\right)_{2}\left(\mathrm{C}_{6} \mathrm{H}_{5} \mathrm{~N}_{2} \mathrm{O}\right)$ with the atom labeling scheme. The thermal ellipsoids are scaled to $30 \%$ probability. CCDC number: 1012360 


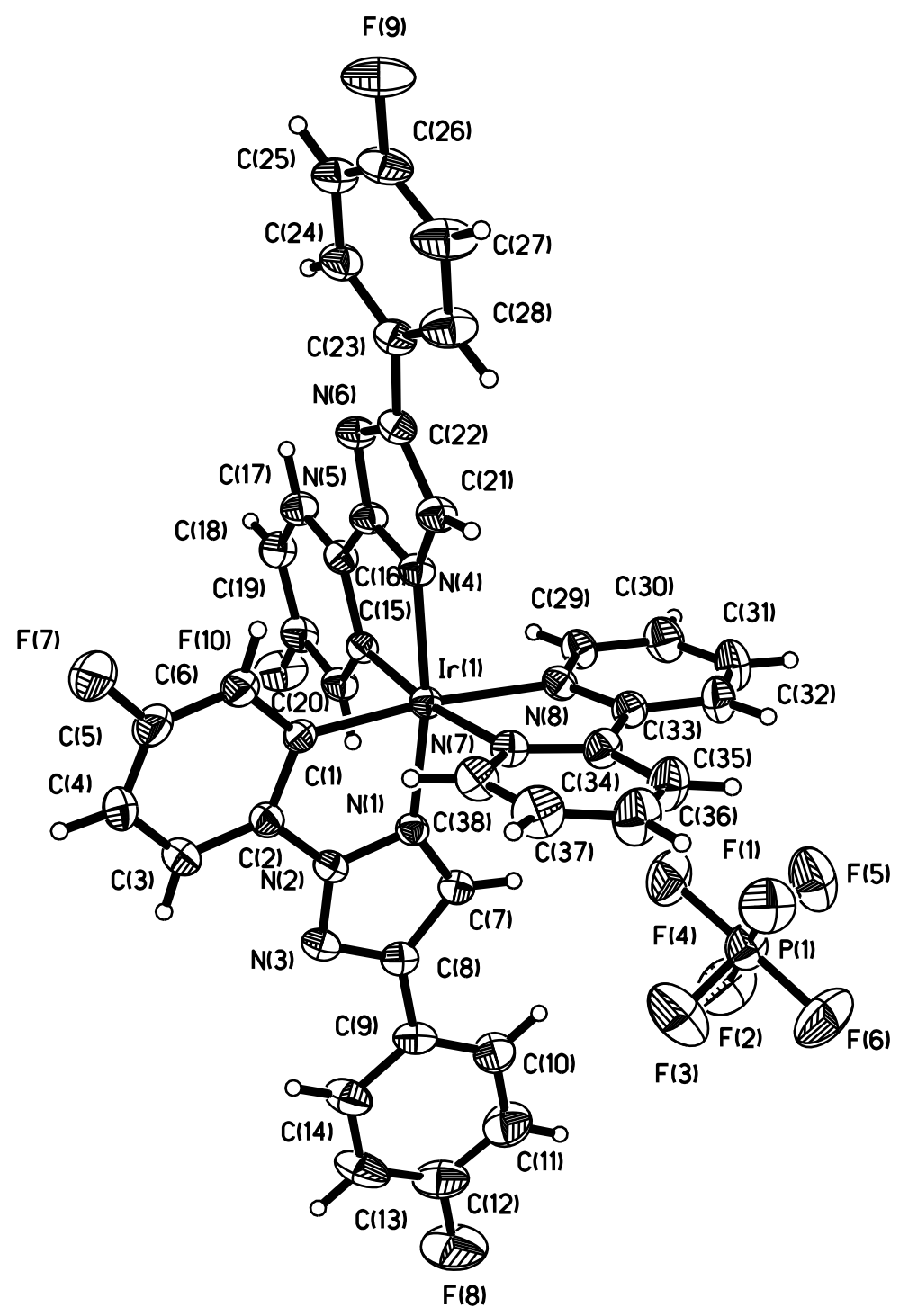

Perspective view of the molecular structure of $\left[\operatorname{Ir}(\mathrm{bpy})\left(\mathrm{C}_{14} \mathrm{H}_{8} \mathrm{~N}_{3} \mathrm{~F}_{2}\right)_{2}\right] \mathrm{PF}_{6}$ with the atom labeling scheme. The thermal ellipsoids are scaled to enclose $30 \%$ probability. CCDC number: 1010939 
S5.4 UV-Vis Spectra and Fluorescence Spectra
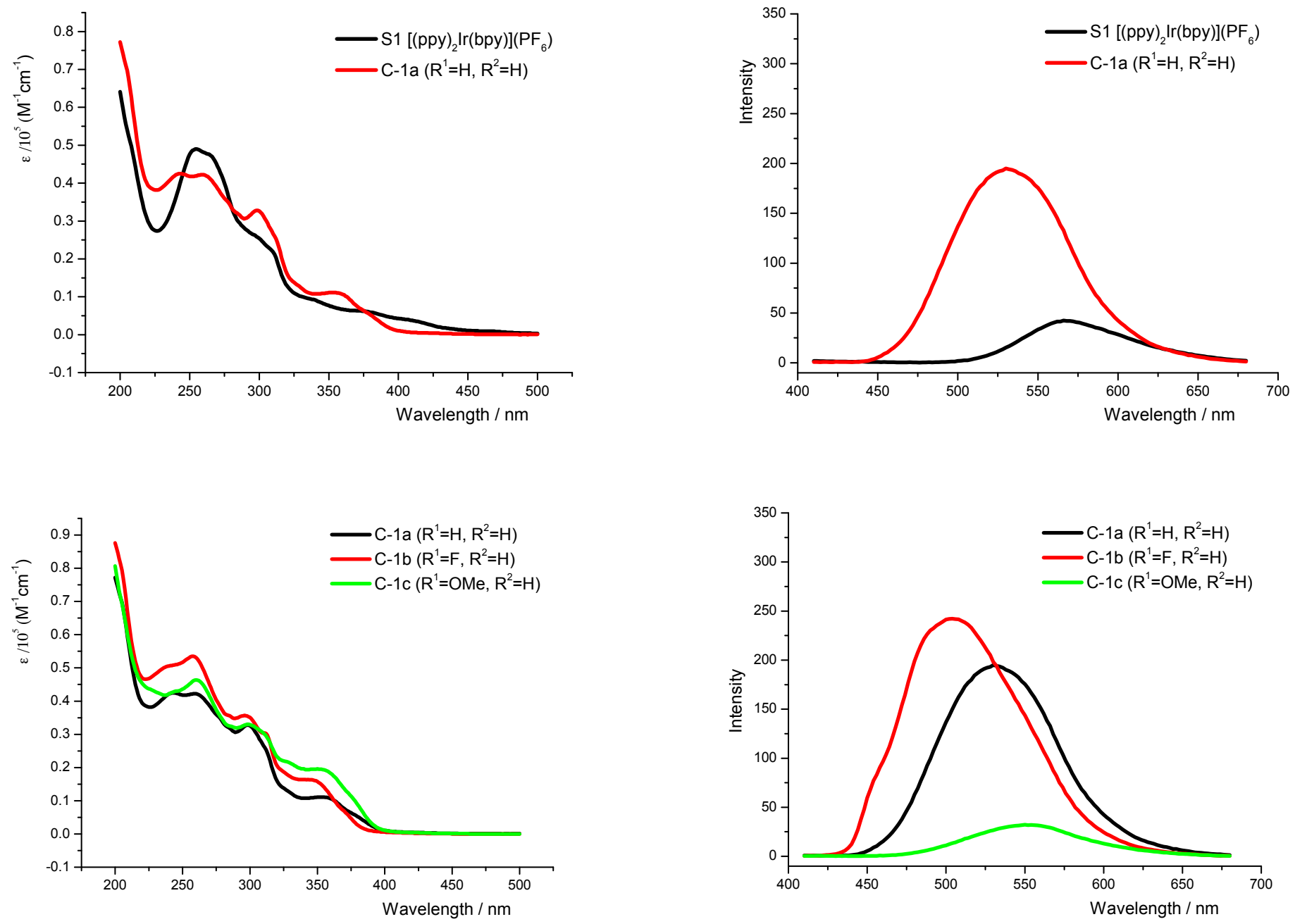

S95 

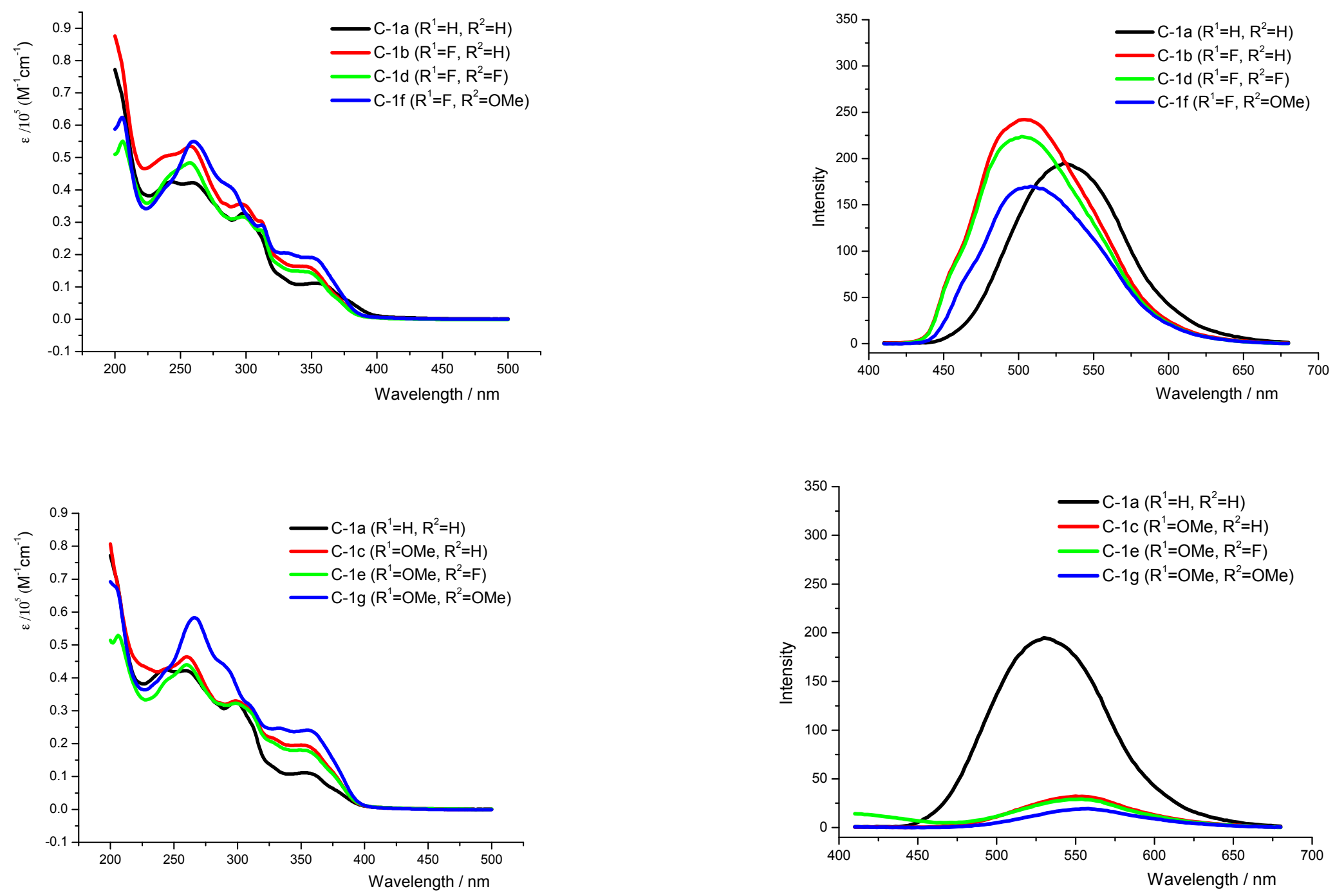

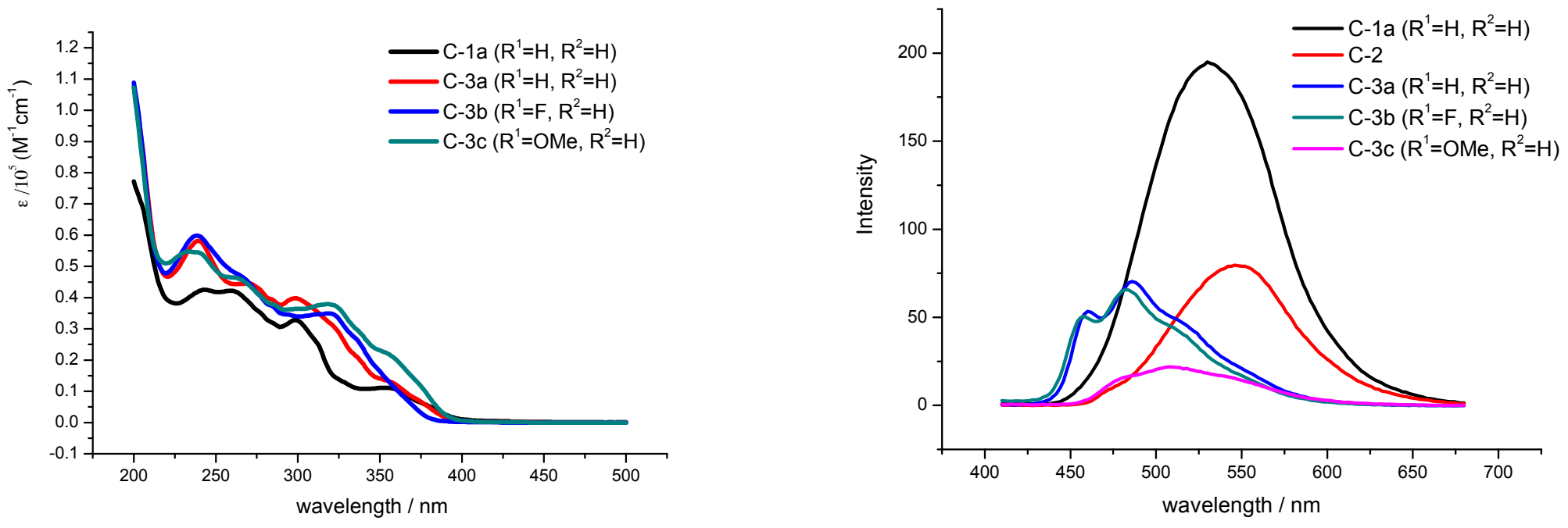

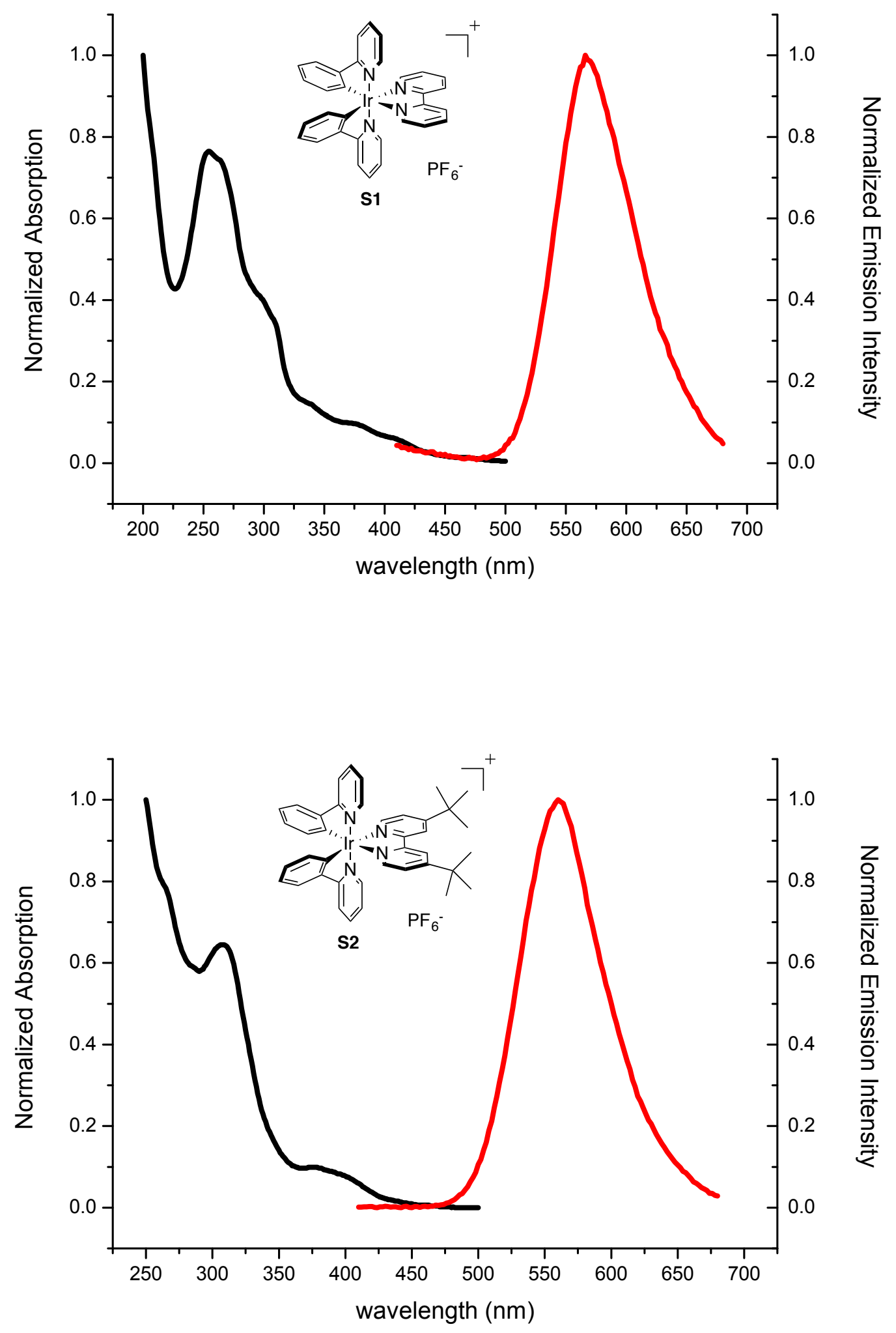

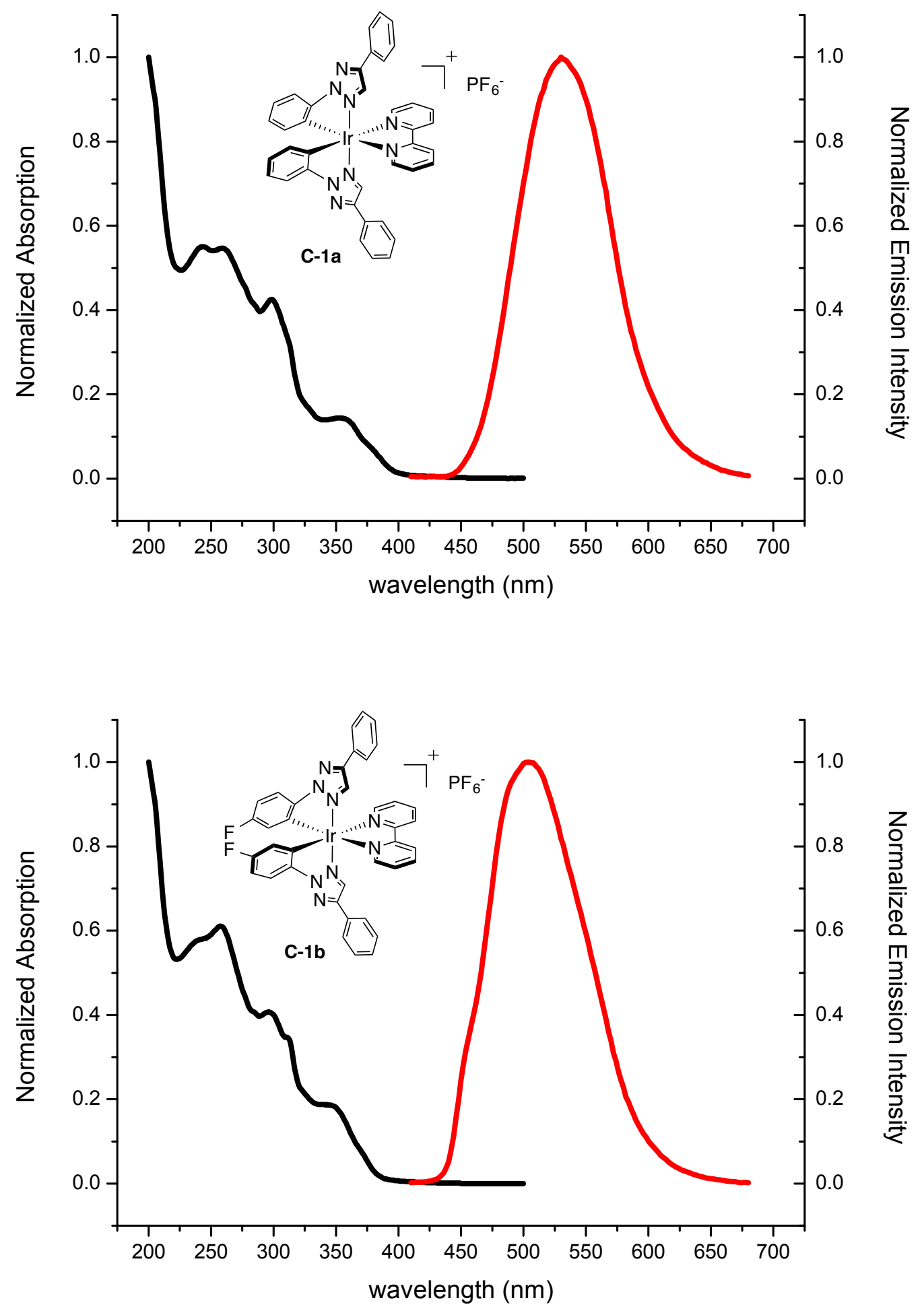

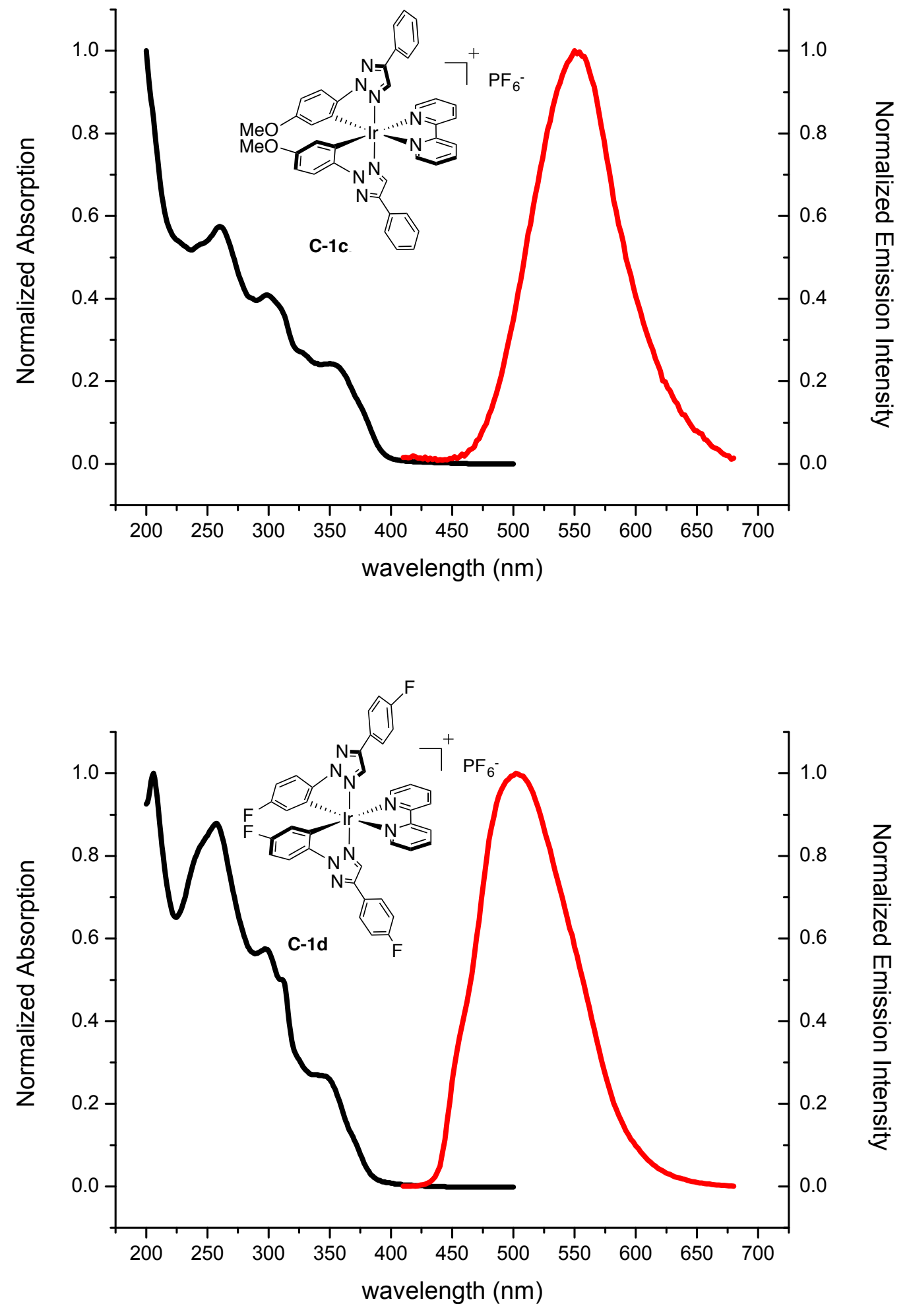

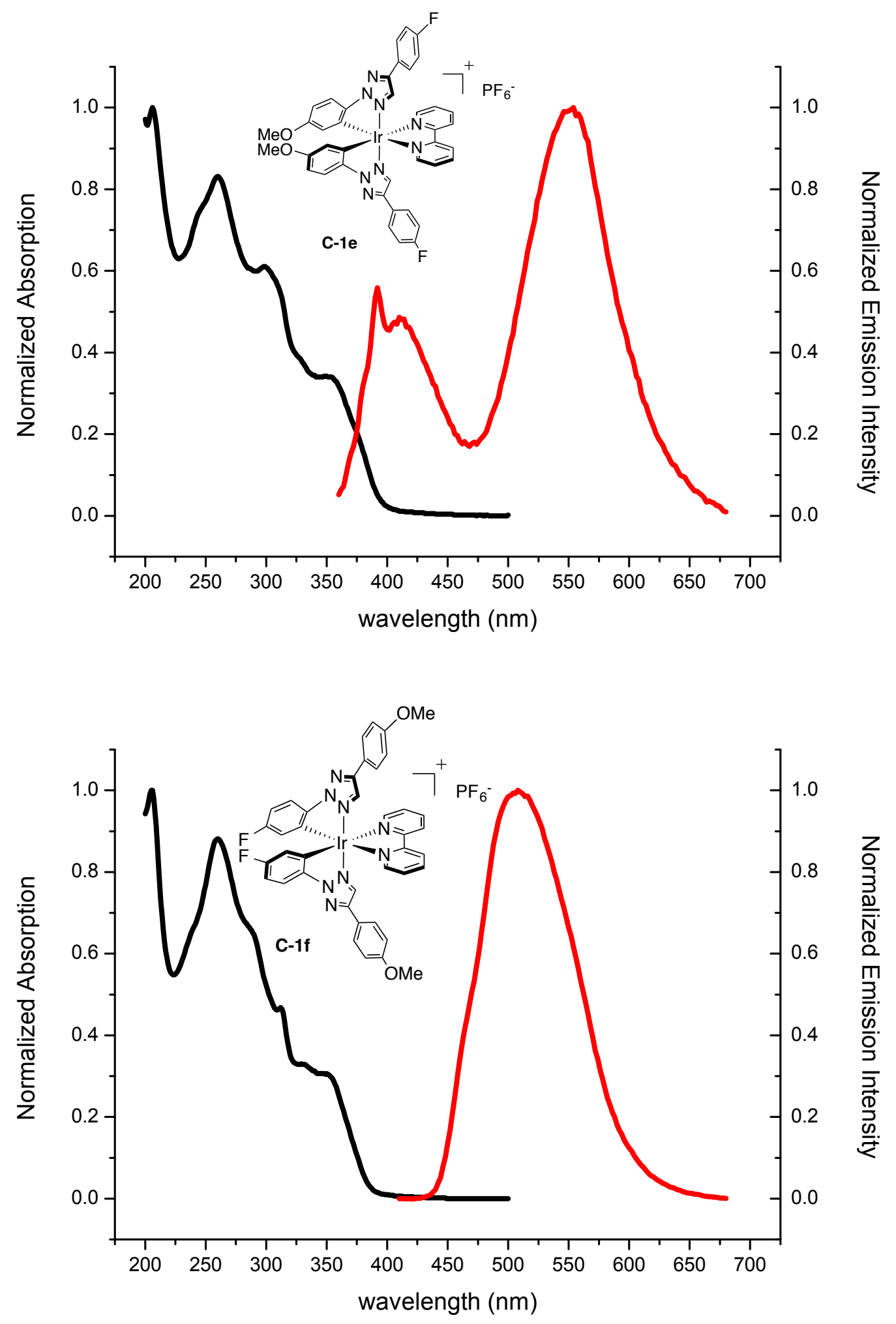

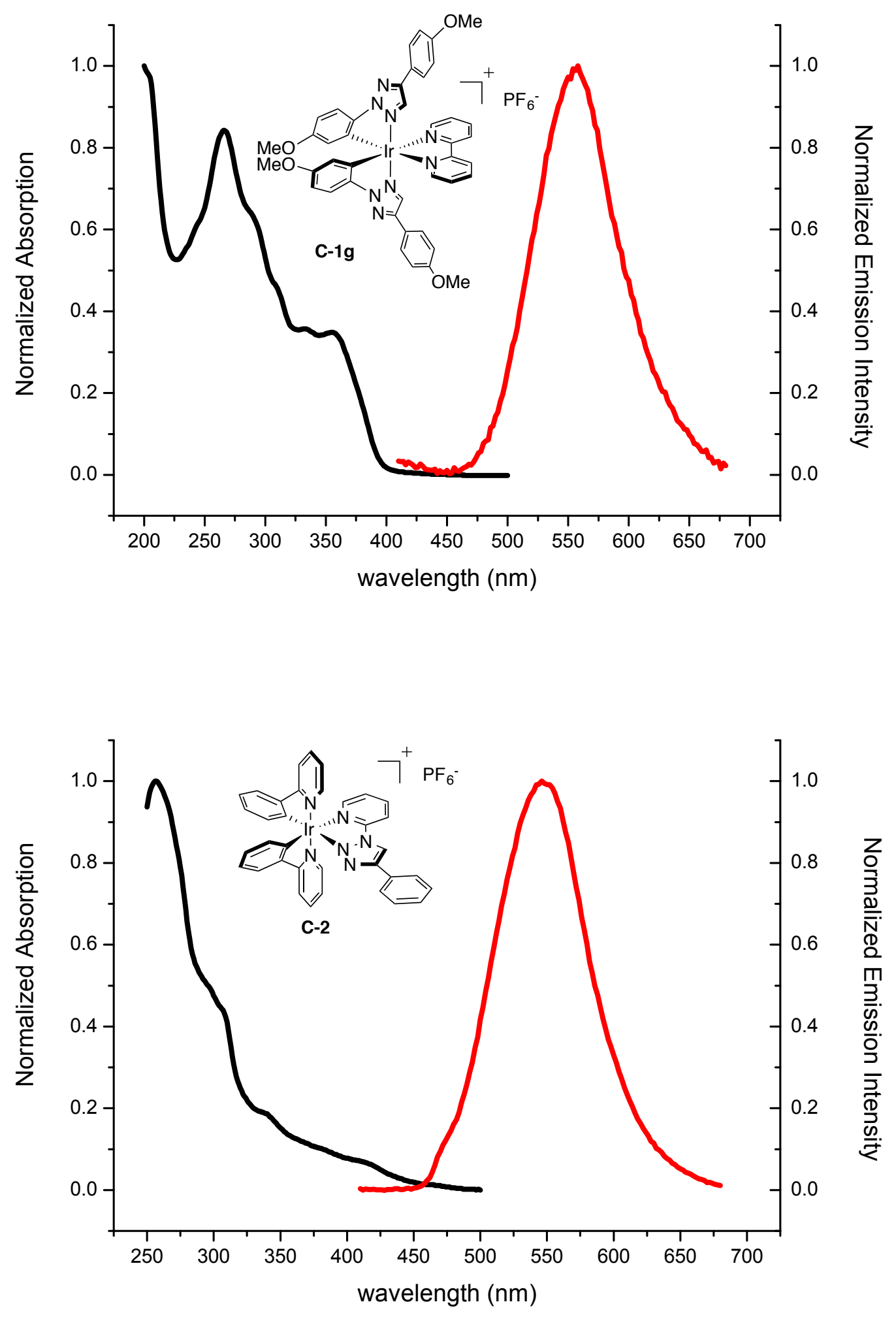

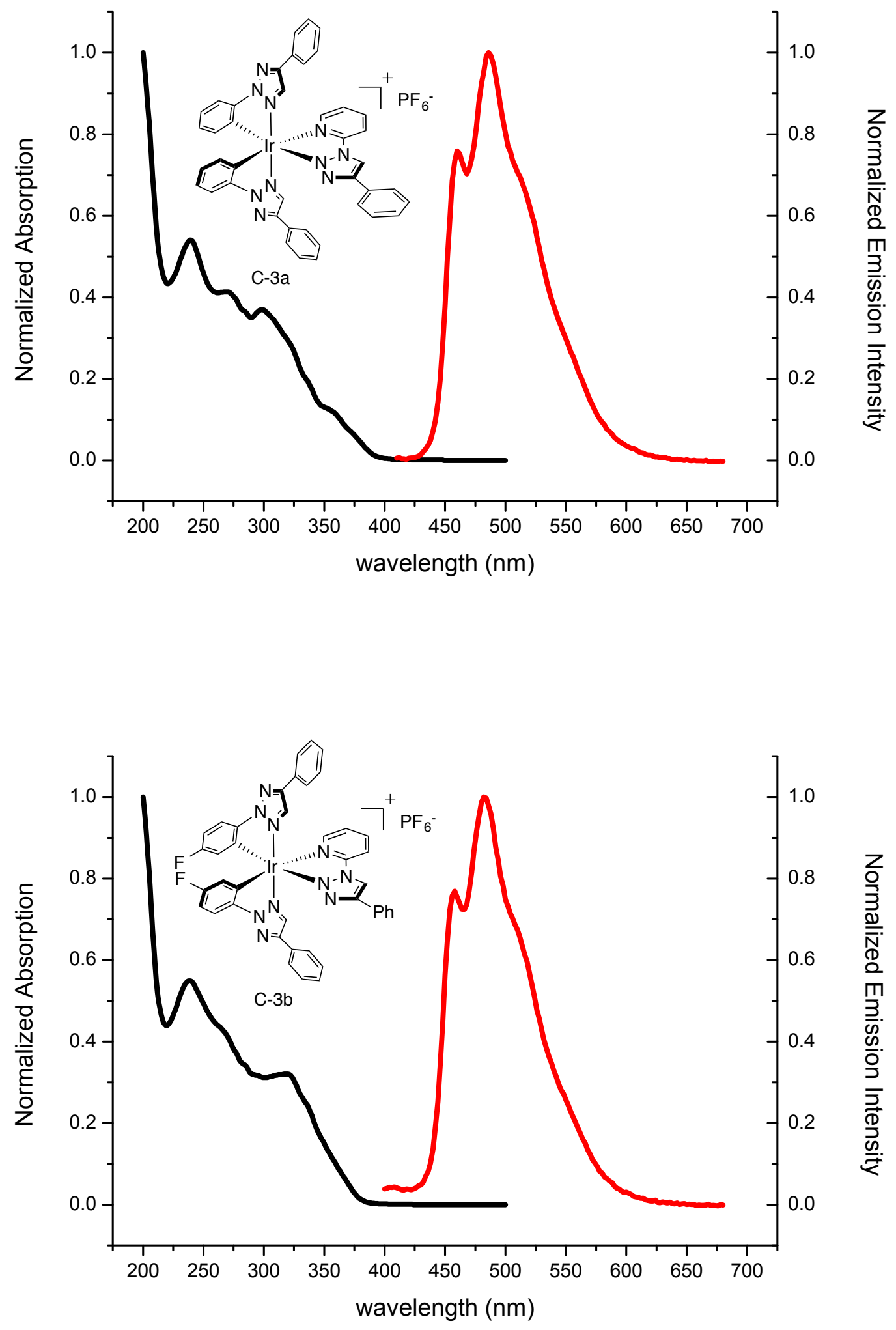


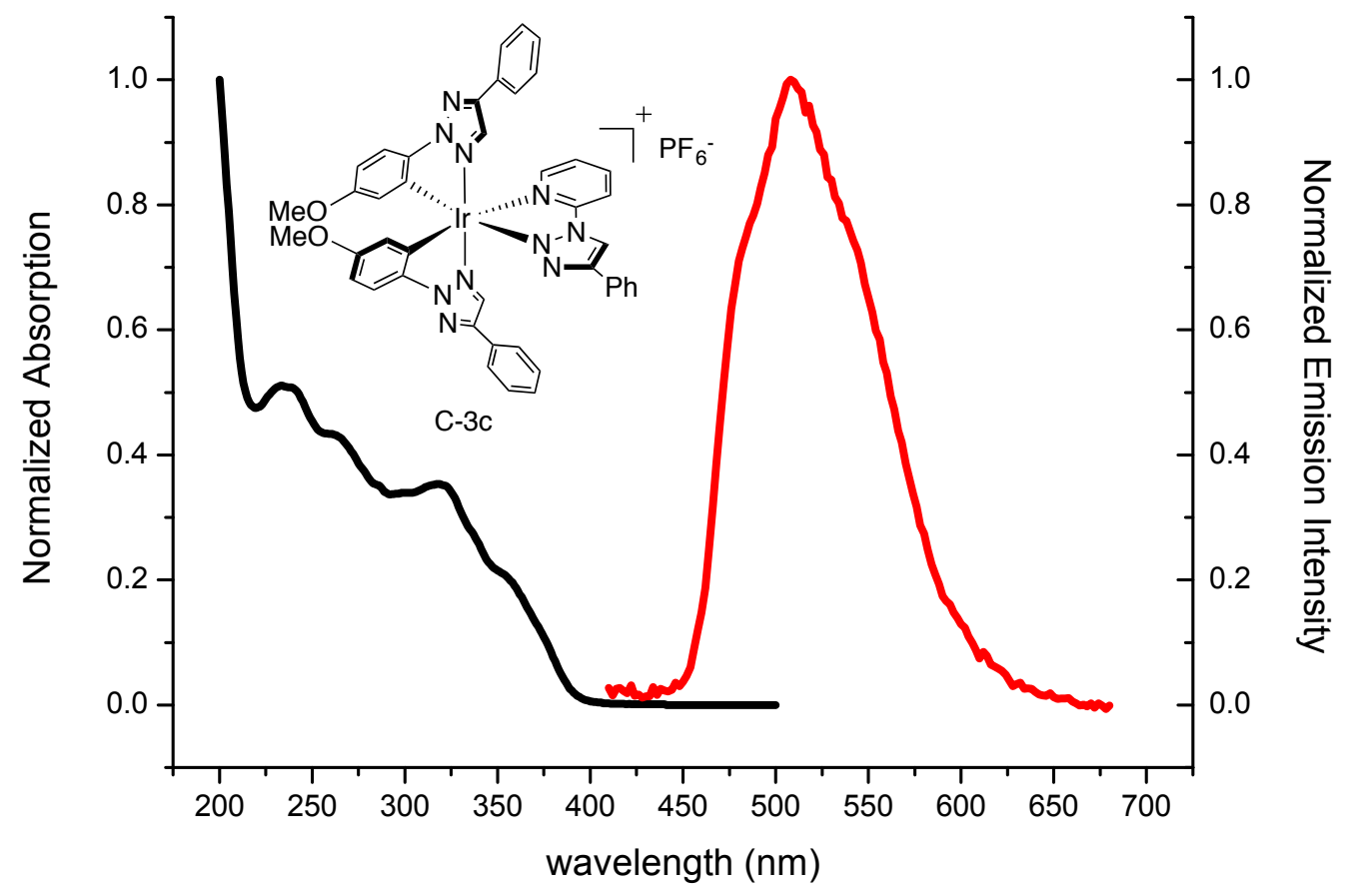




\section{S5.5 Cyclic Voltammetry}
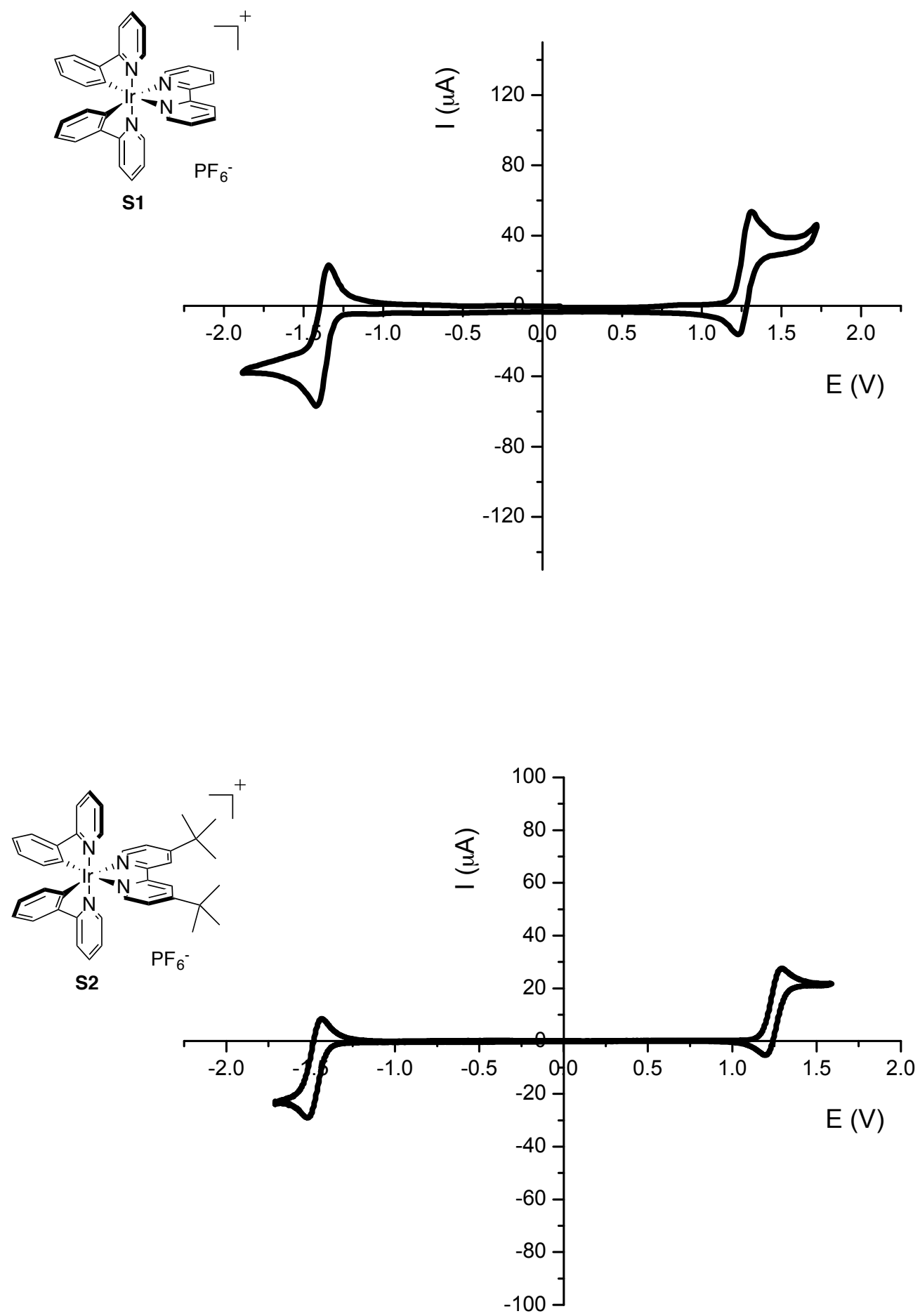

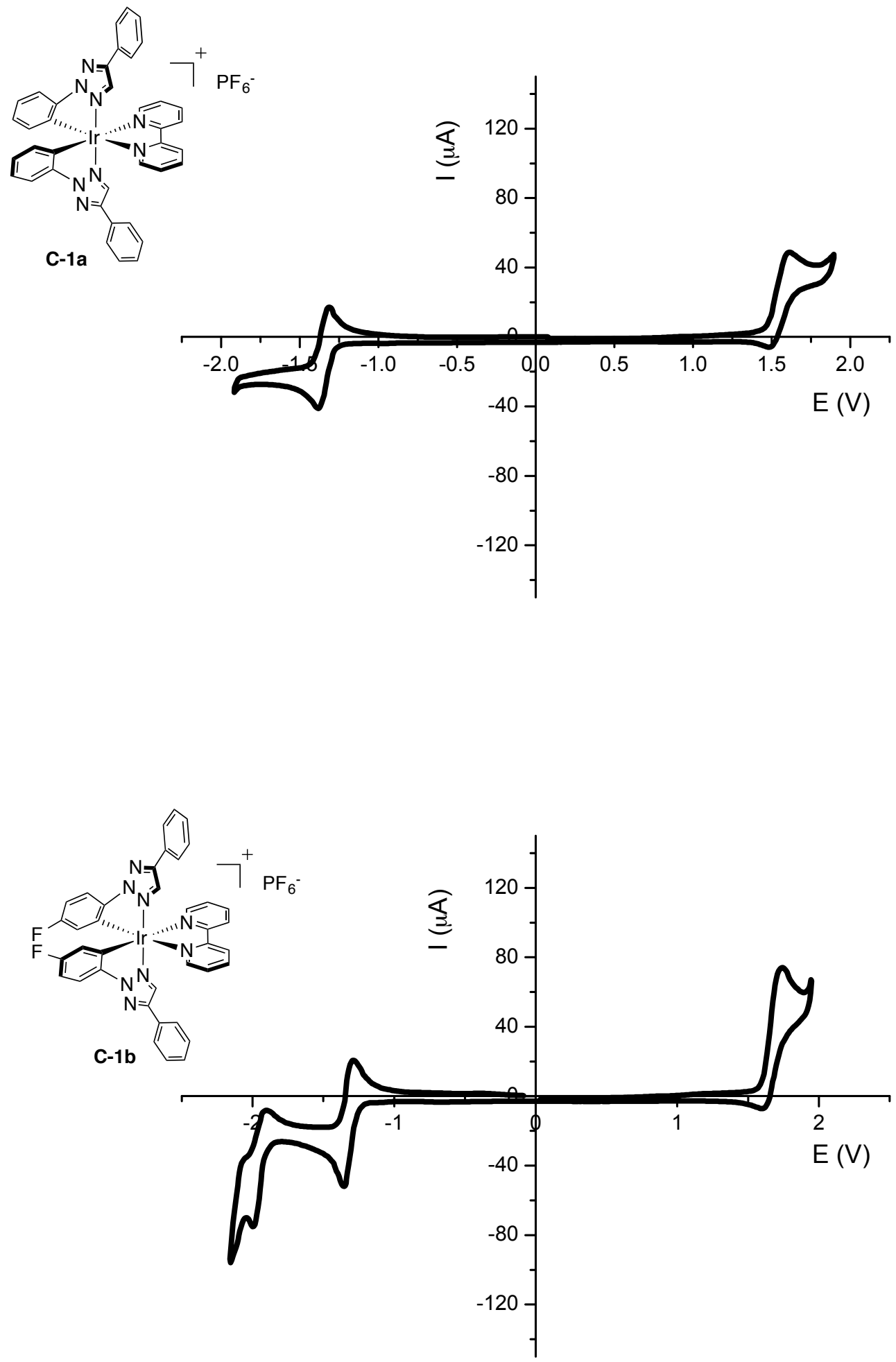

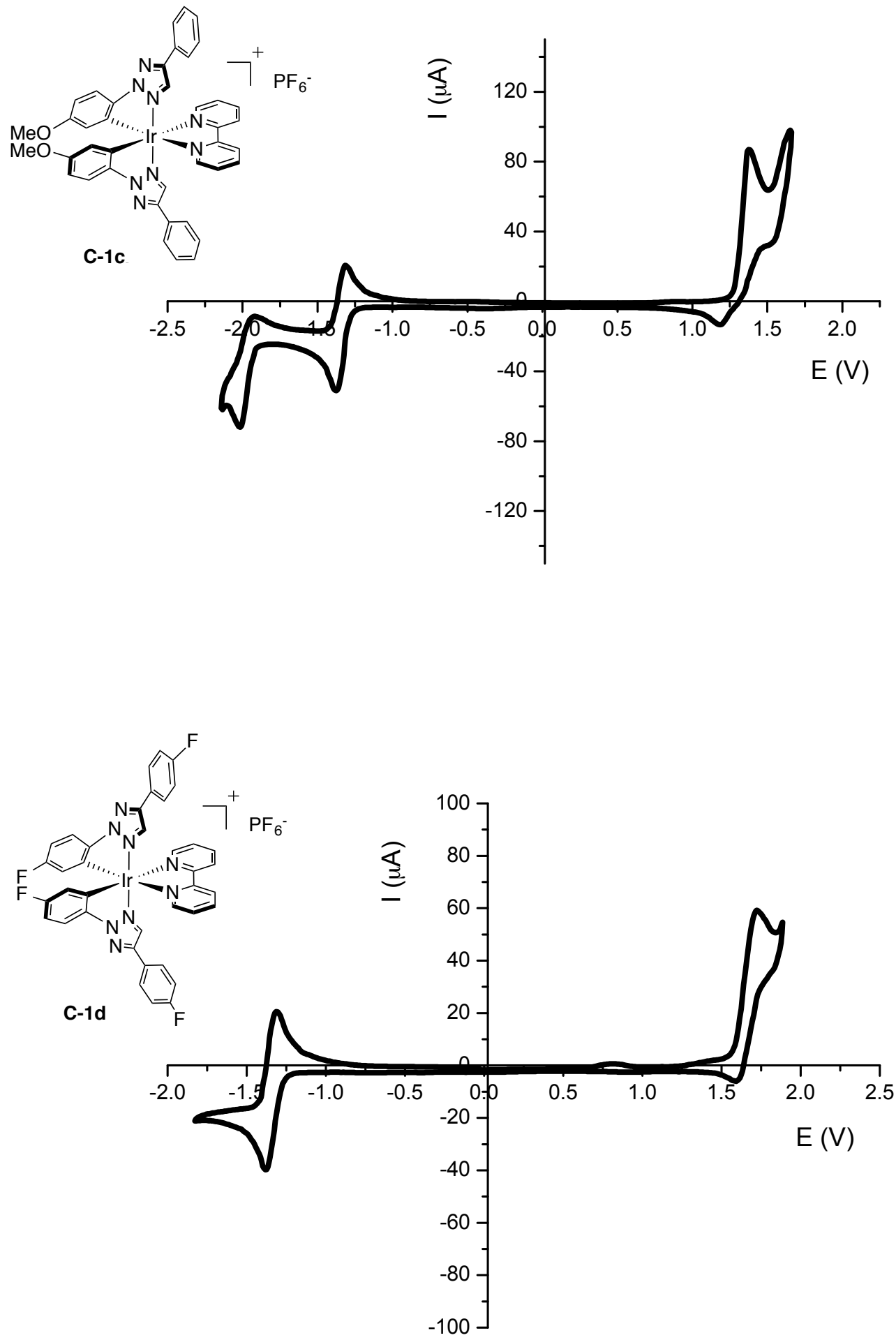

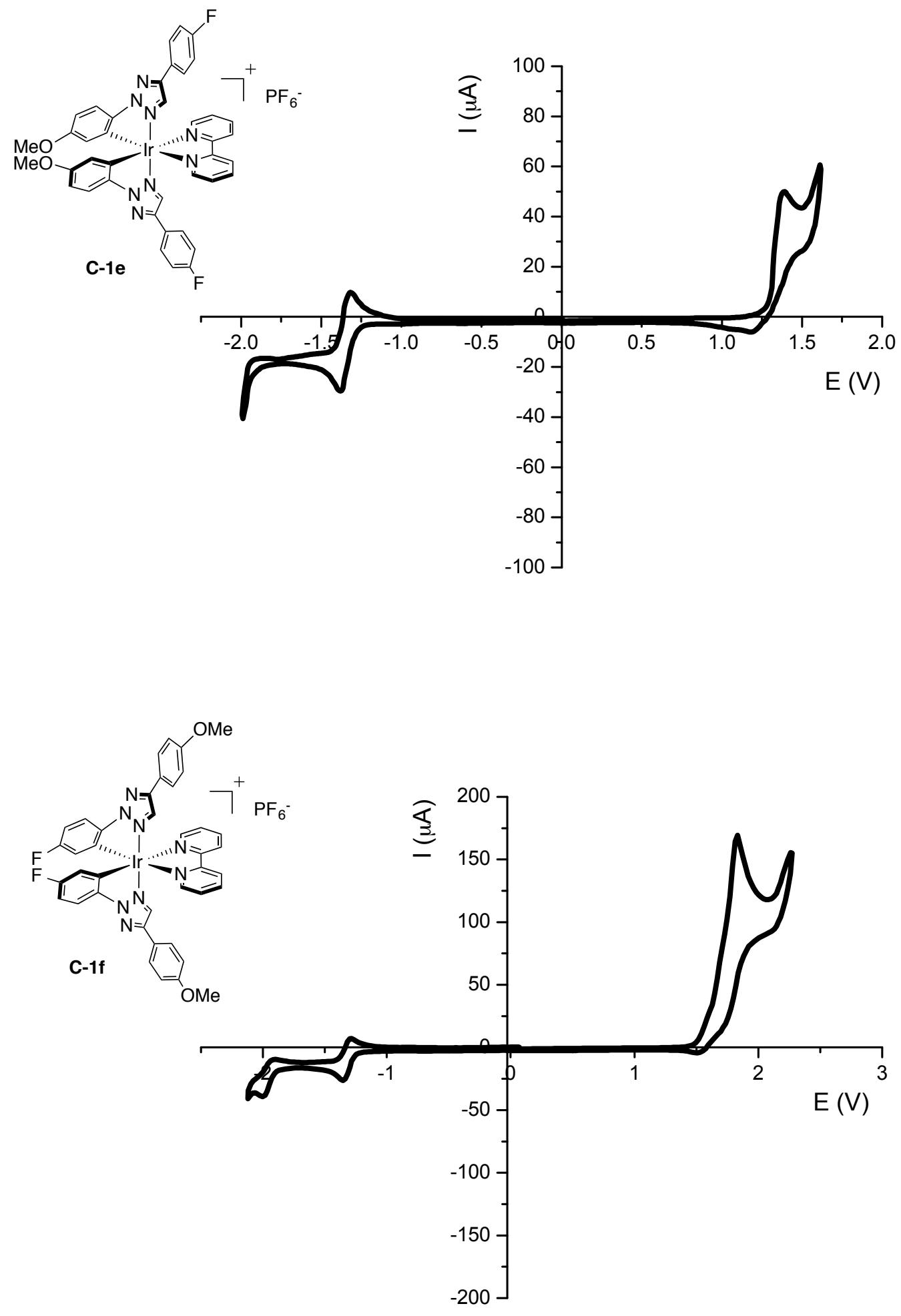

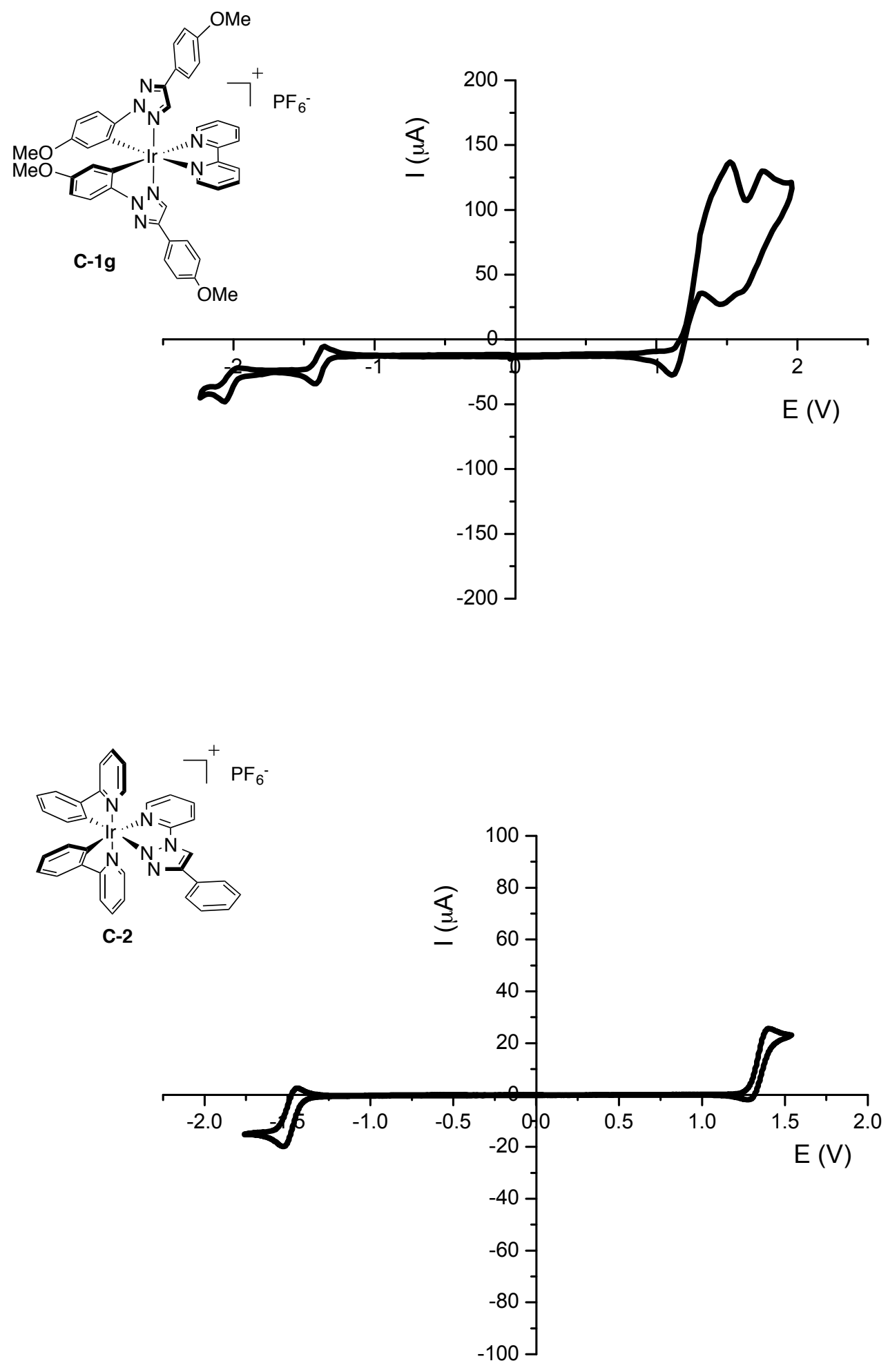

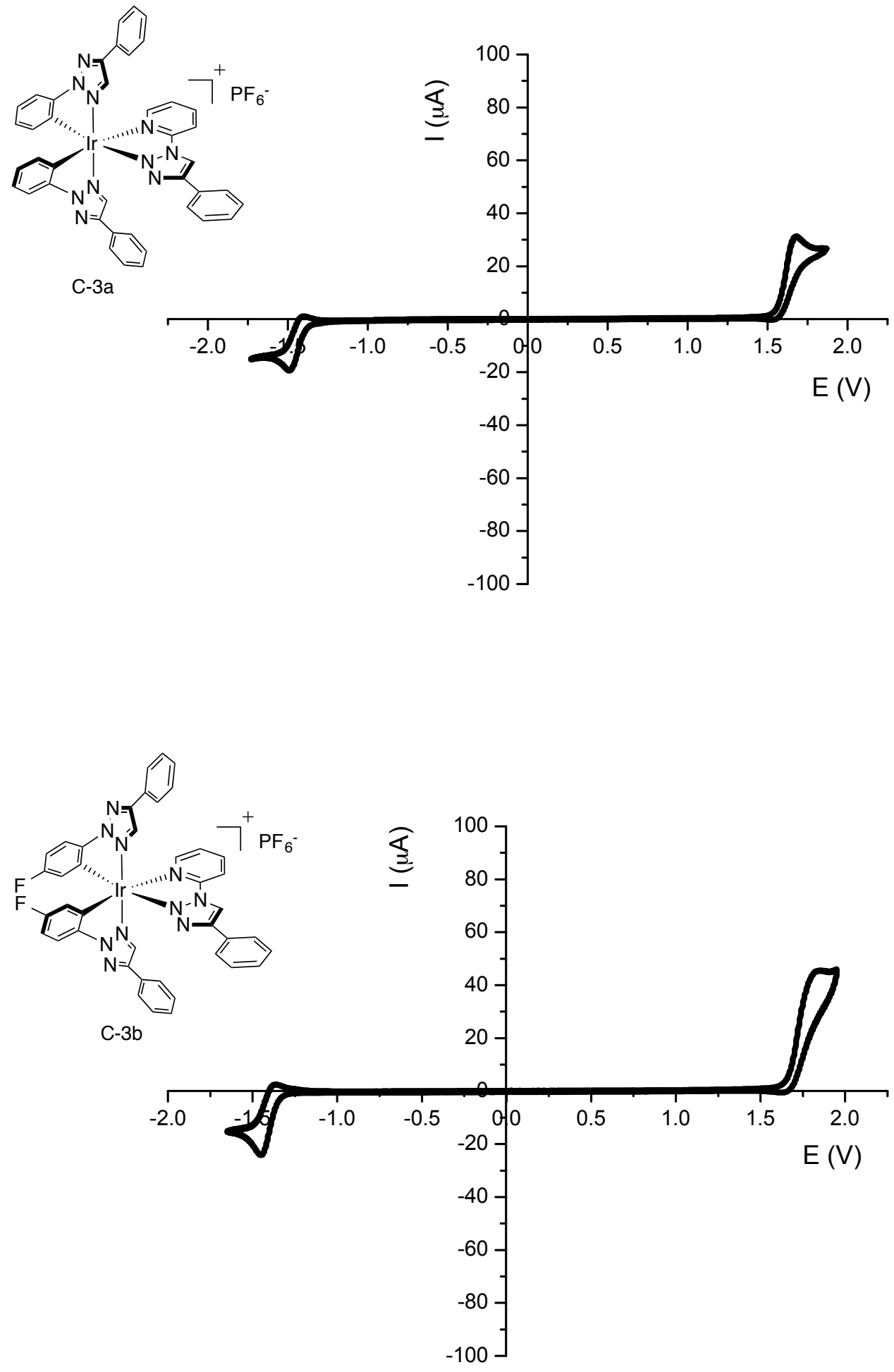


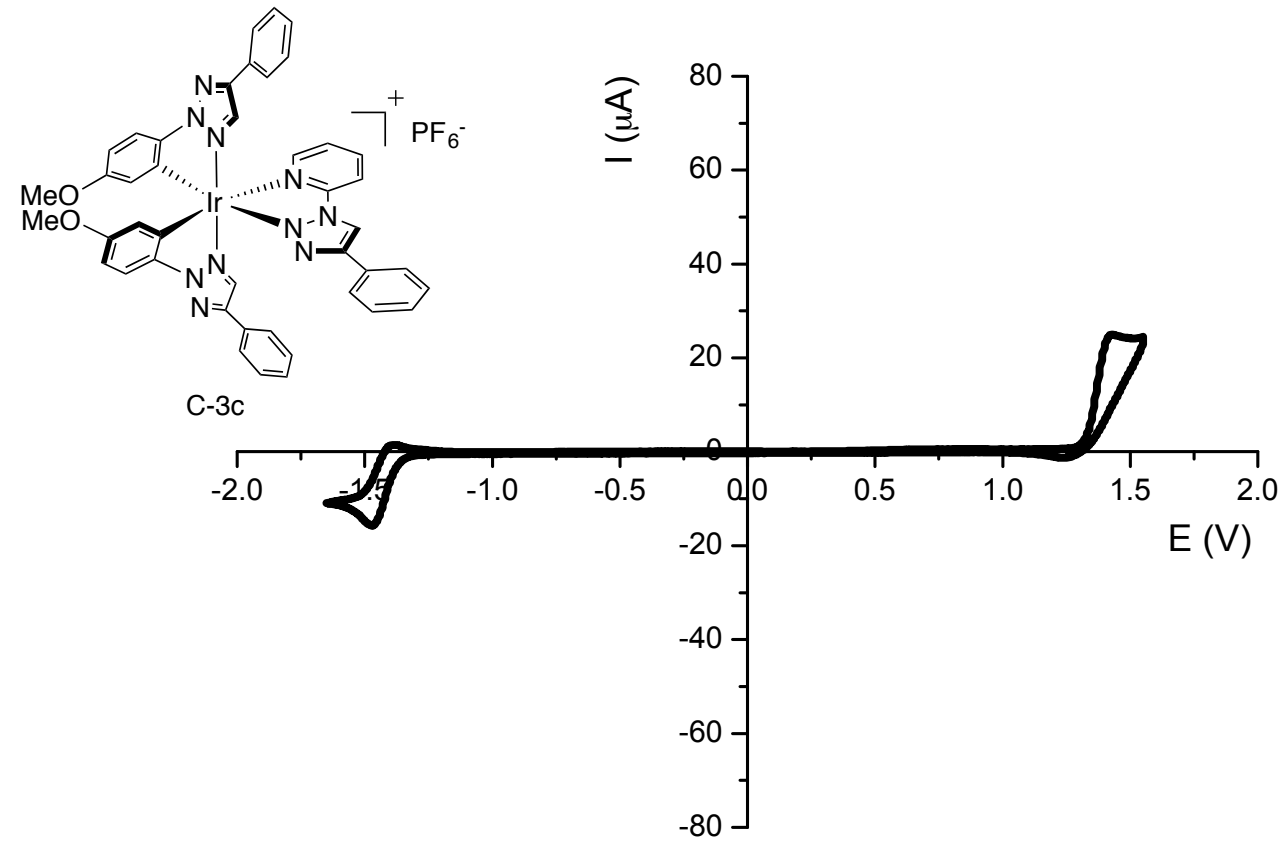

\section{S5.5 Excited-state lifetime}

All the samples are tested under same conditions as described above (Section I). The sample solutions were degassed with nitrogen bubbles for 20 mins, capped with rubber septum and sealed with Parafilm, followed by protection with nitrogen using freeze/thaw techniques prior to the measurement. For parallel comparison, we tested two literature reported samples under our conditions: [(ppy) $\left.{ }_{2} \operatorname{Ir}(\mathrm{dtbbpy})\right] \mathrm{PF}_{6}$ (experimental: $175 \mathrm{~ns}$, literature: $557 \mathrm{~ns})$ and $\mathrm{Ru}(\mathrm{bpy})_{3}\left(\mathrm{PF}_{6}\right)_{2}$ (experimental: $382 \mathrm{~ns}$, literature: $1100 \mathrm{~ns}$ ).

Complexes C-3a, C-3b and C-3c were fitted with two exponentials while all the other complexes were fitted with one exponential using DAS6. 


\section{$\left[(\text { ppy })_{2} \operatorname{Ir}(\mathbf{d t b b p y})\right] \mathrm{PF}_{6}$}
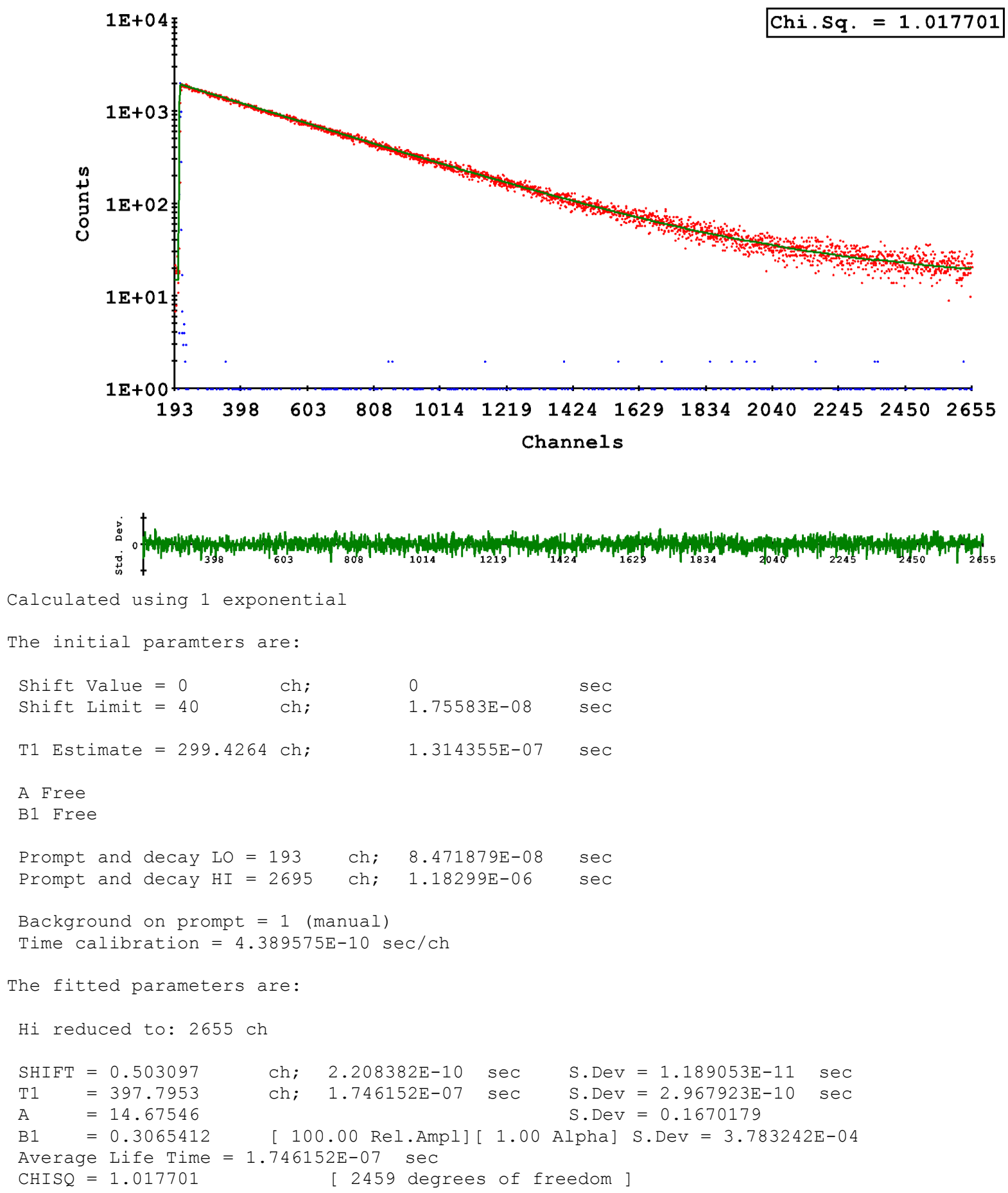


\section{$\mathrm{Ru}(\mathrm{bpy})_{3}\left(\mathrm{PF}_{6}\right)_{2}$}
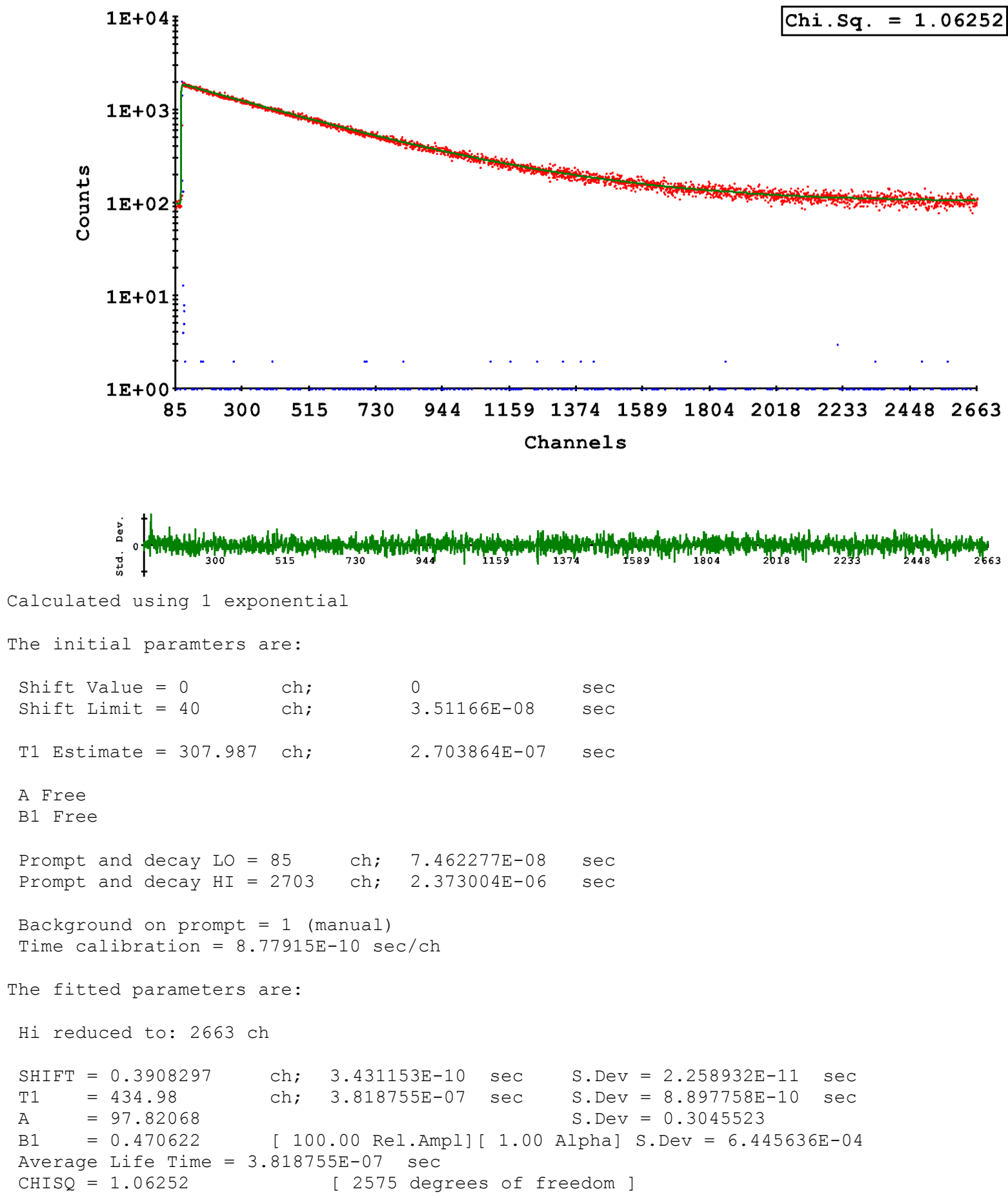


\section{C-1a}
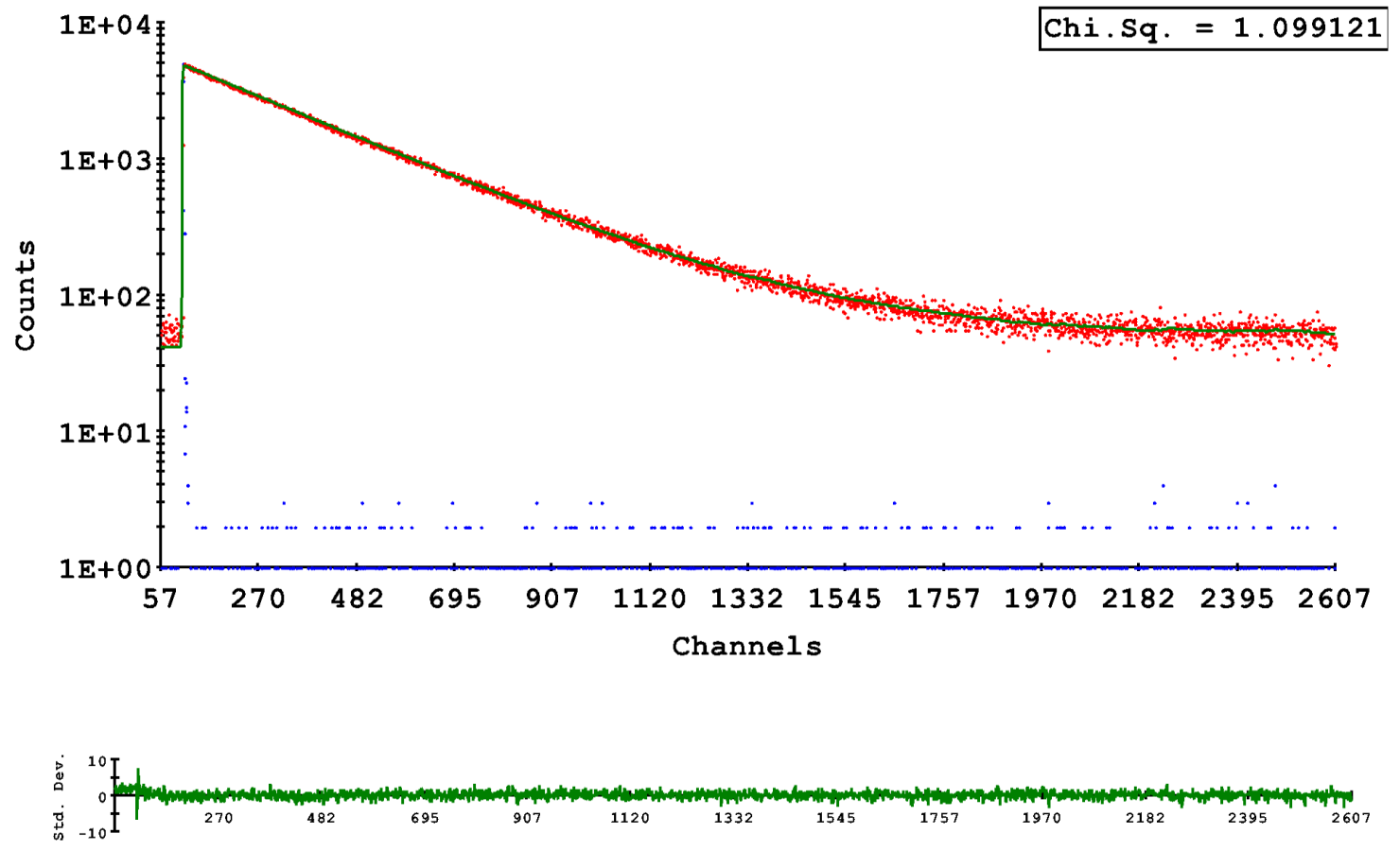

Calculated using 1 exponential

The initial paramters are:

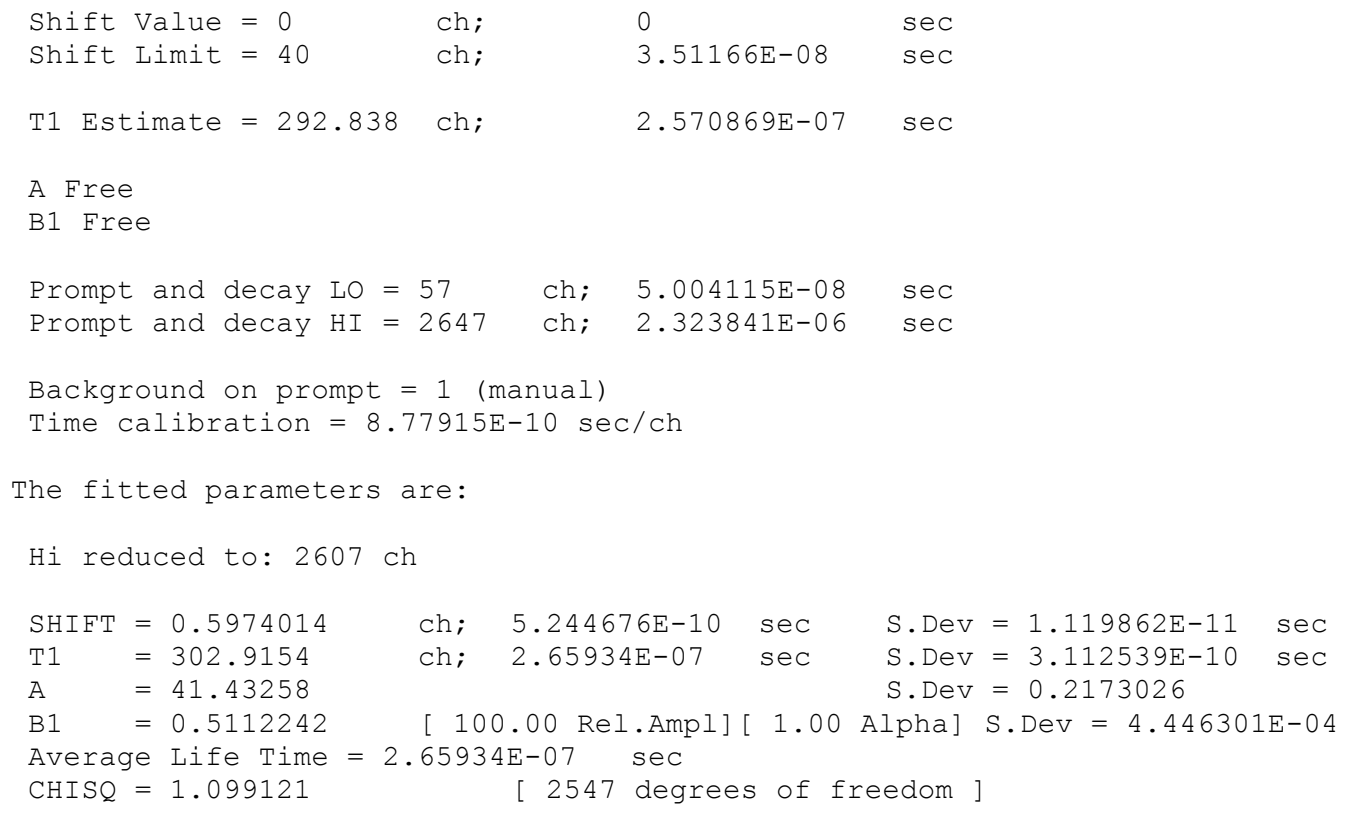




\section{C-1b}
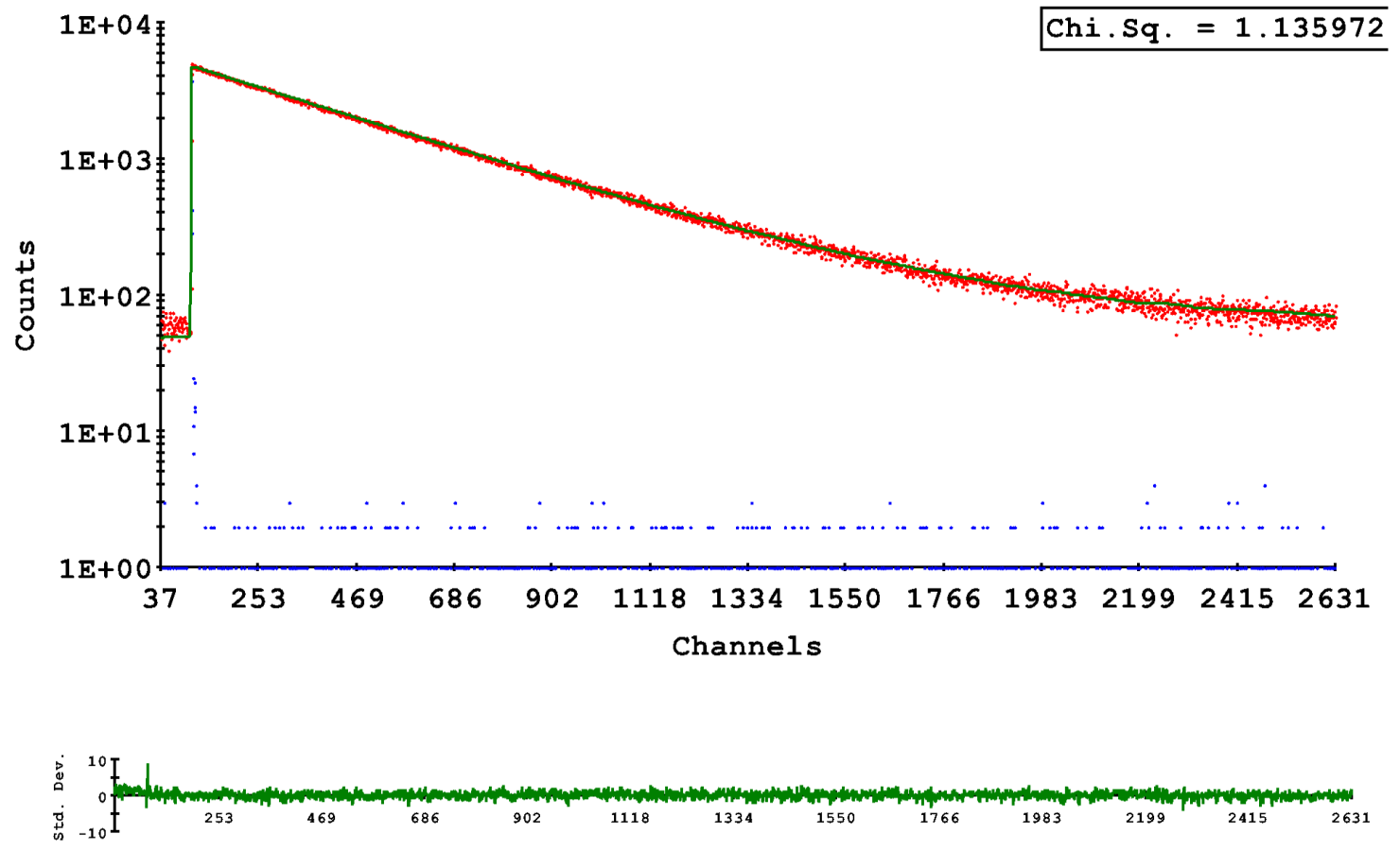

Calculated using 1 exponential

The initial paramters are:

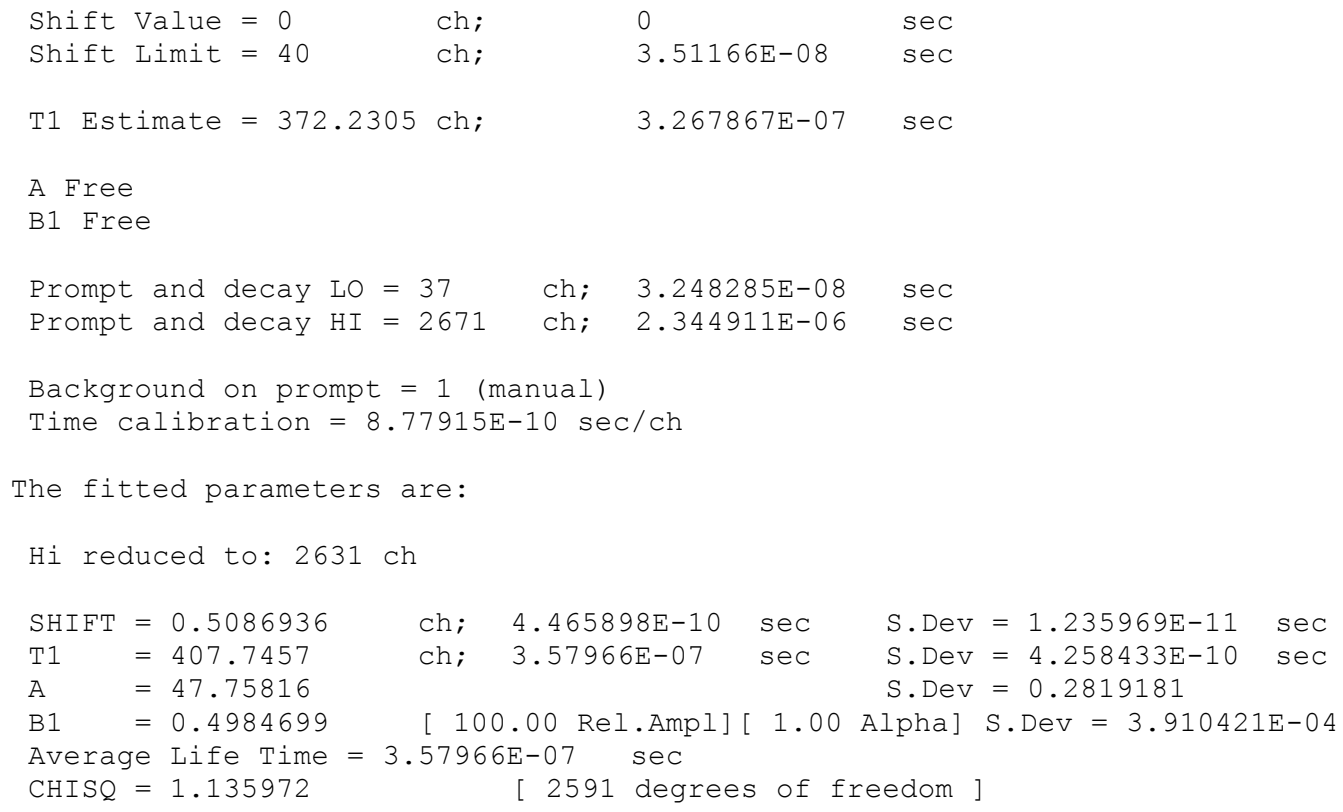




\section{C-1c}
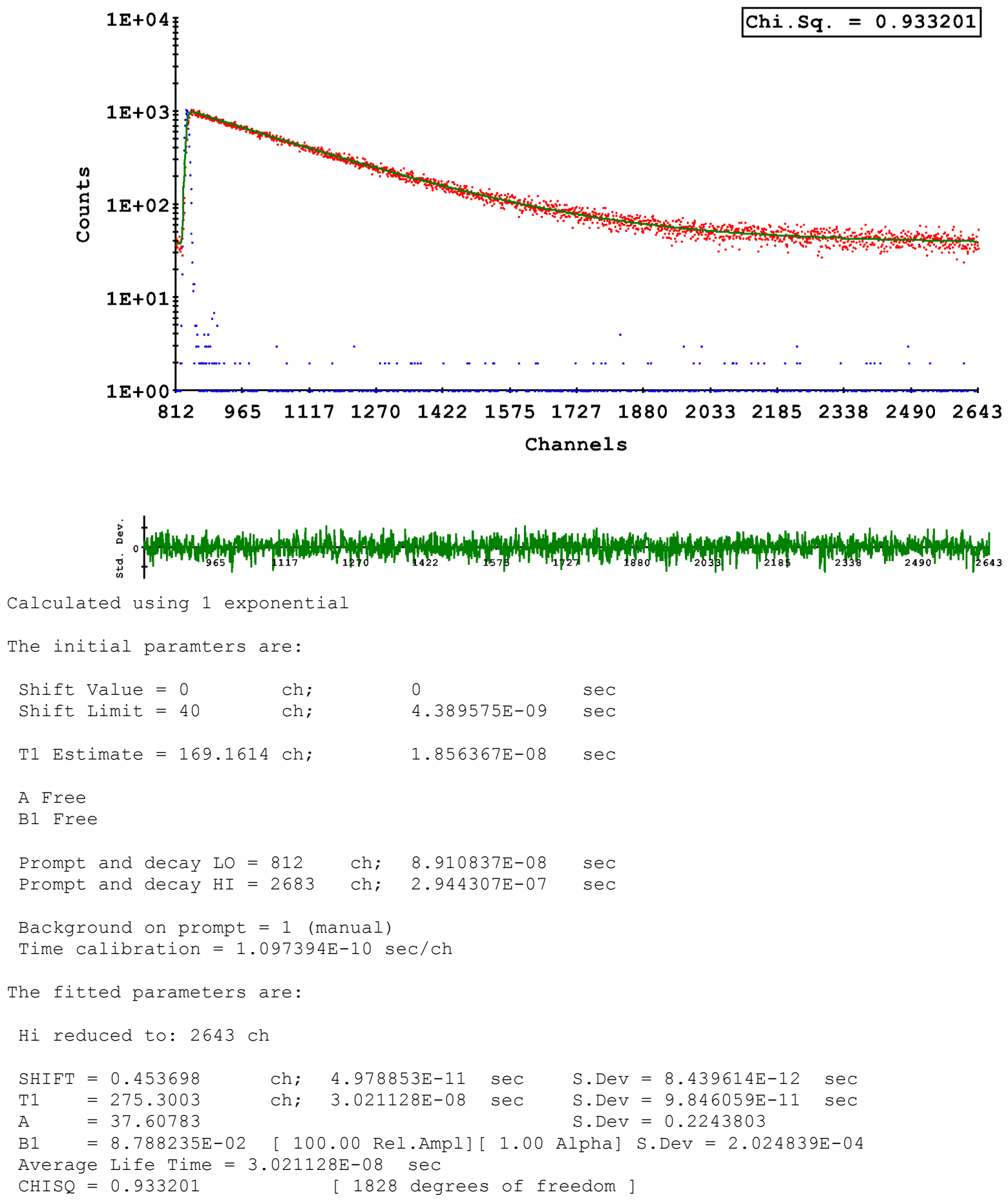


\section{C-1d}
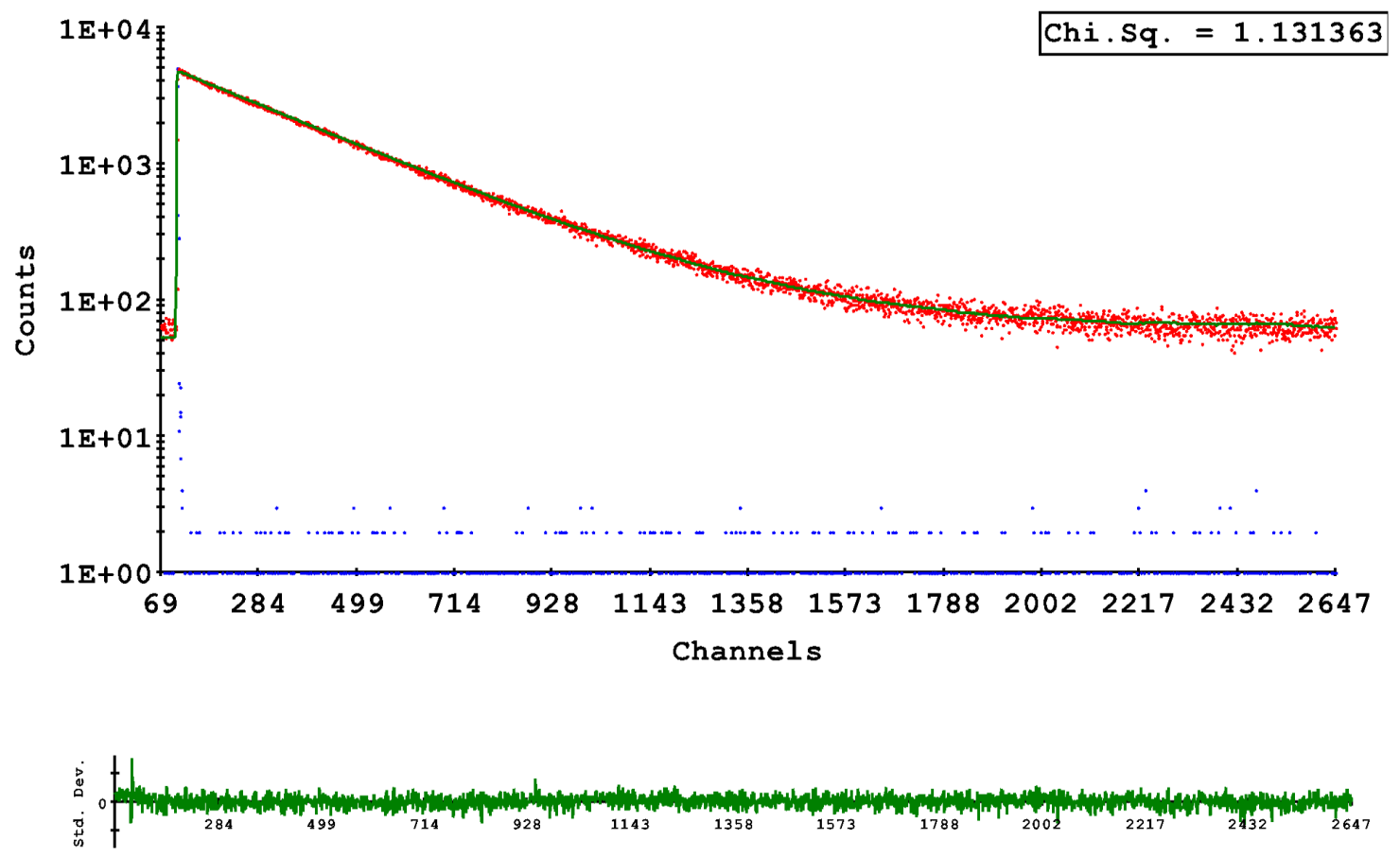

Calculated using 1 exponential

The initial paramters are:

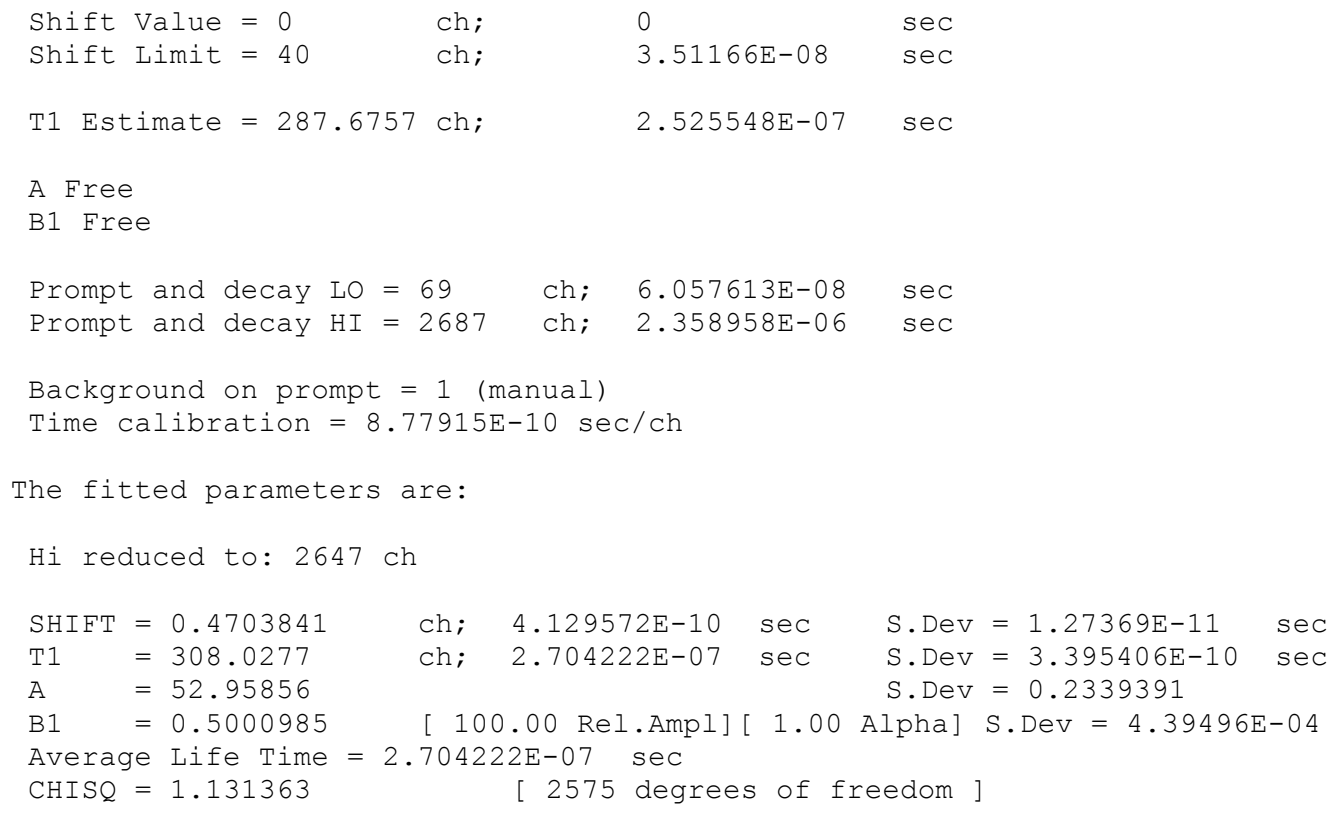




\section{C-1e}
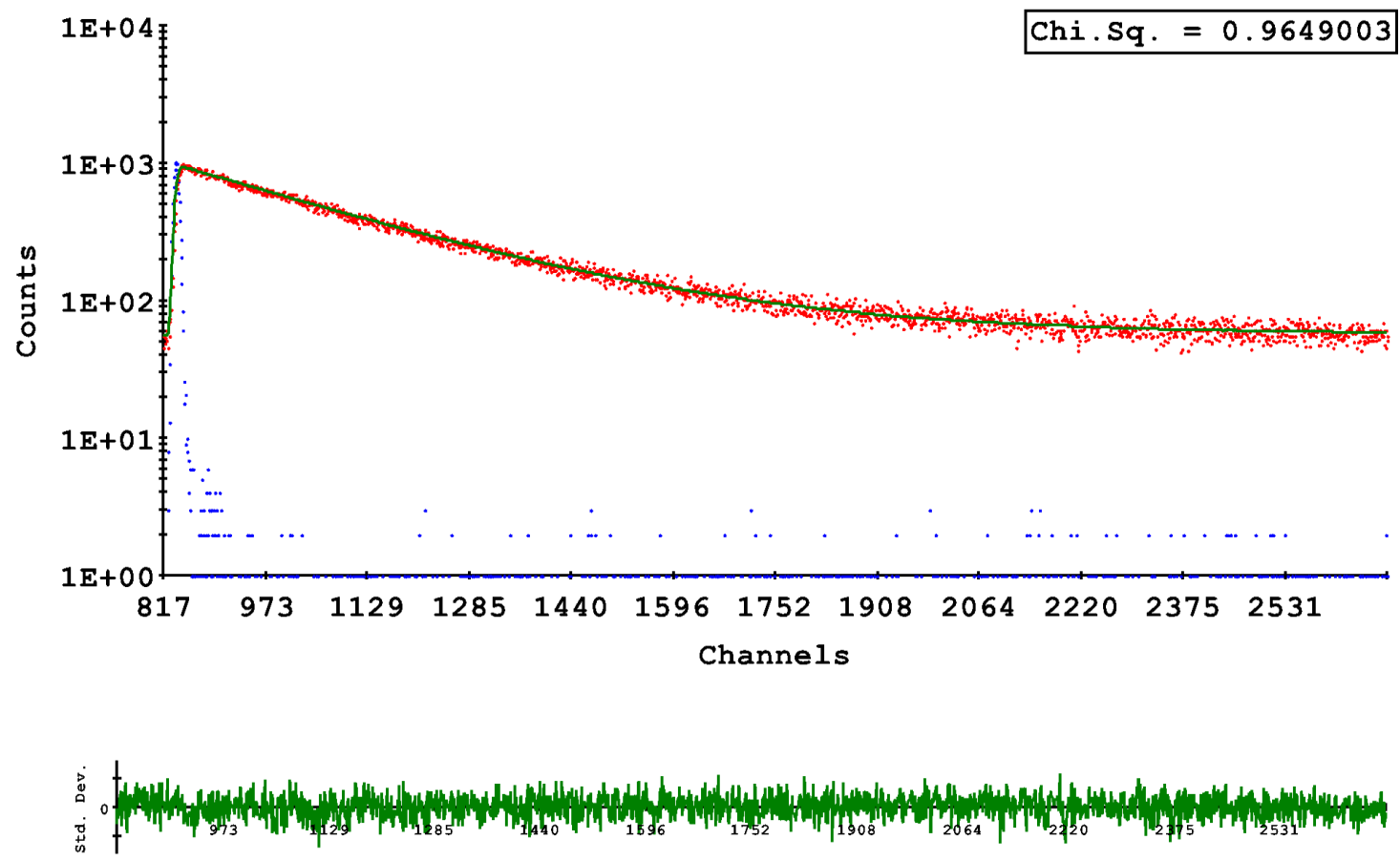

Calculated using 1 exponential

The initial paramters are:

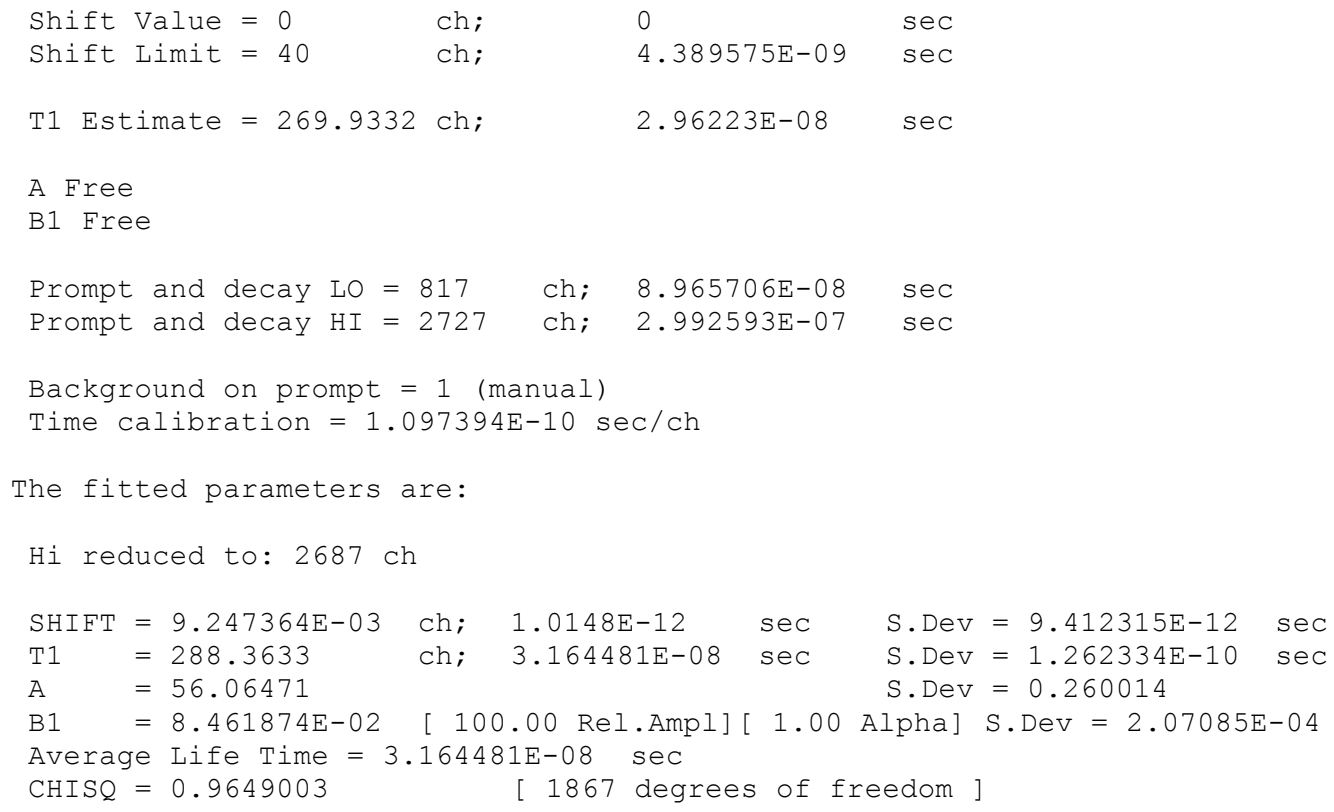




\section{C-1f}
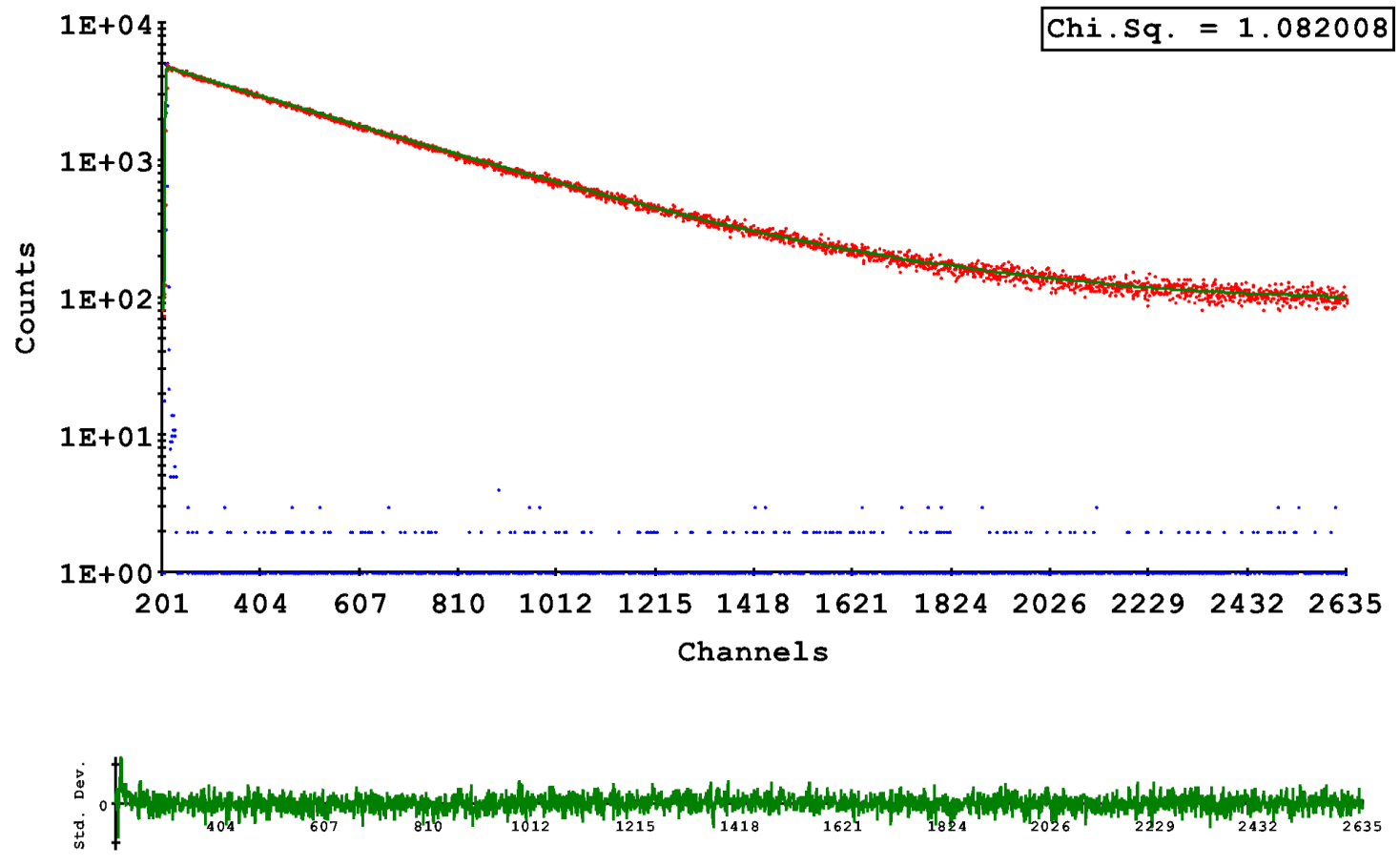

Calculated using 1 exponential

The initial paramters are:

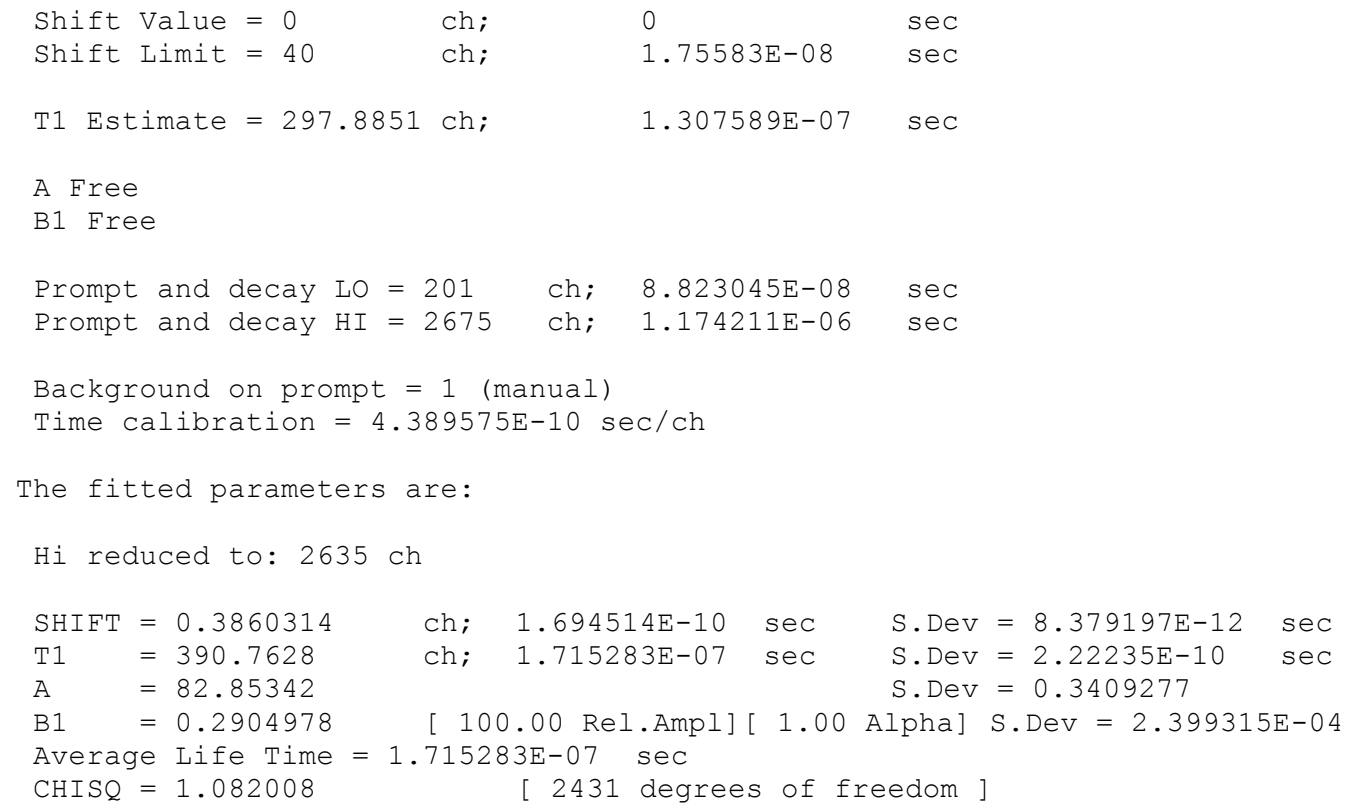




\section{C-1g}
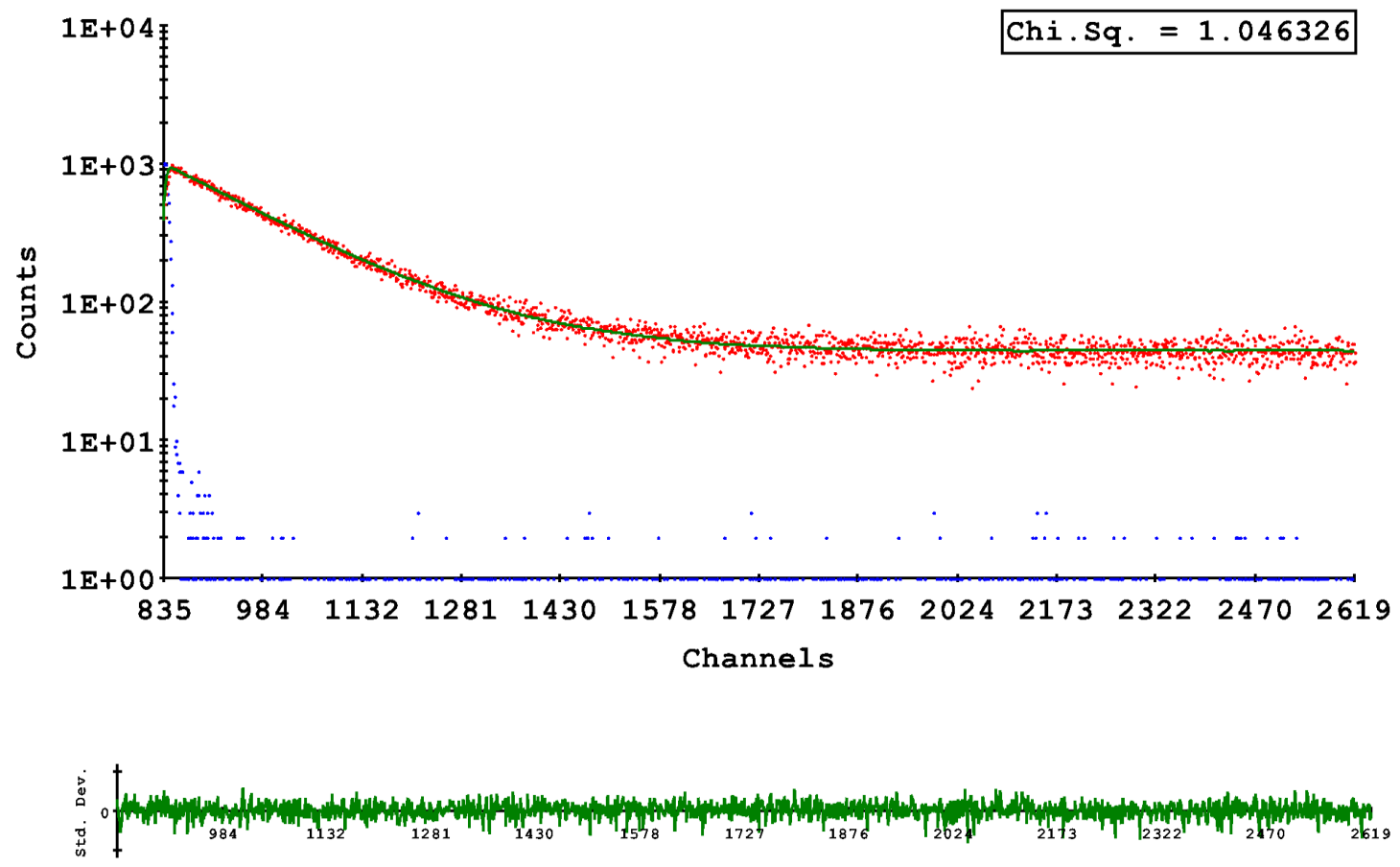

Calculated using 1 exponential

The initial paramters are:

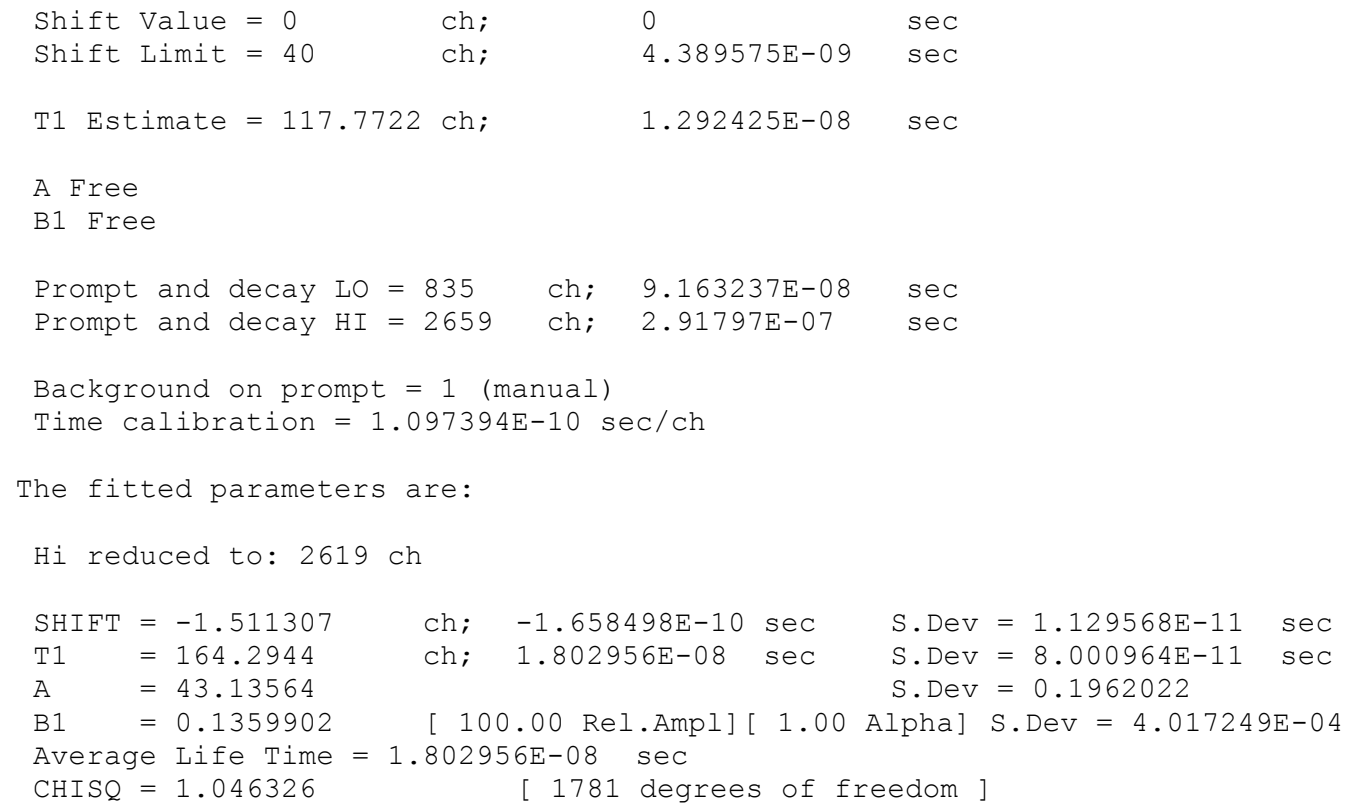




\section{C-2}

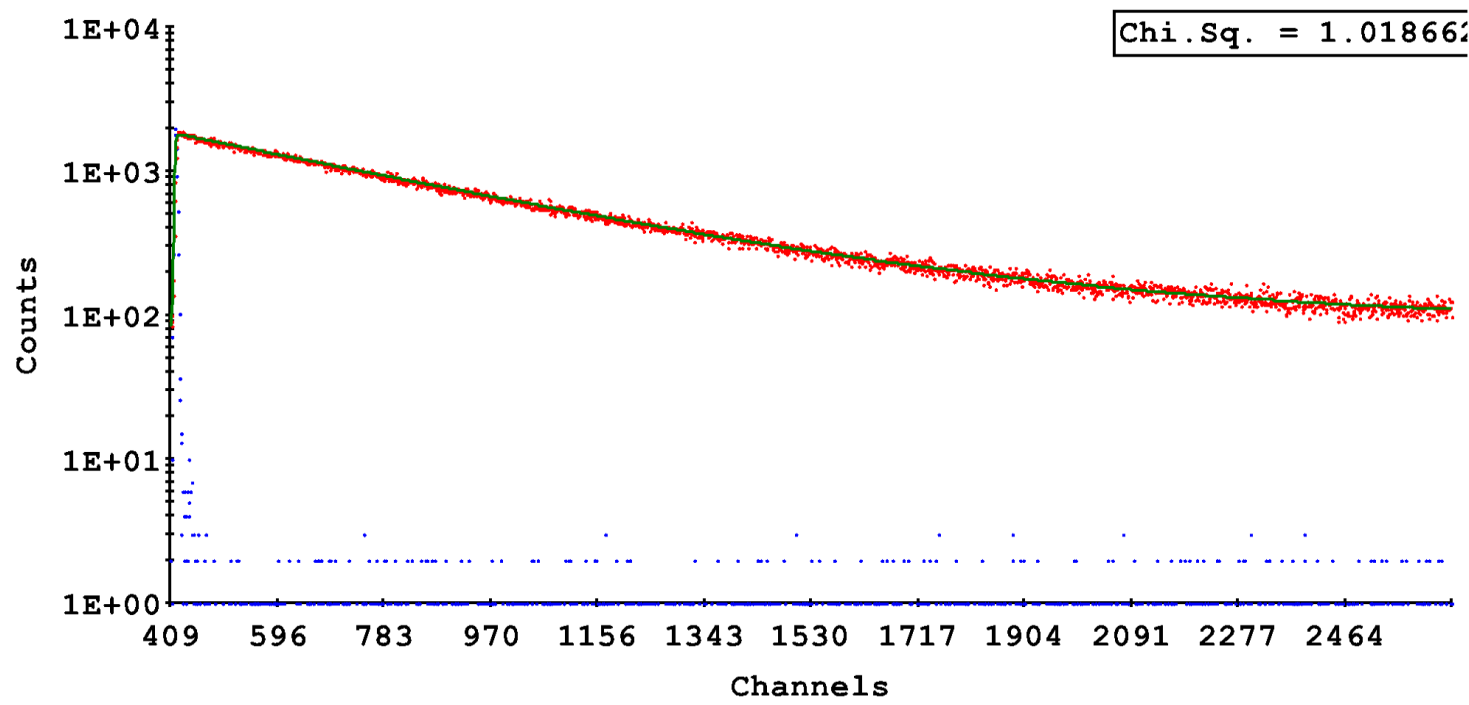

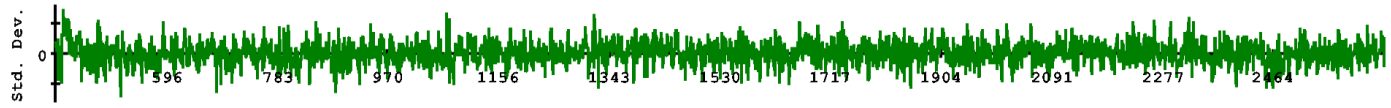

Calculated using 1 exponential

The initial paramters are:

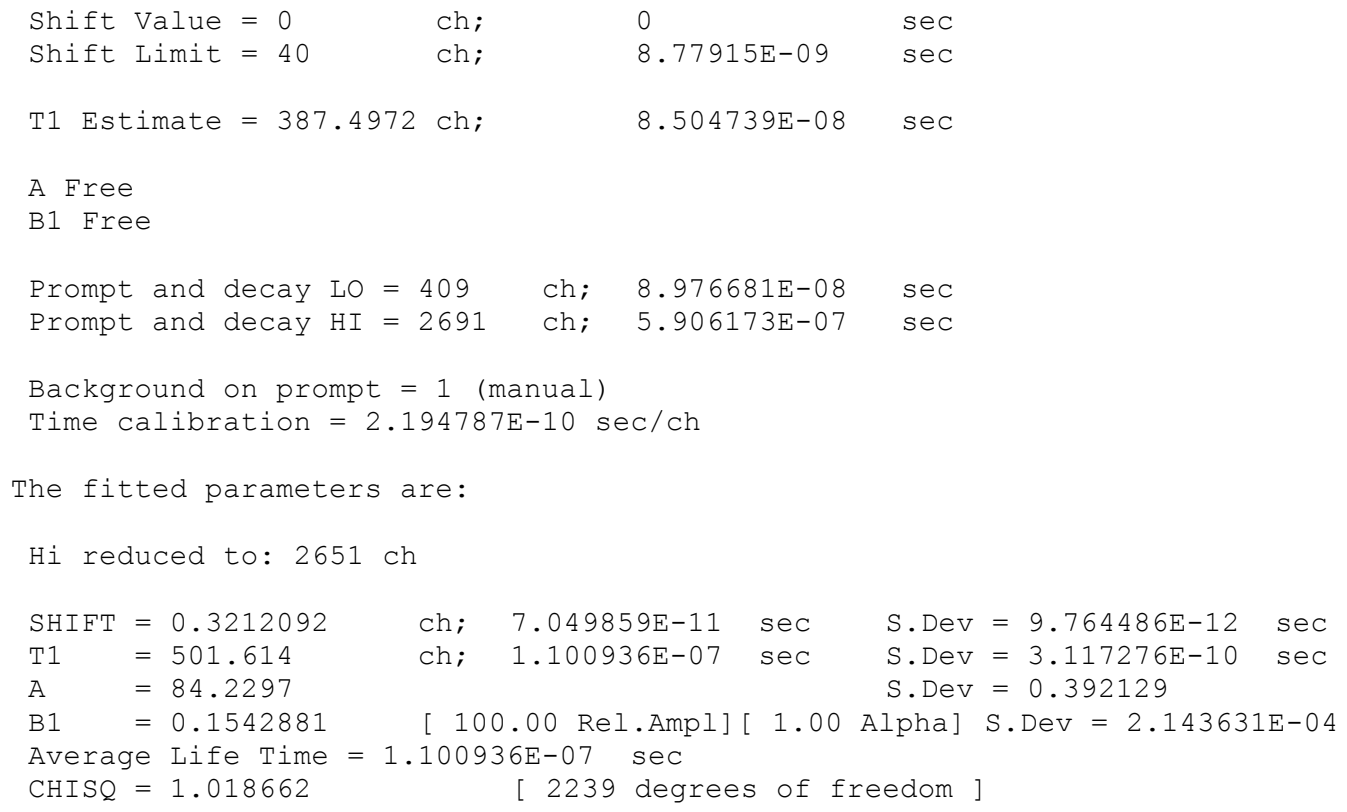




\section{C-3a}

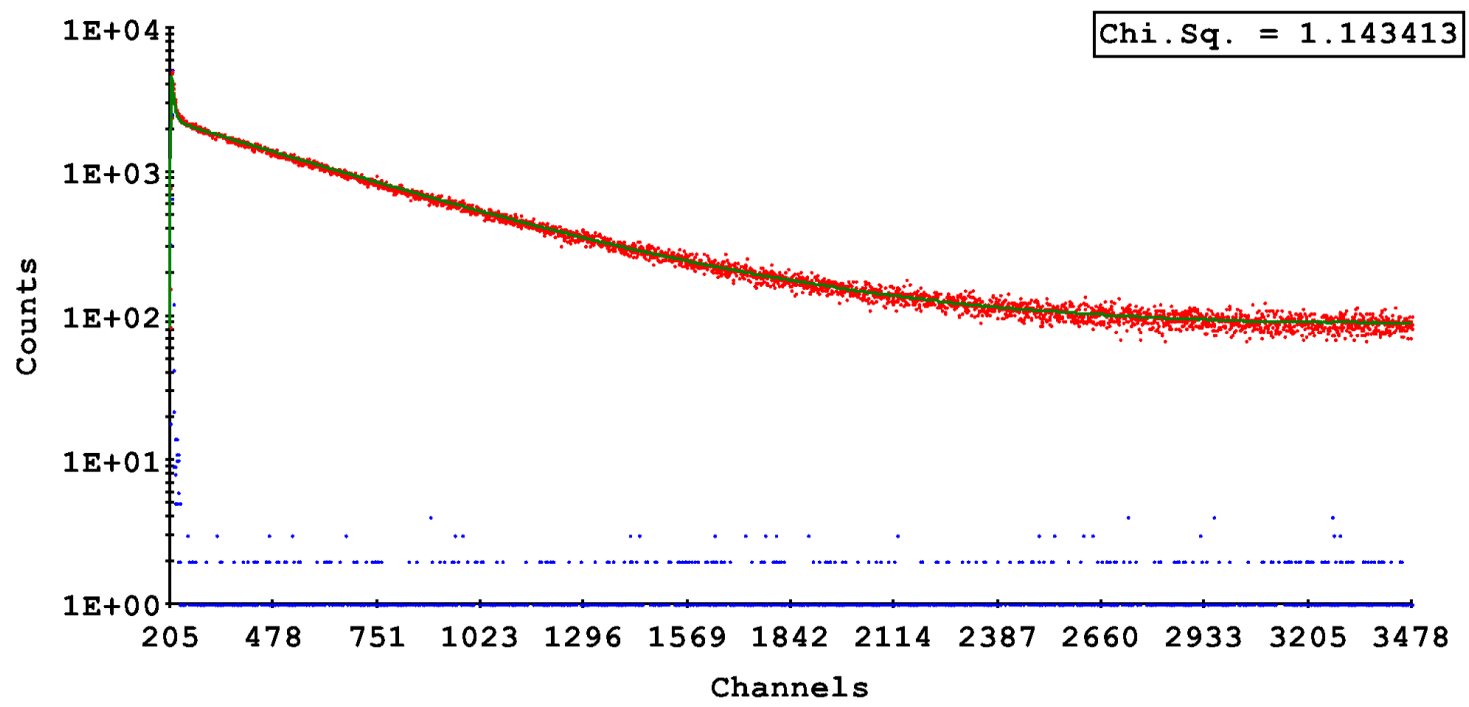

\footnotetext{
竞

Calculated using 2 exponentials

The initial paramters are:

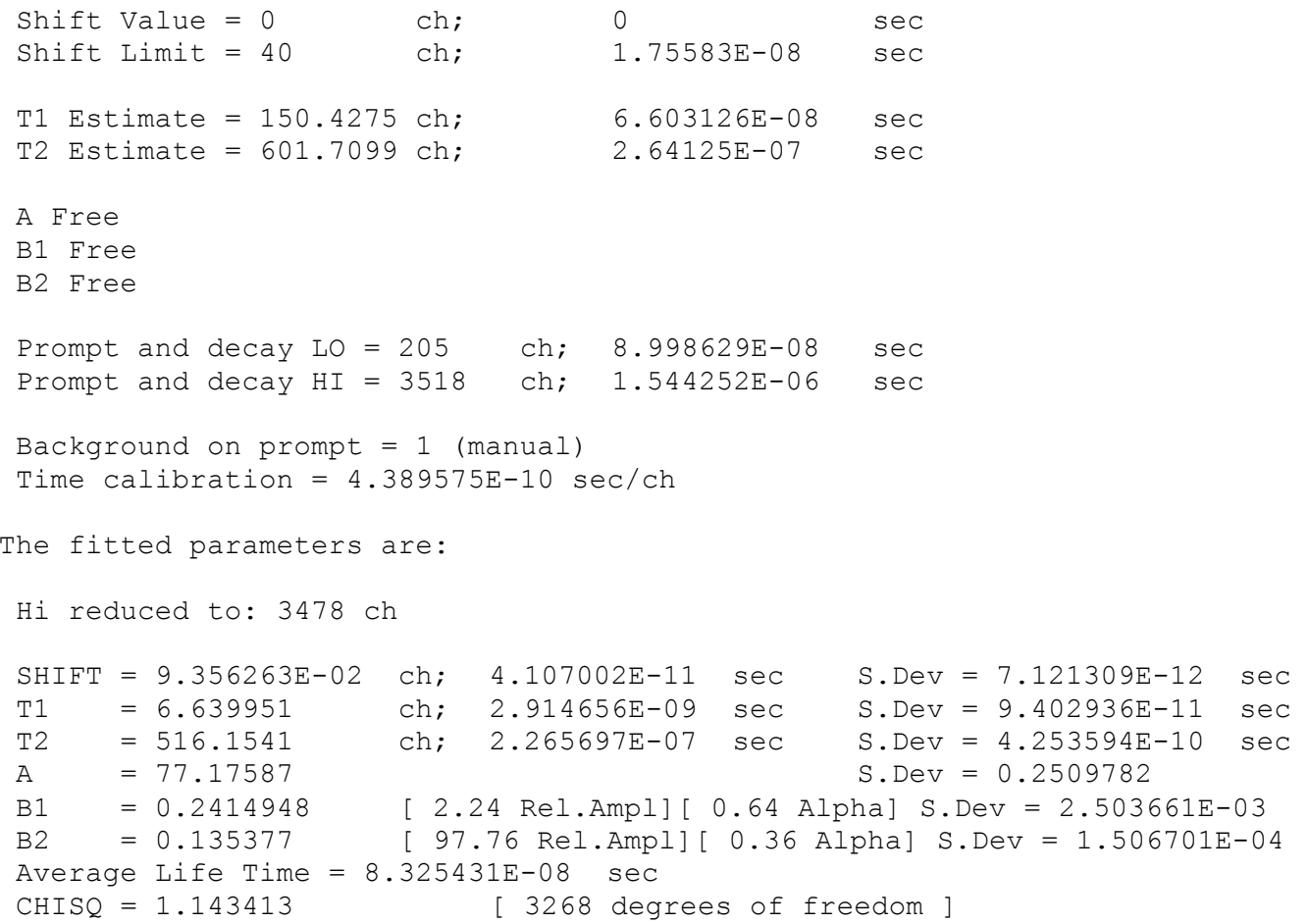




\section{C-3b}
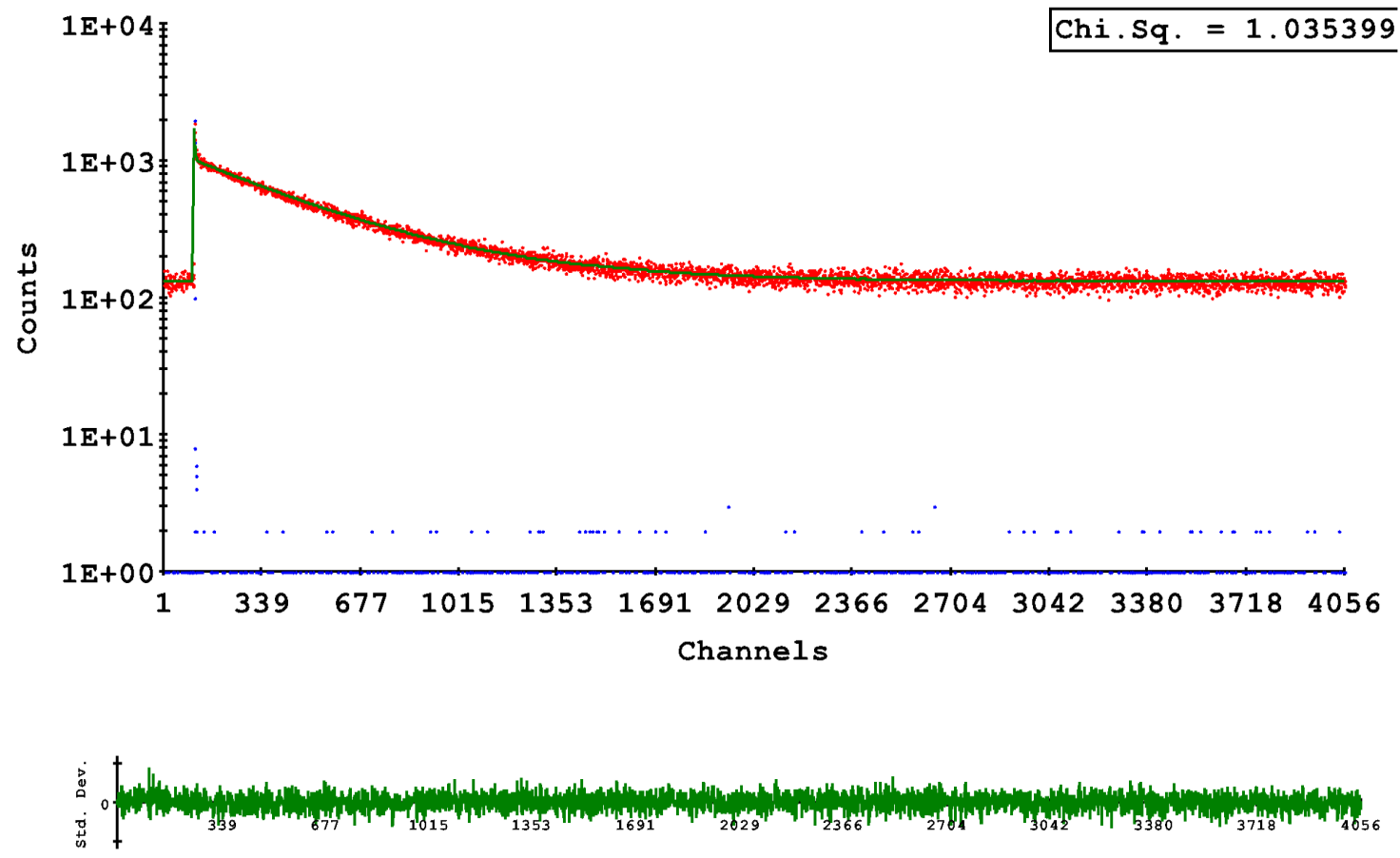

Calculated using 2 exponentials

The initial paramters are:

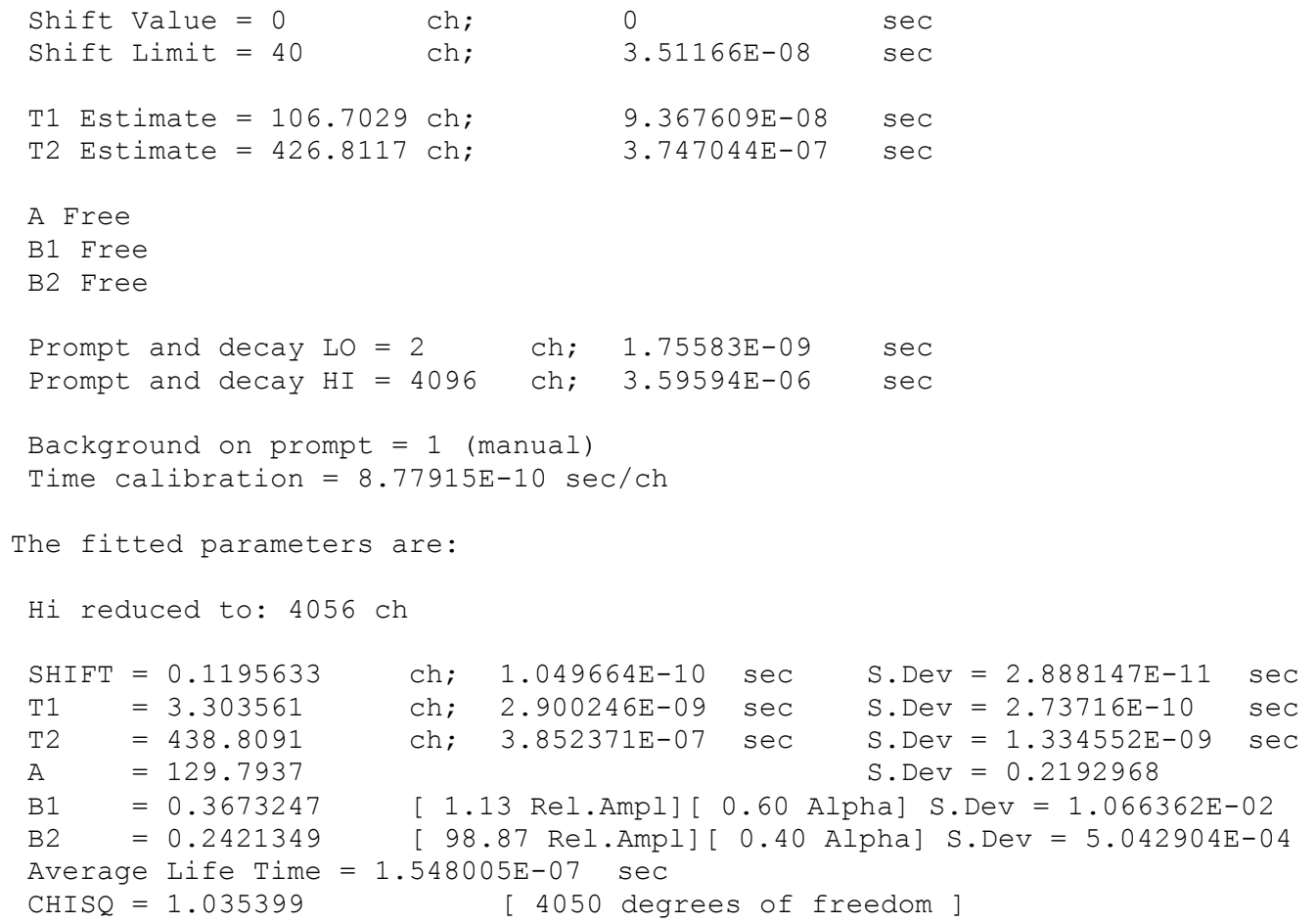




\section{C-3c}
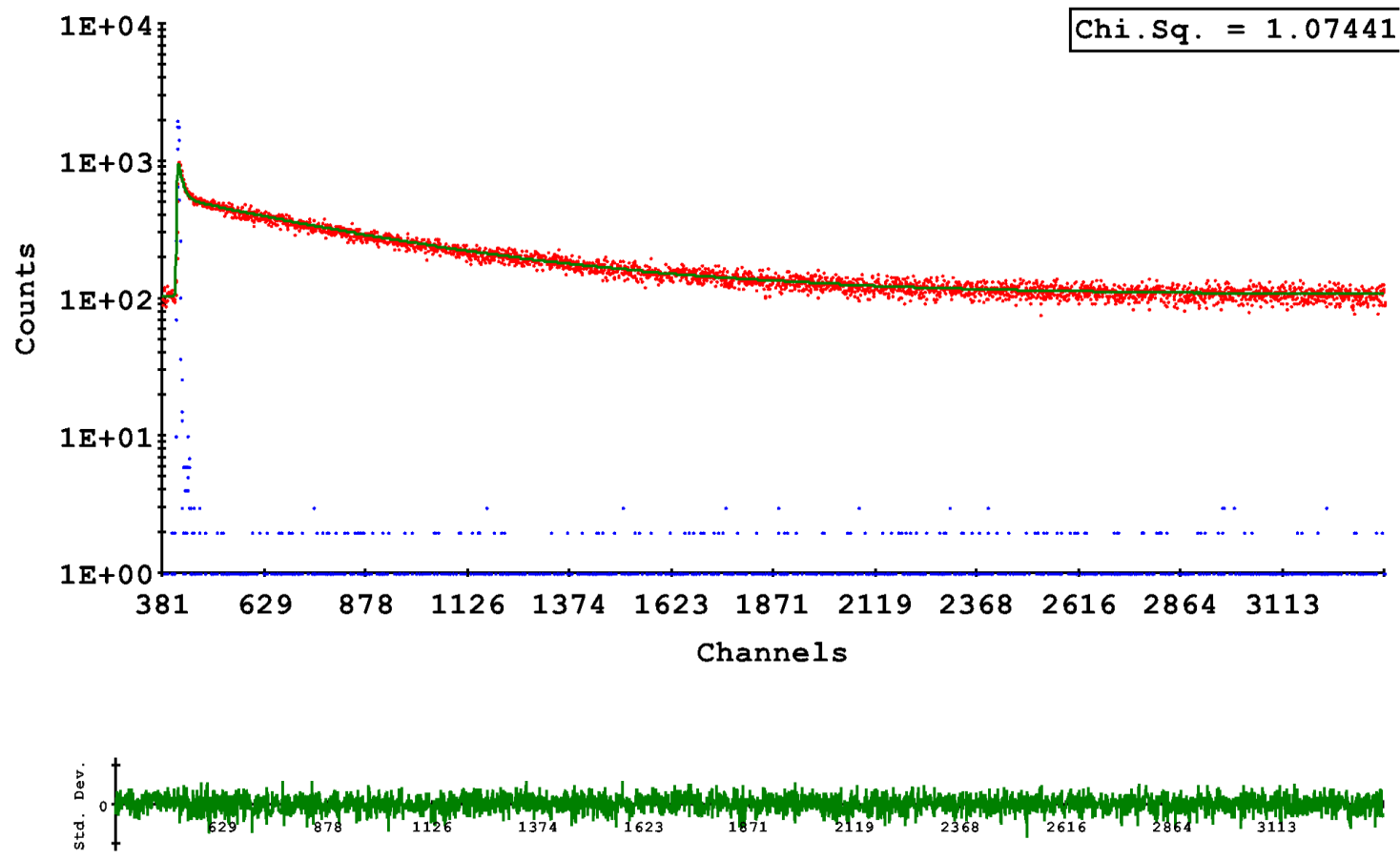

Calculated using 2 exponentials

The initial paramters are:

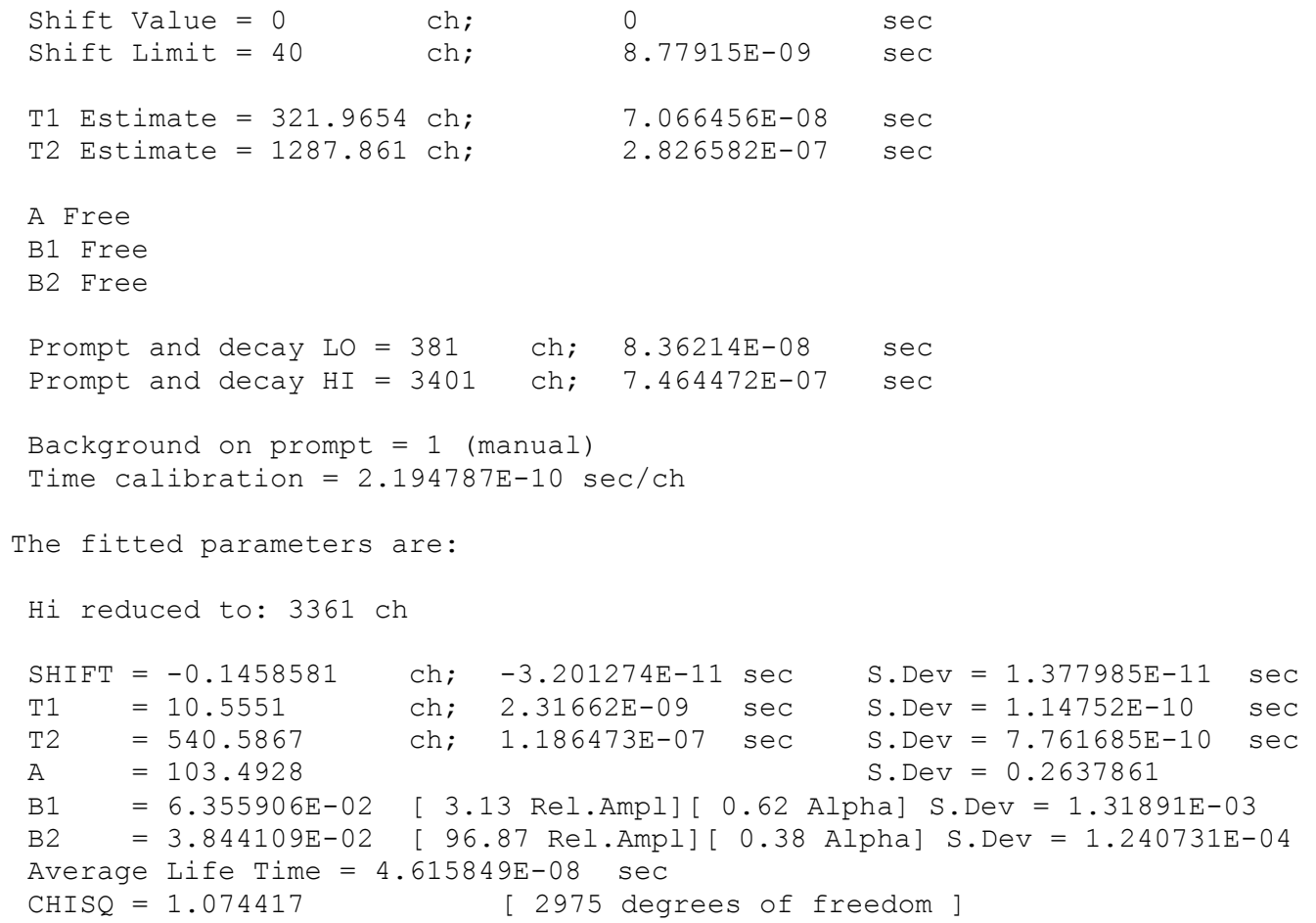




\title{
NMR Spectra
}

Application of 1, 2, 3-Triazole in Gold Catalysis and Photoredox Catalysis

\author{
Rong Cai
}


Chapter S1. Gold-Catalyzed Synthesis of Triazapentalene Zwitterions

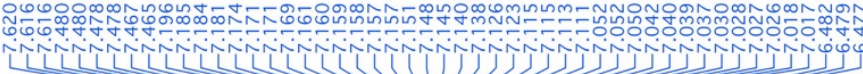

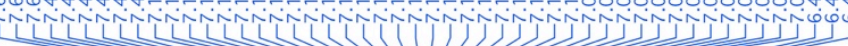

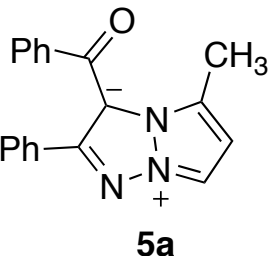

$5 a$

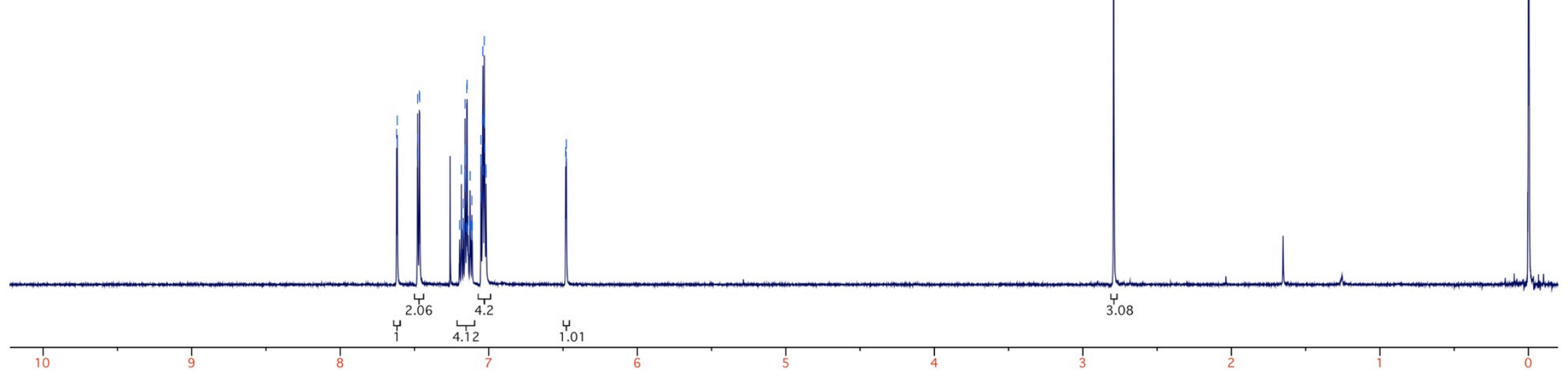




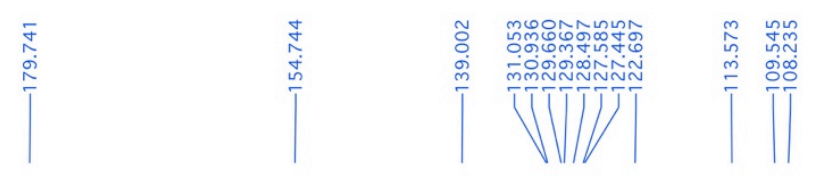

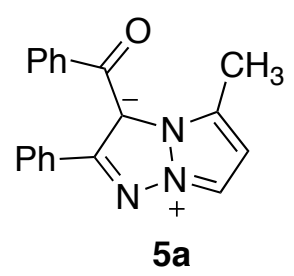

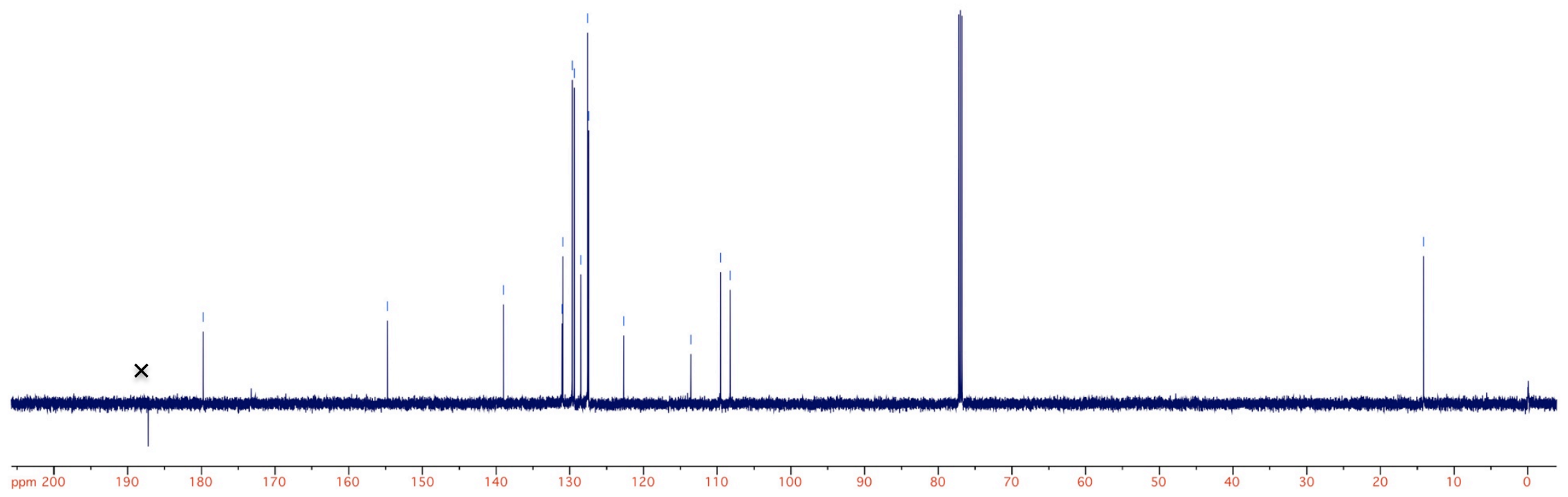



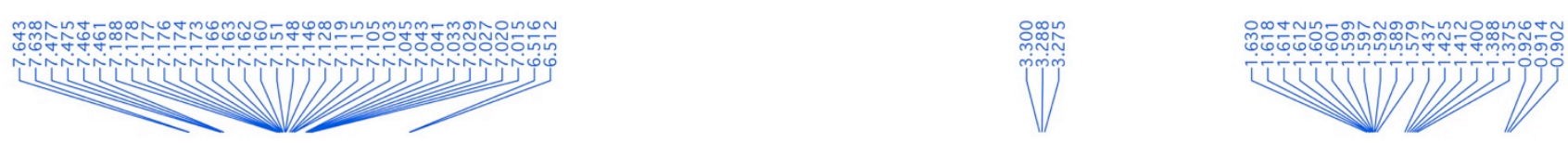

$$
\sum_{\substack{\mathrm{N}_{-}^{-N} \\+}}^{\mathrm{N}}
$$

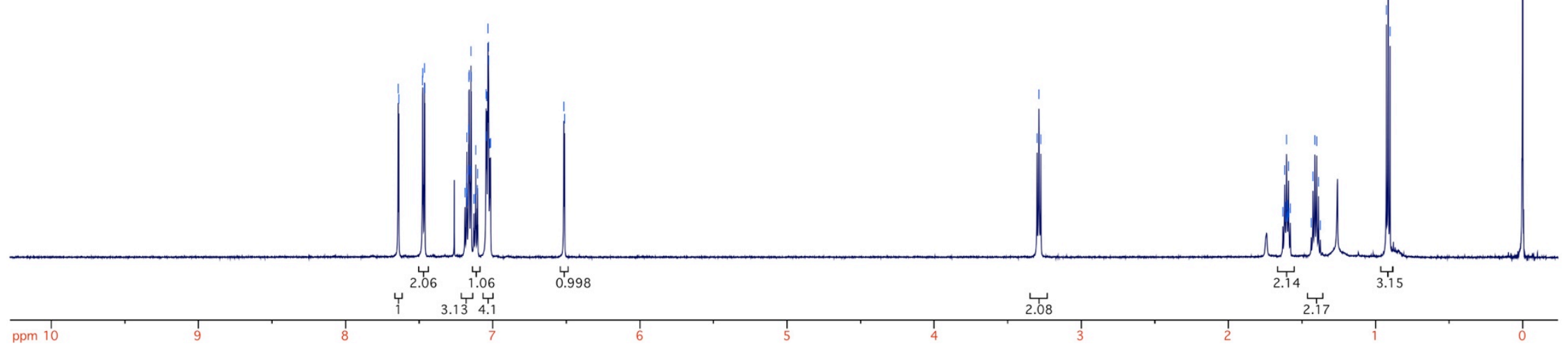



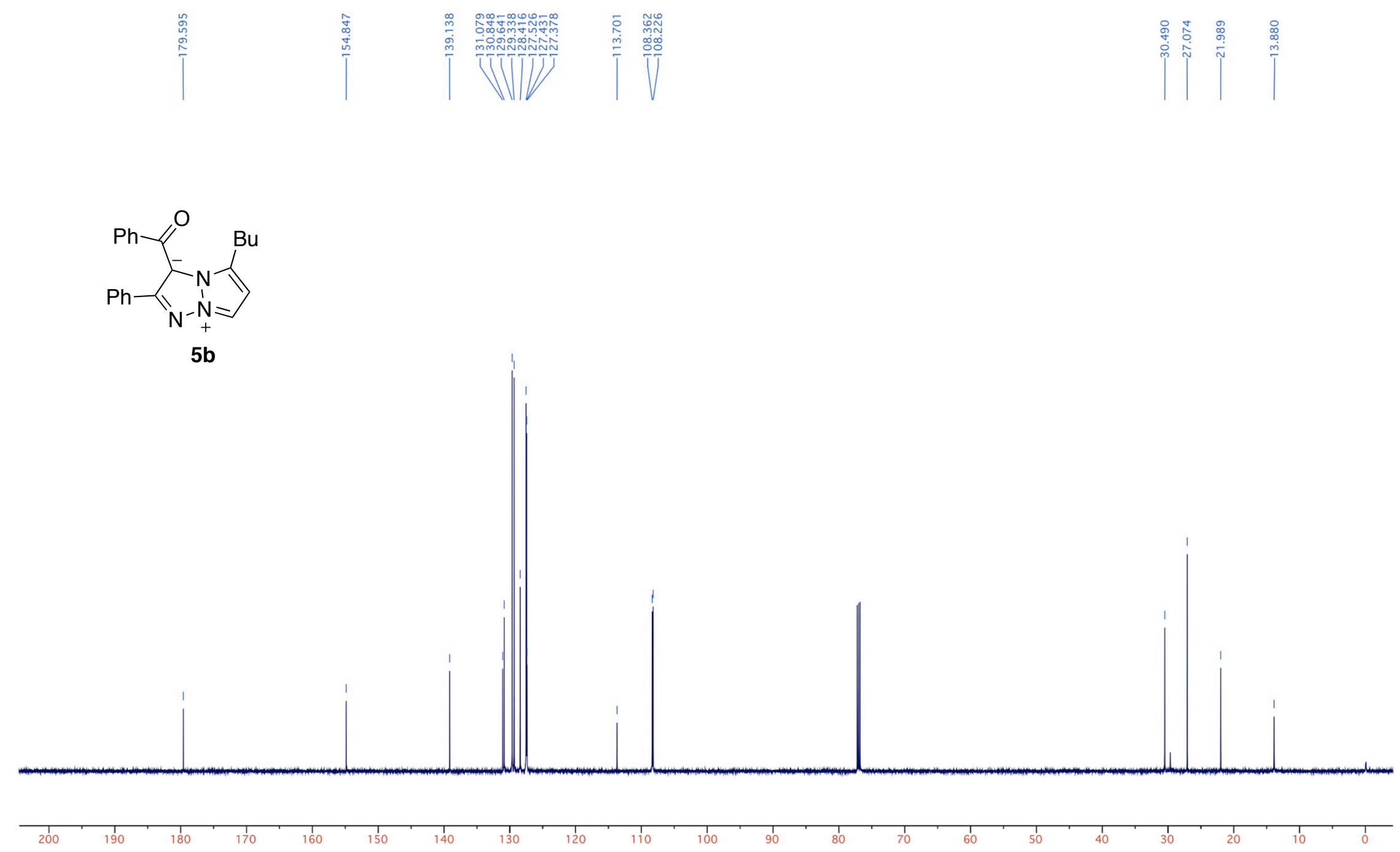

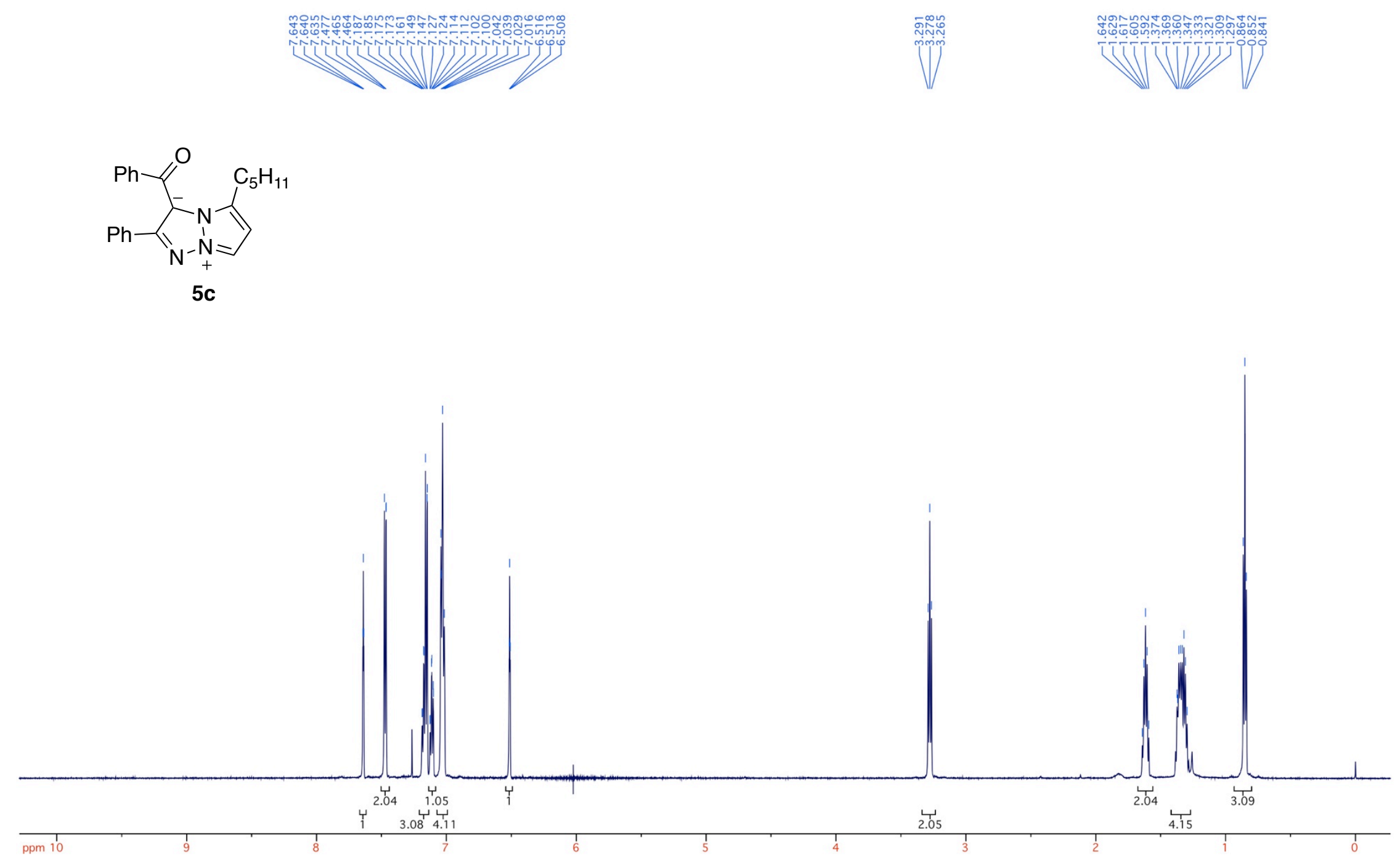


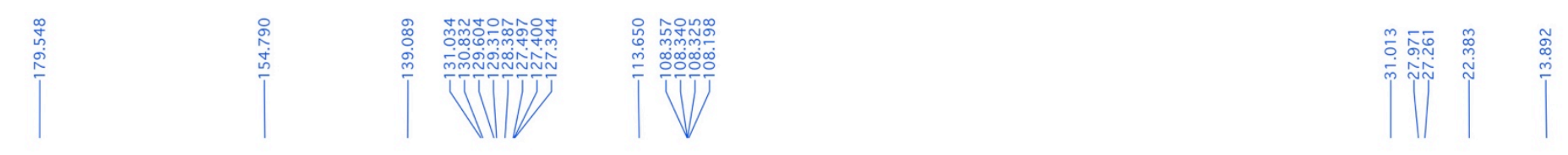

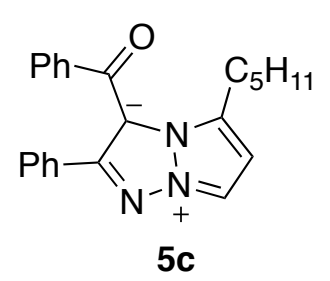

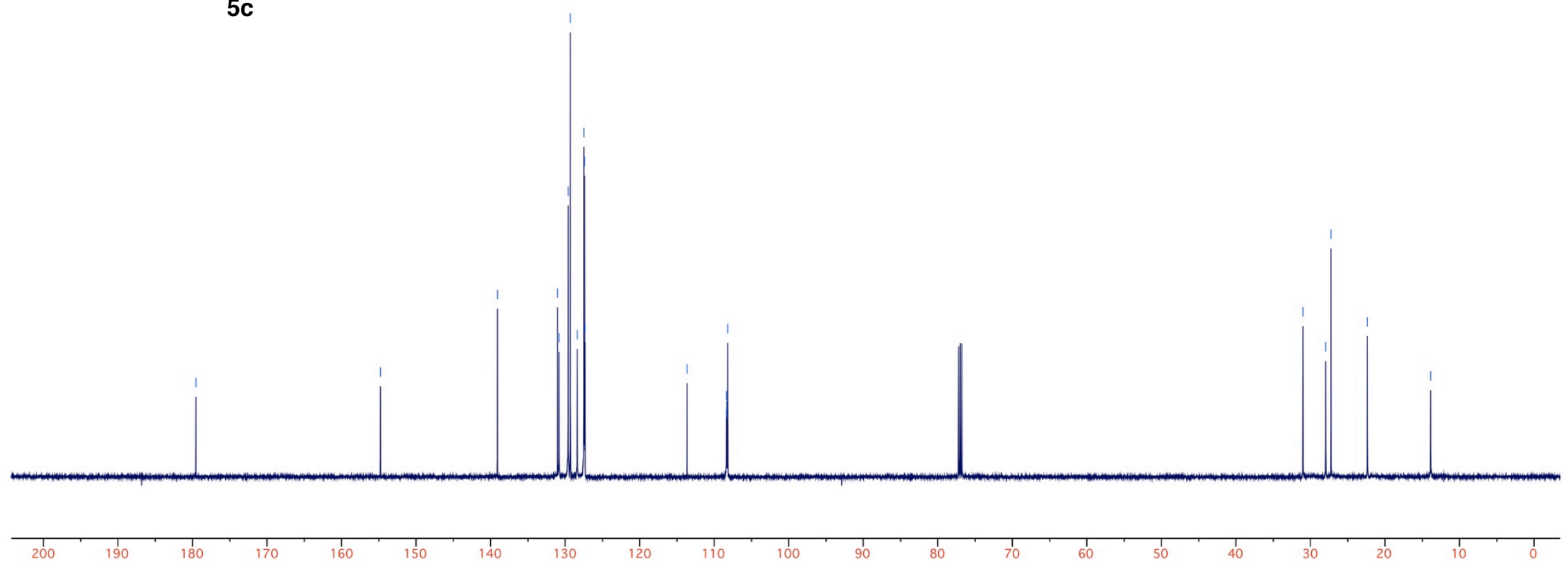



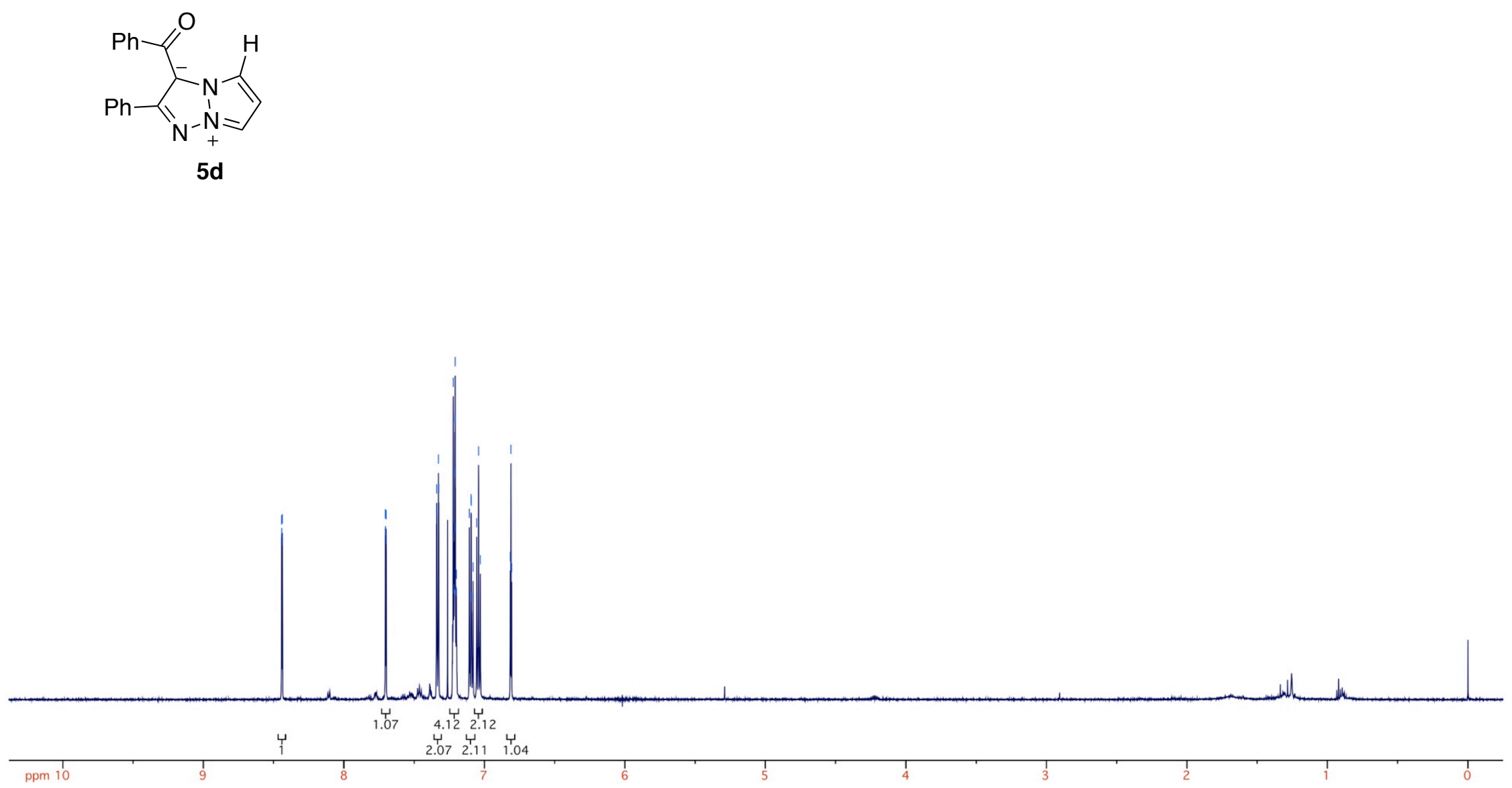
DW-2-216A-13C

Pulse Sequence: s2pul
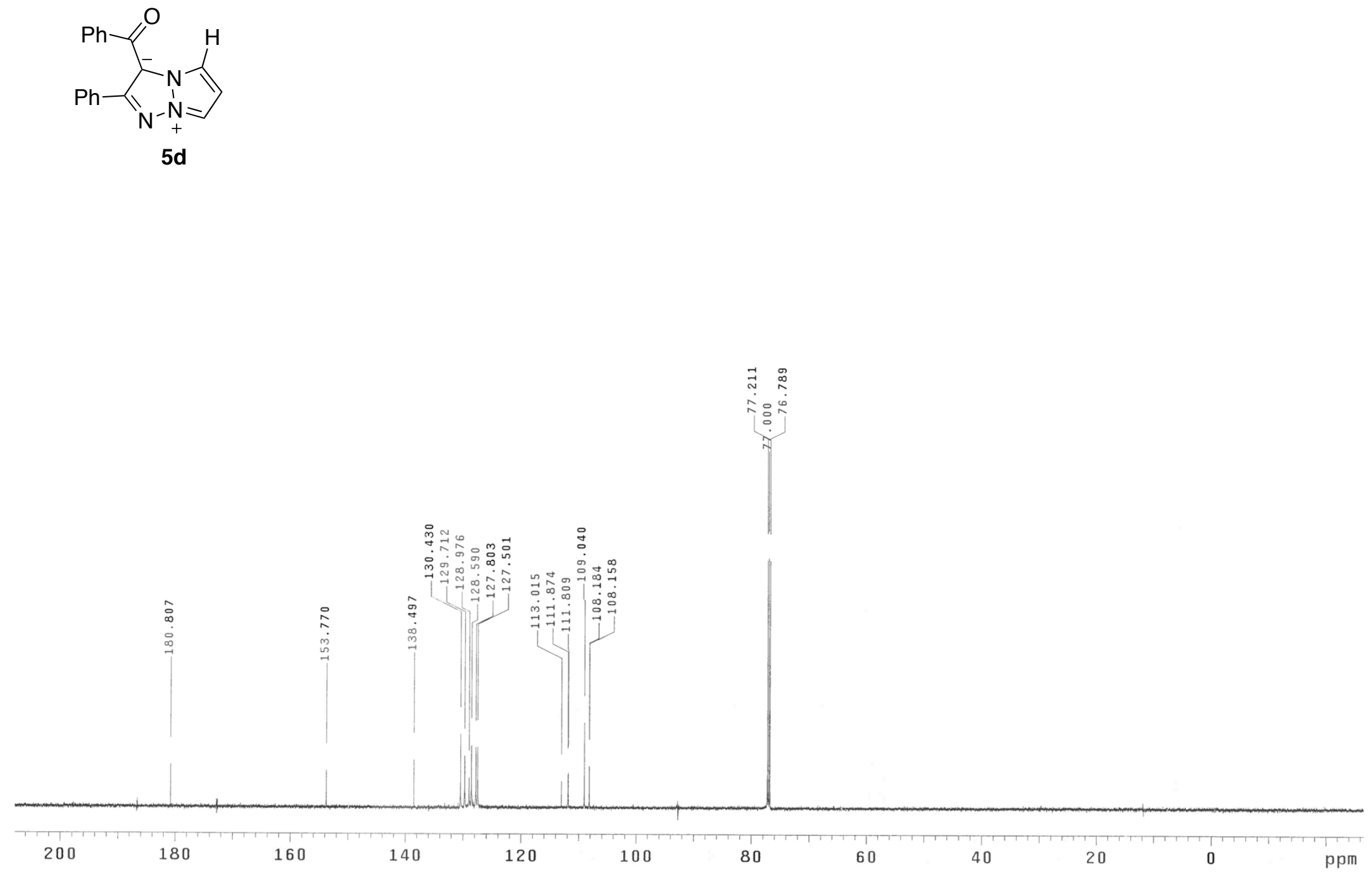

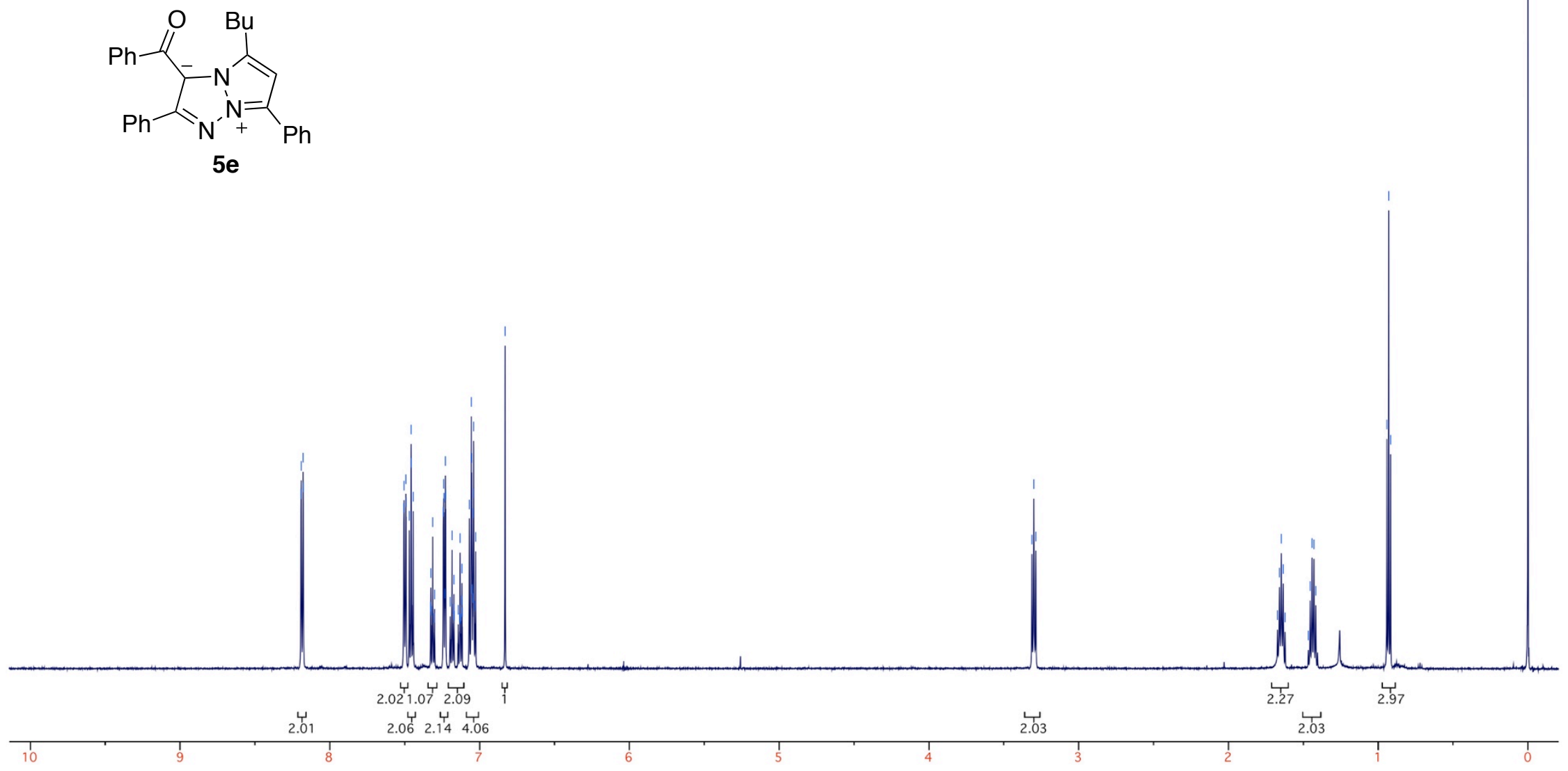


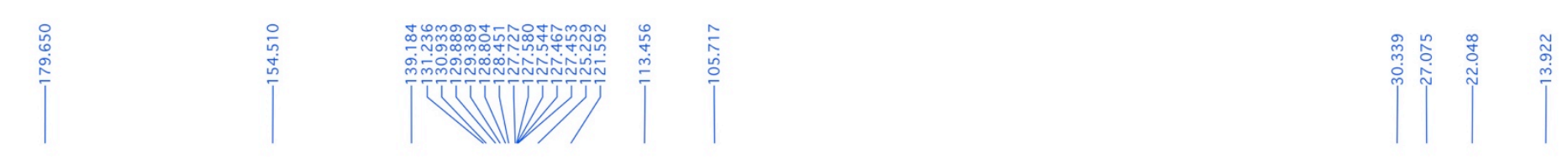

$$
\underbrace{}_{5 e}
$$

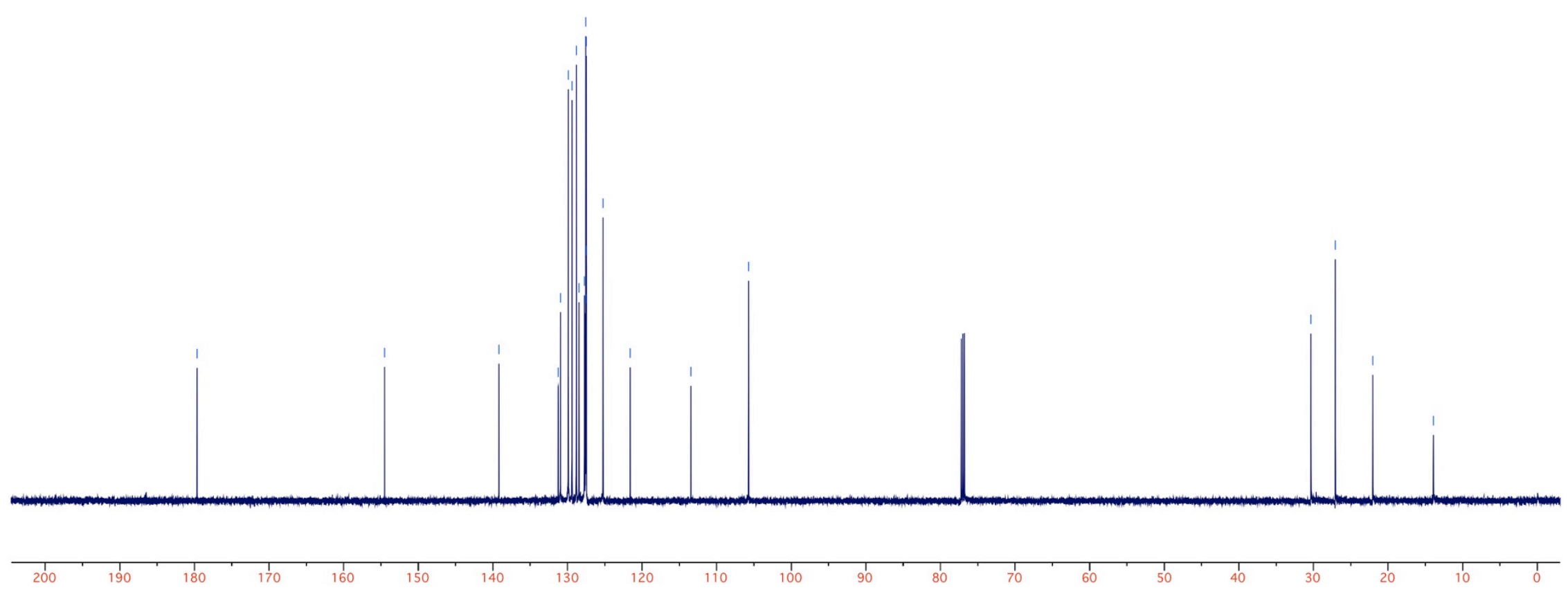



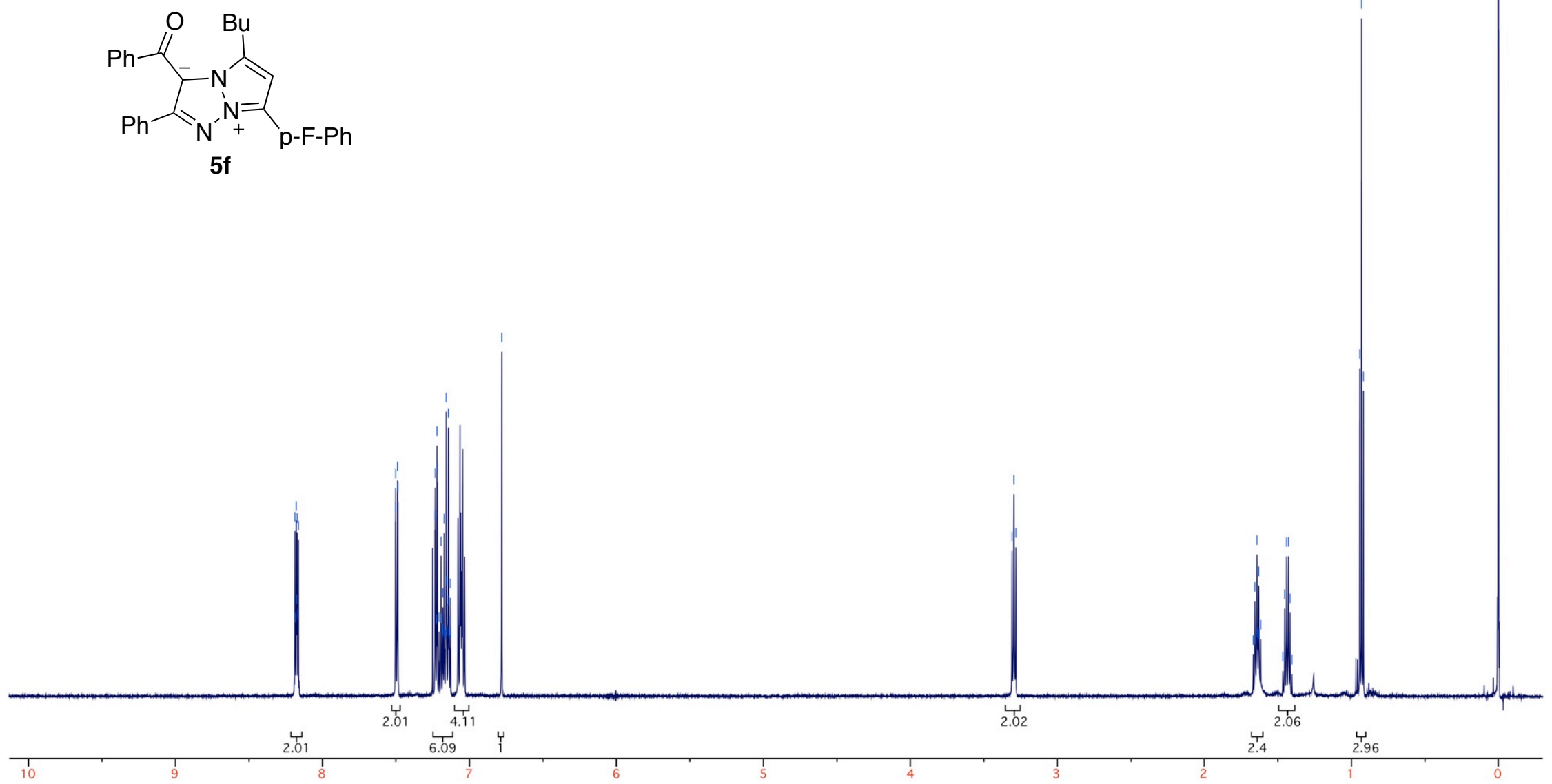


$$
\underbrace{-}_{\mathbf{5}}
$$

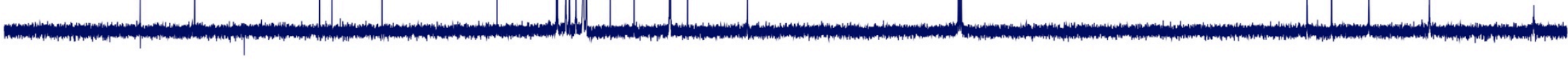



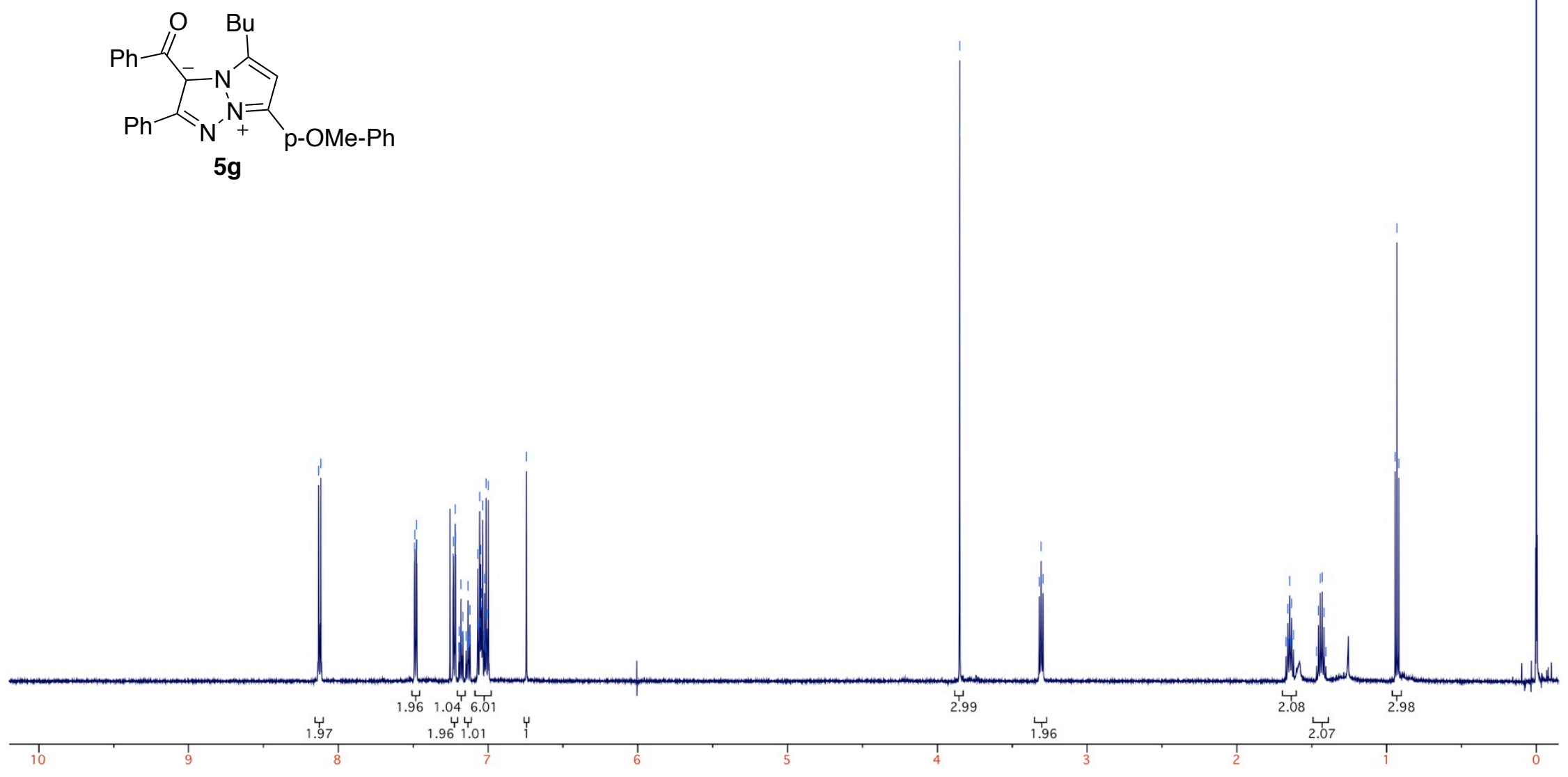

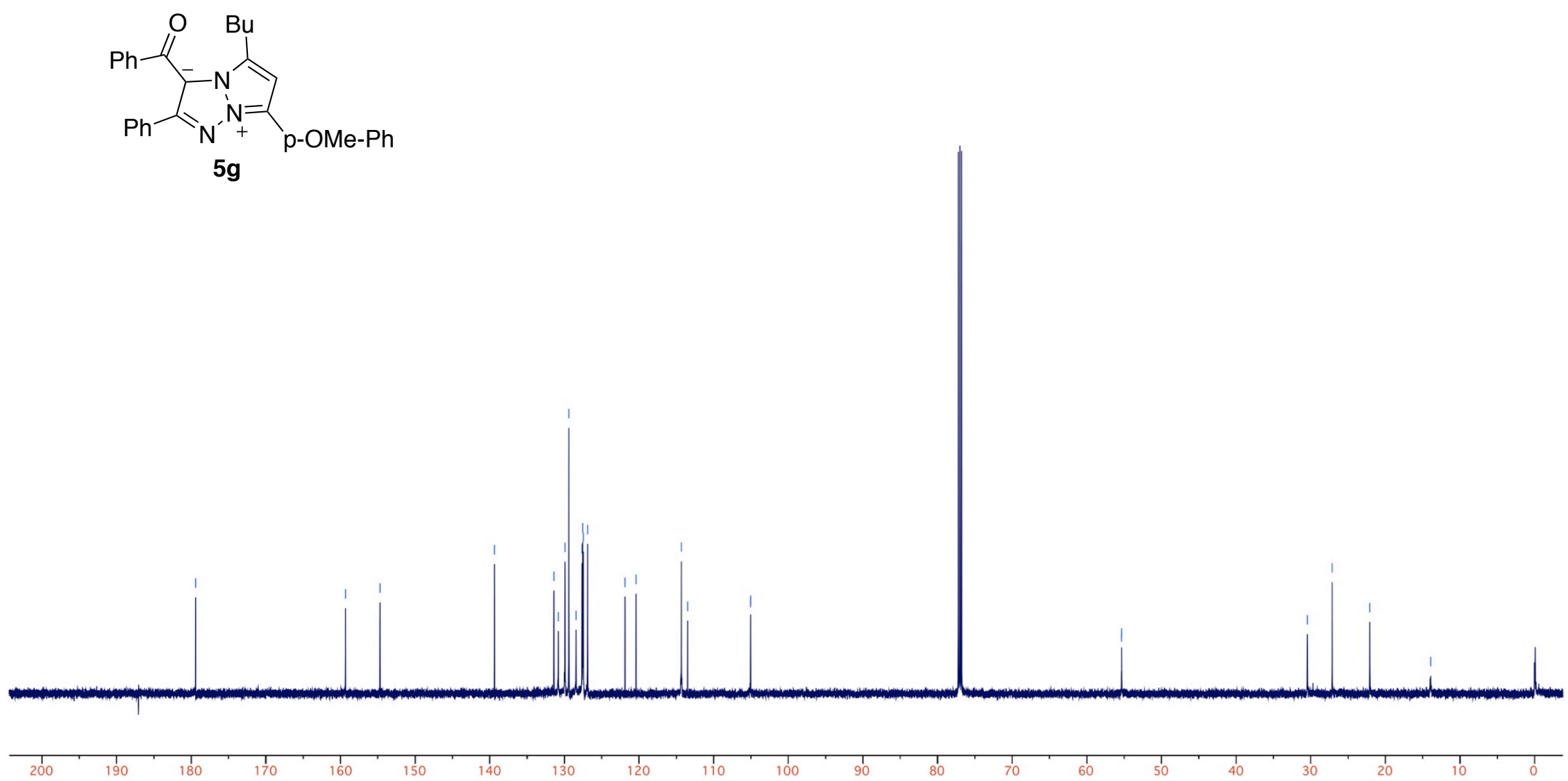

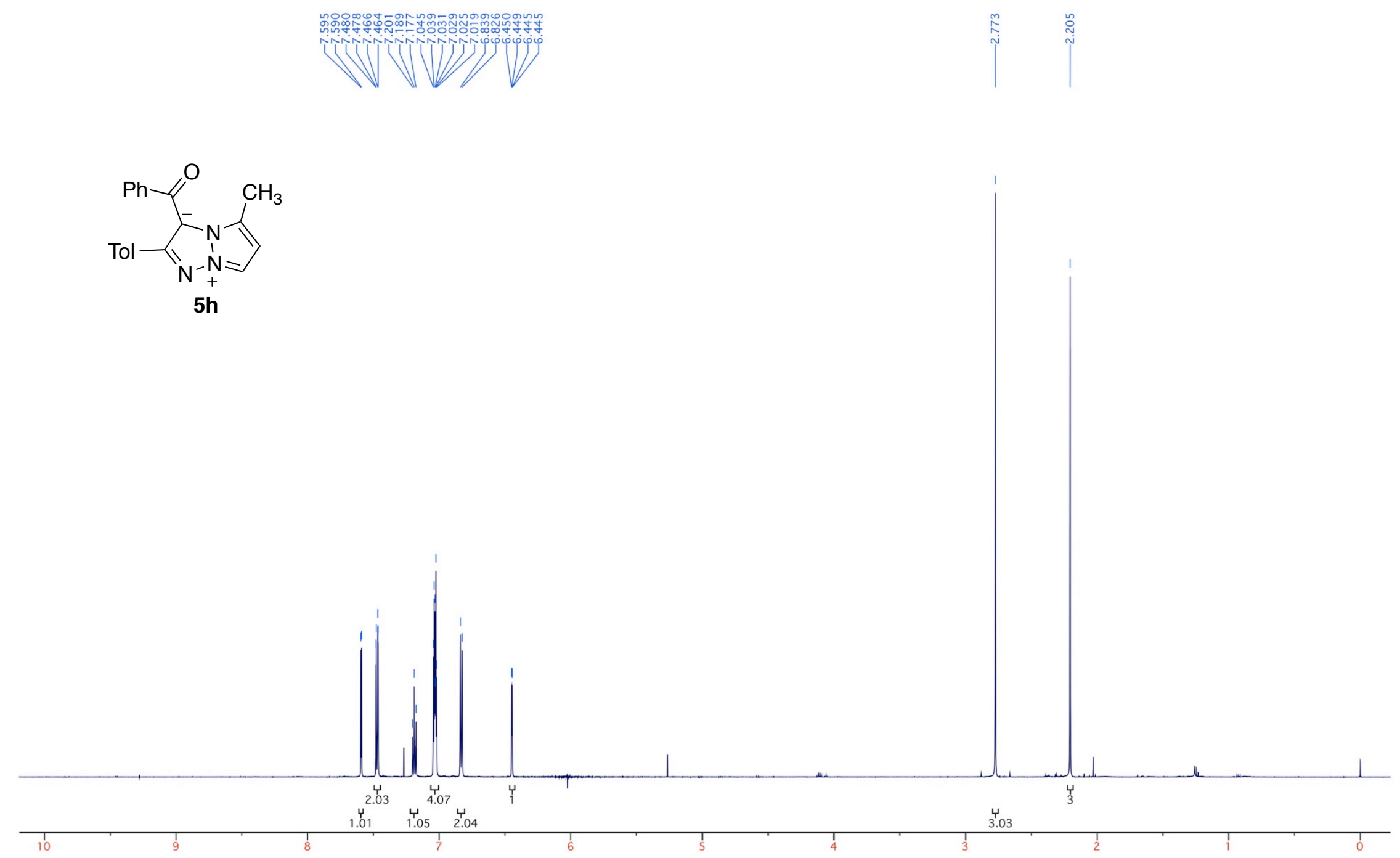

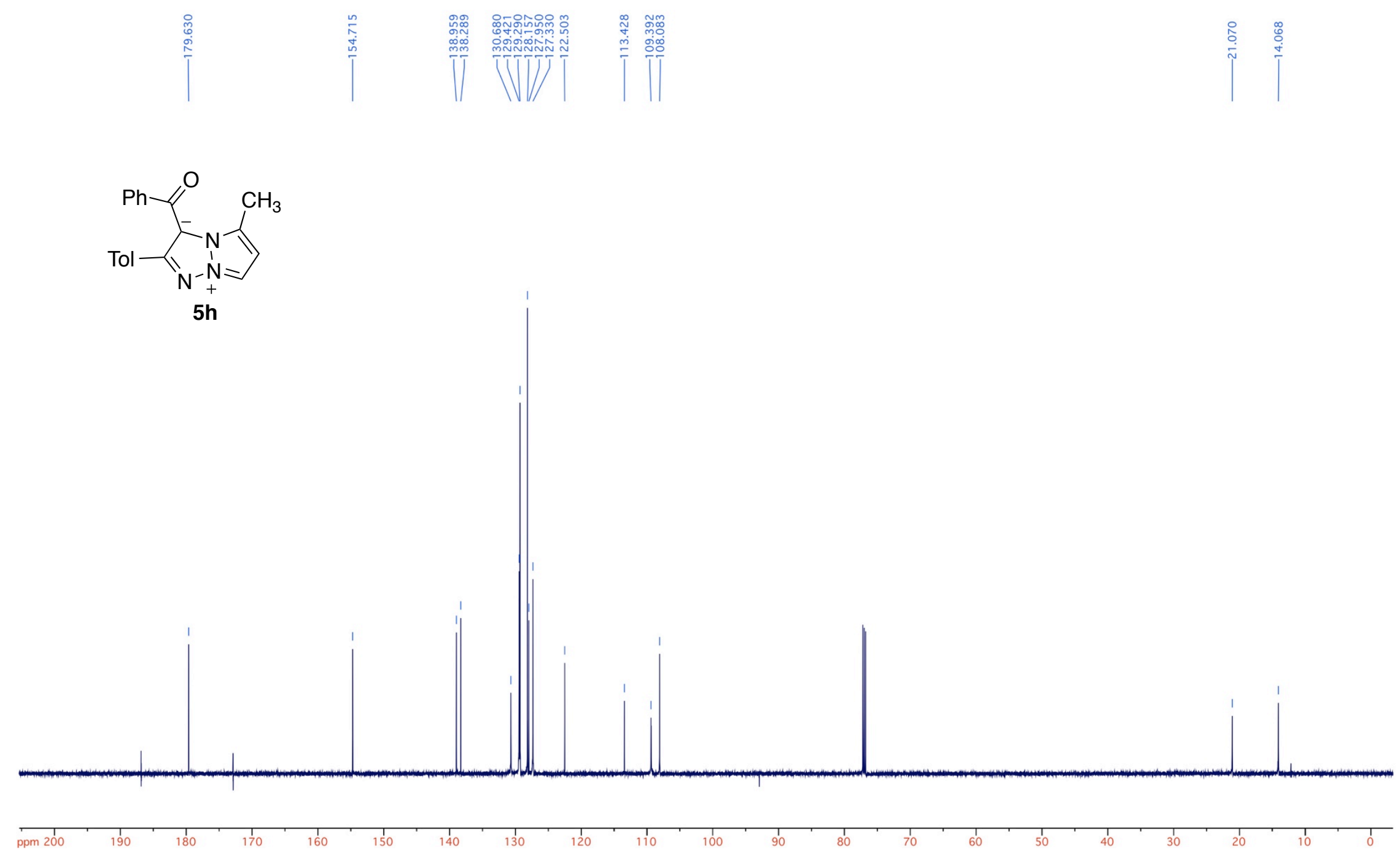

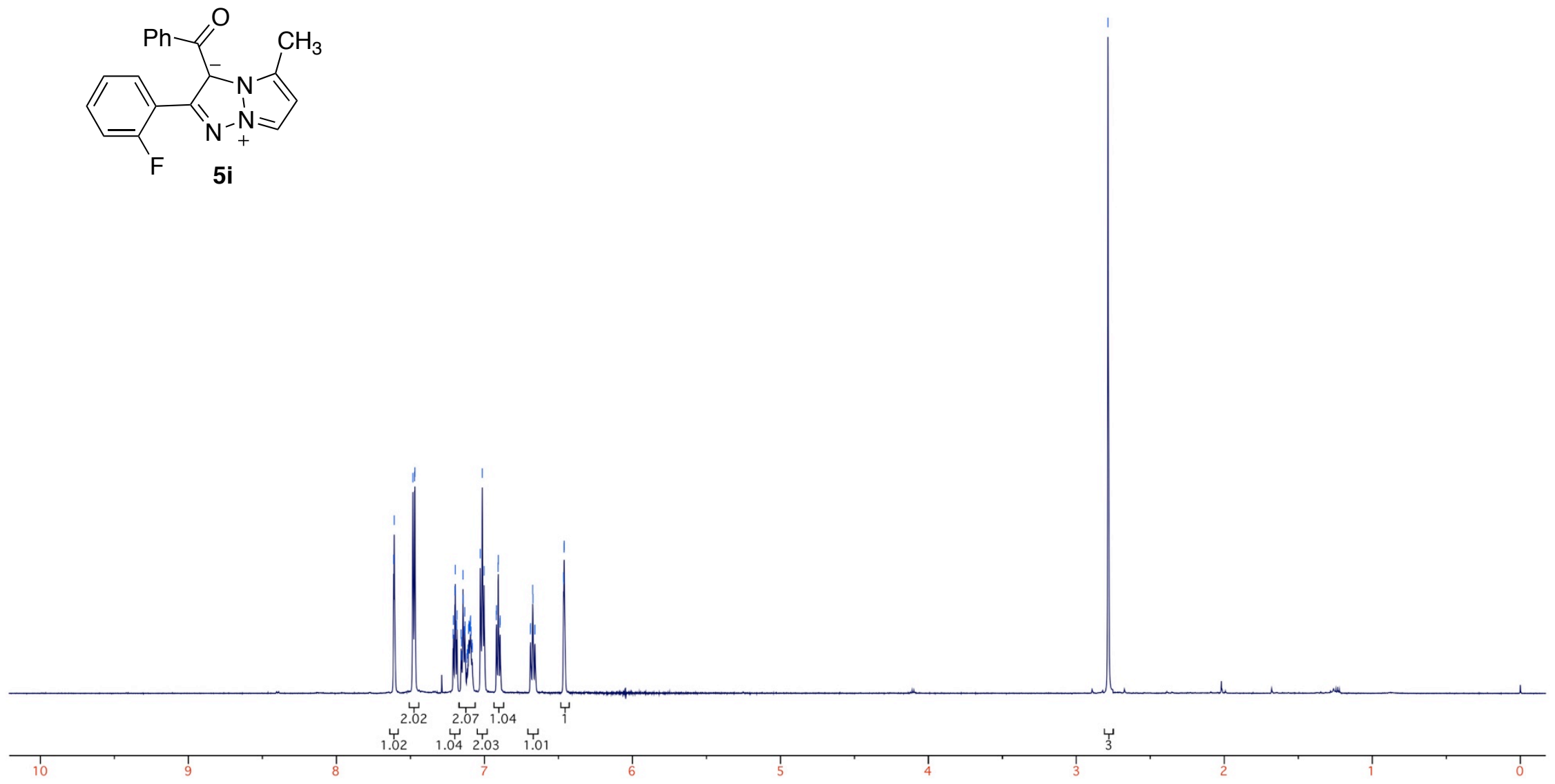

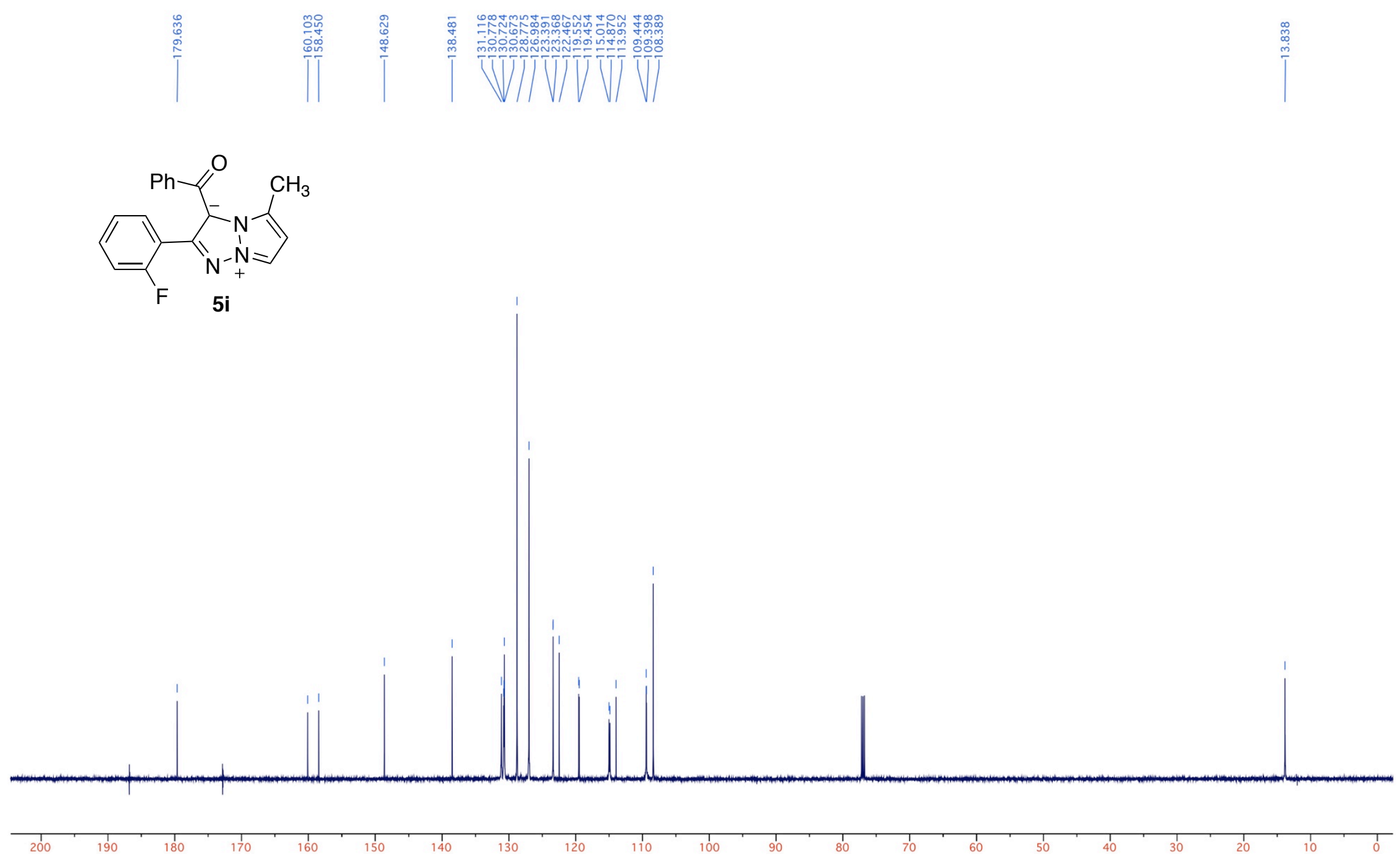


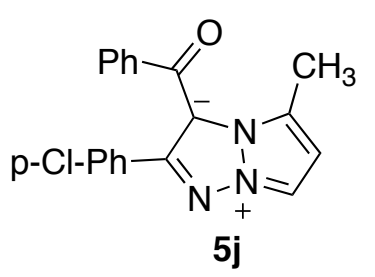

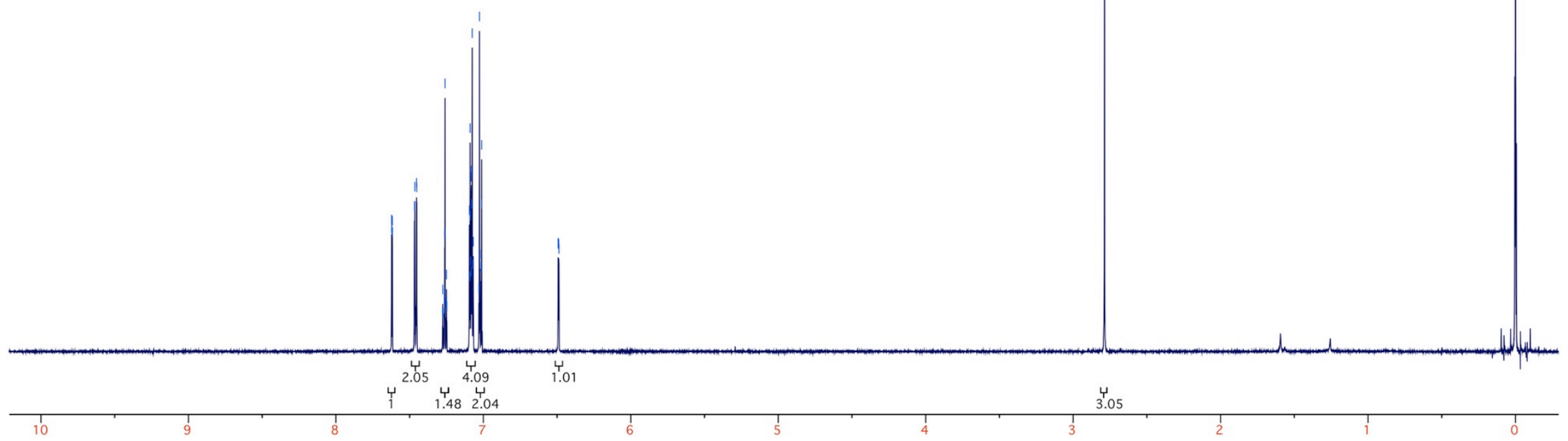




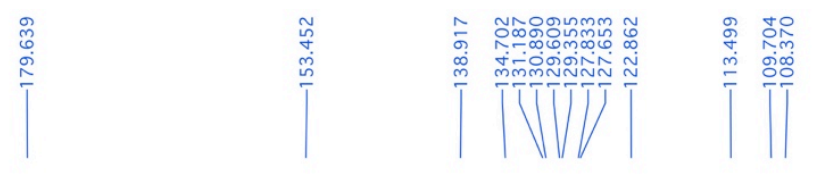

$$
\text { }
$$

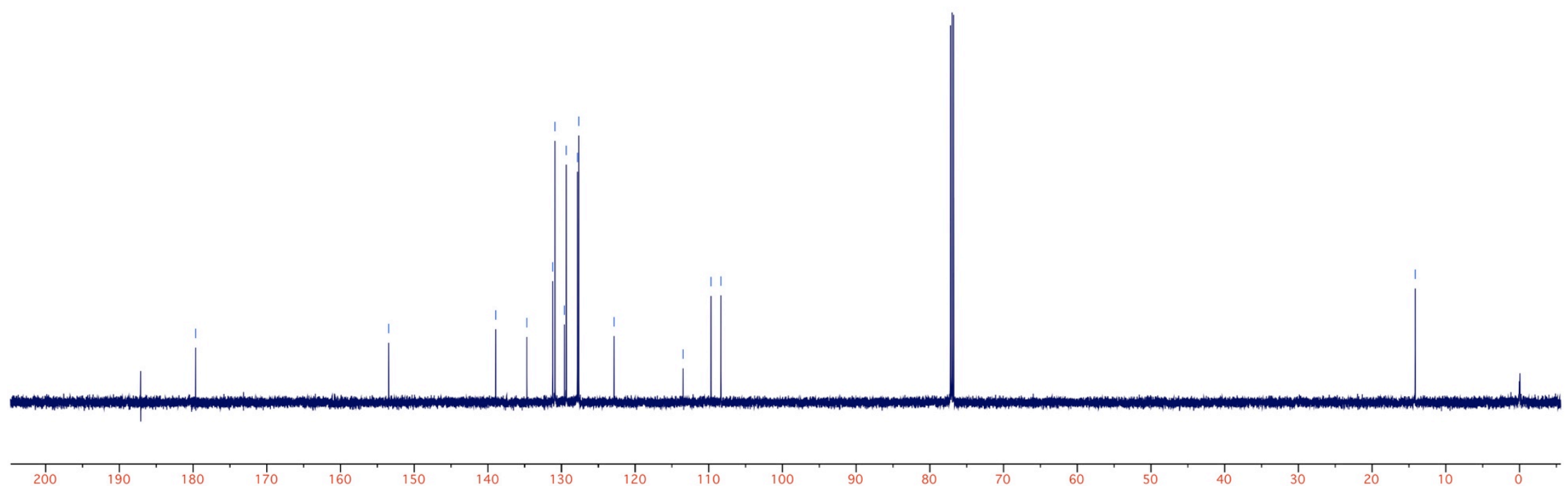




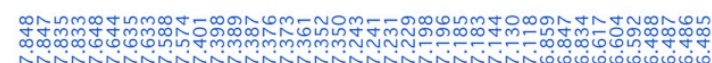

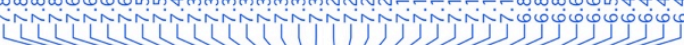

$\sim \cdots$ Vll,
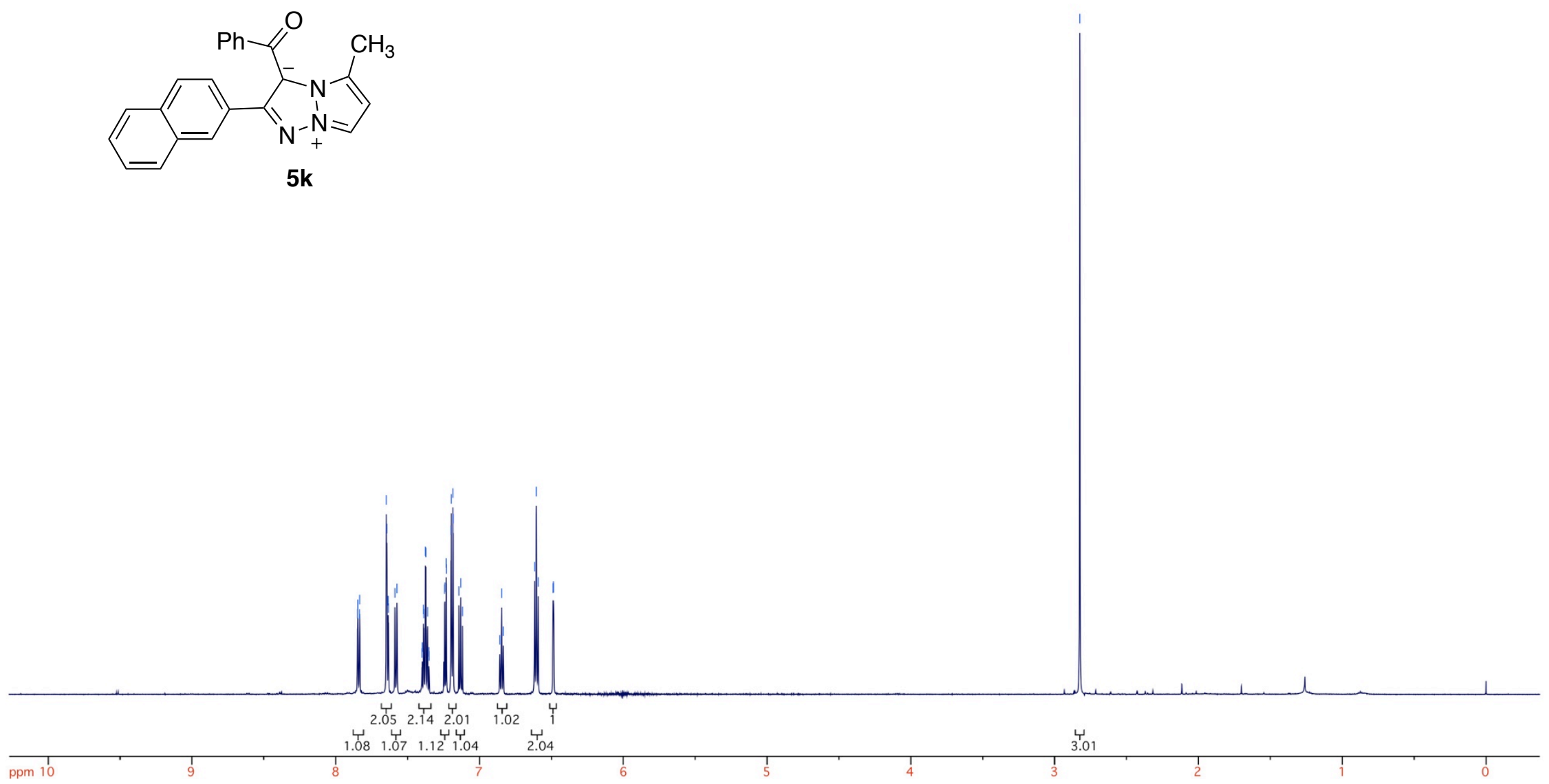

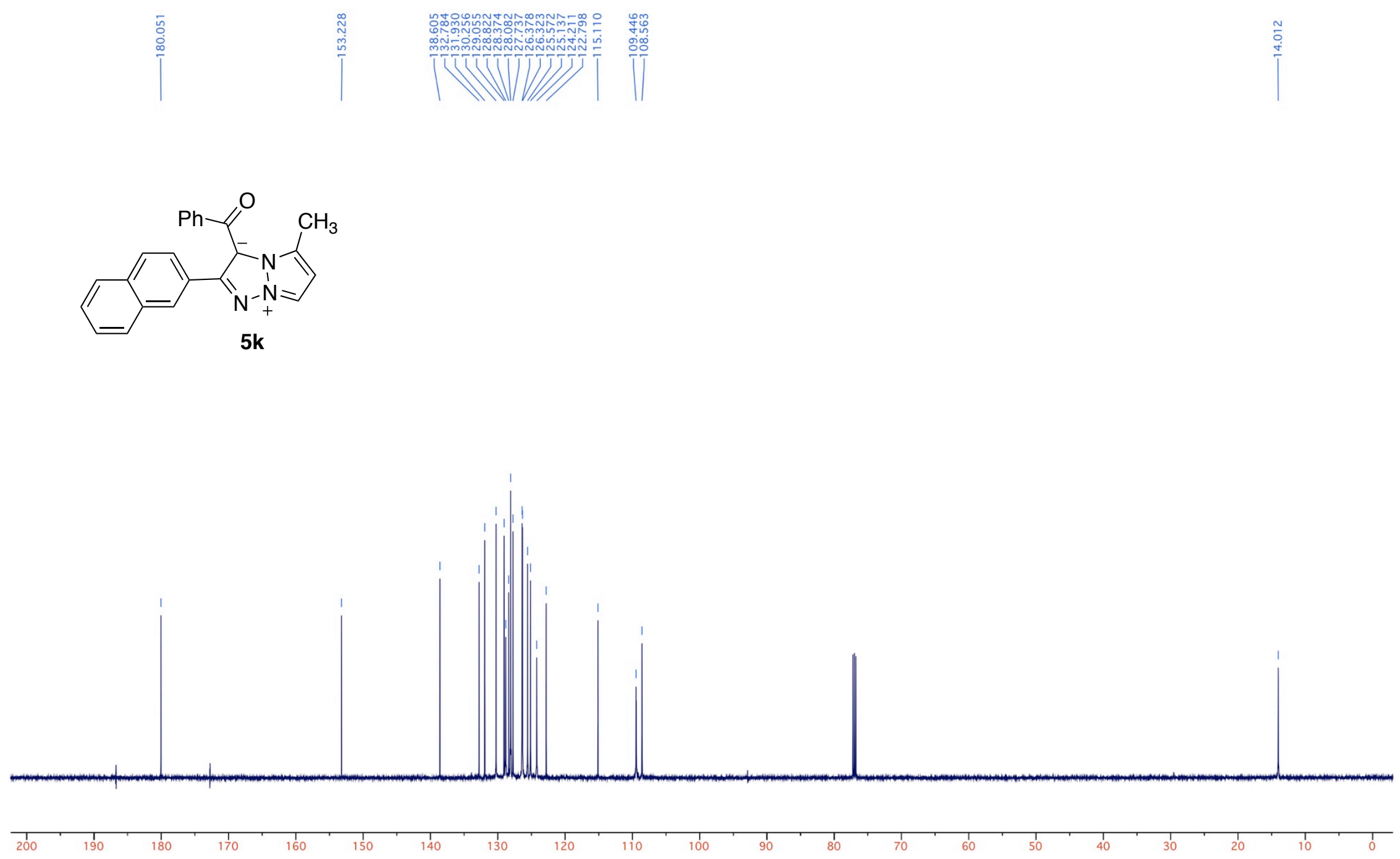

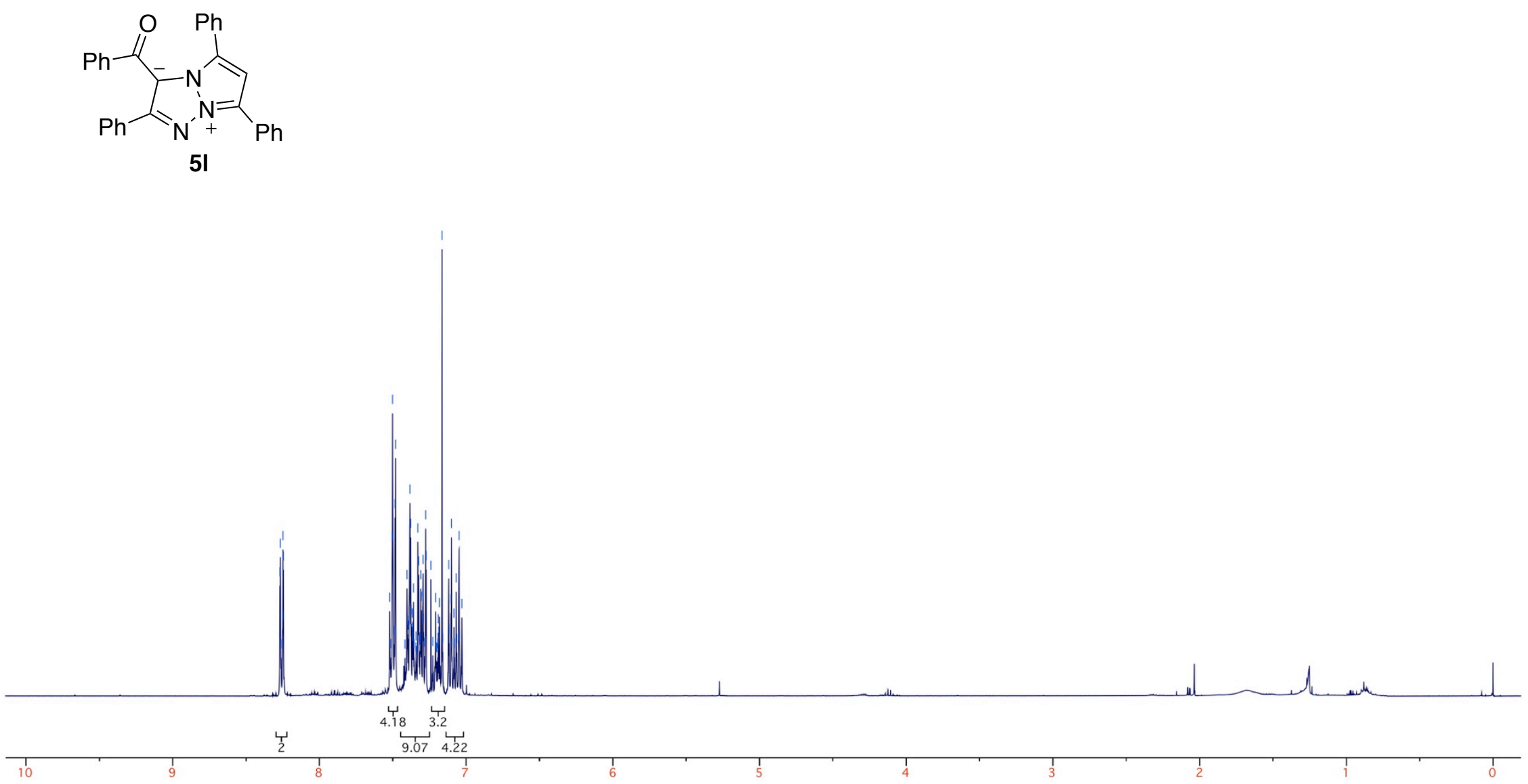


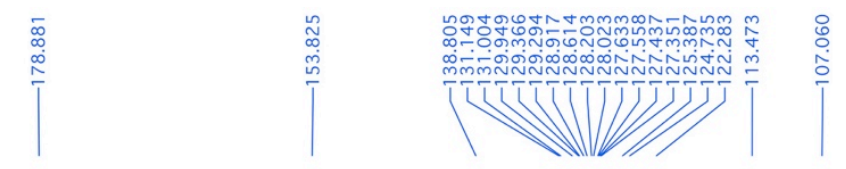

$$
\text { (N) }
$$

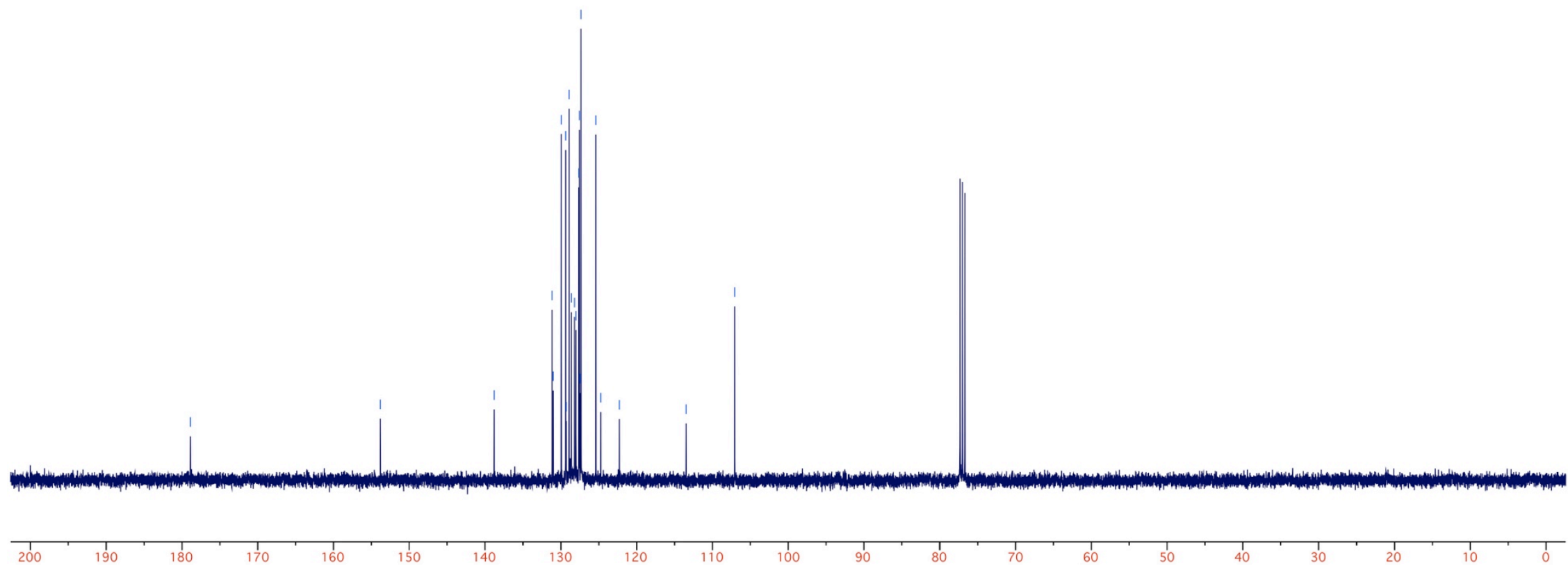



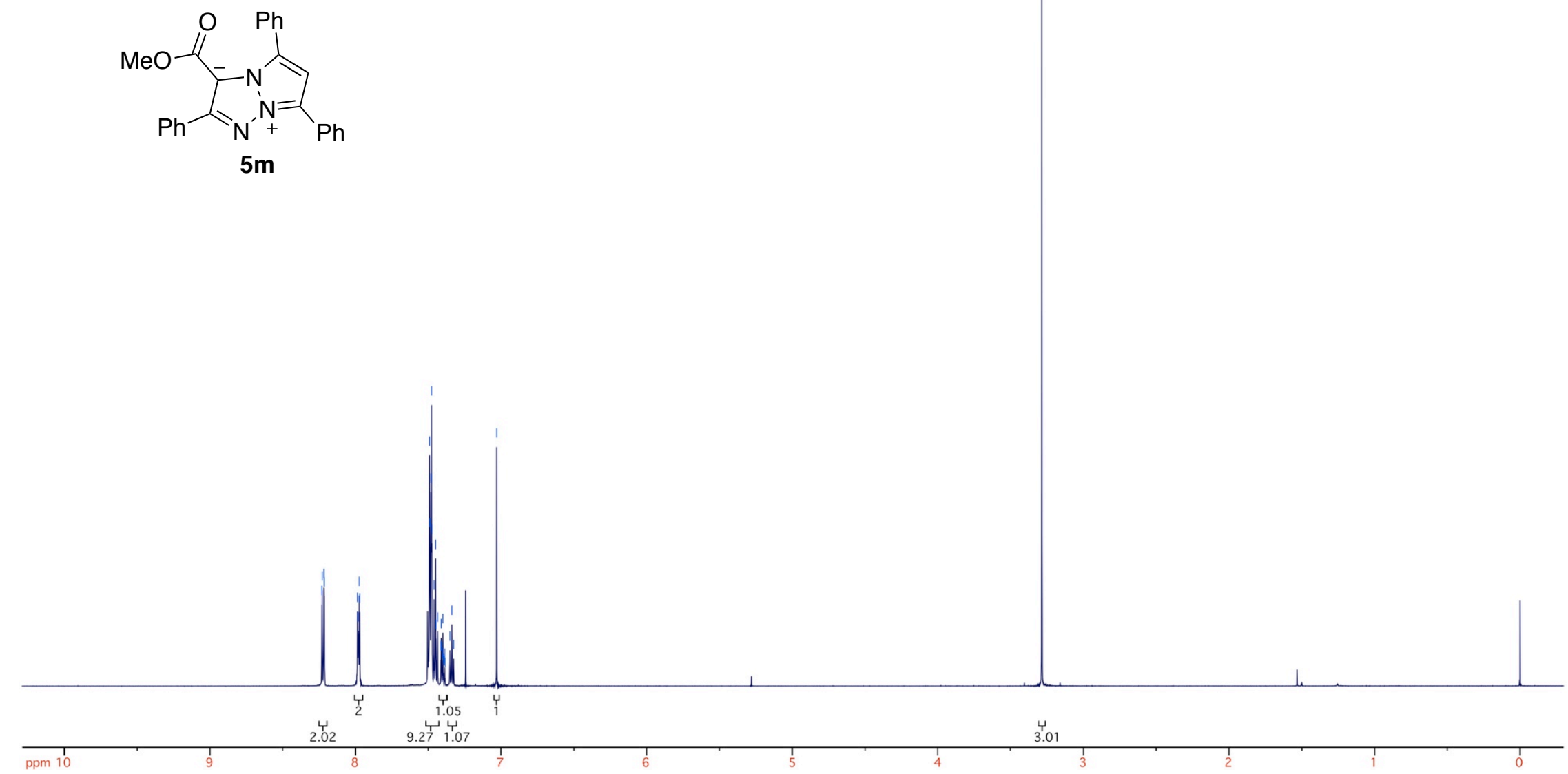


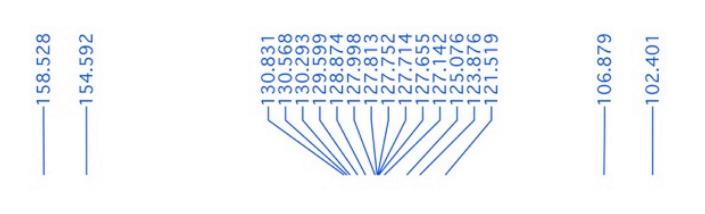

$$
\text { }
$$

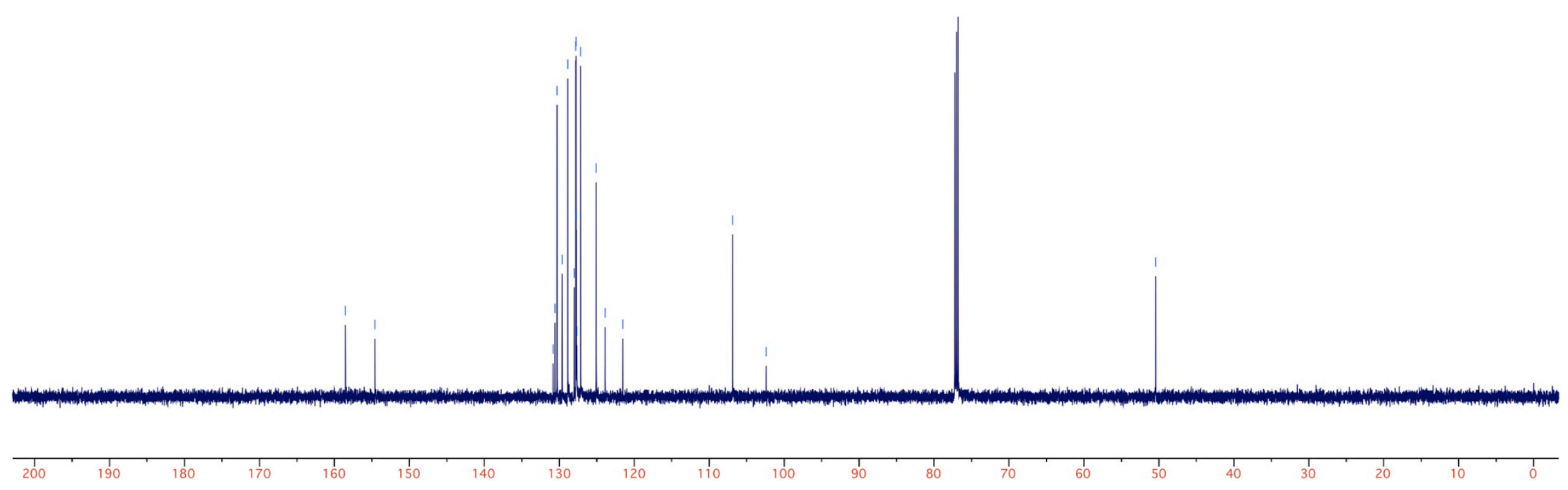



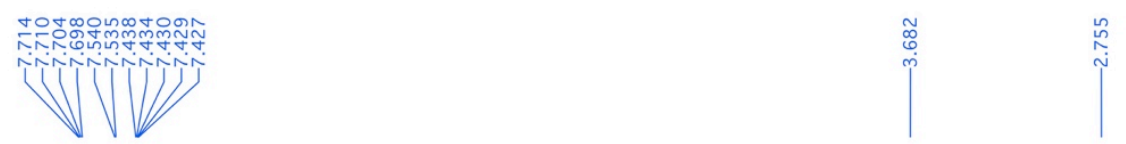

$\sum_{\substack{N_{-}^{-N} \\+}}^{O}$

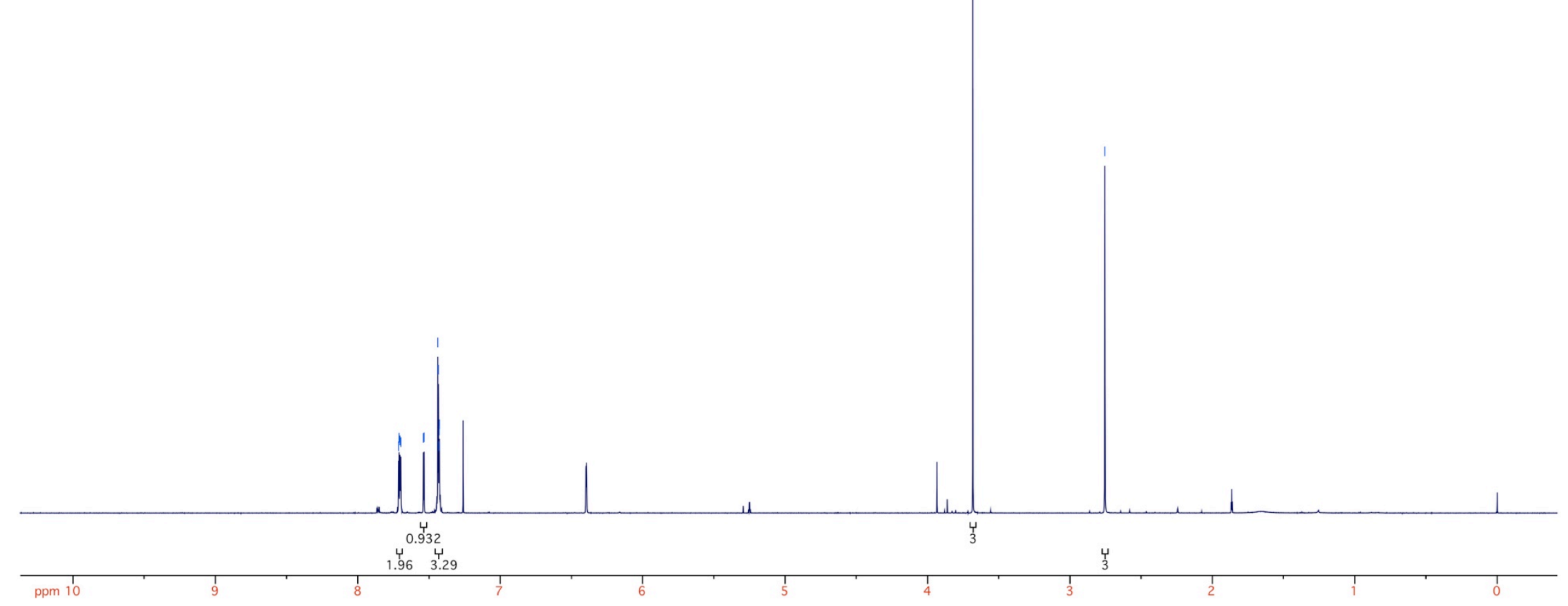




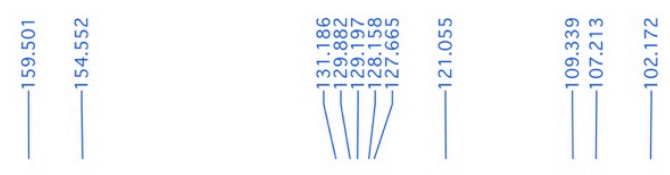
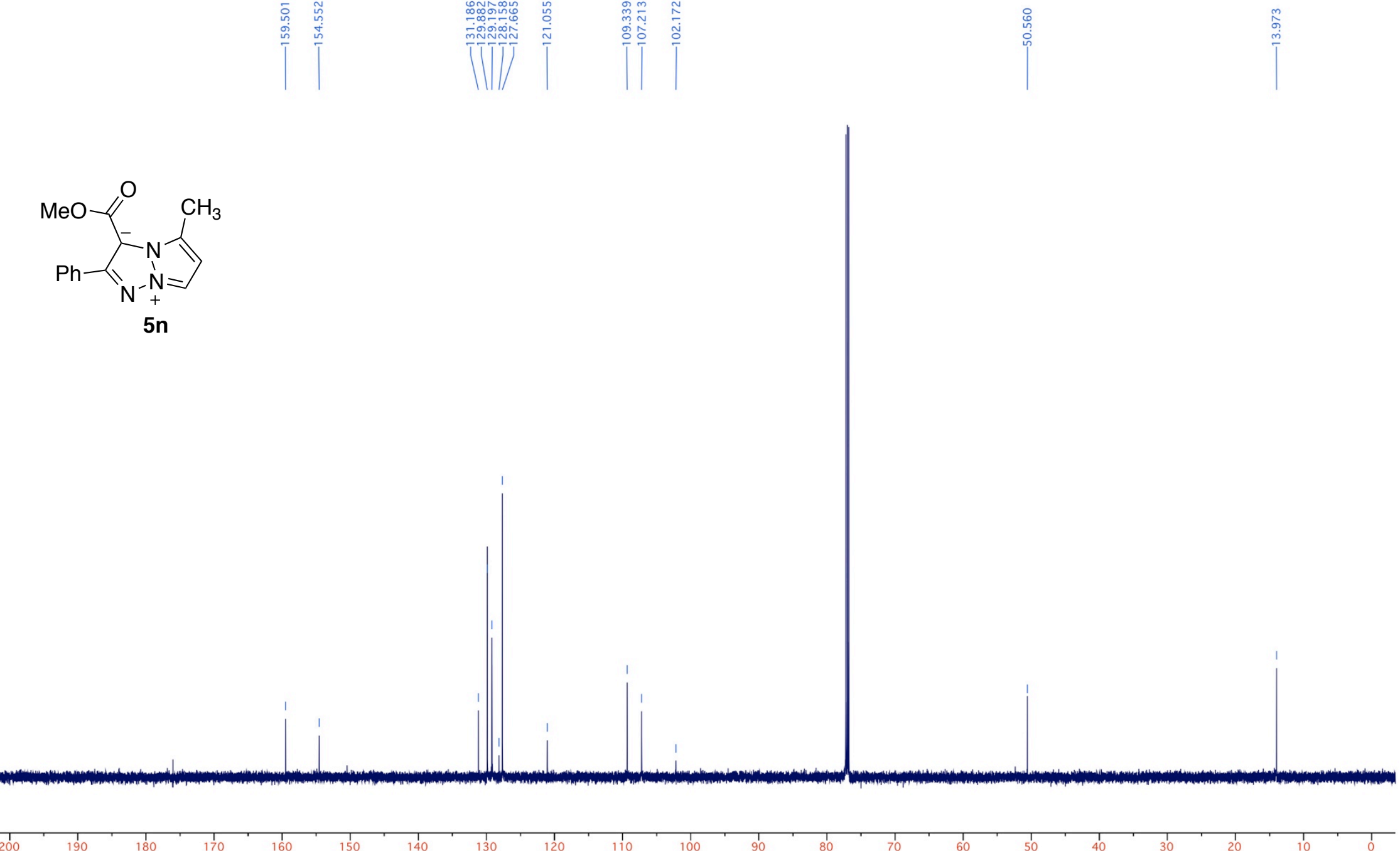
$\mathrm{Ph}-\langle\Theta_{\mathrm{N}^{-N}}^{\mathrm{N}} \overbrace{\mathrm{Ph}}^{\mathrm{Ph}}$

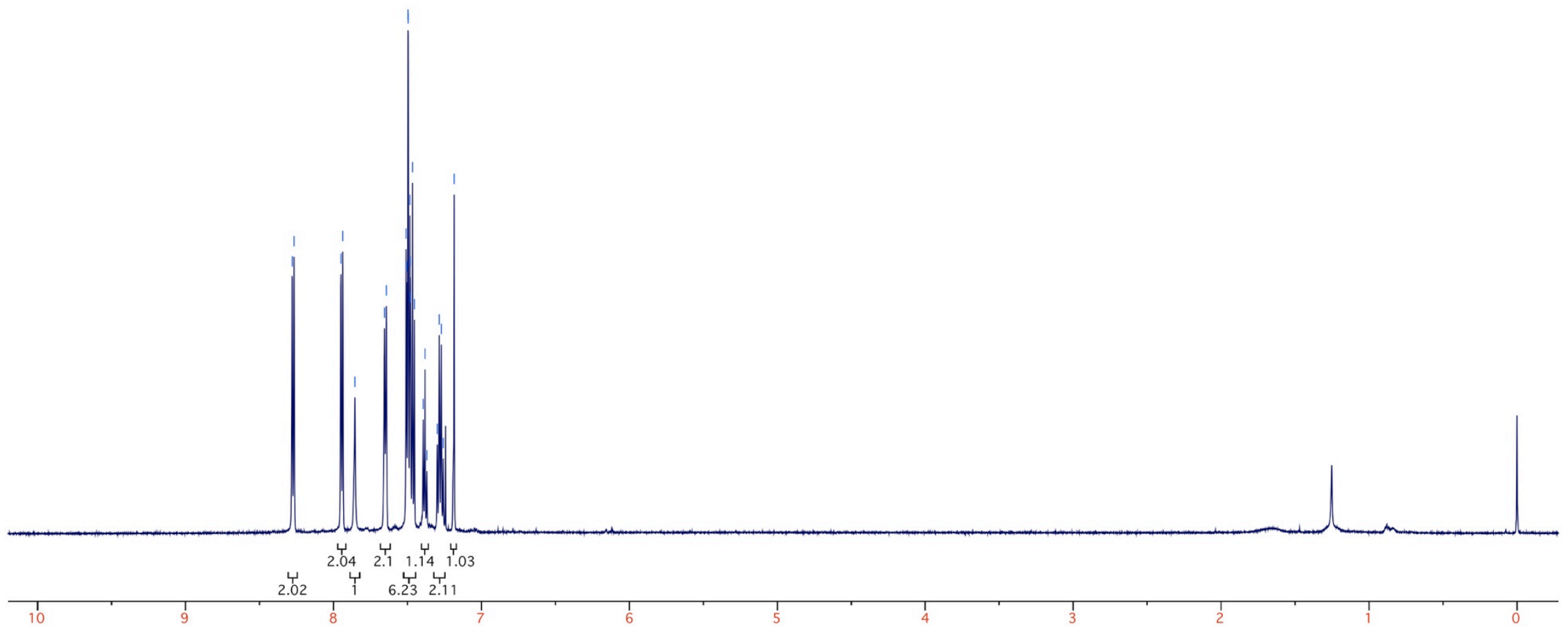




$$
\langle\overbrace{\Theta_{1}^{-}}^{N} \overbrace{P h}^{P h}
$$

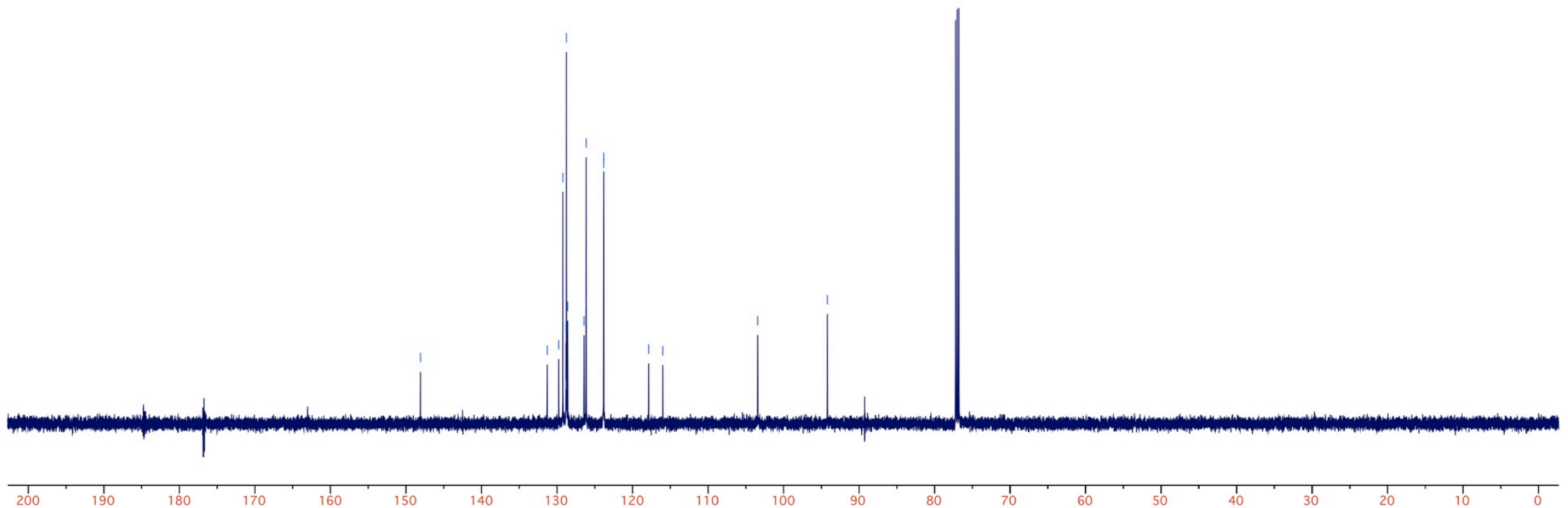



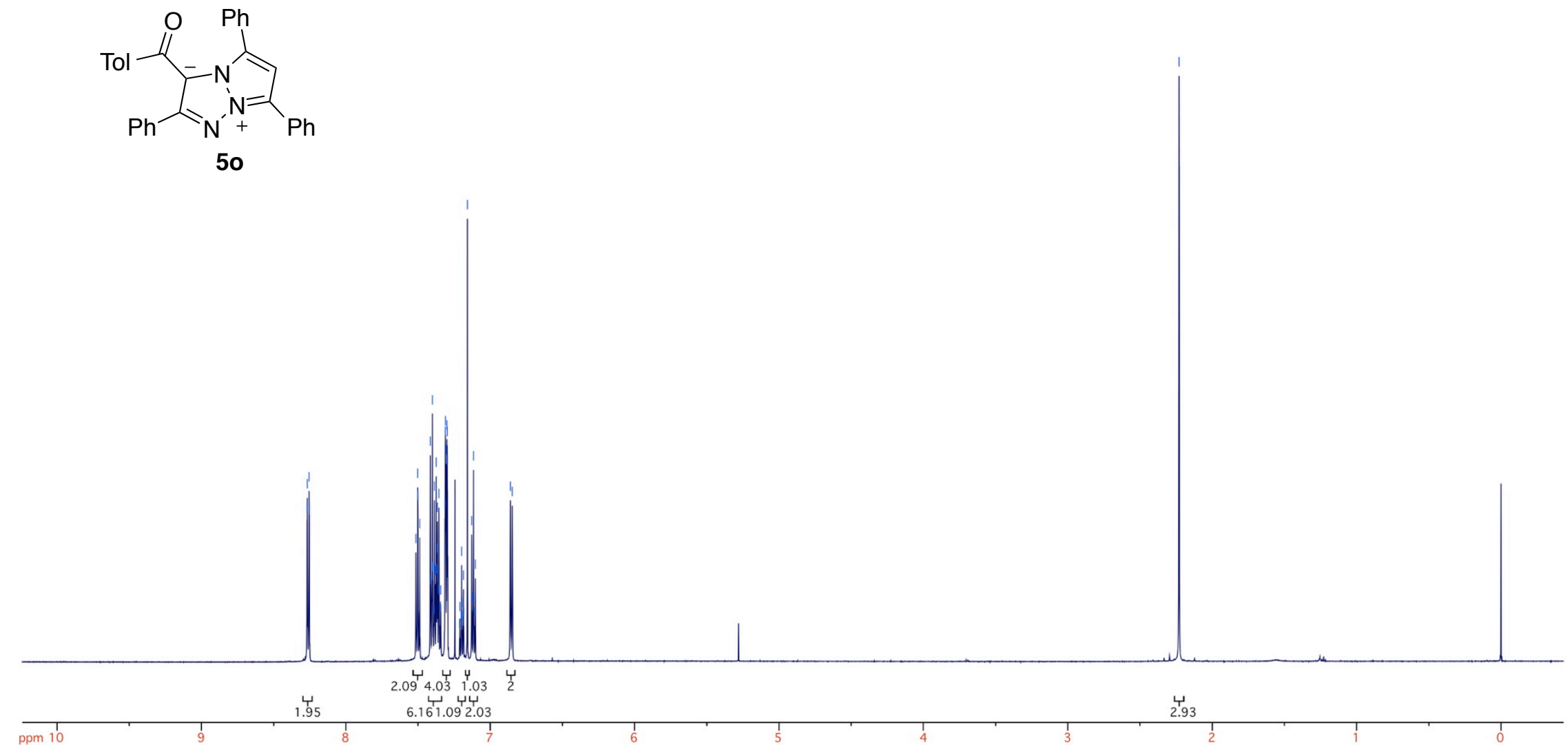

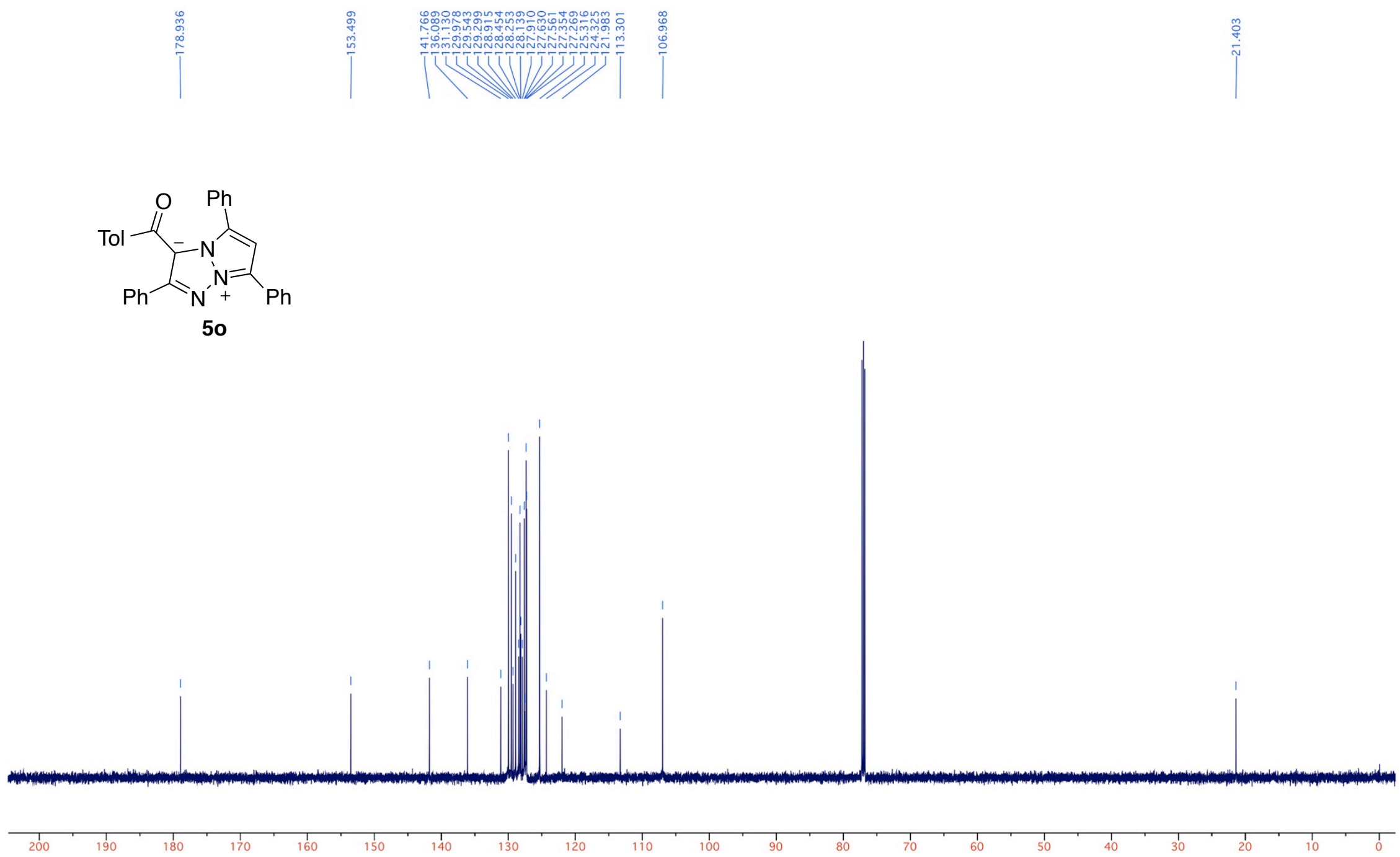

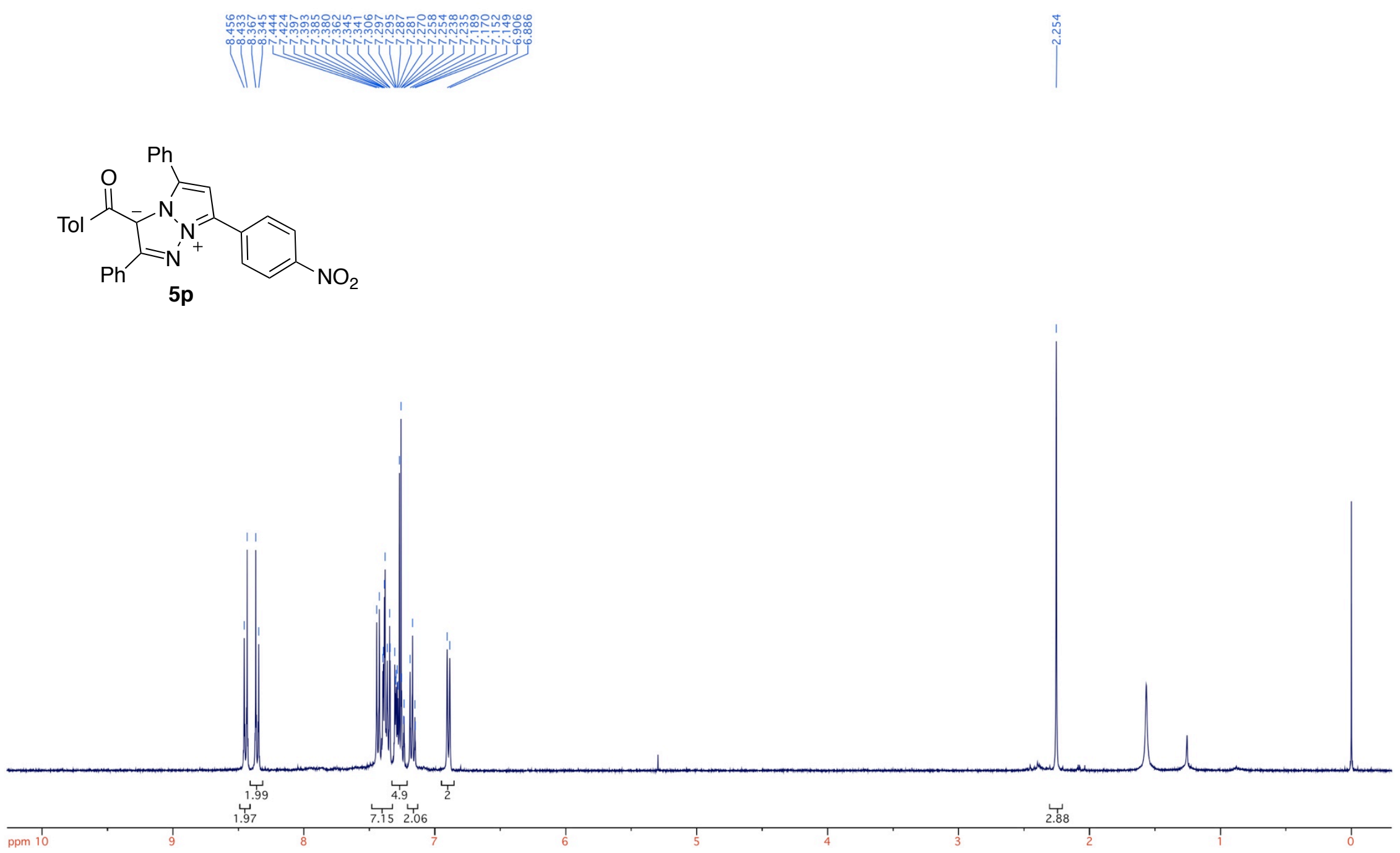

S157 

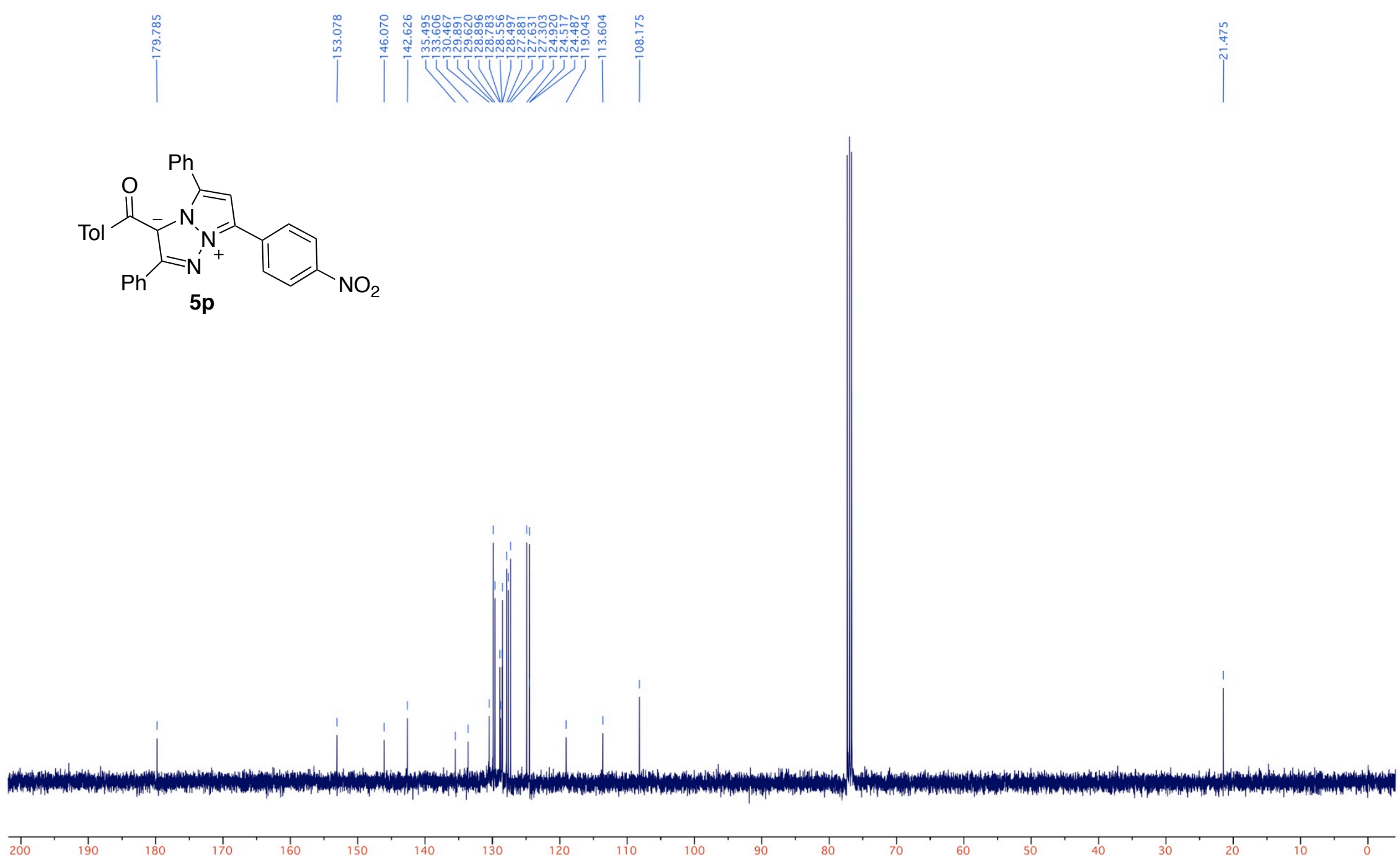

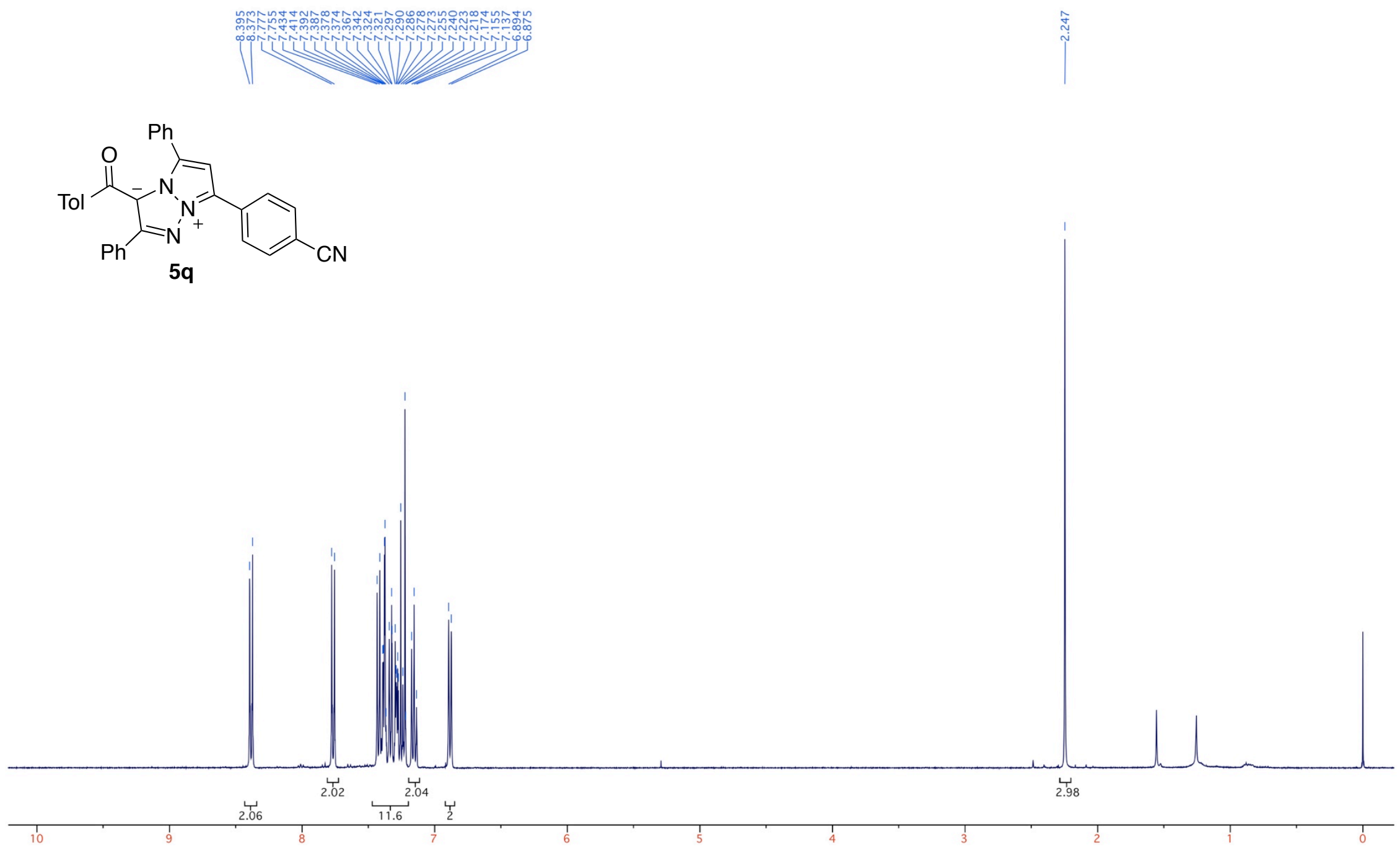

S159 

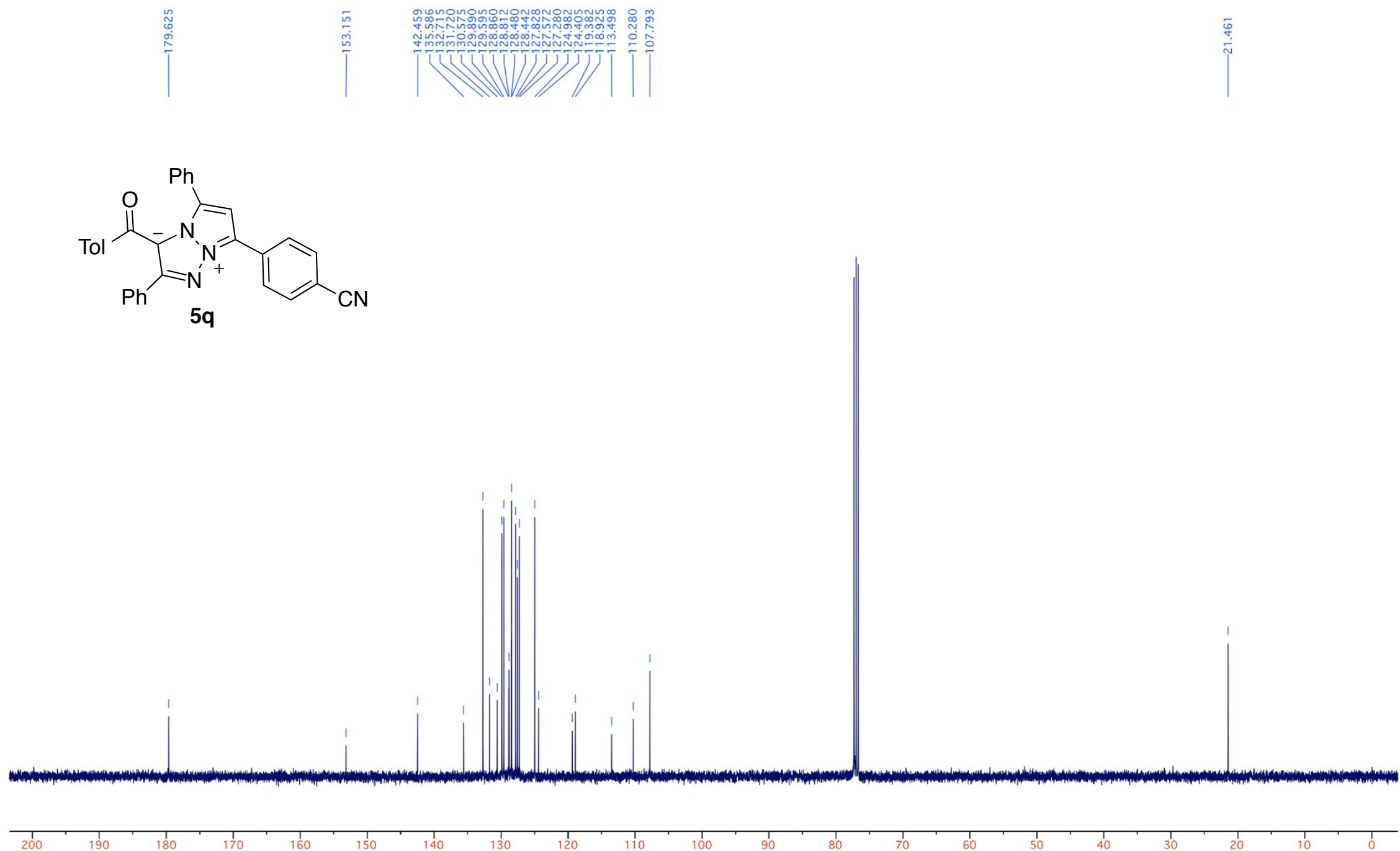


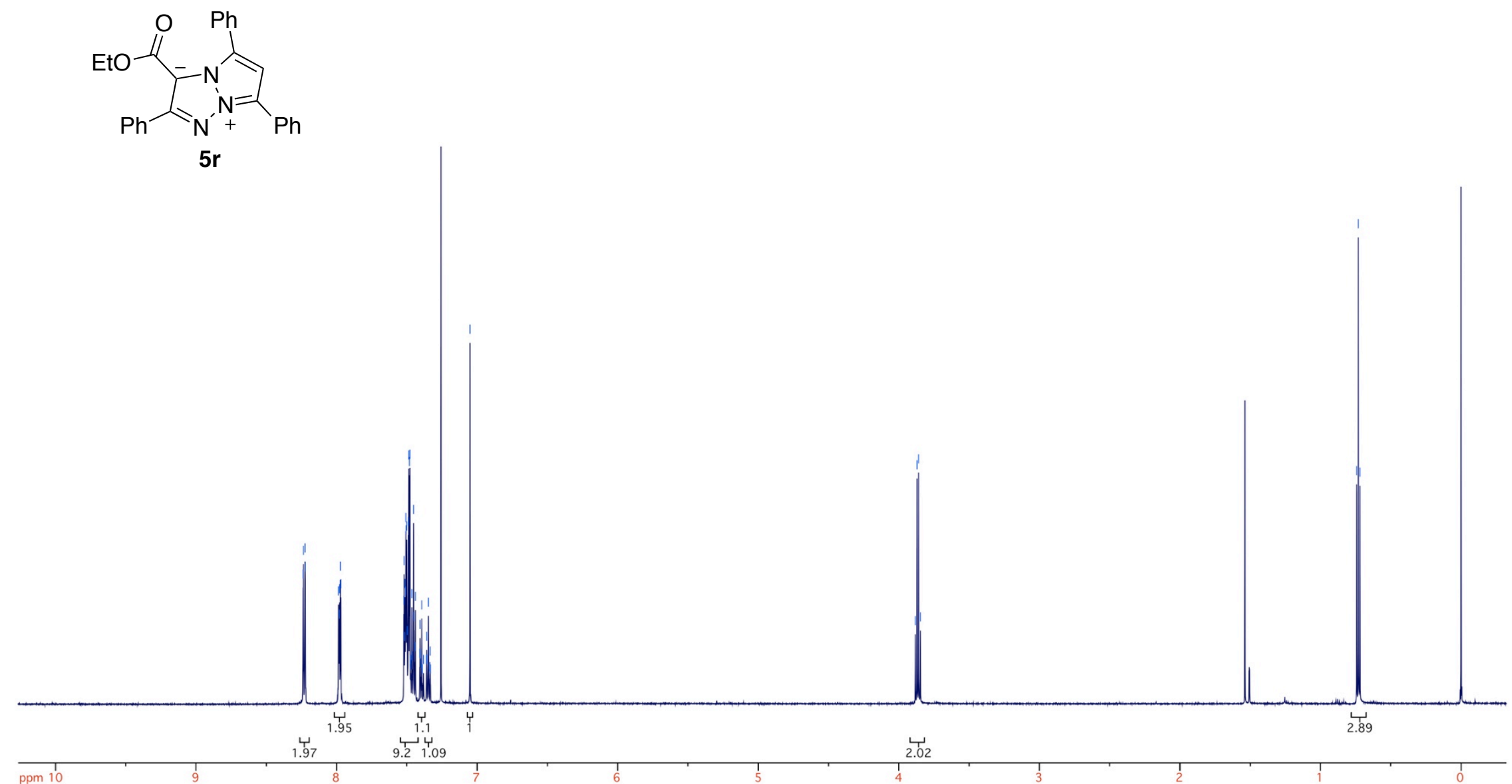



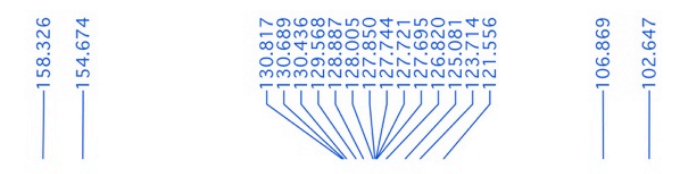

$$
\underbrace{}_{5 r}
$$

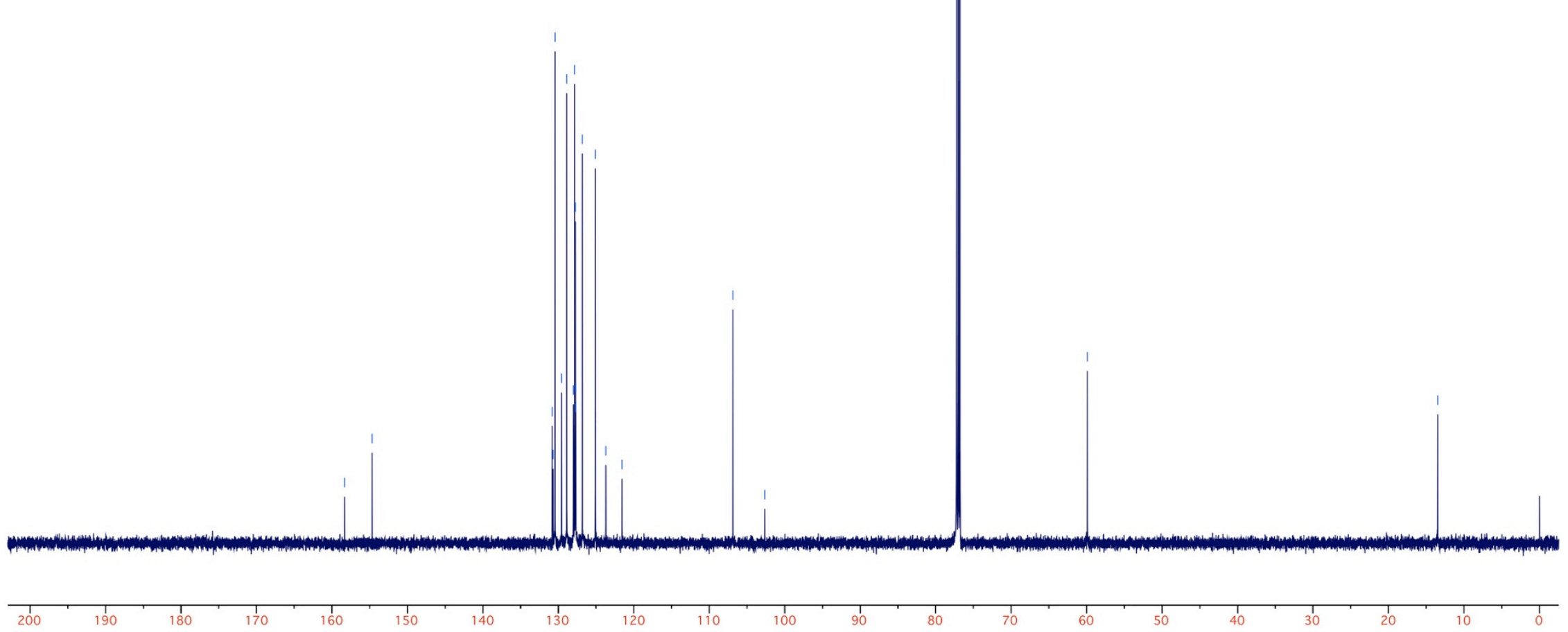




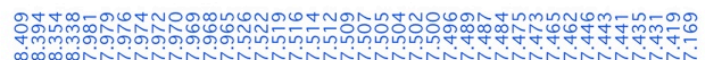

comóñ
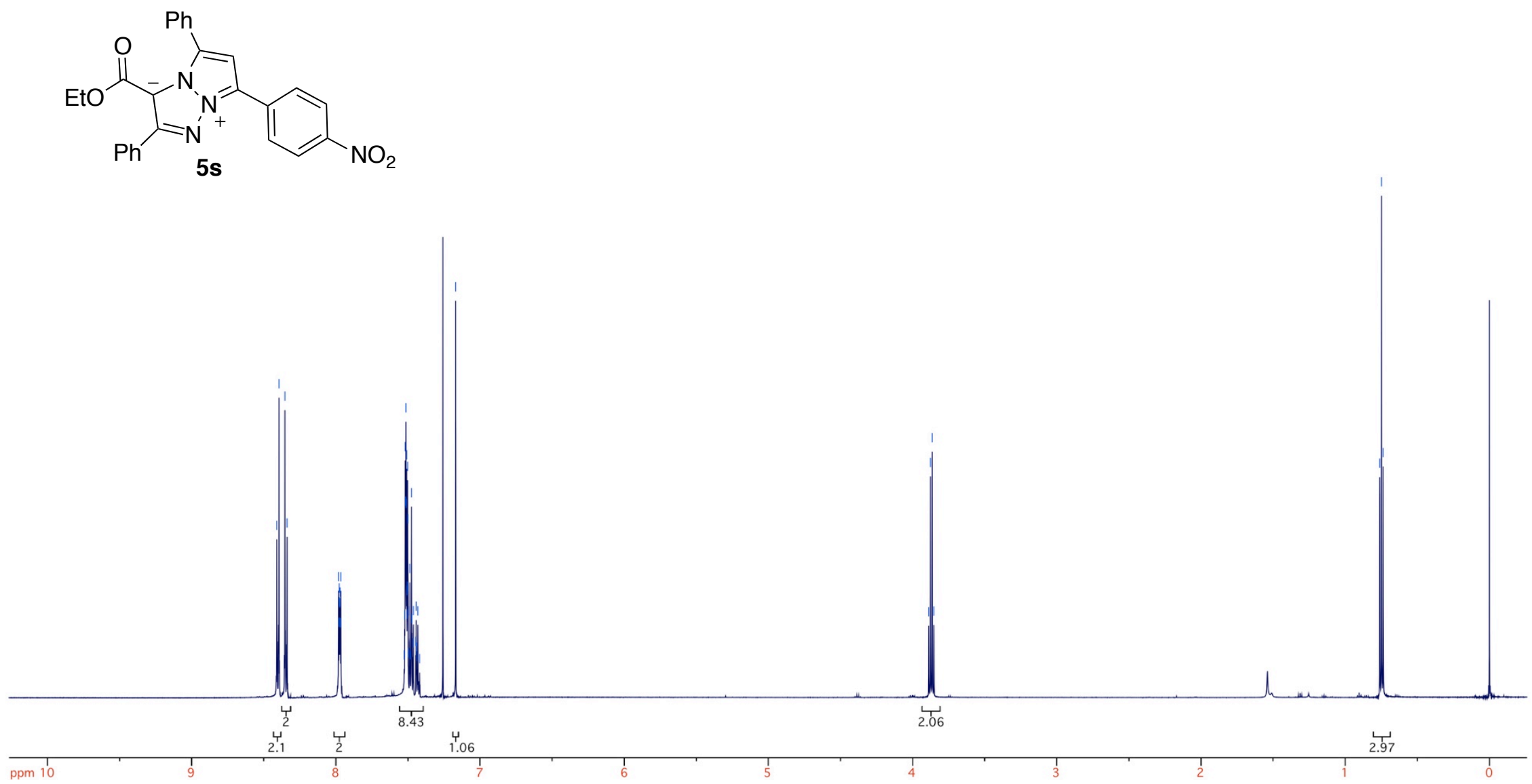


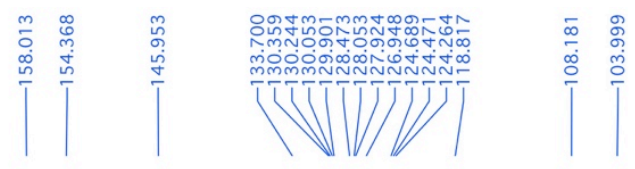
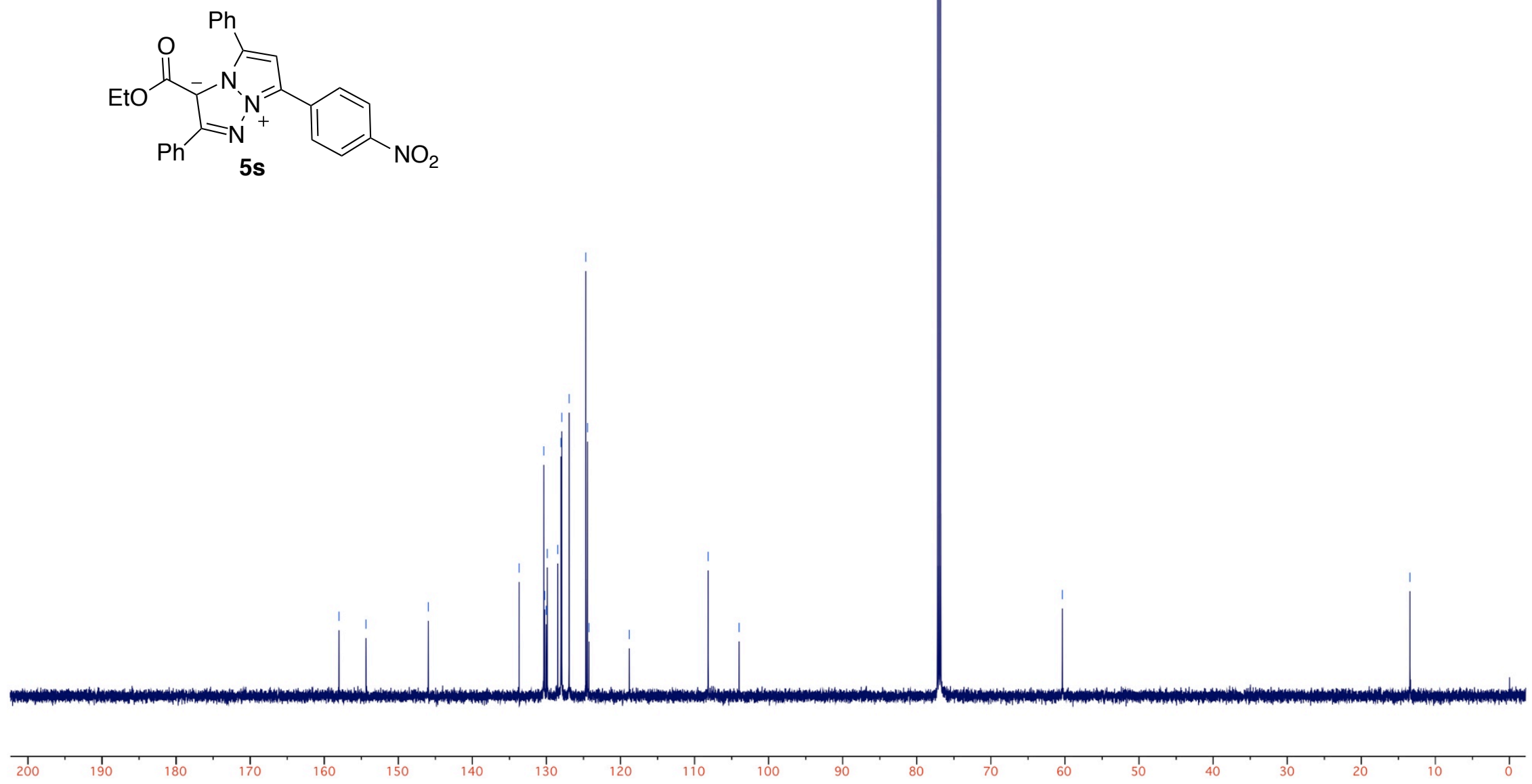


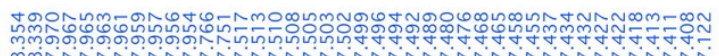

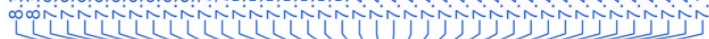

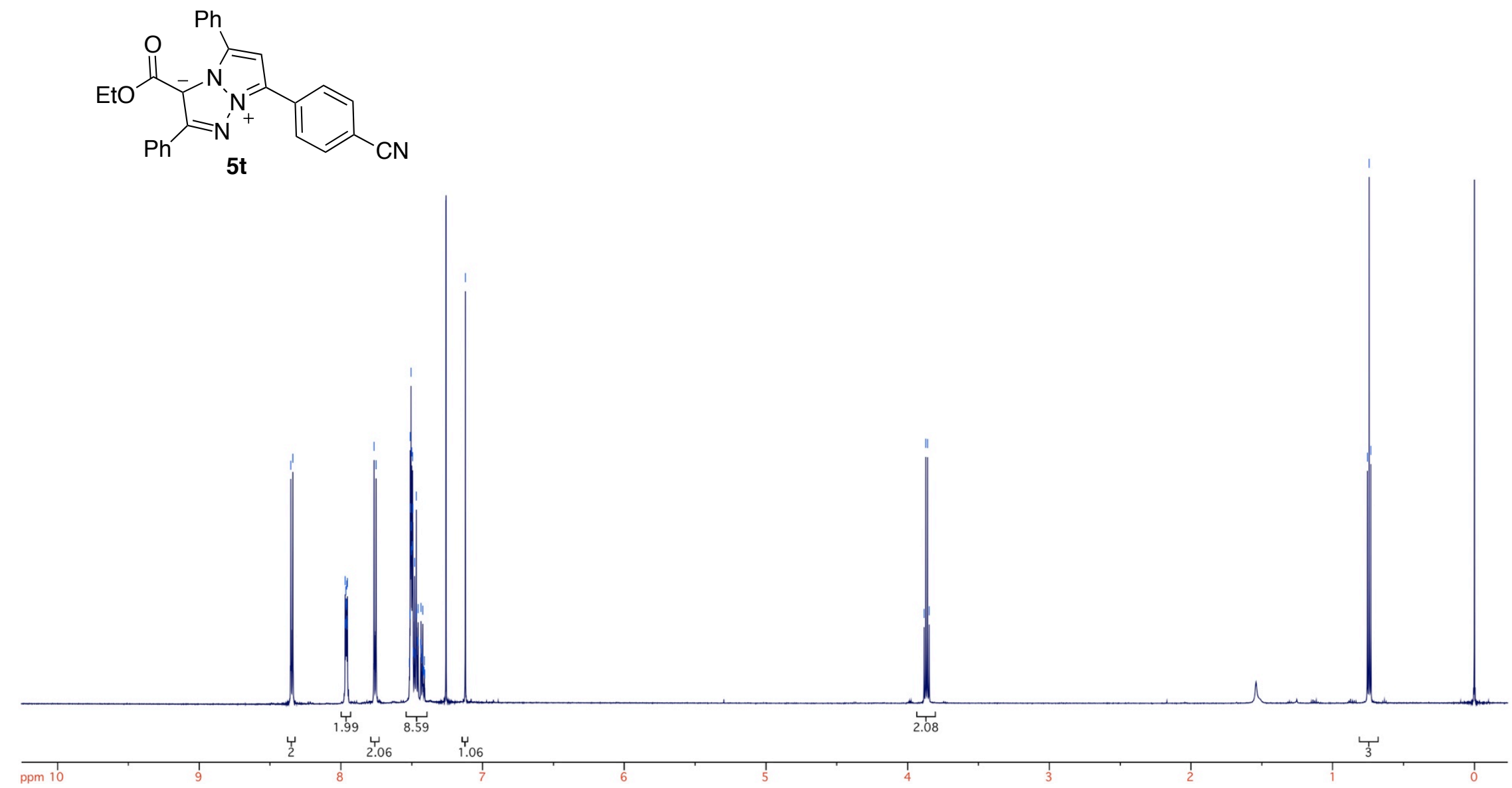



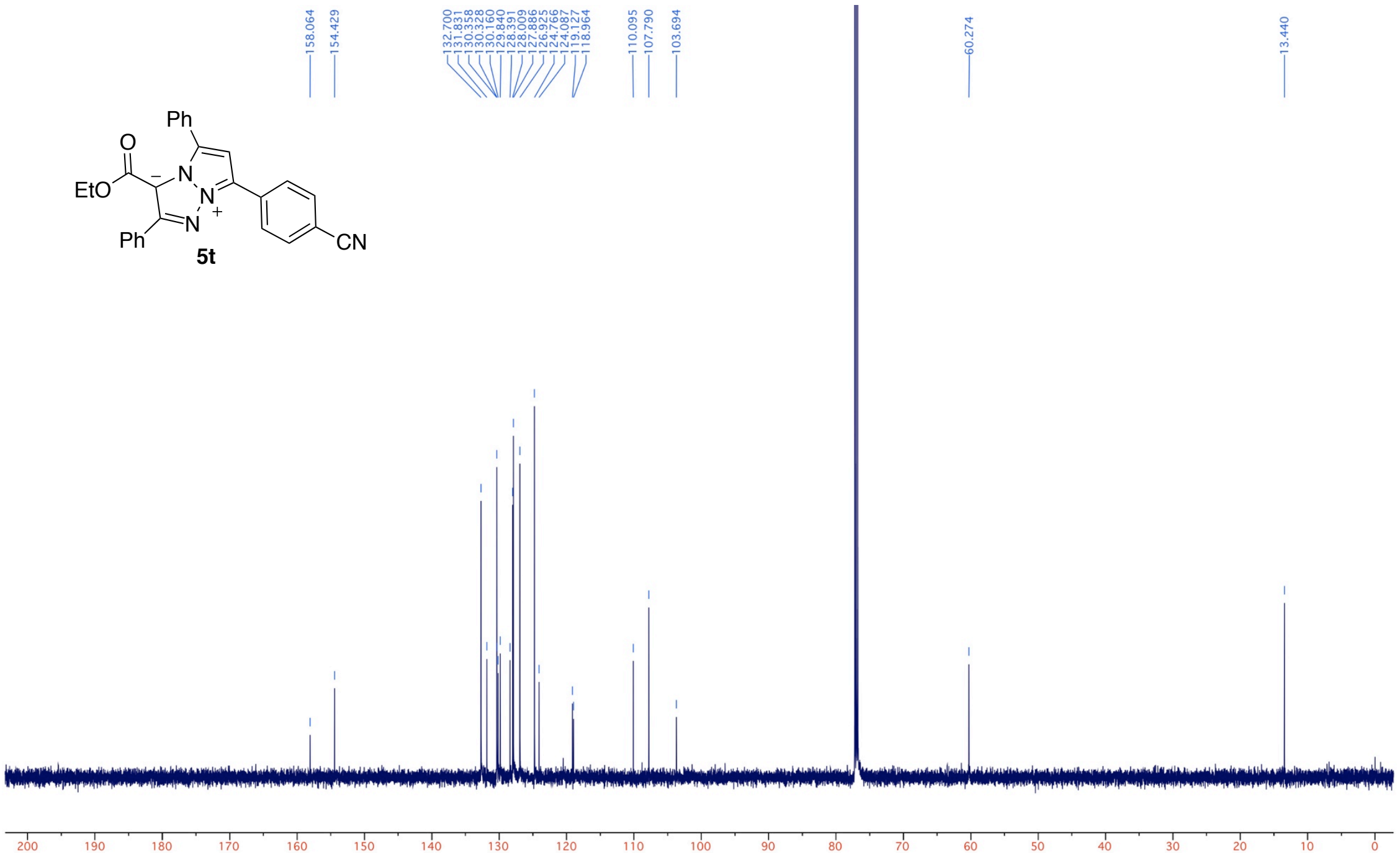


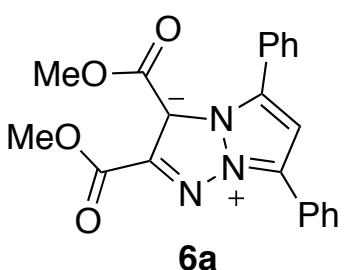

$6 a$

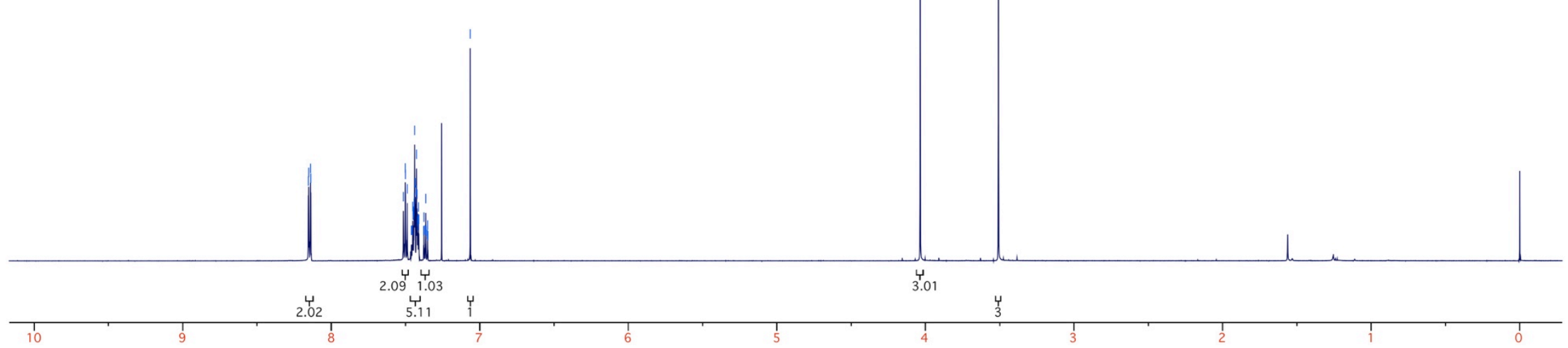




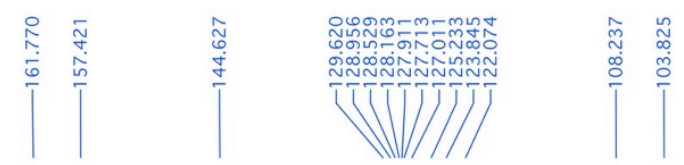
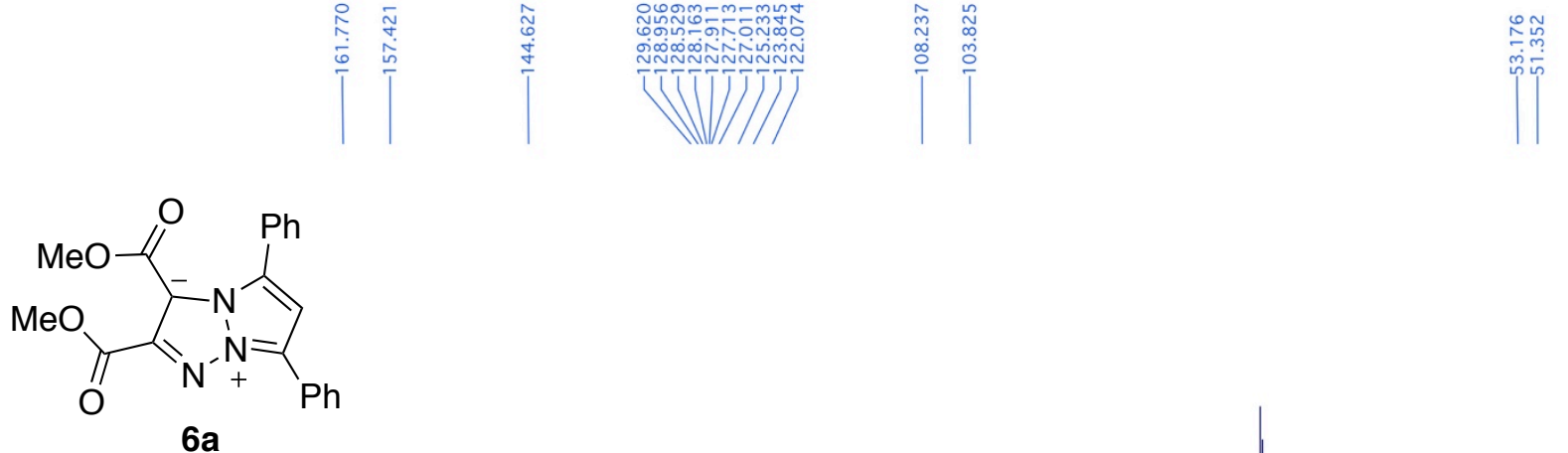

$6 a$

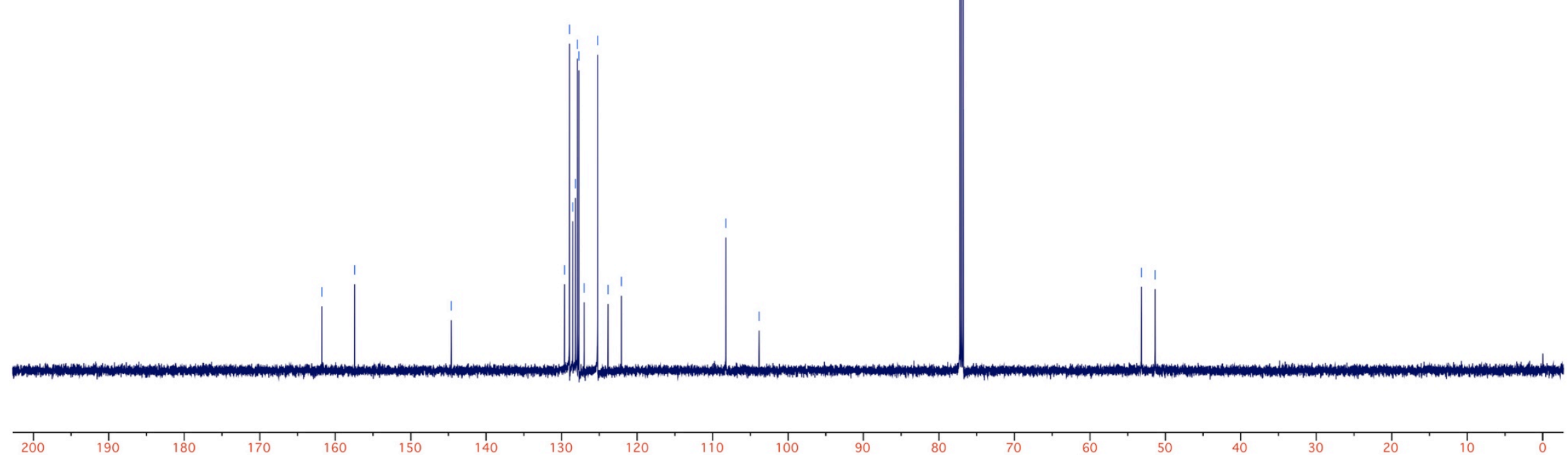



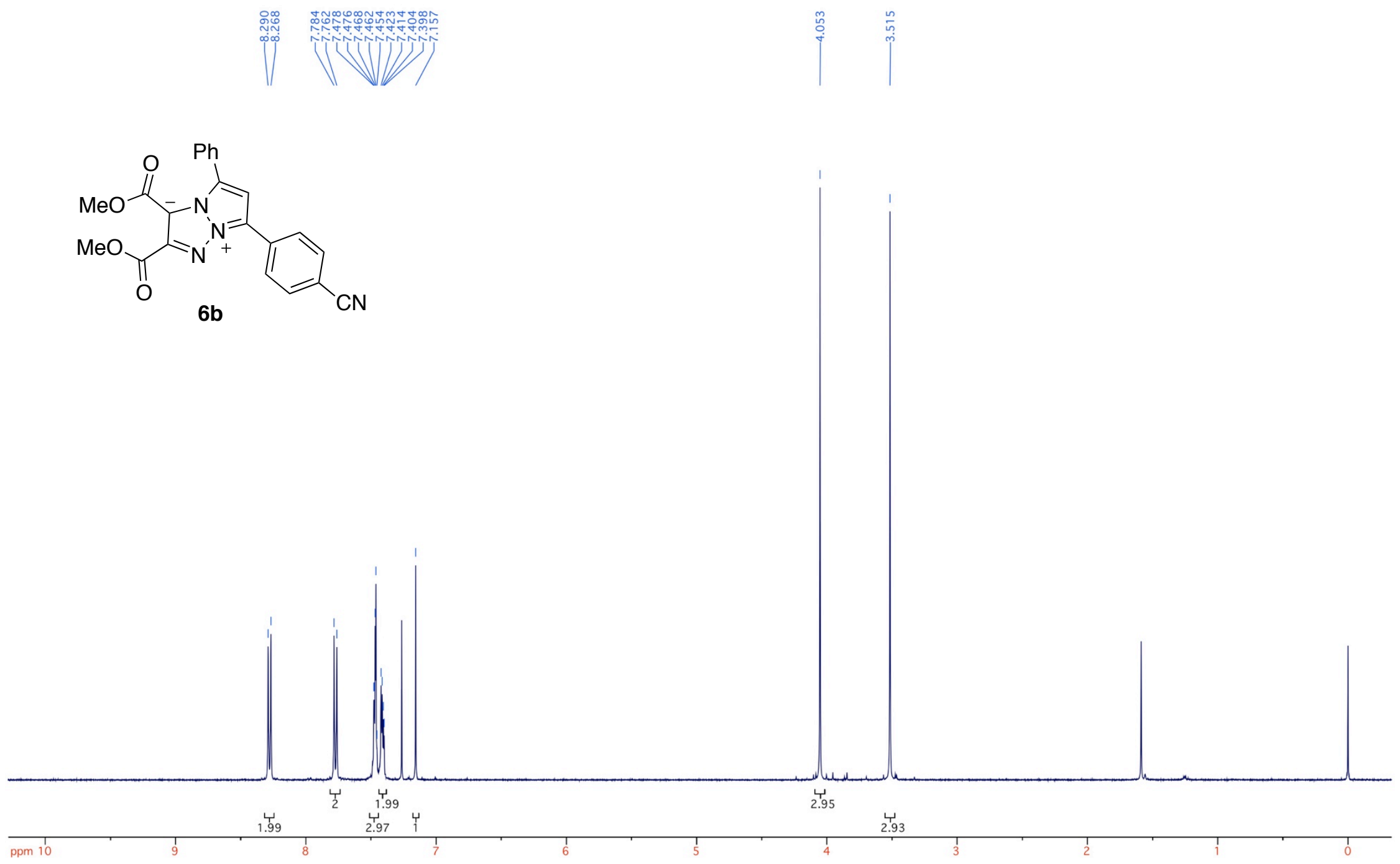


\section{H | W W}
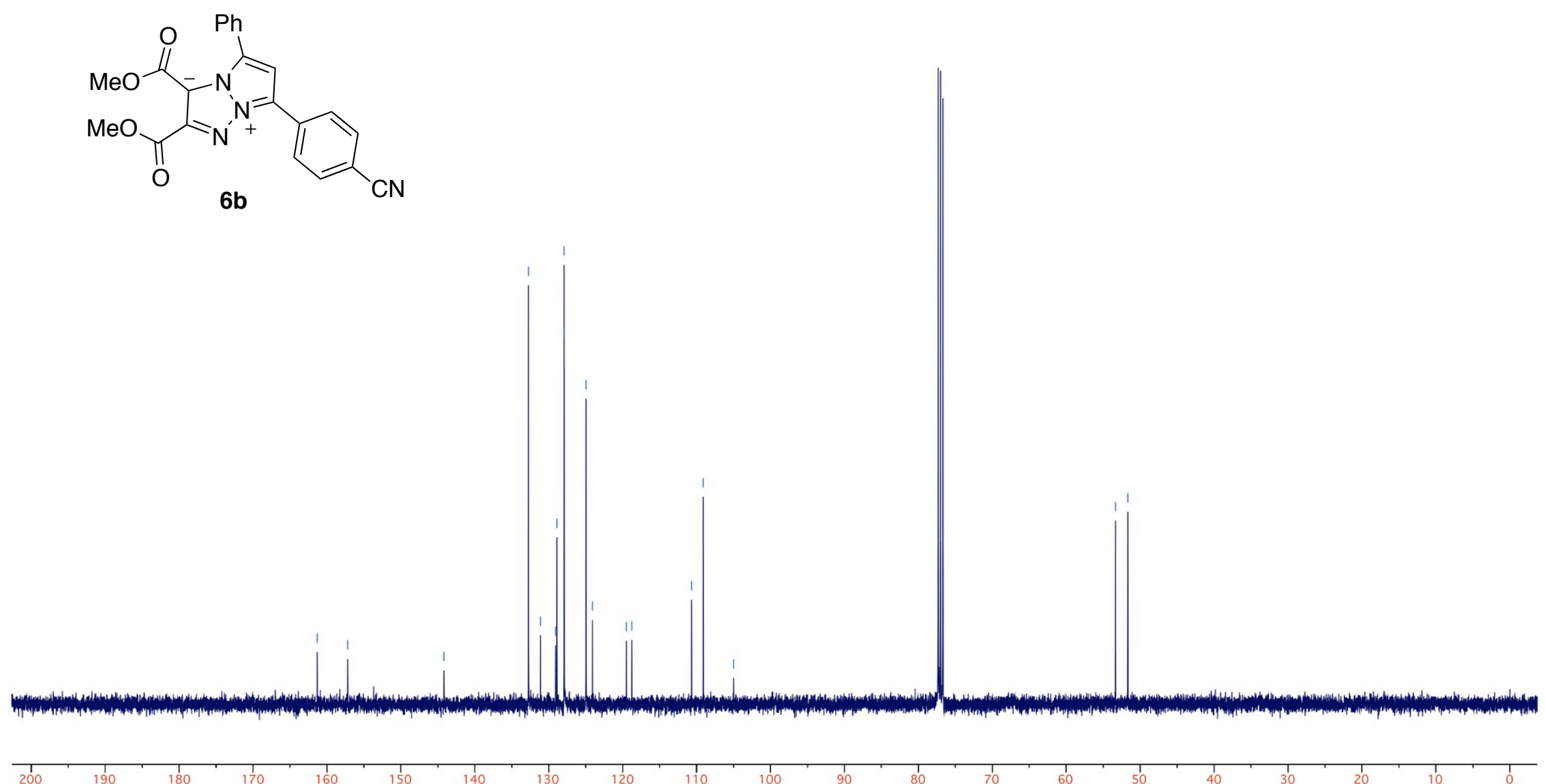

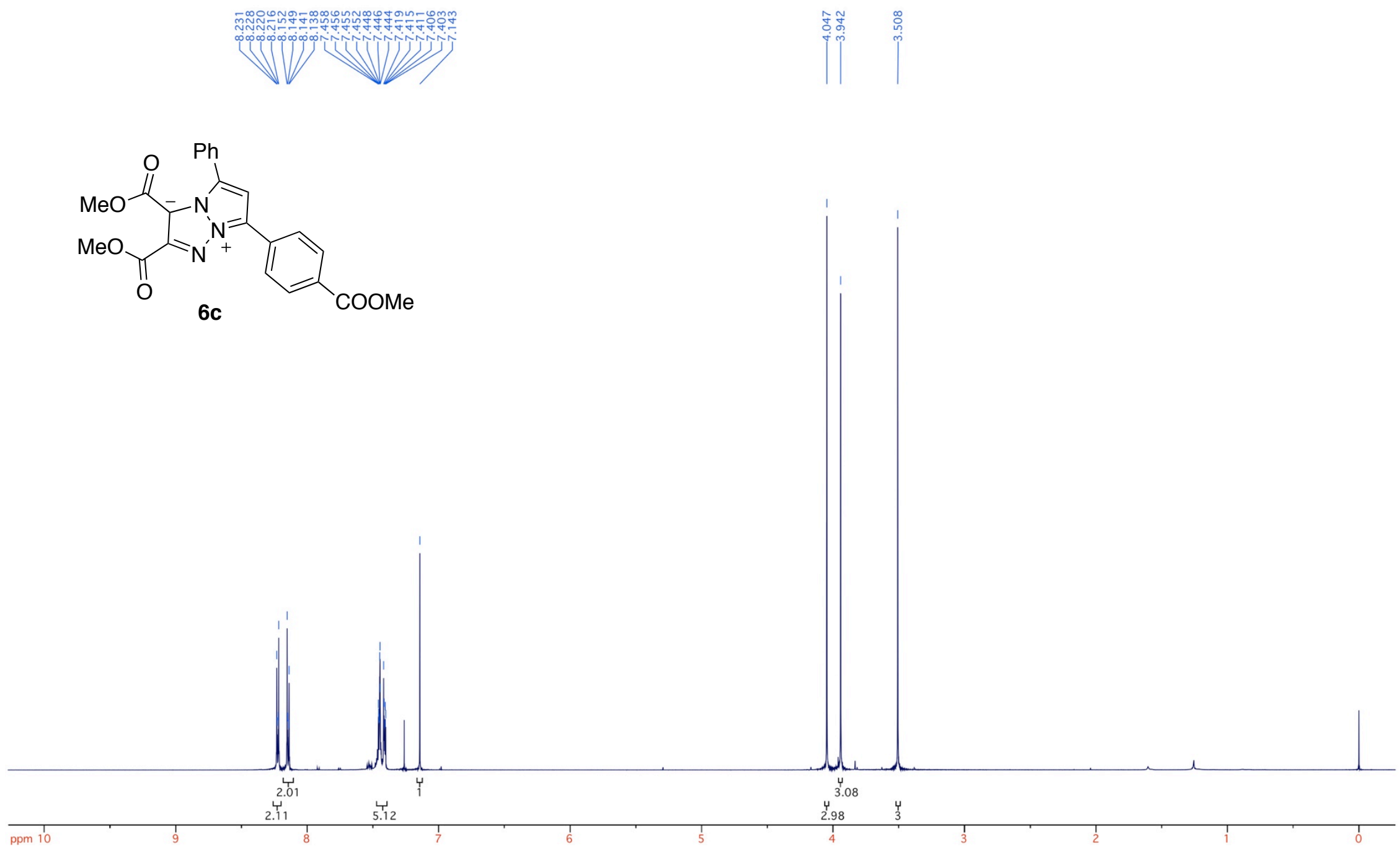

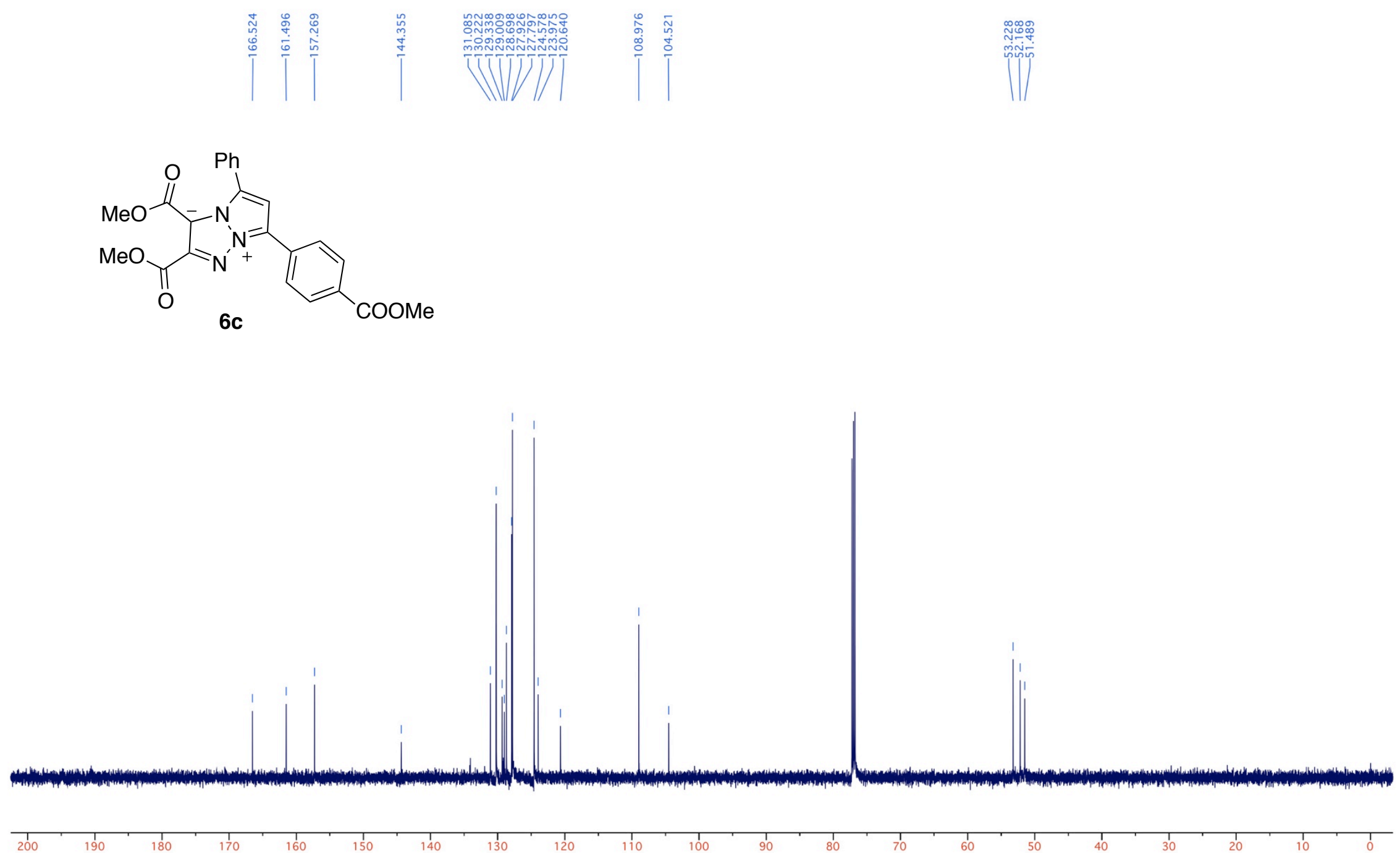

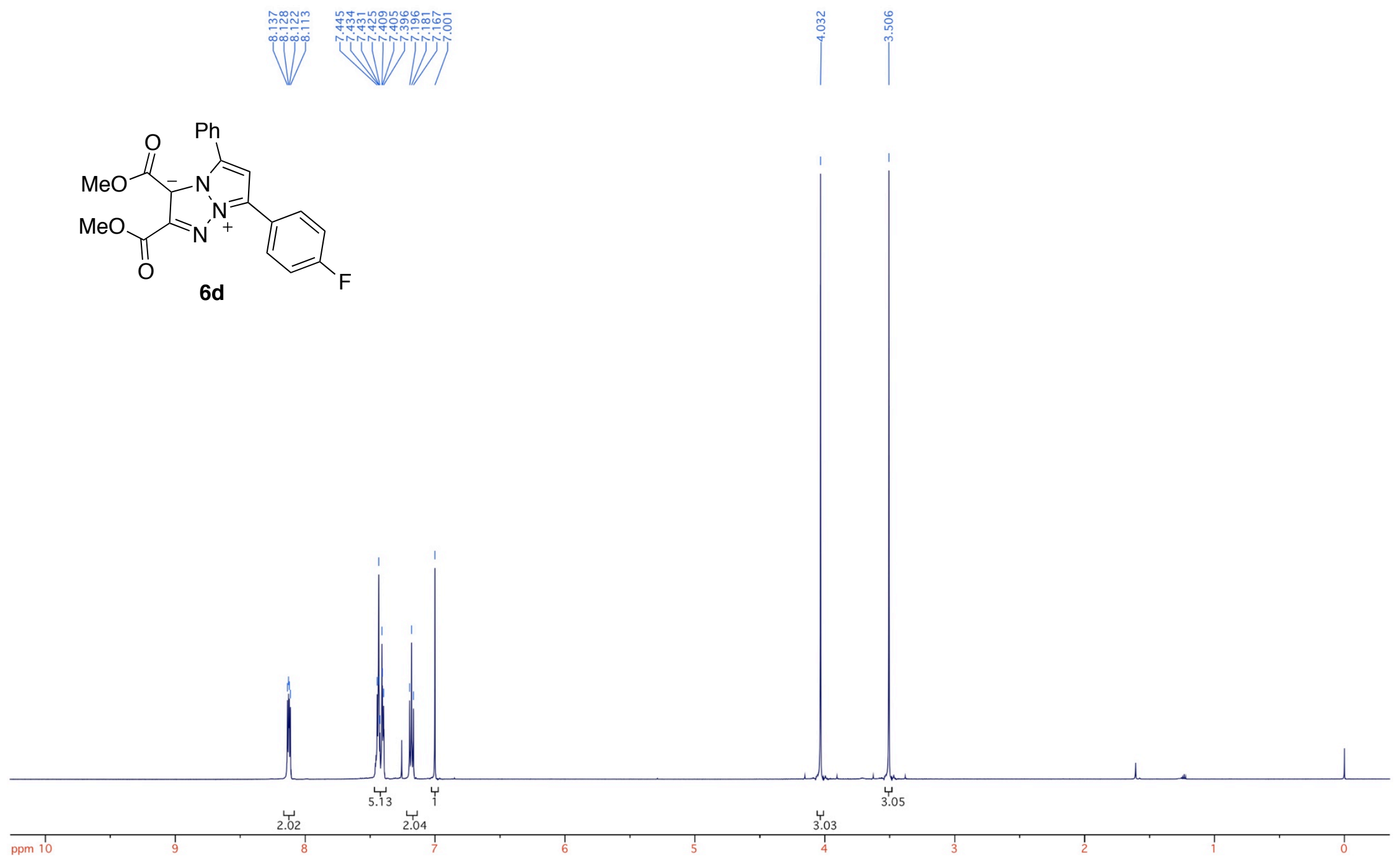


\section{WI}
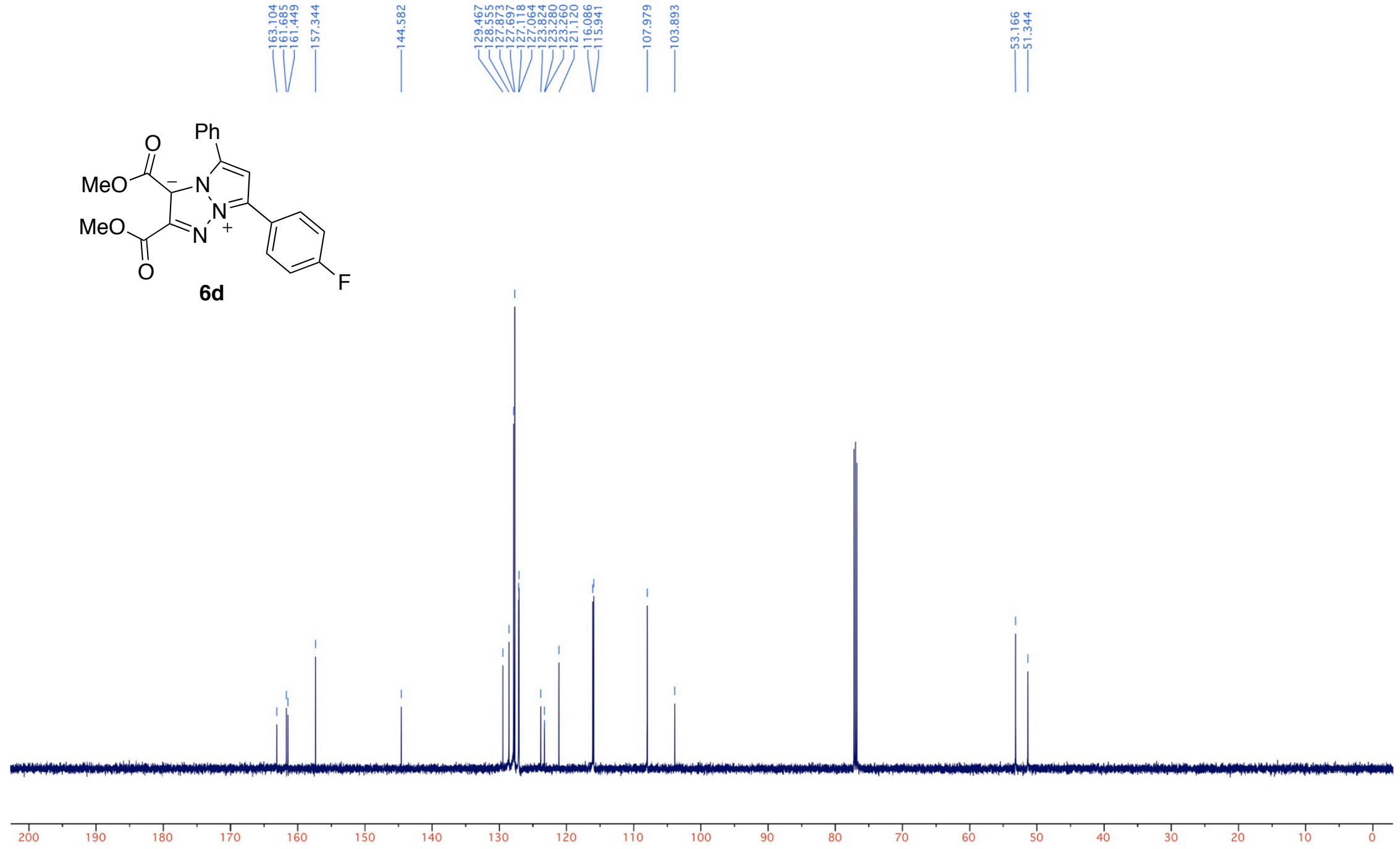


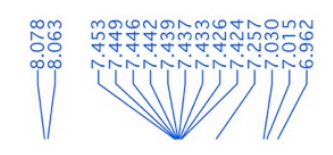

If
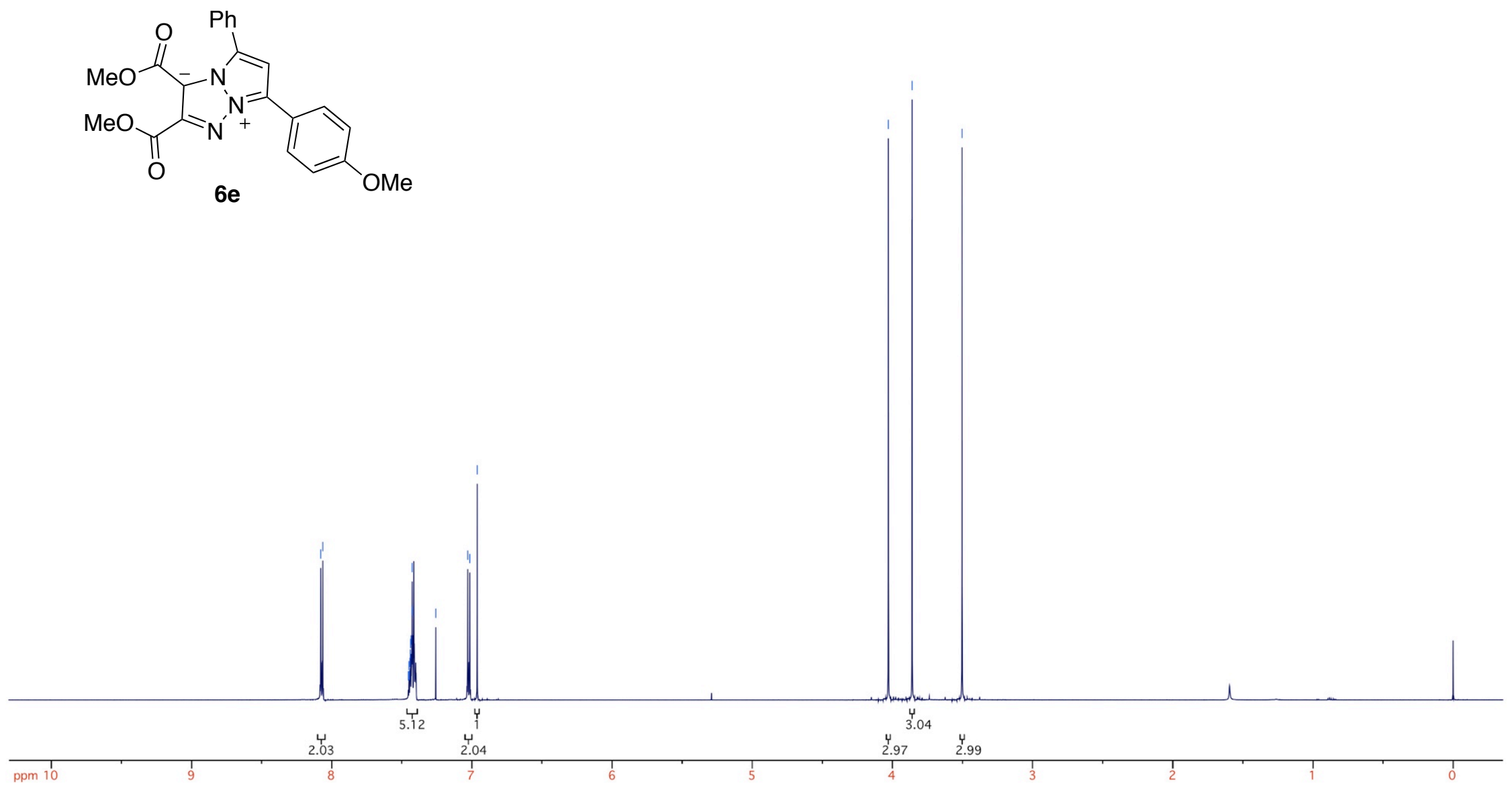


\section{非 I N}
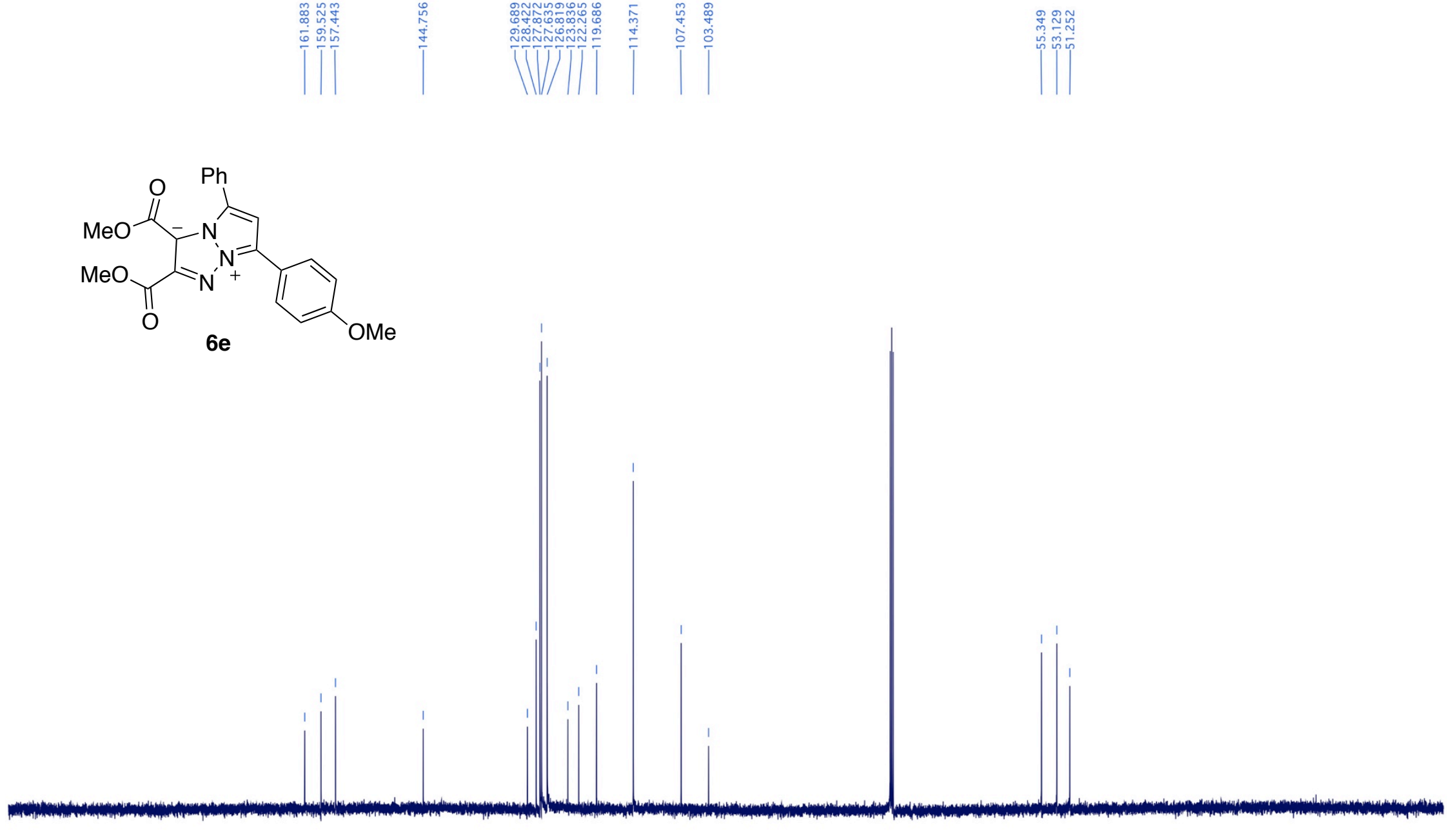

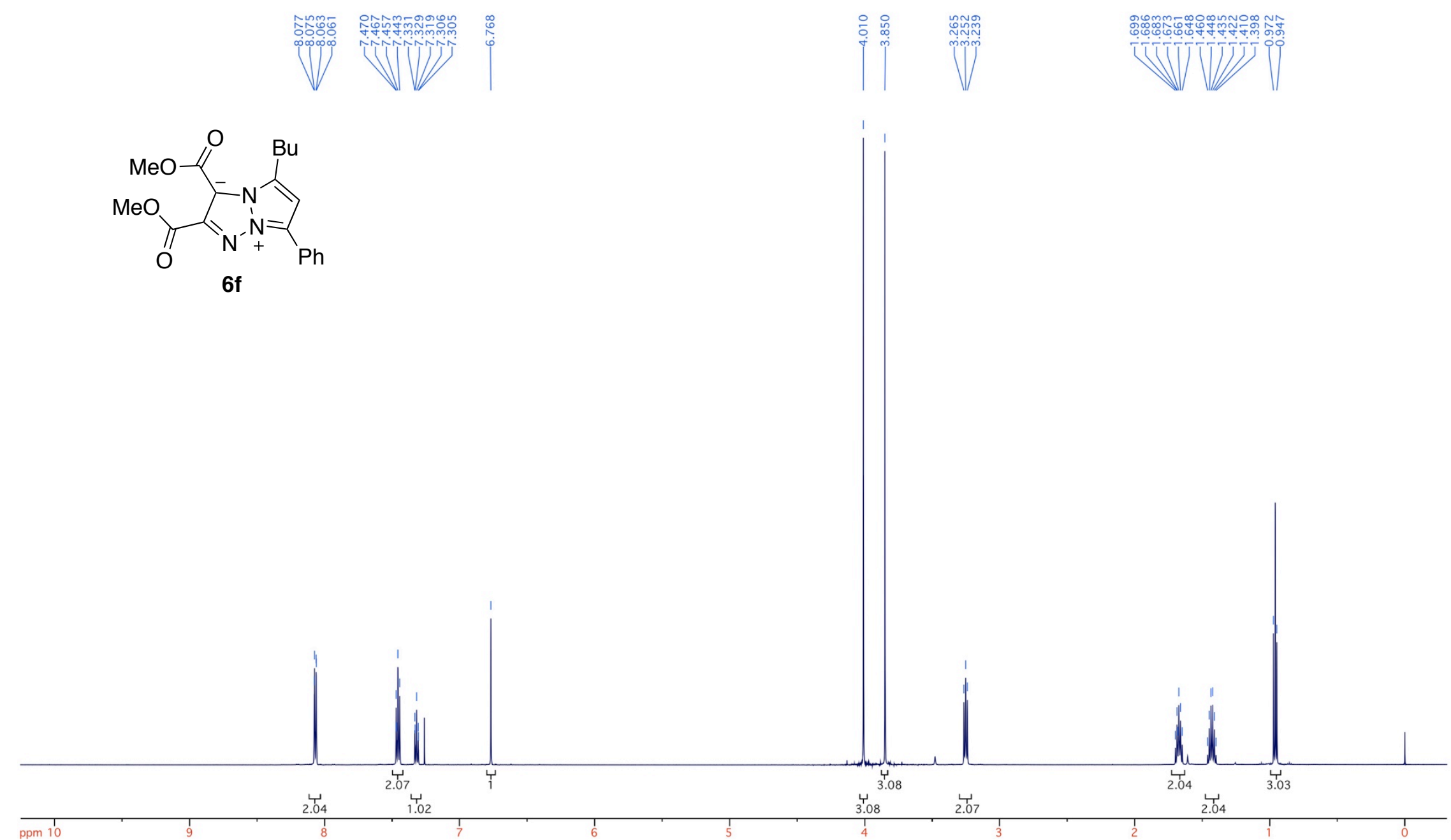

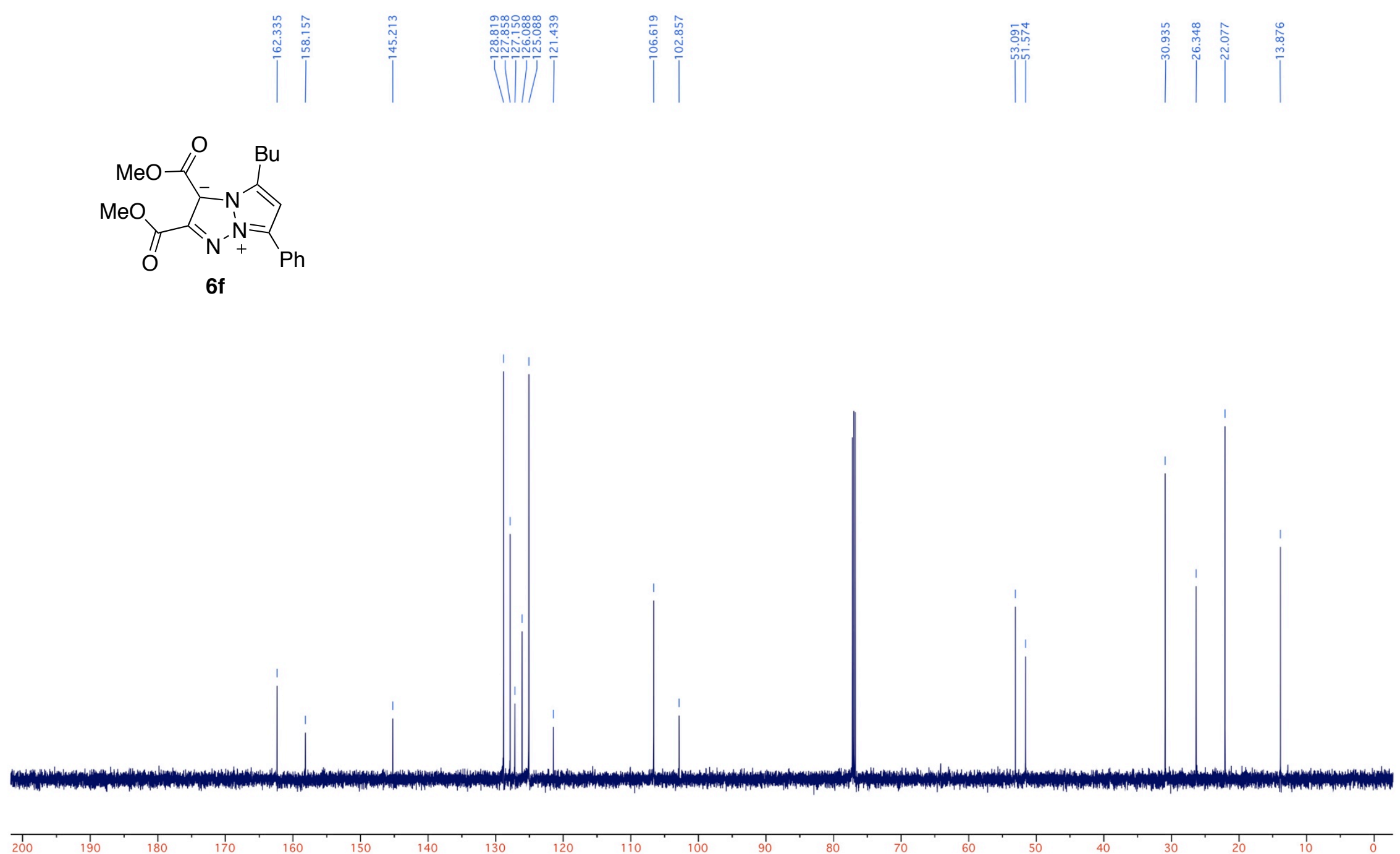

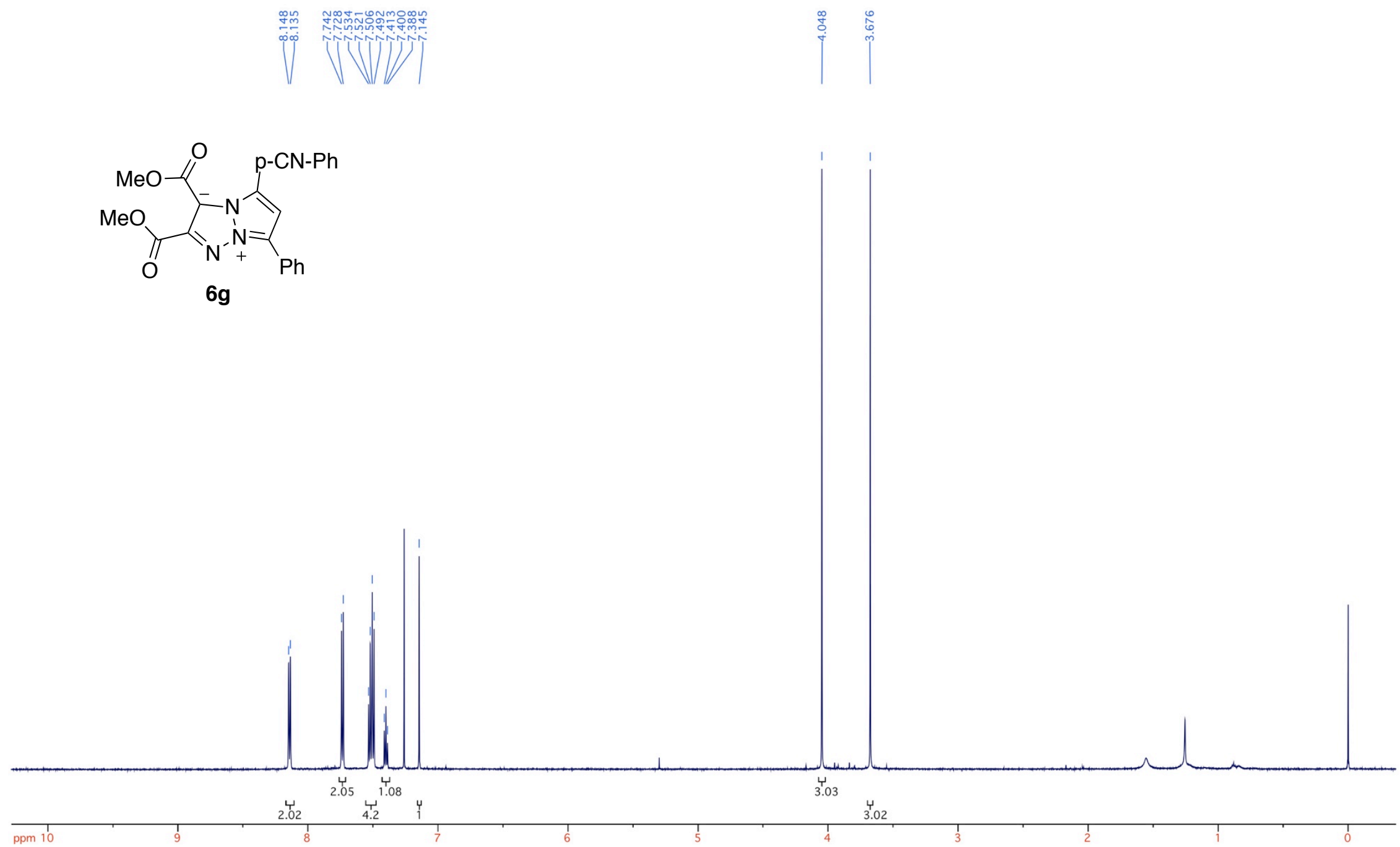


\section{I I I I}
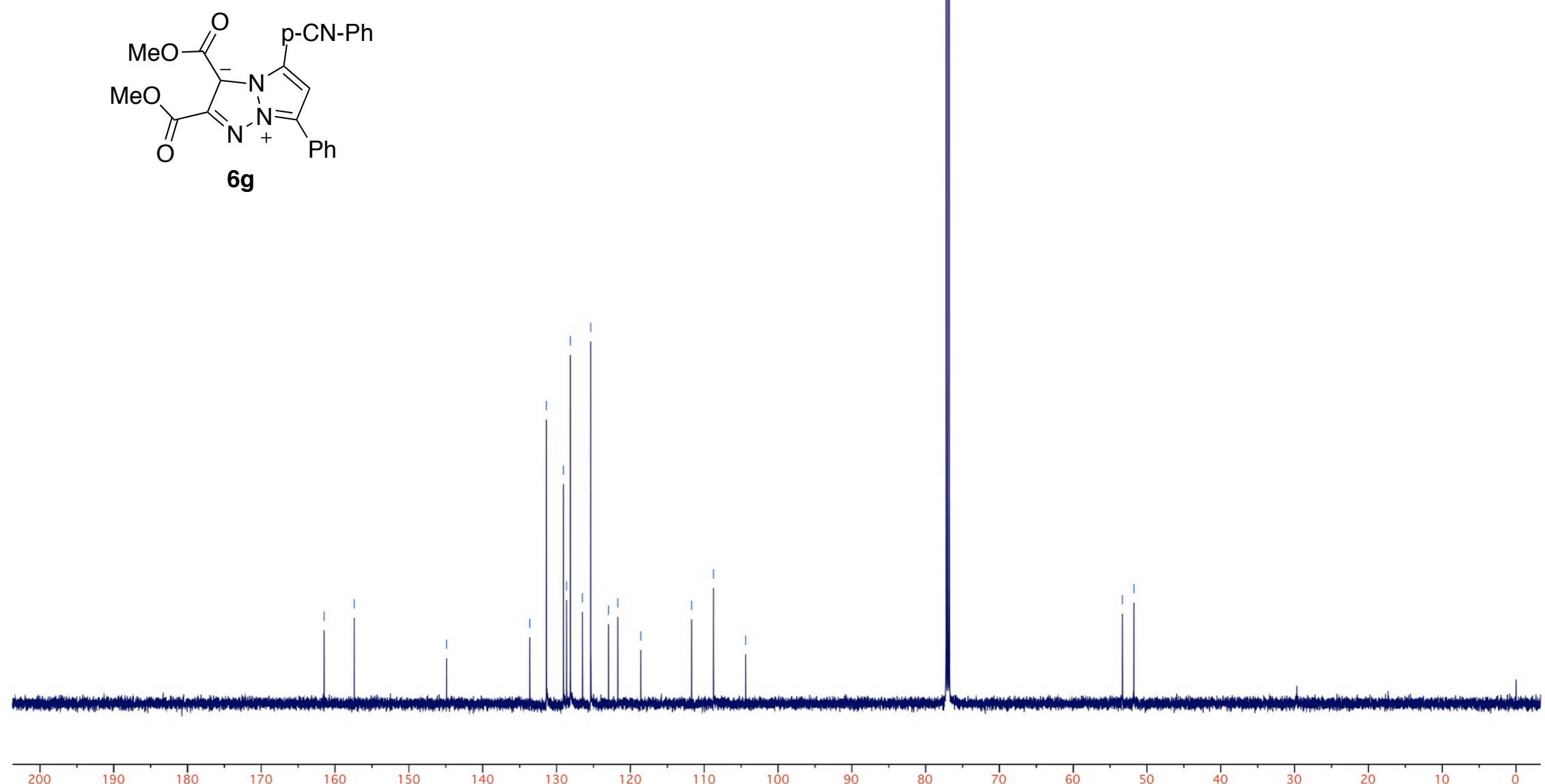


\section{Chapter S2. "Silver Effect" in Gold(I) Catalysis}

on-z-51C-1H

Archive directory: /export/heat/vener 1/venersys/dat

fine: pororou

Pulse sequencei szpui

$\prod_{O}^{O A C}$

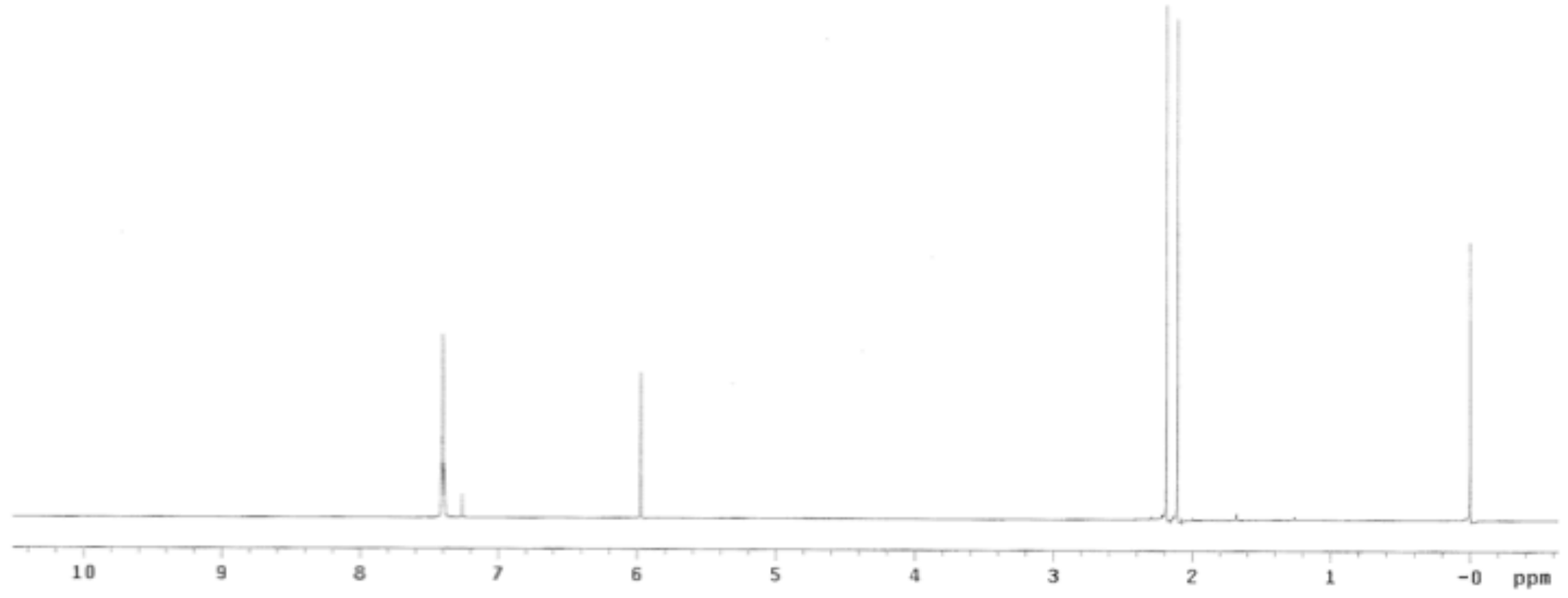


ov-2-51c-13c $\quad 2 a$

Dulse sequence: szpu

$\overbrace{O}^{O A C}$

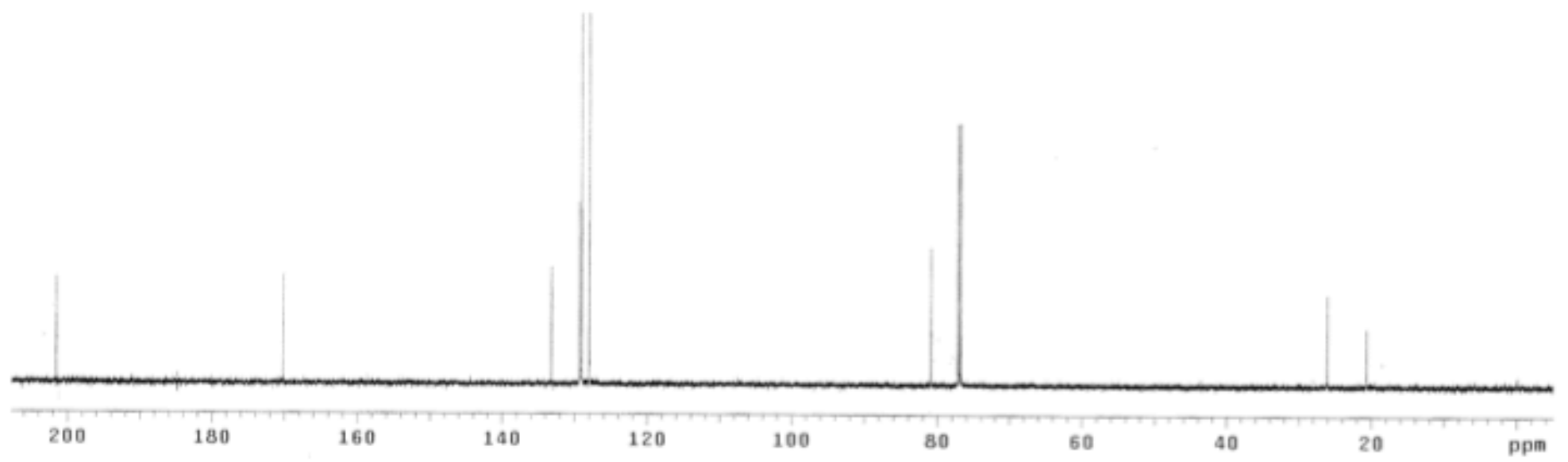




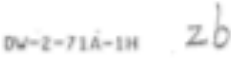

Archive directory: /expert/home/vnar1/vnarsys/data

Simple directiory?

Pulse Sequence: szoul
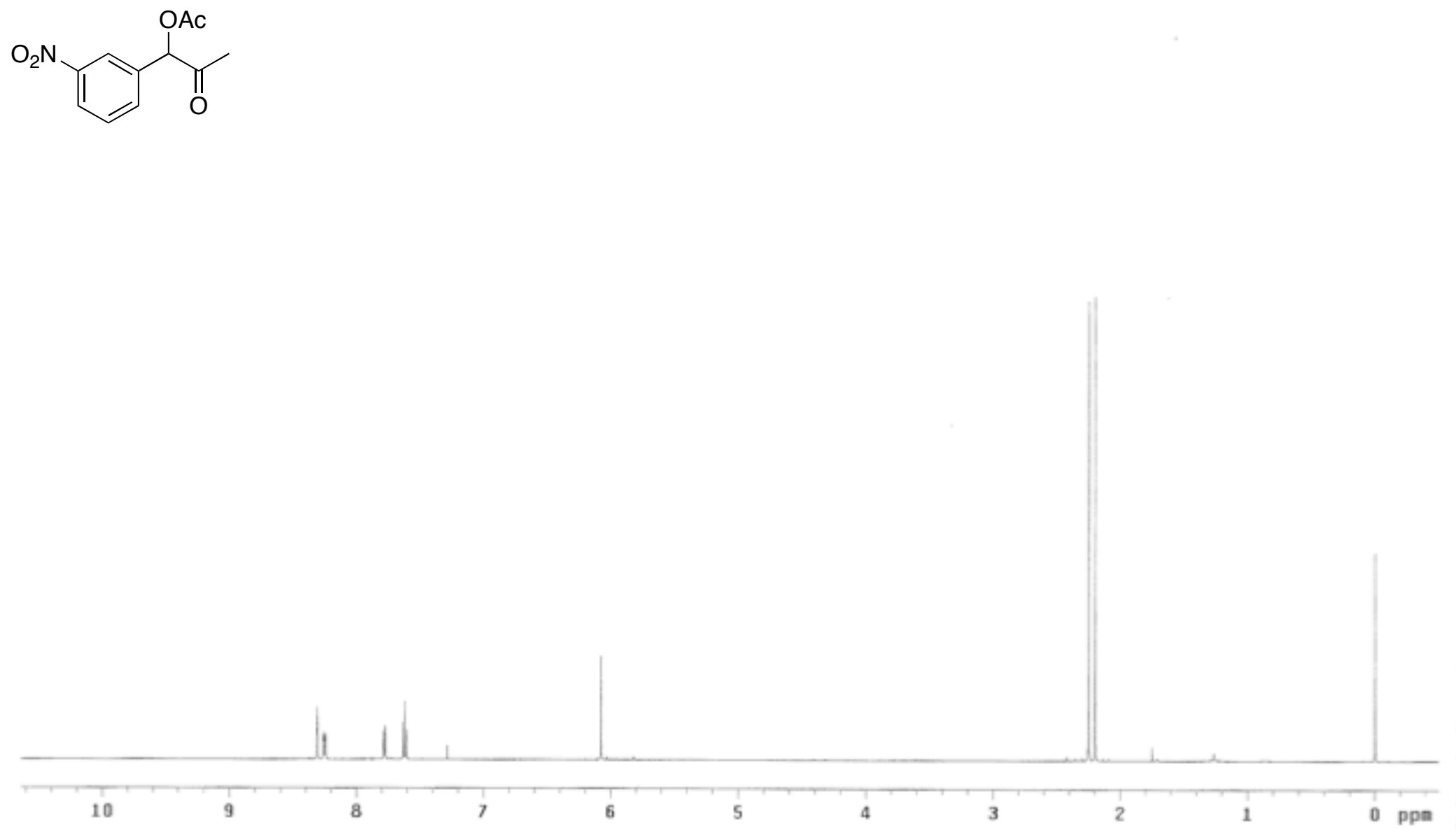
$0 \mathrm{Q}-2-71 \mathrm{~A}-13 \mathrm{~s} \quad 2 \mathrm{~b}$

pulse sequence: szpul
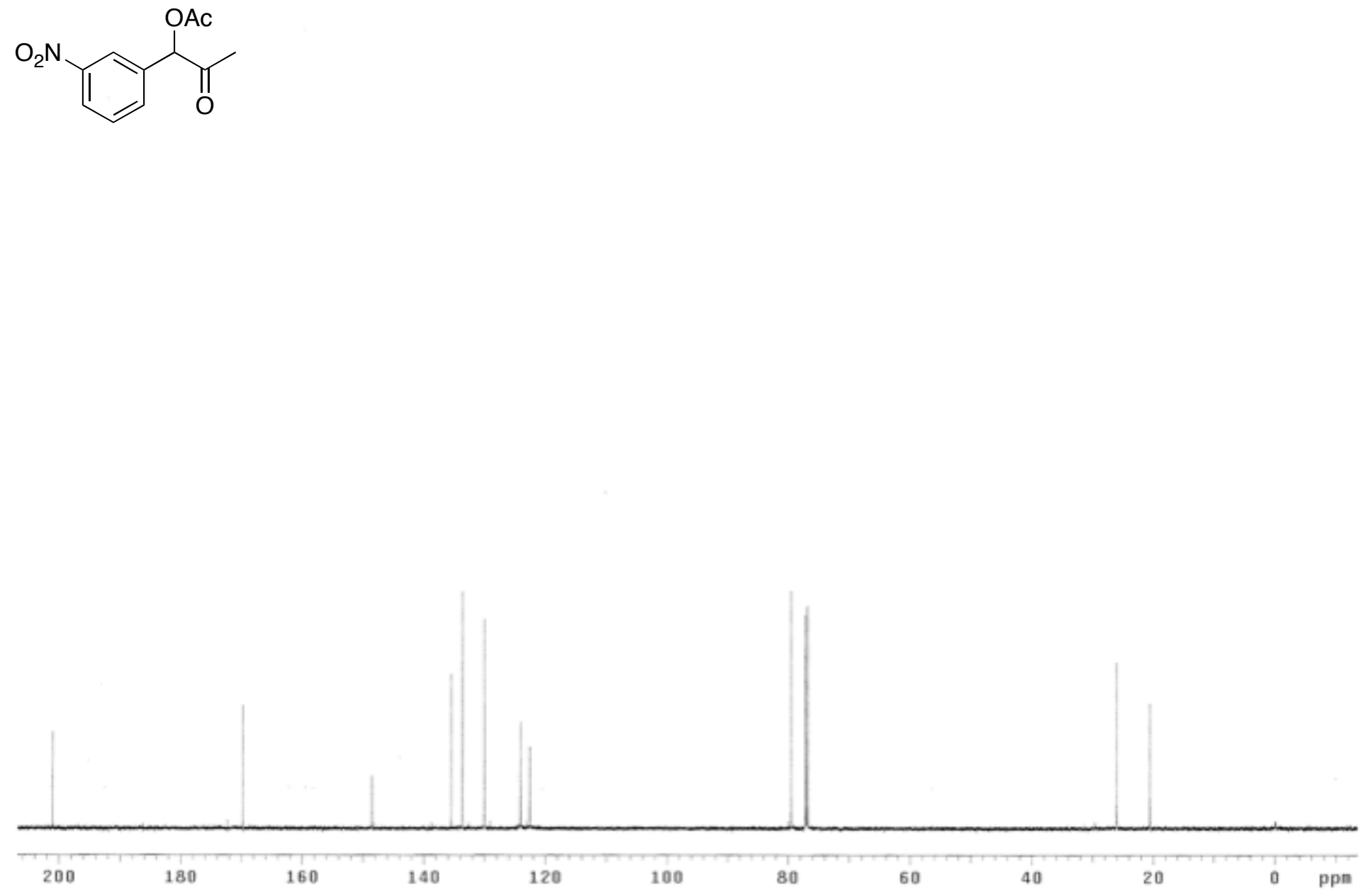
DU-z-110a-1M $2 C$

archive directory: /export/hoae/vnmer 1/vnmrsys/data

File: piorom
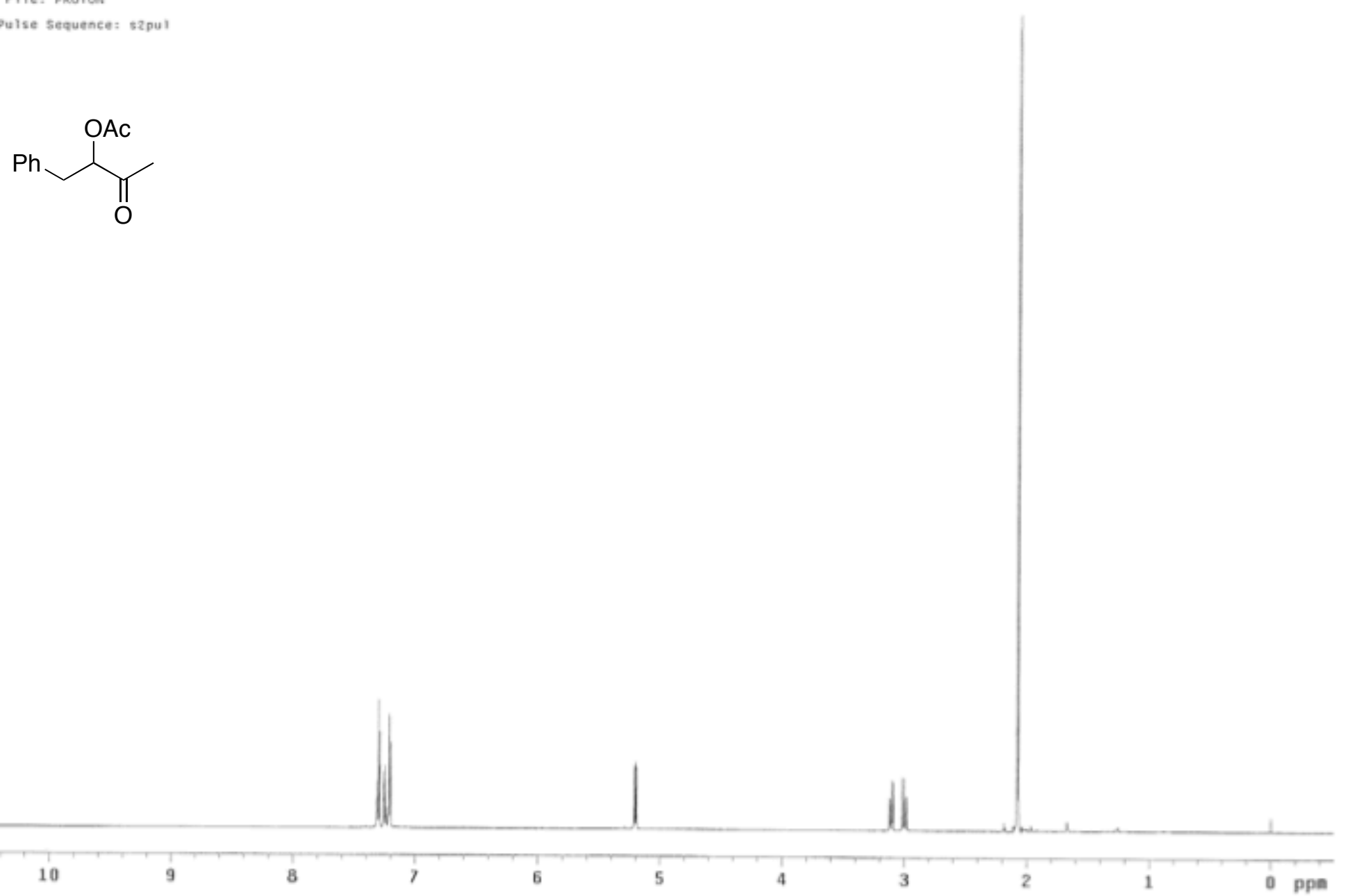
ON-2-118A-13C ZC

Dolse sequencel szpu
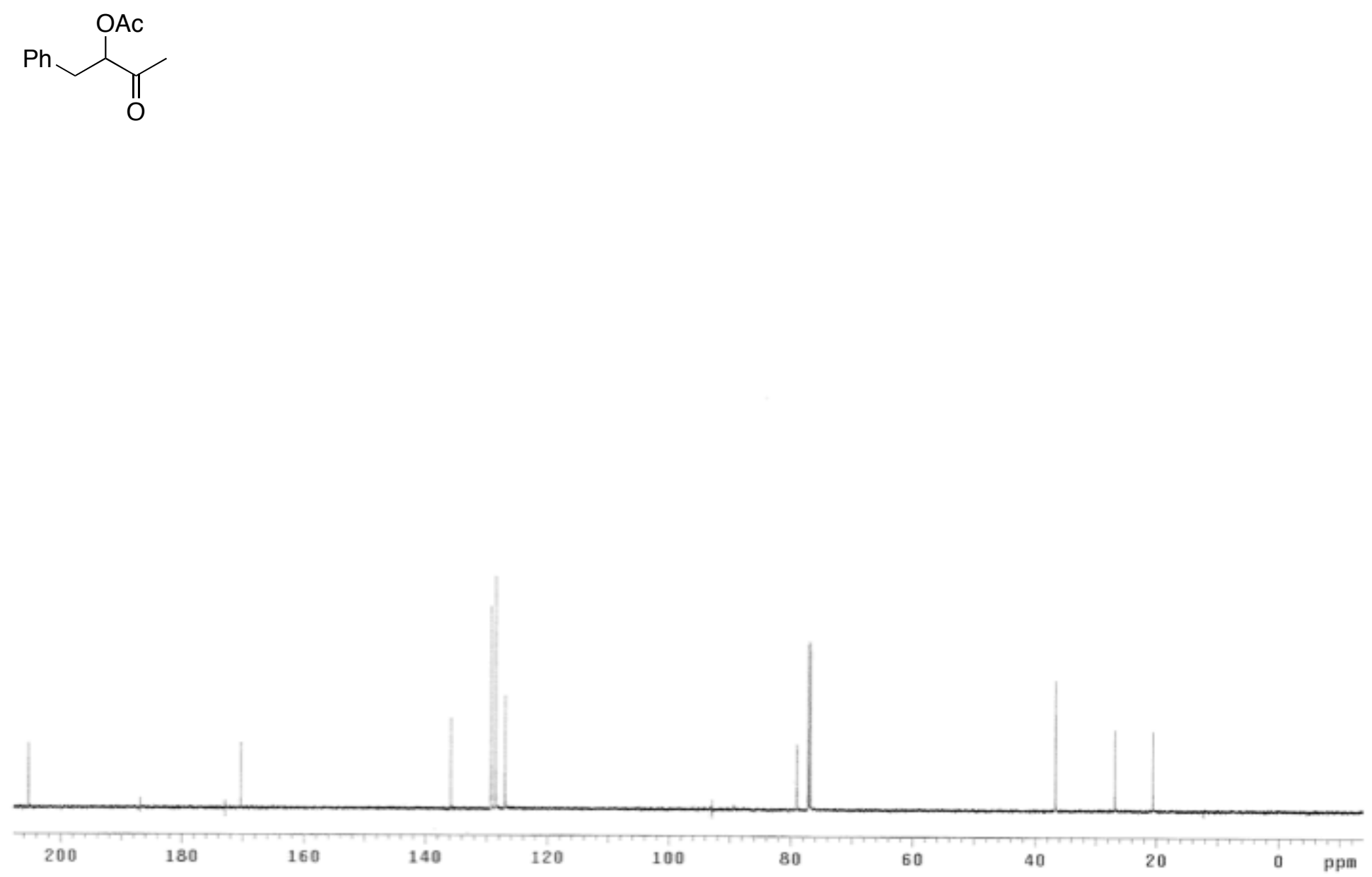
\$5-1-38-1m 20

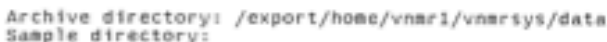

Pulse Sequence: s2pul

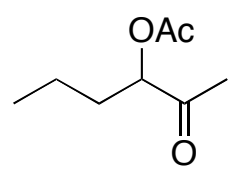


ss-1-58-13c $2 d$

Pulse sequence: szpol

OAc
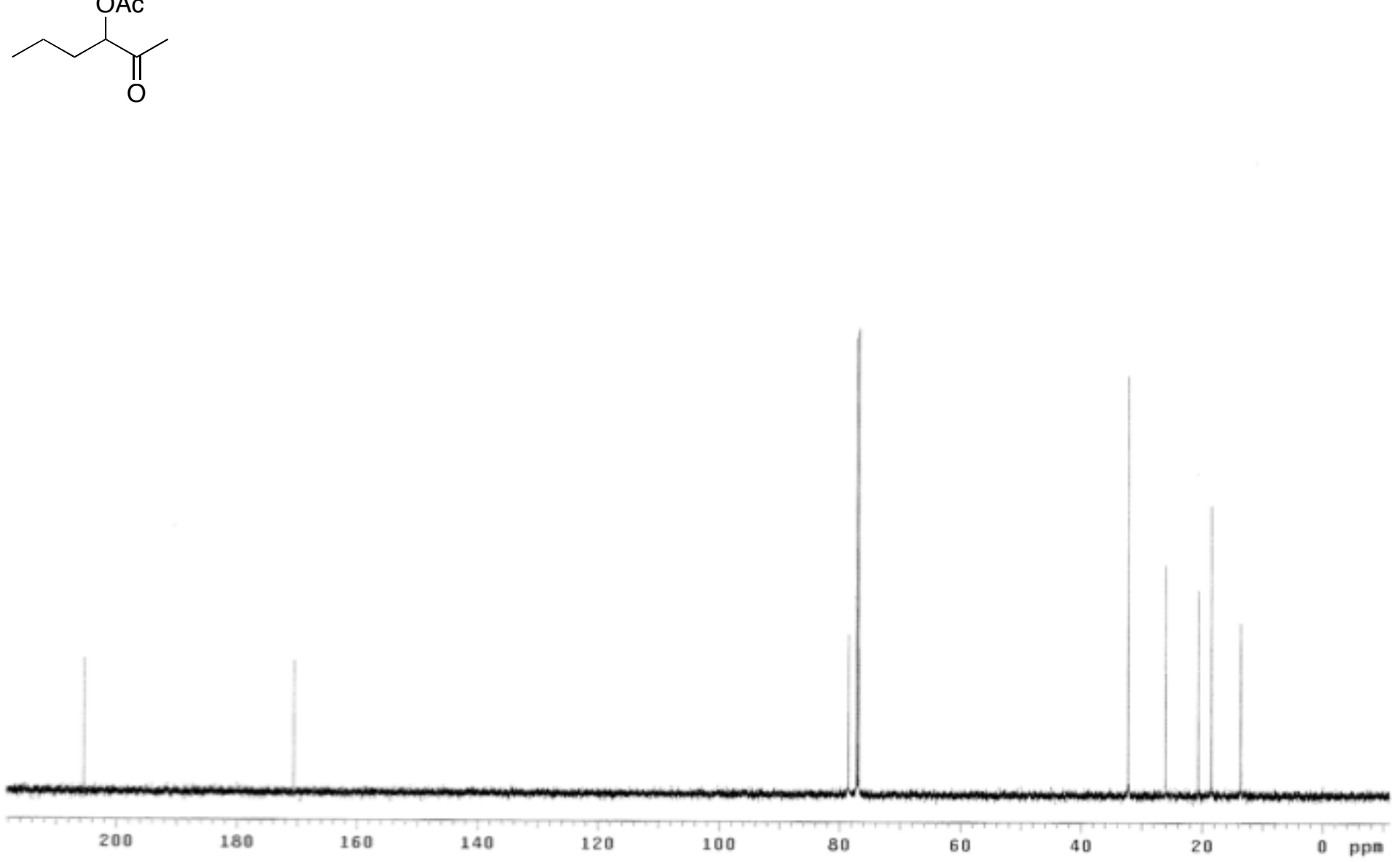
av-2-1188-1H $2 e$

Arehive directory: /export/home/vnar 1/vnarsys/data

Bapple pirfectory?

Pulse Sequence: $52 \mathrm{pu} 1$

OAC

or 
DN-z-113s-13c $2 e$

pulse Sequence: s2pol<smiles>[GeH3]</smiles>

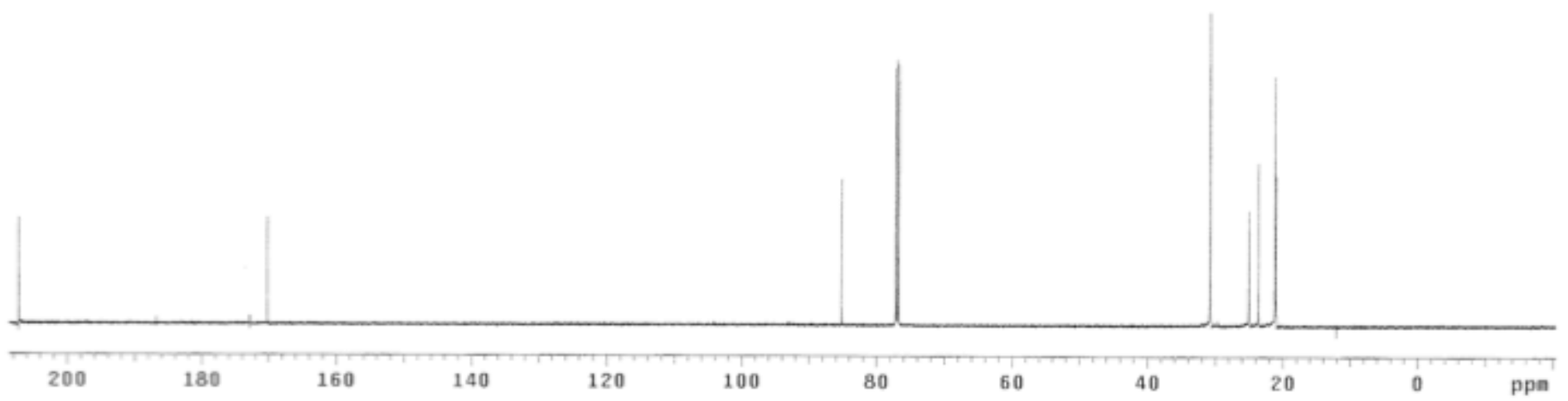


OU-2-79A-1H $2 f$

arehive directory: /export/home/vnar 1/vnersys/data File: PRoTtce

Pulse Sequence: sżpul
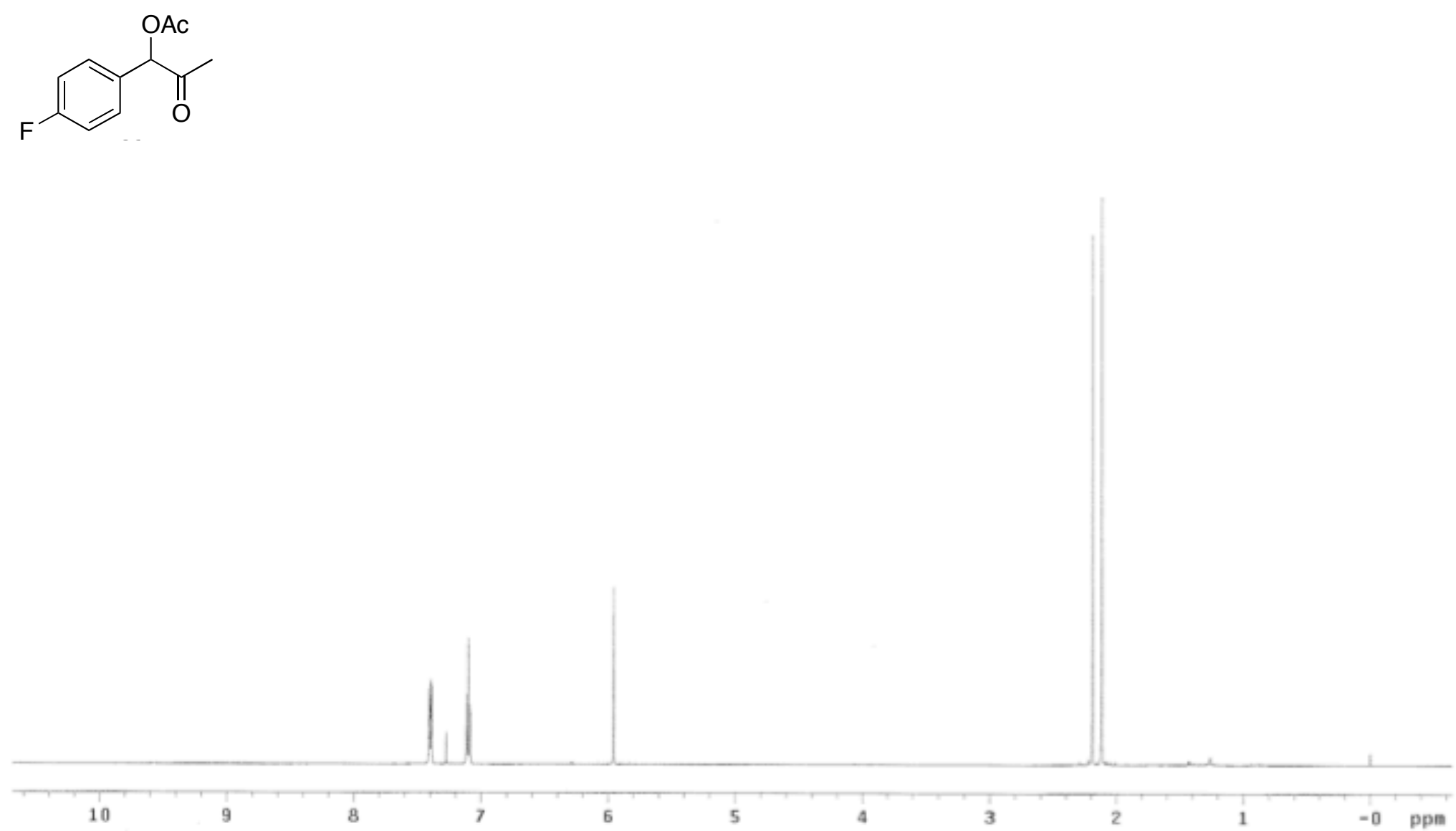
an-z-7na-13e $2 f$

pulse sequencel szpu

OAc
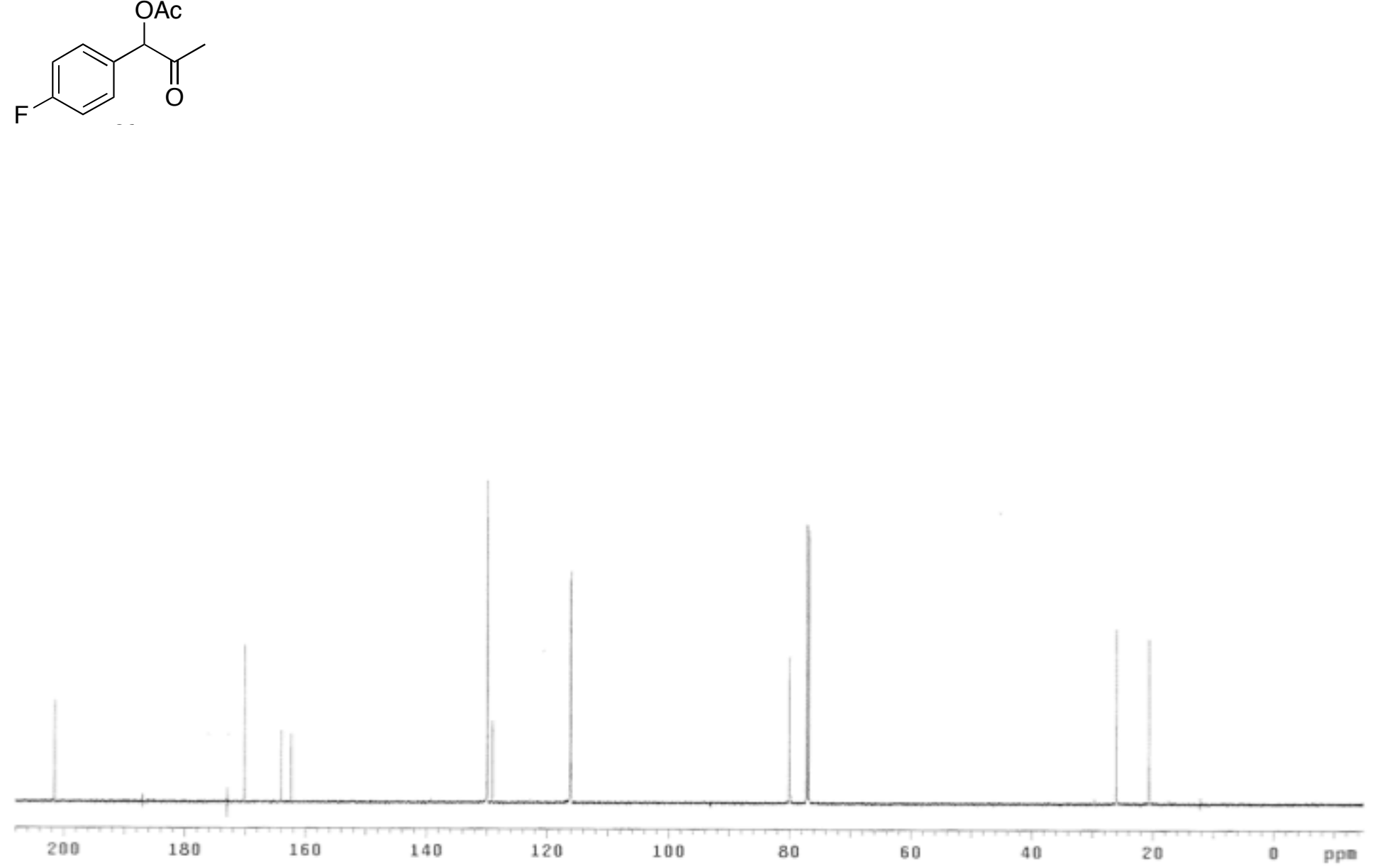
OU-z-12zA-1H 29

Archive directorys /export/hont/vnar 1/vmarsys/data
Sample directoryt
File: protow

Pulse Sequence: s2pul

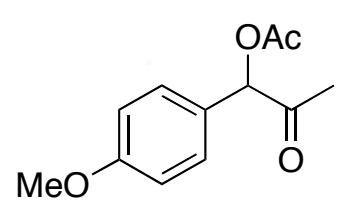


ov-z-12zA-1sc 29

Dulse sequence: szpul
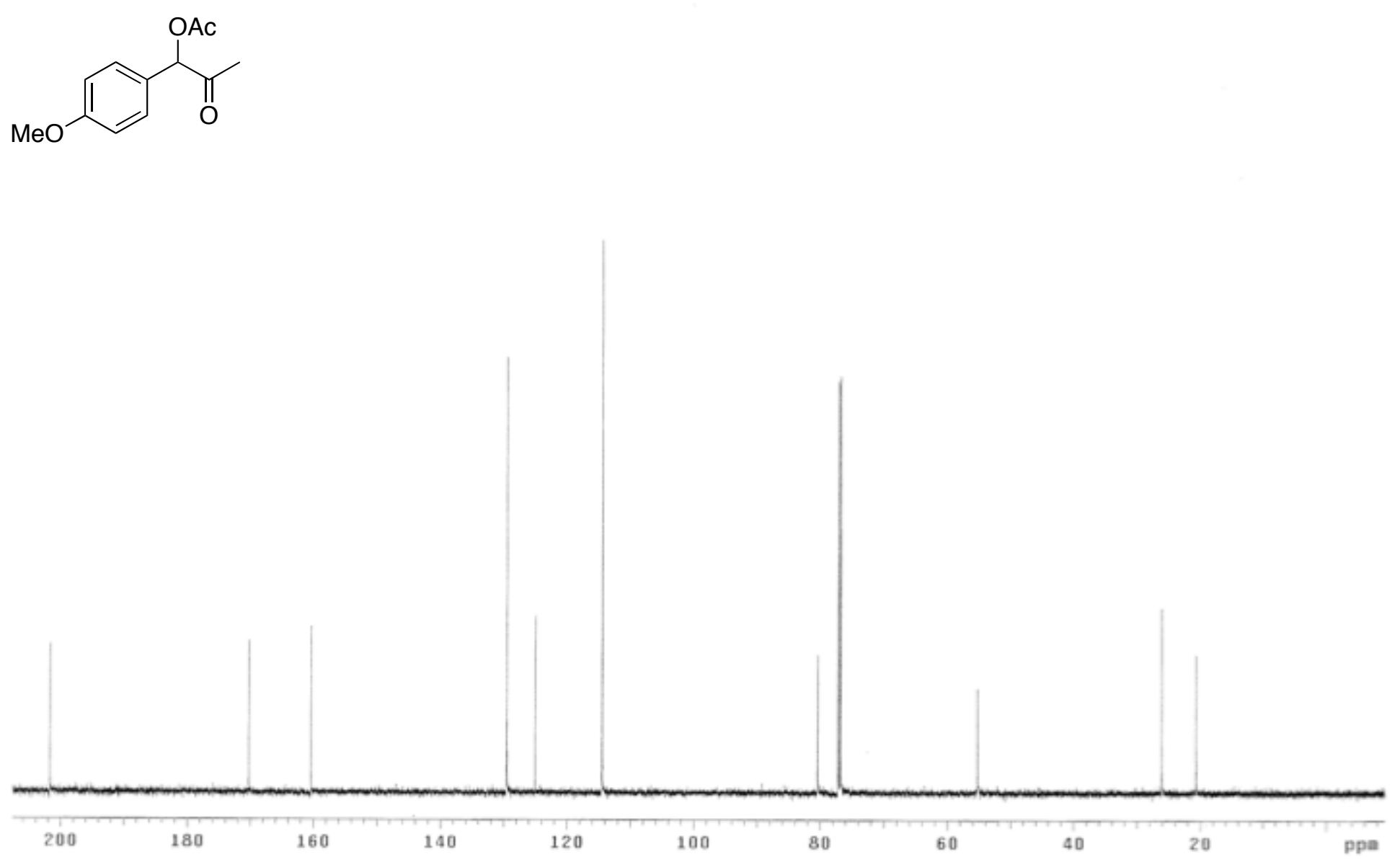
ss-1-101-*1 $2 h$

Archive strectoryi /export/howe/vneri/vnarsys/eats

Sample directior
File proron

Pulse Sequence: s2pul

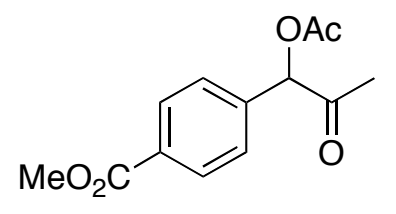$$
\text { M. }
$$

$$
\prod_{0}^{10}
$$

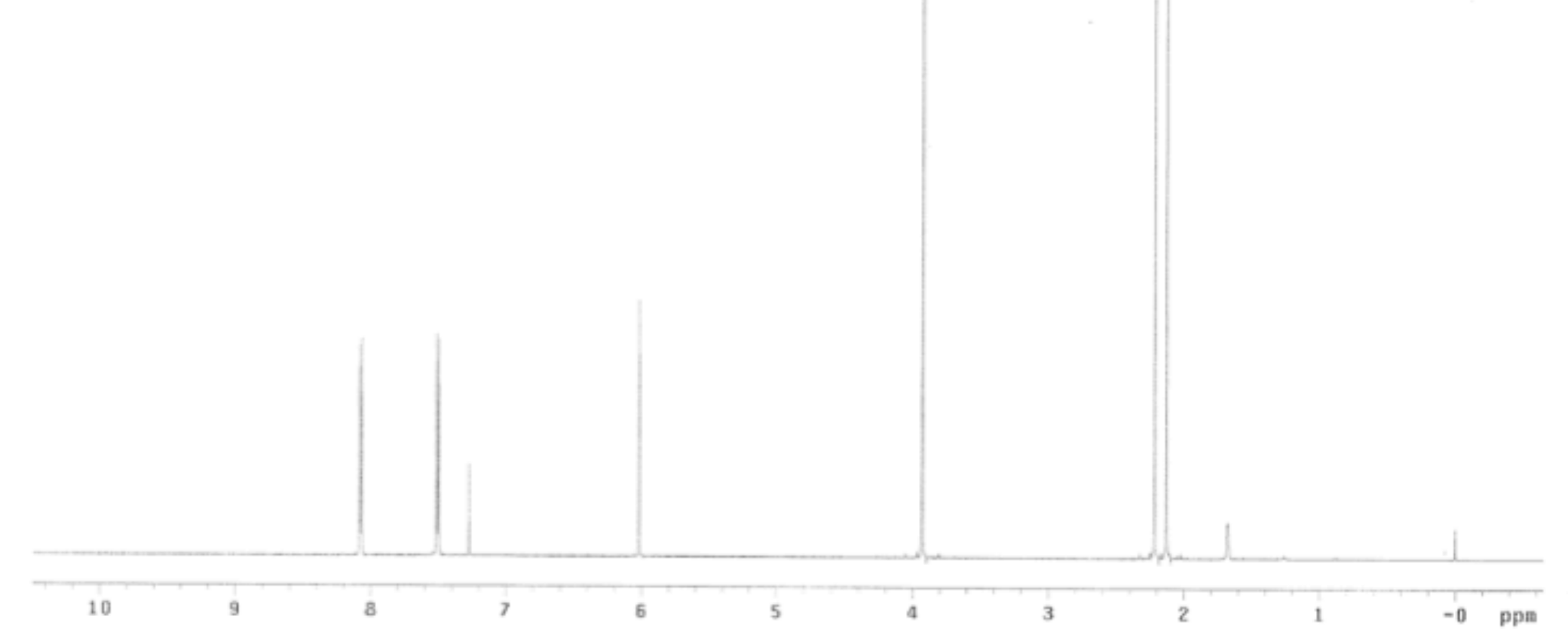


$s s-1-101-c_{13} \quad 2 h$

pulse sequence: s2pul
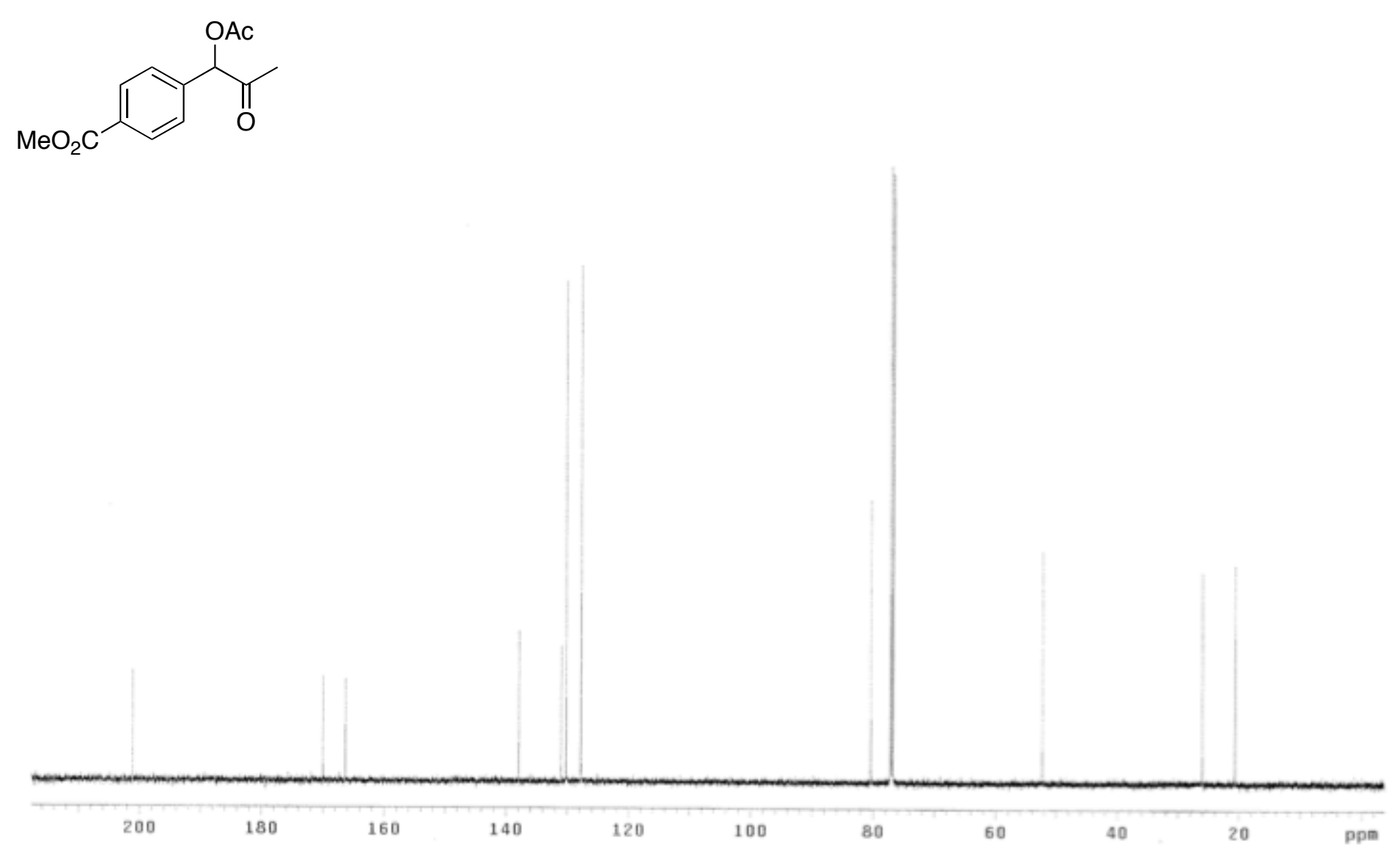
ou-2-12zc-1H $2 l$

Archive directory: /export/home/vmar1/vmarsys/datw

Sasple directory
File: prorow

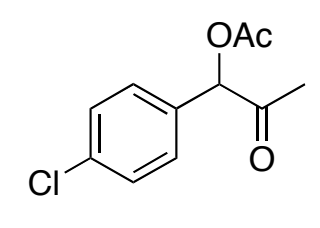

OAc

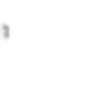


ov-2-122C-13c $2 l$

Pulse sequencel szpur
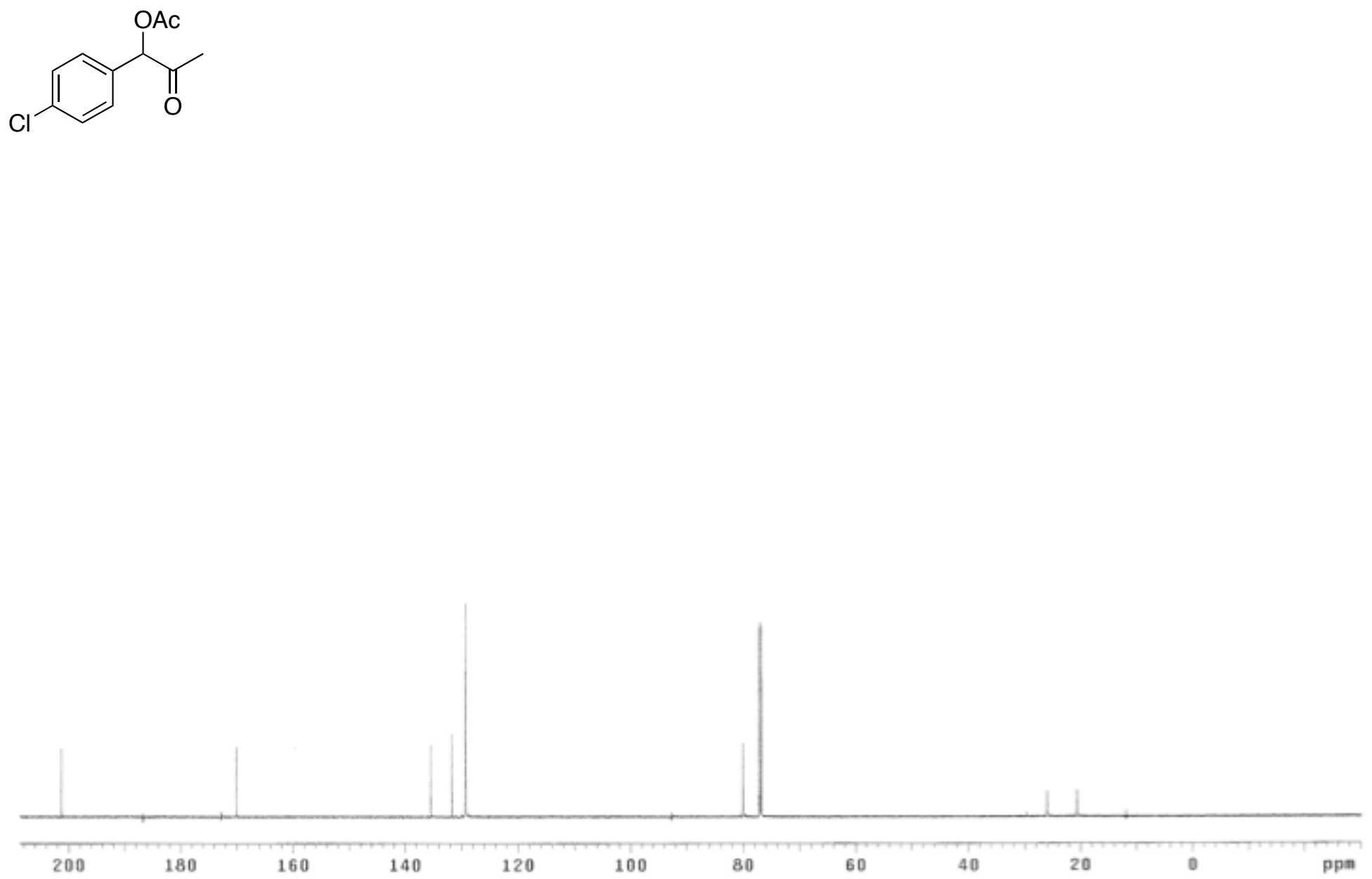
ou-2-79B-1n $\quad 2 j$

Archive directory1 /export/home/vner1/vanarsys/data

pulse Sequence: szpul

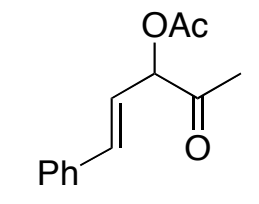

OAc

$\mathrm{Ph}$

O

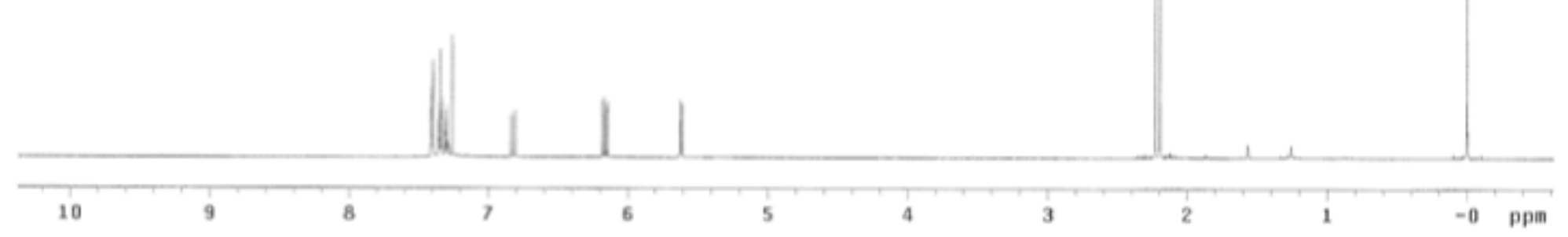


ov-z-mo-ise 2
fulse sequencel szput
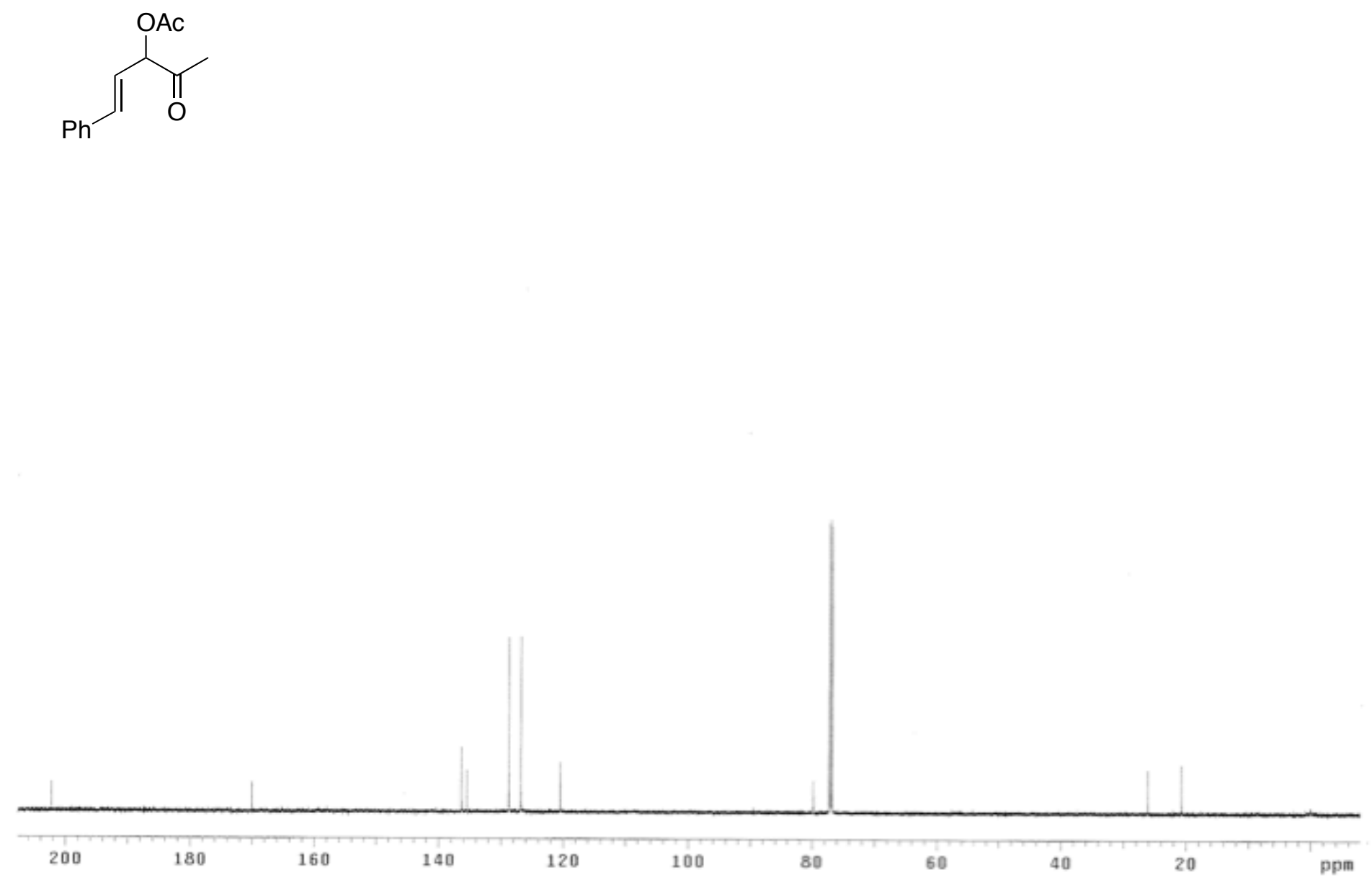
ou-z-zzoc-1h

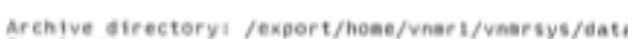
Satppie directory

Pulse sequence: s?pul<smiles>O=C(Cc1ccccc1)c1ccccc1</smiles>

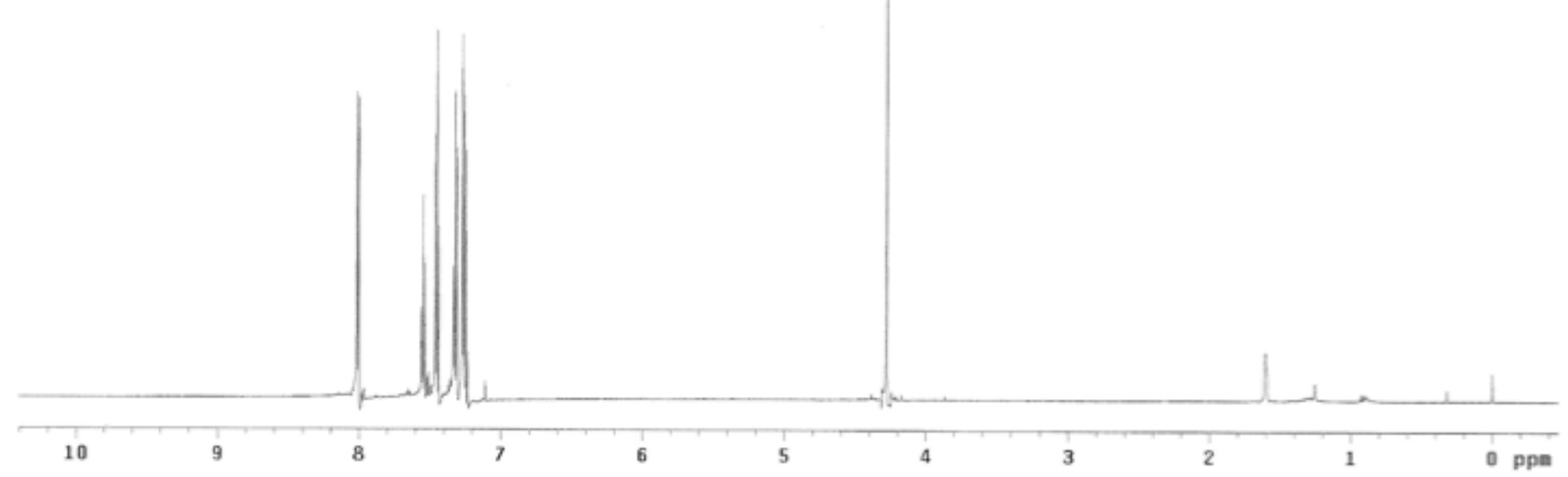


$0 \mathrm{x}-2-220 \mathrm{c}-13 \mathrm{C}$

culse sequence: szpul

${ }_{\mathrm{Ph}} \stackrel{\mathrm{O}}{\mathrm{H}} \mathrm{Ph}$

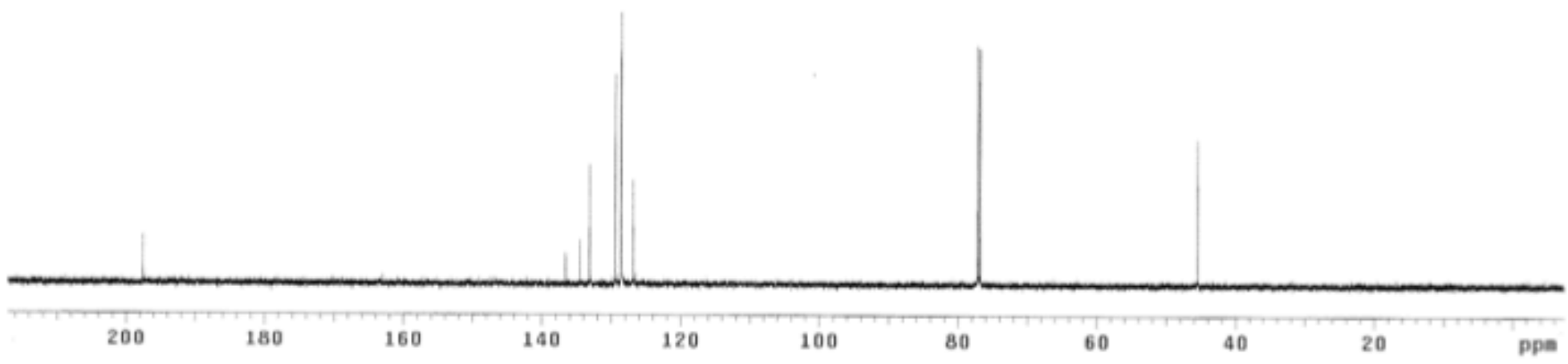




$$
\stackrel{\mathrm{Bu}}{\mathrm{O}}_{\mathrm{Ph}}^{\mathrm{Ph}}
$$

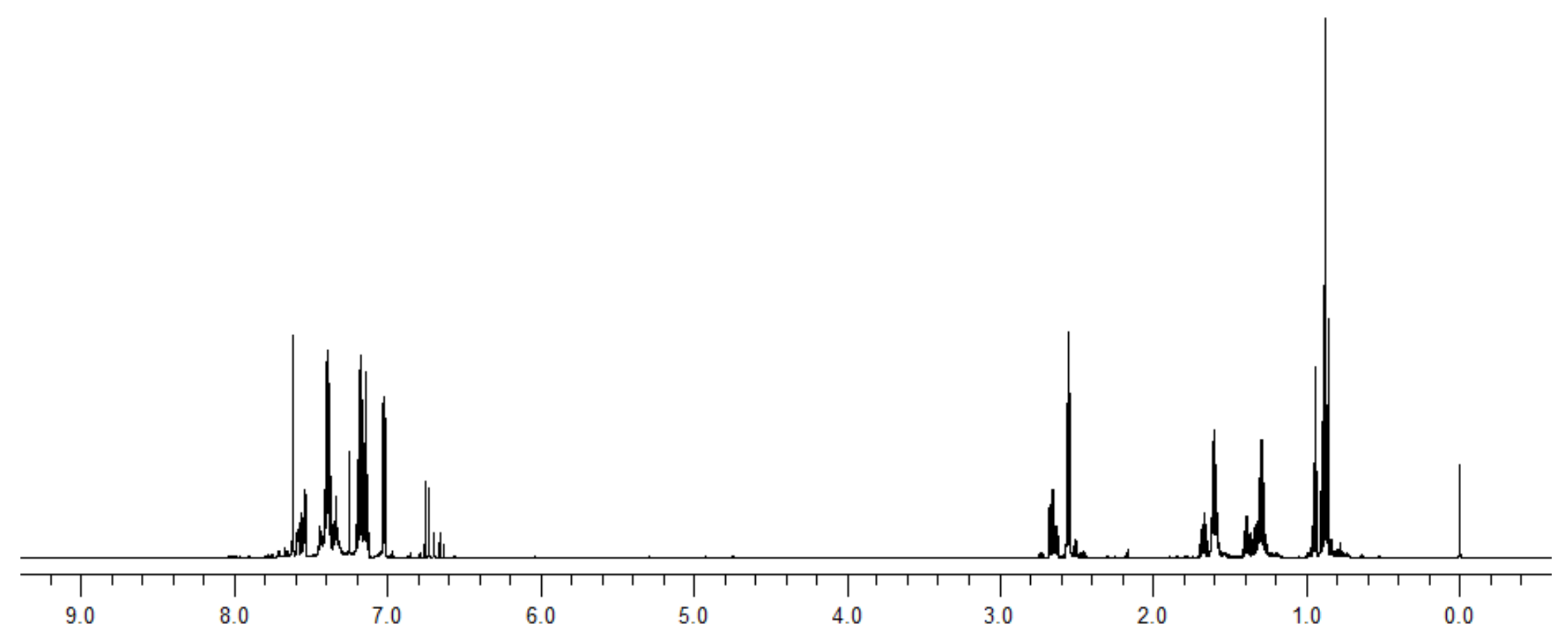



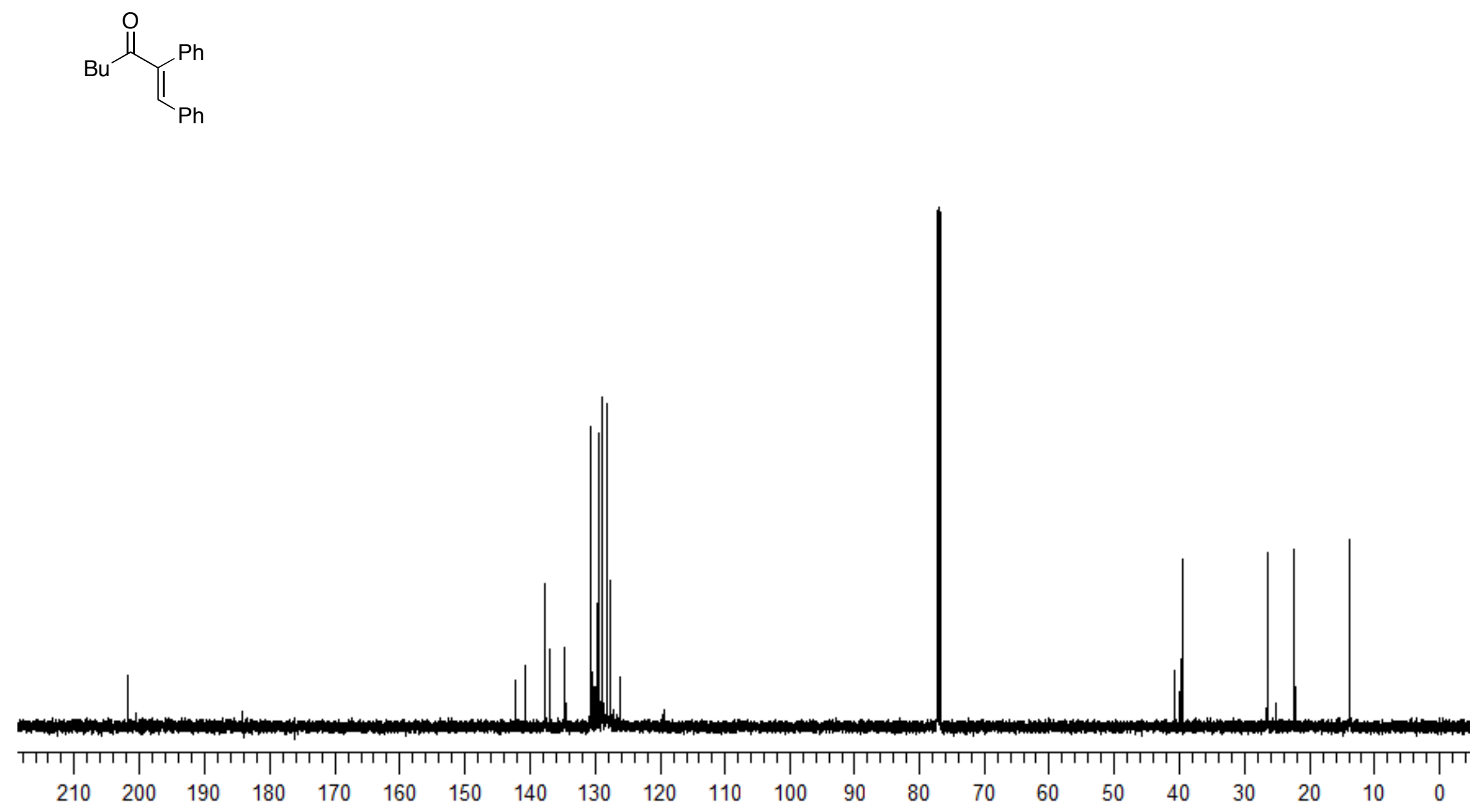

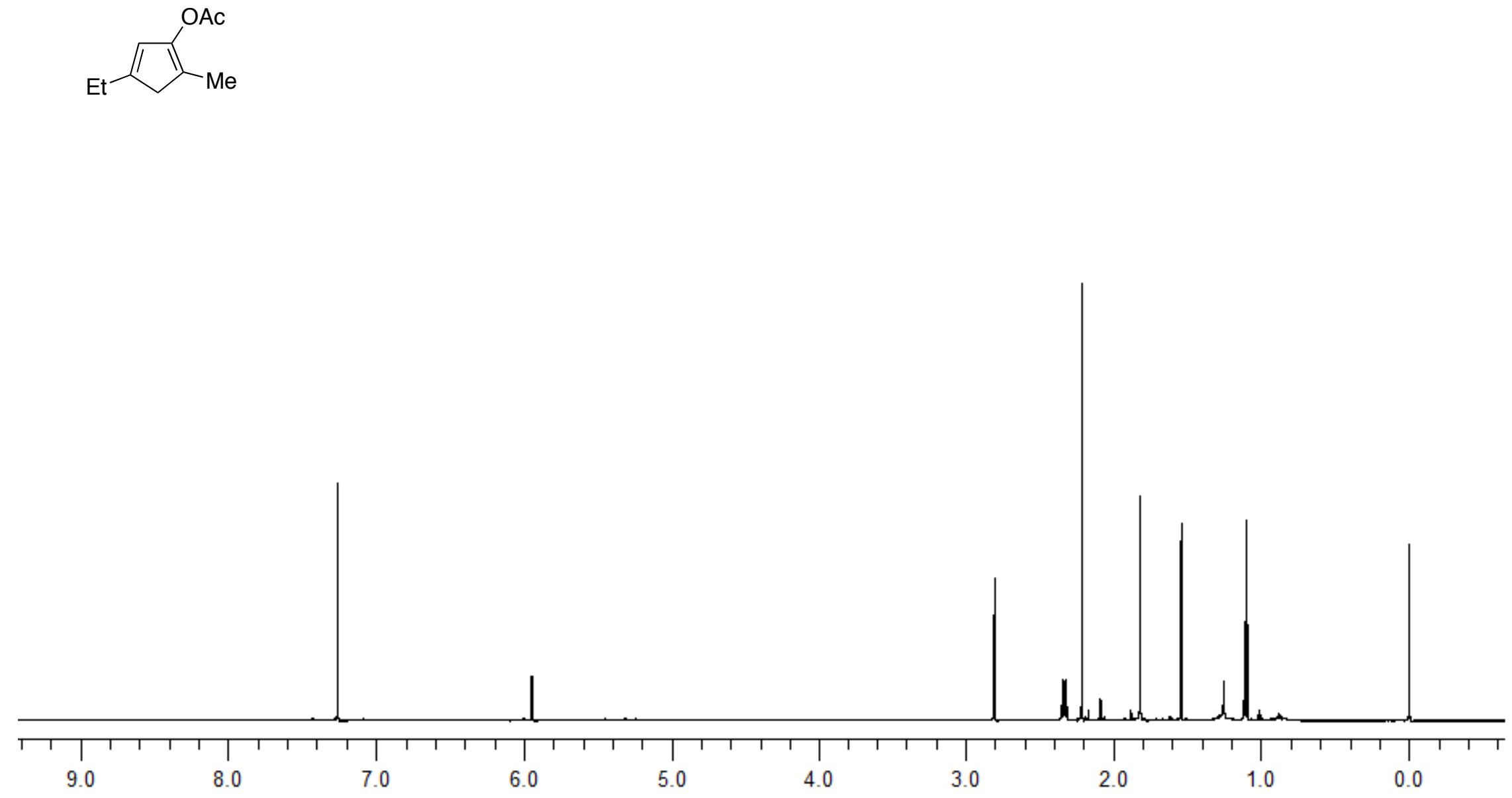

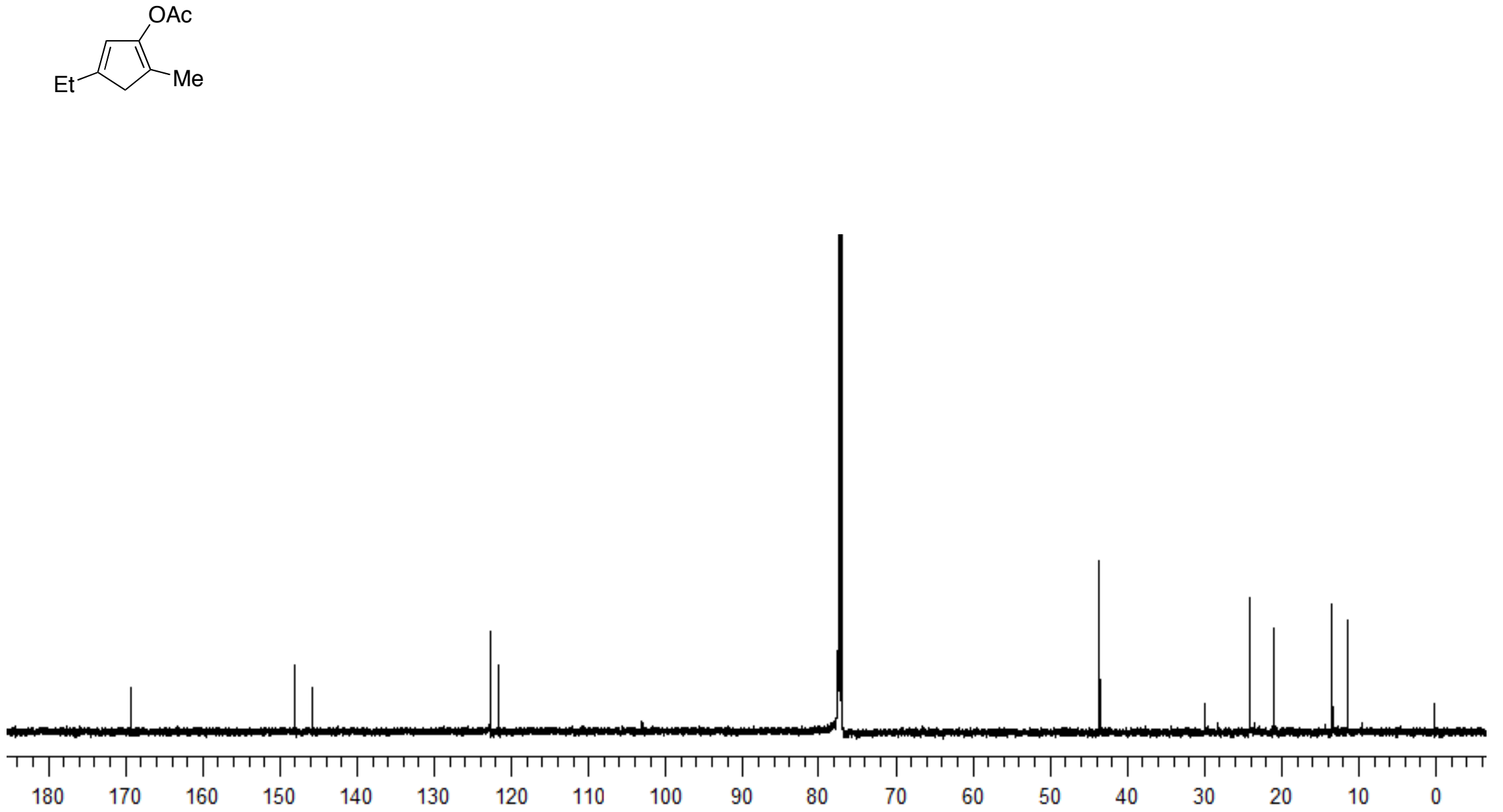

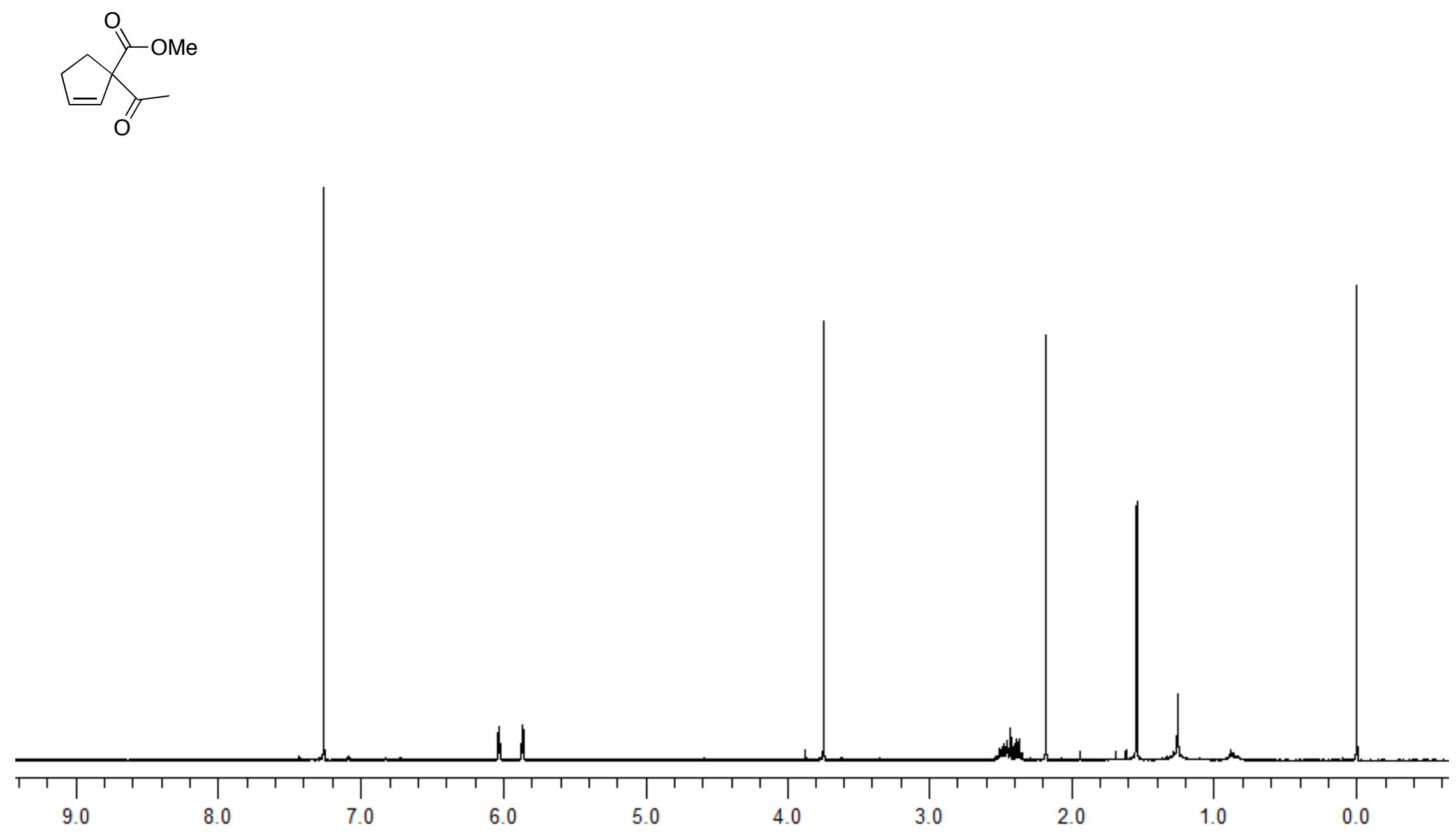


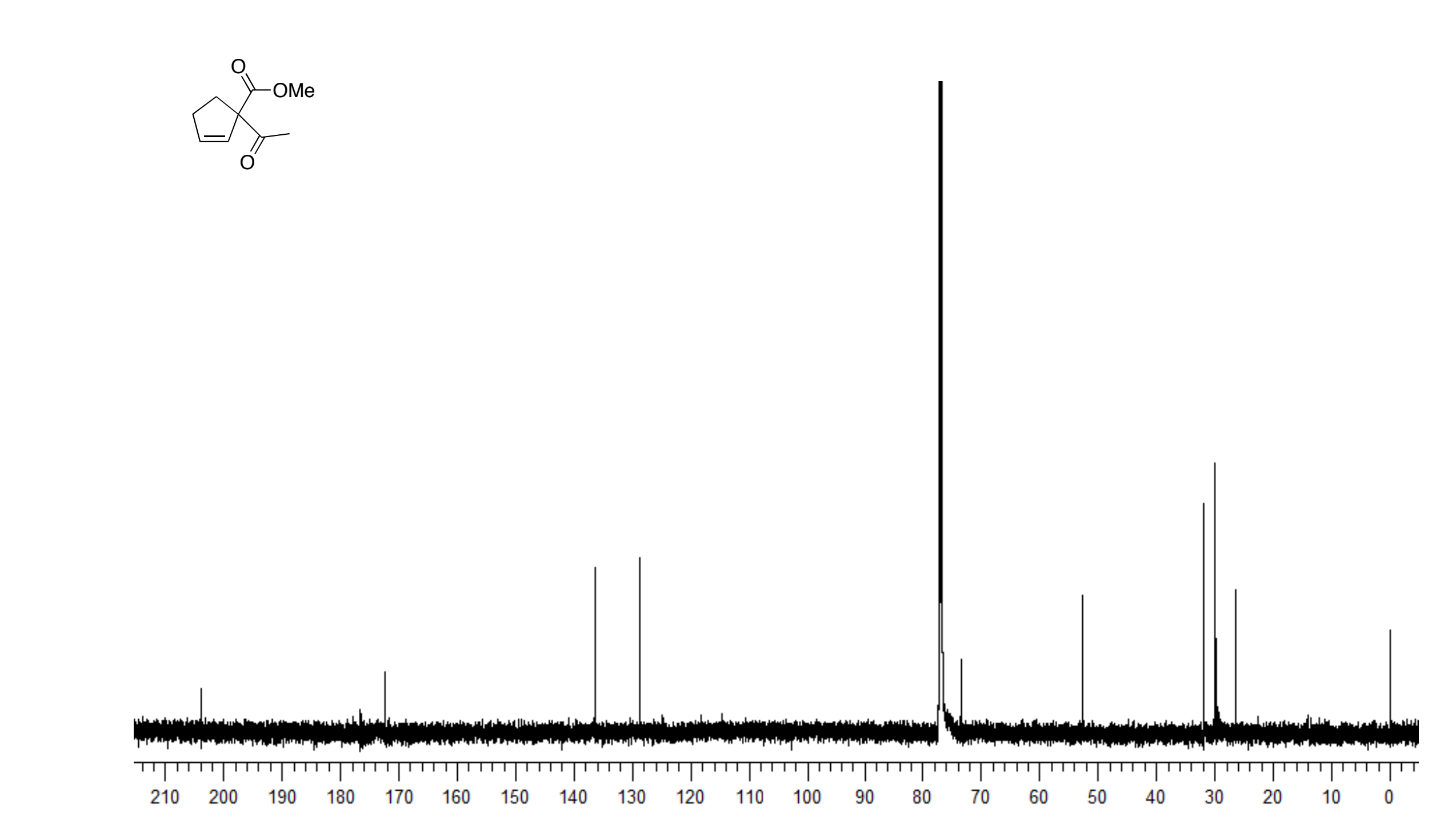




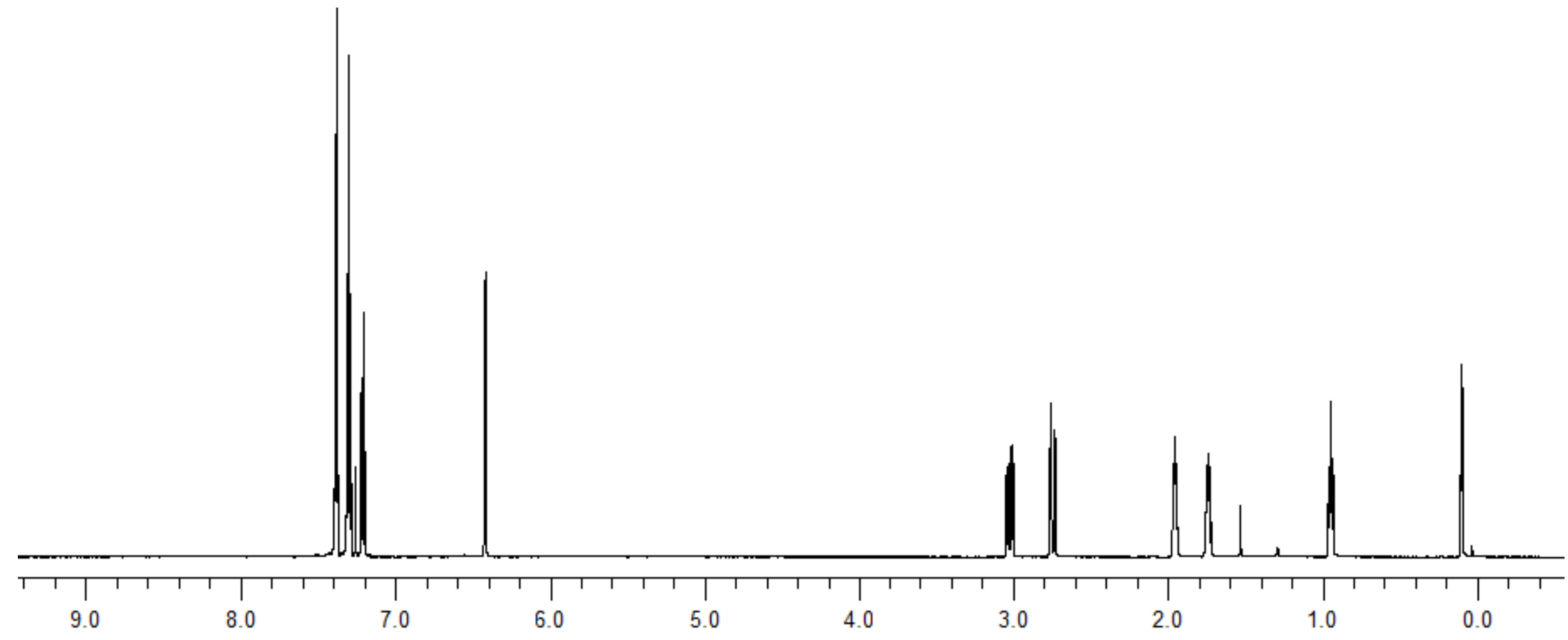



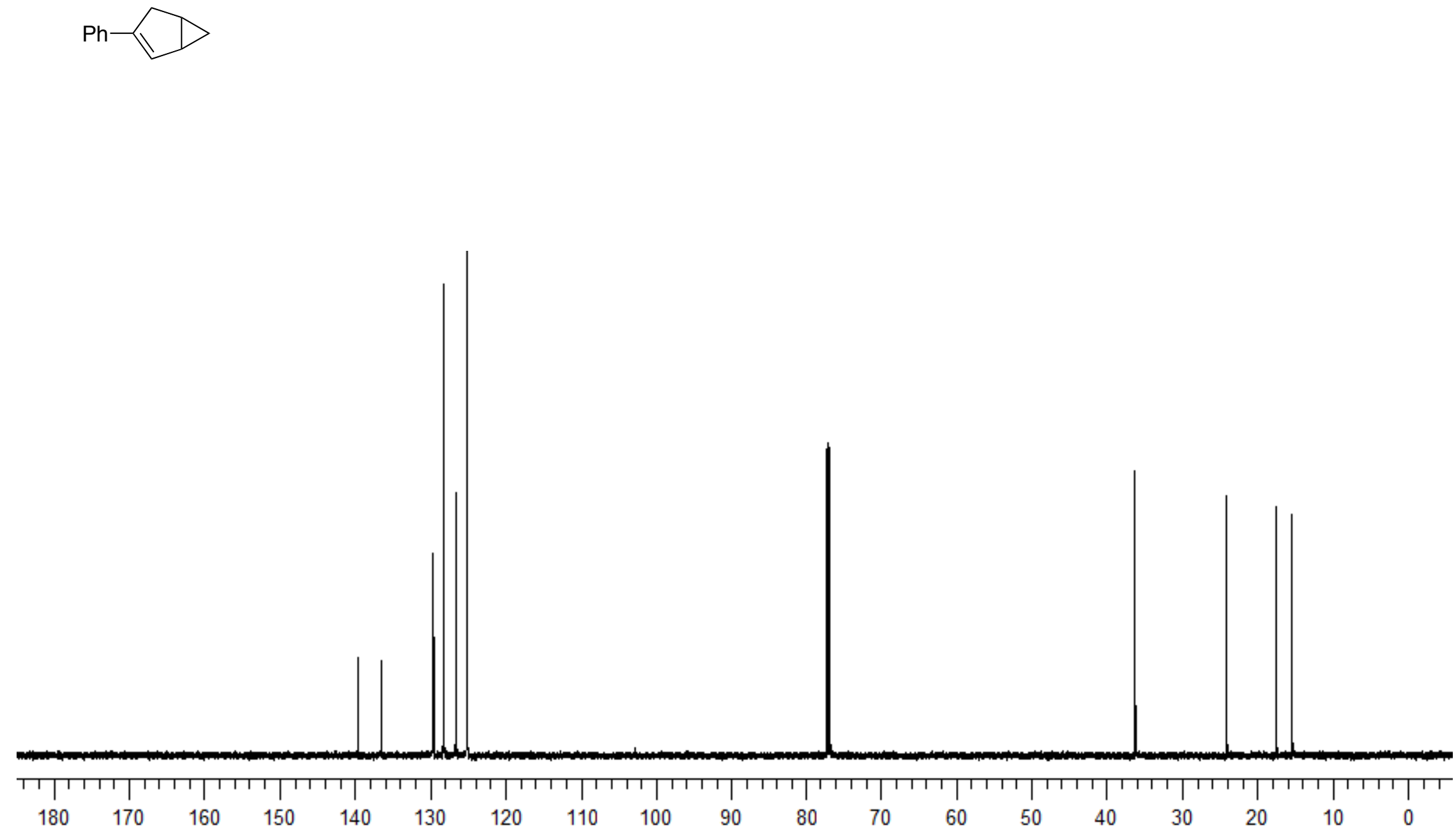
ou-2-120-14 4 a

Archive directory: /export/home/vnar1/vnarsys/data

Sile: parorou

Pulse sequence: szpul
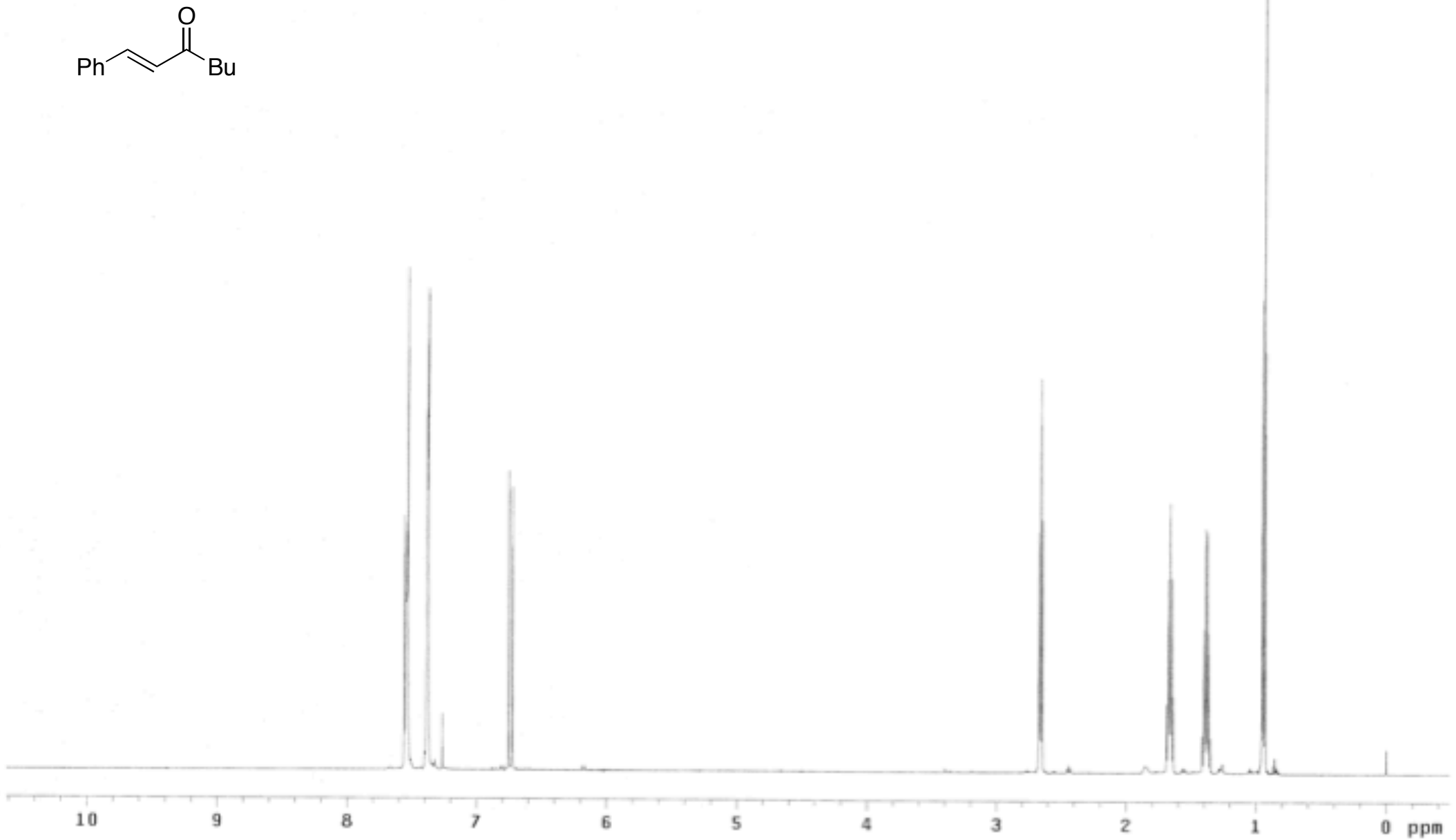
ov-z-120-13C 4 a

Nolse sequencel szow

$$
\overbrace{\mathrm{Bu}}^{\mathrm{O}}
$$

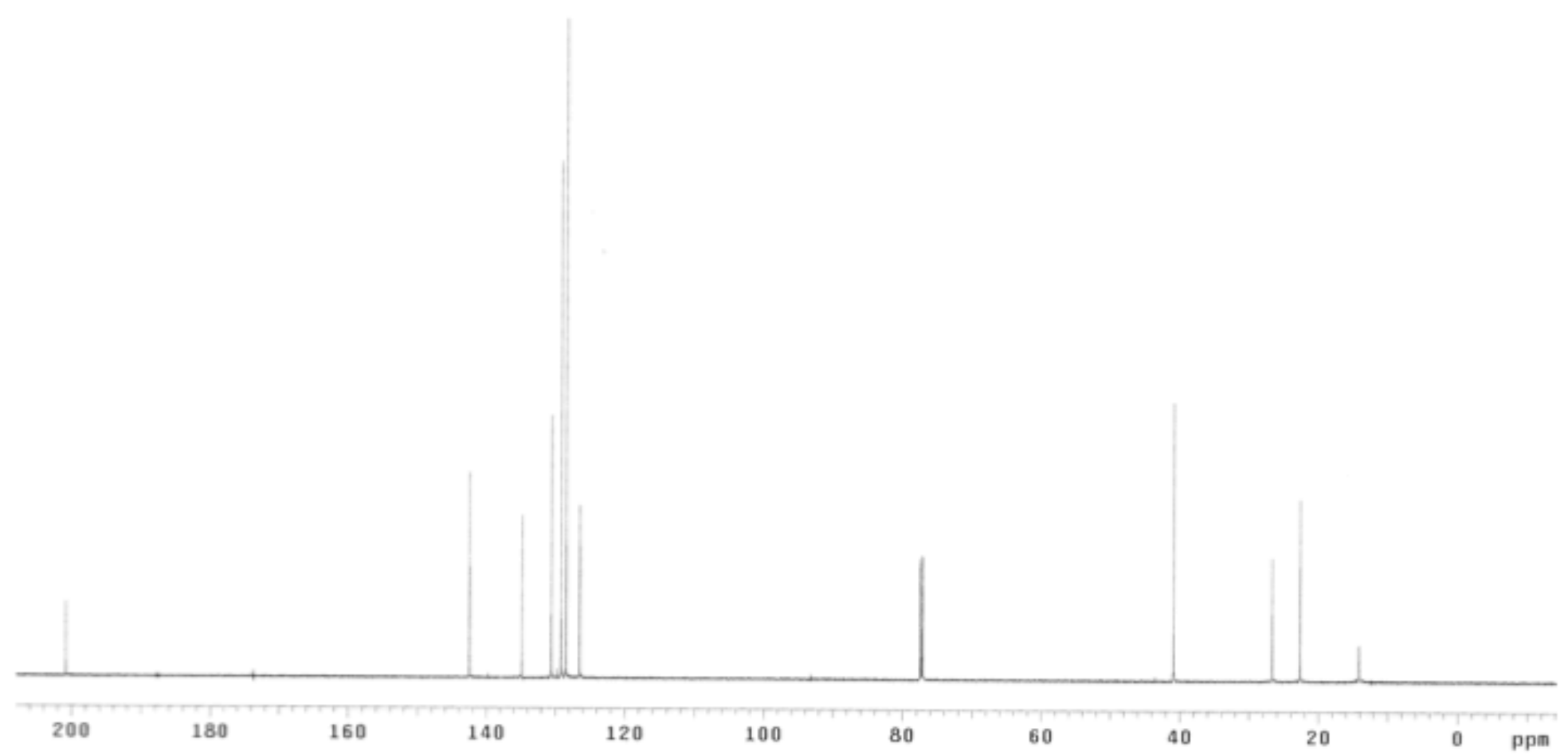



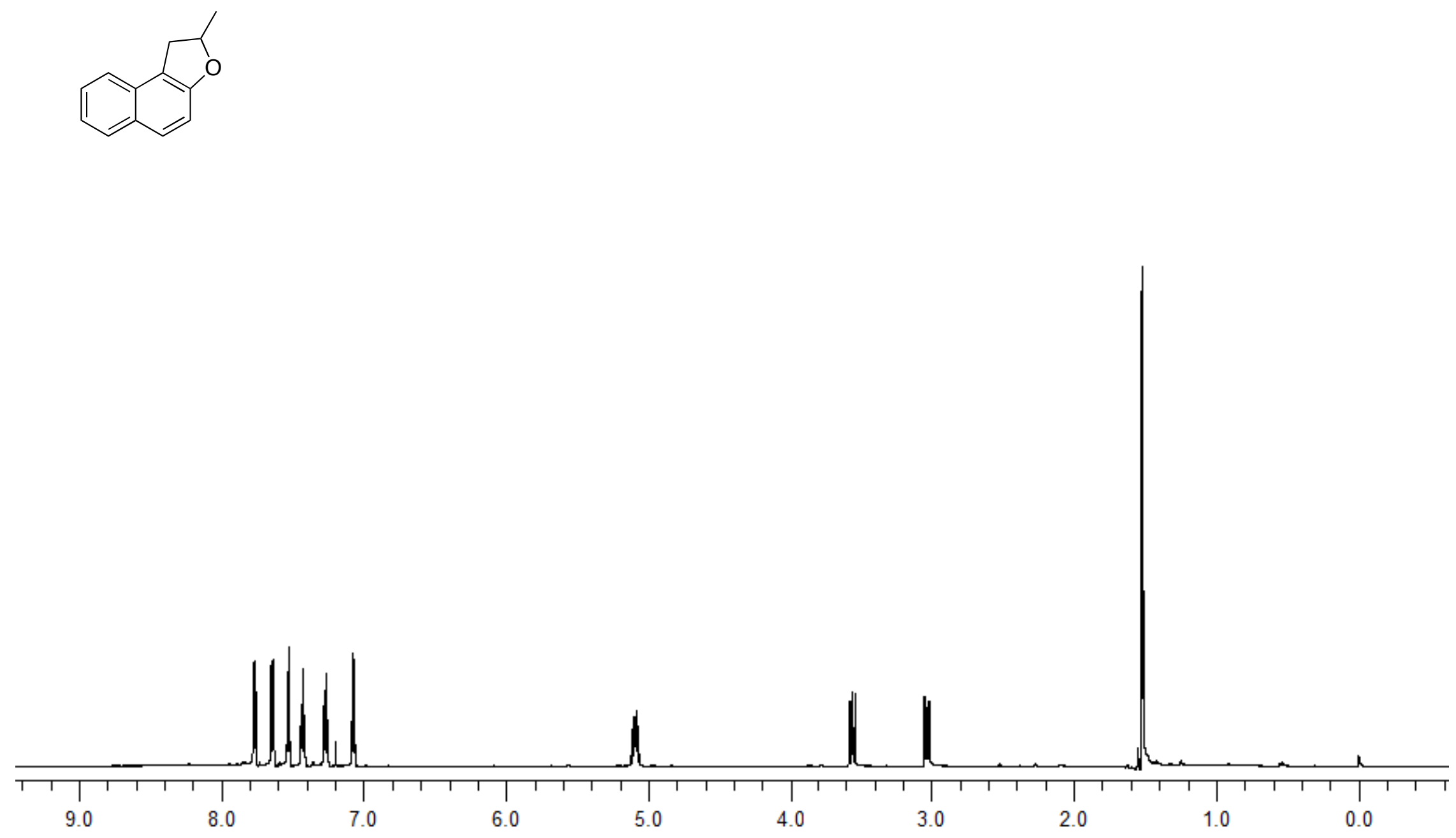

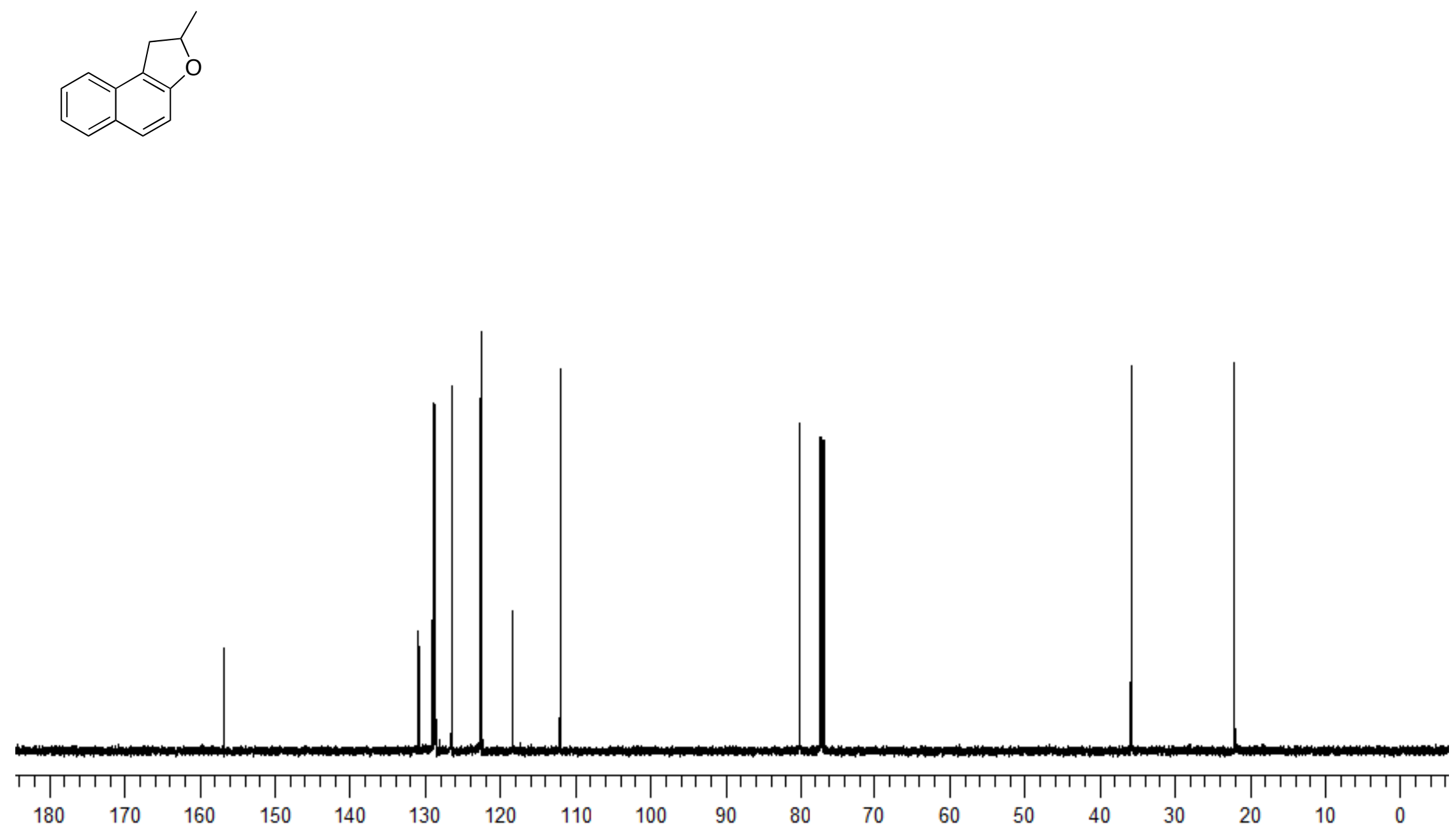
$D W-1-63 A 2-1 H-C D C 13$

Archive directory: /export/home/vnmr1/vnmrsys/data
Sample directory:

Sample directory
File: PROTON

Pulse Sequence: szpu

$\overbrace{\mathrm{Br}}^{\mathrm{O}} \mathrm{Bu}$ 
DW-1-63A2-1C-CDCL3

Pulse Sequence:
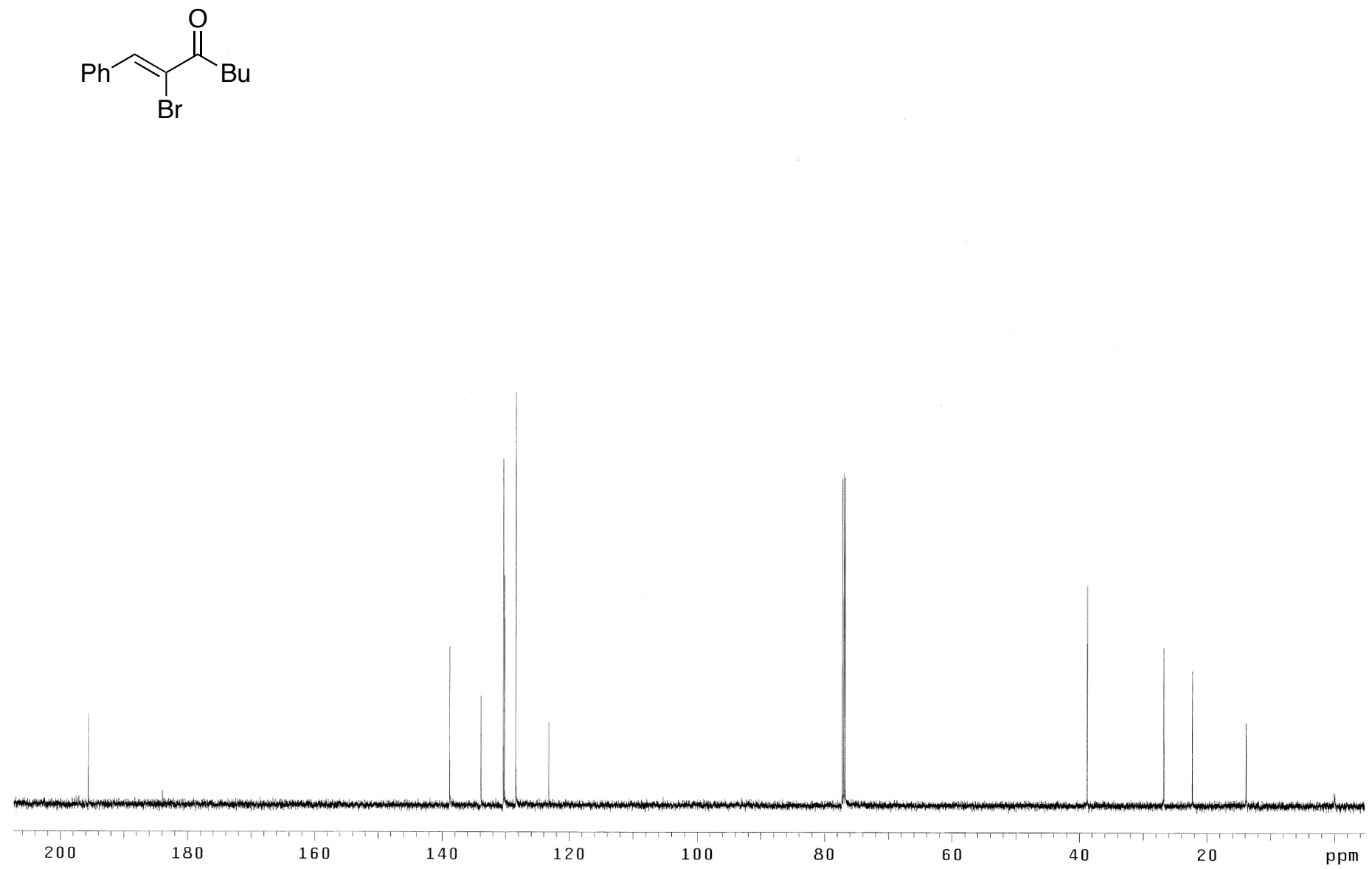
DW-1-63A1-1H-CDC13-600MHZ

Archive directory: /export/home/vnmr1/vnmrsys/data
Sample directory:

Sample directory:
File: PROTON

Pulse Sequence: s2pul

$\underbrace{\mathrm{Ph}}_{\mathrm{Br}} \mathrm{O}$

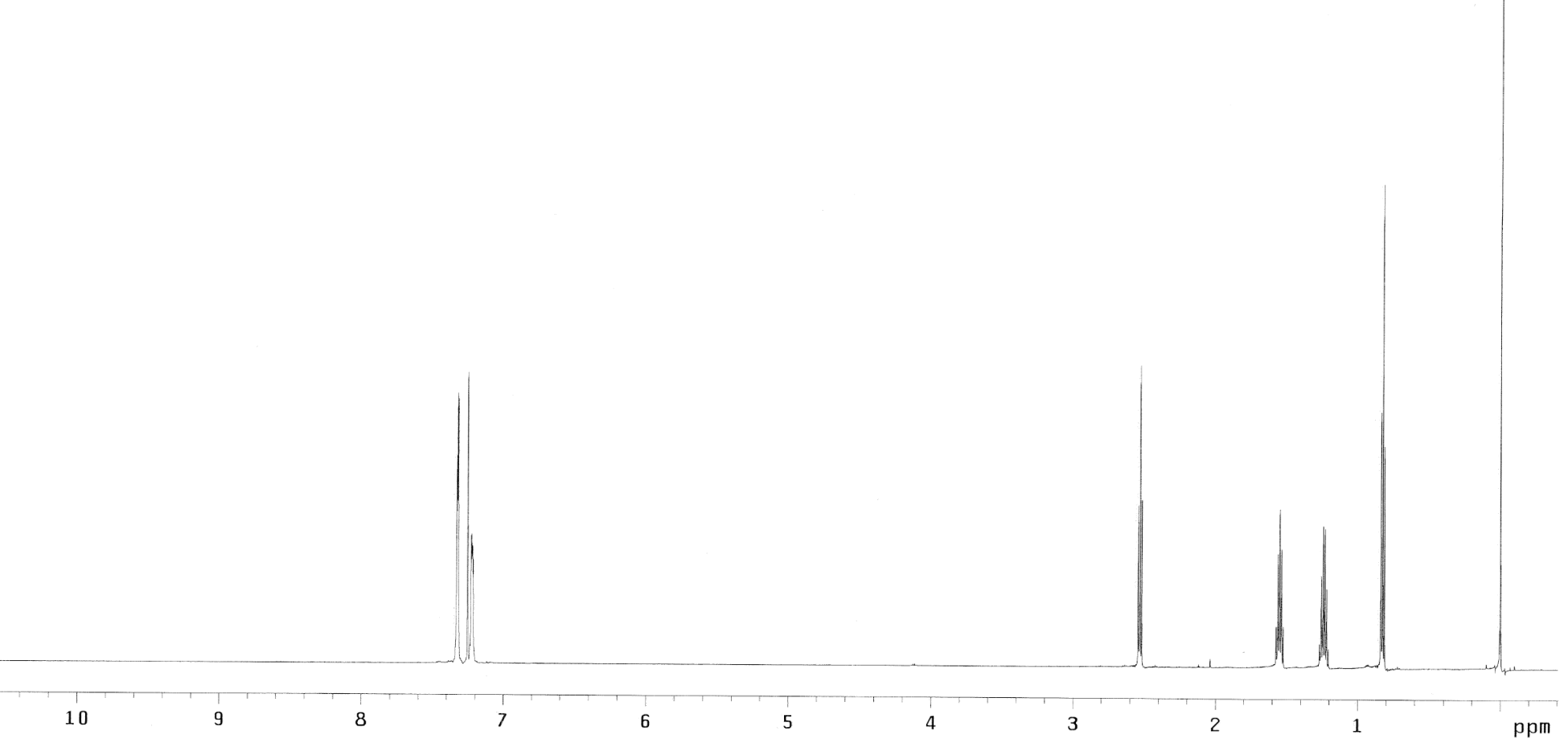


DW-1-63A1-13C

Pulse Sequence: s2pu

$\underbrace{\mathrm{Ph}}_{\mathrm{Br}}$

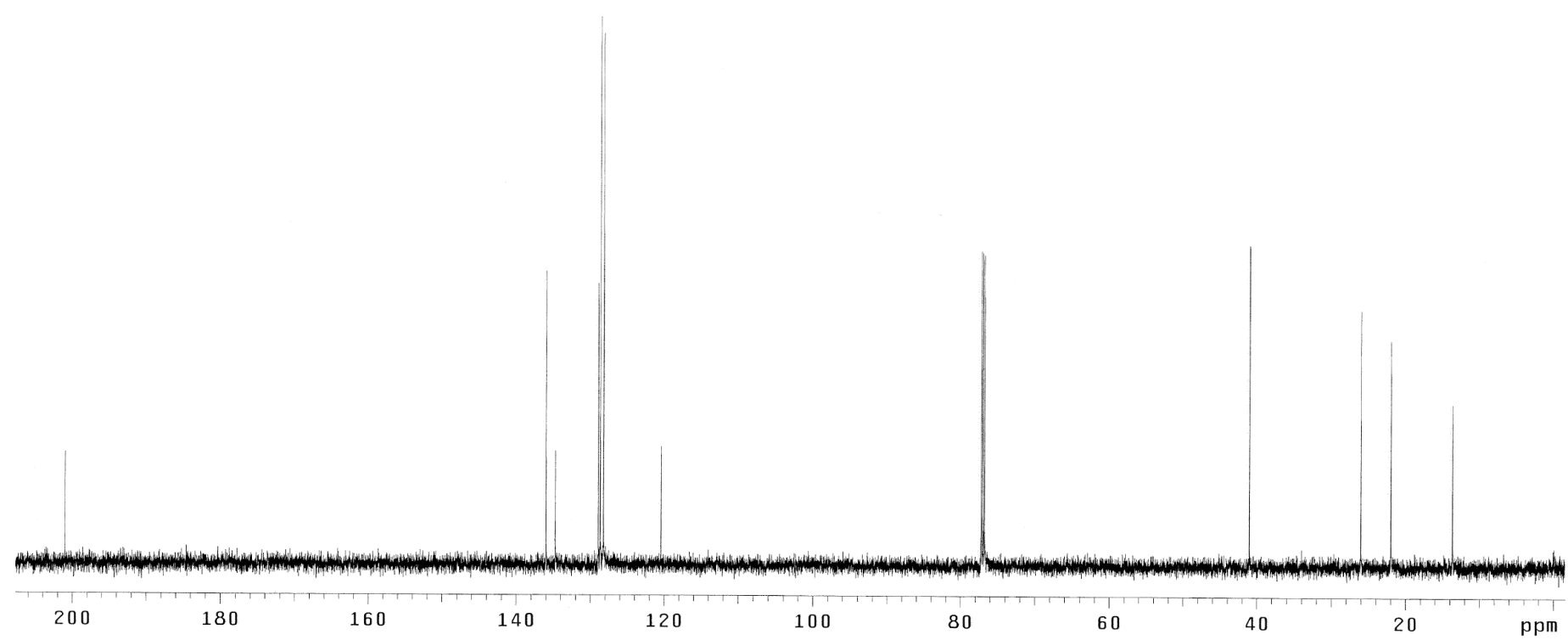


Chapter S3. Gold-Catalyzed Cross-Coupling with Aryldiazonium Salts
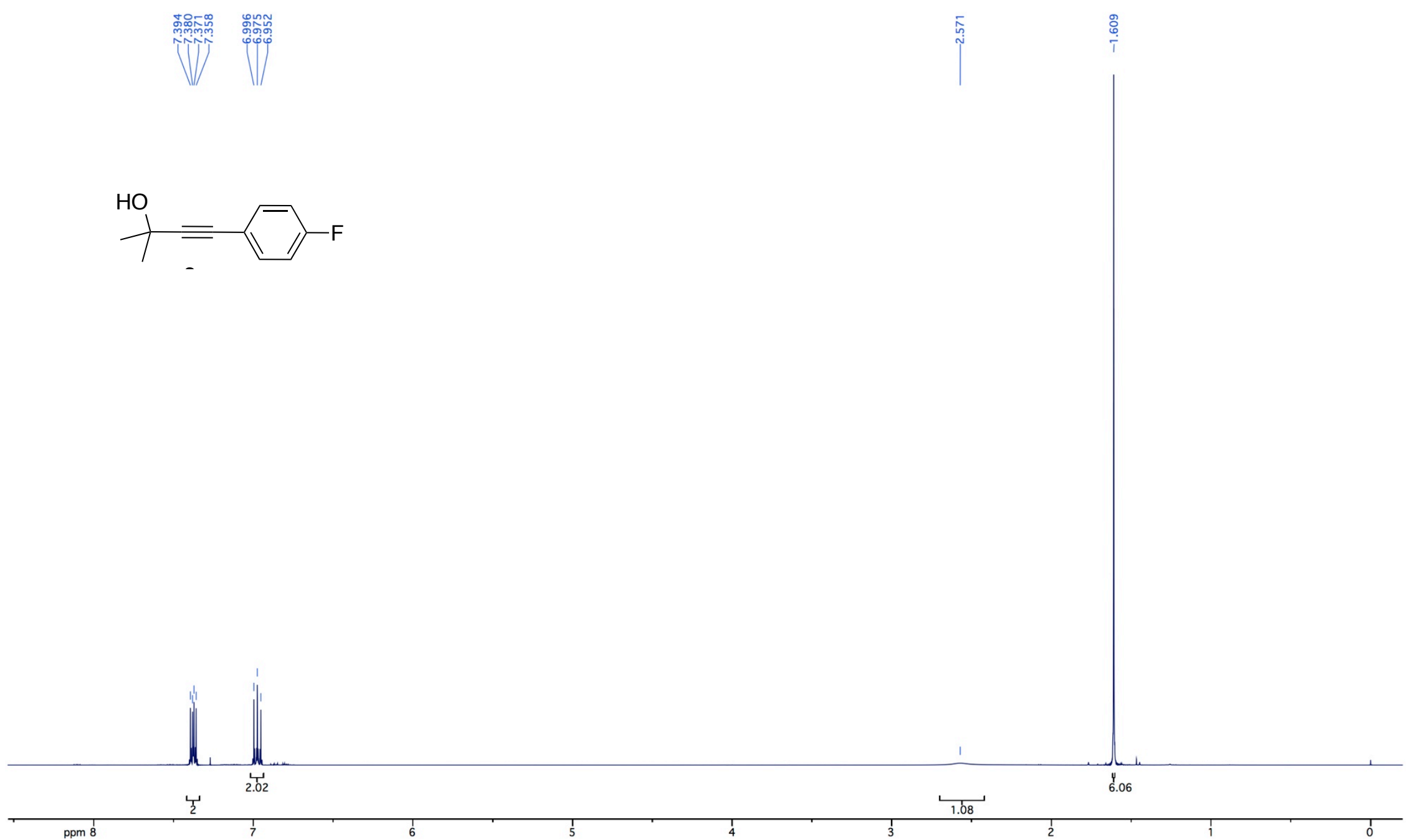
$+=\square \mathrm{F}$

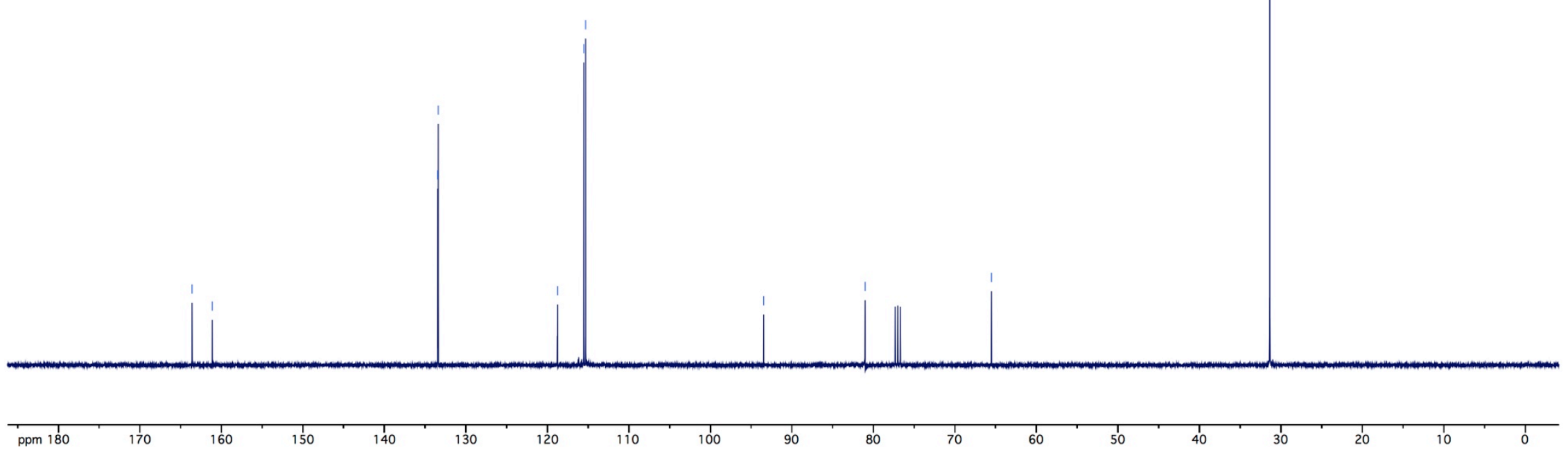




$$
+=\square-\mathrm{F}
$$

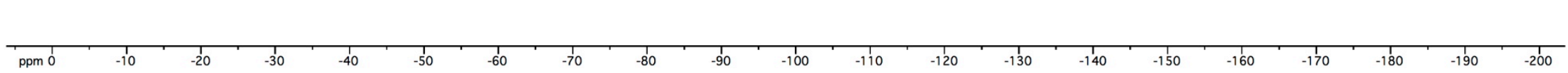


2014

ivivivi

12

$+=$

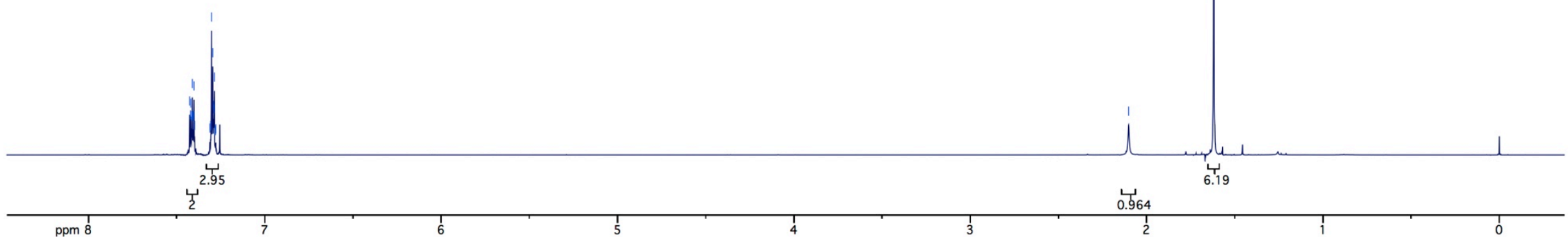



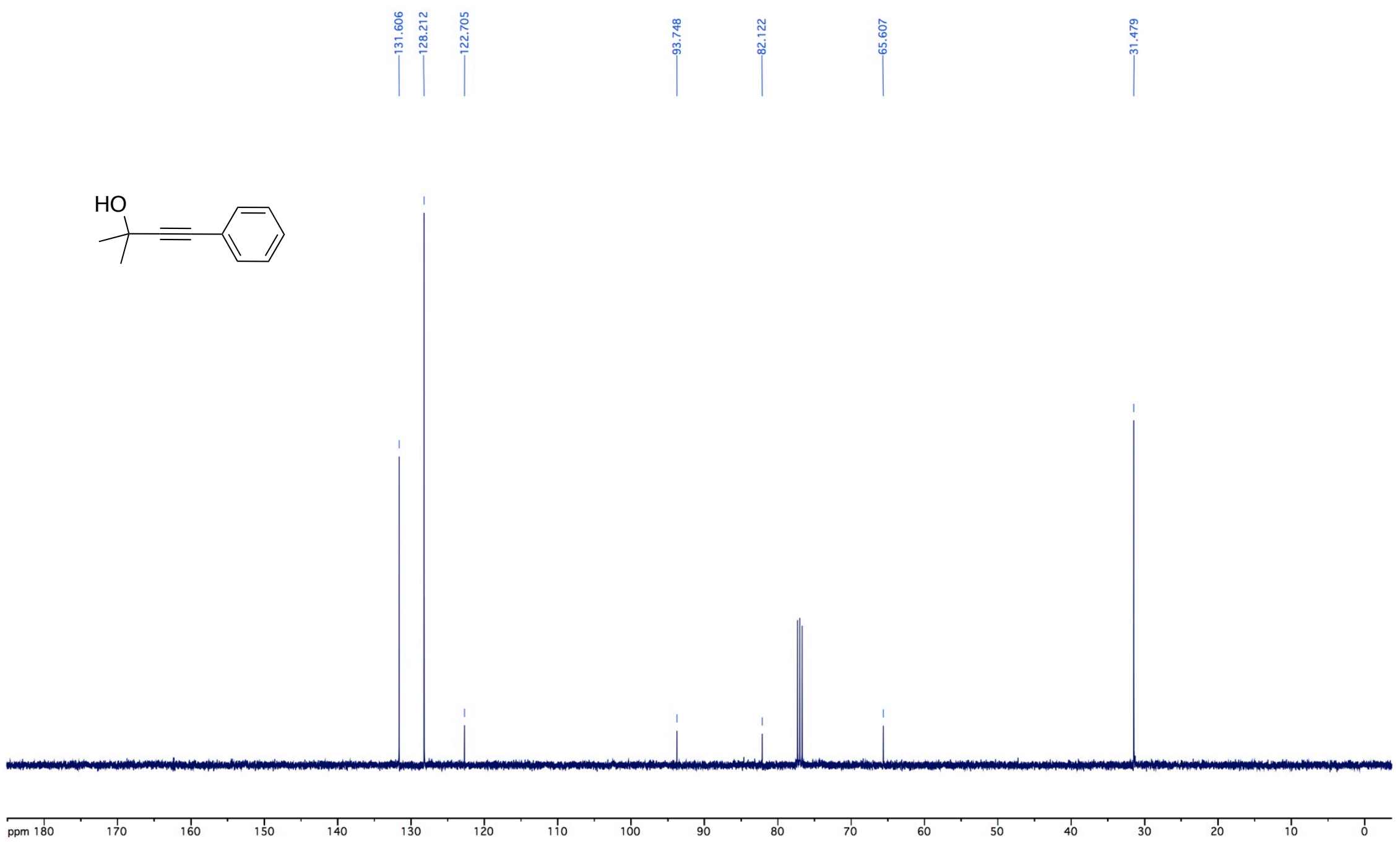


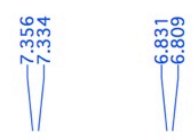

$+=-\mathrm{OMe}$

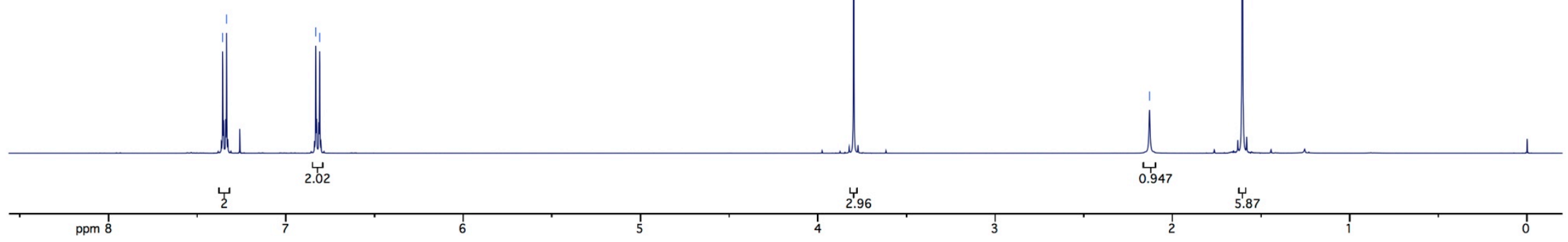




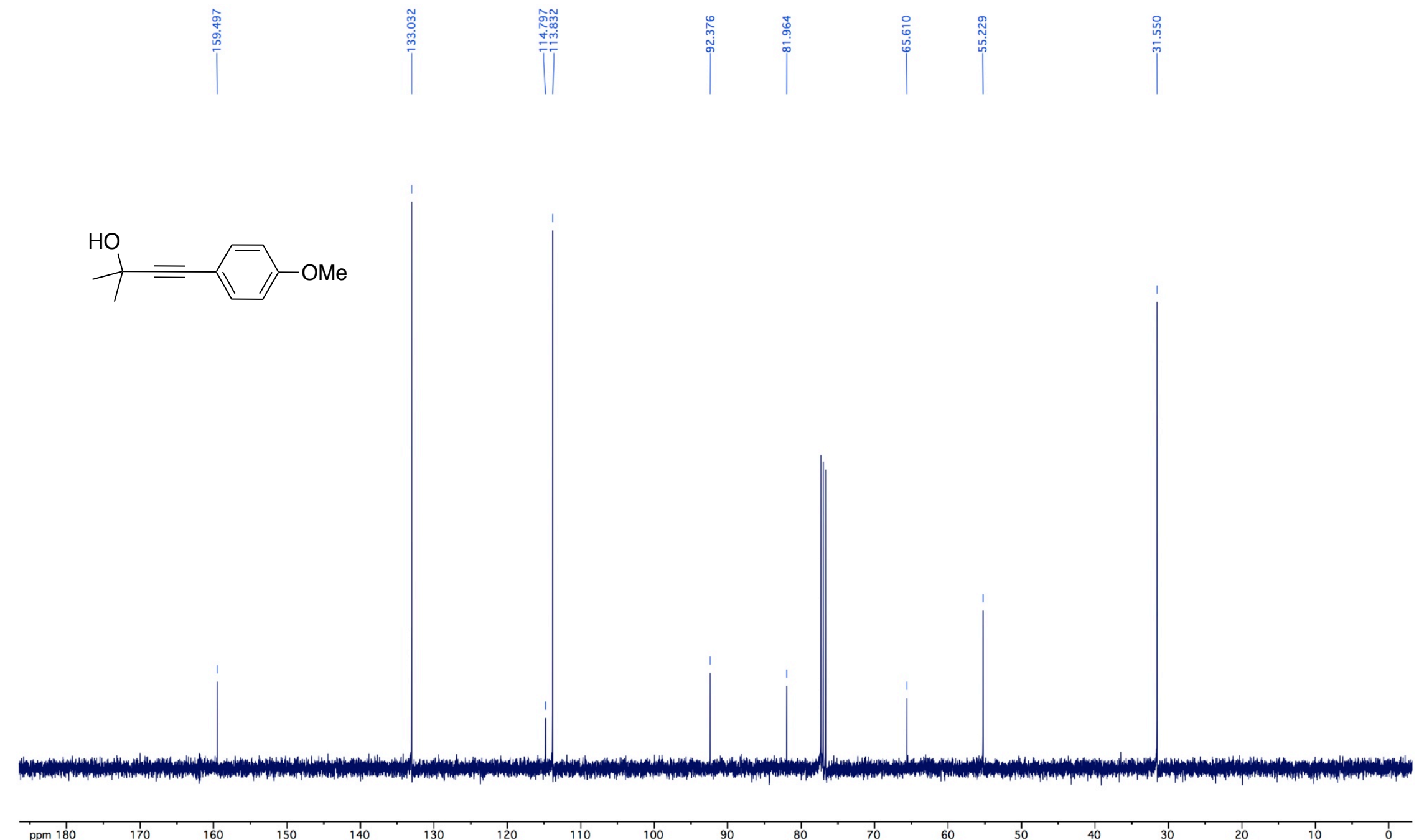




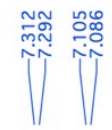

$+=\square-\mathrm{Me}$

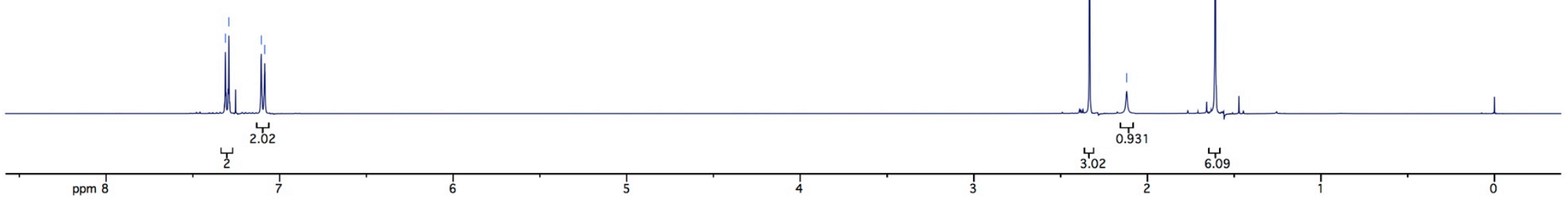




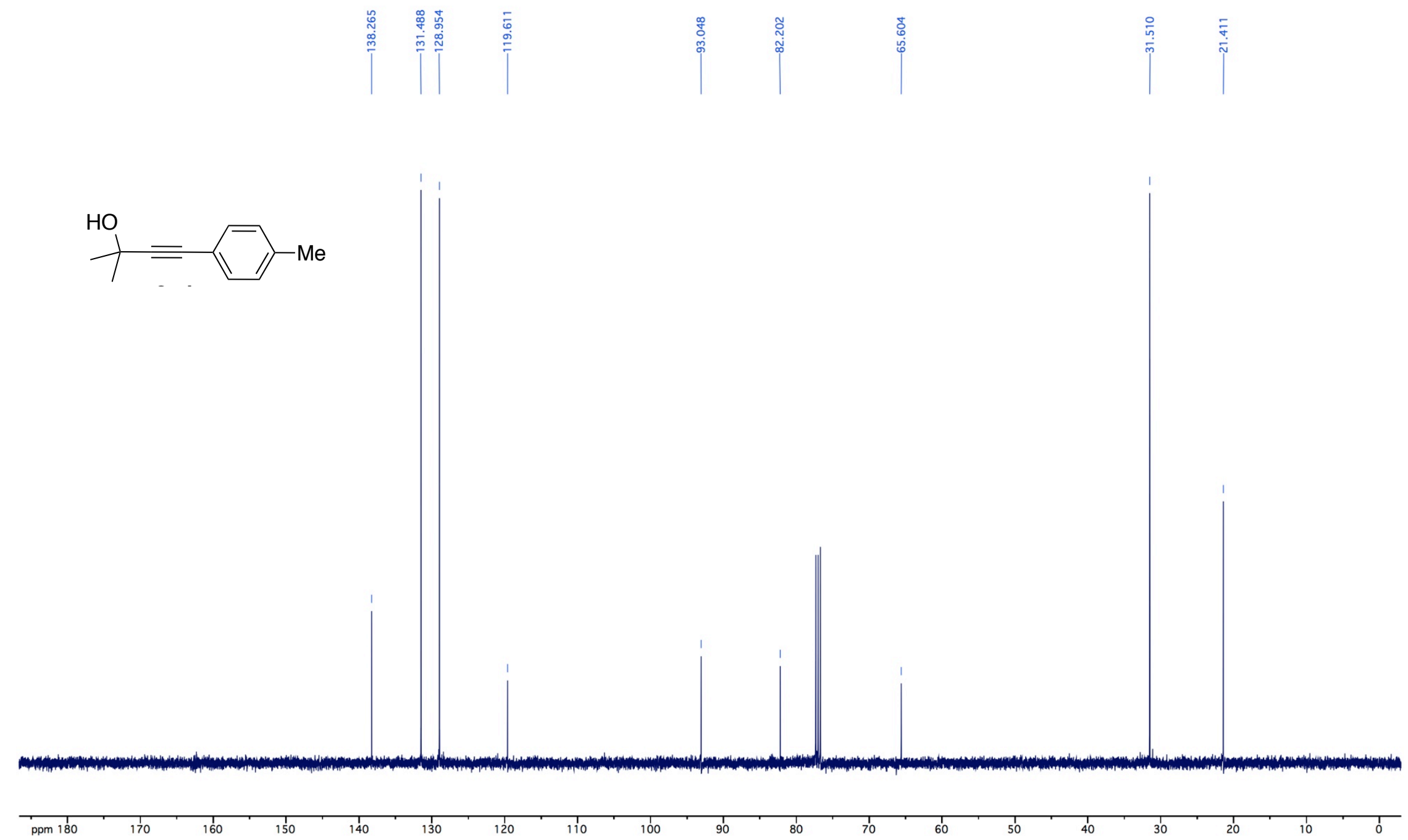




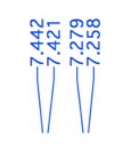

$+=-\mathrm{Br}$

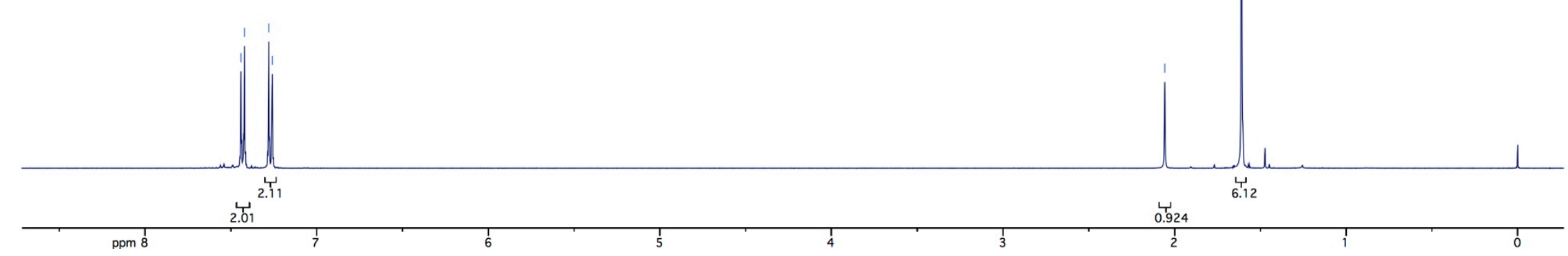




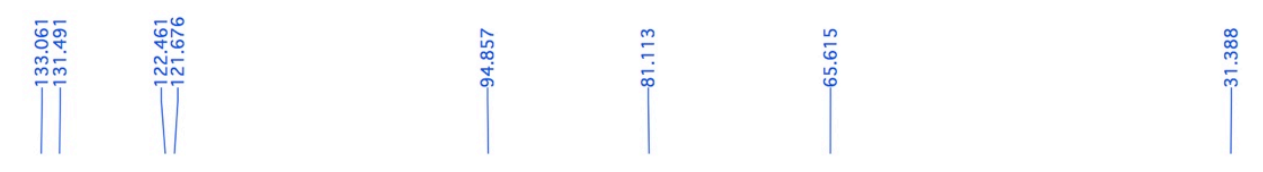

$+=\square \mathrm{Br}$

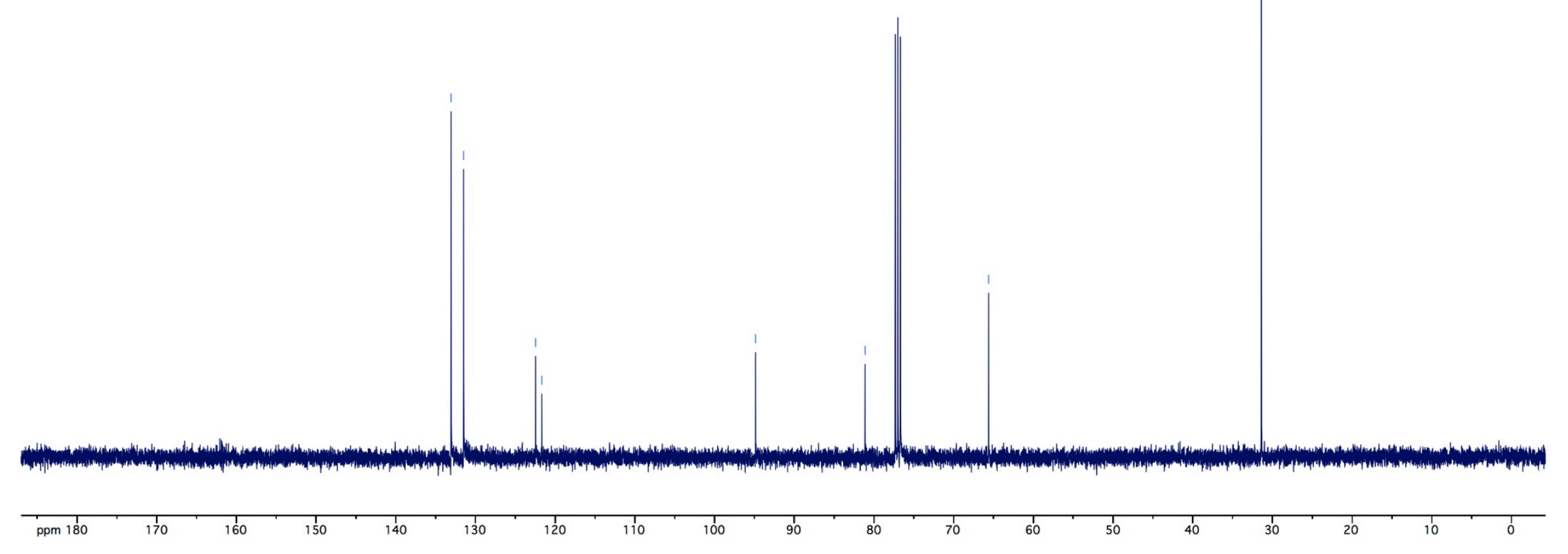




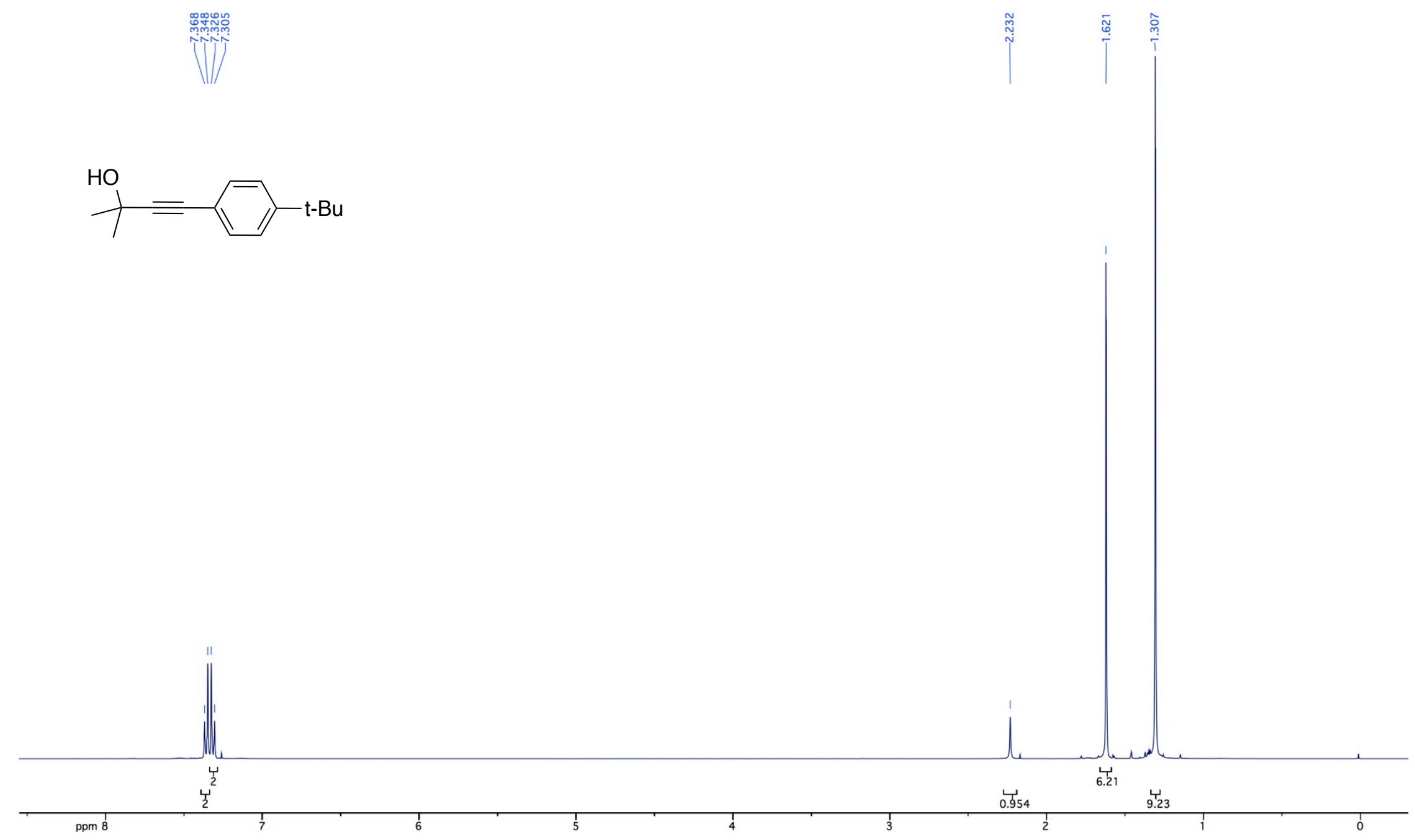




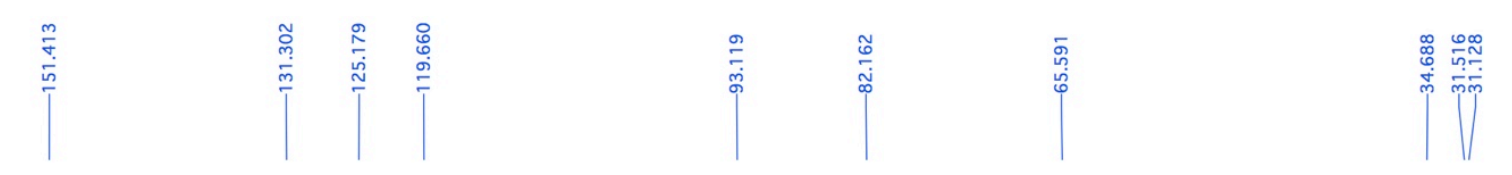

$+=\square-\mathrm{t}-\mathrm{Bu}$

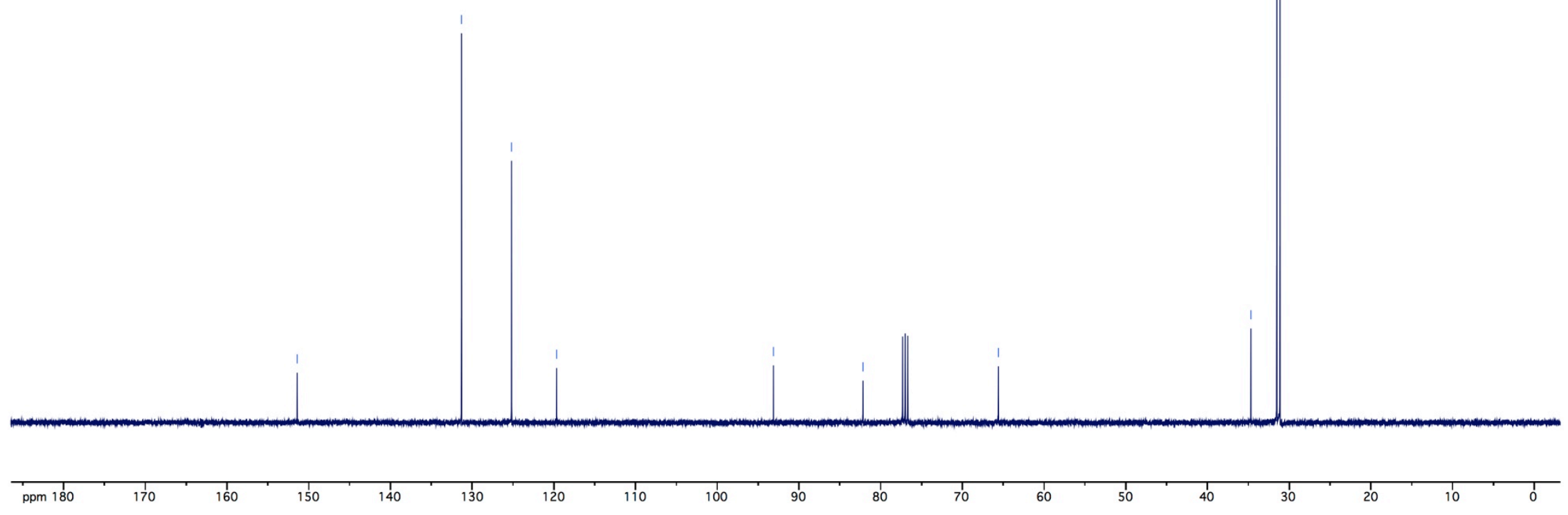




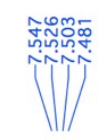

$+=\mathrm{CF}_{3}$

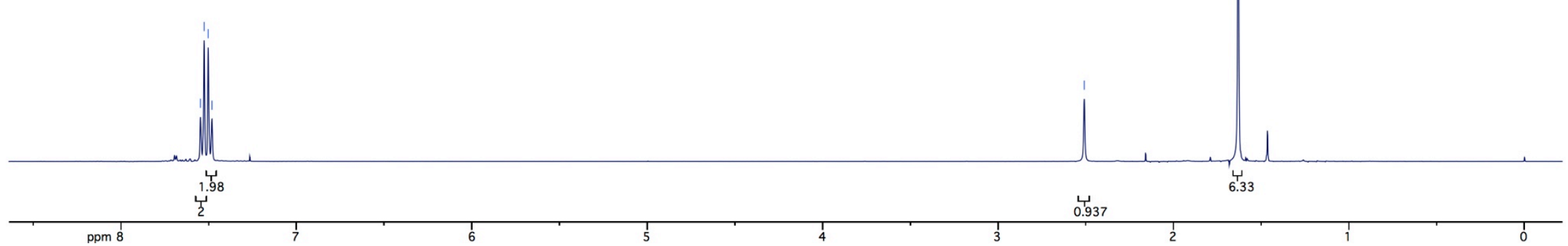





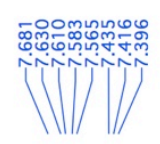

ขึ్యి
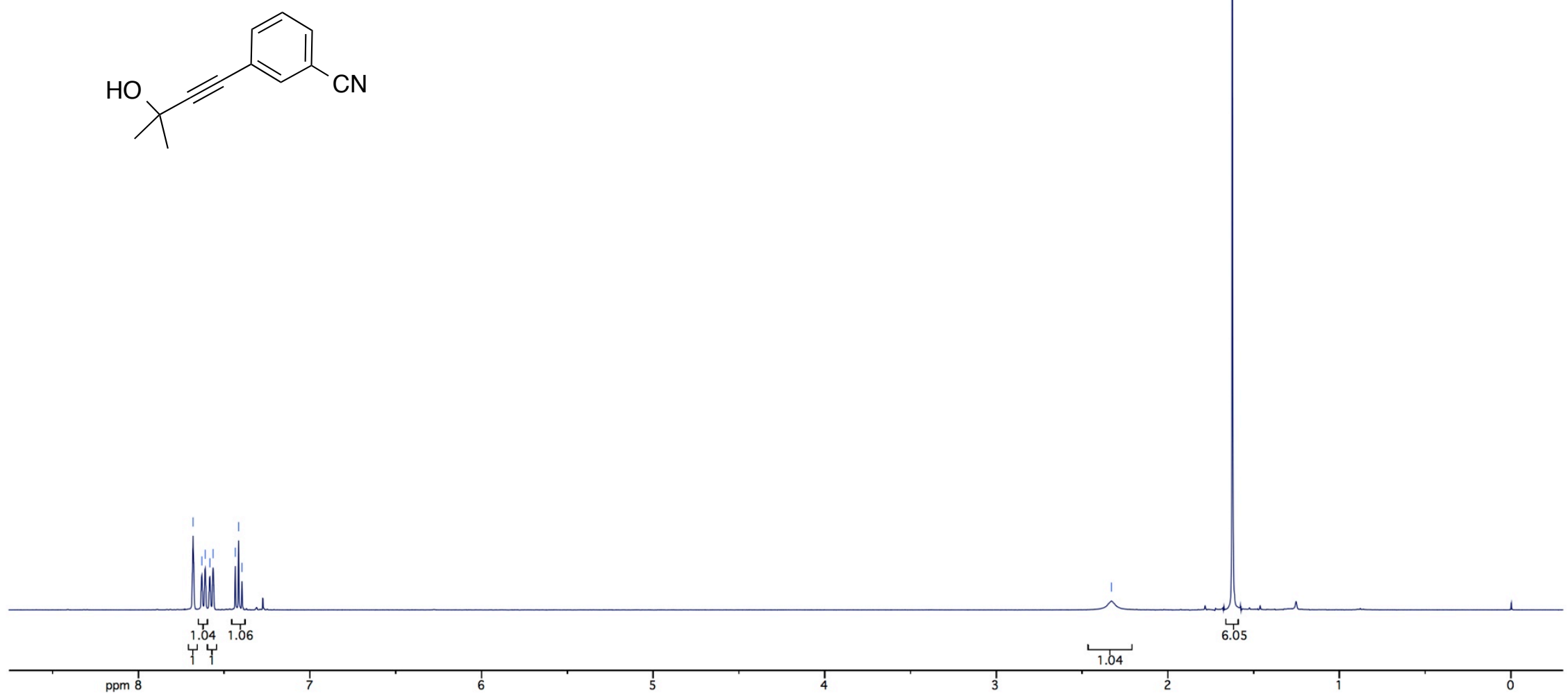

S234 

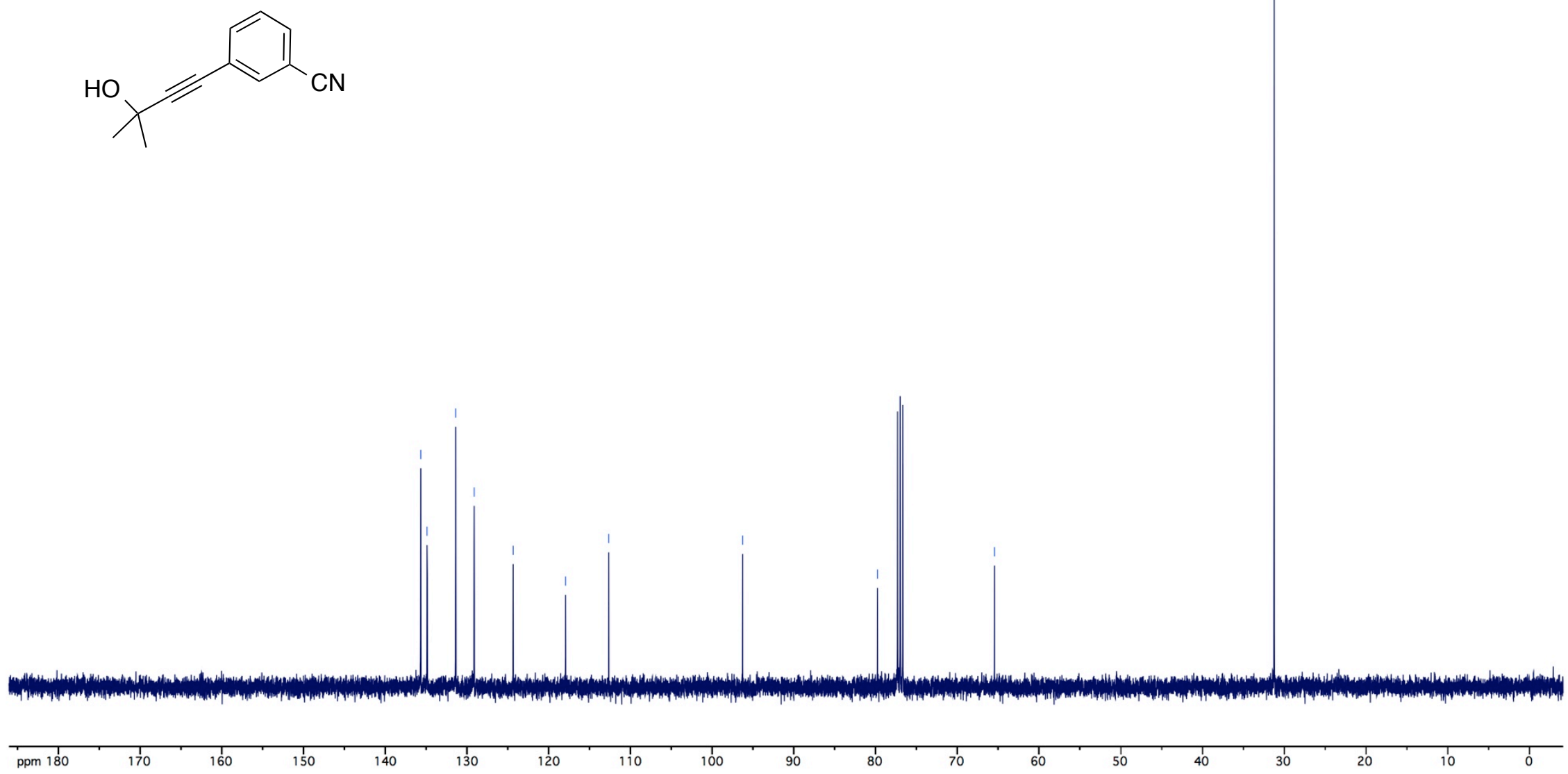

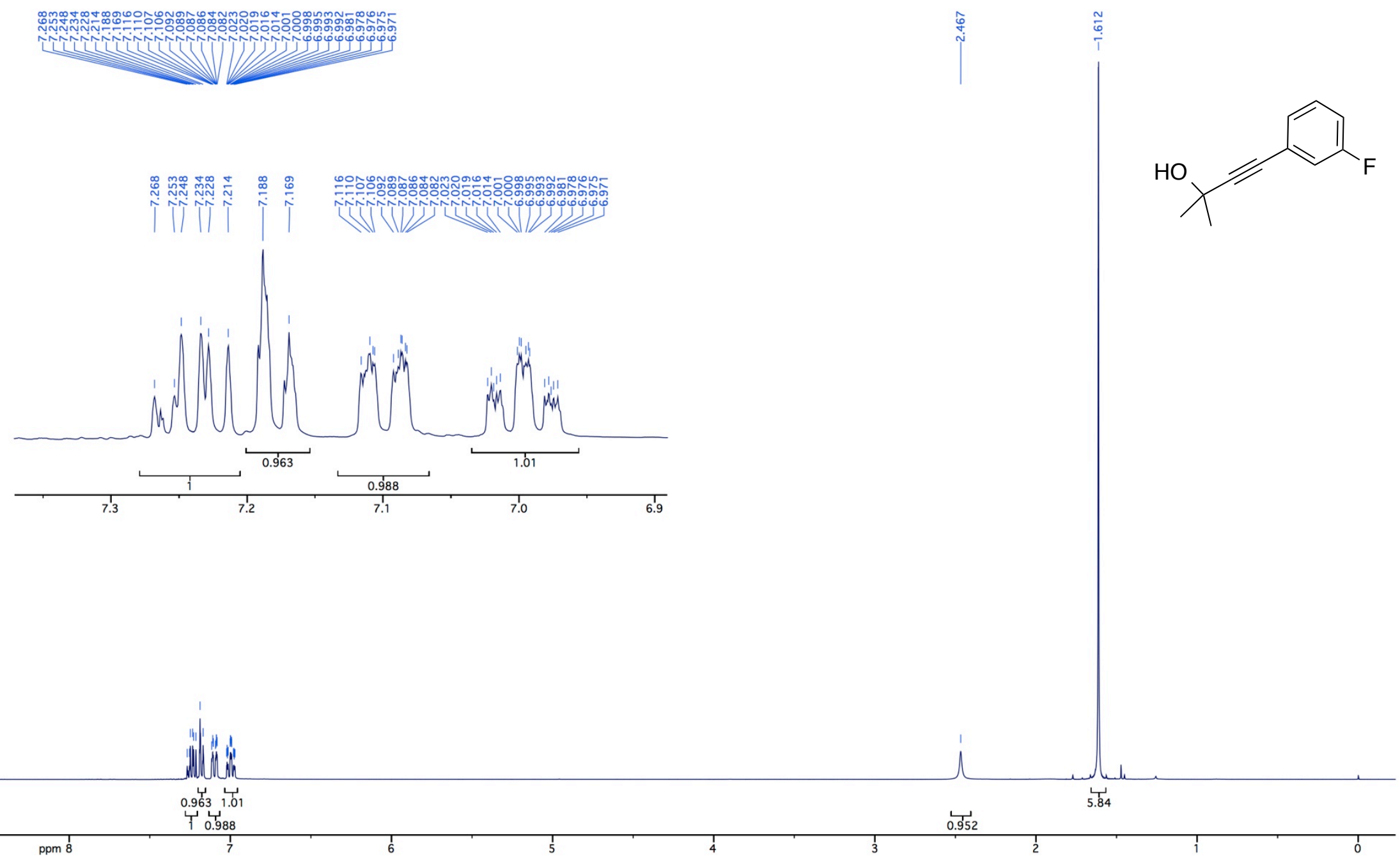


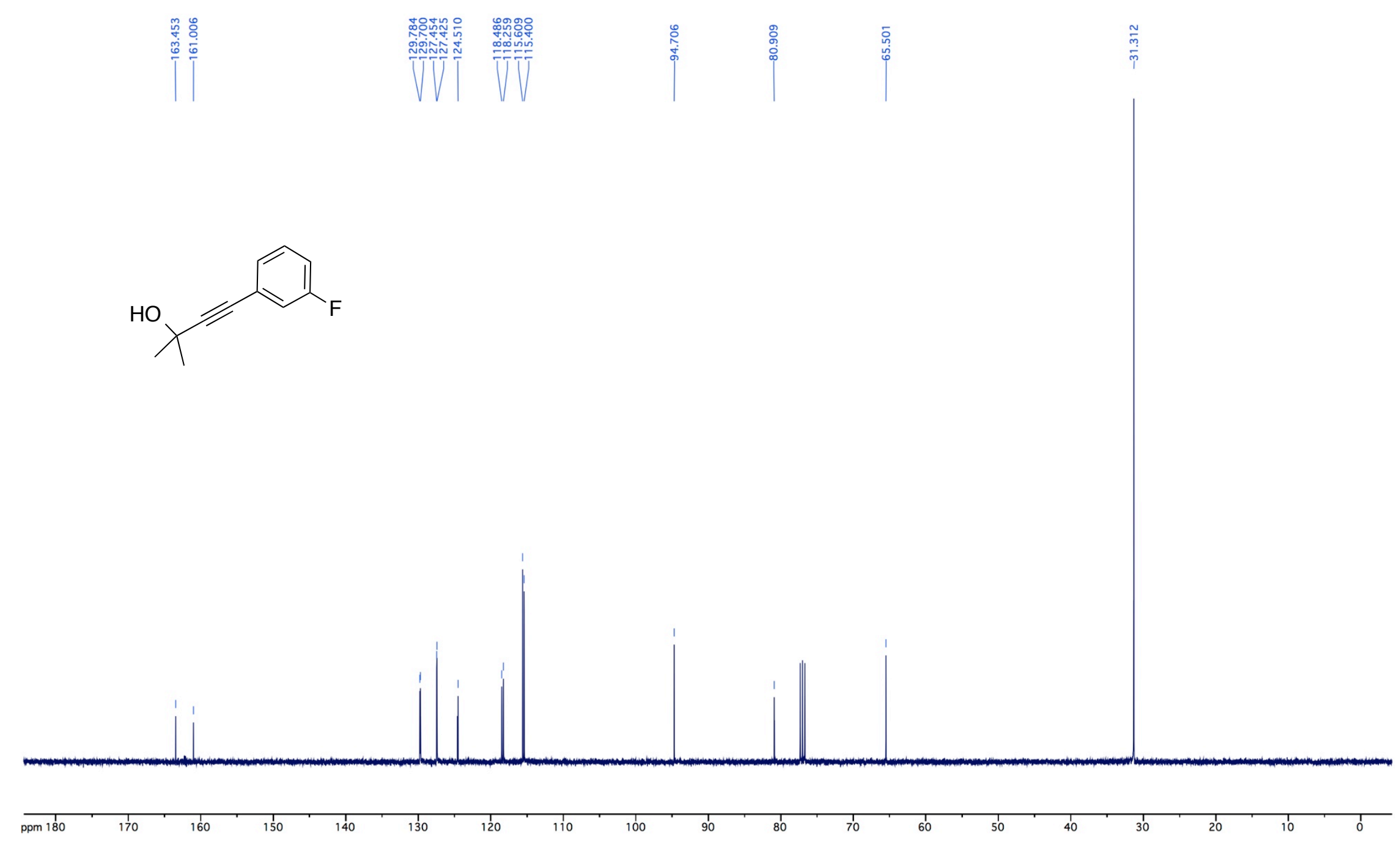




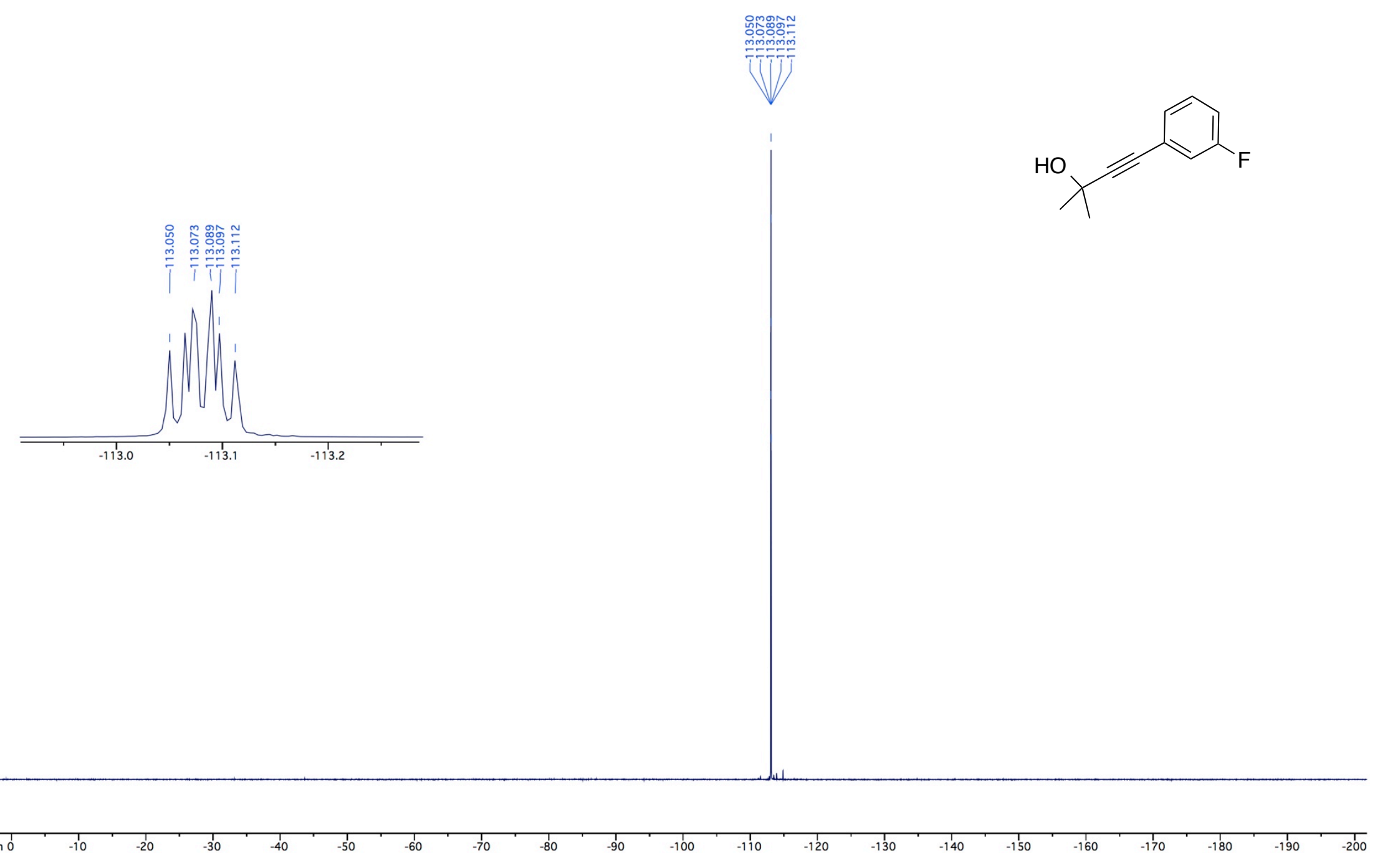




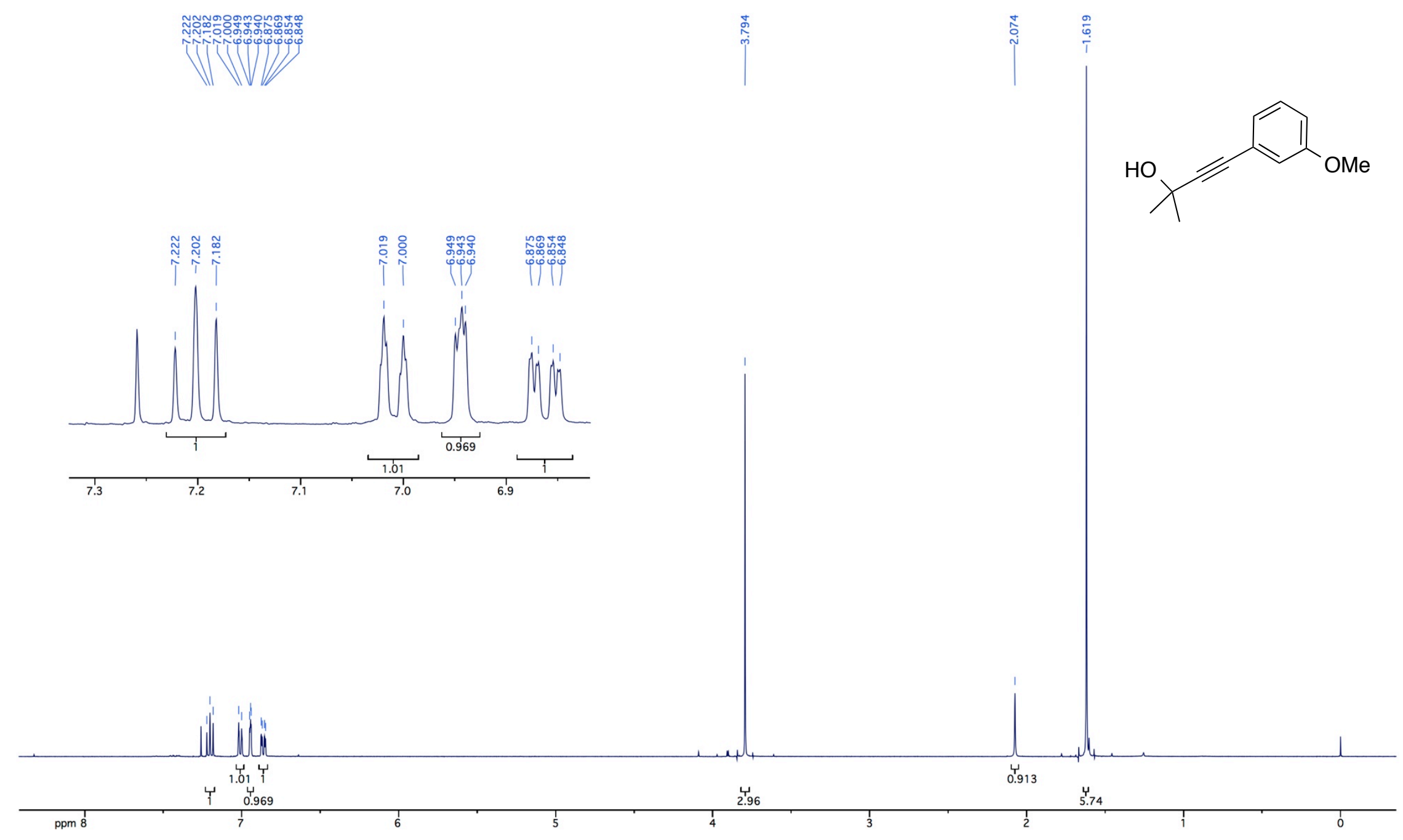




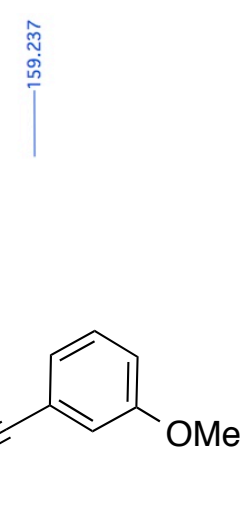



$\prod_{\substack{n \\ 0}}^{\substack{0 \\ 0}}$

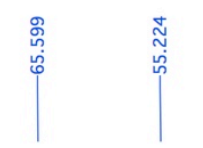

|
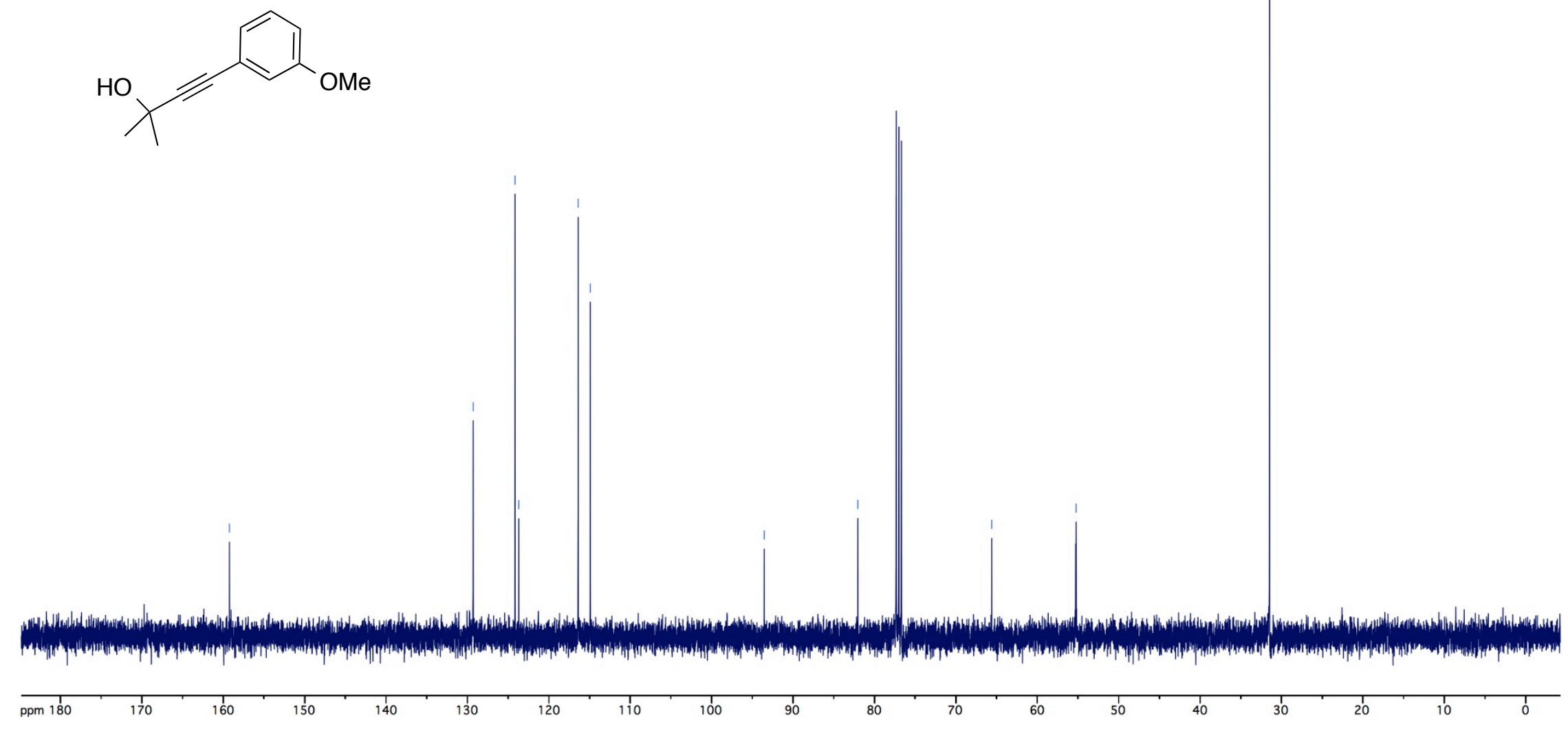
$\mathrm{n}-\mathrm{Bu}=\mathrm{Ph}$

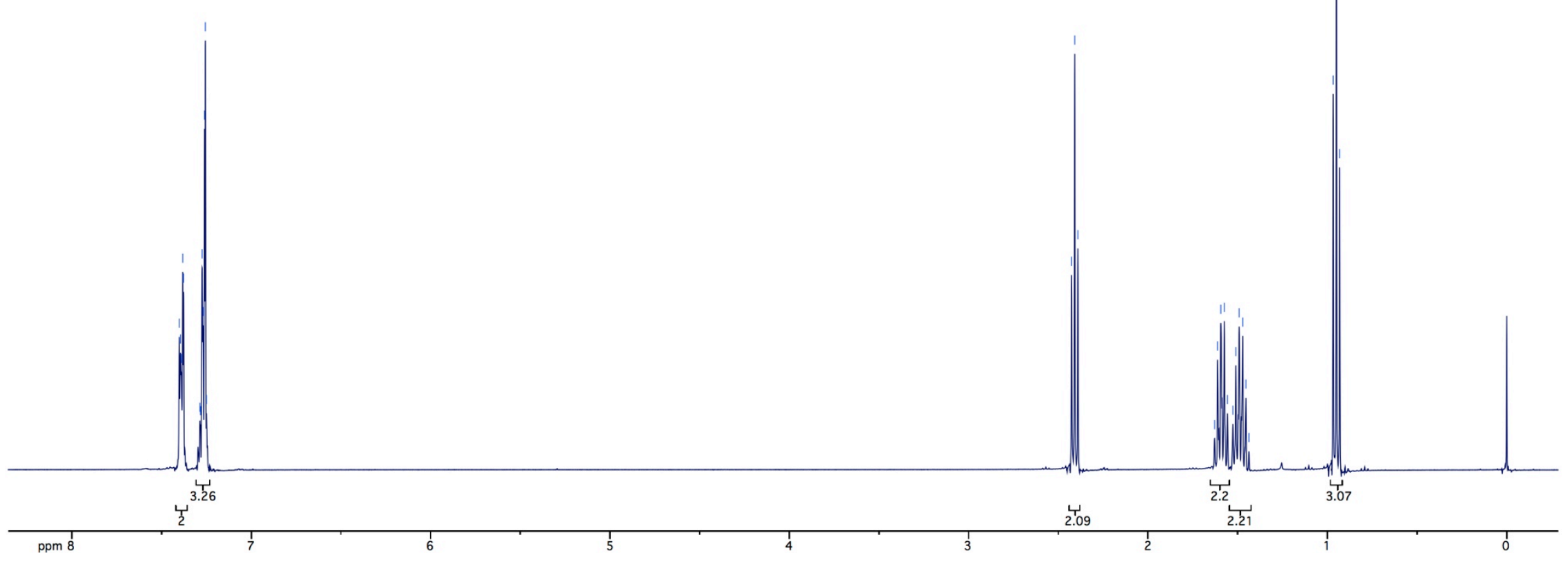




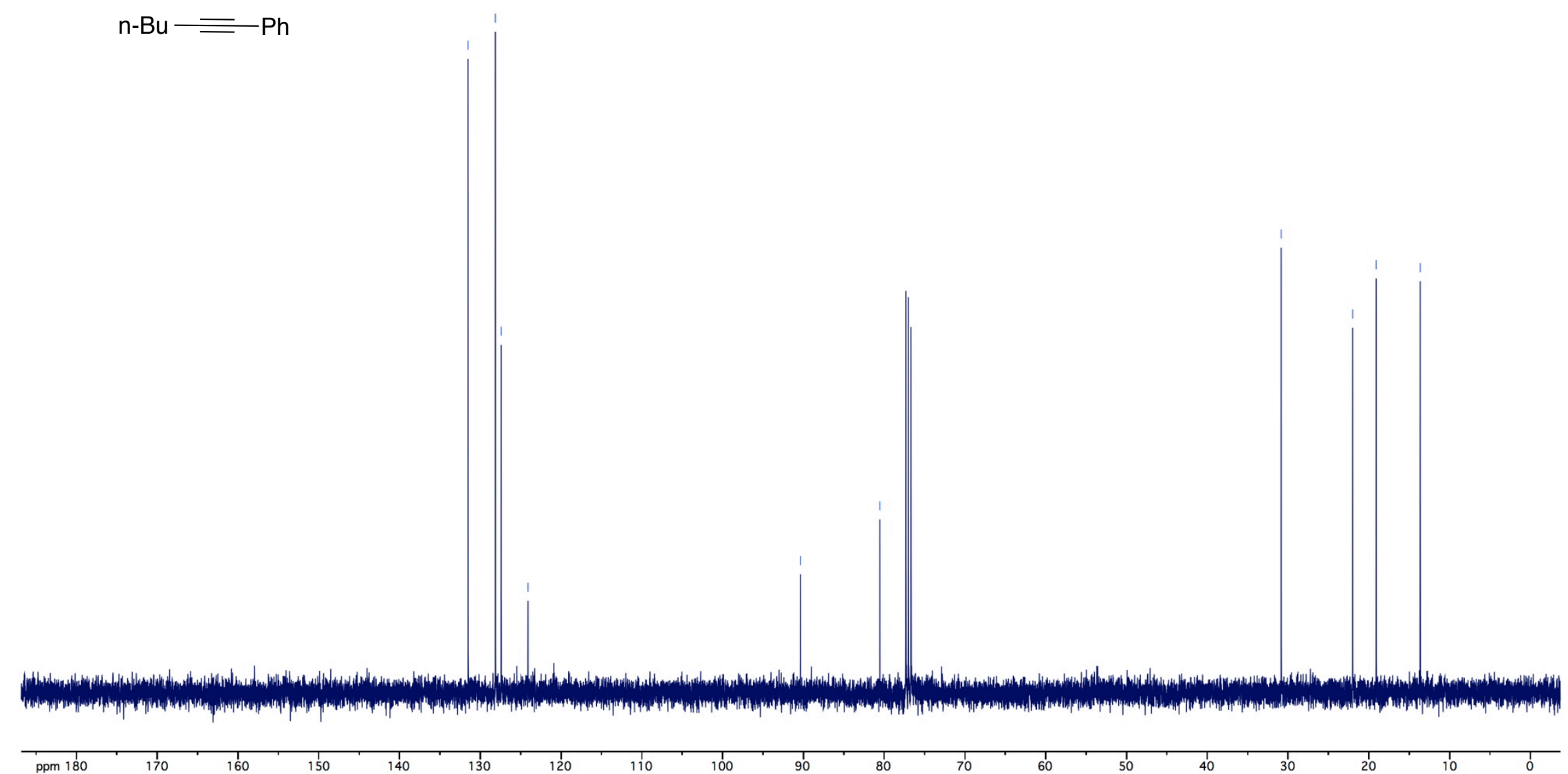



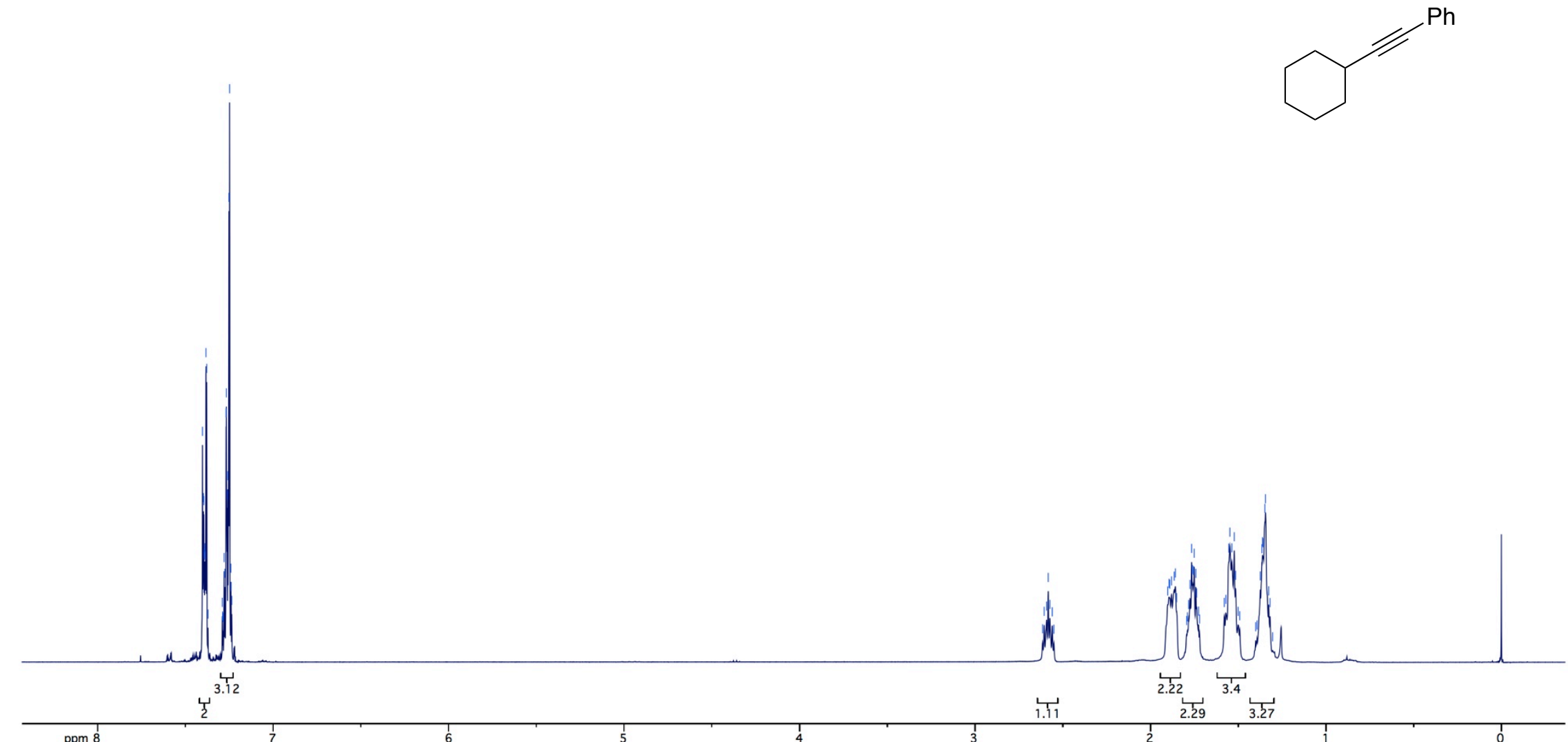
$\prod_{1}^{\substack{0 \\ 0}}$

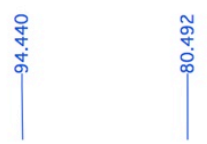

|c

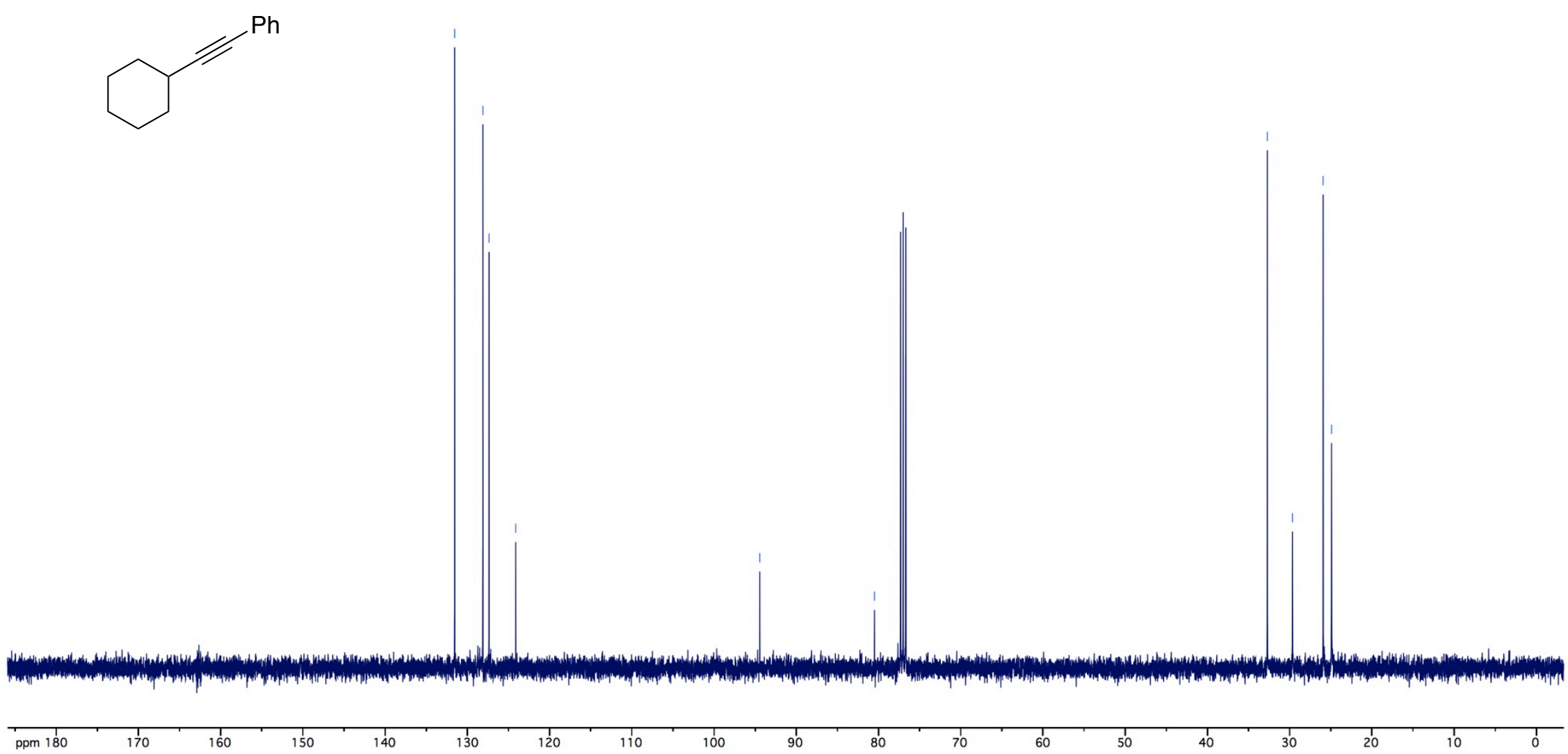




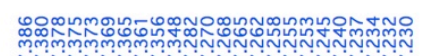

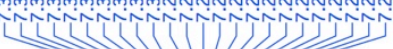

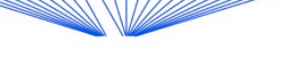

$$
D=\mathrm{Ph}
$$
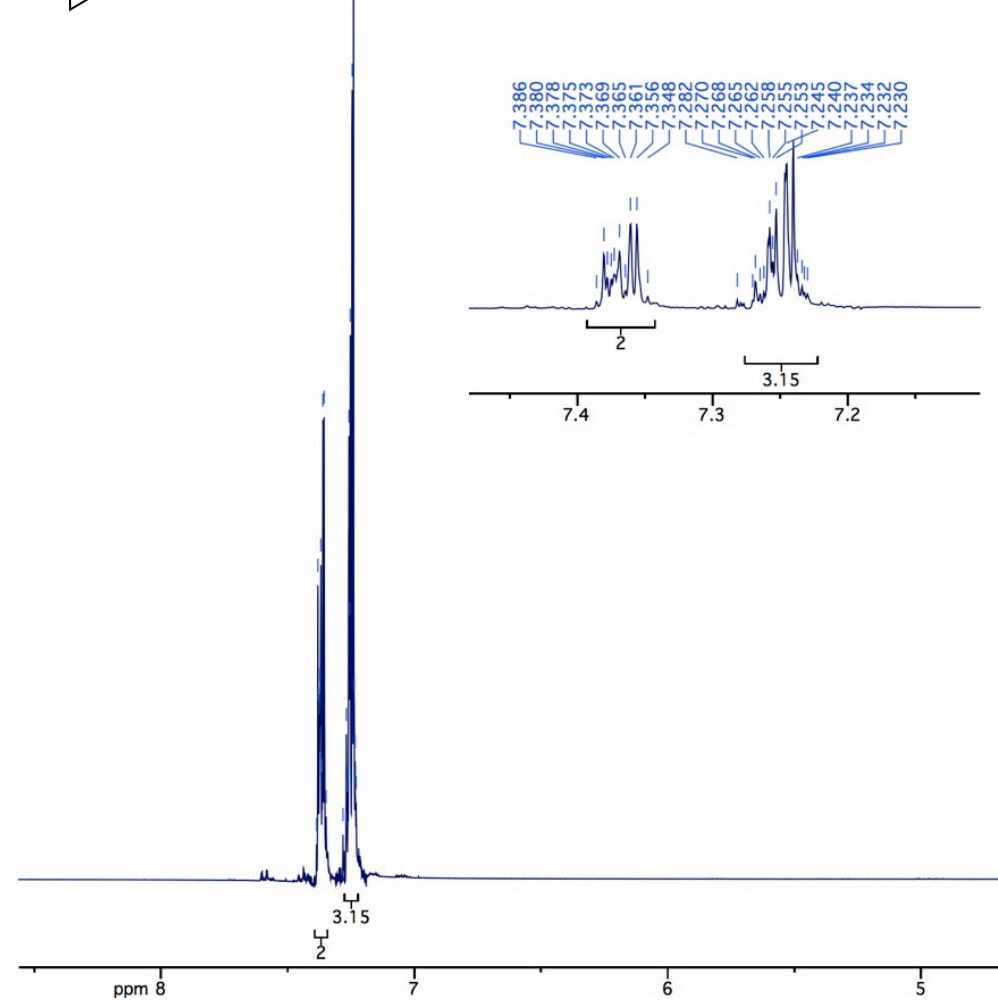

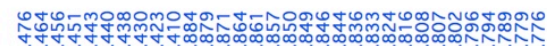

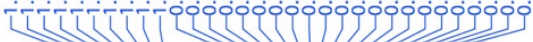

1

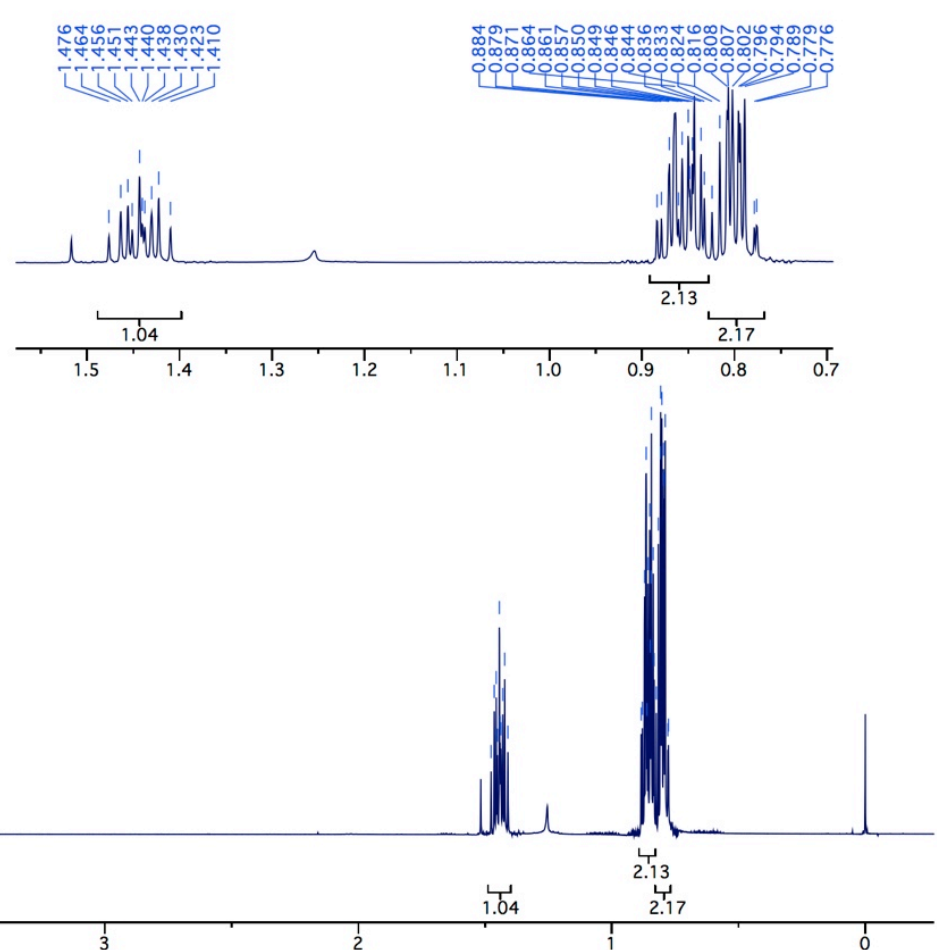




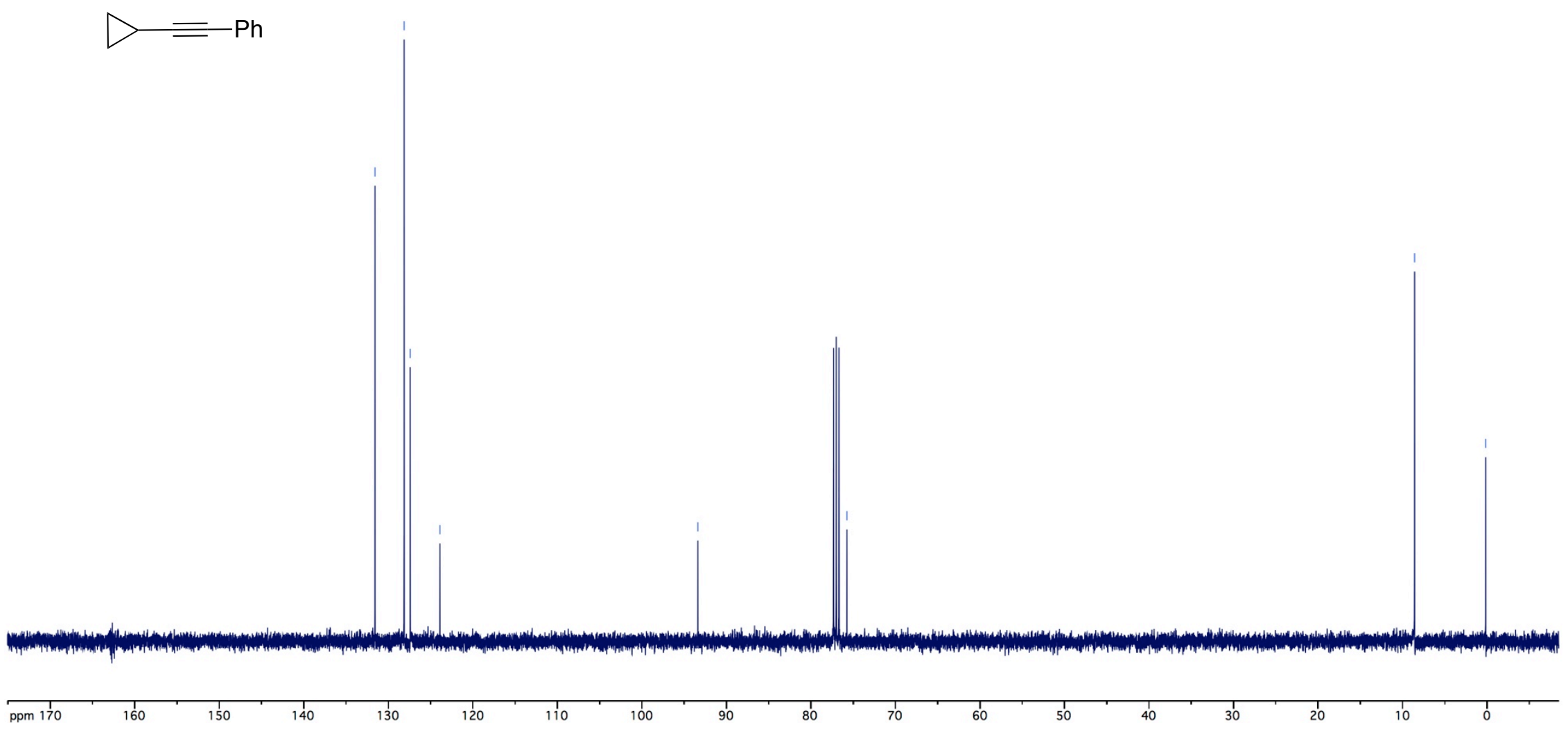


कु.

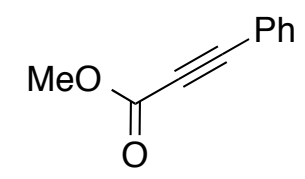

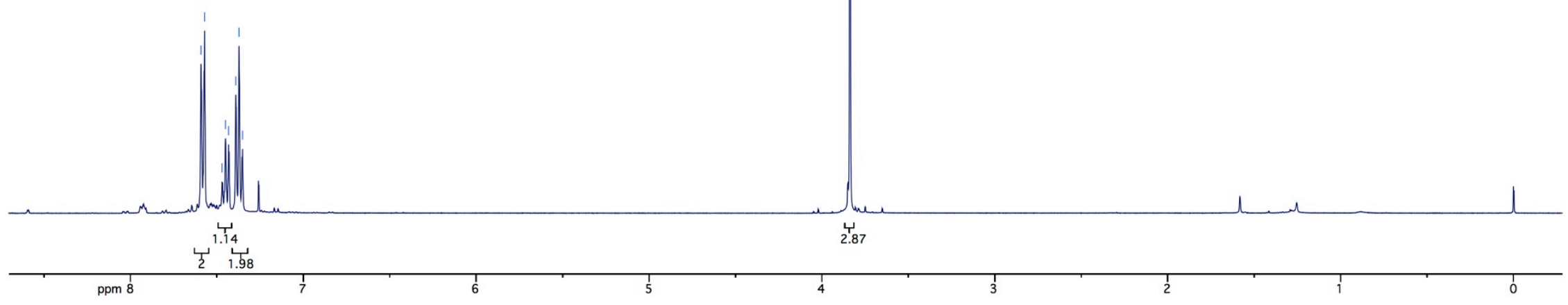




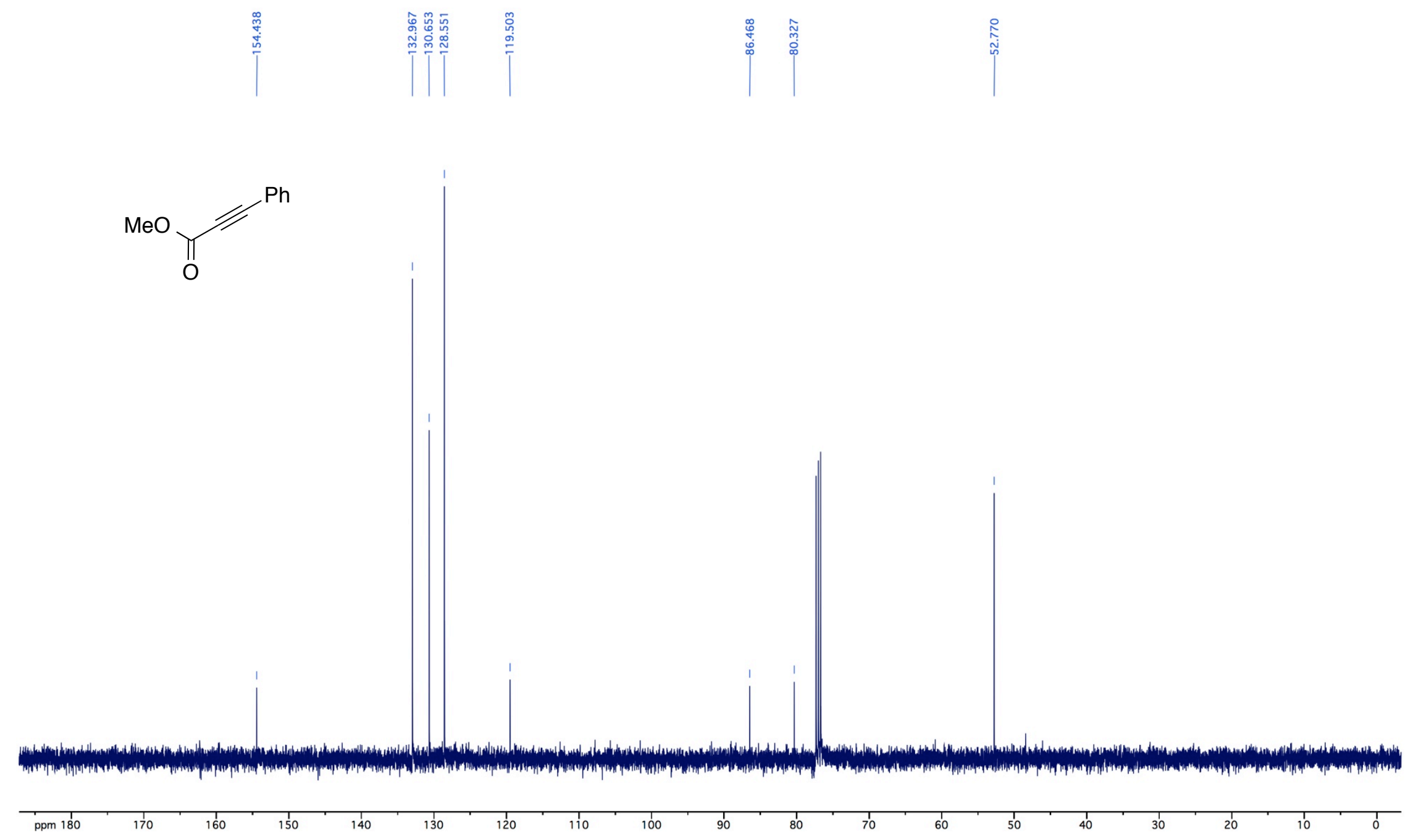




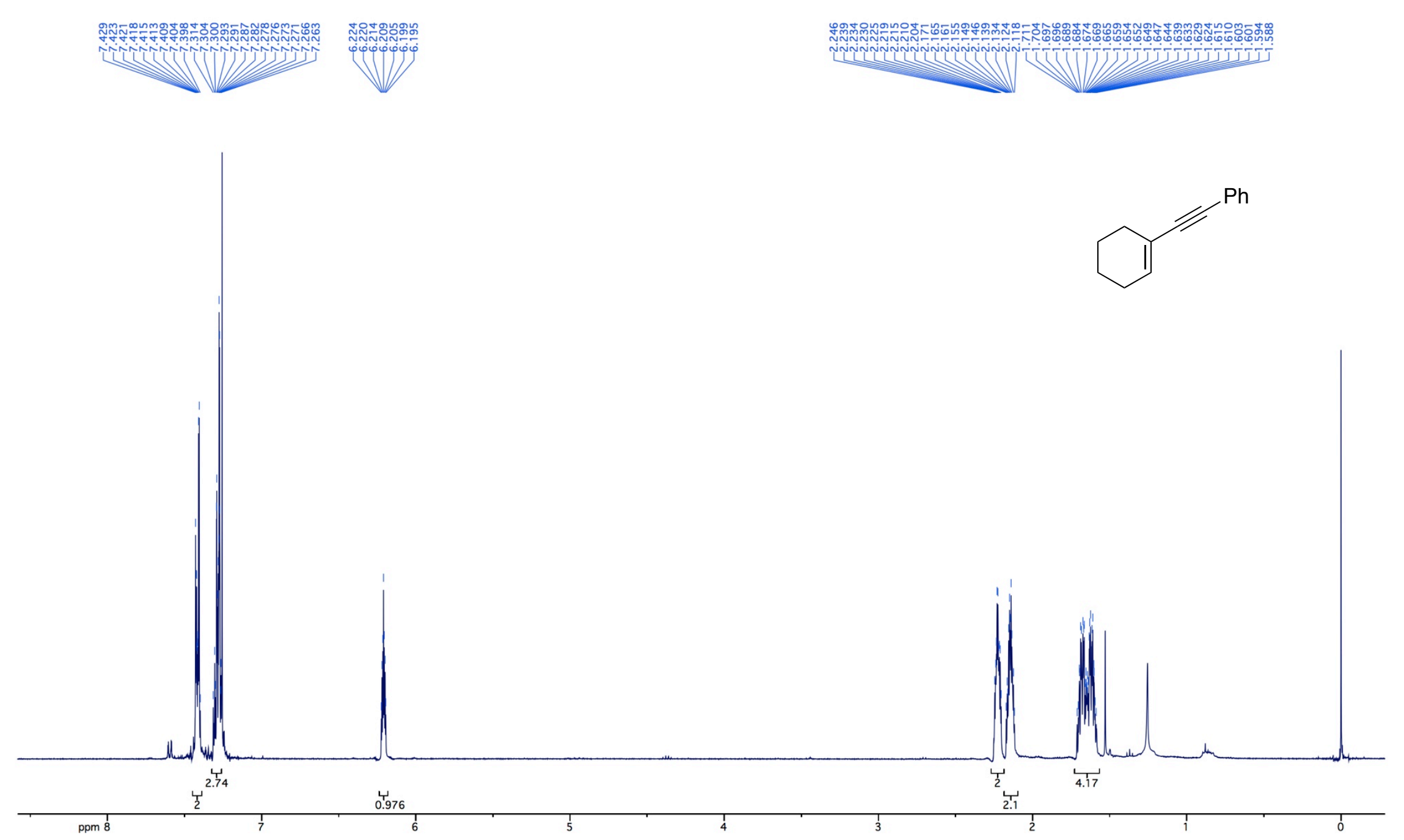




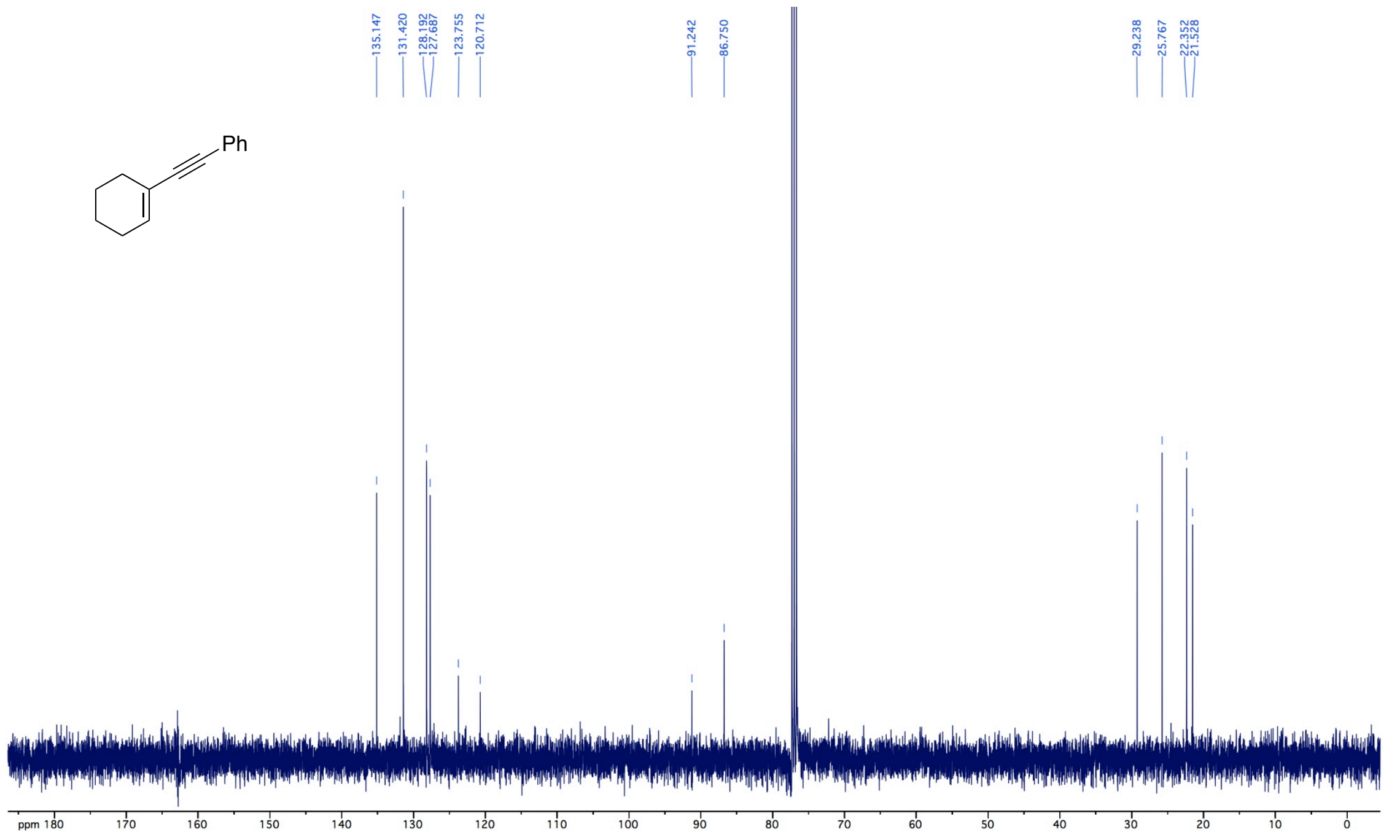



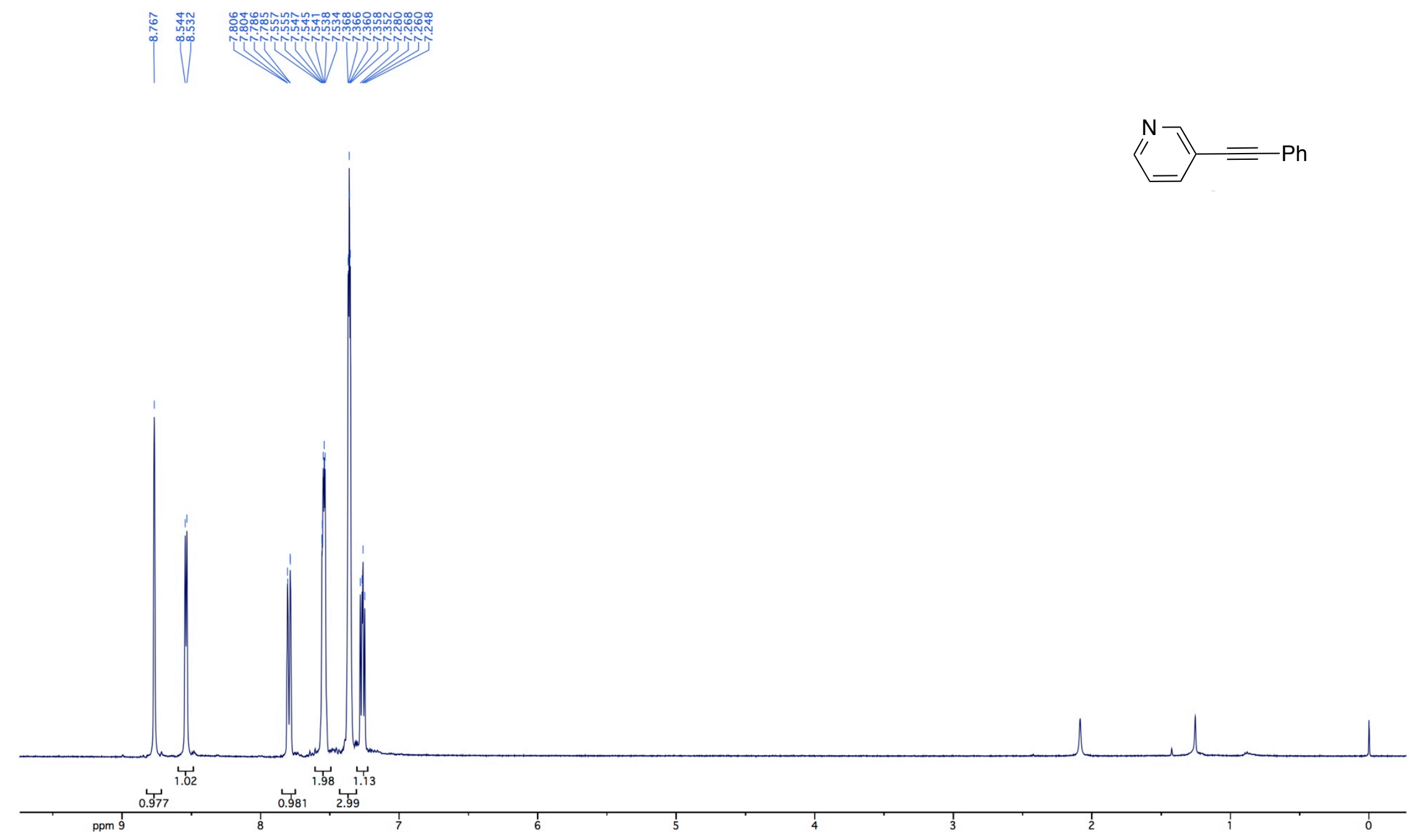


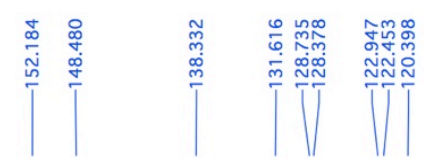

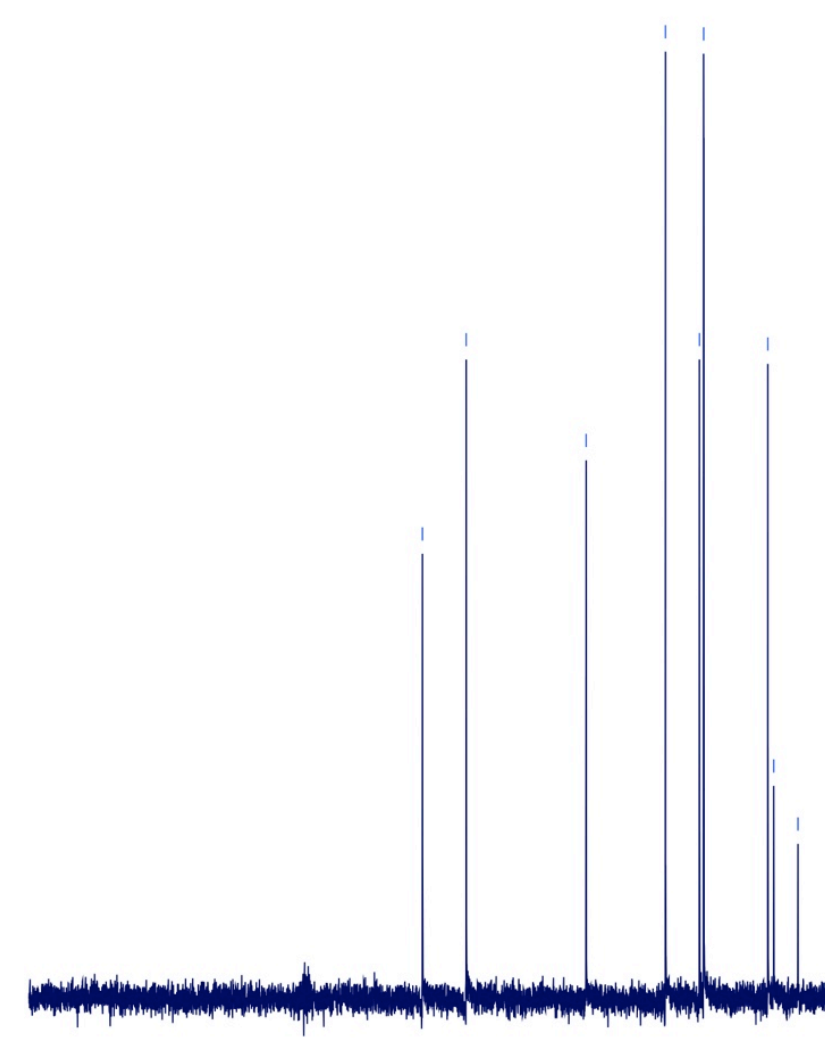

$\prod_{\substack{\infty \\ \stackrel{\infty}{N}}}^{\substack{\infty \\ \infty}}$

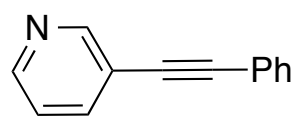
${ }_{170}^{17}$
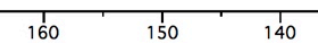

130

120

110

100

90

80

70

60

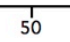

40

30

20 

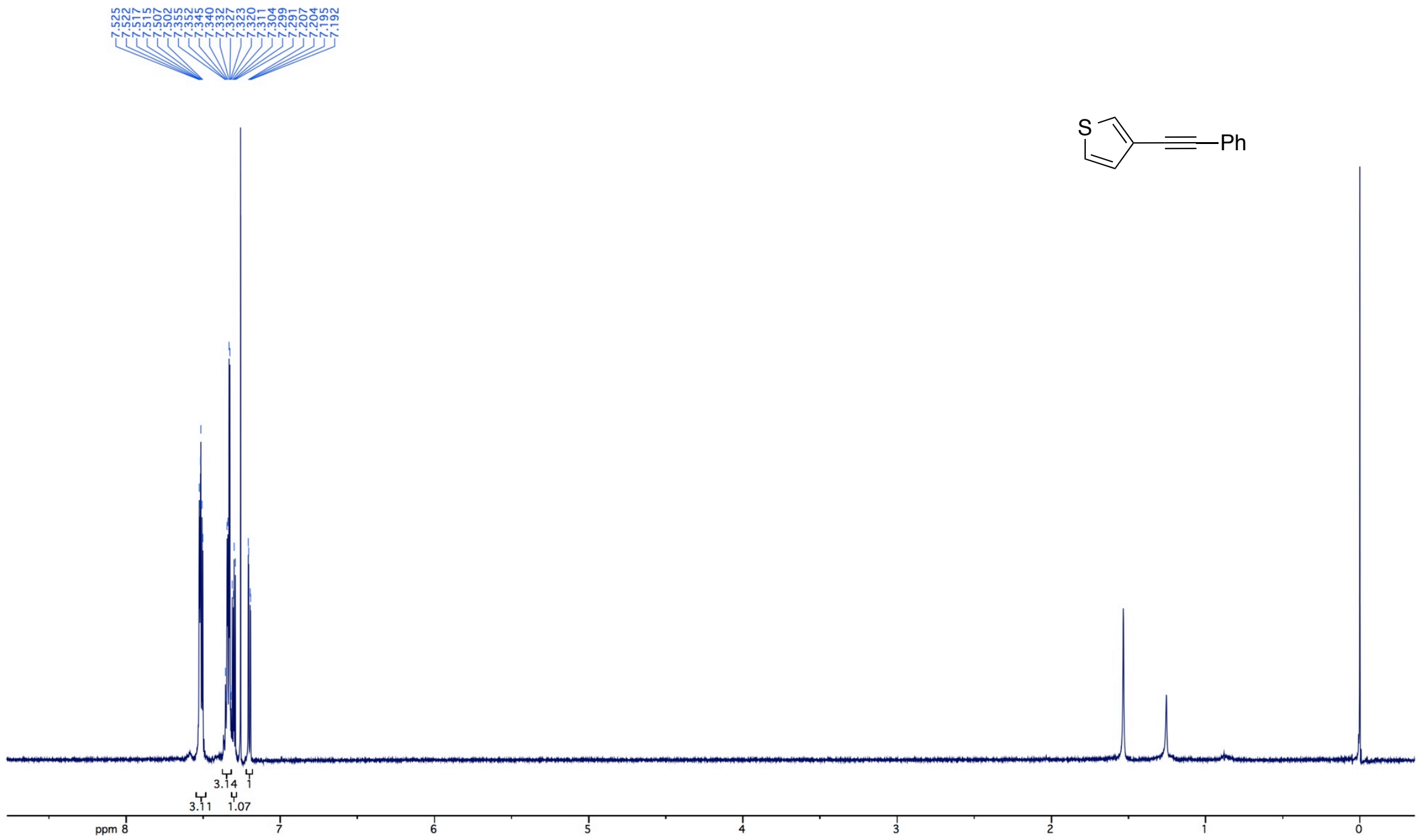

S253 


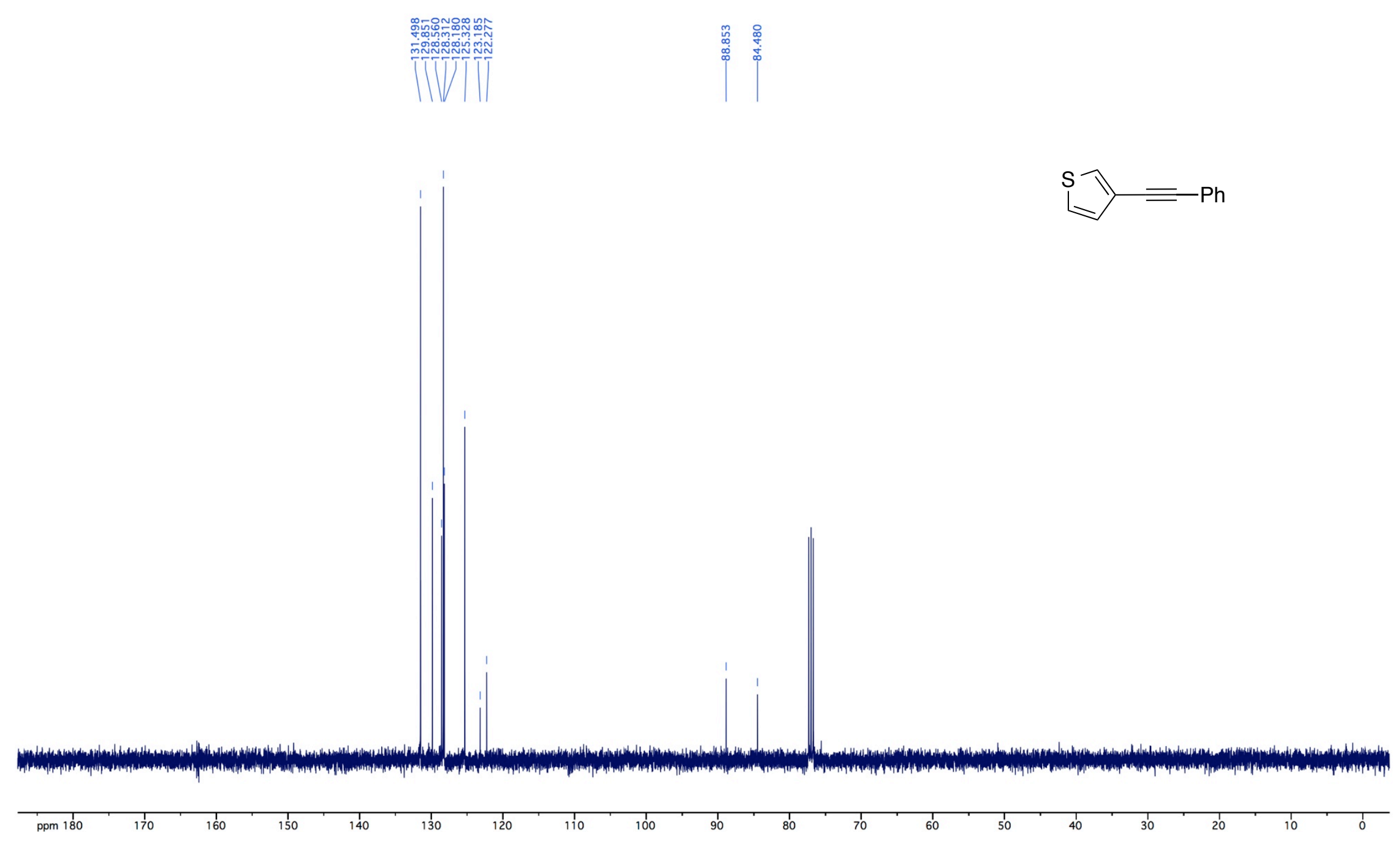




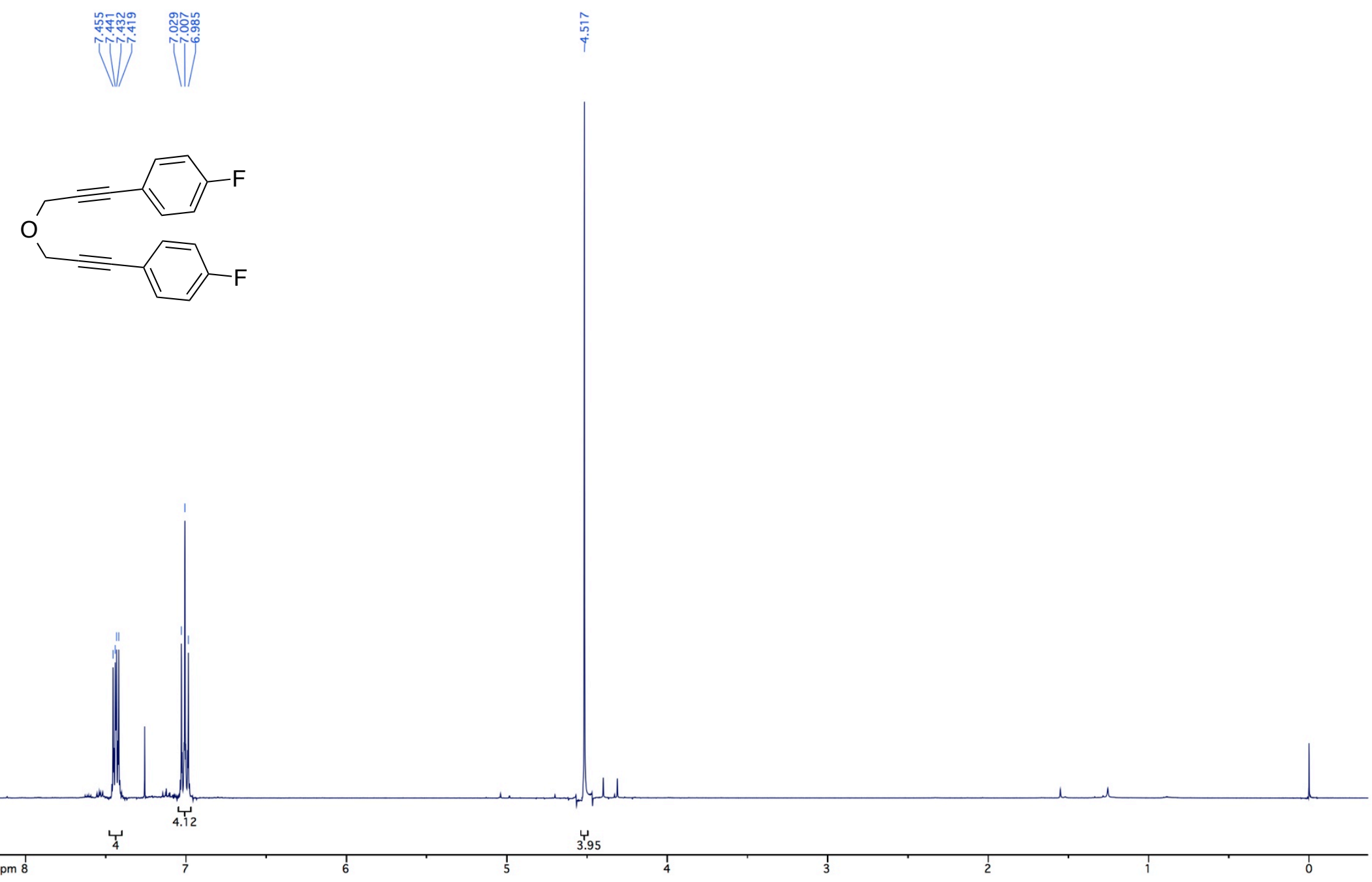

S255 


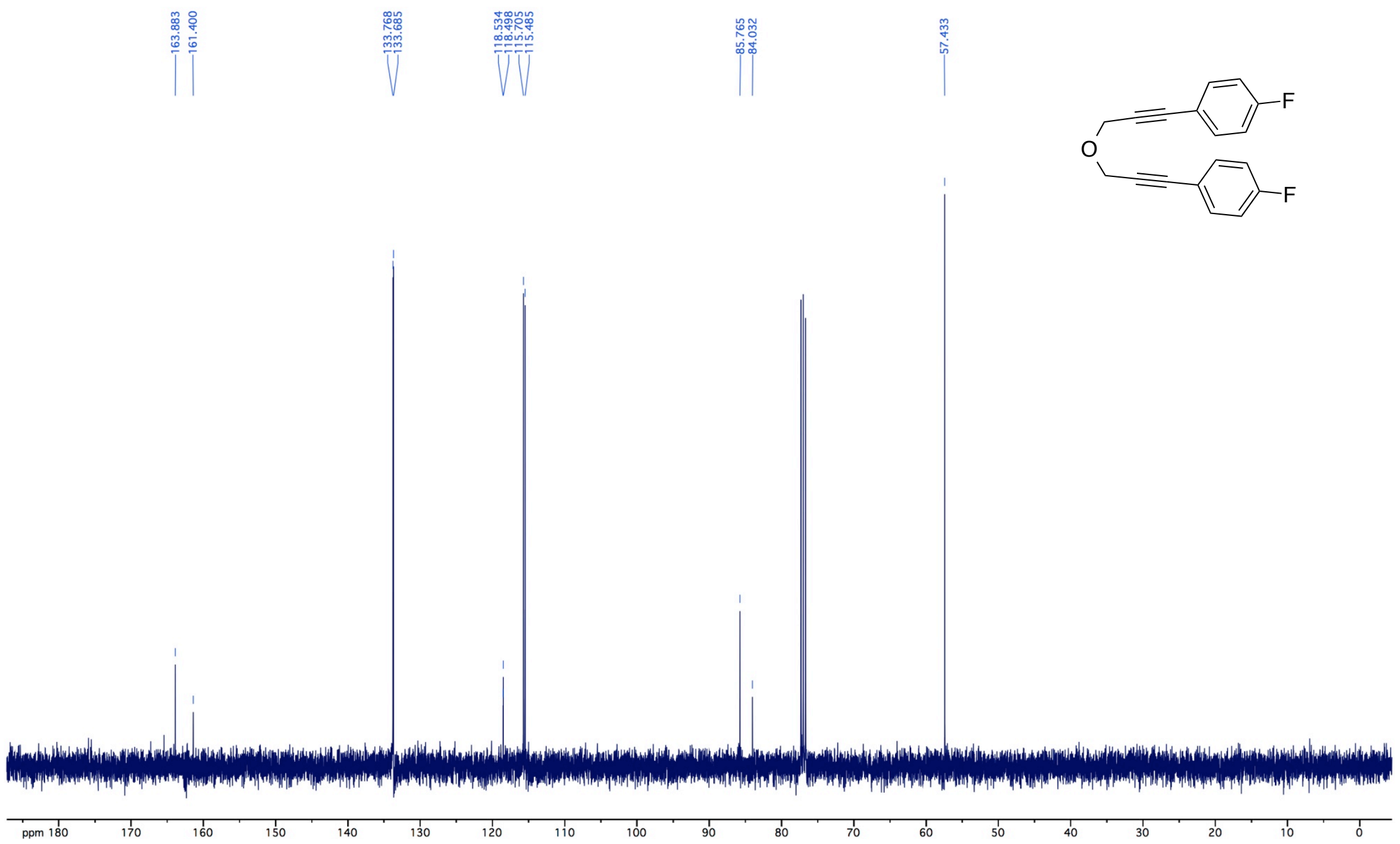



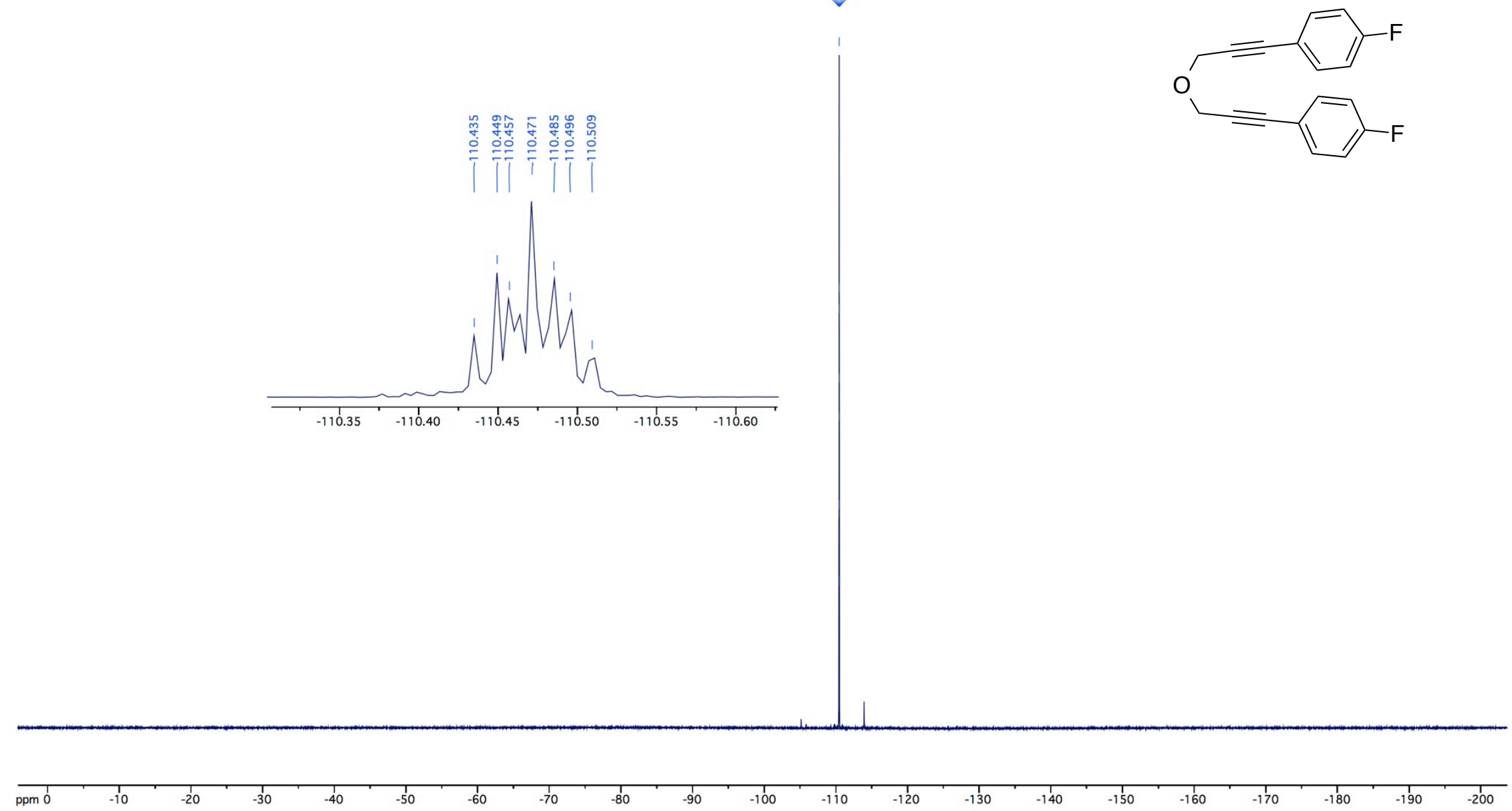


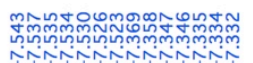

NNTN N TNT

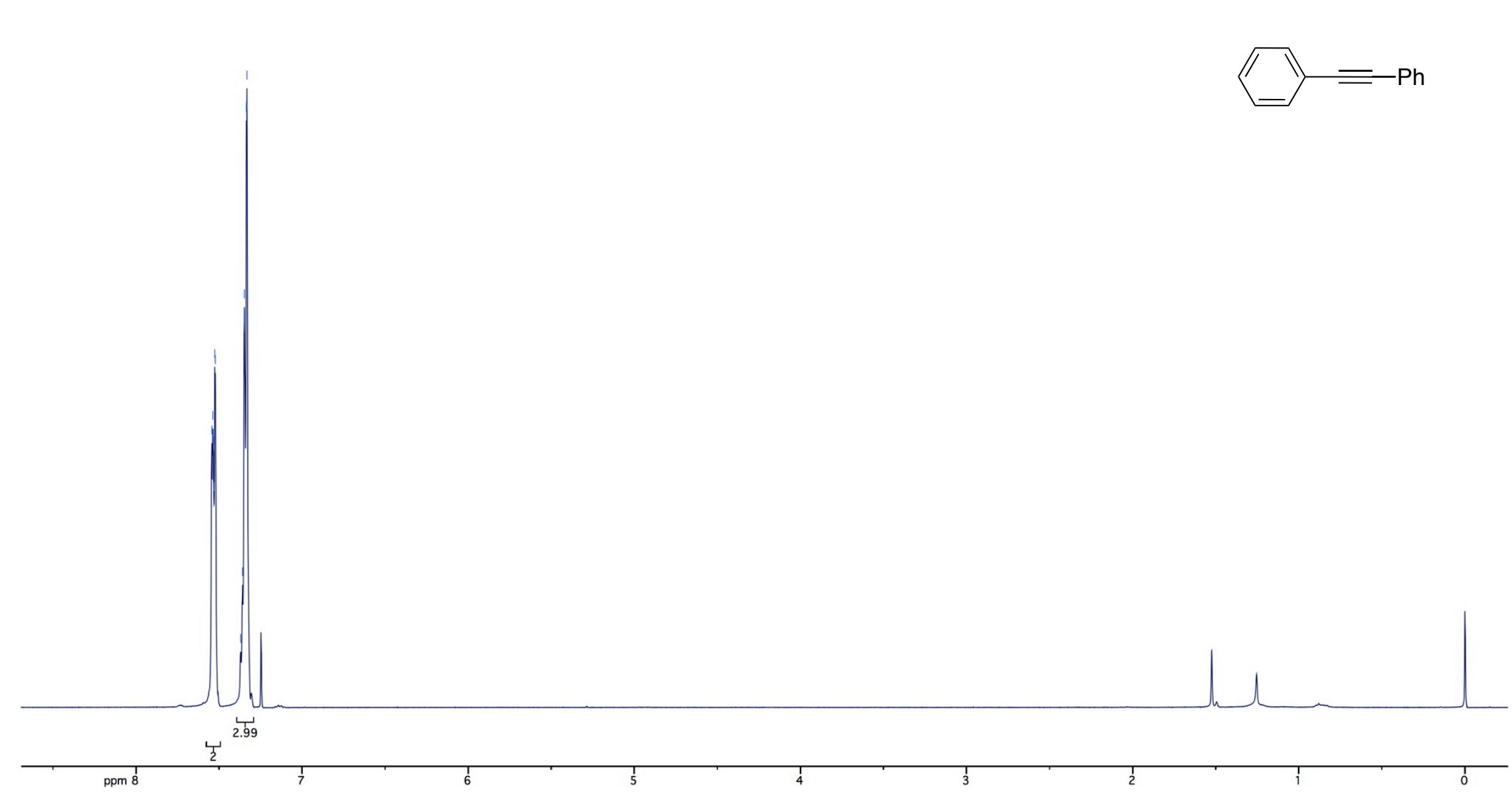




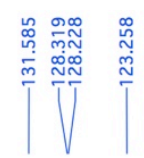

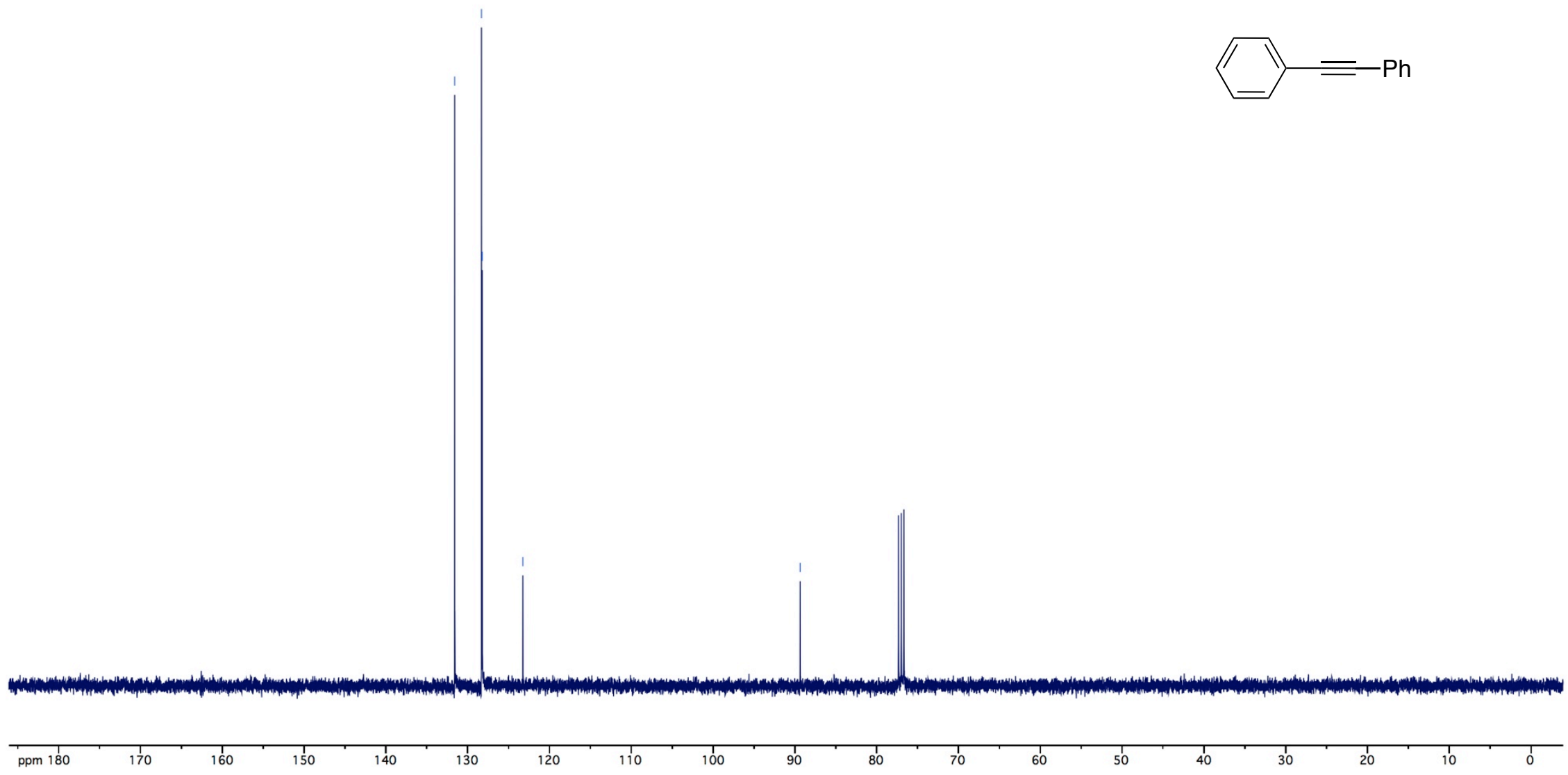


מొ-

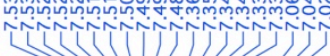

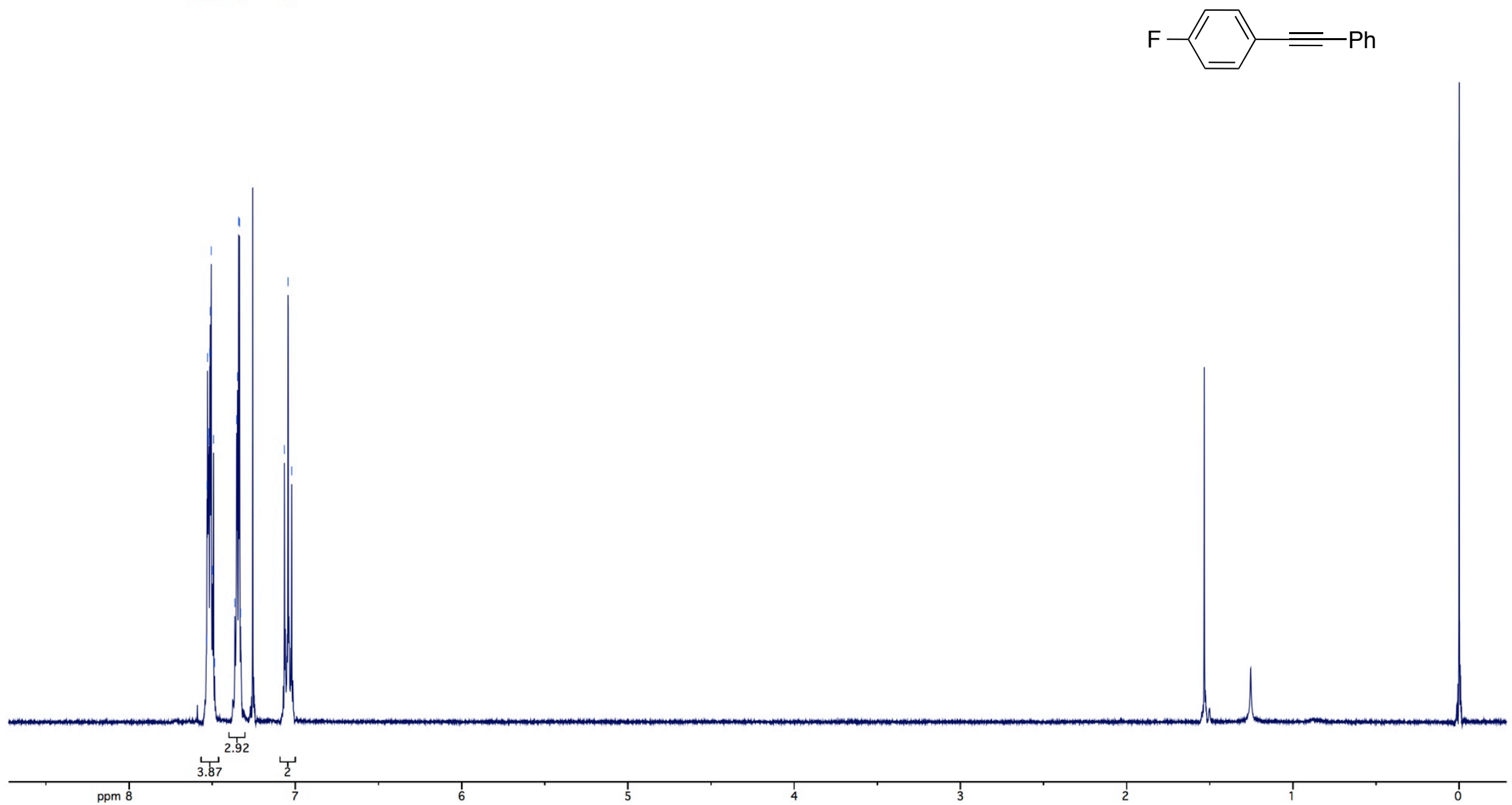




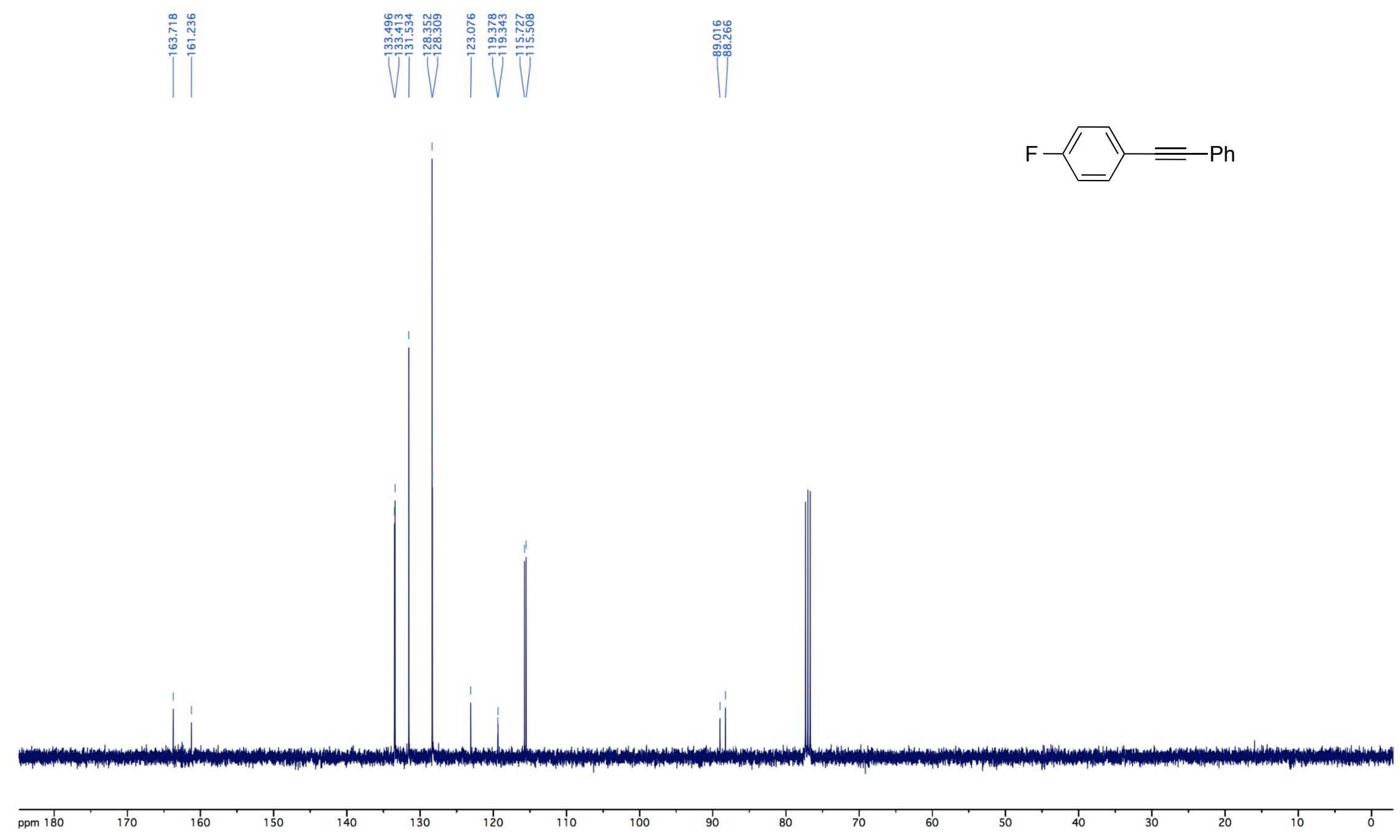



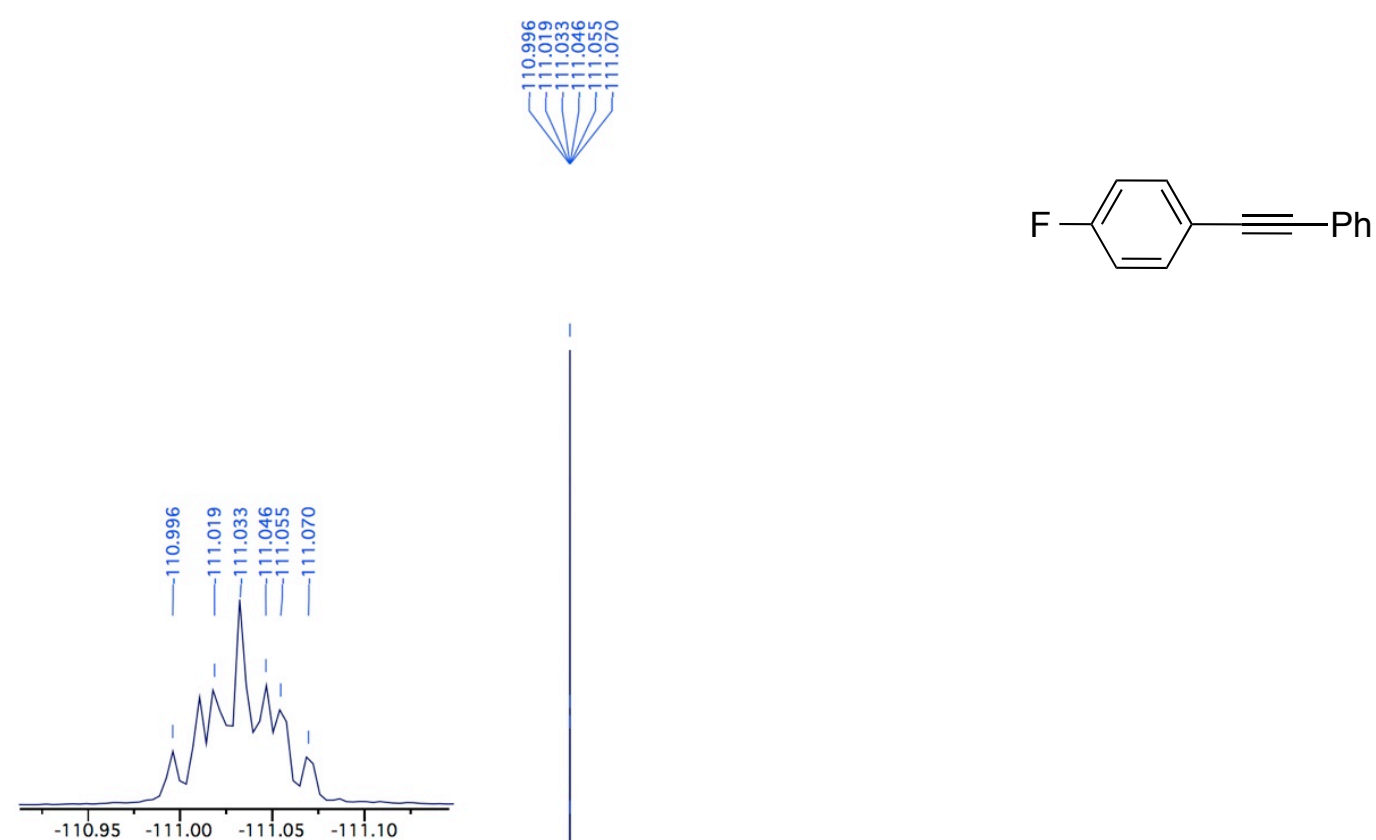

ppm

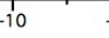

$-20 \quad-30$

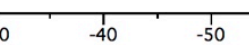

$-60$

$-70 \quad-80$

$-100$

$-110$ 


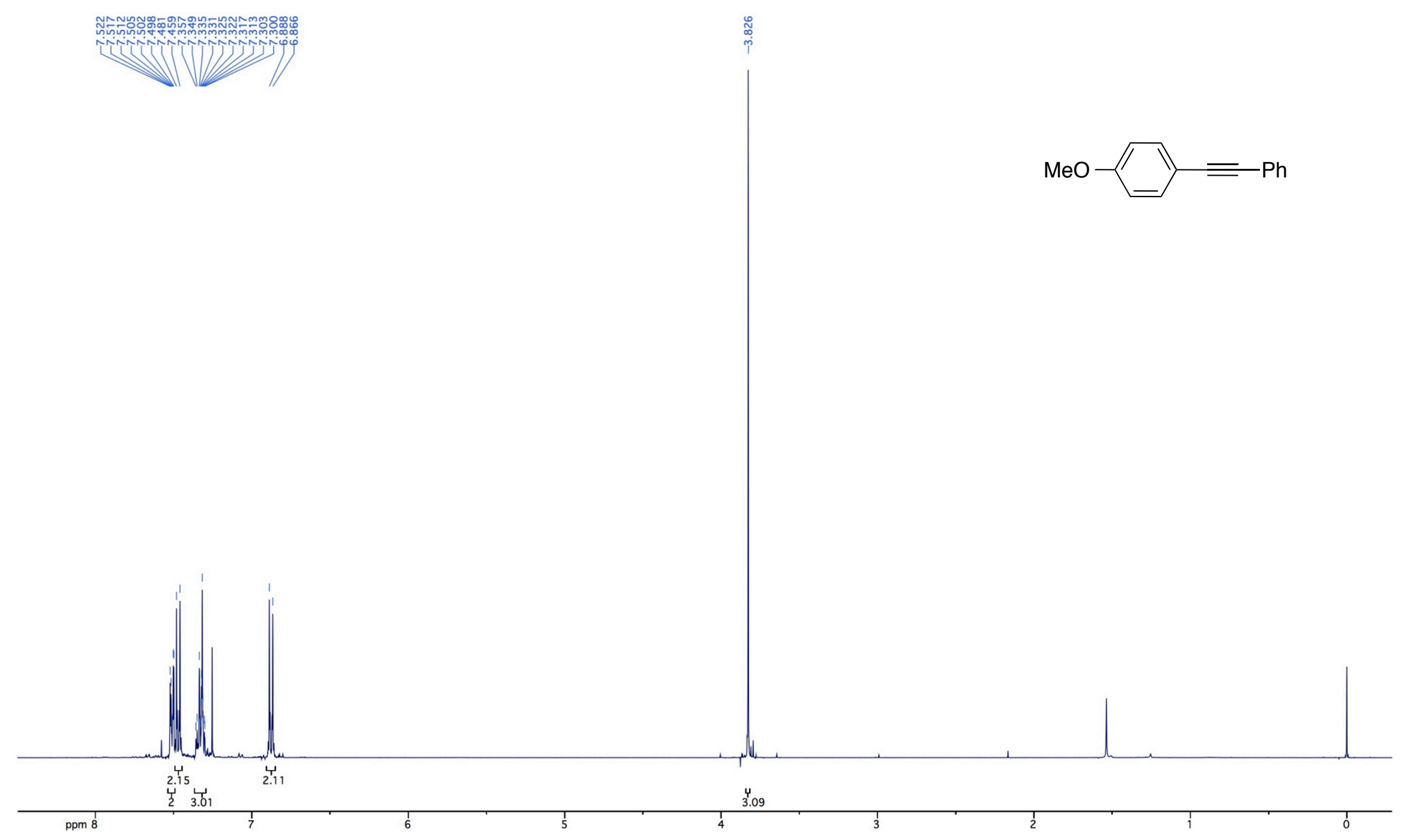




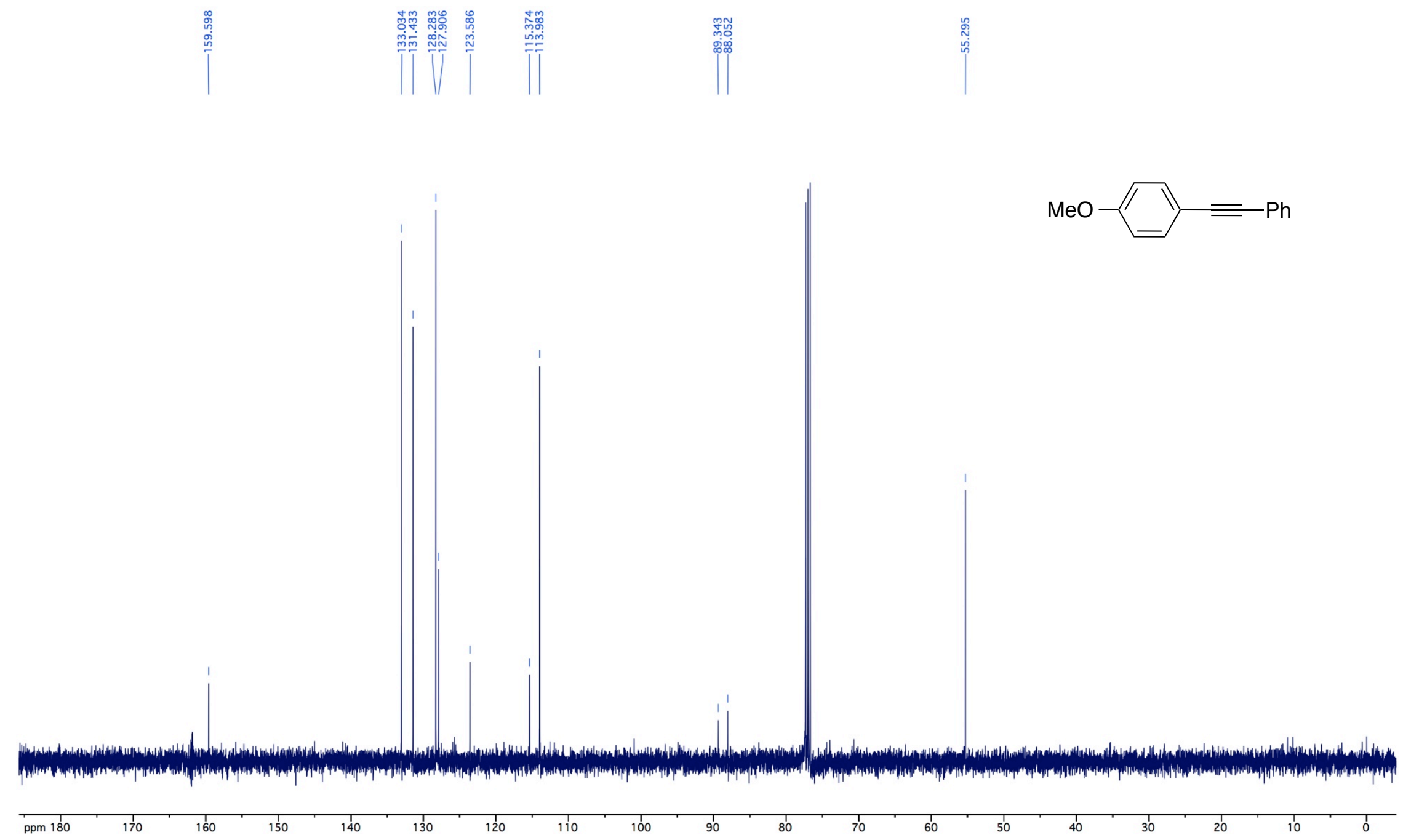



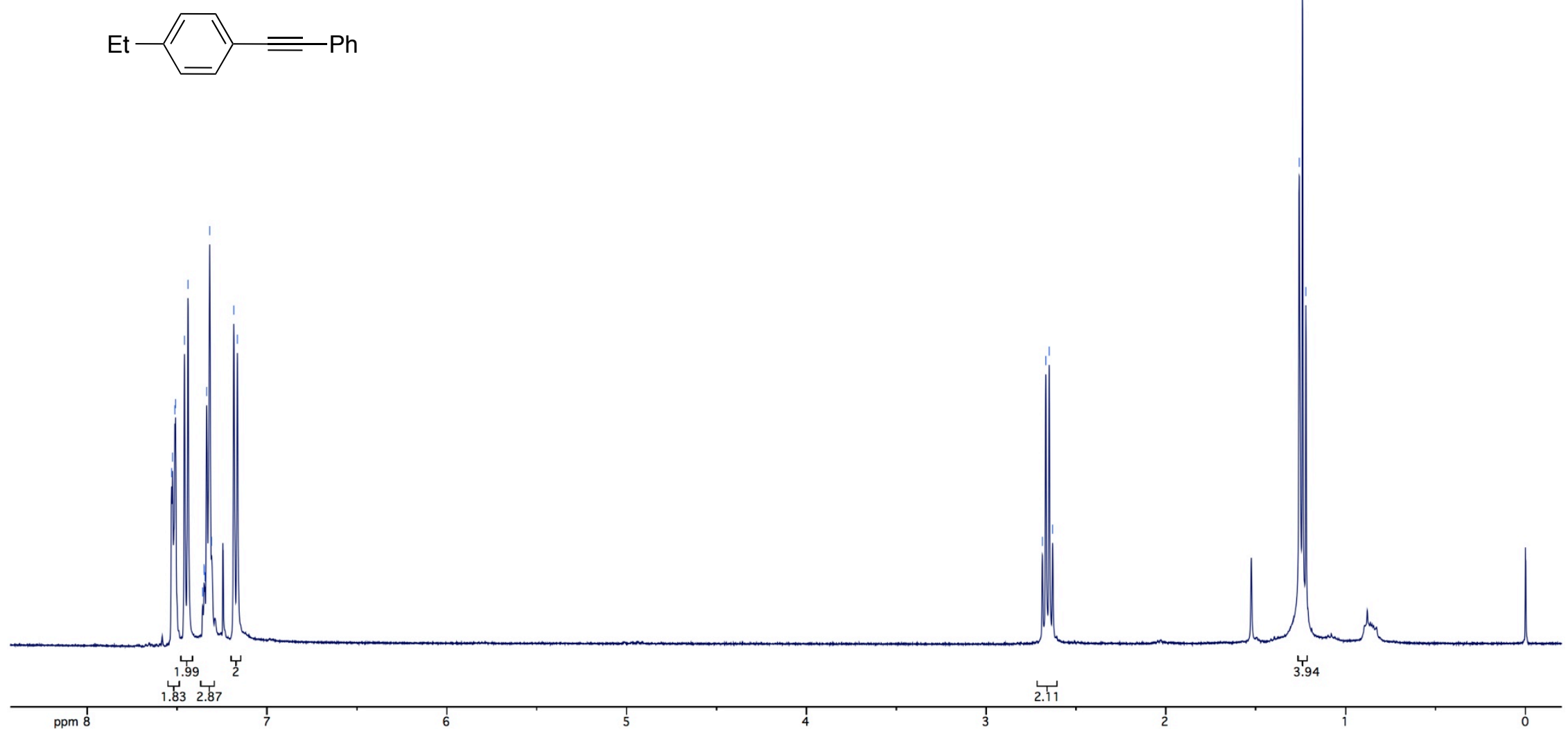


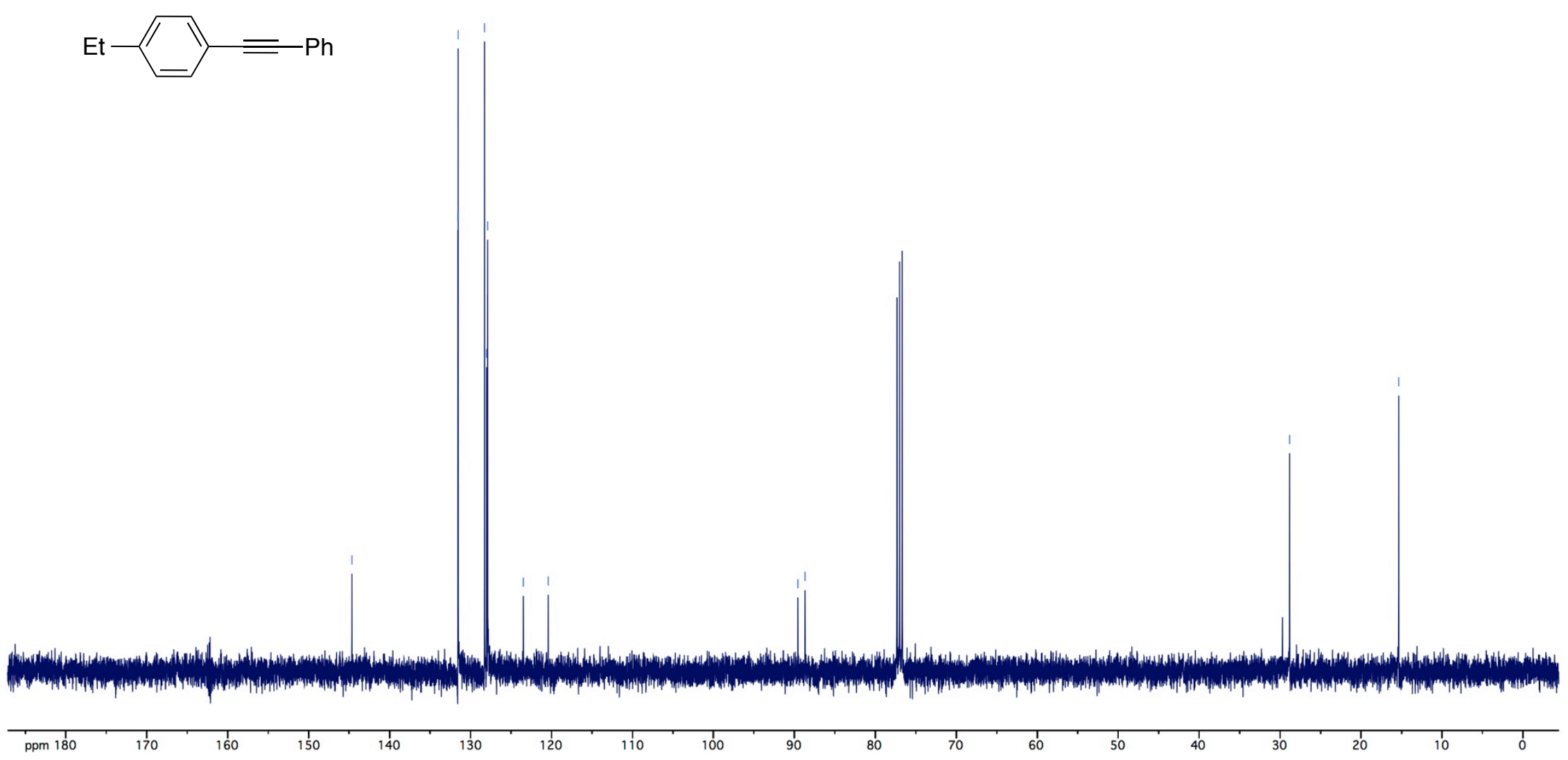




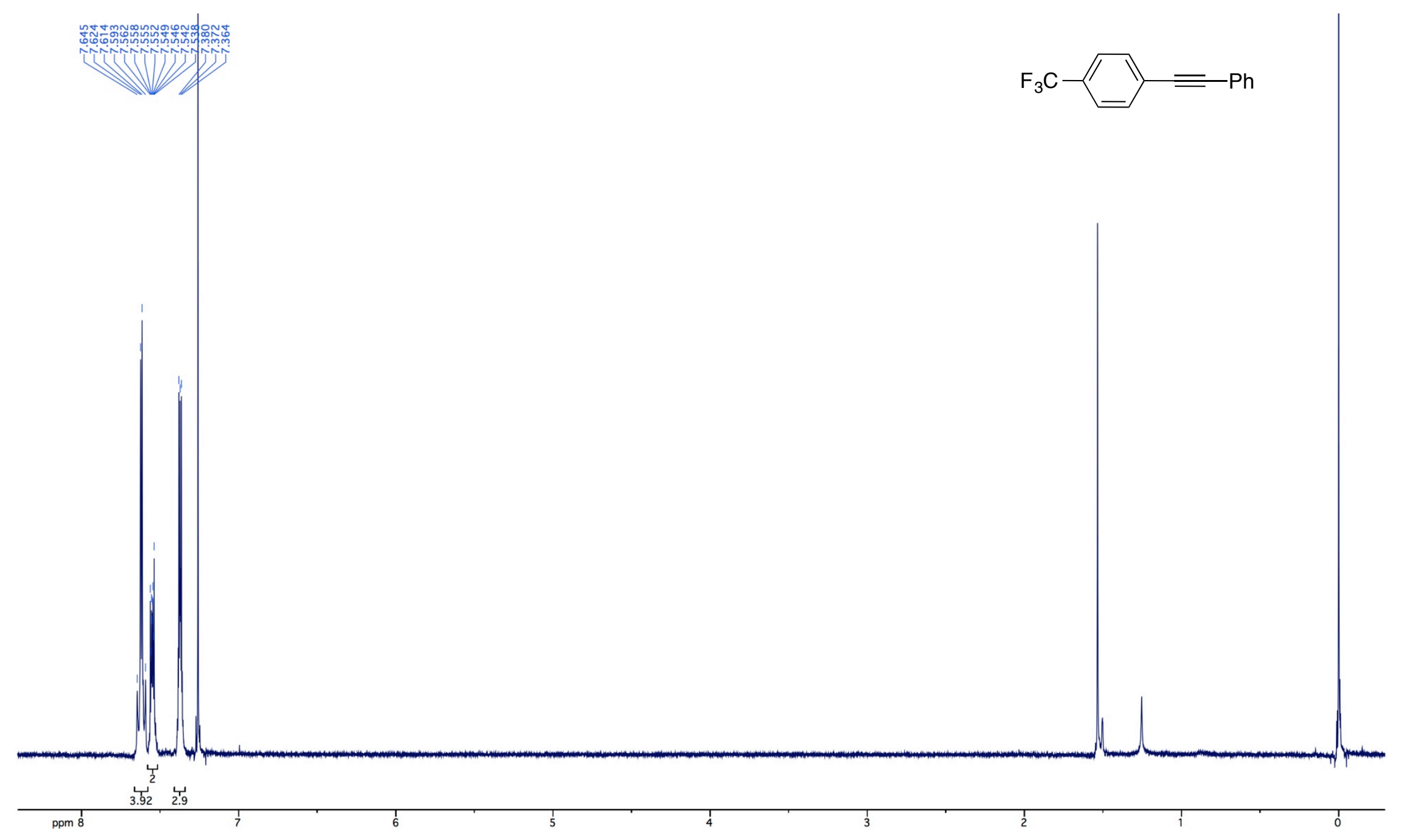




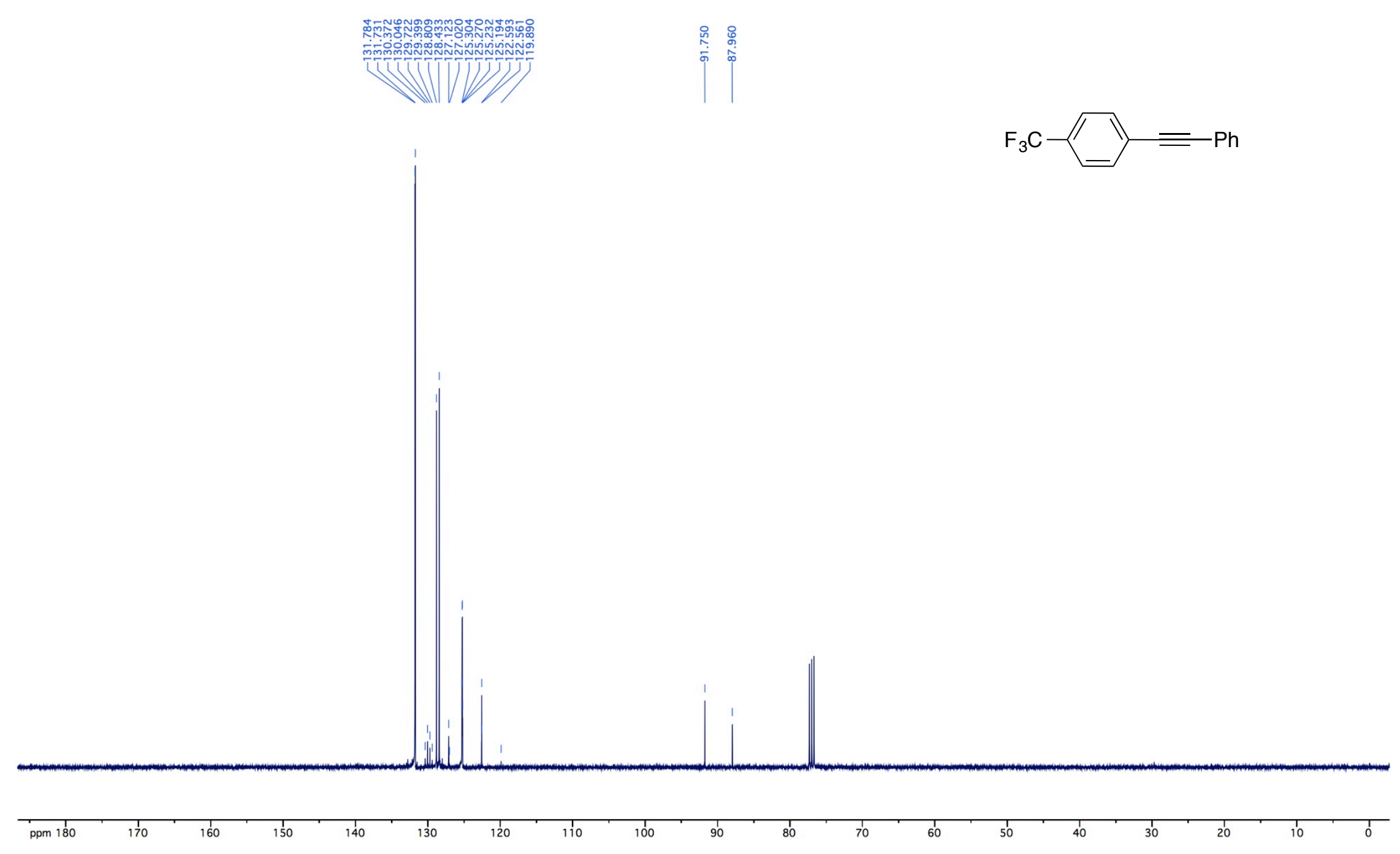




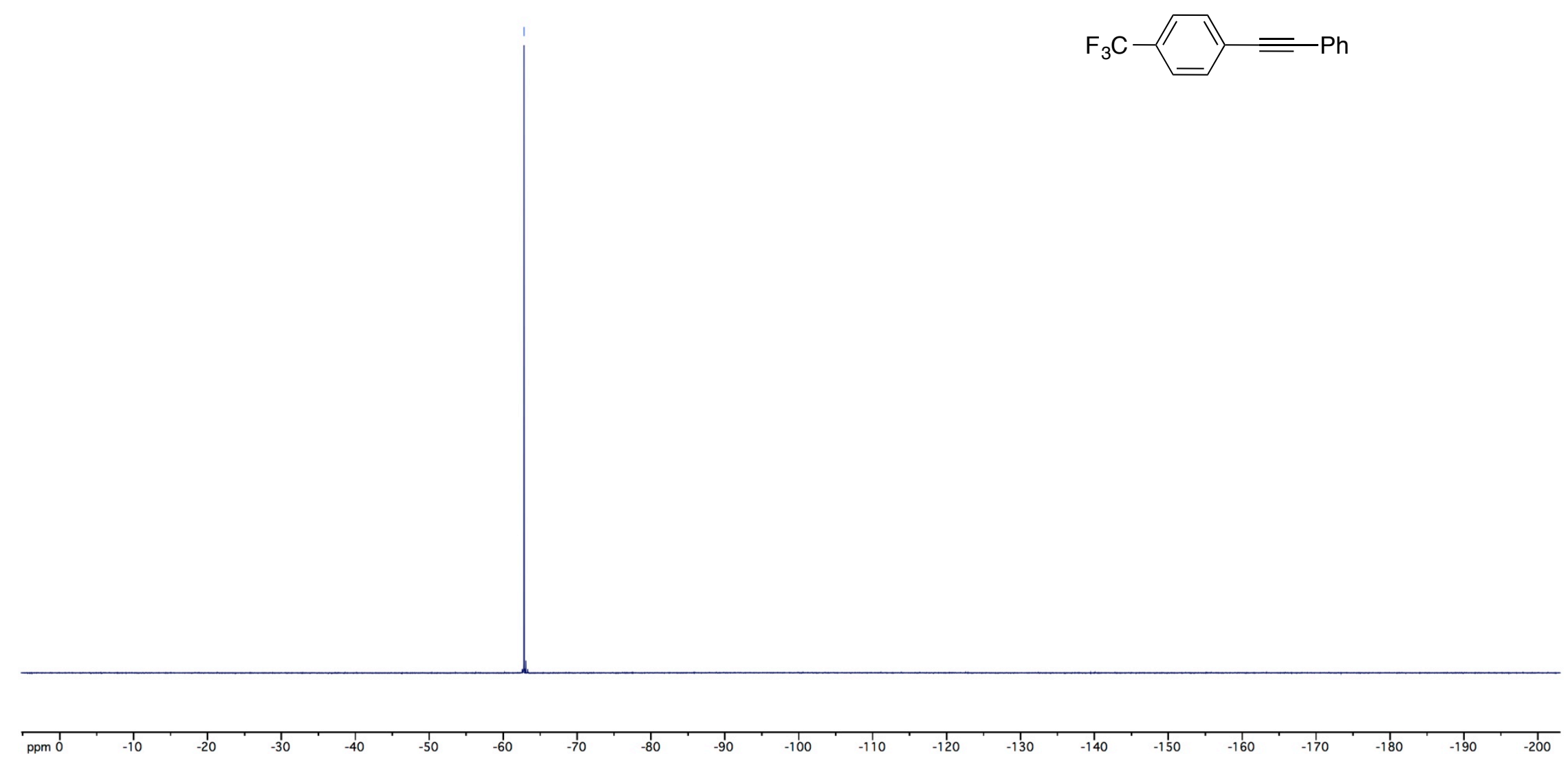




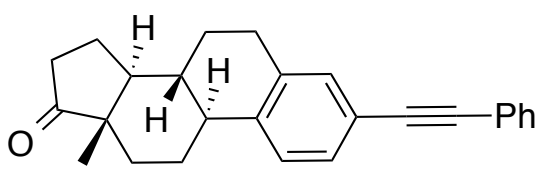

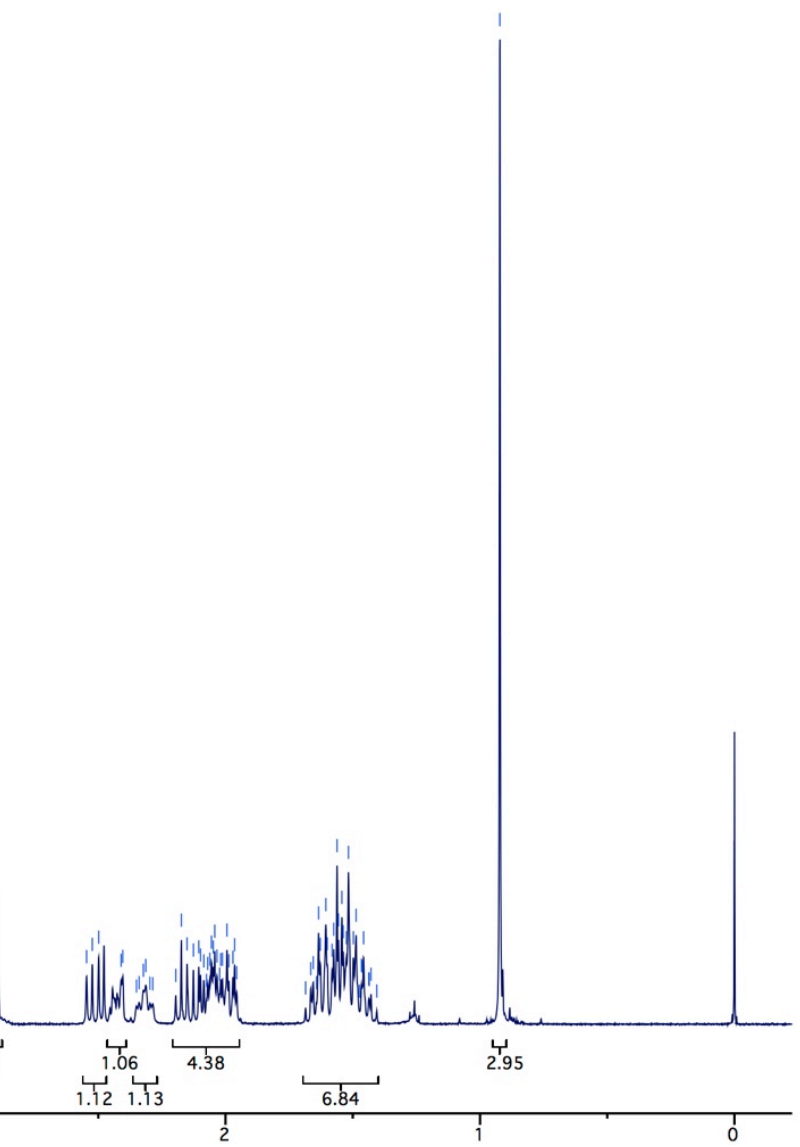




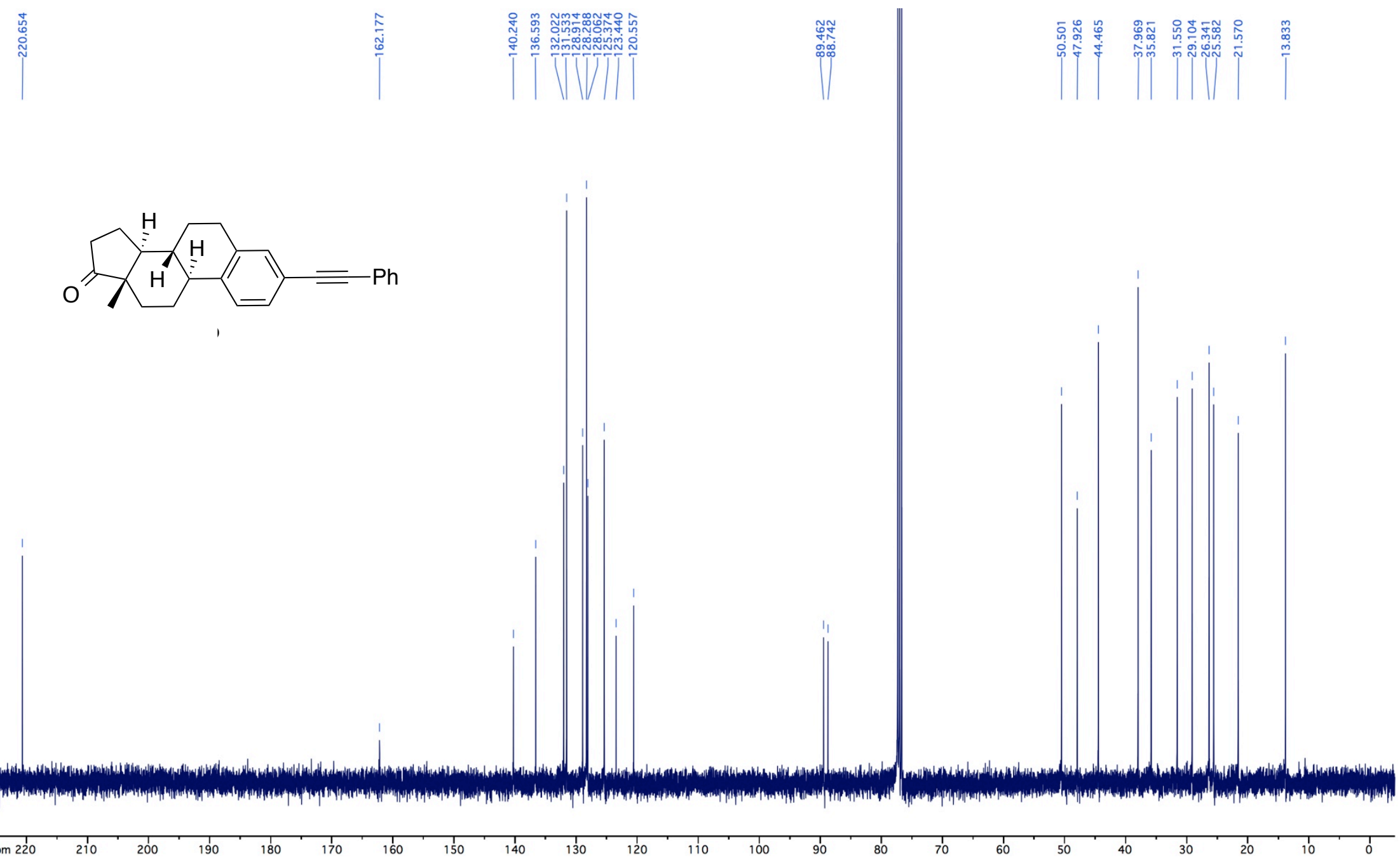




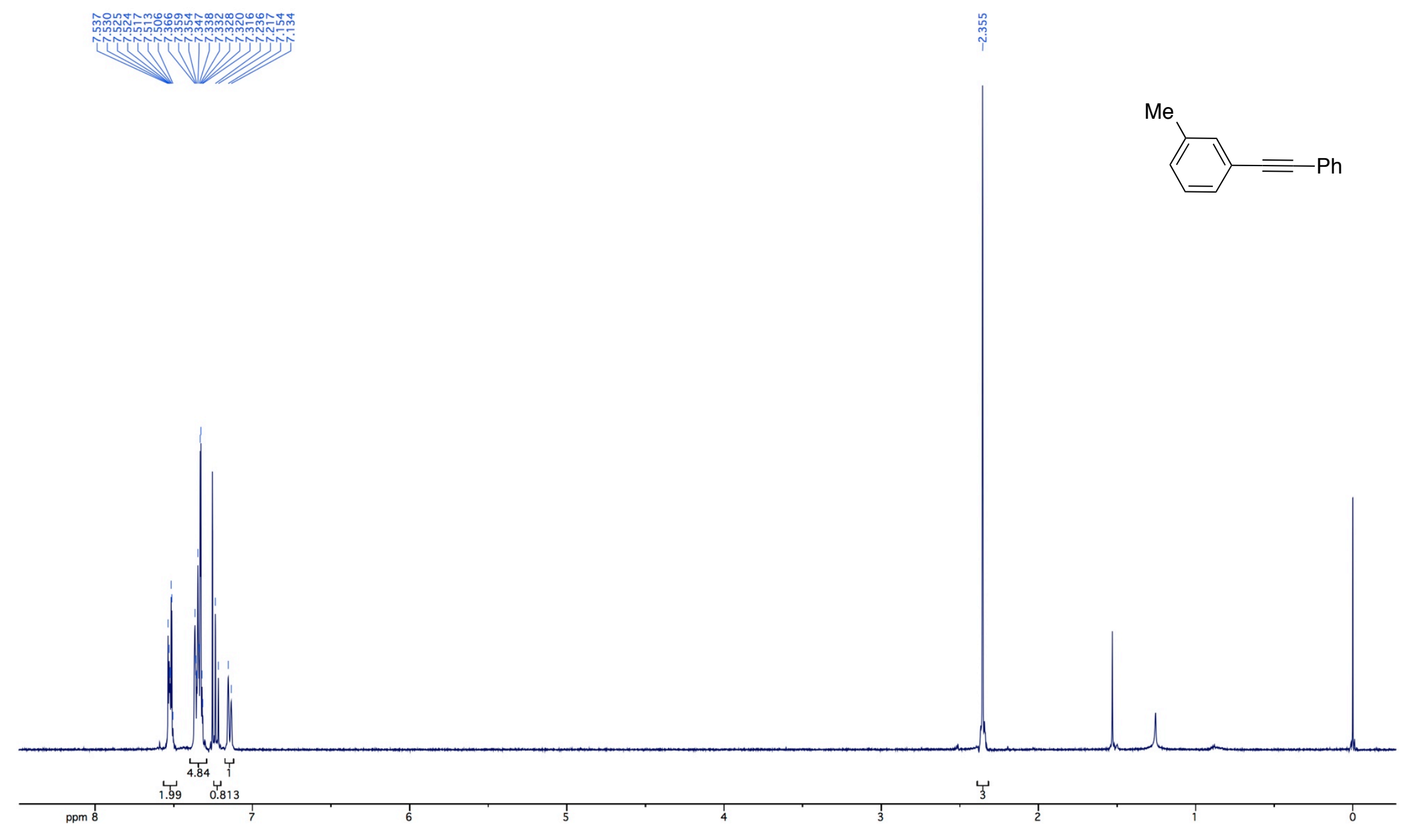



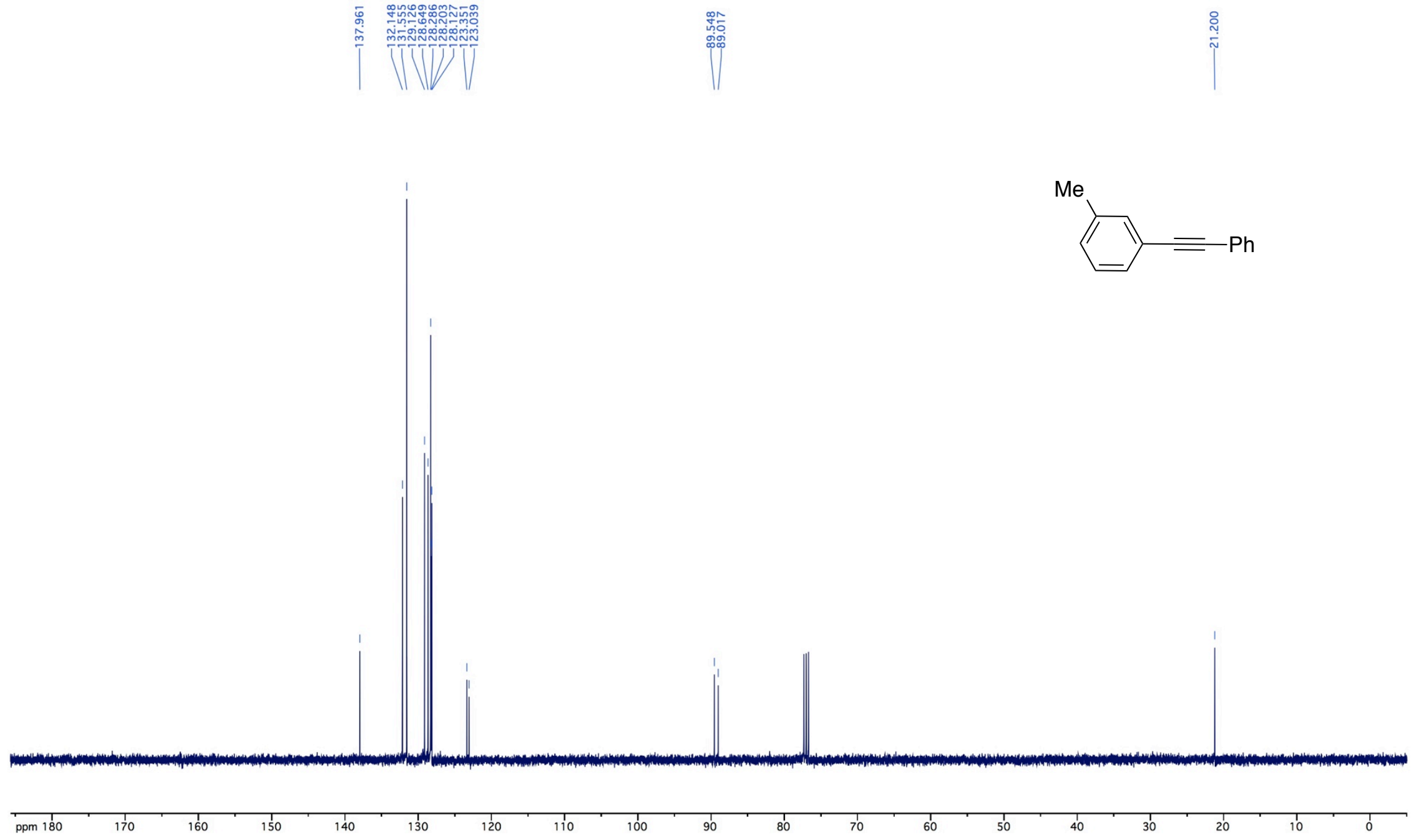


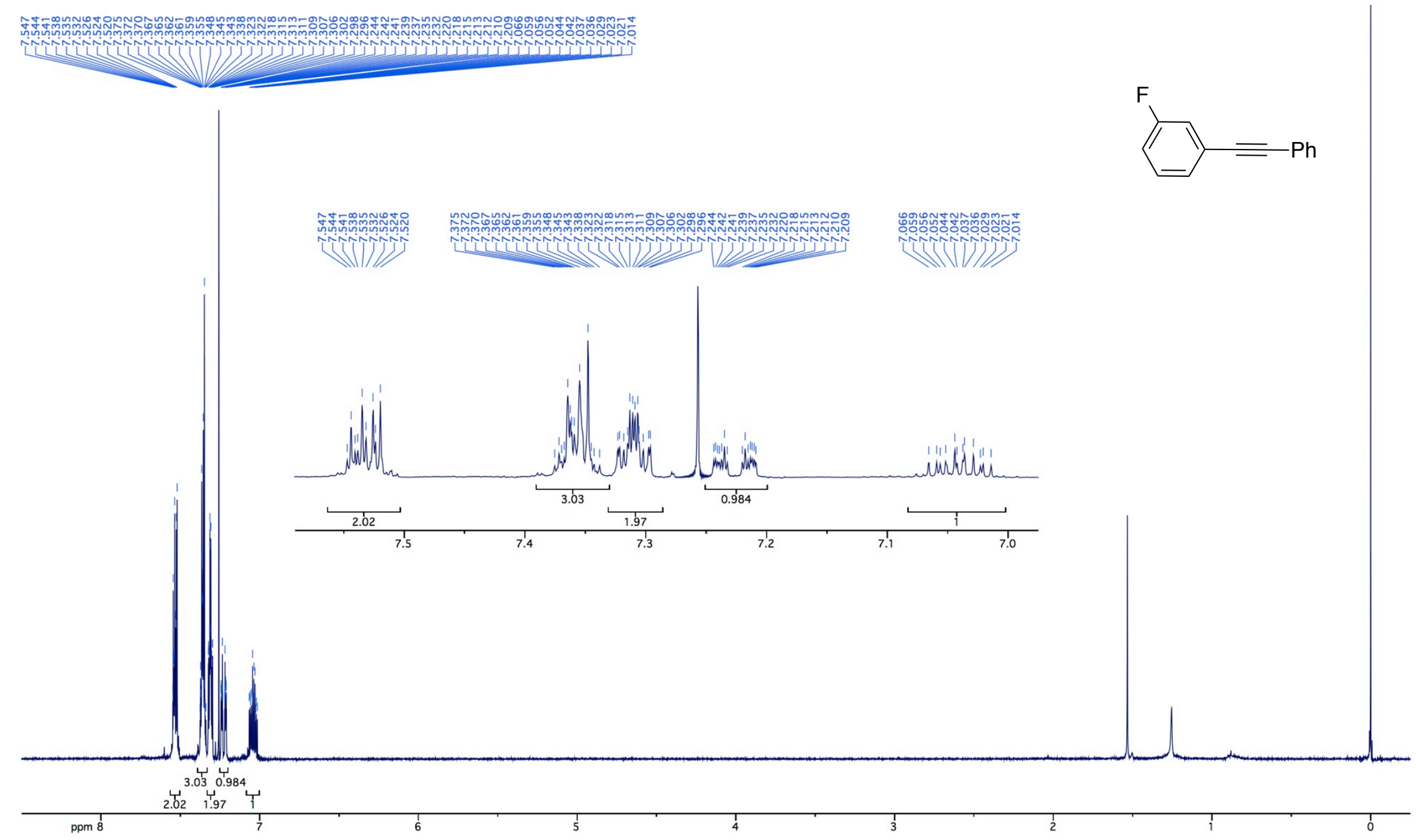




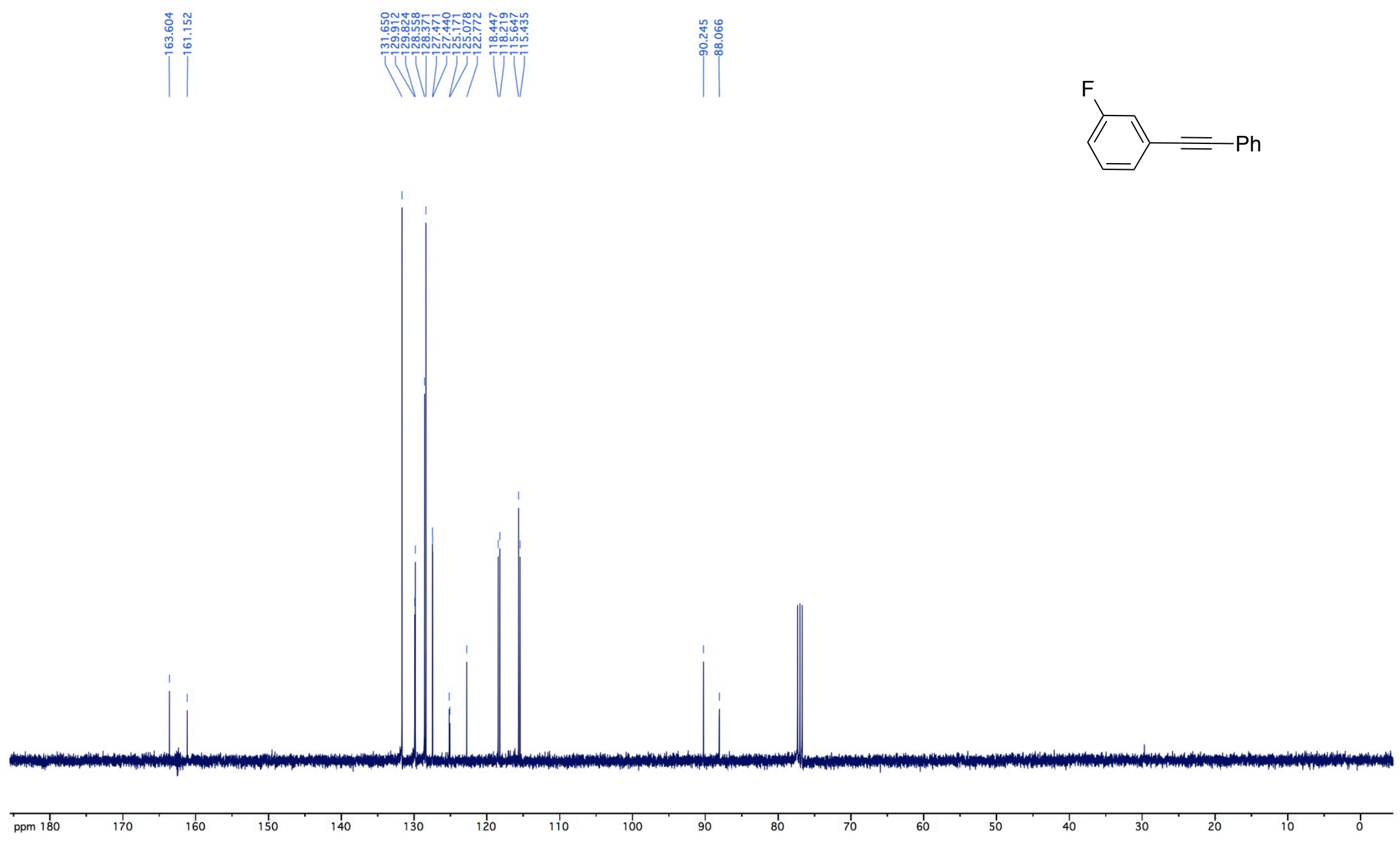


붂ㅉำ
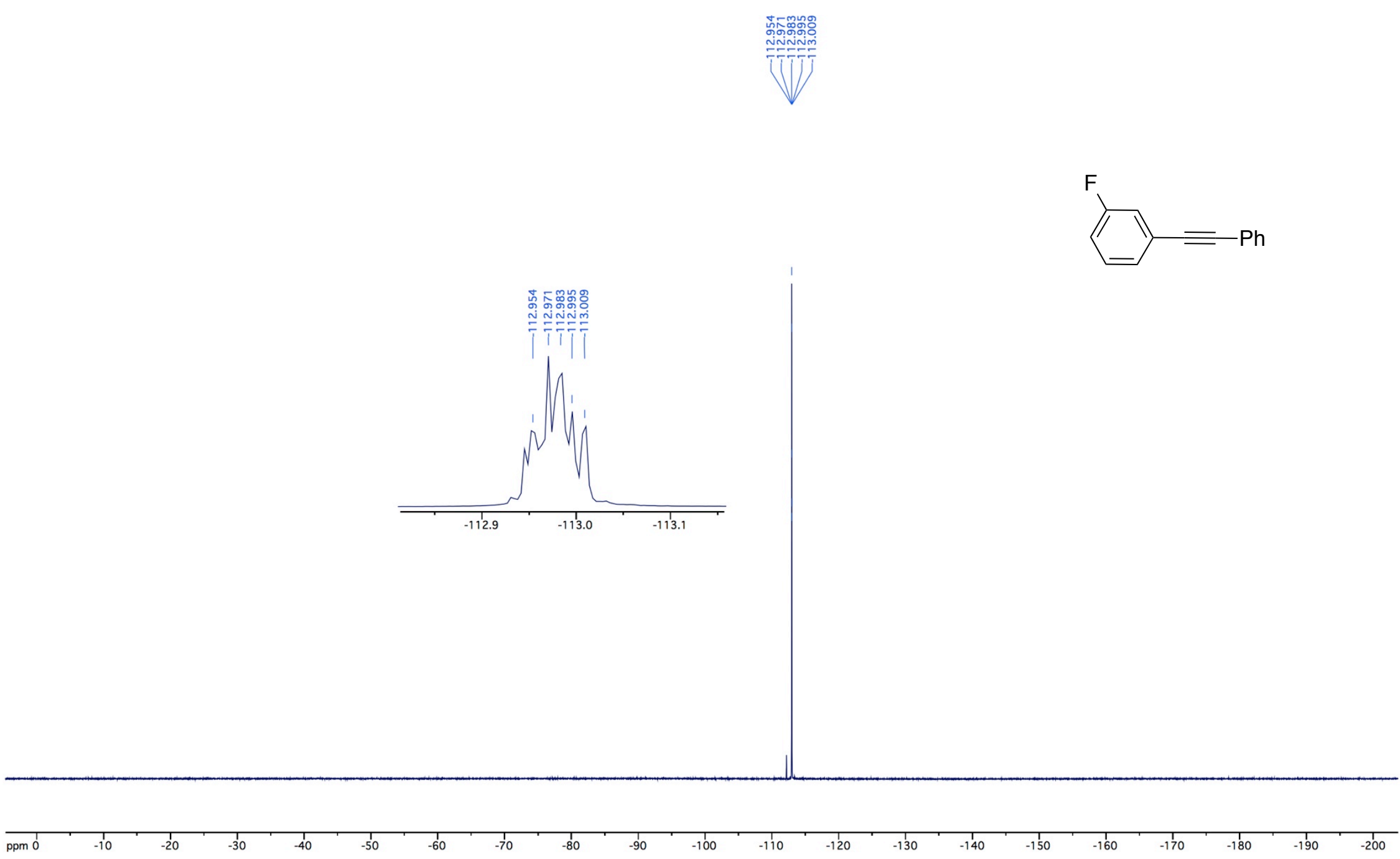


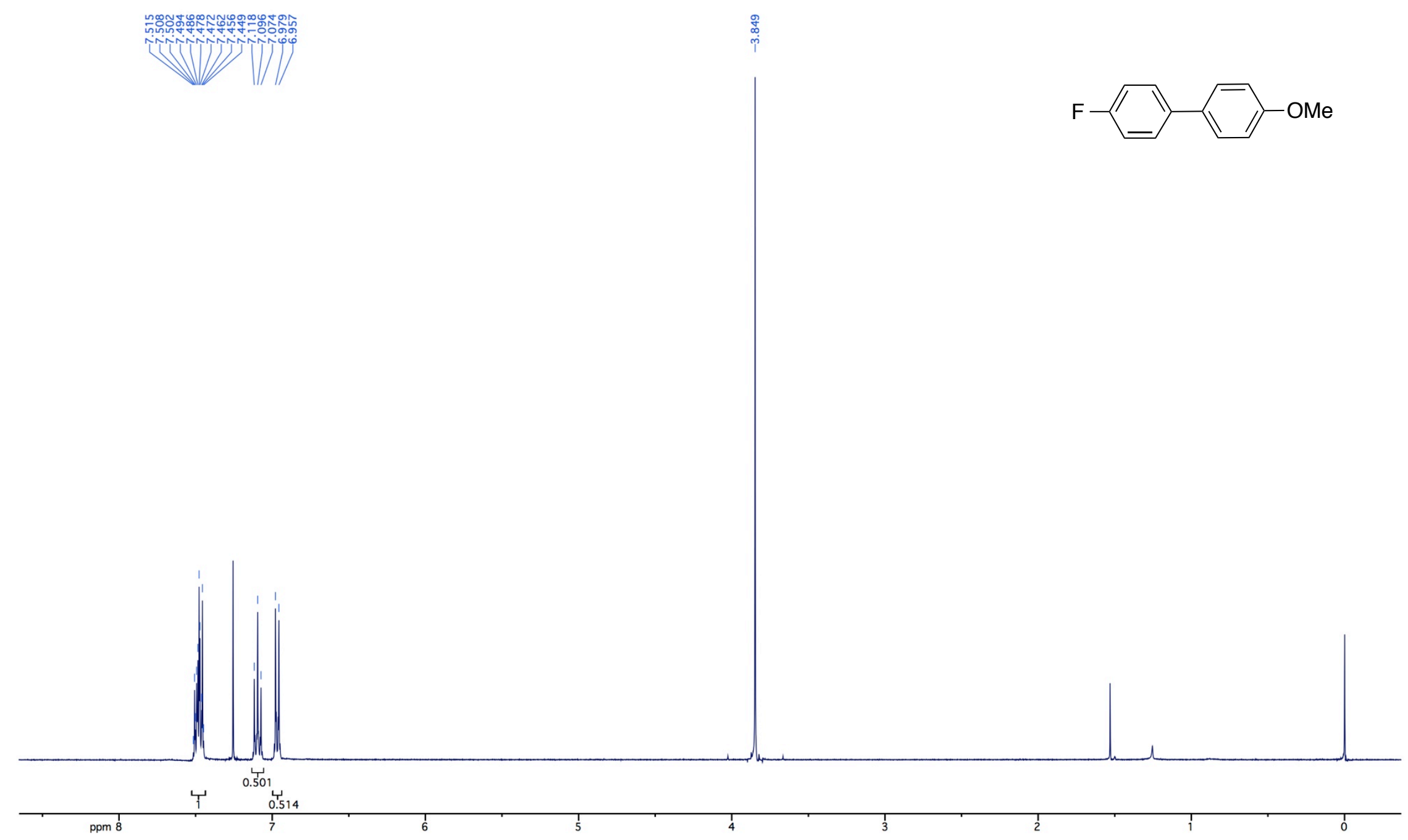




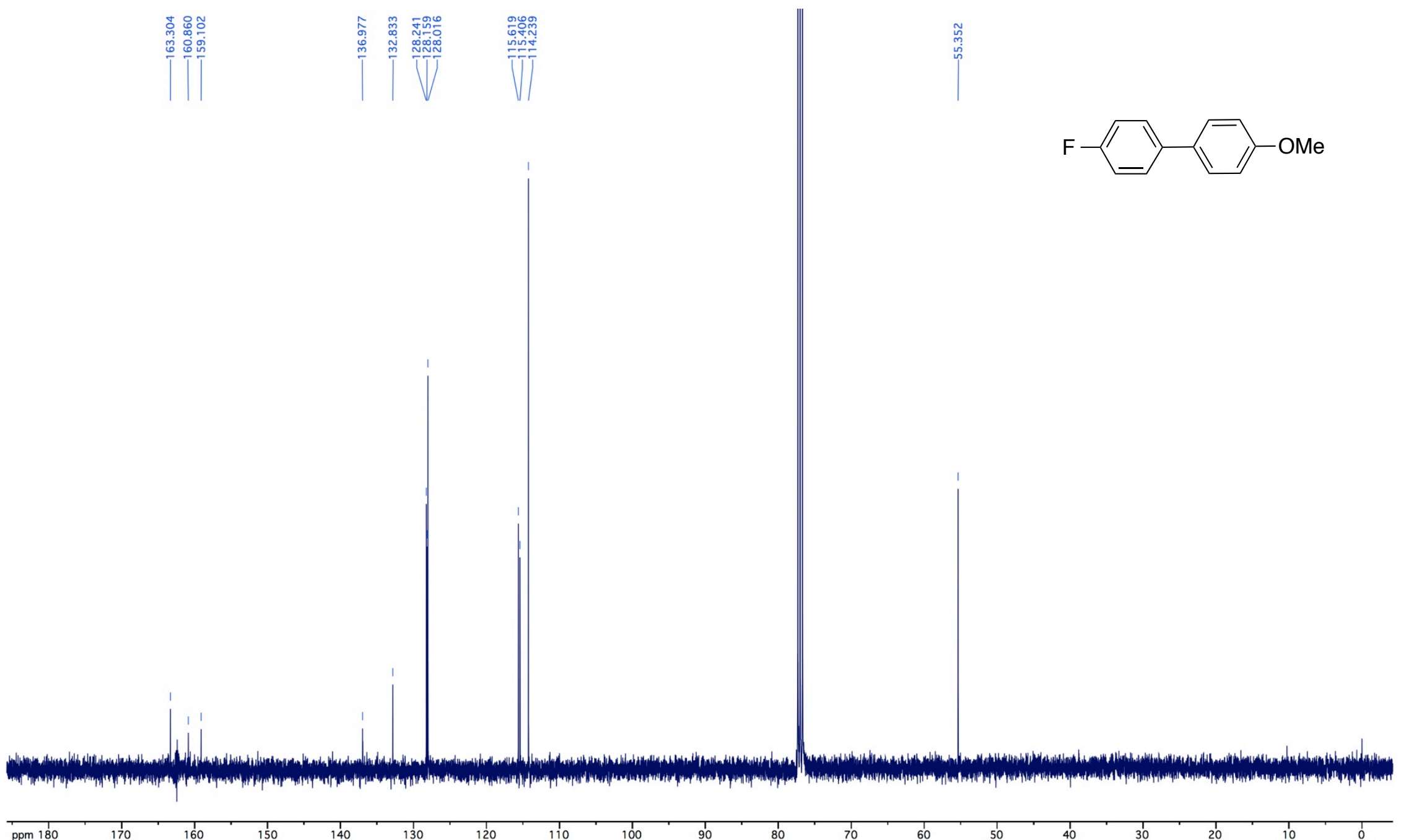




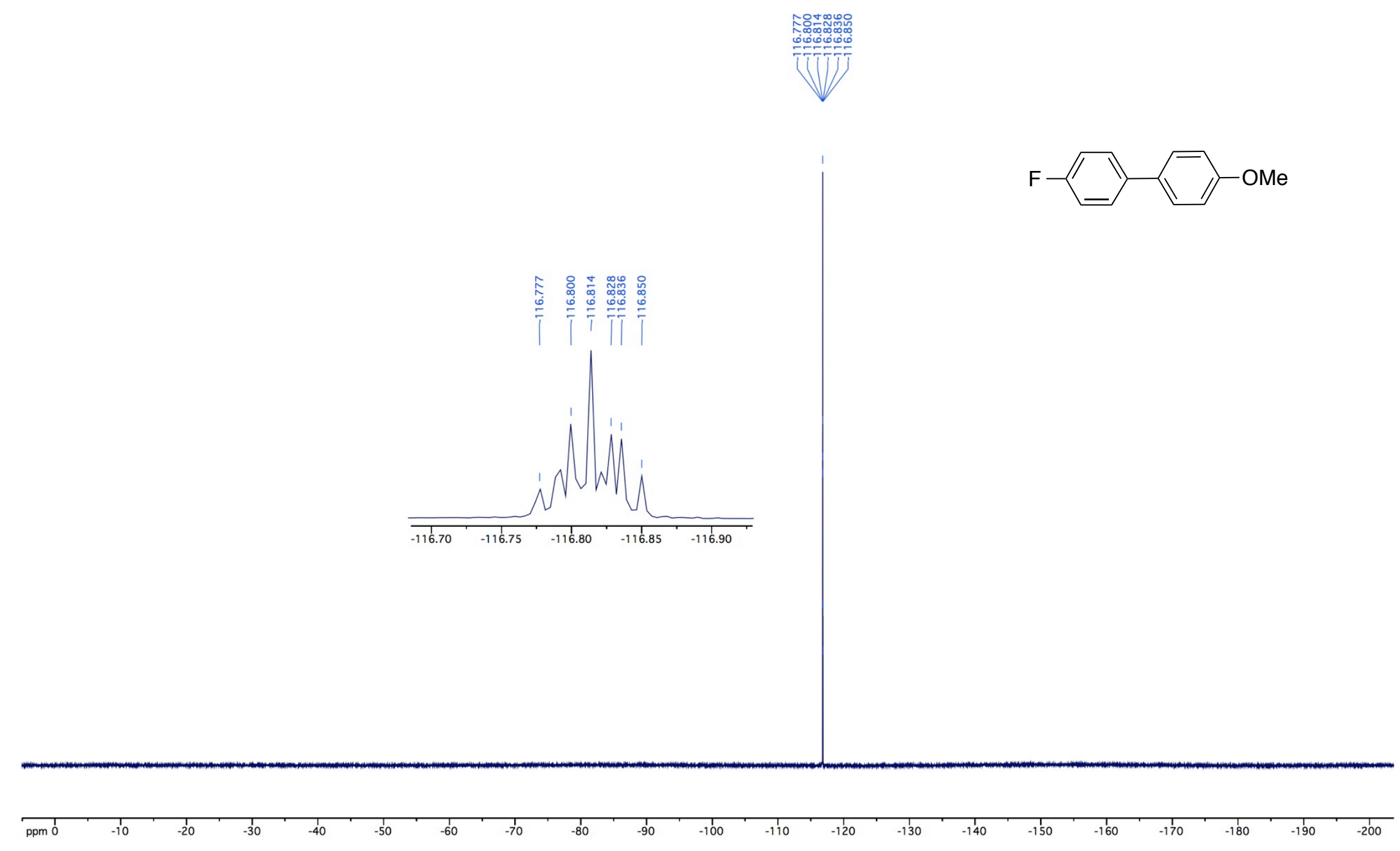




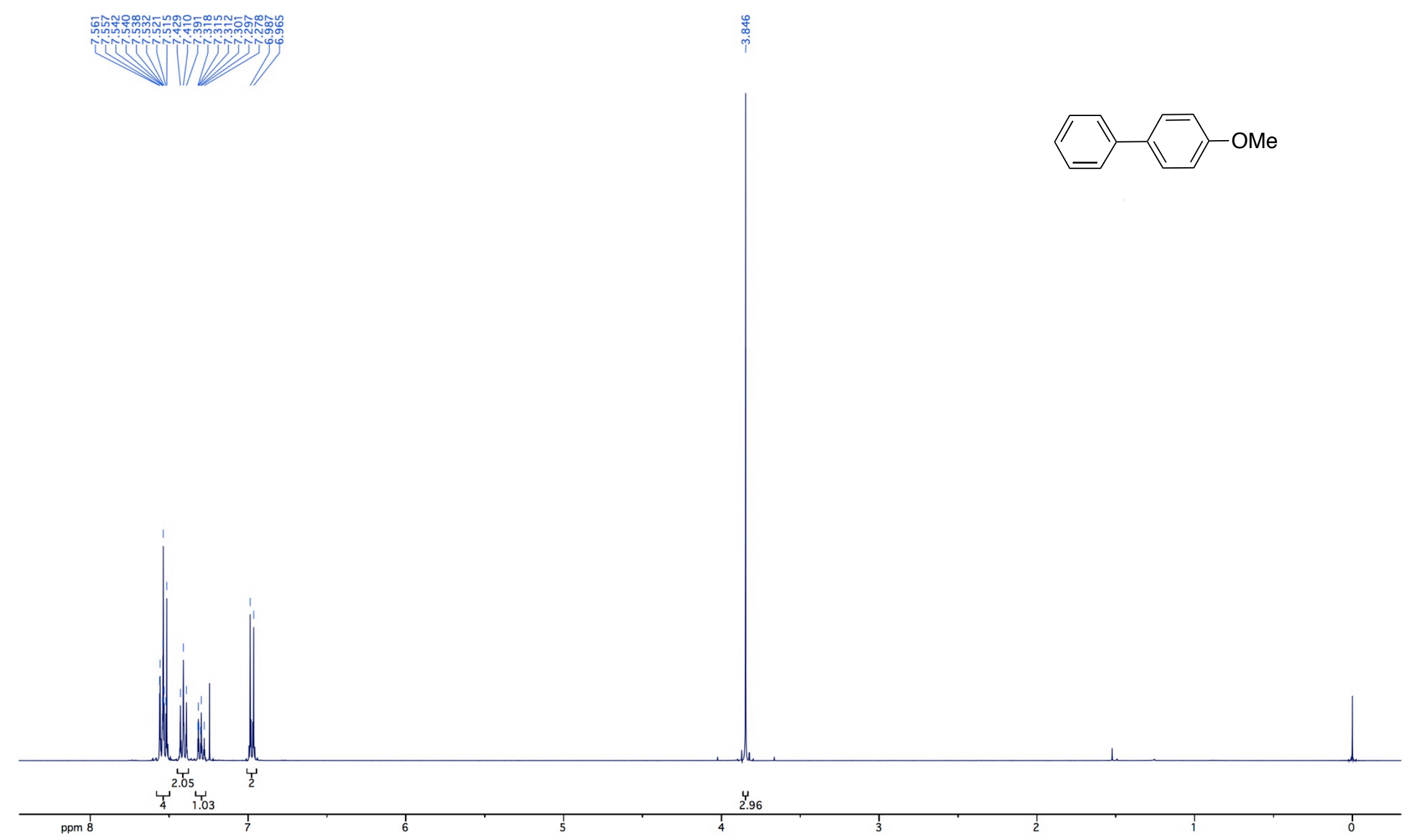




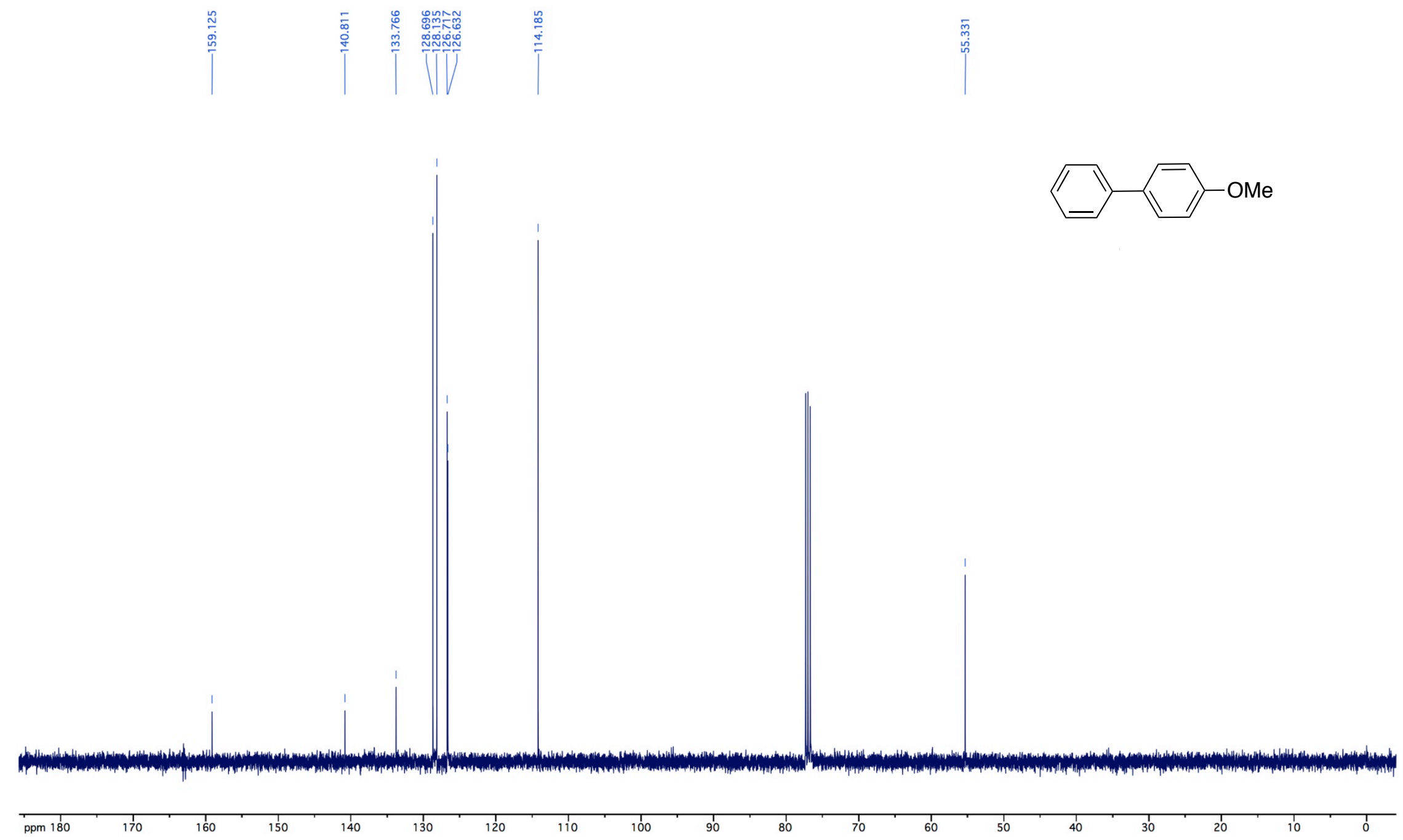




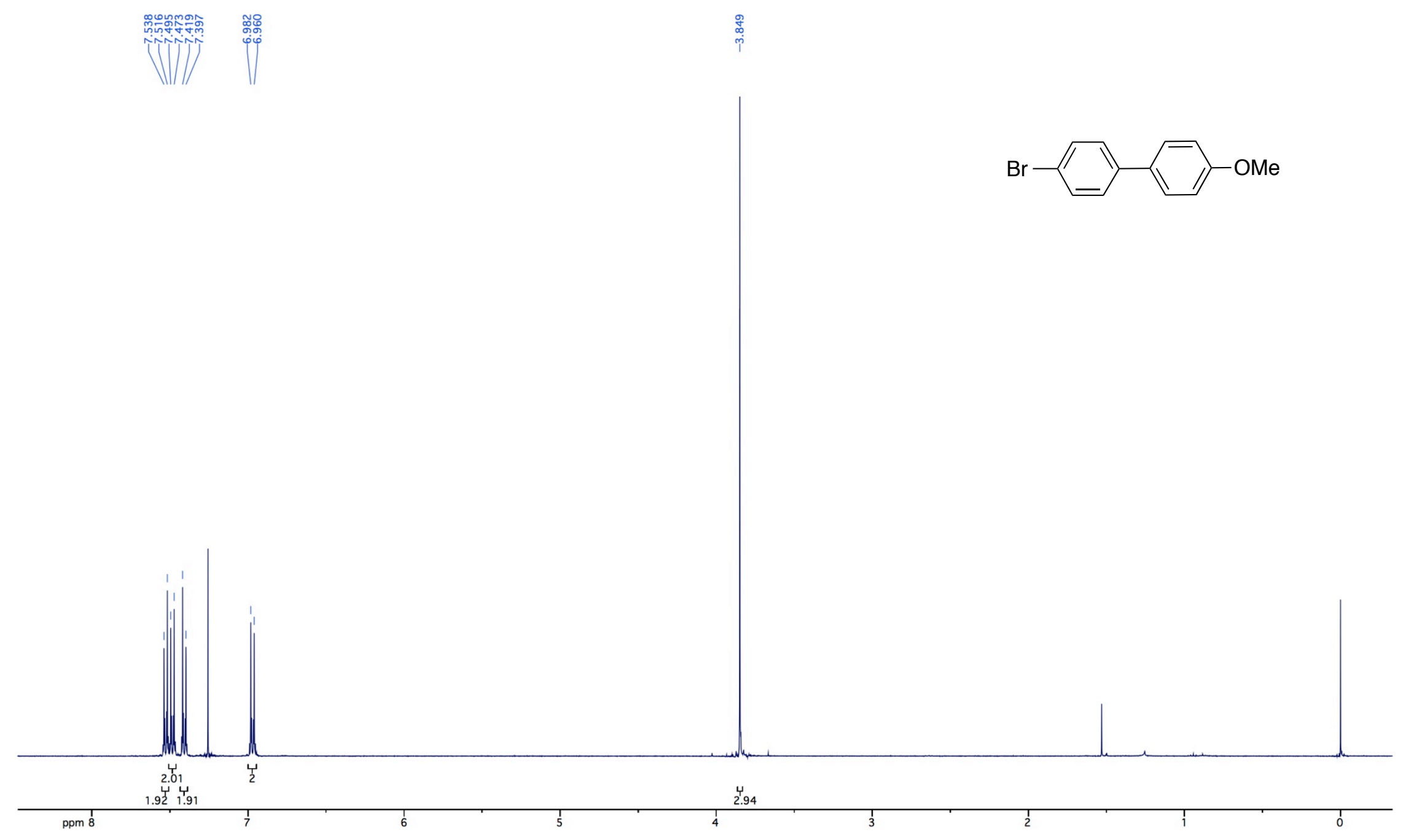




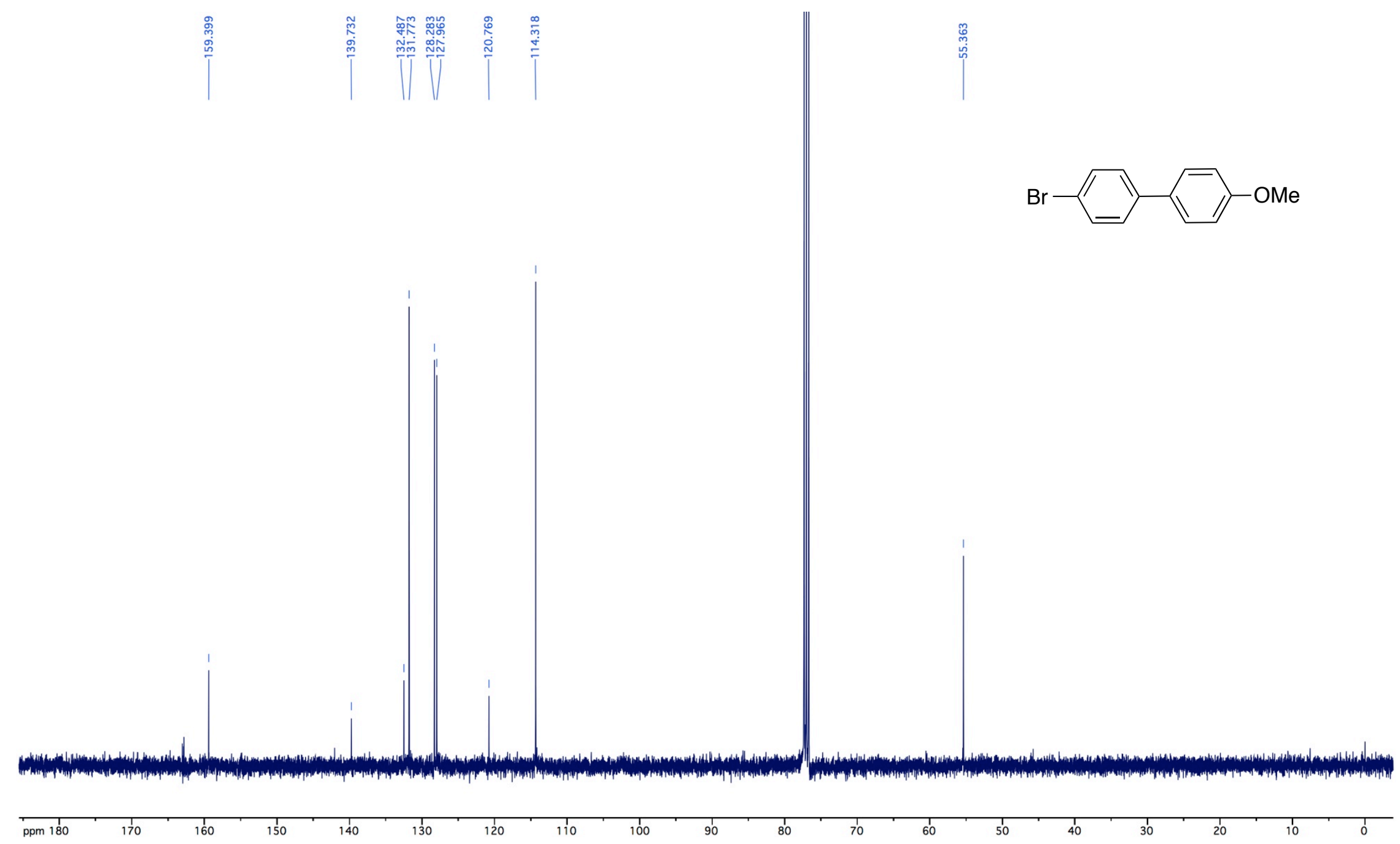




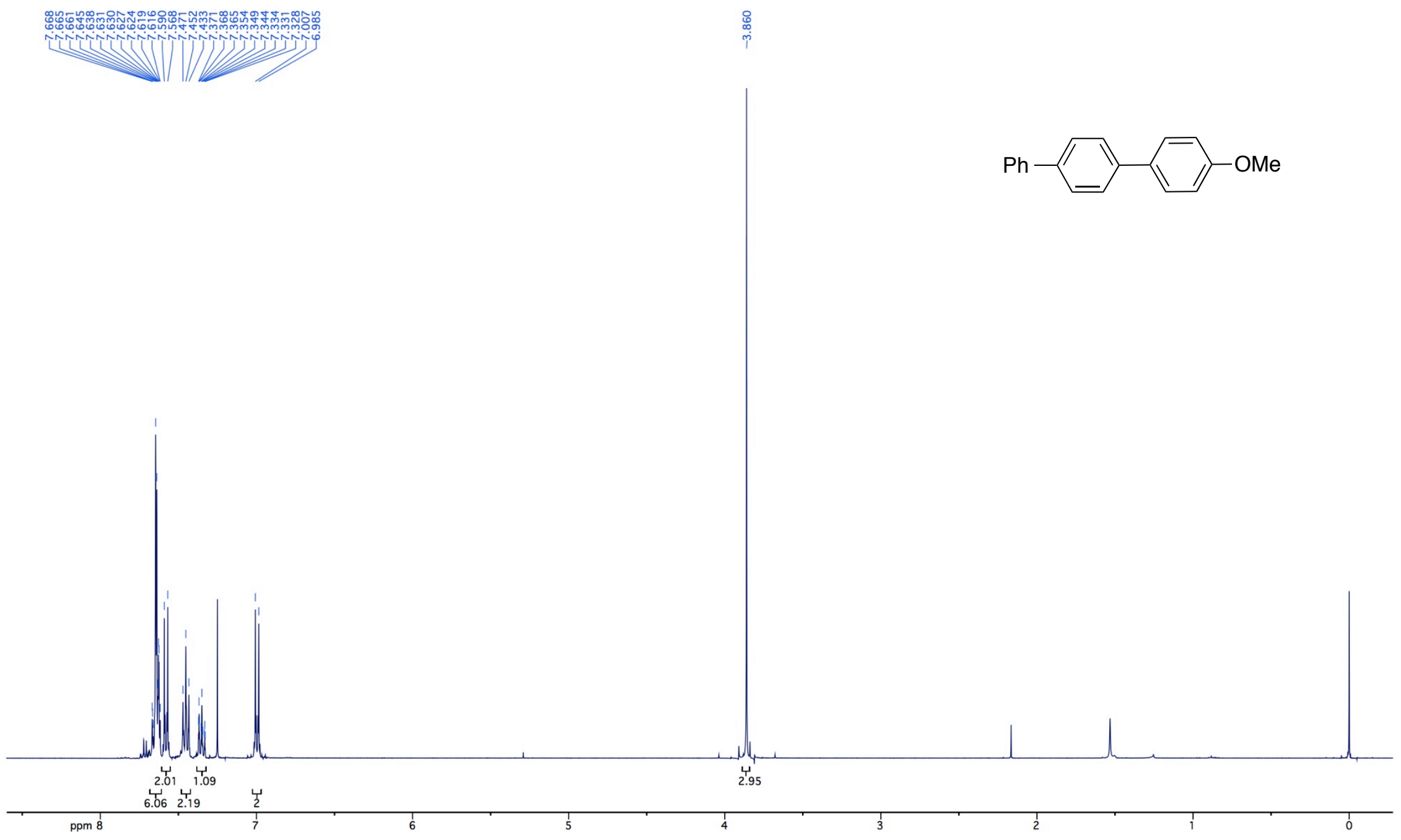




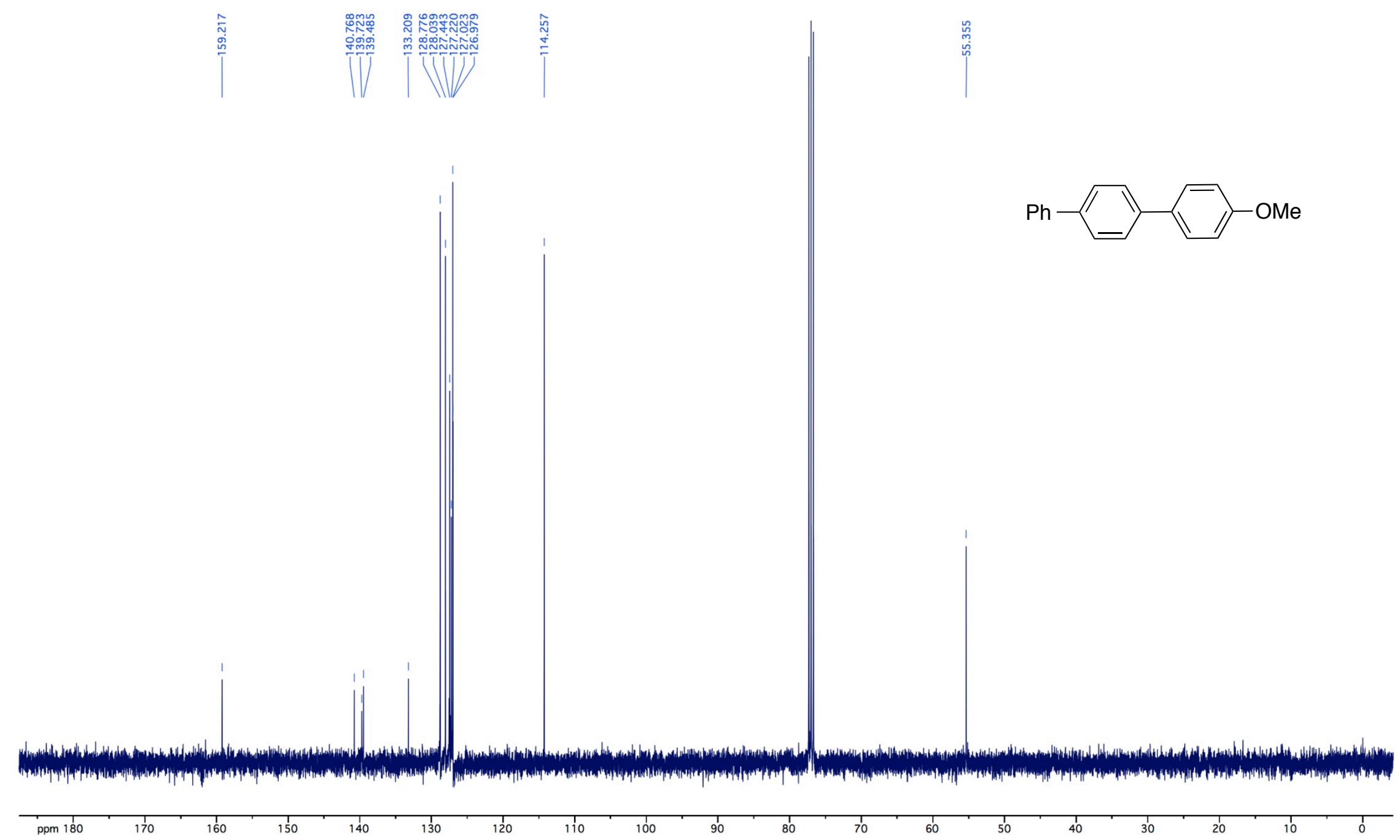




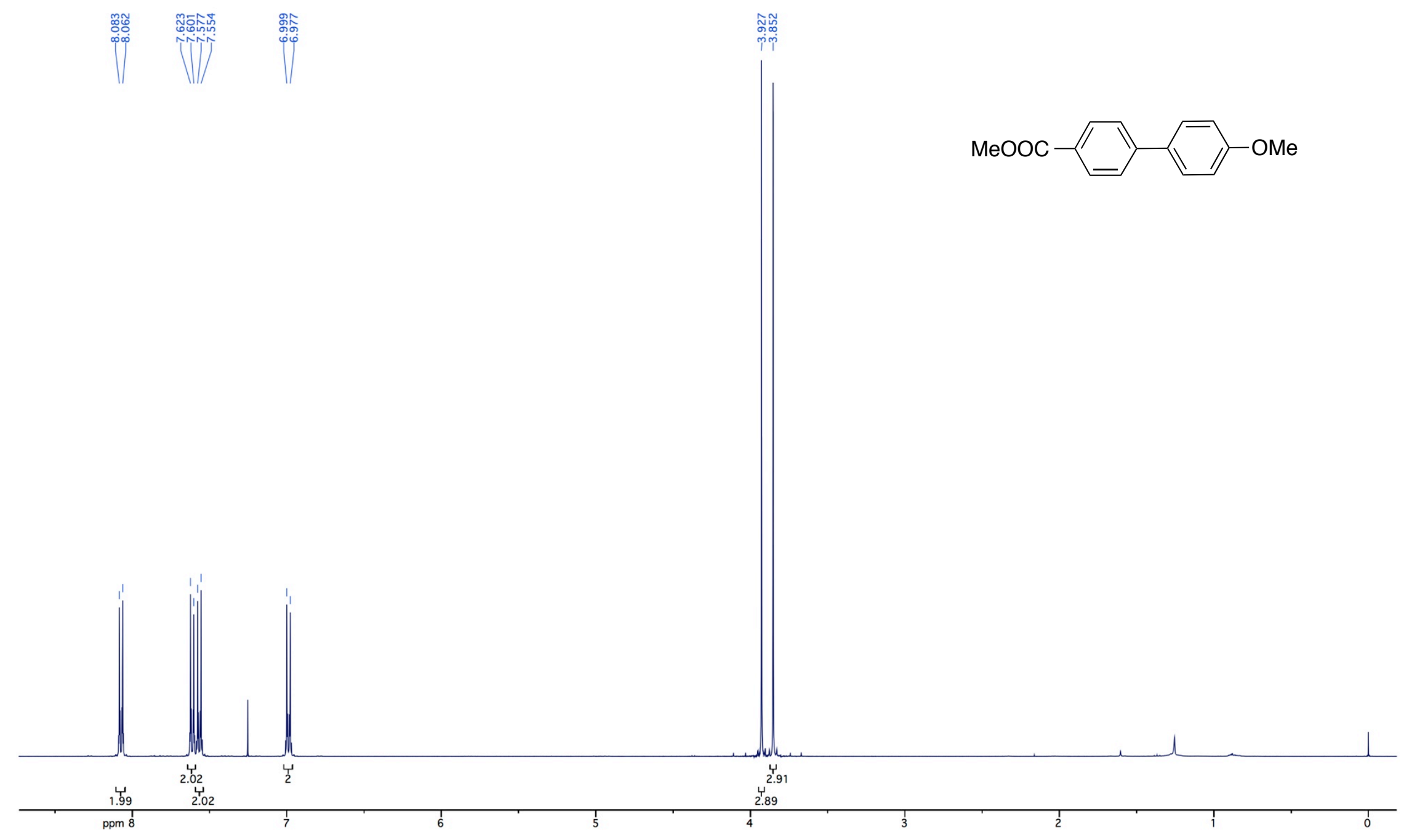



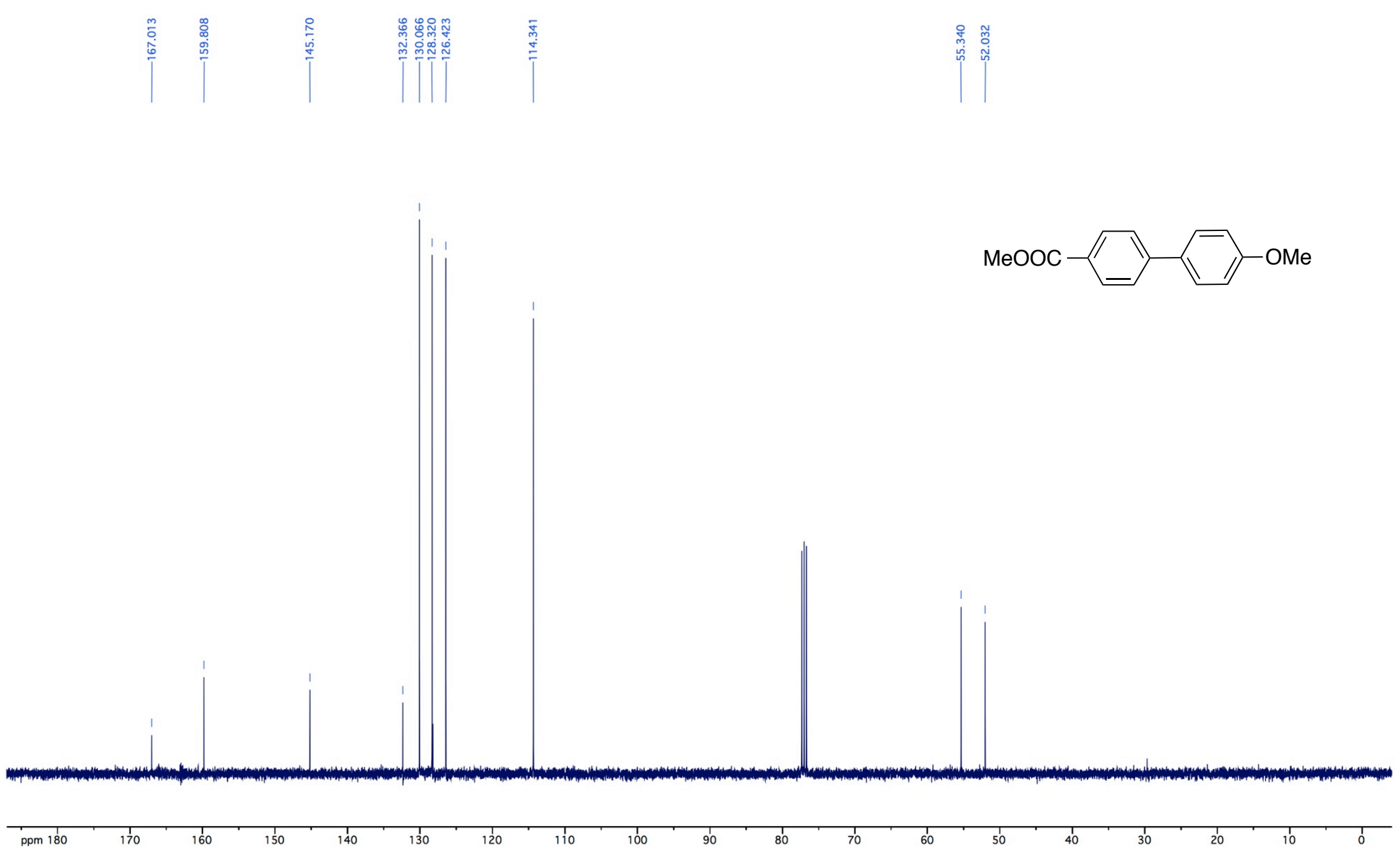


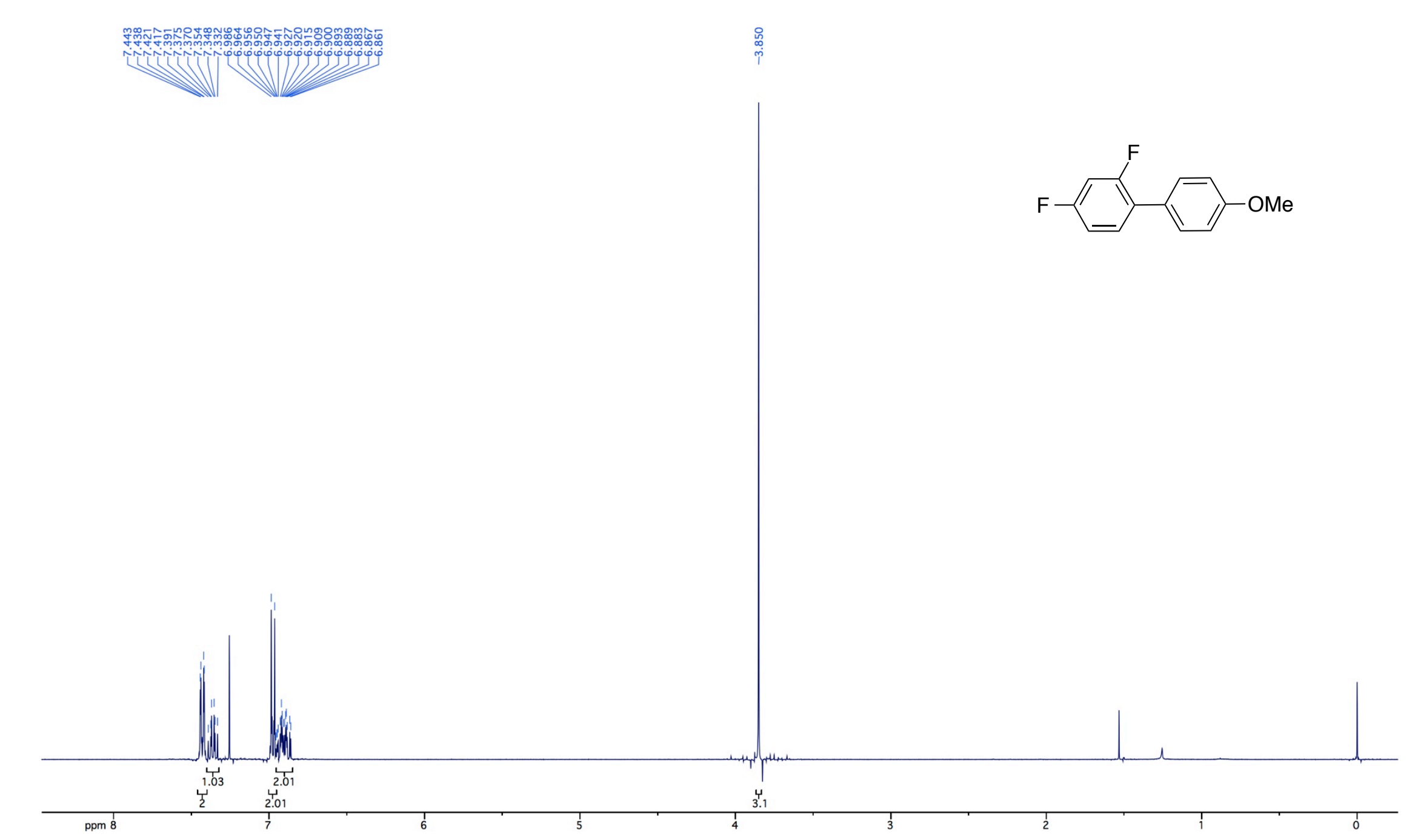




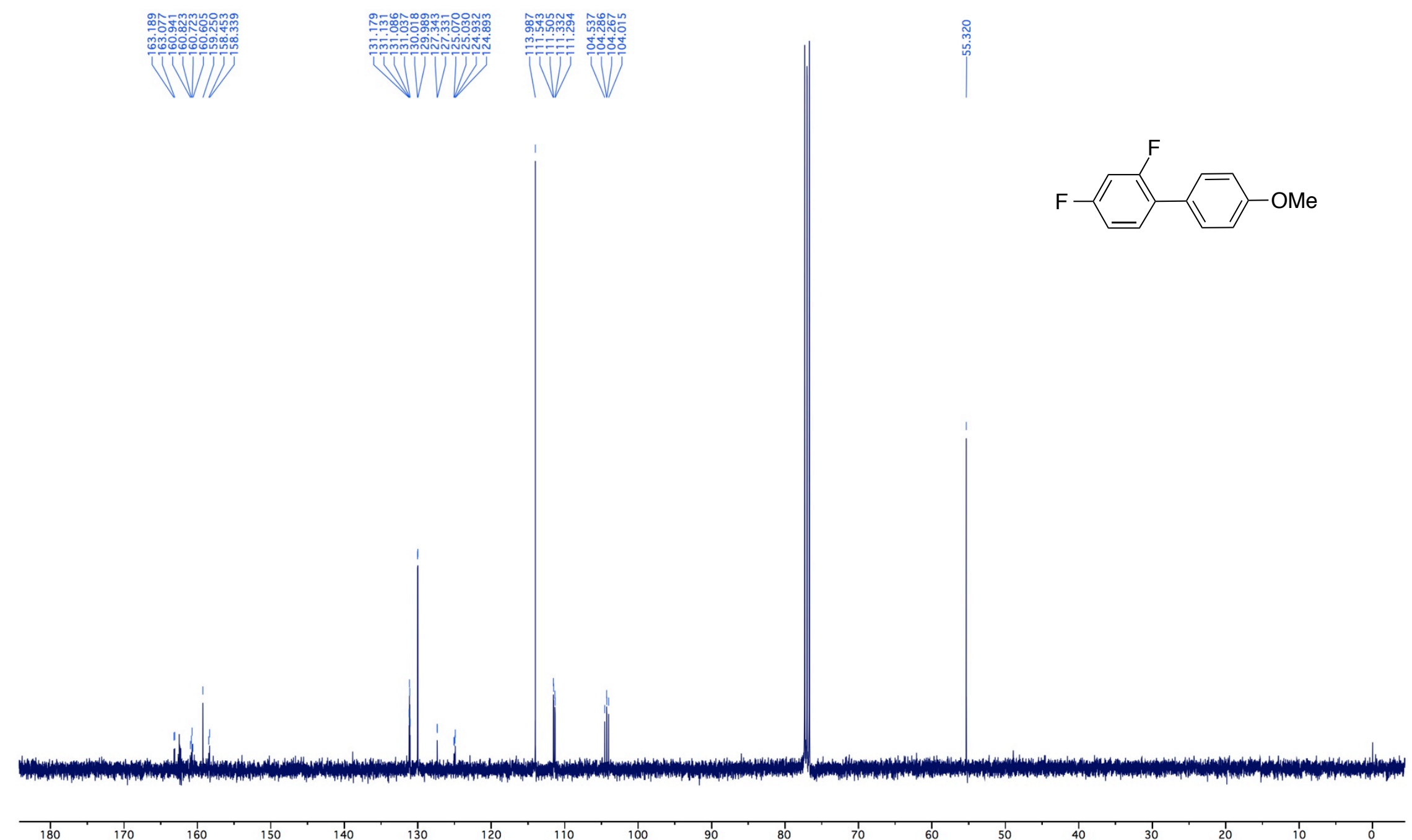




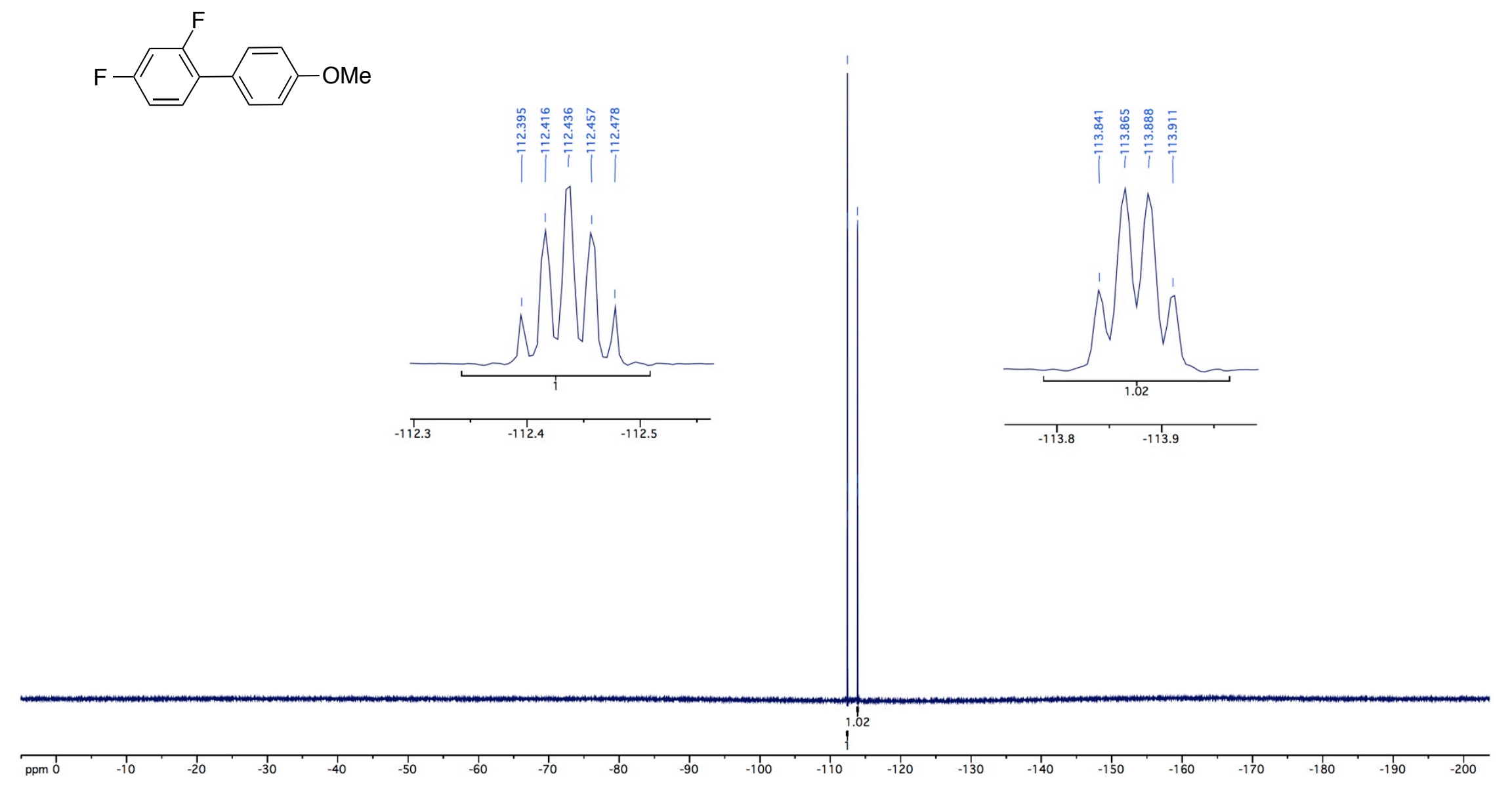




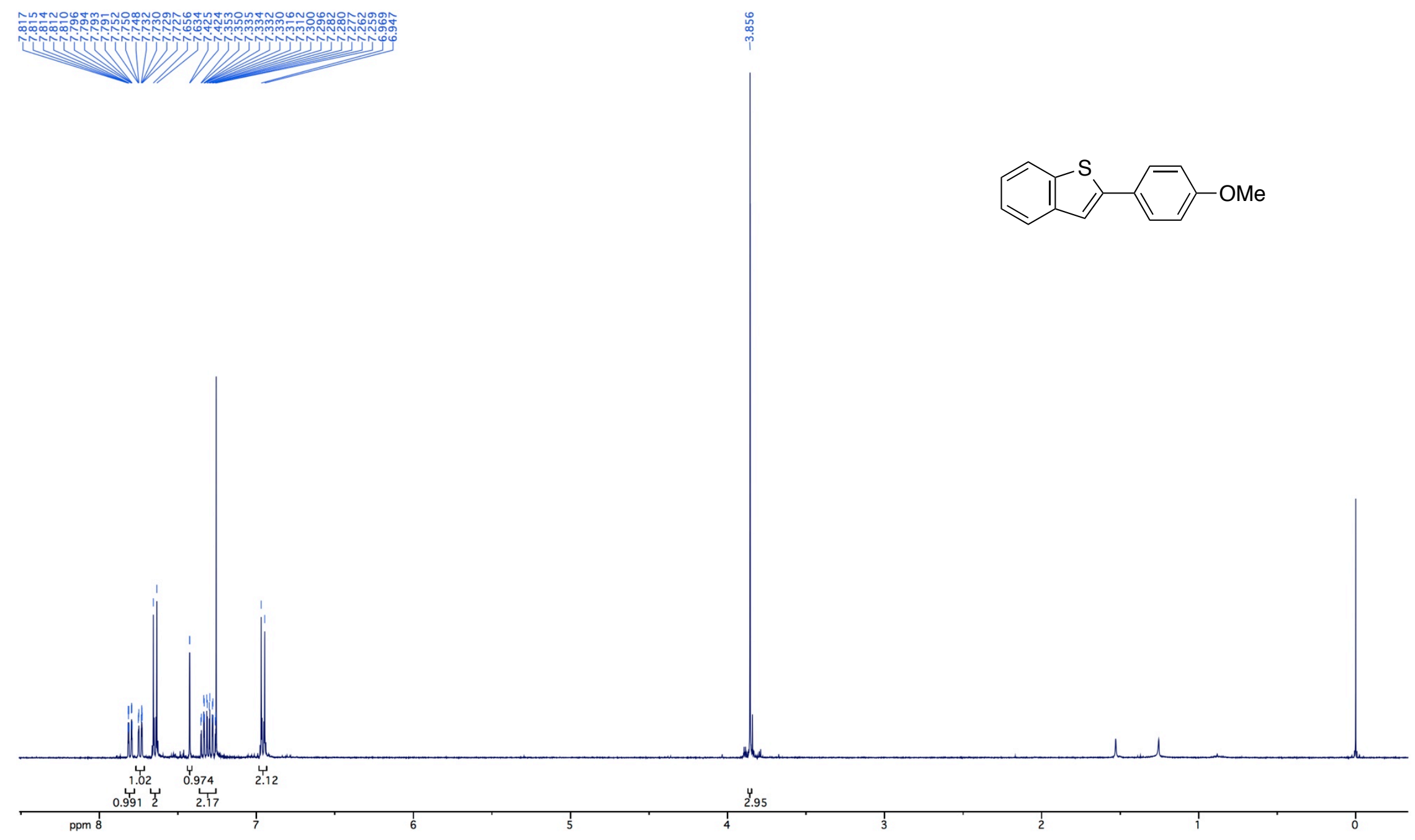




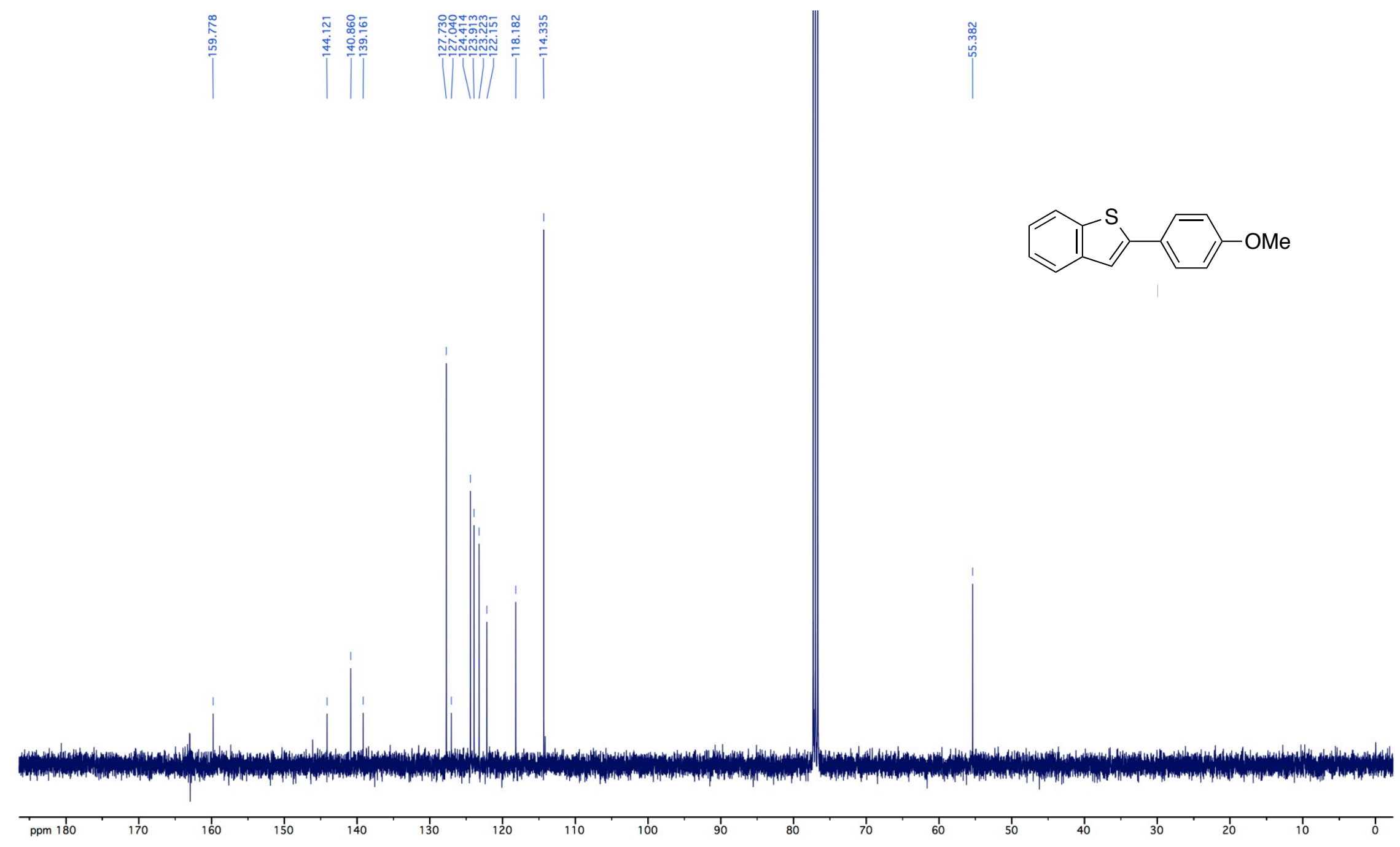




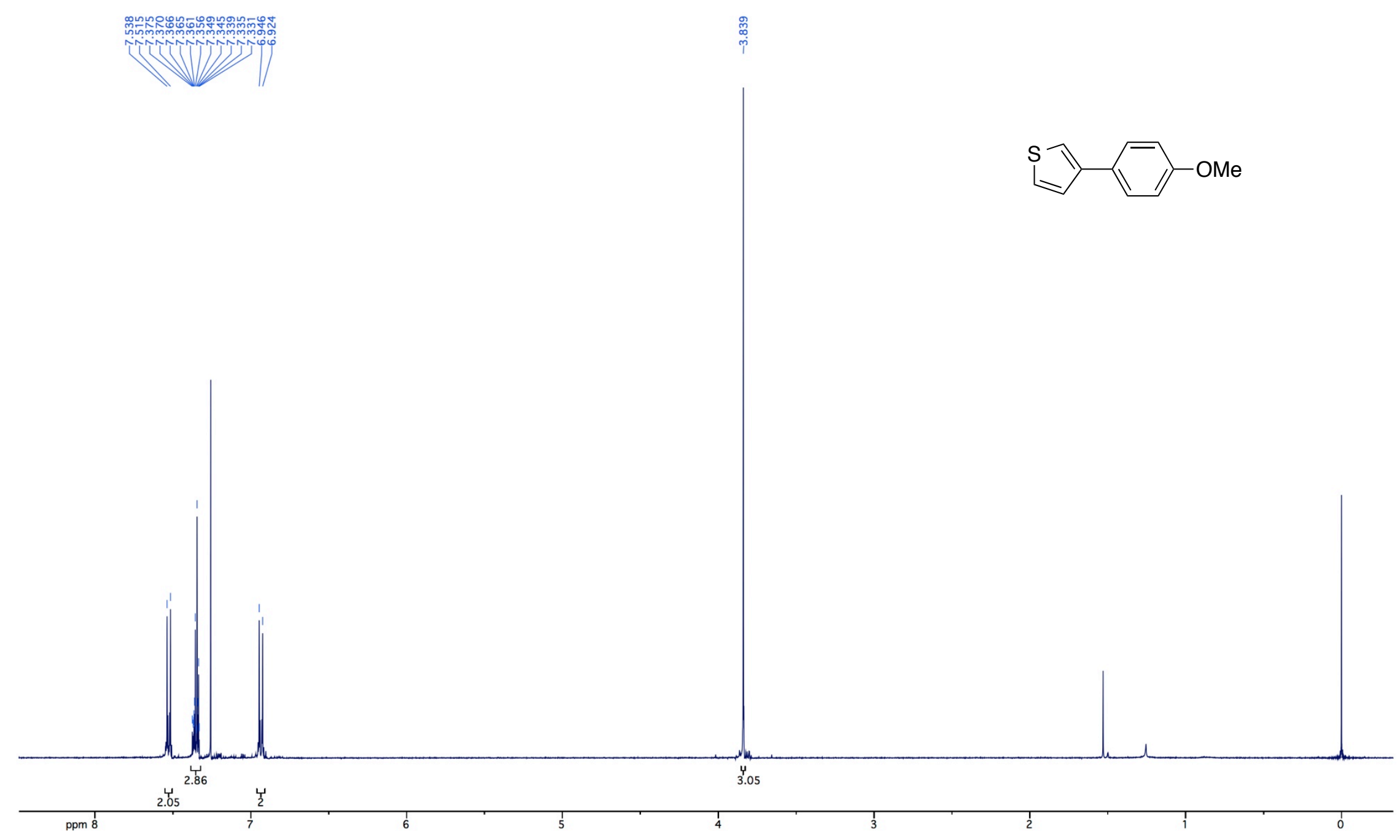




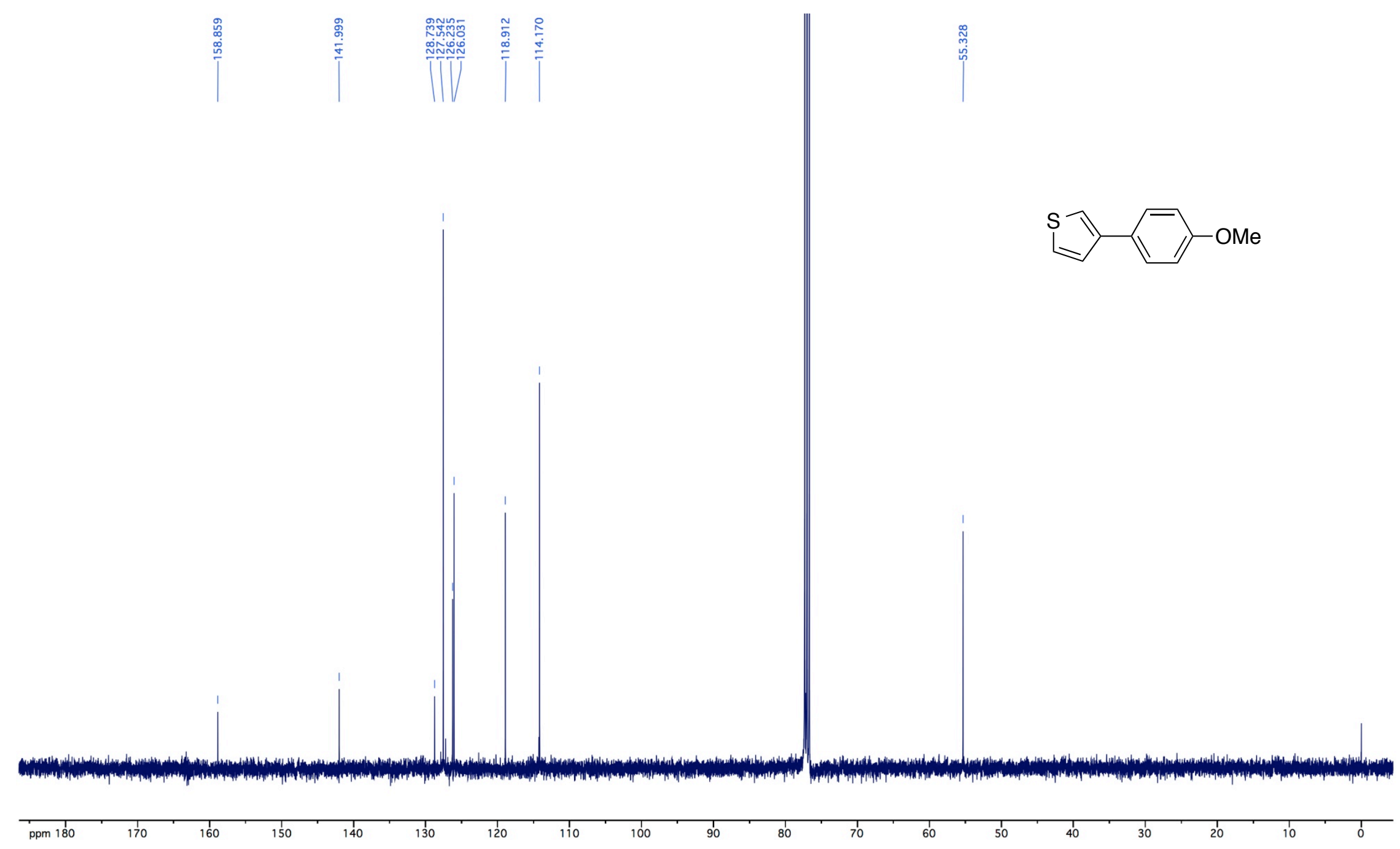




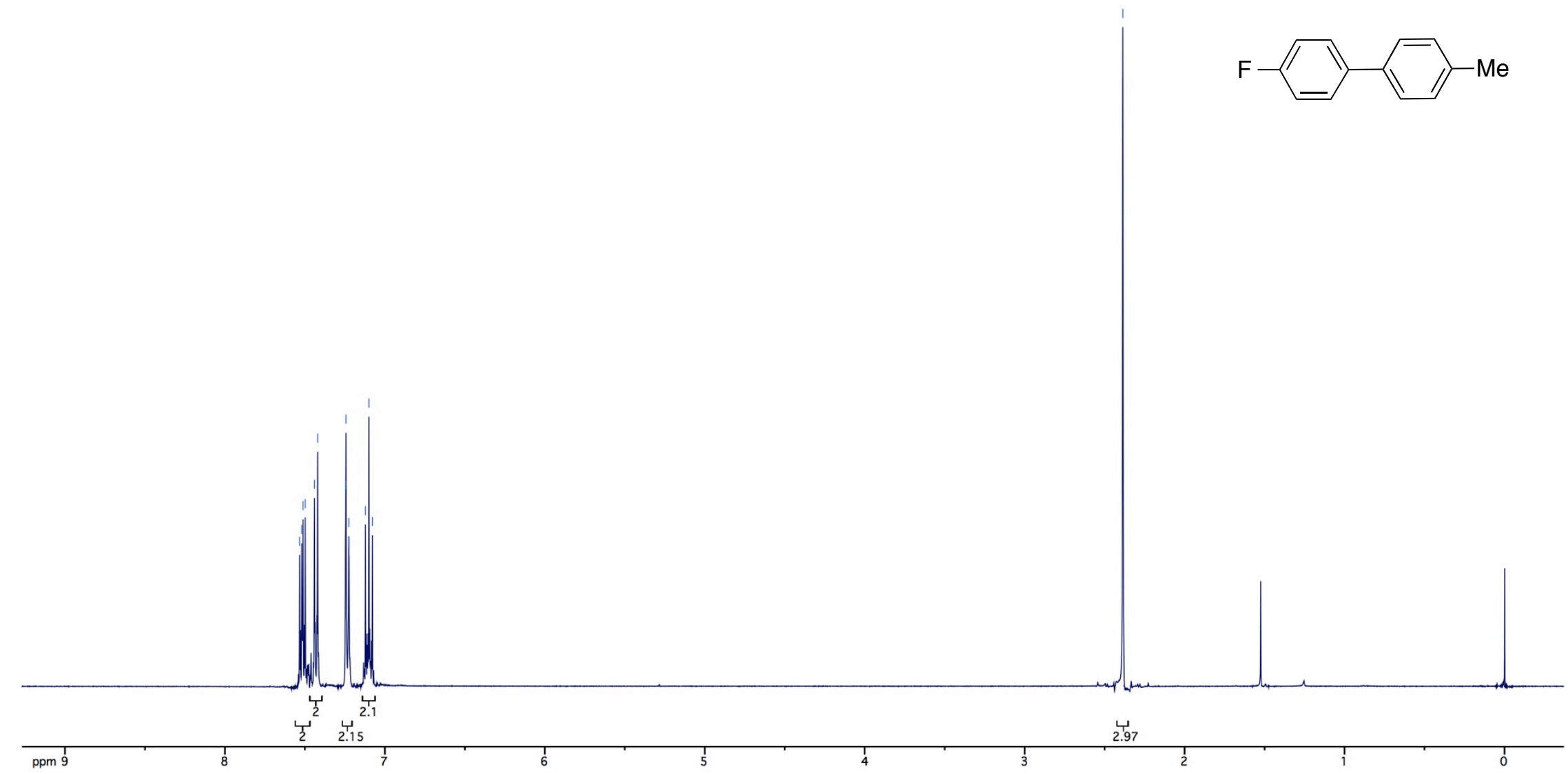



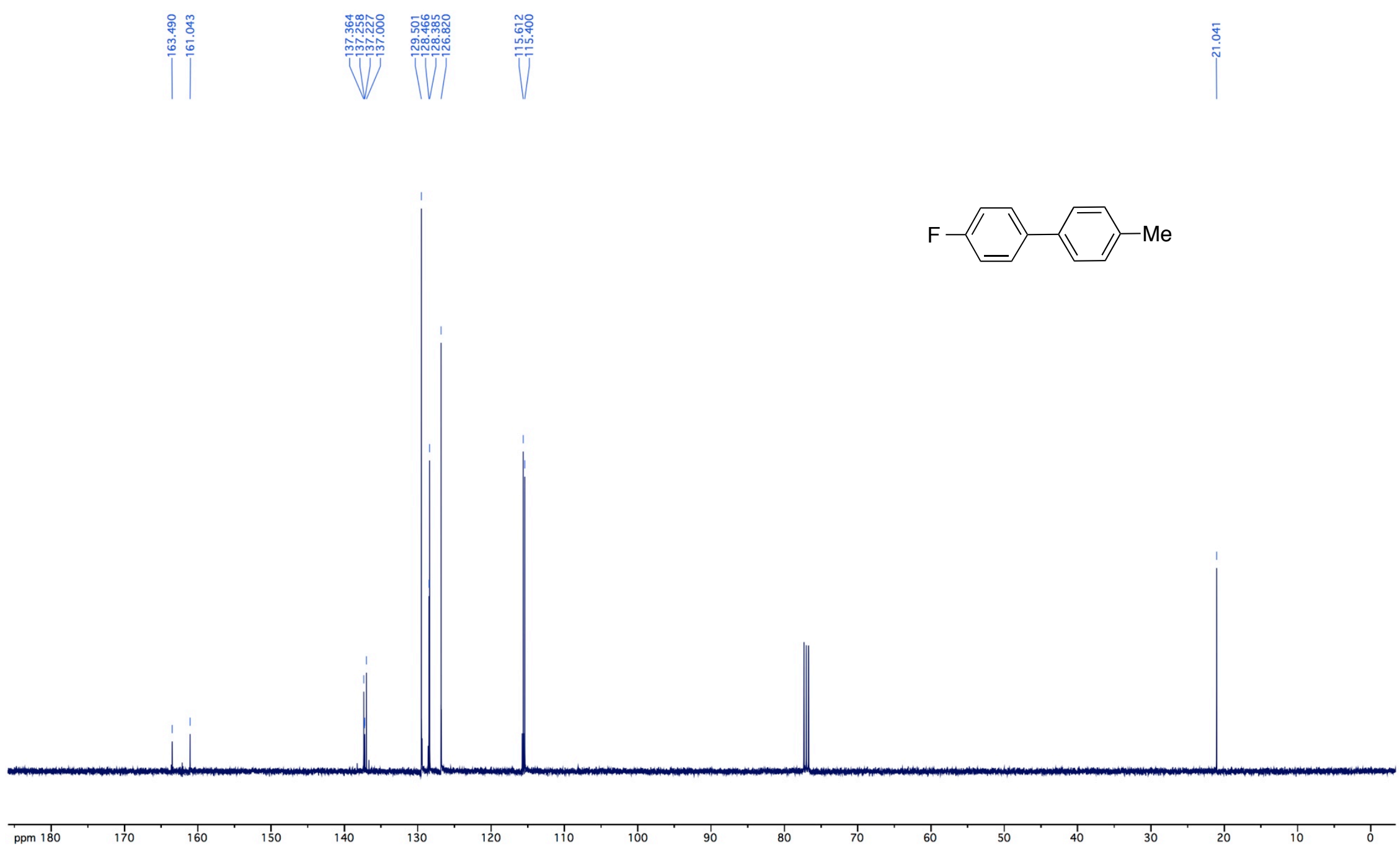

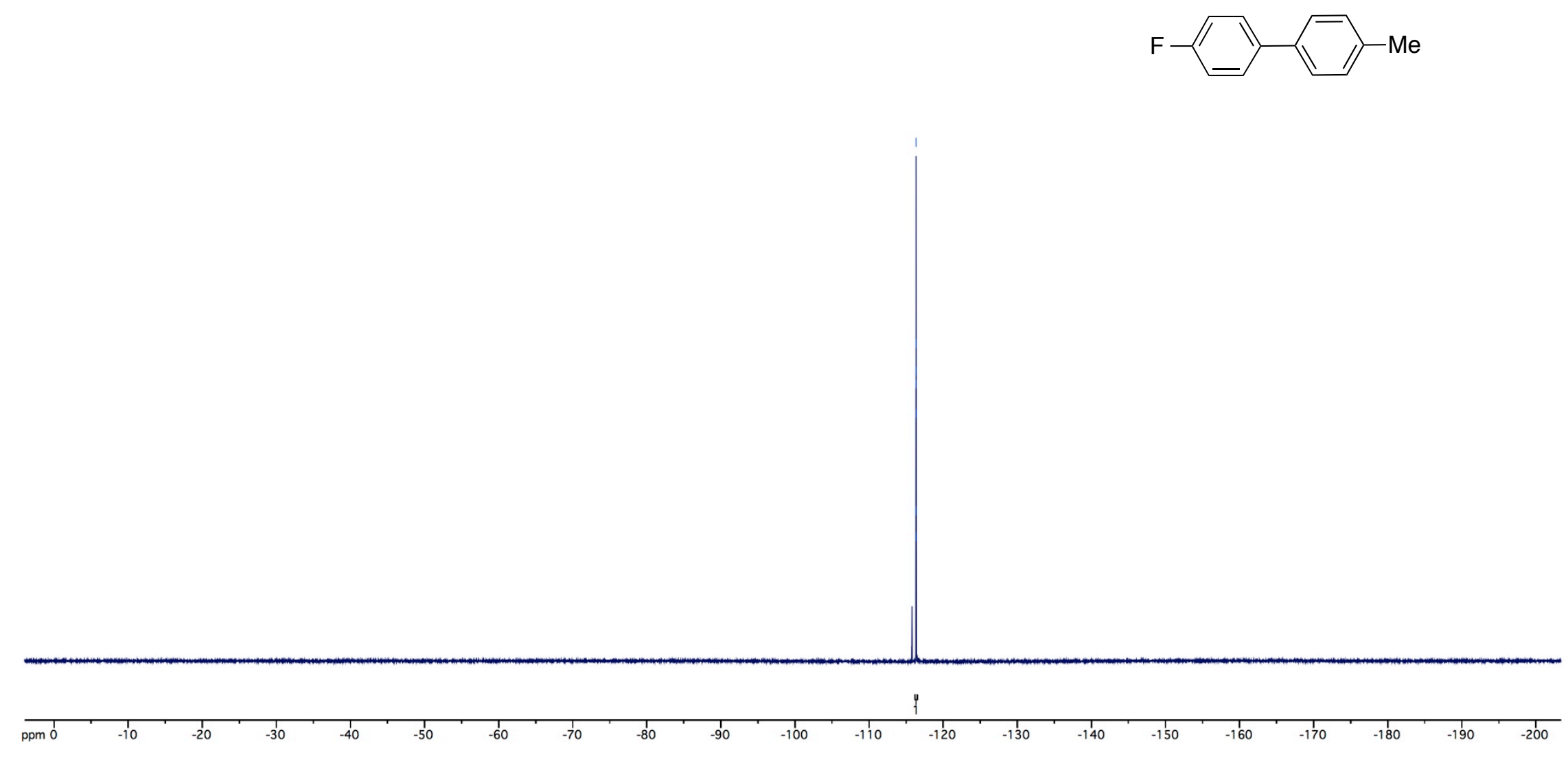


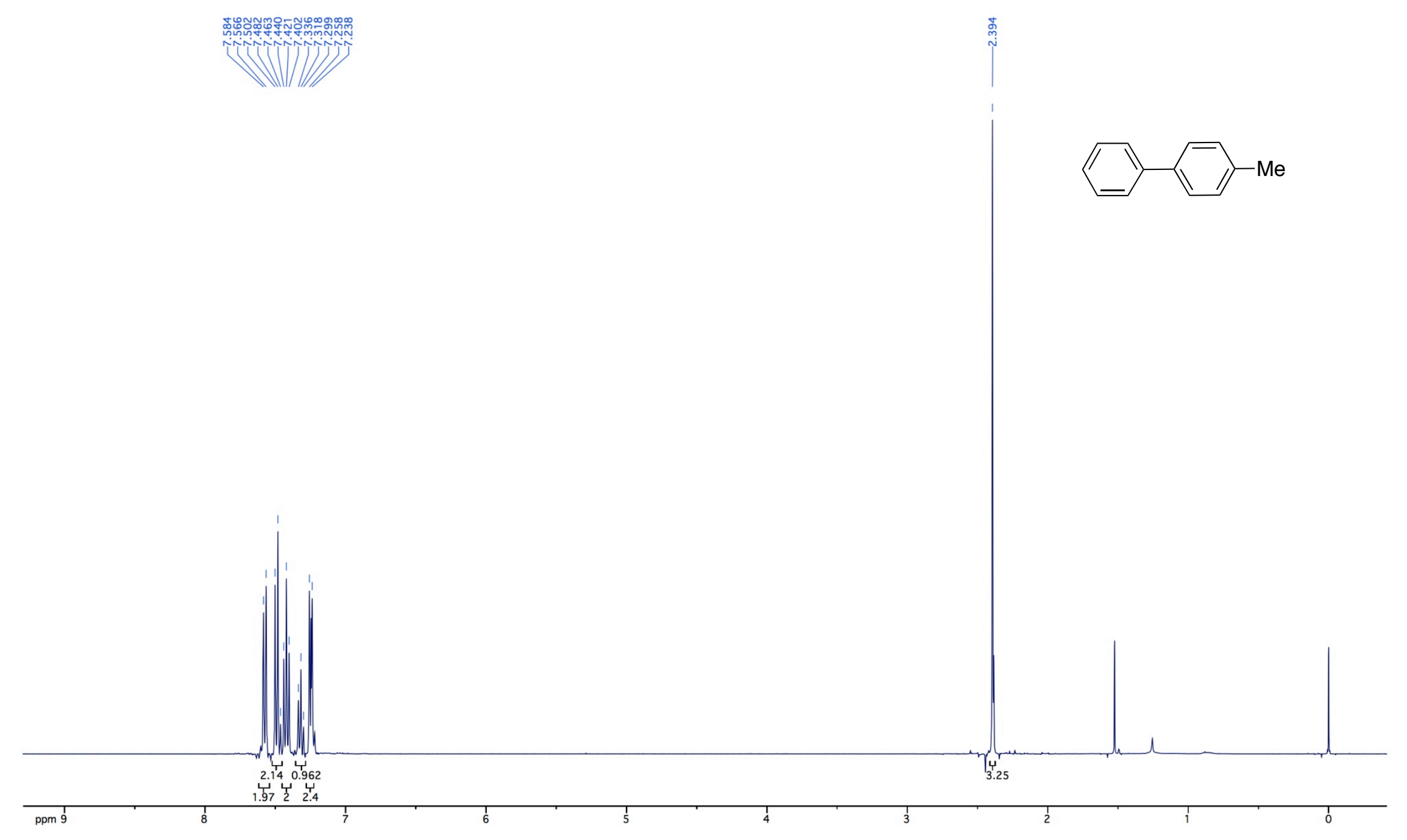

S298 

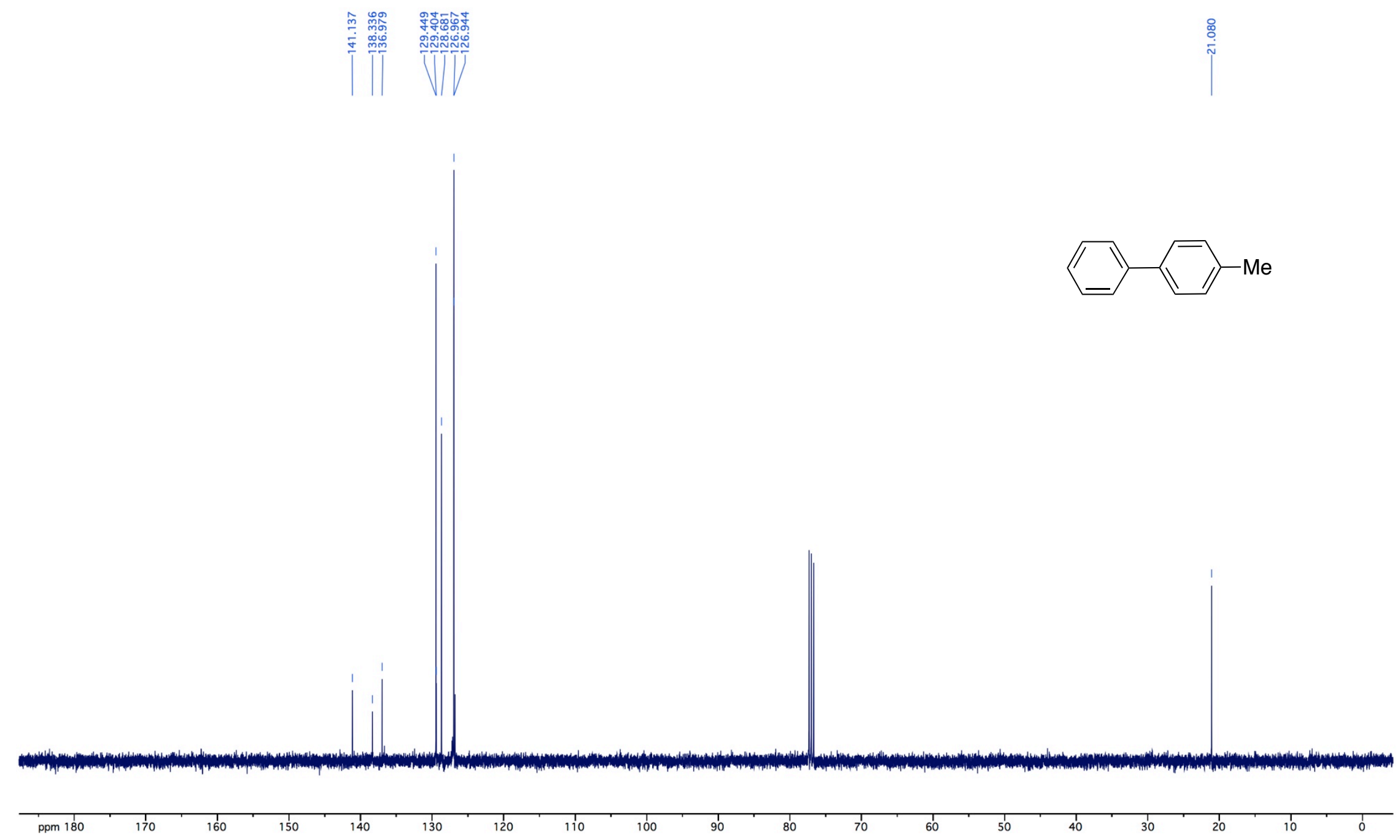


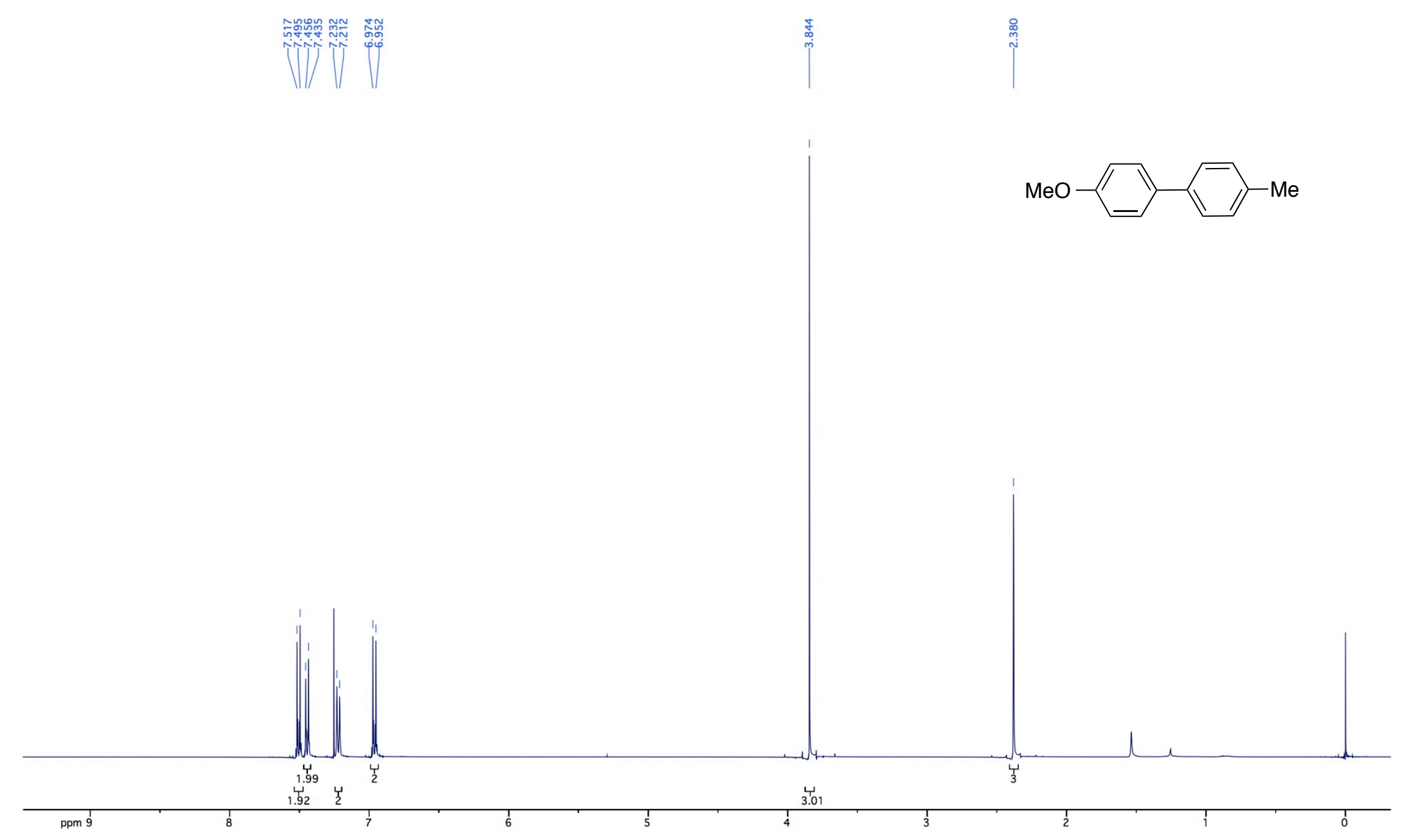



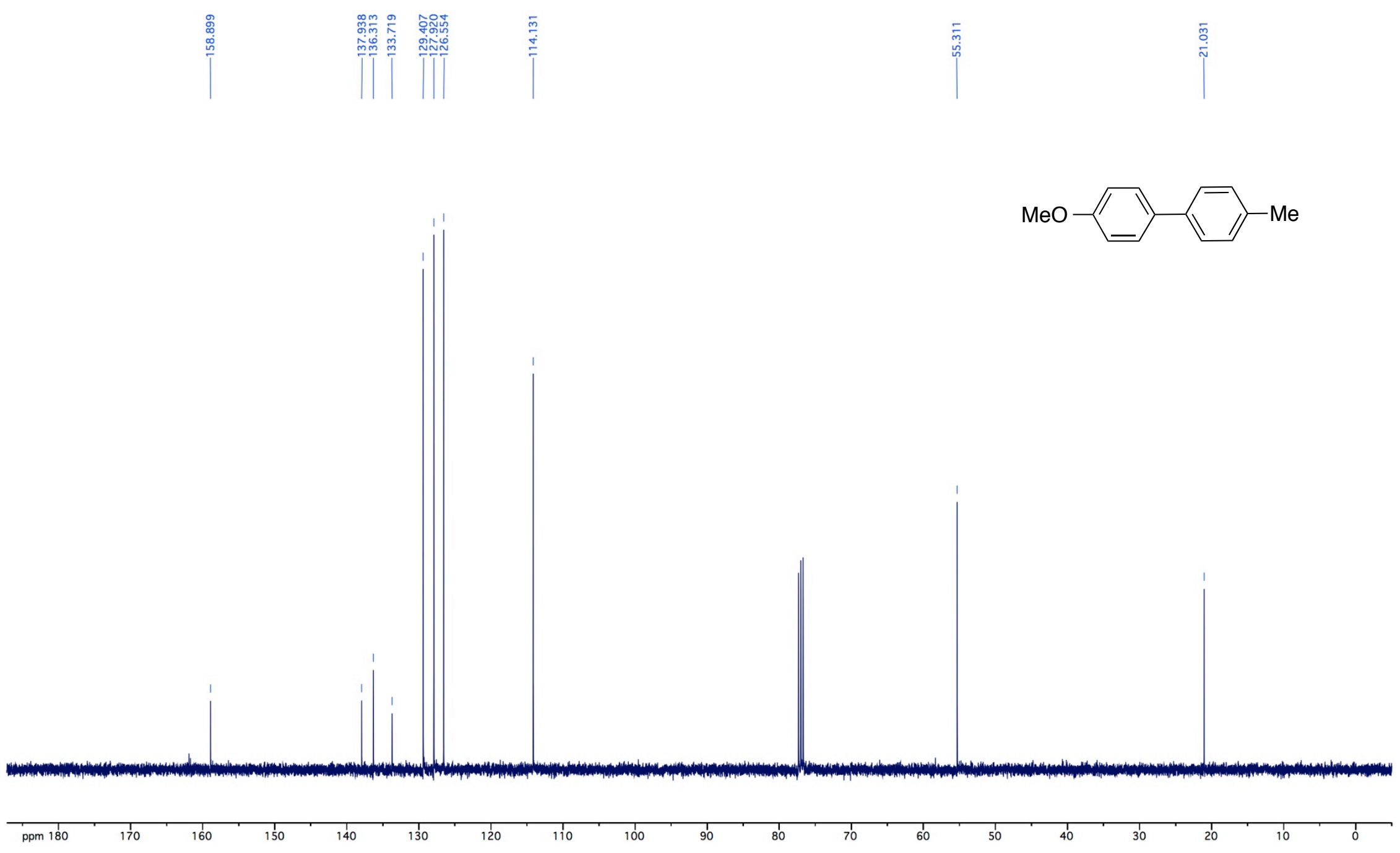


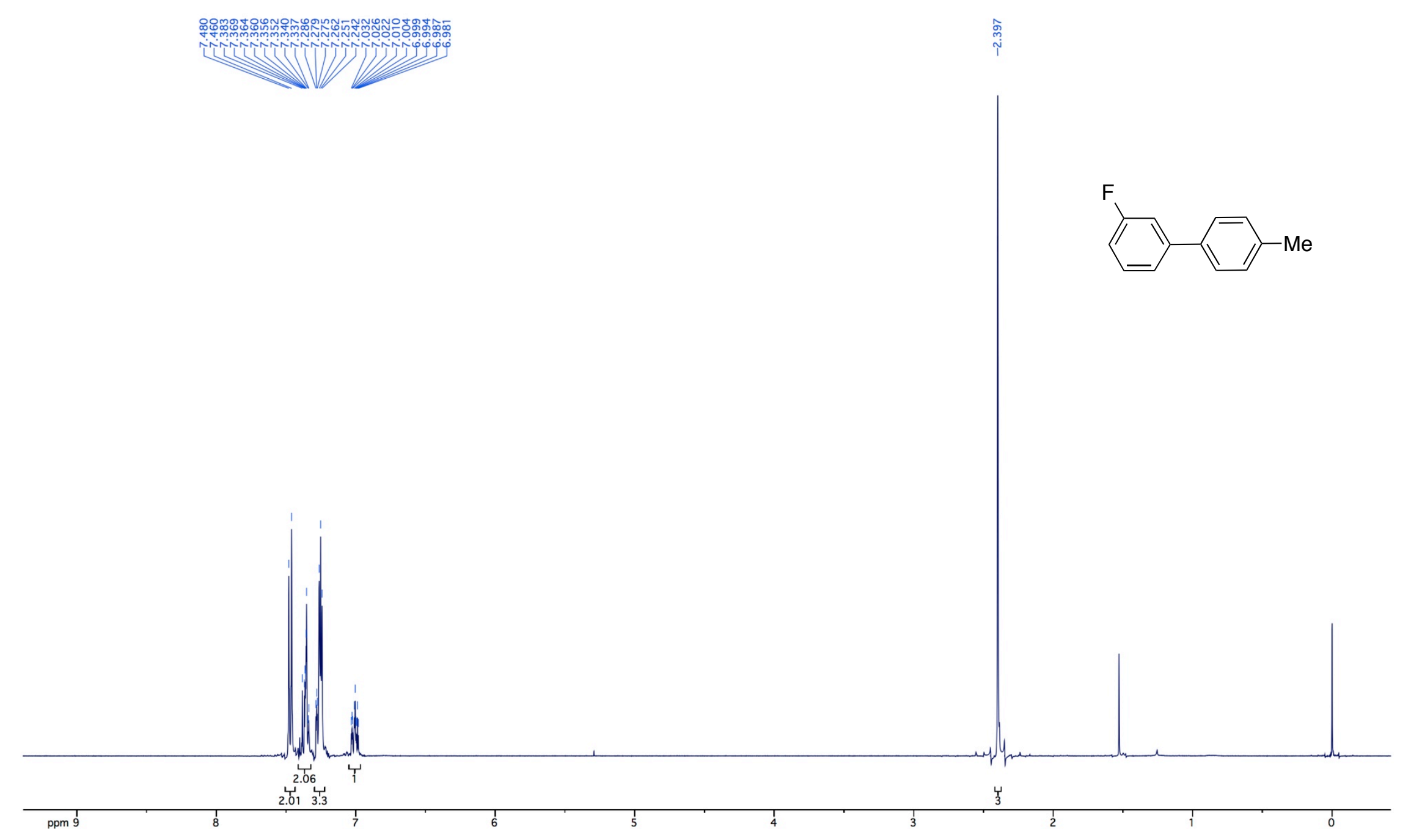



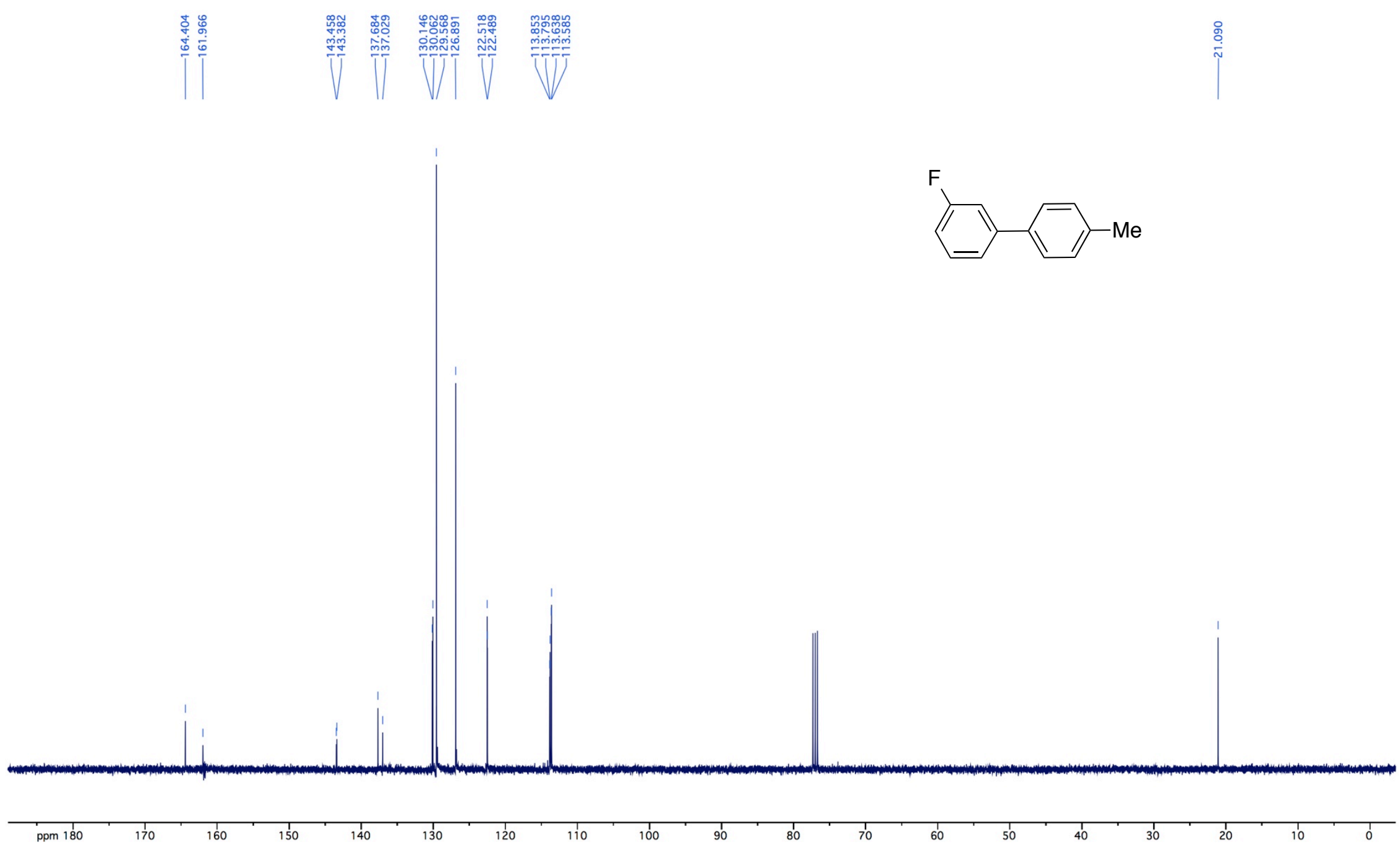

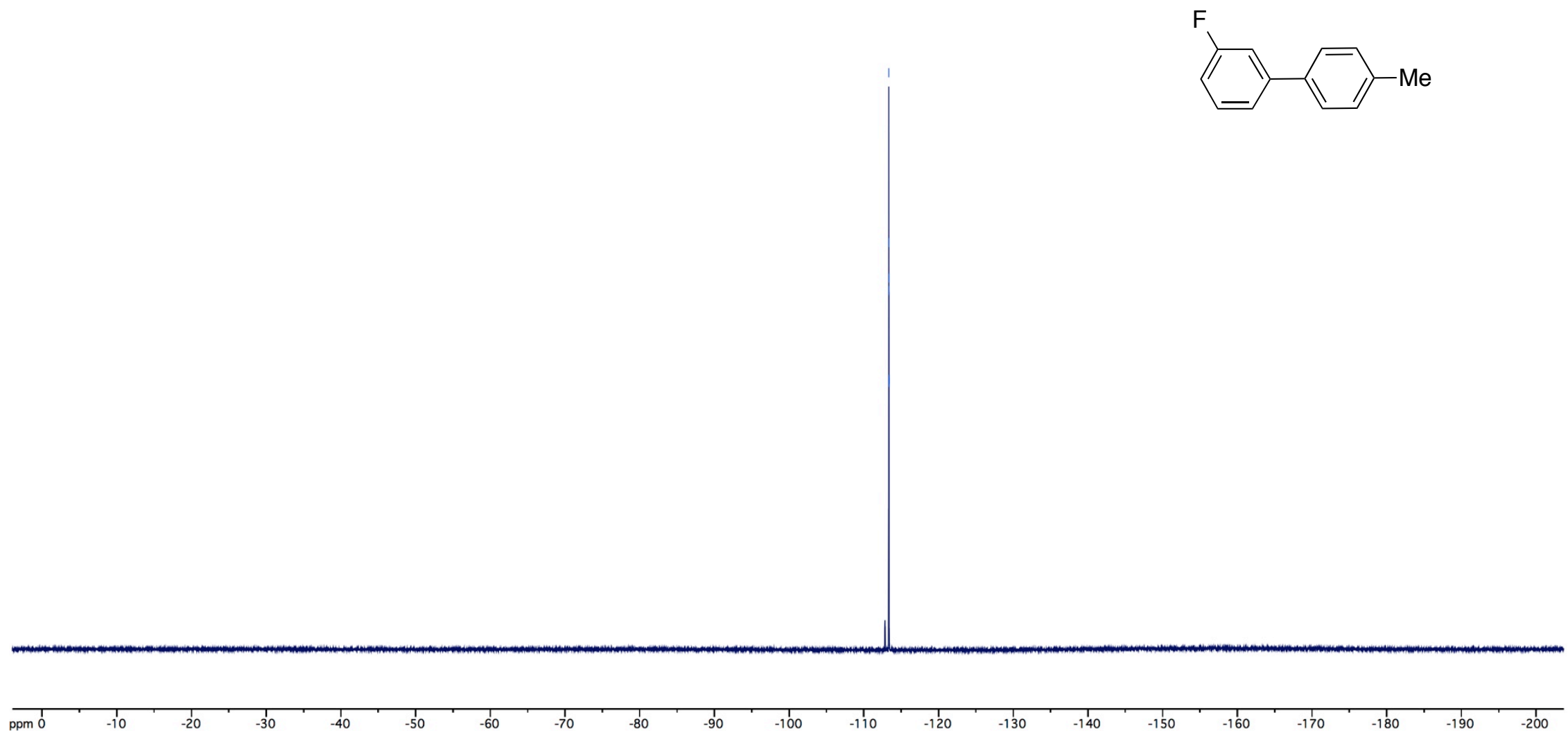


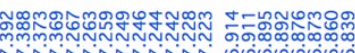

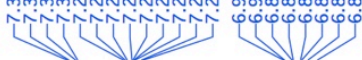

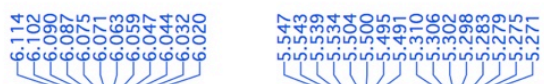

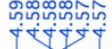
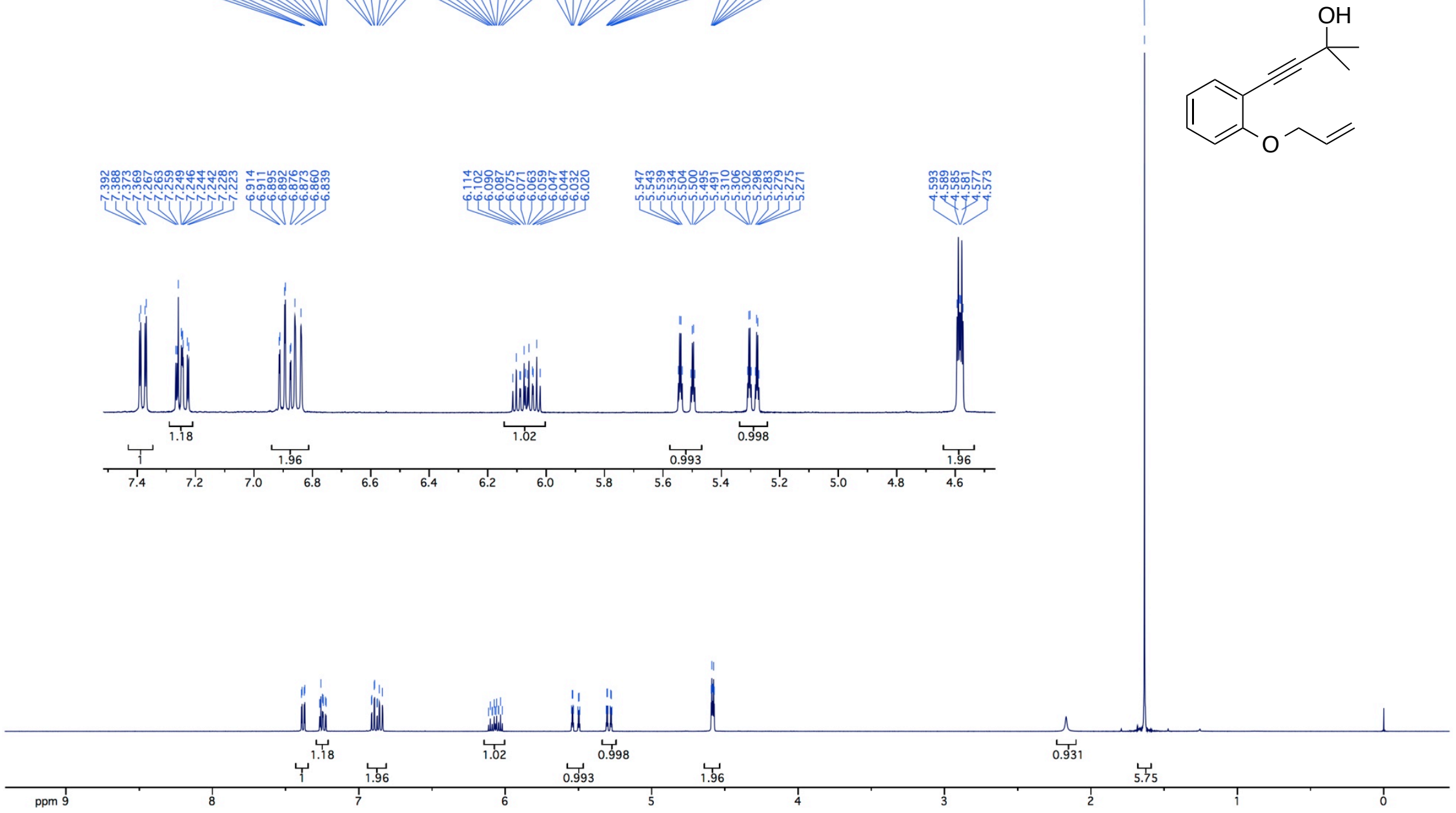


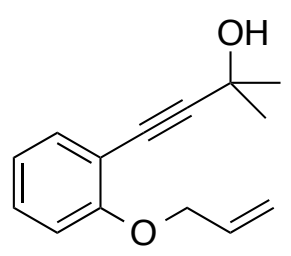

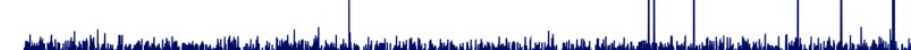

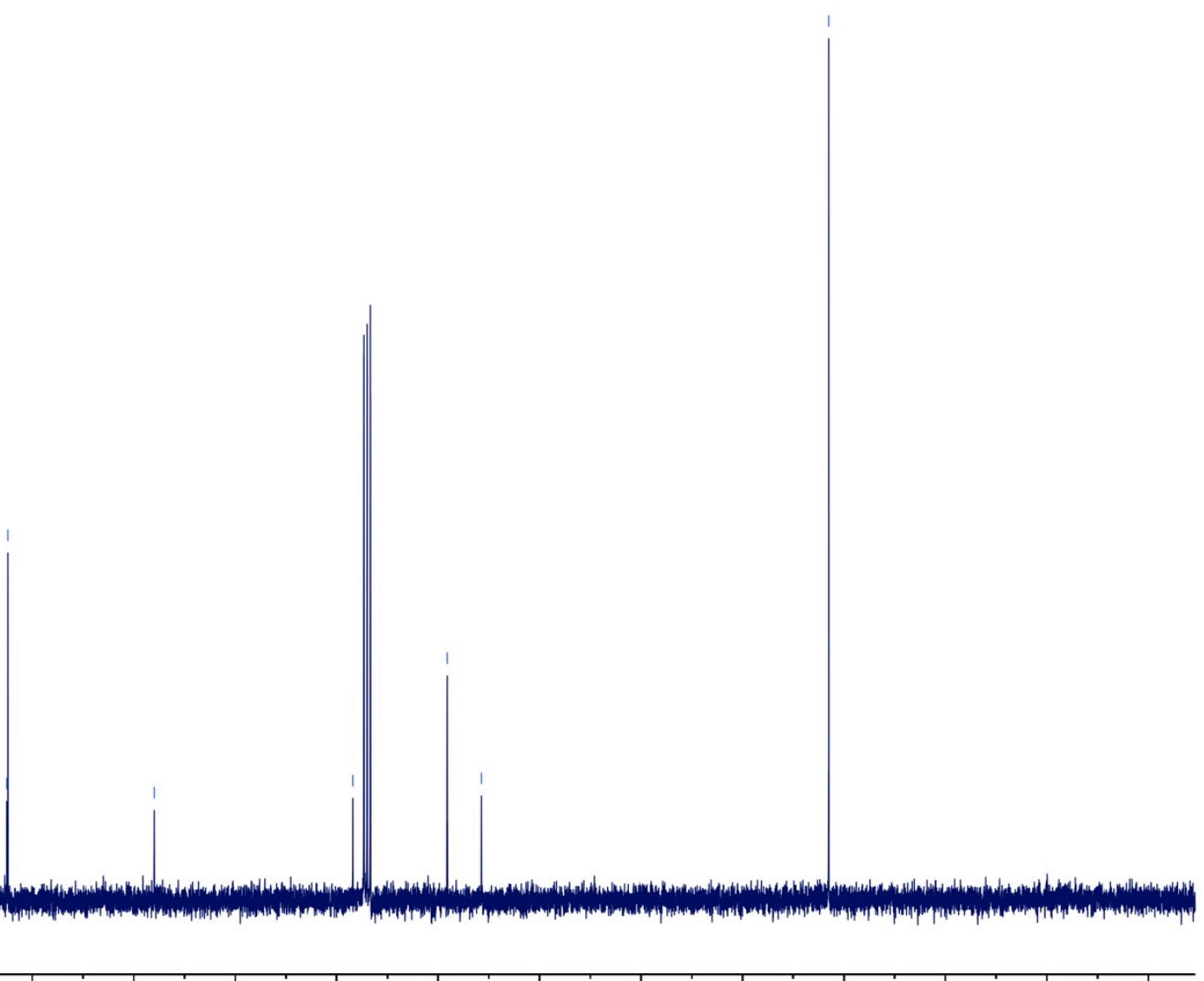




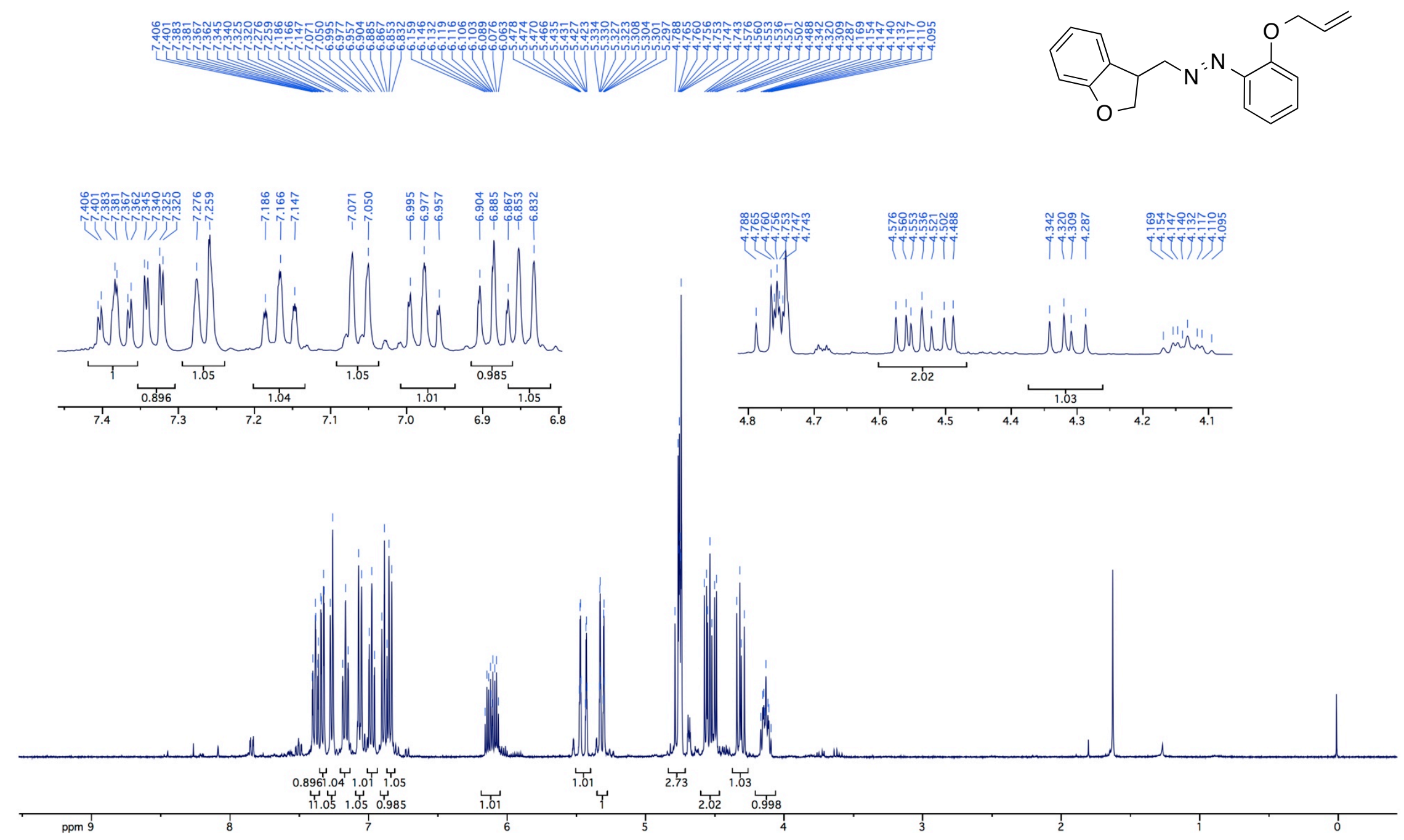




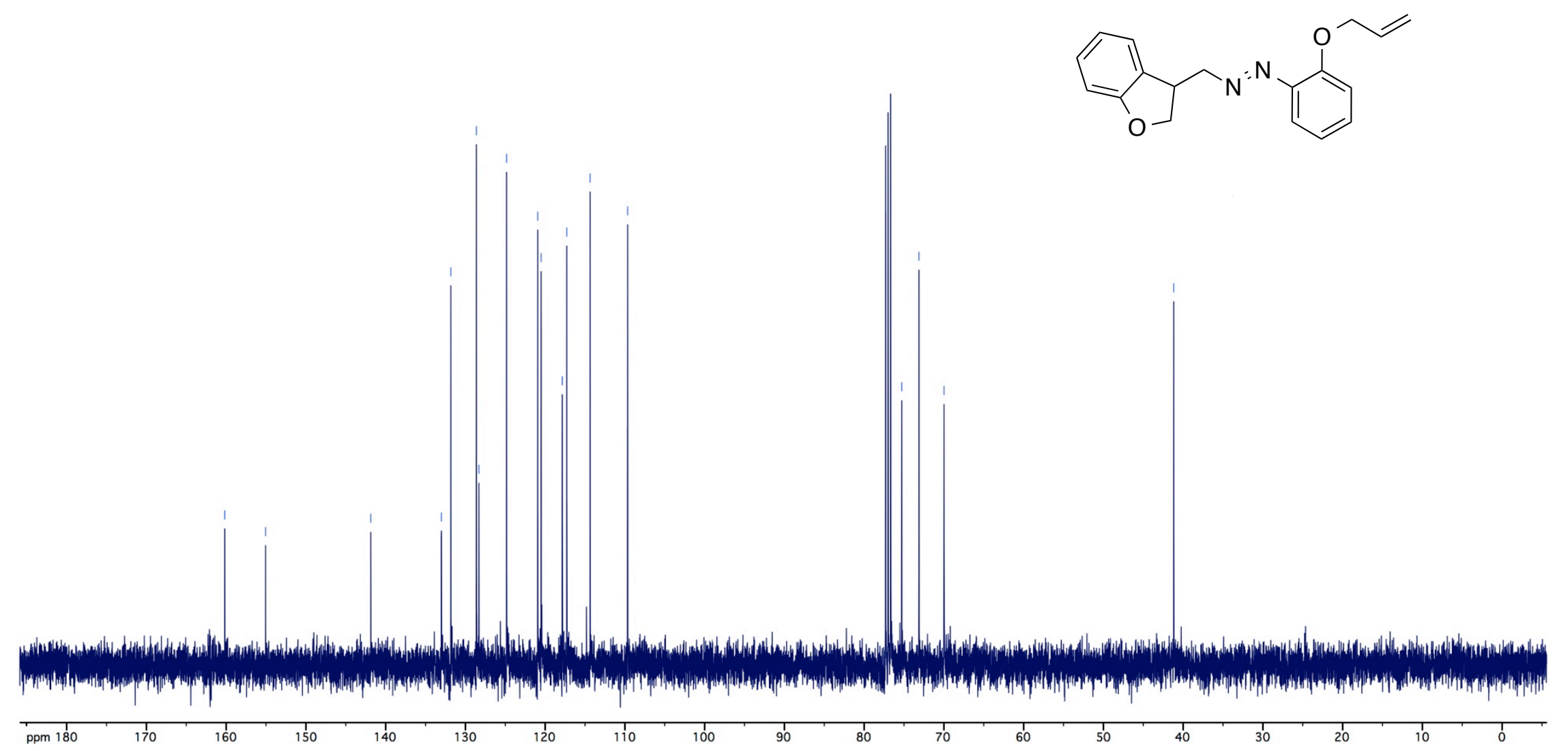




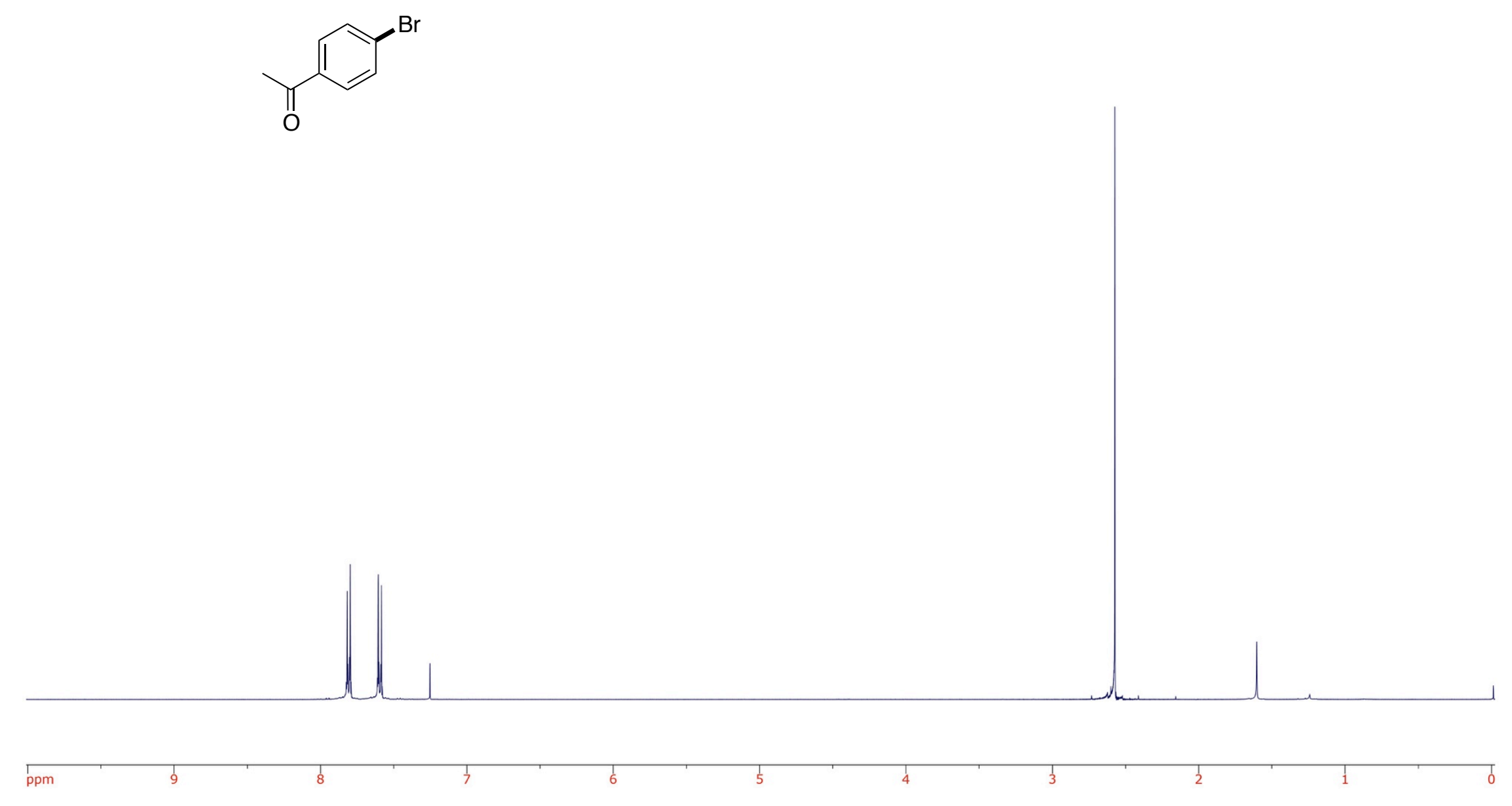



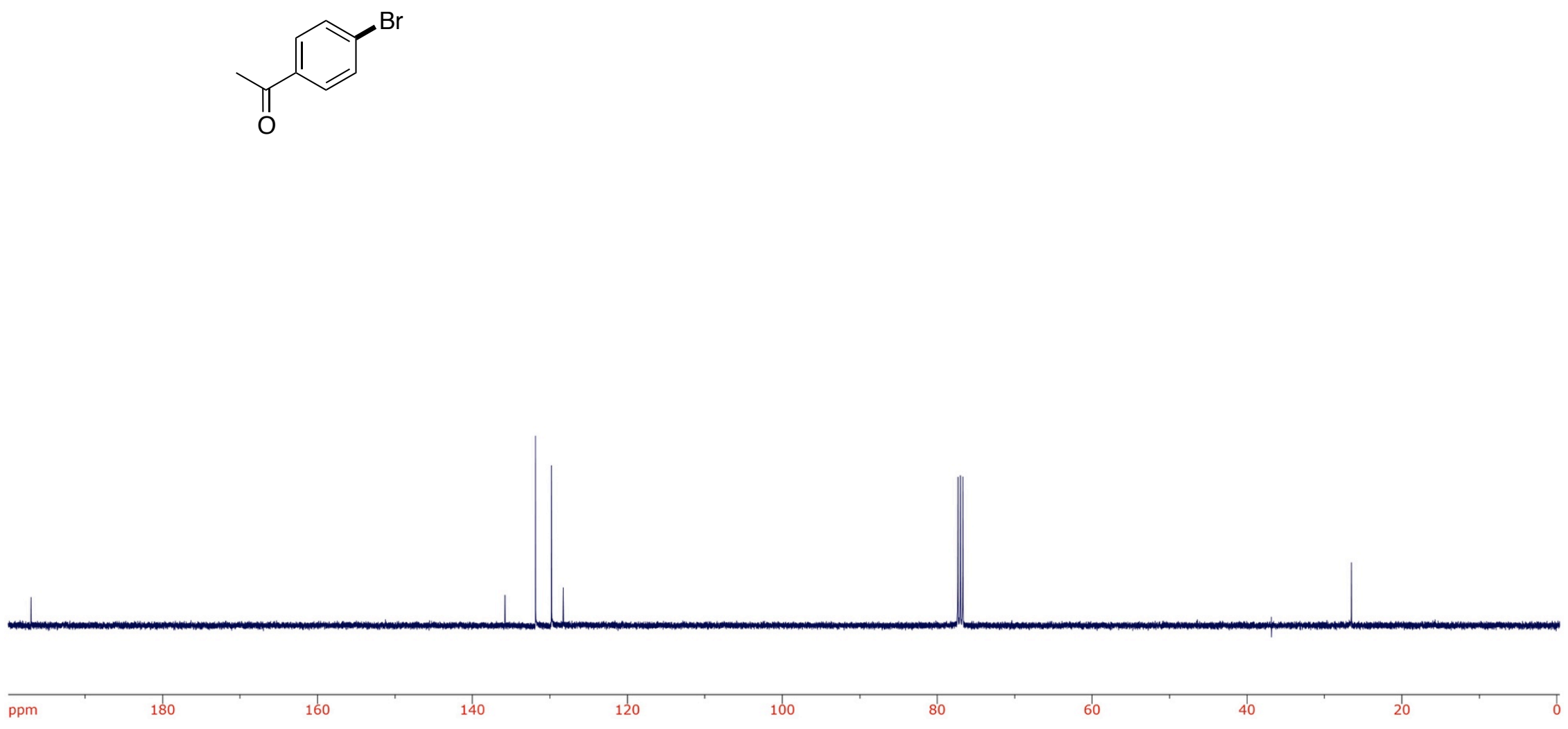

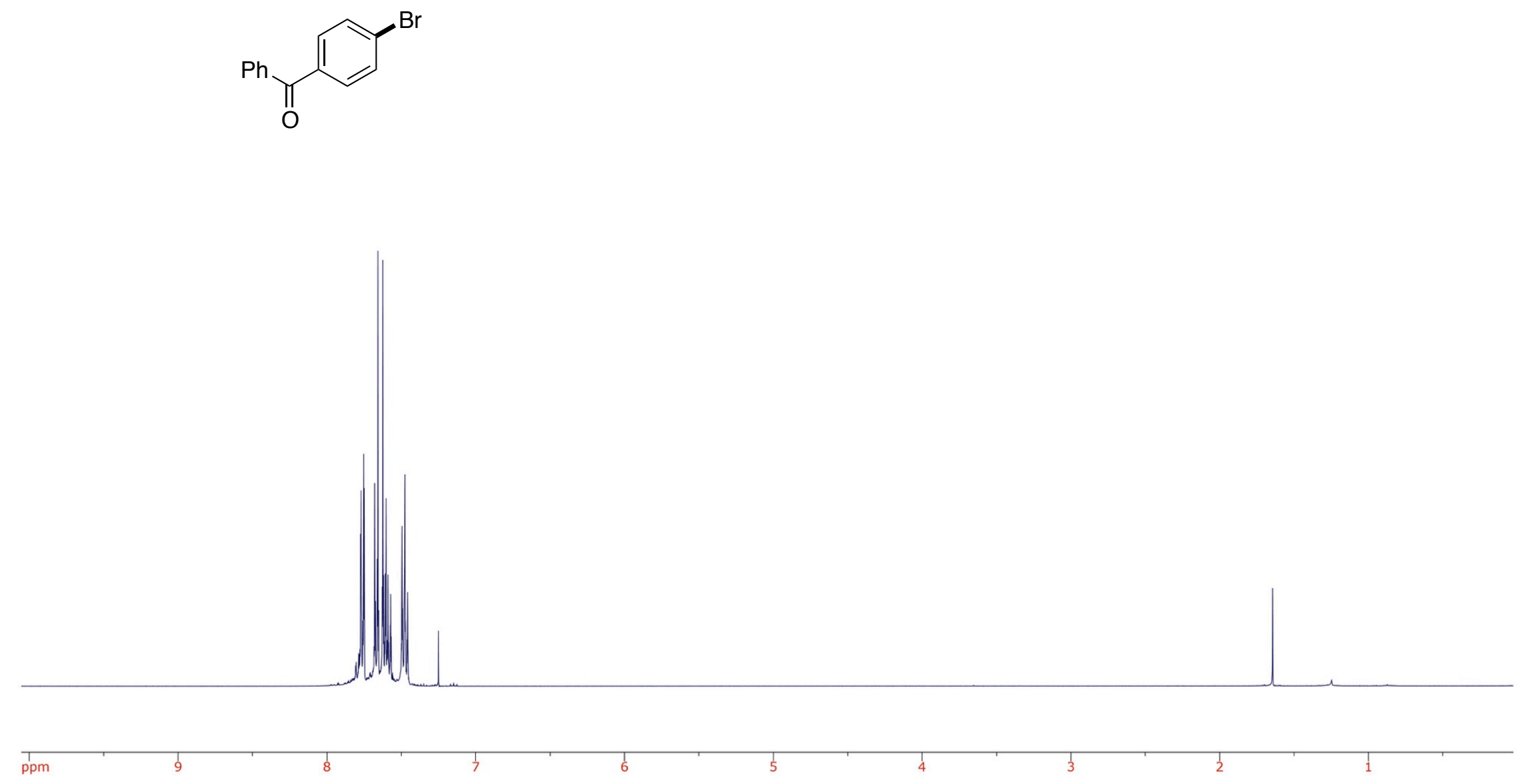

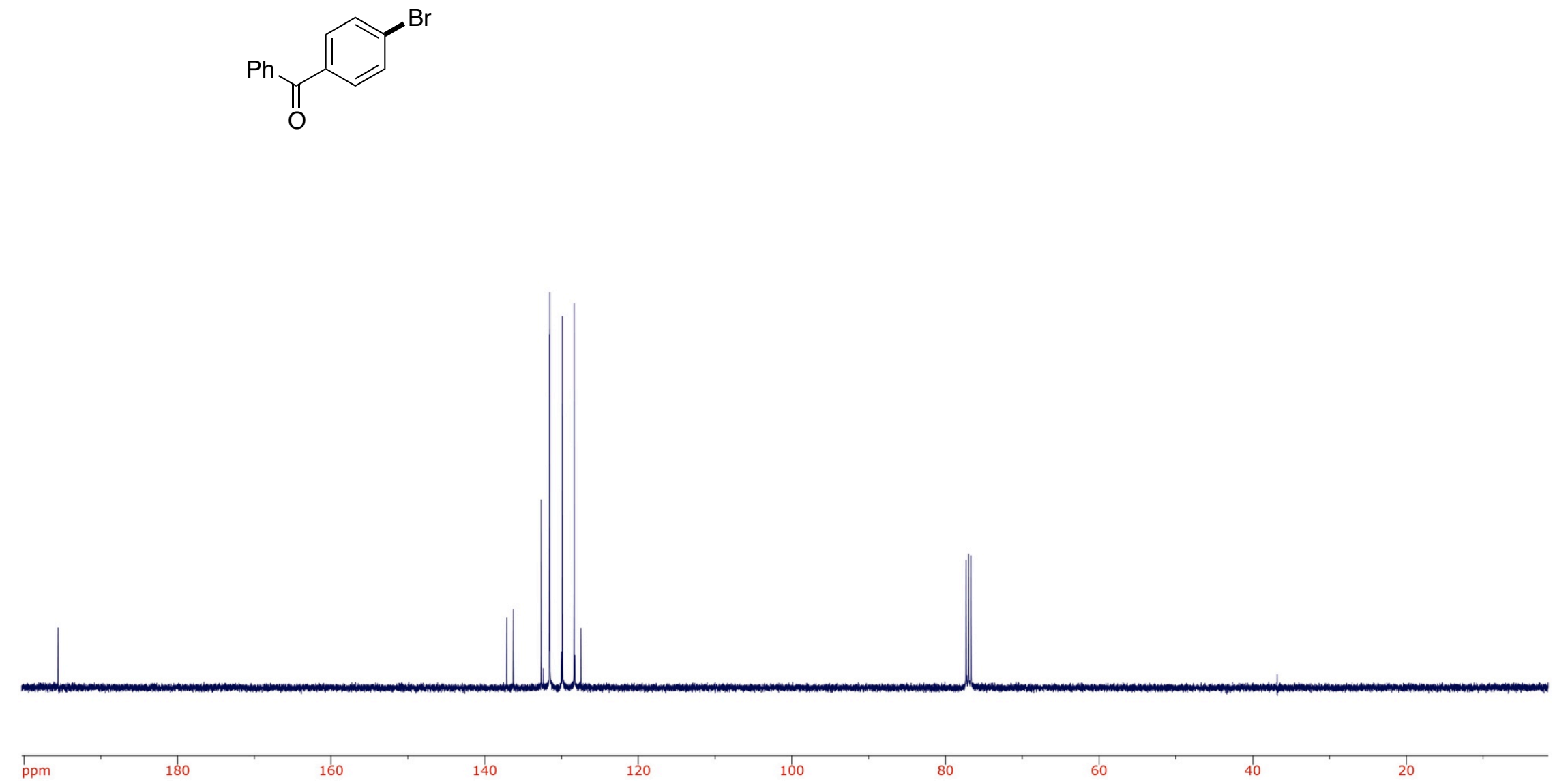
í
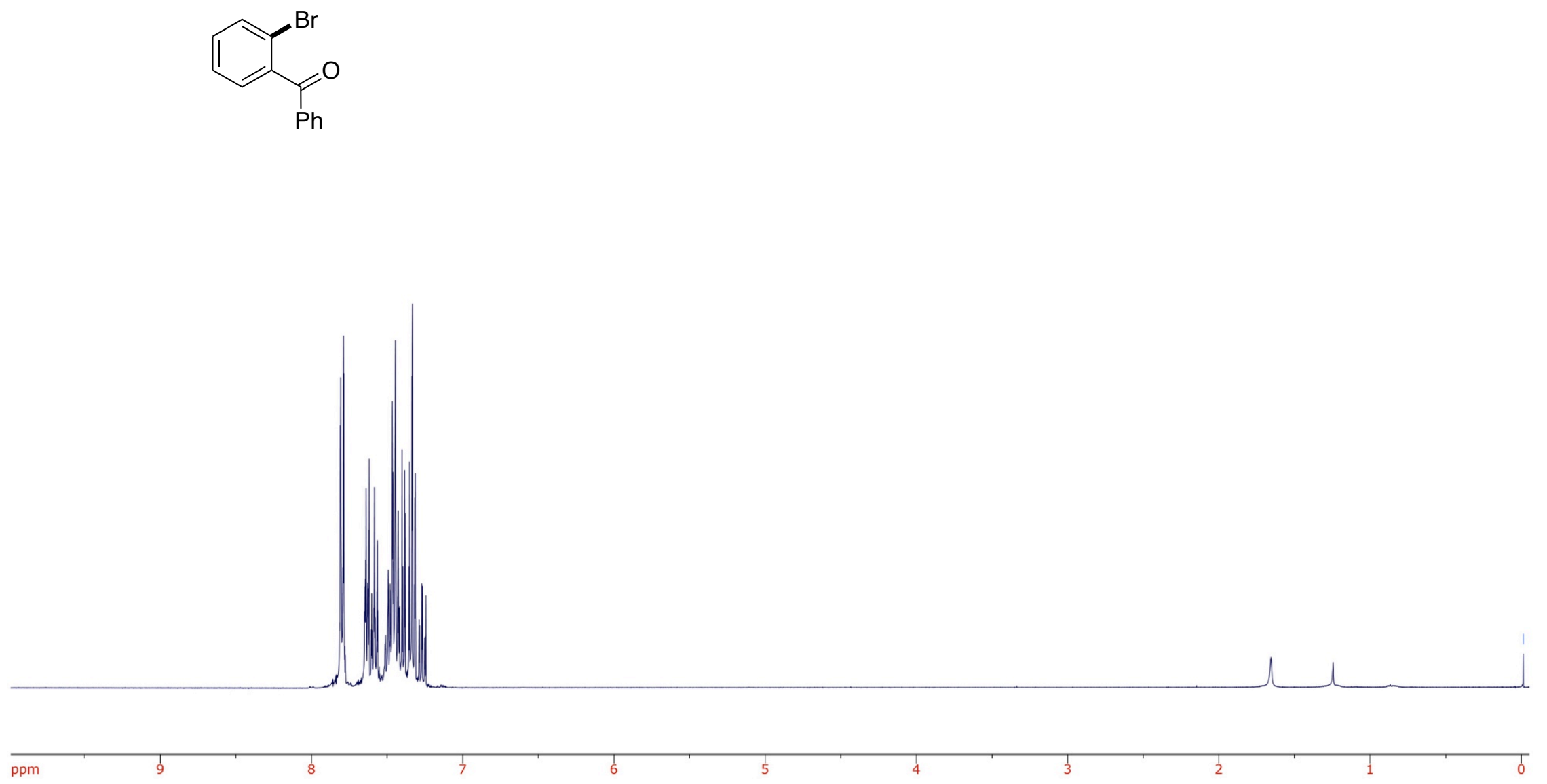

S313 


$$
\overbrace{P h}^{B r}
$$
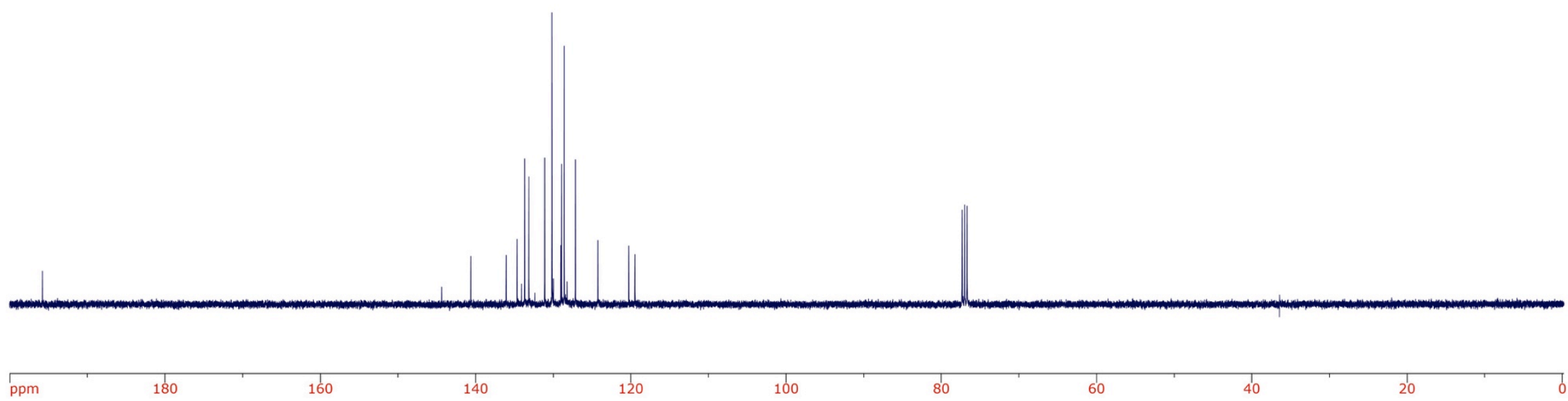

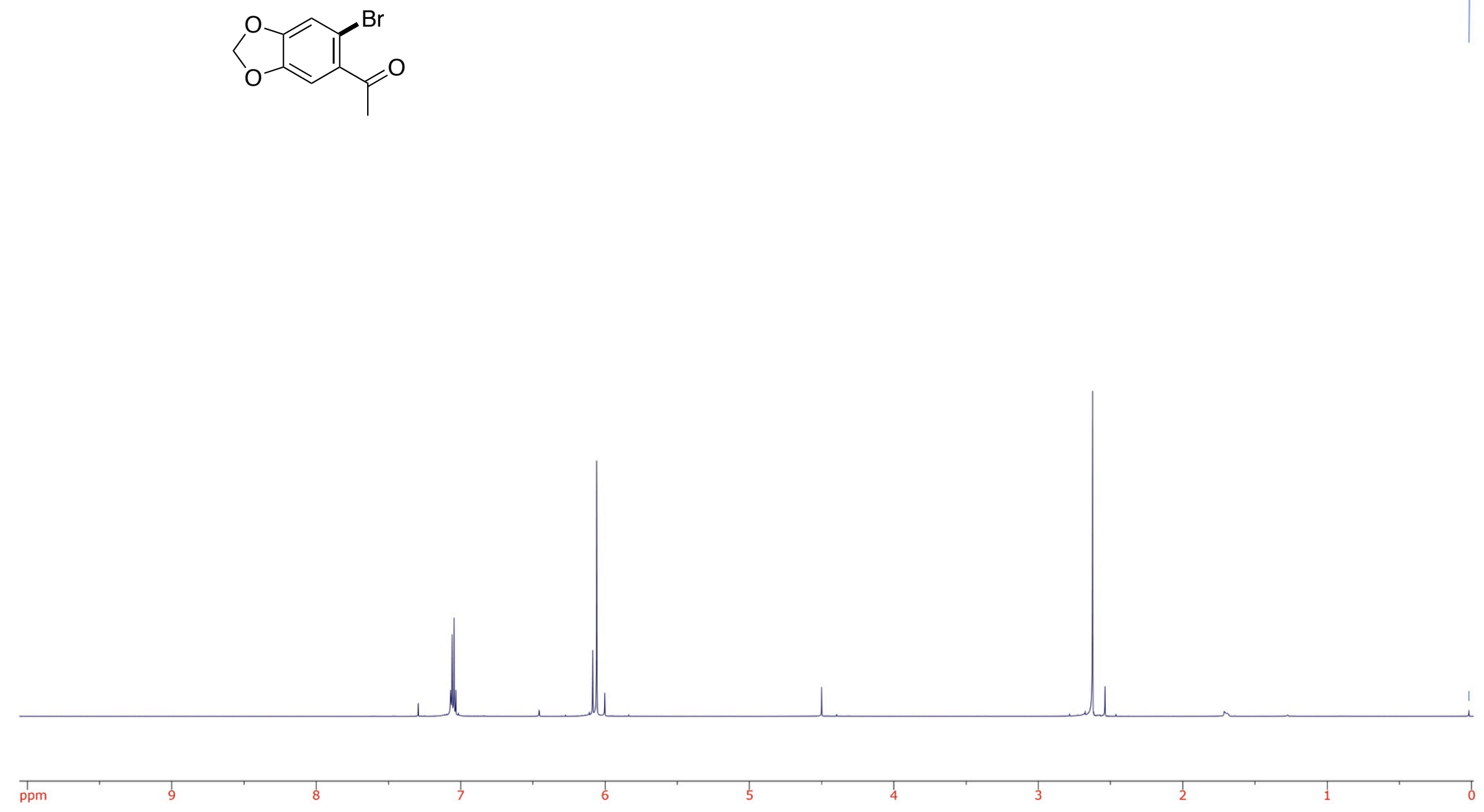

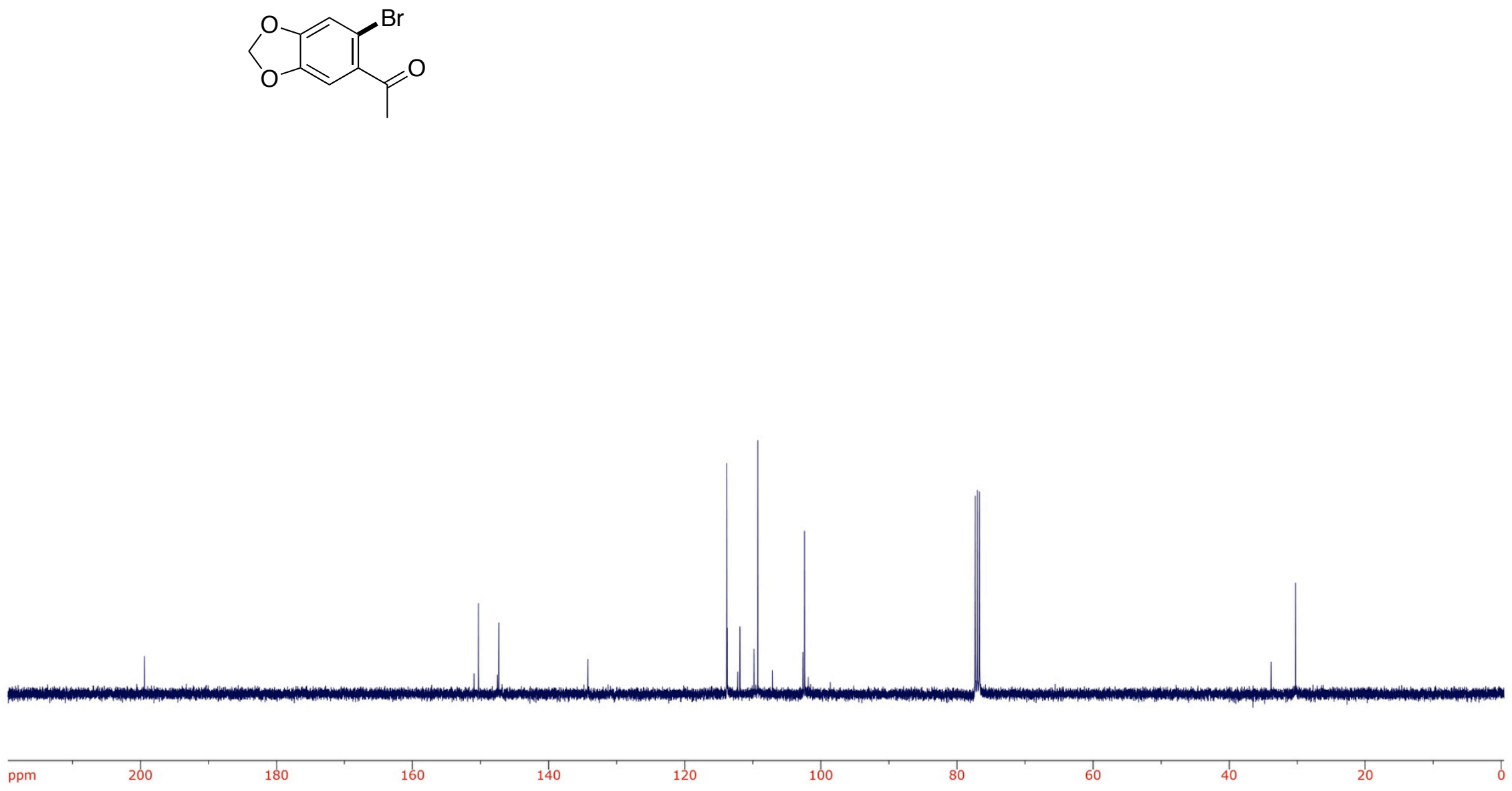

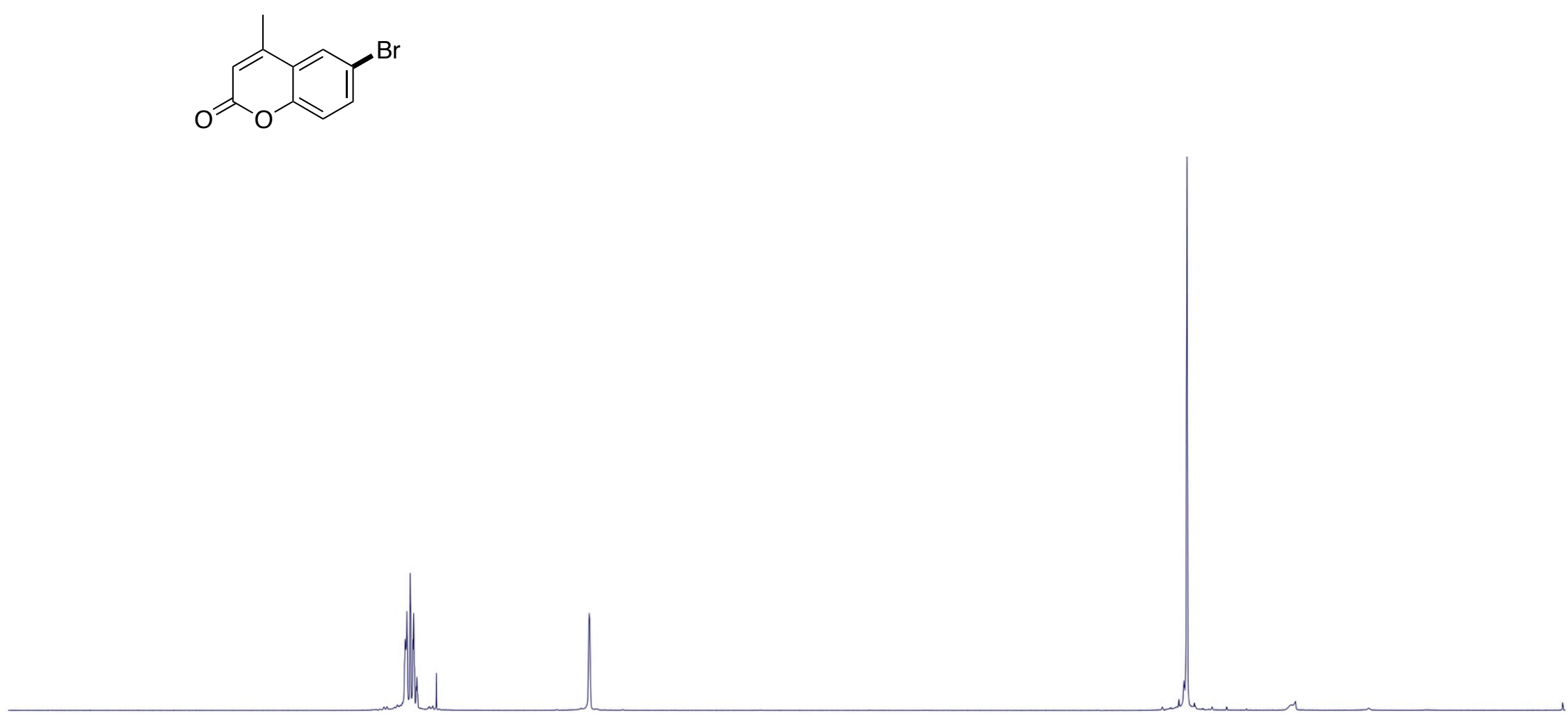

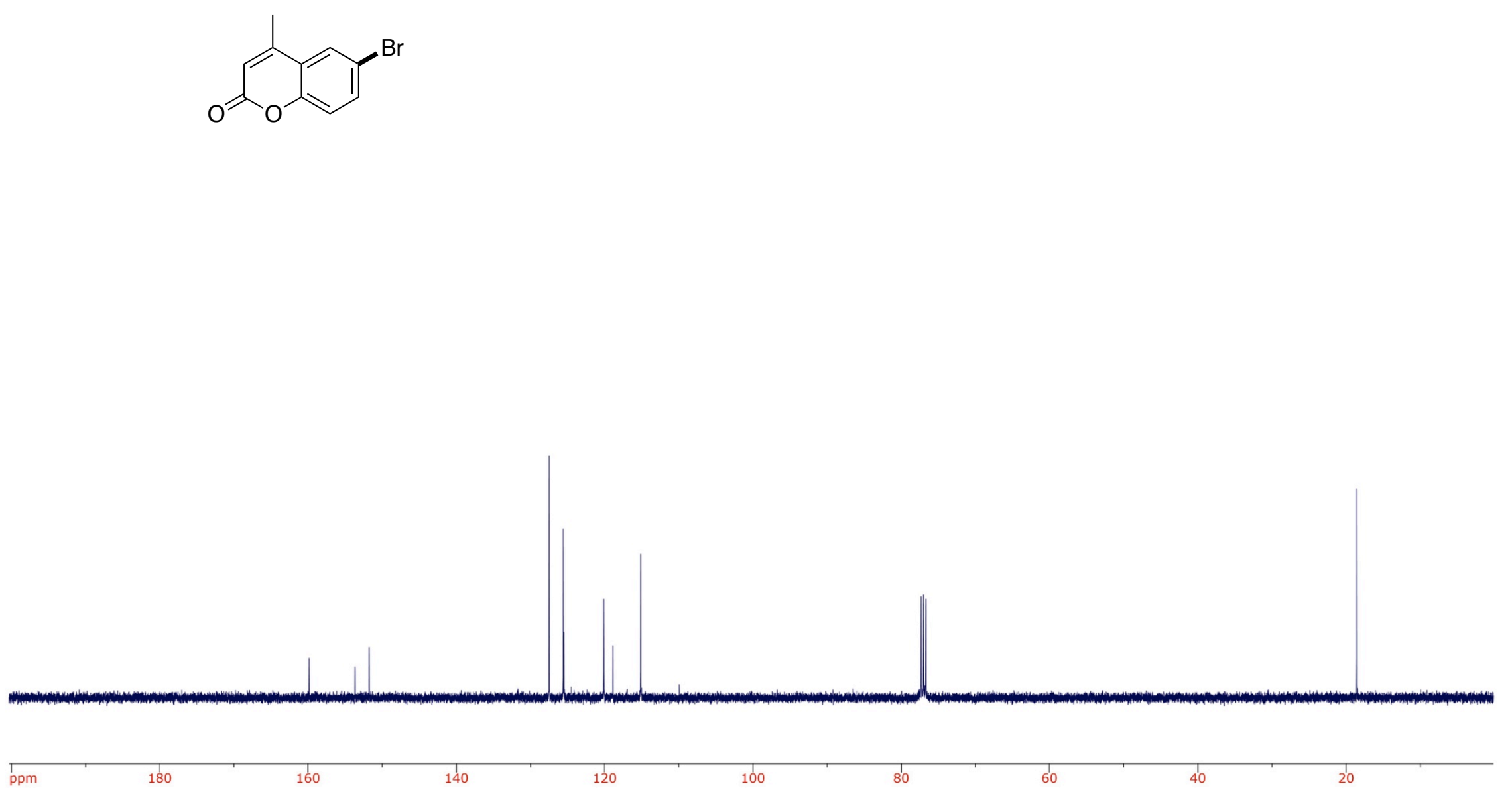

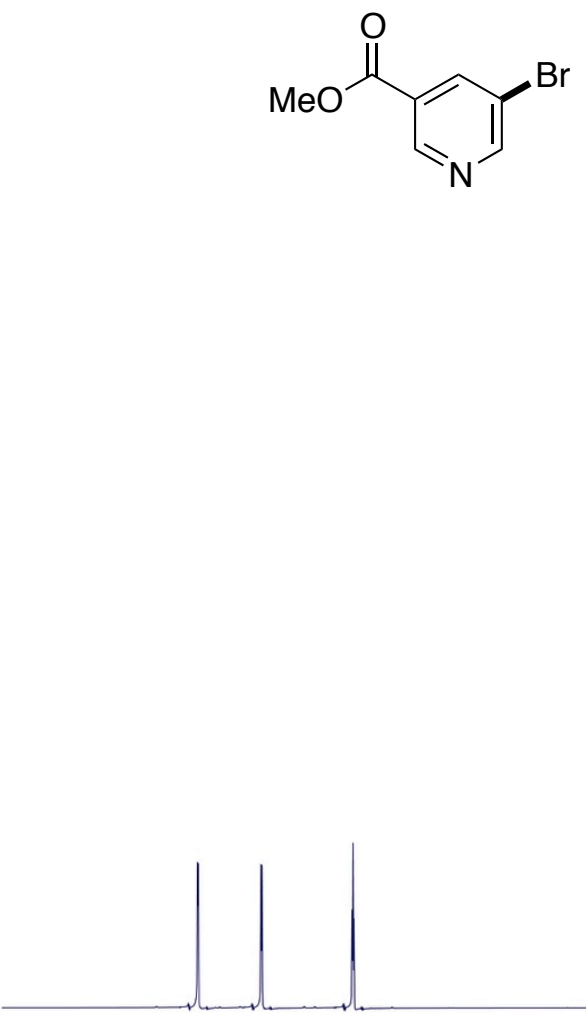

ppm 

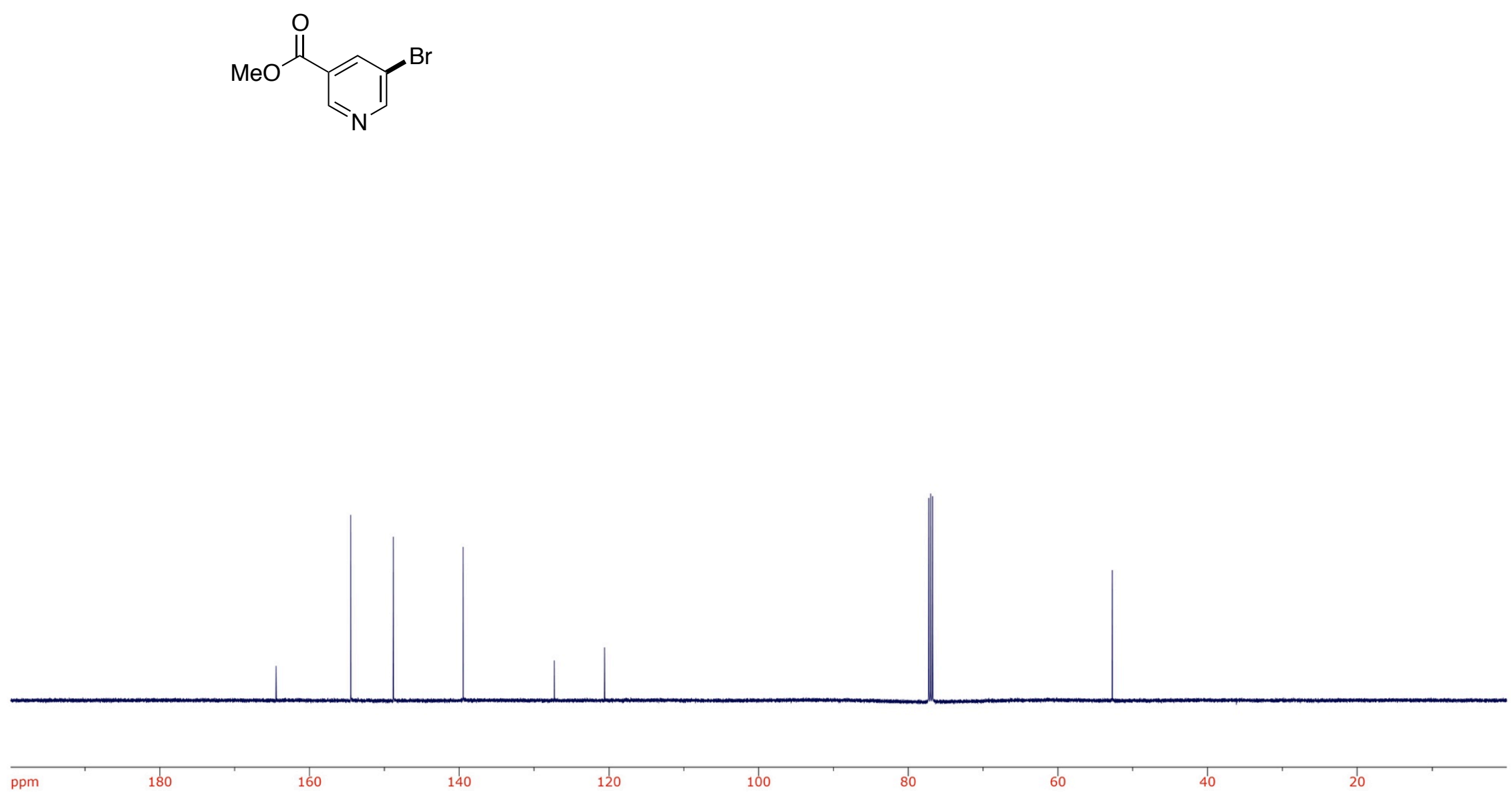


$$
\text { Dro }
$$

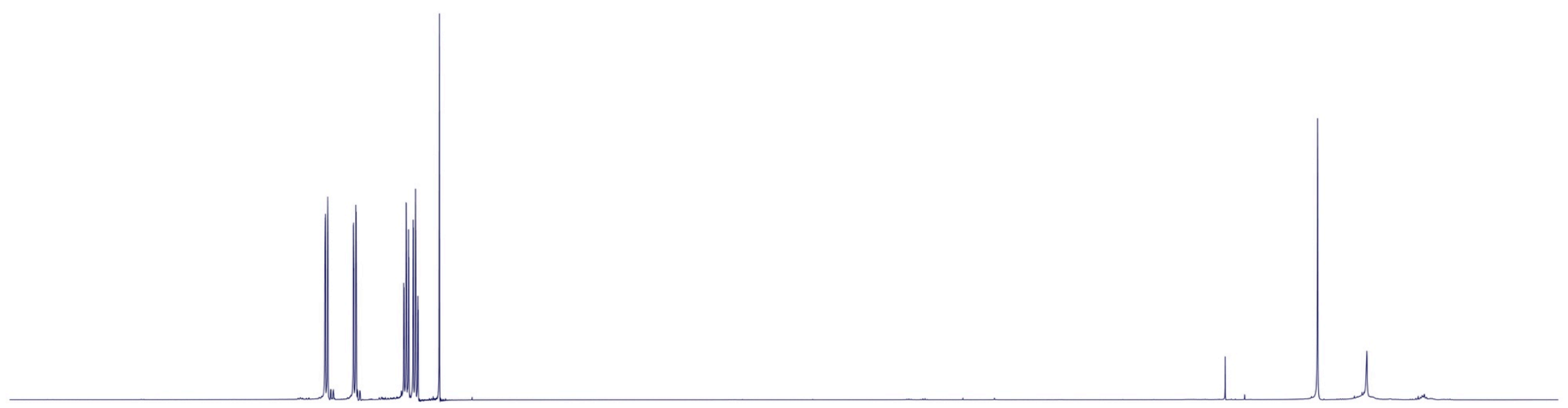




$$
\text { Din }
$$

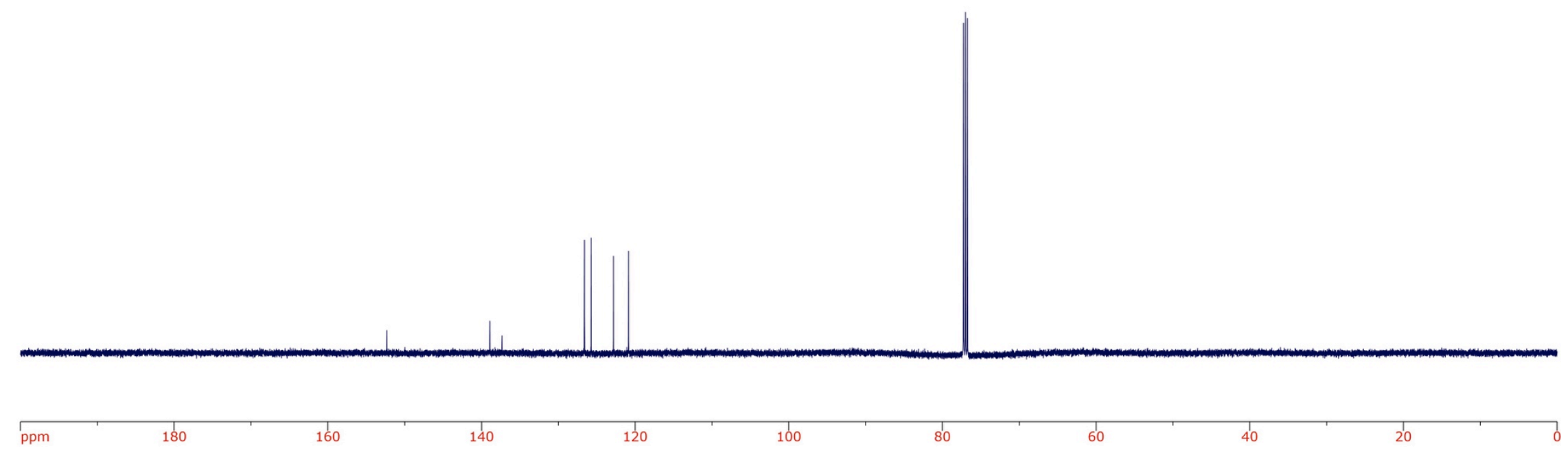



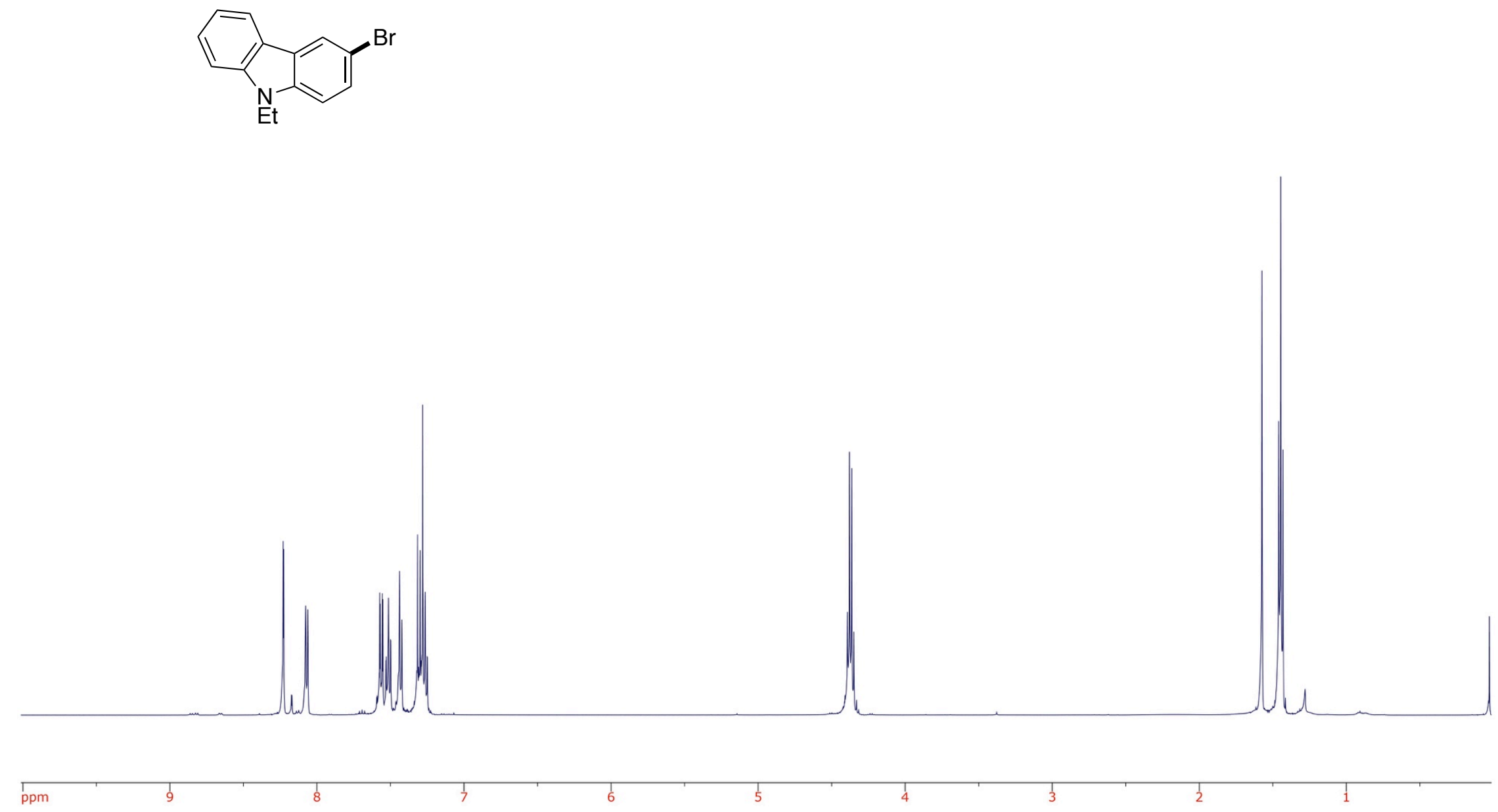

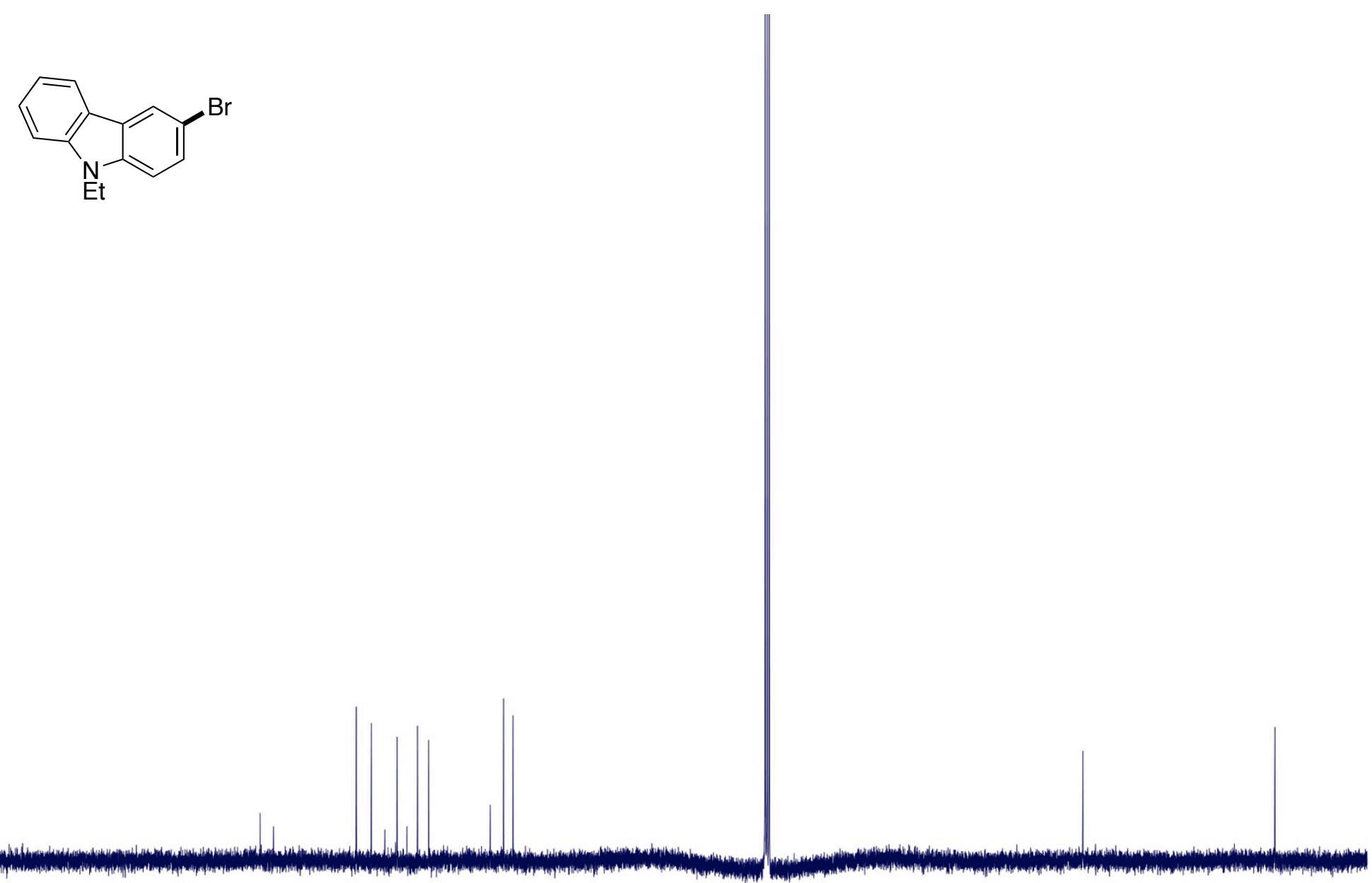

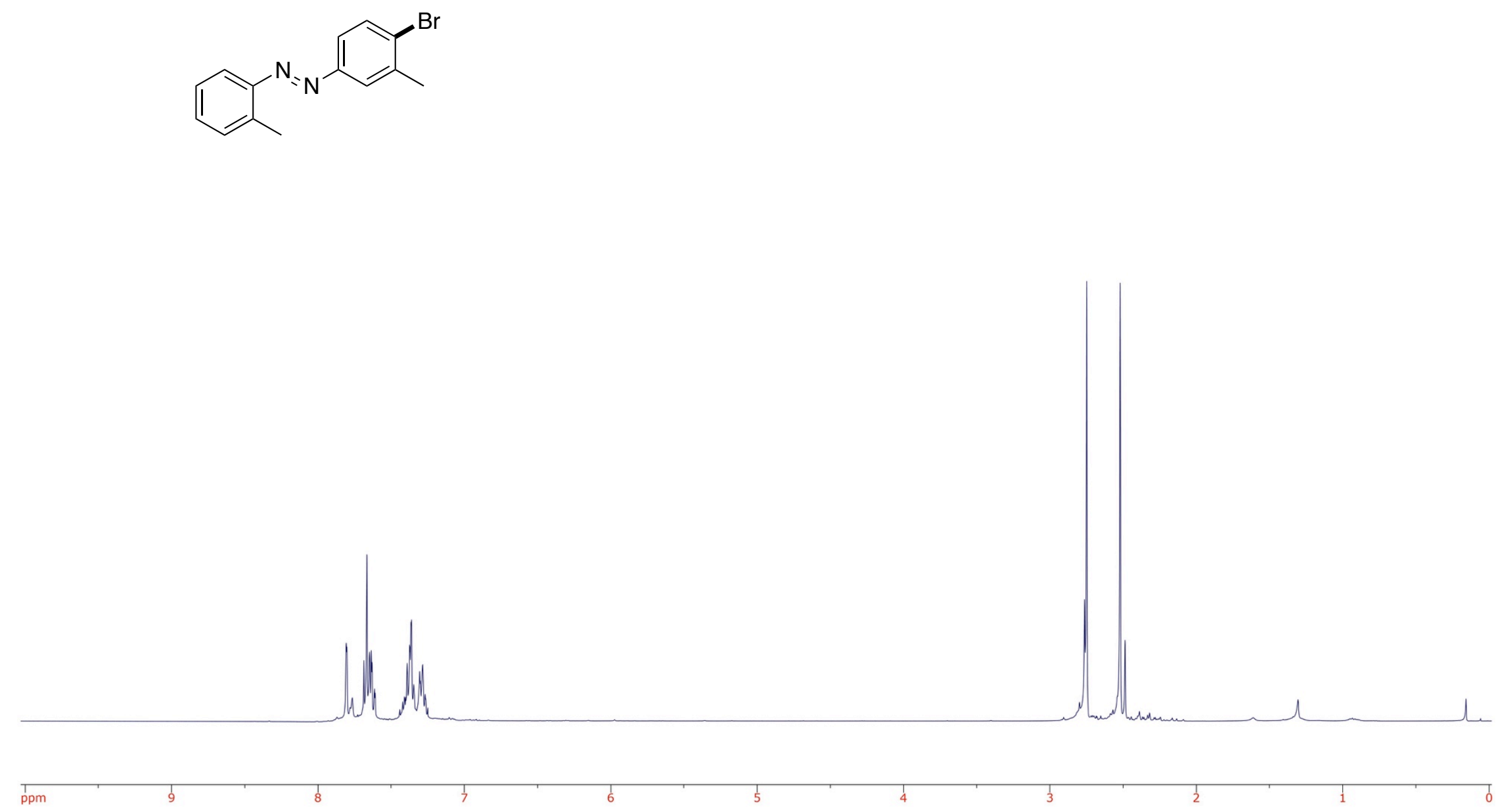

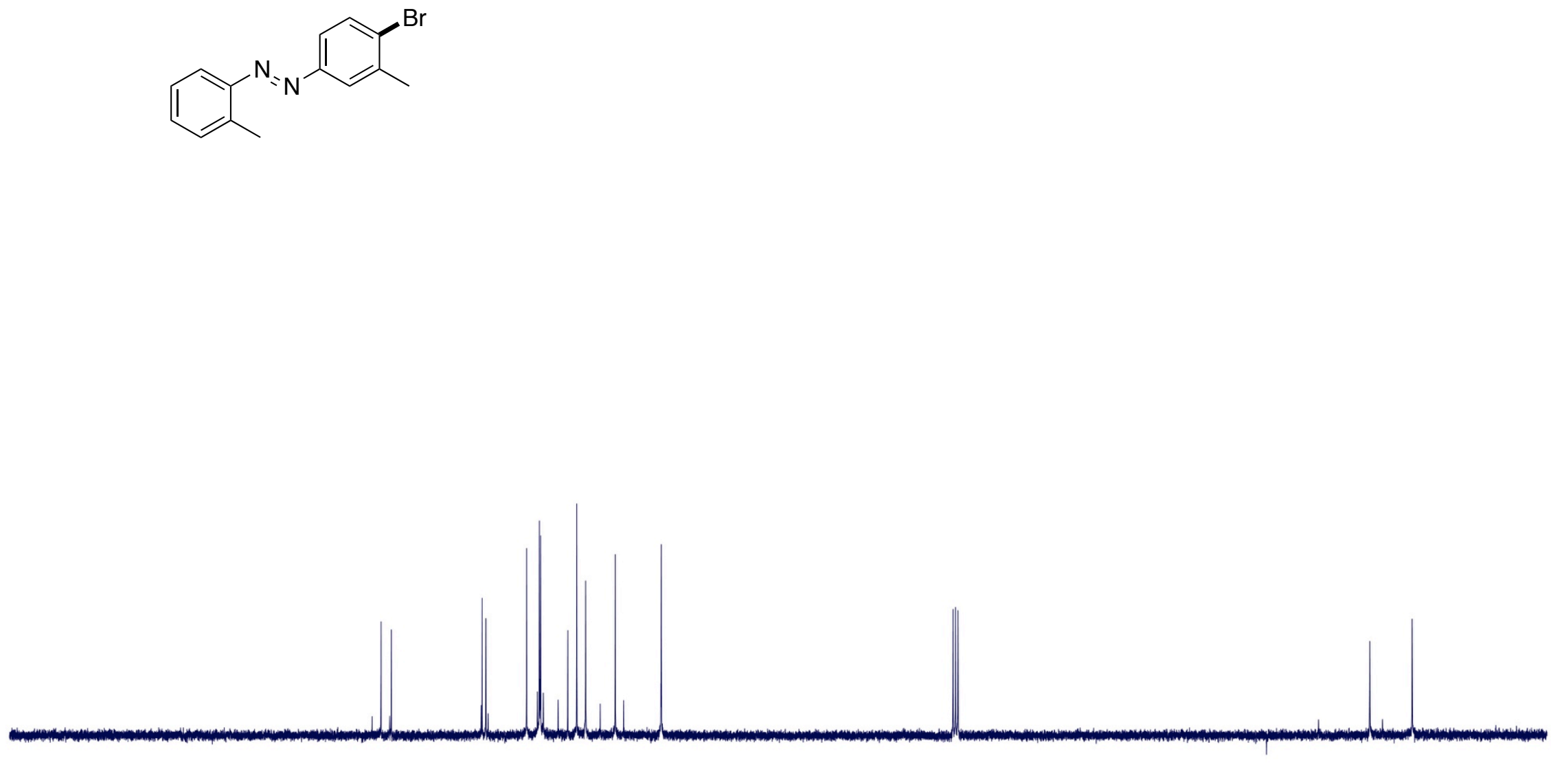

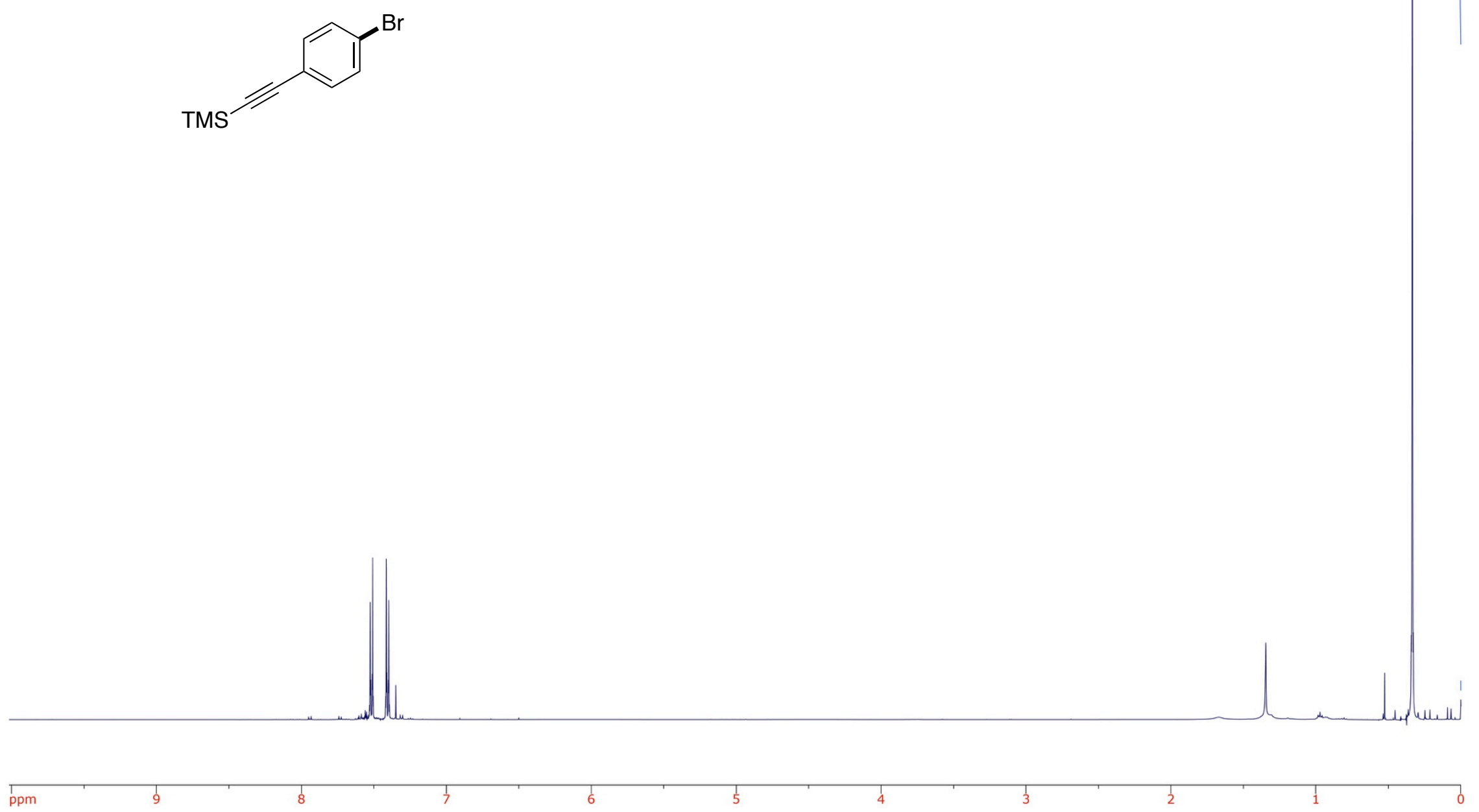

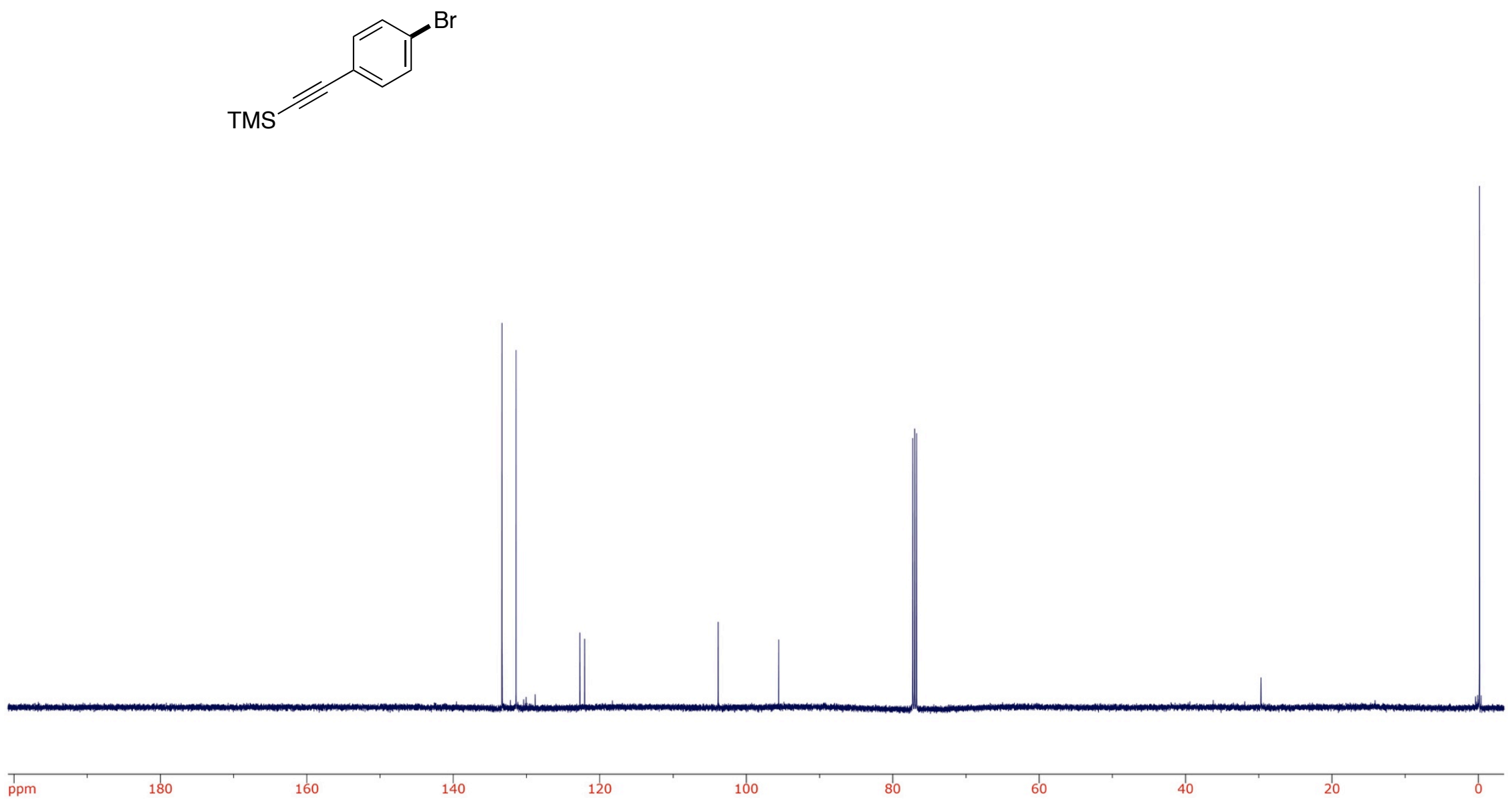

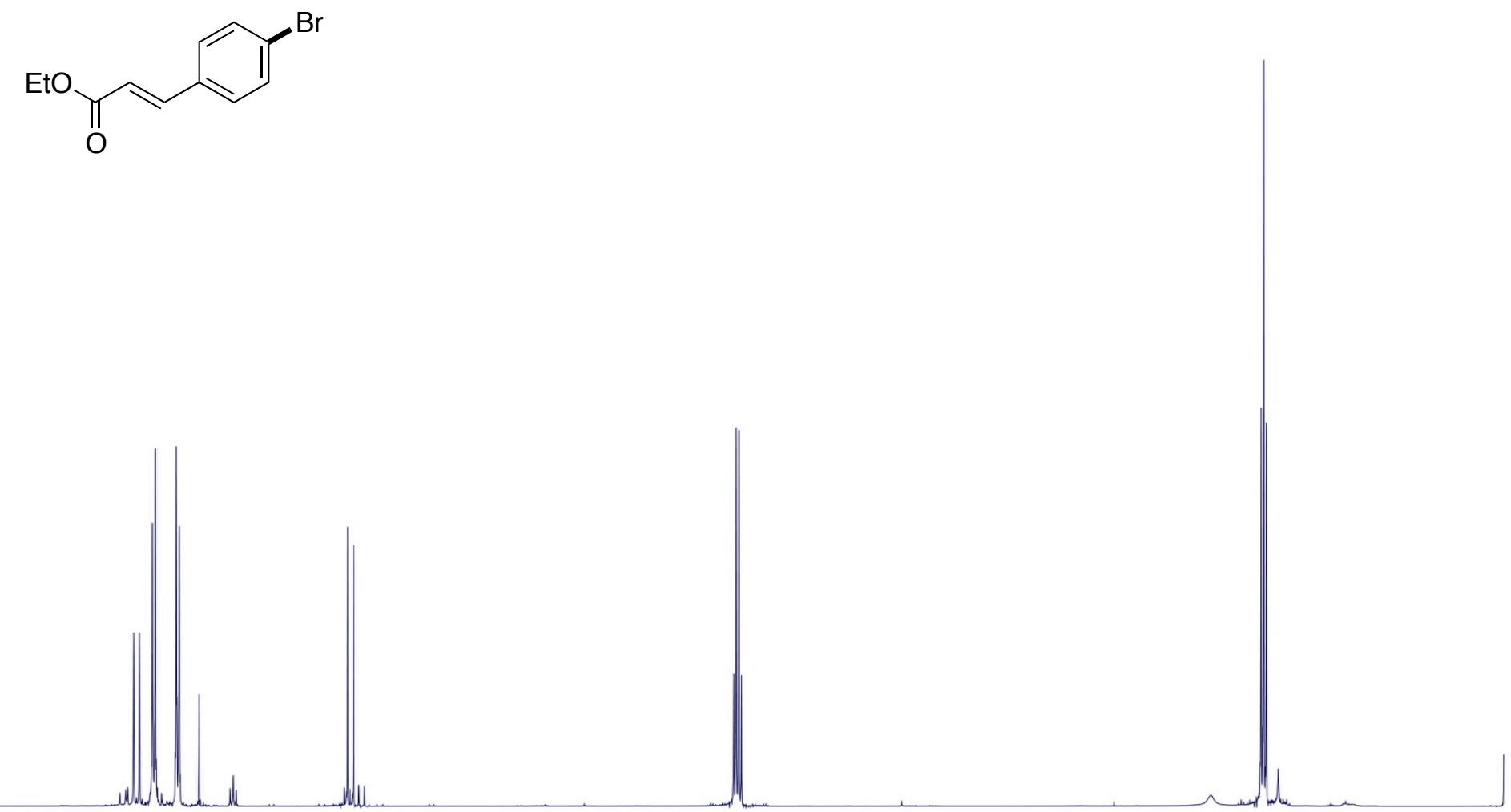

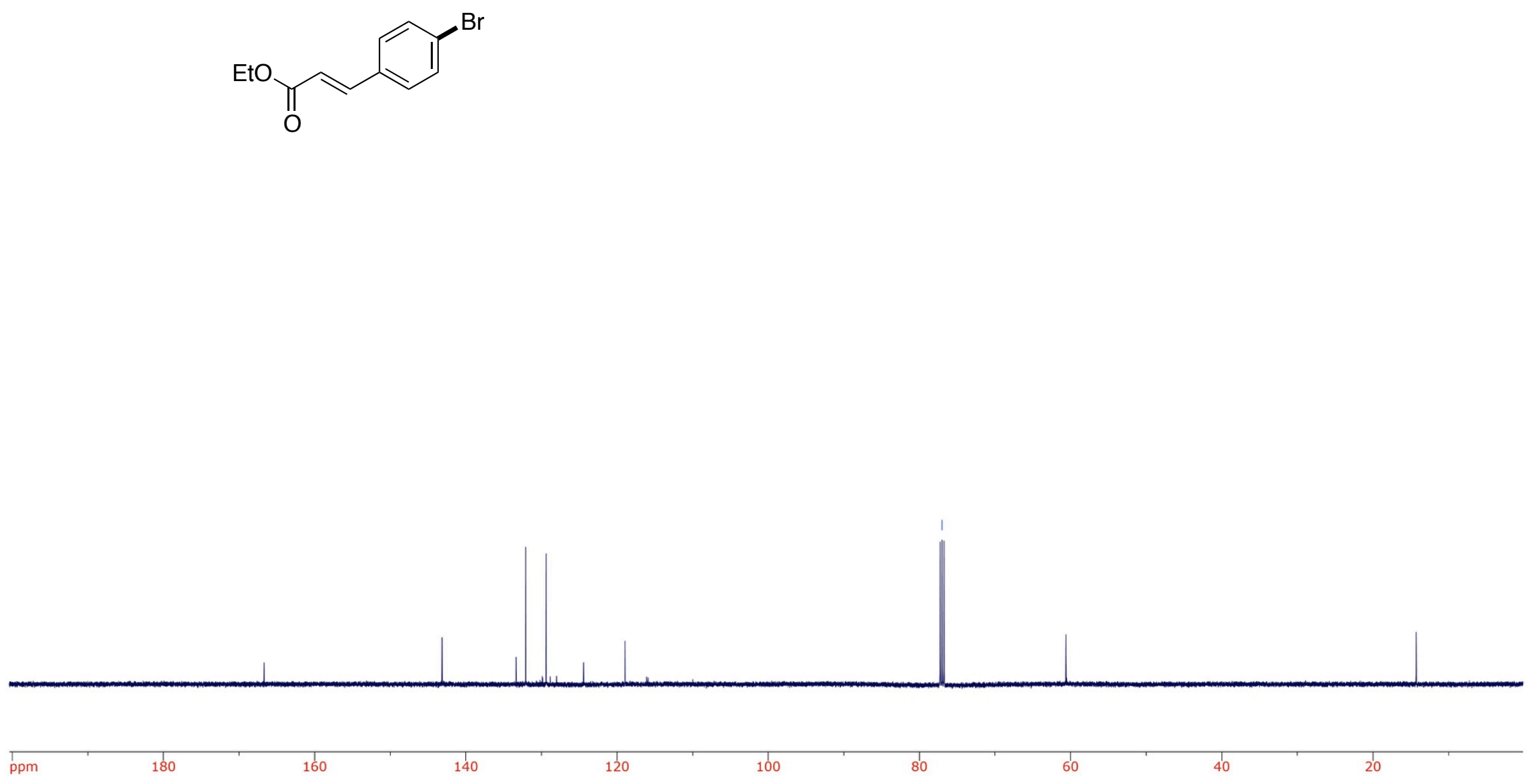

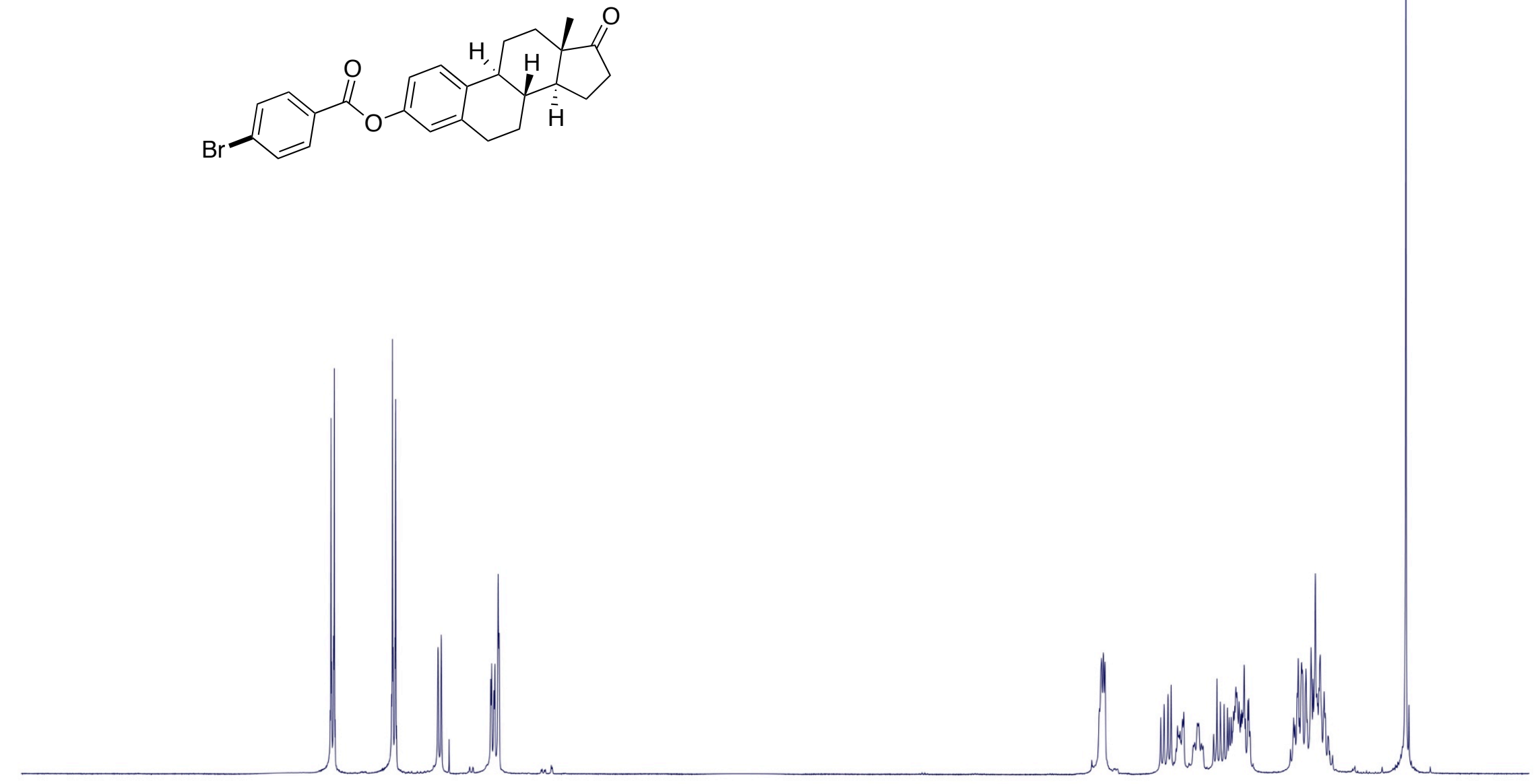
8 

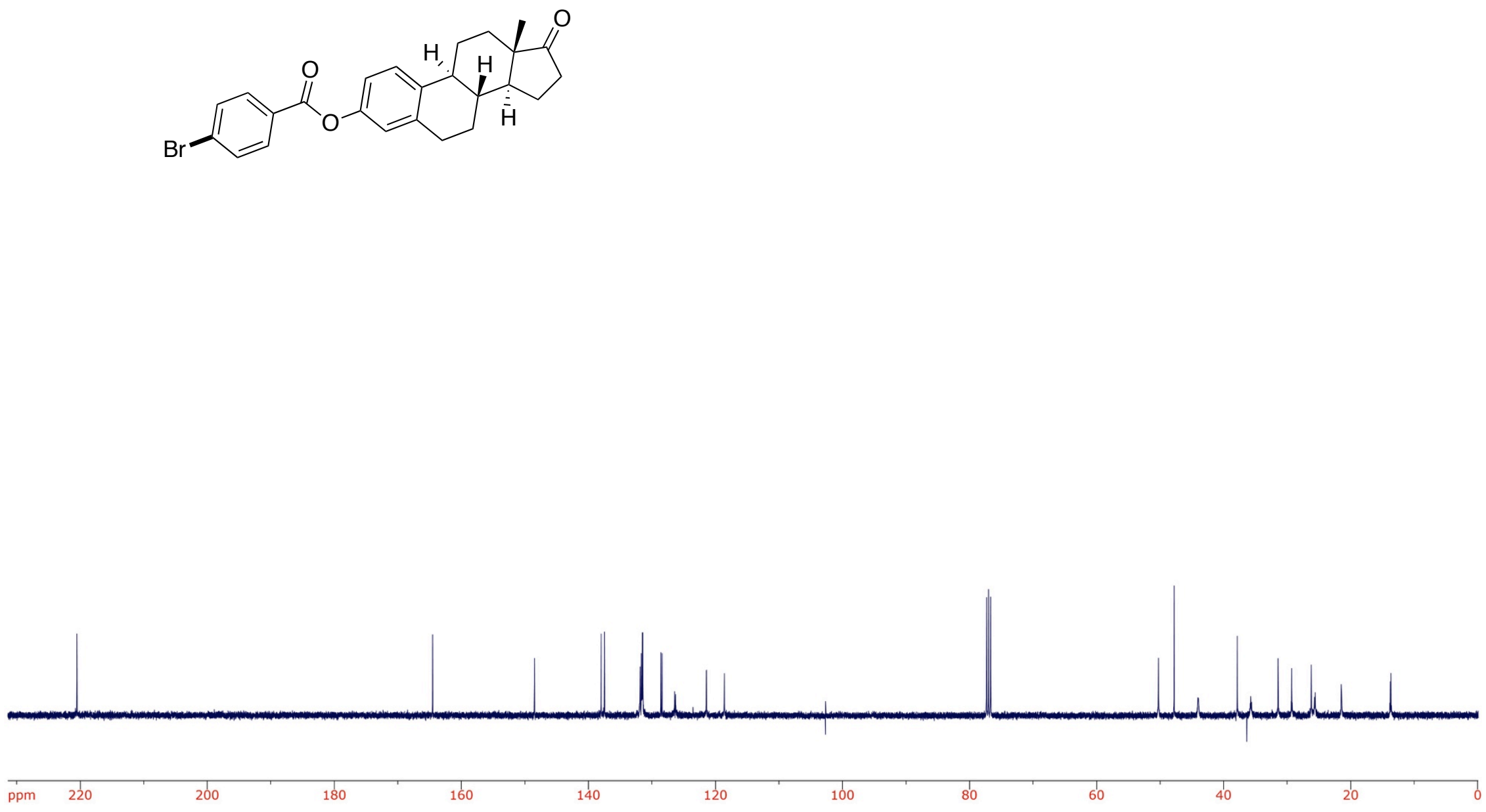

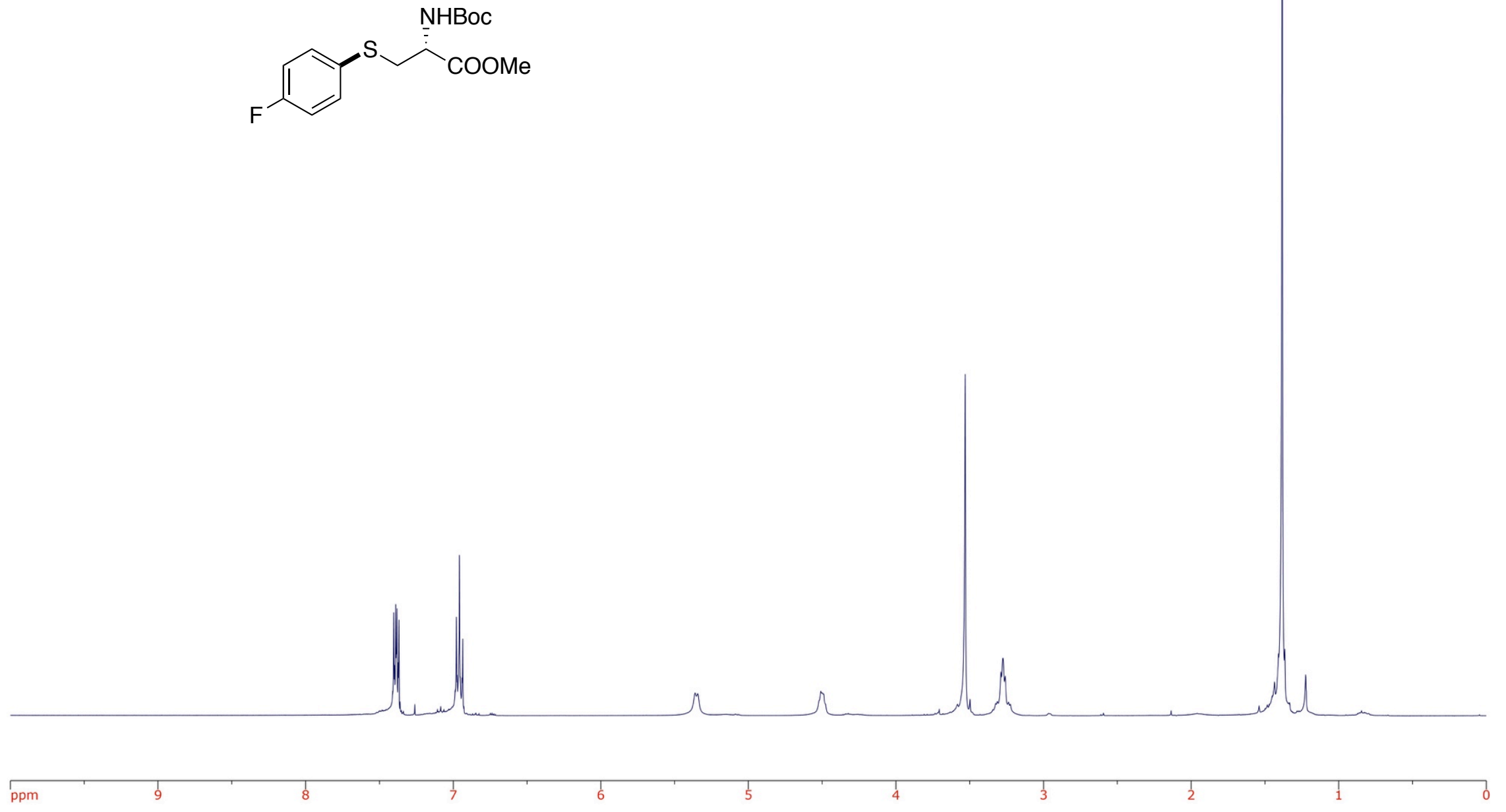

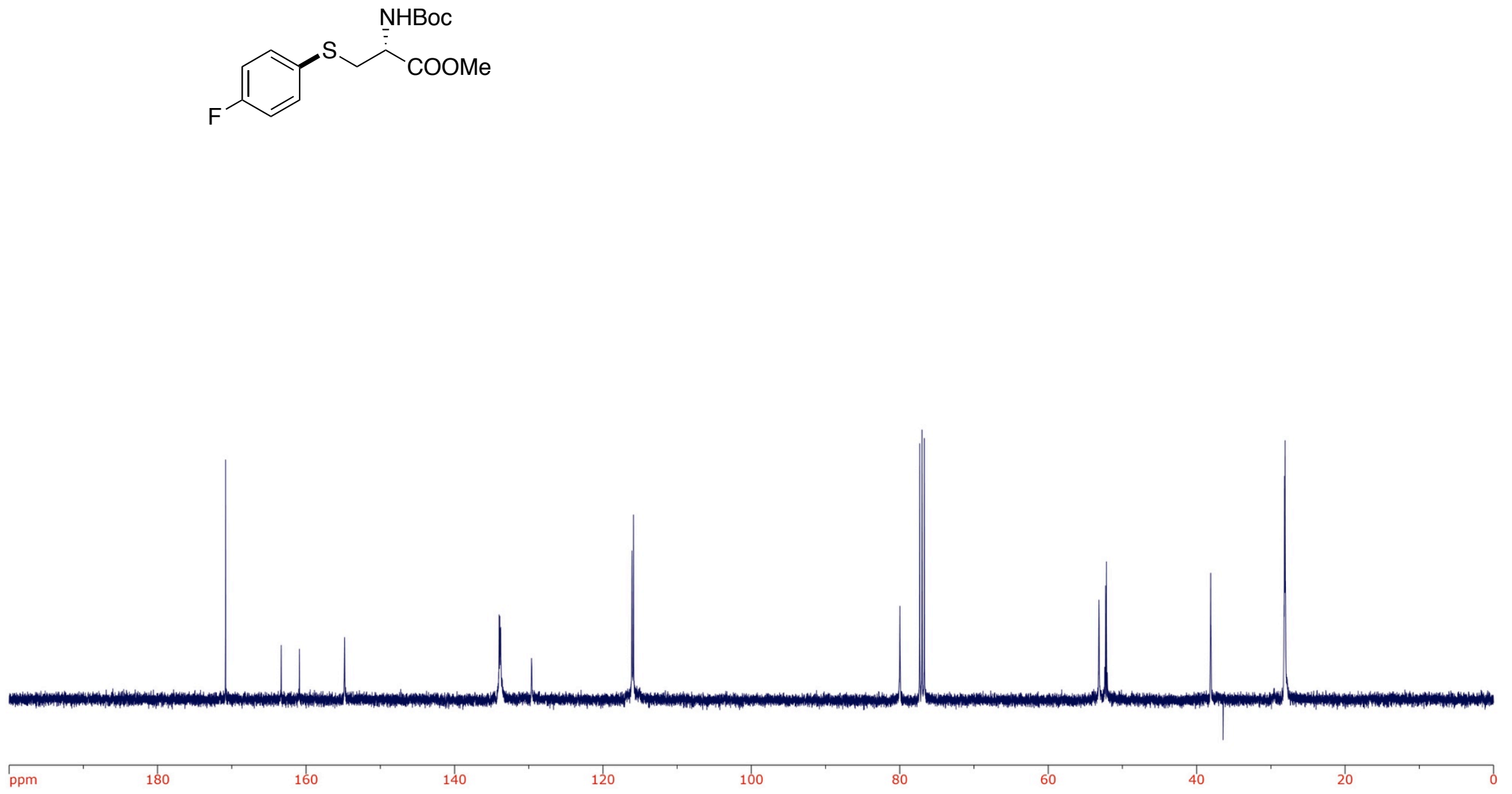


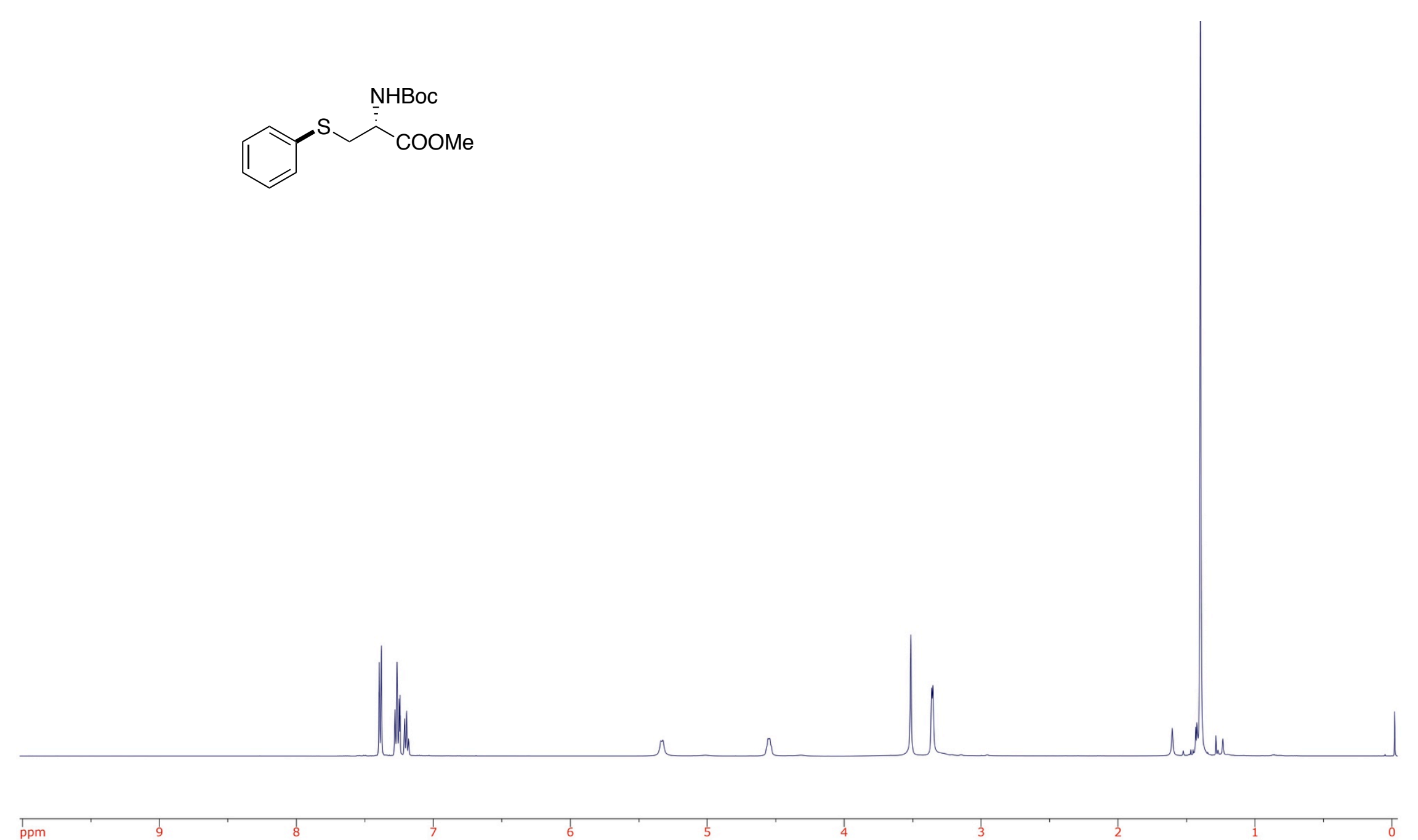


NHBoc

I

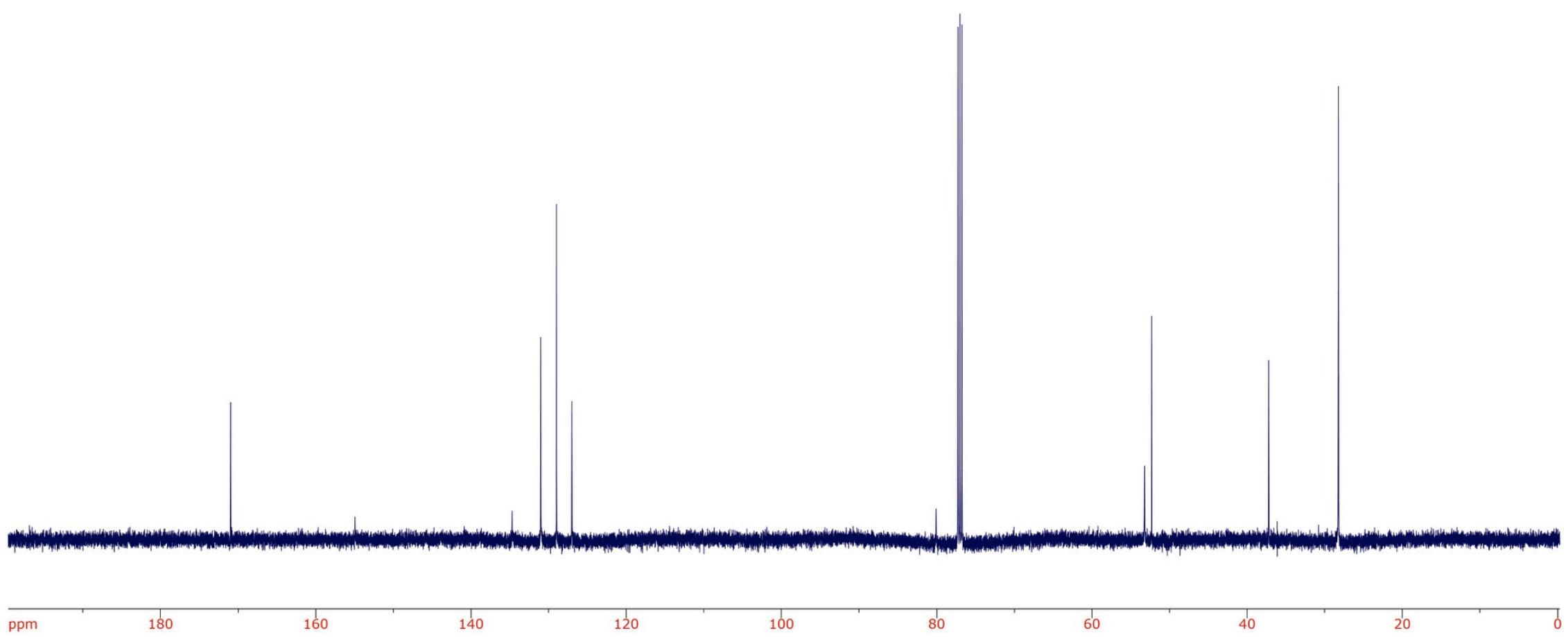


NHBoc
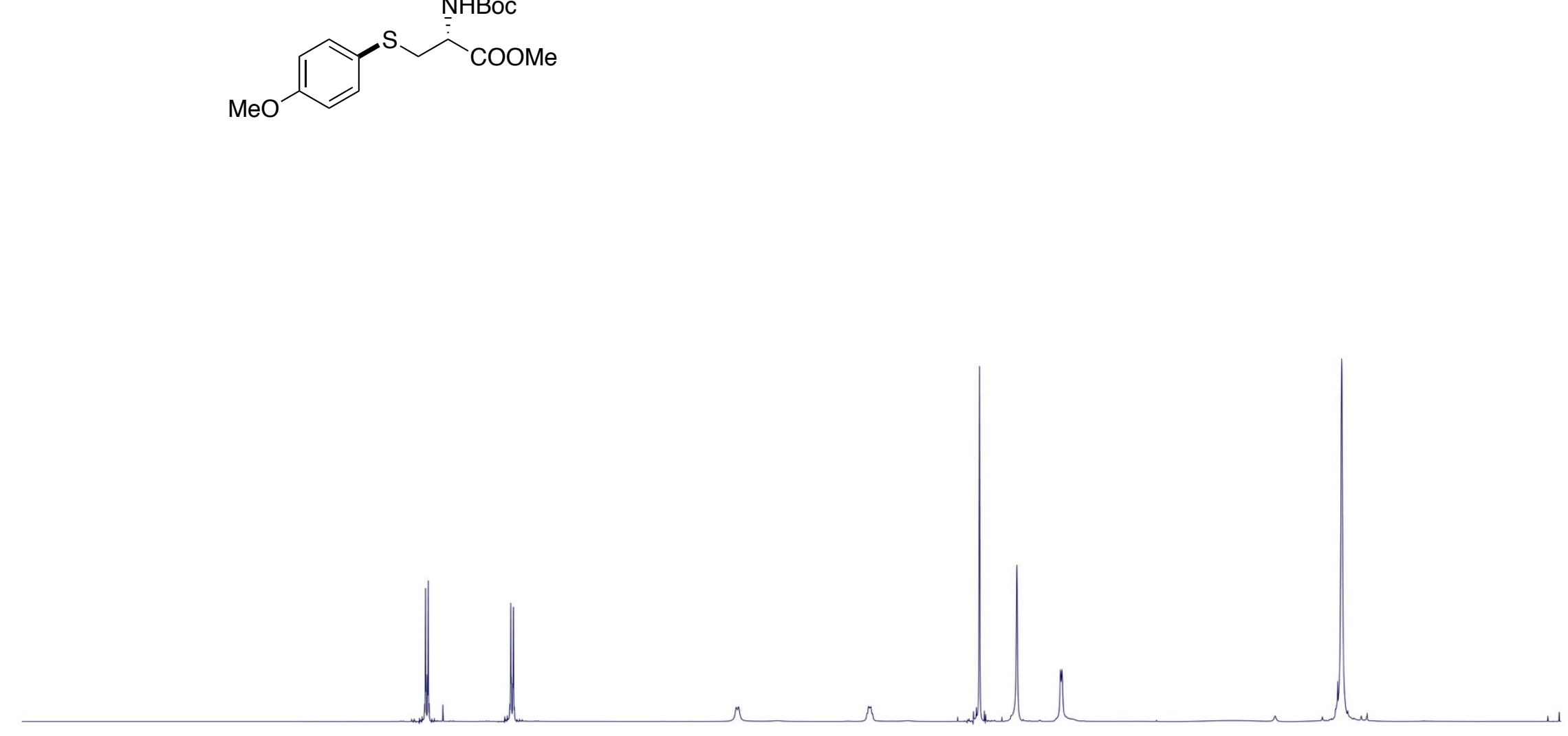


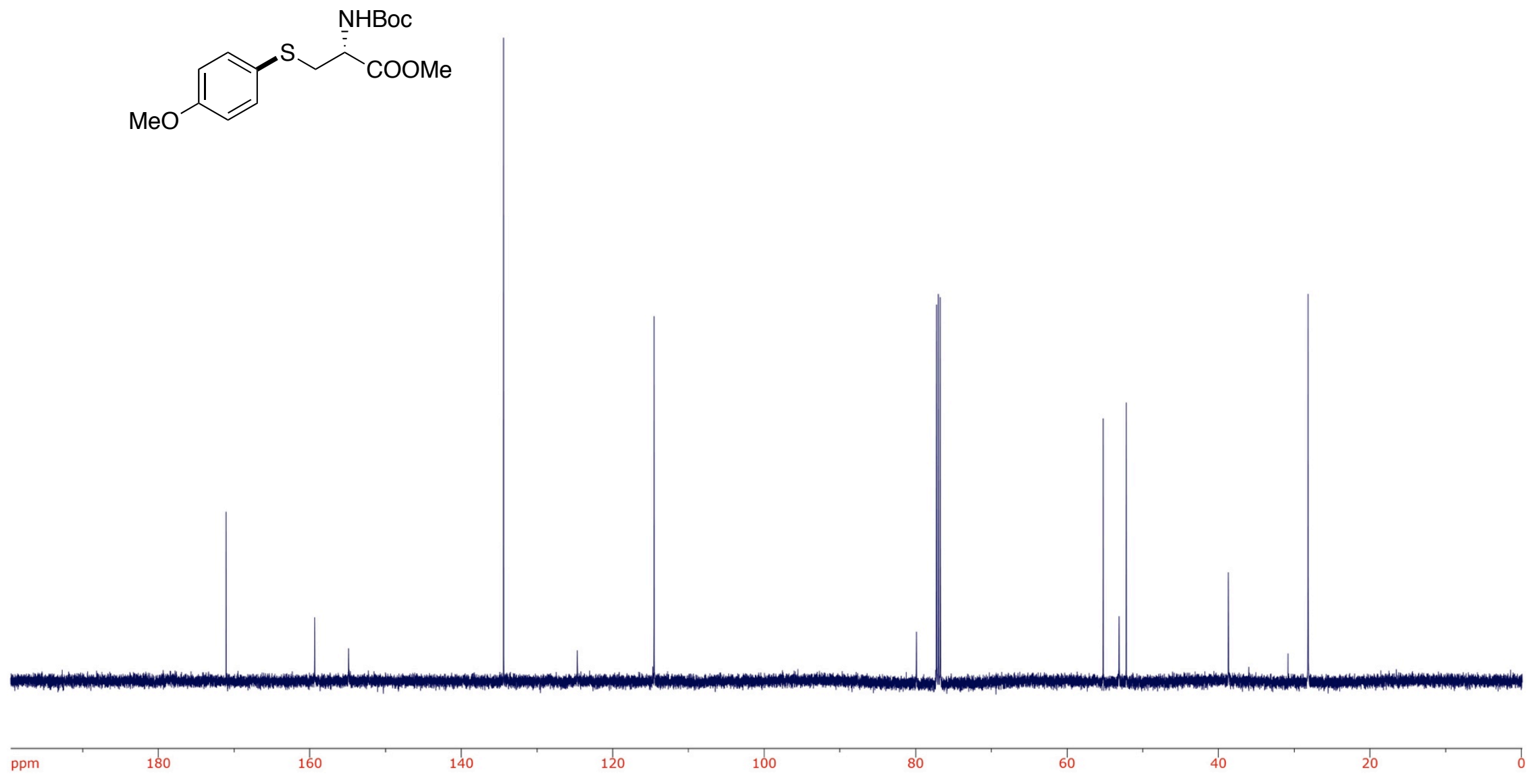




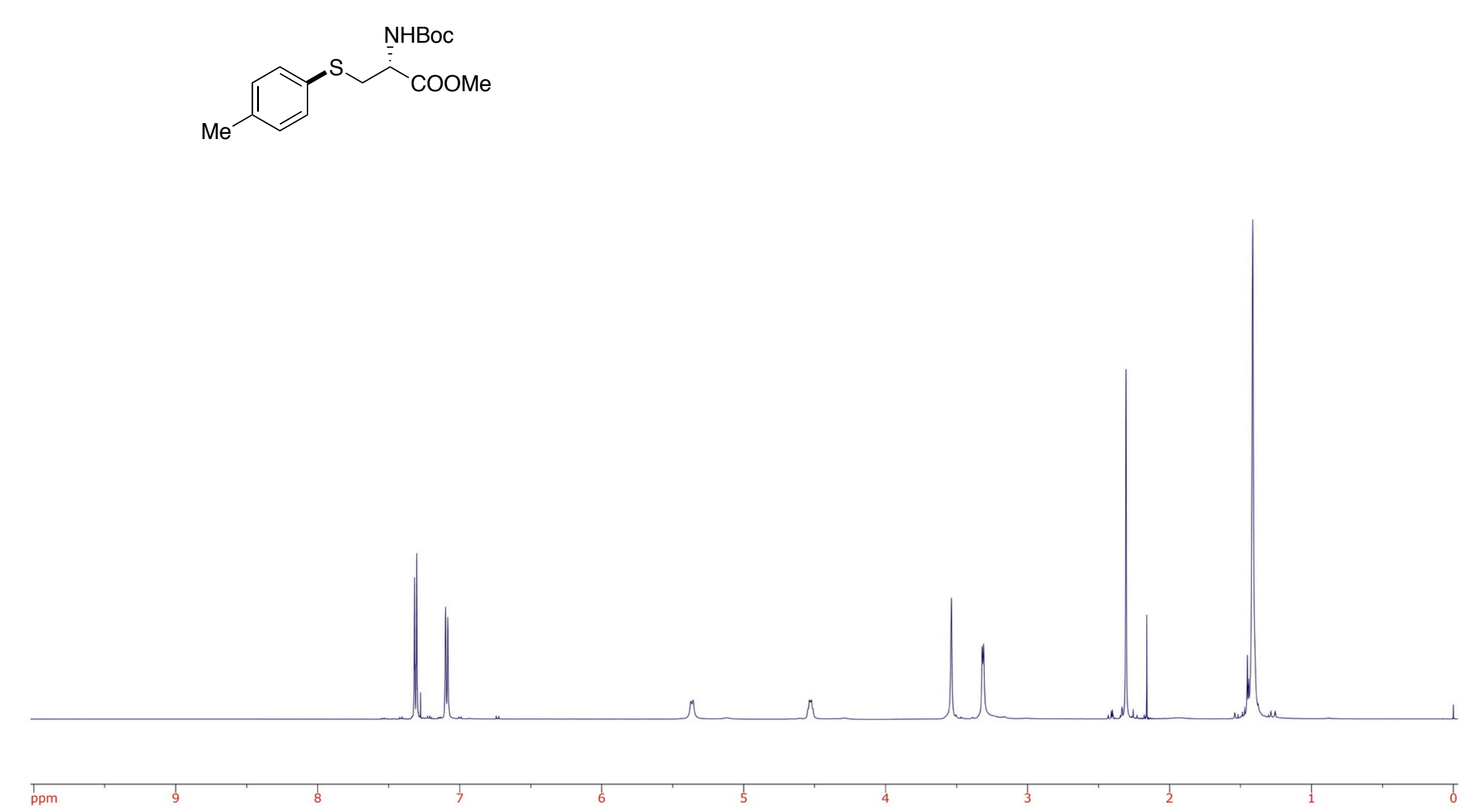


NHBoc
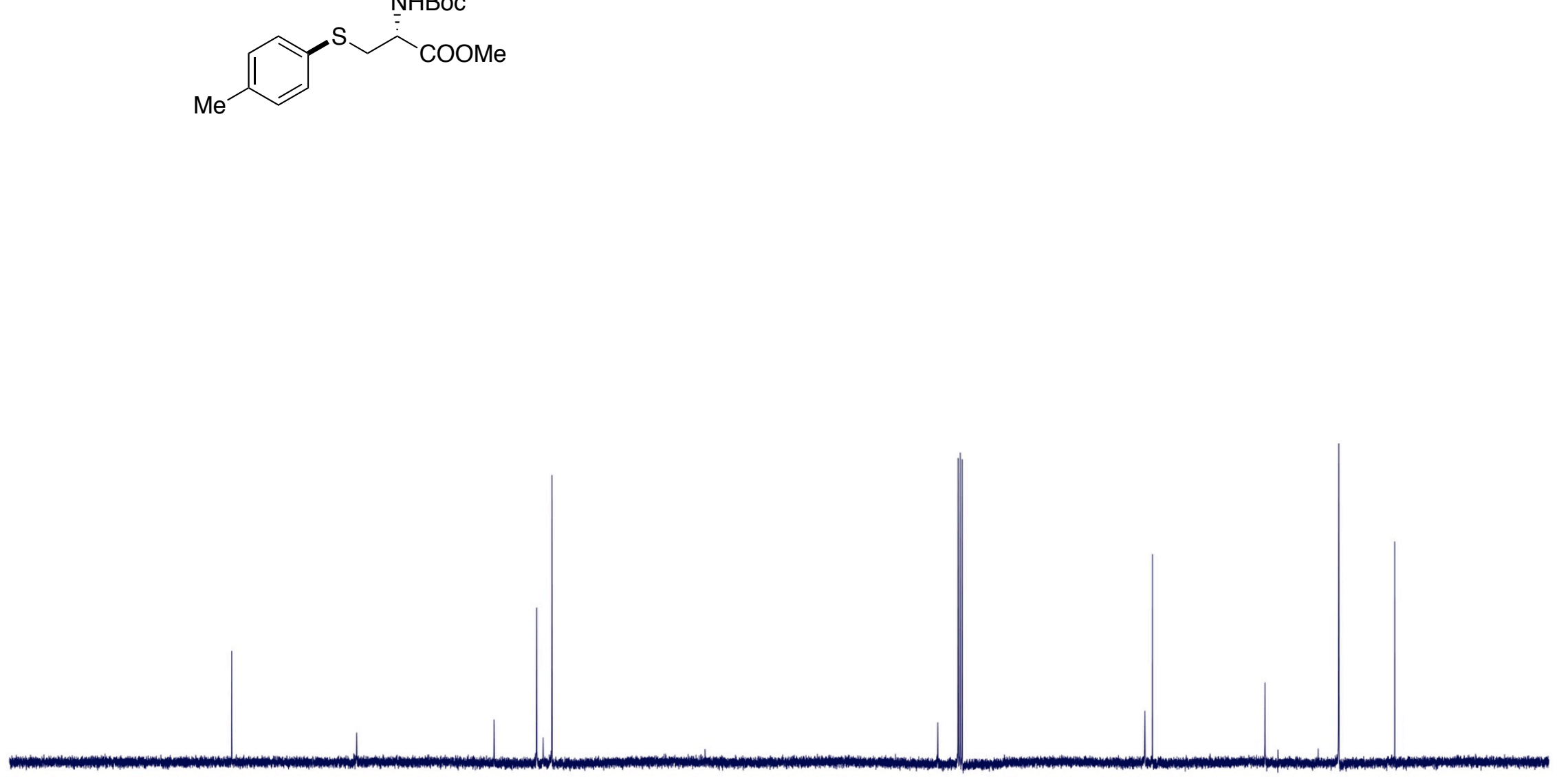

ppm 180 160 140 120 
NHBBoc
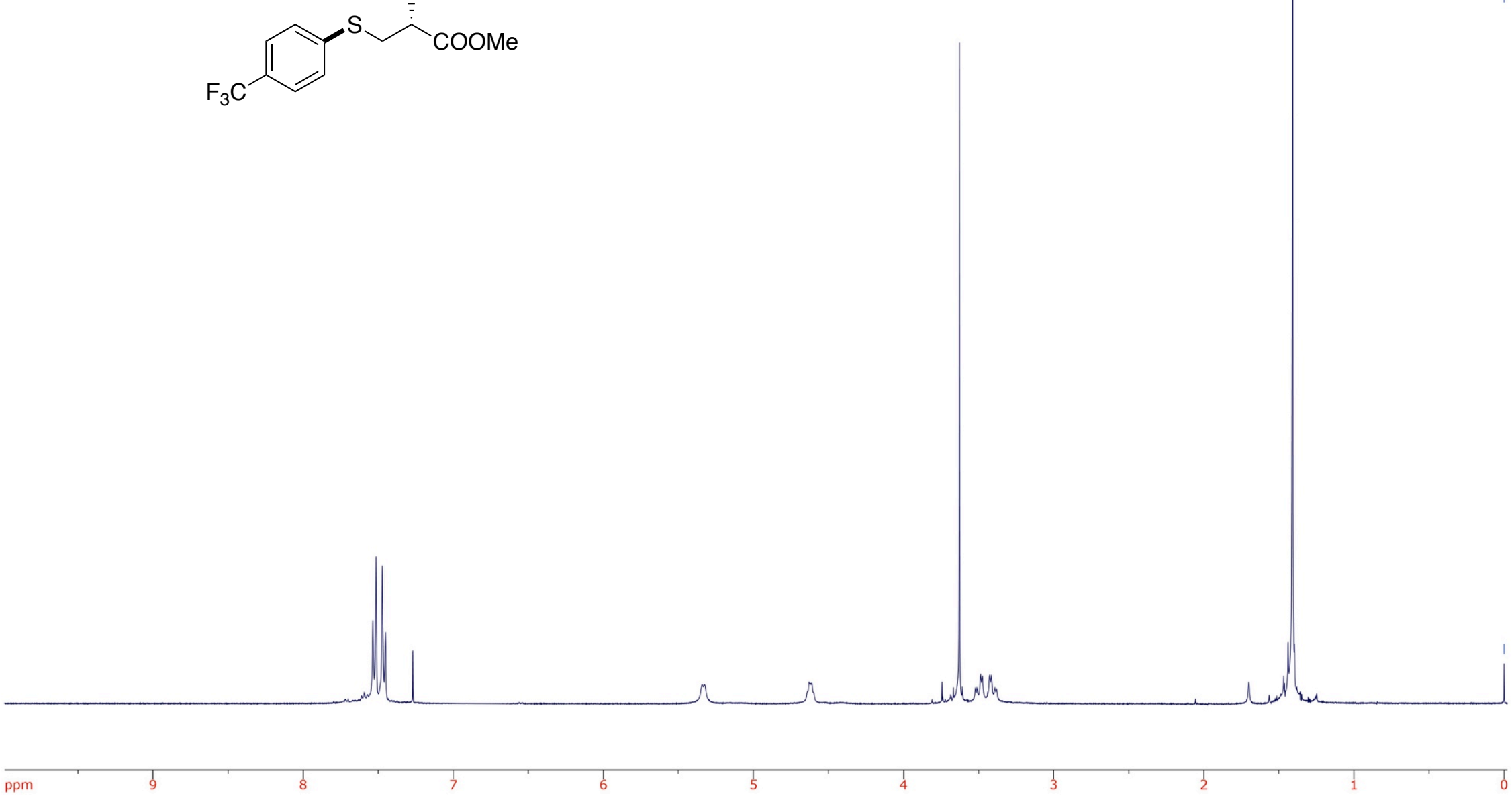
NHBoc

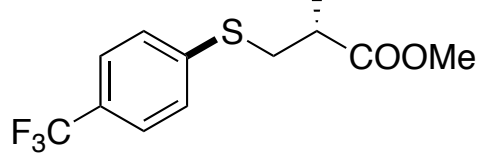


NHBoc
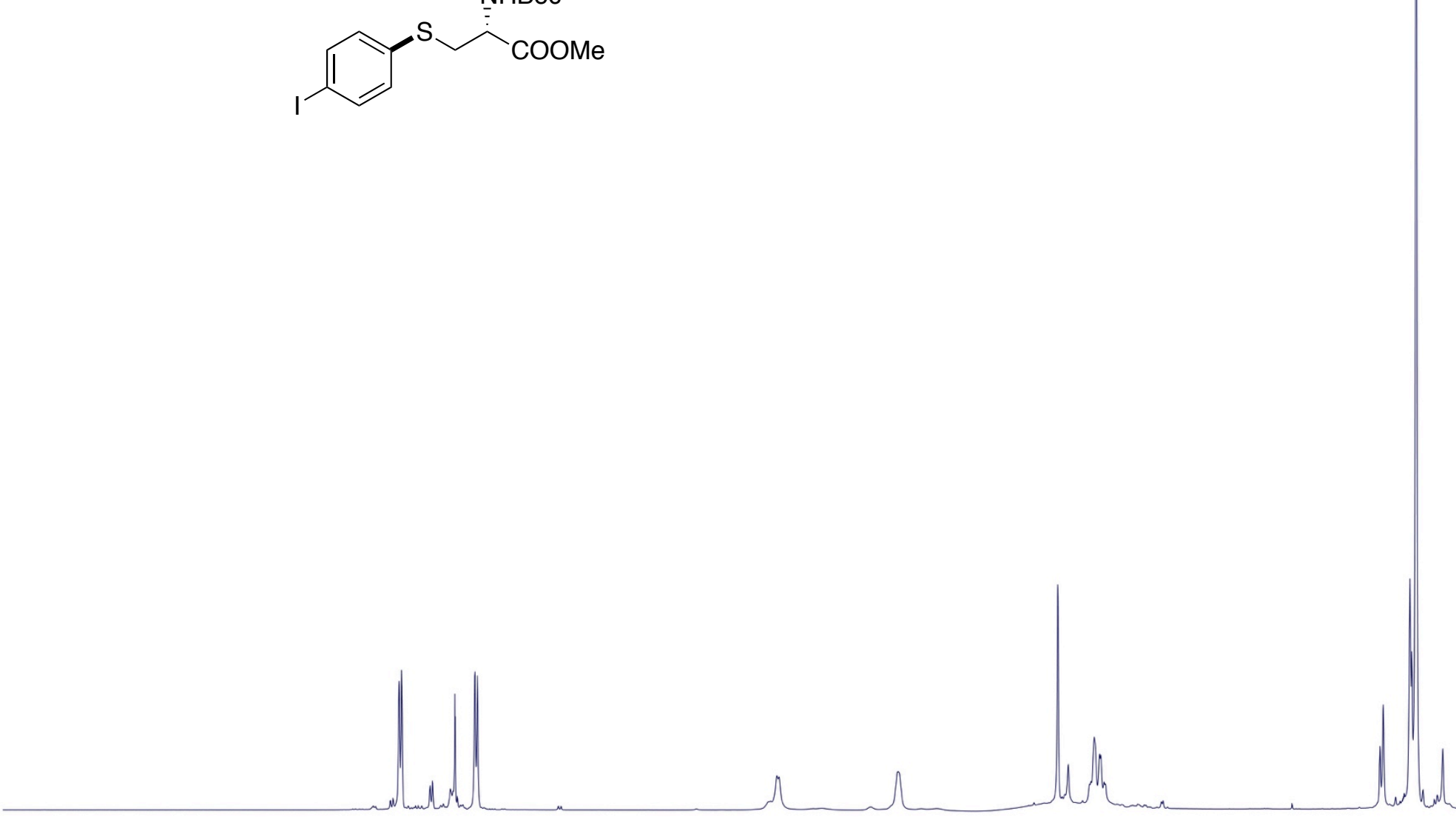

ppm 


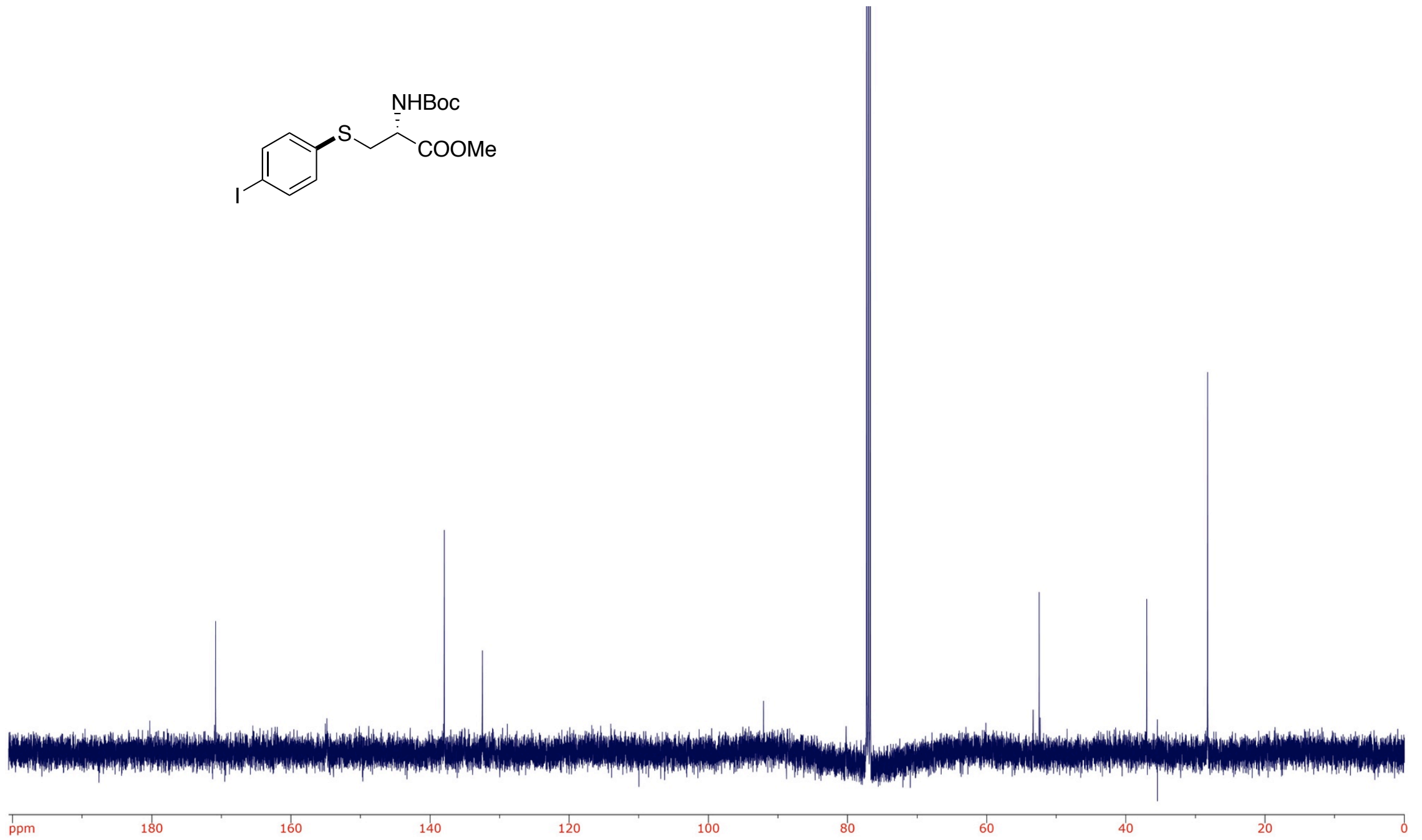



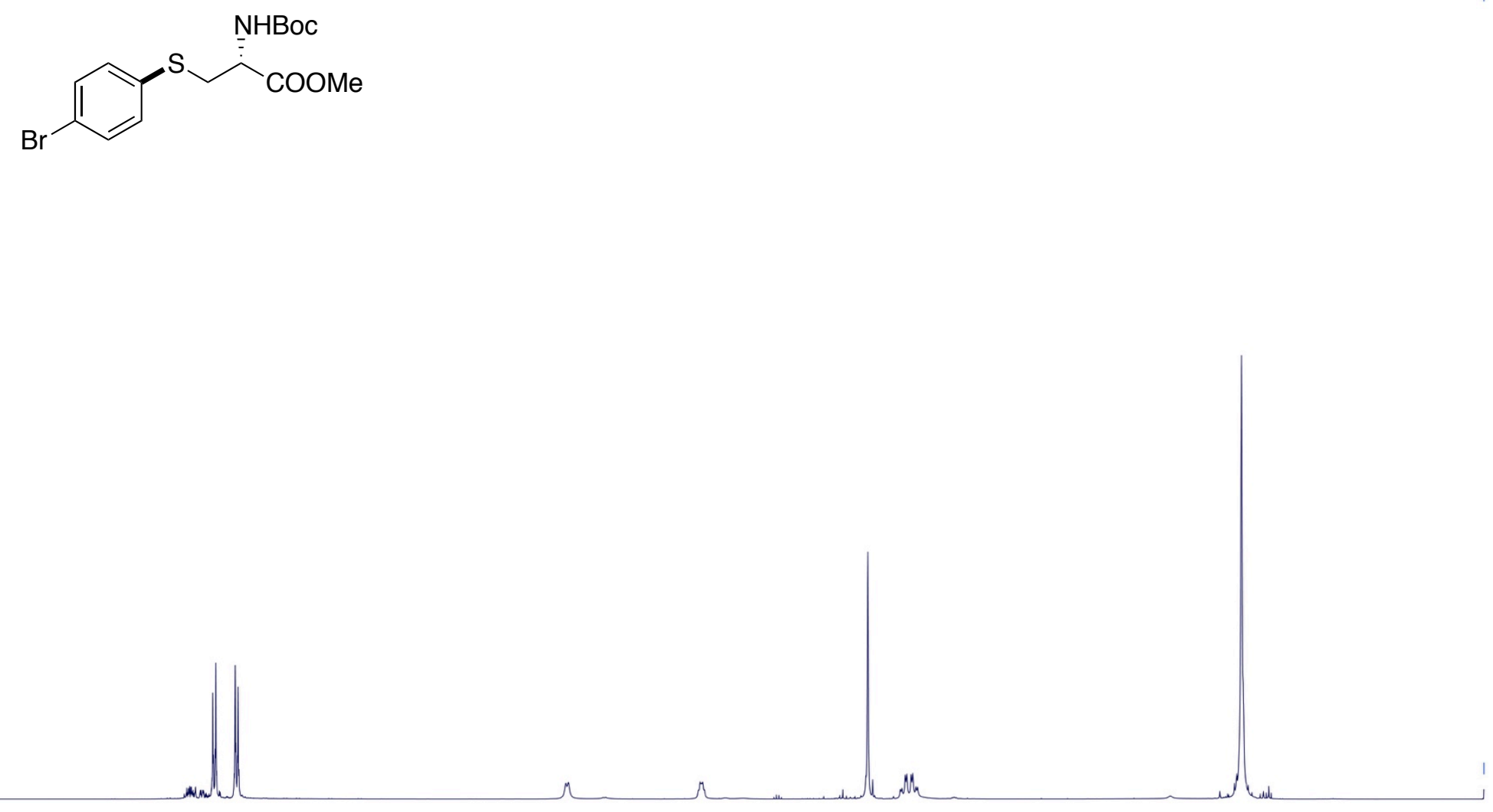

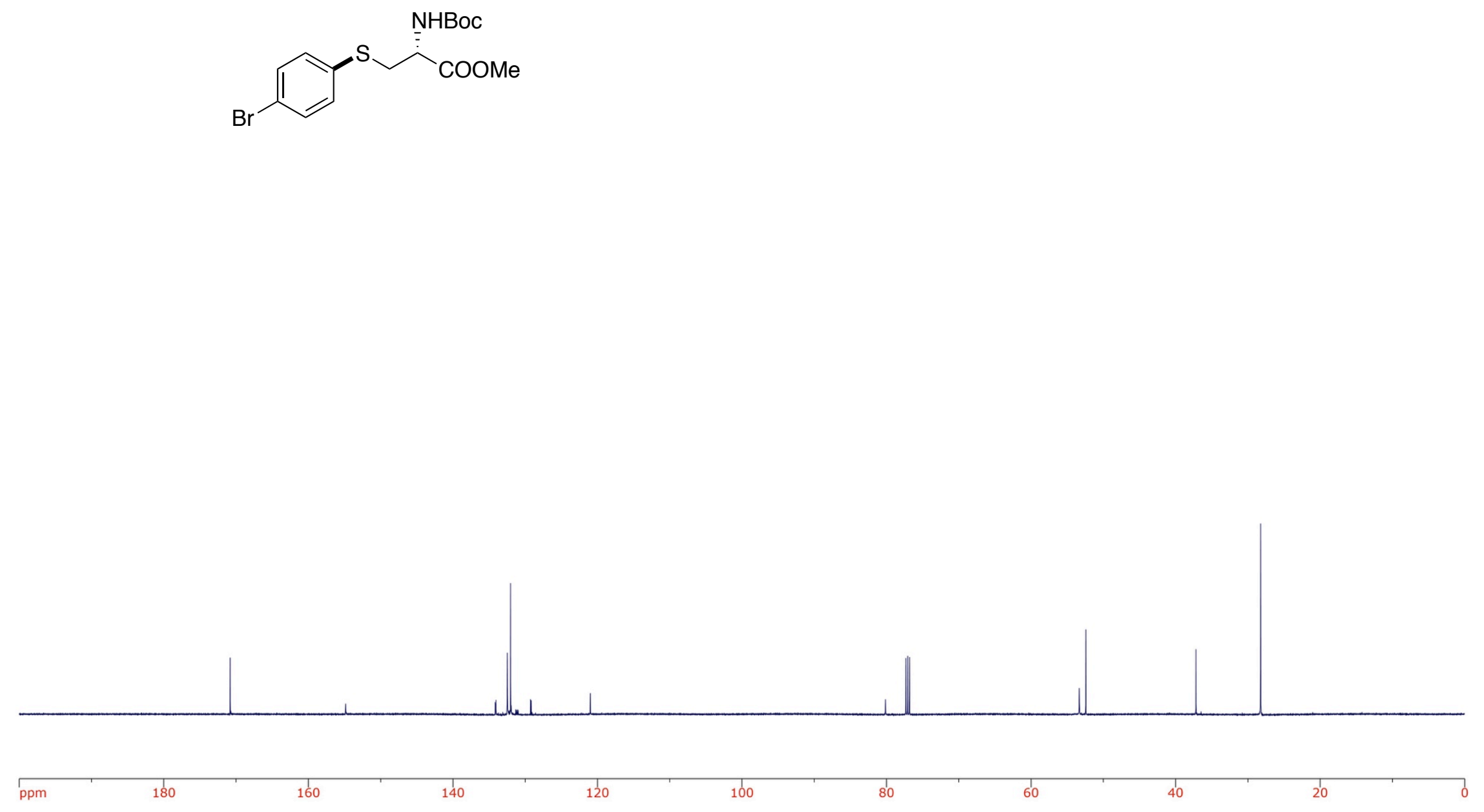
NHBoc
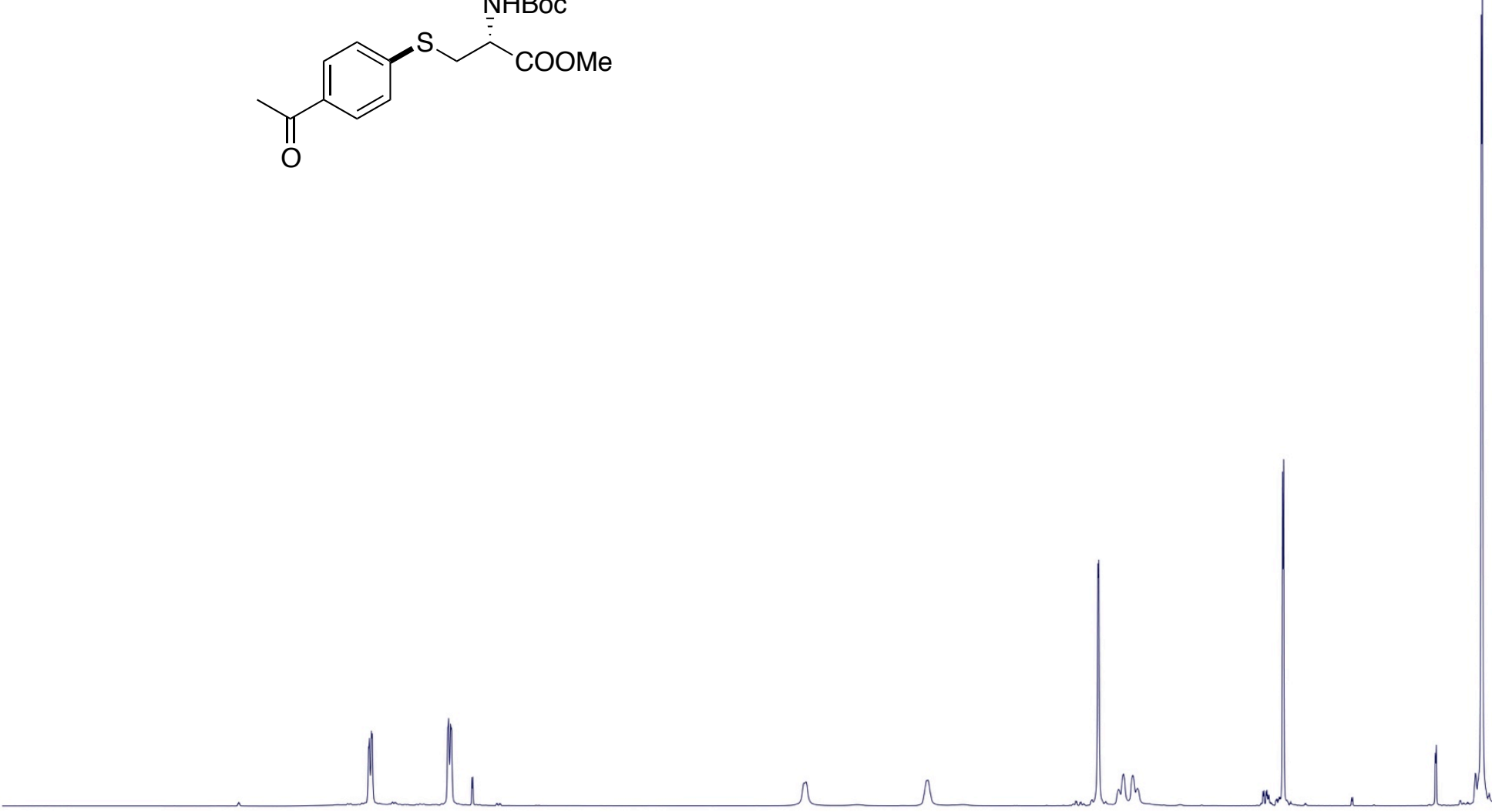
NHBoc
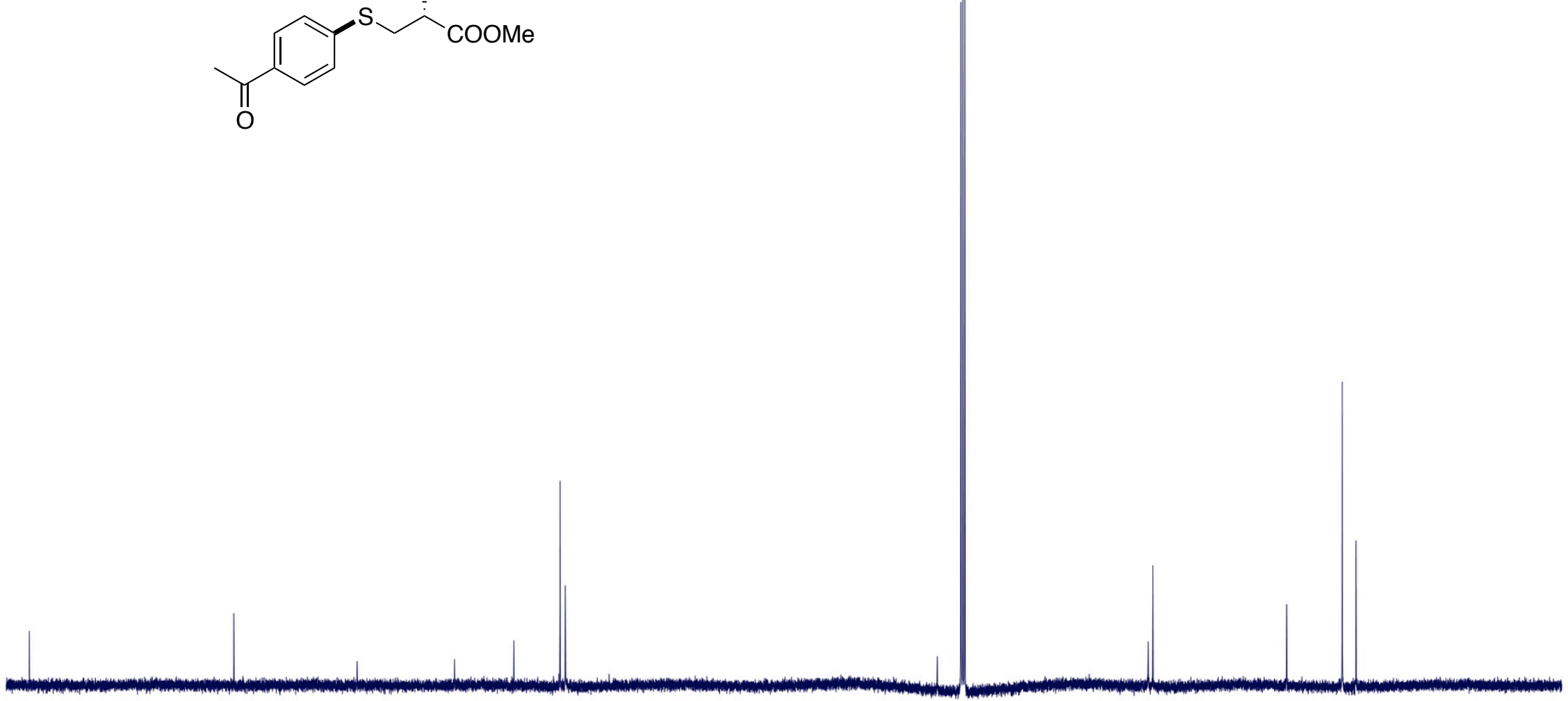

ppm 180 160 120 

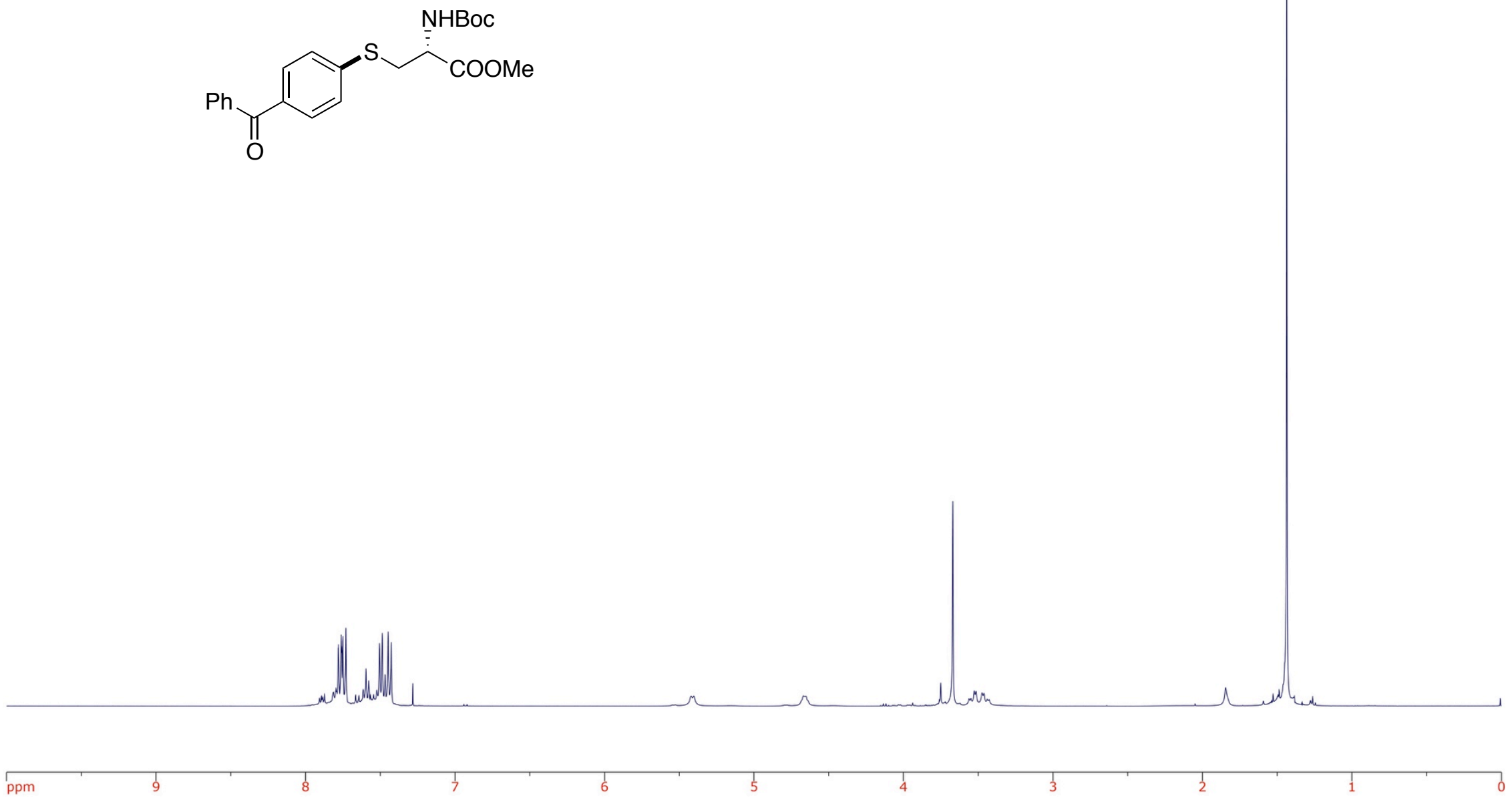


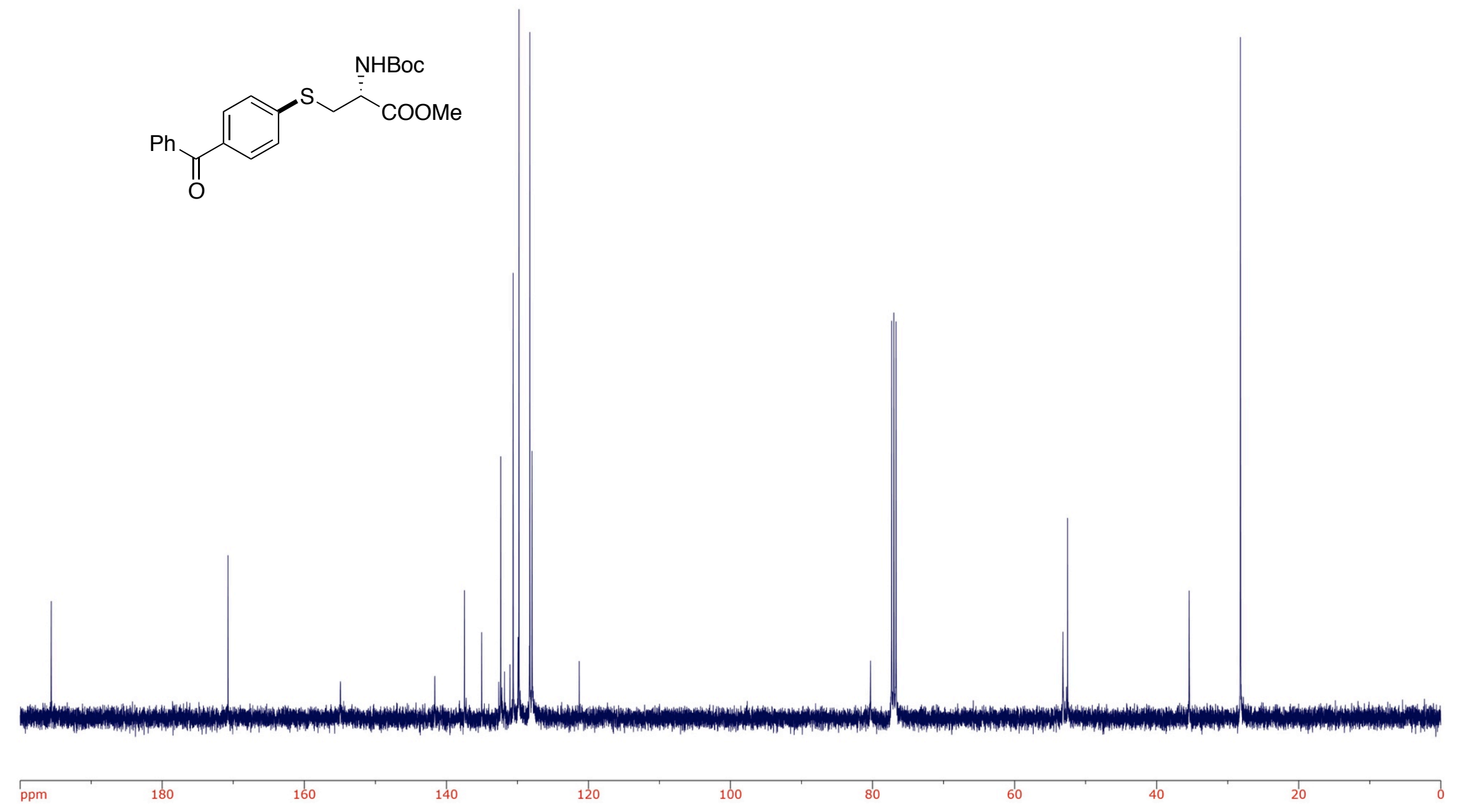


NHBoc
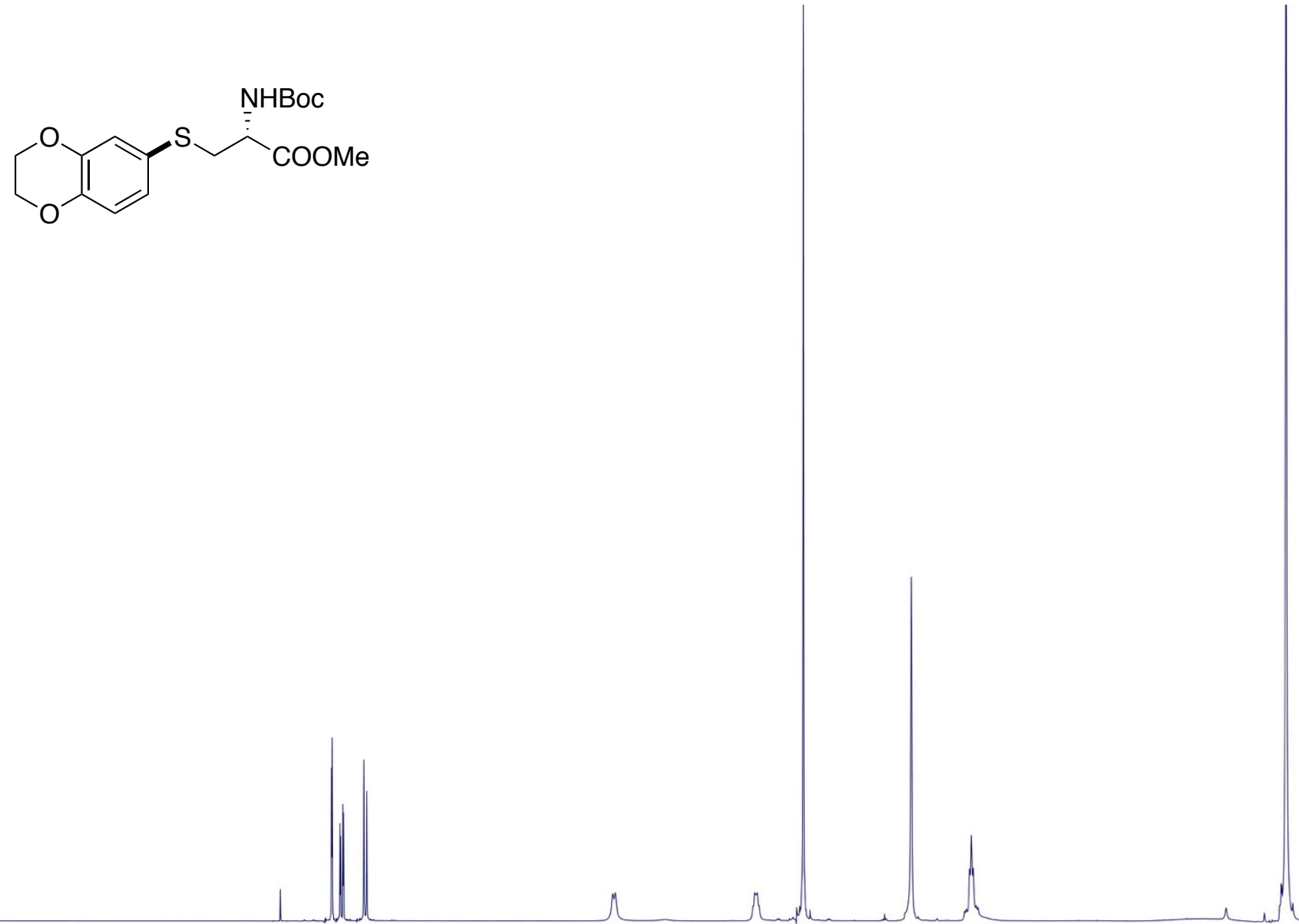

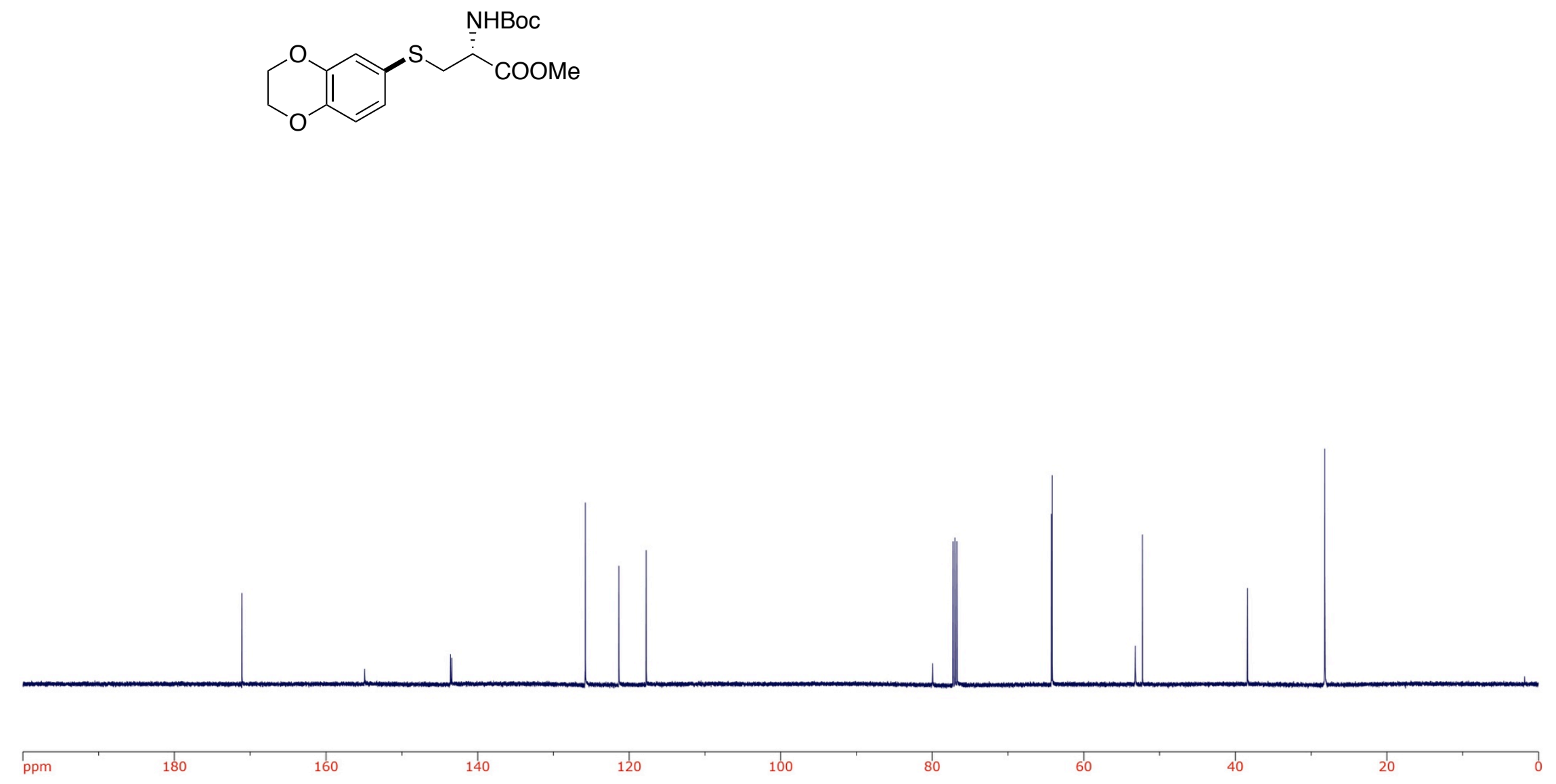


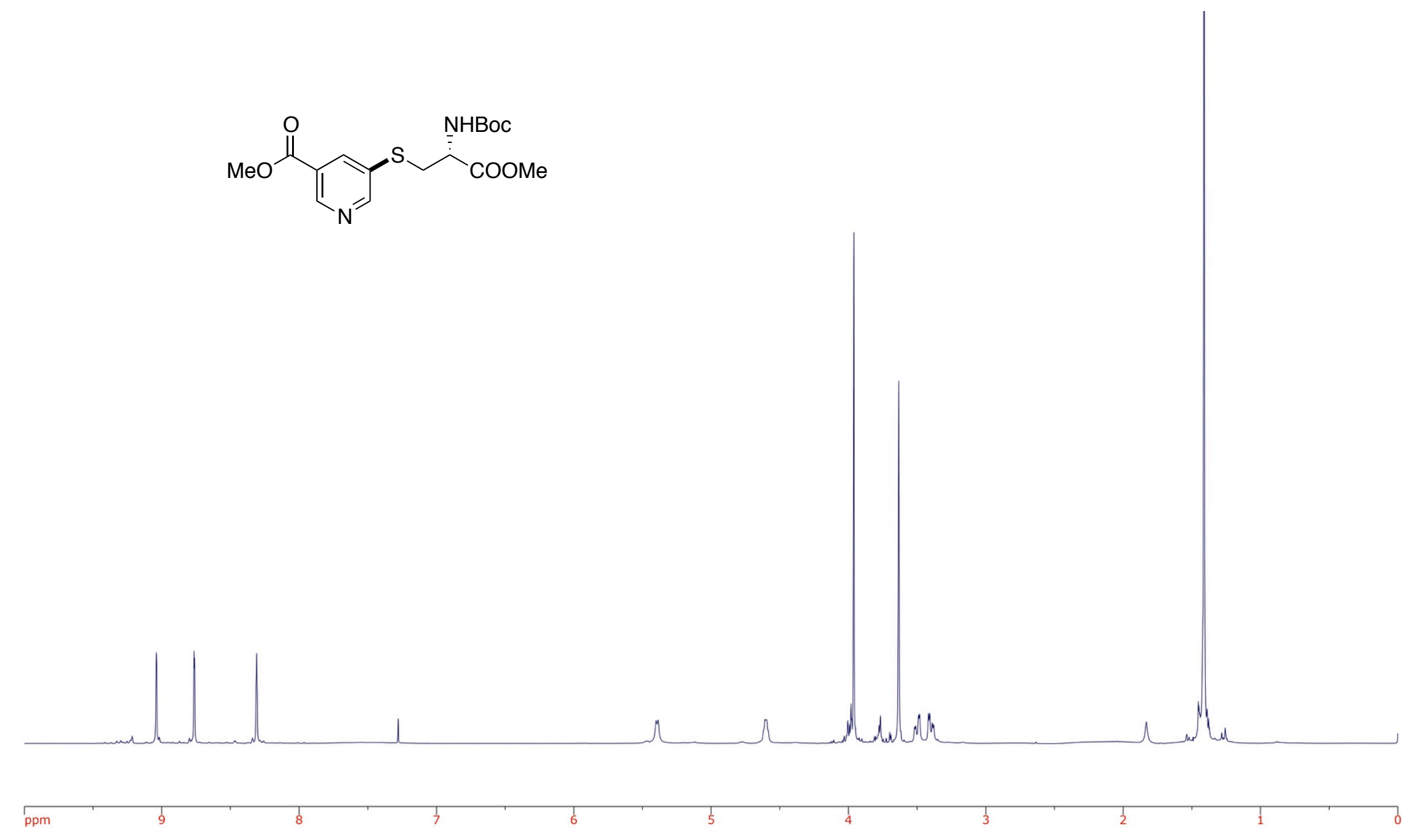



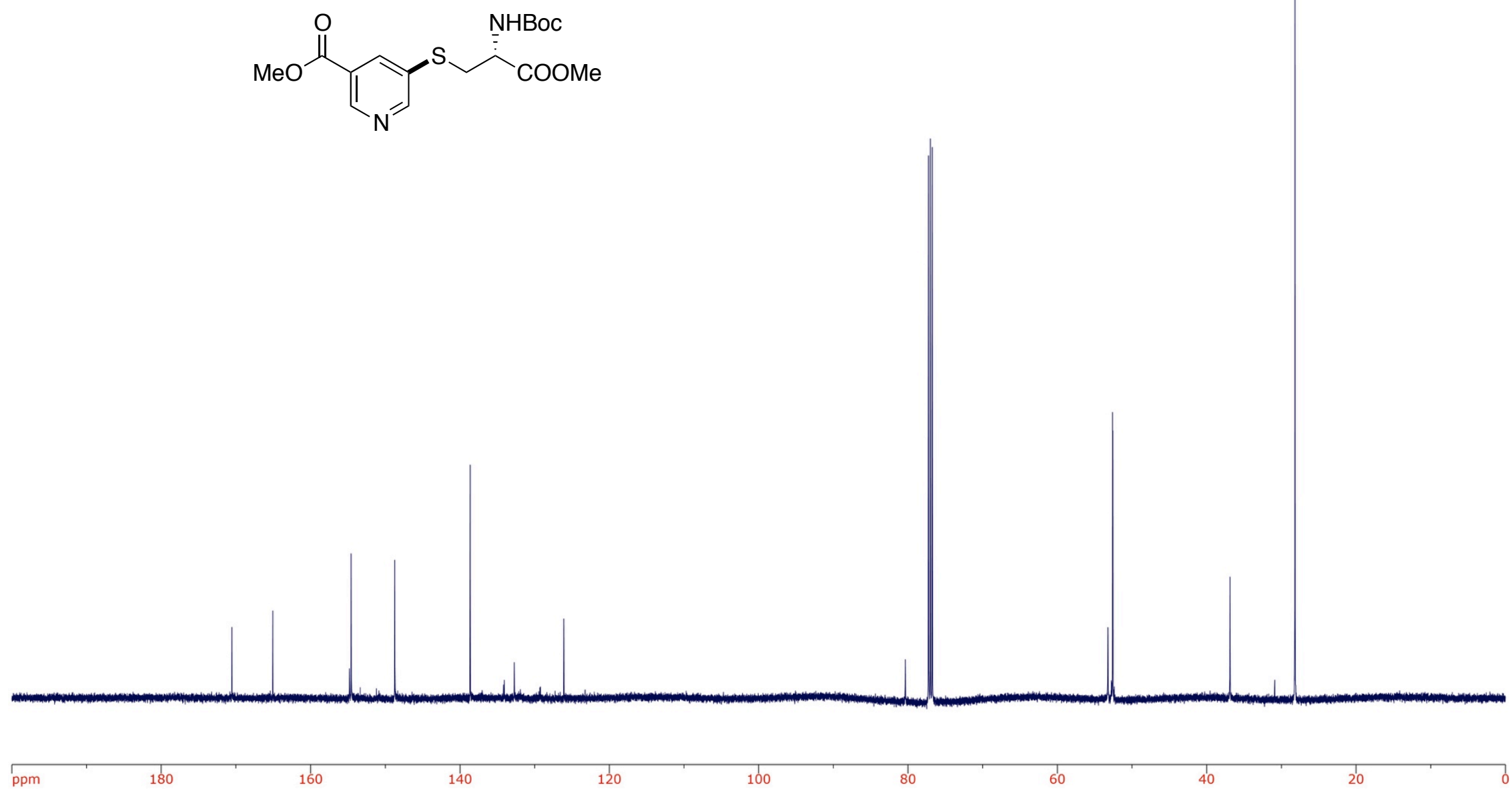

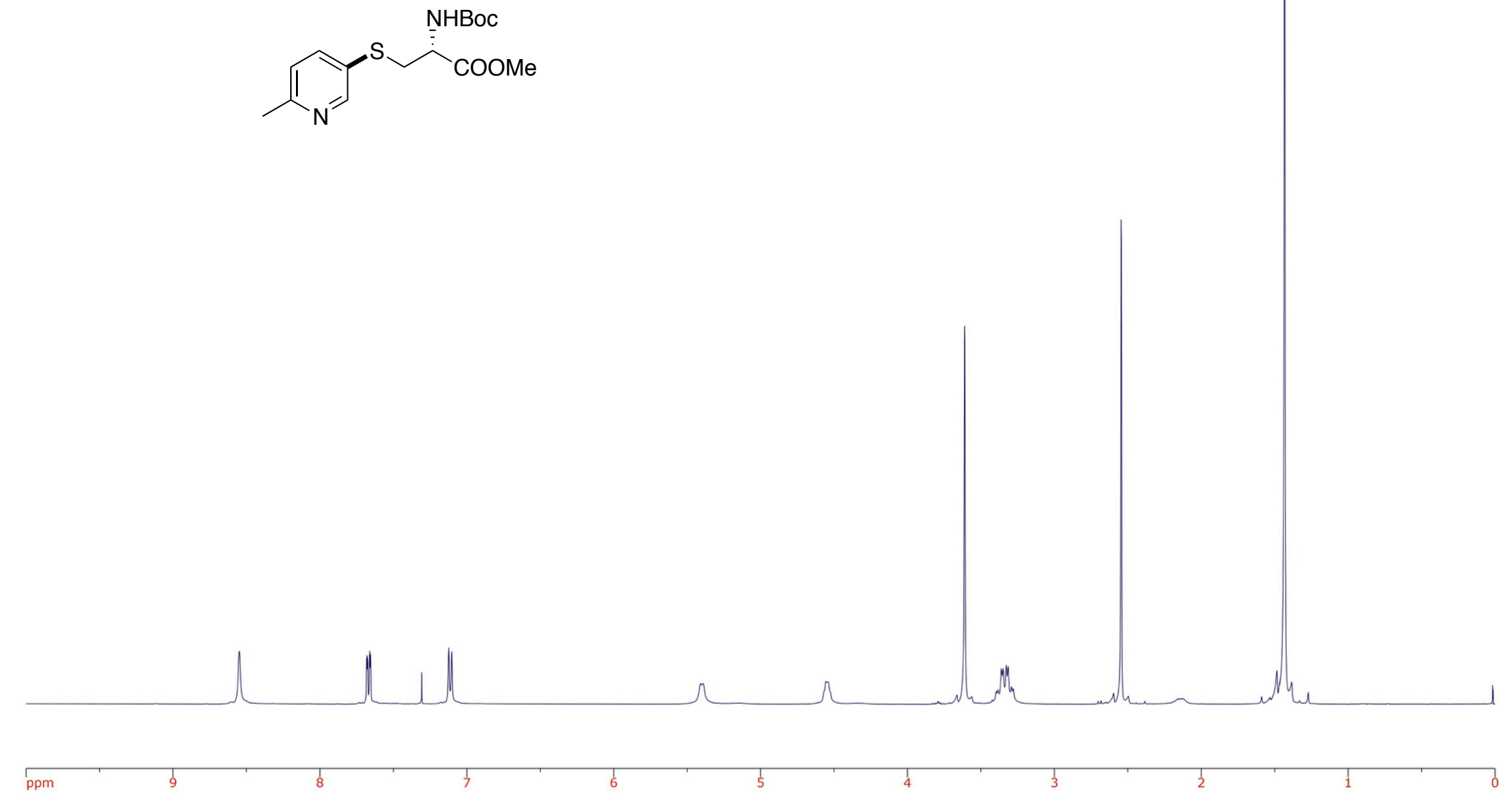

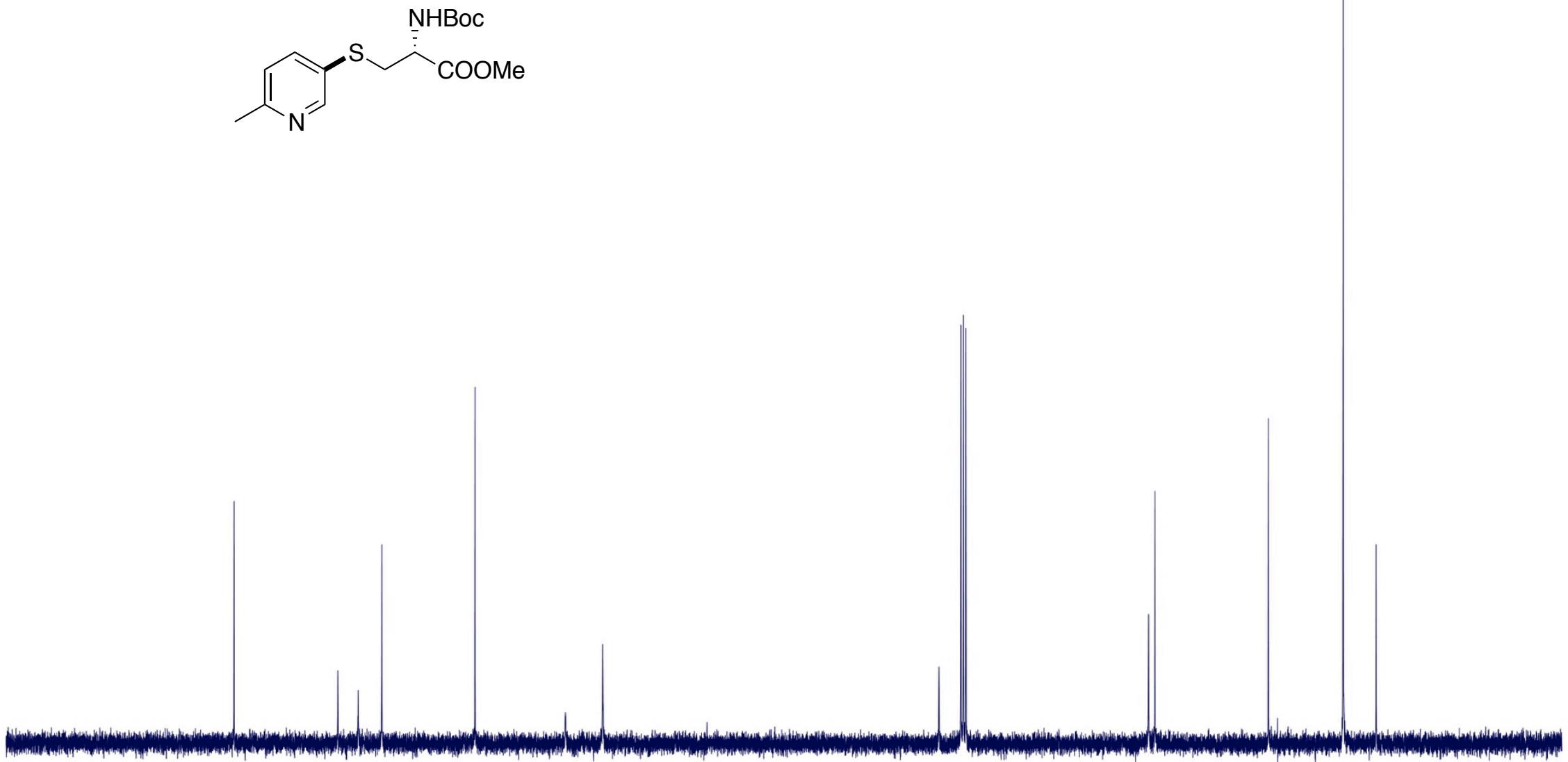

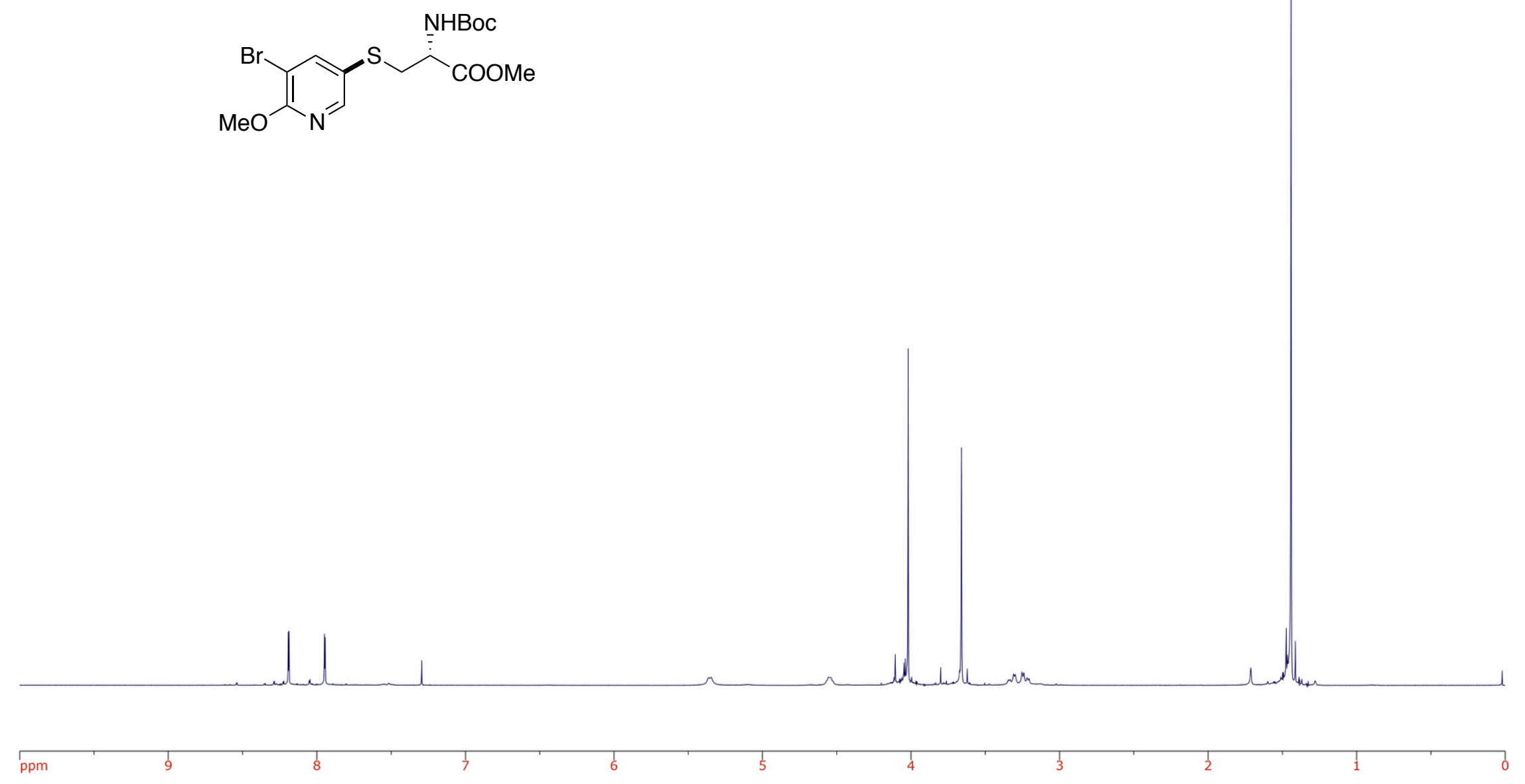


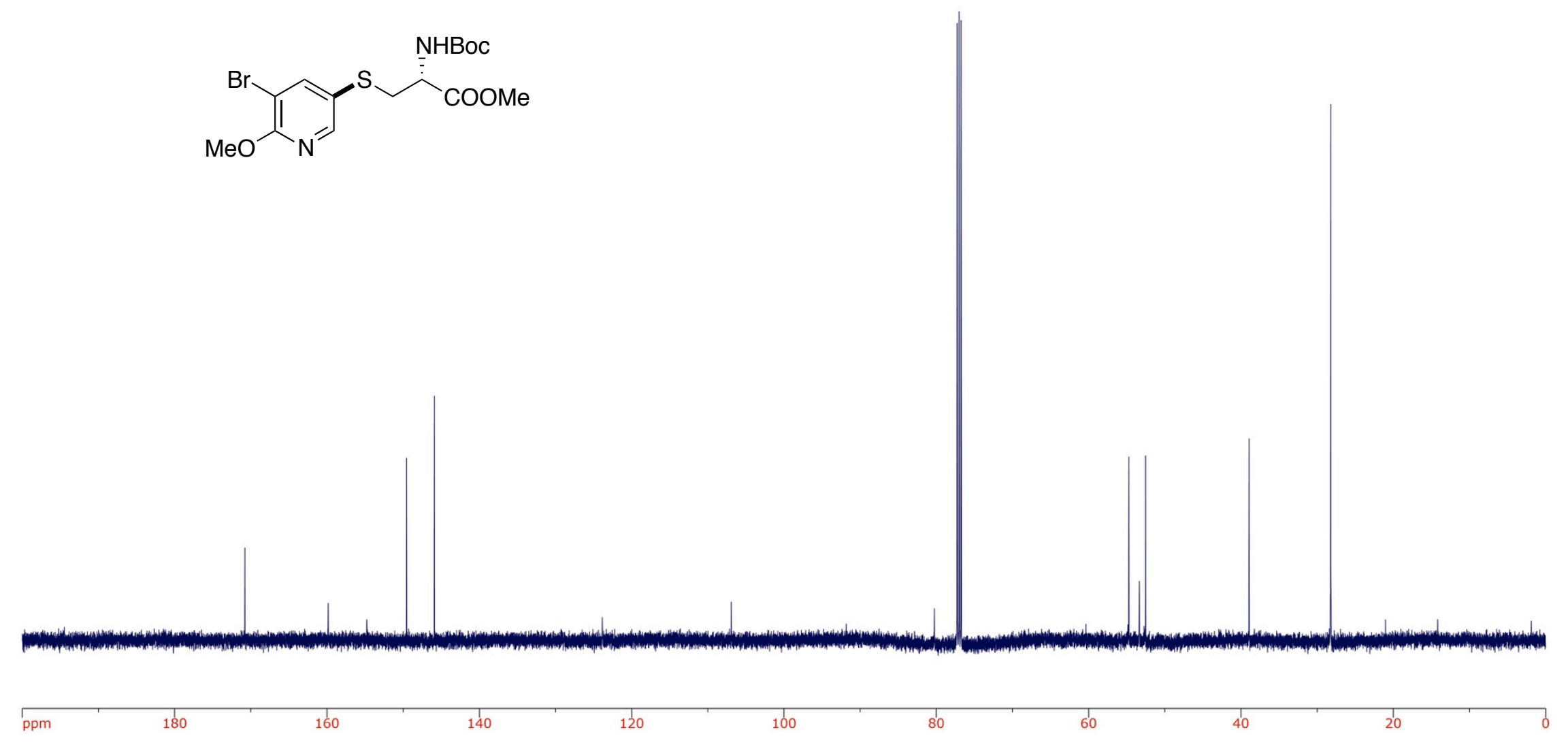



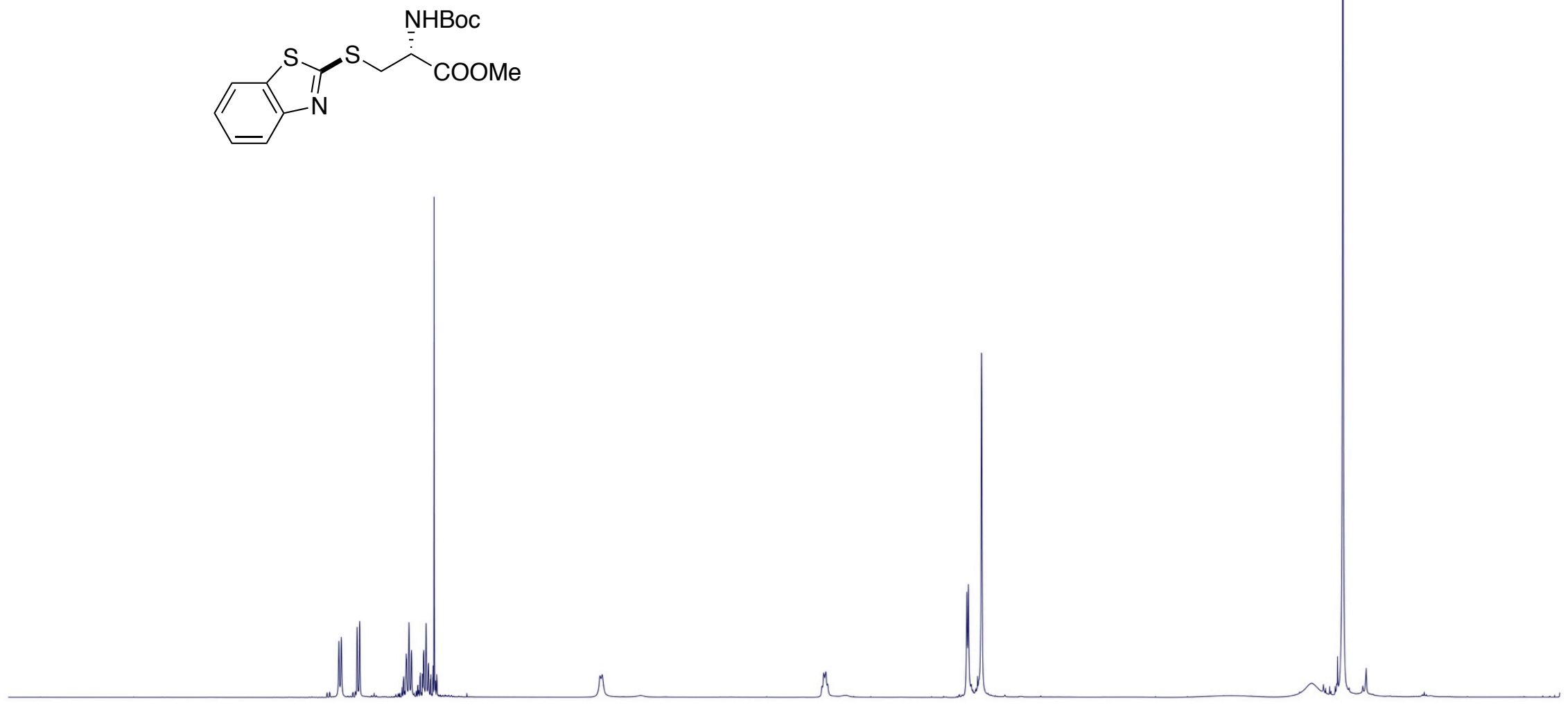


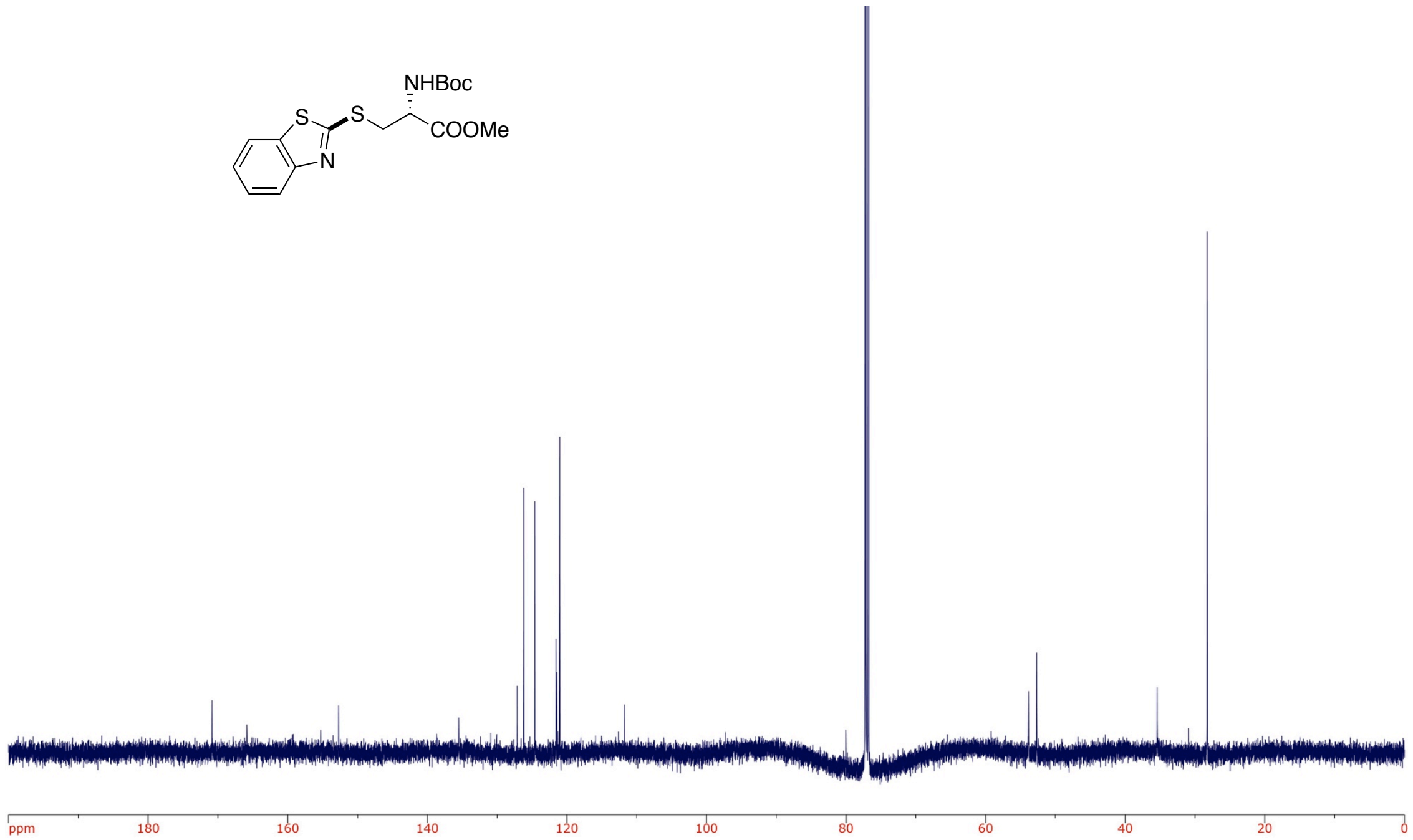


NHBoc

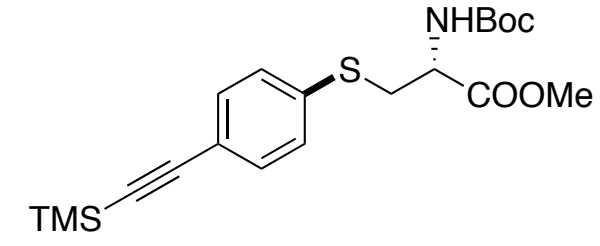

||
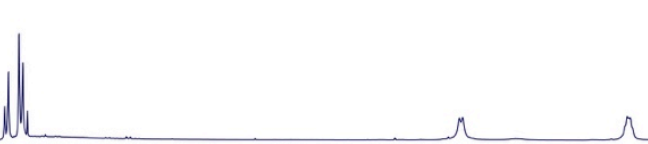
du

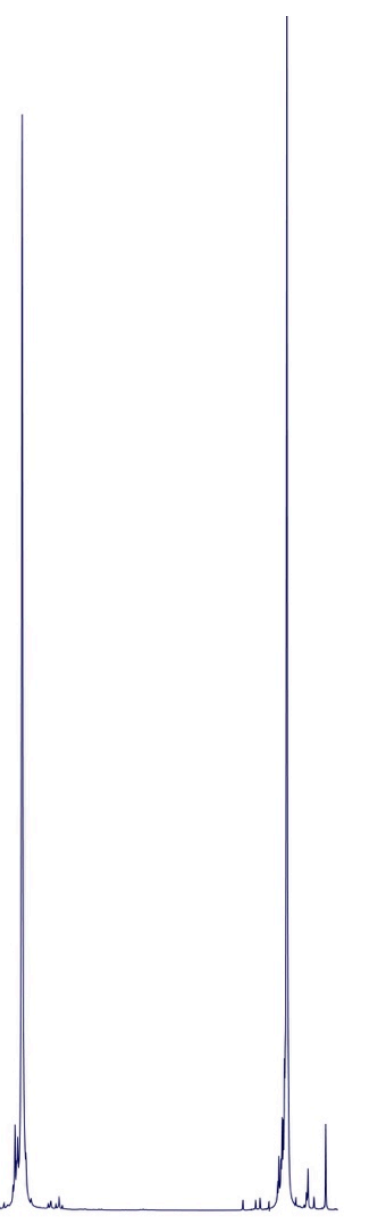



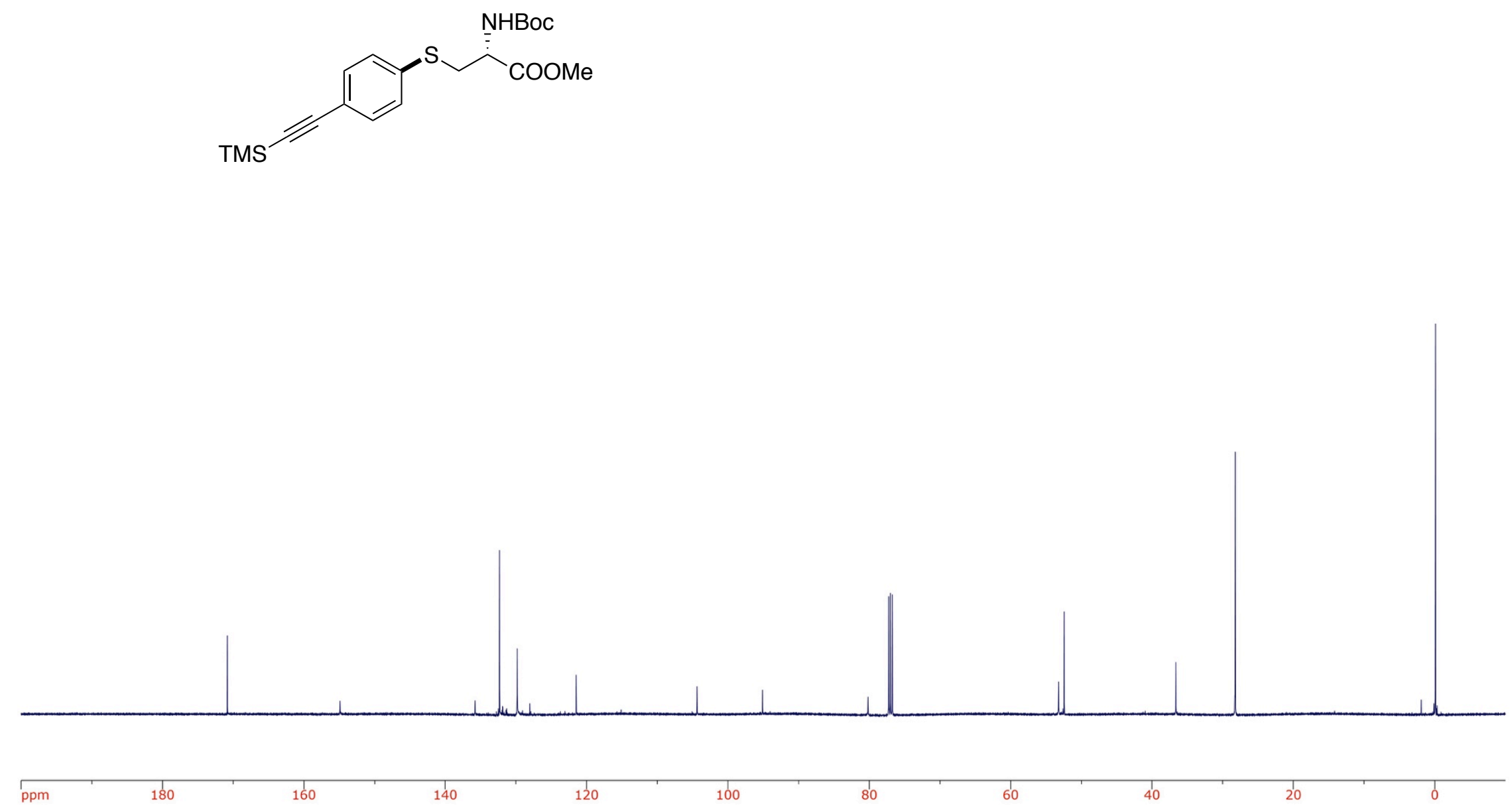

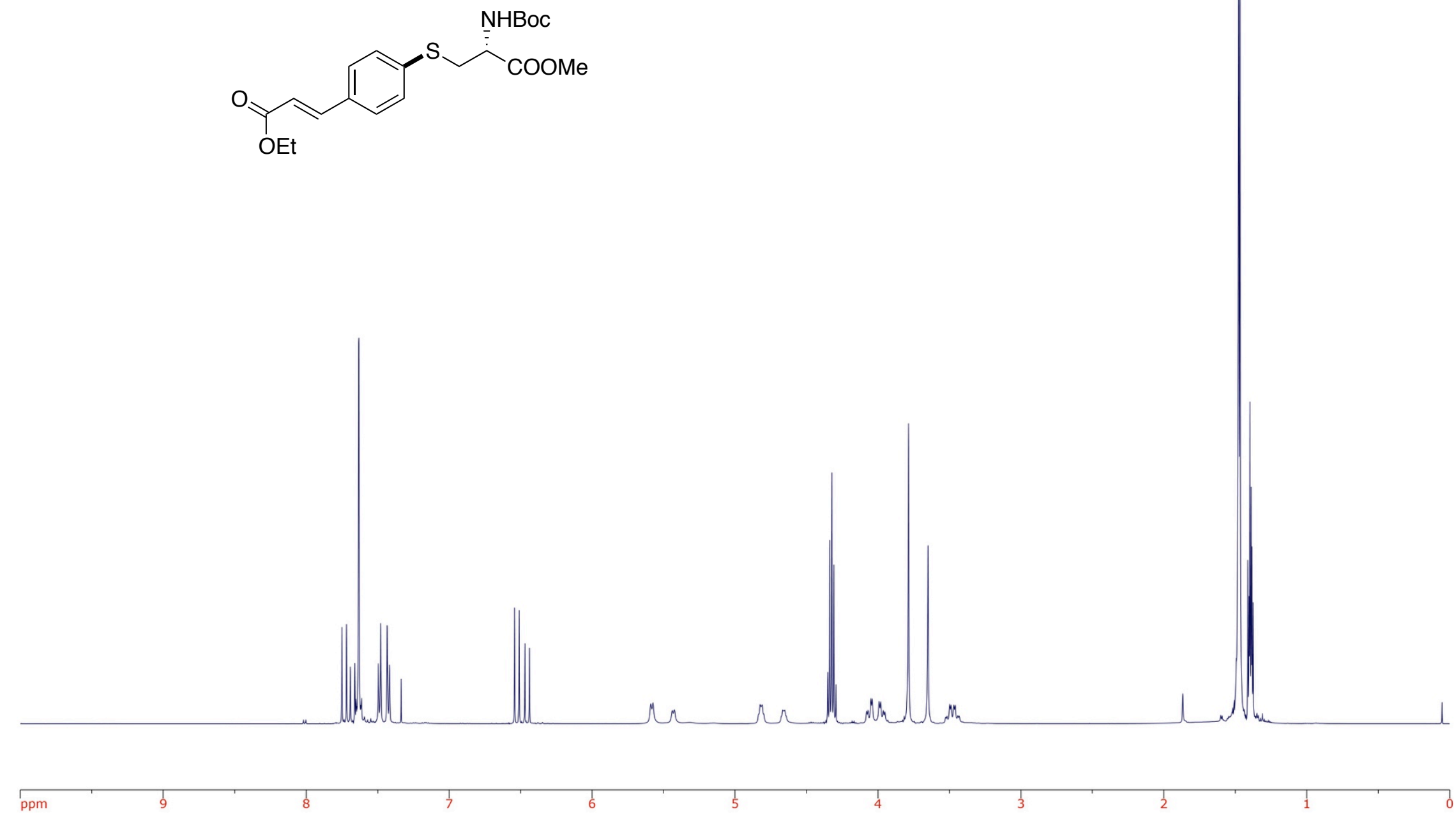

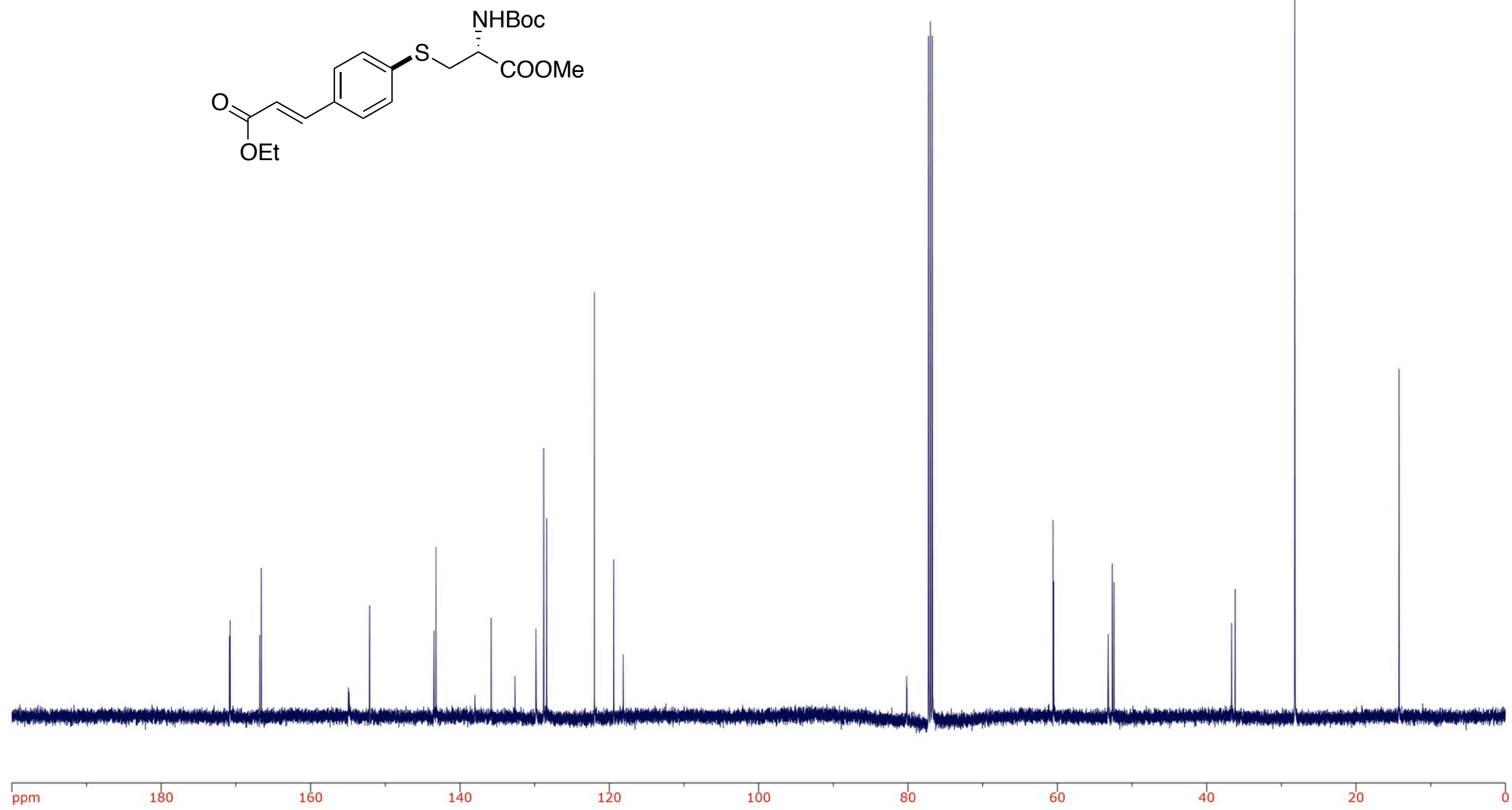

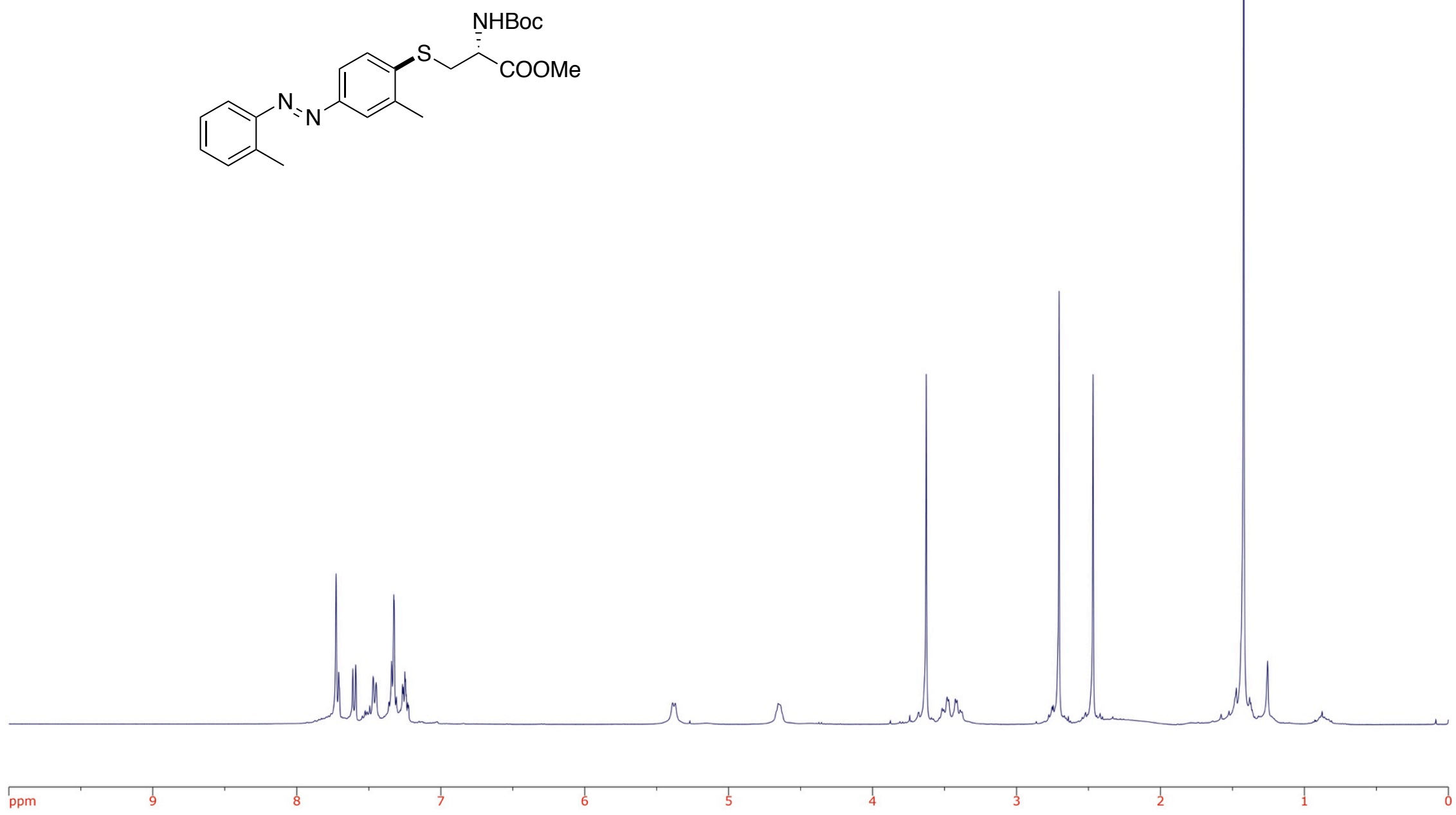

S365 

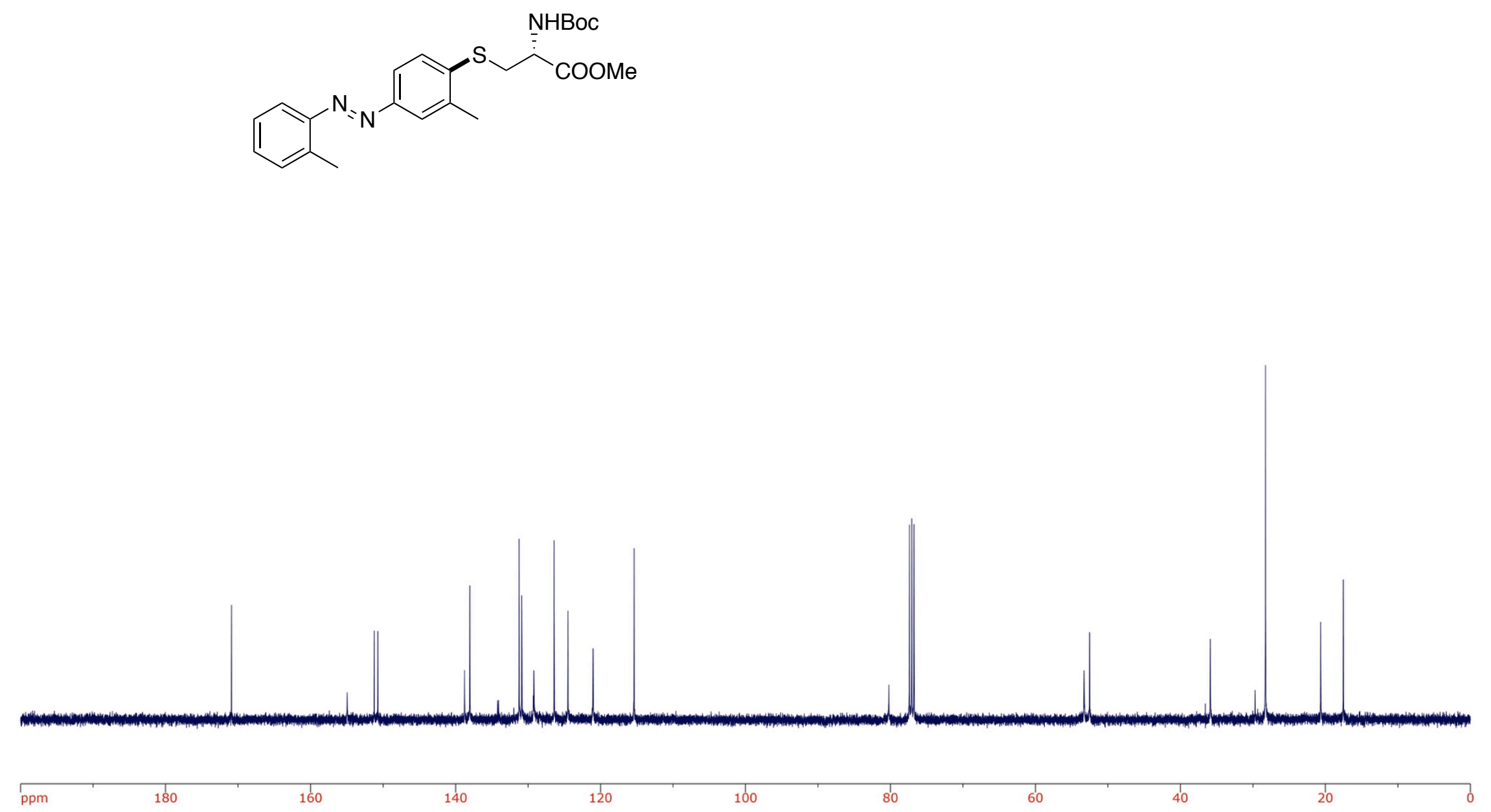

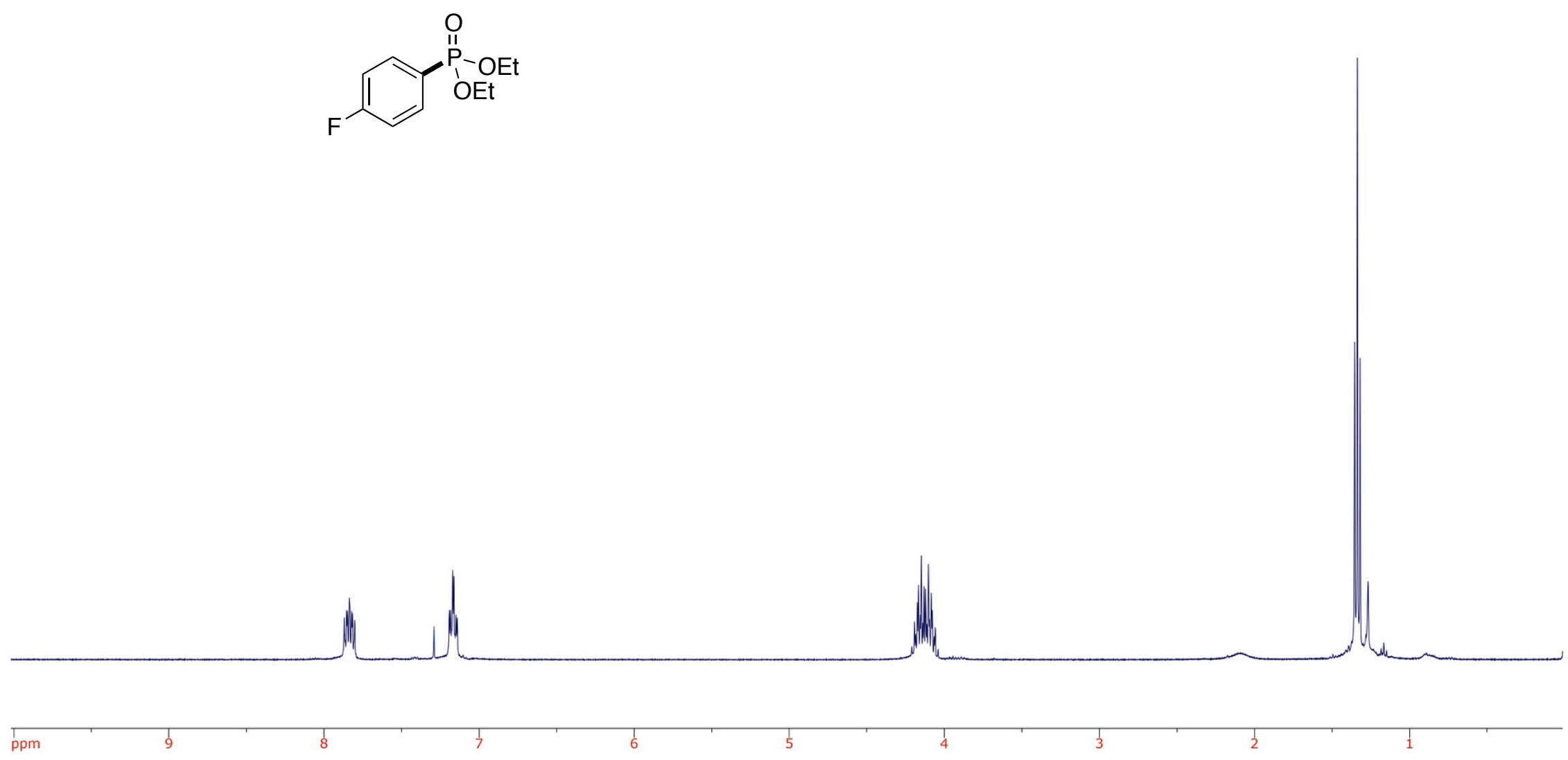

S367 


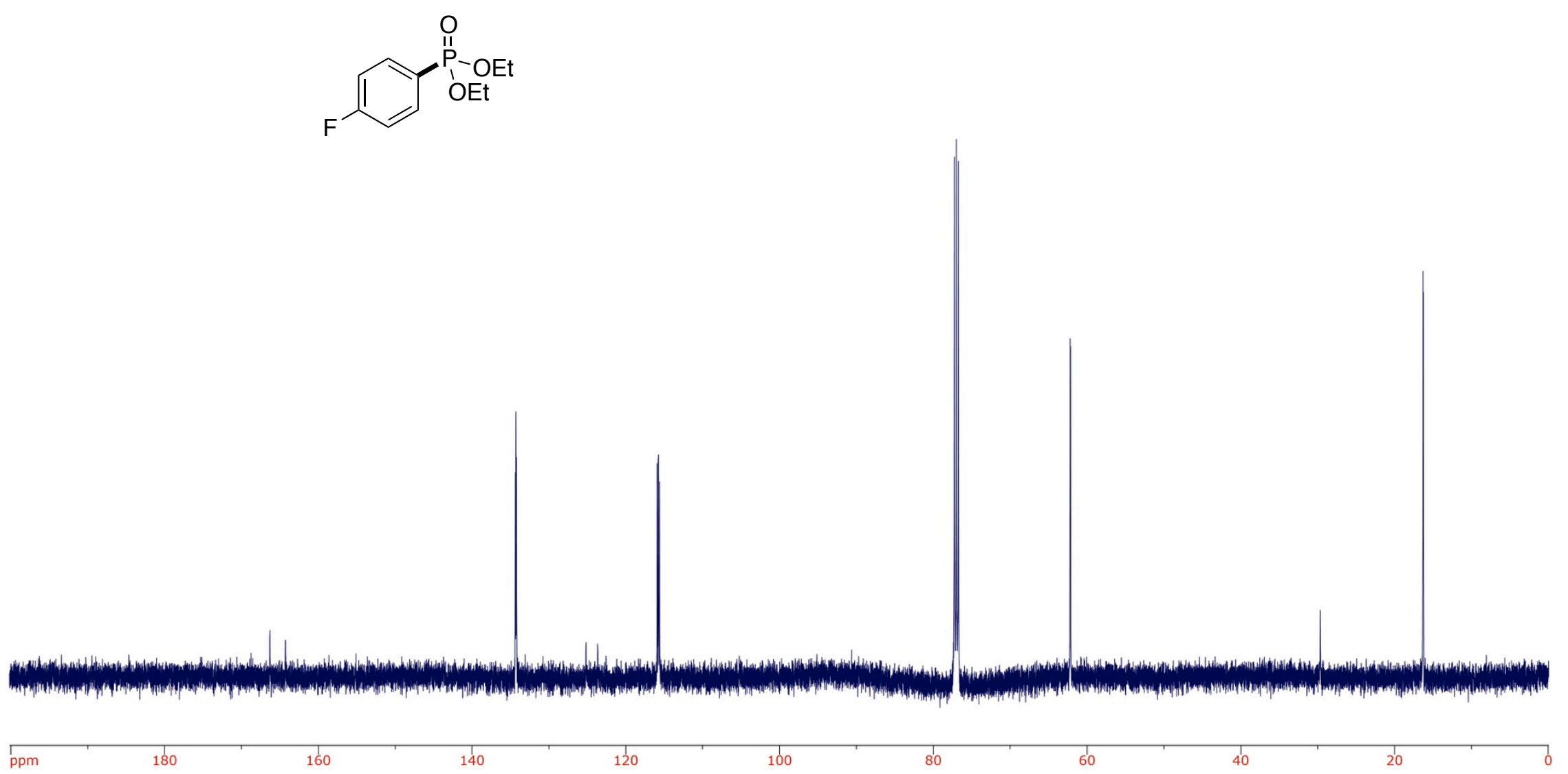




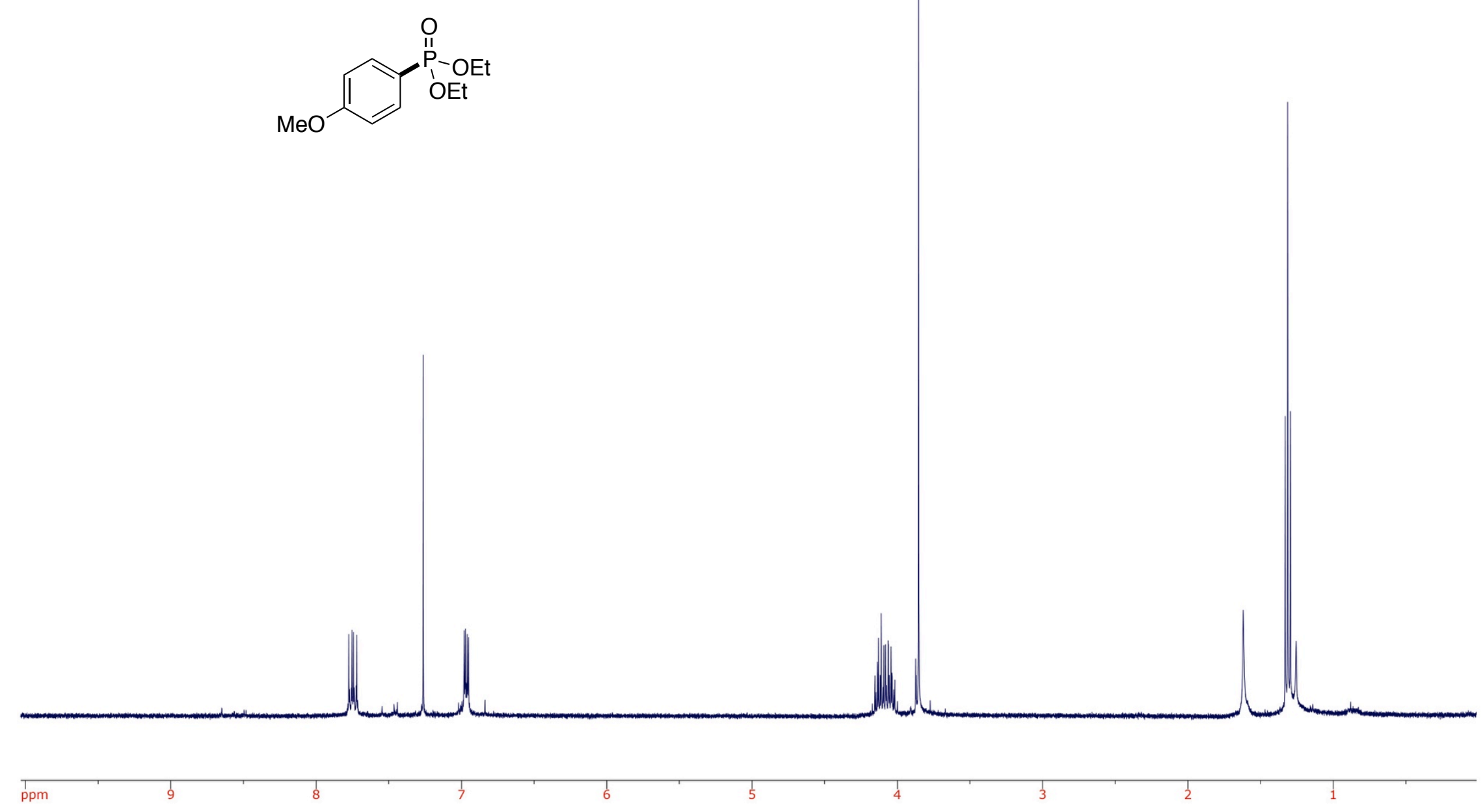



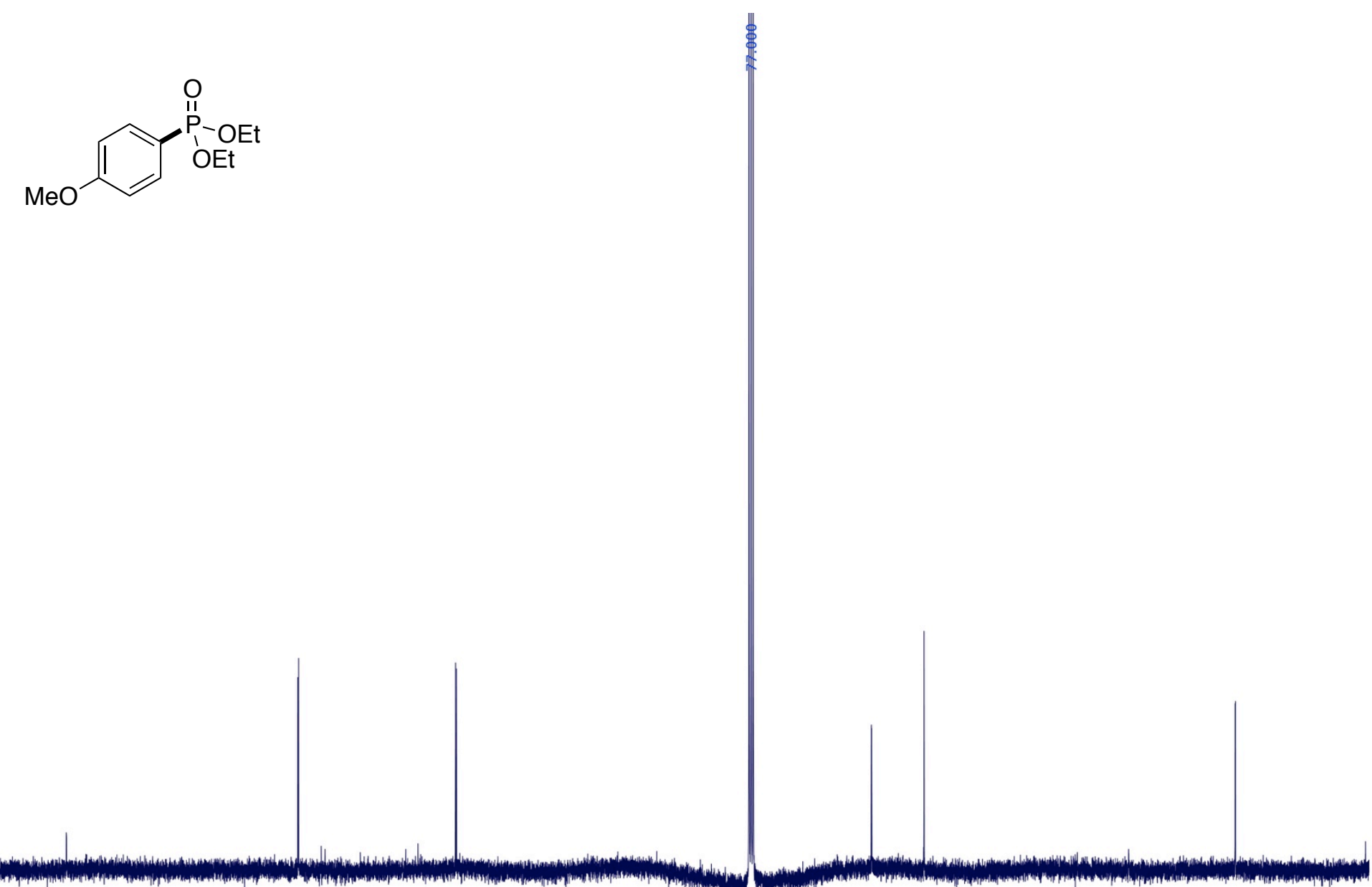

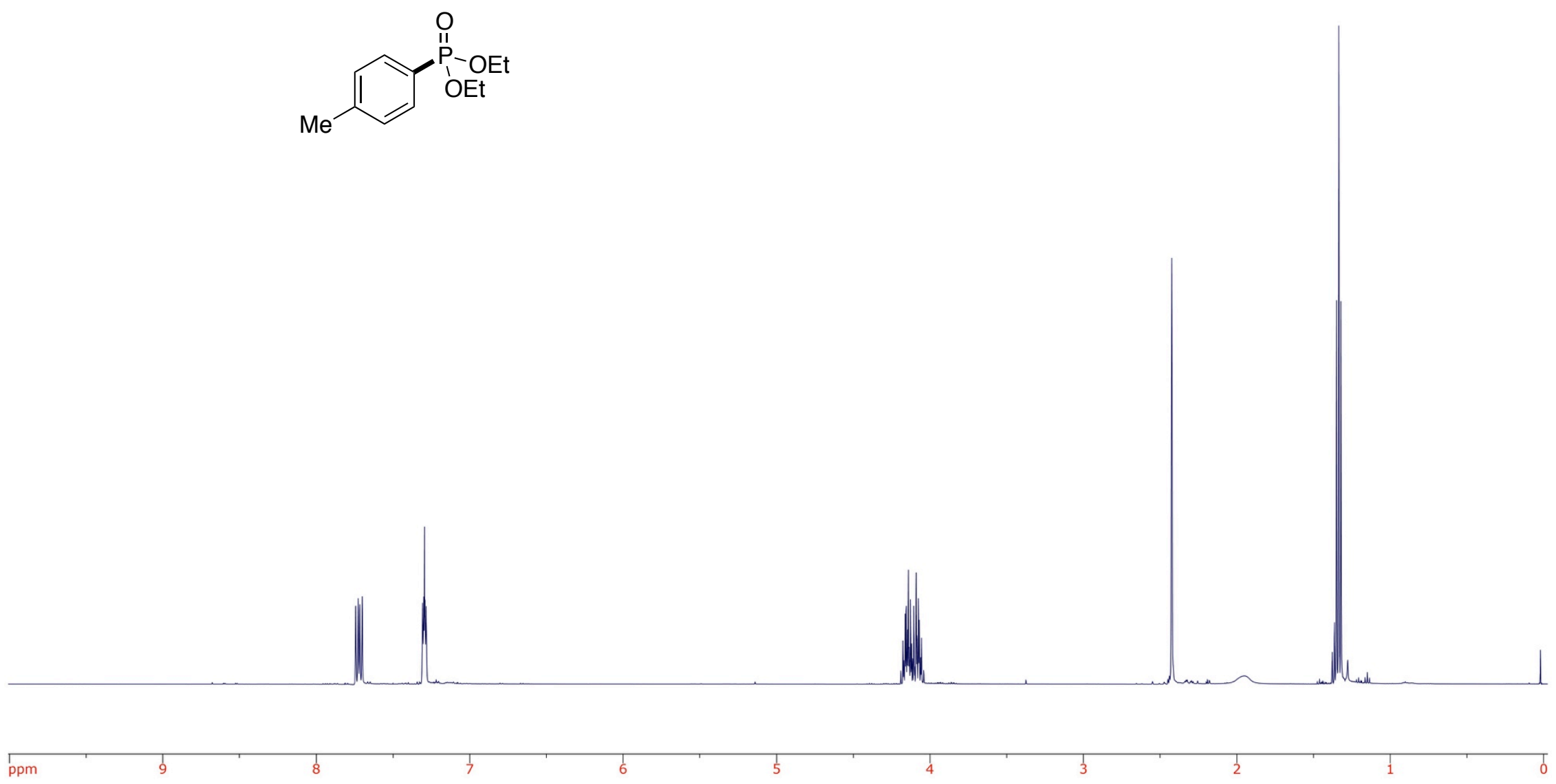

S371 

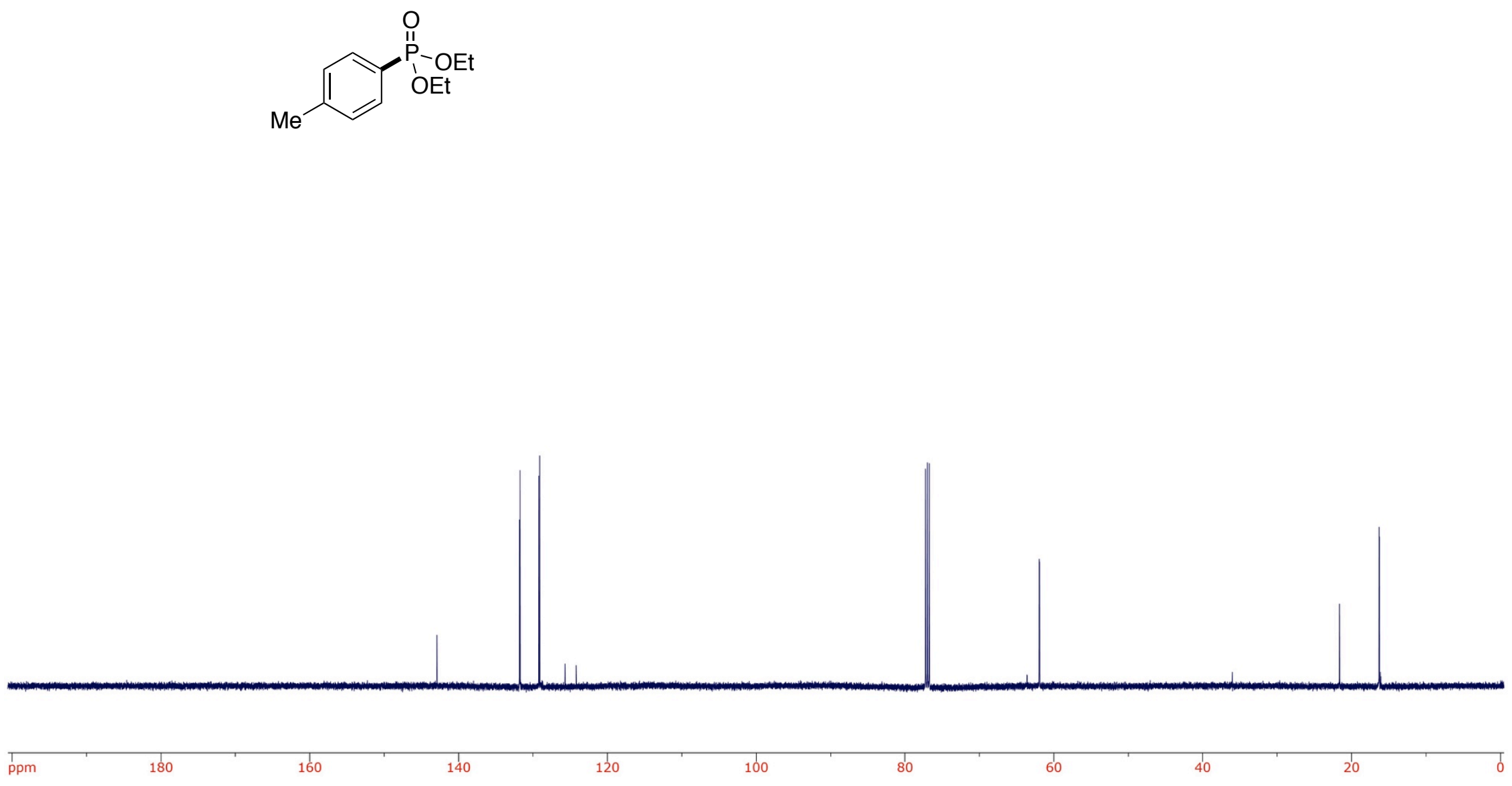

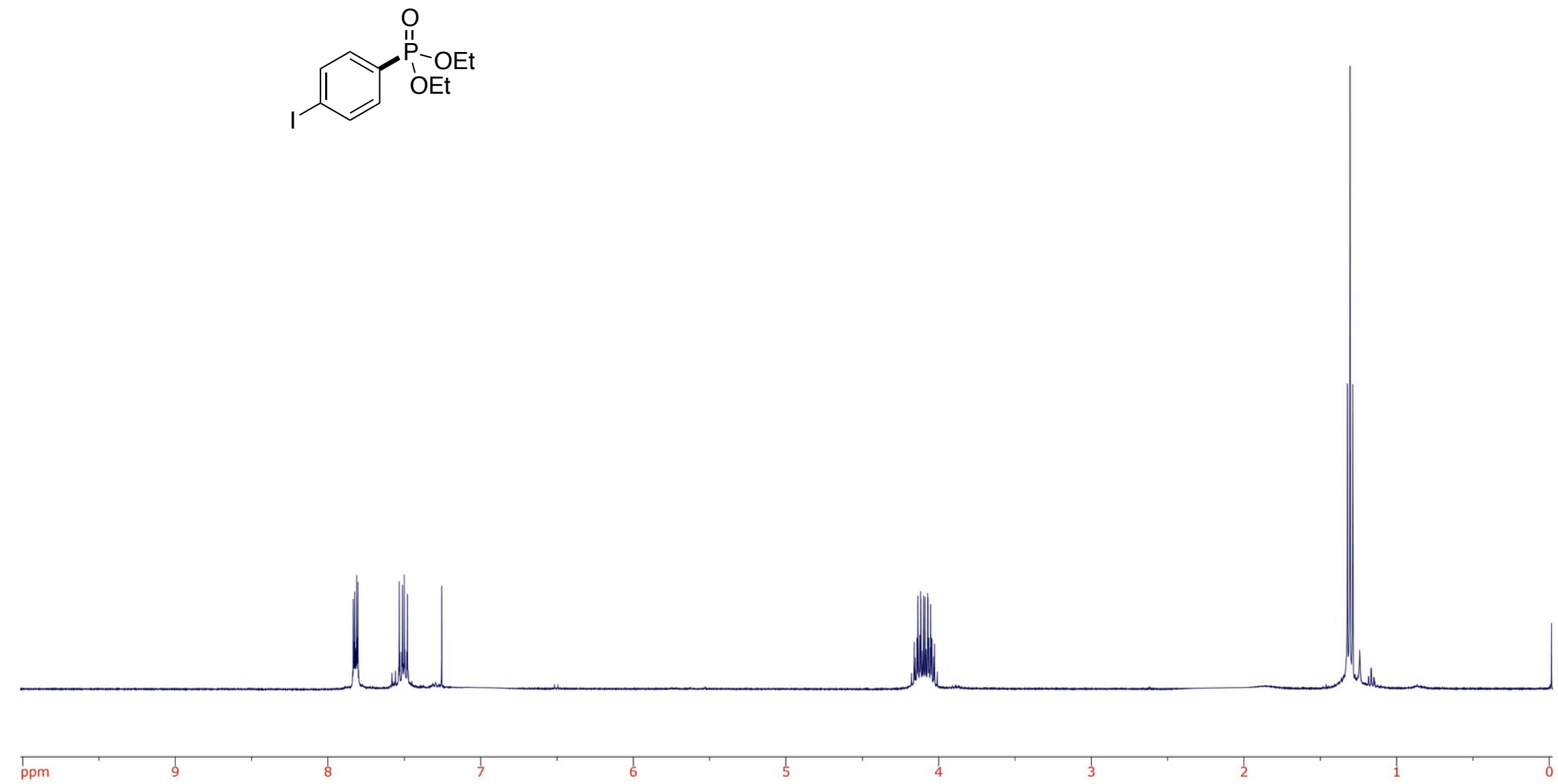

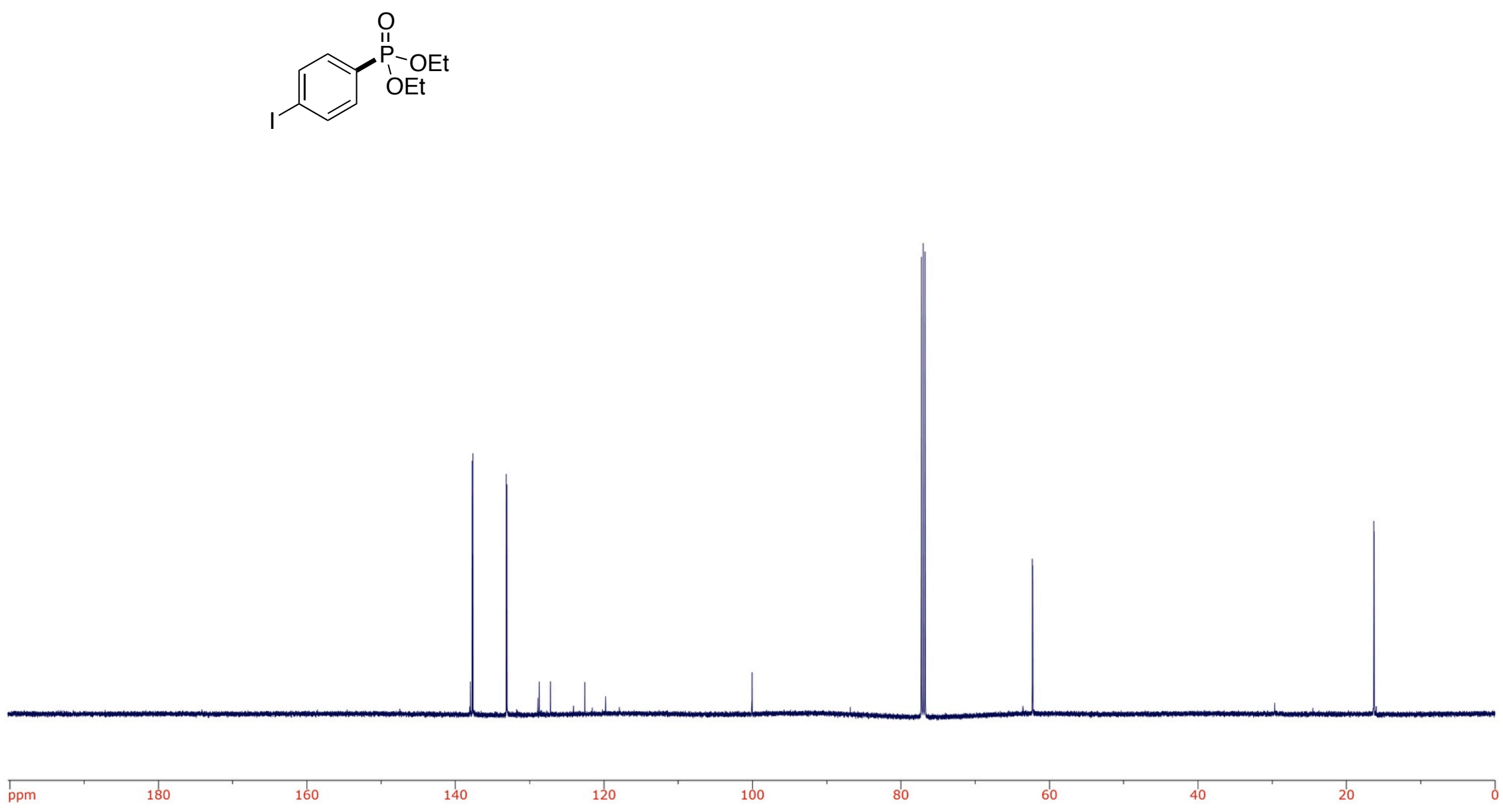

S374 
<smiles>CCOP(=O)(OCC)c1ccc(Br)cc1</smiles>

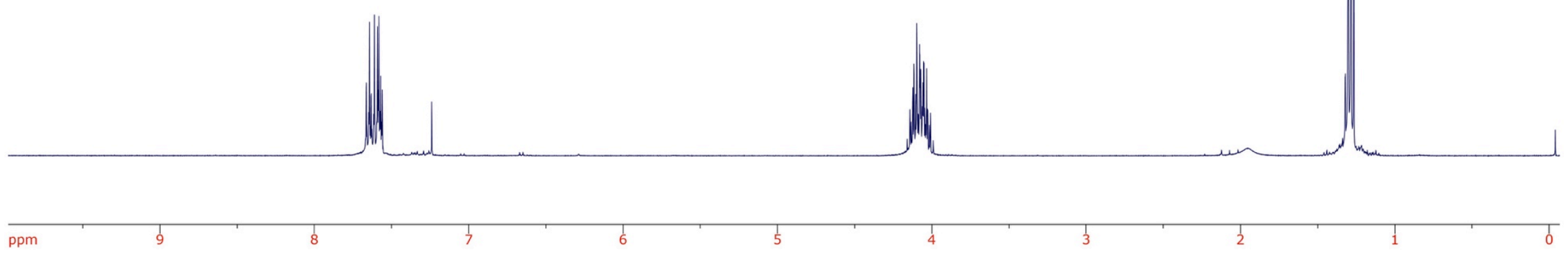

S375 

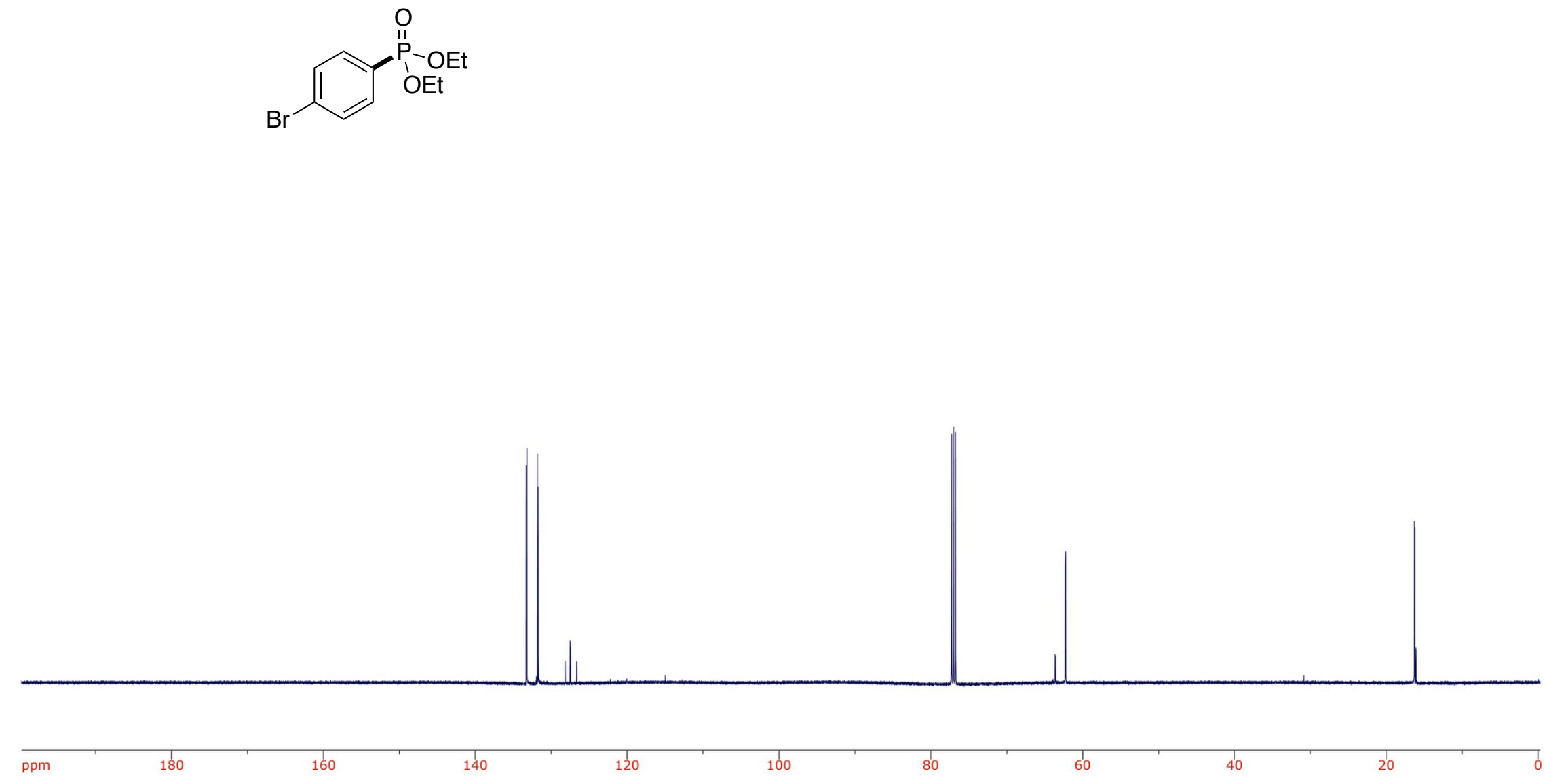

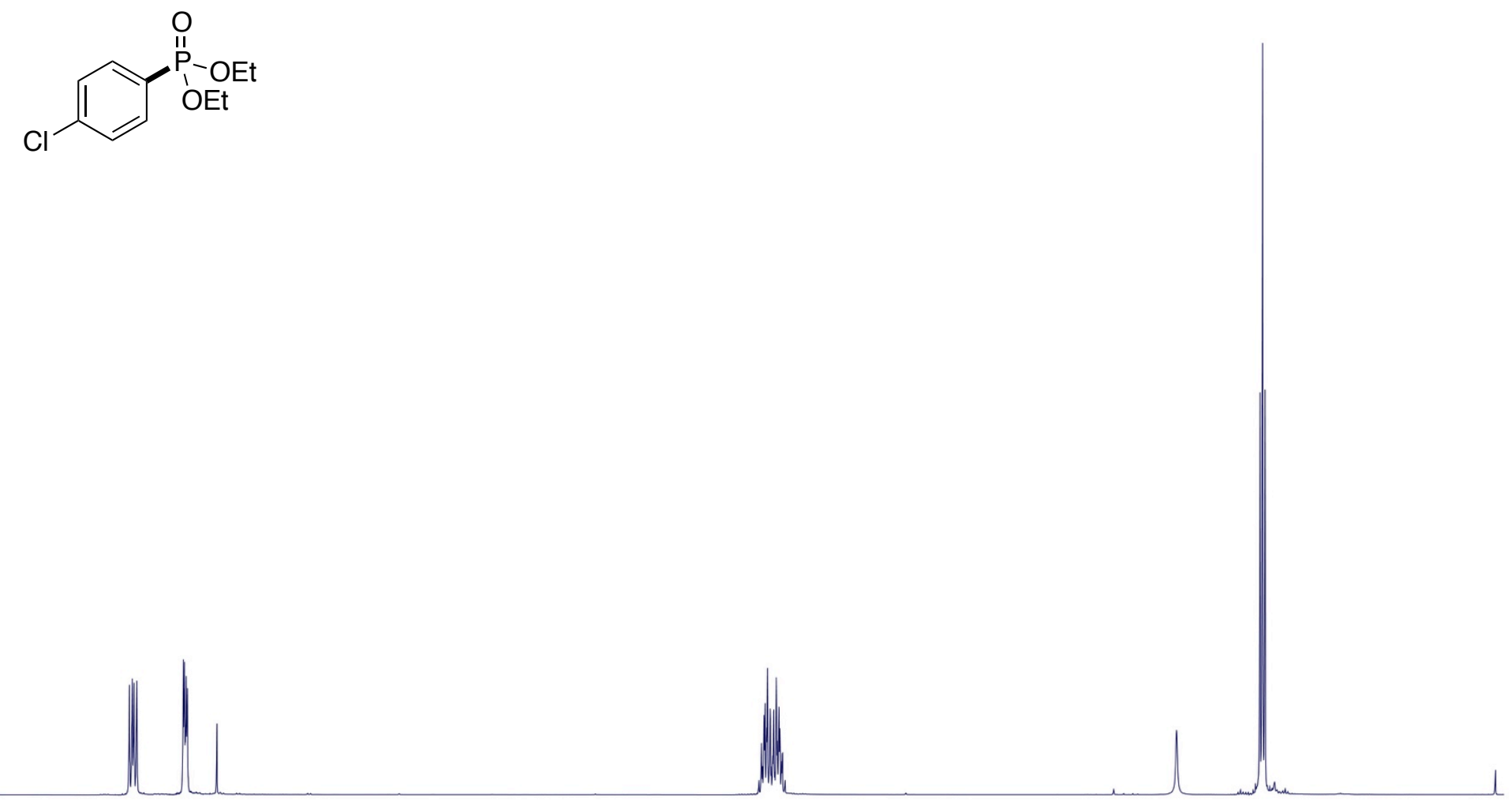

ppm 

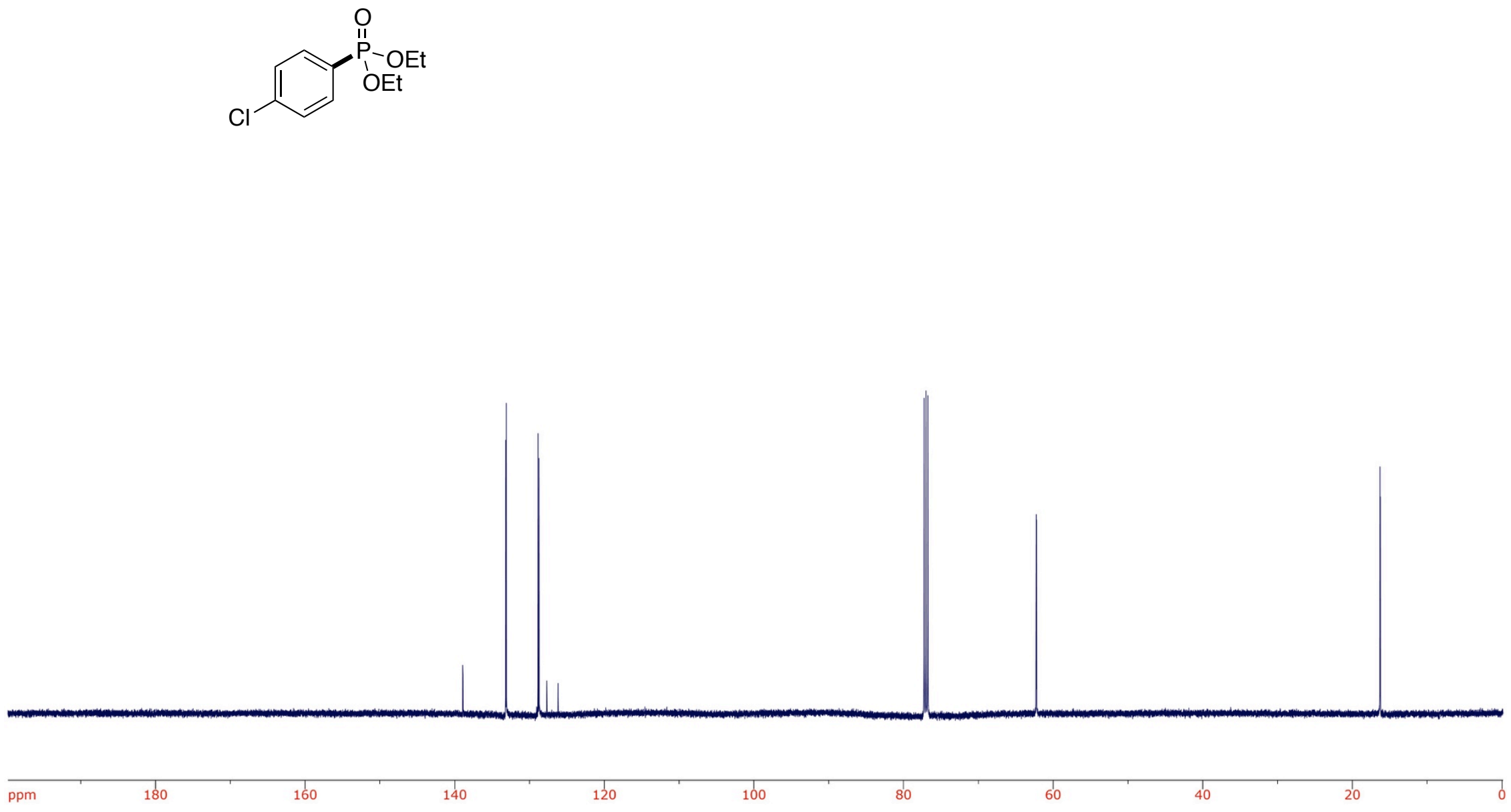


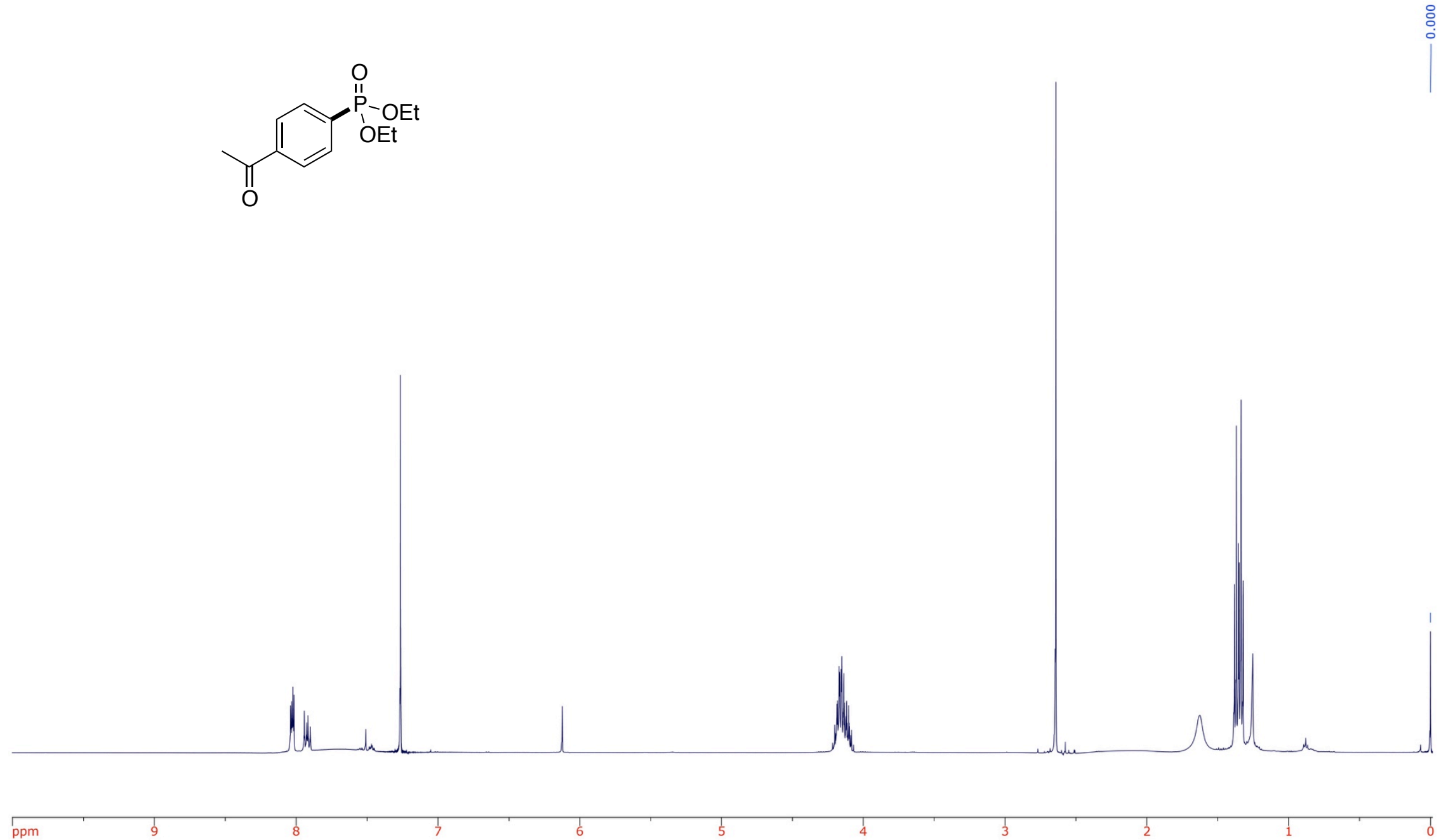




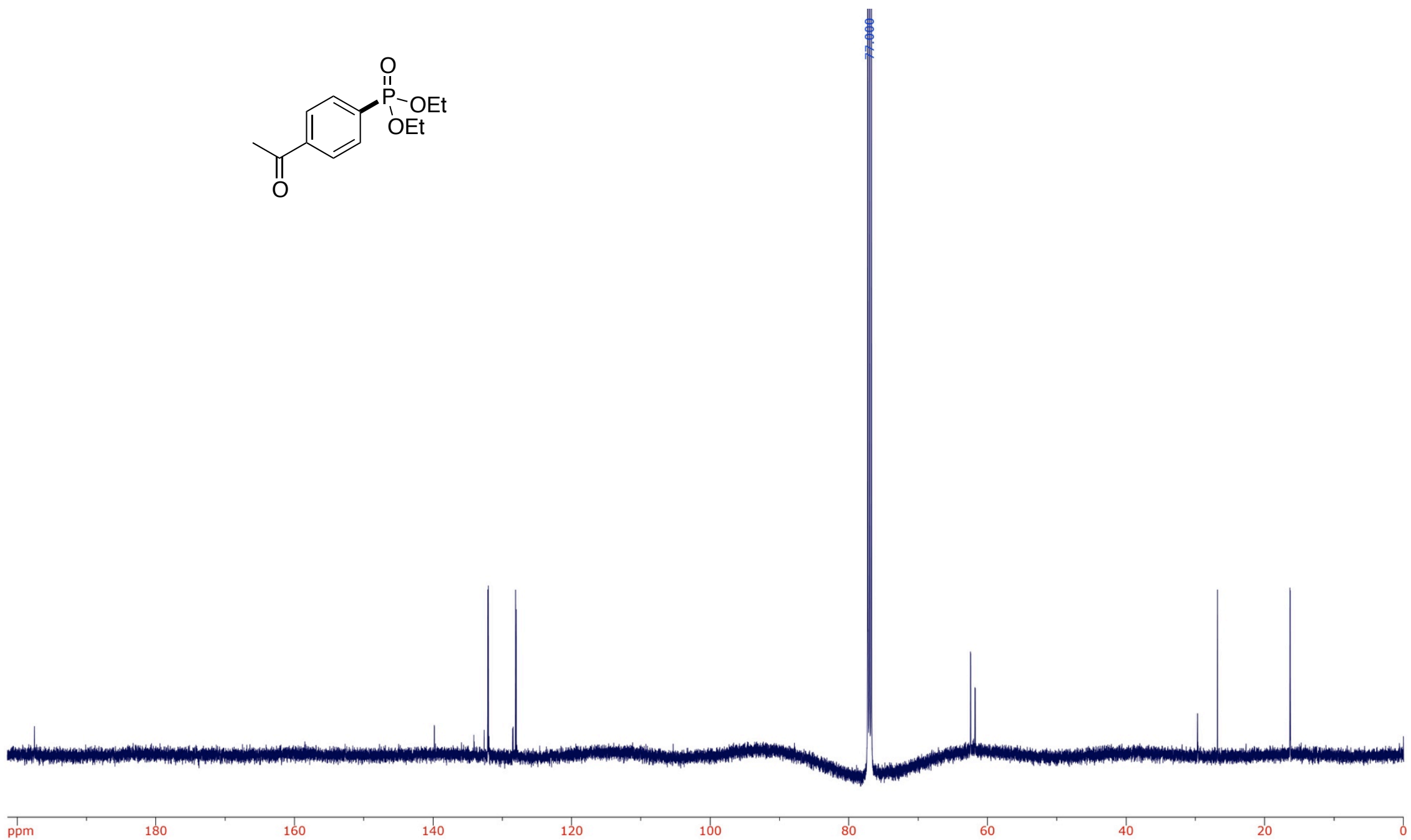




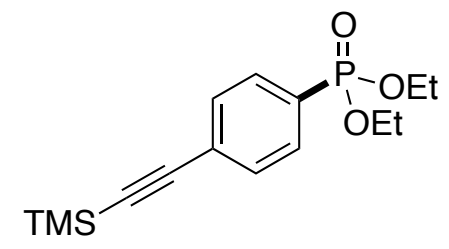

U1 


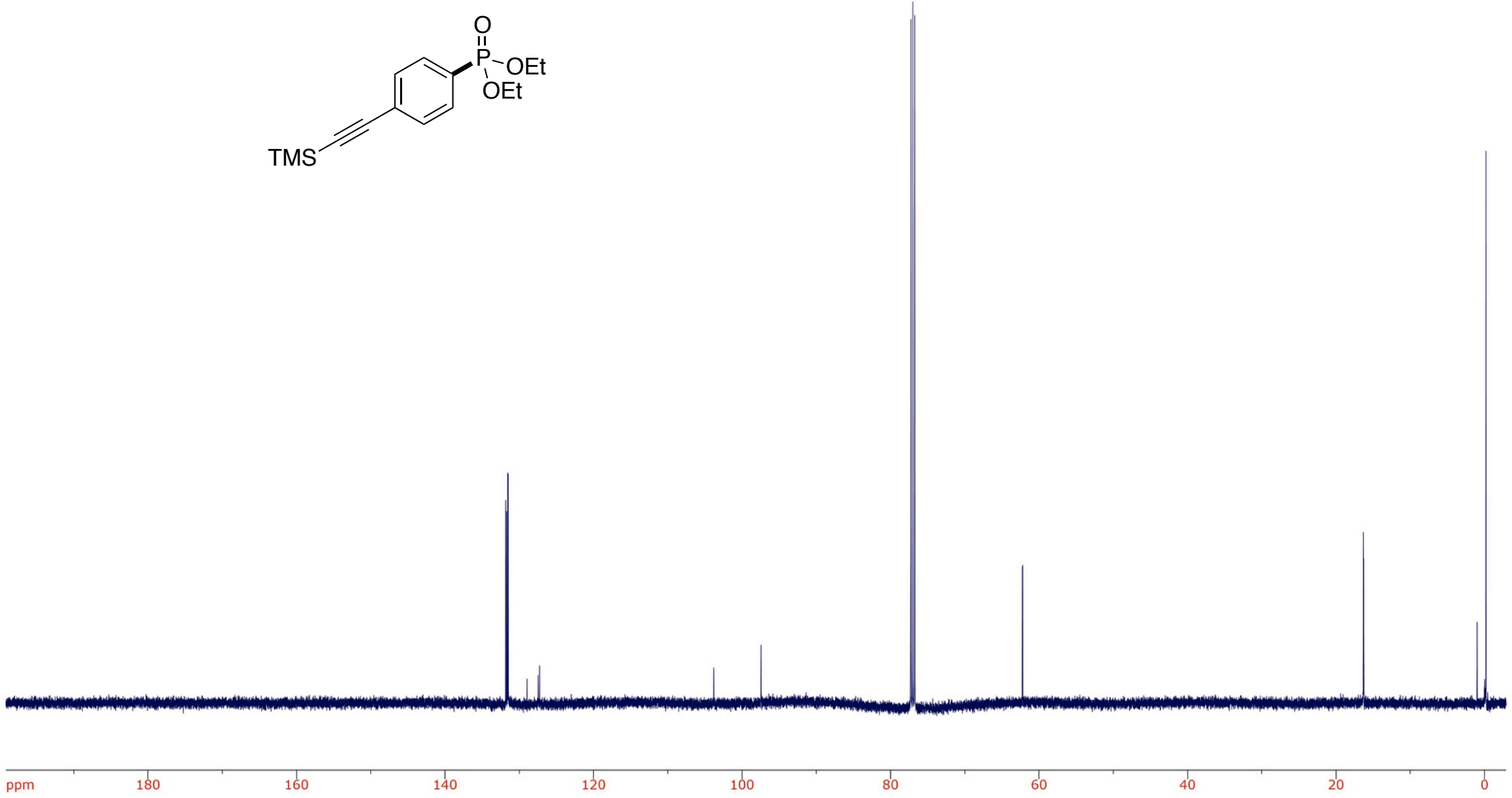



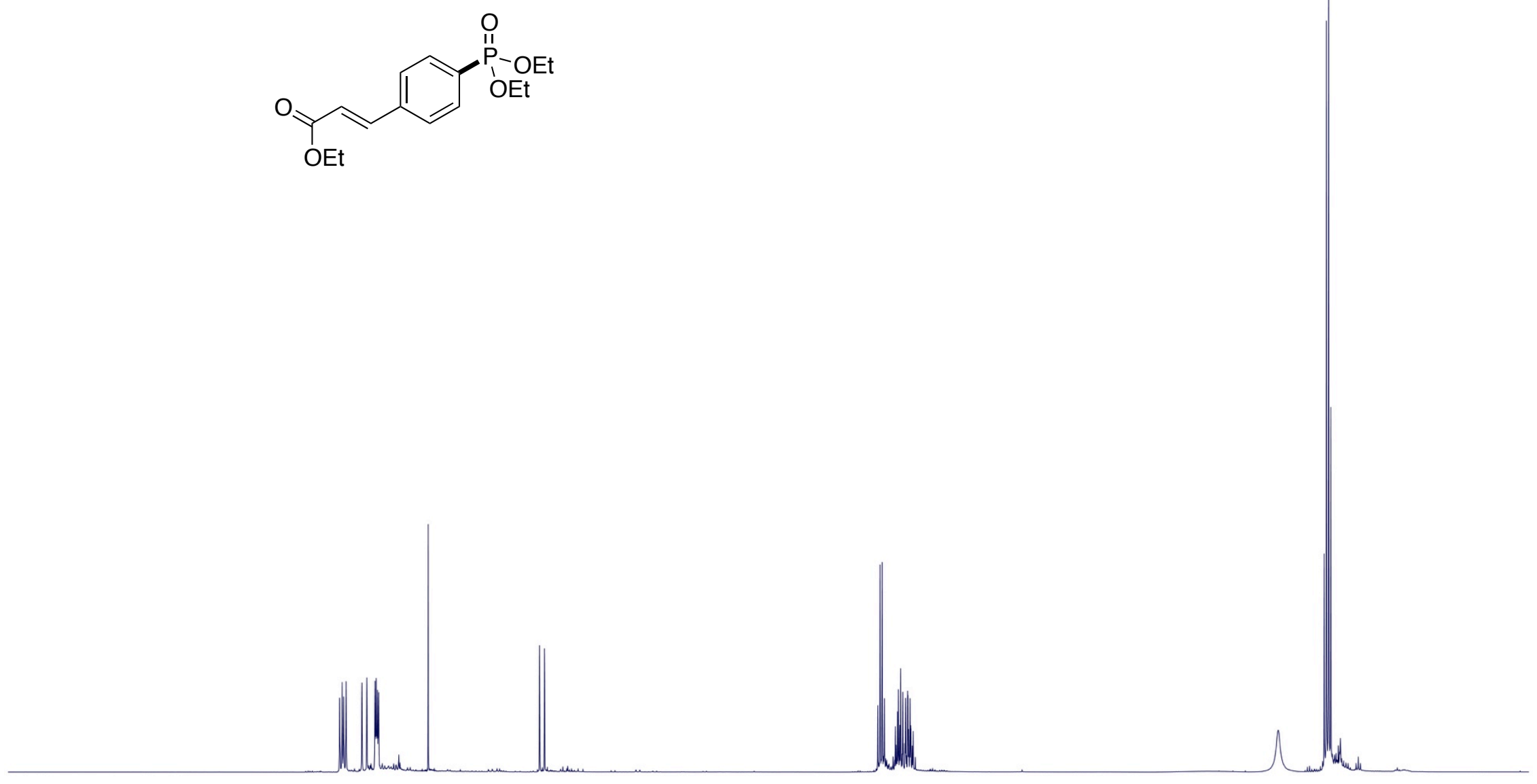

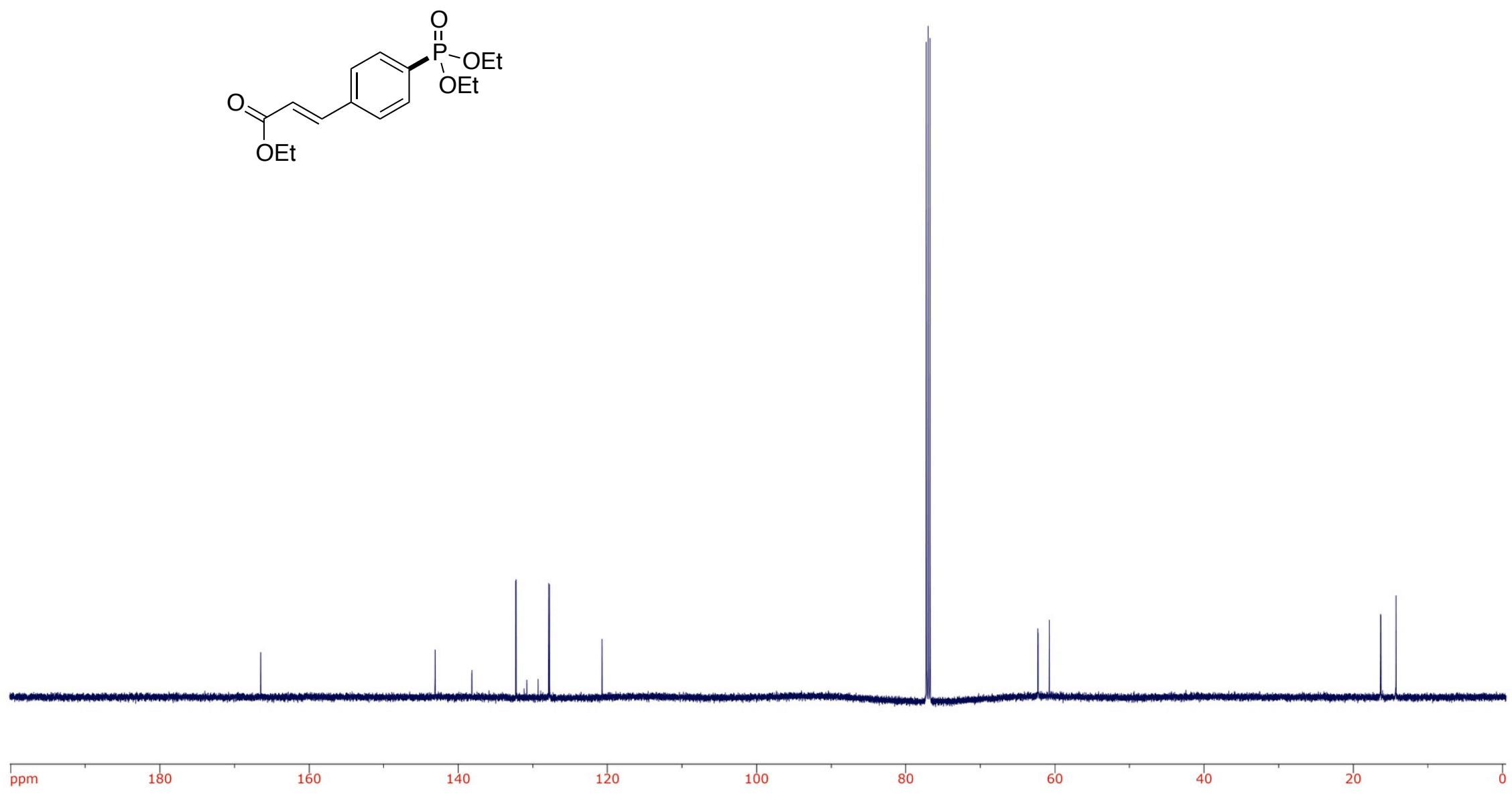

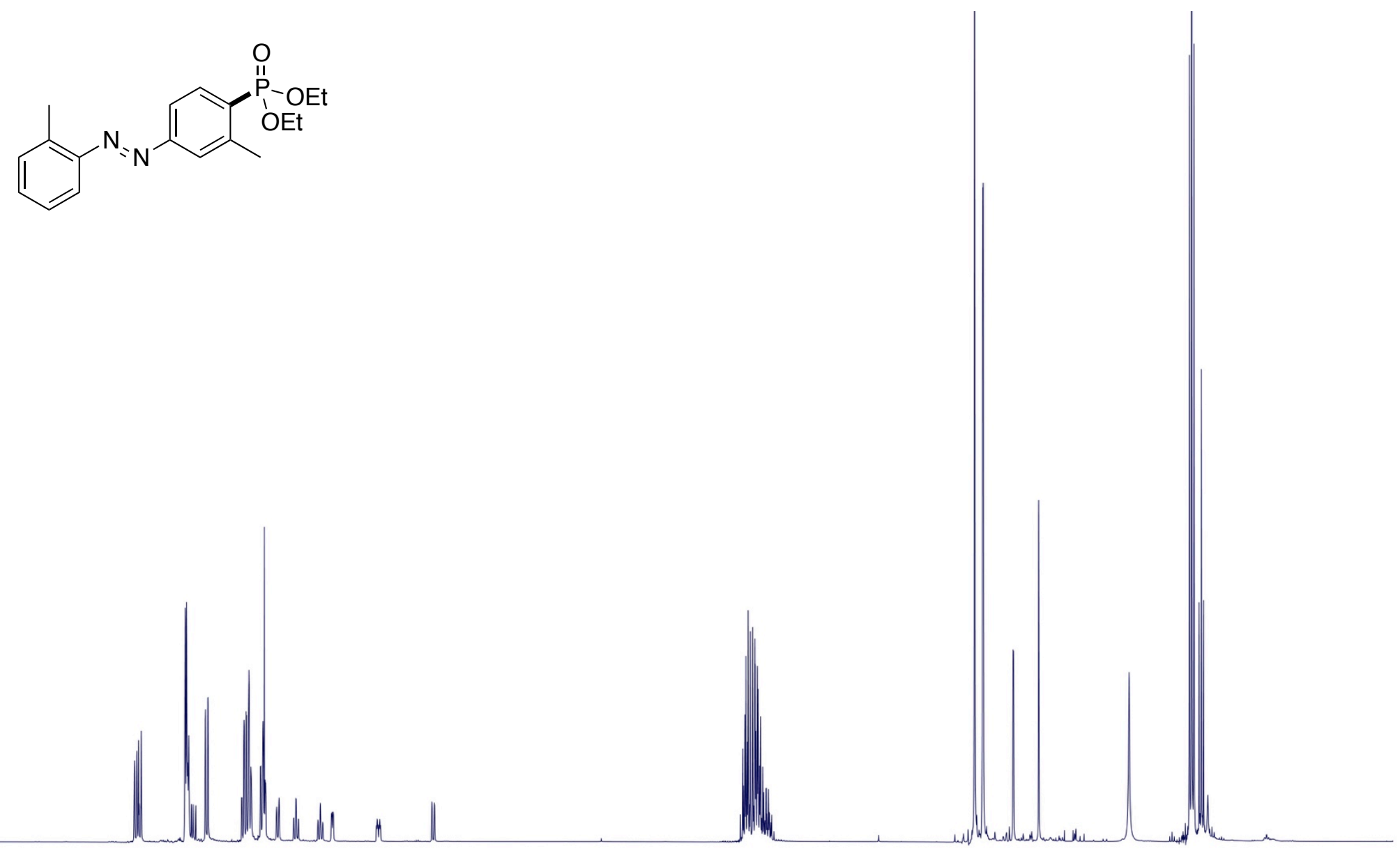

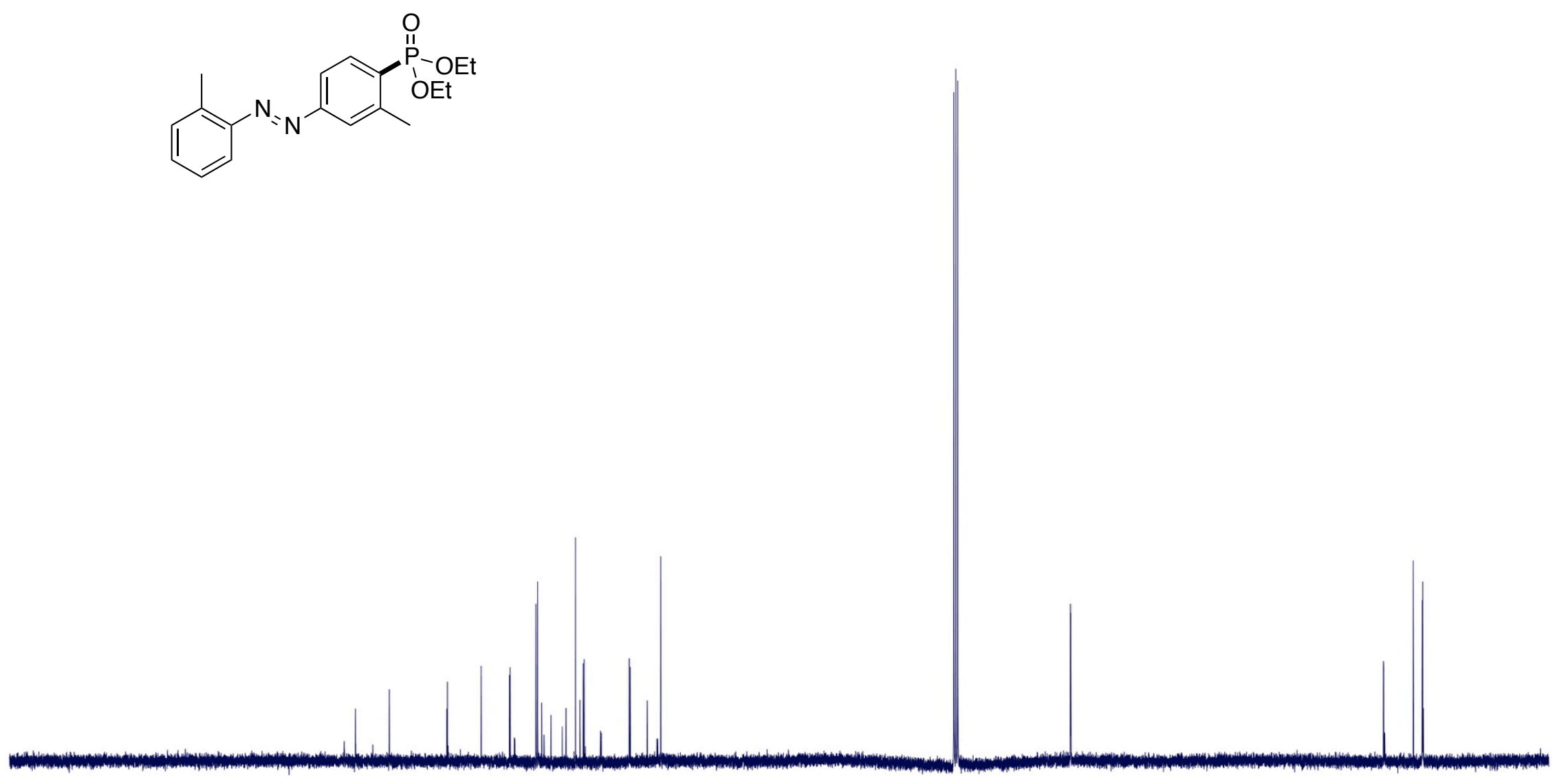


\section{Chapter S5. N-2-Aryl-1,2,3-Triazole as ligand for Iridium Photocatalyst}

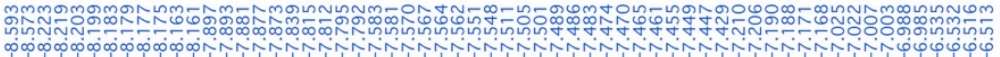

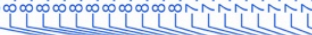
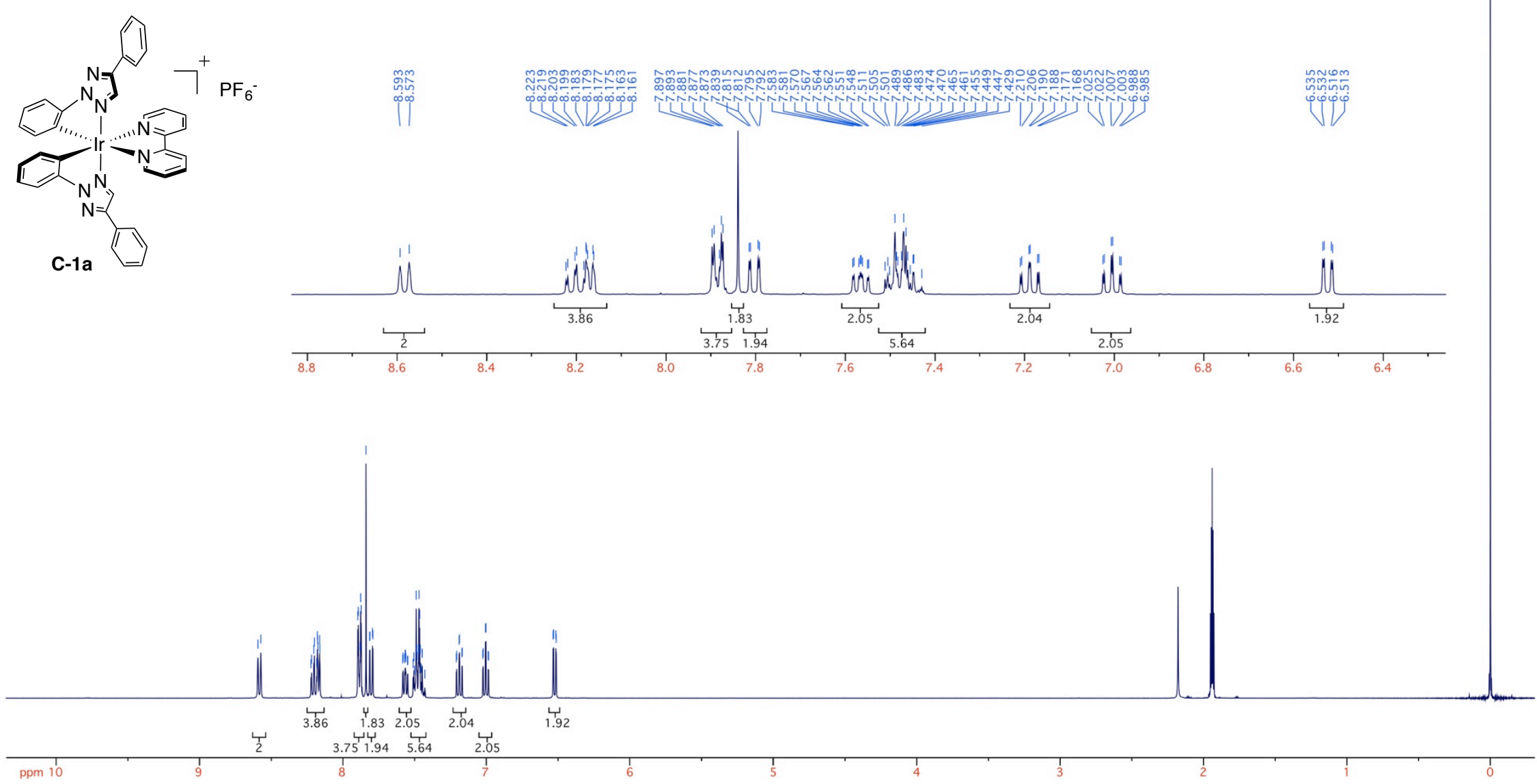

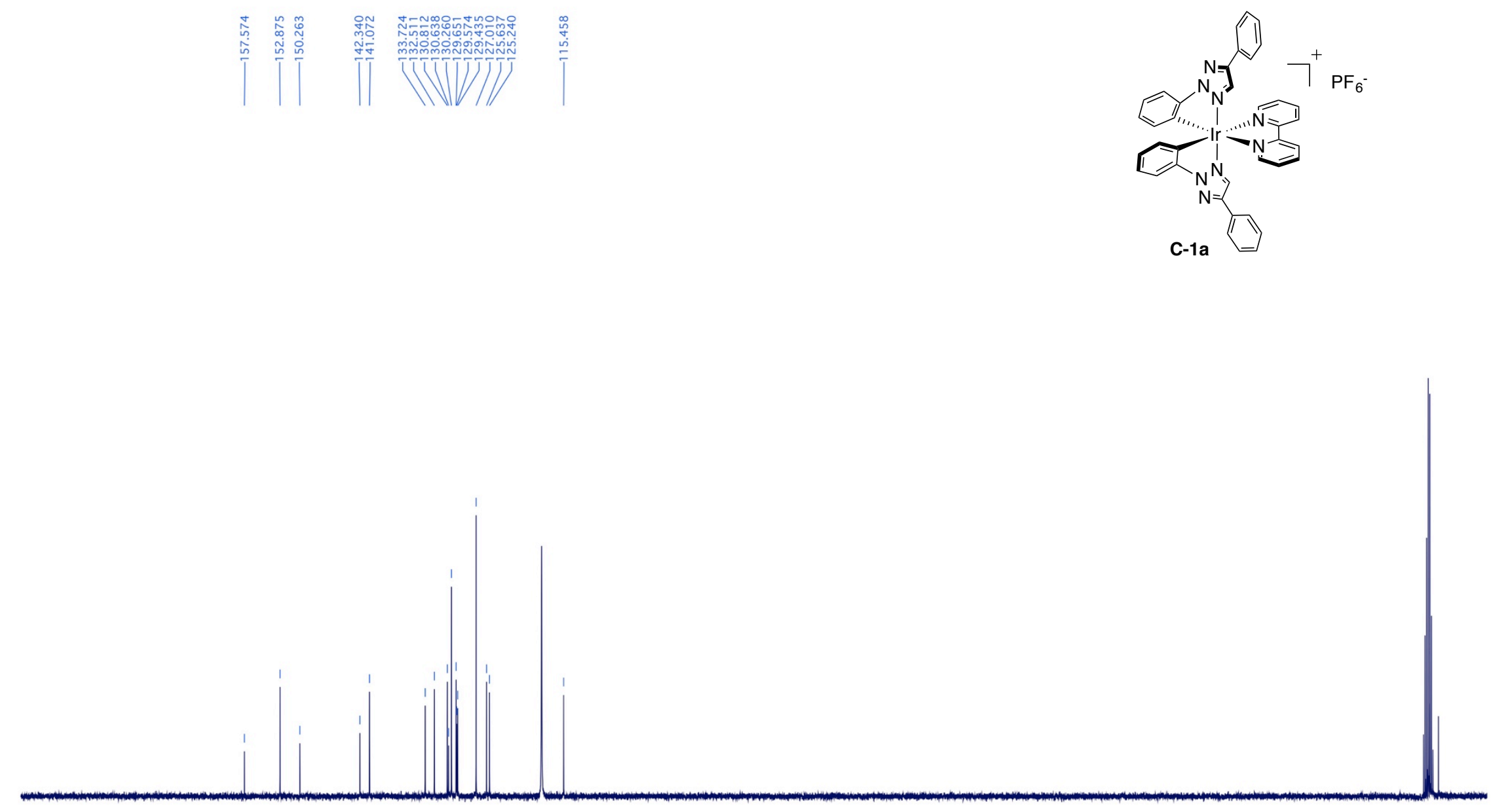


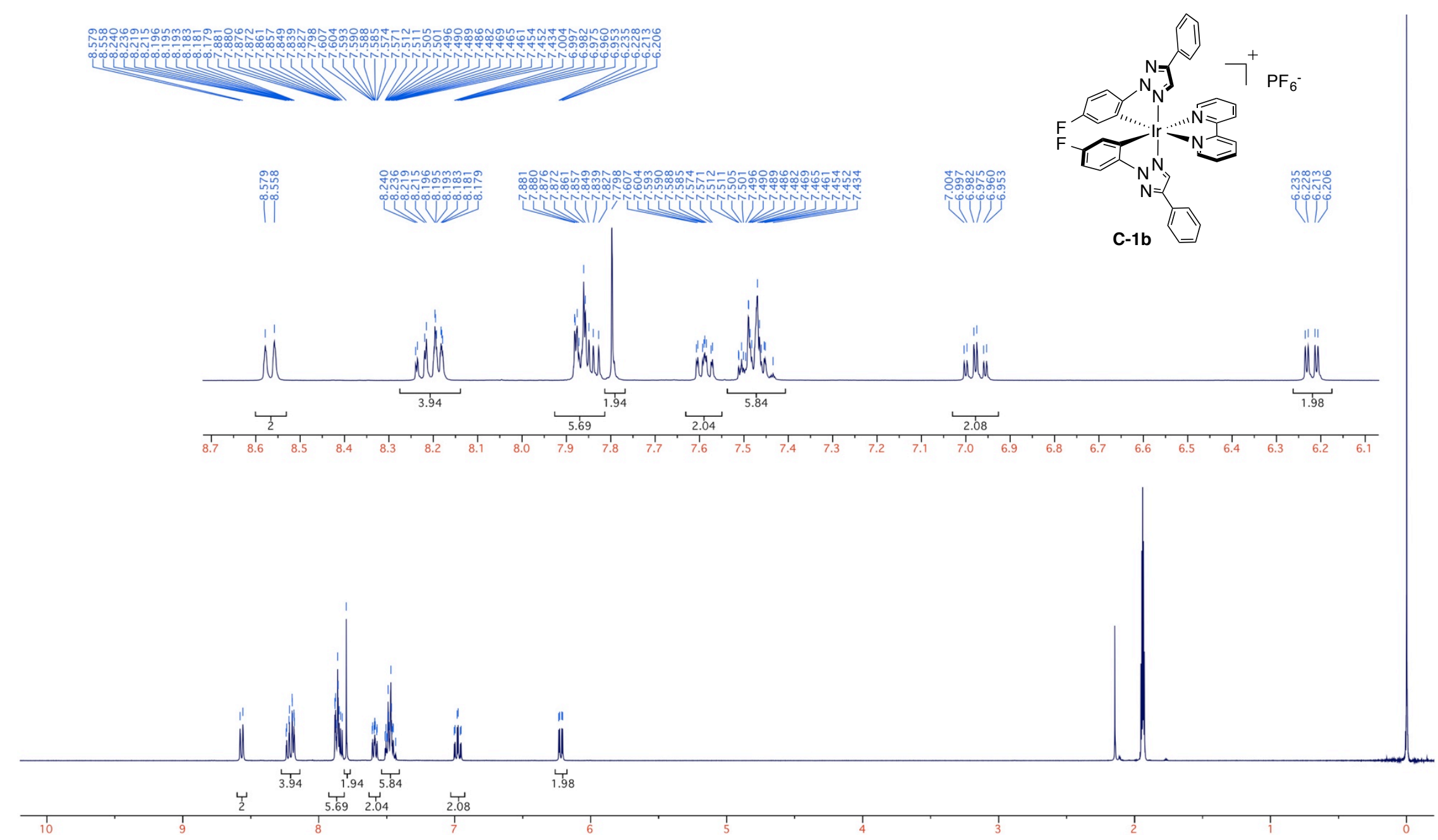



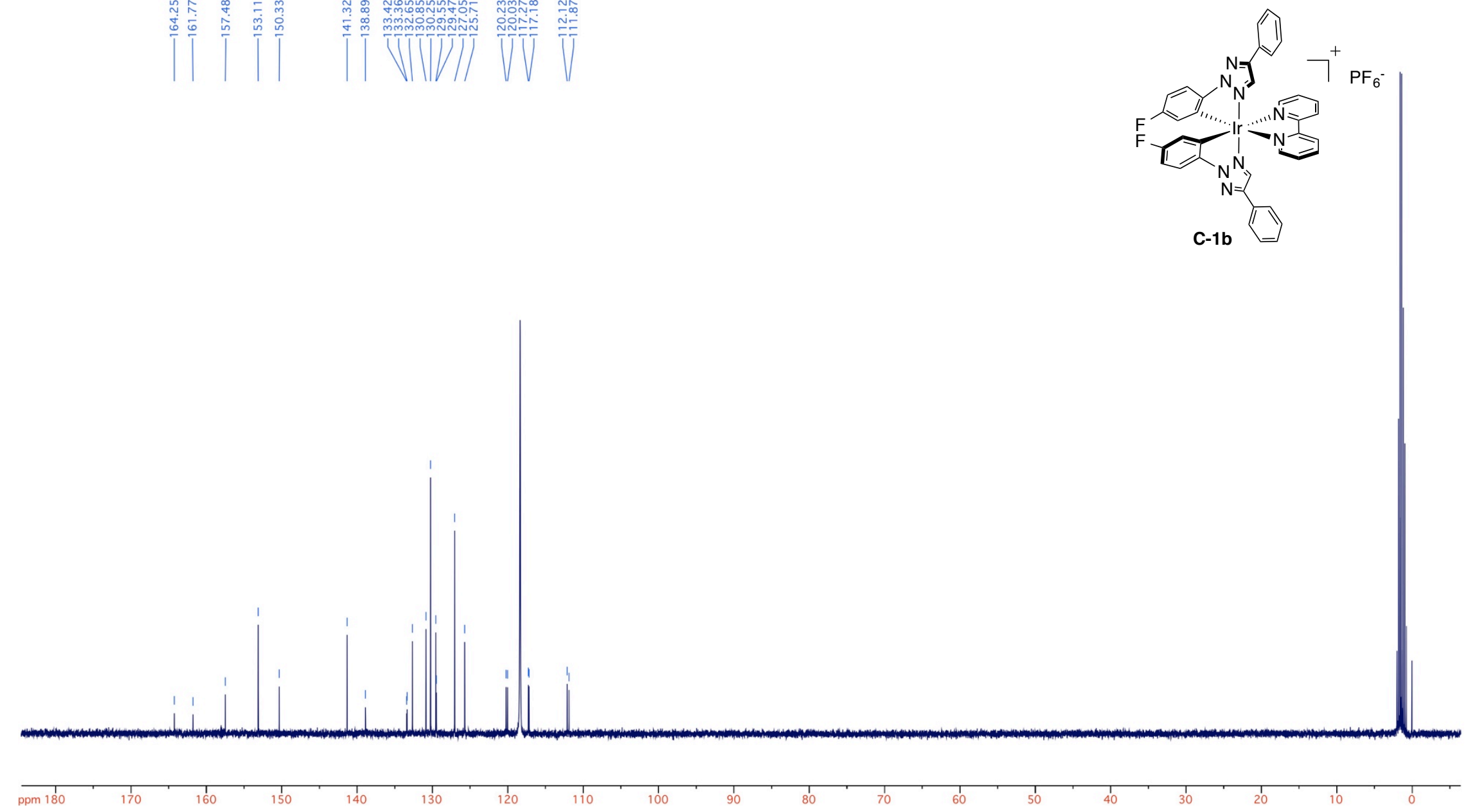


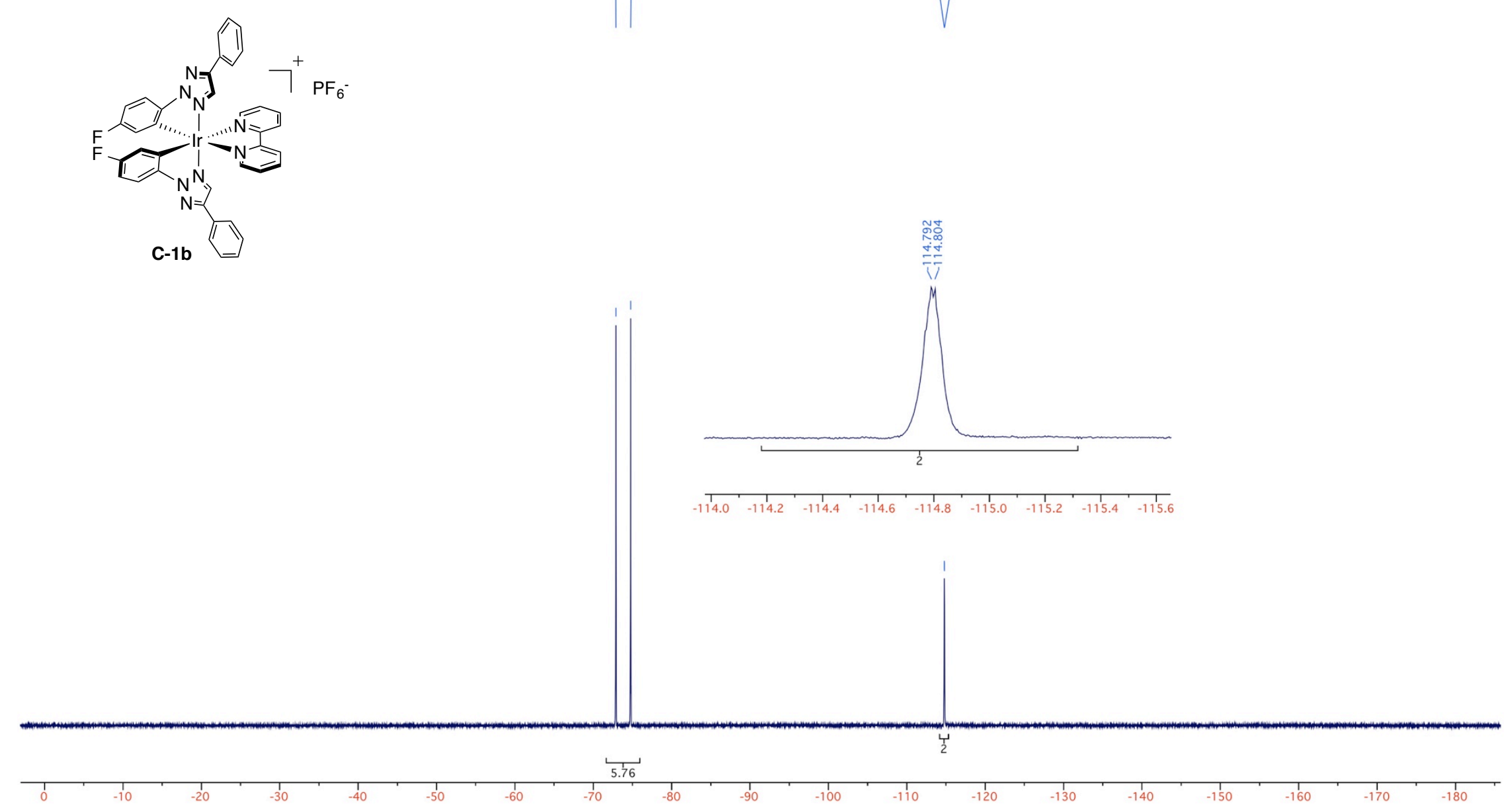




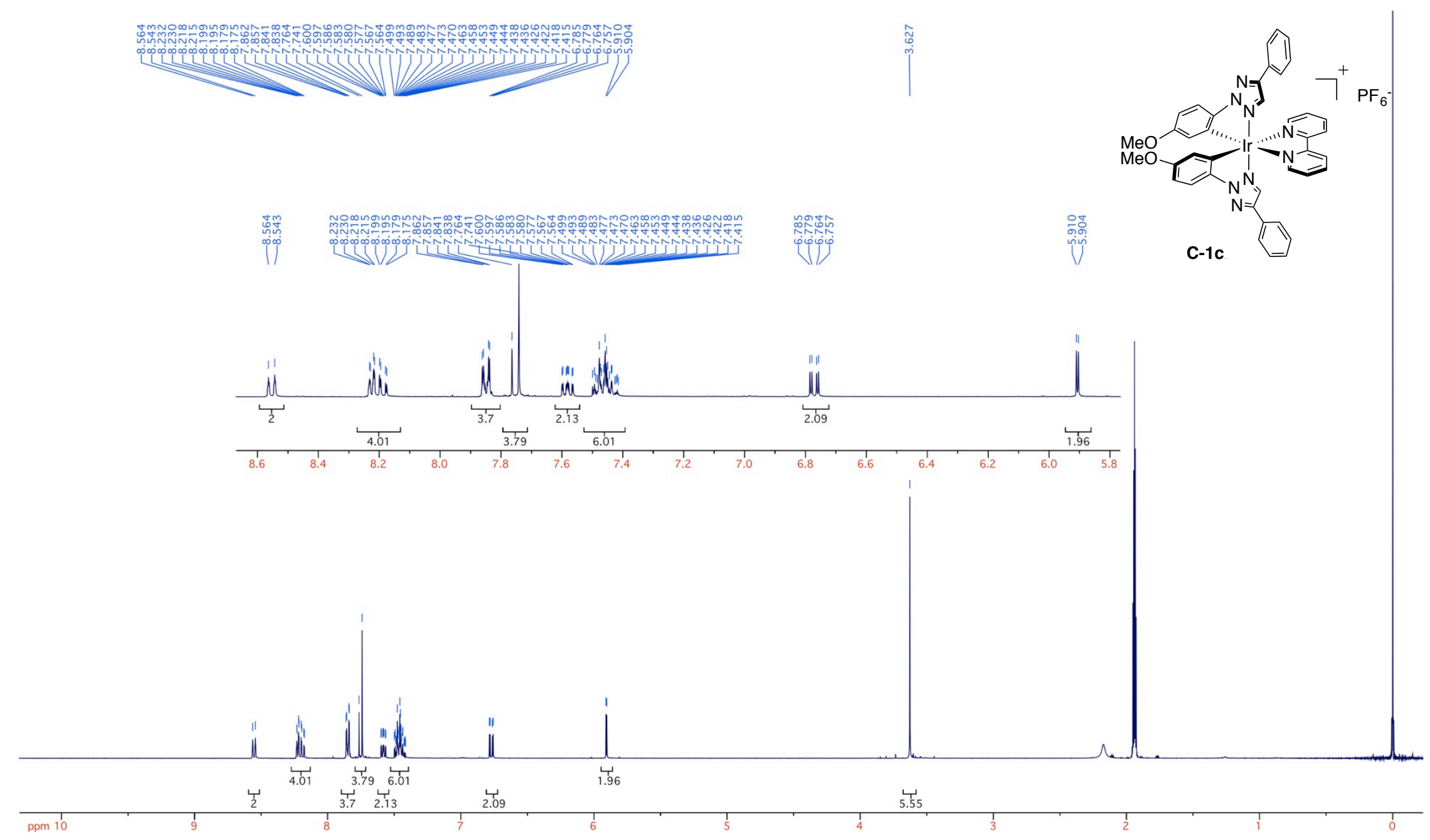



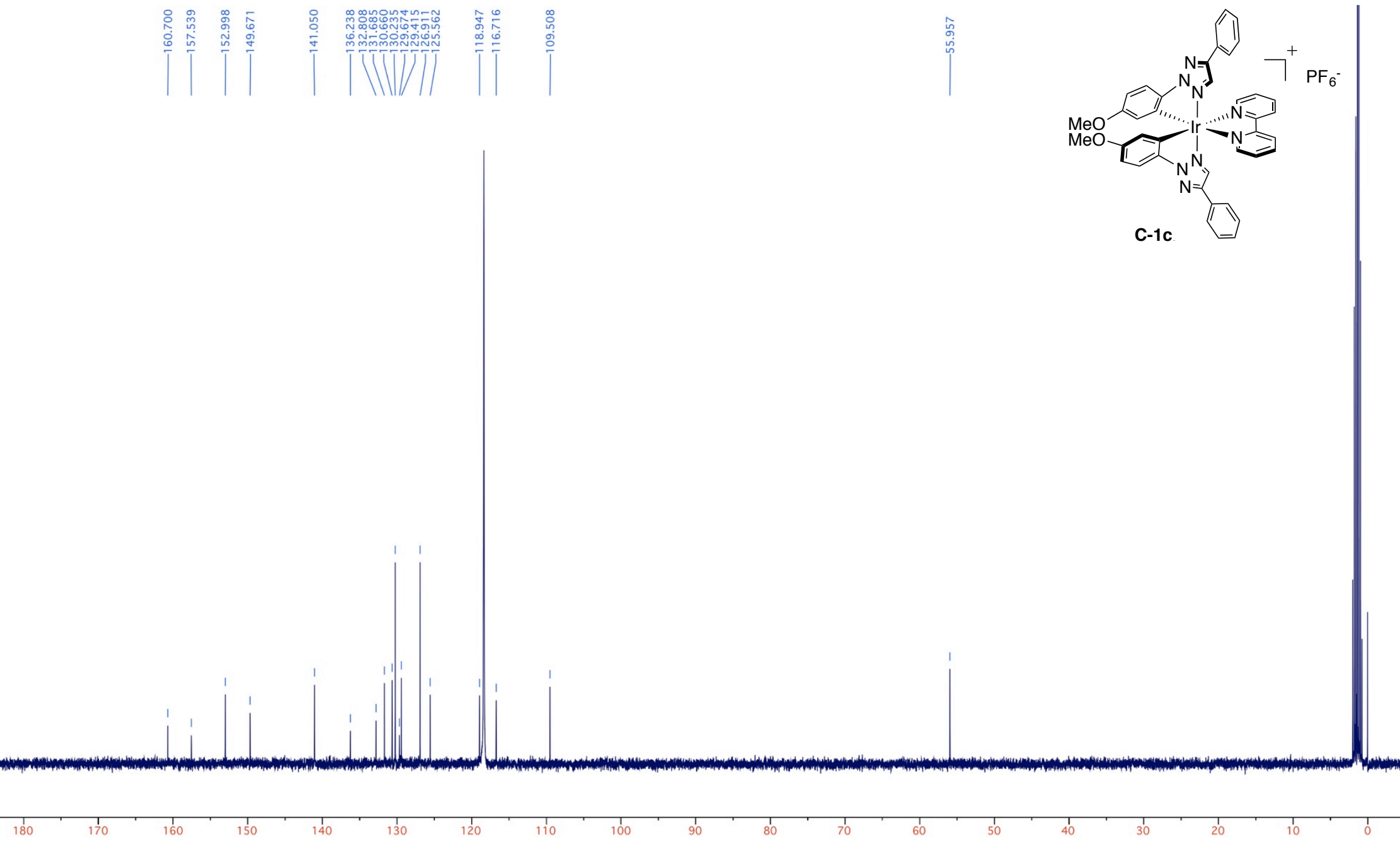


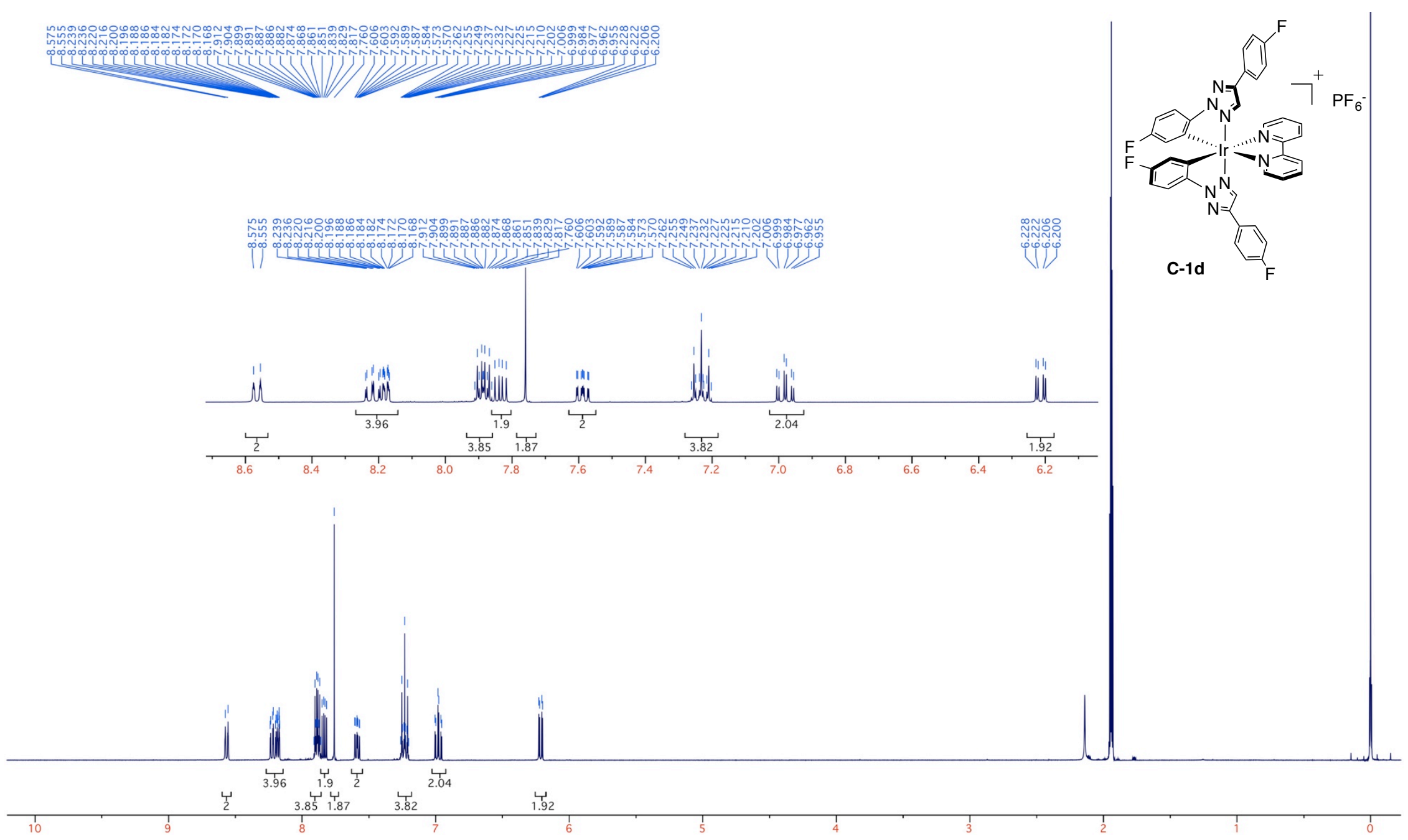




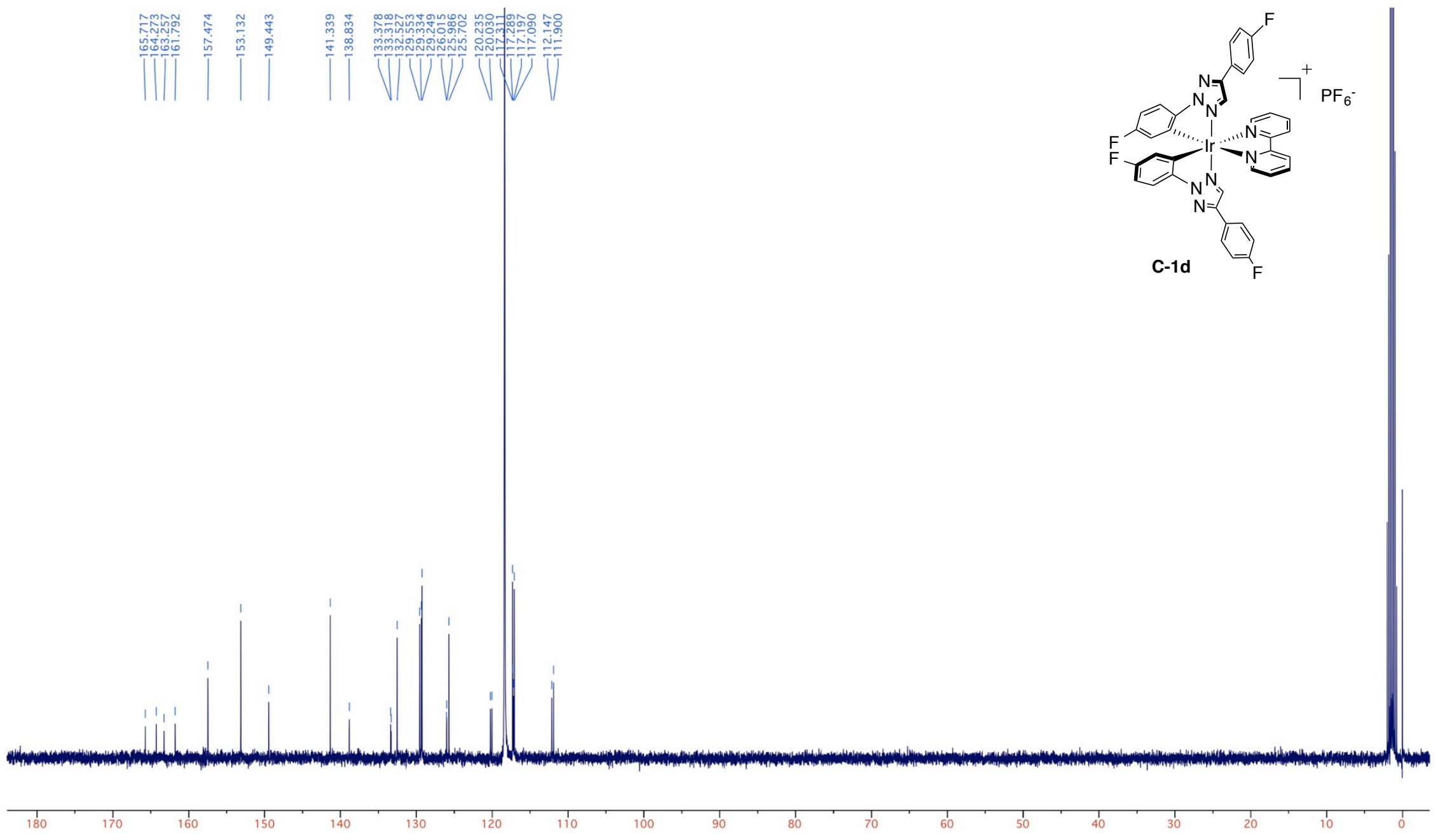




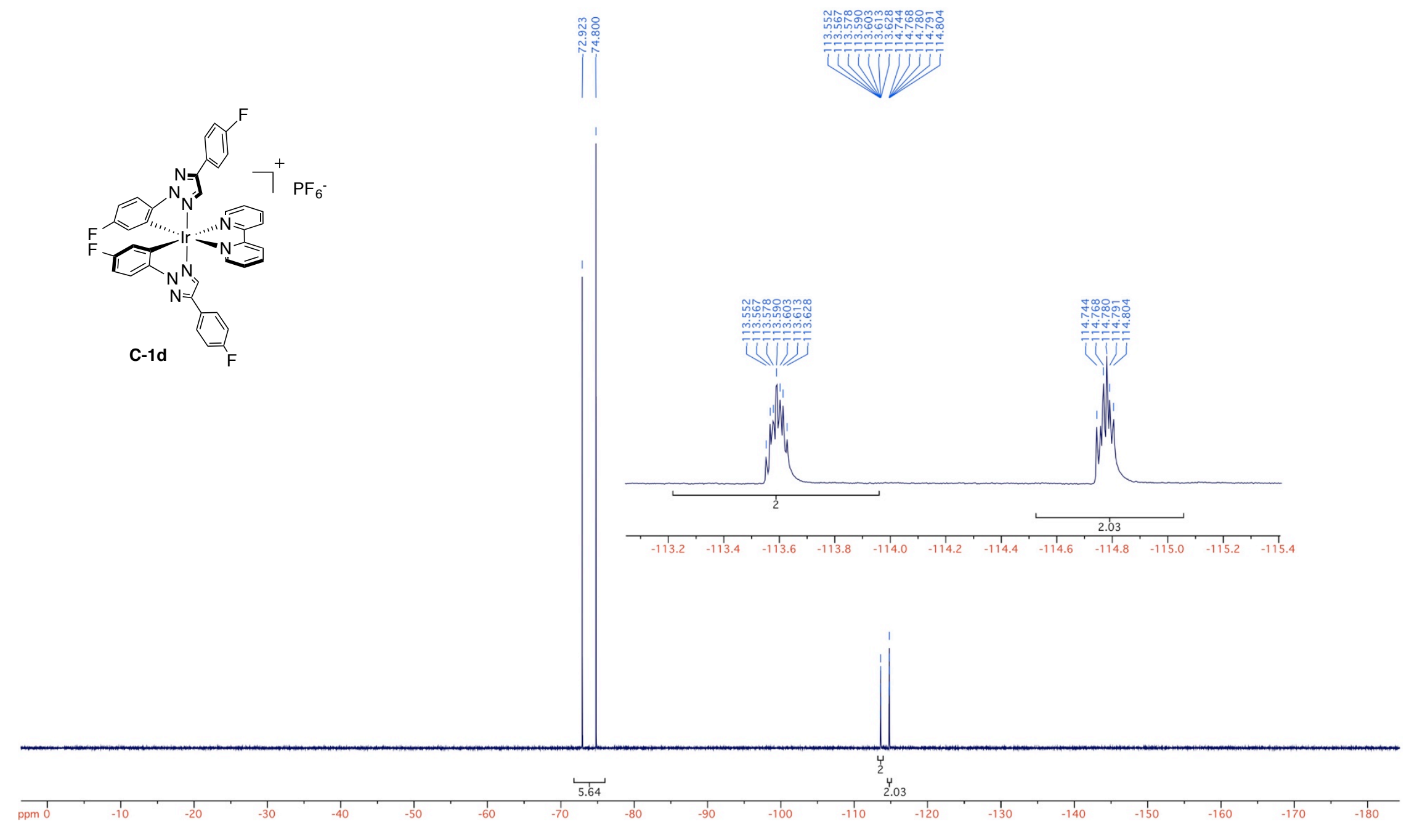




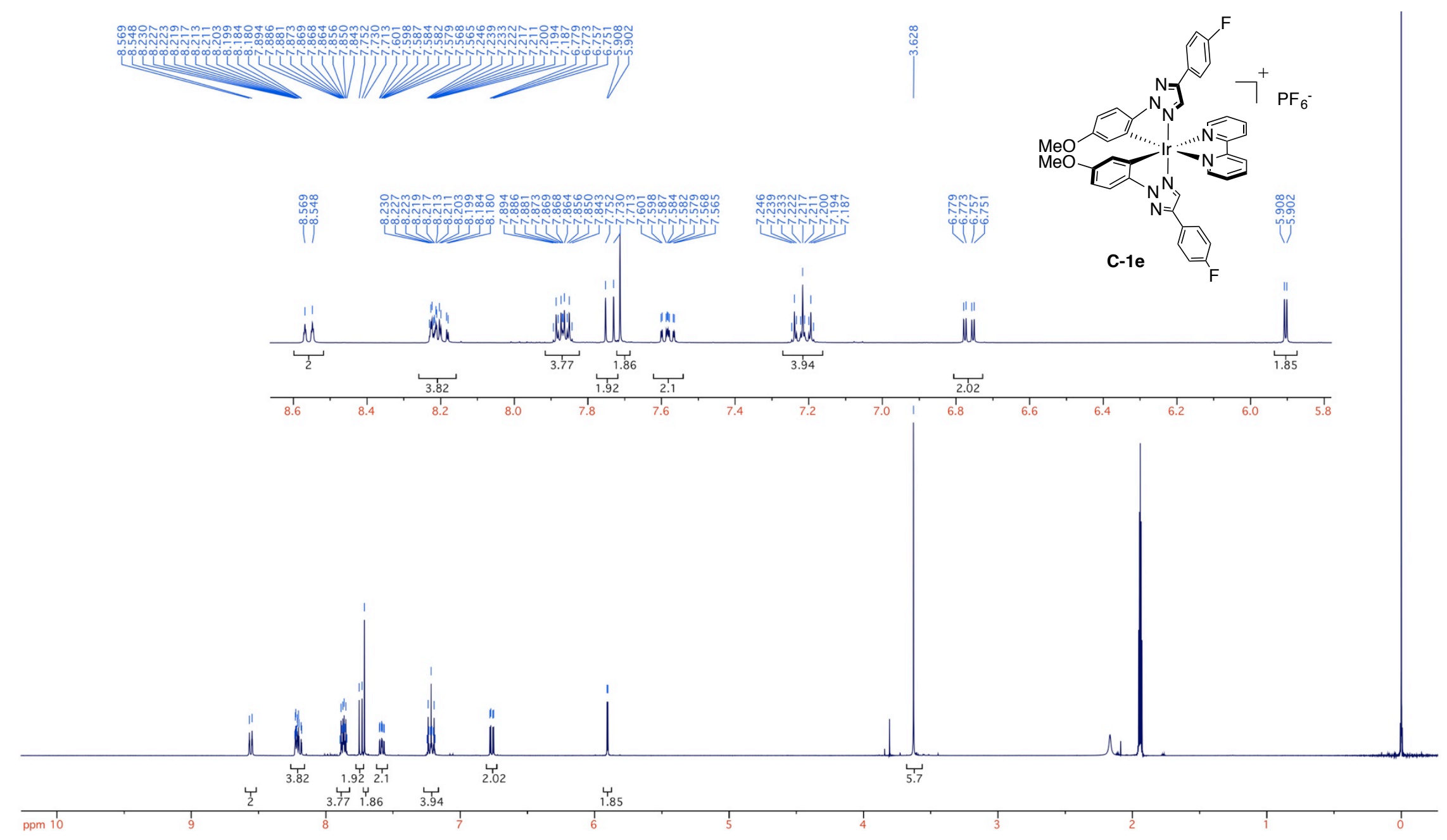




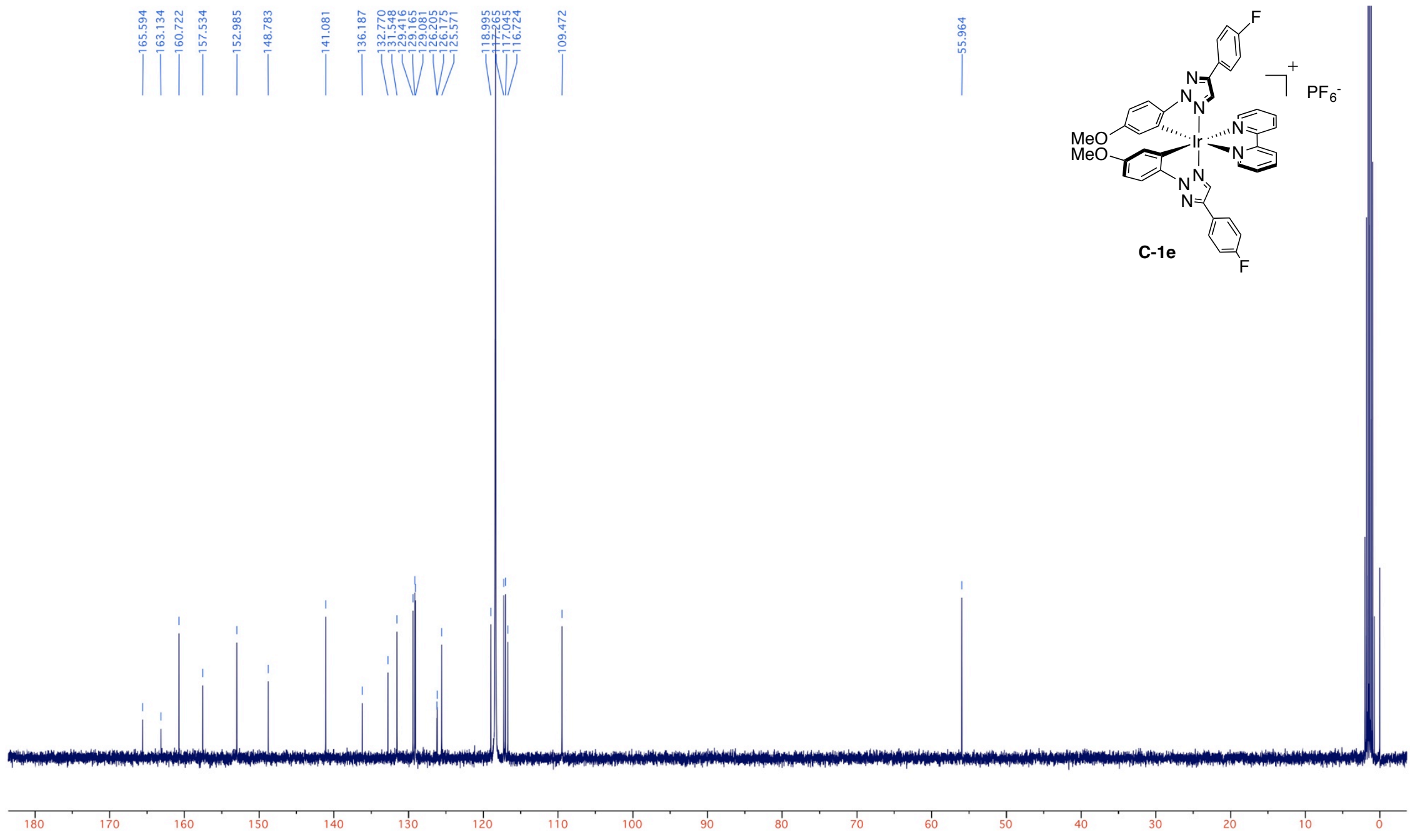




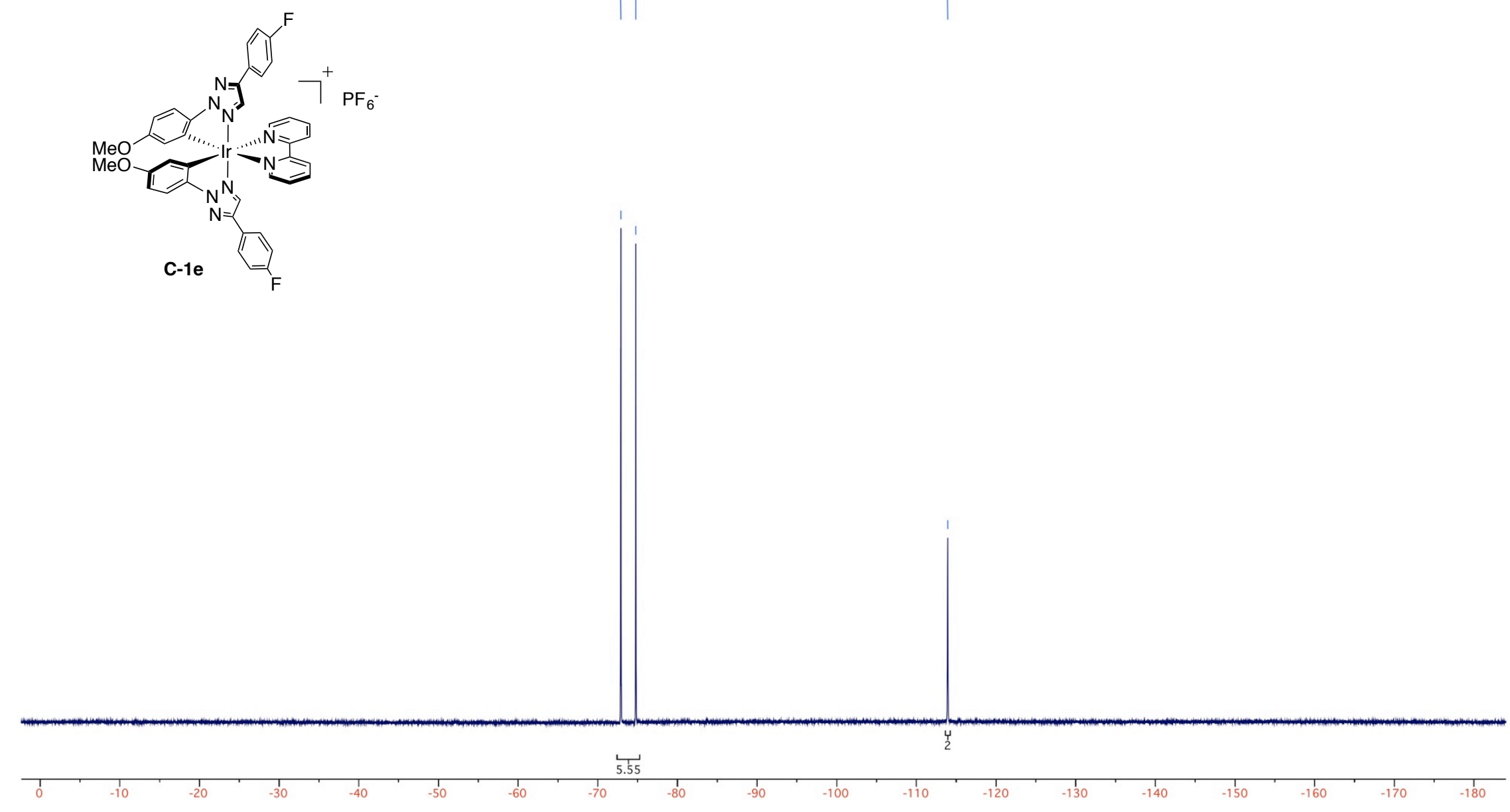




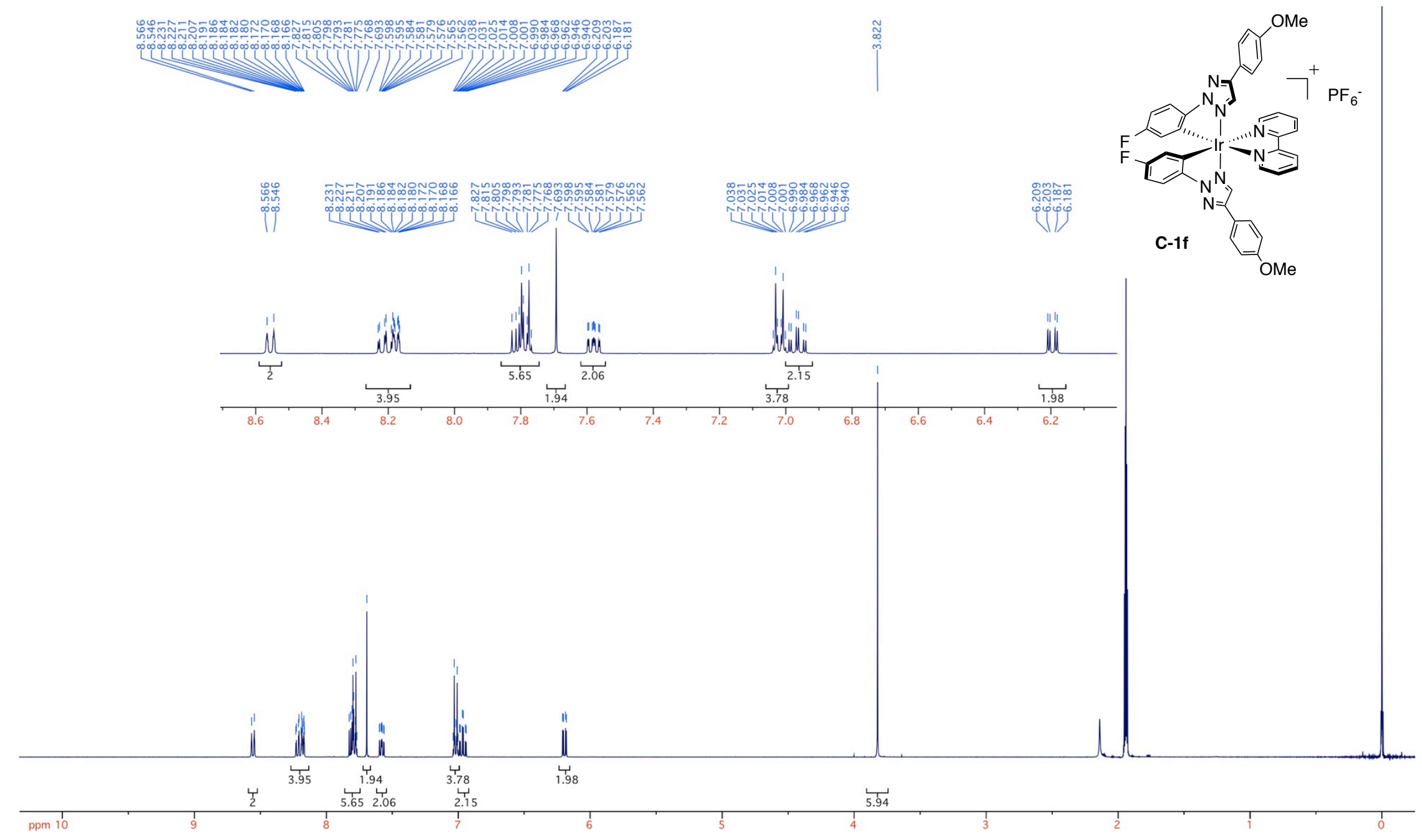




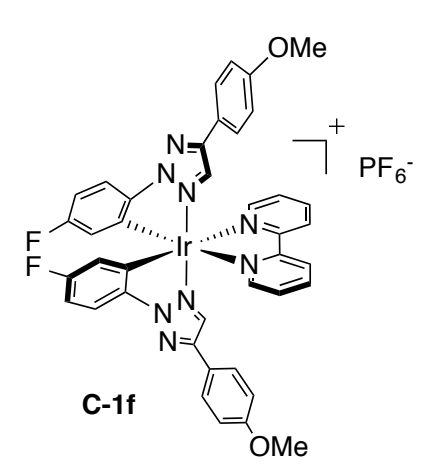




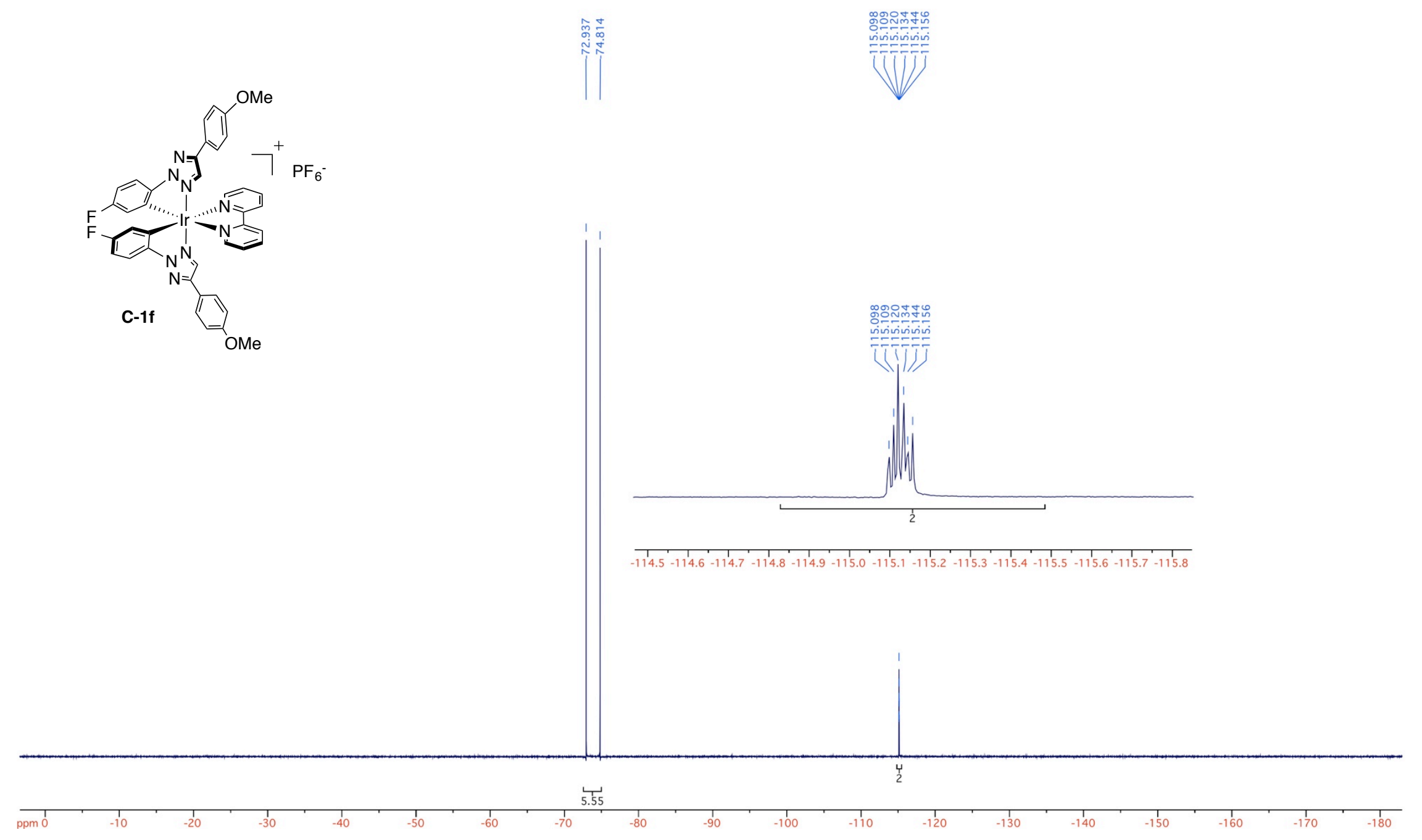




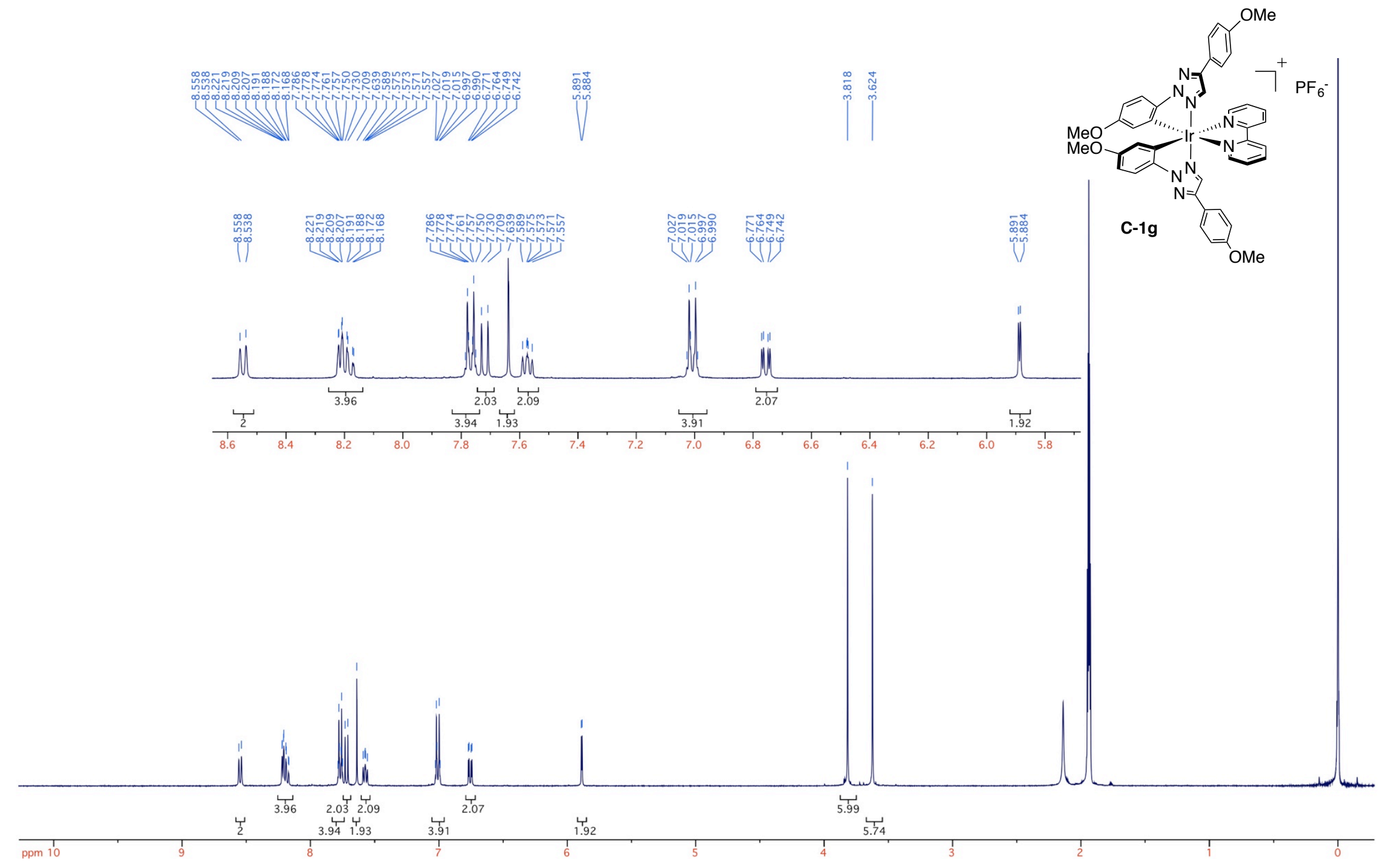




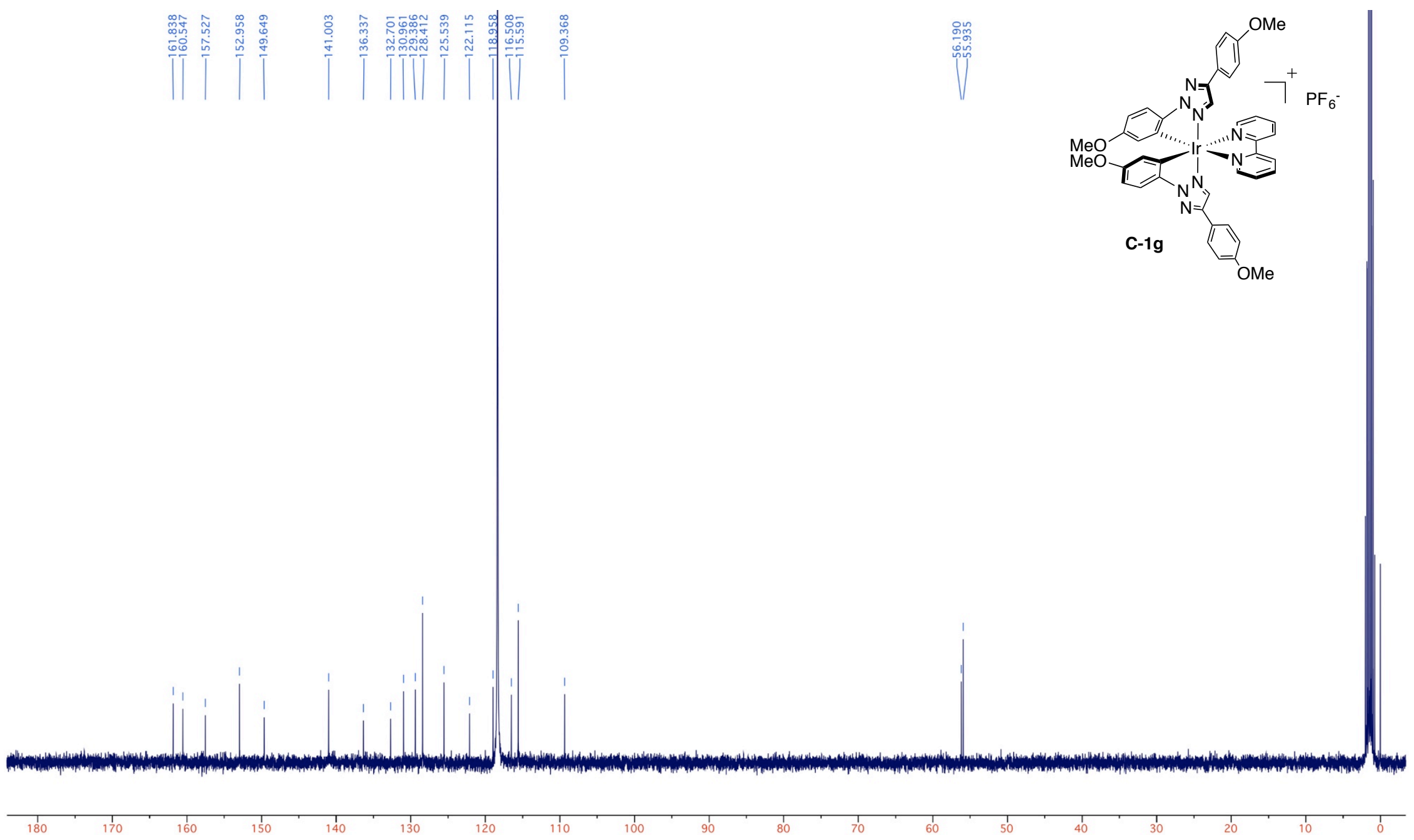




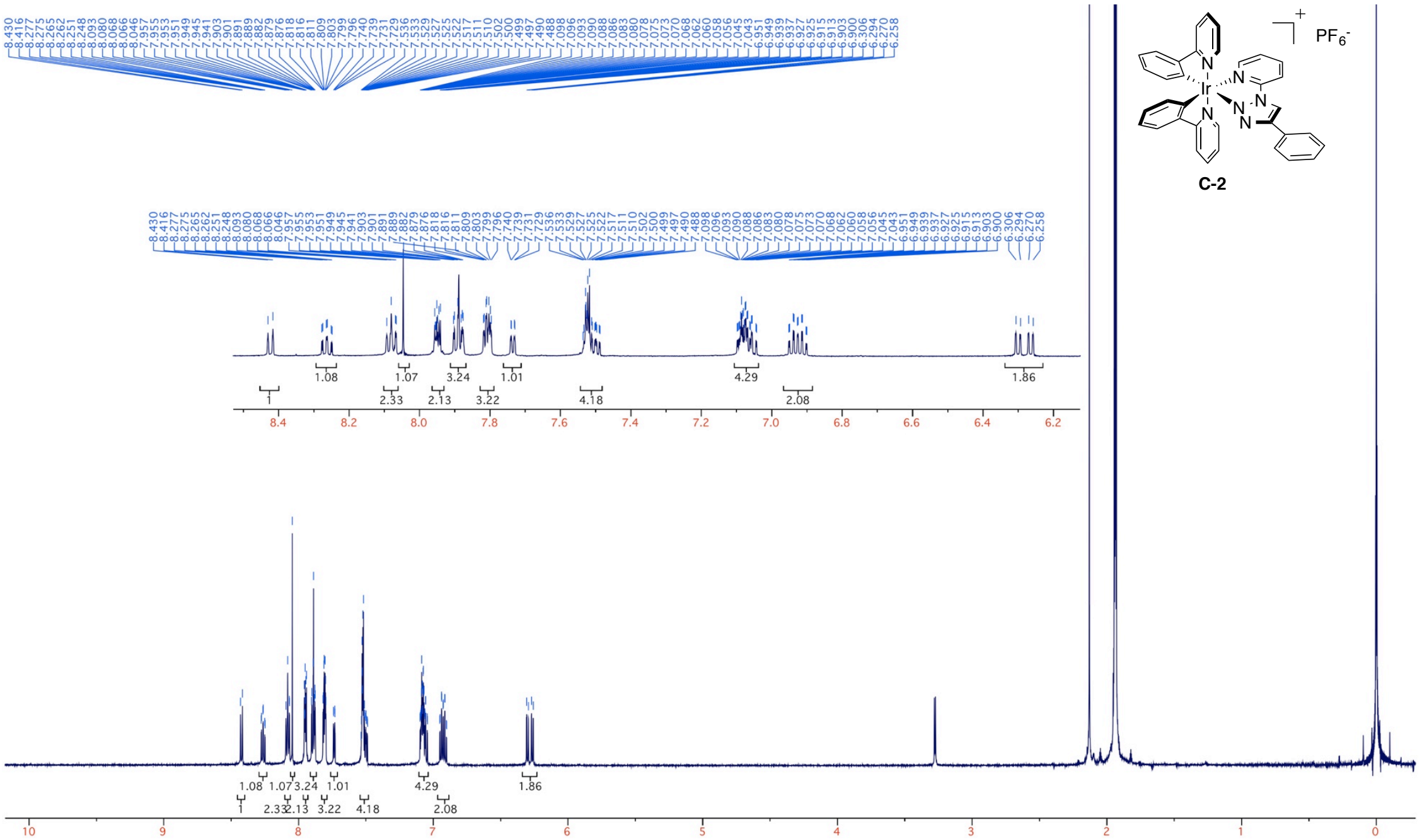




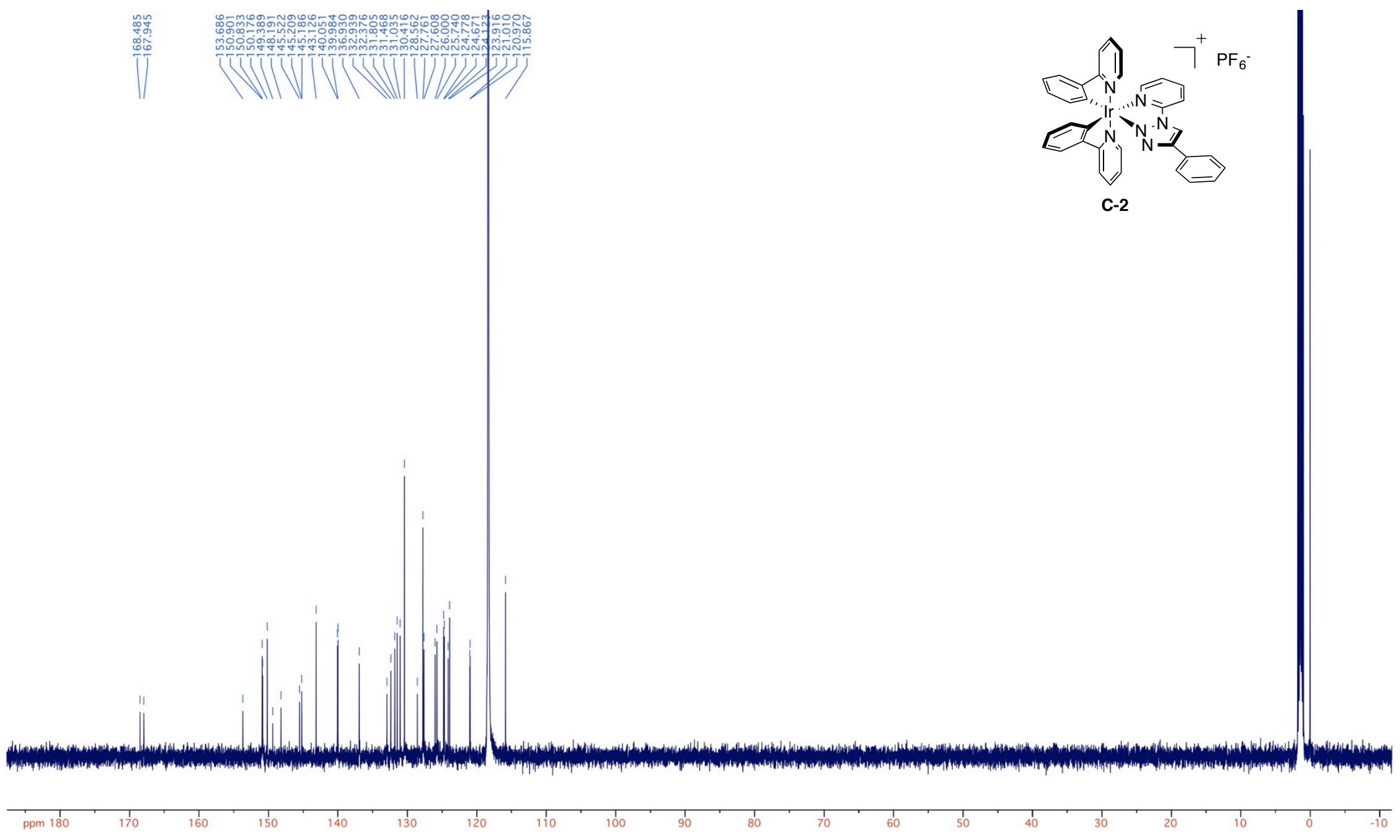




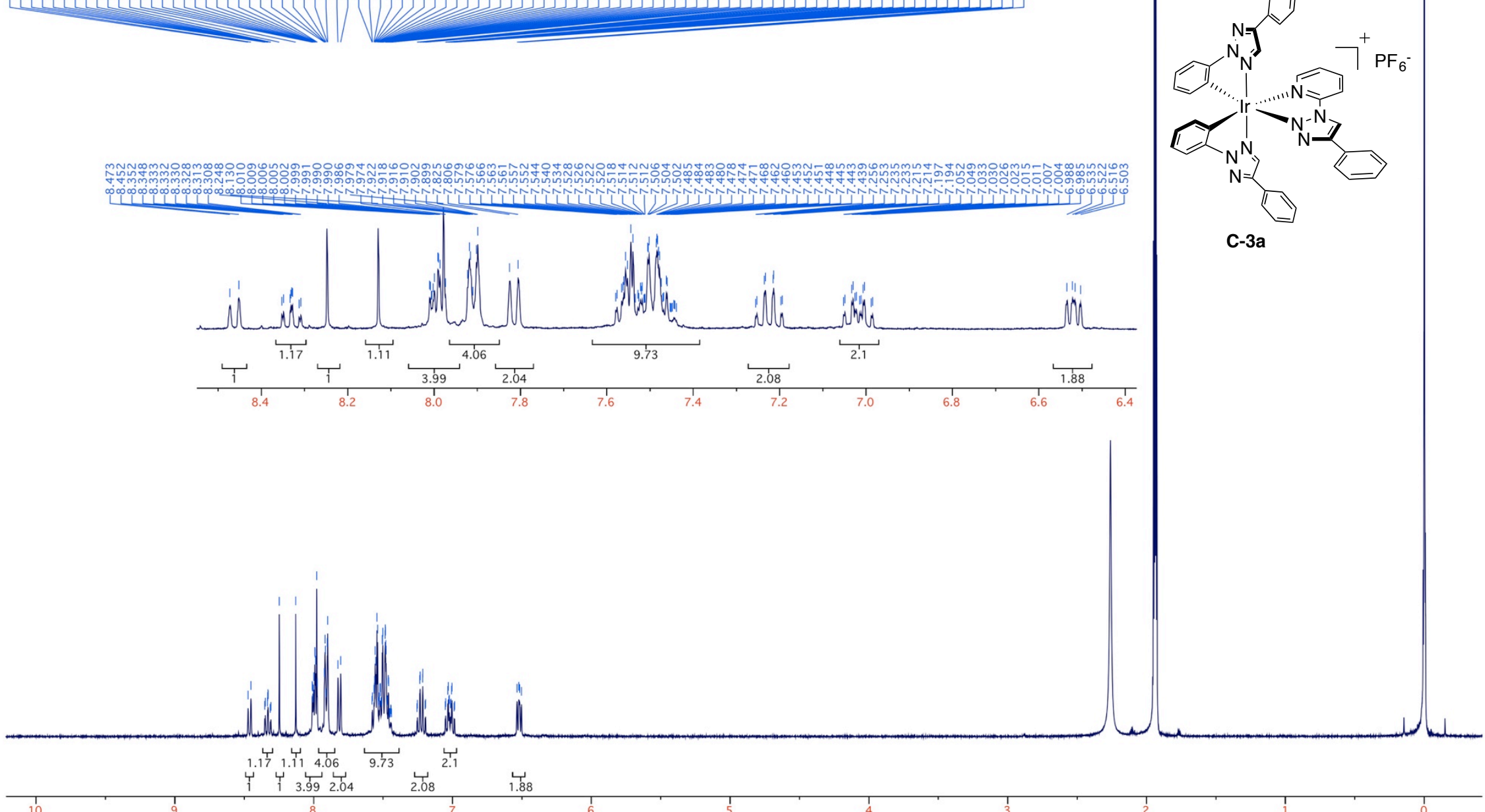




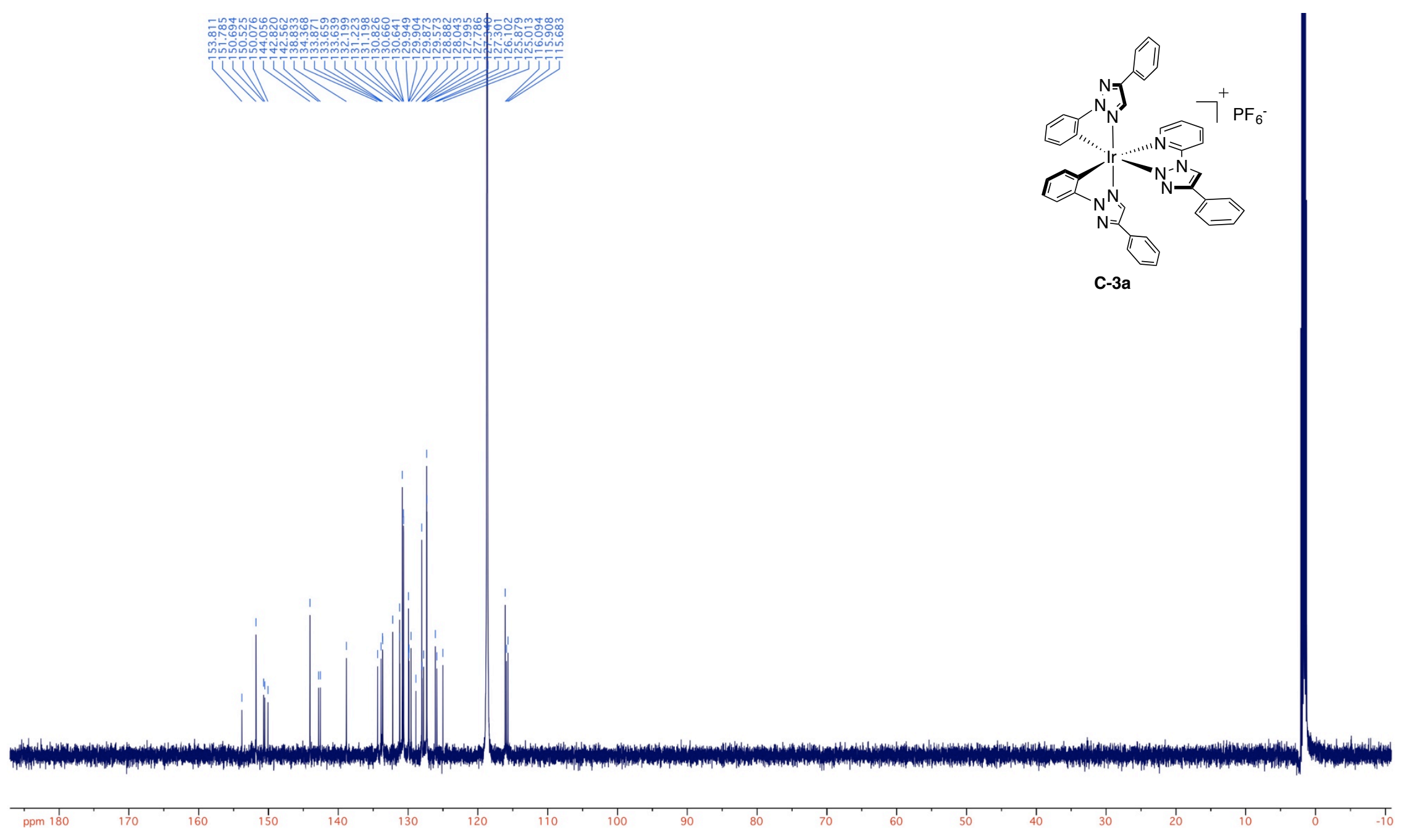




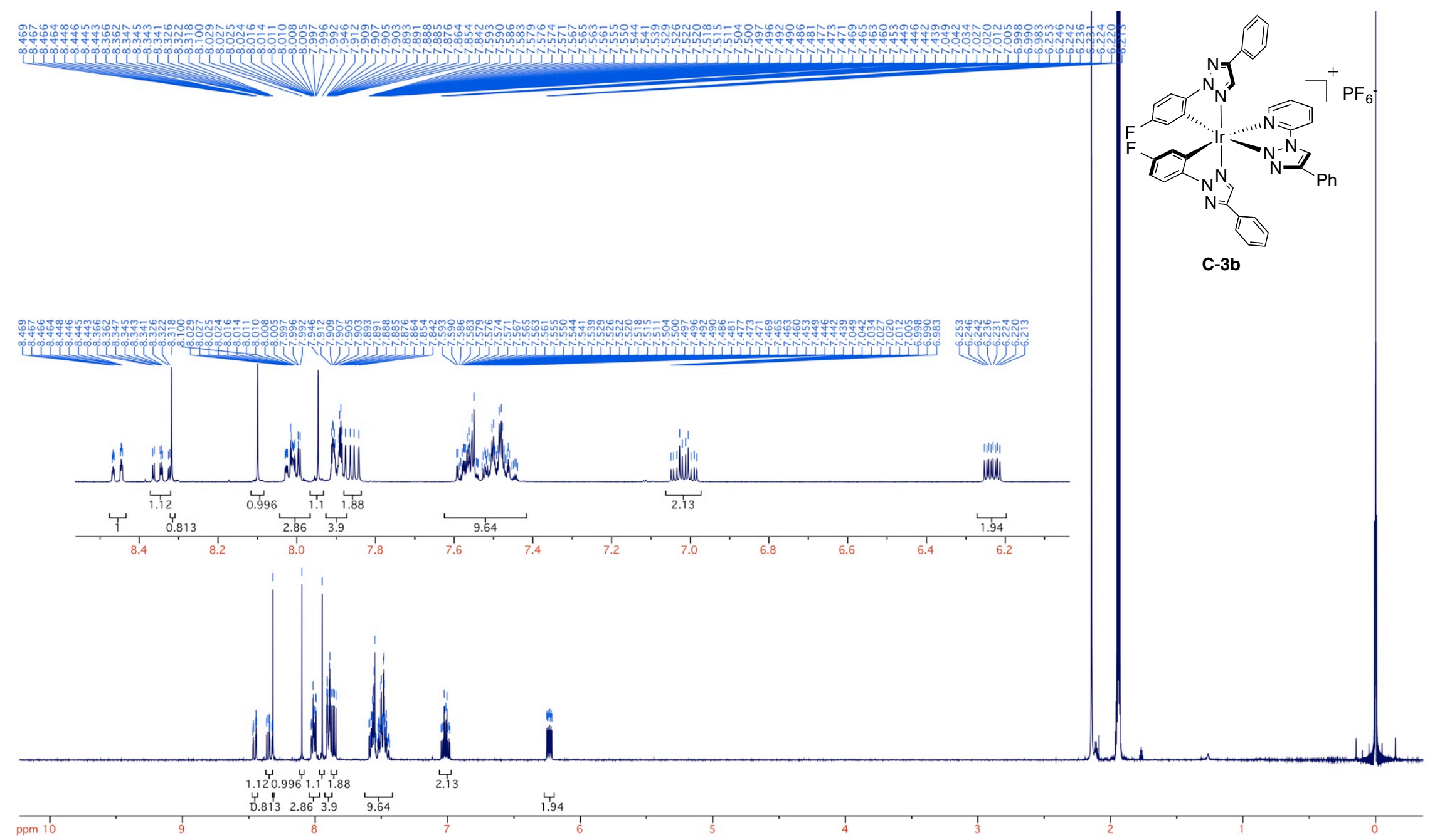




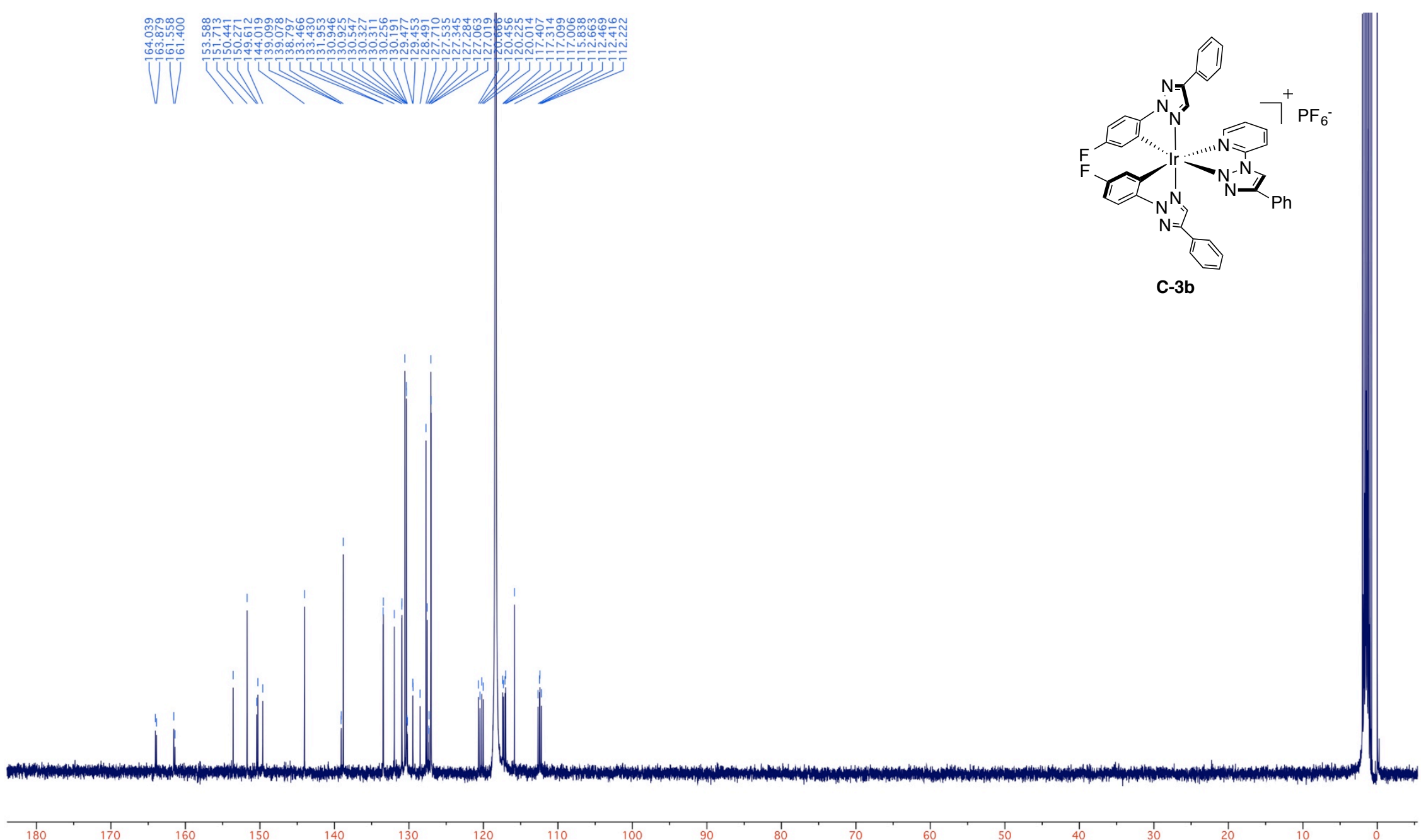



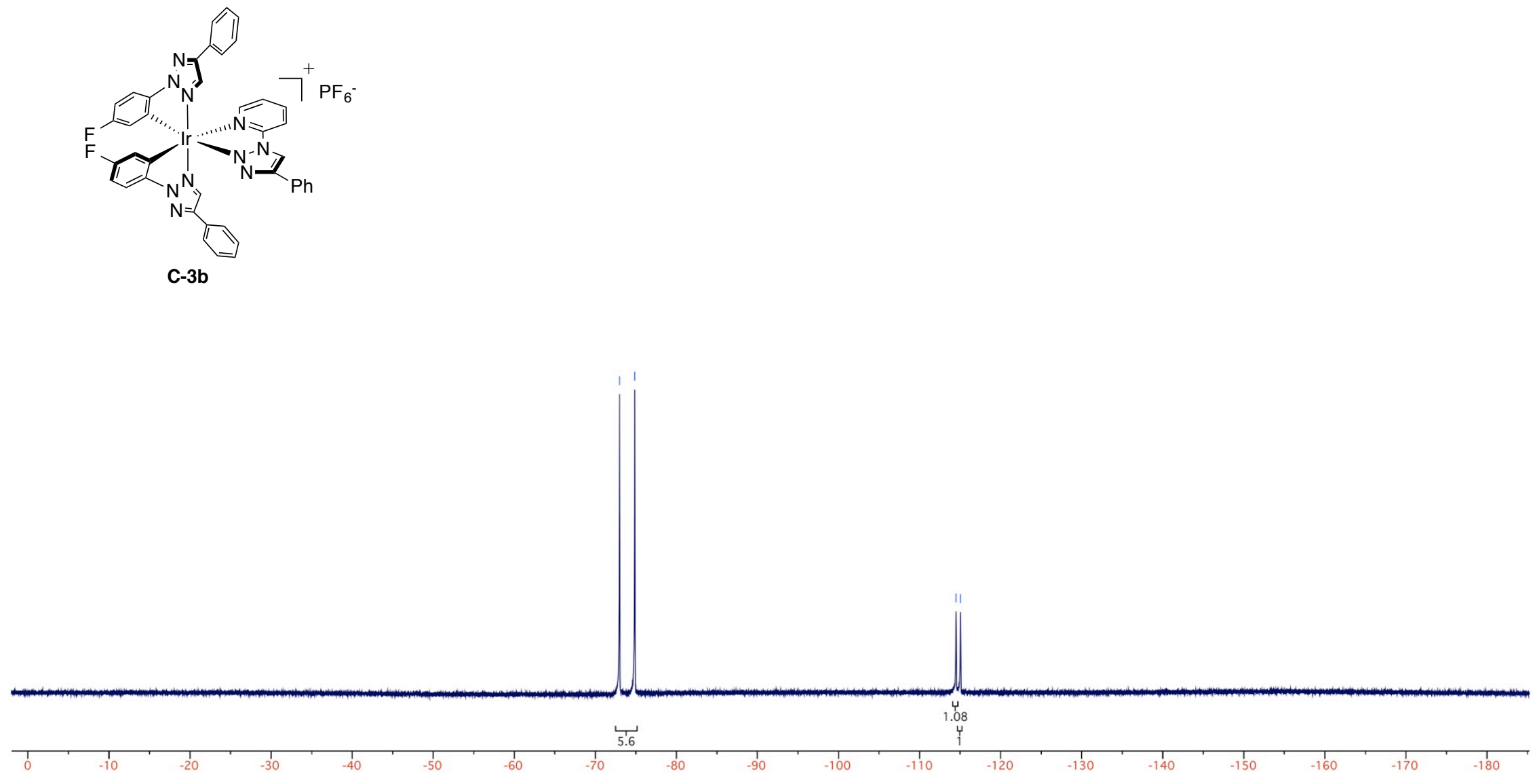


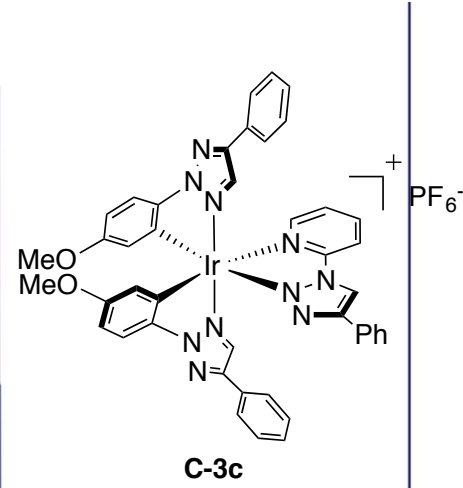

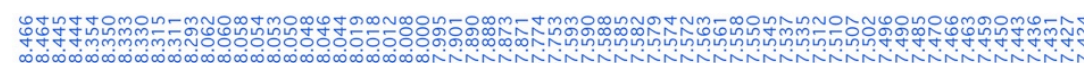
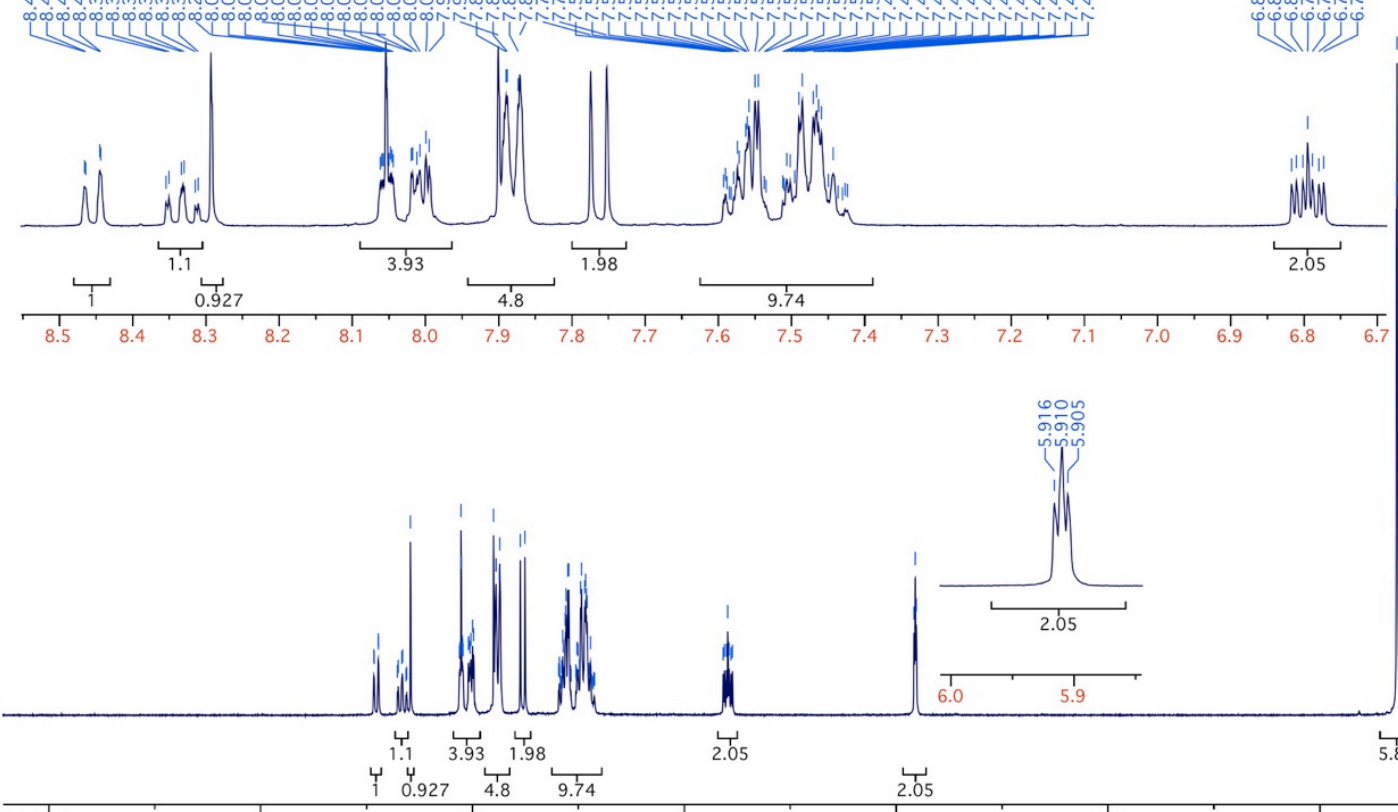

ppm 10

9

\begin{tabular}{lll}
4 & 4 & \multicolumn{1}{c}{4} \\
0.927 & 4.8 & 9.74
\end{tabular}

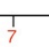

5 


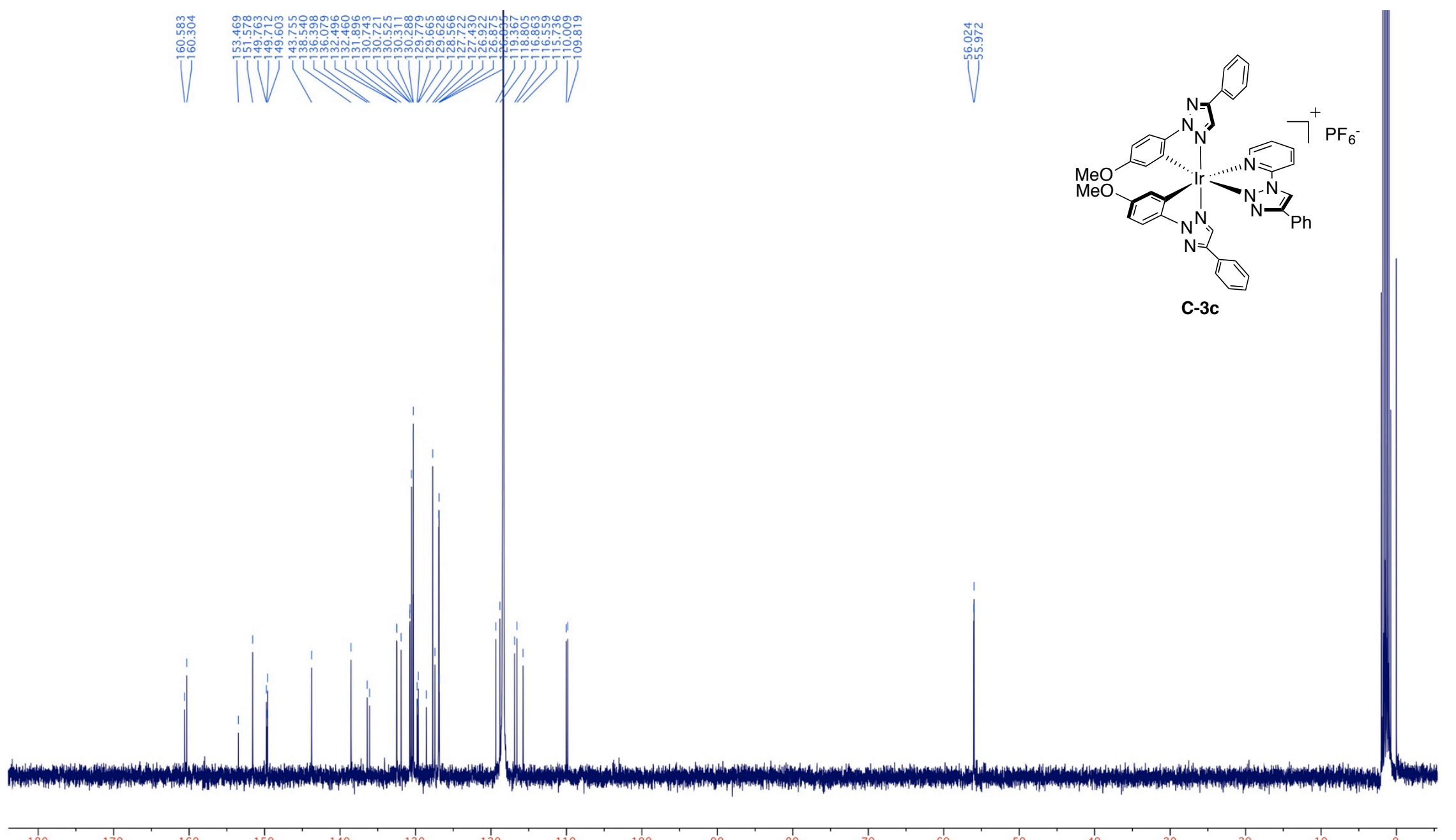

